\title{
DIE ELUATE DES MIKROBIELLEN ABBAUS ORGANISCHER MASSEN IN IHRER ORGANISCH-CHEMISCHEN ZUSAMMENSETZUNG UND IHRER KOPPLUNG MIT FREIGESETZTEN ASCHE- ANTEILEN
}

Dissertation zur Erlangung des Doktorgrades der Fakultät Agrarwissenschaften der Georg-August-Universität Göttingen

\author{
vorgelegt von \\ Heidrun Hofmann \\ geboren in Mandeln
}

Göttingen, 16. Dezember 2004 
D 7

1. Referent: Prof. Dr. Brunk Meyer

2. Koreferent: Prof. Dr. Stefan Gäth

Tag der mündlichen Prüfung: 03.02.2005 


\section{INHALTSVERZEICHNIS}

Tabellenverzeichnis

1. Einleitung 1

1.1 Kompostierung: Rechtliche Rahmenbedingungen / Aktuelle Diskussionen 1

1.2 Kompostierung: Bedeutung der organischen Substanz 6

2. Problemstellung 9

$2.1 \quad$ Fragestellung 9

2.2 Kenntnisstand 9

2.3 Zielsetzung der eigenen Arbeit 11

2.4 Überlegungen zur Methodik 11

3. Versuchsaufbau 13

$\begin{array}{ll}3.1 & \text { Füllmaterialien } \\ & 13\end{array}$

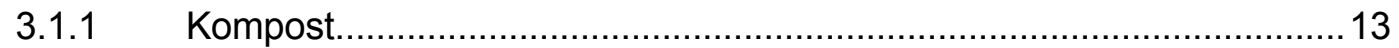

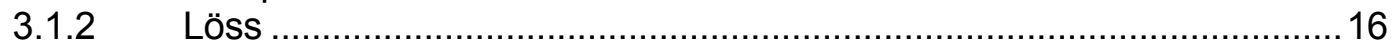

$\begin{array}{lll}3.2 & \text { Lysimeter-Anlage } & 17\end{array}$

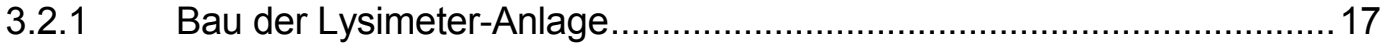

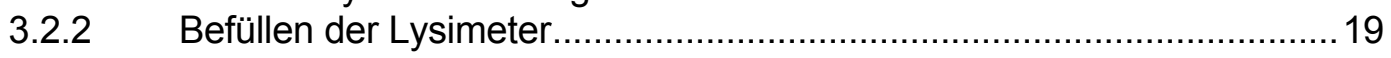

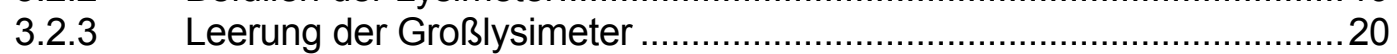

$\begin{array}{lll}3.3 & \text { Probenahmen } & 21\end{array}$

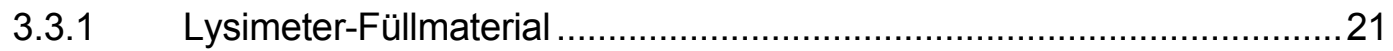

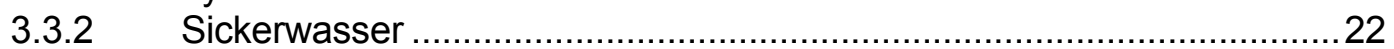

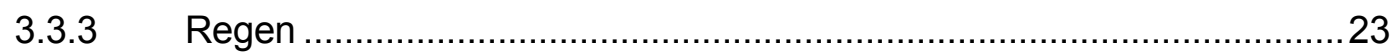

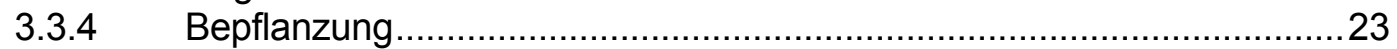

4. Füllmaterialien: Ergebnisse der physikalischen und chemischen Untersuchungen25

4.1 Zeitgang des Wassergehaltes (WG) 25

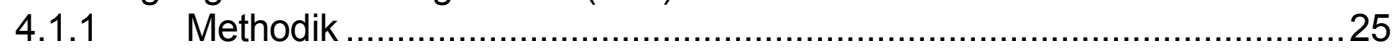

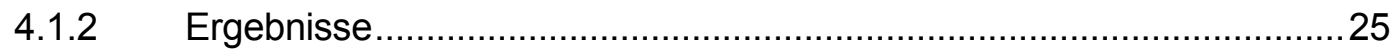

$\begin{array}{lll}4.2 & \text { Sackung } & 29\end{array}$

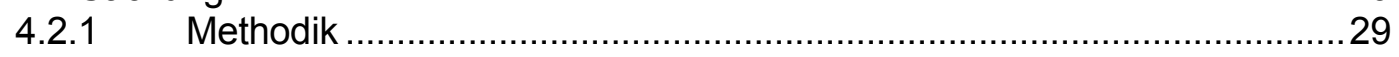

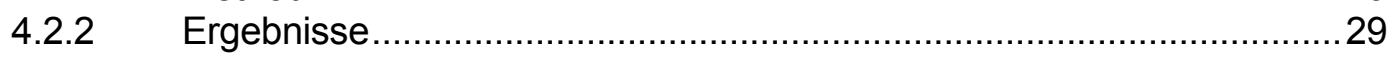

4.3 Trockendichte (TD) 31

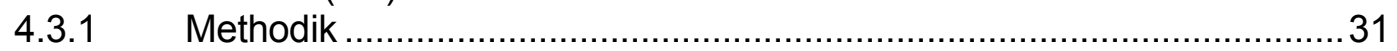

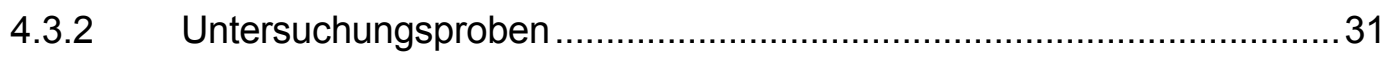

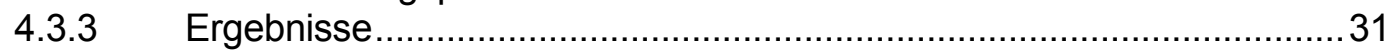

4.4 Einstellung der Porenverteilung 32

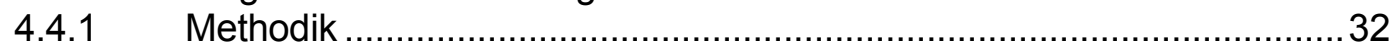

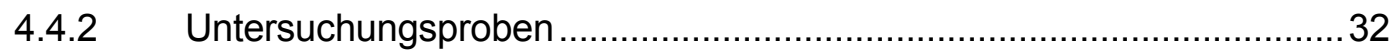

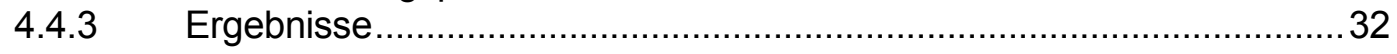

$\begin{array}{lll}4.5 & \text { Aggregat-Zusammensetzung } & 35\end{array}$

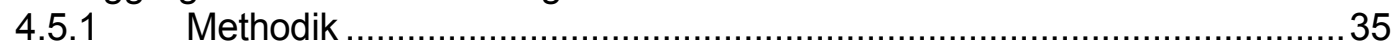

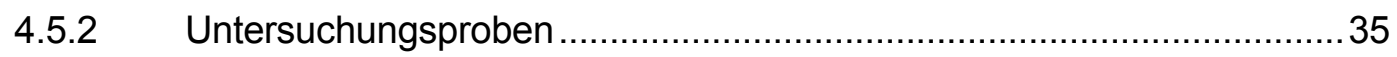

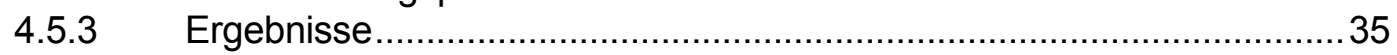

4.6 Korngrößen-Zusammensetzung 40

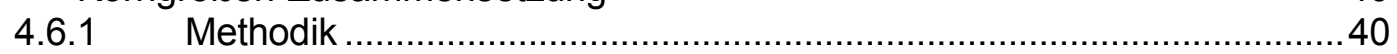

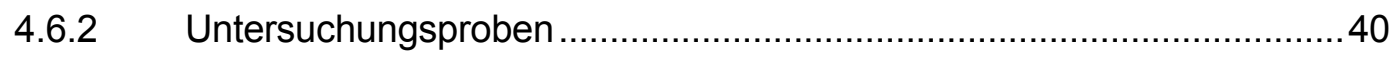

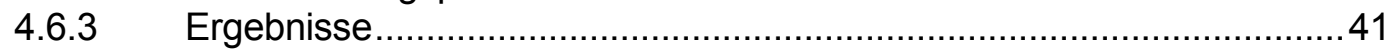

4.6.4 Kohlenstoff- und Stickstoff-Gehalte in den Schlämmfraktionen .................43

$4.7 \quad$ Kalkgehalt $\quad 45$

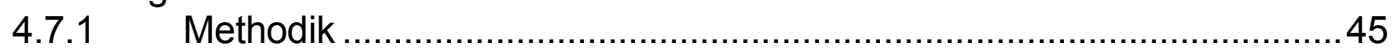

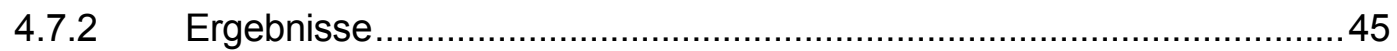


4.8 Zeitgang des Glühverlustes $\quad 47$

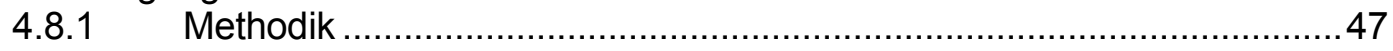

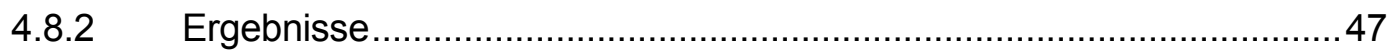

4.9 Zeitgang der Kohlenstoff- und Stickstoff-Gehalte und der C/N-Verhältnisse 51

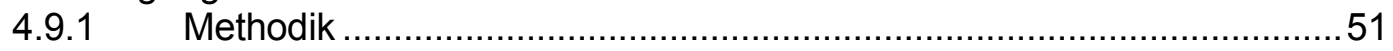

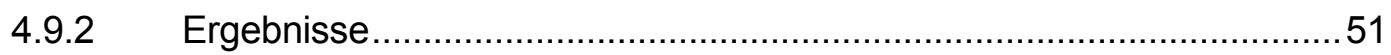

4.10 Organische Substanz / Humusgehalt 56

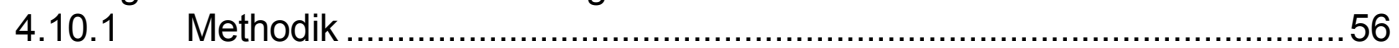

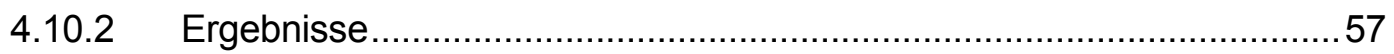

4.11 Kationen-Austausch-Kapazität (KAK) 61

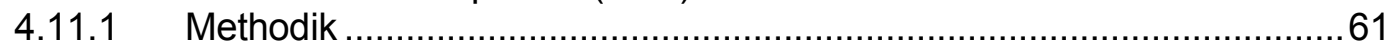

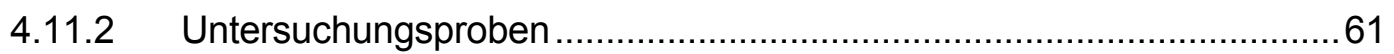

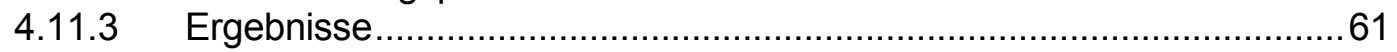

4.12 Gesamtgehalte der Elemente 64

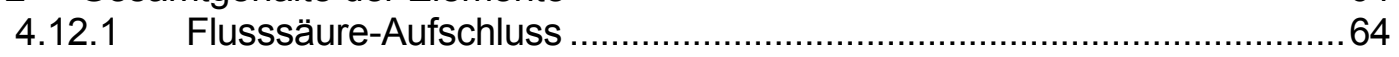

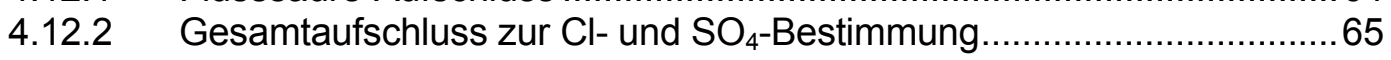

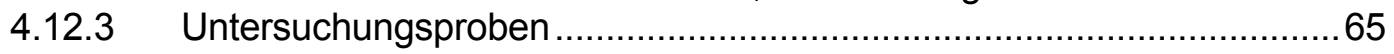

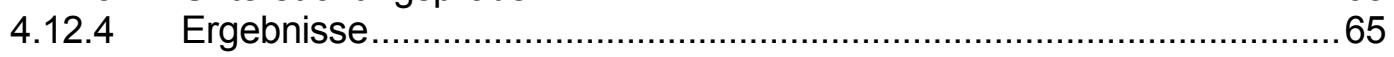

$\begin{array}{lll}4.13 & \text { Schwermetall-Gehalte } & 69\end{array}$

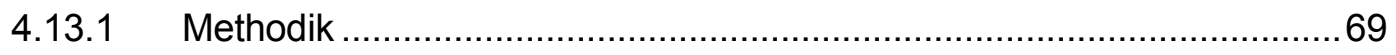

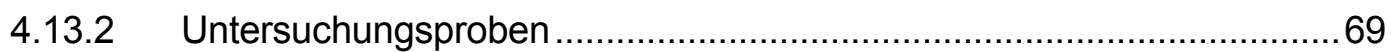

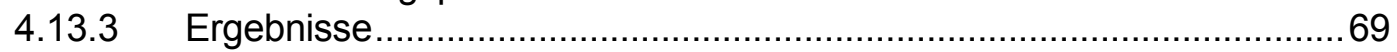

$\begin{array}{lll}4.14 & \text { Biomasse } & 72\end{array}$

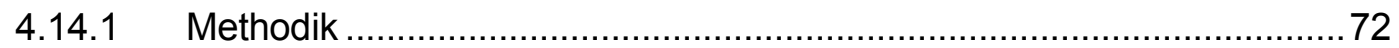

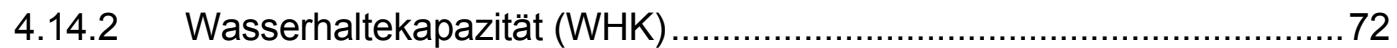

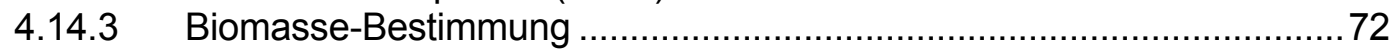

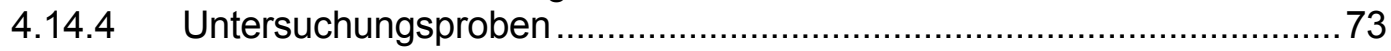

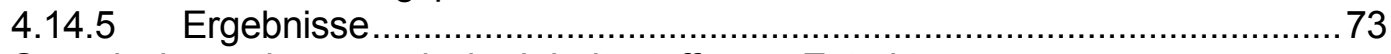

5. Organische und anorganische Inhaltsstoffe von Extrakten 77

$\begin{array}{ll}5.1 \quad \text { Methodik } & 77\end{array}$

$\begin{array}{ll}5.2 & \text { Untersuchungsproben } \\ 5.3 & \text { Ergebnisse }\end{array}$

$\begin{array}{lll}5.3 & \text { Ergebnisse } & 80\end{array}$

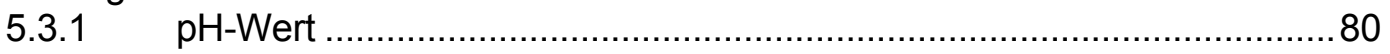

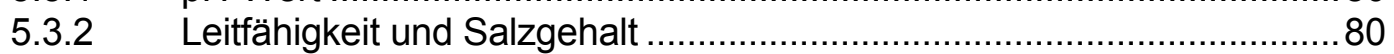

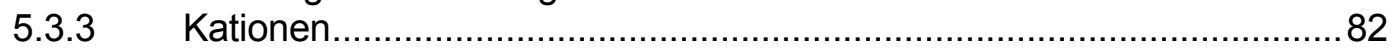

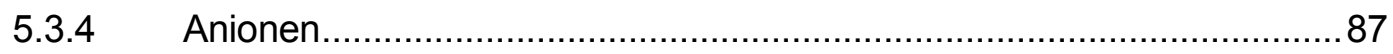

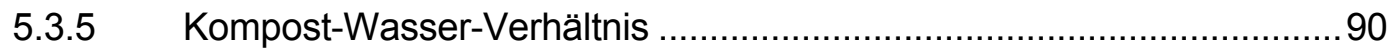

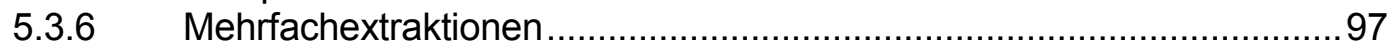

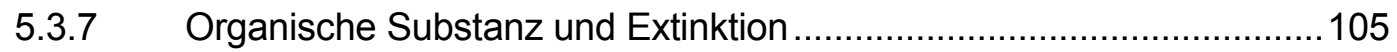

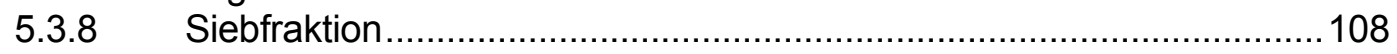

6. Wassereintrag und Sickerwasser 111

$\begin{array}{lll}6.1 & \text { Bewässerung } & 111\end{array}$

6.2 Niederschlagsmengen und Angaben zur Witterung 111

$\begin{array}{ll}\text { 6.3 Zeitlicher Verlauf und Höhe der Sickerwasserspende } & 112\end{array}$

$\begin{array}{ll}6.4 & 116\end{array}$

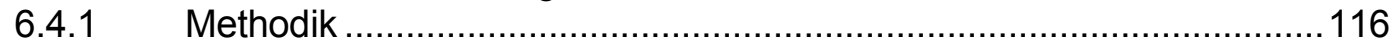

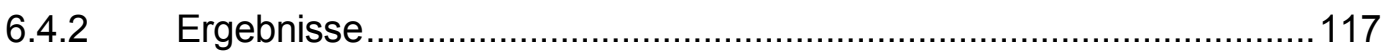

$\begin{array}{lll}6.5 & \text { Inhaltsstoffe im Sickerwasser } & 118\end{array}$

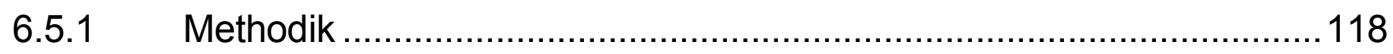

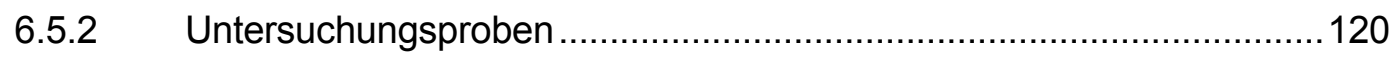

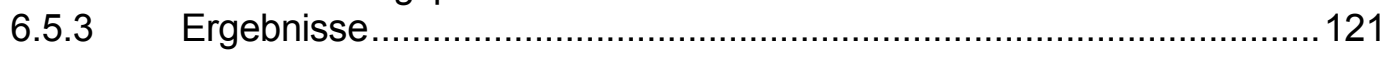

6.5.4 Allgemeine Beschreibung, pH-Wert..............................................121

6.5.5 Leitfähigkeit, Abdampfrückstand und Salzgehalt............................... 121

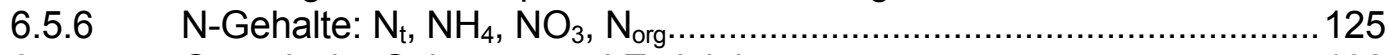

6.5.7 Organische Substanz und Extinktion .......................................... 132

6.5.8 Kationen und Anionen im Sickerwasser ............................................ 142 


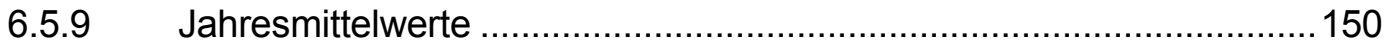

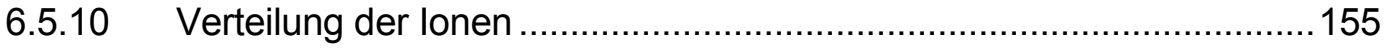

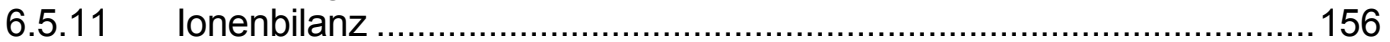

6.5.12 Vergleich:Sickerwasser nach Bewässerung und nach Niederschlag .. 158

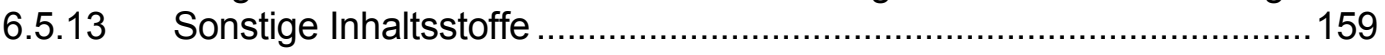

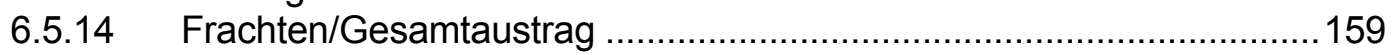

7. Die Fraktionierung organischer und anorganischer Inhaltsstoffe nach

$\begin{array}{lr}\text { Teilchengrößen und Stoffeigenschaften } & 179\end{array}$

$\begin{array}{lll}7.1 & \text { Ultrafiltration } & 179\end{array}$

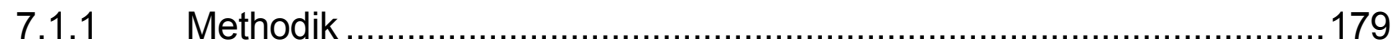

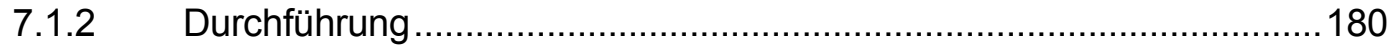

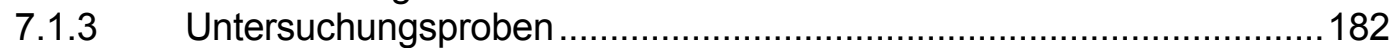

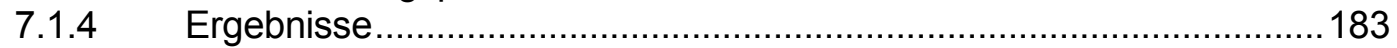

$\begin{array}{llr}7.2 & \text { Gel-Chromatographie } & 199\end{array}$

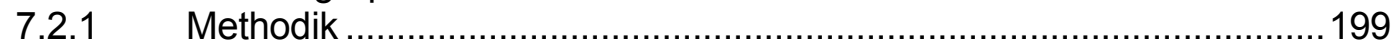

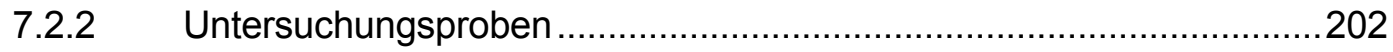

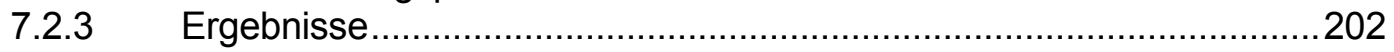

7.3 Adsorptions-Chromatographie 208

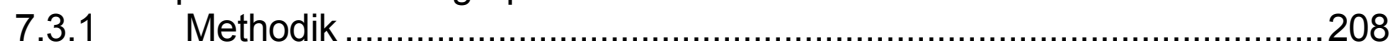

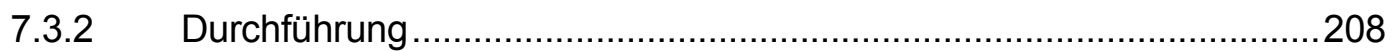

7.3.3 Untersuchungsproben ................................................... 210

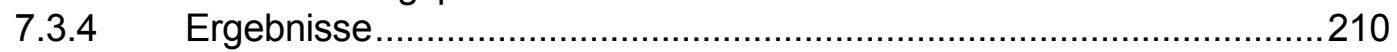

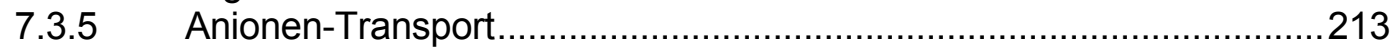

8. Bepflanzung 215

$\begin{array}{lll}8.1 & \text { Anbau, Pflege und Ernte } & 215\end{array}$

$\begin{array}{ll}8.2 \text { Untersuchung der Pflanzen } & 216\end{array}$

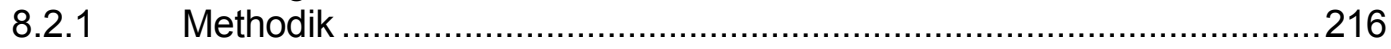

8.2.2 Ergebnisse..............................................................................216

9. Mineralstoff-Bilanz: Einträge, Austräge und Vorratsänderungen des Systems $\begin{array}{ll}\text { Lysimeter } & 229\end{array}$

10. Schlussbetrachtung 234

11. Zusammenfassung 245

12. Literaturverzeichnis 247

13. Anhang: Tabellen und Abbildungen 255

14. Anhang: Fotoaufnahmen 309

15. Danksagung 316

16. Lebenslauf 317 


\section{TABELLENVERZEICHNIS}

Nummer

Seite

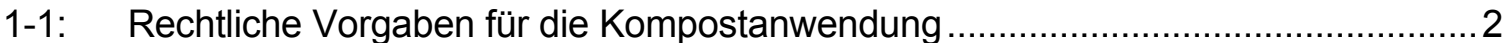

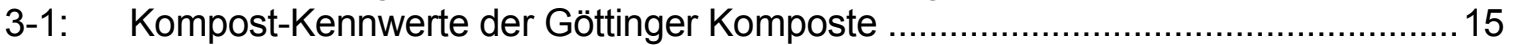

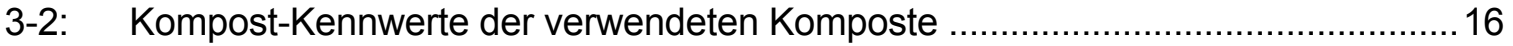

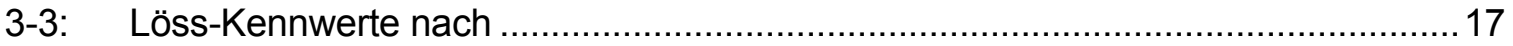

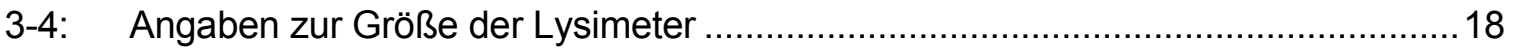

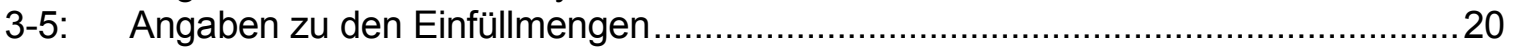

3-6: $\quad$ Lysimeter-Füllmengen bei Abschluss der Freilandversuche ...............................21

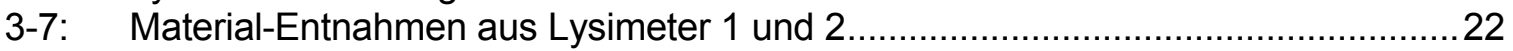

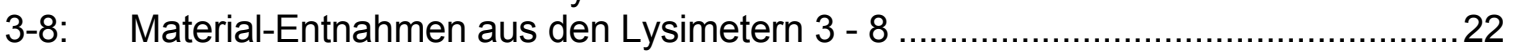

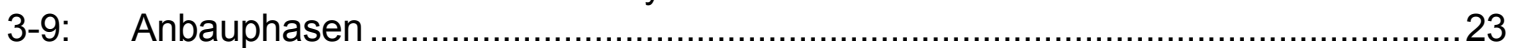

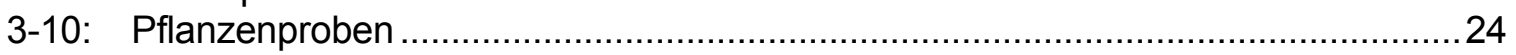

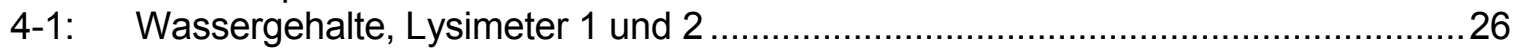

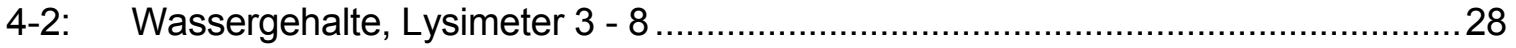

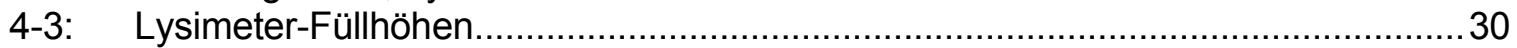

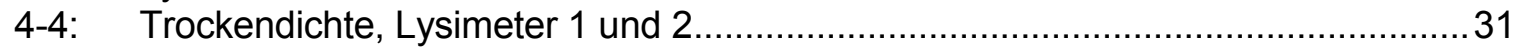

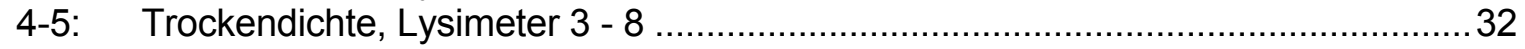

4-6: $\quad$ Gesamt-Porenvolumen (GPV) und Poren-Mengenverteilung .............................. 33

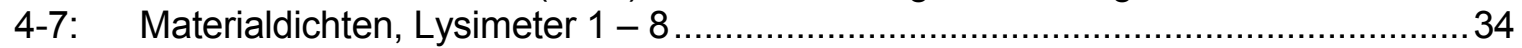

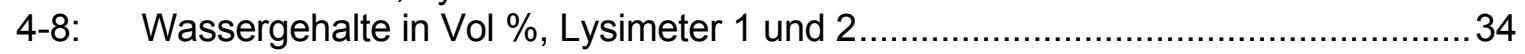

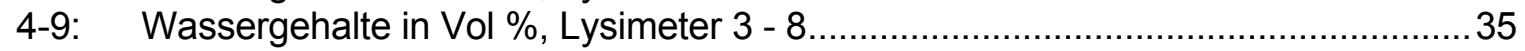

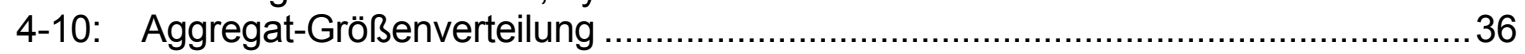

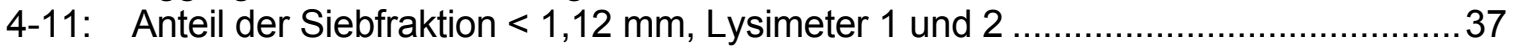

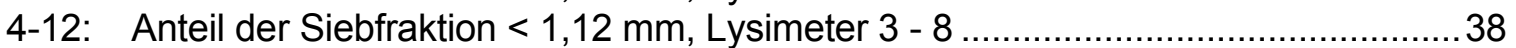

4-13: Mengen-Anteile der Fraktionen $<1,12 \mathrm{~mm}$ und $2 \mathrm{~mm}$, Lysimeter 1 und 2 ............ 39

4-14: Vorbehandlungsmethoden der Korngrößen-Analyse, Lysimeter 1 - 8 .................. 41

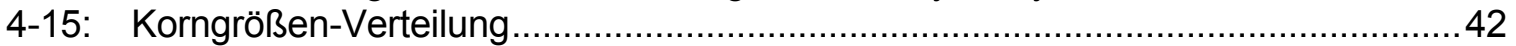

4-16: $\quad$ Mineralische Korngrößen-Zusammensetzung der Kleinlysimeter ..........................43

4-17: Korngrößen-Verteilung der kompostreichen Kleinlysimeter.................................. 43

4-18: C-, N-Gehalte und C/N-Verhältnisse in den Schlämmfraktionen ............................. 44

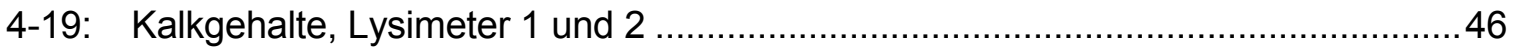

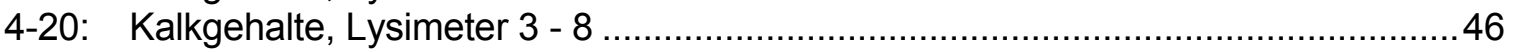

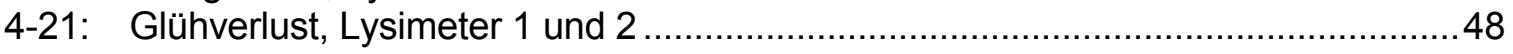

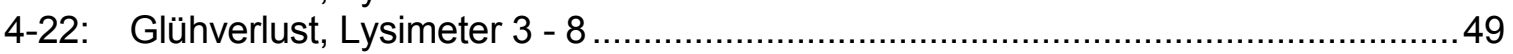

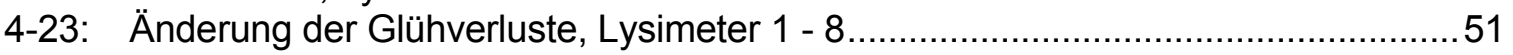

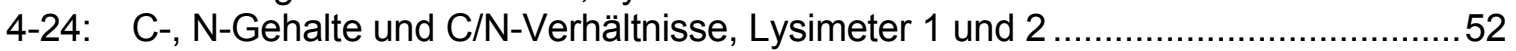

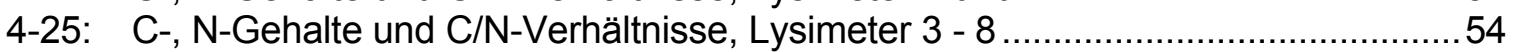

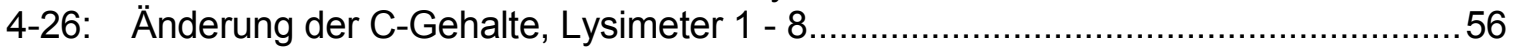

4-27: Durchschnittliche $C_{\text {carb }}$-Gehalte, Lysimeter 1 - 8 ............................................. 57

4-28: Glühverlust, $\mathrm{C}_{\mathrm{t}^{-}}, \mathrm{C}_{\text {org }}$-Gehalte und Glühverlust/ $\mathrm{C}_{\text {org }}$-Verhältnisse,

4-29: Glühverlust, $\mathrm{C}_{\mathrm{t}^{-}}, \mathrm{C}_{\text {org }}$-Gehalte und Glühverlust/C $\mathrm{C}_{\text {org }}$-Verhältnisse,

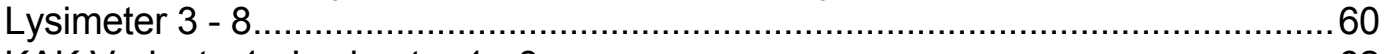

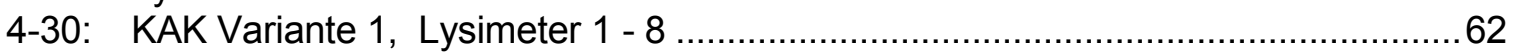

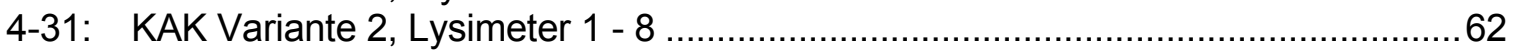

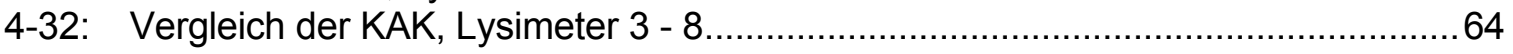

4-33: Gesamtgehalte, Lysimeter 1 und 2 sowie Ausgangsmaterialien Kompost März 1986 und Löss .......................................................................65

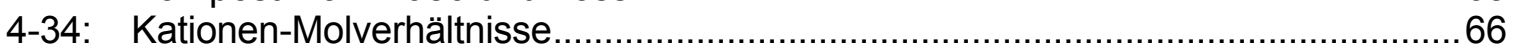

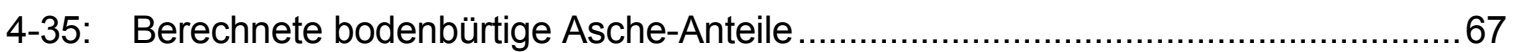

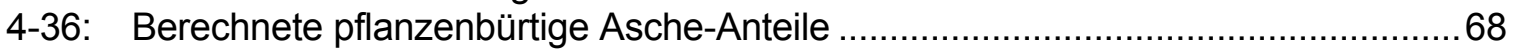

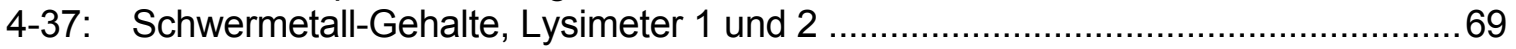


4-38: Schwermetall-Gehalte, Lysimeter $3-8$.

4-39: Schwermetall-Gehalte bezogen auf den Glührückstand,

Lysimeter 1 und 2.

4-40: Schwermetall-Gehalte bezogen auf den Glührückstand,

Lysimeter $3-8$

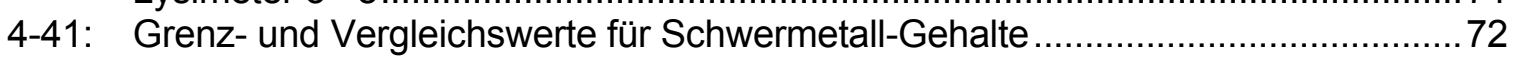

4-42: Messgrößen der Biomasse-Bestimmung, Lysimeter 1 und 2 .............................73

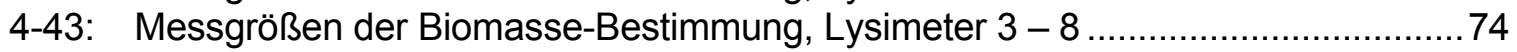

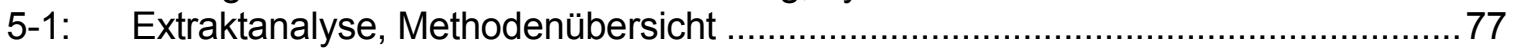

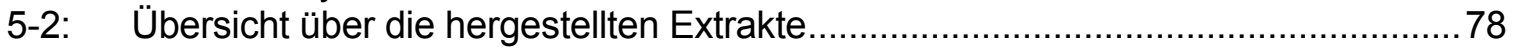

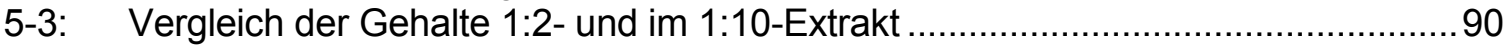

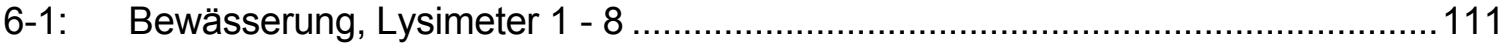

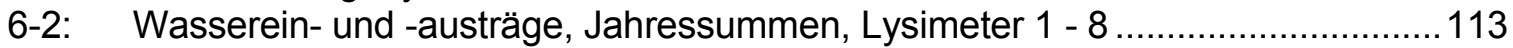

6-3: $\quad$ Regenwasseranalyse, Methodenübersicht ...................................................117

6-4: Durchschnittskonzentrationen an Regenwasser-Inhaltsstoffen ...........................117

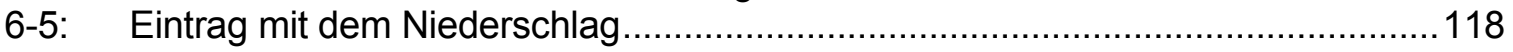

6-6: Sickerwasseranalyse, Methodenübersicht .................................................... 119

6-7: $\quad$ Umfang der Untersuchungen an den Sickerwasser-Proben ............................ 120

6-8: $\quad$ Umrechnungsfaktoren zur Bestimmung der Salzgehalte, Lysimeter 1 und 2 ....... 123

6-9: Abdampfrückstände, C-, N-Gehalte und Verhältnisse sowie N-Verbindungen,

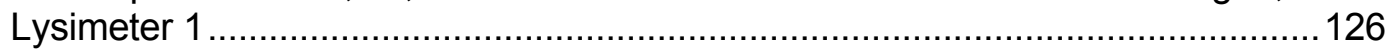

6-10: Abdampfrückstände, C-/N-Gehalte und Verhältnisse sowie N-Verbindungen, Lysimeter 2.

6-11: Abdampfrückstände, C-Gehalte und Extinktionen der Sickerwasser, Lysimeter 1.

6-12: Abdampfrückstände, C-Gehalte und Extinktionen der Sickerwasser,

Lysimeter 2 .....

6-13: Konzentrationen der Inhaltsstoffe, Lysimeter 1 - 8.

6-14: Prozentuale Anteile der Kationen- und Anionen im Sickerwasser,

Lysimeter 1 - 8 ......

6-15: Jahres- und Gesamt-Durchschnittswerte der Anzahl an C-Atomen

pro freier positiver Valenz

6-16: Vergleich der Jahresmittelwerte mit den Werten für die

Sickerwasser-Probe vom Juli 1988

6-17: Gesamt-Austräge mit dem Sickerwasser in g/Lysimeter .................................160

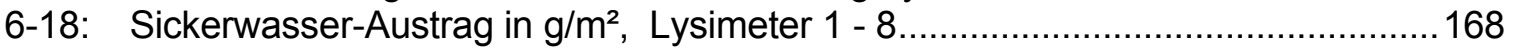

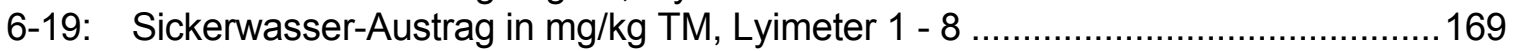

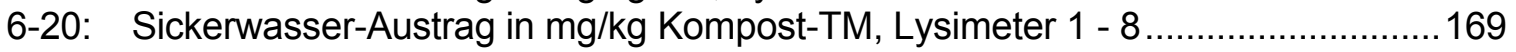

7-1: $\quad$ Komplexbildung und Sorption in natürlichen Gewässern .................................179

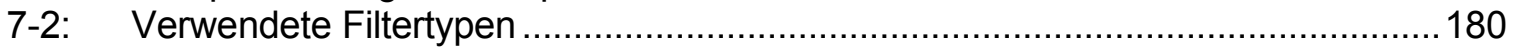

7-3: $\quad$ Fraktionen bei der Ultrafiltration von Sickerwasser .......................................... 182

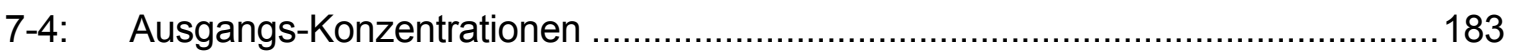

7-5: $\quad$ DOC- und Kationen-Konzentrationen in der Fraktion > $50.000 \mathrm{u} . \ldots \ldots \ldots \ldots \ldots \ldots \ldots . . . . . . . . . . .183$

7-6: $\quad$ DOC- und Kationen-Konzentrationen in der Fraktion $<50.000$ und $>1000$ u .....184

7-7: $\quad$ DOC- und Kationen-Konzentrationen in der Fraktion < $1000 \mathrm{u}$.............................184

7-8: $\quad$ DOC- und Kationen-Konzentrationen in \% in der Fraktion > 50.000 u.................. 185

7-9: $\quad$ DOC- und Kationen-Konzentrationen in \% in der Fraktion $<50.000$

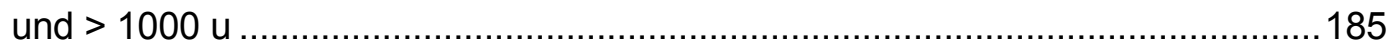

7-10: DOC- und Kationen-Konzentrationen in \% in der Fraktion < 1000 u....................186

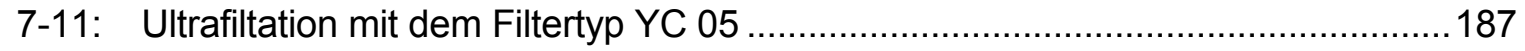

7-12: Ultrafiltration mit zwei Filtertypen BM 500 und YC 05 ..................................... 187

7-13: Anionen-Konzentrationen im 4. Filtrat, Stichproben........................................... 188

7-14: Kationenverteilung, Angaben in \% der Ausgangslösung, Lysimeter 1 ................. 189

7-15: Ionenäquivalent-Verhältnisse in den Fraktionen .............................................. 190

7-16: lonenäquivalent-Verhältnisse in den Fraktionen ohne „Ausreißer“....................... 190 
7-17: Vergleich der Kationen in \% in den Fraktionen $<1000 \mathrm{u}$ und $<500 \mathrm{u}$,

Lysimeter 1 ....

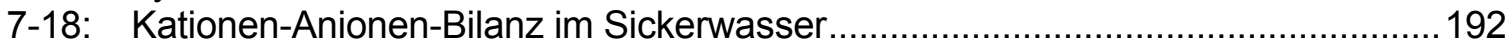

7-19: Kationen-Anionen-Bilanz in der Fraktion > 50.000 u....................................... 193

7-20: Kationen-Anionen-Bilanz in der Fraktion < 50.000 und > $1000 \mathrm{u}$......................... 194

7-21: Kationen-Anionen-Bilanz in der Fraktion < 1000 u........................................... 195

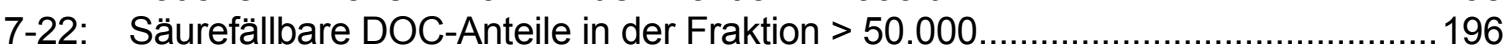

7-23: Kationen in der Fraktion > 50.000 und in der säurefällbaren Fraktion > 50.000 ..198

7-24: C- und Fe-Konzentrationen und C/Fe- Atomverhältnisse in der Fraktion $>50.000 \mathrm{u}$ und in der säurefällbaren Huminsäure-Fraktion > 50.000 u ..............................199

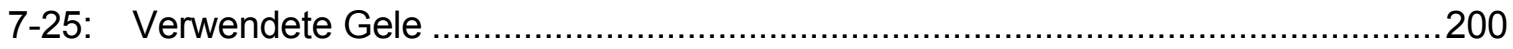

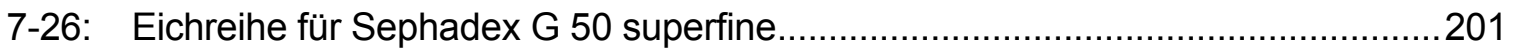

7-27: $\quad$ Mittlere molare Massen in u und Peakhöhen .....................................................204

7-28: Arbeitsschritte und Zuordnung der Eluate der Adsorptions-Chromatographie.....209

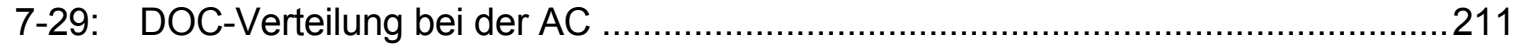

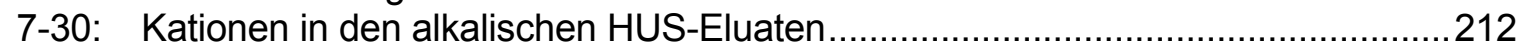

7-31: DOC- Gehalte nach Ultrafiltration der alkalischen HUS-Eluate .........................212

7-32: Humin- und Fulvosäuren in den wässrigen Extrakten.......................................213

7-33: Konzentrationen an $\mathrm{Si}, \mathrm{P}$ und $\mathrm{N}$ in den Filtraten und Eluaten.............................214

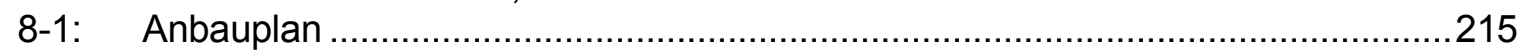

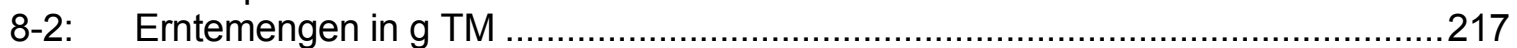

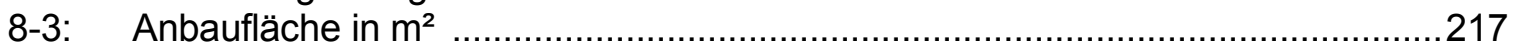

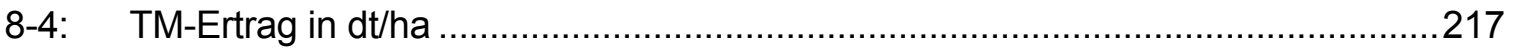

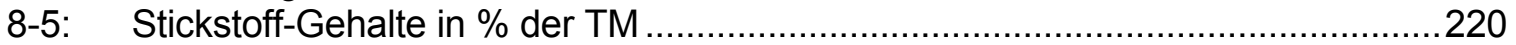

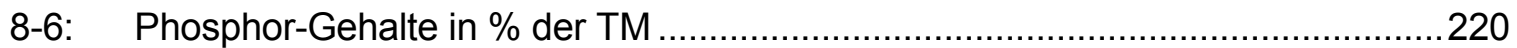

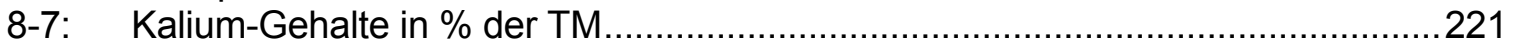

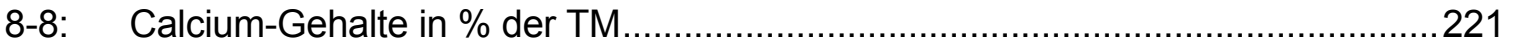

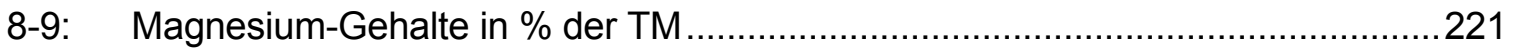

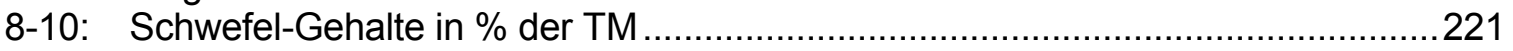

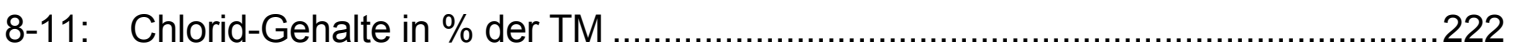

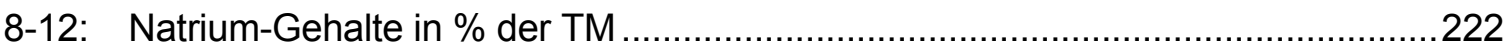

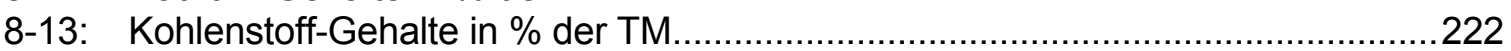

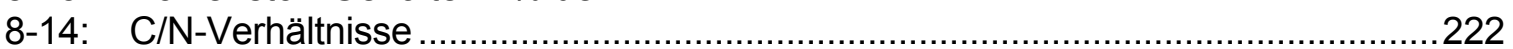

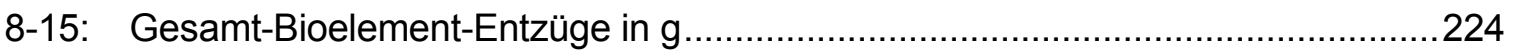

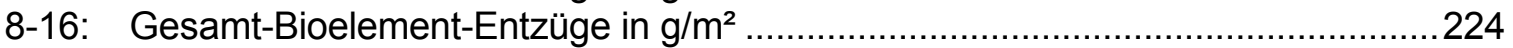

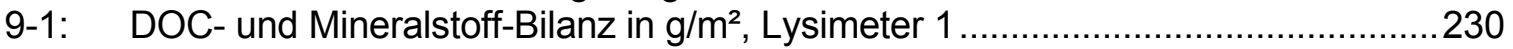

9-2: $\quad$ DOC- und Mineralstoff-Bilanz in $\mathrm{g} / \mathrm{m}^{2}$, Lysimeter 2 .....................................230

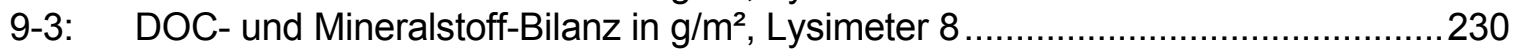

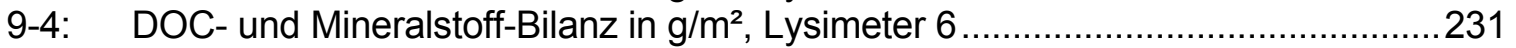

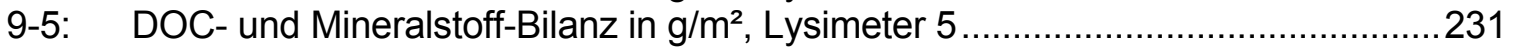

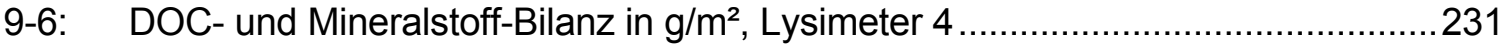

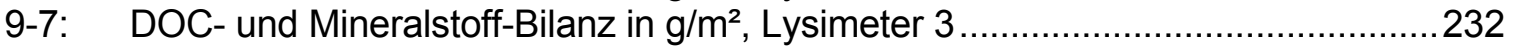

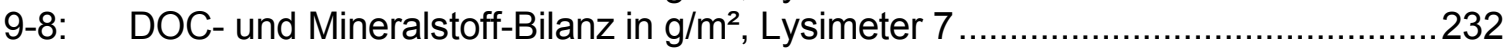

\section{Tabellen im Anhang}

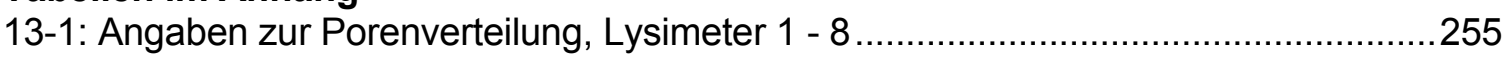

13-2: Korngrößenverteilung nach Anwendung der Vorbehandlungsmethode A ...............256

13-3: Korngrößenverteilung nach Anwendung der Vorbehandlungsmethoden B und C .256

13-4: Korngrößenverteilung nach Anwendung der Vorbehandlungsmethode D.............256

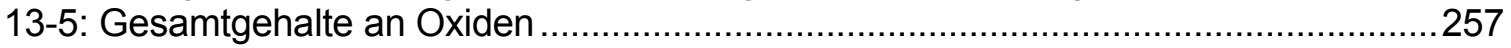

13-6: Wassergehalte bei Sättigung (t-m-s) und nach Lufttrocknung (f-w-s) ....................257

13-7: Zeitgang löslicher lonen im 1:2-Kompost:Wasser-Extrakt, Lysimeter 1 ..................258

13-8: Zeitgang löslicher lonen im 1:2-Kompost:Wasser-Extrakt, Lysimeter 2 ..................259

13-9: Lösliche Verbindungen im 1:2-Kompost:Wasser-Extrakt in mg/l............................260 
13-10: Lösliche Verbindungen im 1:2-Kompost:Wasser-Extrakt in $\mathrm{mg} / \mathrm{kg}$.......................260

13-11: Lösliche Verbindungen im 1:2-Kompost:Wasser-Extrakt in mmol IE/l ..................261

13-12: Lösliche Verbindungen im zweiten 1:2-Kompost:Wasser-Extrakt in in mg/l .........261

13-13: Lösliche Verbindungen im zweiten 1:2-Kompost:Wasser-Extrakt in mg/kg ..........261

13-14: Lösliche Verbindungen im zweiten 1:2-Kompost:Wasser-Extrakt in mmol IE/l .....262

13-15: Lösliche Verbindungen im 1:2-Kompost:Wasser-Extrakt in in $\mathrm{mg} / \mathrm{l} . \ldots \ldots \ldots \ldots \ldots \ldots \ldots . . . . . . . . . . .262$

13-16: Lösliche Verbindungen im 1:2-Kompost:Wasser-Extrakt in in $\mathrm{mg} / \mathrm{kg}$....................262

13-17: Lösliche Verbindungen im 1:2-Kompost:Wasser-Extrakt in mmol IE/l ...................263

13-18: Lösliche Verbindungen im 1:10-Kompost:Wasser-Extrakt in $\mathrm{mg} / \mathrm{l} \ldots \ldots \ldots \ldots \ldots \ldots \ldots \ldots . . . . . . . . . . . . . .263$

13-19: Lösliche Verbindungen im 1:10-Kompost:Wasser-Extrakt in $\mathrm{mg} / \mathrm{kg}$....................263

13-20: Lösliche Verbindungen im 1:10-Kompost:Wasser-Extrakt in mmol IE/l .................263

13-21: Lösliche Verbindungen im zweiten 1:10-Kompost:Wasser-Extrakt in in mg/l .......264

13-22: Lösliche Verbindungen im zweiten 1:10-Kompost:Wasser-Extrakt in mg/kg ........264

13-23: Lösliche Verbindungen im zweiten 1:10-Kompost:Wasser-Extrakt in mg/kg ........264

13-24: Lösliche Verbindungen im 1:10-Kompost:Wasser-Extrakt der Siebfraktionen

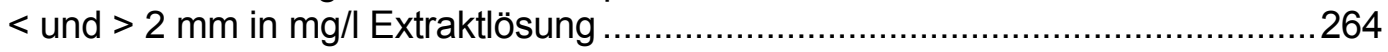

13-25: Lösliche Verbindungen im 1:10-Kompost:Wasser-Extrakt der Siebfraktionen

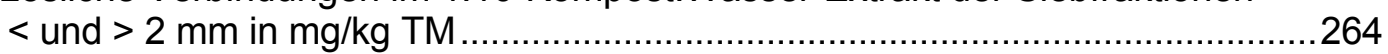

13-26: Lösliche Verbindungen im 1:10-Kompost:Wasser-Extrakt der Siebfraktionen $<$ und > $2 \mathrm{~mm}$ in mmol IE/kg TM..............................................................265

13-27: Lösliche Verbindungen im 1:10-Kompost:Wasser-Extrakt der Siebfraktionen $<$ und > $2 \mathrm{~mm}$ in $\mathrm{mg} / \mathrm{l}$ Extraktlösung ............................................................26

13-28: Lösliche Verbindungen im 1:10-Kompost:Wasser-Extrakt der Siebfraktionen $<$ und $>2 \mathrm{~mm}$ in $\mathrm{mg} / \mathrm{kg} \mathrm{TM}$

13-29: Lösliche Verbindungen im 1:10-Kompost:Wasser-Extrakt der Siebfraktionen $<$ und $>2 \mathrm{~mm}$ in $\mathrm{mmol} \mathrm{IE} / \mathrm{kg}$.

13-30: Extinktion bei $400 \mathrm{~nm}$ in den Extrakten, Lysimeter 1 .......................................26

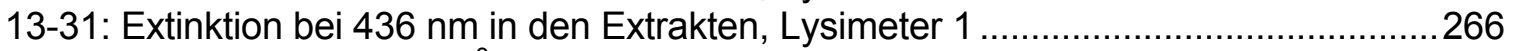

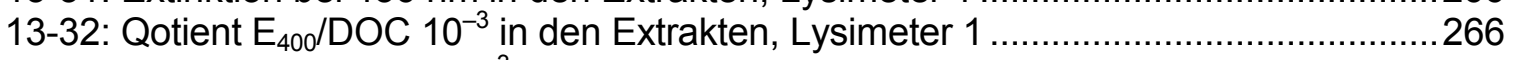

13-33: Quotient $\mathrm{E}_{436} / \mathrm{DOC} 10^{-3}$ in den Extrakten, Lysimeter 1 .......................................26

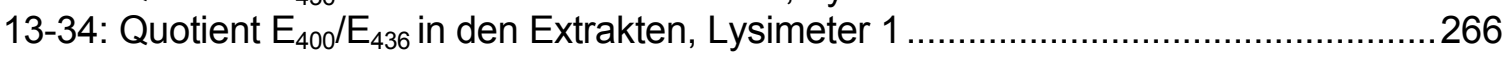

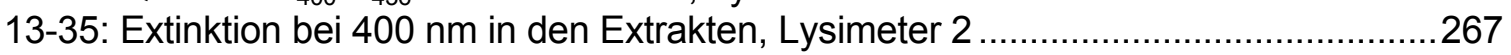

13-36: Extinktion bei $436 \mathrm{~nm}$ in den Extrakten, Lysimeter 2 .....................................267

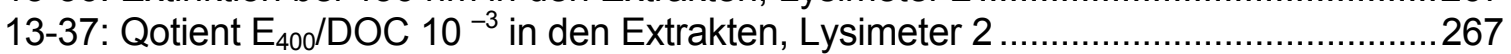

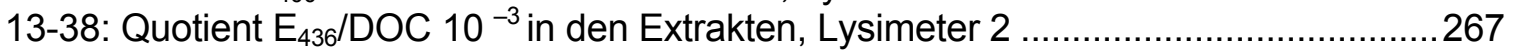

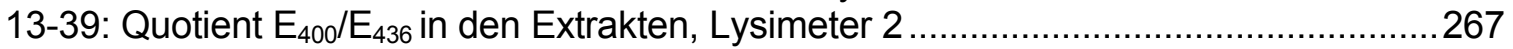

13-40: Extinktion bei $400 \mathrm{~nm}$ in den Extrakten, Kleinlysimeter $3-8 \ldots \ldots \ldots \ldots \ldots \ldots \ldots \ldots \ldots \ldots . . .268$

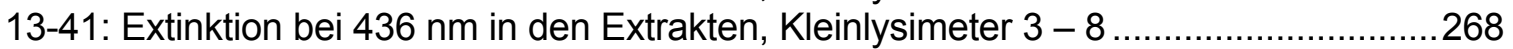

13-42: Qotient $\mathrm{E}_{400} / \mathrm{DOC} 10^{-3}$ in den Extrakten, Kleinlysimeter $3-8 \ldots \ldots \ldots \ldots \ldots \ldots \ldots \ldots \ldots . . .268$

13-43: Quotient $\mathrm{E}_{436} / \mathrm{DOC} 10^{-3}$ in den Extrakten, Kleinlysimeter $3-8 \ldots \ldots \ldots \ldots \ldots \ldots \ldots \ldots \ldots . . .268$

13-44: Quotient $E_{400} / E_{436}$ in den Extrakten, Kleinlysimeter 3 - 8 ................................268

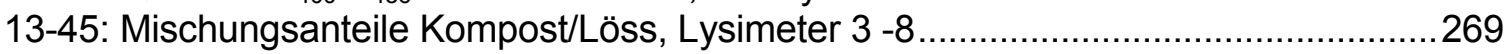

13-46: Berechnete lösliche Ca-Gehalte in den Extrakten, Lysimeter 3 - 8 .......................269

13-47: Berechnete lösliche Na-Gehalte in den Extrakten, Lysimeter 3 - 8 .......................2.269

13-48: Berechnete lösliche K-Gehalte in den Extrakten, Lysimeter 3 - 8 .........................269

13-49: Berechnete lösliche Mg-Gehalte in den Extrakten, Lysimeter 3 - 8.....................269

13-50: Berechnete Leitfähigkeitswerte in $\mathrm{mS} / \mathrm{cm}$ in den Extrakten, Lysimeter 3 - $8 \ldots \ldots . .270$

13-51: Berechnete lösliche DOC-Gehalte in den Extrakten, Lysimeter 3 - 8...................270

13-52: Berechnete lösliche $\mathrm{HCO}_{3}$-Gehalte in den Extrakten, Lysimeter 3 - 8 ..................270

13-53: Berechnete lösliche $\mathrm{SO}_{4}$-Gehalte in den Extrakten, Lysimeter 3 - 8 ......................270

13-54: Berechnete lösliche $\mathrm{NO}_{3}-\mathrm{N}$-Gehalte in den Extrakten, Lysimeter 3 - $8 \ldots \ldots \ldots \ldots \ldots . . . .270$

13-55: Berechnete lösliche Cl-Gehalte in den Extrakten, Lysimeter 3 - 8 .......................271

13-56: Berechnete lösliche $\mathrm{PO}_{4}$-Gehalte in den Extrakten, Lysimeter 3 - 8 .....................271

13-57: Stoffdaten der Sickerwasseruntersuchung, Lysimeter 1 ..................................271

13-58: Stoffdaten der Sickerwasseruntersuchung, Lysimeter 2 ...............................22

13-59: Stoffdaten der Sickerwasseruntersuchung Januar 1991, Lysimeter 1 und 2 ........272 
13-60: Stoffdaten für den Sickerwasser-Austrag 4. Jahr, Lysimeter 1 und 2 ...................272

13-61: Stoffdaten der Sickerwasseruntersuchung, Lysimeter 8 ...................................273

13-62: Stoffdaten der Sickerwasseruntersuchung, Lysimeter 6 ..................................274

13-63: Stoffdaten der Sickerwasseruntersuchung, Lysimeter 5 ..................................275

13-64: Stoffdaten der Sickerwasseruntersuchung, Lysimeter 4 .................................276

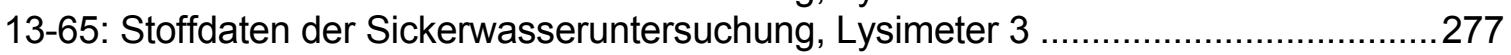

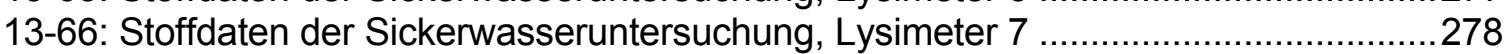

13-67: C-Gehalte und Extinktionen bei 400 und $436 \mathrm{~nm}$ sowie Qotienten

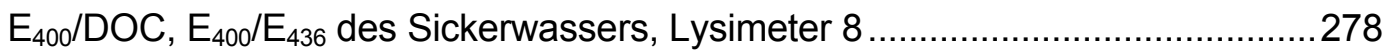

13-68: C-Gehalte und Extinktionen bei 400 und $436 \mathrm{~nm}$ sowie Qotienten

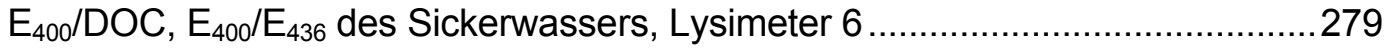

13-69: C-Gehalte und Extinktionen bei 400 und $436 \mathrm{~nm}$ sowie Qotienten

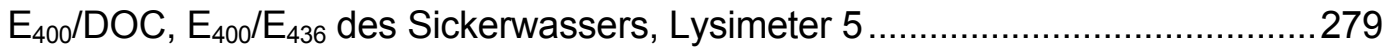

13-70: C-Gehalte und Extinktionen bei 400 und $436 \mathrm{~nm}$ sowie Qotienten

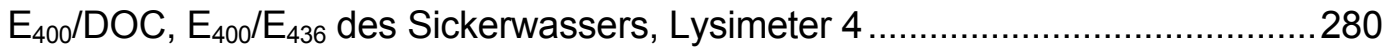

13-71: C-Gehalte und Extinktionen bei 400 und $436 \mathrm{~nm}$ sowie Qotienten

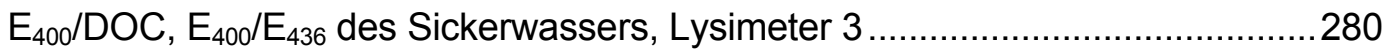

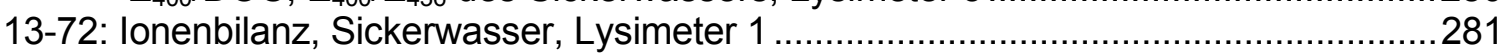

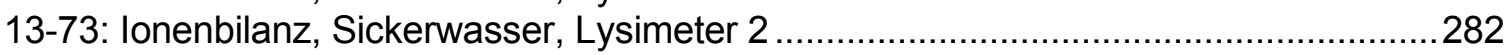

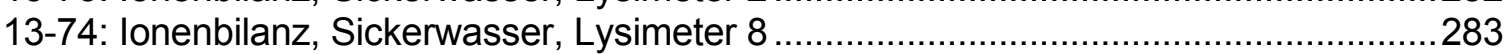

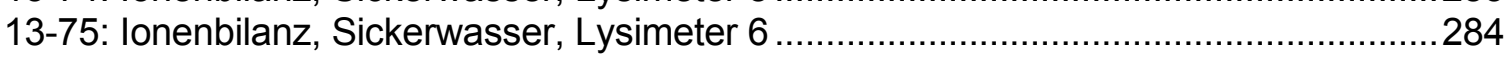

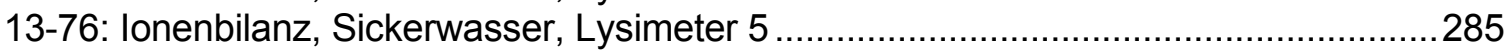

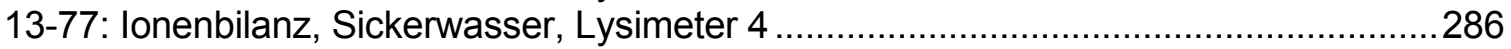

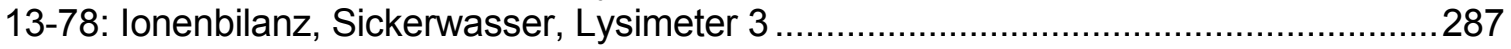

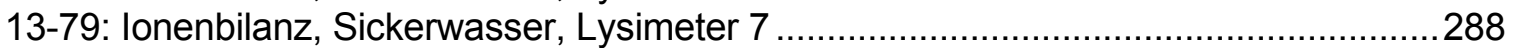

13-80: Gel-chromatographische Fraktionierung, Lysimeter 1 …..................................296

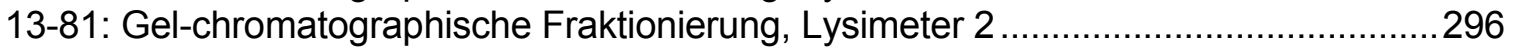

13-82: Gel-chromatographische Fraktionierung, Lysimeter 8 ....................................297

13-83: Gel-chromatographische Fraktionierung, Lysimeter 6 ..................................297

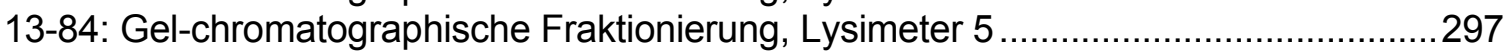

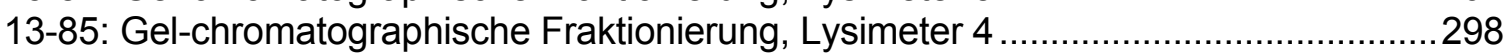

13-86: Gel-chromatographische Fraktionierung, Lysimeter 3 .....................................298

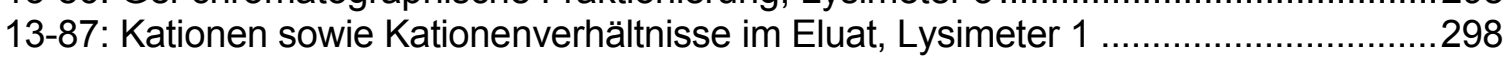

13-88: Kationen sowie Kationenverhältnisse im Eluat, Lysimeter 1 ...............................299

13-89: pH-Wert, DOC, Kationen sowie Kationenverhältnisse im Eluat, Lysimeter 1 ........300

13-90: pH-Wert, DOC, Kationen sowie Kationenverhältnisse im Eluat, Lysimeter 2 .......301

13-91: pH-Wert, DOC, Kationen sowie Kationenverhältnisse bei verlängerter

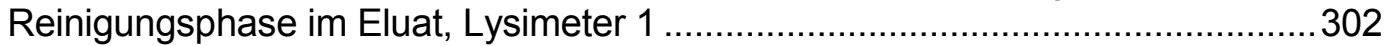

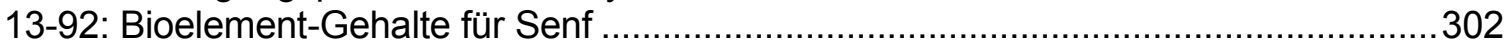

13-93: DOC- und Mineralstoff-Bilanz in g pro Lysimeter, Lysimeter 1 ..............................302

13-94: Bilanzierung der Stoffausträge in g pro Lysimeter, Lysimeter 2 ...........................303

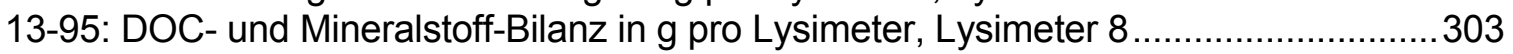

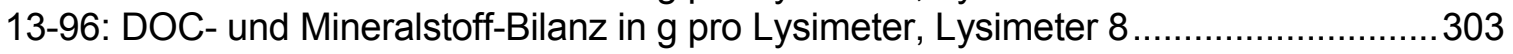

13-97: DOC- und Mineralstoff-Bilanz in g pro Lysimeter, Lysimeter $5 \ldots \ldots \ldots \ldots \ldots \ldots \ldots \ldots \ldots . . . . . . . . . . . . . . . .303$

13-98: DOC- und Mineralstoff-Bilanz in g pro Lysimeter, Lysimeter 4 ..............................304

13-99: DOC- und Mineralstoff-Bilanz in g pro Lysimeter, Lysimeter 3 ..............................304

13-100: DOC- und Mineralstoff-Bilanz in g pro Lysimeter, Lysimeter 7 ..........................304

13-101: DOC- und Mineralstoff-Bilanz in g/kg TM, Lysimeter 1 ...................................305

13-102: DOC- und Mineralstoff-Bilanz in g/kg TM, Lysimeter 2 ....................................305

13-103: DOC- und Mineralstoff-Bilanz in g/kg TM, Lysimeter 8...................................306

13-104: DOC- und Mineralstoff-Bilanz in g/kg TM, Lysimeter 6 ....................................306

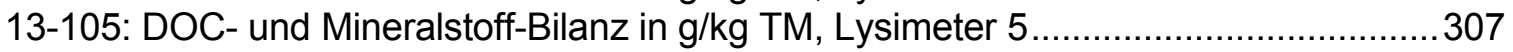

13-106: DOC- und Mineralstoff-Bilanz in g/kg TM, Lysimeter 4 ...................................307

13-107: DOC- und Mineralstoff-Bilanz in g/kg TM, Lysimeter 3 ...................................308

13-108: DOC- und Mineralstoff-Bilanz in g/kg TM, Lysimeter 7 .................................308 


\section{ABBILDUNGSVERZEICHNIS}

Nummer Seite

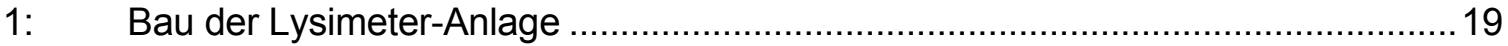

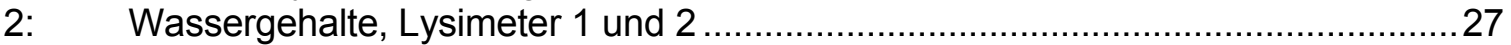

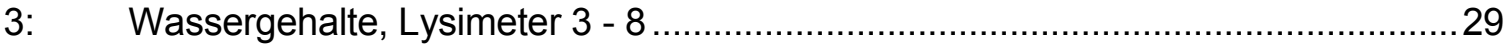

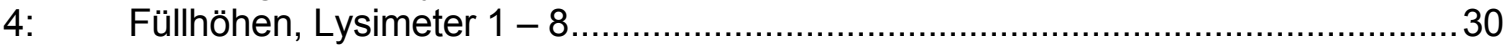

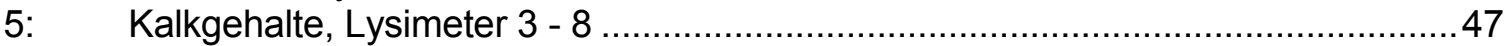

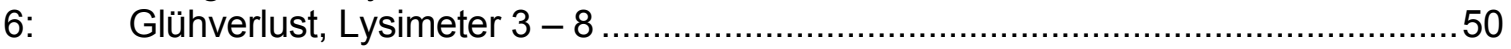

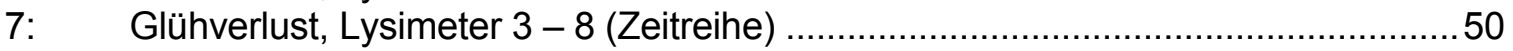

8: $\quad$ C-Gehalte in \% der TM und C/N-Verhältnisse, Lysimeter 1 und $2 \ldots \ldots \ldots \ldots \ldots \ldots \ldots . . . . . . . . . . .53$

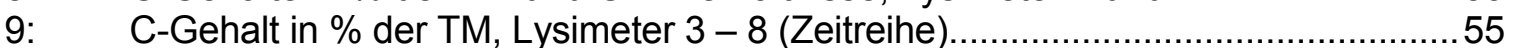

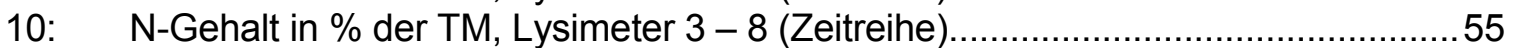

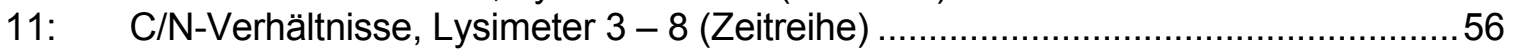

12: $\quad$ Glühverlust/ $\mathrm{C}_{\text {org }}$-Verhältnisse, Lysimeter 1 und 2 ............................................59

13: $\quad$ Glühverlust-/C org Verhältnisse, Lysimeter 3 - 8 (Zeitreihe) …................................60

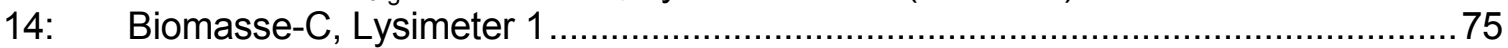

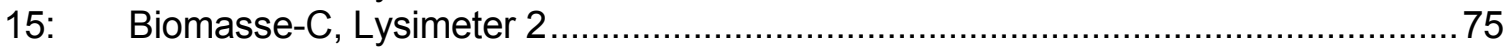

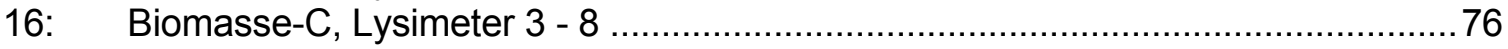

17: $\quad$ Leitfähigkeit im 1:2-Kompost:Wasser-Extrakt, Lysimeter 1 und $2 \ldots \ldots \ldots \ldots \ldots \ldots \ldots \ldots . . . . .11$

18: $\quad$ Leitfähigkeit im 1:2-Kompost:Wasser-Extrakt, Lysimeter 3 - 8 ........................... 82

19: $\quad$ Kationen-Gehalte im 1:2-Kompost:Wasser-Extrakt, Lysimeter 1 .......................... 83

20: $\quad$ Kationen-Gehalte im 1:2-Kompost:Wasser-Extrakt, Lysimeter 2 ........................ 83

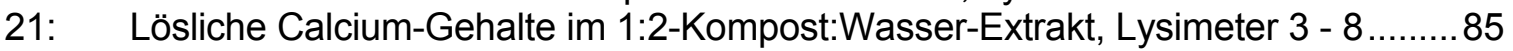

22: Lösliche Magnesium-Gehalte im 1:2-Kompost:Wasser-Extrakt, Lysimeter 3 - $8 \ldots 85$

23: $\quad$ Lösliche Kalium-Gehalte im 1:2-Kompost:Wasser-Extrakt, Lysimeter 3 - $8 \ldots \ldots \ldots . . .86$

24: $\quad$ Lösliche Natrium-Gehalte im 1:2-Kompost:Wasser-Extrakt, Lysimeter 3 - 8 .........86

25: Lösliche Anionen-Gehalte im 1:2-Kompost:Wasser-Extrakt, Lysimeter $1 \ldots \ldots \ldots \ldots . . . .88$

26: Lösliche Anionen-Gehalte im 1:2-Kompost:Wasser-Extrakt, Lysimeter 2 .............88

27: $\quad$ ösliche Sulfat-Gehalte im 1:2-Kompost:Wasser-Extrakt, Lysimeter 3 - 8............ 89

28: $\quad$ Lösliche P-Gehalte im 1:2-Kompost:Wasser-Extrakt, Lysimeter 3 - 8................... 89

29: $\quad$ Vergleich gelöster Verbindungen im 1:10 und 1:2-Kompost:Wasser-Extrakt,

Lysimeter 1 ........................................................................................... 91

30: Vergleich gelöster Verbindungen im 1:10-Kompost:Wasser-Extrakt (f-w-s)

und 1:2-Kompost:Wasser-Extrakt (t-m-s), Lysimeter 1 ...................................... 91

31: Vergleich gelöster Verbindungen im 1:10-Kompost:Wasser-Extrakt (f-w-s) und 1:2-

Kompost:Wasser-Extrakt (t-m-s), Lysimeter 2 .................................................92

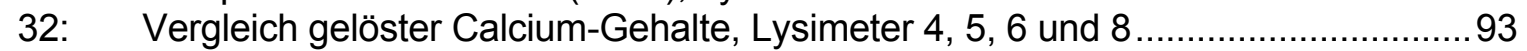

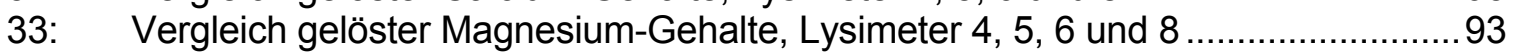

34: $\quad$ Vergleich gelöster Kalium-Gehalte, Lysimeter 4, 5, 6 und 8 ................................. 94

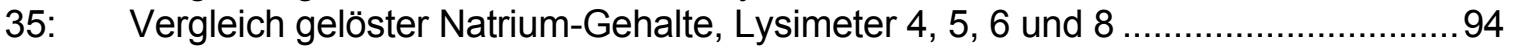

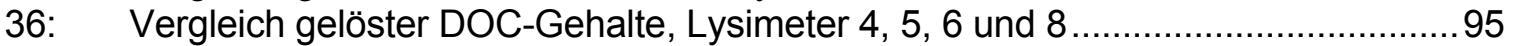

37: $\quad$ Vergleich gelöster $\mathrm{HCO}_{3}$-Gehalte, Lysimeter 4, 5, 6 und 8...............................95

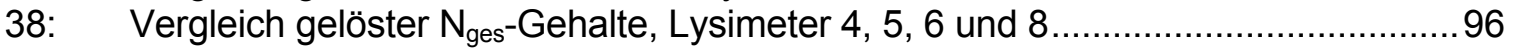

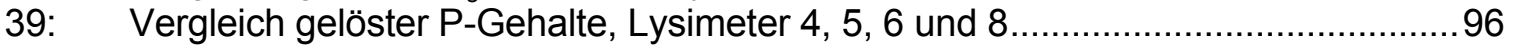

40: $\quad$ Gelöste Kalium-Gehalte im ersten und zweiten Extrakt, Lysimeter 1 .....................98

41: $\quad$ Leitfähigkeit im ersten und zweiten Extrakt, Lysimeter 2 ...................................98

42: $\quad$ Gelöste DOC-Gehalte im ersten und zweiten Extrakt, Lysimeter 1 ....................100

43: $\quad$ Gelöste $\mathrm{HCO}_{3}$-Gehalte im ersten und zweiten Extrakt, Lysimeter 2 .................... 100

44: $\quad$ Gelöste Ca-Gehalte im ersten und zweiten Extrakt, Lysimeter 3 - 8 .................. 102

45: $\quad$ Gelöste $\mathrm{HCO}_{3}$-Gehalte im ersten und zweiten Extrakt, Lysimeter 3 - $8 \ldots \ldots \ldots \ldots \ldots \ldots . . \ldots 102$

46: $\quad$ Gelöste DOC-Gehalte im ersten und zweiten Extrakt, Lysimeter 3 - 8 ............... 103

47: $\quad$ Leitfähigkeit im ersten und zweiten Extrakt, Lysimeter 3 - 8 …........................ 104

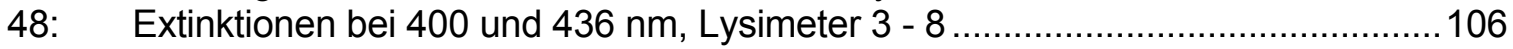


49: $\quad$ Vergleich der Quotienten $\mathrm{E}_{400} / \mathrm{DOC}$ verschiedener Extrakte, Lysimeter 3 - 8 ...... 107

50: $\quad$ Vergleich der Quotienten $\mathrm{E}_{400} / \mathrm{E}_{436}$ verschiedener Extrakte, Lysimeter 3 - 8........107

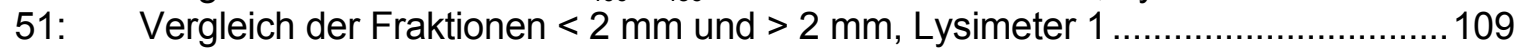

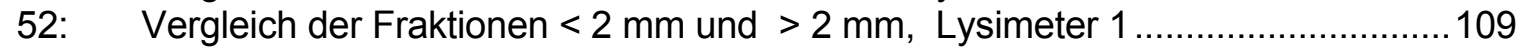

53: Vergleich monatlichen Niederschlagssummen ...............................................112

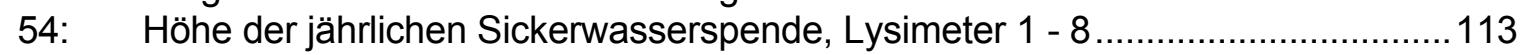

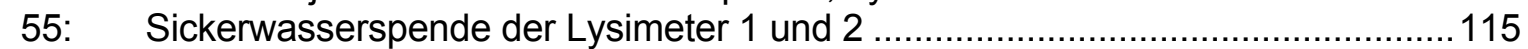

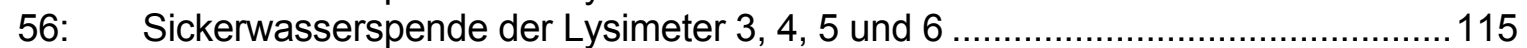

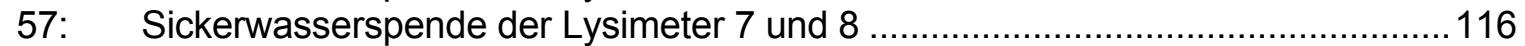

58: $\quad$ Verlauf der Leitfähigkeitswerte im Sickerwasser, Lysimeter 1 und 2...................123

59: $\quad$ Verlauf der Leitfähigkeitswerte im Sickerwasser, Lysimeter 3 bis $8 \ldots \ldots \ldots \ldots \ldots \ldots . . . . .124$

60: Verlauf der $\mathrm{N}_{\min }$ - und $\mathrm{N}_{\text {org }}$-Gehalte im Sickerwasser, Lysimeter 1 und 2 ............. 125

61: Verlauf der $\mathrm{C}_{\mathrm{t}^{-}}, \mathrm{N}_{\mathrm{t}}-$ Gehalte und der $\mathrm{C}_{\mathrm{t}} / \mathrm{N}_{\mathrm{t}^{-}}$-Verhältnisse im Sickerwasser,

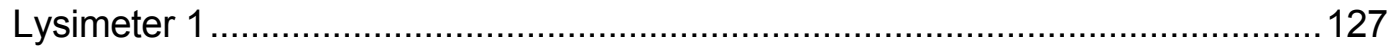

62: Verlauf der $\mathrm{C}_{\mathrm{t}^{-}}, \mathrm{N}_{\mathrm{t}}$-Gehalte und der $\mathrm{C}_{\mathrm{t}} / \mathrm{N}_{\mathrm{t}}$-Verhältnisse im Sickerwasser,

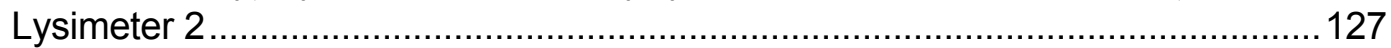

63: Verlauf der $\mathrm{N}_{\mathrm{t}}$ - und $\mathrm{NO}_{3}-\mathrm{N}-$ Gehalte im Sickerwasser, Lysimeter $1 \ldots \ldots \ldots \ldots \ldots \ldots \ldots . . .129$

64: Verlauf der $\mathrm{N}_{\mathrm{t}}$ - und $\mathrm{NO}_{3}-\mathrm{N}$-Gehalte im Sickerwasser, Lysimeter 2 ....................129

65: Verlauf der $\mathrm{NO}_{3}-\mathrm{N}-$ Konzentrationen im Sickerwasser, Lysimeter 8, 6 und $5 \ldots \ldots .131$

66: Verlauf der $\mathrm{NO}_{3}-\mathrm{N}-$ Konzentrationen im Sickerwasser, Lysimeter 4, 3 und 7 ......131

67: Verlauf der DOC- und $\mathrm{HCO}_{3}-\mathrm{C}$-Konzentrationen im Sickerwasser,

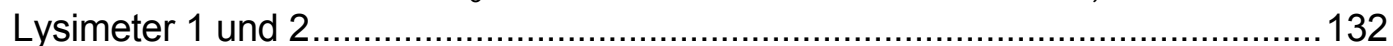

68: Verlauf der Extinktion bei 400 und $436 \mathrm{~nm}$ in den Sickerwasser-Proben,

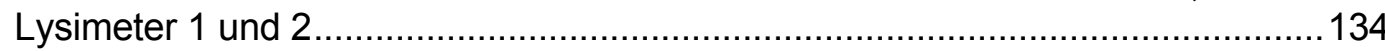

69: Quotienten der Extinktionen bei 400 und $436 \mathrm{~nm}$ der Sickerwasser-Proben,

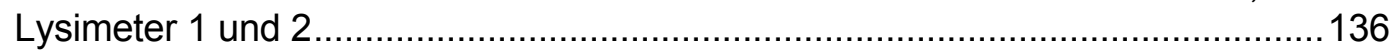

70: Quotienten der Extinktion bei $400 \mathrm{~nm}$ und dem DOC-Gehalt der Sickerwasser-

Proben, Lysimeter 1 und 2 .........................................................................136

71: Verlauf der DOC-Konzentrationen im Sickerwasser, Lysimeter 8, 6 und 5......... 138

72: Verlauf der DOC-Konzentrationen im Sickerwasser, Lysimeter 4, 3 und 7 ..........138

73: $\quad$ Verlauf der Extinktionen bei $400 \mathrm{~nm}$, Lysimeter 3 - 8 ..................................... 140

74: $\quad K$ leinlysimeter 3 -6 und 8: Zeitgang der Quotienten Extinktion 400 nm durch DOC $\mathrm{mg} / \mathrm{l}$.

75: Kleinlysimeter 3 -6 und 8: Zeitgang der Quotienten Extinktion bei 400 und

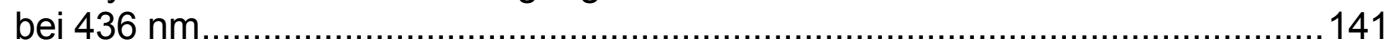

76: Konzentrationsverlauf der Kationen im Sickerwasser, Lysimeter 1 ..................... 143

77: Konzentrationsverlauf der Anionen im Sickerwasser, Lysimeter 1 ......................143

78: Konzentrationsverlauf der Kationen im Sickerwasser, Lysimeter 2 ..................... 145

79: Konzentrationsverlauf der Anionen im Sickerwasser, Lysimeter 2 ...................... 145

80: Konzentrationsverlauf der Kationen im Sickerwasser, Lysimeter 8 …................... 147

81: Konzentrationsverlauf der Kationen im Sickerwasser, Lysimeter 4 ..................... 147

82: Konzentrationsverlauf der Kationen im Sickerwasser, Lysimeter 7 ....................... 148

83: Konzentrationsverlauf der Anionen im Sickerwasser, Lysimeter 8...................... 148

84: Konzentrationsverlauf der Anionen im Sickerwasser, Lysimeter 4 ...................... 149

85: Konzentrationsverlauf der Anionen im Sickerwasser, Lysimeter 7 ...................... 149

86: Vergleich der DOC-Jahres-Durchschnittskonzentrationen, Lysimeter 1 - 8 .........153

87: $\quad$ Vergleich der $\mathrm{SO}_{4}$-Jahres-Durchschnittskonzentrationen, Lysimeter 1 - 8 .......... 153

88: Vergleich der $\mathrm{HCO}_{3}$-Jahres-Durchschnittskonzentrationen, Lysimeter 1 - 8........ 154

89: $\quad$ Vergleich der P-Jahres-Durchschnittskonzentrationen, Lysimeter 1 - 8............... 154

90: $\quad$ Kationen-Anionendifferenz im Sickerwasser, Lysimeter 1 - 8 ..............................158

91: DOC-Sickerwasser-Austrag in g von Mai 87 bis April 90, Lysimeter 3 - 8 ........... 162

92: $\quad \mathrm{HCO}_{3}$-Sickerwasser-Austrag in g von Mai 87 bis April 90, Lysimeter 3 - $8 \ldots \ldots \ldots . .162$

93: Gesamt-C- Sickerwasser-Austrag in g von Mai 87 bis April 90, Lysimeter 3 - 8.. 163

94: $\quad$ Ca-Sickerwasser-Austrag in g von Mai 87 bis April 90, Lysimeter 3 - $8 \ldots \ldots \ldots \ldots \ldots . .163$

95: Mg-Sickerwasser-Austrag in $\mathrm{g}$ von Mai 87 bis April 90, Lysimeter 3 - 8 ..............164

96: K-Sickerwasser-Austrag in g von Mai 87 bis April 90, Lysimeter 3 - 8 ................. 164 
97: Na-Sickerwasser-Austrag in g von Mai 87 bis April 90, Lysimeter 3 - 8 ............... 165

98: $\quad$ Fe-Sickerwasser-Austrag in g von Mai 87 bis April 90, Lysimeter 3 - 8 ................165

99: $\quad \mathrm{SO}_{4}$-Sickerwasser-Austrag in $\mathrm{g}$ von Mai 87 bis April 90, Lysimeter $3-8 \ldots \ldots \ldots \ldots . .166$

100: P-Sickerwasser-Austrag in g von Mai 87 bis April 90, Lysimeter 3 - $8 \ldots \ldots \ldots \ldots \ldots . . .166$

101: Cl-Sickerwasser-Austrag in g von Mai 87 bis April 90, Lysimeter 3 - 8 ............... 167

102: $\quad \mathrm{N}_{\text {min }}$-Sickerwasser-Austrag in g von Mai 87 bis April 90, Lysimeter 3 - $8 \ldots \ldots \ldots \ldots . .167$

103: $\quad N_{\text {org }}$-Sickerwasser-Austrag in g von Mai 87 bis April 90, Lysimeter 3 - 8............ 168

104: DOC-Sickerwasser-Austrag in $\mathrm{g} / \mathrm{kg}$ Kompost-TM von Mai 87 bis April 90,

Lysimeter 1 - 8 ....

105: $\quad \mathrm{HCO}_{3}$-Sickerwasser-Austrag in $\mathrm{g} / \mathrm{kg} \mathrm{Kompost-TM}$ von Mai 87 bis April 90,

Lysimeter 1 - 8 .....

106: $\quad C_{\text {ges }}$-Sickerwasser-Austrag in g/kg Kompost-TM von Mai 87 bis April 90,

Lysimeter 1 - 8 .

107: Ca-Sickerwasser-Austrag in g/kg Kompost-TM von Mai 87 bis April 90,

Lysimeter 1 - 8 .

108: Mg-Sickerwasser-Austrag in g/kg Kompost-TM von Mai 87 bis April 90,

Lysimeter 1 - 8 .

109: K-Sickerwasser-Austrag in $\mathrm{g} / \mathrm{kg}$ Kompost-TM von Mai 87 bis April 90,

Lysimeter 1 - 8.....

110: Na-Sickerwasser-Austrag in g/kg Kompost-TM von Mai 87 bis April 90,

Lysimeter 1 - 8 .....

111: Fe-Sickerwasser-Austrag in g/kg Kompost-TM von Mai 87 bis April 90,

Lysimeter 1 - 8 .

112: P-Sickerwasser-Austrag in $\mathrm{g} / \mathrm{kg}$ Kompost-TM von Mai 87 bis April 90,

Lysimeter 1 - 8

113: $\mathrm{SO}_{4}$-Sickerwasser-Austrag in $\mathrm{g} / \mathrm{kg} \mathrm{Kompost-TM}$ von Mai 87 bis April 90,

Lysimeter 1 - 8 .

114: Cl-Sickerwasser-Austrag in g/kg Kompost-TM von Mai 87 bis April 90,

Lysimeter 1 - 8 .

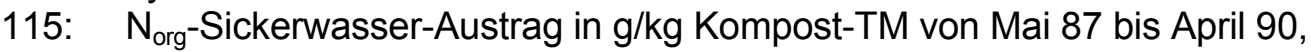

Lysimeter 1 - 8

116: $\quad \mathrm{N}_{\text {min }}$-Sickerwasser-Austrag in $\mathrm{g} / \mathrm{kg}$ Kompost-TM von Mai 87 bis April 90,

Lysimeter 1 - 8 ......

Filtrationsanlage

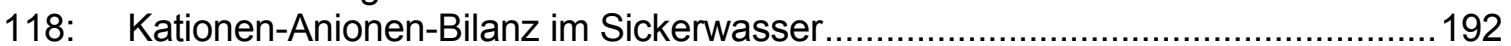

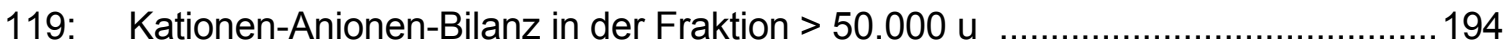

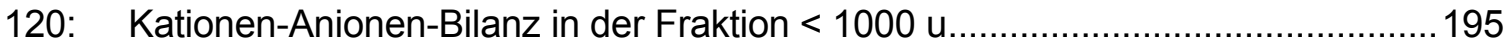

121: Säurefällbare DOC-Anteile in der Fraktion > 50.000 ........................................ 197

122: C-, N-Gehalte in \% der TM und C/N-Verhältnisse der säurefällbaren

Huminstoffe der Fraktion > 50.000 ............................................................. 198

123: Prinzip der Molekülgrößentrennung bei der Gel-Chromatographie ......................200

124: $\quad$ Eichgerade für das Sephadex Gel G 50 superfine...........................................201

125: Schematische Darstellung der Gelpermeations-Chromatographie-Anlage...........202

126: Vergleich der mittleren Peakhöhen und Quotienten P 1/P 3 ..............................204

127: GC-Chromatogramm, Kompost-Ausgangsmaterial März 86 …..........................206

128: GC-Chromatogramme, Kompost- und Kompost-/Löss-Mischungen .....................206

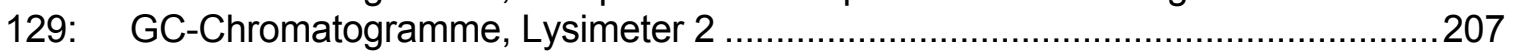

130: Verlauf der DOC- und Kationen-Konzentrationen in den Eluaten der AC,

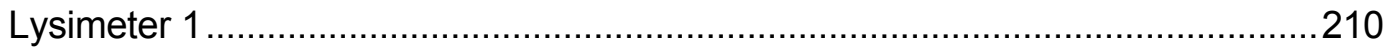

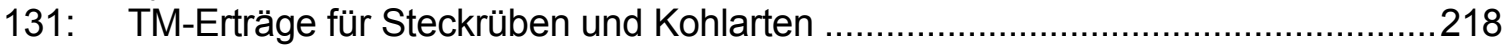

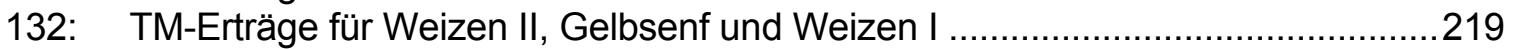

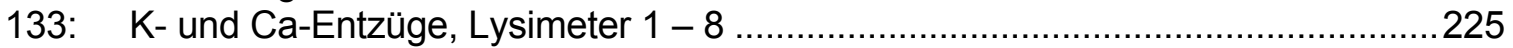

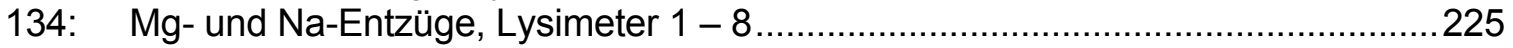

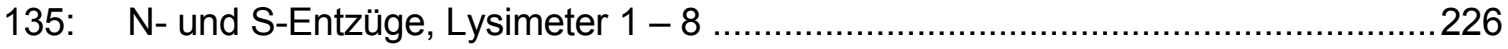

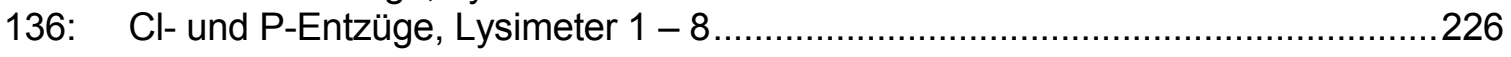




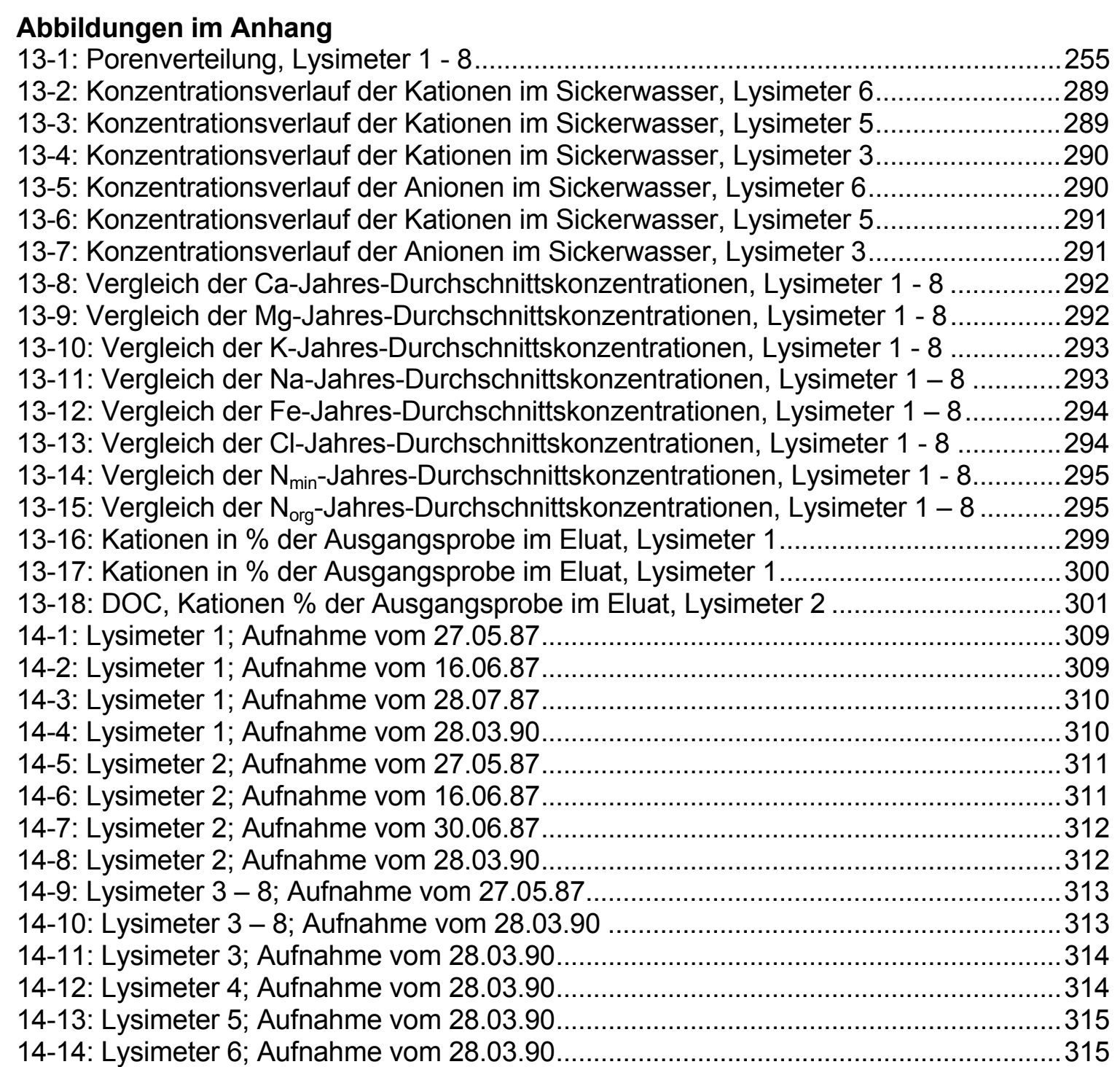


AbfG

a. d.

AAS

Abb.

AC

BAK

BBodSchV

$B_{c}$

BE

ber.

BGK

bidest.

BioAbV

BMU

BMVEL

BRD

c

$C_{\text {org }}$

$\mathrm{C}_{\mathrm{t}}$

D

d.

dest.

DOC

DüMG

DüMV

DüV

$E_{c}$

$E_{400}$

$E_{436}$

EEG

EDTA

EU

f
Abfallbeseitigungsgesetz

aqua destillata

Atom-Absorptions-Spektrometrie

Abbildung

Adsorptions-Chromatographie

Bioabfallkompost

Bundes-Bodenschutzverordnung

Biomasse-Kohlenstoff

Boden-Extrakt

berechnet

Bundesgütegemeinschaft Kompost e. V.

bidestilliertes

Bioabfallverordnung

Bundesministerium für Umwelt, Naturschutz und Reaktorsicherheit

Bundesministerium für Verbraucherschutz, Ernährung und Landwirtschaft

Bundesrepublik Deutschland

Stoffmengen-Konzentration

organischer Kohlenstoff

analytisch bestimmter gesamter organischer und anorganischer Kohlenstoff

Dialysat

der

destilliertes

gelöster organischer Kohlenstoff (engl. dissolved organic carbon)

Düngemittelgesetz

Düngemittelverordnung

Düngeverordnung

Differenz des C-Gehaltes im $\mathrm{K}_{2} \mathrm{SO}_{4}$-Extrakt der begasten und der unbegasten Probe

Extinktion der verdünnten Probe bei $400 \mathrm{~nm}$

Extinktion der verdünnten Probe bei 436 nm

Erneuerbare-Energien-Gesetz

Ethylendiamintetraessigsäure

Europäische Union

frisch 


\begin{tabular}{|c|c|}
\hline f & fumigiert \\
\hline $\mathbf{F}$ & Filtrat \\
\hline FA & Fulvosäure \\
\hline Feb & Februar \\
\hline FES & Flammen-Emissionsspektrometrie \\
\hline FM & Frischmasse \\
\hline GC & Gel-Chromatographie \\
\hline ggfs. & gegebenenfalls \\
\hline Gp & Grobporen \\
\hline GPC & Gelpermeations-Chromatographie \\
\hline GPV & Gesamtporenvolumen \\
\hline GV & Glühverlust \\
\hline h & Stunde \\
\hline HA & Huminsäure \\
\hline HUS & Huminstoffe \\
\hline ID & Innendurchmesser \\
\hline IE & Ionenäquivalent \\
\hline Jan & Januar \\
\hline k. A. & keine Angaben \\
\hline $\mathrm{KAK}_{\text {pot }}$ & potenzielle Kationenaustausch-Kapazität \\
\hline konz. & konzentriert \\
\hline KrW-/AbfG & Kreislaufwirtschafts- und Abfallgesetz \\
\hline $\mathbf{L}$ & Lysimeter \\
\hline $\mathbf{L}$ & Auschlussgrenze \\
\hline LE & Laugenextrakt \\
\hline $\mathbf{m}$ & membranfiltriert \\
\hline m & im Mörser zerkleinert \\
\hline Max & Maximum \\
\hline Mg & Megagramm \\
\hline Min & Minimum \\
\hline Mio & Millionen \\
\hline Mp & Mittelporen \\
\hline Mrz & März \\
\hline MW & Mittelwert \\
\hline nFK & nutzbare Feldkapazität \\
\hline $\mathbf{N}_{\min }$ & Mineralischer Stickstoff \\
\hline $\mathbf{N}_{\text {org }}$ & organischer Stickstoff \\
\hline $\mathbf{N}_{\text {su }}$ & berechnete Summe organischer und mineralischer Stickstof \\
\hline
\end{tabular}




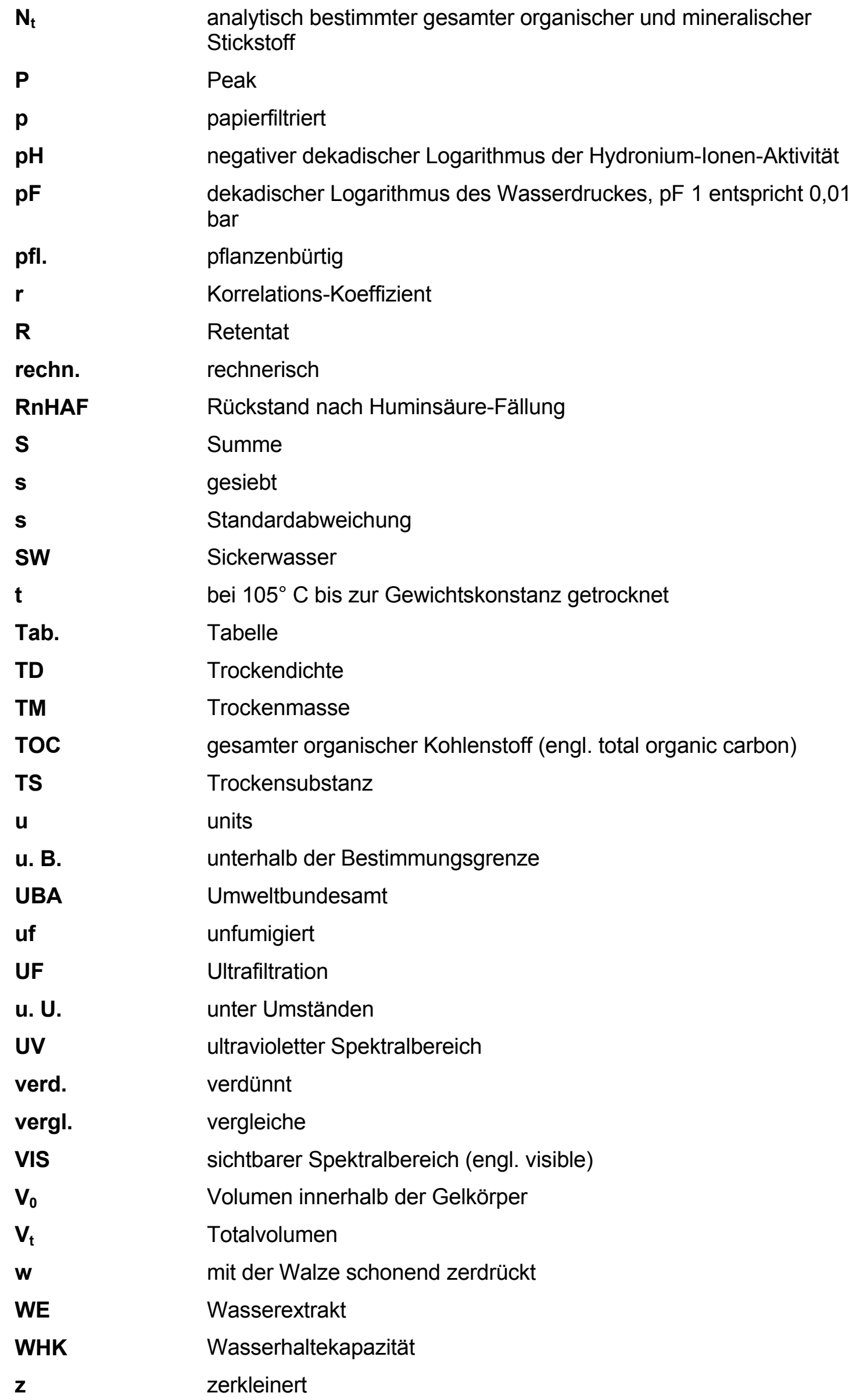




\section{Einleitung}

\subsection{Kompostierung: Rechtliche Rahmenbedingungen / Aktuelle Diskussionen}

Als Maßnahme zur Abfallverwertung ist die Kompostierung seit den fünfziger Jahren in der Bundesrepublik etabliert. Als in den 70er Jahren durch die bis dahin unkontrollierte Abfallbeseitigung Umweltprobleme auftraten, war dies auch der Beginn der Abfallgesetzgebung. Ein vordringliches Ziel des ersten Abfallbeseitigungsgesetzes (AbfG) von $1972^{1}$ war es deshalb, eine geordnete Abfallbeseitigung einzuführen. 1986 wurden die Abfallvermeidung und Abfallverwertung mit dem Gesetz über die Vermeidung und Entsorgung von Abfällen ${ }^{2}$ als vorrangige Ziele eingeführt. Abfallvermeidung hatte in erster Linie die Bedeutung einer Vermeidung durch Verwertung (MARTENS 1999). Die Verwertung bezog sich auf die getrennte Erfassung gut verwertbarer Bestandteile aus dem Hausmüll, wie Papier, Glas, Metalle und Bioabfälle. Trotz dieser Bemühungen stieg das Aufkommen an Siedlungsabfällen weiter an. Die zunehmende Umwelt-Inanspruchnahme durch Deponien machte eine Verringerung der zu beseitigenden Abfallmengen erforderlich. Mit dem Kreislaufwirtschaftsund Abfallgesetz (KrW-/AbfG), das am 27.09.1994 ${ }^{3}$ in Kraft getreten ist, sollte einem geänderten Entsorgungsverständnis Rechnung getragen werden. Aus dem KrW-/AbfG, das zur Schonung der natürlichen Ressourcen verpflichtet, leitete sich die Forderung ab, nativ organische Reststoffe getrennt zu erfassen und durch Kompostierung umweltverträglich zu verwerten. Ab Mitte der achtziger Jahre erlebte die separate Erfassung von Bioabfällen einen Auftrieb, der Mitte der neunziger Jahre seinen Höhepunkt erreichte. Die Behandlung organischer Abfälle in Kompostierungsanlagen galt als ein Paradebeispiel für die nach dem KrW-/AbfG vorgesehene Schließung von Stoffkreisläufen durch die Wiederverwertung von Reststoffen.

Mit der Erarbeitung der Bioabfallverordnung (BioAbfV) von $1998^{4}$ wurde der stark gewachsenen Bioabfallerfassung und -verwertung und den hieraus resultierenden Forderungen nach rechtsverbindlichen Qualitätsvorgaben Rechnung getragen. Die BioAbfV ist die wichtigste Vorgabe für den Einsatz von Kompost auf landwirtschaftlich, forstwirtschaftlich und gärtnerisch genutzten Flächen. Sie regelt im Wesentlichen Untersuchungs- und Nachweispflichten, Anwendungsmengen, zulässige Schadstoffgehalte, Anforderungen an die Phyto- und Seuchenhygiene sowie Vorgaben zum gleichzeitigen Einbringen von Bioabfallkompost und Klärschlamm. In der BioAbfV sind Grenzwerte für maximal zulässige Schwermetall-Konzentrationen in Bioabfällen und Böden, gestaffelt nach Bodenarten, festgelegt. Die Bodenvorsorgewerte der Bundes-Bodenschutz- und Altlastenverordnung (BbodSchV) $1999^{5}$ wurden bei der Erarbeitung der BioAbfV berücksichtigt. Für organische Schadstoffe sind bislang in der BioAbfV noch keine Grenzwerte vorgesehen.

Tabelle 1-1 fasst die rechtlichen Vorgaben für die Kompostanwendung zusammen.

\footnotetext{
${ }^{1}$ Gesetz über die Beseitigung von Abfällen (Abfallbeseitigungsgesetz AbfG) vom 7. Juni 1972 (BGBI. 1 S. 873)

${ }^{2}$ Gesetz über die Vermeidung und Entsorgung von Abfällen (Abfallgesetz AbfG) vom 27. August 1986 (BGBI. 1 S. 1410, 1501), zuletzt geändert durch Gesetz vom 30. September 1994 (BGBI. 1 S. 2771)

3 Gesetz zur Förderung der Kreislaufwirtschaft und Sicherung der umweltverträglichen Beseitigung von Abfällen (Kreislaufwirtschafts-und Abfallgesetz KrW-/AbfG) vom 27. September 1994 (BGBI. I S. 2705) zuletzt geändert am 29. Oktober 2001 (BGBI I S. 2785)

${ }^{4}$ Bioabfallverordnung (BioAbfV)vom 21. September 1998 (BGBI. I S. 2955) zuletzt geändert am 25. April 2002 (BGBI I S. 1488)

${ }^{5}$ Bundes-Bodenschutz- und Altlastenverordnung (BBodSchV) vom 12. Juli 1999 (BGBI I S. 1554)
} 
Tabelle 1-1: Rechtliche Vorgaben für die Kompostanwendung (nach BIDLINGMAIER 2000 ergänzt)

\begin{tabular}{|c|c|c|}
\hline Bereich & Gesetz/Verordnung & Wichtige Anforderungen \\
\hline \multirow[t]{2}{*}{ Boden } & $\begin{array}{l}\text { Bundes-Bodenschutzgesetz } \\
\text { (BBodSchG) vom 17.03.1998 }\end{array}$ & $\begin{array}{l}\text { Unschädliche Verwertung von Abfällen unter Beibehaltung } \\
\text { der Leistungsfähigkeit des Bodens und Beachtung des } \\
\text { Schutzes der Bodenfunktionen. }\end{array}$ \\
\hline & $\begin{array}{l}\text { Bodenschutzverordnung } \\
\text { (BodSchV) vom } 12.07 .99 \text { und } \\
\text { BMU/BMVEL-Konzept vom } \\
03.06 .2002^{7}\end{array}$ & $\begin{array}{l}\text { Maximal zulässige Schadstofffrachten; Beachtung der Vor- } \\
\text { sorgewerte für Schwermetalle und organische Stoffe in } \\
\text { Böden. } \\
\text { Das am } 31.07 .2002 \text { vom UBA vorgeschlagene Modell } \\
\text { „Gleiches zu Gleichem“ bezieht die Schwermetall-Gehalte } \\
\text { von Düngemitteln auf den langfristig im Boden verblei- } \\
\text { benden Anteil. }\end{array}$ \\
\hline \multirow[t]{2}{*}{ Abfall } & $\begin{array}{l}\text { Kreislaufwirtschafts- und Ab- } \\
\text { fallgesetz (KrW-/AbfG) vom } \\
\text { 27.09.1994 }\end{array}$ & $\begin{array}{l}\text { Ermächtigung zum Erlass rechtlicher Vorgaben (Bioabfall- } \\
\text { verordnung) für den Einsatz von Kompost auf landwirt- } \\
\text { schaftlich, forstwirtschaftlich oder gärtnerisch genutzten } \\
\text { Flächen. }\end{array}$ \\
\hline & $\begin{array}{l}\text { Bioabfallverordnung (BioAbfV) } \\
\text { vom 01.10.1998 }\end{array}$ & $\begin{array}{l}\text { Einhaltung der maximal zulässigen Schwermetall-Gehalte } \\
\text { und -frachten. Max. Kompostmengen/ha }\end{array}$ \\
\hline \multirow[t]{2}{*}{ Düngung } & $\begin{array}{l}\text { Düngeverordnung (DüV) (inkl. } \\
\text { Umsetzung der EU-Nitratricht- } \\
\text { linie) vom 06.02.1996 }\end{array}$ & $\begin{array}{l}\text { Anwendung nach guter fachlicher Praxis, d. h. Art, Menge, } \\
\text { Zeitpunkt sind auf den Bedarf der Pflanzen auszurichten. }\end{array}$ \\
\hline & $\begin{array}{l}\text { Düngemittelgesetz (DüMG) } \\
\text { vom 15.11.1977 und Dünge- } \\
\text { mittelverordnung (DüMV) vom } \\
26.11 .2003\end{array}$ & $\begin{array}{l}\text { Anforderungen an Typen, Kennzeichnung und Deklaration } \\
\text { bei gewerbsmäßigem Inverkehrbringen. }\end{array}$ \\
\hline
\end{tabular}

Für die Anwendung von Bioabfall-Komposten gelten außerdem das Düngemittelgesetz $(D u ̈ M G)^{10}$, die Düngemittelverordnung (DüMV) ${ }^{11}$ und die Düngeverordnung (DüV) ${ }^{12}$. Nach der DüMV wird der Kompost bei ausreichendem Nährstoffgehalt als „Sekundärrohstoffdünger" eingeordnet. Unterschreitet er die Mindest-Nährstoffgehalte wird er als Bodenverbesserungsmittel klassifiziert.

Die Bioabfallerfassung war in der BRD 2002 in 232 Verwaltungseinheiten (Flächendeckung $77 \%)$ mit einer mittleren Anschlussquote von $56 \%$ eingeführt. Der einwohnerbezogene Anschlussgrad liegt bundesweit bei $47 \%$. Im Erhebungszeitraum 2001/2002 wurden ca. 4,2 Mio. Mg/a Bioabfälle und 2,8 Mio. Mg/a Grünabfälle erfasst. (KEHRES et al. 2003)

\footnotetext{
${ }^{6}$ Gesetz zum Schutz des Bodens (Bundes-Bodeschutzgesetz BbodG) vom 17. März 1998 (BGBI I S. 502)

${ }^{7}$ Vorschlag zur Begrenzung des Eintrags von Schadstoffen bei der Düngung landwirtschaftlicher Nutzflächen (BMVEL/BMU) 02.06.2002 „Gute Qualität und sichere Erträge“ (www.bmu.de/de/txt/download/b-konzept020603)

8 Umweltbundesamt Berlin 31.07.2002 „Zur einheitlichen Ableitung von Schwermetallgrenzwerten bei Düngemitteln“ (www.bmu.de/de/txt/download/b-konzept020603)

${ }^{9}$ Richtlinie 91/676/EWG des Rates vom 12. Dezember 10991 zum Schutz der Gewässer vor Verunreinigungen durch Nitrat aus landwirtschaftlichen Quellen (ABL. EG Nr. L 375 S. 1)

${ }^{10}$ Düngemittelgesetz (DüMG) vom 15. November 1977 (BgBI I S. 2134) zuletzt geändert am 20. Juli 2000 (BGBI I S. 1045)

${ }^{11}$ Verordnung über das Inverkehrbringen von Düngemittel, Bodenhilfsstoffen, Kultursubstraten und Pflanzenhilfsmitteln (Düngemittelverordnung - DüMV) vom 26. November 2003 (BgBI I S. 2373)

${ }^{12}$ Düngeverordnung(DüV) vom 26. Januar 1996 (BGBI I S. 118) zuletzt geändert am 14. Februar 2003 (BGBI I S. 235)
} 
Rückblickend zeigt sich, dass die jährlich von den privaten Haushalten erzeugten Abfallmengen -trotz der Bemühungen diese zu reduzieren - kontinuierlich angestiegen sind. Während sich im Jahr 1995 die Summe aus Haus- und Sperrmüll, organischen Abfällen und Wertstoffen noch auf rd. 35,7 Mio. Mg belief, wurden im Jahr 2000 bereits 37,1 Mio. Mg Abfälle erzeugt. Abfallvermeidungseffekte sind somit nicht zu erkennen, vielmehr stieg die Pro-Kopf-Menge bei gleichzeitig anwachsender Bevölkerungszahl im genannten Zeitraum von 436,8 kg/Ew auf 451,2 kg/Ew pro Jahr. Erfolge hingegen sind bei der Reduzierung des Aufkommens von Haus- und Sperrmüll zu verzeichnen: Hier sank die Menge aufgrund der zunehmenden Getrennterfassung von organischen Abfällen und Wertstoffen von 260,8 $\mathrm{kg} / \mathrm{Ew}$ auf 217,6 kg/Ew pro Jahr im Bundesdurchschnitt. Die Zahlen des Jahres 2000 und die ersten Ergebnisse 2001 zeigen in vielen Bundesländern bereits eine Stagnation und teilweise sogar einen Rückgang der getrennt erfassten Fraktionen. Die getrennt erfassten Bioabfälle sind von 2 Mio. Mg im Jahr 1995 auf 3.781 .800 Mg im Jahr 2000 angestiegen. Die Zunahme der organischen Abfälle aus der getrennten Erfassung um rd. $88 \%$ wird sich in dieser Form nicht mehr fortsetzen. Steigerungspotenziale resultieren im Wesentlichen nur noch aus einer besseren Nutzung bereits bestehender Erfassungssysteme. Von einer flächendeckenden Einführung der Biotonne in der Bundesrepublik wird nicht mehr ausgegangen. (ALWAST et al. 2003)

Die Verwendung der Bioabfall-Komposte erfolgt zum überwiegenden Teil in der Landwirtschaft. Nach einer Erhebung der Bundesgütegemeinschaft Kompost (BGK) von 1998 werden Komposte zu 40 \% in der Landwirtschaft, zu $21 \%$ im Garten- und Landschaftsbau und zu 17 \% von Hobby- und Kleingärtnern eingesetzt (KEHRES et al. 2003).

Die den Komposten allgemein zugesprochenen positiven Eigenschaften liegen in der Zufuhr von Nährstoffen durch „langsame und nachhaltige“ Freisetzung von Nährstoffen, der Pufferkapazität und dem hohen Anteil an organischer Substanz.

Im Einzelnen werden bei sachgerechter Anwendung von Kompost folgende Vorteile für Boden und Pflanze genannt:

- Aktiviert das Bodenleben,

verbessert die Bodenstruktur, erhöht die Stabilität des Bodengefüges und bewirkt damit Verminderung der Bodenerosion (Ma 1990),

- verbessert das Wasserhaltevermögen, die Durchlüftung und die Sorptionskapazität,

- liefert einen Beitrag zur Humusversorgung des Bodens,

- liefert ein dem pflanzlichen Bedarf entsprechendes Nährstoffangebot,

- erhöht die Speicherfähigkeit für Nährstoffe und bewirkt damit eine Verminderung von Nährstoffverlusten,

- $\quad$ stärkt Pflanzen gegen Krankheiten und Stressbedingungen (BRUNS et al. 2003)

- puffert Bodenversauerung ab und

- verbessert die Qualität angebauter Pflanzen (MEIER-PLOEGER und VOGTMANN 2003).

Für eine vergleichende Bewertung der Qualität von Dünge- und Bodenverbesserungsmitteln hat die BGK (REINHOLD 2003) einen Ansatz entwickelt, wertgebende Eigenschaften und Inhaltstoffe in Bezug zu ihrem Schadstoffpotenzial zu bewerten. Wertgebende Inhaltsstoffe werden dabei in die bodenwirksamen Inhaltsstoffe: organischer Kohlenstoff und basisch wirksames $\mathrm{CaO}$ und die pflanzenwirksamen Inhaltsstoffe: $\mathrm{N}, \mathrm{P}_{2} \mathrm{O}_{5}, \mathrm{~K}_{2} \mathrm{O}$ und $\mathrm{MgO}$ differenziert, wobei der Stickstoff in organischen Materialien mit dem Faktor 0,4 berücksichtigt wird. Für die Gewichtung von Vorsorgeaspekten werden die Grenzwerte der BioAbfV für Schwermetalle und Fremdstoffe zugrunde gelegt. 
Trotz der Erfolge, die die Bioabfallkompostierung in den letzten 20 Jahren erzielt hat, geben verschiedene Aspekte Anlass, über das bisherige Konzept der getrennten Erfassung von Bioabfällen nachzudenken:

Die Getrennthaltung der Bioabfälle funktioniert nicht so wie geplant. Die Zahl der Fehlwürfe, insbesondere von Folienkunststoffen, die u. a. zum Sammeln der Bioabfälle verwendet wurden, ist erheblich, was aufwendige Nachsortierungen und damit Verteuerungen zur Folge hat. Die Bioabfall-Erfassungsquoten sind im Vergleich zu anderen Getrenntsammlungssystemen, wie z. B. Papier und Glas, gering. Das System der Getrenntsammlung von Bioabfällen erfordert einen hohen Aufklärungsbedarf (KAIMER et al. 2002).

In der öffentlichen Diskussion werden im Zusammenhang mit dem Betrieb von Kompostieranlagen zunehmend auch Fragen zu gesundheitlichen Risiken durch Emissionen von Gerüchen und gesundheitsgefährdenden Bioaerosolen vorgebracht (UBA 1999b, KERZEL 2003, KÄMPFER 2003, EIKMANN et al. 2003, SRU 2004). Darüber hinaus werden auch Gesundheitsgefahren durch die getrennte Bereitstellung im Haushalt und beim Transport diskutiert (BIDLINGMAIER 2000).

Der vorhandenen hohen Akzeptanz der Bevölkerung, Bioabfälle getrennt zu sammeln und zu verwerten, steht die geringe Akzeptanz der Landwirtschaft zur Verwertung gegenüber. Die nachhaltige Verwertung organischer Abfälle erfordert die Bereitschaft der Landwirtschaft, die lokale und flächenhafte Verwertung der Bioabfälle als ihre Aufgabe zu begreifen. (GÄTH und SCHUG 1998)

Bioabfallkomposte enthalten auch unter besten technischen Bedingungen nicht unerhebliche Mengen an anorganischen und organischen Schadstoffen (UBA 1996, BEISECKER et al. 1997). In der Vergangenheit hat in den Komposten eine Reduktion der SchwermetallGehalte (mit Ausnahme von Kupfer) durch die Optimierung technischer Prozesse und die Reduktion der Einträge von Störstoffen stattgefunden. Doch wird für die in BioabfallKomposten verbleibende Schwermetallbelastung die Ausgangsbelastung der KompostRohstoffe weiterhin verantwortlich gemacht (KEHRES et al. 2003). Durch die Verluste an organischer Substanz während der Kompostierung findet zwangsläufig eine Anreicherung abbauresistenter Verbindungen im Verlauf der Rotte statt. Die resultierende Schadstoffbelastung stellt eine wesentliche Größe für die Begrenzung der Aufwandmenge dar. Die durch den Effekt der Aufkonzentrierung stattfindende Anreicherung anorganischer und organischer Schadstoffe in Bioabfallkomposten sollte nicht nur dazu Anlass geben, die Anwendung von Bioabfallkomposten $\mathrm{zu}$ begrenzen, sondern auch dazu führen, grundsätzlich über die Verwendung und Eintrittspfade dieser Stoffe und deren Reduktion nachzudenken. Für Böden sollten standortabhängige Grenzwerte unter Berücksichtigung der Filter- und Verlagerungseigenschaften erstellt werden (GÄTH 1998). Vor dem Hintergrund der Schadstoffbelastung wird der Absatz steigender Kompostmengen als kritisch angesehen.

Durch die Kompostzufuhr werden erhebliche Mengen an Salzen in Böden eingetragen, die einen kritisch zu bewertenden Verlagerungsschub an löslichen Salzen bewirken. Durch ihre komplexe Zusammensetzung können Bioabfallkomposte auf vielfältige Weise in die Schadstoffdynamik von Böden eingreifen. Effekte können sowohl von der Veränderung des pHWertes, den hohen Salzgehalten und dem Eintrag gelöster organischer Substanz verursacht werden. (DESCHAUER 1995, MAYR 1999)

Problematisch bei der Anwendung von Bioabfall-Kompost ist die Kalkulation der N-Freisetzung. Übersteigt die Nachlieferung von Nitrat aus organischen Stickstoffverbindungen den Pflanzenentzug, können daraus Belastungen des Grundwassers resultieren. Die Charakterisierung des organischen N-Pools von Bioabfall-Komposten zeigt, dass $50 \%$ des Stickstoffs in nicht identifizierbaren N-Formen vorliegen (SIEBERT 1988). Über die Stickstoff- 
dynamik nach der Anwendung von Bioabfall-Kompost liegen nur unzureichend Erkenntnisse vor.

Bei der ökobilanzmäßigen Betrachtung verschiedener möglicher Verwertungswege von Biound Grünabfällen zeigt sich, dass die mit dem jeweiligen Prozess der Verwertung verbundenen negativen Auswirkungen auf die Umwelt hoch sein können und gerade bei der Kompostierung deutlich höher sein können als die damit verbundenen Substitutionserfolge. Die negativen Umweltwirkungen ergeben sich im Wesentlichen aus dem Verbrauch fossiler Energie und den Lachgas- und Methanemissionen. Deutlich besser sind die Ökobilanzergebnisse für die Vergärung von Bioabfällen. (KNAPPE et al. 2003)

Auch vor dem Hintergrund der Veränderungen rechtlicher Rahmenbedingungen und politischer Zielsetzungen ist die getrennte Erfassung von Bioabfällen neu zu überdenken.

Der Anteil an nativ-organischen Abfällen im Rest-Hausmüll liegt trotz der getrennten Erfassung der Bioabfälle weiterhin im Durchschnitt bei 35 - 40\% (KEHRES 2003). Der Gehalt an nativ-organischen Abfällen im Rest-Hausmüll liegt damit deutlich über den Vorgaben der TA Siedlungsabfall ${ }^{13}$ und der entsprechenden Nachfolgeverordnung ${ }^{14}$, nach der ab 01.06.2005 unbehandelte Abfälle nicht mehr deponiert werden dürfen.

In der Umsetzung der Vorschläge des Bundesumweltministeriums (BMU) und des Bundesverbraucherschutzministeriums (BMVEL) „Gute Qualität und sichere Erträge“ (BMVEL/BMU 2002) sehen viele Betreiber das Ende der Bioabfallverwertung, weil sie eine mit der Umsetzung der Vorschläge einhergehende Verschlechterung der Vermarktungsfähigkeit der erzeugten Komposte befürchten.

Im Rahmen der Debatte zum Erneuerbare-Energien-Gesetz (EEG) ${ }^{15}$ und zur BiomasseVerordnung ist deutlich geworden, dass die thermische Umwandlung organischer Abfälle in Mischabfällen in Strom und Wärme unter Klimagesichtspunkten sachlich gerechtfertigt wäre. Nachwachsende Rohstoffe, darunter auch organische Abfälle im Restmüll gelten als klimaneutral, wenn sie an anderer Stelle $\mathrm{CO}_{2}$-erzeugende Primärenergien substituieren. Die Förderung der Erzeugung von Strom aus Biomasse gemäß der Biomasseverordnung hat bereits zu einer nachhaltigen Veränderung der Verwertungspraxis heizwertreicher Grünabfälle (Baum- und Strauchschnitt) geführt. Schätzungen zufolge werden ca. $20 \%$ dieser Abfälle in Biomassekraftwerken verwertet (KEHRES 2003).

Will Deutschland die ehrgeizigen internationalen Kyoto-Zusagen zur $25 \%$-igen $\mathrm{CO}_{2}$-Reduzierung 2005 gegenüber 1990 einhalten, wird auch die Entsorgungswirtschaft insgesamt und deren positiver Beitrag zur Substitution von Primärenergien durch nachwachsende Rohstoffe im Müll genutzt werden müssen (ARLT 2003, KAIMER et al. 2002).

Die aktuellen Diskussionen erwecken den Eindruck eines Paradigmenwechsels in der Abfallwirtschaft, der in seiner Konsequenz das Aufgeben verschiedener Getrennt-Sammelsysteme zur Folge haben könnte.

Die Kompostierung ist nicht per se positiv zu beurteilen. Trotz der unbestritten vielfältigen positiven Eigenschaften von Kompostprodukten stellt sie nicht immer die beste Lösung dar, sowohl aus Sicht der Entsorgungswirtschaft als auch aus Sicht des Anwenders. Vor dem

\footnotetext{
${ }^{13}$ Dritte Allgemeine Vorschrift zum Abfallgesetz (TA Siedlungsabfall) Technische Anleitung zur Verwertung, Behandlung und sonstigen Entsorgung von Siedlungsabfällen vom 14. Mai 1993 (BAnz S. 4967)

${ }^{14}$ Verordnung über die umweltverträgliche Ablagerung von Siedlungsabfällen und über biologische Abfallbehandlungsanlagen (Abfallablagerungsverordnung - AbfAbIV) vom 20. Februar 2001 (BGBII S: 305)

${ }^{15}$ Gesetz für den Vorrang Erneuerbarer Energien (Erneuerbare-Energien-Gesetz - EEG)vom 21. Juli 2004 (BGBI I S. 1918)
} 
Hintergrund des Verbots der Deponierung unbehandelter Siedlungsabfälle, effektiven „Eine Tonne-Systemen" und der zunehmenden Akzeptanz thermischer Verwertungsverfahren ist die Erweiterung der Kompostierung im Einzelfall kritisch zu hinterfragen.

In der Diskussion um die Vorteile und Nachteile der Getrenntsammlung von Bioabfällen und deren Kompostierung werden gegensätzliche und teilweise provokante Positionen (SEIER 2003) bezogen, in denen die Kompostierung entweder prinzipiell als "gut" oder "schlecht“ dargestellt wird. Die Bewertung der Kompostierung erfordert einen auf den Einzelfall bezogenen Abwägungsprozess. Dies gilt sowohl für Fragen der Verwertung von Kompost als auch für die Frage der Sammlung von Bioabfällen. Denn auch die Einführung der Getrenntsammlung von Bioabfällen sollte vor dem Hintergrund lokalspezifischer Gegebenheiten, wie Anlagekapazitäten, regionaler Vermarktungsmöglichkeiten, Akzeptanz und erreichbarer Produktqualität in Abwägung anderer Alternativen entschieden werden.

Der Erfolg der Getrenntsammlung beruht in hohem Maße auf der Bereitschaft der Bevölkerung hierfür einen Mehraufwand zu leisten. Teilweise beruht diese Bereitschaft auf dem Verständnis praktizierten Umweltschutzes, teilweise ist sie die Folge zunehmender Reglementierung. Es sei dahin gestellt, ob der enorme Umfang sich in der Mülltrennung erschöpfender „Umwelt-Aktivitäten“, in andere Sparten gelenkt, zielführender zur Ressourcenschonung beitragen könnte.

\subsection{Kompostierung: Bedeutung der organischen Substanz}

In der Natur werden von Pflanzen und Mikroorganismen fortlaufend organische Stoffe aus anorganischen Ausgangs-Verbindungen gebildet, die postmortal wiederum von Mikroorganismen zersetzt und mineralisiert werden. Dabei ist die Masse der in der Umwelt "gespeicherten" postmortalen organischen Kohlenstoffverbindungen rund fünf mal größer als die organische Substanz der lebenden Biomasse (BOHN 1976).

Verläuft der Gesamtprozess des biologischen Abbaus von organischen Stoffen in Anwesenheit von Luftsauerstoff ab, handelt es sich um eine aerobe Zersetzung. Wird dieser Prozess mit technischen Mitteln intensiviert, spricht man von Kompostierung. Die Kompostierung ist ein sehr altes Verfahren, das in China bereits 5000 Jahre v. Chr. praktiziert wurde (LE HUNG 2002)

Wenn auch der technische Verlauf vieler Kompostierungsverfahren in einzelne Prozessschritte gegliedert werden kann und anhand von Summenparametern gut beschreibbar ist, ist eine komplette detaillierte Darstellung des mikrobiologisch physiologischen Ablaufs aufgrund der ungeheuren Vielfalt vernetzter Reaktionen nicht möglich (KÄMPFER et al. 2001).

In der Diskussion um die Verwertung von Bioabfällen wird der organischen Substanz vor dem Hintergrund der Humuserhaltung zunehmend mehr Bedeutung beigemessen (NENDEL 2002, HARTMANN 2003). Die organische Substanz des Bodens ist eng mit wichtigen Bodenfunktionen verknüpft und übt einen entscheidenden Einfluss auf die Bodenfruchtbarkeit aus. Der Aspekt der Erhaltung der organischen Substanz in Böden gewinnt auch in den europäischen und nationalen Bodenschutzkonzeptionen an Beachtung. Die Möglichkeit der Zufuhr organischer Substanz durch Kompostgaben wird allerdings beispielsweise für Sandböden durch die Schadstoffgehalte im Kompost wiederum in Frage gestellt (OVERESCH et al. 2003).

Für die Beurteilung der "Qualität" der organischen Substanz im Kompost wird in der Regel grob vereinfachend ein mengenbezogener Ansatz herangezogen, der auf der Bestimmung des Glühverlustes basiert. Weiterhin wird pauschal davon ausgegangen, dass etwa die Hälfte der organischen Substanz als „stabil“ angesehen werden kann (AID 2003), was allerdings näher zu definieren wäre. Auswirkungen der Kompostanwendung auf die Zusammensetzung der organischen Bodensubstanz und auf die Prozesse des Stoffumsatzes im 
Boden werden kaum untersucht (LEIFELD et al. 1998). Mikrobiologische und humuschemische Methoden zur Charakterisierung der organischen Substanz (siehe UBA 1997) werden in der Praxis nicht herangezogen.

Die Stabilisierung der organischen Substanz kann chemisch durch die Anreicherung bzw. Bildung schwer abbaubarer Verbindungen und physikalisch durch Interaktion mit mineralischen Bodenpartikeln oder den Einschluss in Aggregate erfolgen (SOLLINS et al. 1996). Stabile organische Substanzen pflanzlicher oder mikrobieller Herkunft, die der aeroben Zersetzung unterliegen und über längere Zeiträume im Boden verbleiben, gelten als „humifiziert". Die dabei entstehenden sogenannten Huminstoffe bilden die Hauptsenke für organischen Kohlenstoff in Böden und Gewässern. Etwa 60 - 70 \% des gesamten organischen Kohlenstoffs in Böden und rund $40-60$ \% des gelösten Kohlenstoffs in Gewässern werden Huminstoffen zugerechnet (STEVENSON 1994).

Trotz der Kenntnis einer Vielzahl charakteristischer Eigenschaften können Huminstoffe nicht generell definiert werden. Unter dem Begriff Huminstoffe werden in der Regel diejenigen organischen Kohlenstoff-Verbindungen subsummiert, die sich chemisch nicht eindeutig identifizieren lassen. Humifizierung kann auch als Prozess der Abnahme identifizierbarer Streustoffe angesehen werden. Obwohl in den vergangenen drei Jahrzehnten der Huminstoff-Forschung zahlreiche Ansätze zur Identifizierung und Strukturaufklärung unternommen wurden, liefern die daraus resultierenden Modellvorstellungen lediglich anschauliche Modelle zur Darstellung der Vorstellungen über die Wirkungsweise von Huminstoffen in der Umwelt. Viele Fragen bezüglich der Entstehung und Struktur von Huminstoffen sind bis heute nicht eindeutig geklärt. (KÖGEL-KNABNER und GUGGENBERGER 1995, RUMPEL 1999)

Die an isolierten Huminstoffen gewonnenen Erkenntnisse hinsichtlich ihrer chemischen Zusammensetzung und Struktur sind nicht auf natürliche Huminstoffe übertragbar (KHAIRY und ZIECHMANN). Viele Ergebnisse haben sich als zu stark methodenabhängig erwiesen.

Während früher davon ausgegangen wurde, dass kleinere Abbauprodukte durch Polymerisation und Kondensation in Huminstoff-Makromoleküle von bis zu $10^{6}$ Dalton übergehen, ergeben neuere Erkenntnisse, dass es sich hierbei vielmehr um komplexe Mischungen aus Abbauprodukten mit makromolekül-ähnlichen Eigenschaften handelt. Demnach setzen sich Huminstoffe aus Metallkationen, Polysacchariden, Polypeptiden, aliphatischen Ketten und aromatischen Ligninfragmenten zusammen, deren Verhältnis und Struktur von Probenursprung und Extraktionstechnik abhängen. Sie neigen in Gegenwart von Metallen zu Aggregatbildung. Ihre Molekulargewichte liegen unter 2000 Dalton. (SIMPSON et al. 2002, CONTE et al. 1999)

Die Vielzahl der Verbindungen, die in die Bildung von Huminstoffen eingehen können, führt zu einer komplexen und heterogenen Mischung von Stoffsystemen. Diese Humin-Stoffsysteme beeinflussen in komplexer Wirkungsweise die physikalischen und chemischen Eigenschaften des sie umgebenden Mediums.

Für die Wechselwirkungen von Huminstoffen mit den sie umgebenden Systemen sind Molekülgröße und Form von großer Bedeutung. Sowohl die in der Literatur angegebenen Größen als auch die Vorstellungen hinsichtlich der räumlichen Molekülstruktur variieren über einen sehr weiten Bereich (JÄKLE 2002).

Einiges spricht dafür, die Suche nach einem allgemein gültigen Entstehungs- und Strukturmodell für Huminstoffe aufzugeben und die Huminstoffgenese als einen fortlaufend stattfindenden dynamischen Prozess der Bildung und Umbildung von Humin-Stoffsystemen zu verstehen, deren Zusammensetzung jeweils von den konkreten Bedingungen in situ abhängt. 
Wie ZIECHMANN schon 1980 geschrieben hat: "Bedingt durch die große Heterogenität der an der Entstehung von Huminstoffen beteiligten organischen Substanzen sind Huminstoffe keine einheitlichen statischen Verbindungen, sondern stellen Gemische aus polydispersen Makromolekülen unterschiedlichen Polymerisationsgrades dar, die fortgesetzt chemischen, physikalischen und biologischen Veränderungen unterliegen.

Aufgrund ihrer strukturellen und funktionellen Vielfalt sind Huminstoffe an zahlreichen Prozessen in der Umwelt beteiligt. Eine besondere Relevanz haben Huminstoffe für die Bindung, den Transport und die Verfügbarkeit von organischen und anorganischen Schadstoffen (FORSCHUNGSZENTRUM JÜLICH 1991). Gelöste und partikuläre Huminstoffe können insbesondere mit Schwermetall-Ionen sehr stabile Komplexe bilden und damit die Metall-Bindungsformen in Böden und wässrigen Systemen nachhaltig beeinflussen (MONTEIL-RIVERA et al. 2004).

Wie neuere Untersuchungen zeigen, sind die in Huminstoffen nachgewiesenen sogenannten Asche-Anteile nicht als „Verunreinigungen“ anzusehen, wie dies früher oft getan wurde, sondern als essentielle die Struktur beeinflussende Bestandteile der Humin-Stoffsysteme. Die von thermodynamischen und kinetischen Faktoren abhängige Stabilität aquatischer Huminstoff-Metallspezies ist ein Maß für deren biologische Verfügbarkeit. (VAN DEN BERGH 2001)

Die organische Substanz von Komposten insbesondere die als stabil angesehenen Huminstoffe stellen einen wichtigen wertgebenden Bestandteil dar. Dennoch existieren bislang kaum exakte Vorstellungen über die Entstehung und Struktur und ihre Verknüpfung mit Asche-Bestandteilen. Über die Transformationswege der Asche-Bestandteile beim Abbau der organischen Substanz durch Liganden- bzw. Metallaustausch natürlicher Huminstoff-Metallspezies liegen bisher keine Erkenntnisse vor. Zur Erklärung von StoffFlüssen und ökologischen Entwicklungspotenzialen ist die Kenntnis der Zusammensetzung der organischen Substanz eine wichtige Voraussetzung. (KÖGEL-KNABNER \& BEYER 1995)

Die vorliegende Arbeit ist daher der Untersuchung der weiteren Veränderungen der organischen Substanz, der mineralischen Bestandteile und der Struktur eines Bioabfallkompostes unter Nutzungsbedingungen, insbesondere der Bildung wässriger Eluate und der in innen enthaltenen organischen Komponenten sowie deren Kopplung an Asche-Bestandteile gewidmet. 


\section{Problemstellung}

\section{$2.1 \quad$ Fragestellung}

Die Zahl gesicherter Details zur Wirkungsweise der Kompostierung ist beachtlich, wie Standardwerke ausweisen (z. B. THOME-KOZMIENSKY 1995). Es bestehen dennoch erhebliche Wissenslücken zu Detailfragen der Humifizierung und zum Verbleib der Asche.

Die Fragen, zu deren Beantwortung mit der vorliegenden Arbeit ein Beitrag geleistet werden soll, lauten:

Was geschieht beim Abbau des Substrates mit den in inm enthaltenen Asche-Anteilen, d.h. dem $\mathrm{SiO}_{2}, \mathrm{Fe}, \mathrm{Al}, \mathrm{Mn}, \mathrm{Ca}, \mathrm{Mg}, \mathrm{K}, \mathrm{Na}$ sowie den verschiedenen Schwermetallen? Wie verhalten sich Mineralisation und Freisetzung von Stoffen zu Neubildung und Umbau?

Wie groß ist der Anteil organischer und anorganischer - aus der Pflanzenasche stammender bzw. aus Fremdbeimengung herrührender - Inhaltstoffe des Bioabfall-Kompostes, die über die Lösungsphase aus dem System verloren gehen - aufgegliedert nach Raten und Phasen im Zeitablauf der fortschreitenden Mineralisation?

Welche Bindungsverhältnisse zwischen organischer und mineralischer Substanz liegen in den Eluaten vor - getrennt nach freien Ionen, sorbierten und komplexierten Ionen und organischen Verbindungen, klathrierten lonen und Mineralkörpern, korpuskulären Mineralkörpern mit organischer Substanz? Welche organischen und anorganischen Stoffgruppen und Strukturen sind vorhanden?

Wie entstehen die spezifischen Inhaltsstoffe der Eluate? Entstehen sie durch den Transfer organischer Inhaltsstoffe der Substrate auf dem Weg über den Einbau in Biomasse und deren postmortale Zersetzung oder über Reaktionen von Substrat-Inhaltsstoffen mit spezifischen löslichen Produkten der mikrobiellen Biomasse?

\subsection{Kenntnisstand}

Nach neueren Modellvorstellungen, die sowohl in Untersuchungen über den Abbau von Laubstreu-Decken und Auflage-Humus in Wäldern als auch bei der Kompostierung von Ernte-Rückständen, wie z.B. Stroh gewonnen worden sind, vollzieht sich der Abbau von postmortalen Substraten etwa in folgender Weise:

Das Substrat wird - häufig nur unter sehr geringen Veränderungen seiner chemischen Zusammensetzung - langsam unter Heranziehung für den Bau- und Betriebsstoffwechsel der mikrobiellen Aufwuchsflora der mikrobiellen Peripherie schrittweise von außen aufgezehrt (PÖHHACKER 1995). Dabei werden die Mineralisationsprodukte in den atmosphärischen Gasraum oder in die umgebende Lösung entlassen. Andererseits entstehen - auch unter aeroben Verhältnissen - organische Stoffwechselprodukte der mikrobiellen Peripherie oder wasserlösliche Extraktstoffe des Substrates, die in das Wasser übergehen, das den sich zersetzenden Pflanzenrest umgibt und die mit diesem zusammen auf dem Wege des Massentransportes auswaschbar sind. Sie sollen zusammenfassend als Eluate bezeichnet werden.

Nach allem bisher Bekanntem ist ein wesentlicher - wohl weniger von der Menge als von der Wirkung her gesehener - Bestandteil dieser Eluate in Phenolen und Oxiphenolen sowie deren Polymerisationsprodukten - Huminen - zu sehen, die als koppelndes Agens für eine ganze Reihe primärer Pflanzen-Inhaltsstoffe wie Cellulose, Lignin, Proteine etc. wirken und diese zu dem vereinigen, was man heute als Humin-Stoffsystem bezeichnet. (KHAIRY und ZIECHMANN 1981, RUMPEL 1999) 
Diese Eluate können mit verschiedenen anderen Boden-Komponenten wie Tonmineralen, Eisenoxiden etc. aber auch organischen Körpern wie z.B. Proteinen reagieren und diese im Sinne von Gerbung gegen den Abbau stabilisieren. Sie können auch mumifizierend auf das im Abbau befindliche Substrat einwirken und den mikrobiellen Abbau langsam zum Erliegen bringen.

Bei einer vollständigen und raschen Mineralisierung werden die Mineralisationsprodukte als mineralischer Rückstand angereichert, bei einer langsamen Zersetzung, wie oben dargestellt, ist dagegen davon auszugehen, dass sie in den Eluaten in organischer Bindung, metallorganischen Komplexen, Kieselsäureestern und ähnlichen Verbindungen erscheinen und eluiert werden (UBA 1999c).

Für die Erfassung des Stoffumsatzes von Ökosystemen spielt dieses insofern eine wesentliche Rolle, als zu beobachten ist, dass mit der Verstärkung von Rohhumus-Decken in Wäldern die Bäume nicht nur einem zunehmenden Nährstoff-Mangel durch Festlegung dieser zyklierenden Stoffe in der Masse des Auflage-Humus ausgesetzt sind, sondern auch unter Nährstoff-Austrag aus dem Ökosystem in Form organischer Eluate, die einer Mineralisierung und damit Nährstoff-Freigabe nicht mehr zugänglich sind, leiden (WILDEN 2000). Untersuchungen von huminstoffreichem Sicker- und Grundwasser haben die Bindungsfestigkeit kationischer Nährstoffe an solche Humin-Stoffsysteme erwiesen (KÖNIG et al. 1986, BECKER 1987, FINGER 1989).

Versuche, die im Institut für Bodenwissenschaft der Universität Göttingen begleitend zur technisch-experimentellen Probe-Kompostierung der Stadt Göttingen durchgeführt wurden, haben folgendes gravierendes Problem erkennen lassen: Der Kompostierungsprozess des $\mathrm{N}$-reichen Bioabfalls verläuft so hitzig und wenig kontrollierbar, dass er eher einer biologischen Verbrennung mit einer so rapiden Anreicherung der biogenen Asche ähnelt, dass der Wert der organischen Komponente des Kompostes z.B. für Zwecke der physikalischen Verbesserung von Böden $u$. U. nur noch von geringer Bedeutung ist. Feld- und Lysimeterversuche haben zudem gezeigt, dass die bei dem Prozess entstehenden Lösungen und Eluate für Hemmungen des Pflanzenwachstums verantwortlich zu machen sind und darüber hinaus die Gefahr der Belastung des Sicker- und Grundwassers heraufbeschwören. Ein Reihe von Diplomarbeiten hat sich bereits mit Qualitätsparametern dieses Kompostes befasst (ERKENBERG 1985, WALKEMEYER 1987, BANSE 1990, RODEN \& WITTKE 1990).

Bei der Kompostierung organischer Siedlungsabfälle, so z.B. des getrennt eingesammelten Bioabfalls vieler Kommunen, spielt die Eluat-Bildung insofern eine begrenzende Rolle für den Einbau der Komposte in die Landschaft als sie einerseits

- eine beträchtliche Gefährdung des Sicker- und Grundwassers heraufbeschwört, andererseits

- verantwortlich ist für die toxisch wirkenden Salzbelastungen des in den Komposten gehaltenen Kapillarwassers.

Auch hier ist im Hinblick auf die Kontrolle des Kompostierungsprozesses die Kenntnis des Verhaltens der pflanzlichen Asche-Bestandteile im Zusammenhang mit der Eluatbildung wichtig für technologische Maßnahmen wie z.B. den Einbau von Eluat-Sinks.

Nach bisherigen Erkenntnissen ist eine Stabilisierung des kompostierenden Bioabfall-Materials, d.h. eine Drosselung der fortschreitenden Mineralisation und des fortschreitenden Austrages von Huminstoff-Soluten nicht durch Zusätze C-reicher organischer Substanz mit hohem Sorptions- und Fällungsvermögen zu erreichen. Dies können dagegen Eisenoxidverkrustete Tonminerale aus Bodenmaterial tun, die sich mit Huminstoff-Hüllen umgeben und diese aus dem Umsatzgeschehen entziehen (GRUNDMANN 1990). Modelle dafür liefert der auf Anregung des Instituts für Bodenwissenschaft zurückgehende in Regensburg 
durchgeführte Prozess der Bioabfall-Kompostierung mit Zuckerrüben-Spülbodenmaterial. Techniken und Ziele dieser Bioabfall-Kompost-Herstellung sind bislang noch nicht recht festlegbar (Meyer 1987).

\subsection{Zielsetzung der eigenen Arbeit}

Die vorliegende Arbeit befasst sich mit verschiedenen inhaltlichen und methodischen Aspekten der Untersuchung von Bioabfall-Kompost, wobei vorrangig Fragen der stofflichen Veränderung und nach dem Verbleib biogener Asche-Anteile nach der Ausbringung untersucht werden.

Die Ergebnisse werden vor dem Hintergrund aktueller Fragestellungen zur Verwertung von Bioabfall-Komposten betrachtet. Hierzu gehören:

- Die Weiterentwicklung von Verfahren zur Fraktionierung der organischen Substanz in Bioabfall-Kompost.

- Die Beschreibung der stofflichen Veränderungen des organischen Materials nach der Kompostierung durch fortschreitende Mineralisation und Humifizierung.

- Vorhersagen zur Freisetzung von Nähr- und Schadstoffen.

- Die Konkretisierung der Bewertung von Komposten hinsichtlich ihrer Qualität und Anwendungseignung in Bezug auf Wechselwirkungen zwischen der in Komposten enthaltenen organischen Substanz und der Mineralsubstanz.

\section{4 Überlegungen zur Methodik}

Die Untersuchungen beziehen sich auf Kompost aus biogenen Abfällen, wie er in zahlreichen Kommunen getrennt vom üblichen Siedlungsabfall erzeugt wird, um inn in die Landschaft zurückzuführen.

Untersuchungsobjekt sind zwei Lysimeter von je $7 \mathrm{~m}^{2}$ Oberfläche und $100 \mathrm{~cm}$ Höhe, in denen im April 1987 werkseitig als fertig angesehener Bioabfall-Kompost eingefüllt und bilanzmäßig auf seine weiteren Veränderungen untersucht und seine Eignung als Pflanzensubstrat überprüft wird.

Die Lysimeter sind unter dem Gesichtspunkt angelegt worden, dass es am ehesten zu vertreten sei, wenn der Kompost als stärkere pflanzentragende Boden-Deckschicht in die Landschaft eingebaut würde - z.B. zum Zwecke der Standortverbesserung -, weil durch die Flächenbeschränkung mögliche Umweltwirkungen besser kontrollierbar bleiben. Aus diesem Grunde sind auf den Lysimetern landwirtschaftliche Kulturpflanzen angeplanzt worden, die sich der durch Mineralisation freiwerdenden Pflanzennährstoffe bedienen und gleichzeitig als Indikator für mögliche toxische Wirkungen - durch zu hohe Salzkonzentrationen in der Substrat-Lösung - dienen.

Da Vorversuche hatten erkennen lassen, dass es vermutlich die entstehenden Lösungen im Porenraum des Kompostes sind, von denen die genannten Schadwirkungen ausgehen, sind weitere, jedoch kleinere Lysimeter angelegt worden, in denen dem Kompost als „entgiftender Sink" mineralisches Bodenmaterial zugesetzt wurde. Es handelt sich dabei um eine Reihe von 6 weiteren Lysimeter-Varianten, bei denen dem Bioabfall-Kompost in 4 Stufen steigende Mengenanteile von Lössboden-Material zugemischt wurden, nicht zuletzt im Hinblick auf möglicherweise zu entwickelnde Verfahren der Erdkompostierung.

Die Untersuchungen erstrecken sich auf die wässrigen Eluate der Lysimeterfüllungen (Sickerwasser und Extrakte) und auf den Bioabfall-Kompost selbst. Es wird der Zeitgang der stofflichen Veränderungen während der drei Jahre andauernden Freilandversuche verfolgt. Dabei liefert die Untersuchung der Eluate eine wichtige, dynamische Größe für die Beurteilung der Intensität von Stoffumsätzen eines Bioelement-Haushalts und für die Bewertung der Belastungspotenziale für Böden und Gewässer. Die Untersuchungen der 
Festsubstanz beziehen sich auf bodenphysikalische und bodenchemische Eigenschaften der Lysimeter-Füllungen, die Rückschlüsse auf Veränderungen innerhalb des Systems erlauben.

Es wurde angenommen, dass der mineralisierende Abbau des Bioabfall-Kompostes hauptsächlich unter fortschreitender Vermehrung des Asche-Gehaltes, aber ohne wesentliche Veränderung der Zusammensetzung organischer Stoffgruppen ablaufen würde. Bei der Untersuchung der organischen Substanz richtet sich das Hauptaugenmerk auf den Einbau der freigesetzten mineralischen Anteile in die löslichen organischen Umbildungsprodukte.

Da die in wässriger Lösung bzw. Sol-Form oder Dispersion befindlichen organo-mineralischen Körper raschen Veränderungen ihres Verteilungszustandes unterliegen, ist es zweckmäßig, die Eluate sehr schnell nach der Gewinnung einer Trennung nach Molekülgrößen zu unterwerfen. Da es für die Fraktionierung der organischen Komponenten keine alle Fragen abdeckende Methodik gibt und leicht abbaubare Stoffgruppen einer raschen Veränderung unterliegen, sind die Untersuchungen vorrangig auf lösliche Huminstoffe bezogen. Zur Huminstoff-Anreicherung und Fraktionierung werden adsorptions-chromatographische Methoden eingesetzt. Für die Trennung und Bestimmung der Molekülgrößen werden die Ultrafiltration und die Gel-Chromatographie kombiniert. Durch die Bestimmung der Inhaltsstoffe in den so gewonnenen Fraktionen können freie Metallspezies, kinetisch labile und stabile Komplexe der organischen Fraktionen mit sorbierten und komplexierten anorganischen Anteilen differenziert werden.

Die Bilanz der Ein- und Austräge gibt Rechenschaft über Vorratsänderungen innerhalb des Systems. Die Deposition von Stoffen mit dem Niederschlag liefert den Eintrag, die pflanzlichen Ernte-Entzüge und der Sickerwasser-Durchfluss den Austrag. Ein Vergleich der Bilanzglieder ermöglicht Rückschlüsse auf die Vorgänge innerhalb des Systems. Systemanalysen dienen der Überprüfung und Erweiterung aufgestellter Modelle. Auf der Grundlage der Analyse von Stoff-Flüssen und der materiellen Veränderungen von Kompost- und Kompost-Löss-Mischungen sollen Erkenntnisse zur Beschreibung und Erklärung der Prozesse, die die Entstehung und Zusammensetzung der Eluate organischer Massen bestimmen, geliefert werden. 


\section{Versuchsaufbau}

\subsection{Füllmaterialien}

\subsubsection{Kompost}

Bei dem verwendeten Kompostmaterial handelt es sich um kompostierte Küchen- und Gartenabfälle aus dem Modellversuch „Kompost-Tonne Göttingen“ des Stadtreinigungsamtes Göttingen. Die von Mai 1985 bis April 1987 separat eingesammelten organischen Abfälle stammten zunächst aus drei repräsentativ ausgewählten Bezirken der Stadt Göttingen und einem Bezirk des Landkreises Göttingen. Die Kompostierung der Bioabfälle aus Haushalten war 1985 für das Stadtreinigungsamt noch ein neues Arbeitsfeld, auf dem kaum praktische Erfahrungen und Erkenntnisse vorlagen. Der Modellversuch diente daher der Erprobung und Weiterentwicklung des gewählten Verfahrens. Im Laufe des Modellversuchs wurden verschiedene Kenngrößen, wie z.B. Vorzerkleinerung des angelieferten Materials, Absiebung der Komposte, Bewässerung, Zuschläge, Überdachung und Platzbefestigung, versuchsweise verändert bzw. optimiert.

Zu dem Projekt „Komposttonne Göttingen“ wurden insgesamt drei Veröffentlichungen Versuchsaufbau, Zwischenbericht und Schlussbericht - erstellt, die, nachdem die Einzelexemplare vergriffen waren, in einer Gesamtausgabe herausgegeben wurden. Die nachfolgenden Ausführungen wurden der Gesamtausgabe, die von den OBERSTADTDIREKTOREN DER STADT GÖTTINGEN und des LANDKREISES GÖTTINGEN 1988 herausgegeben wurde, entnommen.

Insgesamt wurden in Stadt und Landkreis im Zeitraum von Mai 1985 bis März $19861.650 \mathrm{t}$ kompostierbare Abfälle eingesammelt. Das entspricht $49 \mathrm{Gew}$. \% des insgesamt eingesammelten Hausmülls. Der Anteil an organischem Abfall war in der Gemeinde des Landkreises am höchsten mit $57 \mathrm{Gew}$. \% des gesamten Hausmülls. Das niedrigste Aufkommen an organischem Abfall, 18 Gew. \% des gesamten Hausmülls, lag in dem Versuchsgebiet mit Mehrfamilienhäusern in Geschossbauweise ohne Gärten vor. Bei den übrigen städtischen Versuchsgebieten ergaben Analysen des organischen Abfalls einen sehr hohen Anteil von Gartenabfällen, d. h. ca. 80 Gew. \%.

Die nach Bedarf wöchentlich oder 14-tägig eingesammelte Bioabfall-Menge schwankte im Verlauf des Jahres. Niedrige Abfallmengen lagen in den Monaten Dezember, Januar und Februar vor, die höchsten Mengen im Spätherbst.

Die gesammelten Bioabfälle wurden auf dem Kompostplatz der Stadt Göttingen in Deiderode in offenen Mieten kompostiert. Das im Drehtrommelfahrzeug bereits homogenisierte organische Material wurde in Form einer Dach-(Dreiecks)miete ausgekippt und nach ein bis zwei Wochen Vorrotte aufgesetzt. Die Kompostmieten hatten eine durchschnittliche Höhe von 1,2 m und waren ca. 2,6 m breit. In der Anfangsphase wurden separate Mieten für den Landkreis und jedes der vier städtischen Testgebiete aufgesetzt. Der Grad der Verunreinigung durch sog. Fehlwürfe bei den eingesammelten Bioabfällen lag im ersten Versuchsjahr bezogen auf $95 \%$ des angelieferten Materials bei 0,5 bis $2 \mathrm{Gew}$. \%, in den restlichen $5 \%$ bei über $5 \mathrm{Gew}$. \%. In Wohngebieten mit Mehrgeschossbauweise wurden bis zu 6 Gew. \% Fehlsortierung festgestellt. Diese hoch belasteten Chargen wurden vor der Kompostierung per Hand sortiert.

Nach 6 bis 10 Wochen Rottedauer wurden die Mieten umgesetzt und bei Bedarf bewässert. Die Rottedauer lag insgesamt bei 6 bis 8 Monaten bei zweimaligem Umsetzen. In den Wintermonaten wurde dem Frischkompost, der vor allem aus Küchenabfällen bestand, stark zerfasertes Holzhäcksel zugesetzt. Trotz der Zumischung von Holzhäcksel lagen bei den Januar- und Februar-Komposten teilweise anaerobe Bedingungen durch die starke 
Vernässung der Kompostmieten vor. Zur Absiebung des Kompostes wurde - gemeinsam mit dem „Grüne Tonne Projekt Witzenhausen“ - ein Spanwellensieb der Fa. Lehmann, Siebfläche $1 \mathrm{~m} \times 3 \mathrm{~m}$, Maschenweite $20 \mathrm{~mm}$, verwendet. Mit der Absiebung der ersten verkaufsfertigen Komposte wurde im Spätsommer 1986 begonnen.

Als problematisch erwies sich die Befestigung des Kompostplatzes mit Basaltsteinen der Kornabstufungen 0/45 mm und 0/11 mm. Die Basaltsteine gewährleisteten zwar einen guten Abfluss des Sickerwassers, führten aber dazu, dass beim Auf- und Umsetzen Basaltsteine in den Kompost gelangten, die auch durch Siebung nicht wieder vollständig entfernt werden konnten. Der Anteil an Steinchen $<20$ mm im Kompost betrug bis zu 20 Gew. \%. Der Siebüberlauf, von bis zu $30 \mathrm{Vol}$. \%, bestehend aus unverrotteten Ästen, Verunreinigungen und ebenfalls Basaltsteinen, konnte der Kompostierung nicht erneut zugeführt werden. Die Basaltsteine im Kompost führten zu einer Erhöhung der Nickel-Gehalte und beeinträchtigten die Haltbarkeit der Maschinen.

Ab April 1986 wurden aufgrund der Erfahrungen des ersten Versuchsjahres einige Veränderungen vorgenommen, wie z.B. der Verzicht auf die Bewässerung beim ersten Umsetzen, die versuchsweise Vorzerkleinerung des angelieferten Materials, das Aufsetzen der Winterkomposte auf eine Holzhäckselmatte und die Zumischung von strukturreichem Material zur Vermeidung von Faulprozessen sowie die Einführung einer $7 \mathrm{~mm}$-Absiebung für die Kleinvermarktung.

Die für die Untersuchungen in der vorliegende Arbeit eingesetzten Komposte entstammen dem ersten Versuchsjahr des Modellprojektes „Komposttonne Göttingen“. Sie werden hier mit dem Monat und Jahr ihres Aufsetzdatums also dem Zeitpunkt der Anlieferung der organischen Abfälle bezeichnet. Die Anlieferung des Bioabfalls der verwendeten Komposte erfolgte Januar (Jan 86), Februar (Feb 86) und März 1986 Mrz 86). Nach Fertigstellung der Komposte lagerte das Material noch weitere Zeit offen auf dem Kompostplatz in Deiderode und war Witterungseinflüssen ausgesetzt.

In Tabelle 3-1 sind für einige Merkmale des „Göttinger Kompostes“ die Minima, Maxima und Durchschnittswerte angegeben. 
Tabelle 3-1: Kompost-Kennwerte der Göttinger Komposte nach OBERSTADTDIREKTOR DER STADT GÖTTINGEN und OBERSTADTDIREKTOR DES LANDKREISES GÖTTINGEN 1988

\begin{tabular}{|c|c|c|c|c|c|}
\hline & \multicolumn{5}{|c|}{ Göttinger Kompost } \\
\hline & \multicolumn{3}{|c|}{ Schlussbericht } & \multicolumn{2}{|c|}{ Zwischenbericht } \\
\hline & $\min$ & $\max$ & Mw & $\min$ & $\max$ \\
\hline Volumen-Gewicht in g/l & 424,0 & 824,0 & 620,0 & 650,0 & \\
\hline pH-Wert (CaCl2) & 7,7 & 8,6 & 8,0 & 7,4 & 8,0 \\
\hline \multicolumn{6}{|l|}{ organische Substanz: } \\
\hline Glühverlust in \% der TM & 18,5 & 28,1 & 22,3 & 18,0 & 28,0 \\
\hline $\mathrm{C}$ in \% der TM & 10,0 & 19,0 & 14,0 & 12,0 & 19,0 \\
\hline \multicolumn{6}{|l|}{$\begin{array}{l}\text { Nährstoffe (Gesamtgehalte): } \\
\text { in \% der TM }\end{array}$} \\
\hline $\mathbf{N}$ & 0,9 & 1,6 & 1,1 & 0,9 & 1,6 \\
\hline $\mathbf{P}$ & 0,2 & 0,4 & 0,3 & 0,2 & 0,3 \\
\hline $\mathbf{K}$ & 1,0 & 3,2 & 1,7 & 1,0 & 3,2 \\
\hline $\mathrm{Ca}$ & 1,9 & 5,5 & 3,4 & 2,8 & 6,3 \\
\hline Mg & 0,2 & 0,6 & 0,3 & 0,3 & 0,4 \\
\hline C/N-Verhältnis & 10,0 & 14,0 & 11,8 & 10,0 & 12,0 \\
\hline \multicolumn{6}{|l|}{ Kationenaustausch-Kapazität } \\
\hline in mmol IE/100 g TM & & & & 67,8 & \\
\hline \multicolumn{6}{|l|}{ Salzgehalt } \\
\hline in $\mathbf{g} / \mathbf{l}$ & 3,0 & 5,5 & 4,2 & & \\
\hline in $\%$ der $\mathrm{TM}$ & 0,8 & 2,6 & 1,5 & 0,8 & 1,1 \\
\hline
\end{tabular}

Die Spannbreiten der angegebenen Werte entsprechen den für Komposten aufgrund der heterogenen Zusammensetzung des Ausgangsmaterials üblichen Streuung.

Die hier verwendeten Kompostchargen vom Januar, Februar und März 1986 waren bereits in den Diplomarbeiten von WALKEMEYER 1987 und BANSE 1990 Gegenstand von Untersuchungen. In Tabelle 3-2 sind einige Ergebnisse aus diesen Arbeiten zur Charakterisierung der verwendeten Komposte zusammengestellt. Dabei ist zu berücksichtigen, dass die Untersuchungen von WALKEMEYER im Mai 1986 durchgeführt wurden und sich zu diesem Zeitpunkt die hier eingesetzten Untersuchungsproben Jan 86, Feb 86 und Mrz 86 noch in der thermophilen Abbauphase befanden. Die Untersuchungen von BANSE jedoch wurden im Juni 1987 nach Abschluss der Reifephase und offener Lagerung des Kompostmaterials durchgeführt 
Tabelle 3-2: Kompost-Kennwerte der verwendeten Komposte nach WALKEMEYER 1987 und BANSE 1990

\begin{tabular}{|c|c|c|c|c|c|c|c|}
\hline & \multicolumn{4}{|c|}{ WALKEMEYER 1987} & \multicolumn{3}{|c|}{ BANSE 1990} \\
\hline & \multicolumn{3}{|c|}{ Göttinger Kompost } & \multirow[b]{2}{*}{ Mw } & \multicolumn{3}{|c|}{ Göttinger Kompost März 86} \\
\hline & Jan 86 & Feb 86 & Mrz 86 & & $\min$ & $\max$ & Mw \\
\hline$\%$ TM & & & & & & & 65,0 \\
\hline Volumen-Gewicht in g/l & & & & 630,0 & & & \\
\hline pH-Wert $(\mathrm{CaCl} 2)$ & 7,5 & 8,0 & 7,5 & & & & 7,8 \\
\hline organische Substanz: & & & & & 21,0 & 31,0 & \\
\hline Glühverlust in \% der TM bei $450{ }^{\circ} \mathrm{C}$ & 28,7 & 37,2 & 26,0 & & & & \\
\hline Glühverlust in \% der TM bei $800^{\circ} \mathrm{C}$ & 32,1 & 43,4 & 29,9 & & & & \\
\hline Glühverlust in \% der TM bei $600{ }^{\circ} \mathrm{C}$ & & & & & 28,0 & 34,0 & \\
\hline $\mathrm{C}_{\text {ges }}$ in $\%$ der TM & 16,6 & 23,2 & 14,8 & & & & \\
\hline $\mathrm{C}_{\text {org }}$ in \% der TM & & & & & 13,0 & 19,0 & \\
\hline $\mathrm{CaCO}_{3}$ in \% der TM & & & & & & & 7,7 \\
\hline $\mathrm{SiO}_{2}$ in $\%$ der $\mathrm{TM}$ & 51,5 & 34,9 & 53,6 & & & & \\
\hline Asche in $\%$ der TM bei $450{ }^{\circ} \mathrm{C}$ & 71,1 & 62,8 & 74,0 & & & & \\
\hline \multirow{2}{*}{\multicolumn{8}{|c|}{$\begin{array}{l}\text { Nährstoffe (Gesamtgehalte): } \\
\text { in \% der TM }\end{array}$}} \\
\hline & & & & & & & \\
\hline $\mathbf{N}$ & 1,5 & 1,6 & 1,2 & & 1,3 & 1,9 & \\
\hline $\mathbf{P}$ & 0,4 & 0,4 & 0,3 & & & & 0,4 \\
\hline K & 0,5 & 1,3 & 0,8 & & & & 1,4 \\
\hline $\mathrm{Ca}$ & 1,6 & 6,4 & 4,8 & & & & 3,8 \\
\hline Mg & 0,5 & 1,1 & 1,0 & & & & 1,1 \\
\hline $\mathrm{Na}$ & 0,1 & 0,2 & 0,2 & & & & 0,7 \\
\hline $\mathrm{SO}_{4}-\mathrm{S}$ & & & & & & & 0,2 \\
\hline Cl & & & & & & & 0,1 \\
\hline C/N-Verhältnis & 11,4 & 14,3 & 12,0 & & 7,0 & 14,0 & \\
\hline \multicolumn{8}{|l|}{ Kationenaustausch-Kapazität } \\
\hline in $\mathrm{mmol} \mathrm{IE} / 100 \mathrm{~g} \mathrm{TM}$ & & & & & & & 46,6 \\
\hline Leitfähigkeit im 1:5 Extrakt in mS/cm & & & & & & & 12,0 \\
\hline Leitfähigkeit im Sättigungsextrakt in $\mathrm{mS} / \mathrm{cm}$ & & & & 17,3 & & & \\
\hline Salzgehalt & & & & & & & \\
\hline in \% der TM & 1,0 & 1,8 & 0,9 & & & & \\
\hline
\end{tabular}

\subsubsection{Löss}

Das verwendete Lössboden-Material wurde dem $B_{v}$-Horizont einer Parabraunerde aus Hottenrode entnommen. Das Bodenmaterial wurde mit einem Erdwolf zerkleinert und abgesiebt $(<2 \mathrm{~mm})$.

Tabelle 3-3 zeigt die Löss-Kennwerte nach BANSE 1990. 


\begin{tabular}{|c|c|}
\hline & $\begin{array}{c}\text { BANSE } 1990 \\
\text { Löss-Kennwerte }\end{array}$ \\
\hline$\%$ TM & 89,00 \\
\hline pH-Wert $\left(\mathrm{CaCl}_{2}\right)$ & 6,70 \\
\hline organische Substanz: & \\
\hline Glühverlust in \% der TM bei $600^{\circ} \mathrm{C}$ & 4,40 \\
\hline $\mathrm{C}_{\text {org }}$ in \% der TM & 0,24 \\
\hline $\mathrm{CaCO}_{3}$ in $\%$ der TM & 0,60 \\
\hline Nährstoffe (Gesamtgehalte): & \\
\hline in $\%$ der $\mathrm{TM}$ & \\
\hline $\mathbf{N}$ & 0,03 \\
\hline $\mathbf{P}$ & 0,05 \\
\hline K & 1,69 \\
\hline $\mathrm{Ca}$ & 0,19 \\
\hline Mg & 0,34 \\
\hline $\mathrm{Na}$ & 0,81 \\
\hline $\mathrm{SO}_{4}-\mathrm{S}$ & u.B. \\
\hline $\mathrm{Cl}$ & 0,01 \\
\hline C/N-Verhältnis & 7,27 \\
\hline Kationenaustausch-Kapazität & \\
\hline in $\mathrm{mmol} \mathrm{IE} / 100 \mathrm{~g}$ TM & 13,00 \\
\hline Leitfähigkeit im 1:5 Extrakt in $\mathrm{mS} / \mathrm{cm}$ & 0,40 \\
\hline Tongehalt in \% der TM & 12,80 \\
\hline
\end{tabular}

\subsection{Lysimeter-Anlage}

\subsubsection{Bau der Lysimeter-Anlage}

Die Versuchsanlage besteht aus 10 Einzel-Lysimetern. Dabei handelt es sich um zwei Großlysimeter, die Lysimeter 1 und 2 mit 9,19 $\mathrm{m}^{3}$ Fassungsvermögen und acht Kleinlysimeter, von denen die Lysimeter $3-6$ und die Lysimeter $7 \mathrm{a}, 7 \mathrm{~b}, 8$ a und 8 b jeweils einheitliche Größen aufweisen. Die Anlage wurde ab April 1987 auf dem Gelände des Institutes für Bodenwissenschaft in Göttingen von Erkenberg und Banse (BANSE 1990) eingerichtet und im Juni 1988 für eigene Versuchszwecke übernommen.

Angaben zur Größe der Lysimeter sind in der Tabelle 3-4 aufgeführt. Die Lysimeter 7a und b werden als Lysimeter 7 und die Lysimeter 8 a und b als Lysimeter 8 zusammengefasst. 
Tabelle 3-4: Angaben zur Größe der Lysimeter

\begin{tabular}{l|cccccc} 
Lysimeter & $\begin{array}{c}\text { Höhe } \\
\mathbf{m}\end{array}$ & $\begin{array}{c}\mathbf{I D} \\
\mathbf{m}\end{array}$ & $\begin{array}{c}\text { Breite } \\
\mathbf{m}\end{array}$ & $\begin{array}{c}\text { Länge } \\
\mathbf{m}\end{array}$ & $\begin{array}{c}\text { Oberfläche } \\
\mathbf{m}^{\mathbf{2}}\end{array}$ & $\begin{array}{c}\text { Volumen } \\
\mathbf{m}^{\mathbf{3}}\end{array}$ \\
\hline $\mathbf{1}$ & 1,30 & 3,00 & & & 7,07 & 9,19 \\
$\mathbf{2}$ & 1,30 & 3,00 & & & 7,07 & 9,19 \\
$\mathbf{3}$ & 0,50 & & 0,62 & 1,09 & 0,68 & 0,34 \\
$\mathbf{4}$ & 0,50 & & 0,62 & 1,09 & 0,68 & 0,34 \\
$\mathbf{5}$ & 0,50 & & 0,62 & 1,09 & 0,68 & 0,34 \\
$\mathbf{6}$ & 0,50 & & 0,62 & 1,09 & 0,68 & 0,34 \\
$\mathbf{7}$ & 0,41 & & 0,33 & 1,06 & 0,35 & 0,14 \\
$\mathbf{8}$ & 0,41 & & 0,33 & 1,06 & 0,35 & 0,14
\end{tabular}

Die beiden Großlysimeter wurden im April 1987 angelegt. Hierzu wurden nach Angaben von BANSE 1990 zwei Behälter aus glasfaserverstärktem Polyesterharz mit flachem Boden in $30 \mathrm{~cm}$ Abstand in Nord-Süd-Richtung auf eine Standfläche gesetzt. Die Standfläche war mit Sand in einem Gefälle von 2,5 \% abgezogen und mit Holzlatten abgestützt worden. Die Innenwände der Behälter sind mit einer glasfreien Innenschutzschicht ausgekleidet, die keine Fremdionen in die Bodenlösung abgibt. Bei beiden Lysimetern überragte die Behälterwand die Einfülloberfläche um $30 \mathrm{~cm}$ und wirkte somit als Verdunstungsschutz. Als Drainschicht wurden über $6 \mathrm{~cm}$ Mittelkies (Korndurchmesser $1-2 \mathrm{~cm}$ ) $4 \mathrm{~cm}$ Grobsand eingebracht. Die Abgrenzung von Kompostmaterial zur Drainschicht bildete bei Lysimeter 1 eine Nylongaze (Porendurchmesser $1 \mathrm{~mm}$ ) und bei Lysimeter 2 eine Filtermatte vom Typ Vlies Typar $\left(68 \mathrm{~g} / \mathrm{cm}^{2}\right)$. Die Lysimeter wurden mit Erdkompost $70 \mathrm{~cm}$ breit in Einfüllhöhe ummantelt, um Witterungseinflüsse abzupuffern. Durch diese Mantel-Schicht verliefen die Ablaufschläuche zu den Auffangbehältern aus Kunststoff. Das Volumen der Auffangbehälter entspricht mit 70 I einem Sickerwasser-Durchfluß von etwa $10 \mathrm{~mm}$. Die Behälter waren in den Boden eingelassen und wurden nach Bedarf entleert. Eine Abdeckung des Auffangbehälter-Grabens verhinderte weitere Beeinflussung.

Im Mai 1987 wurden auf eine abgestützte Fläche, wie oben beschrieben, acht weitere Lysimeter gesetzt. Die Drainschicht bestand bei diesen Lysimetern aus einer $4,5 \mathrm{~cm}$ hohen Grobsandschicht, die durch Nylongaze von Füllmaterial abgetrennt war. Die ErdkompostUmmantelung war in Lysimeterhöhe $40 \mathrm{~cm}$ breit aufgefüllt. Das Volumen der Auffangbehälter von 12 I entspricht einer durchfließenden Sickerwassermenge bei Lysimeter 3- 6 von $17,7 \mathrm{~mm}$ und bei Lysimeter 7 und 8 von $44,3 \mathrm{~mm}$. Die Behälter waren in den Boden eingelassen und wurden nach Bedarf entleert. Der Auffangbehälter-Graben wurde ebenfalls abgedeckt.

Die Abbildung 1 zeigt eine Aufnahme der Lysimeter 3 - 8 vom 27.05.87. 


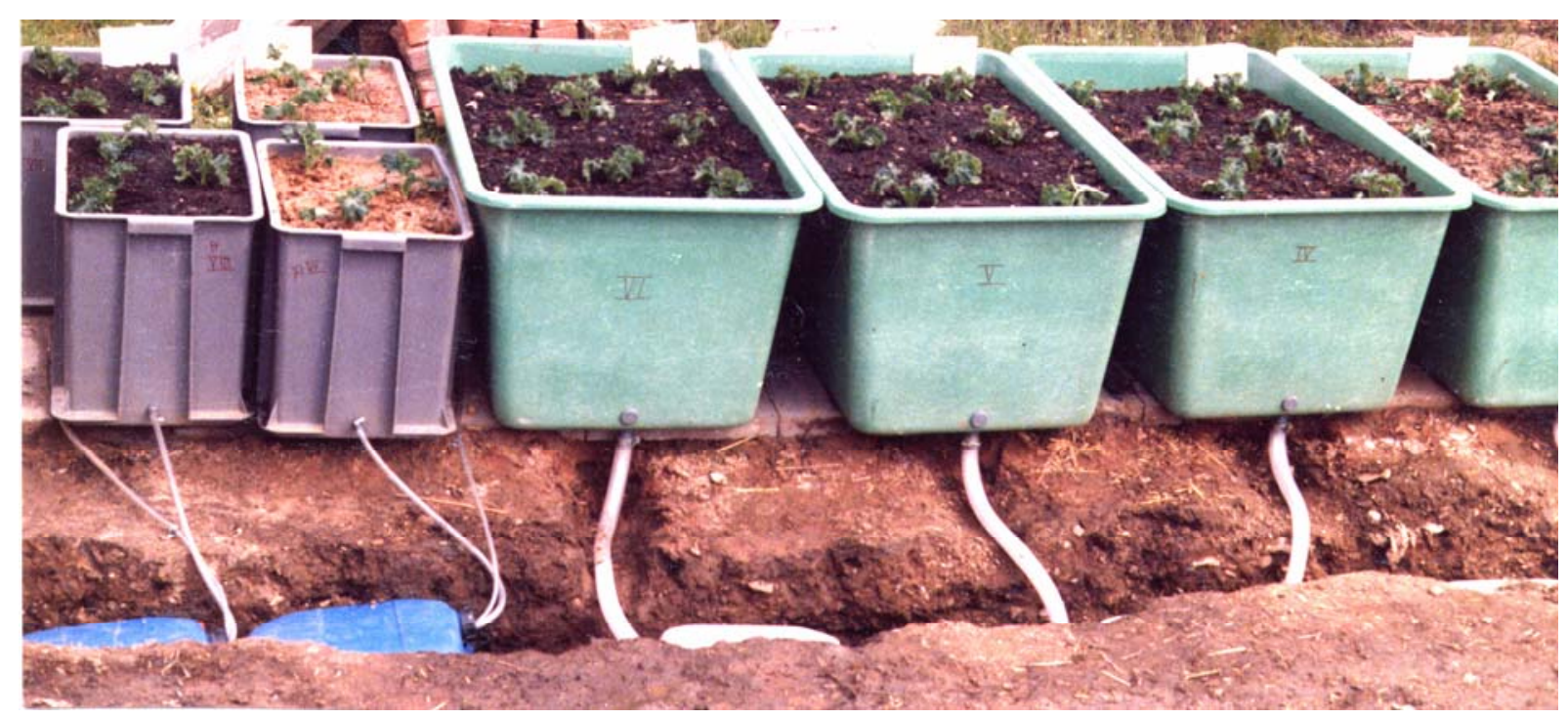

Abbildung 1: Bau der Lysimeter-Anlage (von rechts nach links: Lysimeter 3-6, 7 a und b, 8 a und b), Aufnahme vom 27.05.87 von B. BANSE

\subsubsection{Befüllen der Lysimeter}

Der Kompost in den Großlysimetern (Lysimeter 1 und 2) wurde in 10-cm-Lagen eingefüllt und mit einem mit Metallkegeln bestücktem Handstampfer (Durchmesser $30 \mathrm{~cm}$ ) gleichmäßig verdichtet. Die Kompost-Löss-Mischungen wurden in einem Behälter vorvermischt und nach Einbringen ebenfalls verdichtet. Die Lössvariante wurde dabei stärker verdichtet als die übrigen Varianten.

Die Großlysimeter 1 und 2 wurden mit reinem Kompost befüllt, die Lysimeter $3-6$ mit Kompost-Löss-Mischungen mit unterschiedlichen Mischungsanteilen und die kleineren Lysimeter 7a und b mit Löss und 8 a und $b$ mit Kompost. Die Lysimeter 7 a und 7 b und 8 a und $8 \mathrm{~b}$ werden aufgrund der gemeinsamen Sickerwasserabfuhr unter 7 und 8 zusammengefasst. Zur Befüllung der Großlysimeter wurde für Lyismeter 1 die Kompostcharge Februar 86 und für Lysimeter 2 die Kompostcharge Januar 86 verwendet. Die Mischungsvarianten Lysimeter 3 -6 und die Nullvariante Lysimeter 8 wurden mit der Kompostcharge März 86 angesetzt.

Die Tabelle 3-5 zeigt die Angaben zur eingefüllten TM an Kompost und Löss in $\mathrm{kg}$ und \% sowie die daraus resultierende Schütthöhe und die berechnete Kompost-Aufwandmenge. 
Tabelle 3-5: Angaben zu den Einfüllmengen (Angaben von BANSE 1990 in Klammern, kursiv: berechnete Werte nach Abschlusserhebung)

\begin{tabular}{l|cccccc} 
Lysimeter & $\begin{array}{c}\text { TM gesamt } \\
\mathbf{~ k g}\end{array}$ & $\begin{array}{c}\text { TM Kompost } \\
\mathbf{~ k g}\end{array}$ & $\begin{array}{c}\text { TM Löß } \\
\mathbf{~ k g}\end{array}$ & $\begin{array}{c}\text { TM Kompost } \\
\text { \% Füll-TM }\end{array}$ & $\begin{array}{c}\text { Schütthöhe } \\
\mathbf{m}\end{array}$ & $\begin{array}{c}\text { Kompost- } \\
\text { Aufwandmenge } \\
\text { t/ha }\end{array}$ \\
\hline $\mathbf{1}$ & $(3679) 2146$ & 2146 & 0 & 100 & 0,90 & 3035,36 \\
$\mathbf{2}$ & $(3705) 2982$ & 2982 & 0 & 100 & 0,90 & 4217,82 \\
$\mathbf{3}$ & 224,94 & 69,5 & 155,44 & 30,90 & 0,50 & 1028,41 \\
$\mathbf{4}$ & 164,25 & 83,66 & 80,59 & 50,93 & 0,49 & 1237,94 \\
$\mathbf{5}$ & 131,91 & 77,22 & 54,69 & 58,54 & 0,48 & 1142,65 \\
$\mathbf{6}$ & 135,07 & 123,55 & 11,52 & 91,47 & 0,48 & 1828,20 \\
$\mathbf{7}$ & 132,41 & 0 & 132,41 & 0 & 0,36 & 0,00 \\
$\mathbf{8}$ & 66,92 & 66,92 & 0 & 100 & 0,40 & 1920,78
\end{tabular}

Die Großlysimeter wurden mit 5600 kg (Lysimeter 1) und 5700 kg (Lysimeter 2) KompostFrischmasse befüllt. Leider liegen keine TM-Bestimmungen für den Zeitpunkt des Einfüllens vor. Die in der Arbeit von BANSE 1990 angegebenen Werte von $3679 \mathrm{~kg}$ TM für Lysimeter 1 und $3705 \mathrm{~kg}$ TM für Lysimeter 2 wurden in der Tabelle in Klammern gesetzt, da diese anhand des für die Kompostcharge März 86 bestimmten Wassergehaltes berechnet wurden und nicht den tatsächlich eingefüllten Mengen entsprechen. In der Tabelle 3-5 sind daher kursiv die anhand der Bilanzdaten berechneten Materialmengen für Lysimeter 1 und 2 angegeben.

\subsubsection{Leerung der Großlysimeter}

Wegen des Fehlens exakter Einfülldaten bei Lysimeter 1 und 2 wurden für die Erstellung der Bilanz die Großlysimeter nach Abschluss der Versuche quantifizierend entleert. Hierzu wurde der Kompost aus Lysimeter 1 im Januar 1991 und aus Lysimeter 2 im März 1991 stufenweise in $10 \mathrm{~cm}$ Schichten abgetragen. In jeder Schicht wurden Dichtebestimmungen vorgenommen und Probenmaterial entnommen. Die einzelnen Kompostschichten wurden mehrere Tage luftgetrocknet, durch mehrfaches Umschaufeln homogenisiert und schließlich gewogen. Der Wassergehalt zum Zeitpunkt der Wägung wurde bestimmt. Hieraus wurden die Trockenmassen der einzelnen Schichten sowie die Gesamttrockenmasse der Lysimeter-Inhalte berechnet. Die Kleinlysimeter wurden nicht geöffnet.

Die Daten der Abschlusserhebung zeigt Tabelle 3-6. 
Tabelle 3-6: Lysimeter-Füllmengen bei Abschluss der Freilandversuche, Lysimeter 1 und 2

\begin{tabular}{|c|c|c|}
\hline Lysimeter 1 & $\begin{array}{c}\text { Trockenmasse } \\
\text { kg } \\
\end{array}$ & $\begin{array}{c}\text { Wassergehalt } \\
\text { \% d. TM } \\
\end{array}$ \\
\hline $0-10 \mathrm{~cm}$ & 517 & 43 \\
\hline $10-20 \mathrm{~cm}$ & 414 & 41 \\
\hline $20-30 \mathrm{~cm}$ & 465 & 41 \\
\hline $30-42 \mathrm{~cm}$ & 508 & 42 \\
\hline Summe & 1904 & \\
\hline Durchschnittswert & & 42 \\
\hline \multicolumn{3}{|l|}{ Lysimeter 2} \\
\hline $0-10 \mathrm{~cm}$ & 425 & 50 \\
\hline $10-20 \mathrm{~cm}$ & 400 & 47 \\
\hline $20-30 \mathrm{~cm}$ & 381 & 44 \\
\hline $30-40 \mathrm{~cm}$ & 503 & 42 \\
\hline $40-50 \mathrm{~cm}$ & 481 & 46 \\
\hline $50-58 \mathrm{~cm}$ & 491 & 48 \\
\hline Summe & 2681 & \\
\hline Durchschnittswert & & 46 \\
\hline
\end{tabular}

\subsection{Probenahmen}

\subsubsection{Lysimeter-Füllmaterial}

Die Entnahme von Materialproben am Anfang, während und am Ende der Freilandversuche diente der Untersuchung des Ablaufes physikalischer, chemischer und biochemischer Merkmale der Komposte und seiner Mischungen mit Löss.

Die Entnahme von Materialproben aus den Großlysimetern erfolgte anfangs in kurzen Zeitintervallen. Von April 87 bis August 87 wurden monatlich Mischproben von drei Pürckhauer-Einschlägen aus den Tiefen $0-20 \mathrm{~cm}, 20-45 \mathrm{~cm}$ und $45-70 \mathrm{~cm}$ entnommen. Von Juni 87 bis August 87 wurde wöchentlich eine Mischprobe aus der oberen $20 \mathrm{~cm}$ starken Kompost-Schicht zur Bestimmung der elektrischen Leitfähigkeit entnommen. Weitere Materialentnahmen aus den drei genannten Tiefen erfolgten am 24.06.88 und am 26.07.88.

Da in der Folgezeit der Versuchsbetreuung die Untersuchung der wässrigen Eluate und Sickerwässer im Vordergrund stand, wurden erst zum Abschluss der Lysimeterversuche im März 90 weitere Probenahmen aus den Tiefen $0-30 \mathrm{~cm}$ und $30-60 \mathrm{~cm}$ durchgeführt. Für die Gewinnung der Mischproben wurden etwa 35 über die gesamte Oberfläche gleichmäßig verteilte Einzelproben entnommen. Weiterhin wurden bei der Entleerung der Lysimeter im Januar (Lysimeter 1) und März (Lysimeter 2) 91 Materialproben zur Abschlusserhebung entnommen, die aus den einzelnen $10 \mathrm{~cm}$-Schichten stammten. Die Proben wurden kühl (bei $+4^{\circ} \mathrm{C}$ ) und dunkel gelagert.

In Tabelle 3-7 sind die Entnahmetermine und beprobten Tiefen für Lysimeter 1 und 2 zusammengestellt. 
Tabelle 3-7: Material-Entnahmen aus Lysimeter 1 und 2

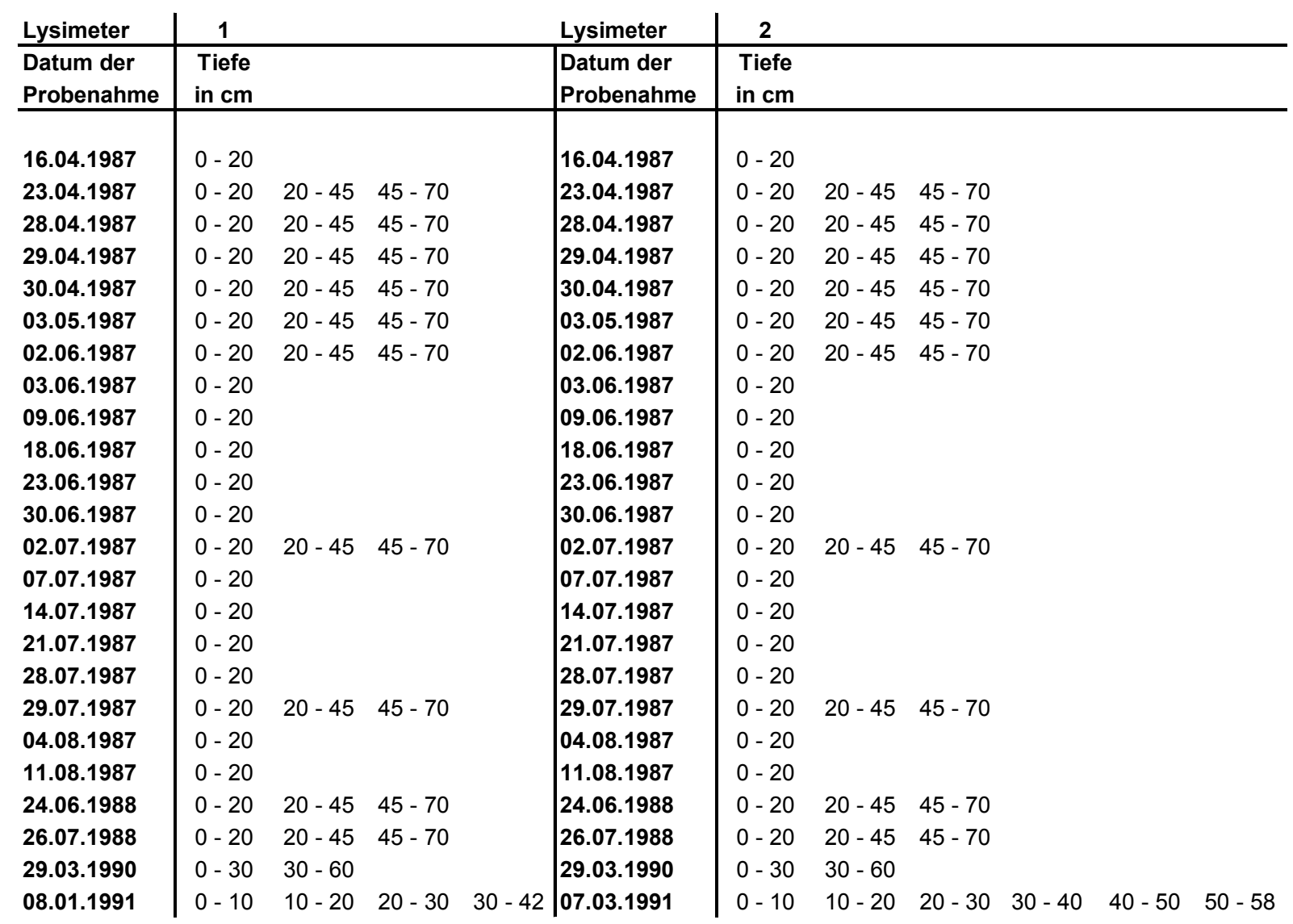

Wegen der geringeren Materialmenge in den Kleinlysimetern erfolgte die Entnahme von Material-Mischproben nur an vier Probenahme-Terminen. Entsprechend der geringeren Schichttiefe der kleineren Lysimeter $7 \mathrm{a}$ und $\mathrm{b}$ und $8 \mathrm{a}$ und $\mathrm{b}$ wurden hier nur die oberen 10 $\mathrm{cm}$ beprobt und bei den Lysimetern $3-6$ die Tiefenabschnitte $0-20 \mathrm{~cm}$. Bei der abschließenden Probenahme am 02.04.90 wurden bei den Lysimetern 3 - 6 die Schichttiefen 0 - 10 $\mathrm{cm}$ und $10-20 \mathrm{~cm}$ getrennt erhoben. Die aus den Lysimetern $7 \mathrm{a}$ und $\mathrm{b}$ und $8 \mathrm{a}$ und $\mathrm{b}$ entnommenen Einzelproben wurden zu einer Mischprobe vereinigt. In Tabelle 3-8 sind die Termine der Material-Probenahme aufgeführt.

Tabelle 3-8: Material-Entnahmen aus den Lysimetern 3 - 8

\begin{tabular}{|c|c|c|}
\hline Lysimeter & 7 und 8 & $3,4,5$ und 6 \\
\hline $\begin{array}{l}\text { Datum der } \\
\text { Probenahme }\end{array}$ & $\begin{array}{c}\text { Tiefe } \\
\text { in } \mathbf{c m}\end{array}$ & $\begin{array}{c}\text { Tiefe } \\
\text { in } \mathbf{c m}\end{array}$ \\
\hline 30.06 .1987 & $0-10$ & $0-20$ \\
\hline 28.07.1987 & $0-10$ & $0-20$ \\
\hline 24.06.1988 & $0-10$ & $0-20$ \\
\hline 02.04.1990 & $0-10$ & $0-10$ \\
\hline
\end{tabular}

\subsubsection{Sickerwasser}

Das Sickerwasser wurde je nach Anfall täglich aus den Auffangbehältern entnommen und quantifiziert. Es wurden den Flussmengen entsprechende Wochen-Mischproben erstellt und in PE-Flaschen im Kühlraum bei $4^{\circ} \mathrm{C}$ gelagert. 


\subsubsection{Regen}

Die Niederschläge wurden über Kunststofftrichter mit $500 \mathrm{~cm}^{2}$ Auffangfläche mit einem Siebeinsatz in zwei offenen Auffangbehältern erfasst und mit den Daten der Wetterstation des Institutes für Bodenwissenschaft verglichen. Die Leerung und Reinigung der Auffangbehälter erfolgte bei Bedarf täglich. Es wurden den Niederschlagsmengen entsprechende 2Wochen-Mischproben erstellt und diese in PE-Flaschen im Kühlraum bei $4{ }^{\circ} \mathrm{C}$ gelagert.

\subsubsection{Bepflanzung}

Es wurden während der Freilandversuche verschiedene Pflanzen auf den Lysimetern angebaut. Insgesamt wurden die in Tabelle 3-9 beschriebenen Anbauphasen durchgeführt (Aussaat- und Erntezeitpunkte siehe Kapitel 8, Tabelle 8-1).

Tabelle 3-9: Anbauphasen

\begin{tabular}{l|cc} 
Anbauphase & Pflanzen & Jahr \\
\hline $\mathbf{1}$ & $\begin{array}{c}\text { verschiedene Kohlarten } \\
\text { und Steckrüben } \\
\text { Winterweizen }\end{array}$ & 87 \\
$\mathbf{3}$ & Gelbsenf & $87 / 88$ \\
$\mathbf{4}$ & Winterweizen & $88 / 89$
\end{tabular}

In Tabelle 3-10 sind die geernteten Pflanzen bzw. Pflanzenteile, von denen Proben für weitere Untersuchungen entnommen wurden, aufgelistet. 
Tabelle 3-10: Pflanzenproben

\begin{tabular}{|c|c|c|c|c|}
\hline \multirow[b]{2}{*}{ Lysimeter } & \multicolumn{4}{|l|}{ Anbauphase } \\
\hline & 1 & 2 & 3 & 4 \\
\hline 1 & $\begin{array}{l}\text { Wirsing, Weißkohl, } \\
\text { Rotkohl, } \\
\text { Steckrübenblatt, } \\
\text { Steckrübenköper }\end{array}$ & $\begin{array}{l}\text { Weizenkorn, } \\
\text { Weizenstroh }\end{array}$ & Gelbsenf & $\begin{array}{l}\text { Weizenkorn, } \\
\text { Weizenstroh }\end{array}$ \\
\hline 2 & $\begin{array}{l}\text { Steckrübenblatt, } \\
\text { Steckrübenköper }\end{array}$ & $\begin{array}{l}\text { Weizenkorn, } \\
\text { Weizenstroh }\end{array}$ & & $\begin{array}{l}\text { Weizenkorn, } \\
\text { Weizenstroh }\end{array}$ \\
\hline 8 & $\begin{array}{c}\text { Steckrübenblatt, } \\
\text { Steckrübenköper, } \\
\text { Grünkohl }\end{array}$ & Weizen gesamt & & Weizen gesamt \\
\hline 6 & $\begin{array}{c}\text { Steckrübenblatt, } \\
\text { Steckrübenköper, } \\
\text { Grünkohl }\end{array}$ & $\begin{array}{l}\text { Weizenkorn, } \\
\text { Weizenstroh }\end{array}$ & & Weizen gesamt \\
\hline 5 & $\begin{array}{c}\text { Steckrübenblatt, } \\
\text { Steckrübenköper, } \\
\text { Grünkohl }\end{array}$ & $\begin{array}{l}\text { Weizenkorn, } \\
\text { Weizenstroh }\end{array}$ & & Weizen gesamt \\
\hline 4 & $\begin{array}{c}\text { Steckrübenblatt, } \\
\text { Steckrübenköper, } \\
\text { Grünkohl }\end{array}$ & $\begin{array}{l}\text { Weizenkorn, } \\
\text { Weizenstroh }\end{array}$ & & Weizen gesamt \\
\hline 3 & $\begin{array}{c}\text { Steckrübenblatt, } \\
\text { Steckrübenköper, } \\
\text { Grünkohl }\end{array}$ & $\begin{array}{l}\text { Weizenkorn, } \\
\text { Weizenstroh }\end{array}$ & & Weizen gesamt \\
\hline 7 & $\begin{array}{c}\text { Steckrübenblatt, } \\
\text { Steckrübenköper, } \\
\text { Grünkohl }\end{array}$ & Weizen gesamt & & Weizen gesamt \\
\hline
\end{tabular}


Kapitel 4

\section{Füllmaterialien: Ergebnisse der physikalischen und chemischen}

\section{Untersuchungen}

\subsection{Zeitgang des Wassergehaltes (WG)}

\subsubsection{Methodik}

Die Bestimmung des Wassergehaltes erfolgte gravimetrisch. Hierzu wurden ca. $25 \mathrm{~g}$ der zu untersuchenden Probe eingewogen und etwa $15-20 \mathrm{~h}$ bei $105^{\circ} \mathrm{C}$ bis zur Gewichtskonstanz getrocknet. Der Wassergehalt entspricht dem Trocknungsverlust der Probe. Er kann auf die TM oder FM bezogen werden. Die Angaben erfolgen in Gew. \% der TM und in Gew. $\%$ der FM.

Der Wassergehalt in Vol. \% der TM ergibt sich rechnerisch aus der Multiplikation des Wassergehaltes in Gew. \% der TM mit der Trockendichte in $\mathrm{g} / \mathrm{cm}^{3}$.

\subsubsection{Ergebnisse}

Großlysimeter

Die Wassergehalte des Kompostes der Großlysimeter 1 und 2 wurden in den ersten Versuchsmonaten von April bis August 1987 in kurzen Zeitabständen untersucht, um bei zu niedrigen Wassergehalten und zu hohen Salzgehalten durch künstliche Bewässerung eine Beeinträchtigung des Pflanzenwachstums zu verhindern. Da in der Folgezeit keine Hemmungen des Pflanzenwachstums aufgrund zu hoher Salzgehalte mehr erwartet wurden, erfolgten die Bestimmungen der Wassergehalte nur noch an vier weiteren ProbenahmeTerminen in Zusammenhang mit der Entnahme von Kompostmaterial zur Bestimmung weiterer physikalischer und chemischer Kenngrößen. An 12 Entnahmeterminen erfolgte die Bestimmung der Wassergehalte nur in der oberen Schicht $(0-20 \mathrm{~cm})$, an den übrigen Entnahmeterminen wurden die Wassergehalte in verschiedenen Tiefenabschnitten über die gesamte Füllhöhe ermittelt. Bei den in Tabelle 1 dargestellten Werten handelt es sich bis auf die Parallel-Entnahme am 24.06.88 um Einzelwerte, die an homogenisierten Mischproben aus drei Entnahmestellen ermittelt wurden. Bei der Probenahme am 24.06.88, Lysimeter 2, wurden die Einzelproben der verschiedenen Entnahmestellen getrennt untersucht, da ein uneinheitliches Wuchsbild der Pflanzen vorlag und überprüft werden sollte, ob Unterschiede in der physikalischen Beschaffenheit des Kompostes vorliegen. Die in Tabelle 4-1 angegebenen Wassergehalte stellen Mittelwerte der drei Entnahmestellen dar.

Tabelle 4-1 zeigt die während der Versuchszeit erhobenen Wassergehalte des Kompostes in den Großlysimetern 1 und 2. 
Tabelle 4-1: Wassergehalte frischer, ungesiebter

Materialproben zu verschiedenen Entnahme-Zeitpunkten und in verschiedenen Tiefen, Lysimeter 1 und 2

\begin{tabular}{|c|c|c|c|c|c|}
\hline $\begin{array}{c}\text { Datum der } \\
\text { Probenahme }\end{array}$ & $\begin{array}{c}\text { Tiefe } \\
\mathbf{c m}\end{array}$ & \begin{tabular}{|c} 
Lysimeter \\
$\%$ d. FM
\end{tabular} & $\%$ d. TM & \begin{tabular}{|c} 
Lysimeter 2 \\
$\%$ d. FM
\end{tabular} & \% d. TM \\
\hline 16.04.1987 & $0-20$ & 51,1 & 104,5 & 46,1 & 85,5 \\
\hline \multirow[t]{3}{*}{ 23.04.1987 } & $0-20$ & 38,0 & 61,3 & 39,4 & 65,1 \\
\hline & $20-45$ & 46,7 & 87,6 & 40,6 & 68,2 \\
\hline & $45-70$ & 46,6 & 87,3 & 42,4 & 73,5 \\
\hline \multirow[t]{3}{*}{ 28.04.1987 } & $0-20$ & 44,6 & 80,5 & 37,6 & 60,2 \\
\hline & $20-45$ & 45,6 & 83,8 & 43,2 & 76,0 \\
\hline & $45-70$ & 53,3 & 114,1 & 44,1 & 79,0 \\
\hline \multirow[t]{3}{*}{ 29.04.1987 } & $0-20$ & 39,2 & 64,5 & 38,6 & 62,8 \\
\hline & $20-45$ & 45,6 & 83,7 & 37,5 & 60,0 \\
\hline & $45-70$ & 45,5 & 83,3 & 46,7 & 87,5 \\
\hline \multirow[t]{3}{*}{30.04 .1987} & $0-20$ & 42,3 & 73,2 & 39,6 & 65,5 \\
\hline & $20-45$ & 44,8 & 81,3 & 37,5 & 60,0 \\
\hline & $45-70$ & 44,3 & 79,6 & 42,1 & 72,6 \\
\hline \multirow[t]{3}{*}{03.05 .1987} & $0-20$ & 43,2 & 75,9 & 41,9 & 72,2 \\
\hline & $20-45$ & 48,1 & 92,7 & 46,6 & 87,2 \\
\hline & $45-70$ & 48,7 & 94,8 & 47,4 & 90,0 \\
\hline \multirow[t]{3}{*}{02.06 .1987} & $0-20$ & 41,8 & 71,9 & 42,9 & 75,0 \\
\hline & $20-45$ & 48,0 & 92,4 & 45,5 & 83,6 \\
\hline & $45-70$ & 48,8 & 95,2 & 49,3 & 97,3 \\
\hline 03.06.1987 & $0-20$ & 38,1 & 61,4 & 44,2 & 79,2 \\
\hline 09.06.1987 & $0-20$ & 52,0 & 108,2 & 38,8 & 63,3 \\
\hline 18.06.1987 & $0-20$ & 49,4 & 97,8 & 47,3 & 89,8 \\
\hline 30.06 .1987 & $0-20$ & 41,8 & 71,9 & 35,7 & 55,4 \\
\hline \multirow[t]{3}{*}{ 02.07.1987 } & $0-20$ & 38,1 & 61,6 & 40,7 & 68,5 \\
\hline & $20-45$ & 45,7 & 84,1 & 46,7 & 87,8 \\
\hline & $45-70$ & 47,4 & 89,9 & 47,2 & 89,5 \\
\hline 07.07.1987 & $0-20$ & 27,8 & 38,4 & 25,7 & 34,7 \\
\hline 14.07.1987 & $0-20$ & 30,0 & 42,9 & 25,0 & 33,4 \\
\hline 21.07.1987 & $0-20$ & 38,0 & 61,3 & 33,5 & 50,4 \\
\hline 28.07.1987 & $0-20$ & 41,5 & 71,0 & 33,8 & 51,1 \\
\hline \multirow[t]{3}{*}{ 29.07.1987 } & $0-20$ & 46,8 & 88,1 & 35,0 & 53,7 \\
\hline & $20-45$ & 40,8 & 68,8 & 34,3 & 52,2 \\
\hline & $45-70$ & 40,7 & 68,5 & 43,2 & 75,9 \\
\hline 04.08 .1987 & $0-20$ & 38,3 & 62,2 & 34,1 & 51,7 \\
\hline 11.08.1987 & $0-20$ & 37,3 & 59,5 & 33,1 & 49,5 \\
\hline \multirow[t]{3}{*}{ 24.06.1988 } & $0-20$ & 32,4 & 47,9 & 24,1 & 31,8 \\
\hline & $20-45$ & 24,9 & 33,2 & 25,3 & 33,9 \\
\hline & $45-70$ & 24,3 & 32,1 & 30,6 & 44,1 \\
\hline \multirow[t]{3}{*}{ 26.07.1988 } & $0-20$ & 25,6 & 34,4 & 30,4 & 43,7 \\
\hline & $20-45$ & 26,0 & 35,1 & 30,4 & 43,7 \\
\hline & $45-70$ & 31,9 & 46,8 & 33,7 & 50,8 \\
\hline \multirow[t]{2}{*}{29.03 .1990} & $0-30$ & 33,0 & 49,3 & 31,3 & 45,6 \\
\hline & $30-60$ & 33,8 & 51,1 & 33,1 & 49,5 \\
\hline \multirow[t]{3}{*}{ 08.01.1991 } & $10-20$ & 39,1 & 64,2 & & \\
\hline & $20-30$ & 32,4 & 47,9 & & \\
\hline & $30-42$ & 33,7 & 50,8 & & \\
\hline \multirow[t]{6}{*}{ 07.03.1991 } & $0-10$ & & & 33,4 & 50,2 \\
\hline & $10-20$ & & & 31,9 & 46,9 \\
\hline & $20-30$ & & & 30,5 & 43,8 \\
\hline & $30-40$ & & & 29,6 & 42,0 \\
\hline & $40-50$ & & & 31,6 & 46,1 \\
\hline & $50-58$ & & & 32,6 & 48,3 \\
\hline Mittelwert & & 40,4 & 70,4 & 37,5 & 61,8 \\
\hline Min & & 24,3 & 32,1 & 24,1 & 31,8 \\
\hline Max & & 53,3 & 114,1 & 49,3 & 97,3 \\
\hline
\end{tabular}


Die Wassergehalte unterliegen witterungsbedingten Schwankungen. Die ermittelten Werte in \% der TM liegen bei $L 1$ zwischen 32,1 und 114,1 und bei $L 2$ zwischen 31,8 und 97,3\%. Direkt nach dem Füllen der Lysimeter wiesen die Komposte einen Wassergehalt in \% der TM von 104,5 (L 1) bzw. 85,2 (L 2) auf. Die niedrigsten Werte wurden am 24.06.88 ermittelt. Die berechneten Mittelwerte liegen bei 70,4 (L 1) und 61,8 (L 2). Über die Versuchszeit hinweg zeigen die Werte Jahreszeit und Witterungs bedingte Schwankungen. Die höchsten Wassergehalte treten in den ersten Monaten nach Anlage der Lysimeter auf. Abbildung 2 zeigt die jeweils in der obersten Schicht gemessenen Werte für die beiden Großlysimeter.

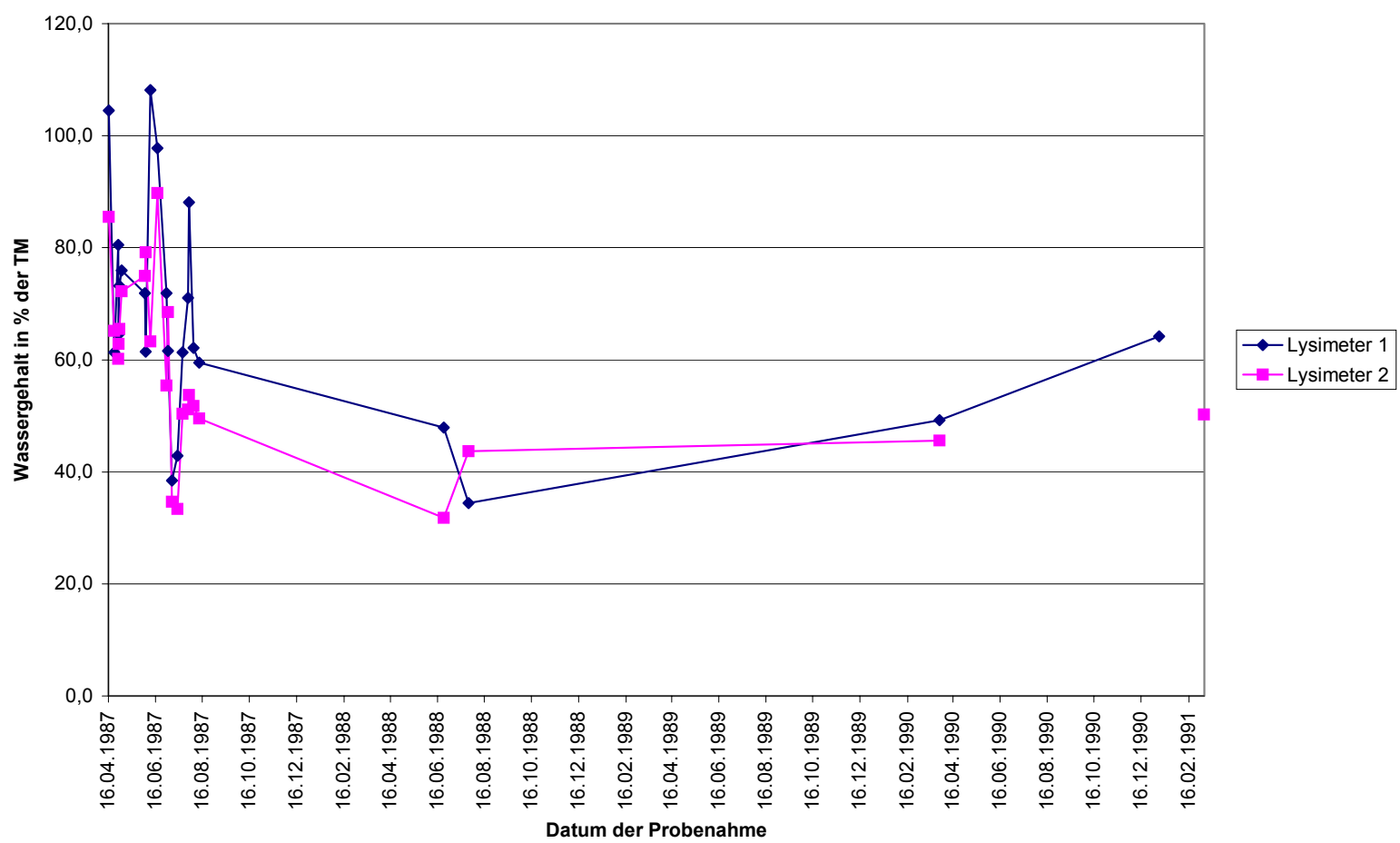

Abbildung 2: Wassergehalte in der Tiefe $0-10 \mathrm{~cm}$, Lysimeter 1 und 2

\section{Kleinlysimeter}

Die Entnahme von Material aus den Kleinlysimetern erfolgte wegen der geringen Einfüllmengen nur an vier Entnahme-Terminen. Bei den Terminen in 87 und 88 erfolgte keine Differenzierung in verschiedene Tiefenabschnitte. Bei der Probenahme am 02.04.90 wurden die Wassergehalte der Lysimeter 3 bis 6 in den Tiefen $0-10 \mathrm{~cm}$ und $10-20 \mathrm{~cm}$ bestimmt. Tabelle 4-2 zeigt die Wassergehalte für die Lysimeter $3-8$. 
Tabelle 4-2: Wassergehalte frischer, ungesiebter Materialproben zu verschiedenen Entnahme-Zeitpunkten und in verschiedenen Tiefen, Lysimeter 3 - 8

\begin{tabular}{|c|c|c|c|c|c|}
\hline $\begin{array}{l}\text { Datum der } \\
\text { Probenahme }\end{array}$ & $\begin{array}{c}\text { Tiefe } \\
\text { cm }\end{array}$ & $\begin{array}{c}\text { Wassergehalt } \\
\% \text { d. FM }\end{array}$ & $\begin{array}{c}\text { Wassergehalt } \\
\% \text { d. TM }\end{array}$ & $\begin{array}{c}\text { Wassergehalt } \\
\% \text { d. FM } \\
\end{array}$ & $\begin{array}{c}\text { Wassergehalt } \\
\% \text { d. TM }\end{array}$ \\
\hline & & Lysimeter 7 & & Lysimeter 8 & \\
\hline 30.06 .1987 & $0-10$ & 20,8 & 26,3 & 34,8 & 53,4 \\
\hline 28.07.1987 & $0-10$ & 20,7 & 26,1 & 30,5 & 43,9 \\
\hline 24.06.1988 & $0-10$ & 11,4 & 12,9 & 18,8 & 23,2 \\
\hline \multirow[t]{2}{*}{ 02.04.1990 } & $0-10$ & 20,5 & 25,8 & 33,0 & 49,3 \\
\hline & & Lysimeter 6 & & Lysimeter 5 & \\
\hline 30.06 .1987 & $0-20$ & 34,9 & 53,6 & 29,6 & 42,0 \\
\hline 28.07.1987 & $0-20$ & 25,8 & 34,8 & 20,8 & 26,3 \\
\hline 24.06.1988 & $0-20$ & 17,6 & 21,4 & 14,1 & 16,4 \\
\hline 02.04.1990 & $0-10$ & 28,5 & 39,9 & 26,3 & 35,7 \\
\hline \multirow[t]{2}{*}{ 02.04.1990 } & $10-20$ & 29,5 & 41,8 & 26,7 & 36,4 \\
\hline & & Lysimeter 4 & & Lysimeter 3 & \\
\hline 30.06 .1987 & $0-20$ & 25,6 & 34,4 & 21,1 & 26,7 \\
\hline 28.07.1987 & $0-20$ & 21,6 & 27,6 & 18,1 & 22,1 \\
\hline 24.06.1988 & $0-20$ & 11,9 & 13,5 & 10,5 & 11,7 \\
\hline 02.04.1990 & $0-10$ & 24,3 & 32,1 & 21,6 & 27,6 \\
\hline 02.04.1990 & $10-20$ & 29,0 & 40,8 & 23,3 & 30,4 \\
\hline
\end{tabular}

Bei den in Tabelle 4-2 dargestellten Werten handelt es sich ebenfalls um Einzelwerte von Mischproben. Die ermittelten Werte in \% der TM liegen zwischen 11,7 und 53,6. Die niedrigsten Werte treten ebenfalls am 24.06.88 auf. Die vor dem Einfüllen ermittelten Wassergehalte betragen für den Kompost 53,8 und für den Löss 12,3\% der TM. Die Wassergehalte steigen, wie Abbildung 3 zeigt, mit zunehmendem Kompostanteil. Die Werte liegen aufgrund der geringen Einfüllhöhe und der stärkeren Austrocknung unter den für $L 1$ und $L 2$ ermittelten Werten. 


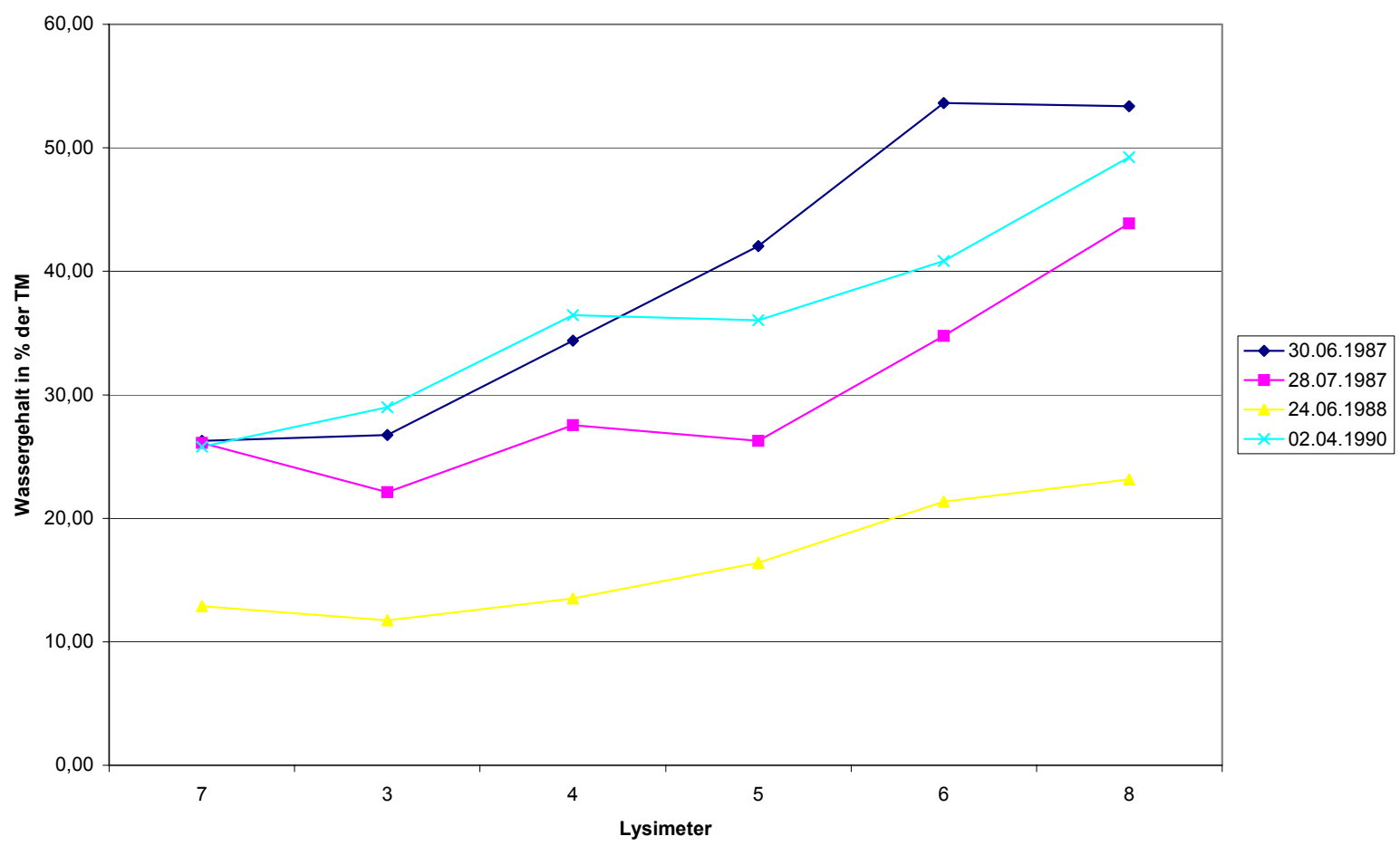

Abbildung 3: Wassergehalte Lysimeter 7 und 8 in $0-10 \mathrm{~cm}$ Tiefe, Lysimeter $3-6$ in $0-20 \mathrm{~cm}$ Tiefe

\subsection{Sackung}

\subsubsection{Methodik}

Die Sackung des in die Lysimeter eingefüllten Materials wurde anhand des Randabstandes zur Oberkante des Behälters berechnet. Aus den an mehreren Stellen pro Lysimeter gemessenen Werten wurden Durchschnittswerte für jedes Lysimeter ermittelt.

\subsubsection{Ergebnisse}

In der Versuchszeit hat eine Volumenverringerung des eingefüllten Materials durch Verdichtung ${ }^{16}$ bzw. Masseverluste in Zusammenhang mit Mineralisierung und Auswaschung stattgefunden. Die Randabstände von der Materialoberfläche zur Behälteroberkante wurden zu verschiedenen Zeitpunkten gemessen: Mai 87 (Versuchsbeginn), August 87, Juni 88, März/April 90 (Abschluss der Freilandversuche Kleinlysimeter) und Januar/März 91 (Leerung der Großlysimeter). Die hierbei für die Lysimeter ermittelten Füllhöhen sind in Tabelle 4-3 aufgeführt.

\footnotetext{
${ }^{16}$ wie später zu zeigen ist: der wichtigere Prozess
} 
Tabelle 4-3: Lysimeter-Füllhöhen zu verschiedenen Zeitpunkten in $\mathrm{m}$, Lysimeter $1-8$

\begin{tabular}{l|rrrrr} 
Lysimeter & Mai $\mathbf{8 7}$ & Aug 87 & Jun 88 & Apr $\mathbf{9 0}$ & Feb 91 \\
\hline $\mathbf{1}$ & 0,90 & 0,82 & 0,64 & 0,48 & 0,42 \\
$\mathbf{2}$ & 0,90 & 0,84 & 0,77 & 0,66 & 0,58 \\
$\mathbf{8}$ & 0,40 & 0,32 & 0,32 & 0,26 & \\
$\mathbf{6}$ & 0,48 & 0,43 & 0,37 & 0,30 & \\
$\mathbf{5}$ & 0,48 & 0,42 & 0,41 & 0,33 & \\
$\mathbf{4}$ & 0,49 & 0,40 & 0,39 & 0,31 & \\
$\mathbf{3}$ & 0,50 & 0,41 & 0,40 & 0,33 & \\
$\mathbf{7}$ & 0,36 & 0,33 & 0,33 & 0,32 &
\end{tabular}

Die Abbildung 4 zeigt die Füllhöhen an den verschiedenen Messzeitpunkten in \% der Ausgangshöhe zu Versuchsbeginn.

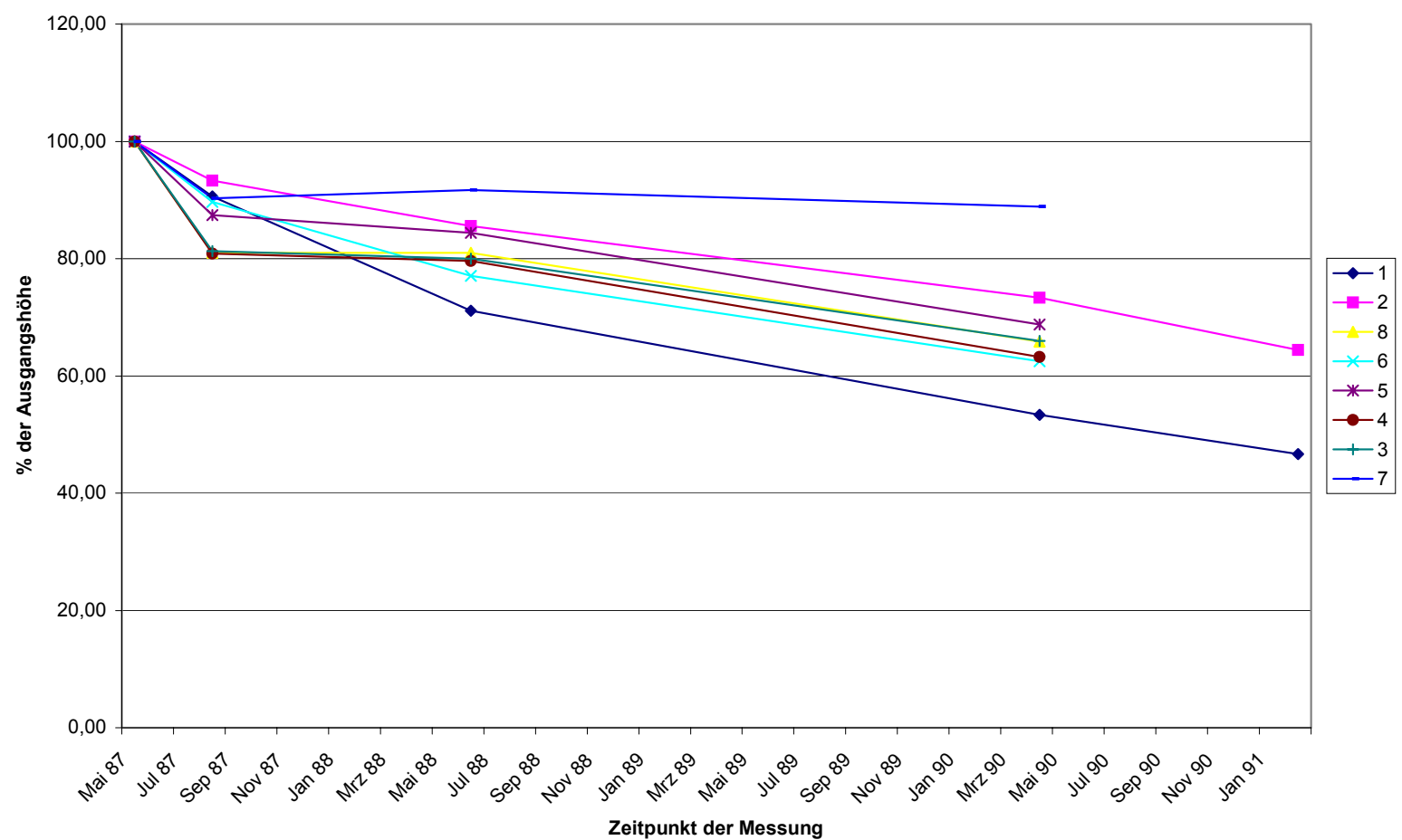

Abbildung 4: Füllhöhen zu verschiedenen Zeitpunkten in \% der Ausgangshöhe, Lysimeter 1 - 8

Bereits drei Monate nach dem Befüllen der Lysimeter hat trotz der Verdichtung mit dem Handstampfer eine weitere Volumenabnahme des eingefüllten Materials stattgefunden. Die seitliche Schrumpfung, die bei den Großlysimetern zu beobachten war, wurde hierbei nicht berücksichtigt. Zu Versuchsende im April 1990 betragen die Füllhöhen der Kleinlysimeter 8, 6, 5, 4, und 3 noch rund $65 \%$ der Ausgangs-Füllhöhe. Der reine Löss (Lysimeter 7) zeigt 
eine Abnahme auf $89 \%$ der Ausgangshöhe. Die Großlysimeter 1 und 2 haben zu Versuchsende im Februar 1991 eine Füllhöhe von 47 \% der Ausgangs-Füllhöhe für Lysimeter 1 und $65 \%$ der Ausgangs-Füllhöhe für Lysimeter 2. Während der Löss nach der anfänglichen Sackung die Höhe beibehält, setzt sich die Sackung bei den Kompost- und Kompost-LössFüllungen über die gesamte Versuchszeit fort.

In Lysimeter 1 hat keine stärkere Verdichtung des Kompostes noch ein vermehrter Abbau des eingefüllten Materials im Vergleich mit den Komposten in Lysimeter 2 und 8 stattgefunden. Die niedrigere Füllhöhe bei Lysimeter $1 \mathrm{zu}$ Versuchsende ist darauf zurückzuführen, dass zu Versuchsbeginn weniger Kompost-TM eingefüllt worden ist. Das Kompostmaterial wurde vermutlich lockerer eingefüllt. Bei Versuchsende liegen die Dichtewerte für Lysimeter 1 und 2 auf gleicher Höhe.

\subsection{Trockendichte (TD)}

\subsubsection{Methodik}

Die Bestimmung der Trockendichte erfolgte gravimetrisch. Hierzu wurden jeweils 5 Stechzylinderproben aus der zu untersuchenden Schicht eines Lysimeters entnommen und bis zur Gewichtskonstanz ofengetrocknet. Das Volumen der verwendeten Stechzylinder betrug $980,55 \mathrm{ml}$. Die Trockendichte in $\mathrm{g} / \mathrm{cm}^{3}$ ergibt sich aus dem Trockenmasse dividiert durch das Volumen des Stechzylinders.

\subsubsection{Untersuchungsproben}

Die Bestimmung der Trockendichte erfolgte am Ende der Versuchszeit und in Zusammenhang mit der Bestimmung der Porenverteilung.

\subsubsection{Ergebnisse}

\section{Großlysimeter}

Die Werte für die Großlysimeter sind in Tabelle 4-4 zusammengestellt. Aus den Mittelwerten der schichtbezogenen Einzelerhebungen ergeben sich jeweils auf die gesamte Schichthöhe gemittelte Werte von 0,69 $\mathrm{g} / \mathrm{cm}^{3}$ für Lysimeter 1 und 2. Die Schwankungen der Einzelwerte sind in Klammern angegeben. Sie sind mit 1,4 bis $5,8 \%$ gering und weisen auf die zu Versuchsende vorliegende weitgehende Homogenität des Füllmaterials hin. Bei Lysimeter 2 ist eine Zunahme der Trockendichte in den unteren Schichten erkennbar.

\footnotetext{
Tabelle 4-4: Trockendichte der verschiedenen Lysimeterschichten in $\mathrm{g} / \mathrm{cm}^{3}$, Zustand bei Versuchsende, Lysimeter 1 und 2
}

\begin{tabular}{c|cc} 
Lysimeter & $\mathbf{1}$ & $\mathbf{2}$ \\
\hline $\begin{array}{c}\text { Tiefe } \\
\text { in } \mathbf{~} \mathbf{c m}\end{array}$ & $\begin{array}{c}\text { TD } \\
\mathbf{g} / \mathbf{c m}^{\mathbf{3}}\end{array}$ & $\begin{array}{c}\text { TD } \\
\mathbf{g} / \mathbf{c m}^{\mathbf{3}}\end{array}$ \\
\hline $\mathbf{0 - 1 0}$ & k. A. & k. A. \\
$\mathbf{1 0 - 2 0}$ & 0,69 & 0,67 \\
$\mathbf{2 0}-\mathbf{3 0}$ & 0,7 & 0,67 \\
$\mathbf{3 0}-\mathbf{4 0}$ & 0,68 & 0,69 \\
$\mathbf{4 0}-\mathbf{5 0}$ & & 0,72 \\
Mw & $\mathbf{0 , 6 9}$ & $\mathbf{0 , 6 9}$
\end{tabular}

Kleinlysimeter

Die für die Kleinlysimeter ermittelten Werte sind in Tabelle 4-5 aufgeführt. 
Tabelle 4-5: Trockendichte der verschiedenen Lysimeterschichten, Zustand bei Versuchsende, Lysimeter 3 - 8

\begin{tabular}{|c|c|c|c|c|c|c|c|c|}
\hline \multirow{2}{*}{$\begin{array}{l}\text { Tiefe } \\
\text { in } \mathbf{c m}\end{array}$} & \multicolumn{7}{|c|}{ Lysimeter } & $7 \mathrm{~b}$ \\
\hline & \multicolumn{8}{|c|}{ TD in $\mathrm{g} / \mathrm{cm}^{3}$} \\
\hline $0-10$ & 0,61 & 0,69 & 0,71 & 1,01 & 1,07 & 1,31 & 1,56 & 1,5 \\
\hline $10-20$ & & & & & 0,96 & & & \\
\hline $20-30$ & & & 0,7 & 0,82 & 0,87 & 1,09 & \multirow{2}{*}{\multicolumn{2}{|c|}{1,53}} \\
\hline Mw & \multicolumn{2}{|c|}{0,65} & 0,71 & 0,91 & 0,97 & 1,22 & & \\
\hline
\end{tabular}

Im Vergleich mit dem Kompost mit seiner Trockendichte von $0,65 \mathrm{~g} / \mathrm{cm}^{3}$ hat das LössbodenMaterials mit $1,53 \mathrm{~g} / \mathrm{cm}^{3}$ eine wesentlich höhere Trockendichte. Dementsprechend steigen die Trockendichten der Mischungsvarianten bei steigenden Lössgehalten von $0,70 \mathrm{~g} / \mathrm{cm}^{3}$ für $L 6$ auf $1,22 \mathrm{~g} / \mathrm{cm}^{3}$ für $\mathrm{L} 3$. Auch bei den Mischungsvarianten wurden die Trockendichten in verschiedenen Tiefen ermittelt. Aufgrund der geringen Einfüllhöhen zeigt sich hier eine witterungsbedingte stärkere Verdichtung in der oberen Schicht. Die Dichteunterschiede in den beiden Tiefen $0-10 \mathrm{~cm}$ und $10-20 \mathrm{~cm}$ sind bei höheren Lössgehalten größer.

\subsection{Einstellung der Porenverteilung}

\subsubsection{Methodik}

Bestimmung des Porenvolumens: Stufenweises Abdrücken wassergesättigter $250 \mathrm{~cm}^{3}$ Stechzylinderproben bei $60-15.000 \mathrm{hPa}$ auf porösen Platten nach RICHARDS (zit. in SCHLICHTING u. BLUME 1966).

Lysimeter 1 - 6: 5-fache Wiederholung,

Lysimeter 7 a und b, 8 a und b: 2-fache Wiederholung

\subsubsection{Untersuchungsproben}

Die Bestimmung der Gesamtporenvolumina und der Poren-Mengenverteilung erfolgte am Ende der Versuchszeit im April 1990.

\subsubsection{Ergebnisse}

In Tabelle 4-6 sind die Werte für alle Lysimeter (1 bis 8) in der Reihenfolge nach sinkendem Glühverlust aufgeführt. Bei Lysimeter 7 und 8 wurden jeweils beide Lysimeter ( $a$ und $b$ ) beprobt. Die Probenahme beschränkte sich auf bei allen die obere Schicht von $0-20 \mathrm{~cm}$. 
Tabelle 4-6: Gesamt-Porenvolumen (GPV) und PorenMengenverteilung in Vol \% Kompost bzw. Kompostmischung, Zustand bei Versuchsende, Lysimeter 1 - 8

\begin{tabular}{|c|c|c|c|c|}
\hline pF-Wert & $<1,8$ & $1,8-4,2$ & $>4,2$ & \\
\hline $\begin{array}{l}\text { Porendurchmesser in } \\
\mu \mathrm{m}\end{array}$ & $>\mathbf{5 0}$ & $50-0,2$ & $<0,2$ & \\
\hline Porenart & Luftporen & $\mathrm{nFk}^{1}$ & Totwasser & GPV $^{2}$ \\
\hline Lysimeter & & & & \\
\hline 1 & 34,4 & 21,0 & 15,9 & 71,2 \\
\hline 2 & 29,2 & 19,3 & 20,4 & 68,8 \\
\hline 8 a & 27,7 & 24,9 & 16,6 & 69,2 \\
\hline $8 \mathrm{~b}$ & 30,7 & 22,6 & 17,7 & 70,9 \\
\hline 6 & 33,2 & 19,5 & 16,4 & 69,1 \\
\hline 5 & 27,3 & 23,4 & 13,5 & 64,2 \\
\hline 4 & 23,0 & 24,2 & 13,0 & 60,1 \\
\hline 3 & 17,6 & 24,9 & 12,6 & 55,1 \\
\hline 7 a & 6,9 & 18,8 & 14,3 & 40,0 \\
\hline $7 \mathrm{~b}$ & 8,3 & 22,6 & 13,3 & 44,2 \\
\hline
\end{tabular}

${ }^{1}$ nutzbare Feldkapazität

${ }^{2}$ Gesamtporenvolumen

Die Gesamt-Porenvolumina steigen mit zunehmendem Kompostgehalt an. Dies ist insbesondere auf den höheren Anteil an Luftporen im Kompost zurückzuführen. Die nutzbare Feldkapazität bleibt etwa gleich, während der Totwasseranteil durch die Lössbeimischung abnimmt - wenn auch nicht stark (Tongehalt Löss: $17,3 \% \times 0,8=13,8 \mathrm{Vol} \%$ ). In den sogenannten ,pflanzenverfügbares Wasser enthaltenden Poren' $50-0,2 \mu \mathrm{m}$ (nFk) sorgt die Lössbeimischung für eine Umverteilung (siehe hierzu Tabelle 1.1 und Abbildung 1-1 im Anhang). Teilt man den $\mathrm{nFk}$-Bereich auf in leicht und schwer pflanzenverfügbares Wasser, so senkt die Lössbeimengung den leicht verfügbaren Anteil und erhöht den schwer verfügbaren Anteil. Man muss jedoch dabei bedenken, dass leicht verfügbar bei Löss heißt: rasches kapillares Fließen, während beim Kompost ein beträchtlicher Teil des leicht verfügbaren Wassers bei geringer Saugspannung statisch gebunden ist. Die Intragranular- und die Intrapartikularporen (Totwasserporen) sind im Kompost wesentlich vermehrt. Bezogen auf den Gehalt an organischer Substanz beträgt das Totwasser-Volumen des Kompostes 0,7 .

Neben der Porenbestimmung wurde auch die Trockendichte ermittelt, so dass anhand der Gesamtporenvolumina und Trockendichte-Werte eine Berechnung der Materialdichten möglich ist. Diese Werte sind in Tabelle 4-7 aufgeführt. 
Tabelle 4-7: Materialdichten für Lysimeter-Füllungen 1 - 8,

Zustand bei Versuchsende

\begin{tabular}{l|ccc} 
Lysimeter & $\begin{array}{r}\text { Volumen der Festsubstanz } \\
\text { in } \mathbf{0}\end{array}$ & $\begin{array}{c}\text { Trockendichte } \\
\text { in } \mathbf{~} / \mathbf{c m}^{\mathbf{3}}\end{array}$ & $\begin{array}{c}\text { Materialdichte } \\
\text { in } \mathbf{~} / \mathbf{c m}^{\mathbf{3}}\end{array}$ \\
\hline & & & \\
$\mathbf{1}$ & 28,80 & 0,64 & 2,22 \\
$\mathbf{2}$ & 31,20 & 0,70 & 2,24 \\
$\mathbf{8} \mathbf{a}$ & 30,80 & 0,70 & 2,27 \\
$\mathbf{8} \mathbf{b}$ & 29,10 & 0,66 & 2,27 \\
$\mathbf{6}$ & 30,90 & 0,69 & 2,23 \\
$\mathbf{5}$ & 35,80 & 0,83 & 2,32 \\
$\mathbf{4}$ & 39,90 & 0,95 & 2,38 \\
$\mathbf{3}$ & 44,90 & 1,09 & 2,43 \\
$\mathbf{7} \mathbf{a}$ & 60,00 & 1,59 & 2,65 \\
$\mathbf{7} \mathbf{b}$ & 55,80 & 1,48 & 2,65
\end{tabular}

Die hier gefundenen Werte für die Trockendichte unterscheiden sich nur geringfügig von den in den Tabellen 4-4 und 4-5 genannten Werten. Bei den Mischungsvarianten sind sie etwas geringer. Die anhand des Volumens der Festsubstanz berechnete Materialdichte der Festsubstanz sinkt entsprechend den steigenden Gehalte an organischer Substanz.

Eine Umrechnung der Wassergehalte (Minimum, Maximum und Mittelwerte; Tab. 4-1) anhand der Trockendichte (Tab. 4-7) in Volumenprozent ist in den beiden folgenden Tabellen vorgenommen worden.

Tabelle 4-8: Wassergehalte in Vol \%, Lysimeter 1 und 2

\begin{tabular}{l|cccc} 
Lysimeter & $\begin{array}{c}\text { Trockendichte } \\
\text { in } \mathbf{~} / \mathbf{c m}^{\mathbf{3}}\end{array}$ & & $\begin{array}{c}\text { Wassergehalt } \\
\text { in } \mathbf{\%} \text { der TS }\end{array}$ & $\begin{array}{c}\text { Wassergehalt } \\
\text { in Volumen } \%\end{array}$ \\
\hline \multirow{2}{*}{$\mathbf{1}$} & \multirow{2}{*}{0,64} & Minimum & 32,10 & 20,54 \\
& & Maximum & 114,10 & 73,02 \\
& & Mittelwert & 70,20 & 44,93 \\
& \multirow{2}{*}{0,70} & Minimum & 31,80 & 22,26 \\
& & Maximum & 97,20 & 68,04 \\
& & Mittelwert & 61,10 & 42,77
\end{tabular}

Es zeigt sich, dass die niedrigsten gefundenen Wassergehalte bei Lysimeter 1 und 2 über dem Totwasseranteil liegen. Die mittleren Wassergehalte liegen etwas oberhalb der Wasserhaltekapazität (WHK; WHK = nFk + Totwasser) von ca. $34 \mathrm{Vol} \%$ Wasser bei Lysimeter 1 und $40 \mathrm{Vol} \%$ bei Lysimeter 2. Die maximalen Wassergehalte entsprechen einer Sättigung des gesamten Porenvolumens mit Wasser. Die Luftporen werden also zeitweise an der Wasserspeicherung beteiligt. Beides ist als Hinweis darauf zu werten, dass die Wasserspeicherung in und zwischen den Kompostaggregaten zu einem erheblichen Teil statischer Natur (Speicher-Blasen) ist und nur eine geringe hydraulische Leitfähigkeit hat. Dies kann als eine Erklärung für den Unterschied zwischen den in der Drucktopf-Apparatur gewonnenen Werten und den natürlichen Werten der Wasserspeicherung dienen. 
Tabelle 4-9: Wassergehalte in Vol \%, Lysimeter 3 - 8

\begin{tabular}{|c|c|c|c|c|c|c|}
\hline Lysimeter & 8 & & 6 & & 5 & \\
\hline Trockendichte in $\mathrm{g} / \mathrm{cm}^{3}$ & 0,68 & & 0,69 & & 0,83 & \\
\hline Wassergehalt & $\%$ der TS & Volumen \% & $\%$ der TS & Volumen $\%$ & $\%$ der TS & Volumen \% \\
\hline Minimum & 23,15 & 15,74 & 21,36 & 14,74 & 16,41 & 13,62 \\
\hline Maximum & 53,37 & 36,29 & 53,61 & 36,99 & 42,05 & 34,9 \\
\hline Mittelwert & 42,42 & 28,45 & 37,65 & 25,98 & 30,19 & 25,06 \\
\hline Lysimeter & 4 & & 3 & & 7 & \\
\hline Trockendichte in $\mathrm{g} / \mathrm{cm}^{3}$ & 0,95 & & 1,09 & & 1,53 & \\
\hline Wassergehalt & $\%$ der TS & Volumen \% & $\%$ der TS & Volumen \% & $\%$ der TS & Volumen \% \\
\hline Minimum & 13,51 & 12,83 & 11,73 & 12,79 & 12,87 & 19,82 \\
\hline Maximum & 36,45 & 34,63 & 29 & 31,61 & 26,26 & 40,44 \\
\hline Mittelwert & 27,98 & 26,58 & 22,39 & 24,41 & 22,75 & 35,04 \\
\hline
\end{tabular}

Die berechneten minimalen Vol \% Wasser im Juni 1988 erreichen bei den Lysimetern 3 - 6 und 8 den Bereich des Totwassers. Bei den Maximalwerten erreicht nur Lysimeter 7 eine Sättigung des gesamten Porenvolumens ähnlich den Großlysimetern

\subsection{Aggregat-Zusammensetzung}

\subsubsection{Methodik}

Die Bestimmung der Aggregat-Zusammensetzung erfolgte gravimetrisch. Hierzu wurden etwa $2000 \mathrm{~g}$ lufttrockener Materialproben schonend zerdrückt und durch Siebung in die Siebfraktionen $>10 \mathrm{~mm}, 10-6,3 \mathrm{~mm}, 6,3-5 \mathrm{~mm}, 5-2 \mathrm{~mm}$ und $<2 \mathrm{~mm}$ zerlegt. Die so erhaltenen Siebfraktionen wurden durch Auswaschen von anhaftenden Staub- und FeinAggregaten befreit und bis zur Gewichtskonstanz getrocknet und gewogen. Die AggregatZusammensetzung in \% der TM ergibt sich aus den prozentualen Gewichtsanteilen der jeweiligen Siebfraktion an der Gesamt-Probenmenge. Der Anteil der Fraktion $<2 \mathrm{~mm}$ wurde aus der Differenz zwischen den Gewichtsanteilen > $2 \mathrm{~mm}$ und der Gesamtmenge berechnet, so dass waschungsbedingte Materialverluste der Fraktion $<2 \mathrm{~mm}$ zugeschlagen werden mussten. Die Fraktion $<2 \mathrm{~mm}$ wird als Feinerde bezeichnet.

\subsubsection{Untersuchungsproben}

Die Abschlussproben der Großlysimeter 1 und 2, die schichtweise durch Abtragen der Lysimeter gewonnen wurden, und das Ausgangsmaterial vom März 86 wurden der oben beschriebenen Siebanalyse unterworfen. Bei den übrigen Materialproben fand nur eine Trennung in die Siebfraktionen $>1,12 \mathrm{~mm}$ und $<1,12 \mathrm{~mm}$ bzw. $>2 \mathrm{~mm}$ und $<2 \mathrm{~mm}$ statt.

\subsubsection{Ergebnisse}

Es bestand die Möglichkeit, dass der zu einem erheblichen Teil in Form von Aggregaten vorliegende Kompost seine Aggregat-Mengen-Verteilung insofern ändern könnte, als er feiner und kohärenter würde, d.h. verbackte. Tabelle 4-13 gibt dazu eine - nach der Methode zerdrücken, sieben, trocknen - erzielte Fraktionierung der Aggregate wieder und zwar bei der Befüllung der Lysimeter und nach Ende des Versuches.

Tabelle 4-10 zeigt die prozentuale Verteilung der Siebfraktionen, die nach schonendem Zerdrücken des Kompostausgangsmaterials vom März 86 und der frischen Proben aus Lysimeter 1 und 2 bei Versuchsende ermittelt wurden. 
Tabelle 4-10: Aggregat-Größenverteilung in \% der TM bei der Versuchsende (Lysimeter 1 und 2) im Vergleich zum Ausgangsmaterial (Kompost März 86)

\begin{tabular}{|c|c|c|c|c|c|}
\hline & Siebfraktio & $\mathrm{mm}$ & & & \\
\hline & $>10$ & $10-6,3$ & $6,3-5,0$ & $5,0-2,0$ & $<2,0$ \\
\hline & & & $\%$ d. TM & & \\
\hline Lysimeter 1 & & & & & \\
\hline $0-10 \mathrm{~cm}$ & 7,29 & 5,21 & 2,40 & 12,05 & 73,05 \\
\hline $10-20 \mathrm{~cm}$ & 9,14 & 3,84 & 2,15 & 11,16 & 73,71 \\
\hline $20-30 \mathrm{~cm}$ & 6,66 & 3,92 & 2,48 & 8,83 & 78,11 \\
\hline $30-42 \mathrm{~cm}$ & 8,97 & 4,59 & 1,94 & 11,47 & 73,27 \\
\hline Durchschnitt & 7,99 & 4,43 & 2,24 & 10,92 & 74,49 \\
\hline Lysimeter 2 & & & & & \\
\hline $0-10 \mathrm{~cm}$ & 9,17 & 4,55 & 1,86 & 9,58 & 74,84 \\
\hline $10-20 \mathrm{~cm}$ & 10,12 & 4,86 & 1,60 & 10,70 & 72,72 \\
\hline $20-30 \mathrm{~cm}$ & 9,12 & 3,69 & 2,15 & 10,24 & 74,80 \\
\hline $30-40 \mathrm{~cm}$ & 10,52 & 3,44 & 1,95 & 8,87 & 74,92 \\
\hline $40-50 \mathrm{~cm}$ & 10,24 & 4,33 & 2,08 & 9,23 & 74,12 \\
\hline $50-58 \mathrm{~cm}$ & 11,39 & 3,67 & 1,66 & 8,71 & 74,57 \\
\hline Durchschnitt & 10,16 & 4,06 & 1,88 & 9,49 & 74,35 \\
\hline Kompost März 86 & 5,55 & 3,10 & 1,43 & 8,05 & 81,87 \\
\hline
\end{tabular}

Für das Kompost-Ausgangsmaterial vom März 86 wurde ein Anteil der Siebfraktion $<2 \mathrm{~mm}$ von $81,9 \%$ festgestellt. Der Rest von 18,1\% verteilt sich zu 8,1\% auf die Fraktion 5 bis 2 $\mathrm{mm}, \mathrm{zu} 4,5 \%$ auf die Fraktion 10 bis $5 \mathrm{~mm}$ und zu 5,6\% auf die Aggregate $>10 \mathrm{~mm}$. Bei Versuchsende beträgt der Anteil der Siebfraktion $<2 \mathrm{~mm}$ im Mittel 74,4 \%. Die restlichen $25,6 \%>2 \mathrm{~mm}$ verteilen sich durchschnittlich zu 10,2\% auf 5 bis $2 \mathrm{~mm}$-Aggregate, zu 6,3 $\% 10-5 \mathrm{~mm}$-Aggregate und zu 9,1\% auf solche $>10 \mathrm{~mm}$. Die Unterschiede zwischen Lysimeter 1 und 2 sind gering. Es ist keine tiefenabhängige Verteilung der Siebfraktionen erkennbar. Gegenüber der Kompostcharge Mrz 86 zeigen die Komposte der Lysimeter 1 und 2 eine gewisse Vermehrung von Aggregaten $>2 \mathrm{~mm}$ und innerhalb dieser Gruppe noch eine Verschiebung zu den größten Aggregaten hin.

Da vor dem Sieben des Füllmaterials dieses schonend zerdrückt worden ist, bestehen die 25 Gew.-Prozent $>2 \mathrm{~mm}$ aus individuellen Festkörpern, wie Steinen, Scherben, verholzten Pflanzenteilen, Knochen, Textilresten sowie Plastik- und Metallteilen. Dabei machen die vom Untergrund des Kompostplatzes eingetragenen Basaltsteine den mengenmäßig größten Anteil aus. Der Glühverlust dieser Fraktion ist entsprechend der überwiegend mineralischen Zusammensetzung gering. Da es sich um Stoffe handelt, die sich nur schwer oder gar nicht zersetzen, reichern sich diese bei fortschreitendem Abbau der organischen Substanz der Siebfraktion $<2 \mathrm{~mm}$ relativ an und führen zu einem weder optisch noch manuell ansprechenden Kompost. Der geringe Anteil an strukturbildendem organischem Material in dieser Fraktion und der Grad der Verunreinigung führen zu Einschränkungen in der Verwertbarkeit.

Die chemischen Analysen der Festsubstanz wurden in den Versuchsjahren 87 und 88 an der Siebfraktion $<1,12 \mathrm{~mm}$ und in den Jahren 90 und 91 an der Siebfraktion $<2 \mathrm{~mm}$ durchgeführt. Die prozentualen Gehalte der Siebfraktion $<1,12 \mathrm{~mm}$ in den vor der Siebung getrockneten und in der Hammermühle zerkleinerten Probe sind in Tabelle 4-11 aufgeführt. Es handelt sich bis auf die Probenahme am 24.06.88 von Lysimeter 2 um Einzelwerte, die an homogenisierten Mischproben aus drei Entnahmestellen ermittelt wurden. Nur bei der 
Probenahme am 24.06.88 von Lysimeter 2 wurden drei Einzelproben von verschiedenen Entnahmestellen getrennt untersucht und der Mittelwert berechnet.

Tabelle 4-11: Anteil der Siebfraktion < 1,12 $\mathrm{mm}$ in \% der

Gesamt-TM, Lysimeter 1 und 2

\begin{tabular}{|c|c|c|c|}
\hline & & Lysimeter & \\
\hline $\begin{array}{l}\text { Datum der } \\
\text { Probenahme }\end{array}$ & $\begin{array}{c}\text { Tiefe } \\
\text { cm }\end{array}$ & $\begin{array}{c}1 \\
\text { Gew. } \%<1,12 \mathrm{~mm}\end{array}$ & $\begin{array}{c}2 \\
\text { Gew. } \%<1,12 \mathrm{~mm}\end{array}$ \\
\hline 16.04.1987 & $0-20$ & 81,5 & 91,0 \\
\hline \multirow[t]{3}{*}{ 23.04.1987 } & $0-20$ & 88,2 & 90,6 \\
\hline & $20-45$ & 87,4 & 85,6 \\
\hline & $45-70$ & 87,4 & 88,2 \\
\hline \multirow[t]{3}{*}{ 28.04.1987 } & $0-20$ & 87,4 & 84,4 \\
\hline & $20-45$ & 92,5 & 88,2 \\
\hline & $45-70$ & 83,1 & 86,1 \\
\hline \multirow[t]{3}{*}{ 29.04.1987 } & $0-20$ & 87,8 & 88,8 \\
\hline & $20-45$ & 87,2 & 89,1 \\
\hline & $45-70$ & 89,7 & 88,0 \\
\hline \multirow[t]{3}{*}{30.04 .1987} & $0-20$ & 82,8 & 87,9 \\
\hline & $20-45$ & 85,3 & 85,9 \\
\hline & $45-70$ & 81,7 & 84,4 \\
\hline \multirow[t]{3}{*}{03.05 .1987} & $0-20$ & 80,8 & 86,9 \\
\hline & $20-45$ & 88,9 & 81,9 \\
\hline & $45-70$ & 82,3 & 84,9 \\
\hline \multirow[t]{3}{*}{02.06 .1987} & $0-20$ & 86,2 & 73,2 \\
\hline & $20-45$ & 76,0 & 86,1 \\
\hline & $45-70$ & 71,2 & 85,3 \\
\hline 03.06 .1987 & $0-20$ & 69,3 & 63,8 \\
\hline 09.06 .1987 & $0-20$ & 57,4 & 77,6 \\
\hline 18.06.1987 & $0-20$ & 63,0 & 70,6 \\
\hline 30.06 .1987 & $0-20$ & 85,4 & 73,4 \\
\hline \multirow[t]{3}{*}{ 02.07.1987 } & $0-20$ & 73,2 & 44,2 \\
\hline & $20-45$ & 78,1 & 73,3 \\
\hline & $45-70$ & 80,9 & 88,2 \\
\hline 07.07.1987 & $0-20$ & 85,9 & 80,5 \\
\hline 14.07.1987 & $0-20$ & 91,4 & \\
\hline 21.07.1987 & $0-20$ & 90,2 & \\
\hline 28.07.1987 & $0-20$ & 92,3 & \\
\hline \multirow[t]{3}{*}{ 29.07.1987 } & $0-20$ & 81,5 & \\
\hline & $20-45$ & 80,5 & \\
\hline & $45-70$ & 73,0 & \\
\hline \multirow[t]{3}{*}{ 24.06.1988 } & $0-20$ & 72,7 & 77,1 \\
\hline & $20-45$ & 72,6 & 68,5 \\
\hline & $45-70$ & 71,0 & 75,5 \\
\hline \multirow[t]{2}{*}{ 29.03.1990 } & $0-30$ & 86,3 & 90,4 \\
\hline & $30-60$ & 86,8 & 91,9 \\
\hline Minimum & & 57,4 & 44,2 \\
\hline Maximum & & 92,5 & 91,9 \\
\hline Mittelwert & & 81,5 & 81,6 \\
\hline
\end{tabular}

Die prozentualen Gehalte der Siebfraktion $<1,12 \mathrm{~mm}$ am Gesamtmaterial unterliegen materialbedingten Schwankungen. Sie liegen bei Lysimeter 1 zwischen 57,4 und 92,5 und bei Lysimeter 2 zwischen 44,2 und 91,9\%. Die berechneten Mittelwerte betragen 81,5\% in 
Lysimeter 1 und 81,6 \% in Lysimeter 2. Eine Tiefenabhängigkeit der Werte ist nicht erkennbar. Lysimeter 1 und 2 unterscheiden sich nicht wesentlich.

Die Entnahme von Material aus den Kleinlysimetern erfolgte wegen der geringen Einfüllmengen nur zu vier Entnahmeterminen. Es liegen nur für die beiden Probenahmetermine 24.06.88 und 29.03.90 Angaben zur prozentualen Verteilung der Siebfraktionen nach dem Trocknen und Zerkleinern vor. Diese Werte sind in Tabelle 4-12 aufgeführt. Auch bei diesen Werten handelt es sich um Einzelwerte die aus Mischproben gewonnen wurden.

Tabelle 4-12: Anteil der Siebfraktion $<1,12 \mathrm{~mm}$ in $\%$ der Gesamt-TM, Lysimeter 3 - 8

\begin{tabular}{l|cccccc}
$\begin{array}{l}\text { Datum der } \\
\text { Probenahme }\end{array}$ & $\begin{array}{c}\text { Lysimeter } \\
\mathbf{8}\end{array}$ & $\mathbf{6}$ & $\mathbf{5}$ & $\mathbf{4}$ & $\mathbf{3}$ & $\mathbf{7}$ \\
\hline & & & & & & \\
$\mathbf{2 4 . 0 6 . 8 8}$ & 80,7 & 69,8 & 76,0 & 85,4 & 87,9 & 100,0 \\
$\mathbf{2 9 . 0 3 . 9 0}$ & 60,2 & 71,0 & 80,7 & 94,5 & 96,5 & 100,0 \\
& & & & & & \\
Mittelwert & $\mathbf{7 0 , 4}$ & $\mathbf{7 0 , 4}$ & $\mathbf{7 8 , 4}$ & $\mathbf{9 0 , 0}$ & $\mathbf{9 2 , 2}$ & $\mathbf{1 0 0 , 0}$
\end{tabular}

Die Löss-Füllung aus Lysimeter 7 besteht zu $100 \%$ aus Aggregaten $<1,12 \mathrm{~mm}$. Dementsprechend steigen die prozentualen Anteile der Fraktion $<1,12 \mathrm{~mm}$ in den Mischungsvarianten mit zunehmenden Löss-Anteilen an. In der reinen Kompostfüllung (Lysimeter 8 ) ist im Lauf der Versuchszeit eine Zunahme der aus Einzelkörpern bestehenden Fraktion $>1,12$ $\mathrm{mm}$ festzustellen, in den lössreicheren Varianten (Lysimeter 5, 4 und 3) nimmt dagegen der Feinanteil zu. Dazwischen besteht Gleichgewicht.

Für die Gewinnung der Fraktion $<1,12 \mathrm{~mm}$ bzw. $<2 \mathrm{~mm}$, im Folgenden kurz als „Feinerde“ bezeichnet, wurden verschiedene Varianten der Probenvorbereitung angewendet und verglichen. In Tabelle 4-13 sind die prozentualen Gehalte der Siebfraktion $<1,12 \mathrm{~mm}$ bzw. $<2 \mathrm{~mm}$ für verschiedene Verfahren der Probenvorbereitung aufgeführt. Zum Vergleich mit dem Vorgang „Trockenen, Zerkleinern, Sieben“ (t-z-s) wurden Proben direkt nach dem Trocknen ohne Zerkleinerung gesiebt (t-s), mit dem Handmörser zerdrückt (t-m-s) oder direkt frisch vorsichtig mit einer Walze zerdrückt und danach gesiebt (f-w-s). 
Tabelle 4-13: Mengen-Anteile der Fraktionen $<1,12 \mathrm{~mm}$ bzw.

$2 \mathrm{~mm}$ nach Aggregat-Aufbereitung durch Sieben nach unterschiedlicher Vorbehandlung, Lysimeter 1 und 2

t-s: $\quad$ Trocknen, ohne Zerkleinern Sieben

t-z-s: $\quad$ Trocknen, Zerkleinern, Sieben

t-m-s: Trocknen, Zerdrücken im Mörser, Sieben

f-w-s: $\quad$ frische Probe mit Walze Zerdrücken, Sieben

\begin{tabular}{|c|c|c|c|}
\hline & & Lysimeter & \\
\hline $\begin{array}{l}\text { Datum der } \\
\text { Probenahme }\end{array}$ & $\begin{array}{c}\text { Tiefe } \\
\text { cm }\end{array}$ & $\begin{array}{c}1 \\
\text { Gew. } \%<1,12 \mathrm{~mm} \\
\mathrm{t}-\mathrm{s}\end{array}$ & $\begin{array}{c}2 \\
\text { Gew. } \%<1,12 \mathrm{~mm} \\
\mathrm{t}-\mathrm{s} \\
\end{array}$ \\
\hline \multirow[t]{2}{*}{ 26.07.88 } & $\begin{array}{r}0-20 \\
20-45 \\
45-70\end{array}$ & $\begin{array}{l}45,90 \\
47,10 \\
50,00\end{array}$ & $\begin{array}{l}48,70 \\
48,30 \\
42,80\end{array}$ \\
\hline & & t-z-s & t-z-s \\
\hline \multirow[t]{2}{*}{ 29.03.1990 } & $\begin{array}{r}0-30 \\
30-60\end{array}$ & $\begin{array}{l}86,32 \\
86,83\end{array}$ & $\begin{array}{l}90,36 \\
91,87\end{array}$ \\
\hline & & $t-m-s$ & $t-m-s$ \\
\hline \multirow[t]{2}{*}{ 29.03.1990 } & $\begin{array}{r}0-30 \\
30-60\end{array}$ & $\begin{array}{l}62,73 \\
68,85\end{array}$ & $\begin{array}{l}67,64 \\
69,44\end{array}$ \\
\hline & & $\begin{array}{c}\text { Gew. } \%<2 \mathrm{~mm} \\
\text { f-w-s }\end{array}$ & $\begin{array}{c}\text { Gew. } \%<2 \mathrm{~mm} \\
\mathrm{f}-\mathrm{w}-\mathrm{s}\end{array}$ \\
\hline 29.03.1990 & $\begin{array}{r}0-30 \\
30-60\end{array}$ & $\begin{array}{l}75,12 \\
73,66\end{array}$ & $\begin{array}{l}73,73 \\
76,87\end{array}$ \\
\hline
\end{tabular}

Je nach Art der Probenvorbereitung ergeben sich unterschiedliche Ausbeuten für den prozentualen Anteil der Fraktion $<1,12 \mathrm{~mm}$. Durch den Trocknungsvorgang werden Aggregate verbacken, so dass die direkte Siebung der getrockneten Proben am 26.07.88 nur einen vergleichsweise geringen Anteil Feinerde - 42,8 bis $50 \%$ für $L 1$ und $L 2$ - in den verschiedenen Tiefen der Probe ergibt. Durch das Zerstoßen getrockneter Proben im Handmörser wird der Anteil Feinerde bei Lysimeter 1 und 2 in den verschiedenen Tiefen der Probe vom 29.03.90 auf 62,7 bis 69,4 \% erhöht. Das Zerkleinern getrockneter Proben in der Hammermühle ergibt eine weitere Zunahme der Feinerde auf 86,3 bis $91,9 \%$. Durch das Zerkleinern werden auch Gesteinsbrocken zerschlagen, wodurch Fehlerquellen für die nachfolgenden chemischen Untersuchungen gegeben sind, die bei den abschließenden Gehaltbestimmungen durch eine schonende Probenvorbereitung vermieden werden sollten. Als Methode der Wahl erwies sich die Bearbeitung frischer Proben, die nach vorsichtiger Zerkleinerung mit einer Walze (sandgefüllte Glasflasche) gesiebt wurden und deren Siebfraktionen durch Auswaschen von kleineren Bestandteilen befreit wurden. Durch diese schonende Art der Probenvorbereitung ergeben sich Feinerde-Anteile für $L 1$ und $L 2$ in den verschiedenen Tiefen der Probe vom 29.03 .90 von 73,7 bis 76,9\%.

Da für die Betrachtung stofflicher Veränderungen während der Versuchszeit aufgrund der Materialzusammensetzung des Kompostes nur die Feinerde relevant ist, wurden für die Bilanzierung die Elementgehalte der Fraktion $<2 \mathrm{~mm}$ herangezogen. Als Bezugsbasis wurden die schonend gewonnenen Fraktionen $<2$ mm gewählt. 


\subsection{Korngrößen-Zusammensetzung}

\subsubsection{Methodik}

Die Bestimmung der mineralischen Korngrößen wurde nach ATTERBERG durchgeführt. Hierzu wurden etwa $20 \mathrm{~g}$ der auf $2 \mathrm{~mm}$ Durchmesser abgesiebten sogenannten Feinerde eingesetzt, die mengenmäßig dominiert. Folgende Verfahren der Probenvorbereitung zur Korngrößen-Trennung wurden miteinander verglichen, wobei in allen Fällen die Dispergierung vor dem Sieben und Schlämmen mit verdünnter Ammoniumlösung erfolgte:

$\begin{array}{ll}\text { Variante } A & \text { Kochen mit } \mathrm{H}_{2} \mathrm{O}_{2}, \text { Kalkzerstörung mit } \mathrm{HCl} \\ \text { Variante } B & \text { Kochen mit } \mathrm{H}_{2} \mathrm{O}_{2} \\ \text { Variante C } & \text { ohne Vorbehandlung } \\ \text { Variante D } & \text { Erhitzen auf } 450^{\circ} \mathrm{C}, \text { Kalkzerstörung mit HCl }\end{array}$

Variante A, Kochen mit $\mathrm{H}_{2} \mathrm{O}_{2}$ zur Humuszerstörung und Kalkzerstörung mit $\mathrm{HCl}$, entspricht dem üblicherweise durchgeführten Verfahren der Probenvorbehandlung. Für die Variante $\mathrm{B}$ wurde die Probe mehrfach (bis zum Ausbleiben sichtbarer Blasenbildung) mit $\mathrm{H}_{2} \mathrm{O}_{2}$ gekocht, um eine möglichst vollständige Zerstörung der organischen Substanz zu erzielen. Es erfolgte keine Kalkzerstörung. Die Variante $\mathrm{C}$ sah keine Vorbehandlung der Probe vor und bei Variante $\mathrm{D}$ erfolgte eine Veraschung bei $450{ }^{\circ} \mathrm{C}$ und Kalkzerstörung mit $\mathrm{HCl}$.

Die Sand- (> $63 \mu \mathrm{m})$ und die Grobschluff-Fraktionen $(63-20 \mu \mathrm{m})$ wurden durch Siebung gewonnen. Die nach dem Sieben durchgeführte Schlämmanalyse der Fraktionen $<20 \mu \mathrm{m}$ Durchmesser erfolgte nach dem Prinzip ATTERBERG durch vollständige Abtrennung und Gewinnung der einzelnen Fraktionen unter wiederholtem Dispergieren und Abschlämmen.

\subsubsection{Untersuchungsproben}

Die Korngrößen-Zusammensetzung des Kompostes wurde an archiviertem Kompost-Ausgangsmaterial (März 86) und an Proben der Lysimeter 1 bis 8 zu Versuchsende des Freilandversuches (März/April 1990 und Januar/März 1991) untersucht. Die Aufstellung in Tabelle 4-14 zeigt an welchen Proben welche Varianten der Vorbehandlungsmethoden angewendet wurden. 
Tabelle 4-14: Übersicht über die Probenahme und die Anwendung verschiedener Vorbehandlungsmethoden der Korngrößen-Analyse, Lysimeter 1 - 8

$\begin{array}{ll}\text { Variante } & \\ \text { A } & \text { Zerstörung von Humus, Kalk, freies Eisenoxyd } \\ \text { B } & \text { Intensive Zerstörung von Humus } \\ \text { C } & \text { Ohne Vorbehandlung } \\ \text { D } & \text { Veraschung bei } 450^{\circ} \mathrm{C} \text { und Kalkzerstörung }\end{array}$

\begin{tabular}{l|c|cc} 
Lysimeter & $\begin{array}{c}\text { Tiefe } \\
\text { in } \mathbf{~ c m ~}\end{array}$ & $\begin{array}{c}\text { Datum der } \\
\text { Probenahme }\end{array}$ & Varianten \\
\hline $\mathbf{1}$ & $\mathbf{0 - 3 0}$ & 30.03 .1990 & $\mathrm{~A} / \mathrm{D}$ \\
$\mathbf{1}$ & $\mathbf{3 0 - 6 0}$ & 30.03 .1990 & $\mathrm{~A} / \mathrm{D}$ \\
$\mathbf{1}$ & $\mathbf{0 - 1 0}$ & 09.01 .1991 & $\mathrm{~B} / \mathrm{C}$ \\
$\mathbf{2}$ & $\mathbf{0 - 3 0}$ & 30.03 .1990 & $\mathrm{~A} / \mathrm{D}$ \\
$\mathbf{2}$ & $\mathbf{3 0 - 6 0}$ & 30.03 .1990 & $\mathrm{~A} / \mathrm{D}$ \\
$\mathbf{2}$ & $\mathbf{0 - 1 0}$ & 08.03 .1991 & $\mathrm{~B} / \mathrm{C}$ \\
$\mathbf{8}$ & & 02.04 .1990 & $\mathrm{~A} / \mathrm{D}$ \\
$\mathbf{6}$ & & 02.04 .1990 & $\mathrm{~A} / \mathrm{D}$ \\
$\mathbf{5}$ & & 02.04 .1990 & $\mathrm{~A} / \mathrm{D}$ \\
$\mathbf{4}$ & & 02.04 .1990 & $\mathrm{~A}$ \\
$\mathbf{3}$ & & $\mathbf{0 2 . 0 4 . 1 9 9 0}$ & $\mathrm{A}$ \\
$\mathbf{7}$ & & 02.04 .1990 & $\mathrm{~A}$ \\
& & & $\mathrm{~B}$
\end{tabular}

Da nicht vorhergesehen werden konnte, ob durch eine weitere Mineralisation der organischen Substanz des Kompostes neue Mineral-Korngrößen-Fraktionen geschaffen würden, wurde neben den Proben aus den Frühjahren 90 und 91 aus den Lysimetern auch das archivierte Kompost-Ausgangsmaterial mit der Bezeichnung März 86, das zur Herstellung der Kleinlysimeter eingesetzt worden war, untersucht.

\subsubsection{Ergebnisse}

Da mit Verklebung der primären und sekundären Mineralkörper im Kompost durch abgeschiedenes $\mathrm{CaCO}_{3}$ und durch Humate zu rechnen war und bekannt ist, dass mit $\mathrm{H}_{2} \mathrm{O}_{2}$ die organische Substanz nicht vollständig aufzuoxidieren ist, wurde auch die thermische Zerstörung bei $450^{\circ} \mathrm{C}$ (Methode $\mathrm{D}$ ) in die Vorbereitung der Proben zur Sieb- und Schlämmanalyse einbezogen .

Bei D zeigte sich unter stereomikroskopischer Betrachtung als Folge der Erhitzung das Auftreten von Schmelzfluss. Dabei versinterten große Anteile des Mittel- und Feinschluffs und des Tons zu sandkorngroßen rundlich-traubigen Aggregaten mit hellockerfarbiger, glatter, glänzender Oberfläche.

Da die Korngrößenanalyse keine neuen Mineral-Korngrößen-Fraktionen zu Versuchsende ergab, sind die Daten für Lysimeter 8 und das Kompost-Ausgangsmaterial in der folgenden Tabelle zusammengefasst. Die Einzelwerte für Lysimeter 8 und das KompostAusgangsmaterial sowie die verschiedenen beprobten Tiefen der Großlysimeter 1 und 2 sind im Anhang aufgeführt. Tabelle 4-15 zeigt eine Zusammenfassung der für die Komposte bei der Korngrößenanalyse ermittelten Daten. Zur besseren Vergleichbarkeit sind die Anteile der Fraktionen auf 100 \% der Fraktionssumme umgerechnet worden. 
Tabelle 4-15: Korngrößen-Verteilung, jeweils gemittelte Werte für Lysimeter 1 und 2 und Lysimeter 8 und Ausgangsmaterial Mrz 86

\begin{tabular}{|c|c|c|c|c|c|c|c|c|}
\hline \multirow{2}{*}{$\begin{array}{l}\text { Lysimeter } \\
\text { Variante }\end{array}$} & \multicolumn{4}{|c|}{1 und 2} & \multicolumn{4}{|c|}{8 und Ausgangsmaterial } \\
\hline & A & B & C & $\mathbf{D}$ & A & B & C & D \\
\hline Korngröße in $\mu \mathrm{m}$ & \multicolumn{8}{|c|}{$\%$ der Fraktionssummen TM } \\
\hline $2000-630$ & 10,03 & 12,18 & 10,49 & 12,05 & 6,19 & 16,06 & 16,20 & 7,02 \\
\hline $630-200$ & 14,03 & 15,77 & 15,50 & 23,56 & 21,58 & 19,57 & 17,76 & 29,34 \\
\hline $200-63$ & 11,75 & 11,89 & 21,97 & 21,33 & 14,25 & 10,72 & 21,24 & 20,64 \\
\hline Sand & 35,81 & 39,83 & 47,95 & 56,94 & 42,02 & 46,35 & 55,20 & 57,00 \\
\hline $63-20$ & 25,84 & 26,18 & 27,97 & 29,00 & 22,63 & 25,31 & 25,15 & 27,62 \\
\hline $20-6$ & 14,40 & 13,63 & 9,66 & & 12,00 & 11,76 & 7,63 & \\
\hline $6-2$ & 10,94 & 4,99 & 8,47 & 14,07 & 11,66 & 4,93 & 6,56 & 15,39 \\
\hline Schluff & 51,18 & 44,79 & 46,09 & & 46,29 & 42,00 & 39,34 & \\
\hline Ton $<2 \mu \mathrm{m}$ & 13,02 & 15,37 & 5,96 & & 11,69 & 11,64 & 5,46 & \\
\hline
\end{tabular}

Die vollständigste Dispergierung der Bodenteilchen wird zweifellos durch das Vorbehandlungsverfahren $A$ erreicht. An diesen Ergebnissen gemessen zeigt Verfahren $B$, bei dem nur der Humus, nicht aber die rund $6 \%$ Kalk zerstört wurden, folgende Abweichung: Die Sandfraktionen sind um 4 Prozentpunkte größer, die Tonfraktion um ca. 2 Punkte, während die Schluff-Fraktionen entsprechend verringert sind. Dies würde einerseits bedeuten, dass der im Kompost vorliegende - eingetragener wie neu gebildeter - Kalk Verteilungsschwerpunkte in den Sandfraktionen wie auch in den Tonfraktionen haben muss. Der Verzicht auf die Zerstörung von $\mathrm{CaCO}_{3}$ in Methode $\mathrm{B}$ führt dazu, dass im Wesentlichen der Feinschluff $(6-2$ $\mu \mathrm{m})$, und weniger der Mittelschluff $(20-6 \mu \mathrm{m})$ verbacken bleiben und zwar als Grobschluff $(63-20 \mu \mathrm{m})$ und Grobsand $(2000-630 \mu \mathrm{m})$. Ohne jede Vorbehandlung bei der Korngrößen-Analyse wird die „verkittende“ Rolle der organischen Substanz deutlich, bei der „verloren" gegangener Ton in die Sandfraktionen transferiert wird. Die Vorbehandlungsvariante D ist insofern unbrauchbar als sie durch Versinterung Sand- und Grobschluff-Partikel erzeugt, die nicht weiter zu dispergieren sind. Die Summe der Fraktionen $<20 \mu \mathrm{m}$ Durchmesser wird von $38,5 \%$ auf $14,1 \%$ bzw. von $35,3 \%$ auf $15,5 \%$ reduziert, wodurch besonders der Anteil des Mittelsandes $(630-200 \mu \mathrm{m})$ erhöht wird.

Gegenüber der Mineralsubstanz des Kompostes hat das in den Kleinlysimetern 3-6 dem Kompost beigemischte Lössboden-Material folgende Zusammensetzung der KorngrößenAnteile (nach Vorbereitungsmethode A):

$\begin{array}{lc}\text { Sand } & 6,3 \% \text { der TM } \\ \text { Schluff } & 76,4 \% \text { der TM } \\ \text { Ton } & 17,3 \% \text { der TM }\end{array}$

Demzufolge ergibt sich bei steigenden Mischungsanteilen von Löss am Kompost eine Abnahme des Sandgehaltes und eine Zunahme des Schluff- und Tongehaltes.

Dies zeigt Tabelle 4-16 anhand der Ergebnisse der Korngrößenanalyse für die Kleinlysimeter 3-8 nach Durchführung der Vorbehandlungsvariante A. 
Tabelle 4-16: Mineralische Korngrößen-Zusammensetzung der Kleinlysimeter mit Mischungen aus Kompost (8) und Löss (7)

\begin{tabular}{|c|c|c|c|c|c|c|}
\hline Lysimeter & 8 & 6 & 5 & 4 & 3 & 7 \\
\hline Variante & & A & & & & \\
\hline Korngröße in $\mu \mathrm{m}$ & \multicolumn{3}{|c|}{$\%$ der $\mathrm{TM}<2 \mathrm{~mm}$} & & & \\
\hline $2000-630$ & 6,19 & 8,23 & 5,56 & 3,64 & 6,30 & 0,33 \\
\hline $630-200$ & 21,58 & 16,80 & 15,46 & 12,13 & 7,03 & 0,94 \\
\hline $200-63$ & 14,25 & 13,16 & 12,97 & 9,90 & 7,56 & 5,01 \\
\hline Sand & 42,02 & 38,19 & 33,99 & 25,67 & 20,89 & 6,28 \\
\hline $63-20$ & 22,63 & 30,13 & 36,24 & 40,40 & 44,62 & 55,45 \\
\hline $20-6$ & 12,00 & 12,52 & 12,40 & 13,22 & 13,05 & 14,81 \\
\hline $6-2$ & 11,66 & 9,59 & 6,95 & 9,39 & 7,00 & 6,16 \\
\hline Schluff & 46,29 & 52,24 & 55,59 & 63,01 & 64,67 & 76,42 \\
\hline Ton $<2 \mu \mathrm{m}$ & 11,69 & 9,57 & 10,42 & 11,33 & 14,45 & 17,30 \\
\hline
\end{tabular}

Tabelle 4-17 bringt die Ergebnisse der Korngrößenanalyse für die Kleinlysimeter 8, 6 und 5 nach Durchführung der Vorbehandlungsvariante D, also nach der thermischen Behandlung.

\section{Tabelle 4-17: Korngrößen-Verteilung der kompostreichen Kleinlysimeter 8, 6 und 5 nach Anwendung der Vorbehand- lungsmethode D}

\begin{tabular}{|c|c|c|c|}
\hline Lysimeter & 8 & 6 & 5 \\
\hline Variante & \multicolumn{3}{|c|}{ D } \\
\hline Korngröße in $\mu \mathrm{m}$ & \multicolumn{3}{|c|}{$\%$ der Fraktionssummen TM } \\
\hline $2000-630$ & 7,02 & 10,23 & 17,44 \\
\hline $630-200$ & 29,34 & 24,59 & 24,96 \\
\hline $200-63$ & 20,64 & 20,88 & 15,41 \\
\hline Sand & 57,00 & 55,70 & 57,81 \\
\hline $63-20$ & 27,62 & 28,56 & 29,31 \\
\hline$<20$ & 15,39 & 15,74 & 12,88 \\
\hline Schluff und Ton & 43,01 & 44,30 & 42,19 \\
\hline
\end{tabular}

Obwohl Lysimeter 5 in der Feinerde bereits $46 \%$ Lössmaterial enthält, ist der bei Erhitzung auf $450{ }^{\circ} \mathrm{C}$ einsetzende Sinterungsprozess mit seiner Korngrößen-Umverteilung fast genauso stark wie in dem reinen Kompostmaterial (8).

Die im Anhang dargestellten ausführlicheren Tabellen 1-2 bis 1-4 zeigen, dass die Unterschiede in der Korngrößen-Zusammensetzung nach Anwendung der Vorbehandlungsmethoden $\mathrm{A}, \mathrm{B}$ und $\mathrm{C}$ der einzelnen Lysimeter-Tiefenabschnitte unbedeutend sind und auch zwischen den Lysimetern 1 und 2 gering sind.

\subsubsection{Kohlenstoff- und Stickstoff-Gehalte in den Schlämmfraktionen}

In den Schlämmfraktionen der Probenvorbereitungsvarianten B und C wurden Bestimmungen der C- und N-Gehalte durchgeführt. Tabelle 4-18 zeigt die hierbei erhaltenen Werte. 
Tabelle 4-18: C-, N-Gehalte und C/N-Verhältnisse in der Feinerde und in den Schlämmfraktionen vor und nach wiederholter $\mathrm{H}_{2} \mathrm{O}_{2}$-Behandlung, Lysimeter 1, 2 und Ausgangsmaterial März 86

\begin{tabular}{|c|c|c|c|c|c|c|c|c|}
\hline Spalte-Nr. & $\begin{array}{c}\text { Fraktion } \% \\
\text { Feinerde } \\
1 \\
\end{array}$ & $\mid \begin{array}{c}\text { C-Gehalt \% } \\
\text { TM Fraktion } \\
2 \\
\end{array}$ & $\begin{array}{c}\text { C-Gehalt } \mathrm{g} / 100 \mathrm{~g} \\
\text { Feinerde } \\
3 \\
\end{array}$ & $\begin{array}{c}\text { C-Gehalt \% } \\
\text { Gesamt-C } \\
4 \\
\end{array}$ & $\begin{array}{c}\text { N-Gehalt \% } \\
\text { TM Fraktion } \\
5 \\
\end{array}$ & $\begin{array}{c}\mathrm{N}-\text { Gehalt } \mathrm{g} / 100 \mathrm{~g} \\
\text { Feinerde } \\
6 \\
\end{array}$ & $\begin{array}{c}\text { N-Gehalt \% } \\
\text { Gesamt-N } \\
7 \\
\end{array}$ & $\begin{array}{c}\mathrm{C} / \mathrm{N}- \\
\text { Verhältnis } \\
8 \\
\end{array}$ \\
\hline \multicolumn{9}{|c|}{$\begin{array}{c}\text { Lysimeter 1, Variante C } \\
\end{array}$} \\
\hline \multicolumn{9}{|l|}{ Fraktion } \\
\hline Feinerde gesamt & 100 & 14,55 & 14,55 & 100,00 & 1,55 & 1,55 & 100,00 & 9,4 \\
\hline $20-6 \mu \mathrm{m}$ & 9,50 & 6,52 & 0,62 & 4,26 & 0,75 & 0,07 & 4,58 & 8,7 \\
\hline $6-2 \mu \mathrm{m}$ & 8,47 & 22,30 & 1,89 & 12,98 & 2,77 & 0,23 & 15,14 & 8,1 \\
\hline$<2 \mu \mathrm{m}$ & 5,94 & 19,23 & 1,14 & 7,85 & 2,76 & 0,16 & 10,56 & 7,0 \\
\hline \multirow[t]{2}{*}{ Summe $<20 \mu \mathrm{m}$} & 23,91 & & 3,65 & 25,09 & & 0,47 & 30,28 & \\
\hline & \multicolumn{8}{|c|}{ Lysimeter 1, Variante B } \\
\hline Feinerde gesamt & 100,00 & 3,17 & 3,17 & 100,00 & 0,47 & 0,47 & 100,00 & 6,7 \\
\hline $20-6 \mu \mathrm{m}$ & 13,21 & 0,60 & 0,08 & 2,50 & 0,03 & 0,00 & 0,87 & 19,4 \\
\hline $6-2 \mu m$ & 5,73 & 3,46 & 0,20 & 6,25 & 0,14 & 0,01 & 1,67 & 25,3 \\
\hline$<2 \mu \mathrm{m}$ & 14,49 & 3,88 & 0,56 & 17,72 & 0,30 & 0,04 & 9,19 & 13,0 \\
\hline \multirow[t]{2}{*}{ Summe $<20 \mu \mathrm{m}$} & 33,43 & & 0,84 & 26,48 & & 0,06 & 11,73 & \\
\hline & \multicolumn{8}{|c|}{ Lysimeter 2, Variante C } \\
\hline Feinerde gesamt & 100,00 & 13,09 & 13,09 & 100,00 & 1,37 & 1,37 & 100,00 & 9,6 \\
\hline $20-6 \mu \mathrm{m}$ & 9,82 & 6,19 & 0,61 & 4,64 & 0,69 & 0,07 & 4,95 & 9,0 \\
\hline $6-2 \mu \mathrm{m}$ & 8,46 & 22,37 & 1,89 & 14,46 & 2,87 & 0,24 & 17,72 & 7,8 \\
\hline$<2 \mu \mathrm{m}$ & 5,97 & 18,23 & 1,09 & 8,31 & 2,85 & 0,17 & 12,40 & 6,4 \\
\hline \multirow[t]{2}{*}{ Summe $<20 \mu \mathrm{m}$} & 24,25 & & 3,59 & 27,42 & & 0,48 & 35,06 & \\
\hline & \multicolumn{8}{|c|}{ Lysimeter 2, Variante B } \\
\hline Feinerde gesamt & 100,00 & 3,26 & 3,26 & 100,00 & 0,34 & 0,34 & 100,00 & 9,6 \\
\hline $20-6 \mu \mathrm{m}$ & 14,05 & & & & & & & \\
\hline $6-2 \mu \mathrm{m}$ & 4,24 & 2,40 & 0,10 & 3,12 & 0,15 & 0,01 & 1,81 & 16,6 \\
\hline$<2 \mu \mathrm{m}$ & 16,25 & 3,02 & 0,49 & 15,05 & 0,26 & 0,04 & 12,24 & 11,8 \\
\hline \multirow[t]{2}{*}{ Summe $<20 \mu \mathrm{m}$} & 34,54 & & 0,59 & \begin{tabular}{l|l}
18,18 \\
\end{tabular} & & 0,05 & 14,04 & \\
\hline & \multicolumn{8}{|c|}{ Ausgangskompost, Variante C } \\
\hline Feinerde gesamt & 100,00 & 14,34 & 14,34 & 100,00 & 1,47 & 1,47 & 100,00 & 9,8 \\
\hline $20-6 \mu \mathrm{m}$ & 7,63 & 5,10 & 0,39 & 2,71 & 0,56 & 0,04 & 2,93 & 9,0 \\
\hline $6-2 \mu \mathrm{m}$ & 6,56 & 22,64 & 1,49 & 10,36 & 3,11 & 0,20 & 13,88 & 7,3 \\
\hline$<2 \mu \mathrm{m}$ & 5,46 & 19,63 & 1,07 & 7,47 & 3,15 & 0,17 & 11,68 & 6,2 \\
\hline \multirow[t]{2}{*}{ Summe $<20 \mu \mathrm{m}$} & 19,65 & & 2,95 & \begin{tabular}{l|l}
20,54 \\
\end{tabular} & & 0,42 & 28,49 & \\
\hline & \multicolumn{8}{|c|}{ Ausgangkompost, Variante B } \\
\hline Feinerde gesamt & 100,00 & 3,51 & 3,51 & 100,00 & 0,47 & 0,47 & 100,00 & 7,5 \\
\hline $20-6 \mu \mathrm{m}$ & 11,76 & 0,65 & 0,08 & 2,18 & 0,04 & 0,00 & 0,88 & 18,6 \\
\hline $6-2 \mu \mathrm{m}$ & 4,93 & 3,67 & 0,18 & 5,15 & 0,16 & 0,01 & 1,72 & 22,4 \\
\hline$<2 \mu \mathrm{m}$ & 11,64 & 4,59 & 0,53 & 15,22 & 0,34 & 0,04 & 8,40 & 13,5 \\
\hline Summe $<20 \mu \mathrm{m}$ & 28,33 & & 0,79 & 22,55 & & 0,05 & 10,99 & \\
\hline
\end{tabular}

Die Gesamt-C-Gehalte der analysierten Kompost-Feinerde liegen zwischen 13,1 und 14,6 $\%$, was abzüglich der $\mathrm{C}_{\text {carb }}$-Gehalte bei Multiplikation mit dem Faktor 1,724 rund $23 \%$ Humus entspricht. Durch die wiederholte Behandlung mit $\mathrm{H}_{2} \mathrm{O}_{2}$ (Variante B) konnte der CGehalt nur auf 3,2 bis 3,5\% C gesenkt werden. Davon ist rund ein Viertel in den auf ihre Cund N-Gehalte untersuchten Schlämmfraktionen $<20 \mu \mathrm{m}$ enthalten und hier besonders im Feinschluff und im Ton - vermutlich sorptiv fest als Humat gebunden. Eine ähnliche prozentuale Verteilung des C-Gehaltes ist auch schon vor der $\mathrm{H}_{2} \mathrm{O}_{2}$-Behandlung (Variante C) festzustellen, wo durchschnittlich $22,4 \% \mathrm{C}$ auf die Schlämmfraktionen entfallen.

Bei beiden Varianten wurde keine Kalkzerstörung durchgeführt. Die $\mathrm{CaCO}_{3}$-Gehalte der Kompost-Feinerden liegen durchschnittlich für Lysimeter 1 bei 6,1\% entsprechend 0,72\% $\mathrm{C}_{\text {carb}}$, und für Lysimeter 2 bei $6,6 \%$ entsprechend $0,79 \% \mathrm{C}_{\text {carb }}$ und für das archivierte Ausgangsmaterial bei 8,4\% der TM entsprechend 1,00\% $\mathrm{C}_{\text {carb. In }}$ den Spalten 1 bis $4 \mathrm{der}$ Tabelle 4-18 sind die C-Gehalte der Fraktionen auf die carbonathaltige TM bezogen, und es bleibt die Frage, auf welche Fraktionen sich das $\mathrm{CaCO}_{3}$ verteilt. 
Zieht man beispielsweise von den in der Tabelle 14-18 für Lysimeter 1 angegebenen Gesamt-C-Gehalten vor und nach der $\mathrm{H}_{2} \mathrm{O}_{2}$-Behandlung das carbonatbürtige $\mathrm{C}$ von $0,72 \%$ ab und bezeichnet diese als $\mathrm{C}_{\text {org }}$, so führt die $\mathrm{H}_{2} \mathrm{O}_{2}$-Behandlung zu einer Absenkung von $13,8 \%$ der TM auf 2,4 \%, was einem $\mathrm{C}_{\text {org }}$-Rest von 17,5\% des Gesamt-C-Gehaltes vor der $\mathrm{H}_{2} \mathrm{O}_{2}$-Behandlung entspricht. Beim $\mathrm{N}$ führt das Kochen eine Absenkung von 1,55\% der TM auf $0,47 \%$ herbei, was $30 \%$ der Ausgangsmenge sind. $\mathrm{C}_{\text {org }}$ wird also stärker verringert als $\mathrm{N}$. In den sogenannten Schlämmfraktionen $<20 \mu \mathrm{m}$ Durchmesser wird dagegen der CAnteil dieser Fraktionen bei $26 \%$ während der N-Anteil auf $12 \%$ abgesenkt wird, was eine Zunahme der C/N-Quotienten der drei Schlämmfraktionen herbeiführt. Das ist ein wenig wahrscheinlicher Befund, da bei fortschreitender Oxidation der organischen Substanz der $\mathrm{C} / \mathrm{N}$-Quotient in der Regel kleiner wird. Die C-Gehalte der Schlämmfraktionen wurden deswegen auf in innen enthaltene $\mathrm{C}_{\text {carb }}$-Anteile rechnerisch überprüft, indem von den $\mathrm{N}$ Gehalten dieser Fraktion über das $\mathrm{C} / \mathrm{N}-$ Verhältnis der Vorbehandlungsvariante $\mathrm{C}$ der theoretische Gehalt an $\mathrm{C}_{\text {org }}$ berechnet wurde. Die Differenz $\mathrm{C}_{\mathrm{t}}-\mathrm{C}_{\text {org }}$ wurde dann dem $\mathrm{CaCO}_{3}$ zugeordnet. Die auch bei der Variante C - ohne Vorbehandlung - noch in den Schlämmfraktionen vorhandenen $\mathrm{C}_{\text {carb }}$-Gehalt können bei dieser Betrachtung vernachlässigt werden, da sie sich aufgrund ihres geringen Anteils am Gesamt-C-Gehalt nicht nennenswert auf das $\mathrm{C} / \mathrm{N}-$ Verhältnis auswirken.

Anders sieht das für die Variante $B$ aus: Geht man von $\mathrm{C}_{\text {carb }}$-Gesamtgehalten der Kompostproben von ca. 0,8 \% der TM und C/N-Verhältnissen von 6 bis 8 in den Schlämmfraktionen aus, dann ergibt sich, dass etwa 40 bis $63 \%$ des $\mathrm{C}_{\text {carb }}$-Gehaltes in den feinen Fraktionen enthalten sind, d.h. dass die Erdalkalicarbonate als feinstkörnige Mineralisationsprodukte abgeschieden wurden und als solche ihre verkittende Wirkung entfalten.

\subsection{Kalkgehalt}

\subsubsection{Methodik}

Das im Probenmaterial enthaltene Erdalkali-Carbonat wurde gasvolumetrisch nach SCHEIBLER ermittelt. Hierzu wurde etwa $1 \mathrm{~g}$ bei $105^{\circ} \mathrm{C}$ getrocknetes und feingemahlenes Material der Feinerde-Fraktion eingewogen und in der SCHEIBLER-Apparatur mit $\mathrm{HCl}$ versetzt. Das freigesetzte $\mathrm{CO}_{2}$-Volumen wurde ermittelt und anhand des Eichwertes für 200 mg CaCO 3 wurde der Carbonat-Gehalt der Probe als $\mathrm{CaCO}_{3}$ berechnet.

\subsubsection{Ergebnisse}

Großlysimeter

Tabelle 4-19 zeigt die Kalkgehalte der Kompostfeinerde aus den Großlysimetern 1 und 2 zu verschiedenen Zeitpunkten der Probenahme und in verschiedenen Tiefenabschnitten. Die jeweils über die gesamte Füllhöhe gemittelten Werte liegen für Lysimeter 1 zwischen 5,3 und $6,1 \%$ und Lysimeter 2 bei 5,6 und $6,6 \%$ der TM $<2 \mathrm{~mm}$. Über die Versuchszeit hinweg zeigen die Werte eine geringfügig steigende Tendenz. Eine gleichmäßige Veränderung der Werte in Abhängigkeit von der Tiefe ist nicht erkennbar. 
Tabelle 4-19: Kalkgehalte in \% der TM $<2 \mathrm{~mm}$ zu verschiedenen Zeitpunkten der Probenahme und in verschiedenen Tiefen, Lysimeter 1 und 2

\begin{tabular}{|c|c|c|c|c|c|c|c|}
\hline Lysimeter & $\begin{array}{l}\text { Tiefe } \\
\text { in } \mathbf{c m}\end{array}$ & $\begin{array}{c}\text { Probenahme } \\
24.06 .1988\end{array}$ & $\begin{array}{c}\text { Probenahme } \\
26.07 .1988 \\
\end{array}$ & $\begin{array}{l}\text { Tiefe } \\
\text { in } \mathbf{c m} \\
\end{array}$ & $\begin{array}{c}\text { Probenahme } \\
29.03 .1990 \\
\end{array}$ & $\begin{array}{l}\text { Tiefe } \\
\text { in } \mathbf{c m}\end{array}$ & $\begin{array}{c}\text { Probenahme } \\
01 . / 03.91 \\
\end{array}$ \\
\hline 1 & $0-20$ & 5,14 & 5,52 & $0-30$ & 5,38 & $0-10$ & 6,33 \\
\hline & $20-45$ & 5,45 & 5,20 & & & $20-30$ & 5,82 \\
\hline & $45-70$ & & & $30-60$ & 5,38 & $30-42$ & 5,61 \\
\hline Mw & & 5,30 & 5,36 & & 5,38 & & 6,05 \\
\hline 2 & $0-20$ & 5,36 & 5,60 & $0-30$ & 5,79 & $\begin{array}{r}0-10 \\
10-20\end{array}$ & $\begin{array}{l}6,73 \\
7,52\end{array}$ \\
\hline & $20-45$ & 5,73 & 5,31 & $30-60$ & 5,99 & $\begin{array}{l}20-30 \\
30-40\end{array}$ & $\begin{array}{l}6,44 \\
6,28\end{array}$ \\
\hline Mwe & $45-70$ & 5,72 & 546 & & 589 & $\begin{array}{l}40-50 \\
50-58\end{array}$ & $\begin{array}{l}6,74 \\
6,10\end{array}$ \\
\hline
\end{tabular}

\section{Kleinlysimeter}

Die Kalkgehalte der Feinerden aus den Kompost- und Löss-Materialien sowie deren Mischungen wurden zu Versuchsbeginn und am Ende der Lysimeterbetreuung bestimmt. In Tabelle 4-20 sind die Gehalte an $\mathrm{CaCO}_{3}$ der Ausgangsmaterialien Kompost und Löss sowie die daraus anhand der Mischungsanteile berechneten theoretischen Kalkgehalte der Mischungen und die gemessenen Kalkgehalte für die Kleinlysimeter aufgeführt. Der Löss weist einen sehr geringen Kalkgehalt von 0,6 \% der TM auf. Der verwendete Kompost hat einen mittleren Kalkgehalt von 8,3\% in der TM $<2 \mathrm{~mm}$.

Tabelle 4-20: Kalkgehalte in \% der TM $<2 \mathrm{~mm}$ anhand der Gehalte der Ausgangsmaterialien berechnet und zu verschiedenen Zeitpunkten der Probenahme gemessen, Lysimeter 3 - 8

\begin{tabular}{l|ccc|c|c} 
Lysimeter & $\begin{array}{c}|c| \\
\text { Probenahme } \\
\mathbf{2 4 . 0 6 . 1 9 8 8}\end{array}$ & $\mathbf{0 2 . 0 4 . 1 9 9 0}$ & $\mathbf{0 2 . 0 4 . 1 9 9 0}$ & Mittelwert & $\begin{array}{c}\text { Werechnete } \\
\text { Werte }\end{array}$ \\
\hline 8 & & & & & \\
6 & 7,41 & 7,70 & 7,87 & 7,66 & 8,35 \\
5 & 5,81 & 8,20 & 7,75 & 7,25 & 7,56 \\
4 & 5,03 & 5,30 & 5,96 & 5,43 & 4,76 \\
3 & 3,49 & 5,00 & 4,38 & 4,29 & 4,16 \\
7 & 2,57 & 2,94 & 3,60 & 3,04 & 2,68 \\
& 0,32 & 0,60 & 0,60 & 0,51 & 0,60
\end{tabular}

Die gemessenen Kalkgehalte der Mischungsvarianten entsprechen etwa den anhand der Ausgangswerte berechneten Gehalten. Die Kalkgehalte nehmen - entsprechend dem geringen Kalkgehalt des Lösses - mit zunehmendem Löss-Anteil ab. Die 2. Probenahme ergibt tendenziell, wie auch bei den Großlysimetern, höhere Werte. Die Abbildung 5 stellt die errechneten und die gemessenen Werte im Vergleich graphisch dar. 


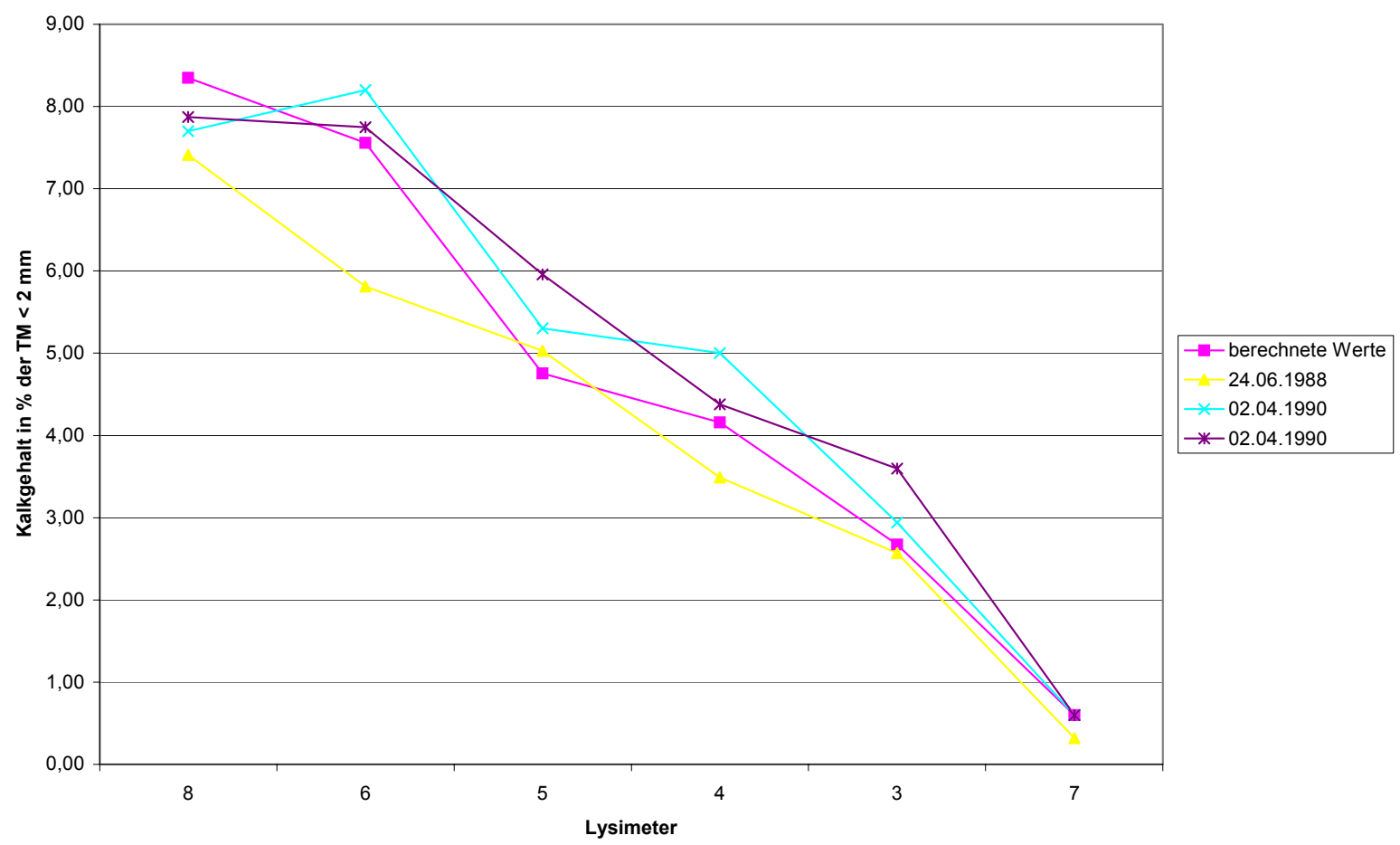

Abbildung 5: Kalkgehalte in \% der TM $<2 \mathrm{~mm}$,

Lysimeter 3 - 8

\section{Resümee}

Der Kalkgehalt zeigt in allen Lysimetern eine, wenn auch nur schwache ansteigende Tendenz. Es wäre zu erwarten, dass bei fortschreitender Verminderung der Masse an organischer Substanz das in ihr enthaltene organisch gebundene $\mathrm{Ca}(\mathrm{Mg})$ als $\mathrm{CaCO}_{3}$ $\left(\mathrm{MgCO}_{3}\right)$ angereichert würde. Da trotz gegenläufiger Prozesse die $\mathrm{CaCO}_{3}$-Gehaltserhöhung nur gering ist, würde dies für eine nur schwache Mineralisation sprechen.

\subsection{Zeitgang des Glühverlustes}

\subsubsection{Methodik}

Die Bestimmung des Glühverlustes erfolgte gravimetrisch. Hierzu wurden $10-20 \mathrm{~g}$ bei 105 ${ }^{\circ} \mathrm{C}$ getrockneter und gemahlener Substanz der Feinerde-Fraktion eingewogen und nach der Vorveraschung im Sandbad bei $600^{\circ} \mathrm{C}$ vollständig oxidiert. Bei $600^{\circ} \mathrm{C}$ treten noch keine Verluste an $\mathrm{CaCO}_{3}$ auf und der organisch gebundene Kohlenstoff wird weitestgehend ausgetrieben. Der Glühverlust errechnet sich aus dem Gewichtsverlust. Er wird in \% der TM angegeben. Die Bestimmungen erfolgten mit vierfacher Wiederholung.

\subsubsection{Ergebnisse}

\section{Großlysimeter}

Die Glühverluste der Komposte aus den beiden Großlysimetern 1 und 2 wurden anfangs in kurzen, später in weiten Zeitabständen untersucht. Tabelle 4-21 zeigt die während der Versuchszeit erhaltenen Werte. Die Glühverluste unterliegen zu Versuchsbeginn größeren Schwankungen als zu Versuchsende. Eine Horizontierung der Werte ist nicht erkennbar. In den ersten beiden Untersuchungsjahren liegt der Glühverlust des Kompostes aus Lysimeter 1 über den Werten für Lysimeter 2. Er beträgt im ersten Untersuchungsjahr durchschnittlich 33,5 \% der TM für Lysimeter 1 und 31,5\% der TM für Lysimeter 2, im zweiten Untersuchungsjahr 27,4 \% der TM für Lysimeter 1 und 25,3\% der TM für Lysimeter 2. Bei Versuchsende und Leerung der Lysimeter im Januar bzw. März 91 erreichen beide Komposte annähernd gleiche Werte von 24,7 (L 1) und 25,5 (L 2) \% der TM. 
In Fortsetzung der vorausgegangenen Kompostierung hat der Glühverlust in der hier betrachteten Versuchszeit noch weiter abgenommen. Die Abnahme, die bei dem an GV reicheren Lysimeter 1 größer ist als bei Lysimeter 2 ist, hat zu etwa gleichen Endwerten beider Lysimeter geführt. Im ersten Versuchsjahr ist der Verlust an organischer Substanz am größten.

Tabelle 4-21: Glühverlust der Feinerden zu verschiedenen Entnahmezeitpunkten und in verschiedenen Tiefen, Lysimeter 1 und 2

\begin{tabular}{|c|c|c|c|c|c|c|}
\hline Lysimeter & 1 & & & 2 & & \\
\hline Tiefe in $\mathrm{cm}$ & $0-20$ & $20-45$ & $45-70$ & $0-20$ & $20-45$ & $45-70$ \\
\hline Datum der & \multicolumn{6}{|c|}{ Glühverlust in \% der TM } \\
\hline Probenahme & & & & & & \\
\hline 16.04.1987 & 33,4 & & & 29,6 & & \\
\hline 23.04.1987 & 40,0 & 35,2 & 37,2 & 31,2 & 35,0 & 30,0 \\
\hline 28.04.1987 & 35,2 & 37,0 & 40,2 & 33,6 & 45,0 & 29,6 \\
\hline 29.04.1987 & 38,6 & 35,2 & 36,4 & 31,8 & 31,2 & \\
\hline 30.04 .1987 & 35,2 & 33,4 & 29,2 & 35,6 & 31,0 & 30,0 \\
\hline 03.05 .1987 & 38,6 & 36,2 & 30,1 & 29,7 & 30,4 & 33,2 \\
\hline 02.06 .1987 & 37,2 & 33,4 & 29,2 & 30,6 & 30,2 & 28,2 \\
\hline 03.06.1987 & 32,0 & & & 27,4 & & \\
\hline 09.06 .1987 & 32,4 & & & 32,0 & & \\
\hline 18.06.1987 & 29,8 & & & 30,8 & & \\
\hline 23.06.1987 & 29,0 & & & 32,8 & & \\
\hline 30.06 .1987 & 28,6 & & & 36,0 & & \\
\hline 02.07.1987 & 29,8 & 31,6 & 29,9 & 29,0 & 44,0 & 25,7 \\
\hline 07.07 .1987 & 31,4 & & & 32,6 & & \\
\hline 14.07.1987 & 31,2 & & & 32,8 & & \\
\hline 21.07.1987 & 30,2 & & & 28,8 & & \\
\hline 28.07.1987 & 30,6 & & & 29,4 & & \\
\hline 29.07.1987 & 27,6 & 29,4 & 33,4 & 27,4 & 27,0 & 27,6 \\
\hline 04.08 .1987 & 31,0 & & & 31,4 & & \\
\hline 11.08.1987 & 46,6 & & & 31,0 & & \\
\hline 24.06 .1988 & 28,7 & 26,3 & 27,2 & 25,2 & 25,4 & 26,5 \\
\hline 29.03.1990 & 27,9 & 26,0 & & 30,1 & 24,0 & \\
\hline 08.01.1991 & 25,0 & 24,4 & & & & \\
\hline 07.03.1991 & & & & 25,8 & 25,2 & 25,0 \\
\hline Mittelwert 87 & 33,5 & & & 31,5 & & \\
\hline Mittelwert 88 & 27,4 & & & 25,3 & & \\
\hline Mittelwert 90 & 26,9 & & & 27,0 & & \\
\hline Mittelwert 91 & 24,7 & & & 25,5 & & \\
\hline Mittelwert 87 - 91 & 28,1 & & & 27,3 & & \\
\hline Min & 24,4 & & & 24,0 & & \\
\hline Max & 46,6 & & & 45,0 & & \\
\hline
\end{tabular}

Kleinlysimeter

Die Glühverluste der Kompost-Löss-Mischungen wurden an vier Entnahmeterminen bestimmt. Dabei wurden die in Tabelle 4-22 gezeigten Werte ermittelt. 
Tabelle 4-22: Glühverlust der Feinerden zu verschiedenen Entnahmezeitpunkten, Lysimeter 3 - 8

\begin{tabular}{|c|c|c|c|}
\hline $\begin{array}{l}\text { Datum der } \\
\text { Probenahme }\end{array}$ & $\begin{array}{c}\text { Tiefe } \\
\mathbf{c m}\end{array}$ & $\begin{array}{c}\text { Glühverlust } \\
\% \text { d. TM }\end{array}$ & $\begin{array}{c}\text { Glühverlust } \\
\% \text { d. TM }\end{array}$ \\
\hline Lysimeter & & 7 & 8 \\
\hline 30.06 .1987 & $0-10$ & 4,4 & 32,5 \\
\hline 28.07.1987 & $0-10$ & 4,5 & 29,3 \\
\hline 24.06.1988 & $0-10$ & 4,1 & 29,6 \\
\hline 02.04.1990 & $0-10$ & 2,6 & 26,1 \\
\hline Lysimeter & & 6 & 5 \\
\hline 30.06 .1987 & $0-20$ & 29,6 & 22,3 \\
\hline 28.07.1987 & $0-20$ & 31,2 & 24,6 \\
\hline 24.06.1988 & $0-20$ & 25,9 & 19,2 \\
\hline 02.04.1990 & $0-20$ & 22,0 & 12,9 \\
\hline Lysimeter & & 4 & 3 \\
\hline 30.06 .1987 & $0-20$ & 15,2 & 10,2 \\
\hline 28.07.1987 & $0-20$ & 15,6 & 11,0 \\
\hline 24.06.1988 & $0-20$ & 12,7 & 9,1 \\
\hline 02.04.1990 & $0-20$ & 10,7 & 7,1 \\
\hline
\end{tabular}

Die Glühverluste sinken mit zunehmendem Löss-Anteil in den Mischungen. Die Abbildung 6 zeigt den Verlauf der Werte für die Lysimeter 3 - 8. In Abbildung 7 sind die Werte nach den jeweiligen Terminen der Probenahme angeordnet. Auch die Glühverluste der Kleinlysimeter nehmen über die Versuchszeit hinweg ab. Während bei der reinen Löss-Variante eine gleichmäßige Abnahme vorliegt, ist bei den kompostreicheren Lysimetern die Abnahme vom ersten zum zweiten Jahr am größten. Bei der zweiten Probenahme am 28.07.1987 im ersten Messjahr sind die Glühverluste gegenüber den Werten der ersten Probenahme vom 30.06.1987 dagegen etwas höher. 


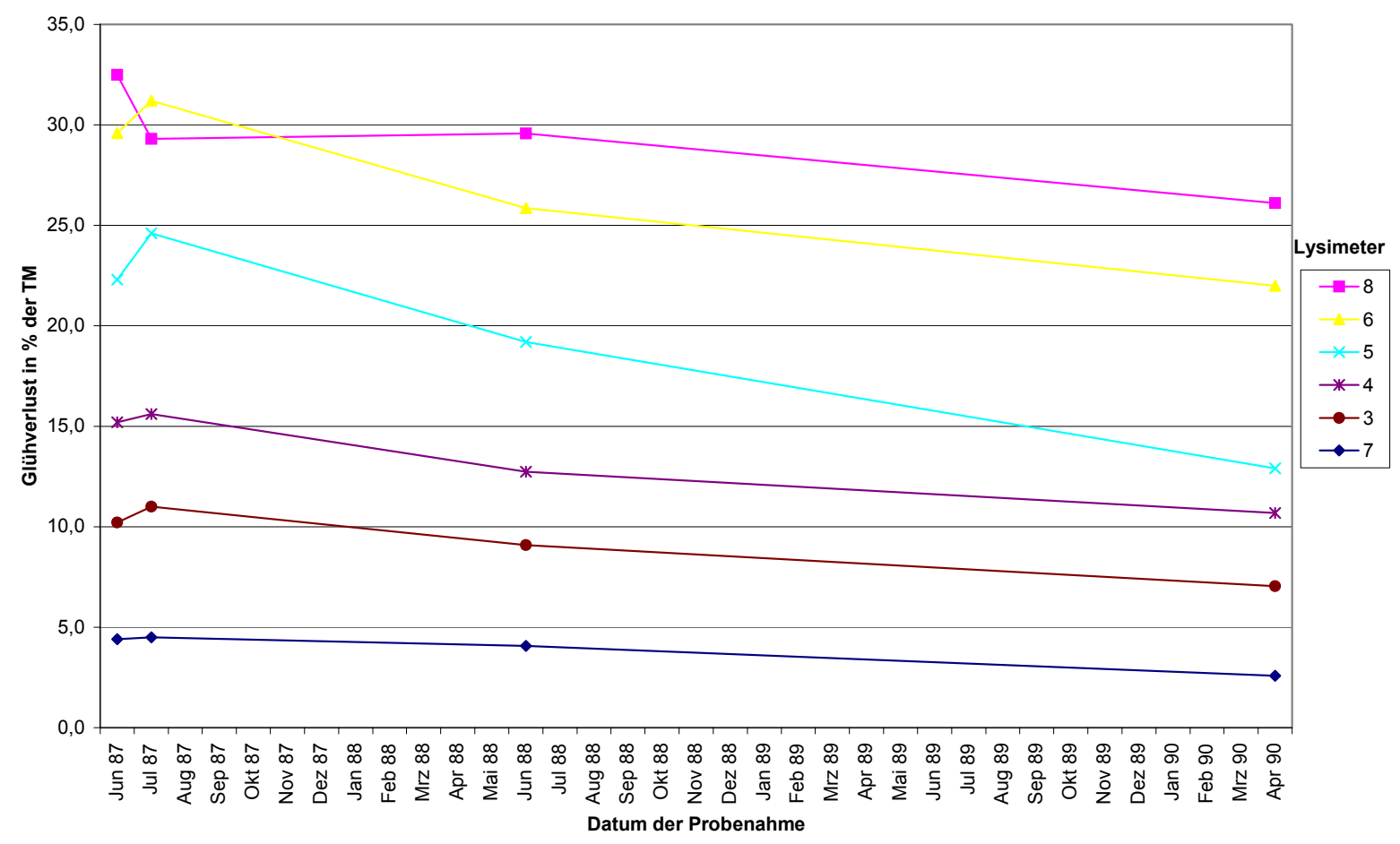

Abbildung 6: Glühverlust in \% der TM, Lysimeter 3-8

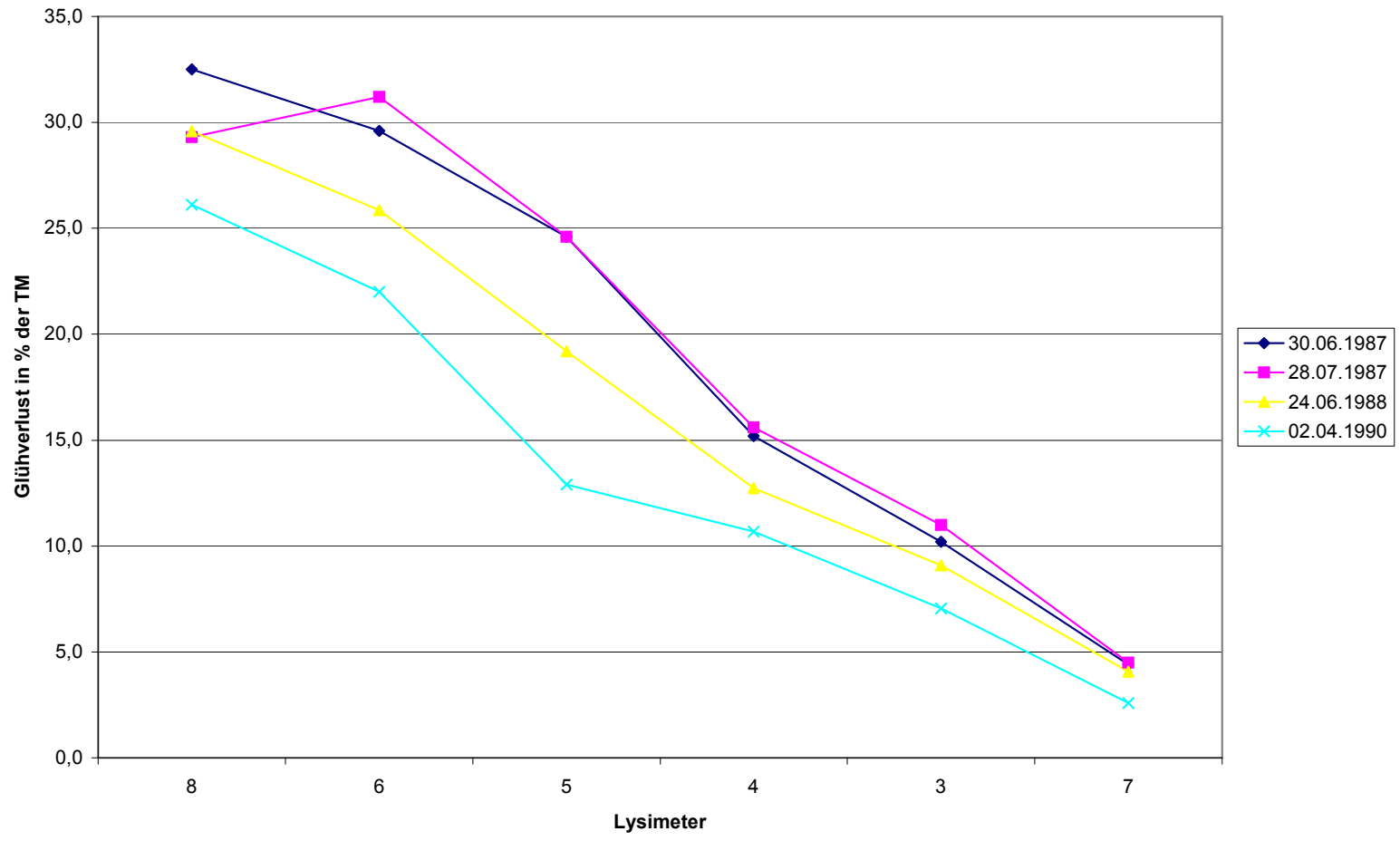

Abbildung 7: Glühverlust in \% der TM, Lysimeter 3-8

(Zeitreihe)

Die prozentuale Abnahme der Glühverluste gegenüber dem Ausgangswert zu Versuchsbeginn für die Lysimeter $1-8$ während der Freilandversuche wird in Tabelle 4-23 gezeigt. 
Tabelle 4-23: Änderung der Glühverluste gegenüber dem Ausgangszustand, Lysimeter 1 - 8

\begin{tabular}{l|cccc} 
Lysimeter & $\begin{array}{c}\text { Glühverlust in \% der TM } \\
\text { Beginn }\end{array}$ & Ende & Abnahme & $\begin{array}{c}\text { Abnahme in \% } \\
\text { vom Anfangswert }\end{array}$ \\
\hline $\mathbf{1}$ & & & & \\
$\mathbf{2}$ & 33,4 & 24,7 & 8,7 & 26,0 \\
$\mathbf{8}$ & 29,6 & 25,2 & 4,4 & 14,8 \\
$\mathbf{6}$ & 32,5 & 26,1 & 6,4 & 19,7 \\
$\mathbf{5}$ & 29,6 & 22,0 & 7,6 & 25,7 \\
$\mathbf{4}$ & 22,3 & 12,9 & 9,4 & 42,2 \\
$\mathbf{3}$ & 15,2 & 10,7 & 4,5 & 29,6 \\
$\mathbf{7}$ & 10,2 & 7,1 & 3,1 & 30,4 \\
& 4,4 & 2,6 & 1,8 & 40,9
\end{tabular}

Die Abnahmen des Glühverlustes liegen bei den Lysimetern 5, 6, 8 und 1 zwischen 6,4 und 9,4 Prozentpunkten, bei den Lysimetern 7, 3, 4 und 2 zwischen 1,8 und 4,5. Die prozentualen Abnahmen des Glühverlustes gegenüber dem Anfangswert sind bei den Mischungsvarianten und beim reinen Löss höher als bei den Kompostvarianten der Lysimeter 1, 2 und 8 sowie der kompostreichen Variante Lysimeter 6 mit einem Kompost-Anteil über $90 \%$. Sie betragen für die Lysimeter 7, 3, 4 und 5 im Durchschnitt 35,8 \% des Anfangswertes und für die Lysimeter 1, 2, 8 und 6 21,6 \%. Die höchste Abnahme an Glühverlust liegt bei Lysimeter 5 vor. Sie beträgt 42,2\% des Anfangswertes.

\subsection{Zeitgang der Kohlenstoff- und Stickstoff-Gehalte und der C/N-Verhältnisse}

\subsubsection{Methodik}

Die Bestimmung der Gesamtgehalte an Kohlenstoff und Stickstoff erfolgte mit dem Kohlenstoff-/Stickstoff-Analysator ANA 1500 der Firma CARLO ERBA. Hierzu wurde $1 \mathrm{~g}$ bei 105 ${ }^{\circ} \mathrm{C}$ getrockneter und gemahlener Substanz der Feinerde-Fraktion eingewogen. Es erfolgte eine vollständige Verbrennung der Probe bei $1200^{\circ} \mathrm{C}$ in einem geschlossenen System. Die zu bestimmenden Gase $\mathrm{CO}_{2}$ und $\mathrm{N}_{2}$ wurden gaschromatographisch getrennt und anhand inrer Wärmeleitfähigkeit quantitativ bestimmt. Die C- und N-Gehalte werden in \% der TM angeben. Das $\mathrm{C} / \mathrm{N}-$ Verhältnis ergibt sich aus dem Quotienten der jeweiligen $\mathrm{C}$ - und $\mathrm{N}$ Gehalte. Die Bestimmungen erfolgten mit zweifacher Wiederholung.

\subsubsection{Ergebnisse}

Die Kohlenstoff- und Stickstoffgehalte sowie die C/N-Verhältnisse der Komposte aus den beiden Großlysimetern 1 und 2 wurden ebenfalls anfangs in kurzen, später in weiten Zeitabständen untersucht. Tabelle 4-24 zeigt die während der Versuchszeit gemessenen Werte. Abbildung 8 zeigt die C-Gehalte und C/N-Verhältnisse der 0-20 cm tiefen Schicht. 
Tabelle 4-24: C-, N-Gehalte und C/N-Verhältnisse in der Feinerde zu verschiedenen Entnahmezeitpunkten und in verschiedenen Tiefen, Lysimeter 1 und 2

\begin{tabular}{|c|c|c|c|c|c|c|c|}
\hline \multicolumn{2}{|l|}{ Lysimeter } & \multicolumn{3}{|l|}{1} & \multicolumn{3}{|l|}{2} \\
\hline \multirow{2}{*}{$\begin{array}{l}\begin{array}{l}\text { Datum der } \\
\text { Probenahme }\end{array} \\
16.04 .1987\end{array}$} & \multirow{2}{*}{$\begin{array}{c}\begin{array}{c}\text { Tiefe } \\
\mathrm{cm}\end{array} \\
0-20\end{array}$} & \multicolumn{2}{|c|}{$\begin{array}{ll}\text { C } & \text { N } \\
\text { in } \% \text { der } & \text { TM } \\
\end{array}$} & $\mathrm{C} / \mathrm{N}$ & \multicolumn{2}{|c|}{$\begin{array}{|lc|}\text { C } & \text { N } \\
\text { in } \% \text { der } & \text { TM } \\
\end{array}$} & $\mathrm{C} / \mathrm{N}$ \\
\hline & & 13,08 & 1,15 & 11,4 & 14,62 & 1,42 & 10,3 \\
\hline \multirow[t]{3}{*}{ 23.04.1987 } & $0-20$ & 19,41 & 1,72 & 11,3 & 15,07 & 1,46 & 10,3 \\
\hline & $20-45$ & 17,92 & 1,56 & 11,5 & 15,43 & 1,48 & 10,4 \\
\hline & $45-70$ & 19,73 & 1,76 & 11,2 & 15,66 & 1,34 & 11,7 \\
\hline \multirow[t]{3}{*}{ 28.04.1987 } & $0-20$ & 16,08 & 1,49 & 10,8 & 14,68 & 1,33 & 11,0 \\
\hline & $20-45$ & 16,66 & 1,51 & 11,0 & 14,98 & 1,38 & 10,9 \\
\hline & $45-70$ & 17,00 & 1,45 & 11,7 & 16,34 & 1,54 & 10,6 \\
\hline \multirow[t]{3}{*}{ 29.04.1987 } & $0-20$ & 15,02 & 1,53 & 9,8 & 16,51 & 1,53 & 10,8 \\
\hline & $20-45$ & 16,80 & 1,51 & 11,1 & 12,43 & 1,16 & 10,7 \\
\hline & $45-70$ & 14,37 & 1,30 & 11,1 & 11,96 & 1,16 & 10,3 \\
\hline \multirow[t]{3}{*}{ 30.04.1987 } & $0-20$ & 12,78 & 1,13 & 11,3 & 15,79 & 1,35 & 11,7 \\
\hline & $20-45$ & 15,03 & 1,88 & 8,0 & 12,89 & 1,07 & 12,0 \\
\hline & $45-70$ & 20,38 & 2,47 & 8,3 & 14,17 & 1,40 & 10,1 \\
\hline \multirow[t]{3}{*}{ 03.05.1987 } & $0-20$ & 17,34 & 1,61 & 10,8 & 15,48 & 1,40 & 11,1 \\
\hline & $20-45$ & 16,38 & 1,42 & 11,5 & 14,28 & 1,38 & 10,3 \\
\hline & $45-70$ & 13,36 & 1,16 & 11,5 & 11,97 & 1,05 & 11,4 \\
\hline 02.06.1987 & $0-20$ & 13,61 & 1,26 & 10,8 & 11,99 & 2,47 & 4,9 \\
\hline & $20-45$ & 11,98 & 1,38 & 8,7 & 12,80 & 1,31 & 9,8 \\
\hline & $45-70$ & 10,75 & 1,20 & 9,0 & 13,74 & 1,94 & 7,1 \\
\hline 03.06 .1987 & $0-20$ & 13,46 & 1,78 & 7,6 & 13,04 & 1,13 & 11,6 \\
\hline 09.06.1987 & $0-20$ & 12,71 & 1,33 & 9,6 & 12,57 & 1,18 & 10,7 \\
\hline 18.06.1987 & $0-20$ & 13,46 & 1,26 & 10,7 & 13,04 & 1,12 & 11,6 \\
\hline 23.06.1987 & $0-20$ & 11,39 & 1,18 & 9,7 & 11,98 & 1,27 & 9,4 \\
\hline 30.06 .1987 & $0-20$ & 13,54 & 1,32 & 10,3 & 12,75 & 2,07 & 6,2 \\
\hline 02.07.1987 & $0-20$ & 16,40 & 1,53 & 10,7 & 12,37 & 1,19 & 10,4 \\
\hline & $20-45$ & 14,07 & 1,29 & 10,9 & 10,80 & 1,06 & 10,2 \\
\hline & $45-70$ & 15,37 & 1,50 & 10,2 & 15,15 & 1,39 & 10,9 \\
\hline 07.07.1987 & $0-20$ & 12,92 & 1,17 & 11,0 & 11,34 & 1,14 & 9,9 \\
\hline 14.07.1987 & $0-20$ & 14,18 & 1,33 & 10,7 & 11,98 & 1,16 & 10,3 \\
\hline 21.07.1987 & $0-20$ & 13,78 & 1,24 & 11,1 & 37,32 & 3,44 & 10,8 \\
\hline 28.07.1987 & $0-20$ & 4,68 & 0,45 & 10,4 & & & \\
\hline 29.07.1987 & $0-20$ & 12,46 & 1,23 & 10,1 & 11,45 & 1,07 & 10,7 \\
\hline & $20-45$ & 14,62 & 1,41 & 10,4 & 11,25 & 1,25 & 9,0 \\
\hline & $45-70$ & 15,88 & 1,59 & 10,0 & 12,05 & 1,23 & 9,8 \\
\hline 04.08 .1987 & $0-20$ & 14,23 & 1,50 & 9,5 & 13,94 & 1,32 & 10,6 \\
\hline 11.08.1987 & $0-20$ & 17,46 & 1,54 & 11,3 & 12,21 & 1,23 & 9,9 \\
\hline 24.06.1988 & $0-20$ & 13,32 & 1,25 & 10,7 & 13,41 & 1,27 & 10,6 \\
\hline & $20-45$ & 12,40 & 1,15 & 10,8 & 13,00 & 1,24 & 10,5 \\
\hline & $45-70$ & 13,41 & 1,25 & 10,7 & 12,63 & 1,22 & 10,4 \\
\hline 26.07.1988 & $0-20$ & 17,76 & 1,55 & 11,5 & 11,86 & 1,15 & 10,3 \\
\hline & $20-45$ & 11,33 & 1,14 & 9,9 & 12,71 & 1,27 & 10,0 \\
\hline & $45-70$ & 16,07 & 1,52 & 10,6 & 13,48 & 1,33 & 10,1 \\
\hline 29.03.1990 & $0-30$ & 12,46 & 1,21 & 10,3 & 12,03 & 1,18 & 10,2 \\
\hline & $30-60$ & 14,58 & 1,39 & 10,5 & 13,48 & 1,25 & 10,8 \\
\hline 08.01.1991 & $0-10$ & 15,69 & 1,49 & 10,5 & & & \\
\hline & $10-20$ & 14,20 & 1,39 & 10,2 & & & \\
\hline & $20-30$ & 13,14 & 1,28 & 10,3 & & & \\
\hline & $30-42$ & 12,79 & 1,27 & 10,1 & & & \\
\hline 07.03.1991 & $0-10$ & & & & 12,46 & 1,17 & 10,6 \\
\hline & $10-20$ & & & & 11,76 & 1,13 & 10,4 \\
\hline & $20-30$ & & & & 11,65 & 1,13 & 10,3 \\
\hline & $30-40$ & & & & 11,29 & 1,11 & 10,2 \\
\hline & $40-50$ & & & & 11,07 & 1,08 & 10,3 \\
\hline & $50-58$ & & & & 11,72 & 1,18 & 9,9 \\
\hline Mittelwert 87 & & 14,7 & & & 14,1 & & \\
\hline Mittelwert 88 & & 14,0 & & & 12,8 & & \\
\hline Mittelwert 90 & & 13,5 & & & 12,8 & & \\
\hline Mittelwert 91 & & 14,0 & & & 11,7 & & \\
\hline Mittelwert 87 - 91 & & 14,5 & 1,4 & 10,4 & 13,6 & 1,4 & 10,2 \\
\hline Min & & 4,7 & 0,5 & 7,6 & 10,8 & 1,1 & 4,9 \\
\hline Max & & 20,4 & 2,5 & 11,7 & 37,3 & 3,4 & 12,0 \\
\hline
\end{tabular}




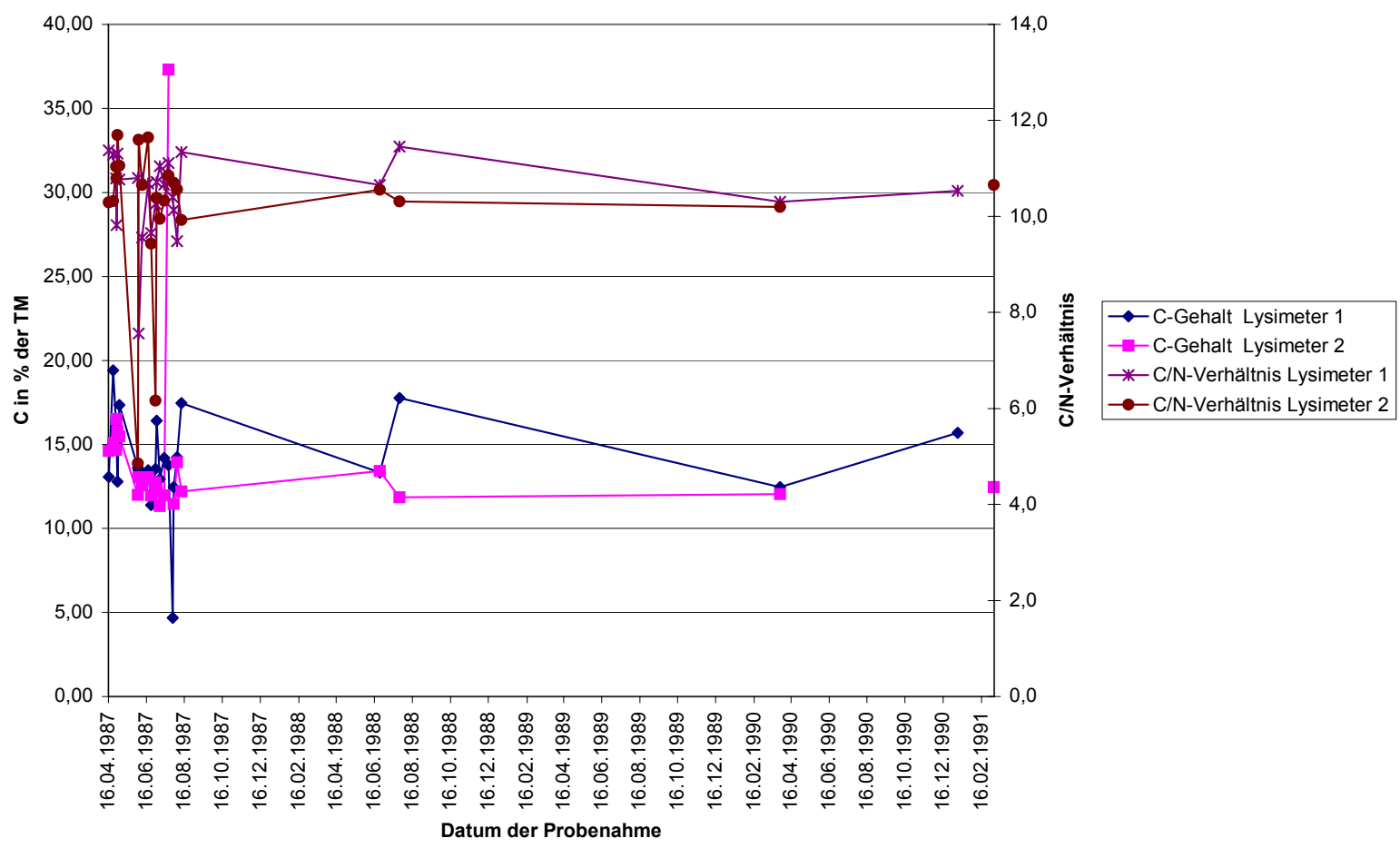

Abbildung 8: $\mathrm{C}-$ Gehalte in \% der TM und $\mathrm{C} / \mathrm{N}-$ Verhältnisse, Lysimeter 1 und $2(0-20 \mathrm{~cm})$

Die C-Gehalte betragen insgesamt im Durchschnitt für Lysimeter 114,5 und für Lysimeter 2 $13,6 \%$ der TM, die N-Gehalte liegen bei beiden Lysimetern bei 1,4\% der TM, und das C/NVerhältnis beträgt 10,4 für Lysimeter 1 und 10,2 für Lysimeter 2. Die niedrigen C/N-Werte entsprechen einem weitgehend durchgerotteten Kompost. Die zum Zeitpunkt der Leerung der Großlysimeter 91 gemessenen Werte zeigen bei beiden Lysimetern eine Abnahme der C-Gehalte mit zunehmender Komposttiefe. Die C-Jahres-Mittelwerte für Lysimeter 1 von 14,7 (87), 14,0 (88), 13,5 (90) und 14,0 (91) lassen nur eine geringfügige Änderung des CGehaltes in der Untersuchungszeit erkennen. Für Lysimeter 2 ist dagegen anhand der Werte eine stärkere Abnahme des C-Gehaltes ersichtlich: 14,1 (87), 12,8 (88), 12,8 (90) und 11,7 (91). Diese Ergebnisse sind umgekehrt gegenüber den Befunden für den Glühverlust bei Lysimeter 1 und 2.

\section{Kleinlysimeter}

Die Kohlenstoff- und Stickstoffgehalte sowie die C/N-Verhältnisse des Kompostes, Lösses sowie deren Mischungen wurden an vier Entnahmeterminen untersucht. Tabelle 4-25 zeigt die dabei festgestellten Werte. 
Tabelle 4-25: C-, N-Gehalte und C/N-Verhältnisse in der

Feinerde zu verschiedenen Entnahmezeitpunkten,

Lysimeter 3 - 8

\begin{tabular}{|c|c|c|c|c|c|c|c|}
\hline \multirow{2}{*}{$\begin{array}{l}\text { Datum der } \\
\text { Probenahme }\end{array}$} & \multirow{2}{*}{$\begin{array}{c}\text { Tiefe } \\
\mathbf{c m}\end{array}$} & C & $\mathbf{N}$ & $\mathrm{C} / \mathrm{N}$ & C & $\mathbf{N}$ & $\mathrm{C} / \mathrm{N}$ \\
\hline & & \multicolumn{3}{|l|}{ in \% der TM } & \multicolumn{3}{|l|}{ in $\%$ der TM } \\
\hline Lysimeter & & 7 & & & 8 & & \\
\hline 30.06 .1987 & $0-10$ & 0,31 & 0,04 & 8,16 & 14,05 & 1,32 & 10,64 \\
\hline 28.07.1987 & $0-10$ & 0,25 & 0,03 & 8,33 & 12,26 & 1,15 & 10,66 \\
\hline 24.06.1988 & $0-10$ & 0,35 & 0,04 & 8,75 & 13,12 & 1,24 & 10,58 \\
\hline 02.04 .1990 & $0-10$ & 0,29 & 0,04 & 7,44 & 13,25 & 1,22 & 10,84 \\
\hline Mittelwert & & 0,30 & 0,04 & 8,17 & 13,17 & 1,23 & 10,68 \\
\hline Lysimeter & & 6 & & & 5 & & \\
\hline 30.06 .1987 & $0-20$ & 9,63 & 0,93 & 10,35 & 7,82 & 0,74 & 10,57 \\
\hline 28.07.1987 & $0-20$ & 8,49 & 0,75 & 11,32 & 7,07 & 0,72 & 9,82 \\
\hline 24.06.1988 & $0-20$ & 11,37 & 1,11 & 10,24 & 8,28 & 0,79 & 10,48 \\
\hline 02.04.1990 & $0-20$ & 11,06 & 1,16 & 9,52 & 7,25 & 0,67 & 10,87 \\
\hline Mittelwert & & 10,14 & 0,99 & 10,36 & 7,61 & 0,73 & 10,43 \\
\hline Lysimeter & & 4 & & & 3 & & \\
\hline 30.06 .1987 & $0-20$ & 4,27 & 0,42 & 10,17 & 3,40 & 0,32 & 10,63 \\
\hline 28.07.1987 & $0-20$ & 4,53 & 0,44 & 10,30 & 13,79 & 1,24 & 11,12 \\
\hline 24.06.1988 & $0-20$ & 5,57 & 0,53 & 10,51 & 4,03 & 0,39 & 10,33 \\
\hline 02.04 .1990 & $0-20$ & 6,02 & 0,57 & 10,49 & 2,83 & 0,29 & 9,79 \\
\hline Mittelwert & & 5,10 & 0,49 & 10,36 & 3,42 & 0,33 & 10,25 \\
\hline
\end{tabular}

Die Kohlenstoff-Gehalte sinken mit abnehmendem Kompost-Anteil. Sie liegen für die reine Kompost-Variante bei durchschnittlich $13,18 \%$ der TM und für den reinen Löss bei 0,30 \% der TM. Die Abbildung 9 stellt die C-Gehalte der Lysimeter $3-8$ an den jeweiligen Entnahmeterminen graphisch dar. Eine Spreizung der Werte an den verschiedenen Terminen ist bei den kompostreichen Lysimetern, z. B. bei Lysimeter 6 mit 90 \% Kompostanteil, ersichtlich, aber es ist keine einheitliche Tendenz zur Abnahme der Werte über die Versuchszeit vorhanden.

Die Abbildung 10 stellt die N-Gehalte der Lysimeter 3 - 8 zu den jeweiligen Entnahmeterminen graphisch dar. Die N-Gehalte in \% der TM steigen ebenfalls mit zunehmendem Kompost-Anteil der Lysimeter-Füllung an. Sie liegen für die reine Kompost-Variante bei durchschnittlich 1,23\% der TM und für den reinen Löss bei 0,04 \% der TM. Eine Spreizung der Werte an den verschiedenen Terminen ist bei den kompostreichen Lysimetern ebenfalls vorhanden, aber wie bei den C-Gehalten ist keine einheitliche Tendenz zur Abnahme der Werte über die Versuchszeit gegeben. 


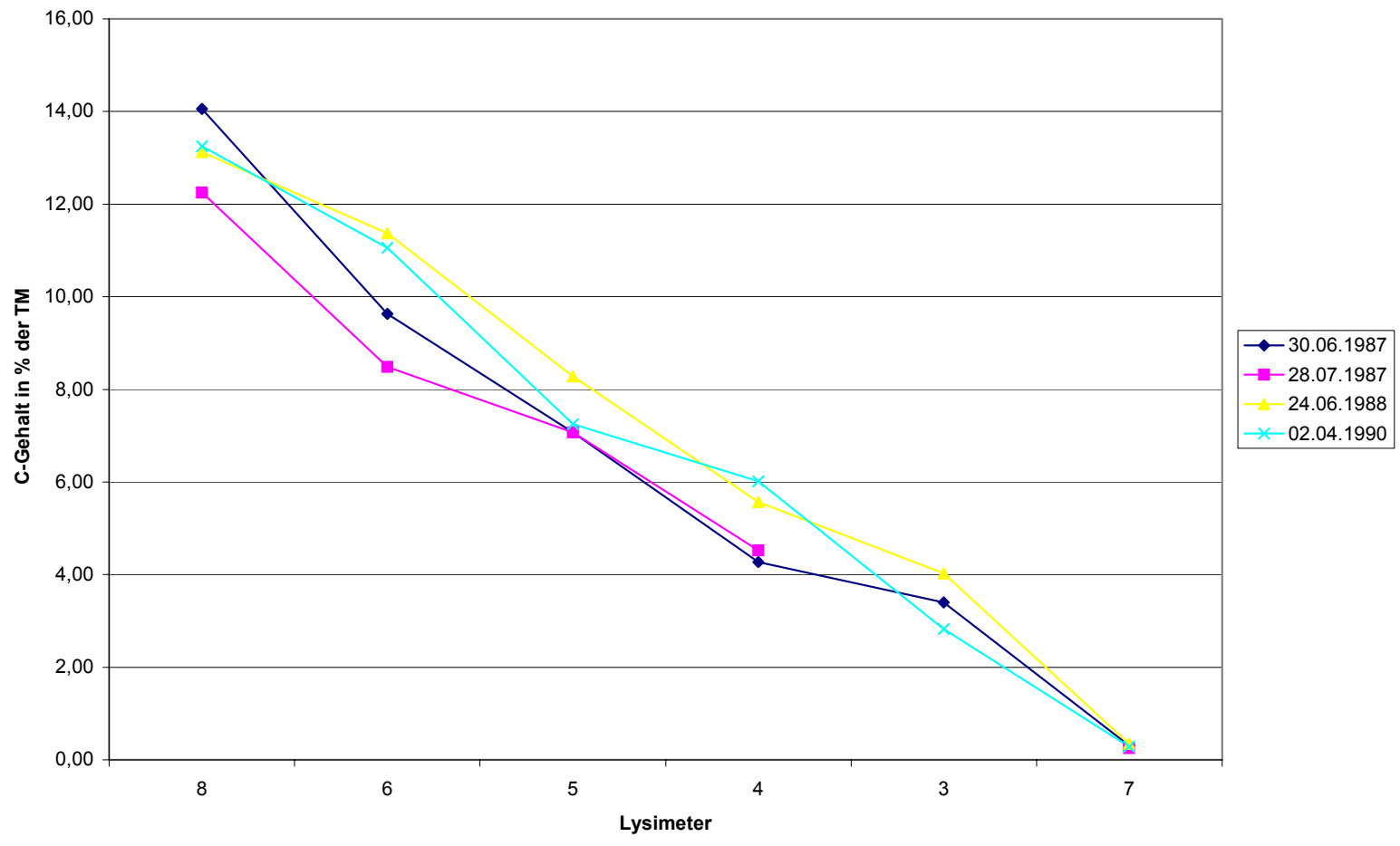

Abbildung 9: C-Gehalt in \% der TM, Lysimeter 3-8

(Zeitreihe)

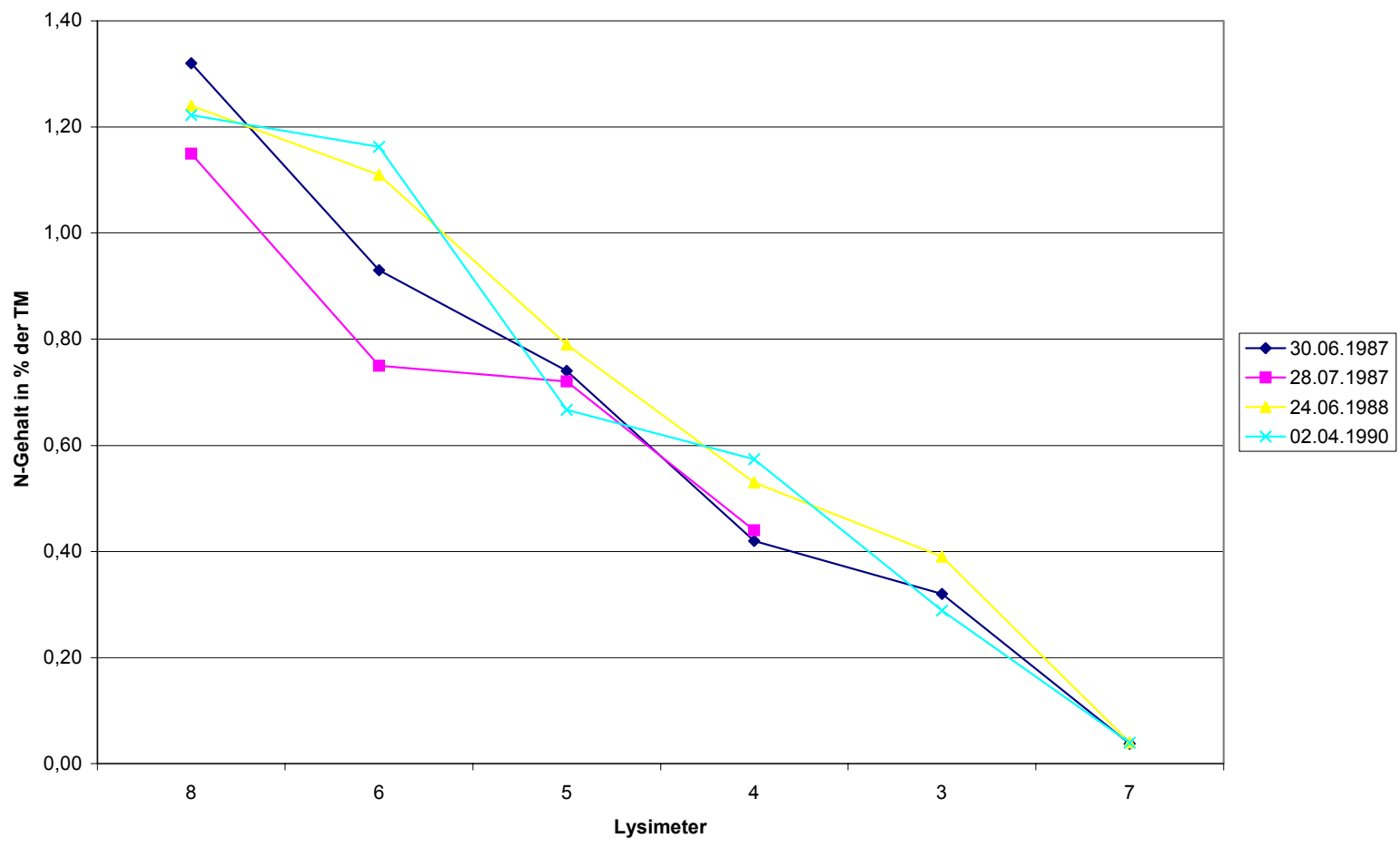

Abbildung 10: N-Gehalt in \% der TM, Lysimeter 3-8

(Zeitreihe)

Die C/N-Verhältnisse der Lysimeter 3, 4, 5, 6 und 8 liegen zwischen 10,25 und 10,68. Die Löss-Variante fällt mit einem $\mathrm{C} / \mathrm{N}-$ Verhältnis von 8,17 dagegen deutlich ab (siehe Abbildung 11). 


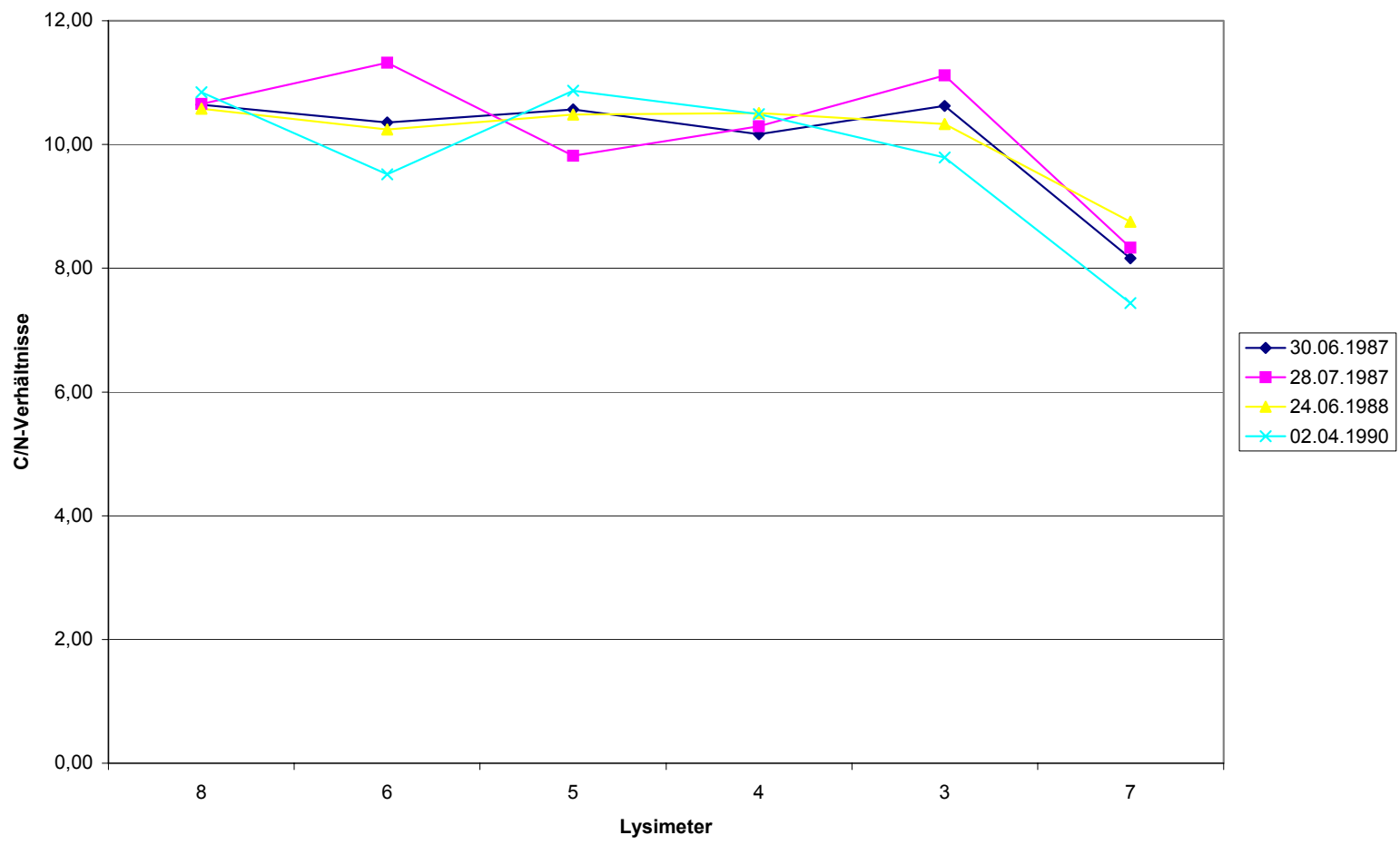

Abbildung 11: C/N-Verhältnisse, Lysimeter 3-8 (Zeitreihe)

In der Tabelle 4-26 sind die C-Gehalte zu Beginn und Ende der Versuche gegenübergestellt und die Änderungen berechnet. Eine Abnahme der C-Gehalte liegt bei den Lysimetern 2, 8, 5 und 3 vor, eine Zunahme bei den Lysimetern 1, 6 und 4. Die Werte für Lysimeter 7, den reinen Löss, sind konstant geblieben.

Tabelle 4-26: Änderung der C-Gehalte gegenüber dem Ausgangszustand, Lysimeter 1 - 8

\begin{tabular}{|c|c|c|c|c|}
\hline \multirow[b]{2}{*}{ Lysimeter } & \multicolumn{3}{|c|}{ C-Gehalt in \% der TM } & \multirow{2}{*}{$\begin{array}{l}\text { Änderung in \% } \\
\text { vom Anfangswert }\end{array}$} \\
\hline & Beginn & Ende & Änderung & \\
\hline 1 & 13,1 & 14,0 & 0,9 & 7,0 \\
\hline 2 & 14,6 & 11,7 & $-2,9$ & $-20,0$ \\
\hline 8 & 14,1 & 13,3 & $-0,8$ & $-5,7$ \\
\hline 6 & 9,6 & 11,1 & 1,4 & 14,8 \\
\hline 5 & 7,8 & 7,3 & $-0,6$ & $-7,3$ \\
\hline 4 & 4,3 & 6,0 & 1,8 & 41,0 \\
\hline 3 & 3,4 & 2,8 & $-0,6$ & $-16,8$ \\
\hline 7 & 0,3 & 0,3 & 0,0 & 0,0 \\
\hline
\end{tabular}

\subsection{Organische Substanz / Humusgehalt}

\subsubsection{Methodik}

Für die Bestimmung der organischen Substanz in Komposten werden verschiedene Methoden angewendet. Da die Bestimmung einzelner Fraktionen einen sehr hohen analytischen Aufwand erfordert, wird im Allgemeinen nur die gesamte organische Substanz als Glühverlust bestimmt (BUNDESGÜTEGEMEINSCHAFT KOMPOST 1994). Eine weitere Möglichkeit ergibt sich aus der Bestimmung des Humusgehaltes. Der Humusgehalt wird rechne- 
risch ermittelt. Hierzu wird zunächst der $C_{\text {org }}-$ Gehalt der Probe aus der Differenz $C_{t}-C_{\text {carb }}$ berechnet. Für die Berechnung der $\mathrm{C}_{\text {org }}$-Gehalte wurden die in Tabelle 4-27 gezeigten, jeweils aus dem durchschnittlichen $\mathrm{CaCO}_{3}$-Gehalt des Lysimeters ermittelten $\mathrm{C}_{\text {carb }}$-Gehalte verwendet.

Tabelle 4-27: Durchschnittliche $\mathrm{C}_{\text {carb-Gehalte, }}$ Lysimeter 1 - 8

\begin{tabular}{l|r} 
Lysimeter & $\begin{array}{l}\mathrm{CaCO}_{3}-\mathrm{C} \\
\% \text { der TM }\end{array}$ \\
\hline & \\
1 & 0,66 \\
2 & 0,70 \\
8 & 0,91 \\
6 & 0,86 \\
5 & 0,65 \\
4 & 0,51 \\
3 & 0,36 \\
7 & 0,06
\end{tabular}

Da für die organische Substanz des Bodens ein mittlerer C-Gehalt von $58 \%$ angenommen wird, wird der Humusgehalt in \% der TM aus der Multiplikation des $\mathrm{C}_{\text {org }}$-Gehaltes mit dem Faktor $1,724^{17}$ errechnet.

Zum Vergleich der verschiedenen Methoden werden die organischen Kohlenstoffgehalte mit den durch gewichtsanalytische Bestimmung nach Veraschung erhaltenen Werte ins Verhältnis gesetzt.

\subsubsection{Ergebnisse}

\section{Großlysimeter}

In Tabelle 4-28 werden für Lysimeter 1 und 2 die Werte für den Glühverlust, $C_{t}, C_{\text {org }}$ und die sich aus der Division des Glühverlustes durch den $\mathrm{C}_{\text {org }}$-Gehalt ergebenden Faktoren aufgeführt. Es zeigt sich, dass die errechneten Faktoren über dem allgemein zur Humusbestimmung herangezogenen Faktor von 1,724 liegen. Sie liegen für Lysimeter 1 bei durchschnittlich 2,17 und für Lysimeter 2 bei 2,34. Bei Lysimeter 1 ist eine Absenkung im ersten Untersuchungsjahr von durchschnittlich 2,53 auf 1,87 im letzten Untersuchungsjahr festzustellen.

\footnotetext{
${ }^{17}$ Der Faktor 1,724 entsprechend $58 \%$ C in der organischen Substanz gilt für ein großes Spektrum landwirtschaftlich genutzter Böden und den Humus in ihrer vorwiegend mineralischen Krume, d. h. überwiegend humifiziertes organisches Material. Für Cellulose mit ca. $44 \%$ C gilt dagegen ein Faktor 2,27, für Oxalsäure mit $26 \%$ C 3,75. In dem so abgegrenzten Bereich könnten sich C-Gehalte und C/organische Substanz- Faktoren in Komposten theoretisch bewegen.
} 
Tabelle 4-28: Glühverlust, $\mathrm{C}_{\mathrm{t}^{-}}, \mathrm{C}_{\text {org }}$-Gehalte und Glühver-

lust/ $C_{\text {org }}$-Verhältnisse in der Feinerde zu verschiedenen

Entnahmezeitpunkten und in verschiedenen Tiefen,

Lysimeter 1 und 2

\begin{tabular}{|c|c|c|c|c|c|c|c|c|c|}
\hline \multirow[b]{2}{*}{$\begin{array}{l}\text { Datum der } \\
\text { Probenahme }\end{array}$} & \multirow[b]{2}{*}{$\begin{array}{c}\text { Tiefe } \\
\mathbf{c m}\end{array}$} & \multicolumn{4}{|l|}{ Lysimeter 1} & \multicolumn{4}{|l|}{ Lysimeter 2} \\
\hline & & $\begin{array}{c}\text { Glühverlust } \\
\% \text { d. TM }\end{array}$ & $\mathrm{C}_{\mathrm{t}}$ & $\mathrm{C}_{\text {org }}$ & $\begin{array}{c}\text { Glühverlust/ } \\
\mathrm{C}_{\text {org }} \\
\end{array}$ & $\begin{array}{c}\text { Glühverlust } \\
\% \text { d. TM }\end{array}$ & $\mathrm{C}_{\mathrm{t}}$ & $\mathrm{C}_{\text {org }}$ & $\begin{array}{c}\text { Glühverlust/ } \\
\mathrm{C}_{\text {org }}\end{array}$ \\
\hline 16.04.1987 & $0-20$ & 33,4 & 13,08 & 12,42 & 2,7 & 29,6 & 14,62 & 13,92 & 2,1 \\
\hline \multirow[t]{3}{*}{ 23.04.1987 } & $0-20$ & 40,0 & 19,41 & 18,75 & 2,1 & 31,2 & 15,07 & 14,37 & 2,2 \\
\hline & $20-45$ & 35,2 & 17,92 & 17,26 & 2,0 & 35,0 & 15,43 & 14,73 & 2,4 \\
\hline & $45-70$ & 37,2 & 19,73 & 19,07 & 2,0 & 30,0 & 15,66 & 14,96 & 2,0 \\
\hline \multirow[t]{3}{*}{ 28.04.1987 } & $0-20$ & 35,2 & 16,08 & 15,42 & 2,3 & 33,6 & 14,68 & 13,98 & 2,4 \\
\hline & $20-45$ & 37,0 & 16,66 & 16,00 & 2,3 & 45,0 & 14,98 & 14,28 & 3,2 \\
\hline & $45-70$ & 40,2 & 17,00 & 16,34 & 2,5 & 29,6 & 16,34 & 15,64 & 1,9 \\
\hline \multirow[t]{3}{*}{ 29.04.1987 } & $0-20$ & 38,6 & 15,02 & 14,36 & 2,7 & 31,8 & 16,51 & 15,81 & 2,0 \\
\hline & $20-45$ & 35,2 & 16,80 & 16,14 & 2,2 & 31,2 & 12,43 & 11,73 & 2,7 \\
\hline & $45-70$ & 36,4 & 14,37 & 13,71 & 2,7 & & 11,96 & 11,26 & \\
\hline \multirow[t]{3}{*}{30.04 .1987} & $0-20$ & 35,2 & 12,78 & 12,12 & 2,9 & 35,6 & 15,79 & 15,09 & 2,4 \\
\hline & $20-45$ & 33,4 & 15,03 & 14,37 & 2,3 & 31,0 & 12,89 & 12,19 & 2,5 \\
\hline & $45-70$ & 29,2 & 20,38 & 19,72 & 1,5 & 30,0 & 14,17 & 13,47 & 2,2 \\
\hline \multirow[t]{3}{*}{03.05 .1987} & $0-20$ & 38,6 & 17,34 & 16,68 & 2,3 & 29,7 & 15,48 & 14,78 & 2,0 \\
\hline & $20-45$ & 36,2 & 16,38 & 15,72 & 2,3 & 30,4 & 14,28 & 13,58 & 2,2 \\
\hline & $45-70$ & 30,1 & 13,36 & 12,70 & 2,4 & 33,2 & 11,97 & 11,27 & 2,9 \\
\hline \multirow[t]{3}{*}{02.06 .1987} & $0-20$ & 37,2 & 13,61 & 12,95 & 2,9 & 30,6 & 11,99 & 11,29 & 2,7 \\
\hline & $20-45$ & 33,4 & 11,98 & 11,32 & 3,0 & 30,2 & 12,80 & 12,10 & 2,5 \\
\hline & $45-70$ & 29,2 & 10,75 & 10,09 & 2,9 & 28,2 & 13,74 & 13,04 & 2,2 \\
\hline 03.06.1987 & $0-20$ & 32,0 & 13,46 & 12,80 & 2,5 & 27,4 & 13,04 & 12,34 & 2,2 \\
\hline 09.06 .1987 & $0-20$ & 32,4 & 12,71 & 12,05 & 2,7 & 32,0 & 12,57 & 11,87 & 2,7 \\
\hline 18.06.1987 & $0-20$ & 29,8 & 13,46 & 12,80 & 2,3 & 30,8 & 13,04 & 12,34 & 2,5 \\
\hline 23.06.1987 & $0-20$ & 29,0 & 11,39 & 10,73 & 2,7 & 32,8 & 11,98 & 11,28 & 2,9 \\
\hline 30.06 .1987 & $0-20$ & 28,6 & 13,54 & 12,88 & 2,2 & 36,0 & 12,75 & 12,05 & 3,0 \\
\hline \multirow[t]{3}{*}{ 02.07.1987 } & $0-20$ & 29,8 & 16,40 & 15,74 & 1,9 & 29,0 & 12,37 & 11,67 & 2,5 \\
\hline & $20-45$ & 31,6 & 14,07 & 13,41 & 2,4 & 44,0 & 10,80 & 10,10 & 4,4 \\
\hline & $45-70$ & 29,9 & 15,37 & 14,71 & 2,0 & 25,7 & 15,15 & 14,45 & 1,8 \\
\hline 07.07.1987 & $0-20$ & 31,4 & 12,92 & 12,26 & 2,6 & 32,6 & 11,34 & 10,64 & 3,1 \\
\hline 14.07.1987 & $0-20$ & 31,2 & 14,18 & 13,52 & 2,3 & 32,8 & 11,98 & 11,28 & 2,9 \\
\hline 21.07.1987 & $0-20$ & 30,2 & 13,78 & 13,12 & 2,3 & 28,8 & 37,32 & 36,62 & 0,8 \\
\hline 28.07.1987 & $0-20$ & 30,6 & 4,68 & 4,02 & 7,6 & 29,4 & & & \\
\hline \multirow[t]{3}{*}{ 29.07.1987 } & $0-20$ & 27,6 & 12,46 & 11,80 & 2,3 & 27,4 & 11,45 & 10,75 & 2,5 \\
\hline & $20-45$ & 29,4 & 14,62 & 13,96 & 2,1 & 27,0 & 11,25 & 10,55 & 2,6 \\
\hline & $45-70$ & 33,4 & 15,88 & 15,22 & 2,2 & 27,6 & 12,05 & 11,35 & 2,4 \\
\hline 04.08 .1987 & $0-20$ & 31,0 & 14,23 & 13,57 & 2,3 & 31,4 & 13,94 & 13,24 & 2,4 \\
\hline 11.08 .1987 & $0-20$ & 46,6 & 17,46 & 16,80 & 2,8 & 31,0 & 12,21 & 11,51 & 2,7 \\
\hline \multirow[t]{3}{*}{24.06 .1988} & $0-20$ & 28,7 & 13,32 & 12,66 & 2,3 & 25,2 & 13,41 & 12,71 & 2,0 \\
\hline & $20-45$ & 26,3 & 12,40 & 11,74 & 2,2 & 25,4 & 13,00 & 12,30 & 2,1 \\
\hline & $45-70$ & 27,2 & 13,41 & 12,75 & 2,1 & 26,5 & 12,63 & 11,93 & 2,2 \\
\hline 26.07 .1988 & $0-20$ & & 17,76 & 17,10 & & & 11,86 & 11,16 & \\
\hline & $20-45$ & & 11,33 & 10,67 & & & 12,71 & 12,01 & \\
\hline & $45-70$ & & 16,07 & 15,41 & & & 13,48 & 12,78 & \\
\hline 29.03.1990 & $0-30$ & 27,9 & 12,46 & 11,80 & 2,4 & 30,1 & 12,03 & 11,33 & 2,7 \\
\hline & $30-60$ & 26,0 & 14,58 & 13,92 & 1,9 & 24,0 & 13,48 & 12,78 & 1,9 \\
\hline 08.01.1991 & 0 - 10 & 26,0 & 15,69 & 15,03 & 1,7 & & & & \\
\hline & $10-20$ & 23,9 & 14,20 & 13,54 & 1,8 & & & & \\
\hline & $20-30$ & 24,0 & 13,14 & 12,48 & 1,9 & & & & \\
\hline & $30-42$ & 24,8 & 12,79 & 12,13 & 2,0 & & & & \\
\hline 07.03.1991 & $0-10$ & & & & & 26,0 & 12,46 & 11,76 & 2,2 \\
\hline & $10-20$ & & & & & 25,6 & 11,76 & 11,06 & 2,3 \\
\hline & $20-30$ & & & & & 25,1 & 11,65 & 10,95 & 2,3 \\
\hline & $30-40$ & & & & & 24,8 & 11,29 & 10,59 & 2,3 \\
\hline & $40-50$ & & & & & 24,9 & 11,07 & 10,37 & 2,4 \\
\hline & $50-58$ & & & & & 25,0 & 11,72 & 11,02 & 2,3 \\
\hline Mittelwert 87 & & 33,48 & 14,67 & 14,01 & 2,53 & 31,48 & 14,12 & 13,42 & 2,46 \\
\hline Mittelwert 88 & & & 15,05 & 14,39 & & & 12,68 & 11,98 & \\
\hline Mittelwert 90 & & 26,93 & 13,52 & 12,86 & 2,11 & 27,01 & 12,76 & 12,06 & 2,26 \\
\hline Mittlewert 91 & & 24,68 & 13,96 & 13,30 & 1,87 & 25,24 & 11,66 & 10,96 & 2,31 \\
\hline Mittelwert 87 - 91 & & 28,36 & 14,30 & 13,64 & 2,17 & 27,91 & 12,80 & 12,10 & 2,34 \\
\hline Min & & 23,88 & 4,68 & 4,02 & 1,48 & 23,95 & 10,80 & 10,10 & 0,79 \\
\hline Max & & 46,60 & 20,38 & 19,72 & 7,61 & 45,00 & 37,32 & 36,62 & 4,36 \\
\hline
\end{tabular}

In der Abbildung 12 sind die Glühverlust/ $\mathrm{C}_{\text {org }}$-Verhältnisse der jeweils obersten Schicht für Lysimeter 1 und 2 graphisch dargestellt. Auffallend sind die für Lysimeter 1 und 2 häufig zeitlich übereinstimmenden Verläufe der Quotienten. Die Abnahme des Quotienten über die 
gesamte Versuchszeit bei Lysimeter 1 ist in dieser Darstellung wegen der fehlenden Zeitsynchronität und der Betrachtung nur der obersten Lysimeterschicht nicht erkennbar.

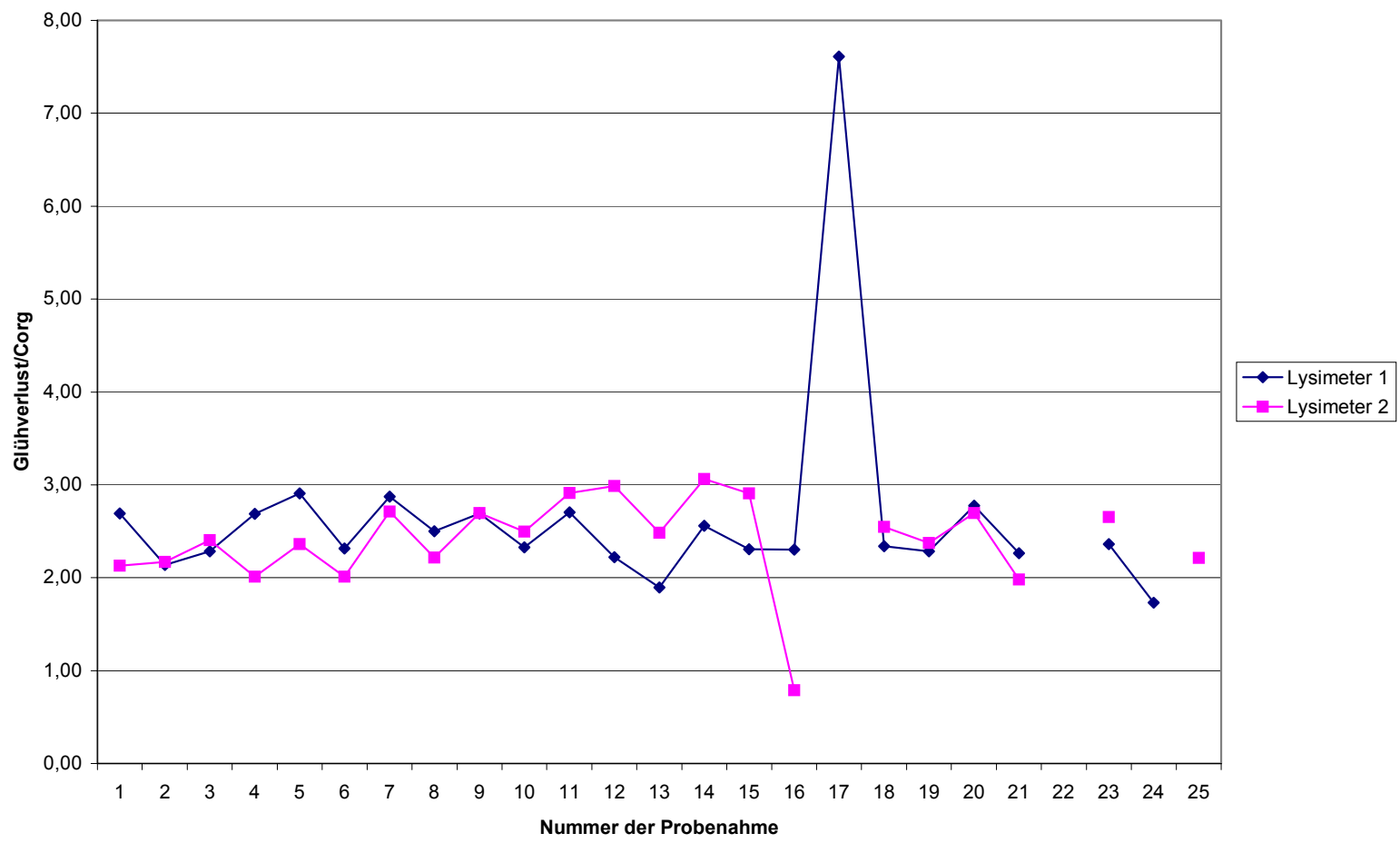

Abbildung 12: Glühverlust/C $\mathrm{C}_{\text {org-Verhältnisse der obersten }}$ Schicht, Lysimeter 1 und 2

Kleinlysimeter

Für die Kleinlysimeter werden die Werte für Glühverlust, $\mathrm{C}_{t}, \mathrm{C}_{\text {org }}$ und die sich aus der Division des Glühverlustes durch $C_{\text {org }}$ ergebenden Faktoren in Tabelle 4-29 aufgeführt.

In der Versuchszeit nehmen die errechneten Faktoren ab. Für die Kompost- und KompostLöss-Lysimeter liegen die Faktoren im Mittel zwischen 2,4 und 3,1. Der für den Löss berechnete Faktor beträgt 16,7 und weist damit deutlich auf die Beteiligung von Kristallwasser bei der Bestimmung des Glühverlustes hin. Dieser Verlust ist auch in den übrigen Kleinlysimetern mit Lössbeimischung zu berücksichtigen. 
Tabelle 4-29: Glühverlust, $\mathrm{C}_{\mathrm{t}^{-}}, \mathrm{C}_{\text {org }}$-Gehalte und Glühverlust/ $\mathrm{C}_{\text {org }}$-Verhältnisse in der Feinerde $\mathrm{zu}$ verschiedenen Entnahmezeitpunkten, Lysimeter 3 - 8

\begin{tabular}{|c|c|c|c|c|c|c|c|c|c|}
\hline $\begin{array}{l}\text { Datum der } \\
\text { Probenahme }\end{array}$ & $\begin{array}{l}\text { Tiefe } \\
\text { cm }\end{array}$ & $\begin{array}{c}\text { Glühverlust } \\
\% \text { d. TM }\end{array}$ & $C_{t}$ & $\mathrm{C}_{\text {org }}$ & $\begin{array}{c}\text { Glühverlust/ } \\
\mathrm{C}_{\text {org }}\end{array}$ & $\begin{array}{c}\text { Glühverlust } \\
\% \text { d. TM }\end{array}$ & $C_{t}$ & $\mathrm{C}_{\text {org }}$ & $\begin{array}{c}\text { Glühverlust } / \\
\mathrm{C}_{\text {org }}\end{array}$ \\
\hline Lysimeter & & 7 & & & & 8 & & & \\
\hline 30.06 .1987 & $0-10$ & 4,4 & 0,31 & 0,25 & 17,60 & 32,5 & 14,05 & 13,14 & 2,47 \\
\hline 28.07.1987 & $0-10$ & 4,5 & 0,25 & 0,19 & 23,68 & 29,3 & 12,26 & 11,35 & 2,58 \\
\hline 24.06.1988 & $0-10$ & 4,1 & 0,35 & 0,29 & 14,07 & 29,6 & 13,12 & 12,21 & 2,42 \\
\hline 02.04 .1990 & $0-10$ & 2,6 & 0,29 & 0,23 & 11,26 & 26,1 & 13,25 & 12,34 & 2,12 \\
\hline Mittelwert & & 3,89 & 0,30 & 0,24 & 16,65 & 29,37 & 13,17 & 12,26 & 2,40 \\
\hline Lysimeter & & 6 & & & & 5 & & & \\
\hline 30.06 .1987 & $0-20$ & 29,6 & 9,63 & 8,77 & 3,38 & 22,3 & 7,82 & 7,17 & 3,11 \\
\hline 28.07.1987 & $0-20$ & 31,2 & 8,49 & 7,63 & 4,09 & 24,6 & 7,07 & 6,42 & 3,83 \\
\hline 24.06.1988 & $0-20$ & 25,9 & 11,37 & 10,51 & 2,46 & 19,2 & 8,28 & 7,63 & 2,52 \\
\hline 02.04 .1990 & $0-20$ & 22,0 & 11,06 & 10,20 & 2,16 & 12,9 & 7,25 & 6,60 & 1,95 \\
\hline Mittelwert & & 27,16 & 10,14 & 9,28 & 3,02 & 19,75 & 7,61 & 6,96 & 2,85 \\
\hline Lysimeter & & 4 & & & & 3 & & & \\
\hline 30.06 .1987 & $0-20$ & 15,2 & 4,27 & 3,76 & 4,04 & 10,2 & 3,40 & 3,04 & 3,36 \\
\hline 28.07.1987 & $0-20$ & 15,6 & 4,53 & 4,02 & 3,88 & 11,0 & 13,79 & 13,43 & 0,82 \\
\hline 24.06.1988 & $0-20$ & 12,7 & 5,57 & 5,06 & 2,52 & 9,1 & 4,03 & 3,67 & 2,47 \\
\hline 02.04 .1990 & $0-20$ & 10,7 & 6,02 & 5,51 & 1,94 & 7,1 & 2,83 & 2,47 & 2,85 \\
\hline Mittelwert & & 13,55 & 5,10 & 4,59 & 3,09 & 9,33 & 3,42 & 3,06 & 2,89 \\
\hline
\end{tabular}

Die Glühverlust-/Corg-Verhältnisse der Lysimeter 3 - 8 sind in Abbildung 13 graphisch dargestellt.

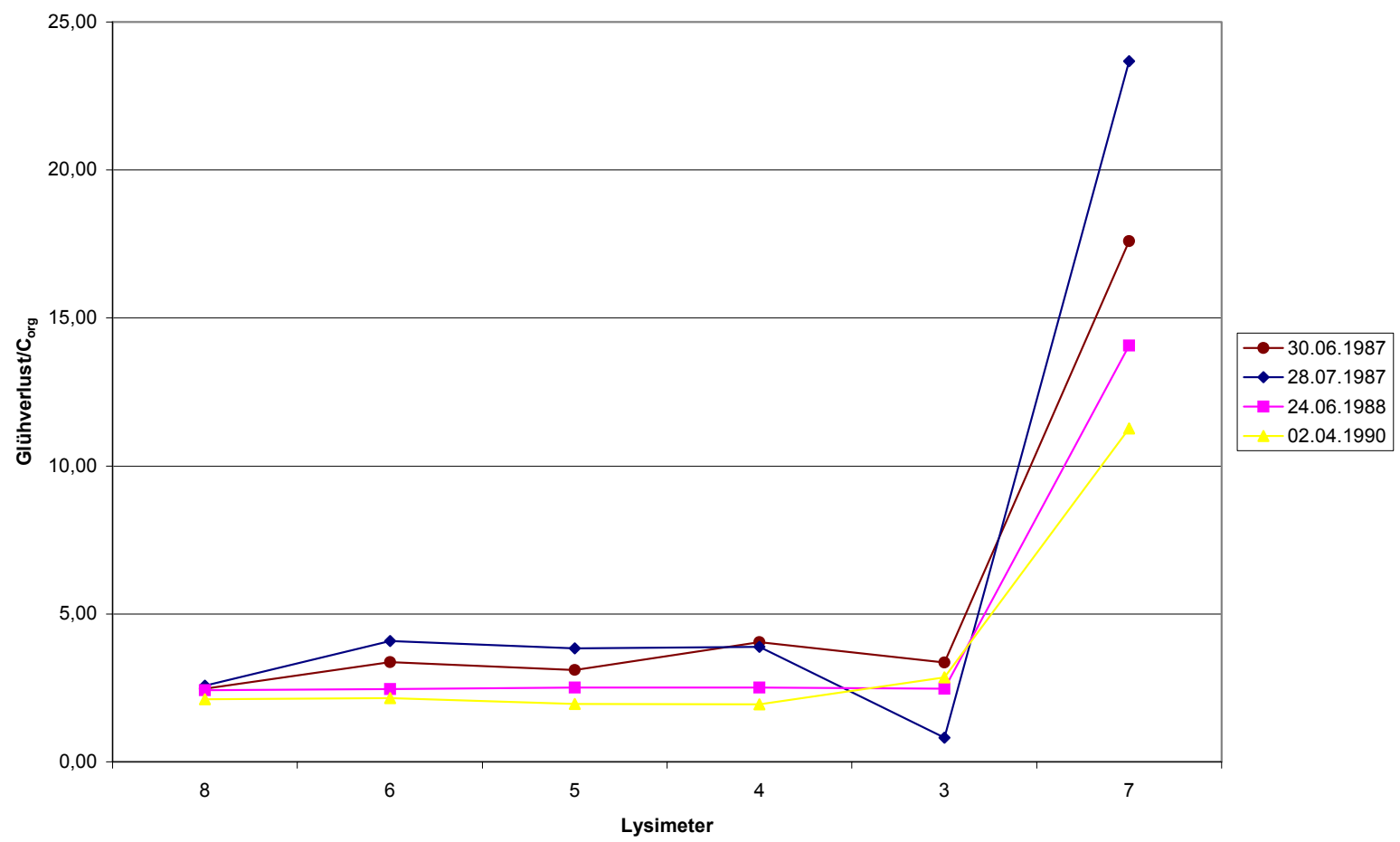

Abbildung 13: Glühverlust-/ $C_{\text {org }}$-Verhältnisse, Lysimeter 3 8 (Zeitreihe)

Resümee

Die Quotienten Glühverlust/C $C_{\text {org }}$ liegen in den ausschließlich mit Kompost gefüllten Lysimetern mit Werten um 2,5 über den Werten, die für reine Cellulose gegeben wären. Das heißt, dass in diese Quotienten auch der Verlust an Mineralwasser, vorwiegend kristallin gebun- 
denen Wassers in den mineralischen Anteilen des Kompostes, eingeht. Geht man unter

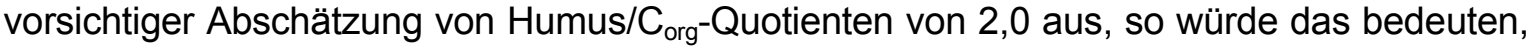
dass bei einem $\mathrm{GV} / \mathrm{C}_{\text {org }}$-Verhältnis von 2,5 etwa 2,0 Anteile auf verglühte organische Anteile entfallen und 0,5 Anteile auf entbundenes Wasser.

Besonders bei den Kleinlysimetern zeichnet sich die Tendenz ab, dass mit fortschreitender Zeit - obwohl die C-Gehalte und die C/N-Verhältnisse annähernd konstant bleiben, bzw. die C-Gehalte der TM sogar etwas steigen - der Quotient GV/C org abnimmt und dabei sogar den Wert von 2,0 unterschreitet. Inwieweit dies allerdings mit einer „Entwässerung“ der Mineralsubstanz bzw. einer Zunahme des C-Gehaltes der organischen Substanz des Kompostes zusammenhängt, ist aufgrund der vorliegenden Daten nicht abzuschätzen.

Auf jeden Fall ist zu zeigen, dass die Beschränkung der Bestimmung eines der wertbestimmenden Bestandteile des Kompostes, seiner organischen Bestandteile, allein auf die Bestimmung des Glühverlustes ein höchst unzuverlässiges Verfahren ist.

\subsection{Kationen-Austausch-Kapazität (KAK)}

\subsubsection{Methodik}

Die Kationen-Austausch-Kapazität wurde nach der Methode MEHLICH bestimmt. Hierzu wurden etwa $5 \mathrm{~g}$ lufttrockene Feinerde in eine Säule gefült und mit triethanolgepufferter $\mathrm{BaCl}_{2}$-Lösung $(\mathrm{pH} \mathrm{8,2)}$ und anschließend mit dest. Wasser gespült. In dieser Lösung wurden die Kationen $\mathrm{K}, \mathrm{Na}, \mathrm{Mg}$ und $\mathrm{Ca}$ bestimmt. Die sorbierten Ba-Kationen wurden mit $\mathrm{CaCl}_{2}$-Lösung verdrängt und ebenfalls bestimmt. Die Summe der zurück getauschten Barium-Ionen in mmol IE pro kg Feinerde liefert die potenzielle Austauschkapazität (KAK $\left.\mathrm{Kot}_{\text {po }}\right)$ der untersuchten Probe.

Dabei wurden zwei Varianten der Vorbehandlung gewählt:

1. Vorausgehendes Auswaschen der in der Porenlösung enthaltenen Kationen mit dest. Wasser, um den störenden Einfluss von Salzen zu reduzieren,

2. keine Vor-Auswaschung.

Als potenzielle KAK bezeichnet man die bei $\mathrm{pH} 8$ unter Verwendung von TriethanolaminPuffer bestimmte KAK, bei der eine maximale Zugänglichkeit des $\mathrm{Ba}$ zu den Austauschpositionen gegeben ist.

\subsubsection{Untersuchungsproben}

Die Kationen-Austauschkapazität (KAK) wurde 1.) an archiviertem Kompost- und LössAusgangsmaterial (März 1986) und 2.) gegen Ende des Freilandversuches (April 1990) an Proben des Kompostes, des Lösses und ihrer Mischungen untersucht. Hierbei wurde die KAK in der üblichen Verfahrensweise nach MEHLICH und - außer beim Löss-Ausgangsmaterial - nach vorheriger Auswaschung der Porenlösung mit dest. Wasser bestimmt.

\subsubsection{Ergebnisse}

Die nachfolgenden Tabellen 4-30 und 4-31 zeigen die Werte für die austauschbaren Kationen Natrium, Kalium, Magnesium und Calcium und deren Summe sowie das nach Verdrängung durch $\mathrm{CaCl}_{2}$ freigesetzte $\mathrm{Ba}$ und die Differenz zwischen der Kationen-Summe und dem Ba-Wert. Die Ergebnisse für die: Variante 1 „ohne Auswaschen“ sind in Tabelle 4-30 aufgeführt und Variante 2 „mit Auswaschen“ in Tabelle 4-31. 
Tabelle 4-30: KAK Variante 1 (ohne vorheriges Auswaschen); Ausgangsmaterialien (Kompost und Löss) und Lysimeterfüllungen vom März/April 1990,

Lysimeter 1 - 8

\begin{tabular}{|c|c|c|c|c|c|c|c|c|}
\hline \multirow{3}{*}{ Lysimeter } & \multirow{3}{*}{$\begin{array}{c}\text { Tiefe } \\
\mathbf{c m} \\
\end{array}$} & \multicolumn{4}{|c|}{ austauschbares } & \multirow{2}{*}{$\begin{array}{l}\text { Kationen- } \\
\text { summe S }\end{array}$} & \multirow{2}{*}{$\begin{array}{c}\text { Ba } \\
\text { KAK }_{\text {pot }}\end{array}$} & \multirow{2}{*}{$\begin{array}{l}\text { Differenz } \\
\mathrm{S}-\mathrm{KAK}_{\mathrm{pot}}\end{array}$} \\
\hline & & $\mathrm{Na}$ & $\mathbf{K}$ & Mg & $\mathrm{Ca}$ & & & \\
\hline & & \multicolumn{6}{|c|}{ mmol IE/kg Feinerde } & \\
\hline 1 & $0-30$ & 1 & 39 & 80 & 462 & 582 & 595 & -13 \\
\hline 1 & $30-60$ & 5 & 67 & 88 & 480 & 640 & 677 & -37 \\
\hline 2 & $0-30$ & 1 & 45 & 85 & 444 & 575 & 597 & -22 \\
\hline 2 & $30-60$ & 4 & 84 & 89 & 429 & 606 & 582 & 24 \\
\hline \multicolumn{2}{|c|}{ Kompost Mz 86} & 33 & 110 & 86 & 339 & 568 & 477 & 91 \\
\hline 8 & $0-10$ & 1 & 25 & 79 & 405 & 510 & 482 & 28 \\
\hline 6 & $0-20$ & 1 & 32 & 80 & 355 & 468 & 448 & 20 \\
\hline 5 & $0-20$ & 1 & 25 & 60 & 298 & 384 & 343 & 41 \\
\hline 4 & $0-20$ & 1 & 24 & 55 & 290 & 370 & 333 & 37 \\
\hline 3 & $0-20$ & 1 & 18 & 44 & 255 & 318 & 281 & 37 \\
\hline 7 & $0-10$ & 1 & 2 & 13 & 122 & 138 & 107 & 31 \\
\hline Löss & & 2 & 5 & 13 & 110 & 130 & 117 & 13 \\
\hline
\end{tabular}

Tabelle 4-31: KAK Variante 2 (mit vorherigem Auswaschen); Ausgangsmaterialien (Kompost) und Lysimeterfüllungen vom März/April 1990, Lysimeter 1 - 8

\begin{tabular}{|c|c|c|c|c|c|c|c|c|c|c|c|c|}
\hline \multirow{3}{*}{ Lysimeter } & \multirow{3}{*}{$\begin{array}{c}\text { Tiefe } \\
\mathbf{c m} \\
\end{array}$} & \multicolumn{4}{|c|}{ austauschbares } & \multirow{2}{*}{$\begin{array}{l}\text { Kationen- } \\
\text { summe S }\end{array}$} & \multirow{2}{*}{$\begin{array}{c}\text { Ba } \\
\mathrm{KAK}_{\text {pot }}\end{array}$} & \multirow{2}{*}{$\begin{array}{l}\text { Differenz } \\
\text { S - KAK }\end{array}$} & \multicolumn{3}{|c|}{ Bodenlösung } & \multirow[b]{2}{*}{$\mathrm{Ca}$} \\
\hline & & $\mathrm{Na}$ & $\mathbf{K}$ & Mg & $\mathbf{C a}$ & & & & $\mathrm{Na}$ & $\mathbf{K}$ & Mg & \\
\hline & & \multicolumn{11}{|c|}{ mmol IE/kg Feinerde } \\
\hline 1 & $0-30$ & 1 & 28 & 89 & 503 & 621 & 622 & -1 & 0 & 11 & -9 & -38 \\
\hline 1 & $30-60$ & 1 & 40 & 81 & 447 & 569 & 573 & -4 & 4 & 27 & 7 & 33 \\
\hline 2 & $0-30$ & 1 & 28 & 79 & 411 & 519 & 511 & 8 & 1 & 17 & 6 & 33 \\
\hline 2 & $30-60$ & 3 & 55 & 97 & 468 & 623 & 631 & -8 & 1 & 29 & -8 & -39 \\
\hline \multicolumn{2}{|c|}{ Kompost Mz 86} & 12 & 67 & 91 & 381 & 551 & 510 & 41 & 21 & 43 & -5 & -42 \\
\hline 8 & $0-10$ & 1 & 19 & 82 & 420 & 522 & 522 & 0 & 0 & 6 & -3 & -15 \\
\hline 6 & $0-20$ & 1 & 25 & 88 & 401 & 515 & 506 & 9 & 0 & 7 & -8 & -46 \\
\hline 5 & $0-20$ & 1 & 21 & 68 & 362 & 452 & 451 & 1 & 0 & 4 & -8 & -64 \\
\hline 4 & $0-20$ & 1 & 19 & 61 & 333 & 414 & 406 & 8 & 0 & 5 & -6 & -43 \\
\hline 3 & $0-20$ & 1 & 13 & 38 & 281 & 333 & 306 & 27 & 0 & 5 & -6 & -26 \\
\hline 7 & $0-10$ & 1 & 3 & 12 & 114 & 130 & 107 & 23 & 0 & 0 & 1 & 8 \\
\hline
\end{tabular}

Die reinen Komposte erreichen eine durchschnittliche $\mathrm{KAK}_{\text {pot }}$ von $565 \mathrm{mmol} \mathrm{IE}$ pro $\mathrm{kg}$. Die Unterschiede zwischen den Lysimetern und deren verschiedenen Tiefen sind gering. Die Austauschkapazität gut zersetzter organischer Substanz liegt bei $\mathrm{pH} \approx 8$ meist im Bereich von $1800-3200 \mathrm{mmol}$ IE pro $\mathrm{kg}$ und ist damit deutlich höher als die der Tonminerale. Rechnet man die erzielte KAK der Komposte ausschließlich der organischen Substanz zu, so erreicht die Austauschkapazität der organischen Kompost-Substanz bei Gehalten von etwa 25 \% TM im Kompost Werte von 1900 - 2500 mmol IE pro kg.

Die für das Löss-Material erzielte KAK von $117 \mathrm{mmol}$ IE pro kg Feinboden entspricht dem zu erwartenden Wert bei einem Tongehalt von 17,3\% bei einer durchschnittlichen Zusammensetzung des Tons aus je einem Drittel Illit, Smectit und Vermiculit mit den spezifischen Austauschkapazitäten von etwa 400, 800 und 1200 mmol IE pro kg Ton. In den Mischungsvarianten sinkt die Austauschkapazität mit steigendem Löss-Anteil in der Füllung ab. 
Bei den beiden Varianten mit und ohne Vor-Auswaschung zeigt sich, dass die Kationensumme bei den Füllungen der Kleinlysimeter vor und nach dem Freilandversuch über der $\mathrm{KAK}_{\text {pot }}$ liegt. Besonders deutlich ist diese Differenz bei dem archivierten Kompost. Ohne vorheriges Auswaschen liegt die Kationensumme rund $20 \%$ über der $\mathrm{KAK}_{\text {pot, }}$, nach dem Auswaschen sind es nur noch rund $10 \%$. Die Differenz ist also zumindest teilweise auf den Beitrag löslicher Salze bei der Bestimmung der Kationensumme zurückzuführen. Da die Salzgehalte der Komposte über die Versuchszeit hinweg weiterhin abgenommen haben, wird die Differenz zwischen der $\mathrm{KAK}_{\text {pot }}$ und der Kationensumme kleiner. Bei den beiden Großlysimetern liegt die $\mathrm{KAK}_{\text {pot }}$ sogar über der Kationensumme.

Das die KAK dominierende Kation ist das Calcium. Es liegt im Kompost-Ausgangsmaterial mit einem Anteil von rund $70 \%$ an der Kationensumme deutlich über den übrigen Kationen. Durch das Auswaschen und während des Versuches ist ein Rückgang der Na- und K-Kationen am Austauscher eingetreten bei etwa gleichbleibenden Mg-Werten und steigenden Ca-Werten. Der Anteil des Calciums an der Kationensumme steigt auf rund $80 \%$ an. Diese Anreicherung spiegelt sich auch in den Molverhältnissen, die sich zugunsten des Ca verschieben.

Geht man davon aus, dass durch das Auswaschen, die in der Bodenlösung gelösten Salze verdrängt werden, so kann aus der Differenz an austauschbaren Kationen „ohne auswaschen“ und "mit auswaschen" auf die der Bodenlösung zuzuschreibenden Anteile an der Kationensumme geschlossen werden. Diese Berechnung ist in Tabelle 4-31 angegeben.

Ein Vergleich der Tabellen 4-30 (ohne Vor-Auswaschung) und 4-31 (mit Vor-Auswaschung) zeigt folgendes: Sowohl in dem archivierten Kompost-Material von 1986 wie auch in dem archivierten Löss sind erhebliche Mengen an auswaschbaren Na- und K-Salzen (Tabelle 430) enthalten. In den aus den Lysimetern entnommenen Proben ist als Folge der natürlichen Durchwaschung der Gehalt an Na-Salzen auf geringe Werte abgesenkt. Nur in den tieferen Abschnitten der Lysimeter 1 und 2 ist (noch?) gelöstes $\mathrm{Na}$ vorhanden. Bildet man wie in Tabelle 4-30 die Differenz der Summe $S$ (aus gelösten und sorbierten Kationen) und der potenziellen (Ba-) Austauschkapazität, so zeigen die positiven Differenzen - besonders bei den Kleinlysimetern 3 bis 8, dass sich unter den $\mathrm{K}$ - und Mg-lonen noch als Rest oder als Ergebnis weiter fortschreitender Mineralisation salzförmig gelöste Mengenanteile befinden.

Die Tabelle 4-31 zeigt, dass der archivierte Kompost vom März 86 durch die wenn auch noch nicht vollständige Vor-Auswaschung seiner Salze $63 \%$ des $\mathrm{Na}$ und $39 \%$ des K verloren hat. Bei den Kleinlysimeter-Füllungen, die bereits der natürlichen Durchwaschung unterlegen haben, bringt die Vor-Auswaschung der Salze - d. h. hier besonders der durch Kompostierung gebildeten K-Salze - eine Angleichung der Kationensumme an die potenzielle Ba-Austauschkapazität. Dabei ist zu beachten, dass die Vor-Auswaschung die Ba$\mathrm{KAK}_{\text {pot }}$ vergrößert indem besonders die Mengen an austauschbarem $\mathrm{Mg}$ und $\mathrm{Ca}$ gegenüber den Werten in der Tabelle 4-30 beträchtlich zunehmen. Möglicherweise ist dies eine Folge der Fällung von vorher als Hydrogencarbonat gelösten Erdalkali-Kationen bzw. deren Reaktion mit dem $\mathrm{BaCl}_{2}$.

In den Kompost-Großlysimetern 1 und 2 ist das Bild uneinheitlicher. Auch hier bewirkt die Vor-Auswaschung besonders die Verminderung von kompostierungsbedingten K-Salzen.

Generell zeigt sicht sich, dass in der „Bodenlösung“ überwiegend Kalium dominiert und die zweiwertigen Kationen aufgrund ihrer höheren Affinität zu den Austauscherplätzen bereits während des Auswaschens angereichert werden.

Hervorzuheben ist, dass die der KAK-Bestimmung vorausgehende Auswaschung mit Wasser eine Erhöhung der mit Barium im Durchflussverfahren zu bestimmenden KAK bewirkt dieses aber vor allem bei Mischungen des Kompostes mit Löss, nicht aber beim reinen Kompost und beim reinen Löss. Wie Tabelle 4-32 zeigt, folgt die Erhöhung einer Optimum- 
kurve. Rechnet man aus den auf den organischen Anteil des Kompostes entfallenden KAKWerten die spezifische KAK dieser organischen Substanz aus, so ergeben sich für die Spalte "nach Auswaschung" Werte von 3000 - 3400 mmol IE pro kg, während aus der Spalte „Vor Auswaschung“ Werte von etwa 2400 resultieren. Die ersteren Werte entsprechen mehr den aus Böden (Bodenhumus) bekannten Werten. Sie legen die Annahme nahe, dass sie den „wahren“ Werten näher kommen als die aus der Serie „ohne Auswaschung". Die Tatsache, dass die Verminderung der KAK durch nicht erfolgte vorherige Auswaschung einer Optimumkurve folgt, d.h. bei einem Mischungsverhältnis von etwa 50:50 am stärksten ist, lässt vermuten, dass es sich hierbei um physikalisch-sterische Behinderungen handelt, die durch den Prozess der Auswaschung aufgehoben werden bzw. um die genannte Möglichkeit der Fällung von Carbonat.

Tabelle 4-32: Vergleich der KAK verschiedener Komponenten ohne und mit Vor-Auswaschung, Lysimeter 3 - 8

\begin{tabular}{|c|c|c|c|c|c|c|c|}
\hline \multicolumn{2}{|c|}{$\begin{array}{l}\text { Zeilen- } \\
\text { Nr. } \\
\end{array}$} & \multicolumn{6}{|l|}{\begin{tabular}{|c} 
Lysimeter \\
7 \\
\end{tabular}} \\
\hline 1 & Humusgehalt in $\%$ der TM $<2 \mathrm{~mm}$ & 0,5 & 4,88 & 10,38 & 12,25 & 19,07 & 22,84 \\
\hline 2 & Verh. Kompost : Löss (<2 mm) & $0: 100$ & $27: 73$ & $46: 54$ & $54: 46$ & $90: 10$ & $100: 0$ \\
\hline 3 & KAK in mmol IE/kg Löß-Anteil & 110 & 80,3 & 59,4 & 50,6 & 11 & 0 \\
\hline & Vor dem Auswaschen: & & & & & & \\
\hline 4 & KAK in mmol IE/kg Gesamt & 110 & 281 & 333 & 343 & 448 & 482 \\
\hline 5 & KAK in mmol IE/kg Kompost-Anteil & 0 & 200,7 & 273,6 & 292,4 & 437 & 482 \\
\hline 6 & $\begin{array}{l}\text { KAK in mmol IE/kg org. Substanz } \\
\text { Nach dem Auswaschen: }\end{array}$ & & 4113 & 2636 & 2335 & 2292 & 2115 \\
\hline 7 & KAK in mmol IE/kg Gesamt & 110 & 306 & 406 & 451 & 506 & 525 \\
\hline 8 & $\mathrm{KAK}$ in mmol IE/kg Kompost-Anteil & 0 & 225,7 & 346,6 & 400,4 & 495 & 525 \\
\hline 9 & KAK in mmol IE/kg org. Substanz & & 4625 & 3339 & 3198 & 2596 & 2299 \\
\hline 10 & Zuwachs Zeile Nr. 8 - Zeile Nr. 5 & 0 & 25 & 73 & 108 & 58 & 43 \\
\hline 11 & Zuwachs Zeile Nr. 9 - Zeile Nr. 6 & & 512 & 703 & 863 & 304 & 184 \\
\hline
\end{tabular}

\subsection{Gesamtgehalte der Elemente}

\subsubsection{Flusssäure-Aufschluss}

Die Bestimmung der Gesamtgehalte an Kationen wurde mittels Flusssäure-Aufschluss durchgeführt, da hierbei auch silikatische Bindungen aufgeschlossen werden. Hierzu wurden ca. $0,75 \mathrm{~g}$ bei $105^{\circ} \mathrm{C}$ getrockneter und gemahlener Substanz der Feinerde-Fraktion in Teflonbecher eingewogen und mit Schwefelsäure, Perchlorsäure und Flusssäure versetzt. Der Aufschluss erfolgte zunächst bei Raumtemperatur $(3-4 \mathrm{~h})$ und anschließend im Trockenschrank bei $200{ }^{\circ} \mathrm{C}(7-8 \mathrm{~h})$. Die abgekühlten Proben wurden mit bidestilliertem Wasser versetzt und in Glaskolben filtriert. Eventuell im Teflonbecher verbliebene Aufschlussreste wurden noch durch Erhitzen mit Salpetersäure in Lösung gebracht und ebenfalls in die Kolben filtriert. Die quantitative Bestimmung der Kationen erfolgte atomabsorptions-spektrometrisch. Der P-Gehalt der zu untersuchenden Probe wurde nach Zugabe des Anfärbereagenz aus Ammoniummolybdat- und Kaliumantimontartrat-Lösung und Ascorbinsäure-Lösung bei $\mathrm{pH} 0,8-0,9$ bei $882 \mathrm{~nm}$ photometrisch bestimmt. Die Gesamtgehalte werden in $\mathrm{mg}$ pro $100 \mathrm{~g}$ Feinerde angegeben. 


\subsubsection{Gesamtaufschluss zur $\mathrm{Cl}$ - und $\mathrm{SO}_{4}$-Bestimmung}

Für die Bestimmung der Chlorid- und Sulfat-Gehalte wurden $2 \mathrm{~g}$ bei $105{ }^{\circ} \mathrm{C}$ getrockneter und gemahlener Substanz der Feinerde-Fraktion in Tiegel eingewogen und mit $5 \mathrm{ml} \mathrm{NaOH}$ $(c=0,1 \mathrm{~mol} I E / \mathrm{l})$ über Nacht vorgequollen. Nach Vorveraschung im Sandbad wurden die Proben bei $450{ }^{\circ} \mathrm{C}$ über Nacht erhitzt und der Rückstand mit der das zu bestimmende Anion nicht enthaltenden Säure $\mathrm{HCl}$ bzw. $\mathrm{H}_{2} \mathrm{SO}_{4}$ aufgenommen.

\subsubsection{Untersuchungsproben}

Die Gesamtgehalte an $\mathrm{Na}, \mathrm{K}, \mathrm{Mg}, \mathrm{Ca}, \mathrm{Fe}, \mathrm{Al}, \mathrm{Mn}, \mathrm{P}, \mathrm{Cl}$ und $\mathrm{S}$ wurden an archiviertem Lössund Kompost-Ausgangsmaterial (März 86) sowie an Proben aus den verschiedenen Tiefenabschnitten der Lysimeter 1 und 2 gegen Ende des Freilandversuches (März 1990 und Januar/März 1991) untersucht. Die Gesamtgehalte der Kompost/Löss-Mischungen wurden rechnerisch aus den Werten für den reinen Kompost und den reinen Löss ermittelt.

\subsubsection{Ergebnisse}

Die Bestimmung der Element-Gehalte ergibt die in Tabelle 4-33 gezeigten Werte. In Tabelle 1-5 im Anhang sind die analysierten Element-Gehalte in die oxidischen Bindungsformen umgerechnet.

Tabelle 4-33: Gesamtgehalte in der Feinerde, Lysimeter 1 und 2 (März 1990 und Jan/März 1991) sowie Ausgangsmaterialien Kompost März 1986 und Löss

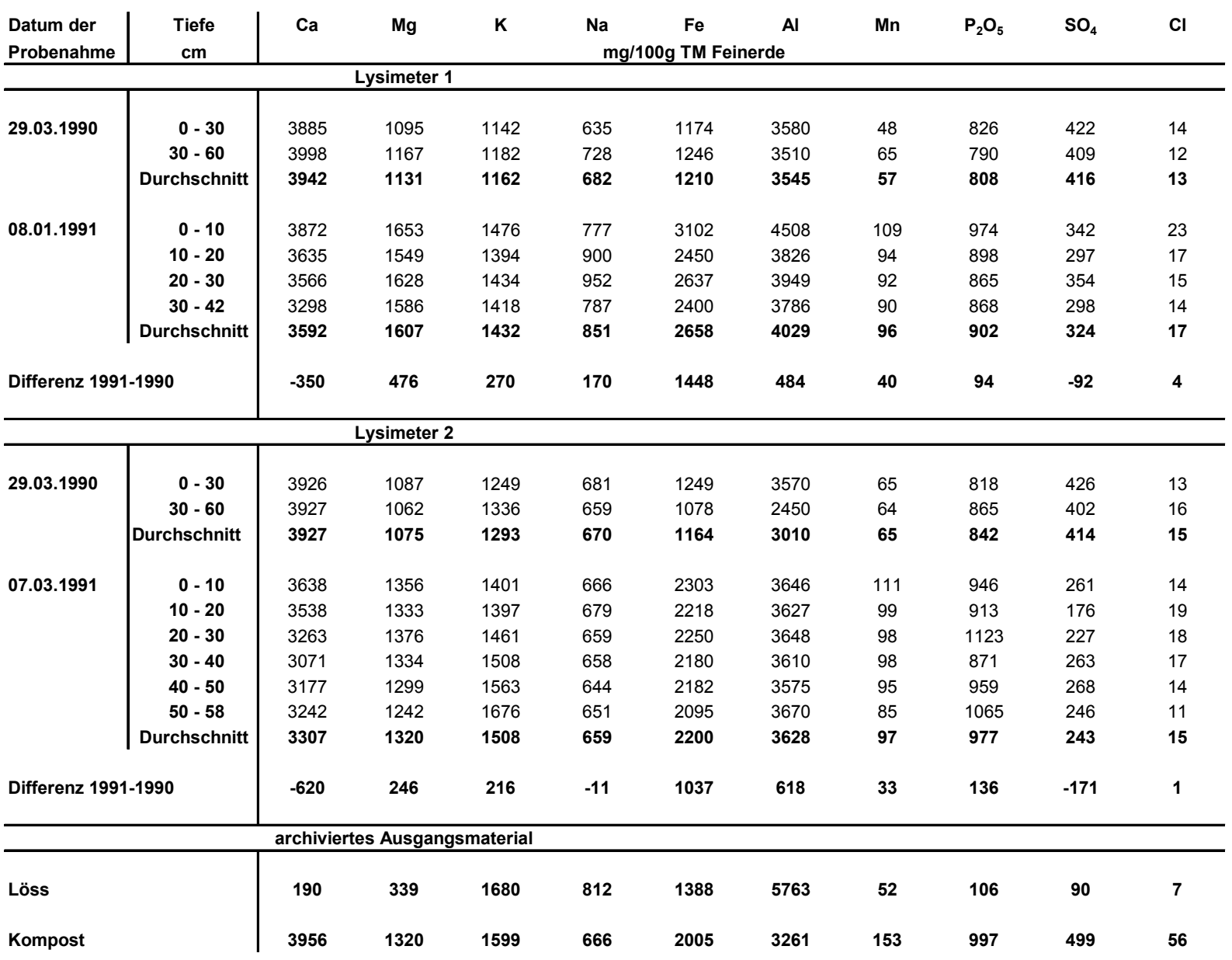

Die Löss-Werte entsprechen den für Löss üblichen Gehalten (vergl.: GLASOW 2000). 
Die angegebenen Differenzen in den Element-Gehalten der Kompost-Feinerde zwischen dem 1. und dem 2. Termin deuten zeitliche Veränderungen an. Sie bestehen im Wesentlichen in der Abnahme bei $\mathrm{Ca}$ und $\mathrm{SO}_{4}$ und der Zunahme der übrigen Element-Gehalte. Dies könnte darauf zurückgeführt werden, dass organische Substanz mineralisiert worden ist das heißt Verlust an organischer Substanz - und dadurch die Mineralsubstanz relativ angereichert worden ist. Andererseits müssen die Mengenangaben insofern mit Vorsicht betrachtet werden als die Feinerde zum 1. Termin nach Zertrümmerung im Backenbrecher durch eine 1,12 mm Sieb abgetrennt wurde, zum 2. Termin dagegen durch ein $2 \mathrm{~mm}$ Sieb nach einem vorher erfolgten schonenden Zerdrücken durch Überrollen mit einer Flasche. Da die „Kalkverluste“ größer sind als die entsprechenden Sulfatverluste, ist anzunehmen, dass im 2. Fall weniger zerschlagene Kalksteinbrocken in die untersuchte Probe gelangt sind.

Unterschiede zwischen den Komposten der beiden Großlysimeter sind vorhanden. Für die Proben aus 91 nach Abschluss des Freilandversuches sind für einige Elemente Tiefenabhängigkeiten erkennbar, die element- und lysimeterspezifisch auftreten. So sinken beispielweise die Ca- und Fe-Gehalte bei beiden Lysimetern mit zunehmender Tiefe, während der K-Gehalt bei Lysimeter 2 mit zunehmender Tiefe steigt und bei Lysimeter 1 etwa konstant bleibt. Die Al-Gehalte sinken bei Lysimeter 1 mit zunehmender Tiefe und bleiben bei Lysimeter 2 in etwa konstant.

Vergleicht man in Tabelle 4-34 die Kationenverhältnisse im Gesamtaufschluss der untersuchten Proben mit Werten für Pflanzenmaterial, z. B mit Grasschnitt, ergeben sich keine Übereinstimmungen. Dies lässt sich wie folgt erklären: Einerseits bedingt der Rotteprozess die Auswaschung der leicht löslichen Kationen $\mathrm{Na}$ und $\mathrm{K}$ und andererseits bewirkt der von vorneherein hohe Anteil an beigemischtem Bodenmaterial im angelieferten Bio-Abfall deutliche Unterschiede gegenüber reinem Grasschnitt, was die relative Anreicherung der Erdalkali-Kationen bewirkt haben kann.

Tabelle 4-34: Kationen-Molverhältnisse der untersuchten Proben im Vergleich mit Grasschnitt (Werte nach HERMENING 1994)

pfl.: als rein pflanzenbürtig angenommen (berechnet)

\begin{tabular}{|c|c|c|c|c|c|c|c|}
\hline \multirow[b]{2}{*}{ Probe } & \multirow{2}{*}{$\begin{array}{c}\text { Datum der } \\
\text { Probenahme }\end{array}$} & \multicolumn{6}{|c|}{ Molverhältnisse } \\
\hline & & Ca:Mg & $\mathrm{Ca}: \mathrm{K}$ & $\mathrm{Ca}: \mathrm{Na}$ & Mg:K & $\mathrm{Mg}: \mathrm{Na}$ & $\mathrm{K}: \mathrm{Na}$ \\
\hline Löß 0 & & 0,34 & 0,11 & 0,13 & 0,32 & 0,39 & 1,22 \\
\hline Kompost 0 & & 1,82 & 2,41 & 3,41 & 1,33 & 1,87 & 1,41 \\
\hline Grasschnitt & & 3,48 & 0,66 & 5,34 & 0,19 & 1,53 & 8,14 \\
\hline Kompost 0 pfl. & & 2,07 & 5,79 & 10,69 & 2,80 & 5,17 & 1,85 \\
\hline Lysimeter 1 pfl. & 29.03.1990 & 2,51 & 29,02 & 12,05 & 11,54 & 4,79 & 0,42 \\
\hline Lysimeter 1 pfl. & 08.01.1991 & 1,53 & 13,11 & 7,00 & 8,56 & 4,57 & 0,53 \\
\hline Lysimeter 2 pfl. & 29.03.1990 & 2,59 & 9,00 & 8,93 & 3,48 & 3,45 & 0,99 \\
\hline Lysimeter 2 pfl. & 07.03.1991 & 1,75 & 6,90 & 12,37 & 3,95 & 7,08 & 1,79 \\
\hline
\end{tabular}

Geht man davon aus, dass die Al-Gehalte über bodenbürtige Mineral-Beimengungen in den Kompost gelangt sind, da Pflanzen kein Aluminium anreichern und es sich bei den Bodenbeimengungen überwiegend um Lössboden-Material handeln dürfte, lassen sich anhand der Al/Element-Verhältnisse des Lösses die bodenbürtigen Element-Gehalte der Komposte berechnen. Diese Werte zeigt Tabelle 4-35. 
Tabelle 4-35: Berechnete bodenbürtige Asche-Anteile

(Mineralbeimengungen), Lysimeter 1 und 2 (März 1990 und

Jan/März 1991) sowie archivierte Ausgangsmaterialien

Kompost März 1986 und Löss

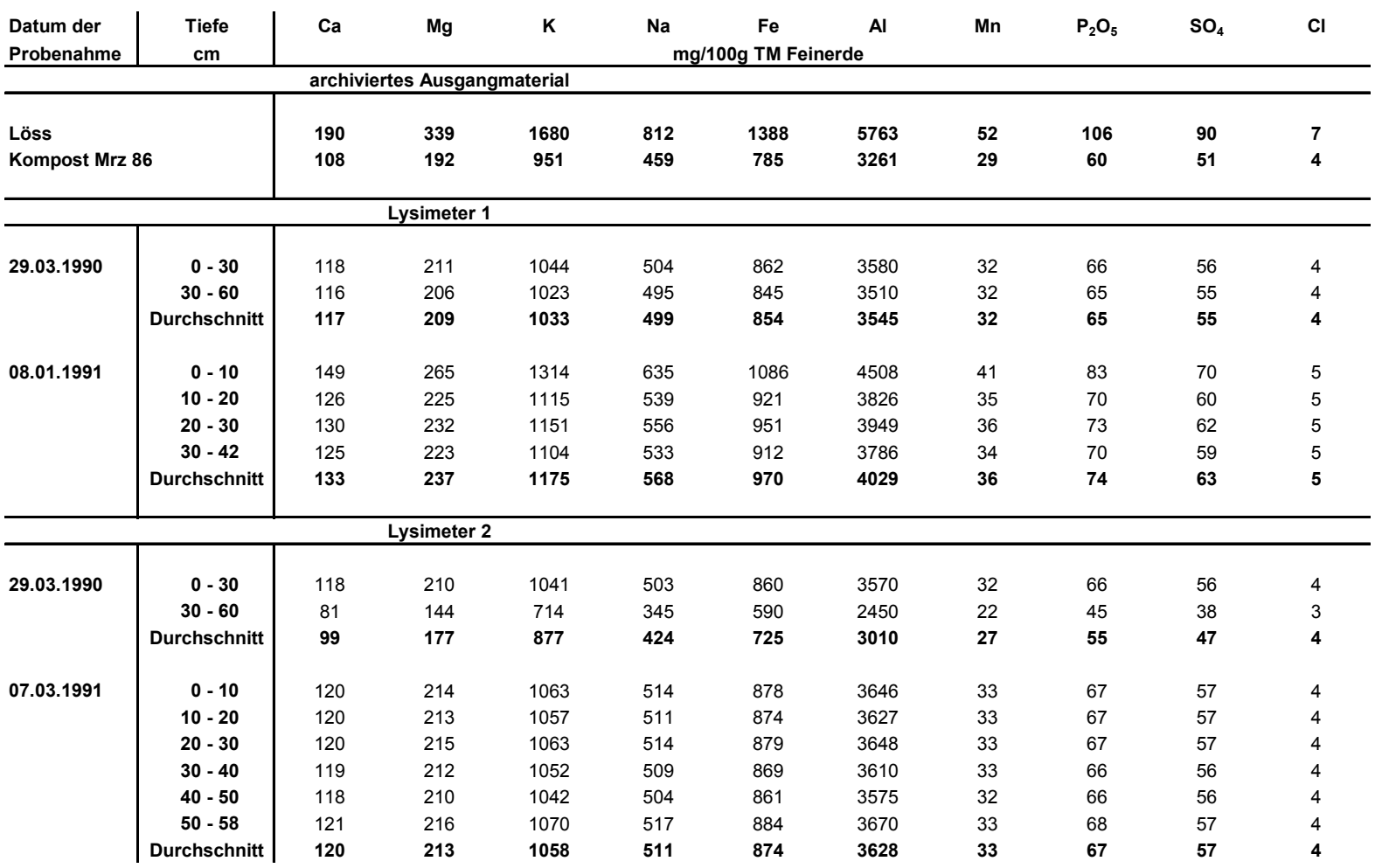

Zieht man von den Gesamtgehalten der Kompost-Feinerde in Tabelle 4-33 die bodenbürtigen Element-Gehalte in der Tabelle 4-35 ab, erhält man die den pflanzenbürtigen Anteilen zuzurechnenden Element-Gehalte. Diese Werte sind in Tabelle 4-36 dargestellt. 
Tabelle 4-36: Berechnete pflanzenbürtige Asche-Anteile, Lysimeter 1 und 2 (März 1990 und Jan/März 1991) sowie archivierte Ausgangsmaterialien Kompost März 1986 und Löss

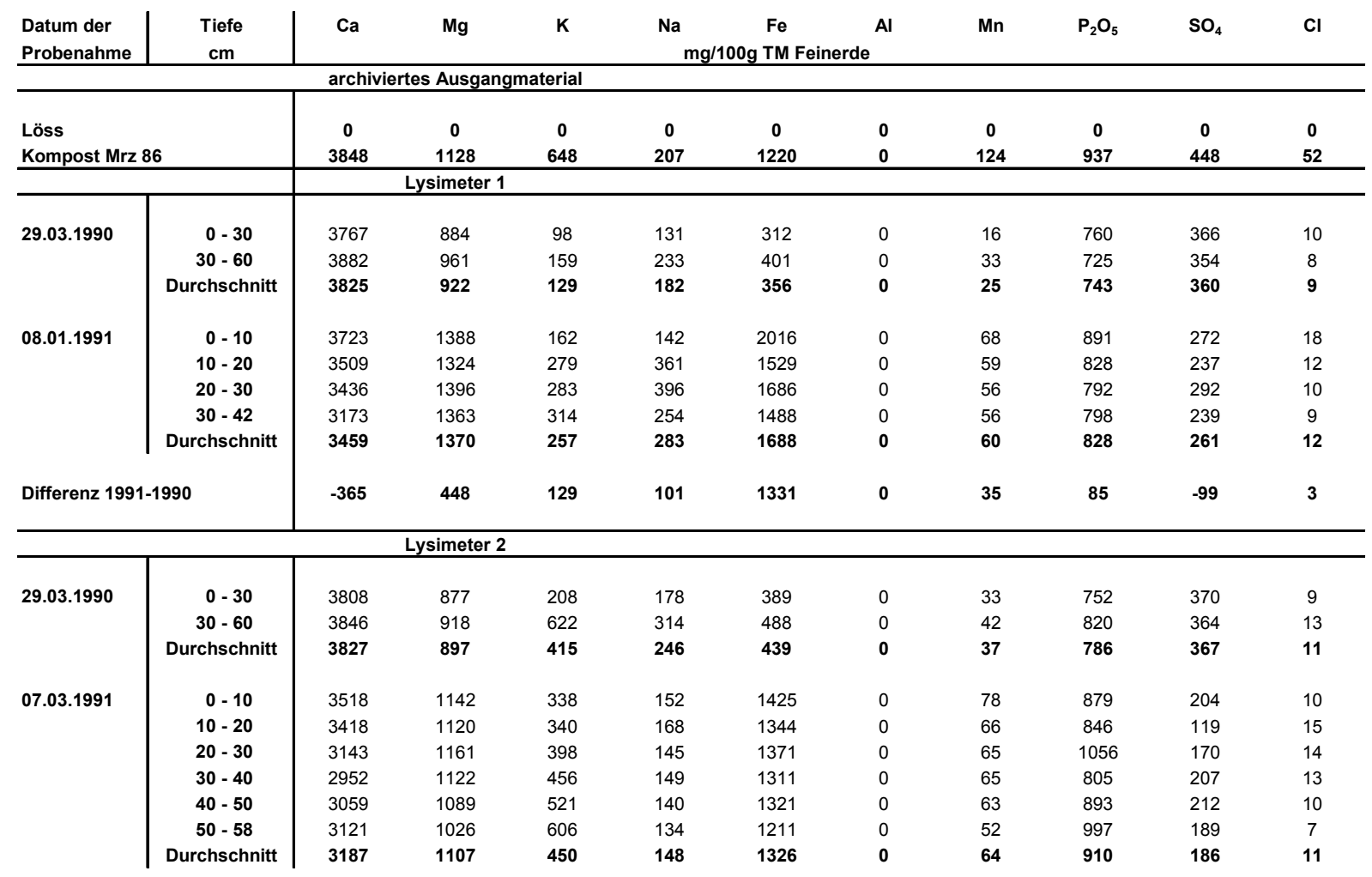

Tabelle 4-36 lässt erkennen, dass zwischen den Terminen der Probenahme beträchtliche Verluste aus der pflanzenbürtigen Kompostsubstanz an Sulfat auftreten (30 - 50 \%) und bei Lysimeter 2 mit seinem etwas geringeren primären Zersetzungsgrad auch beim Na. Neben der zu erwartenden Anreicherung von $\mathrm{Mg}$ und $\mathrm{K}$ aus vegetativen Pflanzenteilen sowie $\mathrm{P}$ ist besonders die extreme Anreicherung der Schwermetalle Fe und Mn hervorzuheben, auf die später zurückzukommen sein wird.

Auch die Molverhältnisse der anschließend durch Subtraktion der bodenbürtigen ElementGehalte von den Gesamtgehalten berechneten pflanzenbürtigen Element-Gehalte ergeben keine Übereinstimmung mit den Molverhältnissen frischer organischer Substanz (siehe Tabelle 4-34) mehr. Legt man die gefundenen 70,64 \% Glührückstand des Kompostes zugrunde und berechnet anhand der Al-Gehalte den Anteil an beigemischten mineralischen Bodenmaterial, so ergibt sich, das $76,58 \%$ des gefundenen Glührückstandes aus dieser Beimischung stammen würden, d. h. 54,09 Prozentpunkte. Entsprechend wären die restlichen 15,55 Prozentpunkte der pflanzlichen Asche zu zurechnen. Diese Annahme geht, um es zu wiederholen, davon aus, dass die bodenbürtige Beimischung zum Kompost den Charakter des archivierten Lösses hat. 


\subsection{Schwermetall-Gehalte}

\subsubsection{Methodik}

Die Bestimmung der Schwermetall-Kationen $\mathrm{Zn}, \mathrm{Cd}, \mathrm{Pb}, \mathrm{Cu}, \mathrm{Ni}, \mathrm{Cr}$ und $\mathrm{Mn}$ wurde im Königswasser-Auszug in Anlehnung an die Klärschlammverordnung (AbfKlärV $1982^{18}$ ) durchgeführt. Es wurden ca. $1 \mathrm{~g}$ bei $105{ }^{\circ} \mathrm{C}$ getrockneter und gemahlener Substanz der Feinerde-Fraktion in Aufschlusstiegel eingewogen und mit Königswasser (Säuregemisch aus $\mathrm{HCl}$ und $\mathrm{HNO}_{3}$ im Verhältnis 3:1) versetzt, abgedeckt und über Nacht stehen gelassen. Nach zweistündigem Kochen wurden die abgekühlten Proben mit bidest. Wasser versetzt und in Kolben filtriert. Die quantitative Bestimmung der Kationen erfolgte atom-absorptionsspektrometrisch. Die Schwermetall-Gehalte werden in $\mathrm{mg} / \mathrm{kg}$ Feinerde und $\mathrm{mg} / \mathrm{kg}$ FeinerdeAsche angegeben.

Obwohl die zu bestimmenden Elemente beim Königswasser-Aufschluss elementspezifisch in unterschiedlichen Anteilen, der im Totalaufschluss gelösten Elementkonzentration in Lösung gebracht werden, gilt der Königswasser-Auszug als Standardmethode zur Bestimmung von Schwermetallen in Böden und Abfällen.

\subsubsection{Untersuchungsproben}

Untersucht wurden archiviertes Löss- und Kompost-Ausgangsmaterial (März 86) sowie Proben aus den verschiedenen Tiefenabschnitten der Lysimeter 1 und 2 gegen Ende des Freilandversuches (März 1990 und Januar/März 1991) und aus den Kleinlysimetern (April 1990).

\subsubsection{Ergebnisse}

Die hierbei für die Großlysimeter 1 und 2 und die Kleinlysimeter 3 bis 8 erzielten Werte zeigen die Tabellen 4-37 und 4-38.

Tabelle 4-37: Schwermetall-Gehalte in der Feinerde in verschiedenen Tiefenabschnitten, Lysimeter 1 und 2

\begin{tabular}{|c|c|c|c|c|c|c|c|c|c|}
\hline $\begin{array}{l}\text { Datum der } \\
\text { Probenahme }\end{array}$ & $\begin{array}{c}\text { Tiefe } \\
\text { cm }\end{array}$ & \multicolumn{8}{|c|}{ in $\mathrm{mg} / \mathrm{kg}$ Feinerde } \\
\hline \multicolumn{10}{|c|}{ Lysimeter 1} \\
\hline \multirow[t]{5}{*}{ 08.01.1991 } & $0-10$ & 196,43 & 1,00 & 45,09 & 34,43 & 35,45 & 13,00 & 37,18 & 844,15 \\
\hline & $10-20$ & 188,22 & 1,00 & 70,50 & 35,23 & 35,62 & 13,05 & 36,54 & 863,15 \\
\hline & $20-30$ & 181,44 & 1,00 & 43,15 & 33,30 & 34,79 & 13,02 & 36,88 & 827,50 \\
\hline & $30-42$ & 178,40 & 1,00 & 41,35 & 32,75 & 33,48 & 12,75 & 33,53 & 830,85 \\
\hline & Durchschnitt & 187,25 & 1,00 & 50,24 & 33,95 & 34,87 & 13,02 & 36,16 & 843,94 \\
\hline \multicolumn{10}{|c|}{ Lysimeter 2} \\
\hline \multirow[t]{7}{*}{ 07.03.1991 } & $0-10$ & 267,38 & 1,11 & 81,58 & 40,47 & 31,18 & 12,06 & 37,13 & 1014,00 \\
\hline & $10-20$ & 284,38 & 1,10 & 85,71 & 35,90 & 30,12 & 11,52 & 36,72 & 948,75 \\
\hline & $20-30$ & 246,25 & 1,10 & 65,48 & 36,47 & 30,75 & 11,85 & 37,07 & 935,45 \\
\hline & $30-40$ & 243,77 & 1,10 & 66,38 & 44,05 & 29,56 & 11,69 & 35,33 & 925,40 \\
\hline & $40-50$ & 213,50 & 1,00 & 57,45 & 33,65 & 30,00 & 11,55 & 34,85 & 877,00 \\
\hline & $50-60$ & 211,02 & 1,04 & 55,66 & 32,38 & 29,40 & 11,07 & 33,32 & 826,70 \\
\hline & Durchschnitt & 246,34 & 1,08 & 69,48 & 37,43 & 30,21 & 11,65 & 35,88 & 926,78 \\
\hline
\end{tabular}

\footnotetext{
${ }^{18}$ Klärschlammverordnung (AbfKlärV) vom 15. April 1992 (BGBI I S. 912)
} 
Tabelle 4-38: Schwermetall-Gehalte, Lysimeter 3 - 8 April 1990 und archivierte Ausgangsmaterialien Kompost März 1986 und Löss

\begin{tabular}{|c|c|c|c|c|c|c|c|c|c|}
\hline Probe & $\begin{array}{c}\text { Datum der } \\
\text { Probenahme }\end{array}$ & \multicolumn{8}{|c|}{ in $\mathrm{mg} / \mathrm{kg}$ Feinerde } \\
\hline \multicolumn{2}{|c|}{ Kompost archiviert (1986) } & 336,11 & 1,29 & 150,40 & 42,78 & 26,64 & 11,55 & 28,88 & 1441,50 \\
\hline \multicolumn{2}{|c|}{ Löss archiviert } & 26,73 & 0,44 & 14,14 & 10,01 & 22,16 & 9,62 & 26,49 & 516,25 \\
\hline \multicolumn{10}{|c|}{ Kleinlysimeter } \\
\hline 8 & 02.04 .1990 & 300,88 & 1,29 & 146,14 & 42,98 & 24,17 & 11,59 & 29,99 & 1401,50 \\
\hline 6 & 02.04.1990 & 323,12 & 1,31 & 111,09 & 45,47 & 25,75 & 9,67 & 26,66 & 1145,00 \\
\hline 5 & 02.04 .1990 & 161,27 & 0,76 & 76,33 & 27,62 & 27,47 & 10,53 & 28,48 & 1013,00 \\
\hline 4 & 02.04 .1990 & 110,45 & 1,20 & 67,14 & 23,50 & 24,04 & 10,55 & 29,68 & 863,60 \\
\hline 3 & 02.04 .1990 & 91,11 & 0,69 & 27,05 & 19,15 & 22,30 & 11,47 & 27,90 & 753,45 \\
\hline 7 & 02.04 .1990 & 32,83 & 0,38 & 12,1 & 11,16 & 19,98 & 10,23 & 22,98 & 527,8 \\
\hline
\end{tabular}

Die Unterschiede zwischen den beiden Großlysimetern sind gering. Tiefenabhängigkeiten sind erkennbar, bei Lysimeter 2 stärker als bei Lysimeter 1 mit einer Tiefen-Abnahme der Gehalte besonders bei $\mathrm{Zn}, \mathrm{Pb}, \mathrm{Cu}$ und $\mathrm{Mn}$. Hier ist eine Anreicherung dieser Schwermetalle in den oberen Schichten zu erkennen. Gegenüber dem Kompost-Ausgangsmaterial sind deutliche Unterschiede vorhanden; insbesondere für $\mathrm{Pb}, \mathrm{Zn}$ und in geringerem Umfang auch $\mathrm{Cd}$ sind die Werte im Kompost-Ausgangsmaterial höher. Die Schwermetall-Gehalte der Mischungen entsprechen etwa den Mischungsverhältnissen der Gehalte des Kompostes und des Lösses.

Da langfristig gesehen die organische Substanz des Kompostes einem weiteren Abbau unterliegt, sind in den Tabellen 4-39 und 4-40 die Schwermetall-Gehalte auf mg/kg Glührückstand umgerechnet.

Tabelle 4-39: Schwermetall-Gehalte in der Feinerde bezogen auf den Glührückstand (Asche), Lysimeter 1 und 2

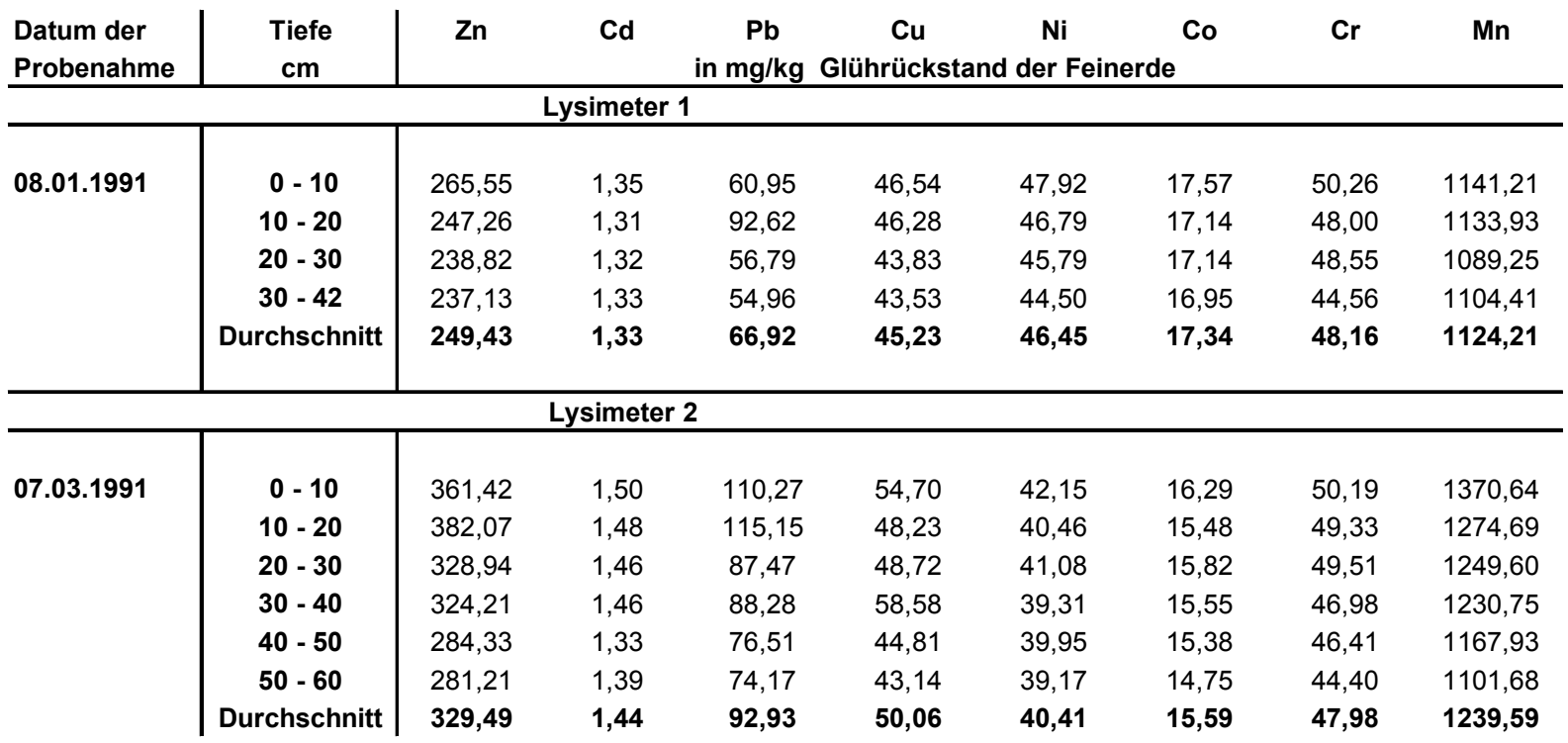


Tabelle 4-40: Schwermetall-Gehalte der Feinerde bezogen auf den Glührückstand, Lysimeter 3-8 April 1990 und archiviertes Ausgangsmaterialien Kompost März 1986 und Löss

\begin{tabular}{|c|c|c|c|c|c|c|c|c|c|}
\hline \multirow[b]{2}{*}{ Probe } & Datum der & $\mathrm{Zn}$ & $\mathrm{Cd}$ & $\mathrm{Pb}$ & $\mathrm{Cu}$ & $\mathbf{N i}$ & Co & $\mathrm{Cr}$ & Mn \\
\hline & Probenahme & \multicolumn{8}{|c|}{ in mg/kg Glührückstand der Feinerde } \\
\hline \multicolumn{2}{|c|}{ Kompost archiviert (1986) } & 470,81 & 1,81 & 210,67 & 59,92 & 37,32 & 16,18 & 40,45 & 2019,19 \\
\hline \multicolumn{2}{|c|}{ Löss archiviert } & 27,65 & 0,46 & 14,62 & 10,36 & 22,92 & 9,95 & 27,40 & 534,09 \\
\hline \multicolumn{10}{|c|}{ Kleinlysimeter } \\
\hline 8 & 02.04 .1990 & 407,19 & 1,74 & 197,77 & 58,17 & 32,71 & 15,68 & 40,58 & 1896,74 \\
\hline 6 & 02.04.1990 & 414,26 & 1,67 & 142,42 & 58,29 & 33,01 & 12,40 & 34,17 & 1467,95 \\
\hline 5 & 02.04 .1990 & 185,15 & 0,87 & 87,63 & 31,71 & 31,53 & 12,09 & 32,69 & 1163,03 \\
\hline 4 & 02.04.1990 & 123,66 & 1,34 & 75,17 & 26,30 & 26,91 & 11,81 & 33,23 & 966,86 \\
\hline 3 & 02.04.1990 & 98,02 & 0,74 & 29,10 & 20,60 & 23,99 & 12,34 & 30,02 & 810,60 \\
\hline 7 & 02.04 .1990 & 33,70 & 0,39 & 12,42 & 11,46 & 20,51 & 10,50 & 23,59 & 541,83 \\
\hline
\end{tabular}

Im Vergleich mit dem Löss-Material sind im Kompost deutlich höhere Schwermetall-Gehalte vorhanden. Der Gehalt von Schwermetallen in Komposten stellt den relevanten Schadstoffeintrag von Komposten in die Umwelt dar. Die weiträumige Verteilung von Schwermetallen in der Umwelt sollte aufgrund ihrer Toxizität und ihrer Persistenz vermieden werden. Die ökologische Wirksamkeit von Schwermetallen in Böden ist abhängig von Ihrem Gehalt und der Art der Metallspezies in der Feststoff- und der Lösungsphase (BRUEMMER et al. 1986, Gäth et al. 1999). Da durch den Einsatz von Kompost mit einer Erhöhung der SchwermetallGehalte in Böden zu rechnen ist, werden die Gehalte von Schwermetallen in Komposten und die Aufwandmengen gesetzlich geregelt. Mit der Bioabfallverordnung (BioAbfV 1998) sind bundeseinheitlich Grenzwerte für Schwermetall-Gehalte in Komposten festgelegt. Weitere Richtwerte und Empfehlungen hinsichtlich der Schwermetall-Gehalte von Komposten sind in den Qualitätskriterien für die Vergabe von Gütezeichen enthalten. Eine weitere Absenkung der Grenzwerte wird im Rahmen der neuen Bodenschutzkonzeptionen des UBA/BMU/BMVEL (BMU/BMVEL 2002, UBA 2002) diskutiert. Hierbei sind unter Berücksichtigung des Filtervermögens von Böden nach Bodenarten gestaffelte Grenzwerte vorgesehen, die sich auf die langfristig im Boden verbleibende Mineralsubstanz beziehen. Dabei werden $71 \%$ mineralische Trockensubstanz im Mittel als gegeben angesehen. Dieser Vorschlag hat in den vergangenen Jahren eine noch andauernde kontroverse Debatte über die Begrenzung von Schadstoff-Einträgen in Böden durch Düngemittel in Gang gesetzt (KNAPPE et al. 2002, BANNICK et al. 2003, WALLMANN und MÜLLER 2003, LOLL 2003).

In der Tabelle 4-41 werden verschiedene Vorschläge zur Gestaltung von Grenz-, Richt- und Orientierungswerten Vergleichswerten aus Kompostuntersuchungen gegenübergestellt. 
Tabelle 4-41: Grenz- und Vergleichswerte für SchwermetallGehalte in Komposten und Böden

\begin{tabular}{|c|c|c|c|c|c|c|c|c|c|c|}
\hline \multirow[b]{2}{*}{ Schwermetall } & \multirow[b]{2}{*}{ Bodenart } & \multirow[b]{2}{*}{$\begin{array}{c}\text { Vorsorgewerte } \\
\text { BBodSchV } \\
\text { Boden } \\
\mathrm{mg} / \mathrm{kg} \text { TS } \\
\end{array}$} & \multicolumn{4}{|c|}{ Grenzwerte } & \multicolumn{3}{|c|}{ eigene Messwerte } & \multirow[b]{2}{*}{$\begin{array}{c}\text { UBA/BGK-Studie } \\
2003 \\
\text { Mittelwert BAK } \\
\text { mg/kg TM }\end{array}$} \\
\hline & & & $\begin{array}{c}\text { BMVEL\&BMU } \\
2002 \\
\text { Bioabfall } \\
\mathrm{mg} / \mathrm{kg} \mathrm{m}_{\mathrm{T}} \\
\end{array}$ & $\begin{array}{c}\text { BioAbfV } \\
1998 \\
\text { Kompost } \\
\text { mg/kg m } \mathrm{m}_{\mathrm{T}} \\
\end{array}$ & $\begin{array}{c}\text { NRW- } \\
\text { Vorschlag } \\
\text { KÖNIG } 2003 \\
\text { mg/kg TS } \\
\end{array}$ & $\begin{array}{c}\text { EU-Öko- } \\
\text { landbauV } \\
\text { Düngemittel } \\
\text { mg/kg mT } \\
\end{array}$ & $\begin{array}{c}\text { Kompost } \\
\text { Mrz } 86 \\
\text { mg/kg TM }\end{array}$ & $\begin{array}{l}\begin{array}{l}\text { Eigenkom- } \\
\text { postierung }\end{array} \\
\mathrm{mg} / \mathrm{kg} \mathrm{TM} \\
\end{array}$ & $\begin{array}{c}\text { Löss } \\
\text { mg/kg TM } \\
\end{array}$ & \\
\hline \multirow[t]{3}{*}{ Blei } & Ton & 100 & 105 & 100 & 70 & 45 & 150 & $10-18$ & 14 & 46,4 \\
\hline & Lehm/Schluff & 70 & 75 & & & & & & & \\
\hline & Sand & 40 & 45 & & & & & & & \\
\hline \multirow[t]{3}{*}{ Cadmium } & Ton & 1,5 & 1,6 & 1,0 & 1,0 & 0,7 & 1,3 & $0,3-0,8$ & 0,4 & 0,47 \\
\hline & Lehm/Schluff & 1,0 & 1,0 & & & & & & & \\
\hline & Sand & 0,4 & 0,4 & & & & & & & \\
\hline \multirow[t]{3}{*}{ Chrom } & Ton & 100 & 100 & 70 & 60 & 70 & 29 & $15-27$ & 26 & 25,3 \\
\hline & Lehm/Schluff & 60 & 70 & & & & & & & \\
\hline & Sand & 30 & 30 & & & & & & & \\
\hline \multirow[t]{3}{*}{ Kupfer } & Ton & 60 & 75 & 70 & 70 & 70 & 43 & $11-18$ & 11 & 57,7 \\
\hline & Lehm/Schluff & 40 & 45 & & & & & & & \\
\hline & Sand & 20 & 30 & & & & & & & \\
\hline \multirow[t]{3}{*}{ Nickel } & Ton & 70 & 75 & 35 & 35 & 25 & 27 & $7-18$ & 22 & 16,3 \\
\hline & Lehm/Schluff & 50 & 50 & & & & & & & \\
\hline & Sand & 15 & 15 & & & & & & & \\
\hline \multirow[t]{3}{*}{ Zink } & Ton & 200 & 270 & 300 & 250 & 200 & 336 & $44-84$ & 31 & 203,7 \\
\hline & Lehm/Schluff & 150 & 210 & & & & & & & \\
\hline & Sand & 60 & 120 & & & & & & & \\
\hline
\end{tabular}

Ein Vergleich der im Kompost-Ausgangsmaterial vom März 86 gefundenen SchwermetallGehalte (Zahlenspalte 6) mit den aktuellen Werten der Bundesgütegemeinschaft Kompost für 2003 (Zahlenspalte ) zeigt, dass bis auf Kupfer bei den heutigen Komposten die Gehalte insbesondere für $\mathrm{Pb}$ und $\mathrm{Cd}$ deutlich gesunken sind. Dennoch liegen auch diese aktuellen Gehalte noch über den für die Komposte aus Eigenkompostierung ermittelten Werten (Zahlenspalte 7) und überschreiten damit die für sandige Böden vorgesehenen Vorsorgewerte der BBodSchV.

\subsection{Biomasse}

\subsubsection{Methodik}

\subsubsection{Wasserhaltekapazität (WHK)}

Die Wasserhaltekapazität wurde nach SCHLICHTING \& BLUME (1966) gravimetrisch bestimmt. Hierzu wurde $50 \mathrm{~g}$ frisches, ungesiebtes Probenmaterial in einem Becherglas mit $100 \mathrm{ml}$ dest. Wasser gesättigt, $30 \mathrm{~min}$ stehen gelassen und nach dem Abtropfen über einem Trichter mit Filterwatte gewogen. Die Wasserhaltekapazität errechnet sich aus der Gewichtsdifferenz der mit Wasser gesättigten Probe und der bei $105{ }^{\circ} \mathrm{C}$ bis zur Gewichtskonstanz getrockneten Probe. Die Wasserhaltekapazität wird in Gew. \% der TM angegeben.

\subsubsection{Biomasse-Bestimmung}

Die Biomasse-Bestimmung erfolgte nach der Fumigation-Extraction-Methode nach VANCE et al. (1987). Die Biomasse ergibt sich hierbei aus der Differenz des lösbaren Gehaltes an organischem Kohlenstoff mit und ohne Begasung durch Chloroform. Hierzu wurden je nach TM-Gehalt 35 bis $40 \mathrm{~g}$ frisches, ungesiebtes Material eingewogen. Steine und Fremdbestanteile wurden vorher aussortiert. Die TS-Einwaage sollte bei etwa $25 \mathrm{~g}$ liegen. Die zu begasenden Proben wurden durch Wasserzugabe auf einen Wassergehalt von mindestens $40 \%$ der WHK eingestellt und zusammen mit ca. $25 \mathrm{ml}$ ethanolfreiem Chloroform, drei feuchten Tüchern und einem Becherglas mit Natronkalk in einen Exsikkator gegeben. Der Exsikkator wurde evakuiert und das Chloroform für 2 min zum Sieden gebracht. Nach $24 \mathrm{~h}$ Inkubationszeit bei $25^{\circ} \mathrm{C}$ im Dunkeln wurde das Chlorform durch sechsmal wiederholtes zweiminütiges Absaugen entfernt. Die Extraktion erfolgte durch Überführung des Probematerials in PE-Flaschen und Zugabe von $170 \mathrm{ml} \mathrm{K}_{2} \mathrm{SO}_{4}(\mathrm{c}=0,5 \mathrm{~mol} / \mathrm{l})$. Die Proben wurden 45 min geschüttelt und anschließend abfiltriert. Zur Ermittlung des nicht-mikrobiellen Kohlenstoffs dienten unbegaste Proben, die ebenfalls mit $\mathrm{K}_{2} \mathrm{SO}_{4}$-Lösung versetzt, 45 min geschüttelt und abfiltriert wurden. Die Messung des gelösten organischen Kohlenstoffs (DOC $=$ Dissolved Organic Carbon) wurde mit dem automatischen Kohlenstoffanalysator 
Dohrman DC 80 durchgeführt. Dabei wurde der organische Kohlenstoff mit UV-Licht und Kaliumpersulfat oxidiert.

Der Biomasse-Kohlenstoff $B_{c}$ wurde nach folgender Formel berechnet (WU et al., 1990):

$$
B_{c}=E_{c} \times 2,22
$$

$\mathrm{E}_{\mathrm{c}}$ wurde aus der Differenz des $\mathrm{C}$-Gehaltes im $\mathrm{K}_{2} \mathrm{SO}_{4}$-Extrakt der begasten Probe und des C-Gehaltes im $\mathrm{K}_{2} \mathrm{SO}_{4}$-Extrakt der unbegasten Probe berechnet. Der Biomasse-Kohlenstoff wird in $\mathrm{mg} / \mathrm{kg} \mathrm{TM}$ und in $\mathrm{mg} / \mathrm{kg} \mathrm{C}_{\text {org }}$ angegeben. Die Bestimmungen wurden mit vierfacher Wiederholung durchgeführt.

\subsubsection{Untersuchungsproben}

Untersucht wurden Proben des Kompostes (Lysimeter 1, 2 und 8), des Lösses und ihrer Mischungen gegen Ende der Freilandversuche.

\subsubsection{Ergebnisse}

Die Ergebnisse der Biomasse-Bestimmungen zeigen die Tabellen 4-42 (Lysimeter 1 und 2) und 4-43 (Lysimeter 3 - 8). Die Wasserhaltekapazitäten der Komposte und Kompost/LössMischungen sind in Tabelle 1-6 im Anhang aufgeführt.

Tabelle 4-42: Messgrößen der Biomasse-Bestimmung in den verschiedenen Tiefenabschnitten, Lysimeter 1 und 2

uf unfumigiert, f fumigiert

\begin{tabular}{|c|c|c|c|c|c|c|}
\hline $\begin{array}{l}\text { Datum der } \\
\text { Probenahme }\end{array}$ & $\begin{array}{l}\text { Tiefe } \\
\text { cm }\end{array}$ & $\begin{array}{c}C_{\text {org }} \\
\text { g/kg TM }\end{array}$ & $\begin{array}{c}\mathrm{DOC}_{\text {uf }} \\
\mathrm{mg} / \mathrm{g} \mathrm{C} \mathrm{C}_{\text {org }}\end{array}$ & $\begin{array}{c}\mathrm{DOC}_{\mathrm{f}} \\
\mathrm{mg} / \mathrm{g} \mathrm{C} \mathrm{C}_{\text {org }}\end{array}$ & $\begin{array}{c}\text { Biomasse-C } \\
\mathrm{mg} / \mathrm{g} \mathrm{C}_{\text {org }}\end{array}$ & $\begin{array}{c}\text { Biomasse-C } \\
\mu \mathrm{g} / \mathrm{g} \text { TM }\end{array}$ \\
\hline \multicolumn{7}{|c|}{ Lysimeter 1} \\
\hline \multirow[t]{5}{*}{ 08.01.1991 } & $0-10$ & 149,3 & 2,81 & 5,45 & 5,87 & 876,43 \\
\hline & $10-20$ & 134,2 & 3,52 & 6,53 & 6,69 & 898,44 \\
\hline & $20-30$ & 124,5 & 4,46 & 7,23 & 6,16 & 766,60 \\
\hline & $30-42$ & 121,2 & 5,12 & 8,16 & 6,49 & 786,15 \\
\hline & Durchschnitt & 132,30 & 3,98 & 6,84 & 6,30 & 831,91 \\
\hline \multicolumn{7}{|c|}{ Lysimeter 2} \\
\hline \multirow[t]{7}{*}{ 07.03.1991 } & $0-10$ & 116,6 & 3,77 & 7,33 & 7,91 & 922,20 \\
\hline & $10-20$ & 108,7 & 3,99 & 7,93 & 8,74 & 950,33 \\
\hline & $20-30$ & 108,8 & 3,86 & 7,57 & 8,25 & 897,58 \\
\hline & $30-40$ & 105,4 & 4,50 & 8,80 & 9,57 & 1008,56 \\
\hline & $40-50$ & 102,7 & 6,11 & 10,84 & 10,86 & 1115,73 \\
\hline & $50-60$ & 109,9 & 6,14 & 11,56 & 12,04 & 1322,85 \\
\hline & Durchschnitt & 108,68 & 4,73 & 9,00 & 9,56 & 1036,21 \\
\hline
\end{tabular}


Tabelle 4-43: Messgrößen der Biomasse-Bestimmung, Lysimeter 3 - 8

uf unfumigiert, f fumigiert

\begin{tabular}{|c|c|c|c|c|c|c|}
\hline Lysimeter & $\begin{array}{c}\text { Datum der } \\
\text { Probenahme }\end{array}$ & $\begin{array}{c}\mathrm{C}_{\text {org }} \\
\mathrm{g} / \mathrm{kg} \text { TM }\end{array}$ & $\begin{array}{c}\mathrm{DOC}_{\mathrm{uf}} \\
\mathrm{mg} / \mathrm{g} \mathrm{C}_{\text {org }}\end{array}$ & $\begin{array}{c}\mathrm{DOC}_{\mathrm{f}} \\
\mathrm{mg}^{\mathrm{g}} \mathrm{C}_{\text {org }}\end{array}$ & $\begin{array}{c}\text { Biomasse-C } \\
\mathrm{mg} / \mathrm{g} \mathrm{C}_{\text {org }}\end{array}$ & $\begin{array}{c}\text { Biomasse-C } \\
\mu \mathrm{g} / \mathrm{g} \text { TM }\end{array}$ \\
\hline 8 & 02.04 .1990 & 132,5 & 2,43 & 5,89 & 7,62 & 1009,28 \\
\hline 6 & 02.04.1990 & 110,6 & 2,67 & 6,45 & 7,31 & 808,28 \\
\hline 5 & 02.04.1990 & 72,6 & 3,59 & 7,62 & 8,96 & 650,41 \\
\hline 4 & 02.04.1990 & 60,2 & 4,24 & 8,51 & 9,50 & 571,76 \\
\hline 3 & 02.04.1990 & 28,3 & 6,30 & 11,22 & 10,94 & 309,52 \\
\hline 7 & 02.04.1990 & 2,9 & 18,03 & 23,95 & 13,16 & 38,17 \\
\hline
\end{tabular}

Die Biomasse-Gehalte der Komposte liegen bei etwa 1000 mg/kg TM. Im reinen Löss werden demgegenüber $38 \mathrm{mg} / \mathrm{kg}$ TM festgestellt. Bezieht man die Biomasse-Gehalte auf den organischen Kohlenstoff erreicht der Kompost nur etwa die Hälfte der Biomasse im Vergleich zum reinen Löss. Die Biomasse-Gehalte in $\mathrm{mg} / \mathrm{g} \mathrm{C}_{\text {org }}$ liegen beim Löss um 1,3 \%, im Kompost dagegen zwischen von 0,5 und 1,2 \% Die für den Kompost und seine Mischungen mit Löss erhaltenen $\mathrm{B}_{\mathrm{c}}$-Werte stimmen gut mit Literaturwerten überein (vergl. hierzu JÖRGENSEN 1992, LAVAHUN et al. 1995, SCHACHT et al. 1999).

Wie die nachfolgenden Abbildungen 14 und 15 für Lysimeter 1 und 2 zeigen, ist eine deutliche Tiefenabhängigkeit der Werte erkennbar. Entgegen der für Böden festgestellten Abnahme des mikrobiellen Kohlenstoffs in tieferen Bodenschichten, steigen die auf den $\mathrm{C}_{\text {org }}$ bezogenen Biomasse-Gehalte mit zunehmender Tiefe an. Lysimeter 2 für das primär ein geringerer Zersetzungsgrad zu unterstellen ist erreicht die höheren Werte. In der Abbildung 16 sind die DOC- und Biomasse-C-Gehalte für die Kleinlysimeter 3 bis 8 dargestellt. 


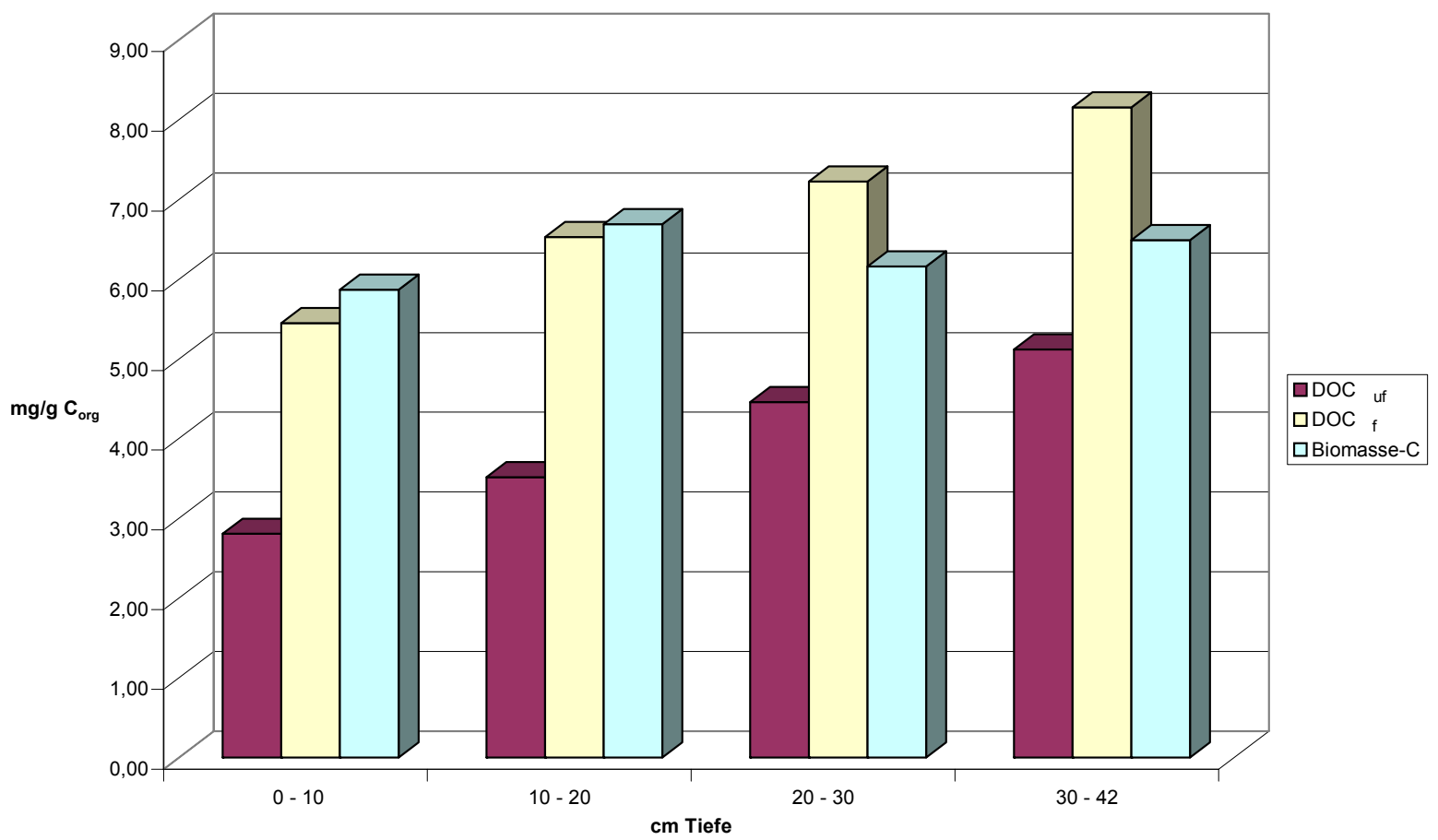

Abbildung 14: DOC bezogen auf $C_{\text {org }}(\mathrm{mg} / \mathrm{g})$ des Kompostes unfumigierter (uf) und fumigierter (f) Proben und BiomasseC, Lysimeter 1 (Januar 1991) in den verschiedenen Tiefenabschnitten

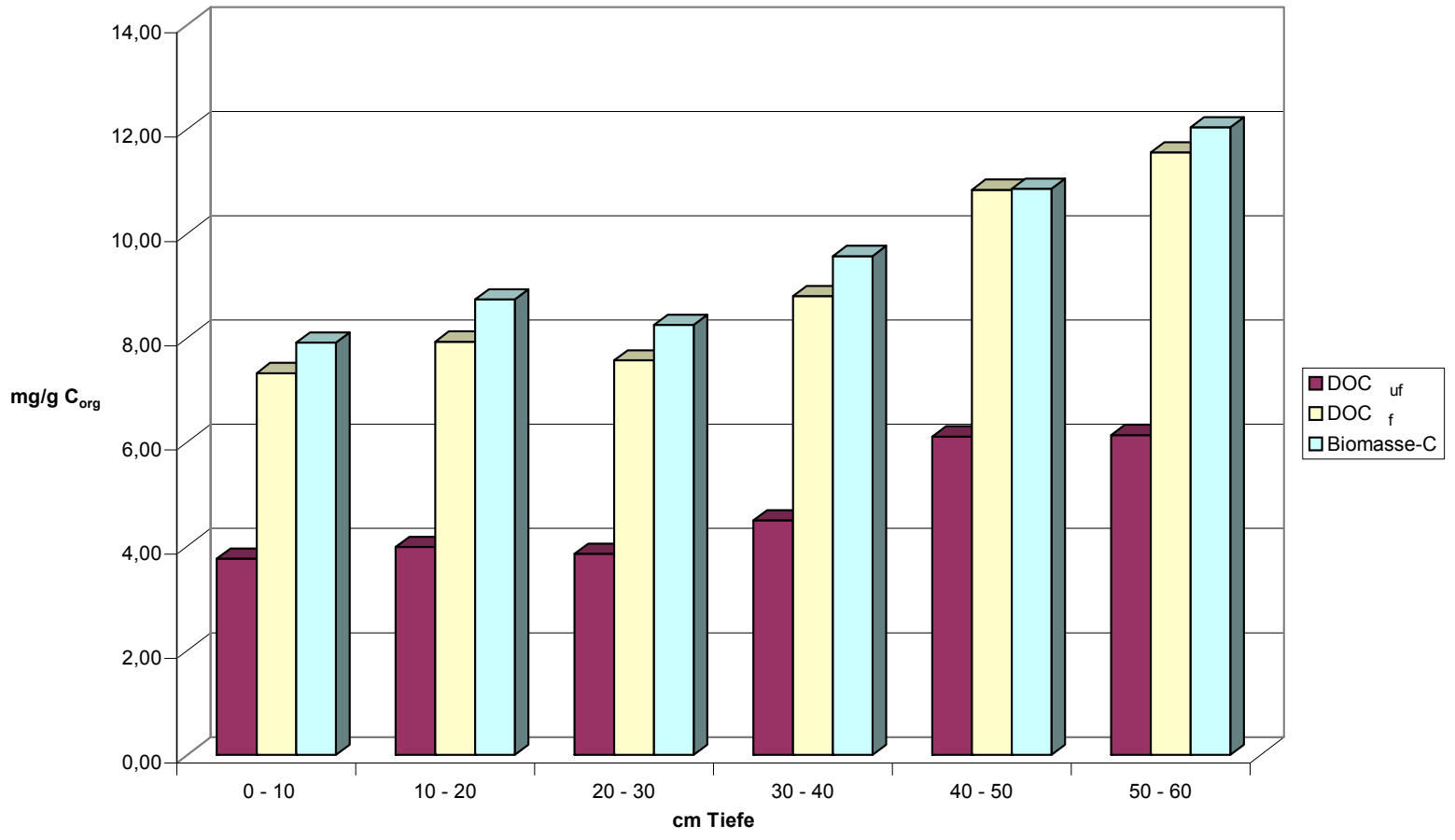

Abbildung 15: DOC bezogen auf $C_{\text {org }}(\mathrm{mg} / \mathrm{g})$ des Kompostes unfumigierter (uf) und fumigierter (f) Proben und BiomasseC, Lysimeter 2 (März 1991) in den verschiedenen Tiefenabschnitten 


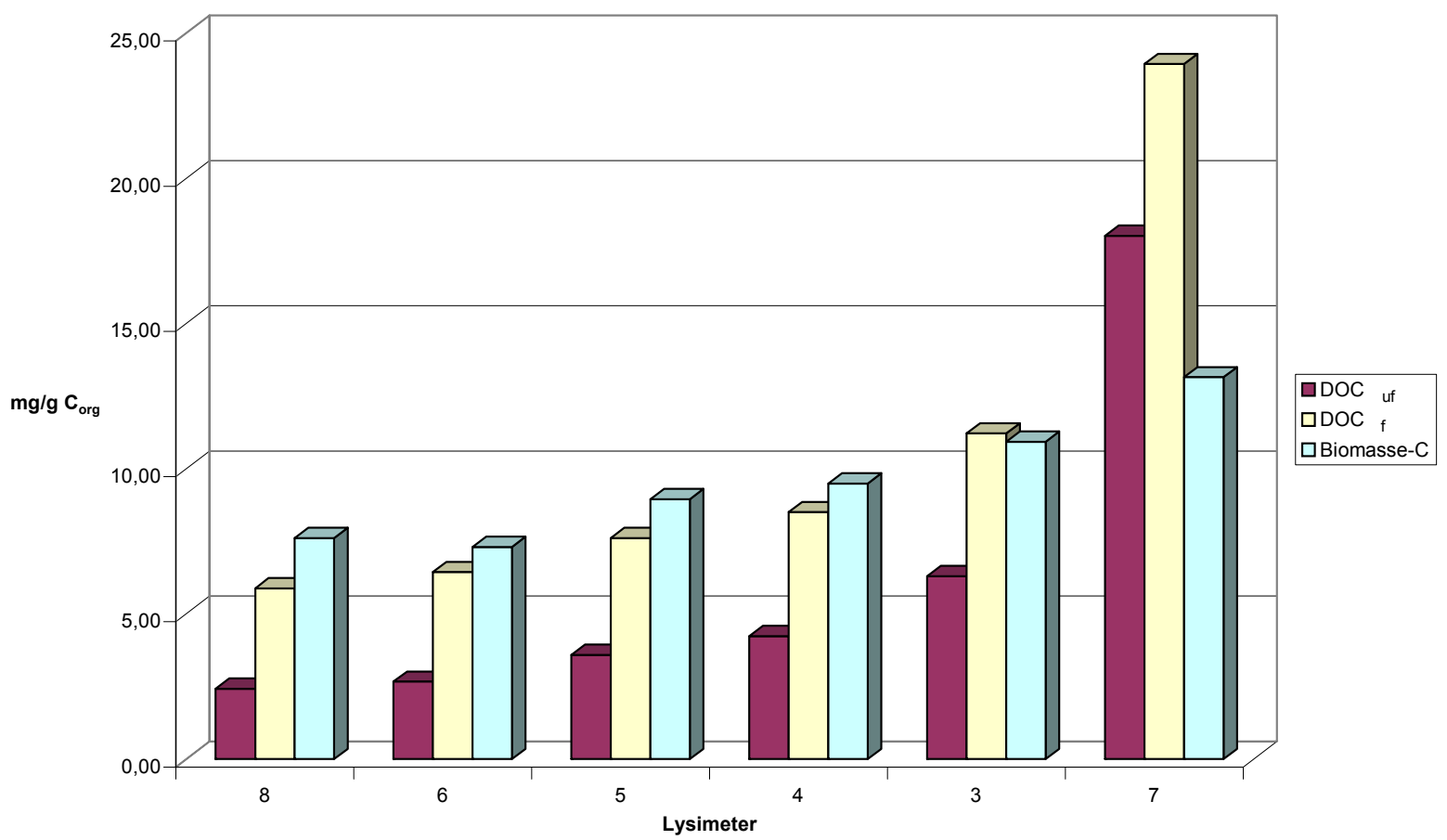

Abbildung 16: DOC bezogen auf $C_{\text {org }}(\mathrm{mg} / \mathrm{g})$ des Kompostes unfumigierter (uf) und fumigierter (f) Proben Proben und Biomasse-C, Lysimeter 3 - 8 (April 1990)

Auffällig ist beim Vergleich von Kompost und Löss-Bodenmaterial, dass der Kompost deutlich geringere Anteile an extrahierbarem Kohlenstoff bezogen auf den Gesamt-C-Gehalt aufweist. Dies legt die Annahme nahe, dass die organische Substanz in den Komposten für eine Besiedlung durch Mikroorganismen nur beschränkt zugänglich ist oder dass die humifizierte organische Substanz generell nur noch eine geringe Wasserlöslichkeit besitzt. Möglicherweise handelt es sich um große $\mathrm{C}_{\text {org }}$-Körper oder von im Zuge der Mineralisation von sekundär abgeschiedener Mineralsubstanz umhüllte Körper, die für Mikroorganismen nicht als Substrat zugänglich sind. (siehe hierzu auch GRUNDMANN 1990, MUNDHENKE 2002) 


\section{Organische und anorganische Inhaltsstoffe von Extrakten}

\subsection{Methodik}

Für die Bestimmung der löslichen Gehalte in Komposten und Böden werden unterschiedliche Extraktionsverfahren vorgeschlagen (VDLUFA 1991, BUNDESGÜTEGEMEINSCHAFT KOMPOST 1994). Die Löslichkeit der Inhaltsstoffe ist vor allem abhängig von der Konzentration des Extraktionsmittels, dem pH-Wert, dem Feststoff/Lösungmittel-Verhältniss und der Schütteldauer. Die Ergebnisse der verschiedenen Extraktionsverfahren sind zur allgemeinen Charakterisierung von Substraten gut geeignet, dennoch ergeben sie keine gesicherten Aussagen über die tatsächlichen Bindungsformen (ZEIEN 1995). Eluatprognosen auf der Basis von Schüttelversuchen werden trotz der unrealistischen Bedingungnen zur Bewertung der stofflichen Gefährdung von Grundwasser eingesetzt.

Die Gehalte an wasserlöslichen Elementen wurden hier in wässrigen Extrakten bestimmt. Es wurden verschiedene Varianten der Probenvorbereitung und Durchführung angesetzt. Hierzu wurden vorher an der Luft und bei $105^{\circ} \mathrm{C}$ getrocknete Proben mit unterschiedlichen Mischungsverhältnissen destillierten Wassers versetzt. 20 bis $30 \mathrm{~g} \mathrm{TM}<2 \mathrm{~mm},>2 \mathrm{~mm}$ und $<1,12 \mathrm{~mm}$ der Probe wurden eingewogen, mit dest. Wasser im Mischungsverhältnis 1:2 oder 1:10 Kompost:Wasser versetzt und $24 \mathrm{~h}(1: 2)$ bzw. $1 \mathrm{~h}(1: 10)$ horizontal geschüttelt. Anschließend wurden die Proben zentrifugiert und über Papierfilter abfiltriert. Bei drei Probeserien wurde direkt an die erste Extraktion eine zweite angeschlossen. Hierfür wurden die Proben nach dem Abfiltrieren der ersten Extraktionslösung erneut mit dest. Wasser entsprechend dem Gesamtgewicht (Kompost und dest. Wasser) der ersten Extraktion aufgefüllt.

In den Extrakten wurden die Konzentrationen der Kationen $\mathrm{Ca}, \mathrm{Mg}, \mathrm{K}, \mathrm{Na}$ durchgehend untersucht. Die Leitfähigkeit, sowie die Konzentrationen an $\mathrm{Fe}, \mathrm{Zn}, \mathrm{Cl}, \mathrm{SO}_{4}, \mathrm{P}, \mathrm{NO}_{3}, \mathrm{~N}_{\text {ges }}$, $\mathrm{HCO}_{3}, \mathrm{DOC}$, die Extinktionen bei 400 und $436 \mathrm{~nm}$ und der $\mathrm{pH}$-Wert wurden nur in einem Teil der Extrakte untersucht. Tabelle 5-1 zeigt eine Übersicht der hierfür eingesetzten Methoden.

Tabelle 5-1: Extraktanalyse, Methodenübersicht

\begin{tabular}{|l|l|}
\hline Messgröße & Methode \\
\hline $\mathrm{pH}-$ Wert & $\begin{array}{l}\text { Potenziometrische pH-Wert-Bestimmung, pH-Meter und Glaselektrode } \\
\text { der Fa. Metrohm }\end{array}$ \\
\hline Leitfähigkeit & Leitfähigkeitsmesszelle von WTW, Messung bei $25^{\circ} \mathrm{C}$ \\
\hline Extinktion & $\begin{array}{l}\text { Photometrische Bestimmung der Extinktion bei } 400 \text { und } 436 \mathrm{~nm} \text { in der } \\
1: 4 \text { mit dest. Wasser verdünnten Sickerwasser-Probe, Photometer } \\
\text { Spectronic 20 der Fa. Bausch und Lomb }\end{array}$ \\
\hline DOC & $\begin{array}{l}\text { Verbrennungsofen, TOC-Analysengerät TOCOR 2, photometrische } \\
\mathrm{CO}_{2} \text {-Detektion, Maihak AG }\end{array}$ \\
\hline
\end{tabular}




\begin{tabular}{|c|c|}
\hline Messgröße & Methode \\
\hline$N_{\text {ges }}$ & $\begin{array}{l}\text { Nach Abdestillation von } \mathrm{NH}_{4}-\mathrm{N} \text { und } \mathrm{NO}_{3}-\mathrm{N} \text { Bestimmung des Kjeldahl- } \\
\mathrm{N} \text {, nasse Veraschung mit konz. } \mathrm{H}_{2} \mathrm{SO}_{4} \text { und Selenreaktionsgemisch, } \\
\text { Destillation mit } \mathrm{NaOH} \text { und Rücktitration mit verd. } \mathrm{H}_{2} \mathrm{SO}_{4} \text { auf den Aus- } \\
\text { gangs-pH-Wert }\end{array}$ \\
\hline $\mathrm{NO}_{3}$ & $\begin{array}{l}\text { Reduktion im Sauren mit aktivierten Zink-Plättchen, Wasserdampf- } \\
\text { destillation des } \mathrm{NH}_{3} \text { in } \mathrm{H}_{3} \mathrm{BO}_{3} \text {-Vorlage, Rücktitration mit verd. } \mathrm{HCl}\end{array}$ \\
\hline $\mathrm{Cl}$ & $\begin{array}{l}\text { Potenziometrische Fällungstitration mit } \mathrm{AgNO}_{3} \text { am Titroprozessor 636, } \\
\text { Metrohm }\end{array}$ \\
\hline $\mathrm{SO}_{4}$ & $\begin{array}{l}\text { Kationenaustausch, Fällung als } \mathrm{BaSO}_{4} \text {, Eindampfen, komplexo- } \\
\text { metrische Rücktitration des unverbrauchten Bariums mit EDTA am } \\
\text { Titroprozessor 636, Metrohm }\end{array}$ \\
\hline $\mathrm{HCO}_{3}$ & Potenziometrische Titration mit verd. $\mathrm{HCL}$ auf $\mathrm{pH}$-Wert $=5,00$ \\
\hline $\mathrm{P}$ & $\begin{array}{l}\text { Aufschluss mit konzentrierter } \mathrm{H}_{2} \mathrm{SO}_{4} \text {, Bildung des blau gefärbten } \mathrm{P} \text { - } \\
\text { Molybdat-Komplexes, photometrische Bestimmung, Spectronic 20, } \\
\text { Bausch \& Lomb }\end{array}$ \\
\hline $\mathrm{Ca}, \mathrm{Na}, \mathrm{K}$ & $\begin{array}{l}\text { FES, Eichkurvenmethode unter Standardbedingungen, Eppendorf } \\
\text { Flammenphotometer }\end{array}$ \\
\hline $\mathrm{Mg}, \mathrm{Fe}, \mathrm{Zn}$ & $\begin{array}{l}\text { Flammen-AAS, Eichkurvenmethode unter Standardbedingungen, } \\
\text { AA775, Varian Techtron }\end{array}$ \\
\hline
\end{tabular}

\subsection{Untersuchungsproben}

Untersucht wurden Proben des Kompostes, des Lösses und der Mischungen beider während des Freilandversuches. In Tabelle 5-2 sind die verschiedenen Verfahren der Extraktion den Untersuchungsproben zugeordnet.

Tabelle 5-2: Übersicht über die hergestellten Extrakte

\begin{tabular}{|c|l|l|l|l|l|}
\hline Serie & $\begin{array}{l}\text { Datum der } \\
\text { Probenahme }\end{array}$ & $\begin{array}{l}\text { Lysimeter und } \\
\text { Tiefen }\end{array}$ & $\begin{array}{l}\text { Probenvorbe- } \\
\text { reitung }\end{array}$ & $\begin{array}{l}\text { Kompost:Was- } \\
\text { ser-Verhältnis }\end{array}$ & Durchführung \\
\hline $\mathbf{1}$ & $\begin{array}{l}\text { Lysimeter 1: } \\
0-20 \mathrm{~cm} \text { durchgehend, } \\
20-45 \mathrm{~cm} \text { teilweise, } \\
45-70 \mathrm{~cm} \text { teilweise } \\
\text { Lysimeter 2: } \\
0-20 \mathrm{~cm} \text { durchgehend, } \\
20-45 \mathrm{~cm} \text { teilweise, } \\
45-70 \mathrm{~cm} \text { teilweise }\end{array}$ & $\begin{array}{l}\text { Bei } 105^{\circ} \mathrm{C} \\
\text { getrocknete, } \\
\text { gemörserte, } \\
\text { gesiebte Fraktion } \\
<1,12 \mathrm{~mm}\end{array}$ & $1: 2$ & $\begin{array}{l}24 \mathrm{~h} \text { horizontal } \\
\text { schütteln, } \\
\text { zentrifugieren, } \\
\text { über Papier- } \\
\text { Faltenfilter } \\
\text { abfiltrieren }\end{array}$ \\
\hline $\mathbf{2}$ & 24.08 .87 & $\begin{array}{l}\text { Lysimeter } 1: \\
0-20 \mathrm{~cm}, \\
20-45 \mathrm{~cm}, \\
45-70 \mathrm{~cm}\end{array}$ & $\begin{array}{l}\text { Bei } 105^{\circ} \mathrm{C} \\
\text { getrocknete, } \\
\text { gemörserte, } \\
\text { gesiebte Fraktion }\end{array}$ & $\begin{array}{l}1: 2, \\
\text { Erstextraktion }\end{array}$ & $\begin{array}{l}\text { 24 h horizontal } \\
\text { schütteln, } \\
\text { zentrifugieren, } \\
\text { über Papier- } \\
\text { Faltenfilter }\end{array}$ \\
\hline
\end{tabular}




\begin{tabular}{|c|c|c|c|c|c|}
\hline Serie & $\begin{array}{l}\text { Datum der } \\
\text { Probenahme }\end{array}$ & $\begin{array}{l}\text { Lysimeter und } \\
\text { Tiefen }\end{array}$ & $\begin{array}{l}\text { Probenvorbe- } \\
\text { reitung }\end{array}$ & $\begin{array}{l}\text { Kompost:Was- } \\
\text { ser-Verhältnis }\end{array}$ & Durchführung \\
\hline & & $\begin{array}{l}\text { Lysimeter } 2: \\
0-20 \mathrm{~cm}, \\
20-45 \mathrm{~cm}, \\
45-70 \mathrm{~cm} \\
\text { Lysimeter } 7 \text { und } 8: \\
0-20 \mathrm{~cm} \\
\text { Lysimeter } 3-6: \\
0-30 \mathrm{~cm}\end{array}$ & $<1,12 \mathrm{~mm}$ & & abfiltrieren \\
\hline 2.1 & 24.06 .88 & $\begin{array}{l}\text { Lysimeter } 1: \\
0-20 \mathrm{~cm}, \\
20-45 \mathrm{~cm}, \\
45-70 \mathrm{~cm} \\
\text { Lysimeter } 2: \\
0-20 \mathrm{~cm}, \\
20-45 \mathrm{~cm}, \\
45-70 \mathrm{~cm} ; \\
\text { Lysimeter } 7 \text { und } 8: \\
0-20 \mathrm{~cm} \\
\text { Lysimeter } 3-6: \\
0-30 \mathrm{~cm}\end{array}$ & $\begin{array}{l}\text { Bei } 105^{\circ} \mathrm{C} \\
\text { getrocknete, } \\
\text { gemörserte, } \\
\text { gesiebte Fraktion } \\
<1,12 \mathrm{~mm}\end{array}$ & $\begin{array}{l}1: 2 \\
\text { Folgeextraktion }\end{array}$ & $\begin{array}{l}24 \text { h horizontal } \\
\text { schütteln, } \\
\text { zentrifugieren, } \\
\text { über Papier- } \\
\text { Faltenfilter } \\
\text { abfiltrieren }\end{array}$ \\
\hline 3 & 26.07.88 & $\begin{array}{l}\text { Lysimeter } 1 \text { und } 2: \\
0-20 \mathrm{~cm}, \\
20-45 \mathrm{~cm}\end{array}$ & $\begin{array}{l}\text { Bei } 105^{\circ} \mathrm{C} \\
\text { getrocknete, } \\
\text { gemörserte, } \\
\text { gesiebte Fraktion } \\
<1,12 \mathrm{~mm}\end{array}$ & $1: 2$ & $\begin{array}{l}24 \text { h horizontal } \\
\text { schütteln, } \\
\text { zentrifugieren, } \\
\text { über Papier- } \\
\text { Faltenfilter } \\
\text { abfiltrieren }\end{array}$ \\
\hline 4 & 29.03 .90 & $\begin{array}{l}\text { Lysimeter } 1: \\
0-30 \mathrm{~cm}, \\
30-60 \mathrm{~cm} \\
\text { Lysimeter } 2: \\
0-30 \mathrm{~cm} \text {, } \\
30-60 \mathrm{~cm} \\
\text { Lysimeter } 8,6,5,4: \\
0-20 \mathrm{~cm}\end{array}$ & $\begin{array}{l}\text { Bei } 105^{\circ} \mathrm{C} \\
\text { getrocknete, } \\
\text { gemörserte, } \\
\text { gesiebte, Fraktion } \\
<1,12 \mathrm{~mm}\end{array}$ & $1: 2$ & $\begin{array}{l}24 \text { h horizontal } \\
\text { schütteln, } \\
\text { zentrifugieren, } \\
\text { über Papier- } \\
\text { Faltenfilter } \\
\text { abfiltrieren }\end{array}$ \\
\hline 5.1 & 29.03 .90 & $\begin{array}{l}\text { Lysimeter } 1: \\
0-30 \mathrm{~cm}, \\
30-60 \mathrm{~cm} \\
\text { Lysimeter } 2: \\
0-30 \mathrm{~cm} \\
30-60 \mathrm{~cm} \\
\text { Lysimeter } 8,6,5,4: \\
0-20 \mathrm{~cm}\end{array}$ & $\begin{array}{l}\text { Luftgetrocknete, } \\
\text { schonend } \\
\text { zerdrückte, } \\
\text { gesiebte Fraktion } \\
<2 \mathrm{~mm}\end{array}$ & $\begin{array}{l}\text { 1:10 } \\
\text { Erstextraktion }\end{array}$ & $\begin{array}{l}1 \mathrm{~h} \text { horizontal } \\
\text { schütteln, stehen } \\
\text { lassen, über } \\
\text { Papier- } \\
\text { Faltenfilter } \\
\text { abfiltrieren }\end{array}$ \\
\hline 5.2 & 29.03 .90 & $\begin{array}{l}\text { Lysimeter } 1: \\
0-30 \mathrm{~cm}, \\
30-60 \mathrm{~cm} \\
\text { Lysimeter } 2: \\
0-30 \mathrm{~cm} \\
30-60 \mathrm{~cm} \\
\text { Lysimeter } 8,6,5,4:\end{array}$ & $\begin{array}{l}\text { Luftgetrocknete, } \\
\text { schonend } \\
\text { zerdrückte, } \\
\text { gesiebte Fraktion } \\
<2 \mathrm{~mm}\end{array}$ & $\begin{array}{l}\text { 1:10 } \\
\text { Folgeextraktion }\end{array}$ & $\begin{array}{l}1 \mathrm{~h} \text { horizontal } \\
\text { schütteln, stehen } \\
\text { lassen, über } \\
\text { Papier- } \\
\text { Faltenfilter } \\
\text { abfiltrieren }\end{array}$ \\
\hline
\end{tabular}




\begin{tabular}{|c|l|l|l|l|l|}
\hline Serie & $\begin{array}{l}\text { Datum der } \\
\text { Probenahme }\end{array}$ & $\begin{array}{l}\text { Lysimeter und } \\
\text { Tiefen }\end{array}$ & $\begin{array}{l}\text { Probenvorbe- } \\
\text { reitung }\end{array}$ & $\begin{array}{l}\text { Kompost:Was- } \\
\text { ser-Verhältnis }\end{array}$ & Durchführung \\
\hline $\mathbf{6 . 1}$ & 18.04 .90 & $\begin{array}{l}\text { Lysimeter 1: } \\
0-5 \mathrm{~cm}\end{array}$ & $\begin{array}{l}\text { Luftgetrocknete, } \\
\text { schonend } \\
\text { zerdrückte, } \\
\text { gesiebte, Fraktion } \\
<2 \mathrm{~mm} \text { und } \\
\text { Fraktion }>2 \mathrm{~mm}\end{array}$ & $\begin{array}{l}1: 10 \\
\text { Erstextraktion }\end{array}$ & $\begin{array}{l}\text { 1 h horizontal } \\
\text { schütteln, stehen } \\
\text { lassen, über } \\
\text { Papier- } \\
\text { Faltenfilter } \\
\text { abfiltrieren }\end{array}$ \\
\hline $\mathbf{6 . 2}$ & 18.04 .90 & $\begin{array}{l}\text { Lysimeter 1: } \\
0-5 \mathrm{~cm}\end{array}$ & $\begin{array}{l}\text { Luftgetrocknete, } \\
\text { schonend } \\
\text { zerdrückte, } \\
\text { gesiebte, Fraktion } \\
<2 \text { mm und } \\
\text { Fraktion }>2 \text { mm }\end{array}$ & $\begin{array}{l}1: 10 \\
\text { Folgeextraktion }\end{array}$ & $\begin{array}{l}1 \text { h horizontal } \\
\text { schütteln, stehen } \\
\text { lassen, über } \\
\text { Papier- } \\
\text { Faltenfilter } \\
\text { abfiltrieren }\end{array}$ \\
\hline $\mathbf{7}$ & $\begin{array}{l}\text { Ausgangs- } \\
\text { material }\end{array}$ & Kompost März 86 & $\begin{array}{l}\text { Bei 105 C C } \\
\text { getrocknete, } \\
\text { gemörserte, } \\
\text { gesiebte Fraktion } \\
<1,12 \text { mm }\end{array}$ & $\begin{array}{l}1: 2 \\
1: 10\end{array}$ & $\begin{array}{l}1 \text { h horizontal } \\
\text { schütteln, stehen } \\
\text { lassen, über } \\
\text { Papier- } \\
\text { Faltenfilter } \\
\text { abfiltrieren }\end{array}$ \\
\hline
\end{tabular}

\subsection{Ergebnisse}

Die Tabellen 1-7 bis 1-29 im Anhang zeigen die in den Probenserien für jede Extraktionsvariante im Extrakt erzielten Werte in $\mathrm{mg} / \mathrm{l}$ und, umgerechnet auf die TM, in $\mathrm{mg} / \mathrm{kg} \mathrm{TS}$ und $\mathrm{mmol} \mathrm{IE} / \mathrm{kg}$ TM. Für die Mischungsvarianten werden zum Vergleich auch die aus den Werten für die reinen Materialien Kompost und Löss entsprechend den Mischungsverhältnissen berechneten Werte angegeben (siehe Tabellen 1-45 bis 1-56 im Anhang). Dabei ist zu berücksichtigen, dass sich die Mischungsanteile in den gesiebten Proben von den ungesiebten unterscheiden, da der Löss vollständig in Aggregaten kleiner $2 \mathrm{~mm}$ vorliegt während im Kompost nur etwa $82 \%$ der Aggregate kleiner $2 \mathrm{~mm}$ sind, so dass sich in den gesiebten Proben die Mischungsanteile zugunsten des Lösses verschieben.

\subsection{1 pH-Wert}

Die in den unterschiedlichen Extrakten erreichten $\mathrm{pH}$-Werte liegen durchgängig im schwach alkalischen Bereich ( $\mathrm{pH}$-Wert: 7,4-8,8). Die ermittelten Werte entsprechen den üblicherweise für Bioabfall-Komposte festgestellten pH-Werten in wässriger Lösung (GEORGIJÄNSCH et al. 1988).

Die pH-Werte vom 24.06.88 in den 1:2-Extrakten der Kleinlysimeter liegen bei der 1. Extraktion zwischen 7 und 7,4 und bei der 2. Extraktion zwischen 7,9 und 8,1.

\subsubsection{Leitfähigkeit und Salzgehalt}

\section{Großlysimeter}

Die Leitfähigkeit in den 1:2-Extrakten geht von 10,2 $\mathrm{mS} / \mathrm{cm}$ zu Versuchsbeginn bereits nach 4 Monaten auf etwa $3 \mathrm{mS} / \mathrm{cm}$ zurück. Bei Lysimeter 2 steigen die Werte im Juli kurzfristig sehr stark, sogar über den Anfangswert hinaus, bis auf $12 \mathrm{mS} / \mathrm{cm}$ an und sinken anschließend wieder auf den Wert von etwa $3 \mathrm{mS} / \mathrm{cm}$ ab.

Die Abbildung 17 zeigt den Verlauf der Leitfähigkeitswerte im 1:2-Kompost:Wasser-Extrakt für die Lysimeter 1 und 2. 
Errechnet man näherungsweise den Salzgehalt der Kompostproben entsprechend dem Extraktionsverhältnis und dem in Kapitel 6.5 .5 berechneten Umrechnungsfaktor $(1 \mathrm{mS} / \mathrm{cm}$ entspricht 0,69 g Salz/l), so erhält man für das Kompost-Ausgangsmaterial vom März 86 in der TM $<1,12 \mathrm{~mm}$ je nach Extraktionsverhältnis Salzgehalte zwischen 0,66 \% (1:2-Extrakt) und 0,97\% (1:10-Extrakt). Die Großlysimeter weisen in der TM $<1,12 \mathrm{~mm}$ zu Versuchsbeginn Werte zwischen 1,4 und 1,7 \% Salz auf, die gegen Ende der Freilandversuche durch Auswaschung auf Werte zwischen 0,14 und 0,25 zurückgehen.

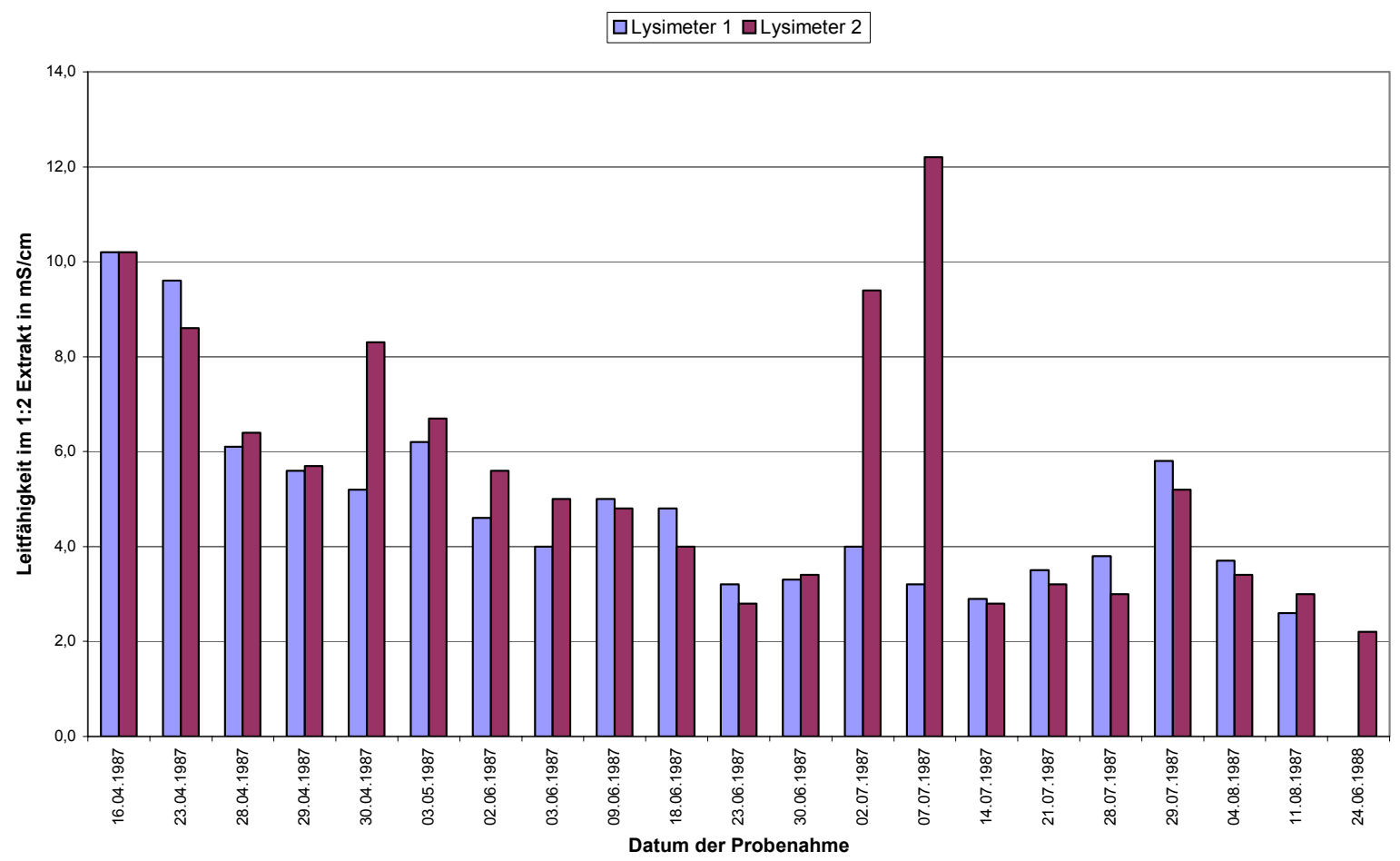

\footnotetext{
Abbildung 17: Leitfähigkeit im 1:2-Kompost:Wasser-Extrakt der $\mathrm{TM}<1,12 \mathrm{~mm}$ in $\mathrm{mS} / \mathrm{cm}$, Lysimeter 1 und 2, Tiefe $0-20$ cm
}

\section{Kleinlysimeter}

Die Leitfähigkeit der Extrakte steigt mit zunehmendem Kompostanteil in den Mischungen. Die Leitfähigkeit im 1:2-Extrakt liegt beim reinen Löss bei Werten zwischen 0,5 (1987) und $0,4(1988) \mathrm{mS} / \mathrm{cm}$ und beim reinen Kompost zwischen 3,6 (1987) und 1,7 (1988) $\mathrm{mS} / \mathrm{cm}$. Der höchste Wert ist in der Probe vom 28.07.1987 bei L 6 ermittelt worden. Die Leitfähigkeit im 1:2-Extrakt des für die Kleinlysimeter verwendeten Kompost-Ausgangsmaterials liegt bei deren Anlage mit 4,8 $\mathrm{mS} / \mathrm{cm}$ deutlich unter den zu Versuchsbeginn bei Lysimeter 1 und 2 festgestellten Werten.

Die Abbildung 18 zeigt die im 1:2-Extrakt gemessenen Leitfähigkeitswerte für die Lysimeter 3 bis 8 . 


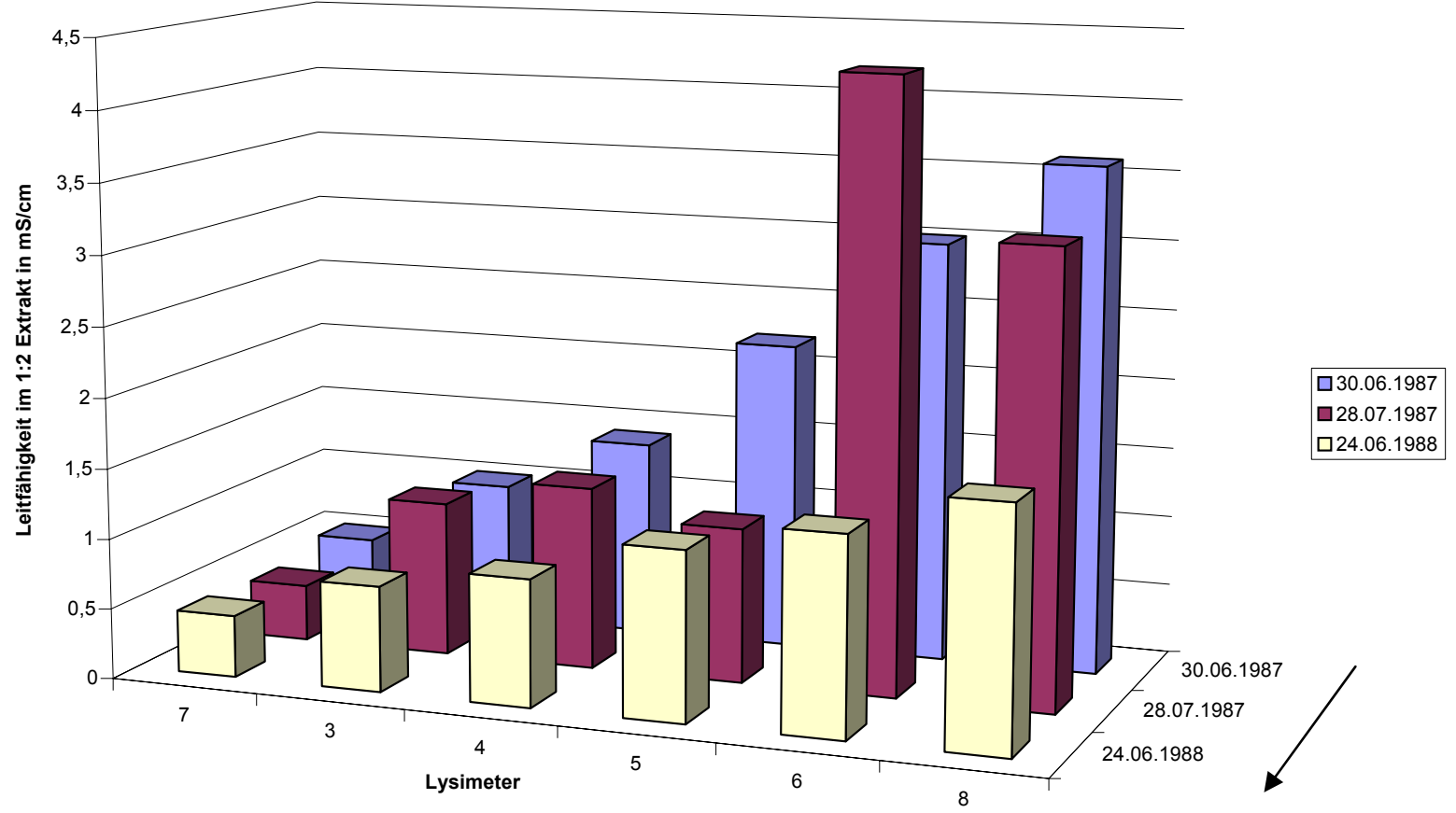

Abbildung 18: Leitfähigkeit im 1:2-Kompost:Wasser-Extrakt der $\mathrm{TM}<1,12 \mathrm{~mm}$ in $\mathrm{mS} / \mathrm{cm}$, Lysimeter $3-8$, Tiefe $0-30 \mathrm{~cm}$ (bzw. 0 - $20 \mathrm{~cm}$, Lysimeter 7 und 8)

\subsubsection{Kationen}

\section{Großlysimeter}

In Abbildung 19 und Abbildung 20 sind die Kationen-Konzentrationen in den 1:2 Kompost:Wasser-Extrakten für die oberste Lysimeterschicht $(0-20 \mathrm{~cm}$ bzw. am 29.03.1990 0 $30 \mathrm{~cm}$ ) dargestellt. 


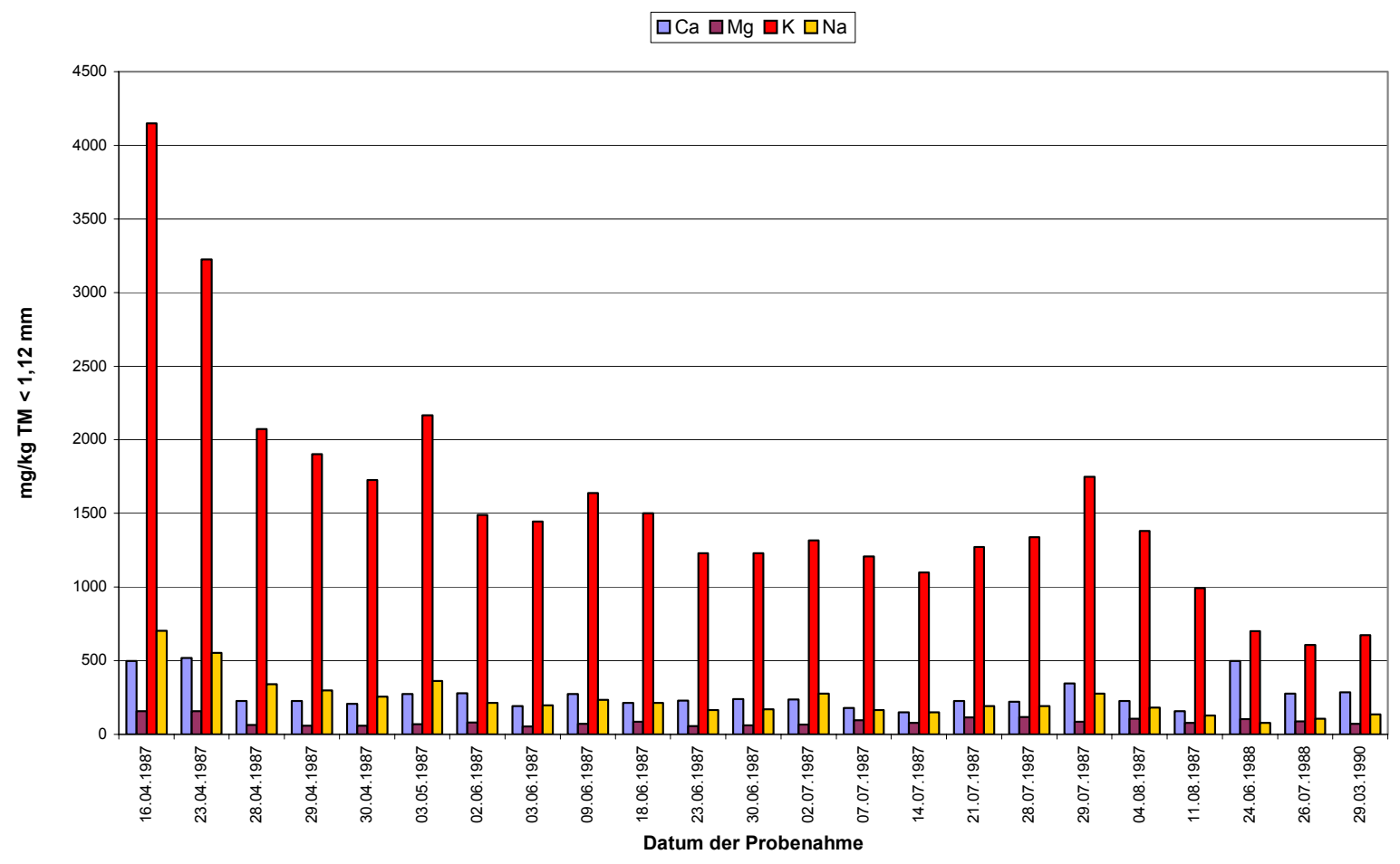

Abbildung 19: Kationen-Gehalte im 1:2-Kompost:WasserExtrakt in $\mathrm{mg} / \mathrm{kg} \mathrm{TM}<1,12 \mathrm{~mm}$, Lysimeter 1 , Tiefe $0-20 \mathrm{~cm}$ (bzw. 0 - 30 cm, 29.03.1990)

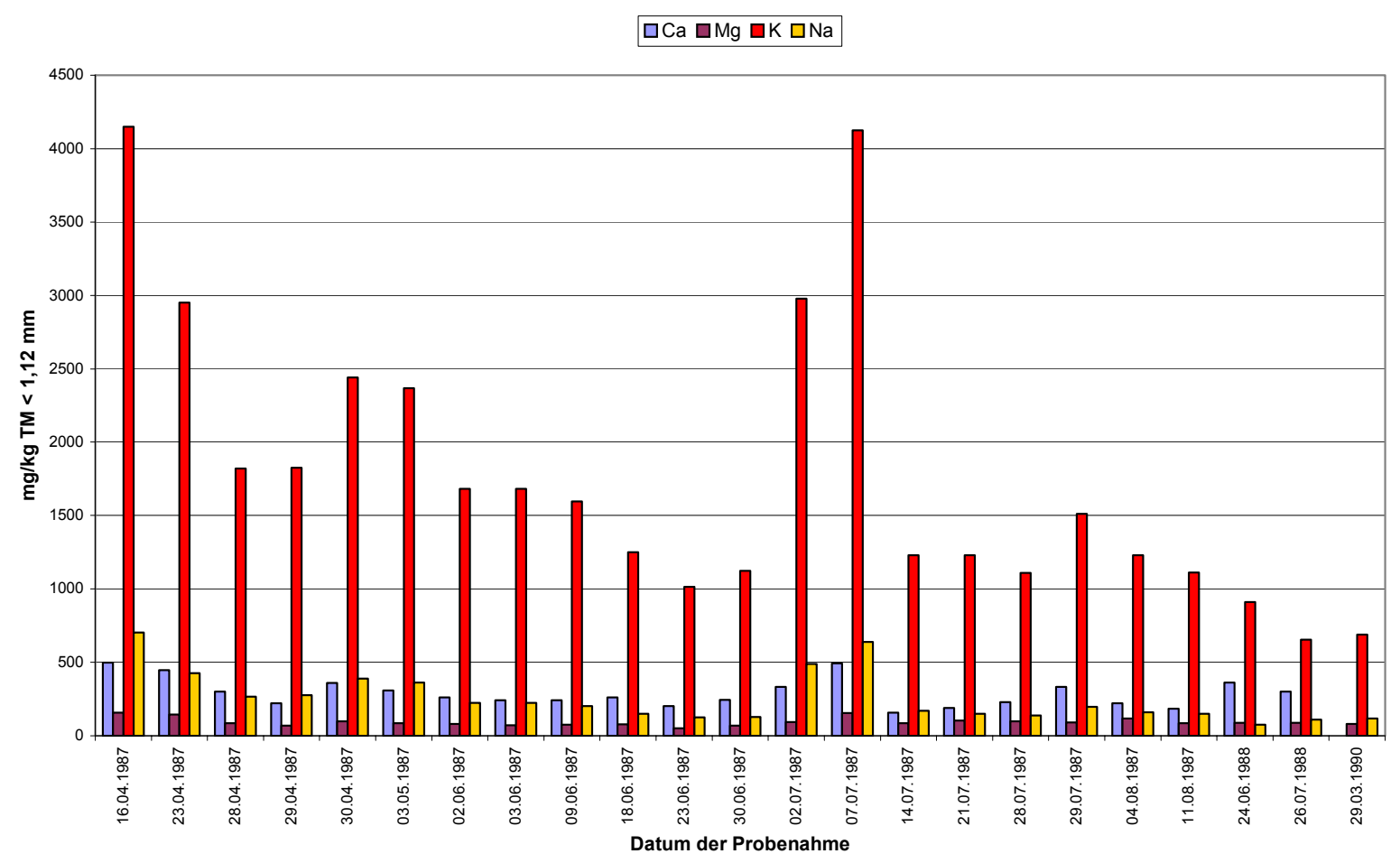

Abbildung 20: Kationen-Gehalte im 1:2-Kompost:WasserExtrakt in $\mathrm{mg} / \mathrm{kg} \mathrm{TM}<1,12 \mathrm{~mm}$, Lysimeter 2, Tiefe $0-20 \mathrm{~cm}$ (bzw. 0 - $30 \mathrm{~cm}, 29.03 .1990$ )

Das dominierende Kation in den Extrakten ist $\mathrm{K}$, gefolgt von $\mathrm{Ca}, \mathrm{Na}$ und $\mathrm{Mg}$. Die Werte sinken innerhalb der ersten Untersuchungsmonate deutlich $a b$. Dies ist insbesondere für die 
Alkalielemente zu beobachten. Die Abnahme liegt bei Ca und $\mathrm{Mg}$ bei rund $50 \%$; bei $\mathrm{K}$ und $\mathrm{Na}$ bei rund $70 \%$. Während der Na-Gehalt zu Versuchsbeginn noch über dem Ca-Gehalt liegt, sinkt er im Laufe der Versuchszeit unter die Ca-Werte. Die Unterschiede zwischen Lysimeter 1 und Lysimeter 2 sind gering, bis auf den kurzfristigen Kationenanstieg bei Lysimeter 2 im Juli 1987

Für $\mathrm{K}$ und $\mathrm{Na}$ sind deutliche Unterschiede in Abhängigkeit von der Entnahme-Tiefe im Lysimeter festzustellen (siehe Tabellen 1-7 bis 1-23 im Anhang). Mit zunehmender Tiefe werden bis zu $100 \%$ höhere Gehalte im Vergleich zu den Werten aus der obersten Schicht ermittelt. Während der Freilandversuche findet eine Verlagerung und Anreicherung der löslichen K- und Na-Salze in den unteren Schichten statt. Bei $\mathrm{Ca}$ und $\mathrm{Mg}$ sind nur geringe Tiefenunterschiede vorhanden.

Es liegt insgesamt keine gleichmäßige Abnahme der Gehalte bzw. Tiefenverlagerung vor, so dass Veränderungen der Löslichkeit auch durch Nachlieferung aus Mineralisationsvorgängen und/oder physikalisch-chemischen Umwandlungen zu vermuten sind.

Die Interpretation dieses Befundes legt, wenn man entsprechend Tab. 4-33 die Gehalte der einzelnen Kationen in der Asche zugrunde legt, den Schluss nahe, dass die bei der Mineralisation freigesetzten Kationen $\mathrm{Ca}$ und $\mathrm{Mg}$ als wenig lösliche Carbonate festgelegt werden, während die in all ihren Salzen hochlöslichen Kationen $\mathrm{K}$ und $\mathrm{Na}$ mobil bleiben und in tiefere Schichten verlagert bzw. ausgewaschen werden.

\section{Kleinlysimeter}

Die ersten Werte im 1:2-Extrakt der Kleinlysimeter liegen für die Probenahme vom 30.06.1987 vor, etwa 10 Wochen nach Anlage der Lysimeter. Es ist anzunehmen, dass vergleichbar mit dem Verlauf bei $L 1$ und $L 2$ direkt zu Versuchsbeginn höhere Werte im Extrakt erzielt worden wären. Insgesamt stehen bei den Kleinlysimetern nur für 4 Probenahme-Termine vergleichbare Extraktuntersuchungen zur Verfügung.

Das in der Fraktion $<2 \mathrm{~mm}$ dominierende Kation ist in den Extrakten der Mischungsvarianten ab 46 \% Kompost (Lysimeter 4, 5, 6 und 8) ebenfalls K, gefolgt von $\mathrm{Ca}$, Na und Mg. In den Extrakten der Löss-Variante (7) dominiert dagegen Ca gefolgt von Mg, Na und $\mathrm{K}$. In der Mischungsvariante (Lysimeter 3) mit rund 73 \% Löss ist die Reihenfolge $\mathrm{Ca}, \mathrm{K}, \mathrm{Mg}$ und $\mathrm{Na}$.

Wie die Abbildungen 21 - 24 zeigen, sind folgende Veränderungen über die Untersuchungszeit hinweg zu beobachten:

Eine durchgängige Abnahme der Konzentration im Extrakt liegt für Natrium (keine Speicherung) vor. Für Kalium ist bei $L 8$ eine Abnahme, bei $L 3$ und $L 7$ sind geringe Änderungen und bei $L$ 4, 5 und 6 Erhöhungen zu verzeichnen. Für Calcium ist bei allen Lysimetern eine Zunahme der löslichen Verbindungen während des Versuches erkennbar. Für Mg liegt eine Zunahme bei den Lysimetern 3, 4, 5 und 6 vor, eine Abnahme bei L 8 und geringe Unterschiede bei $L 3$. Möglicherweise bildet die Löss-Beimischung einen Senke für lösliche Verbindungen, die dadurch verzögert freigesetzt werden. Eine Erklärung dafür ist in der Befähigung des Lösses zur Fixierung des $\mathrm{K}$ im Zwischenschichtraum der Tonminerale zu suchen, die K vor der Auswaschung schützt. Die Kationengehalte in den Extrakten steigen bis auf wenige Abweichungen mit zunehmendem Kompostgehalt an. 


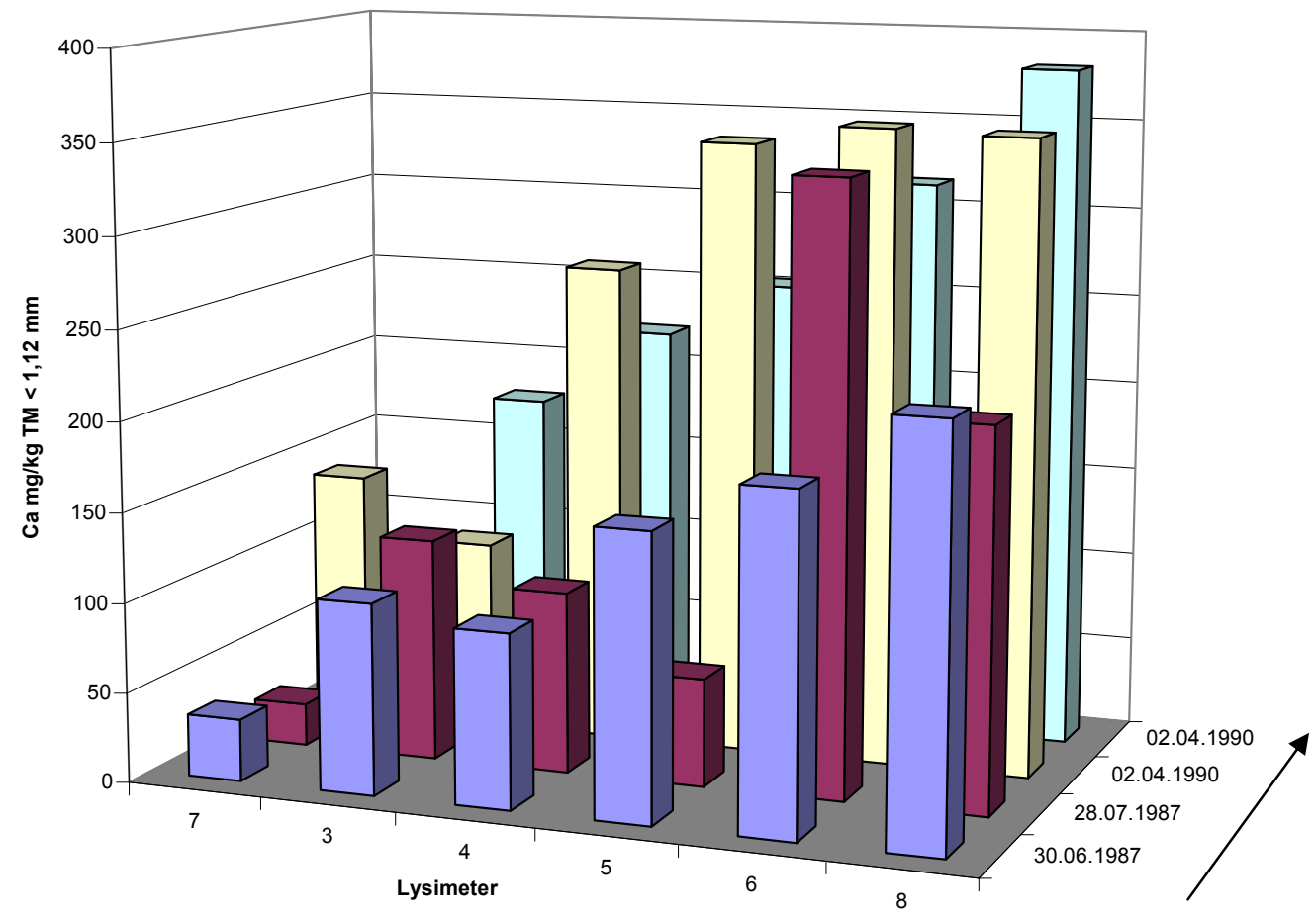

Abbildung 21: Lösliche Calcium-Gehalte im 1:2-

Kompost:Wasser-Extrakt in $\mathrm{mg} / \mathrm{kg} \mathrm{TM}<1,12 \mathrm{~mm}$, Lysimeter

3 - 8, Tiefe $0-30 \mathrm{~cm}$ (bzw. 0 - $20 \mathrm{~cm}$, Lysimeter 7 und 8)

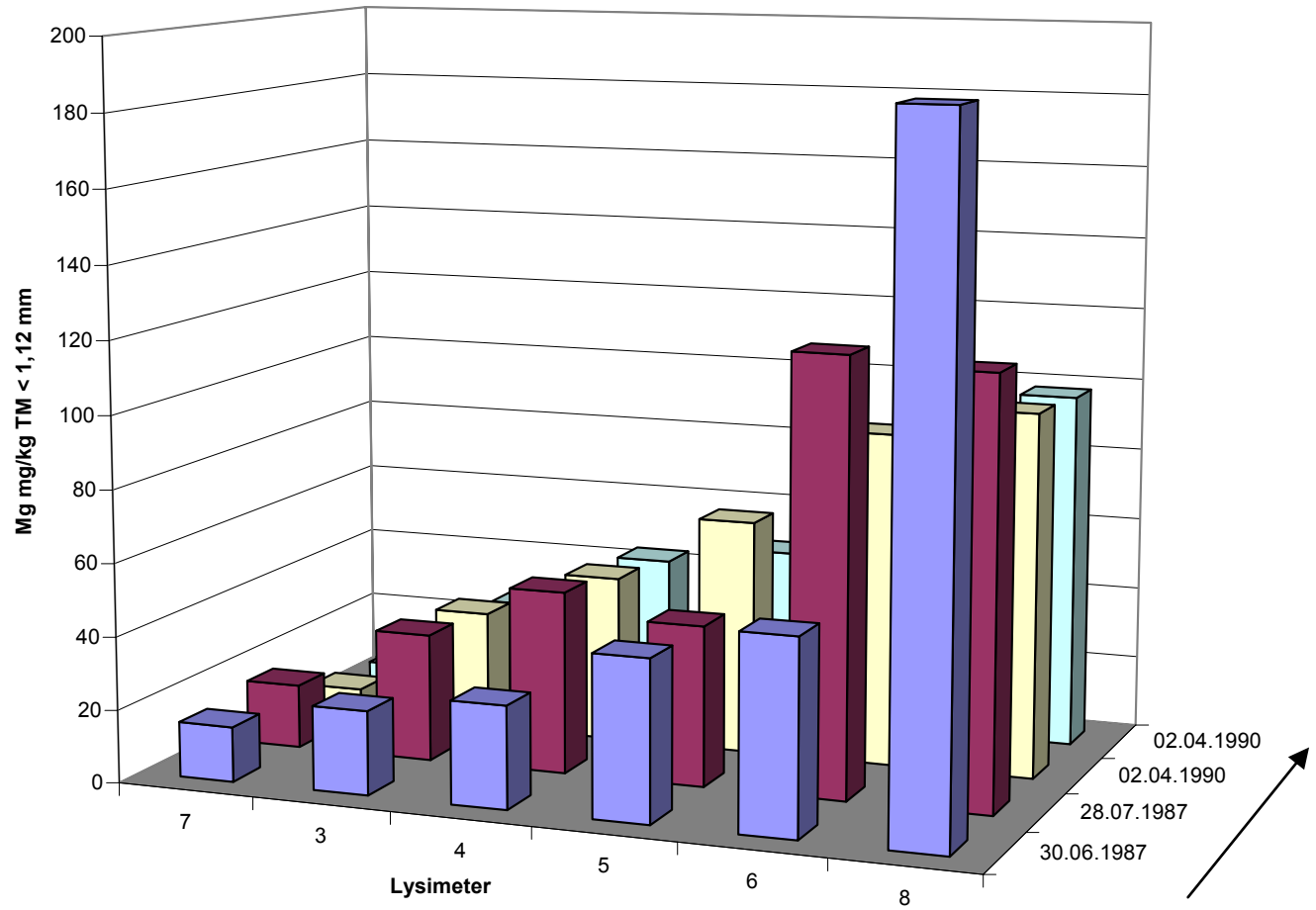

Abbildung 22: Lösliche Magnesium-Gehalte im 1:2-

Kompost:Wasser-Extrakt in $\mathrm{mg} / \mathrm{kg} \mathrm{TM}<1,12 \mathrm{~mm}$, Lysimeter

3 - 8, Tiefe $0-30 \mathrm{~cm}$ (bzw. 0 - $20 \mathrm{~cm}$, Lysimeter 7 und 8) 


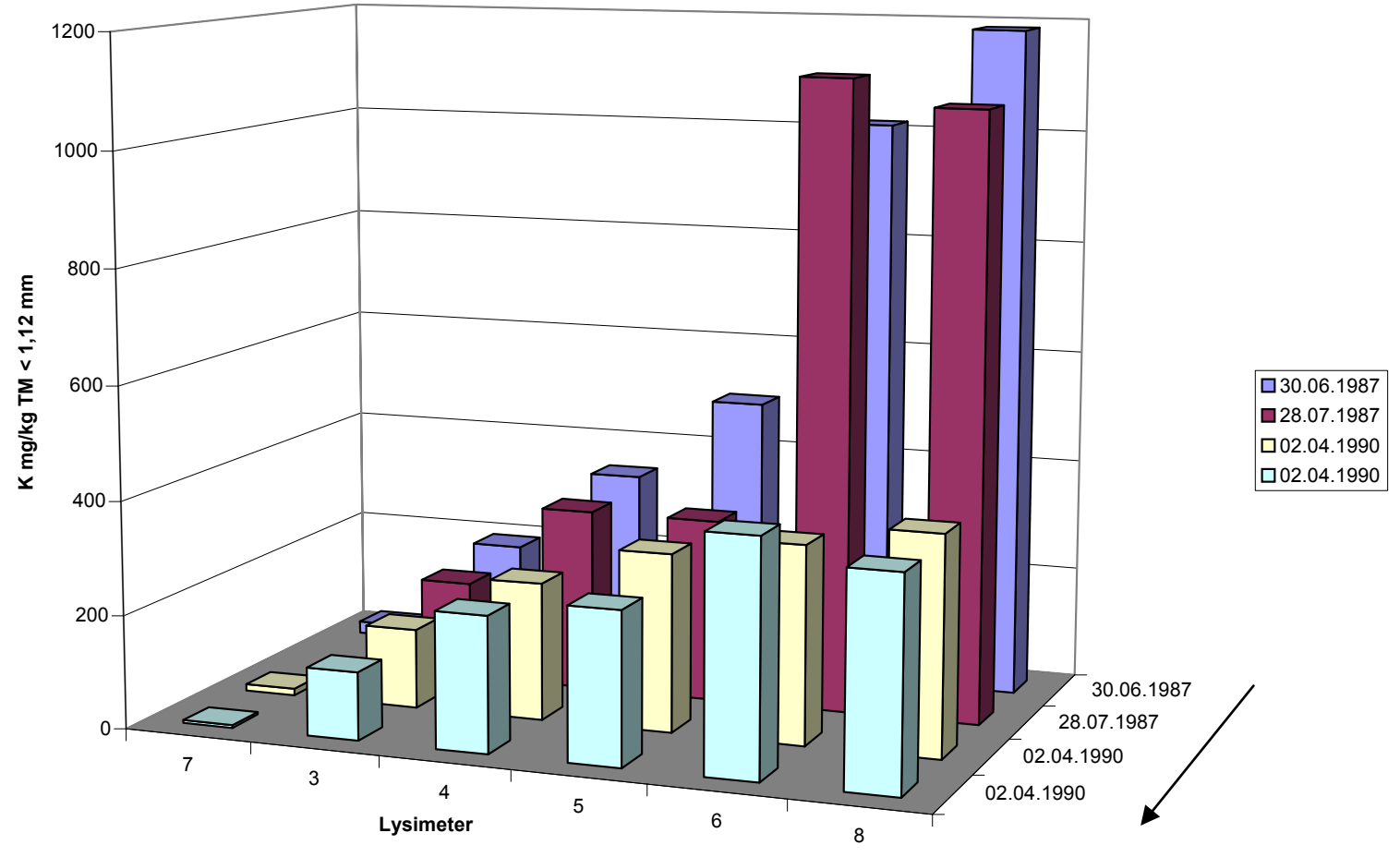

Abbildung 23: Lösliche Kalium-Gehalte im 1:2-

Kompost:Wasser-Extrakt in $\mathrm{mg} / \mathrm{kg}$ TM $<1,12 \mathrm{~mm}$, Lysimeter

3 - 8, Tiefe $0-30 \mathrm{~cm}$ (bzw. 0 - $20 \mathrm{~cm}$, Lysimeter 7 und 8)

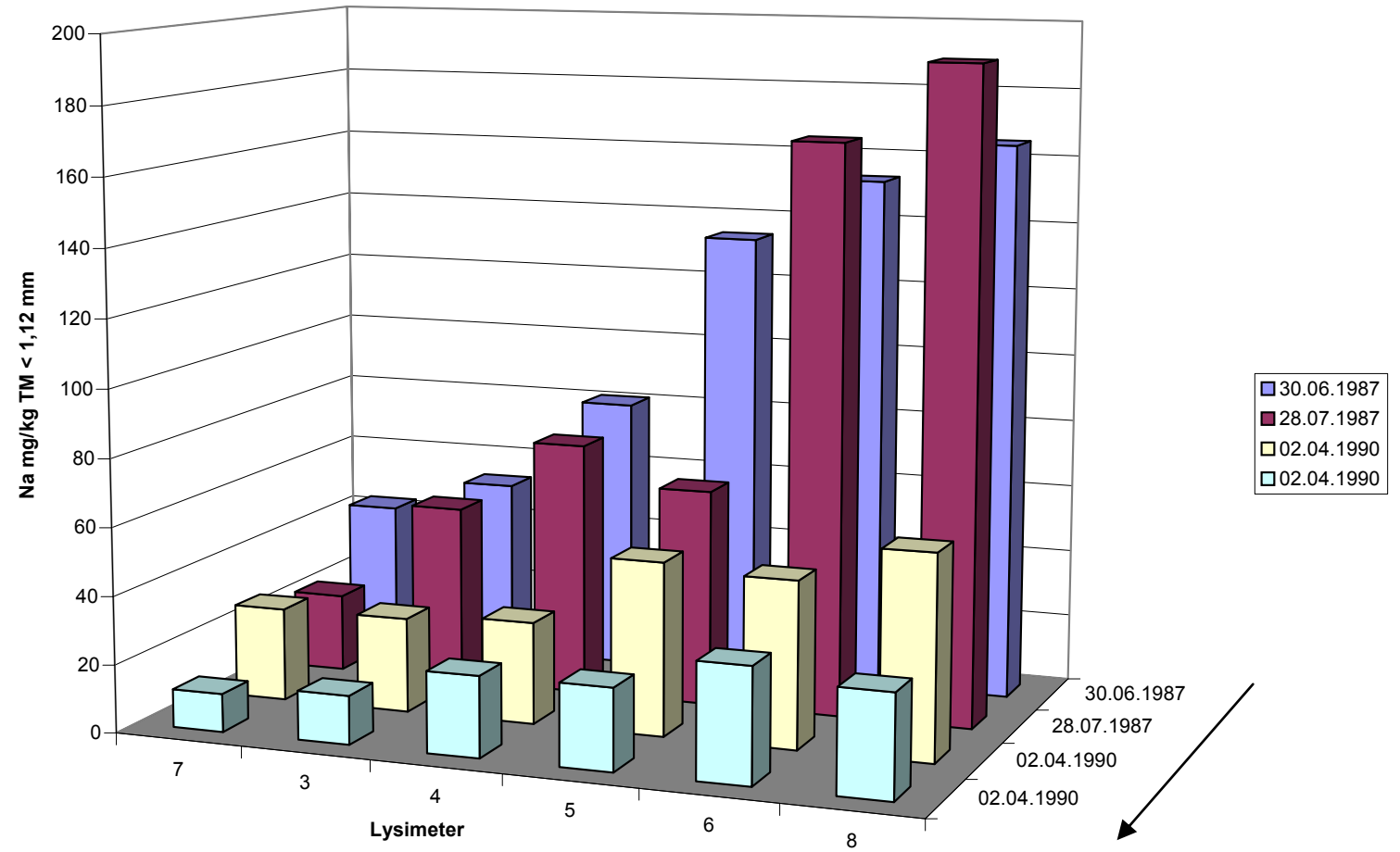

Abbildung 24: Lösliche Natrium-Gehalte im 1:2-

Kompost:Wasser-Extrakt in $\mathrm{mg} / \mathrm{kg} \mathrm{TM}<1,12 \mathrm{~mm}$, Lysimeter

3 - 8, Tiefe $0-30 \mathrm{~cm}$ (bzw. 0 - $20 \mathrm{~cm}$, Lysimeter 7 und 8) 


\subsubsection{Anionen}

\section{Großlysimeter}

Bei den im ersten Untersuchungsjahr im 1:2-Extrakt gemessenen Anionen $\mathrm{Cl}, \mathrm{SO}_{4}$ und $\mathrm{PO}_{4}$ (als $\mathrm{P}$ ) ist für $\mathrm{Cl}$ und $\mathrm{SO}_{4}$ ebenfalls eine starke Abnahme zu verzeichnen. Auch hier sind Verlagerungen in tiefere Kompostschichten erkennbar. Während $\mathrm{Cl}$ nahezu komplett ausgewaschen wird, bleibt bei $\mathrm{SO}_{4}$ eine gewisse Restmenge erhalten, die kontinuierlich nachgeliefert wird. Die Werte für $\mathrm{P}$ steigen während der Freilandversuche im Extrakt an. Lysimeter 1 und 2 erreichen insgesamt ähnliche Werte. Die Anionen wurden nicht durchgängig in allen Extrakten bestimmt.

Die Abbildungen 25 und 26 zeigen die Gehalte der genannten Anionen in den 1:2-Kompost:Wasser-Extrakten für die oberste Lysimeterschicht.

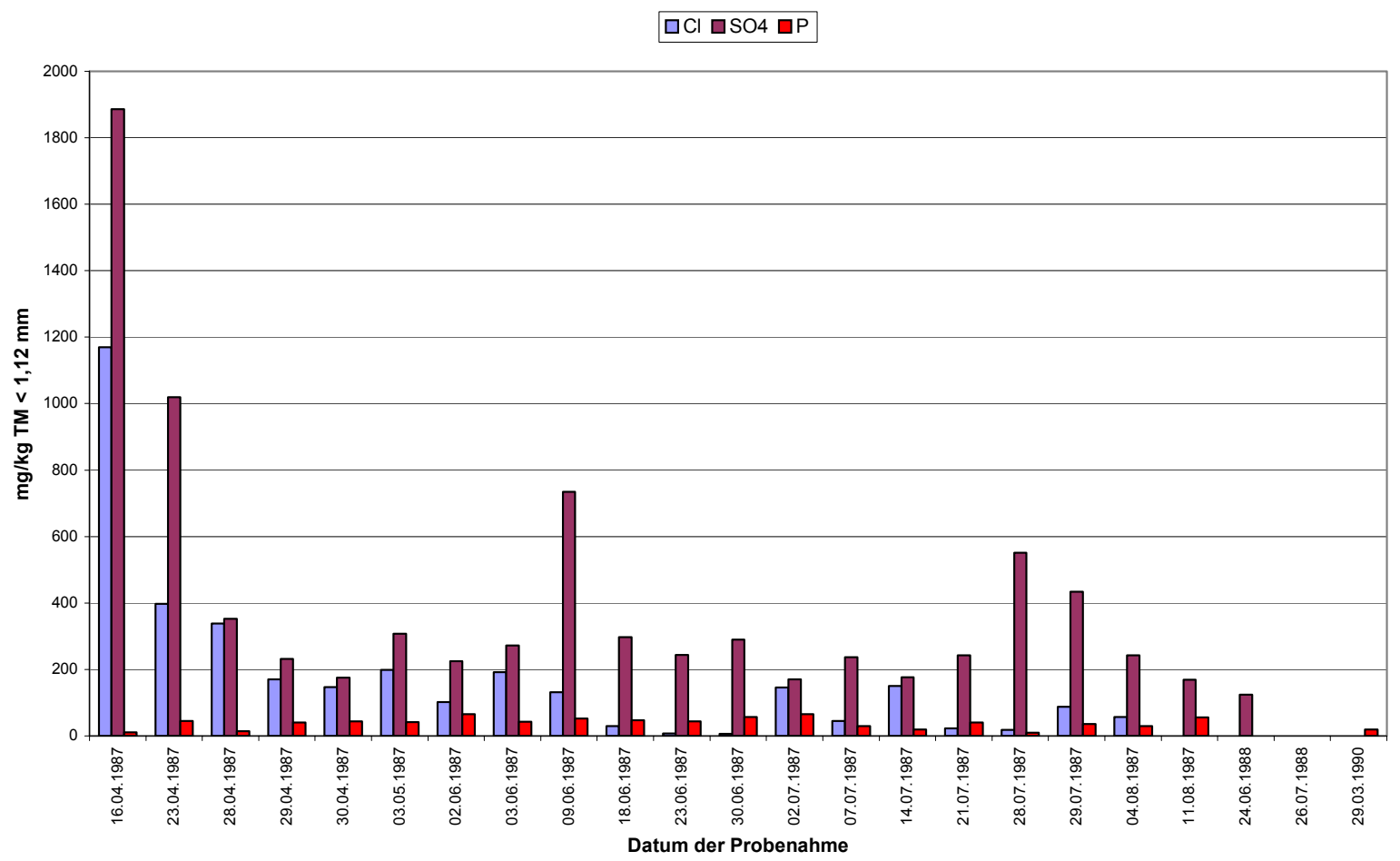


Abbildung 25: Lösliche Anionen-Gehalte im 1:2-

Kompost:Wasser-Extrakt in $\mathrm{mg} / \mathrm{kg}$ TM $<1,12 \mathrm{~mm}$, Lysimeter

1, Tiefe $0-20 \mathrm{~cm}$ (bzw. 0 - $30 \mathrm{~cm}, 29.03 .1990)$

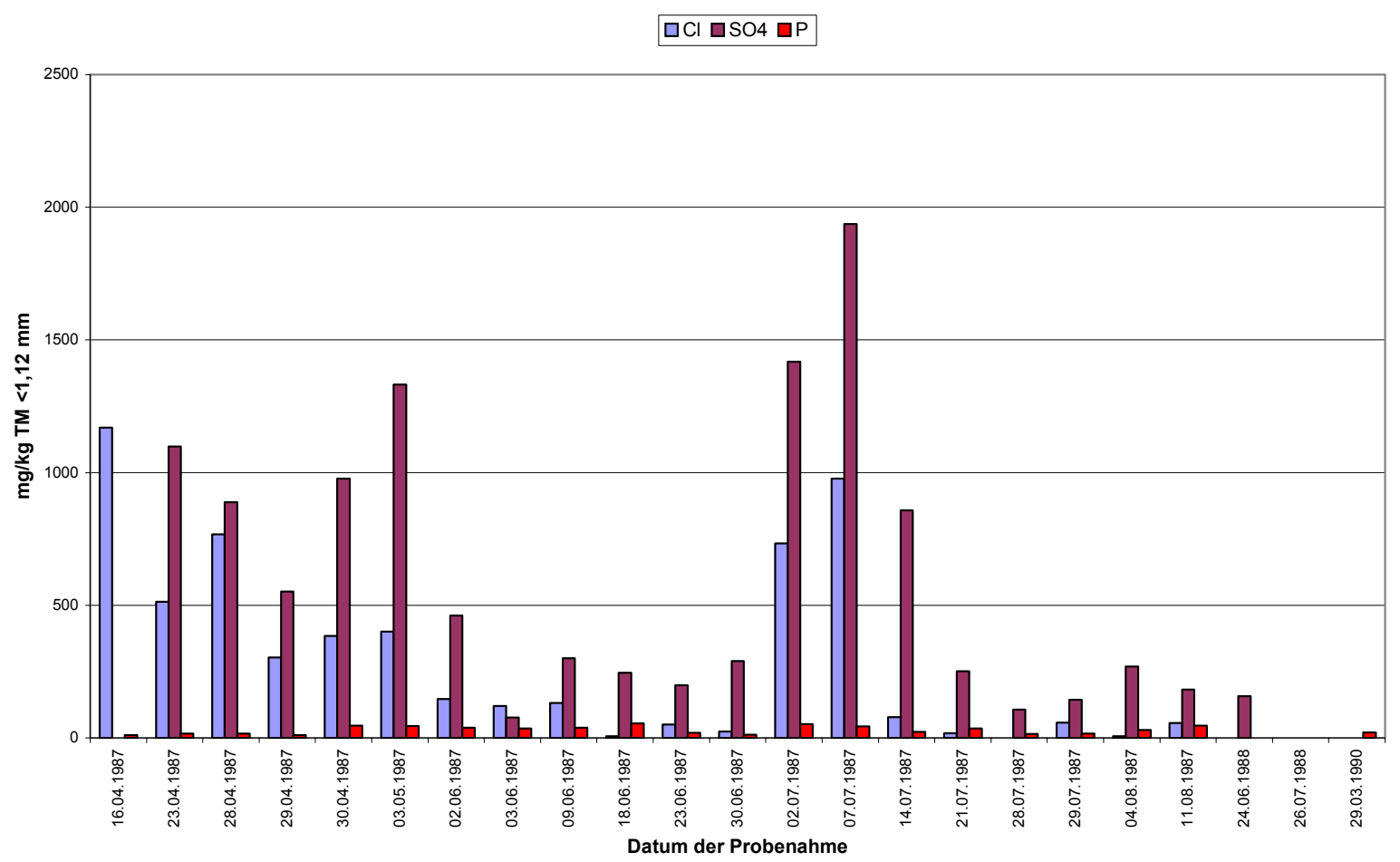

Abbildung 26: Lösliche Anionen-Gehalte im 1:2Kompost:Wasser-Extrakt in $\mathrm{mg} / \mathrm{kg}$ TM $<1,12 \mathrm{~mm}$, Lysimeter 2, Tiefe $0-20 \mathrm{~cm}$ (bzw. 0 - $30 \mathrm{~cm}, 29.03 .1990$ )

Die hohen $\mathrm{SO}_{4}$-Konzentrationen am 02. und 07.07.1987 korrespondieren gut mit den zeitlich entsprechenden K-Werten in Abb. 20. Geht man davon aus, dass es sich hier um Mineralisationsschübe handelt, so sollte das molare Verhältnis $\mathrm{K}: \mathrm{SO}_{4}$ betrachtet werden, das am 02.07. 5,2 und am 07.07. 5,3 beträgt bzw. das Verhältnis $\mathrm{K}: \mathrm{S}$, das 1,74 und 1,75 beträgt.

\section{Kleinlysimeter}

Für die ab 30.06.1987 im Extrakt gemessenen Anionen ist bis auf die N-Verbindungen eine Zunahme der löslichen Gehalte mit zunehmendem Kompostanteil erkennbar. Die $\mathrm{NO}_{3}-\mathrm{N}$ bzw. $\mathrm{N}_{\text {ges }}$-Werte der Mischungsvarianten übertreffen in der Probe vom 02.04.90 die Werte für den reinen Kompost (siehe Tabellen 1-12 bis 1-23 im Anhang). Die $\mathrm{SO}_{4}$-Werte gehen bei den Lysimetern 8, 5, 4 und 3 über die Versuchszeit hinweg zurück, während die Werte bei Lysimeter 3 ansteigen und bei den Lysimetern 6 und 7 etwa gleich bleiben. Die PGehalte steigen zum 2. Probenahmetermin im Juli 1987 hin an und sinken bis zum Versuchsende deutlich ab. Das dominierende Anion in den Extrakten der Kleinlysimeter ist $\mathrm{HCO}_{3}$, gefolgt von $\mathrm{SO}_{4}, \mathrm{PO}_{4}, \mathrm{Cl}$ und $\mathrm{NO}_{3}$. Die Anionen wurden nicht durchgängig in allen Extrakten bestimmt.

Die Abbildungen 27 und 28 zeigen die Sulfat- und P-Gehalte der 1:2-Substrat:WasserExtrakte für die drei Probenahme-Termine. 


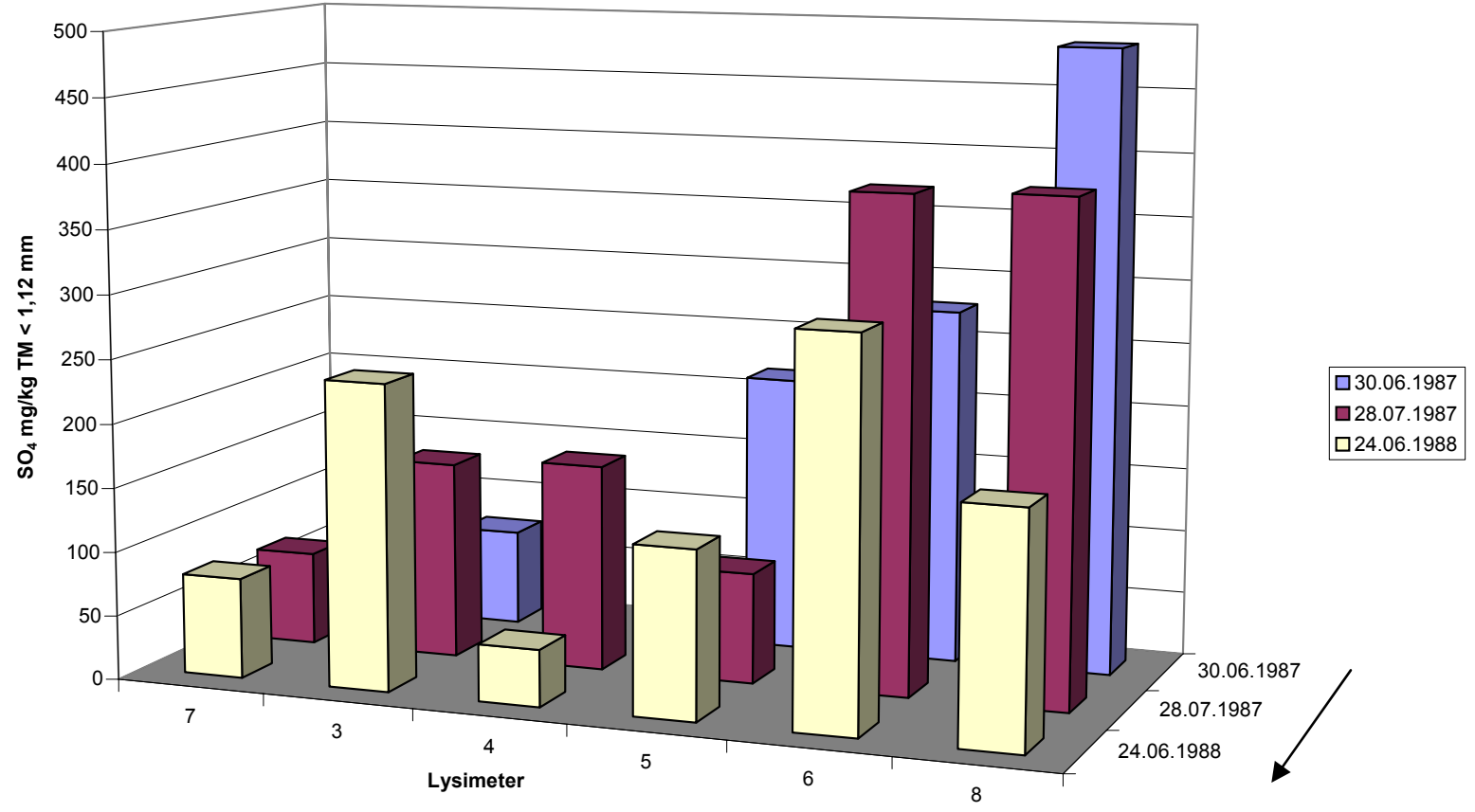

Abbildung 27: Lösliche Sulfat-Gehalte im 1:2-

Kompost:Wasser-Extrakt in $\mathrm{mg} / \mathrm{kg} \mathrm{TM}<1,12 \mathrm{~mm}$, Lysimeter

3 - 8, Tiefe $0-30 \mathrm{~cm}$ (bzw. 0 - $20 \mathrm{~cm}$, Lysimeter 7 und 8)

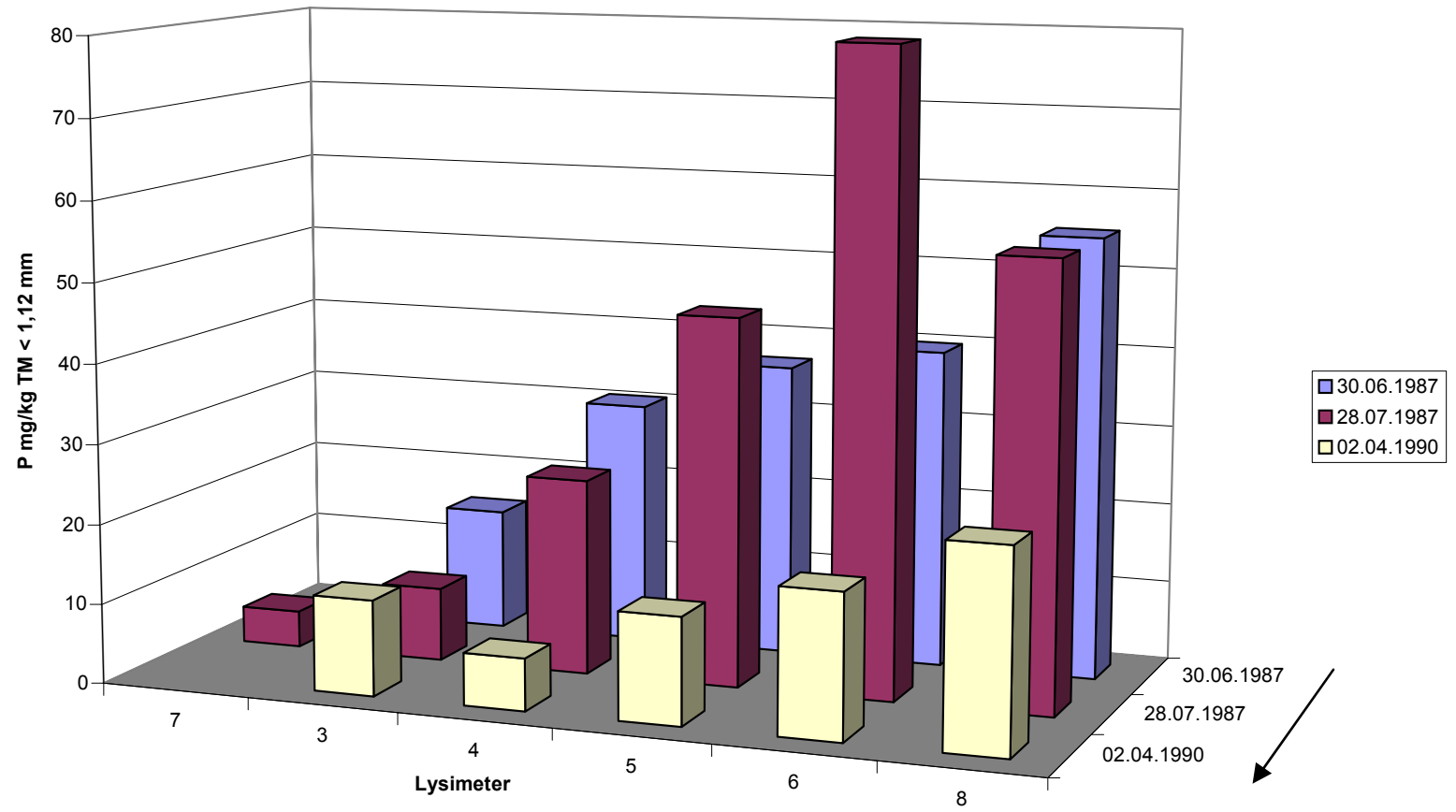

Abbildung 28: Lösliche P-Gehalte im 1:2-Kompost:WasserExtrakt in $\mathrm{mg} / \mathrm{kg} \mathrm{TM}<1,12 \mathrm{~mm}$, Lysimeter $3-8$, Tiefe $0-30$ cm (bzw. 0 - 20 cm, Lysimeter 7 und 8) 


\subsubsection{Kompost-Wasser-Verhältnis}

Großlysimeter

Die Tabelle 5-3 zeigt die in den verschiedenen Extrakten für den Kompost gemessenen Gehalte an gelösten Verbindungen.

Tabelle 5-3: Vergleich der Gehalte an gelösten Verbindungen im 1:2- und im 1:10-Extrakt, Kompost-Ausgangsmaterial (März 1986) und von den Lysimetern 1 und 2, vom 29.03.1990, Mittelwerte über die gesamte Tiefe

\begin{tabular}{|c|c|c|c|c|c|c|c|c|c|c|c|c|c|}
\hline Lysimeter & Probenahme & Serie & K:W-Verhältnis & DOC & $\mathrm{Ca}$ & Mg & K & $\begin{array}{c}\mathrm{Na} \\
\mathrm{mg} / \mathrm{kg}\end{array}$ & $\mathrm{NH}_{4}-\mathrm{N}$ & $\mathrm{HCO}_{3}$ & SO4 & $\mathrm{NO}_{3}-\mathrm{N}$ & $\mathbf{P}$ \\
\hline A 0 & März 1986 & 7 & $1: 2$ & 2827,10 & 463,60 & 148,70 & 1378,90 & 478,70 & 47,80 & 899,60 & 1329,90 & 11,30 & 5,67 \\
\hline A 0 & März 1986 & 7 & $1: 10$ & 3924,10 & 581,00 & 183,20 & 4516,20 & 634,80 & 35,10 & 2167,20 & 1753,80 & 49,20 & 56,06 \\
\hline 1 & 29.03.90 & 4 & $1: 2$ & & 301,80 & 72,59 & 878,77 & 163,27 & & 1629,58 & & 229,71 & 11,68 \\
\hline 1 & 29.03.90 & 5.1 & $1: 10$ & 983,47 & 154,38 & 32,94 & 895,29 & 86,99 & & 958,74 & & 724,78 & 48,01 \\
\hline 1 & 29.03.90 & 5.2 & $1: 10$ & & 110,23 & 19,74 & 692,52 & 61,21 & & 980,44 & & 446,98 & 24,23 \\
\hline 2 & 29.03 .90 & 4 & $1: 2$ & & 293,96 & 69,72 & 1002,55 & 193,75 & & 1722,56 & & 43,70 & 11,77 \\
\hline 2 & 29.03.90 & 5.1 & $1: 10$ & 983,67 & 137,78 & 29,21 & 1005,58 & 100,06 & & 958,74 & & 174,58 & 40,80 \\
\hline 2 & 29.03.90 & 5.2 & $1: 10$ & & 101,99 & 19,74 & 726,33 & 70,97 & & 1093,84 & & 112,19 & 20,51 \\
\hline
\end{tabular}

Während bei dem Kompost-Ausgangmaterial vom März 1986 die Erhöhung der Lösemittelmenge von 1:2 auf 1:10 zu einer Erhöhung der gelösten Menge an Salzen führt, sinken bei der Probe vom 29.03.90 die extrahierbaren Gehalte in $\mathrm{mg} / \mathrm{kg}$ TM im 1:10-Extrakt gegenüber dem 1:2-Extrakt ab.

In den Abbildungen 29, 30 und 31 sind die auf die TM bezogenen Gehalte für den 1:2- und den 1:10-Extrakt dargestellt.

Im Kompost-Ausgangsmaterial steigen bis auf $\mathrm{NH}_{4}-\mathrm{N}$ alle Werte für den 1:10-Extrakt an. Besonders hohe Steigerungen lassen sich für $\mathrm{P}$ (Faktor 9,9), $\mathrm{NO}_{3}-\mathrm{N}$ (Faktor 4,4), $\mathrm{K}$ (Faktor 3,3 ) und $\mathrm{HCO}_{3}$ (Faktor 2,4) erzielen. Der DOC steigt um $39 \%$ an. Die Werte für Ammonium sinken im 1:10-Extrakt um etwa $30 \%$ gegenüber dem 1:2-Extrakt.

Bei den beiden Großlysimetern sind durch das weitere Extraktionsverhältnis nur noch $\mathrm{NO}_{3}$ $\mathrm{N}$ und $\mathrm{P}$ vermehrt extrahiert. Die Gehalte für $\mathrm{HCO}_{3}, \mathrm{Na}, \mathrm{Mg}$ und $\mathrm{Ca}$ sinken, die KaliumWerte bleiben konstant. 


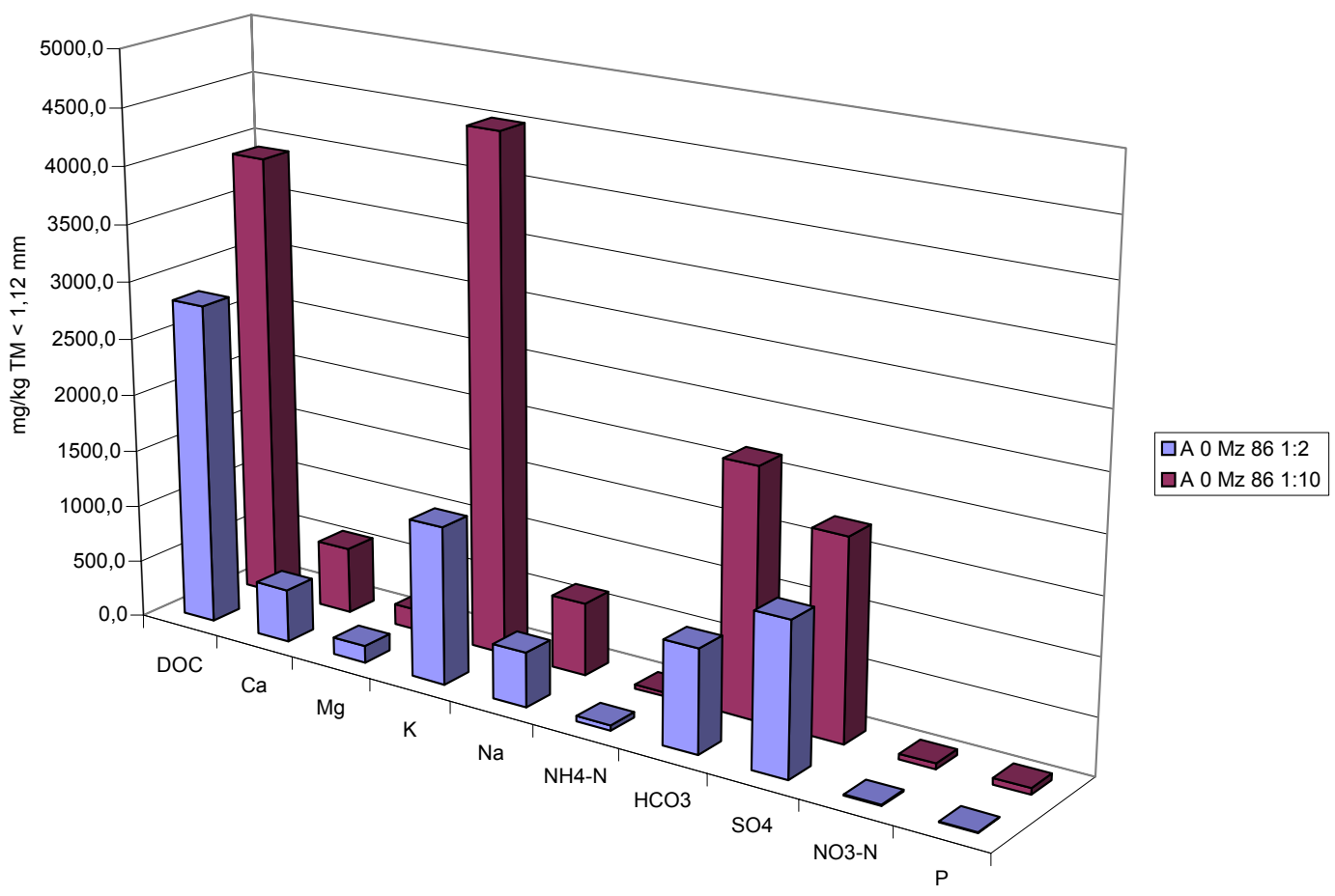

Abbildung 29: Vergleich gelöster Verbindungen in $\mathrm{mg} / \mathrm{kg}$ $\mathrm{TM}<1,12 \mathrm{~mm}$ im 1:10 und 1:2-Kompost:Wasser-Extrakt, Kompost-Ausgangsmaterial vom März 1986 (t-m-s)

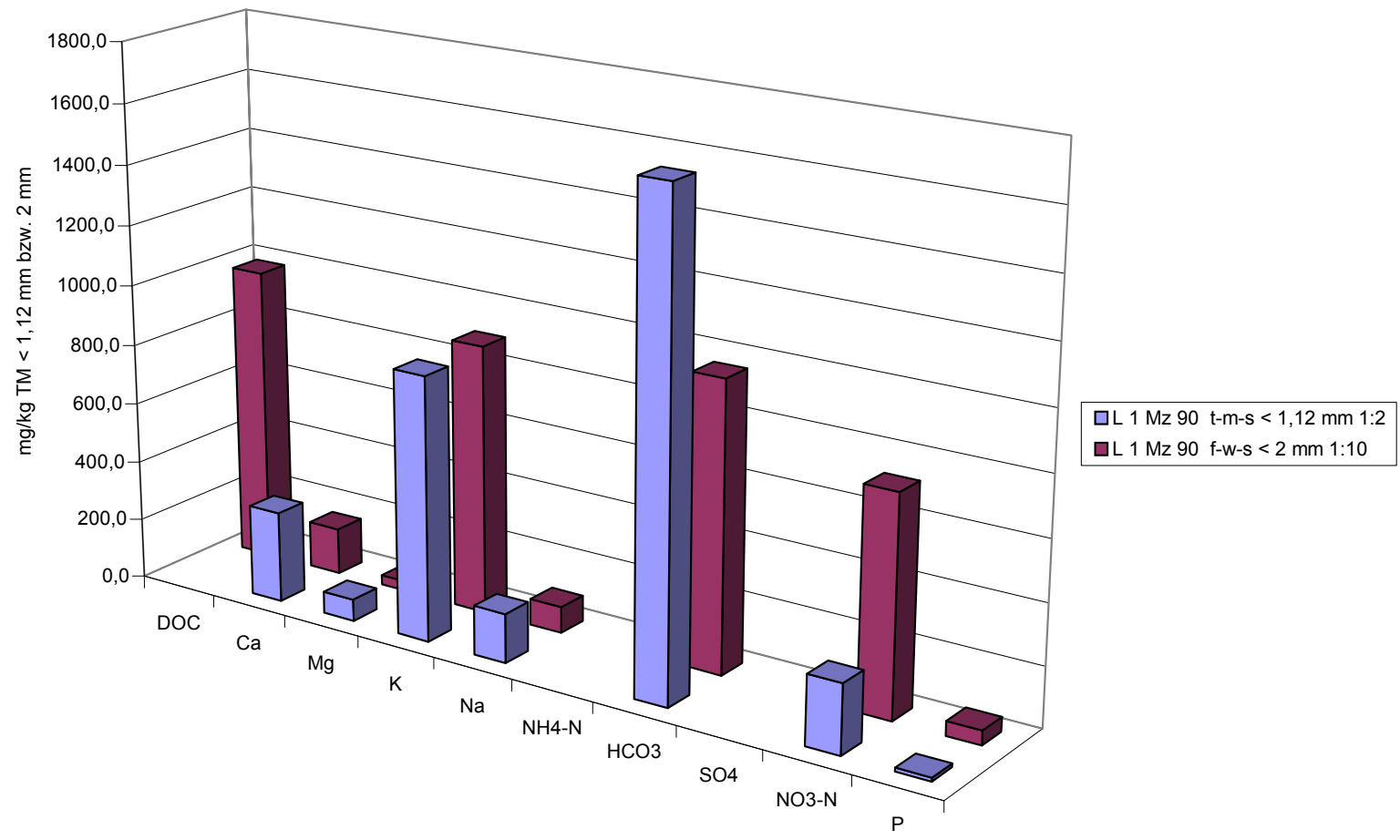

Abbildung 30: Vergleich gelöster Verbindungen in $\mathrm{mg} / \mathrm{kg}$ TM $<1,12$ bzW. $<2$ mm im 1:10-Kompost:Wasser-Extrakt (fw-s) und 1:2-Kompost:Wasser-Extrakt (t-m-s), Probe vom 29.03.1990, Lysimeter 1 


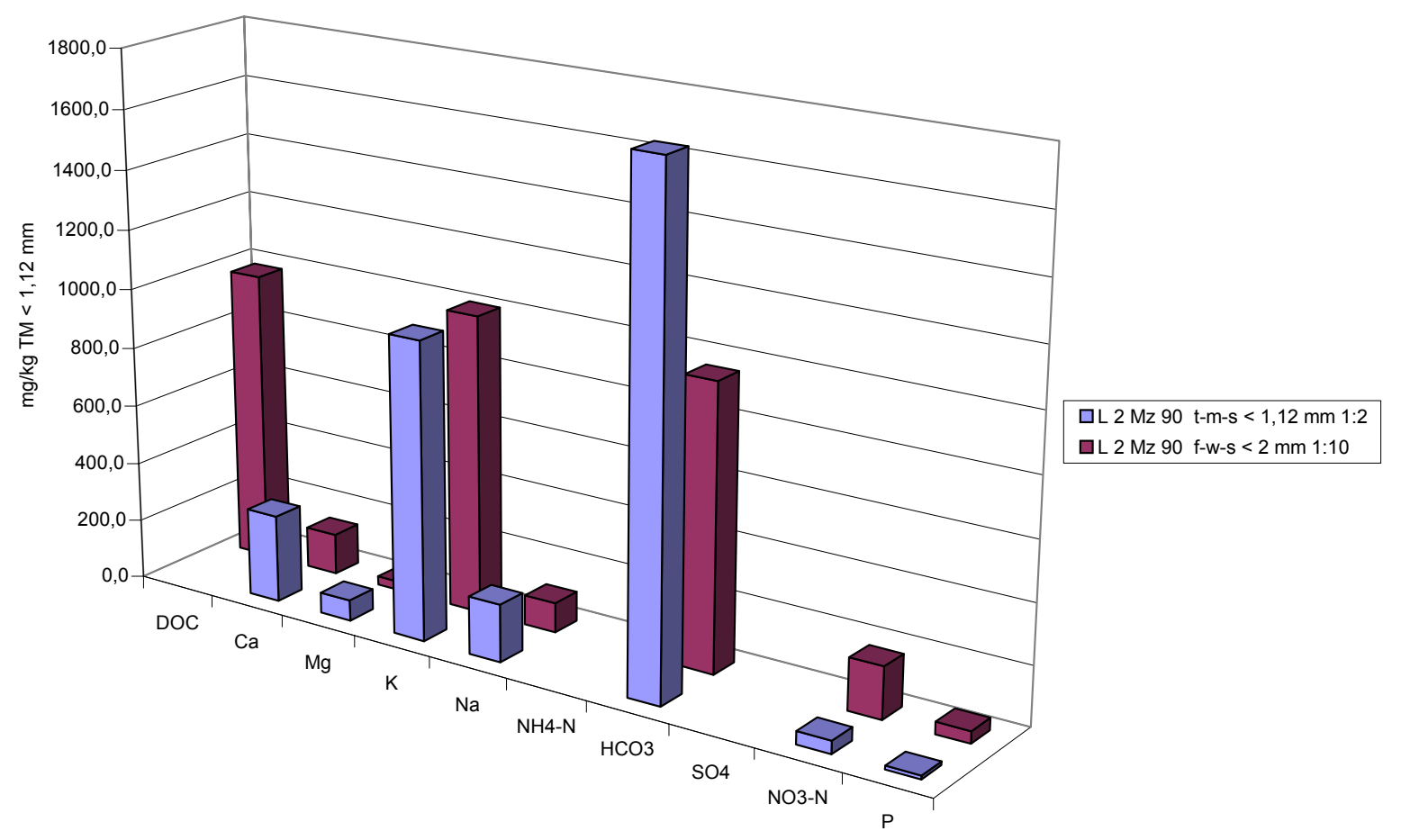

Abbildung 31: Vergleich gelöster Verbindungen in $\mathrm{mg} / \mathrm{kg}$ TM $<1,12$ bzw. $<2$ mm im 1:10-Kompost:Wasser-Extrakt (fw-s) und 1:2-Kompost:Wasser-Extrakt (t-m-s), Probe vom 29.03.1990, Lysimeter 2

\section{Kleinlysimeter}

Im 1:10-Extrakt sind die Gehalte für $\mathrm{Ca}, \mathrm{Mg}, \mathrm{DOC}$ und $\mathrm{HCO}_{3}$ kleiner als im 1:2-Extrakt und die Gehalte für $\mathrm{Na}, \mathrm{K}, \mathrm{N}$ und $\mathrm{P}$ größer als im 1:2-Extrakt. Die N- und P-Gehalte sind in den luftgetrockneten Proben im 1:10-Extrakt deutlich höher als im 1:2-Extrakt. Für $\mathrm{Cl}$ und $\mathrm{SO}_{4}$ liegen keine Vergleichswerte vor.

In den Abbildungen $32-39$ werden die beiden Extraktionsvarianten 1:2 (t-m-s $<1,12 \mathrm{~mm}$ ) und 1:10 (f-w-s < 2mm) für die Lysimeter 8, 6, 5 und 4 der Probe vom 02.04.1990 dargestellt. 


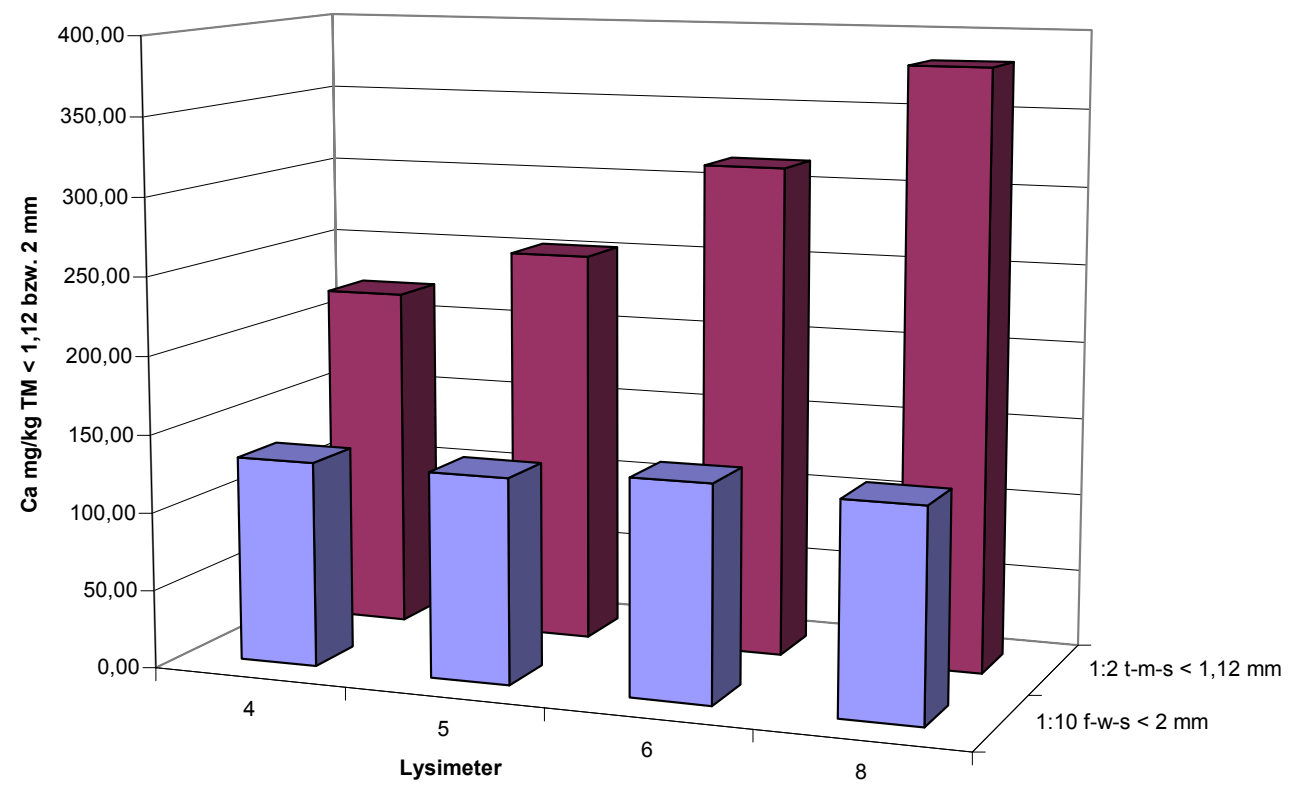

$\square 1: 10 \mathrm{f}-\mathrm{w}-\mathrm{s}<2 \mathrm{~mm}$ $\square 1: 2 \mathrm{t}-\mathrm{m}-\mathrm{s}<1,12 \mathrm{~mm}$

Abbildung 32: Vergleich gelöster Calcium-Gehalte in $\mathrm{mg} / \mathrm{kg}$ TM $<1,12$ bzW. $<2$ mm im 1:10-Kompost:Wasser-Extrakt (fw-s) und 1:2-Kompost:Wasser-Extrakt (t-m-s), Proben vom 02.04.1990, Lysimeter 4, 5, 6 und 8

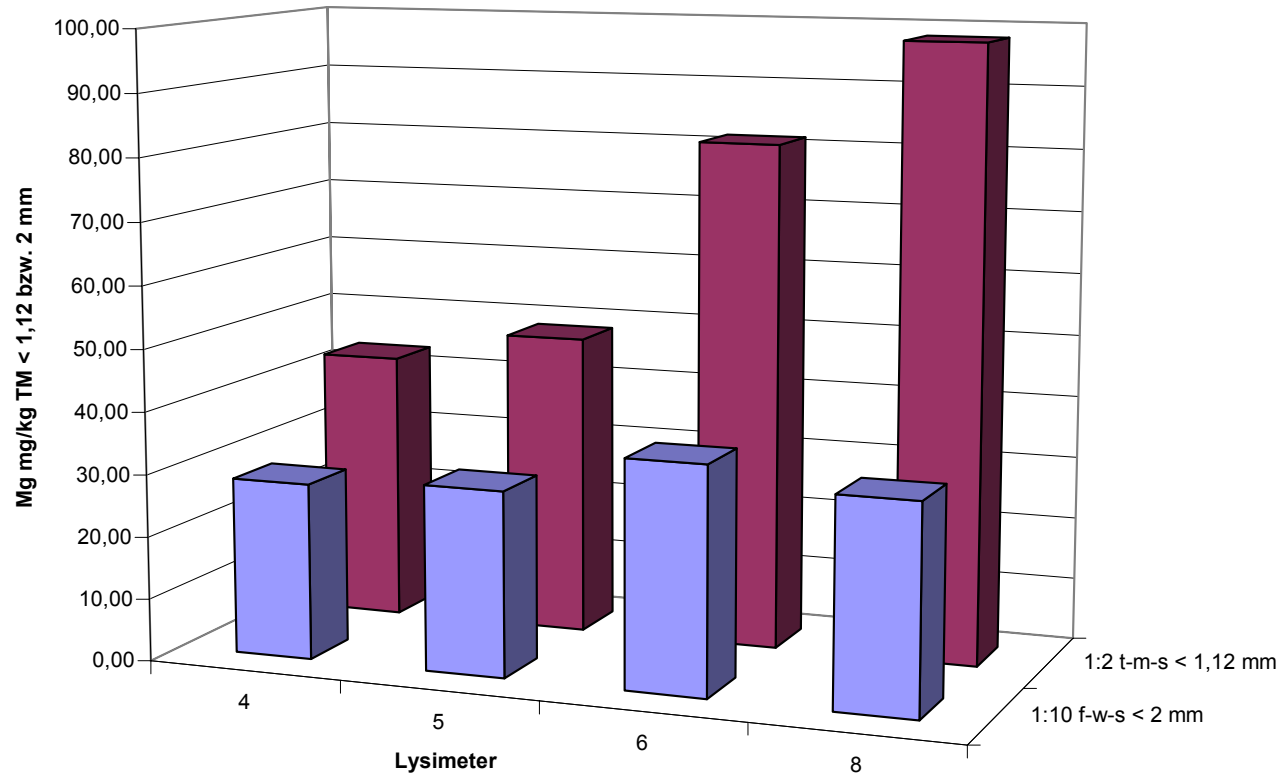

Abbildung 33: Vergleich gelöster Magnesium-Gehalte in $\mathrm{mg} / \mathrm{kg}$ TM $<1,12$ bzw. $<2$ mm im 1:10-Kompost:WasserExtrakt (f-w-s) und 1:2-Kompost:Wasser-Extrakt (t-m-s), Proben vom 02.04.1990, Lysimeter 4, 5, 6 und 8 


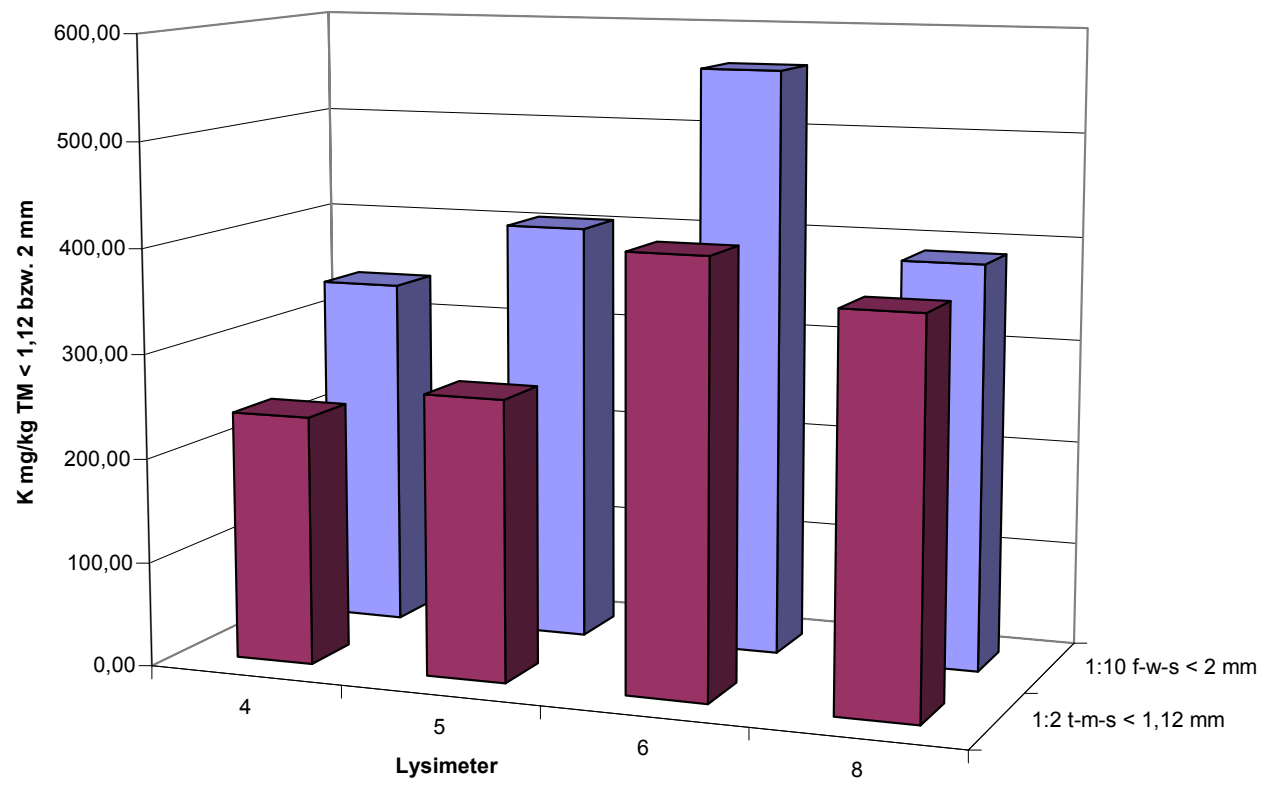

$\square 1: 10 \mathrm{f}-\mathrm{w}-\mathrm{s}<2 \mathrm{~mm}$ $\square 1: 2 \mathrm{t}-\mathrm{m}-\mathrm{s}<1,12 \mathrm{~mm}$

Abbildung 34: Vergleich gelöster Kalium-Gehalte in $\mathrm{mg} / \mathrm{kg}$ TM $<1,12$ bzw. $<2$ mm im 1:10-Kompost:Wasser-Extrakt (fw-s) und 1:2-Kompost:Wasser-Extrakt (t-m-s), Proben vom 02.04.1990, Lysimeter 4, 5, 6 und 8

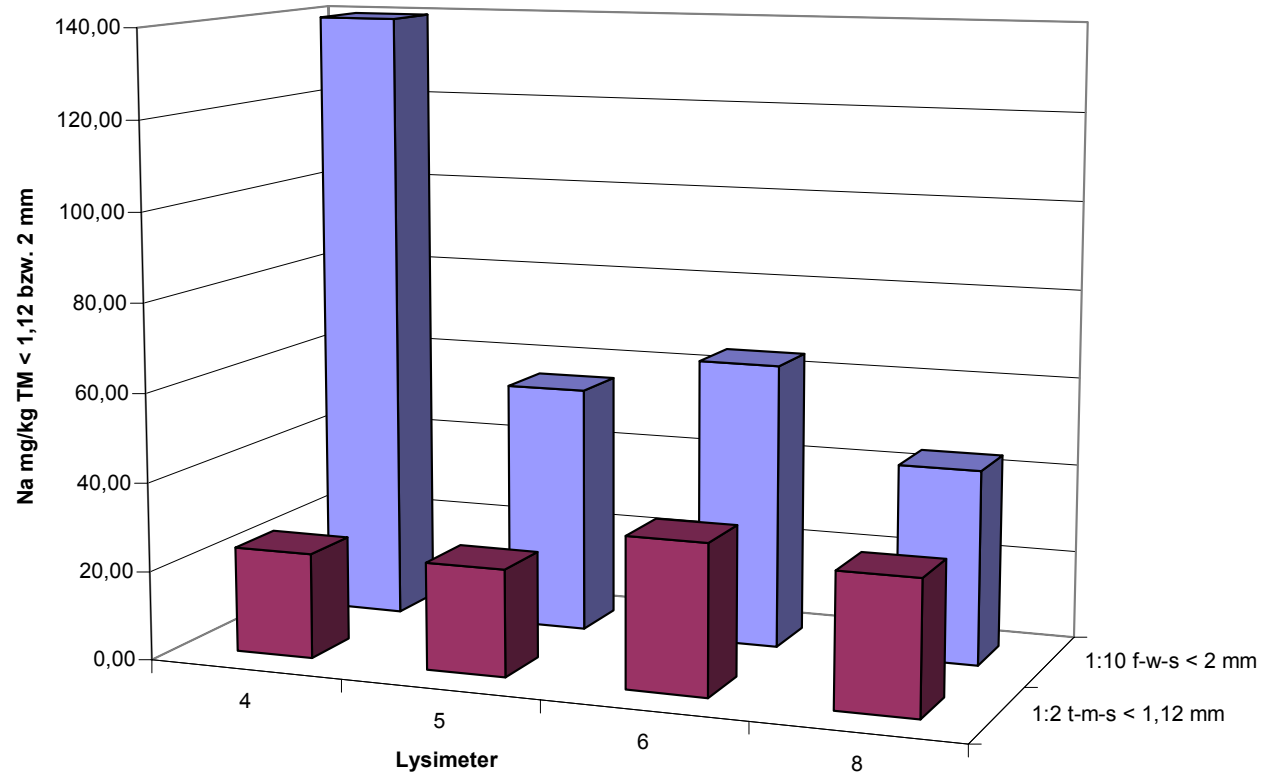

Abbildung 35: Vergleich gelöster Natrium-Gehalte in $\mathrm{mg} / \mathrm{kg}$ TM $<1,12$ bzw. $<2$ mm im 1:10-Kompost:Wasser-Extrakt (fw-s) und 1:2-Kompost:Wasser-Extrakt (t-m-s), Proben vom 02.04.1990, Lysimeter 4, 5, 6 und 8 


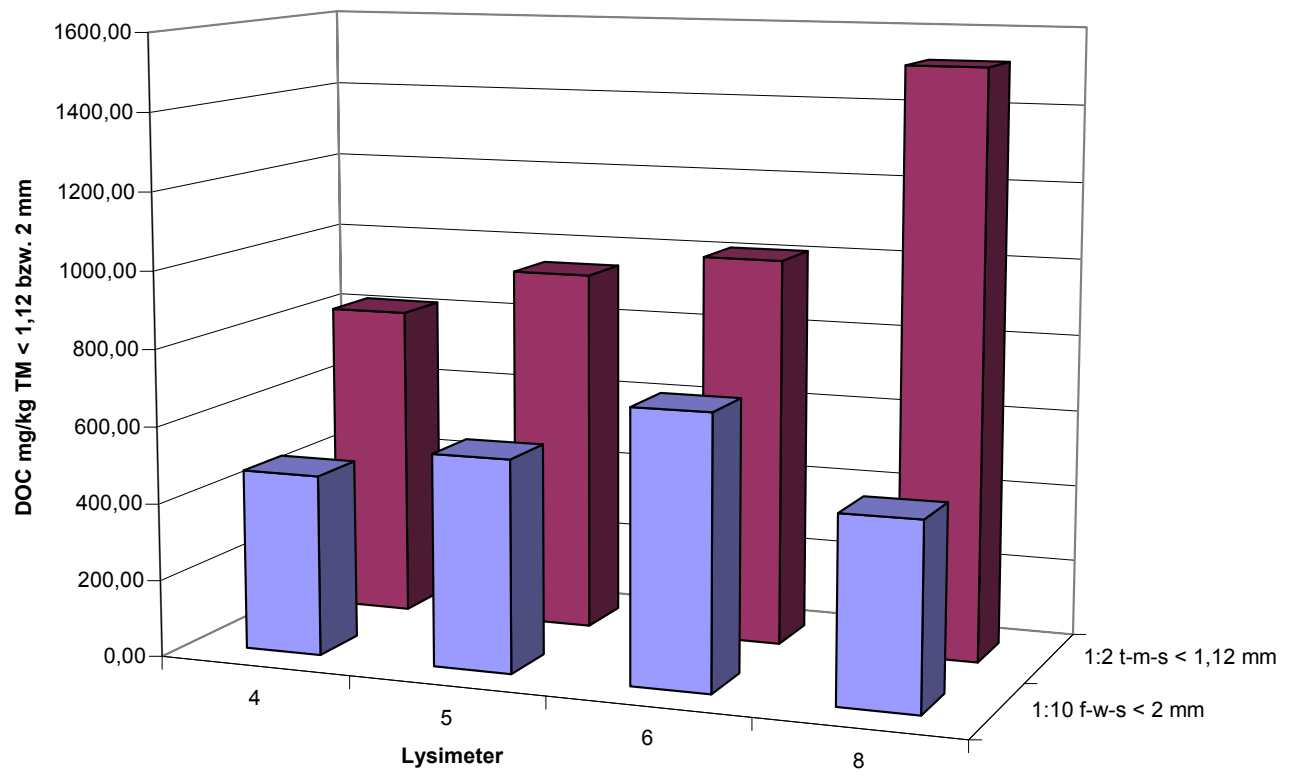

$\square 1: 10 \mathrm{f}-\mathrm{w}-\mathrm{s}<2 \mathrm{~mm}$ $\square 1: 2 \mathrm{t}-\mathrm{m}-\mathrm{s}<1,12 \mathrm{~mm}$

Abbildung 36: Vergleich gelöster DOC-Gehalte in $\mathrm{mg} / \mathrm{kg}$ TM $<1,12$ bzw. < 2 mm im 1:10-Kompost:Wasser-Extrakt (f-w-s) und 1:2-Kompost:Wasser-Extrakt (t-m-s), Proben vom 02.04.1990, Lysimeter 4, 5, 6 und 8

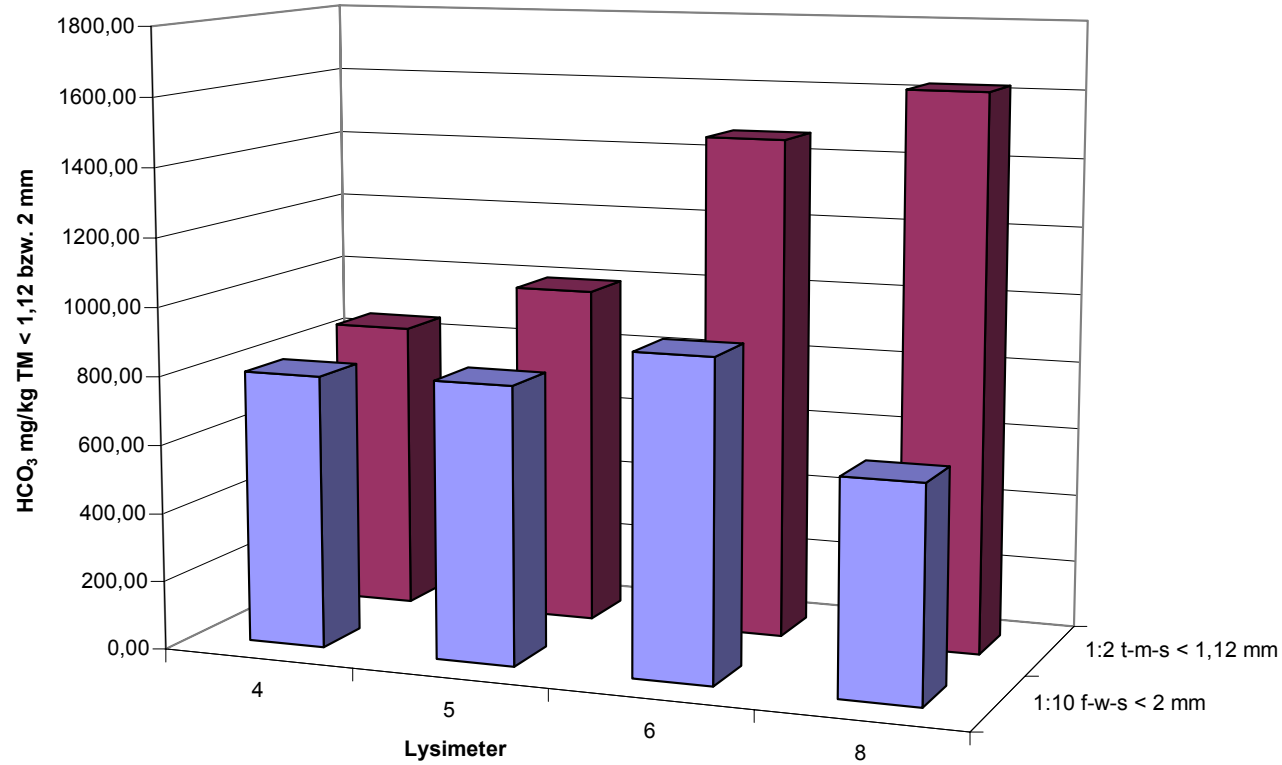

Abbildung 37: Vergleich gelöster $\mathrm{HCO}_{3}$-Gehalte in $\mathrm{mg} / \mathrm{kg} \mathrm{TM}$ $<1,12$ bzw. $<2$ mm im 1:10-Kompost:Wasser-Extrakt (f-w-s) und 1:2-Kompost:Wasser-Extrakt (t-m-s), Proben vom 02.04.1990, Lysimeter 4, 5, 6 und 8 


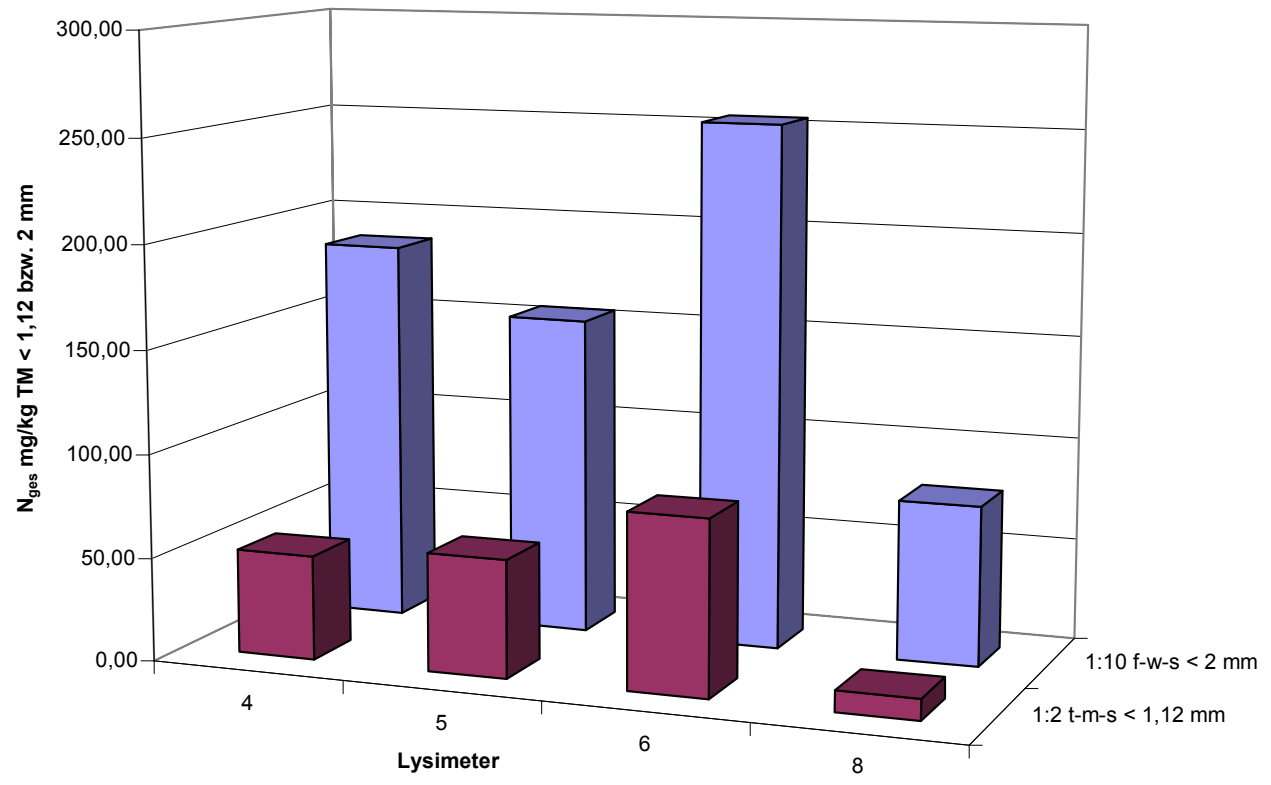

$\square 1: 10 \mathrm{f}-\mathrm{w}-\mathrm{s}<2 \mathrm{~mm}$ $\square 1: 2 \mathrm{t}-\mathrm{m}-\mathrm{s}<1,12 \mathrm{~mm}$

Abbildung 38: Vergleich gelöster $\mathrm{N}_{\text {ges }}$-Gehalte in $\mathrm{mg} / \mathrm{kg}$ TM $<1,12$ bzw. < 2 mm im 1:10-Kompost:Wasser-Extrakt (f-w-s) und 1:2-Kompost:Wasser-Extrakt (t-m-s), Proben vom 02.04.1990, Lysimeter 4, 5, 6 und 8

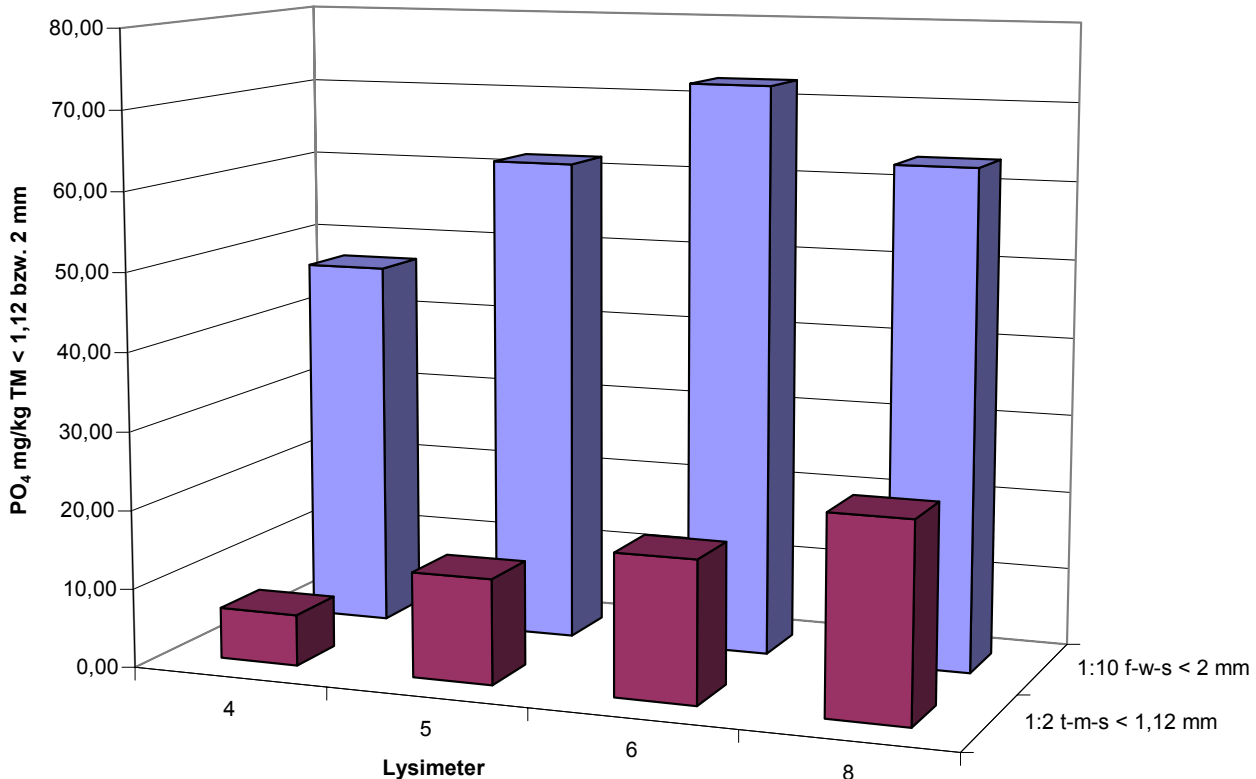

Abbildung 39: Vergleich gelöster P-Gehalte in $\mathrm{mg} / \mathrm{kg} \mathrm{TM} \mathrm{<}$ 1,12 bzw. < 2 mm im 1:10-Kompost:Wasser-Extrakt (f-w-s) und 1:2-Kompost:Wasser-Extrakt (t-m-s), Proben vom 02.04.1990, Lysimeter 4, 5, 6 und 8 
Die 8 Abbildungen 32 - 39 stellen die mit Wasser extrahierten Proben dar und zwar:

- beim Extraktionsverhältnis 1:2 der getrockneten(t), gemörserten $(m)$ und gesiebten Substanz und

- beim Extraktionsverhältnis 1:10 der frischen (f), mit der Walze zerdrückten (w) und gesiebten Substanz

an den Kleinlysimetern 4, 5 und 6 mit Löss/Kompost-Mischung und dem reinen Kompost (8) zum Beprobungstermin 02.04.1990 für $\mathrm{Ca}, \mathrm{Mg}, \mathrm{K}, \mathrm{Na}, \mathrm{DOC}, \mathrm{HCO}_{3}, \mathrm{~N}_{\text {ges }}$ und $\mathrm{P}$.

Der Vergleich der Wirkung der Vorbehandlungsmethoden 1:2 mit Trocknung und 24 stündiger Extraktionszeit gegenüber 1:10 ohne Trocknung und nur 1 stündiger Extraktionszeit zeigt Folgendes: Bei $\mathrm{Ca}, \mathrm{Mg}$, DOC und $\mathrm{HCO}_{3}$ bringt der Trocknungsvorgang mehr an Substanz in Lösung, bei $\mathrm{K}, \mathrm{Na}, \mathrm{N}_{\text {ges }}$ und $\mathrm{P}$ das Belassen in frischem Zustand bei weitem Extraktionsverhältnis. Bei den ersten vier genannten lonen und DOC steigt die extrahierte Menge mit der Zunahme des Kompostanteils in der Lysimeterfüllung von Lysimeter 4 bis 8. Bei fast allen Frischsubstanz-Extraktionen tritt das lössarme Lysimeter 6 mit höheren Werten als das mit reinem Kompost gefüllte Lysimeter 8 hervor. Dies ist besonders in der 2. Gruppe, $\mathrm{K}, \mathrm{Na}, \mathrm{N}_{\text {ges }}$ und $\mathrm{P}$, deutlich.

\subsubsection{Mehrfachextraktionen}

Bei der Durchführung einer zweiten direkt auf die erste folgenden Extraktion zeigt sich, dass weiterhin beträchliche Mengen an Salzen und organischer Substanz extrahierbar sind, aber die in Lösung zu bringenden Konzentrationen überwiegend unter denen der ersten Extraktion liegen. Bei der ersten Extraktion wird also nur ein Teil der vorhandenen Salze in Lösung gebracht. Durch eine nachfolgende Extraktion werden weiterhin Salze entsprechend ihrer Löslichkeit in Lösung gebracht bzw. aus anderen Bindungsformen in die Lösung abgegeben. Hinsichtlich der Lösungsmechanismen ist bei der zweiten Extraktion die Vorquellung der Probe zu berücksichtigen.

\section{Großlysimeter}

Bis auf die DOC- und die $\mathrm{HCO}_{3}$-Konzentrationen sinken die Werte in den 2. Extrakten der Lysimeter 1 und 2 ab. Die Unterschiede nehmen in einigen Fällen mit zunehmender Bodentiefe zu, wie das Beispiel für Kalium, Lysimeter 1, Probe vom 24.06.88, 1:2-Extrakt, t-m-s < $1,12 \mathrm{~mm}$, in Abbildung 40 zeigt.

Der Rückgang der lösbaren Salze drückt sich auch in der Abnahme der Leitfähigkeit beispielsweise im 1:10-Extrakt der Probe vom 29.03.1990 für Lysimeter 1 von 0,20 auf 0,16 und von 0,30 auf 0,22 bzw. für Lysimeter 2 von 0,20 auf 0,17 und von 0,34 auf 0,23 aus. In Abbildung 41 sind entsprechend für Lysimeter 2 die Leitfähigkeitswerte in $\mathrm{mS} / \mathrm{cm}$ im 1:2Kompost:Wasser-Extrakt der Probe vom 24.06.88 (t-m-s < 1,12 mm) abgebildet. 


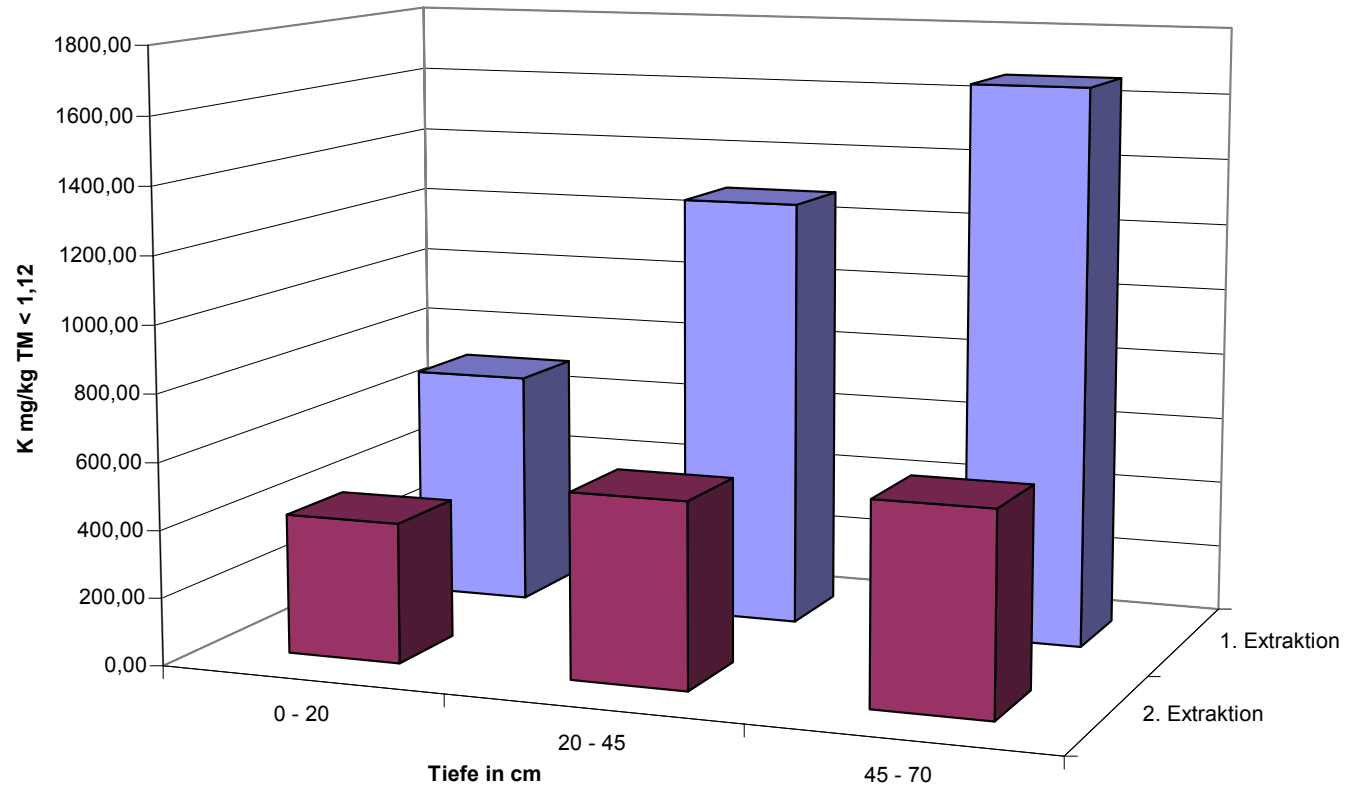

口1. Extraktion

⒉ Extraktion

Abbildung 40: Gelöste Kalium-Gehalte im ersten und zweiten Extrakt der Proben vom 24.06.88, 1:2-Extrakt, t-m-s < $1,12 \mathrm{~mm}$, Lysimeter 1

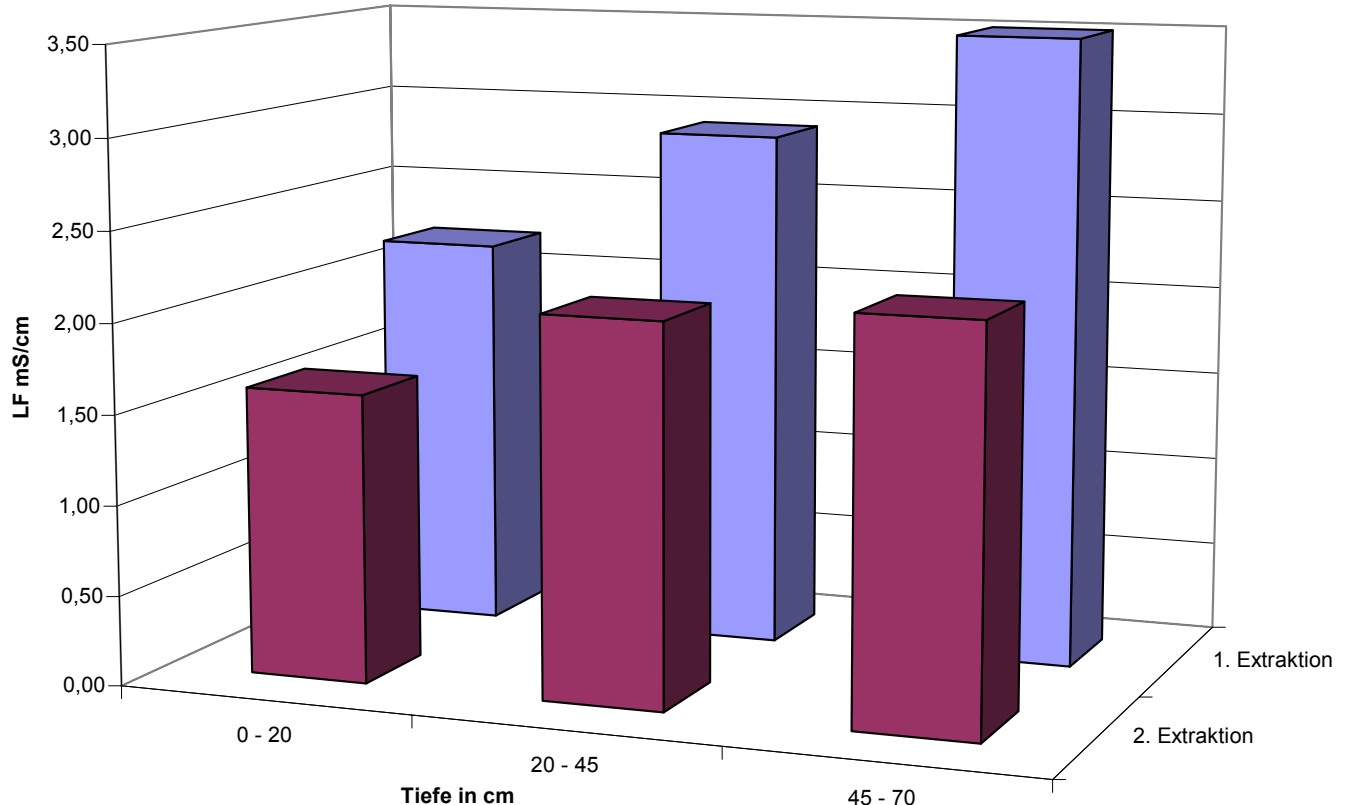

Abbildung 41: Leitfähigkeit im ersten und zweiten Extrakt der Proben vom 24.06.88, 1:2-Extrakt, t-m-s < 1,12 mm, Lysimeter 2 
Beim DOC und $\mathrm{HCO}_{3}$ liefert die zweite Extraktion gemäß Abbildung 42 und 43 für Lysimeter 1 im 1:2-Kompost:Wasser-Extrakt der Probe vom 24.06.88 höhere Werte als im ersten Extraktionsgang. 


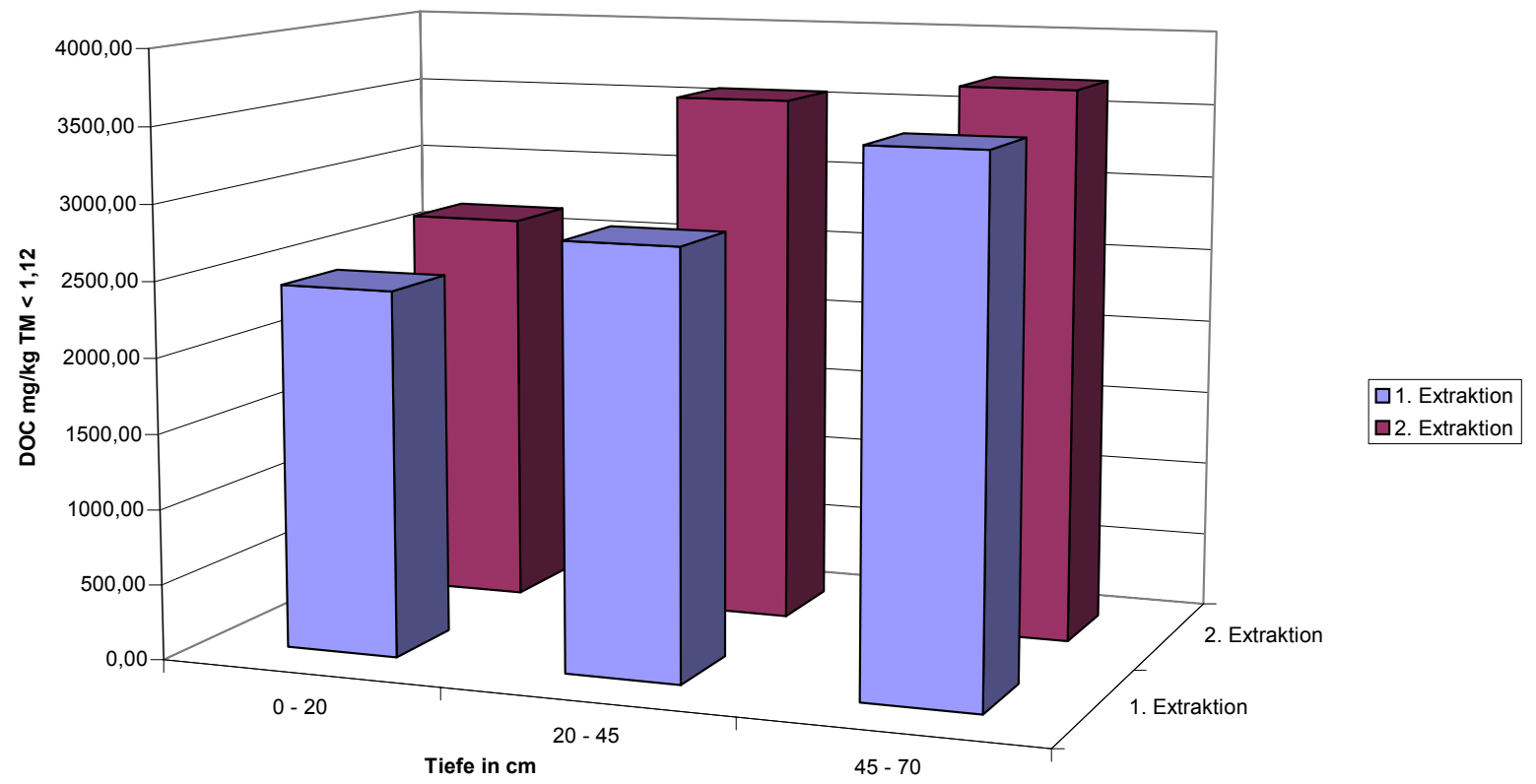

Abbildung 42: Gelöste DOC-Gehalte im ersten und zweiten Extrakt der Proben vom 24.06.88, 1:2-Extrakt, t-m-s < 1,12 $\mathrm{mm}$, Lysimeter 1

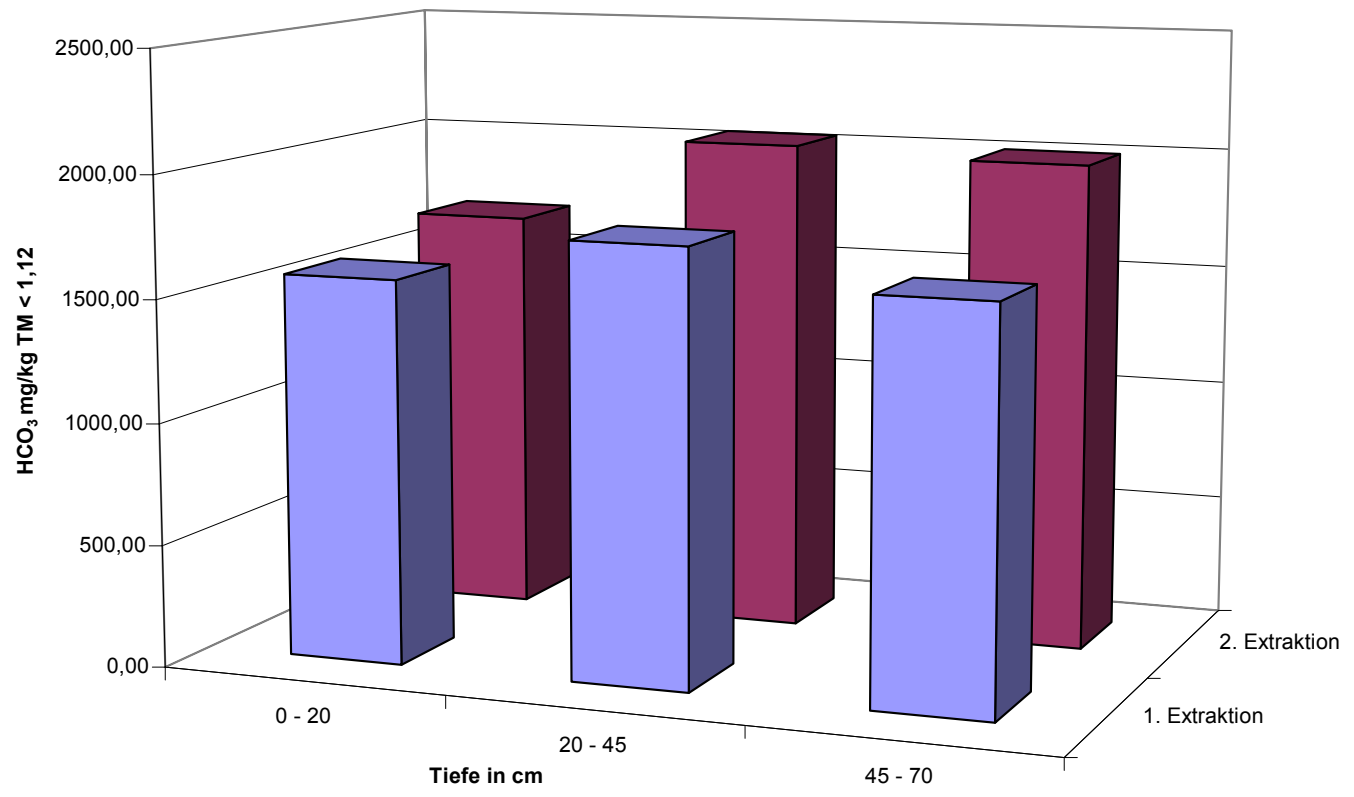

Abbildung 43: Gelöste $\mathrm{HCO}_{3}$-Gehalte im ersten und zweiten Extrakt der Proben vom 24.06.88, 1:2-Extrakt, t-m-s < 1,12 $\mathrm{mm}$, Lysimeter 2 


\section{Kleinlysimeter}

Bei den Mehrfachextraktionen der Kleinlysimeter-Füllungen zeigt sich, dass die Elementgehalte in der zweiten Extraktionslösung für die Kationen $\mathrm{Ca}$, $\mathrm{Na}$ (mit Ausnahme von Lysimeter 3) und $\mathrm{K}, \mathrm{DOC}$ und $\mathrm{N}_{\text {ges }}$ zurückgehen. Hiervon abweichend nehmen die gelösten $\mathrm{Ca}-$ und Na-Gehalte bei Lysimeter 3 im zweiten Extrakt zu. Die Mg-Gehalte verändern sich von der ersten zur zweiten Extraktion kaum. Die $\mathrm{HCO}_{3}$-Gehalte nehmen - wie bei den Großlysimetern - von der ersten zur zweiten Extraktion zu. Bei den übrigen Anionen ist für $\mathrm{SO}_{4}$ bei $L 8$ und $L 4$, für $\mathrm{Cl}$ bei $\mathrm{L} 4$ und für $\mathrm{PO}_{4}$ bei $\mathrm{L} 8$ eine Zunahme von der ersten zur zweiten Extraktion festzustellen während bei den übrigen Lysimetern die Gehalte abnehmen.

Die Abbildungen 44 - 46 zeigen für die Proben der Kleinlysimeter vom 24.06.88die Gehalte an gelösten $\mathrm{Ca}, \mathrm{HCO}_{3}$ und $\mathrm{DOC}$ in $\mathrm{mg} / \mathrm{kg} \mathrm{TM}<1,12 \mathrm{~mm}$ im 1. und 2. Extrakt. 


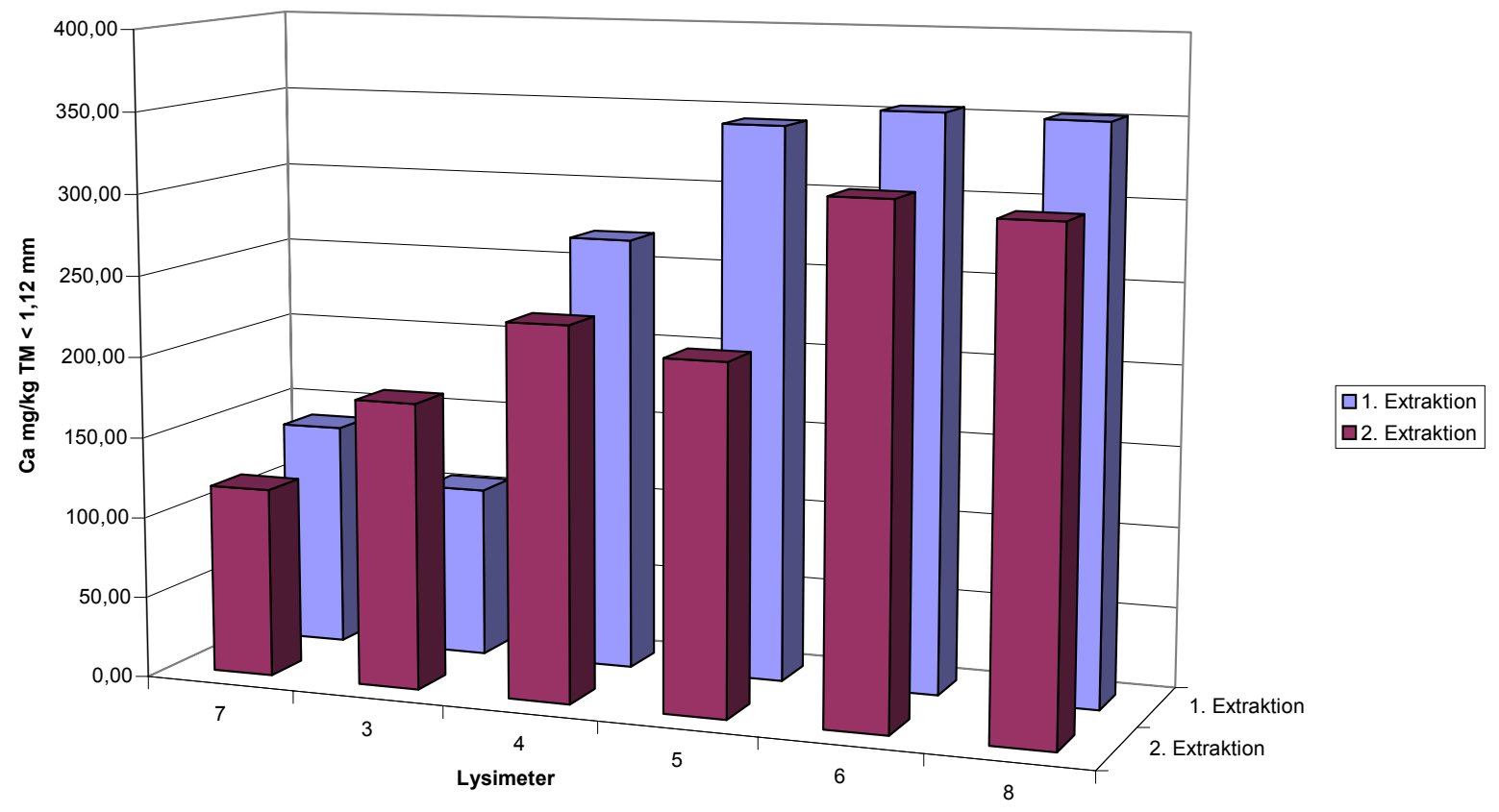

Abbildung 44: Gelöste Ca-Gehalte im ersten und zweiten Extrakt der Proben vom 24.06.88, 1:2-Extrakt, t-m-s $<1,12$ $\mathrm{mm}$, Lysimeter 3 - 8

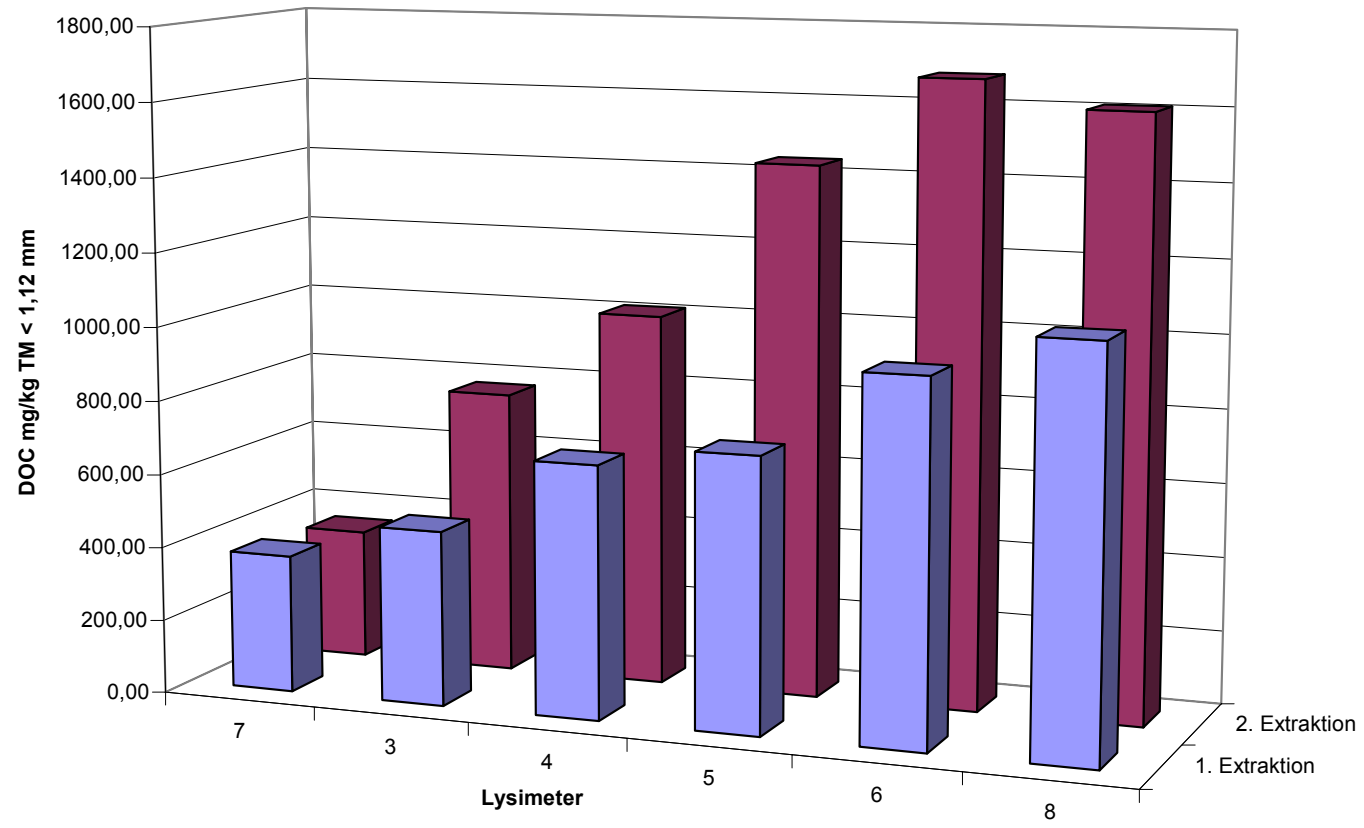

Abbildung 45: Gelöste $\mathrm{HCO}_{3}$-Gehalte im ersten und zweiten Extrakt der Proben vom 24.06.88, 1:2-Extrakt, t-m-s < 1,12 $\mathrm{mm}$, Lysimeter 3 - 8 


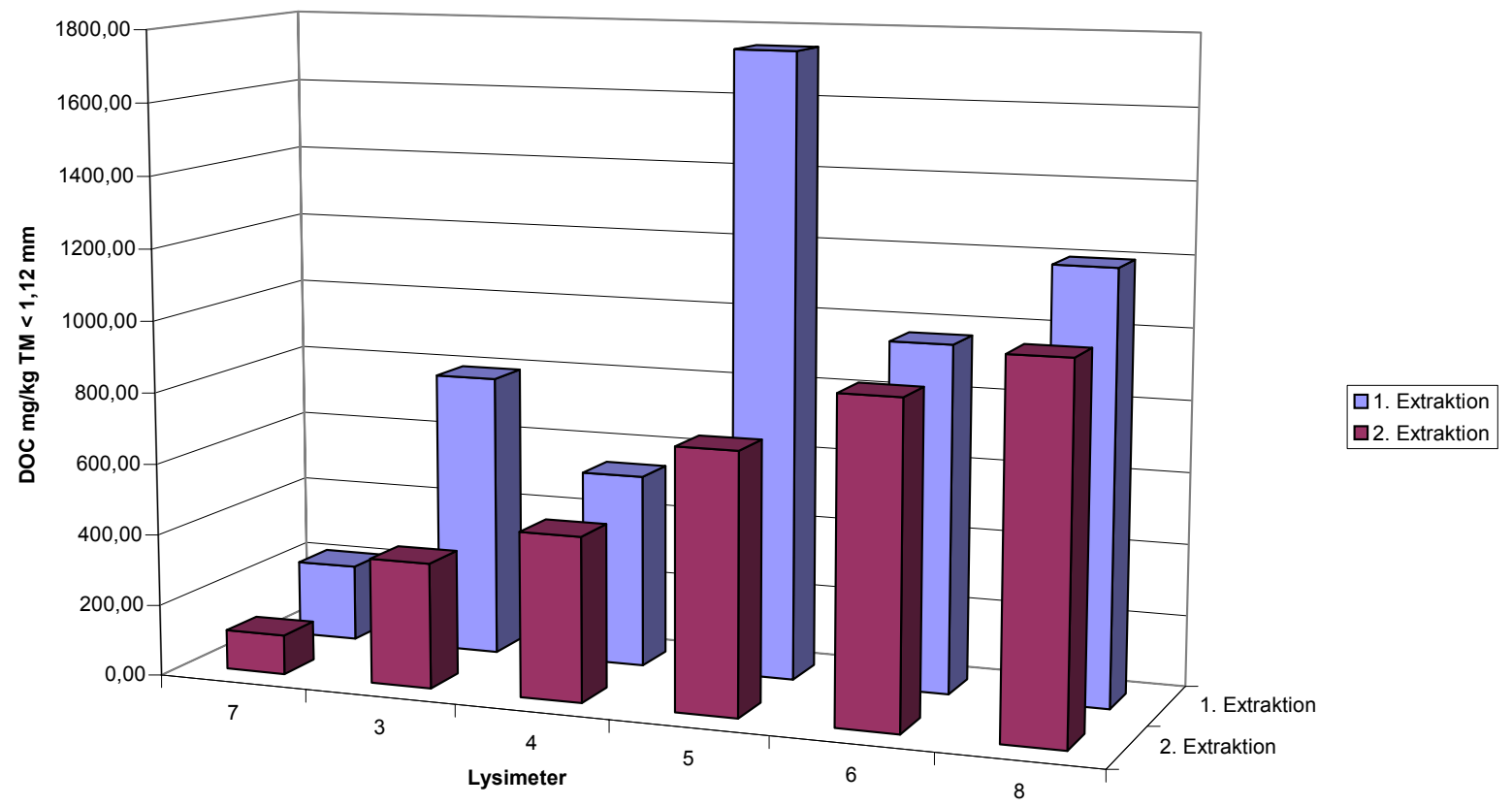

Abbildung 46: Gelöste DOC-Gehalte im ersten und zweiten Extrakt der Proben vom 24.06.88, 1:2-Extrakt, t-m-s $<1,12$ mm, Lysimeter 3 - 8

Die vorhandenen Abnahmen von der ersten zur zweiten Extraktion sind geringer als bei den Großlysimetern und drücken sich, wie Abbildung 47 zeigt, in entsprechend geringen Unterschieden zwischen den Leitfähigkeiten der ersten und zweiten Extrakte aus. 


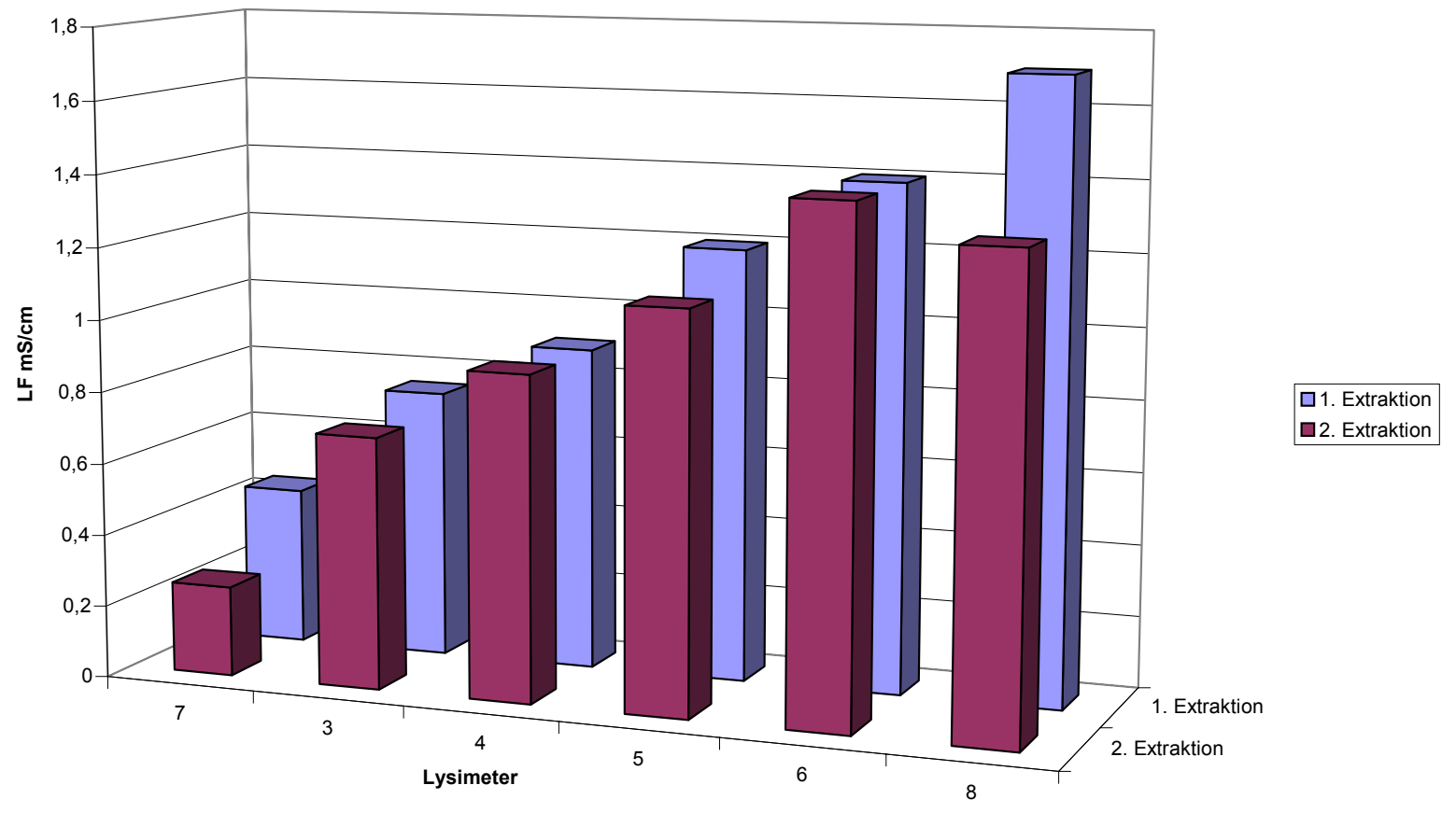

Abbildung 47: Leitfähigkeit im ersten und zweiten Extrakt der Proben vom 24.06.88, 1:2-Extrakt, t-m-s $<1,12 \mathrm{~mm}$, Lysimeter 3 - 8

Während die gemessenen Leitfähigkeiten für die Lysimeter 3, 4, 5 und 6 im ersten Extrakt unterhalb der aus den Reinlysimetern berechenbaren Werte liegen, überschreiten die im zweiten Extrakt gemessenen Leitfähigkeiten diese Werte.

\section{Interpretation}

Für die wiederholten Extraktionen wurden die Proben bei $105^{\circ} \mathrm{C}$ getrocknet und dann im Verhältnis ein Teil Trockenmasse mit zwei Teilen Wasser versetzt, $24 \mathrm{~h}$ geschüttelt, zentrifugiert und über Papierfilter abfiltriert. Die Wasserhaltekapazität liegt bei den reinen Komposten bei 116 bis $133 \%$ der TM und bei der Lössprobe bei $56 \%$ der TM (siehe Tabelle 1$6 \mathrm{im}$ Anhang). Das nach dem Zentrifugieren in der Probe verbleibende Wasser liegt in den Kompostproben bei ca. $66 \%$, in der Lössprobe ca. $25 \%$ der TM (entsprechend etwa Feldkapazität). Danach wurden die Proben entsprechend dem Verlust an abzentrifugiertem Wasser wieder mit $\mathrm{H}_{2} \mathrm{O}$ auf das ursprüngliche Verhältnis TM:Wasser aufgefüllt und erneut $24 \mathrm{~h}$ geschüttelt.

Das Verhältnis von gebunden gebliebenem Wasser (ca. $66 \%$ ) zu erneut zugefügtem Wasser wird zur 2. Extraktion auf 1,5 gebracht. Geht man davon aus, dass das in der porösen Festsubstanz verbliebene Wasser dieselbe Konzentration an gelösten Stoffen wie die abzentrifugierte Lösung gehabt hat und dass sich diese jetzt im Zuge einer erneuten Einstellung des Lösungsgleichgewichtes von ca. 66 Teilen Lösung auf 100 Teile verteilen müsste, so dürfte die im 2. Extrakt gefundene Konzentration nur $66 \%$ der des ersten Extraktes betragen.

Diese Vorhersage trifft - abgesehen vom $\mathrm{NO}_{3}$ und $\mathrm{Cl}$, für die zu wenig Vergleichsdaten vorliegen - für das $\mathrm{Mg}$ und auch weniger gut für das $\mathrm{Ca} z u$. Beim $\mathrm{Na}$ und $\mathrm{K}$, sowie $\mathrm{SO}_{4}$ und beim $\mathrm{HCO}_{3}$ betragen die Konzentrationen des zweiten Extraktes über $80 \%$ des ersten. Die Überlegung, dass dieses mit einem fortschreitenden lonenaustausch erklärt werden könnte, scheitert daran, dass das gerade $\mathrm{K}$ und $\mathrm{Na}$ von organischer Substanz gegenüber $\mathrm{Ca}$ und Mg kaum sorptiv gespeichert werden. Die Tatsache, dass DOC beim zweiten Extrakt 
gegenüber dem ersten noch zunimmt lässt dagegen vermuten, dass die fortschreitende zeitbedürftige „Hydrolyse“ (Depolymerisation) der organischen Substanz die Freilegung von ionischen Bindungen an den Wänden der Poren bedingt. Sie kann demgegenüber als der wesentlichere Faktor angesehen werden (Meyer 2004).

Da im vorliegenden Fall die in der Probe verbliebenen Restmengen an Wasser und ihr Verhältnis zu der neu hinzugefügten Wassermenge nicht exakt bestimmt wurden, kann der Verdünnungsfaktor auch bei höheren Werten als 1,5 liegen. Dann würde auch für das $\mathrm{Mg}$ eine Freisetzung aus organischer Bindung zu konstatieren sein.

\subsubsection{Organische Substanz und Extinktion}

Großlysimeter

Die Gehalte an gelöster organischer Substanz wurden ab Juni 88 in den Extrakten 1:2 und 1:10 (s. o.) fortlaufend untersucht. In der bei $105^{\circ} \mathrm{C}$ getrockneten Probe aus Lysimeter 1 sind zwischen 2,4 und 3,5 g DOC pro kg TM extrahierbar. Die organische Substanz des Kompostes aus Lysimeter 2 weist dagegen eine geringere Lösbarkeit auf. Hier werden zwischen 1,2 und 1,7 g DOC pro kg TM im 1:2-Extrakt in Lösung gebracht. Bei beiden Lysimetern ist eine deutliche Zunahme der Extrahierbarkeit mit der Tiefe erkennbar. Die zweite Extraktion der bei $105^{\circ} \mathrm{C}$ getrockneten Proben ergibt bei beiden Lysimetern eine Erhöhung der Gehalte an gelöster organischer Substanz im Extrakt. Die DOC-Gehalte der ersten Extrakte zeigen über die Versuchszeit hinweg eine abnehmende Tendenz. Dabei lässt auch hier das kurzfristige Wiederansteigen der Gehalte an gelösten Kohlenstoffverbindungen in den Extrakten auf eine Nachmineralisation bzw. Depolymerisation schließen.

Die Färbung der Extrakte wurde anhand der Extinktionen bei 400 und $436 \mathrm{~nm}$ gemessen. Diese Werte zeigen die Tabellen 1-30 bis 1-39 im Anhang. Anhand der Farbintensität kann auf den Gehalt an färbenden Bestandteilen geschlossen werden. Das Verhältnis des Anteils färbender Bestandteile im Extrakt bezogen auf das extrahierte DOC ist bei Lysimeter 2 deutlich größer als bei Lysimeter 1. Es steigt bei beiden Lysimetern mit zunehmender Schichttiefe. Die Extinktion nimmt im Laufe der Versuchszeit stärker ab als die Gehalte an organischer Substanz in den Extrakten. Der Quotient zwischen der Extinktion bei 436 und $400 \mathrm{~nm}$ liegt im Durchschnitt für Lysimeter 1 bei 1,57 .

\section{Kleinlysimeter}

Die Gehalte an gelöster organischer Substanz wurden in den Extrakten der KleinlysimeterFüllungen von Juni 88 an untersucht. In den bei $105^{\circ} \mathrm{C}$ getrockneten Proben aus Lysimeter 8 (reiner Kompost) sind im 1:2-Extrakt 1,2 bis $1,5 \mathrm{~g}$ DOC pro kg TM extrahierbar. Diese Werte liegen unter den für das Großlysimeter 1 ermittelten Werten und entsprechen denen von Lysimeter 2. Die DOC-Gehalte in den Extrakten steigen mit zunehmendem Kompostanteil in der Mischung mit Löss an (Ausnahme: Lysimeter 8 am 02.04.90). Die zweite Extraktion der bei $105^{\circ} \mathrm{C}$ getrockneten Proben ergibt geringere Gehalte an lösbarer organischer Substanz. Die DOC-Gehalte in den ersten Extrakten zeigen fortschreitender Versuchszeit eine abnehmende Tendenz. 


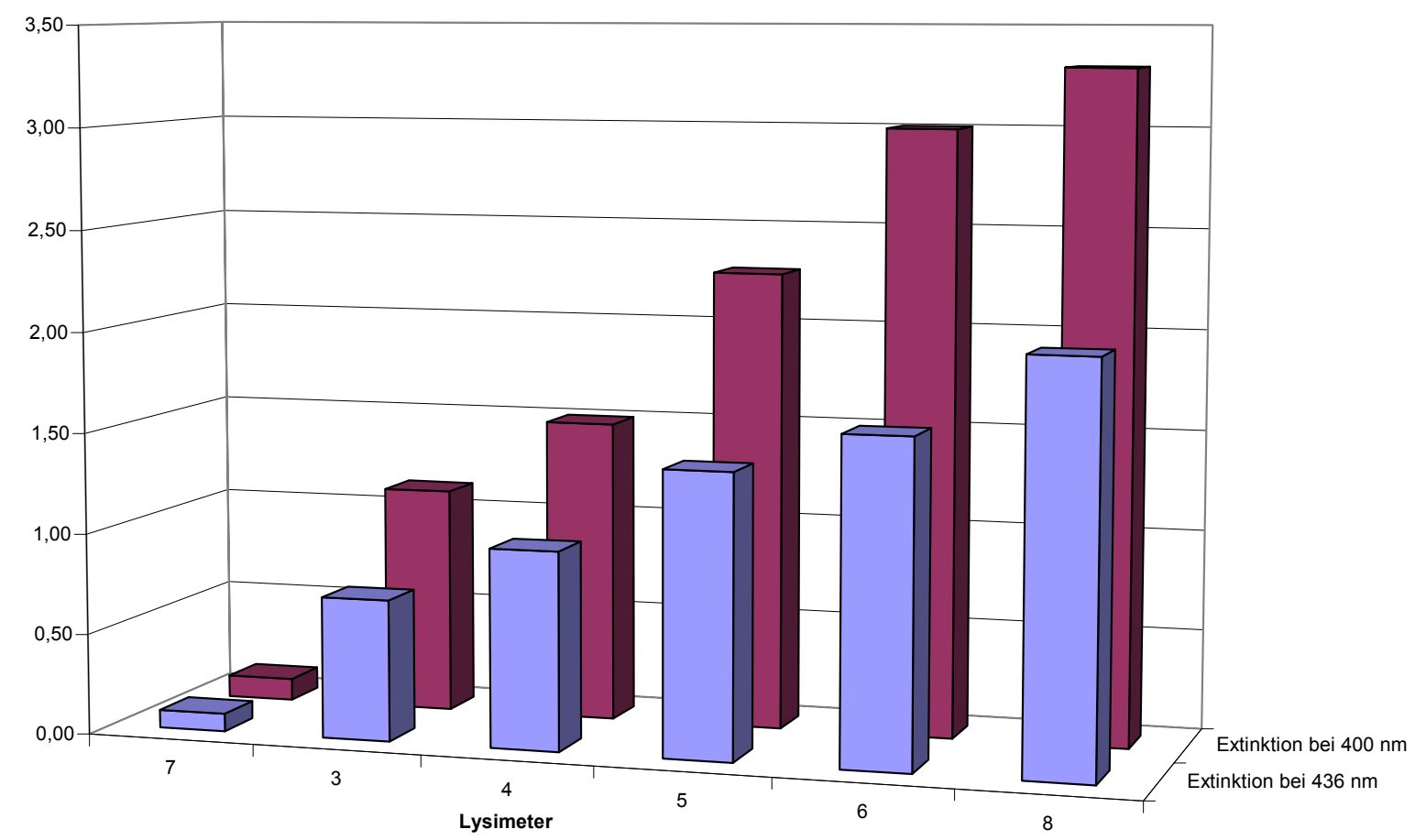

Abbildung 48: Extinktionen bei 400 und $436 \mathrm{~nm}$ in den Extrakten der Proben vom 24.06.1988 (t-m-s < 1,12 mm), Lysimeter 3 - 8

In den Tabellen 1-40 bis 1-44 im Anhang sind die Extinktionen bei 400 und $436 \mathrm{~nm}$, und die Qotienten $\mathrm{E}_{400} / \mathrm{DOC}, \mathrm{E}_{436} / \mathrm{DOC}, \mathrm{E}_{400} / \mathrm{E}_{436}$ für die Extrakte der Kleinlysimeter aufgeführt. Die Abildungen 48, 49 und 50 zeigen die Extinktionen bei 400 und $436 \mathrm{~nm}$, und die Qotienten $\mathrm{E}_{400} / \mathrm{DOC}$ und $\mathrm{E}_{400} / \mathrm{E}_{436}$. Die Verhältnisse zwischen der Extinktion und dem DOC-Gehalt ergeben für den reinen Kompost Werte, die zwischen den für $L 1$ und $L 2$ errechneten Werten liegen. Die Lysimeter 4 und 6 erzielen vergleichsweise hohe Farbintensitäten. Mit steigendem Verdünnungsfaktor nähern sich die Verhältnisse einer Konstanten. Die Färbung der 1:2-Extrakte geht von 1988 bis 1990 stark zurück. Sie nimmt stärker ab als die Gehalte an organischer Substanz in den Extrakten. Setzt man die bei 400 und bei 436 gemessenen Extinktionen zueinander ins Verhältnis, so liegen die Mittelwerte für Lysimeter 7 bei 1,3 und für die übrigen Kleinlysimeter bei 1,5 bis 1,7. 


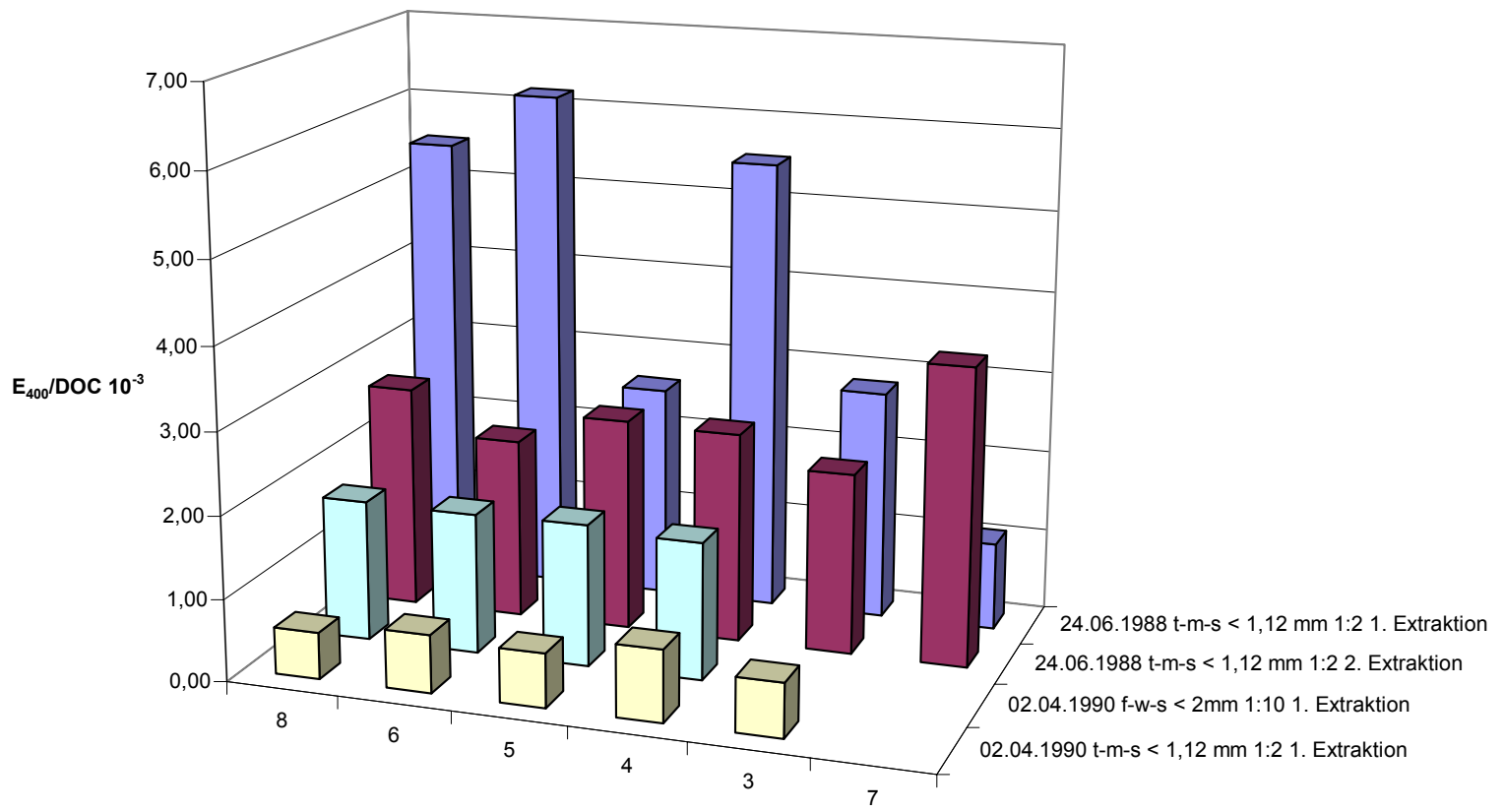

Abbildung 49: Vergleich der Quotienten $\mathrm{E}_{400} / \mathrm{DOC}$ verschiedener Extrakte, Lysimeter 3 - 8

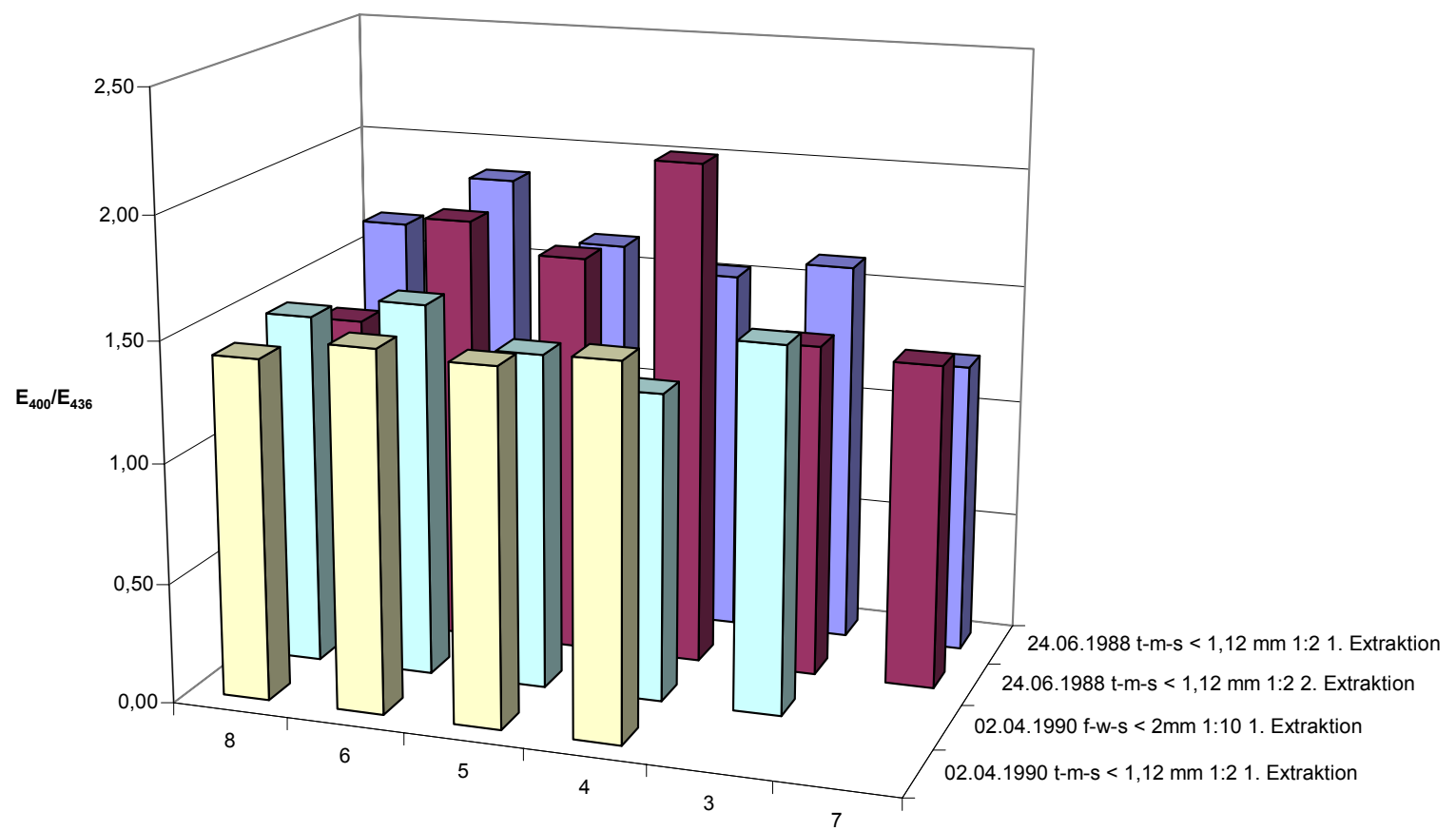

Abbildung 50: Vergleich der Quotienten $E_{400} / E_{436}$ verschiedener Extrakte, Lysimeter 3 - 8 


\subsubsection{Siebfraktion}

\section{Großlysimeter}

Üblicherweise wurden in den Versuchsreihen gesiebte Proben mit einer Siebgröße der Maschenweite 1,12 $\mathrm{mm}$ oder $2 \mathrm{~mm}$ eingesetzt. Vergleichend wurden bei der Probenahme am 18.04.90 von Lysimeter 1 aus der oberen $0-5 \mathrm{~cm}$ Schicht 1:10-Kompost:WasserExtrakte der Fraktionen $<2 \mathrm{~mm}$ und $>2 \mathrm{~mm}$ hergestellt und untersucht. Abbildung 51 zeigt, dass sich die Gehalte an DOC und Ionen in den Extrakten der Fraktionen $<2 \mathrm{~mm}$ und $>2$ $\mathrm{mm}$ kaum unterscheiden. Auch die an beiden Siebfraktionen durchgeführte 2. Extraktion ergibt, wie die Abbildung 51 zeigt, für beide jeweils ähnlich hohe Gehalte an lösbaren Verbindungen. Der DOC liegt hier deutlich unter den bei der 1. Extraktion ermittelten Werten. Die Färbung der 1. und 2. Extrakte aus der Schicht $0-5 \mathrm{~cm}$ Tiefe ist dagegen im Vergleich mit den übrigen Extrakten des Feinkompostes aus den Schichttiefen $0-20 \mathrm{~cm}$ oder $0-30 \mathrm{~cm}$ trotz der ähnlich hohen DOC-Gehalte geringer. 


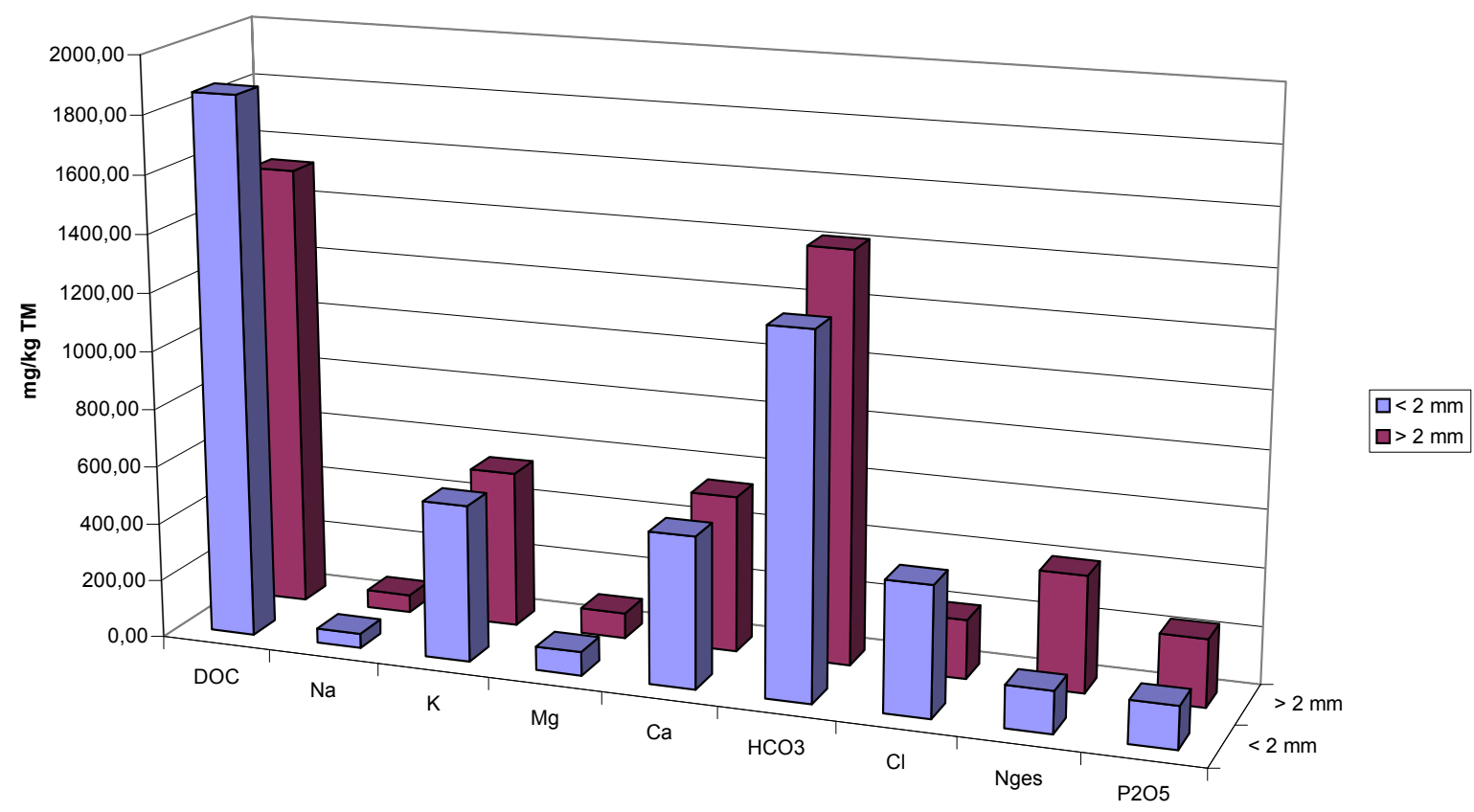

Abbildung 51: Vergleich der gelösten Gehalte im ersten 1:10

Kompost:Wasser-Extrakt der Fraktionen $<2 \mathrm{~mm}$ und $>2$

$\mathrm{mm}$, Probe vom 18.04.90 f-w-s, Lysimeter 1, Tiefe 0 - $5 \mathrm{~cm}$

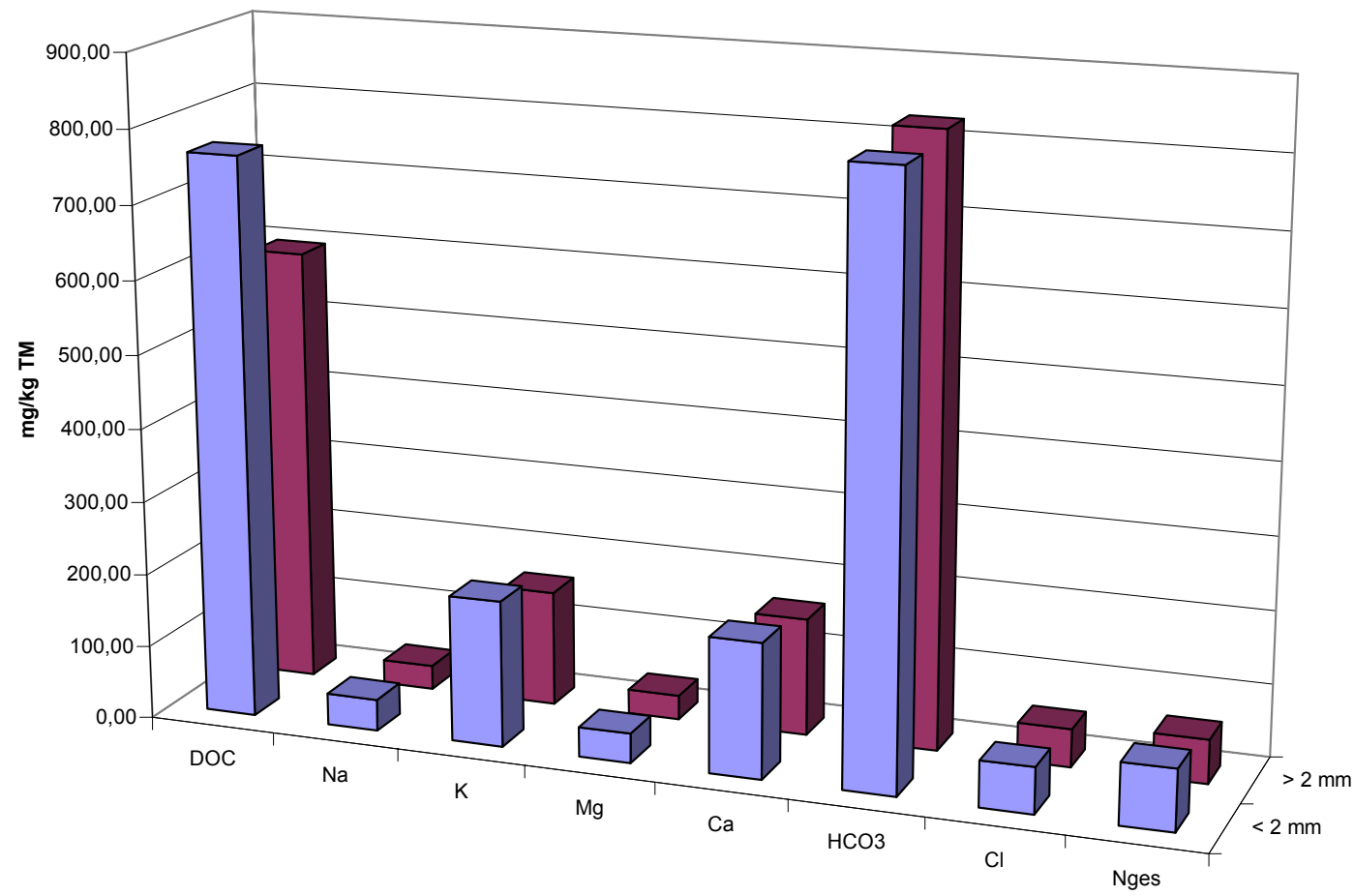

Abbildung 52: Vergleich der gelösten Gehalte im zweiten 1:10 Kompost:Wasser-Extrakt der Fraktionen $<2 \mathrm{~mm}$ und $>2 \mathrm{~mm}$, Probe vom 18.04.90 f-w-s,

Lysimeter 1 , Tiefe $0-5 \mathrm{~cm}$ 
Im Vergleich zu den übrigen Bodentiefen weist das Kompostmaterial aus der Schicht obersten, $0-5 \mathrm{~cm}$ tiefen Schicht mehr $\mathrm{Ca}$, DOC und $\mathrm{N}_{\text {ges }}$ in den Extrakten auf.

Eine Ursache für die geringere Extrahierbarkeit von gefärbten organischen Substanzen könnte sein, dass, wenn man die relative Anreicherung von „unzersetztem“ Material an der Oberfläche (wie Eierschalen, verholzten Pflanzenresten) zurückstellt, deren fortschreitende Tiefenverlagerung zu einer Verarmung an der Oberfläche und Anreicherung in der Tiefe geführt hat. 


\section{Wassereintrag und Sickerwasser}

\subsection{Bewässerung}

Zu Beginn der Freilandversuche Mai/Juli 87 wurden alle Lysimeter mehrfach bewässert, um den für die Pflanzen notwendigen Wassergehalt im Substrat aufrecht zu erhalten und eine bessere Anpassung der Jungpflanzen an die hohen Salzgehalte der eingesetzten Komposte zu bewirken. Eine weitere Bewässerung der beiden Großlysimeter 1 und 2 fand im Juli 88 statt, um einen für Untersuchungszwecke benötigten Sickerwasseraustrag zu bewirken.

Die Bewässerungen wurden mit destilliertem Wasser aus Gießkannen gleichmäßig über die gesamte Lysimeteroberfläche durchgeführt.

In der Tabelle 6-1 sind die Bewässerungsmengen als Summenwerte für die Monate Mai 87, Juli 87 und Juli 88 aufgeführt. Die Werte sind in I und in $\mathrm{mm}$ entsprechend der Lysimetergröße angegeben.

Tabelle 6-1: Zeitpunkt und Menge der Bewässerung in I und mm, Lysimeter 1 - 8

\begin{tabular}{l|ccc|ccc} 
& \multicolumn{3}{|c|}{ Bewässerung in I } & \multicolumn{3}{|c}{ Bewässerung in mm } \\
Lysimeter & Mai 87 & Jul 87 & Jul 88 & Mai 87 & Jul 87 & Jul 88 \\
\hline & & & & & & \\
$\mathbf{1}$ & 242,5 & 282,8 & 322,0 & 34,3 & 40,0 & 45,5 \\
$\mathbf{2}$ & 251,7 & 282,8 & 322,0 & 35,6 & 40,0 & 45,5 \\
$\mathbf{8}$ & 26,9 & 13,9 & & 77,3 & 40,0 & \\
$\mathbf{6}$ & 55,1 & 27,0 & & 81,5 & 40,0 & \\
$\mathbf{5}$ & 55,1 & 27,0 & & 81,5 & 40,0 & \\
$\mathbf{4}$ & 55,1 & 27,0 & & 81,5 & 40,0 & \\
$\mathbf{3}$ & 55,1 & 27,0 & & 81,5 & 40,0 & \\
$\mathbf{7}$ & 24,4 & 13,9 & & 70,0 & 40,0 &
\end{tabular}

\subsection{Niederschlagsmengen und Angaben zur Witterung}

Die monatlichen Niederschlagshöhen wurden im ersten Versuchsjahr von Mai 87 bis April 88 anhand der eigenen vor Ort erhobenen Niederschlagsdaten und im zweiten Versuchsjahr von Mai 88 bis Juli 89 anhand der Daten der Klimastation des Institutes für Bodenwissenschaft berechnet. Für die restliche Zeit ab August 89 bis zur Leerung der Großlysimeter im Januar bzw. März 91 wurden die Daten des monatlichen Witterungsberichtes für Göttingen West herangezogen (DEUTSCHER WETTERDIENST 89, 90 und 91). Die vor Ort erhobenen Niederschlagsdaten stimmen mit den Angaben der Klimastation des Institutes für Bodenwissenschaft überein, im Vergleich mit den Angaben aus dem monatlichen Witterungsbericht für Göttingen West sind sie geringfügig niedriger (DEUTSCHER WETTERDIENST 87 und 88).

Die Abbildung 53 zeigt die zugrunde gelegten monatlichen Niederschlagssummen während der Versuchszeit im Vergleich mit dem langjährigen Monatsmittel des Deutschen Wetterdienstes für die Klimastation Göttingen West. (DEUTSCHER WETTERDIENST 87 -91) 


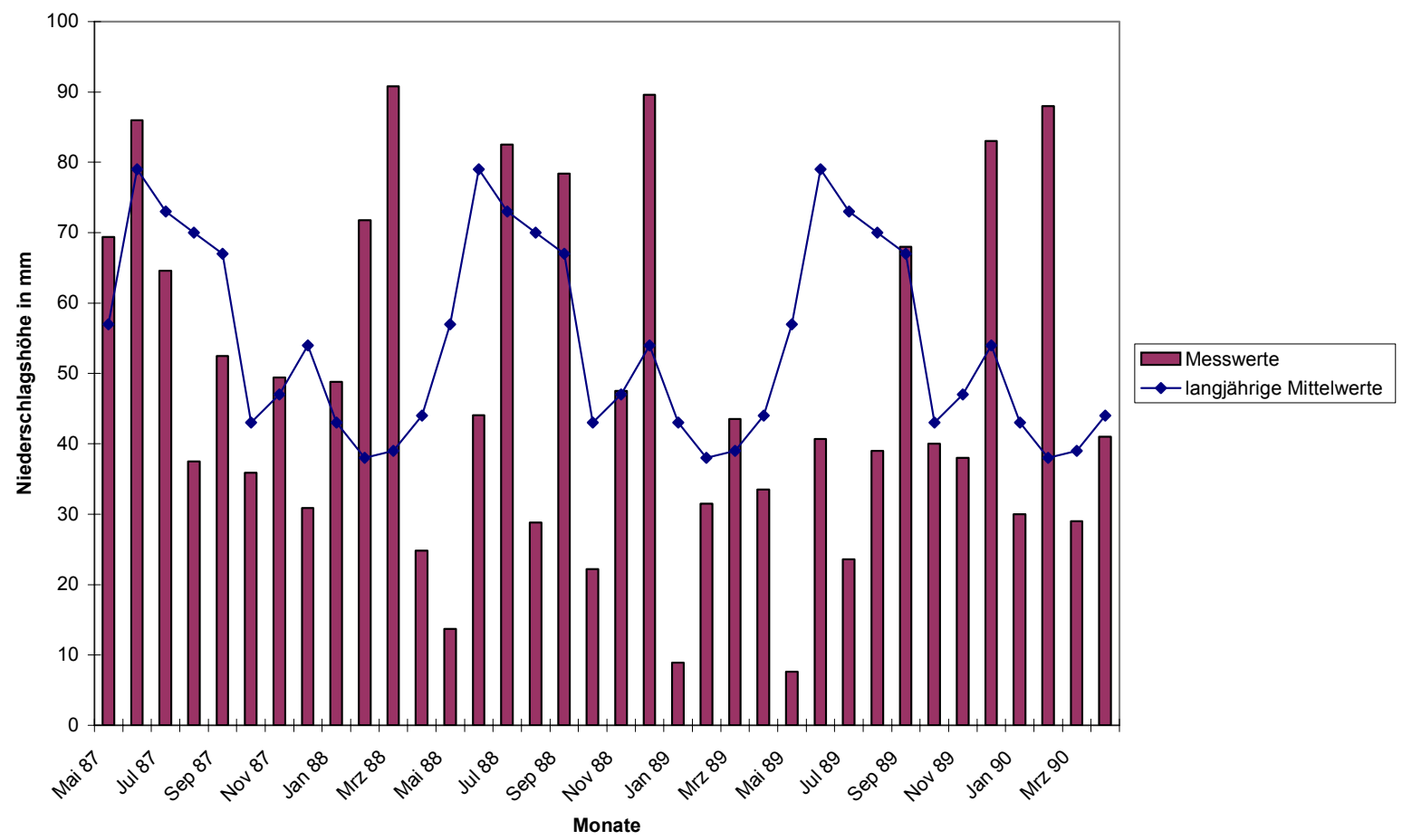

Abbildung 53: Vergleich der zugrundegelegten monatlichen Niederschlagssummen für Mai 87 bis April 90 mit den langjährigen Monatsmittelwerten des Deutschen Wetterdienstes (DEUTSCHER WETTERDIENST 87 - 91)

Der anhand der langjährigen Monatsmittelwerte des Deutschen Wetterdienstes für Göttingen West errechnete Jahresniederschlag beträgt $654 \mathrm{~mm}$. Während im ersten Versuchsjahr dieser Wert mit $662,4 \mathrm{~mm}$ Jahresniederschlag geringfügig überschritten ist, werden mit $524,2 \mathrm{~mm}(88 / 89)$ und $527,9 \mathrm{~mm}(89 / 90)$ in den beiden darauffolgenden Untersuchungsjahren nur etwa $80 \%$ des durchschnittlichen Jahresniederschlags erreicht. Auffallend sind die deutlich geringeren Niederschlagshöhen im Frühsommer 88 und im Sommer 89.

Der Deutsche Wetterdienst beschreibt die Jahre 1987 - 1990 folgendermaßen: „Das Jahr 1987 war im Vergleich zu den vieljährigen Mittelwerten bei unterdurchschnittlicher Sonnenscheindauer zu kalt und zu nass. Das Jahr 1988 war bei meist unterdurchschnittlicher Sonnenscheindauer zu warm und verbreitet zu nass. Dagegen waren die Jahre 1989 und 1990 bei meist überdurchschnittlicher Sonnenscheindauer zu warm sowie nach den Flächenmitteln des Niederschlags zu trocken." (DEUTSCHER WETTERDIENST 88, 89 und 90)

\subsection{Zeitlicher Verlauf und Höhe der Sickerwasserspende}

In Tabelle 6-2 sind die Wassereinträge- und Sickerwasser-Austräge für jedes Lysimeter jährlich von Mai bis April zusammengefasst. Die Sickerwassermenge in I wurde entsprechend der Lysimetergröße in mm Sickerwasserhöhe umgerechnet. In der Abbildung 54 ist die gebildete Sickerwassermenge in \% des Gesamteintrages für die Lysimeter $1-8$ in den drei Untersuchungsjahren von Mai 87 bis April 90 dargestellt. 
Tabelle 6-2: Wasserein- und -austräge, Jahressummen, Lysimeter 1 - 8

\begin{tabular}{|c|c|c|c|c|c|c|c|c|}
\hline & $\begin{array}{c}\text { Lysimeter } \\
1 \\
\end{array}$ & 2 & 8 & 6 & 5 & 4 & 3 & 7 \\
\hline $\begin{array}{l}\text { 1. Jahr } \\
\text { Mai } 87 \text { - April } 88\end{array}$ & & & & & & & & \\
\hline Niederschlag in mm & 662,4 & 662,4 & 662,4 & 662,4 & 662,4 & 662,4 & 662,4 & 662,4 \\
\hline Bewässerung in mm & 74,3 & 75,6 & 117,3 & 121,5 & 121,5 & 121,5 & 121,5 & 110 \\
\hline Gesamteintrag in $\mathrm{mm}$ & 736,7 & 738 & 779,7 & 783,9 & 783,9 & 783,9 & 783,9 & 772,4 \\
\hline $\begin{array}{l}\text { Sickerwasserspende in mm } \\
\text { Sickerwasserspende in \% des Gesamteintrags }\end{array}$ & $\begin{array}{l}266,4 \\
36,16\end{array}$ & $\begin{array}{l}238,6 \\
32,33\end{array}$ & $\begin{array}{l}328,8 \\
42,17\end{array}$ & $\begin{array}{l}330,9 \\
42,21\end{array}$ & $\begin{array}{l}305,9 \\
39,02\end{array}$ & $\begin{array}{l}300,8 \\
38,37\end{array}$ & $\begin{array}{c}270 \\
34,44\end{array}$ & $\begin{array}{l}292,4 \\
37,86\end{array}$ \\
\hline $\begin{array}{l}\text { 2. Jahr } \\
\text { Mai } 88 \text { - April } 89\end{array}$ & & & & & & & & \\
\hline $\begin{array}{l}\text { Niederschlag in mm } \\
\text { Bewässerung in mm }\end{array}$ & $\begin{array}{c}524,2 \\
45,5\end{array}$ & $\begin{array}{c}524,2 \\
45,5\end{array}$ & 524,2 & 524,2 & 524,2 & 524,2 & 524,2 & 524,2 \\
\hline Gesamteintrag in $\mathrm{mm}$ & 569,7 & 569,7 & 524,2 & 524,2 & 524,2 & 524,2 & 524,2 & 524,2 \\
\hline $\begin{array}{l}\text { Sickerwasserspende in mm } \\
\text { Sickerwasserspende in \% des Gesamteintrags }\end{array}$ & $\begin{array}{c}59,3 \\
10,42\end{array}$ & $\begin{array}{l}51,7 \\
9,07\end{array}$ & $\begin{array}{c}155 \\
29,57\end{array}$ & $\begin{array}{l}118,4 \\
22,59\end{array}$ & $\begin{array}{l}115,4 \\
22,01\end{array}$ & $\begin{array}{l}112,5 \\
21,46\end{array}$ & $\begin{array}{l}112,5 \\
21,46\end{array}$ & $\begin{array}{l}186,6 \\
35,60\end{array}$ \\
\hline $\begin{array}{l}\text { 3. Jahr } \\
\text { Mai } 89 \text { - April } 90\end{array}$ & & & & & & & & \\
\hline $\begin{array}{l}\text { Niederschlag in mm } \\
\text { Bewässerung in mm }\end{array}$ & 527,9 & 527,9 & 527,9 & 527,9 & 527,9 & 527,9 & 527,9 & 527,9 \\
\hline Gesamteintrag in $\mathrm{mm}$ & 527,9 & 527,9 & 527,9 & 527,9 & 527,9 & 527,9 & 527,9 & 527,9 \\
\hline Sickerwasserspende in $\mathrm{mm}$ & 102,8 & 67,9 & 142,5 & 141,6 & 137,2 & 58,3 & 137,2 & 142,7 \\
\hline Sickerwasserspende in \% des Gesamteintrags & 19,47 & 12,86 & 26,99 & 26,82 & 25,99 & 11,04 & 25,99 & 27,03 \\
\hline
\end{tabular}

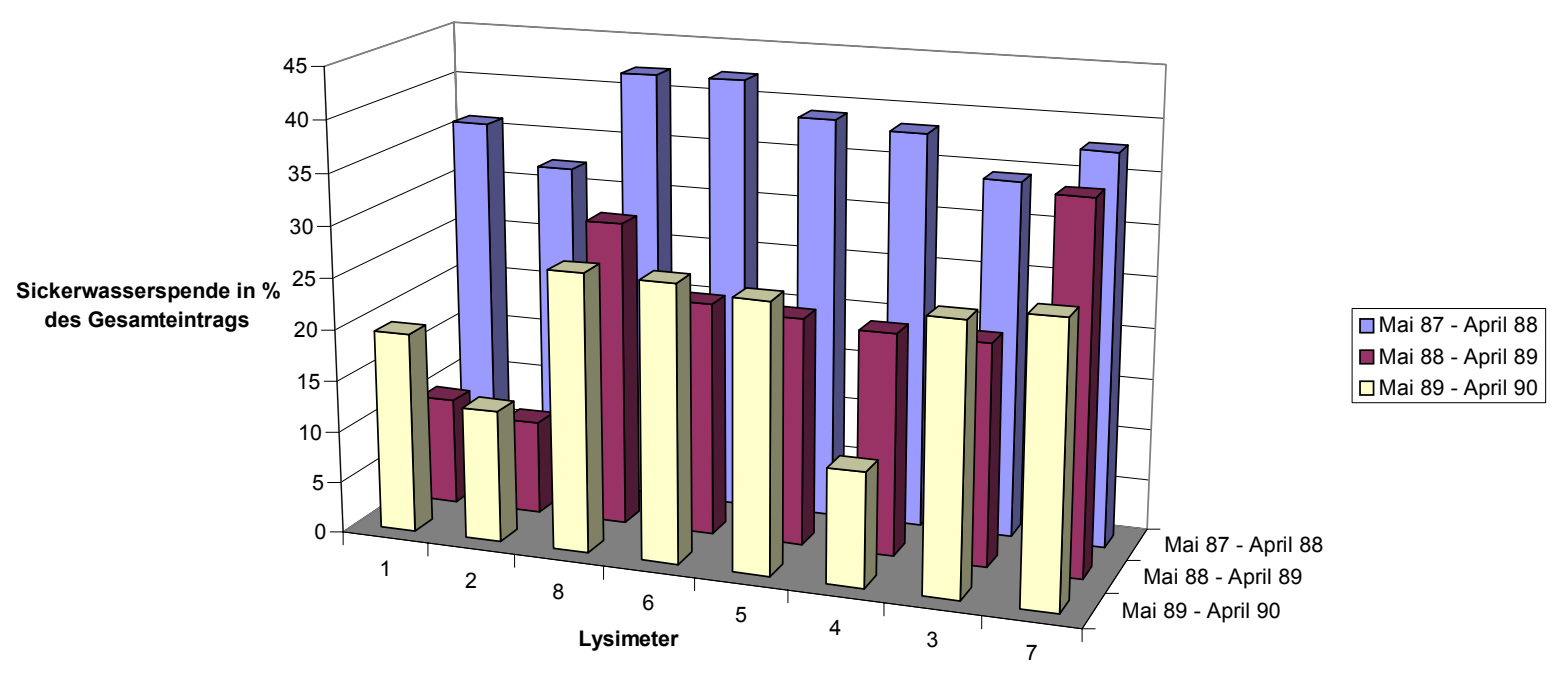

Abbildung 54: Höhe der jährlichen Sickerwasserspende in $\%$ des Gesamt-Wassereintrags, Lysimeter 1 - 8

Im ersten Versuchsjahr fällt die freigesetzte Sickerwassermenge der Mischungsvarianten 6, 5, 4 und 3 mit zunehmendem Lössanteil ab. Sie liegt im Durchschnitt bei $39 \%$ des Wassereintrags. Die Sickerwasserspende der reinen Löß-Variante beträgt im ersten Jahr etwa $38 \%$, für die reine Kompost-Variante beträgt sie $42 \%$ und für die beiden Großlysimeter werden $36 \%$ für Lysimeter 1 und $32 \%$ für Lysimeter 2 ermittelt. Die 
Sickerwasserspenden in den beiden Folgejahren liegen unter diesen Werten. Im Durchschnitt erreichen die Mischungsvarianten im zweiten und dritten Versuchsjahr $22 \%$ und die reine Kompost-Variante im zweiten Versuchsjahr $30 \%$ und im dritten Versuchsjahr $27 \%$. Die Löss-Variante sinkt von $36 \%$ im zweiten Jahr auf $27 \%$ im dritten Jahr. Bei den beiden Großlysimetern geht die Höhe der Sickerwasserspende im zweiten Jahr auf etwa 10 $\%$ des Wassereintrags zurück und steigt im dritten Jahr bei Lysimeter 1 auf $19 \%$ und Lysimeter 2 auf $13 \%$ an. Der Wiederanstieg der Sickerwassermenge bei Lysimeter 1 kann auf den fehlenden Bewuchs im dritten Jahr zurückgeführt werden bzw. auch auf die im Vergleich zu Lysimeter 2 geringere Mächtigkeit des eingefüllten Kompostes, da die Höhe der Sickerwasserspende mit zunehmender Verweildauer im Material abnimmt. Entsprechend ist auch der Rückgang der gebildeten Sickerwassermenge vom ersten zum zweiten Versuchsjahr vor allem auf Setzung und Verdichtung der Lysimeter-Füllungen zurückzuführen.

Aus der Summe der Einträge (Niederschläge und Bewässerung) und der gebildeten Sickerwassermenge pro Lysimeter lassen sich die Bilanzglieder für die Berechnung der Wasserhaushalts-Bilanz ermitteln. Aus der Differenz ergeben sich die Evapotranspiration und Interception (ohne Berücksichtigung der Änderung der Bodenfeuchte), die nach GENID (1982) den Haupt-Einflussfaktor der Wasserhaushalts-Bilanz darstellen.

Zu berücksichtigen ist allerdings, dass es bei zu gering dimensionierten Feldlysimetern aufgrund des veränderten Lösungs/Feststoff-Verhältnisses und der auftretenden Randeffekte zu beträchtlichen Beeinflussungen des Wasser- und Stofftransports kommen kann. Im ersten Fall kommt es zu einer Verdünnung der Lösungsfracht und im zweiten Fall, durch die Verkürzung des Kontaktes zwischen Substrat und Lösung, zu einem höheren Sickerwasseraustritt bei Verminderung der Inhaltsstoffkonzentration. Bei zu geringer Substratmächtigkeit sind keine wasserhaushaltlichen Kennwerte zu erzielen. Frachtberechnungen würden aufgrund des gegenüber größeren Tiefen veränderten Bodenfeuchteregimes zu Fehleinschätzungen führen. (GROTHEER 1998)

Die Abbildungen 55 - 57 zeigen die Höhe der monatlichen Wassereinträge und die gebildeten Sickerwassermengen der Lysimeter 1 bis 8 von Mai 1987 bis April 1990. In den Abbildungen sind die jeweils größengleichen Lysimeter - Lysimeter 1 und 2, Lysimeter 3 6 , Lysimeter 7 und 8 - zusammengefasst. 


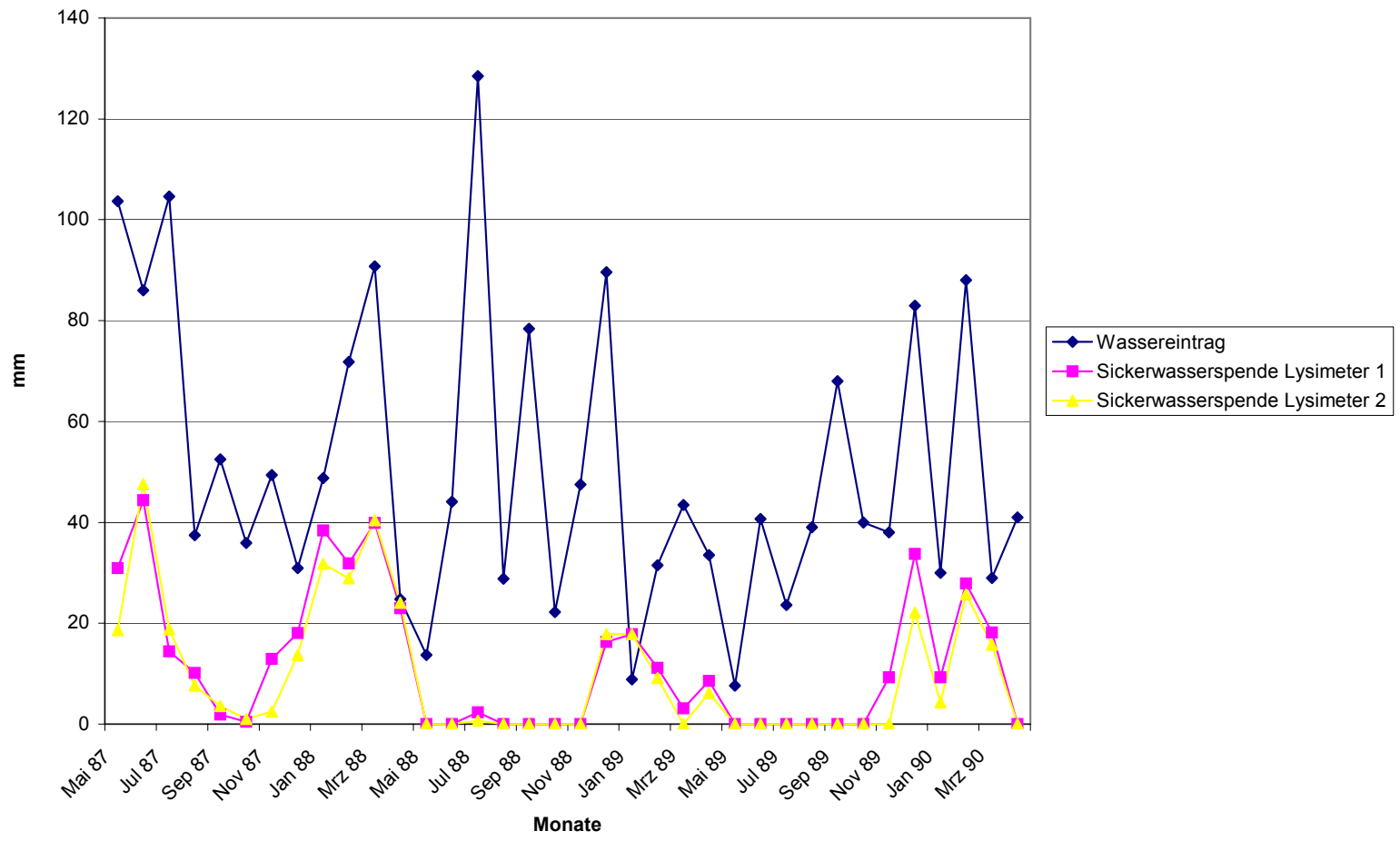

Abbildung 55: Sickerwasserspende der Lysimeter 1 und 2 im Vergleich zum Gesamt-Wassereintrag

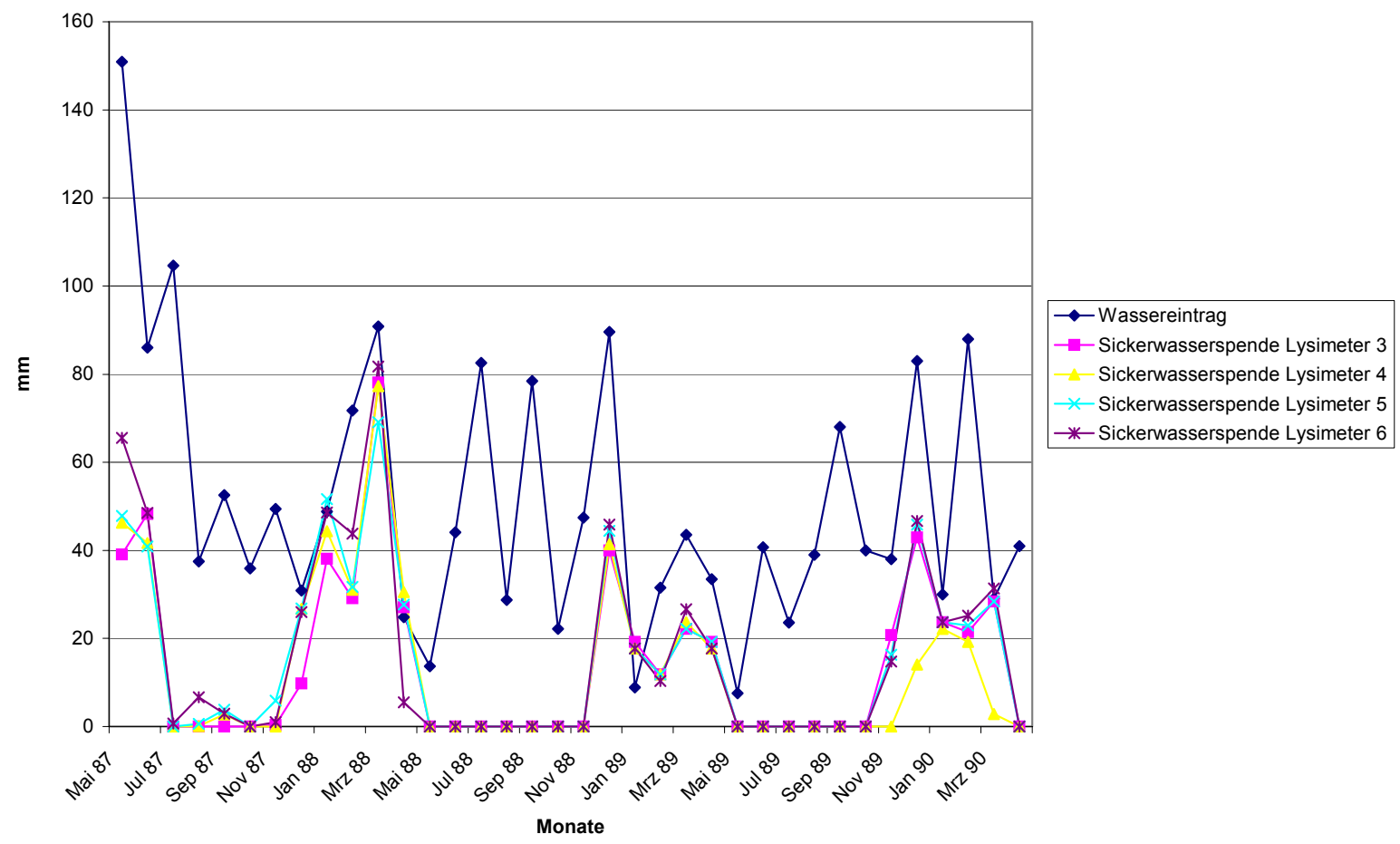

Abbildung 56: Sickerwasserspende der Lysimeter 3, 4, 5 und 6 im Vergleich zum Gesamt-Wassereintrag 


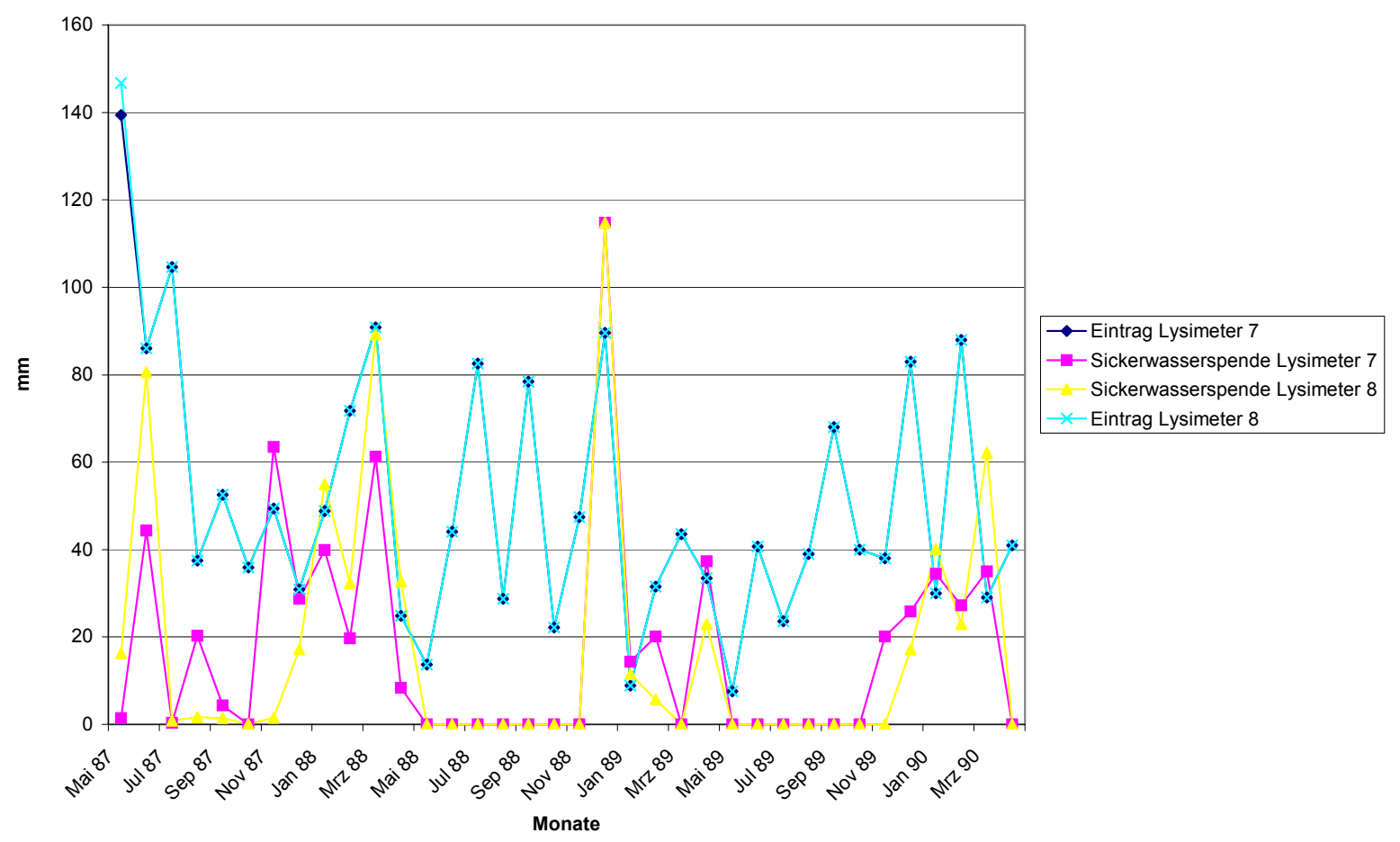

Abbildung 57: Sickerwasserspende der Lysimeter 7 und 8 im Vergleich zum Gesamt-Wassereintrag

Die monatlichen Wassereinträge sind gegenüber den Niederschlagswerten durch die Bewässerung im Mai/Juli 87 und Juli 88 erhöht. Große Mengen an Sickerwasser fallen direkt nach Inbetriebnahme der Anlage im Mai und im Juni 87 an. Hier ist davon auszugehen, dass der hohe Quellwiderstand des trockenen Kompostmaterials, die zu Beginn eher lockere Schüttung und der noch geringe Pflanzenbewuchs dazu geführt haben, dass die eingebrachten Wassermengen die Lysimeter schnell passiert haben. In der Folgezeit erfolgt die Sickerwasserbildung bei allen Lysimetern nur noch von November bis April. Während die monatlichen Sickerwasserspitzen der Mischungsvarianten im ersten Jahr annähernd die Höhe der Wassereinträge erreichen, bleiben die Großlysimeter deutlich unter den Einträgen. Die noch kleineren Lysimeter 7 und 8 mit reinem Löss bzw. reinem Kompost zeigen Sickerwasserspitzen, welche sogar die monatlichen Einträge übersteigen. Obwohl der reine Kompost gegenüber dem Löss mehr Grobporen besitzt führt die höhere, innerhalb der Versuchszeit noch ansteigende Wasserhaltekapazität des Kompostes, zu etwa gleich großen Sickerwasser-Mengen. Insgesamt zeigen die jeweils größengleichen Lysimeter einen ähnlichen Verlauf.

\subsection{Inhaltsstoffe im Niederschlag}

\subsubsection{Methodik}

Die im Kühlraum bei $4^{\circ} \mathrm{C}$ in PE-Flaschen gelagerten Niederschlagsproben (2-WochenMischproben) wurden auf die in Tabelle 6-3 aufgelisteten Messgrößen hin untersucht. In dieser Tabelle sind auch die eingesetzten Methoden genannt. 
Tabelle 6-3: Regenwasseranalyse, Methodenübersicht

\begin{tabular}{|l|l|}
\hline Messgröße & Methode \\
\hline $\mathrm{pH}-$ Wert & $\begin{array}{l}\text { Potenziometrische pH-Wert-Bestimmung, pH-Meter und Glaselektrode } \\
\text { der Fa. Metrohm }\end{array}$ \\
\hline $\mathrm{DOC}$ & $\begin{array}{l}\text { Verbrennungsofen, TOC-Analysengerät TOCOR 2, photometrische } \\
\mathrm{CO}_{2} \text {-Detektion, Maihak } \mathrm{AG}\end{array}$ \\
\hline $\mathrm{NO}_{3}-\mathrm{N}$ & $\begin{array}{l}\text { Reduktion im Sauren mit aktivierten Zink- Plättchen, Wasserdampf- } \\
\text { destillation des } \mathrm{NH}_{3} \text { in } \mathrm{H}_{3} \mathrm{BO}_{3} \text {-Vorlage, Rücktitration mit verd. HCl }\end{array}$ \\
\hline $\mathrm{NH}_{4}-\mathrm{N}$ & $\begin{array}{l}\text { Destillation mit MgO und Rücktitration mit verd. } \mathrm{H}_{2} \mathrm{SO}_{4} \text { auf den Aus- } \\
\text { gangs-pH-Wert }\end{array}$ \\
\hline $\mathrm{Cl}$ & $\begin{array}{l}\text { Potenziometrische Fällungstitration mit AgNO }{ }_{3} \text { am Titroprozessor 636, } \\
\text { Metrohm }\end{array}$ \\
\hline $\mathrm{SO}_{4}$ & $\begin{array}{l}\text { Kationenaustausch, Fällung als BaSO } \\
\text { metrische Rücktitration des unverbrauchten Bariums mit EDTA am } \\
\text { Titroprozessor 636, Metrohm }\end{array}$ \\
\hline $\mathrm{Ma}^{\mathrm{N}} \mathrm{Na}, \mathrm{K}$ & $\begin{array}{l}\text { FES, Eichkurvenmethode unter Standardbedingungen, Eppendorf } \\
\text { Flammenphotometer }\end{array}$ \\
\hline $\begin{array}{l}\text { Flammen-AAS, Eichkurvenmethode unter Standardbedingungen, } \\
\text { AA775, Varian Techtron }\end{array}$ \\
\hline
\end{tabular}

\subsubsection{Ergebnisse}

In der Tabelle 6-4 sind die Durchschnittskonzentrationen der untersuchten Inhaltsstoffe für die 4 Messjahre jeweils als Jahres-Mittelwerte zusammengestellt. Durch die Aufwirbelung von Kompostmaterial wurden zeitweise höhere Konzentration im Regenwasser des Sammlers direkt neben der Versuchsanlage gemessen. Daher werden für die Berechnung der Einträge von Regenwasser-Inhaltsstoffen die Werte der Löss-Lysimeter-Station des Institutes für Bodenwissenschaft für $\mathrm{SO}_{4}, \mathrm{Cl}, \mathrm{NO}_{3}-\mathrm{N}, \mathrm{NH}_{4}-\mathrm{N}, \mathrm{K}, \mathrm{Na}, \mathrm{Mg}$ und $\mathrm{Ca}$ herangezogen. Da die DOC-Gehalte im Regenwasser des Sammlers der Löss-Lysimeter-Station nicht analysiert wurden, werden hier die Werte des Sammlers direkt neben der KompostLysimeter-Versuchsanlage eingesetzt.

Tabelle 6-4: Durchschnittskonzentrationen der untersuchten Regenwasser-Inhaltsstoffe, Jahres-Mittelwerte

\begin{tabular}{l|c|ccccccccc} 
& $\begin{array}{c}\mathbf{p H}- \\
\text { Wert }\end{array}$ & $\mathbf{S O}_{\mathbf{4}}$ & $\mathbf{C l}$ & $\mathbf{N O}_{3}-\mathbf{N}$ & $\mathbf{D O C}$ & $\begin{array}{c}\mathbf{N H}_{\mathbf{4}}-\mathbf{N} \\
\mathbf{m g} / \mathbf{l}\end{array}$ & $\mathbf{K}$ & $\mathbf{N a}$ & $\mathbf{M g}$ & $\mathbf{C a}$ \\
\hline Mai 87 - April 88 & 5,94 & 10,06 & 2,32 & 0,84 & 4,07 & 0,95 & 1,86 & 0,53 & 0,60 & 2,62 \\
Mai 88 - April 89 & 5,59 & 3,97 & 1,39 & 0,67 & 3,36 & 0,35 & 1,58 & 1,22 & 0,39 & 2,61 \\
Mai 89 - April 90 & 5,75 & 4,19 & 2,19 & 0,95 & 5,02 & 0,35 & 1,53 & 0,74 & 0,40 & 3,60 \\
Mai 90 - März 91 & 6,09 & 3,89 & 1,53 & 0,64 & 5,00 & 0,18 & 2,39 & 0,55 & 0,29 & 3,35
\end{tabular}


Die Konzentrationen der Inhaltsstoffe im Niederschlag unterliegen jahreszeitlichen und witterungsbedingten Schwankungen. Die chemische Zusammensetzung der sauren Niederschläge wird von anthropogenen Emissionen und maritimen Einflüssen bestimmt. Durch den Reinigungseffekt eines Niederschlagsereignisses auf die Luft nimmt die Konzentration der Stoffe im Regenwasser mit zunehmender Regendauer ab.

Die in Tabelle 6-4 aufgeführten Durchschnittskonzentrationen entsprechen den Werten für den Verhältnissen in Göttingen ähnelnden Standorten.

Die Berechnung der Eintragsmengen wird anhand der Niederschlagshöhe und der in Tabelle 6-4 angegebenen Konzentrationen durchgeführt. Tabelle 6-5 zeigt die hierbei ermittelten jährlichen Eintragsmengen in $\mathrm{g} / \mathrm{m}^{2}$.

\footnotetext{
Tabelle 6-5: Jährliche Menge des Eintrags mit dem Niederschlag in $\mathrm{g} / \mathrm{m}^{2}$
}

\begin{tabular}{l|lllllllll} 
& $\mathbf{S O}_{\mathbf{4}}$ & $\mathbf{C l}$ & $\mathbf{N O}_{\mathbf{3}}-\mathbf{N}$ & $\mathbf{D O C}$ & $\begin{array}{c}\mathbf{N H}_{\mathbf{4}}-\mathbf{N} \\
\mathbf{g} / \mathbf{m}^{\mathbf{2}}\end{array}$ & $\mathbf{K}$ & $\mathbf{N a}$ & $\mathbf{M g}$ & $\mathbf{C a}$ \\
\hline Mai 87 - April 88 & 6,66 & 1,54 & 0,56 & 2,69 & 0,63 & 1,23 & 0,35 & 0,40 & 1,73 \\
Mai 88 - April 89 & 1,82 & 0,73 & 0,33 & 1,76 & 0,17 & 0,82 & 0,62 & 0,19 & 1,29 \\
Mai 89 - April 90 & 2,09 & 0,97 & 0,45 & 2,65 & 0,17 & 0,73 & 0,35 & 0,18 & 1,70 \\
Mai 90 - März 91 & 2,11 & 0,83 & 0,35 & 2,72 & 0,10 & 1,30 & 0,30 & 0,16 & 1,82
\end{tabular}

Für die Höhe der Einträge in den einzelnen Jahren ist die Niederschlagsmenge von Bedeutung, sofern Unterschiede nicht durch die Konzentration kompensiert werden. Sowohl die Niederschlagsmenge als auch die Konzentrationen verschiedener lonen im Regenwasser sind im ersten Messjahr am höchsten. Die Sulfatfrachten ab dem zweiten Messjahr liegen deutlich unter dem Wert im ersten Messjahr. Dies entspricht dem europaweiten Trend, nach dem sich die Sulfatfrachten in den Niederschlägen seit 1988 etwa halbiert haben (MEIER 2000, UMWELTBUNDESAMT 1999a). Der seit 1988 gemessene Rückgang der Schwefelsäure-Konzentration ist auf die Verminderung der Emissionen von Schwefeldioxid zurückzuführen.

\subsection{Inhaltsstoffe im Sickerwasser}

\subsubsection{Methodik}

Das Sickerwasser der Lysimeter 1 bis 8 wurde mittels Schlauchverbindungen in Auffangbehälter geleitet (siehe Kapitel 3.2.1 Bau der Lysimeter). Die Leerung der Auffangbehälter erfolgte in der dreijährigen Versuchszeit nach Bedarf täglich, mindestens jedoch einmal wöchentlich. Das Volumen des aus den Auffangbehältern entnommenen Sickerwassers wurde bestimmt. Die entsprechend den Flussmengen erstellten Wochen-Mischproben wurden in PE-Flaschen gefüllt und im Kühlraum bei $4^{\circ} \mathrm{C}$ gelagert. In den über Papierfilter filtrierten Proben wurden die in Tabelle 6-6 genannten Messgrößen bestimmt.

Tabelle 6-6 zeigt die zur Bestimmung der Messgrößen angewendeten Analysemethoden. 
Tabelle 6-6: Sickerwasseranalyse, Methodenübersicht

\begin{tabular}{|c|c|}
\hline Messgröße & Methode \\
\hline pH-Wert & $\begin{array}{l}\text { Potenziometrische pH-Wert-Bestimmung, pH-Meter und } \\
\text { Glaselektrode der Fa. Metrohm }\end{array}$ \\
\hline Leitfähigkeit & Leitfähigkeitsmesszelle von WTW, Messung bei $25^{\circ} \mathrm{C}$ \\
\hline Abdampfrückstand & $\begin{array}{l}\text { Eindampfen der Probe im Rotationsverdampfer bei } 50^{\circ} \mathrm{C} \text {, Rückstand } \\
\text { im Trockenschrank bei } 45^{\circ} \mathrm{C} \text { trocknen, wiegen }\end{array}$ \\
\hline $\begin{array}{l}\text { Asche-Gehalt im } \\
\text { Abdampfrückstand }\end{array}$ & $\begin{array}{l}\text { Gravimetrische Bestimmung nach Vorveraschung im Sandbad und } \\
\text { nach Glühen bei } 600^{\circ} \mathrm{C}\end{array}$ \\
\hline $\begin{array}{l}\text { C-/N-Gehalt im } \\
\text { Abdampfrückstand }\end{array}$ & $\begin{array}{l}\text { Vollständige Verbrennung der Probe und gaschromatographische } \mathrm{N}_{2}- \\
\text { und } \mathrm{CO}_{2} \text {-Bestimmung, Kohlenstoff-/Stickstoff-Analysator ANA } 1400 \\
\text { der Fa. Carlo Erba }\end{array}$ \\
\hline Extinktion & $\begin{array}{l}\text { Photometrische Bestimmung der Extinktion bei } 400 \text { und } 436 \mathrm{~nm} \text { in der } \\
1: 4 \text { mit dest. Wasser verdünnten Sickerwasser-Probe, Photometer } \\
\text { Spectronic } 20 \text { der Fa. Bausch und Lomb }\end{array}$ \\
\hline DOC & $\begin{array}{l}\text { Verbrennungsofen, TOC-Analysengerät TOCOR 2, photometrische } \\
\mathrm{CO}_{2} \text {-Detektion, Maihak AG }\end{array}$ \\
\hline$N_{\text {org }}$ & $\begin{array}{l}\text { Berechnet anhand der Differenz aus } \mathrm{N}_{\mathrm{t}} \text { (aus C-/N-Gehalt im Abdampf- } \\
\text { rückstand) - } \mathrm{N}_{\min } \text { (aus Summe } \mathrm{NH}_{4}-\mathrm{N} \text { und } \mathrm{NO}_{3}-\mathrm{N} \text { im Sickerwasser) }\end{array}$ \\
\hline $\mathrm{N}_{\text {ges }}$ & $\begin{array}{l}\text { Nach Abdestillation von } \mathrm{NH}_{4}-\mathrm{N} \text { und } \mathrm{NO}_{3}-\mathrm{N} \text { Bestimmung des Kjeldahl- } \\
\mathrm{N} \text {, nasse Veraschung mit konz. } \mathrm{H}_{2} \mathrm{SO}_{4} \text { und Selenreaktionsgemisch, } \\
\text { Destillation mit } \mathrm{NaOH} \text { und Rücktitration mit verd. } \mathrm{H}_{2} \mathrm{SO}_{4} \text { auf den Aus- } \\
\text { gangs-pH-Wert }\end{array}$ \\
\hline $\mathrm{NO}_{3}-\mathrm{N}$ & $\begin{array}{l}\text { Reduktion im Sauren mit aktivierten Zink-Plättchen, Wasserdampf- } \\
\text { destillation des } \mathrm{NH}_{3} \text { in } \mathrm{H}_{3} \mathrm{BO}_{3} \text {-Vorlage, Rücktitration mit verd. } \mathrm{HCl}\end{array}$ \\
\hline $\mathrm{NH}_{4}-\mathrm{N}$ & $\begin{array}{l}\text { Destillation mit } \mathrm{MgO} \text { und Rücktitration mit verd. } \mathrm{H}_{2} \mathrm{SO}_{4} \text { auf den Aus- } \\
\text { gangs-pH-Wert }\end{array}$ \\
\hline $\mathrm{Cl}$ & $\begin{array}{l}\text { Potenziometrische Fällungstitration mit } \mathrm{AgNO}_{3} \text { am Titroprozessor 636, } \\
\text { Metrohm }\end{array}$ \\
\hline $\mathrm{SO}_{4}$ & $\begin{array}{l}\text { Kationenaustausch, Fällung als } \mathrm{BaSO}_{4} \text {, Eindampfen, komplexo- } \\
\text { metrische Rücktitration des unverbrauchten Bariums mit EDTA am } \\
\text { Titroprozessor 636, Metrohm }\end{array}$ \\
\hline $\mathrm{HCO}_{3}$ & Potenziometrische Titration mit verd. $\mathrm{HCL}$ auf $\mathrm{pH}-$ Wert $=5,00$ \\
\hline$P$ & $\begin{array}{l}\text { Aufschluss mit konzentrierter } \mathrm{H}_{2} \mathrm{SO}_{4} \text {, Bildung des blau gefärbten P- } \\
\text { Molybdat-Komplexes, photometrische Bestimmung, Spectronic } 20 \text {, } \\
\text { Bausch \& Lomb }\end{array}$ \\
\hline
\end{tabular}




\begin{tabular}{|l|l|}
\hline Messgröße & Methode \\
\hline $\mathrm{SiO}_{4}$ & $\begin{array}{l}\text { Molybdänblau-Methode: Bildung von Siliciummolybdat und Überfüh- } \\
\text { rung in Molybdänblau durch Reduktion, photometrische Bestimmung, } \\
\text { Spectronic 20, Bausch \& Lomb }\end{array}$ \\
\hline $\mathrm{Ca}, \mathrm{Na}, \mathrm{K}$ & $\begin{array}{l}\text { FES, Eichkurvenmethode unter Standardbedingungen, Eppendorf } \\
\text { Flammenphotometer }\end{array}$ \\
\hline $\mathrm{Mg}$ & $\begin{array}{l}\text { Flammen-AAS, Eichkurvenmethode unter Standardbedingungen, } \\
\text { AA775, Varian Techtron }\end{array}$ \\
\hline $\mathrm{Fe}$ & $\begin{array}{l}\text { Flammen-AAS, Eichkurvenmethode unter Standardbedingungen, } \\
\text { AA775, Varian Techtron }\end{array}$ \\
\hline
\end{tabular}

Anhand der ermittelten Einzelwerte werden entsprechend den Sickerwassermengen Monats- und Jahres-Durchschnittswerte berechnet. Hierzu werden die zum jeweiligen Entnahmetermin berechneten Frachten pro Monat bzw. Untersuchungsjahr addiert und durch die entsprechende Sickerwassermenge pro Monat bzw. Jahr dividiert. Für die Berechnung der Gesamtausträge werden fehlende Frachten anhand der von vorhandenen Analysenwerten berechneten Mittelwerte hochgerechnet. Hierauf wird im Einzelfall hingewiesen. Die Angaben der Konzentrationen erfolgen in $\mathrm{mg} / \mathrm{l}$ und $\mathrm{mmol} / \mathrm{l}$, die Frachten werden in $\mathrm{g}$ berechnet.

\subsubsection{Untersuchungsproben}

Während der Versuchszeit von drei Jahren (Mai 1987 bis April 1990) wurde das Sickerwasser der Lysimeter 1 bis 8 kontinuierlich aufgefangen, quantifiziert und auf die genannten Inhaltsstoffe hin untersucht. Tabelle 6-7 gibt den Untersuchungsumfang der untersuchten Proben in der Zeit von Mai 1987 bis April 1990 an.

Tabelle 6-7: Umfang der Untersuchungen an den Sickerwasser-Proben

\begin{tabular}{|c|c|}
\hline Untersuchungsumfang & Probenumfang \\
\hline $\begin{array}{l}\text { Volumen, pH-Wert, Leitfähigkeit, } \mathrm{DOC}, \mathrm{Ca}, \mathrm{Mg}, \mathrm{K}, \mathrm{Na}, \mathrm{NH}_{4} \text {, } \\
\mathrm{NO}_{3}, \mathrm{Cl}, \mathrm{SO}_{4}, \mathrm{HCO}_{3}, \mathrm{P}\end{array}$ & $\begin{array}{l}\text { durchgehend in allen Proben ab } \\
\text { Mai } 1987 \text { bis April } 1990\end{array}$ \\
\hline $\begin{array}{l}\text { Abdampfrückstand, C-,N- und Asche-Gehalte des Abdampf- } \\
\text { rückstandes, Extinktionen bei } 400 \text { und } 436 \mathrm{~nm}, \mathrm{Fe}, \mathrm{N}_{\text {org }}\end{array}$ & $\begin{array}{l}\text { durchgehend in allen Proben ab } \\
\text { Juni } 1988 \text { bis April } 1990\end{array}$ \\
\hline $\mathrm{SiO}_{4}$ & $\begin{array}{l}\text { stichprobenhaft in einigen } \\
\text { Proben von Dezember } 1988 \text { bis } \\
\text { Januar } 1989\end{array}$ \\
\hline $\begin{array}{l}\text { Volumen, pH-Wert, } \mathrm{DOC}, \mathrm{Ca}, \mathrm{Mg}, \mathrm{K}, \mathrm{Na}, \mathrm{NO}_{3}, \mathrm{Cl}, \mathrm{SO}_{4} \text {, } \\
\mathrm{HCO}_{3} \text {, Abdampfrückstand, C-, } \mathrm{N} \text { - und Asche-Gehalte des } \\
\text { Abdampfrückstandes, Extinktionen bei } 400 \text { und } 436 \mathrm{~nm} \text {, } \\
\mathrm{N}_{\text {org }}\end{array}$ & Lysimeter 1 und 2, Januar 1991 \\
\hline
\end{tabular}


Von den Lysimetern 1 und 2 wurden zusätzlich weitere Sickerwasserproben entnommen, da die Entleerung der Lysimeter erst im Januar 1991 (Lysimeter 1) und im März 1991 (Lysimeter 2) stattgefunden hat und für die Bilanz die Stoffausträge mit dem Sickerwasser bis dahin berücksichtigt werden sollten. Hierzu wurden am 08.01.91 Sickerwasserproben von Lysimeter 1 und 2 entnommen, die Mischproben der vorangegangenen SickerwasserBildungszeit darstellen, und darüber hinaus am 09.01.91 eine frische Durchflussprobe. Bei Lysimeter 1 konnte zusätzlich eine weitere Sickerwasser-Probe am 11.01.91 aufgefangen werden, bei welcher der Niederschlag nur die Sand- und Kiesschichten passiert hatte, da das eingefülte Kompostmaterial bereits abgetragen worden war. Dies ergab sich bei Lysimeter 2 mangels Niederschlags während der Leerung des Lysimeters nicht. In diesen Proben wurden ebenfalls die in den Zeilen 1 und 2 der Tabelle 6-7 genannten Messgrößen - bis auf $P$ - erhoben.

Anhand der bei Versuchsabschluss für Lysimeter 1 und 2 erhobenen Sickerwasserdaten wird der Stoffaustrag mit dem Sickerwasser für das 4. Jahr jeweils bis zum Zeitpunkt der Öffnung der Großlysimeter hochgerechnet.

Die durch Bewässerung der Großlysimeter herbeigeführte Sickerwasserspende im Juli 88 wird wegen der auffallend niedrigen Stoffkonzentrationen in diesen Proben bei der Bildung der Monats- und Jahresmittelwerte nicht berücksichtigt, aber in die Berechnung der Frachten und Gesamtausträge einbezogen.

\subsubsection{Ergebnisse}

Der Stoffaustrag mit dem Sickerwasser ist das Produkt einer Vielzahl von Prozessen. Diese sind abhängig von Witterungs-Faktoren, wie Temperatur und Niederschlag und von Eigenschaften des Filterkörpers, die physikalischer, chemischer und biologischer Natur sind. Hierzu gehören unter anderem Stoff-Ausgangsgehalt, Lösungseigenschaften, Porenverteilung, Wasserleitfähigkeit, Aktivität des Bodenlebens. Diese Faktoren beeinflussen sich gegenseitig in vielfältiger Weise. Der Sickerwasserfluss stellt eine wichtige dynamische Größe für die Beurteilung der Intensität von Stoffumsätzen eines Bioelement-Haushalts dar sowie für die Erkennung möglicher Belastungspotenziale für Böden und Gewässer.

Die Tabellen 1-57 bis 1-66 im Anhang zeigen die im Laufe der Versuchsbetreuung im Sickerwasser der Lysimeter 1 bis 8 ermittelten Stoffkonzentrationen. Die Tabellen geben die Monatsmittelwerte für die Lysimeter 1 bis 8 von Mai 87 bis April 90 an sowie die Einzelergebnisse der Sickerwasser-Proben während der Abschlusserhebung im Januar 1991 für die Lysimeter 1 und 2.

\subsubsection{Allgemeine Beschreibung, $\mathrm{pH}$-Wert}

Bei den meist klaren Sickerwasser-Proben der Kompost-Lysimeter handelt es sich um hellgelb bis dunkelbraun gefärbte Lösungen mit teilweise hohen Gehalten löslicher anorganischer und organischer Salze sowie einer Vielzahl organischer Verbindungen. Mit zunehmender Versuchsdauer und steigenden Kompost-Gehalten in den Lysimetern tritt eine Farbvertiefung auf. Diese Färbung kann sowohl durch kolloid gelöste Huminstoffe als auch durch die Bildung von komplex gebundenem Eisen, Mangan, Kupfer oder Zink hervorgerufen sein. Das Sickerwasser der Löss-Variante ist farblos. Eine Trübung der SickerwasserProben war nur vereinzelt zu Versuchsbeginn gegeben. Die Sickerwasser-Proben der Mischungs- und Löss-Varianten sind überwiegend geruchlos. Die Proben der KompostLysimeter weisen dagegen einen süßlich modrigen Geruch auf, der auf die hohen Gehalte an organischen Verbindungen zurückzuführen ist. Die $\mathrm{pH}$-Werte liegen bei allen Proben zwischen $\mathrm{pH} 7$ und 8,5.

\subsubsection{Leitfähigkeit, Abdampfrückstand und Salzgehalt}

Großlysimeter

Die Leitfähigkeitswerte im Sickerwasser der Lysimeter 1 und 2 bewegen sich zwischen 2,4 
und 10,8 $\mathrm{mS} / \mathrm{cm}$. Sie steigen in den ersten zwei Monaten steil an und erreichen zwischen Dezember 87 und März 88 Maximalwerte von 8,5 für Lysimeter 1 und 10,8 für Lysimeter 2. Nach allmählichem Absinken bleiben sie ab Dezember 88 auf annähernd gleichem Niveau, das für Lysimeter 1 bei Werten zwischen 2,2 und 3,7 liegt und bei Lysimeter 2 noch Werte um $7 \mathrm{mS} / \mathrm{cm}$ erreicht. Innerhalb der Bildungsphasen von Sickerwasser treten darin Leitfähigkeitspitzen auf. Die Abbildung 58 zeigt den geschilderten Verlauf für die beiden Großlysimeter. Die Messwerte für Lysimeter 2 liegen deutlich über den Werten für Lysimeter 1. Die Differenz zwischen den beiden Lysimetern nimmt mit fortschreitender Versuchsdauer zu.

Die Abdampfrückstände liegen bei Lysimeter1 zwischen 2 und $3 \mathrm{~g} / \mathrm{l}$, bei Lysimeter 2 zwischen 6 und $7 \mathrm{~g} / \mathrm{l}$. Wie von GARVERT 1977 vorgeschlagen wurden die Abdampfrückstände verascht, um anhand des Glührückstandes Umrechnungsfaktoren für die Bestimmung des mineralischen Salzgehaltes aus der Leitfähigkeit zu ermitteln. Die Veraschung der Abdampfrückstände wurde wegen des beträchtlichen Aufwandes nur mit einer begrenzten Anzahl von Proben der Lysimeter 1, 2 und 5 durchgeführt. Die hierbei gewonnenen Daten und die anhand dieser Werte berechneten Umrechnungsfaktoren sind in Tabelle 6-8 zusammengestellt. 


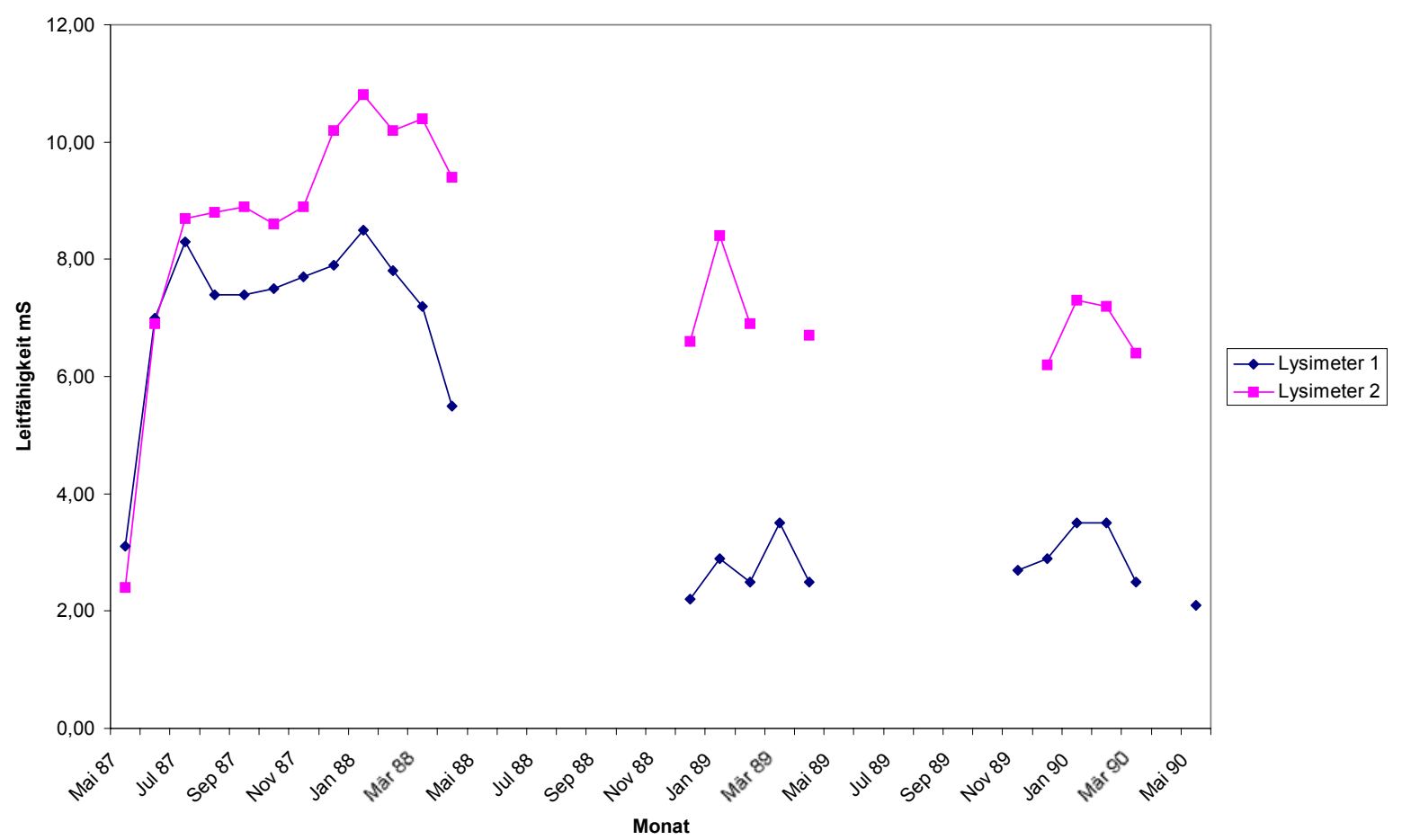

Abbildung 58: Verlauf der Leitfähigkeitswerte im Sickerwasser, Lysimeter 1 und 2

Tabelle 6-8: Berechnung der Umrechnungsfaktoren zur Bestimmung von Salzgehalten anhand der Leitfähigkeitswerte, Lysimeter 1 und 2

\begin{tabular}{l|c|ccccc} 
Lysimeter & $\begin{array}{c}\text { Probenahme- } \\
\text { Datum }\end{array}$ & $\begin{array}{c}\text { Abdampfrück- } \\
\text { stand g/l }\end{array}$ & $\begin{array}{c}\text { Asche } \\
\text { g/l }\end{array}$ & $\begin{array}{c}\text { Asche } \\
\text { \% der TM }\end{array}$ & $\begin{array}{c}\text { Leitfähigkeit } \\
\text { mS/cm }\end{array}$ & $\begin{array}{c}\text { Umrechnungs- } \\
\text { faktor }\end{array}$ \\
\hline \multirow{3}{*}{$\mathbf{1}$} & & & & & & \\
& $\mathbf{2 2 . 1 2 . 8 8}$ & 3,05 & 1,55 & 50,82 & 2,10 & 0,74 \\
& $\mathbf{2 2 . 1 2 . 8 8}$ & 3,05 & 1,62 & 53,11 & 2,10 & 0,77 \\
& $\mathbf{0 6 . 0 1 . 8 9}$ & 3,11 & 1,66 & 53,38 & 3,00 & 0,55 \\
& $\mathbf{1 7 . 0 4 . 8 9}$ & 3,04 & 1,70 & 55,92 & 2,50 & 0,68 \\
& $\mathbf{0 8 . 1 2 . 8 9}$ & 3,25 & 1,98 & 60,92 & 2,80 & 0,71 \\
& $\mathbf{0 3 . 0 1 . 9 0}$ & 4,15 & 2,75 & 66,27 & 3,50 & 0,79 \\
& $\mathbf{0 9 . 0 3 . 9 0}$ & 3,35 & 2,10 & 62,69 & 2,80 & 0,75 \\
$\mathbf{2}$ & Mittelwert & & & & & $\mathbf{0 , 7 1}$ \\
& $\mathbf{1 4 . 1 2 . 8 8}$ & 5,60 & 3,34 & 59,64 & 6,38 & 0,52 \\
& $\mathbf{2 2 . 1 2 . 8 8}$ & 6,44 & 3,58 & 55,59 & 6,80 & 0,53 \\
& $\mathbf{1 4 . 0 2 . 8 9}$ & 6,68 & 4,58 & 68,56 & 7,00 & 0,65 \\
& $\mathbf{0 3 . 0 1 . 9 0}$ & 7,59 & 5,42 & 71,41 & 7,30 & 0,74 \\
& $\mathbf{2 2 . 0 2 . 9 0}$ & 7,52 & 5,58 & 74,20 & 6,80 & 0,82 \\
& $\mathbf{0 9 . 0 3 . 9 0}$ & 7,34 & 4,74 & 64,58 & 6,40 & 0,74 \\
& $\mathbf{2 9 . 0 3 . 9 0}$ & 6,92 & 4,58 & 66,18 & 6,38 & 0,72 \\
& $\mathbf{M i t t e l w e r t}$ & & & & & $\mathbf{0 , 6 8}$
\end{tabular}

Der berechnete Mittelwert für den Umrechnungsfaktor beträgt 0,69. In der Literatur werden je nach Substrat und dem durchschnittlichen zu erwartenden Aquivalentgewicht der gelösten Salze unterschiedliche Werte zwischen 0,64 und 1,00 angegeben (JACKSON 1965, KRETSCHMAR 1972, GARVERT 1977). Für die Berechnung substratbezogener Salzgehalte ist die Berücksichtigung des Extraktionsverhältnisses erforderlich. Mittels dieser 
Umrechnungsfaktoren können Leitfähigkeitswerte näherungsweise in Salzgehalte umgerechnet werden. Verwendet man den hier für Sickerwasser ermittelten Wert von 0,69 zur Umrechnung, so erreichen die Salzgehalte im Sickerwasser der Lysimeter 1 und 2 im ersten Jahr Maxima von 5,5 g/l für Lysimeter 1 und 7,5 g/l für Lysimeter 2. In den folgenden beiden Versuchsjahren sinken sie bei Lysimeter 1 auf durchschnittlich 1,9 g/l und bei Lysimeter 2 auf 4,8 g/l ab. Die Salzgehalte der untersuchten Sickerwasser-Proben sind hoch. Sie liegen in der Größenordnung der Salzgehalte im Sickerwasser von Hausmüll-Deponien (LÄNDERARBEITSGEMEINSCHAFT ABFALL 1985).

Zur Berechnung der anorganischen und organischen Salzgehalte sei auf das Kapitel Ionenbilanz verwiesen (Kapitel 6.5.13).

\section{Kleinlysimeter}

Die höchsten Leitfähigkeitswerte im Sickerwasser der Kleinlysimeter treten direkt nach Versuchsbeginn im Juni 1987 auf. Im weiteren Verlauf der Sickerwasserspende sinken die Werte ab und steigen im Frühjahr 1988 wiederum an. Die Abbildung 59 zeigt den Verlauf der Leitfähigkeit in den Sickerwasser-Proben der Lysimeter 3 bis 8.

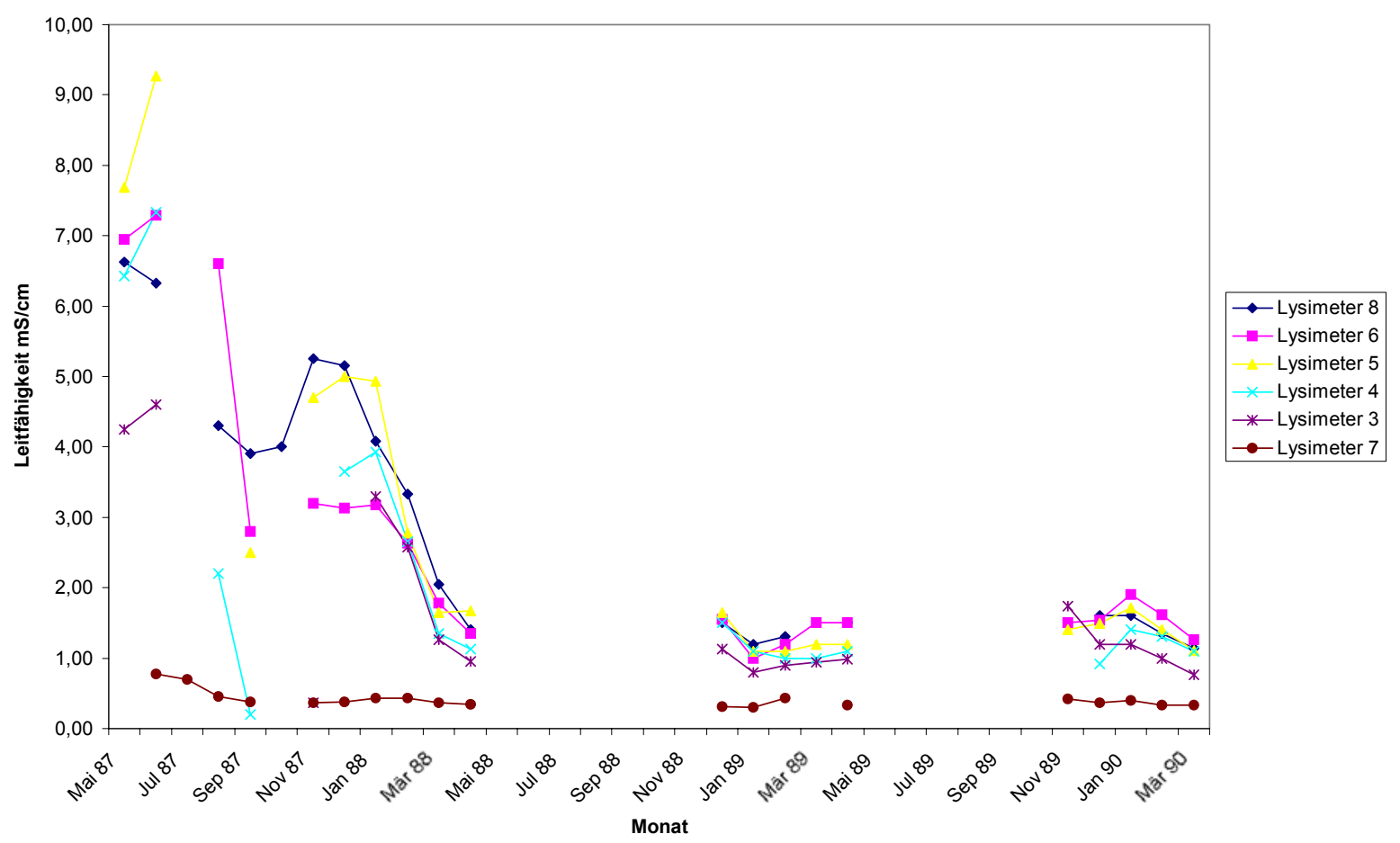

Abbildung 59: Verlauf der Leitfähigkeitswerte im Sickerwasser, Lysimeter 3 bis 8

$\mathrm{Zu}$ Versuchsbeginn erzielt Lysimeter 5 mit $9,3 \mathrm{mS} / \mathrm{cm}$ den höchsten Wert. Die Leitfähigkeiten in den Sickerwasser-Proben der Lysimeter 8, 6, 4 und 3 liegen zwischen 7,3 und $4,6 \mathrm{mS} / \mathrm{cm}$. Auch bei Lysimeter 7, der reinen Lössboden-Variante, weist das Sickerwasser zu Versuchsbeginn höhere Leitfähigkeitswerte auf als in der Folgezeit: Die Werte im Juni /Juli 1987 erreichen 0,74 mS/cm, in den darauffolgenden Monaten liegen sie durchschnittlich bei $0,37 \mathrm{mS} / \mathrm{cm}$. Die Leitfähigkeitswerte für die reine Kompost-Variante und die Kompost-Löss-Mischungen liegen in den Versuchsjahren 88/89 und 89/90 bei durchschnittlich $1,3 \mathrm{mS} / \mathrm{cm}$. Dabei zeigen sich für die verschiedenen Mischungen unterschiedliche Trends: Die Werte für Lysimeter 6 mit dem höchsten Kompostanteil der Mischungsvarianten sind im ersten Versuchsjahr vergleichsweise niedrig, im zweiten und dritten Versuchjahr erzielen sie die höchsten Werte. Die Werte für Lysimeter 5 sind durchgängig vergleichsweise hoch, Lysimeter 8 mit reinem Kompost erreicht nur im Winter 
87 die höchsten Werte gegenüber den übrigen Lysimetern. Für alle Kompost-Lysimeter deuten sich Zunahmen der Leitfähigkeitswerte während der Sickerwasserbildung in den Wintermonaten an. Für die Deutung dieser Effekte, wie auch der Unterschiede zwischen den Lysimetern sind Lösungsvorgänge, Temperatureinflüsse, besonders aber wohl Mineralisationsprozesse zu berücksichtigen.

\subsubsection{N-Gehalte: $\mathrm{N}_{t}, \mathrm{NH}_{4}, \mathrm{NO}_{3}, \mathrm{~N}_{\text {org }}$}

\section{Großlysimeter}

Die Abbildung 60 zeigt den Verlauf der $\mathrm{N}_{\min }$ - Konzentrationen von Mai 87 bis Mai 90 und der $\mathrm{N}_{\text {org }}$-Konzentrationen ab Dez 88 bis Mai 90 im Sickerwasser der Lysimeter 1 und 2 anhand der Monatsmittelwerte. In den ersten vier Monaten der Versuchsbetreuung addieren sich die $\mathrm{N}_{\text {min }}$-Konzentrationen aus den $\mathrm{NO}_{3}-\mathrm{N}$ - und geringen $\mathrm{NH}_{4}-\mathrm{N}-\mathrm{Gehalten}$. Ab September 87 ist kein $\mathrm{NH}_{4}$ mehr im Sickerwasser der Großlysimeter nachweisbar (siehe Tabellen 1-57 und 1-58 im Anhang). Die Nitrat-Gehalte bleiben in der gesamten Versuchszeit auf einem hohen Niveau, wobei im ersten Untersuchungsjahr Lysimeter 1 die höchsten Werte von bis zu $700 \mathrm{mg} \mathrm{NO}_{3}-\mathrm{N}$ pro I Sickerwasser freisetzt und in den beiden folgenden Untersuchungsjahren Lysimeter 2 die höheren Werte im Sickerwasser erreicht. Die $\mathrm{N}_{\text {org }}$-Gehalte im Sickerwasser erreichen im Schnitt $29 \%$ der für total-N $\left(N_{t}\right)$ berechneten Werte.

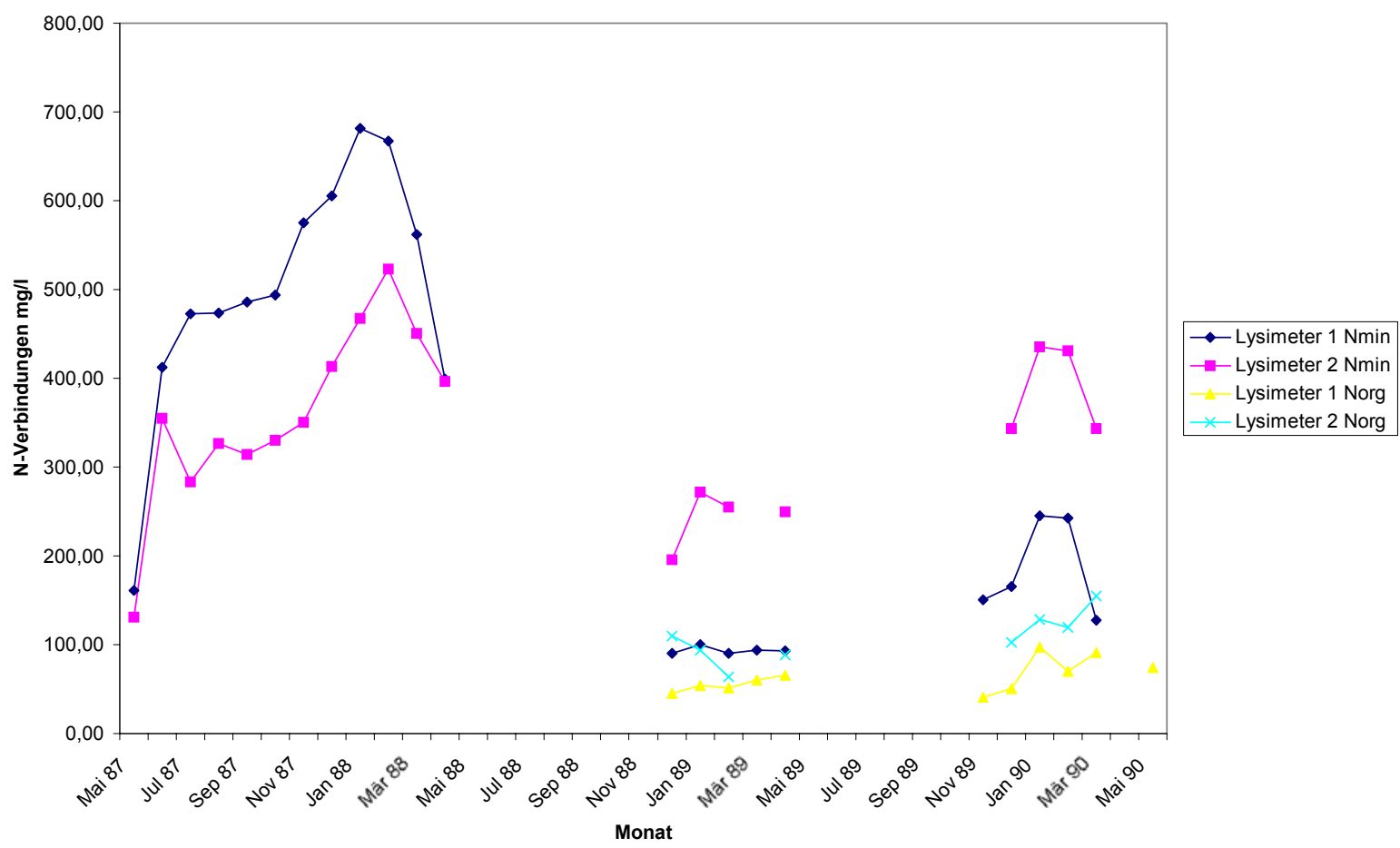

Abbildung 60: Verlauf der $\mathrm{N}_{\min }$ - und $\mathrm{N}_{\text {org }}$-Gehalte im Sickerwasser, Lysimeter 1 und 2

Die Tabellen 6-9 und 6-10 zeigen die für die Einzelproben anhand der C/N-Bestimmung der Abdampfrückstände berechneten $\mathrm{N}_{t}$ und $\mathrm{N}_{\text {org }}$-Gehalte. Aus den im Abdampfrückstand bestimmten $\mathrm{N}_{\mathrm{t}}$-Werten wurden durch Subtraktion der $\mathrm{N}_{\text {min }}$-Gehalte die im Sickerwasser enthaltenen $\mathrm{N}_{\text {org }}$-Werte berechnet. An einigen Proben wurden zusätzlich Kjeldahl-Aufschlüsse durchgeführt und deren Ergebnisse mit den berechneten Werten verglichen. Es zeigt sich bis auf die Probe vom 08.01.91 für Lysimeter 2 - eine gute Übereinstimmung zwischen beiden Methoden. 
Tabelle 6-9: Abdampfrückstände, C-, N-Gehalte und

Verhältnisse sowie N-Verbindungen im Sickerwasser, Einzelproben, Lysimeter 1

\begin{tabular}{|c|c|c|c|c|c|c|c|c|c|c|}
\hline \multirow[b]{2}{*}{$\begin{array}{l}\text { Probenahme- } \\
\text { Datum }\end{array}$} & \multicolumn{3}{|c|}{ Lysimeter 1} & \multirow[b]{2}{*}{$\begin{array}{c}\text { Ct/Nt- } \\
\text { Verhältnis } \\
\text { im ADR }\end{array}$} & & \multirow[b]{2}{*}{$\begin{array}{c}\mathrm{NO}_{3}-\mathrm{N} \\
\mathrm{mg} / \mathrm{l}\end{array}$} & \multirow[b]{2}{*}{$\begin{array}{c}\mathrm{N}_{\text {org }} \text { ber. } \\
\mathrm{mg} / \mathrm{l}\end{array}$} & \multirow[b]{2}{*}{$\begin{array}{c}\mathrm{N}_{\text {org }} \text { gem. } \\
\mathrm{mg} / \mathrm{l}\end{array}$} & \multirow[b]{2}{*}{$\begin{array}{c}N_{\text {org }} \text { ber } \\
\%\end{array}$} \\
\hline & $\begin{array}{l}\text { Abdampf- } \\
\text { rückstand } \\
(A D R) g / l\end{array}$ & $\begin{array}{c}\mathrm{C}_{\mathrm{t}} \text {-Gehalt } \\
\% \text { ADR TM }\end{array}$ & $\begin{array}{c}\mathbf{N}_{\mathrm{t}} \text {-Gehalt } \\
\% \text { ADR TM }\end{array}$ & & $\begin{array}{c}\mathrm{N}_{\mathrm{t}} \\
\mathrm{mg} / \mathrm{l}\end{array}$ & $\begin{array}{c}\mathrm{NO}_{3}-\mathrm{N}+ \\
\mathrm{N}_{\text {org }} \text { gem. } \\
\mathrm{mg} / \mathrm{l}\end{array}$ & & & & \\
\hline 22.07 .88 & 2,01 & 9,58 & 7,66 & 1,3 & 153,93 & & 122,50 & 31,43 & & 20,42 \\
\hline 14.12 .88 & 2,50 & 21,40 & 4,96 & 4,3 & 124,00 & 126,28 & 86,52 & 37,48 & 39,76 & 30,23 \\
\hline 22.12.88 & 3,05 & 22,16 & 4,88 & 4,5 & 148,78 & & 85,30 & 63,48 & & 42,67 \\
\hline 06.01 .89 & 3,11 & 20,72 & 5,06 & 4,1 & 157,46 & & 108,70 & 48,76 & & 30,97 \\
\hline 11.01 .89 & 3,12 & 21,15 & 4,87 & 4,3 & 151,82 & & 91,80 & 60,02 & & 39,53 \\
\hline 14.02 .89 & 2,89 & 20,88 & 4,87 & 4,3 & 140,69 & & 94,20 & 46,49 & & 33,04 \\
\hline 27.02.89 & 2,81 & 22,51 & 5,04 & 4,5 & 141,62 & & 86,10 & 55,52 & & 39,21 \\
\hline 06.03 .89 & 3,03 & 22,38 & 5,10 & 4,4 & 154,47 & & 94,20 & 60,27 & & 39,02 \\
\hline 17.04 .89 & 3,04 & 22,20 & 5,21 & 4,3 & 158,29 & & 92,60 & 65,69 & & 41,50 \\
\hline 10.11 .89 & 3,11 & 18,30 & 6,14 & 3,0 & 190,95 & & 150,54 & 40,41 & & 21,16 \\
\hline 08.12 .89 & 3,25 & 17,76 & 6,21 & 2,9 & 201,83 & & 144,10 & 57,73 & & 28,60 \\
\hline 15.12 .89 & 3,01 & 13,52 & 7,61 & 1,8 & 229,06 & & 186,76 & 42,30 & & 18,47 \\
\hline 18.12 .89 & & & & & & & 103,85 & & & \\
\hline 03.01 .90 & 4,15 & 14,49 & 8,24 & 1,8 & 341,96 & & 244,72 & 97,24 & & 28,44 \\
\hline 05.02 .90 & 3,77 & 13,89 & 8,42 & 1,6 & 317,43 & & 261,22 & 56,21 & & 17,71 \\
\hline 16.02 .90 & 4,07 & 15,17 & 8,14 & 1,9 & 331,30 & & 252,37 & 78,93 & & 23,82 \\
\hline 22.02 .90 & 3,79 & 17,35 & 7,63 & 2,3 & 289,18 & & 214,54 & 74,64 & & 25,81 \\
\hline 09.03 .90 & 3,35 & 19,79 & 7,07 & 2,8 & 236,85 & & 154,96 & 81,89 & & 34,57 \\
\hline 29.03 .90 & 3,23 & 21,94 & 6,18 & 3,6 & 199,61 & & 99,82 & 99,79 & & 49,99 \\
\hline 11.05 .90 & 2,88 & 23,15 & 5,59 & 4,1 & 160,99 & & 95,76 & 65,23 & & 40,52 \\
\hline 23.05 .90 & 3,18 & 23,29 & 5,66 & 4,1 & 179,99 & & 97,20 & 82,79 & & 46,00 \\
\hline 08.01 .91 & 3,96 & 9,48 & 9,16 & 1,0 & 362,74 & 383,04 & 332,92 & 29,82 & 50,12 & 8,22 \\
\hline 09.01 .91 & 3,30 & 10,80 & 8,65 & 1,2 & 285,45 & 280,28 & 255,36 & 30,09 & 24,92 & 10,54 \\
\hline 11.01 .91 & 3,11 & 11,46 & 8,45 & 1,4 & 262,80 & 251,72 & 225,96 & 36,84 & 25,76 & 14,02 \\
\hline
\end{tabular}

Tabelle 6-10: Abdampfrückstände, C-/N-Gehalte und Verhältnisse sowie N-Verbindungen im Sickerwasser, Einzelproben, Lysimeter 2

\begin{tabular}{|c|c|c|c|c|c|c|c|c|c|c|}
\hline \multirow[b]{2}{*}{$\begin{array}{l}\text { Probenahme- } \\
\text { Datum }\end{array}$} & \multicolumn{10}{|c|}{ Lysimeter 2} \\
\hline & $\begin{array}{l}\text { Abdampf- } \\
\text { rückstand } \\
(A D R) g / l\end{array}$ & $\begin{array}{l}\mathrm{C}_{\mathrm{t}} \text {-Gehalt } \\
\% \text { ADR TM }\end{array}$ & $\begin{array}{l}\mathrm{N}_{\mathrm{t}} \text {-Gehalt } \\
\% \text { ADR TM }\end{array}$ & $\begin{array}{c}\text { Ct/Nt- } \\
\text { Verhältnis } \\
\text { im ADR }\end{array}$ & $\begin{array}{c}\mathrm{N}_{\mathrm{t}} \\
\mathrm{mg} / \mathrm{l}\end{array}$ & $\begin{array}{c}\mathrm{NO}_{3}-\mathrm{N}+ \\
\mathrm{N}_{\text {org }} \text { gem. } \\
\text { mg/l }\end{array}$ & $\begin{array}{c}\mathrm{NO}_{3}-\mathrm{N} \\
\mathrm{mg} / \mathrm{l}\end{array}$ & $\begin{array}{c}\mathrm{N}_{\text {org }} \text { ber. } \\
\mathrm{mg} / \mathrm{l}\end{array}$ & $\begin{array}{c}\mathrm{N}_{\text {org }} \text { gem. } \\
\mathrm{mg} / \mathrm{l}\end{array}$ & $\begin{array}{c}N_{\text {org }} \text { ber. } \\
\%\end{array}$ \\
\hline 22.07.88 & 4,32 & 6,92 & 4,92 & 1,4 & 212,37 & & 204,40 & 7,97 & & 3,75 \\
\hline 14.12 .88 & 5,60 & 10,13 & 4,78 & 2,1 & 567,28 & & 213,00 & 354,28 & & 62,45 \\
\hline 22.12 .88 & 6,44 & 10,14 & 5,32 & 1,9 & 342,80 & & 178,70 & 164,10 & & 47,87 \\
\hline 06.01 .89 & 7,00 & 10,04 & 5,23 & 1,9 & 366,03 & & 276,90 & 89,13 & & 24,35 \\
\hline 11.01 .89 & 6,73 & 9,70 & 5,41 & 1,8 & 364,36 & & 266,50 & 97,86 & & 26,86 \\
\hline 14.02 .89 & 6,68 & 10,57 & 5,06 & 2,1 & 338,01 & & 274,50 & 63,51 & & 18,79 \\
\hline 27.02 .89 & 6,01 & 11,02 & 4,97 & 2,2 & 298,88 & & 235,10 & 63,78 & & 21,34 \\
\hline \multicolumn{11}{|l|}{06.03 .89} \\
\hline 17.04 .89 & 6,08 & 11,47 & 5,57 & 2,1 & 338,35 & & 249,60 & 88,75 & & 26,23 \\
\hline \multicolumn{11}{|l|}{10.11 .89} \\
\hline \multicolumn{11}{|l|}{08.12 .89} \\
\hline 15.12 .89 & 6,67 & 9,22 & 6,68 & 1,4 & 445,56 & & 343,74 & 101,82 & & 22,85 \\
\hline \multicolumn{11}{|l|}{18.12 .89} \\
\hline 03.01 .90 & 7,59 & 10,06 & 7,43 & 1,4 & 564,20 & & 435,51 & 128,69 & & 22,81 \\
\hline 05.02 .90 & 7,42 & 10,19 & 7,47 & 1,4 & 554,48 & & 422,63 & 131,85 & & 23,78 \\
\hline 16.02 .90 & 7,61 & 10,55 & 7,06 & 1,5 & 537,27 & & 417,80 & 119,47 & & 22,24 \\
\hline 22.02 .90 & 7,52 & 11,42 & 7,46 & 1,5 & 560,98 & & 453,22 & 107,76 & & 19,21 \\
\hline 09.03 .90 & 7,34 & 13,95 & 7,02 & 2,0 & 515,46 & & 355,01 & 160,45 & & 31,13 \\
\hline 29.03 .90 & 6,92 & 15,22 & 6,96 & 2,2 & 481,82 & & 332,47 & 149,35 & & 31,00 \\
\hline \multicolumn{11}{|l|}{11.05 .90} \\
\hline \multicolumn{11}{|l|}{23.05 .90} \\
\hline 08.01 .91 & 6,93 & 13,01 & 7,29 & 1,8 & 505,20 & 362,32 & 332,92 & 172,28 & 29,40 & 34,10 \\
\hline 09.01 .91 & 4,23 & 13,77 & 7,36 & 1,9 & 311,18 & 293,72 & 255,36 & 55,82 & 38,36 & 17,94 \\
\hline
\end{tabular}

Die $\mathrm{N}_{\mathrm{t}}$-Gehalte im Sickerwasser bleiben auch in dem nicht mehr vollständig erhobenen vierten Untersuchungsjahr hoch, wie die Standprobe vom 08.01. und die Durchflussprobe vom 09.01.91 zeigen. Die Abbildungen 61 und 62 geben den Verlauf der $\mathrm{C}_{t}$ - und $\mathrm{N}_{\mathrm{t}}$-Gehalte und der $\mathrm{C}_{\mathrm{t}} / \mathrm{N}_{\mathrm{t}}$-Verhältnisse in den Einzelproben wieder. 


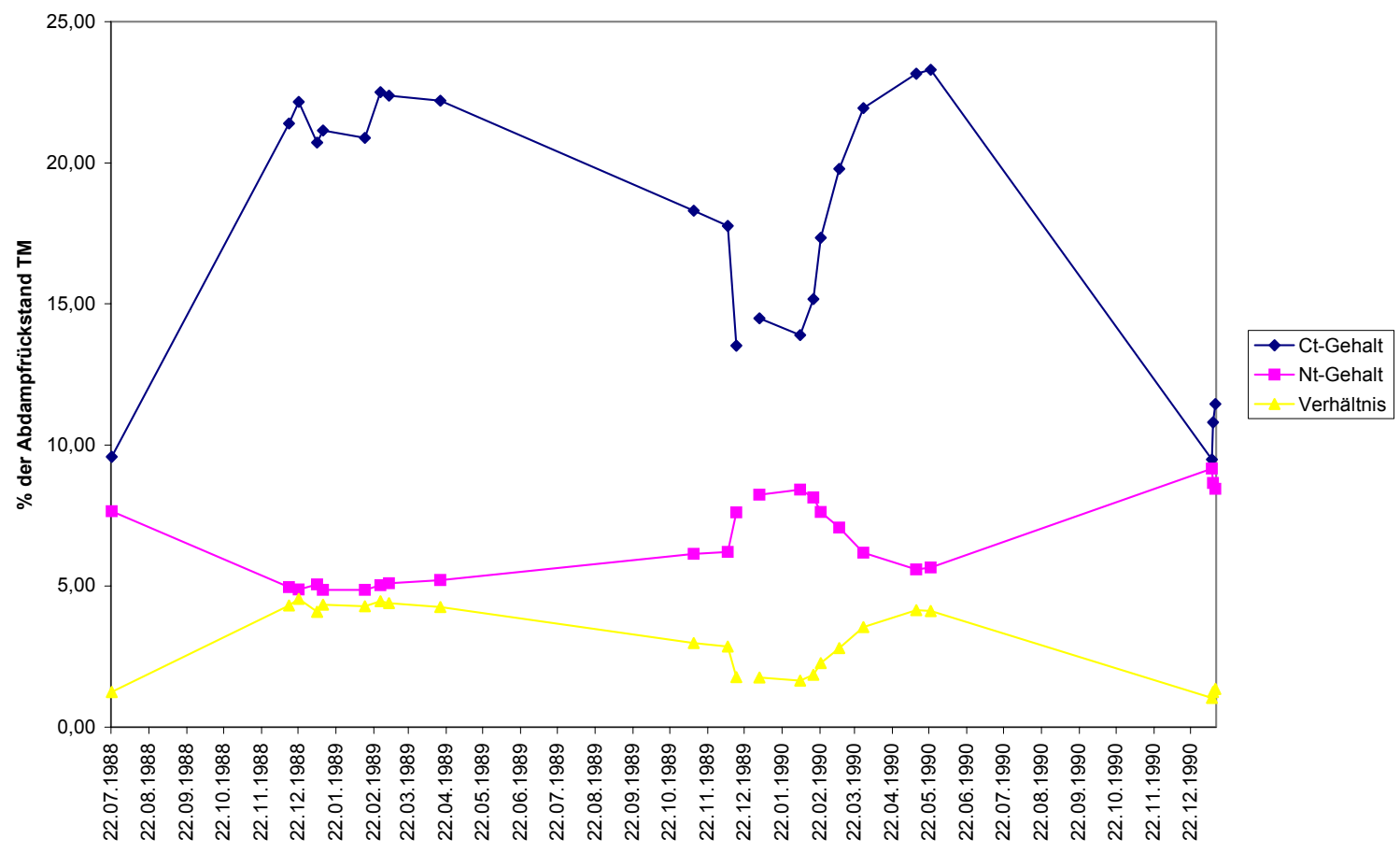

Abbildung 61: Verlauf der $C_{t^{-}}, N_{t^{-}}$Gehalte und der $C_{t} / N_{t^{-}}$ Verhältnisse im Sickerwasser, Lysimeter 1

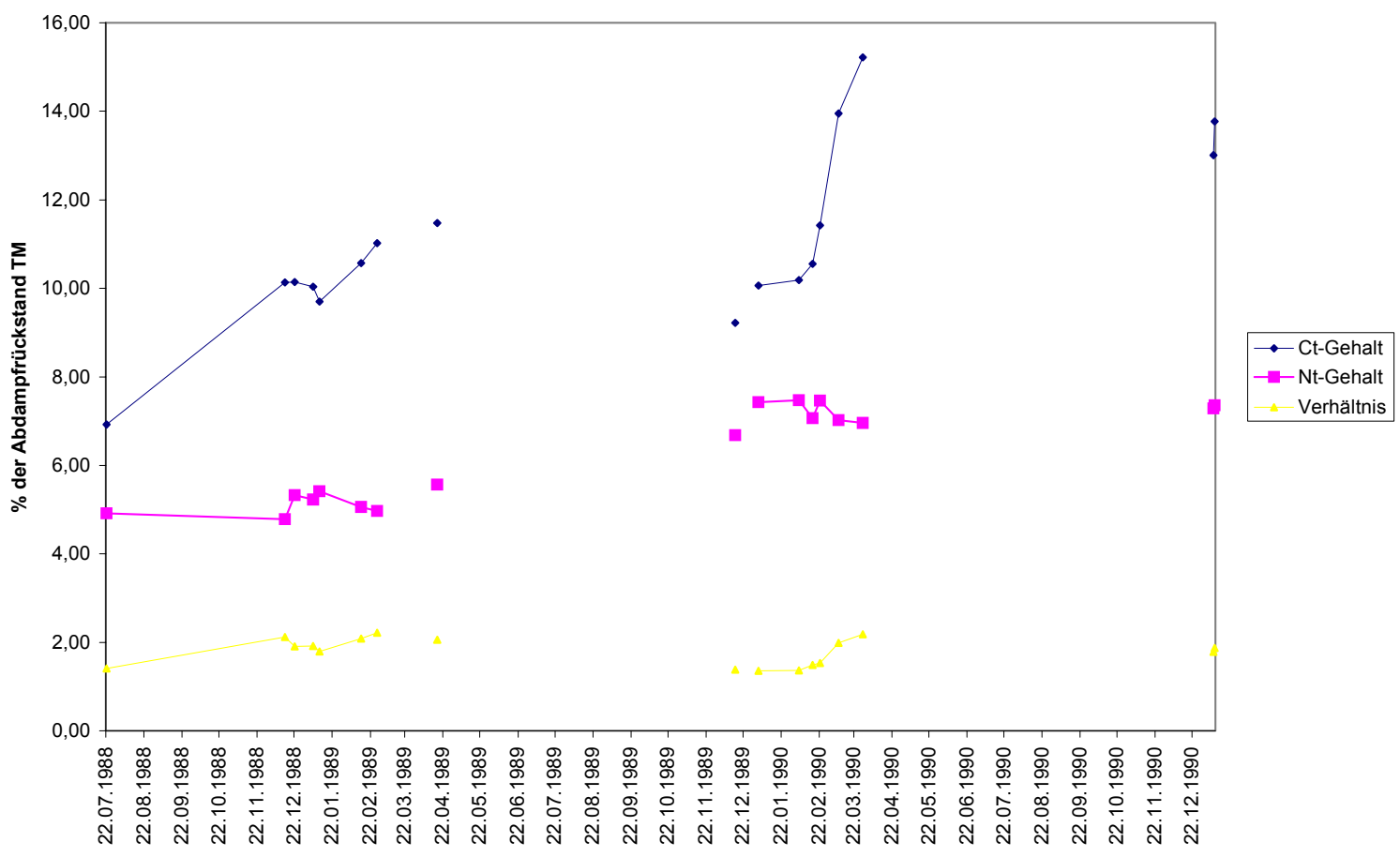

Abbildung 62: Verlauf der $\mathrm{C}_{\mathrm{t}^{-}}, \mathrm{N}_{\mathrm{t}}$-Gehalte und der $\mathrm{C}_{\mathrm{t}} / \mathrm{N}_{\mathrm{t}^{-}}$ Verhältnisse im Sickerwasser, Lysimeter 2

Bei Lysimeter 1 verlaufen die C und N-Gehalte im Sickerwasser zum Teil entgegengesetzt, das heißt die C-Gehalte steigen während die N-Gehalte fallen und umgekehrt. Bei Lysimeter 2 dagegen verlaufen die Änderungen der $\mathrm{C}$ - und N-Gehalte überwiegend synchron. Die $\mathrm{C} / \mathrm{N}-$ Verhältnisse der Abdampfrückstände sind sehr niedrig. Sie liegen für Lysimeter 1 zwischen 1 und 4,5, für Lysimeter 2 in einen engeren Bereich zwischen 1,4 und 2,2. 
Die $\mathrm{N}_{t}$ - und $\mathrm{N}_{\min }-$ Konzentrationen im Sickerwasser steigen vom zweiten zum dritten Untersuchungsjahr an, wie die Abbildungen 63 und 64 mit den Einzeldaten für die Lysimeter 1 und 2 zeigen. Dieser Anstieg ist bei Lysimeter 1 auch im vierten Jahr noch erkennbar. 


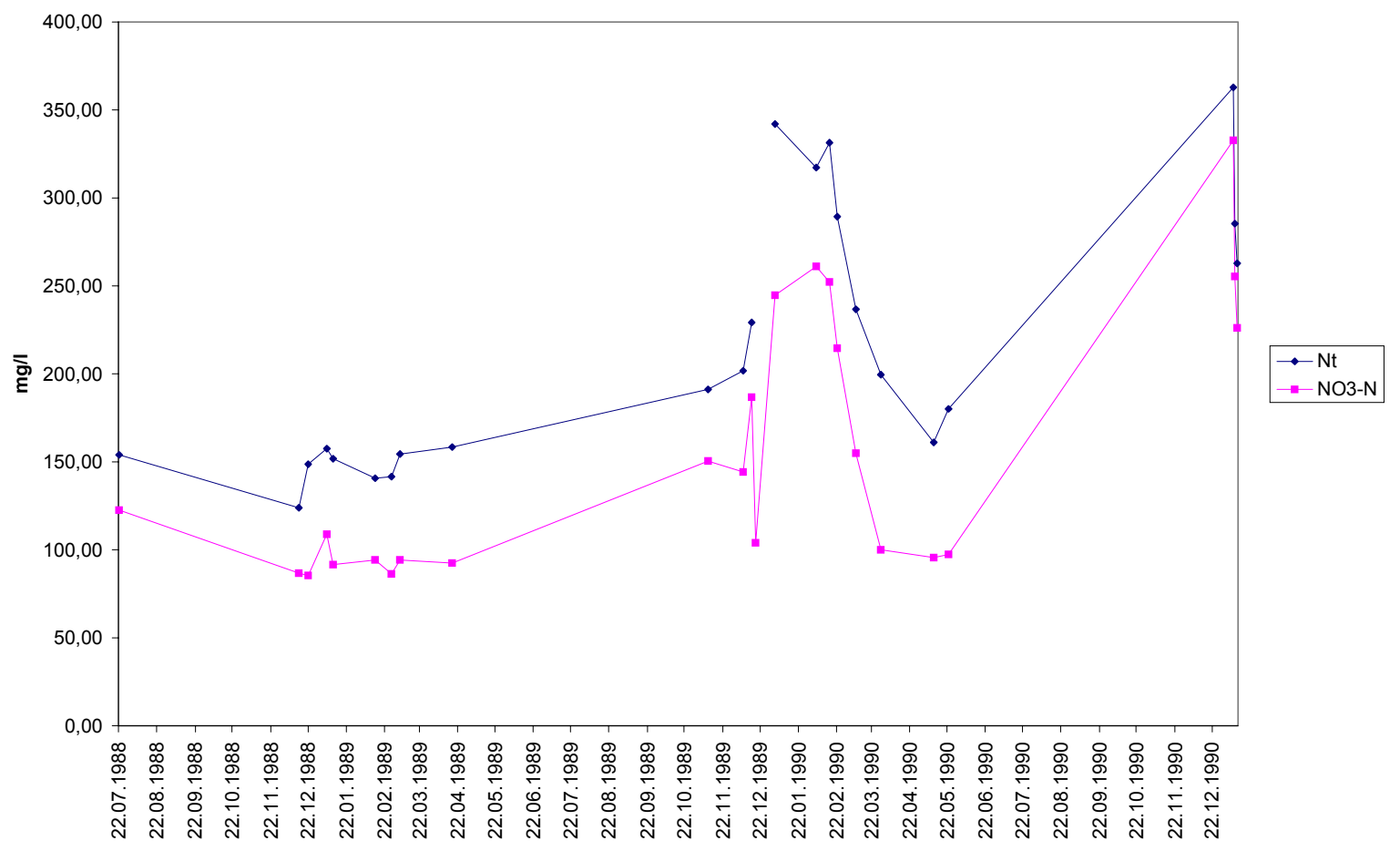

Abbildung 63: Verlauf der $\mathrm{N}_{\mathrm{t}}$ - und $\mathrm{NO}_{3}-\mathrm{N}-$ Gehalte im Sickerwasser, Lysimeter 1

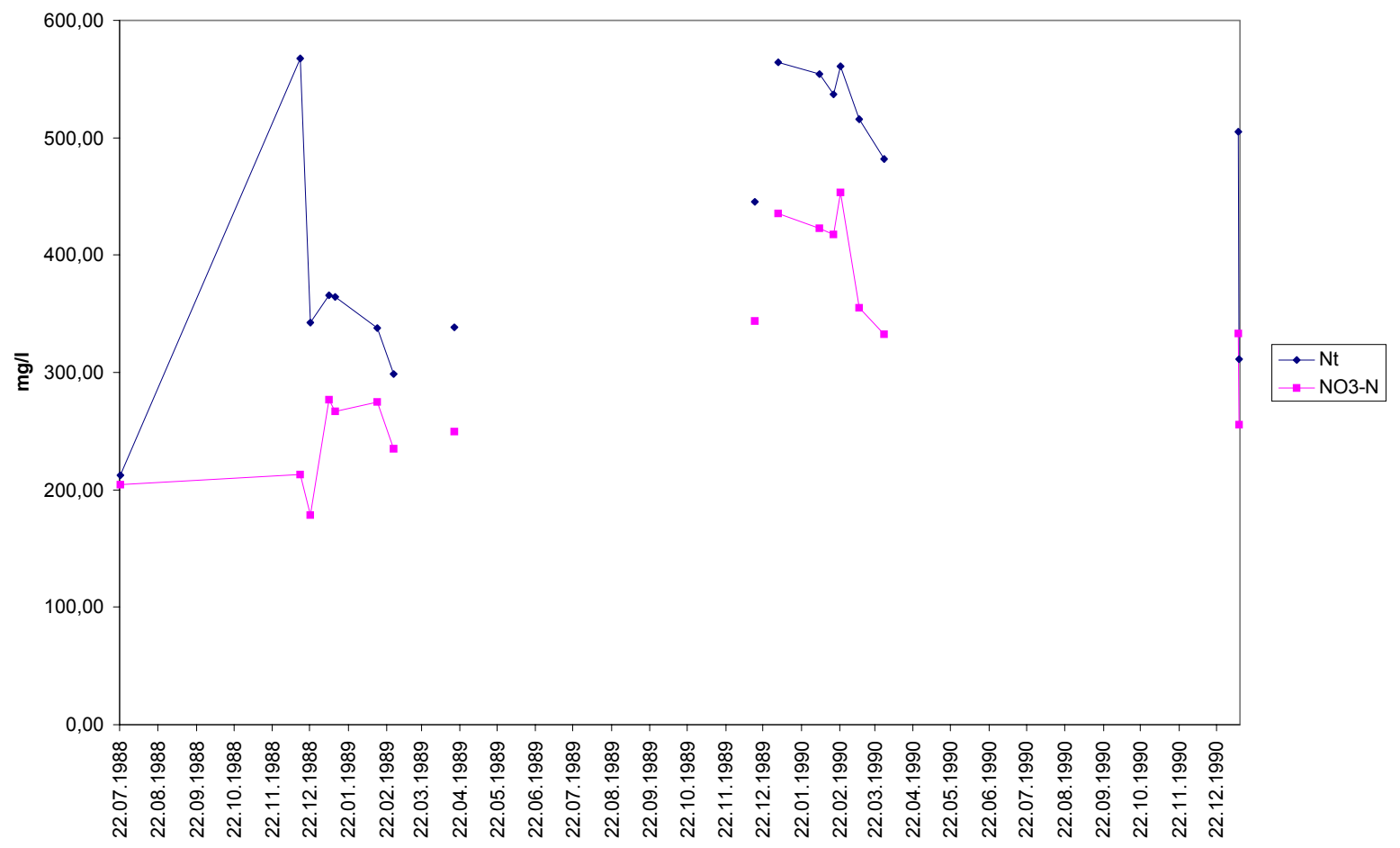

Abbildung 64: Verlauf der $\mathrm{N}_{\mathrm{t}}$ - und $\mathrm{NO}_{3}-\mathrm{N}-$ Gehalte im Sickerwasser, Lysimeter 2

Kleinlysimeter

Die Abbildungen 65 und 66 zeigen den Verlauf der $\mathrm{NO}_{3}$-Konzentrationen im Sickerwasser der Kleinlysimeter. Bei allen sechs Lysimetern liegen sehr hohe Werte für $\mathrm{NO}_{3}-\mathrm{N}$ direkt zu Versuchsbeginn vor. Bei Lysimeter 7, der reinen Löss-Variante, sinken die Werte schnell 
auf ein gleichbleibendes niedriges Niveau von durchschnittlich $5 \mathrm{mg} / \mathrm{N} \mathrm{NO}_{3}-\mathrm{N}$ im Sickerwasser ab. Die Schwankungen sind geringer als bei Lysimeter 1 und 2. Über die Versuchszeit hinweg ist eine Abnahme der $\mathrm{NO}_{3}-\mathrm{N}$-Konzentration im Sickerwasser zu beobachten. Die Unterschiede zwischen der reinen Kompost-Variante und den Kompost-Mischungen sind gering. Die $\mathrm{NO}_{3}-\mathrm{N}-$ Konzentration im Sickerwasser der reinen Kompost-Variante ist niedriger als bei der $90 \%$-Kompost-Variante, was auf das geringere Kompost-Einfüllvolumen zurückzuführen ist. 


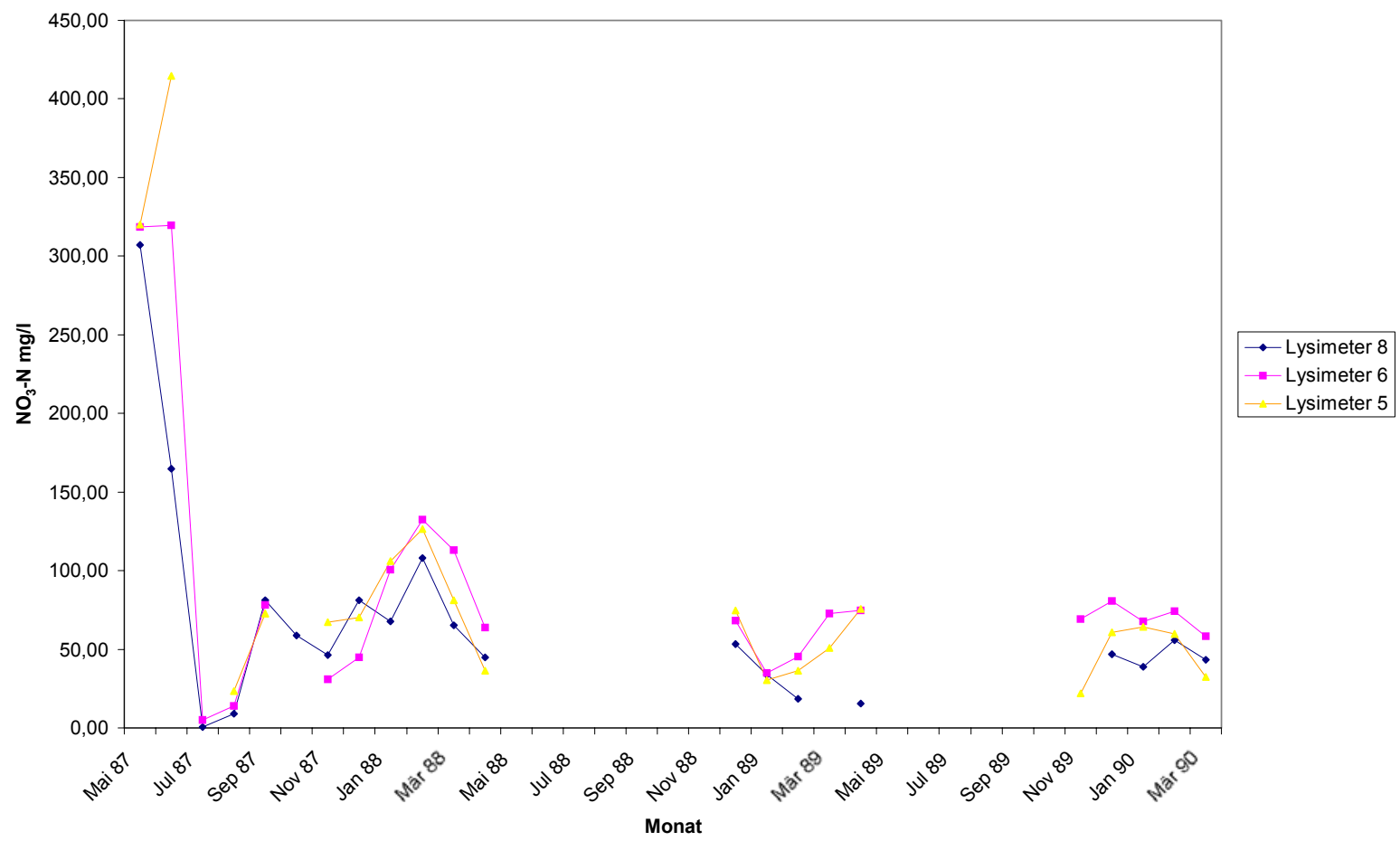

Abbildung 65: Verlauf der $\mathrm{NO}_{3}-\mathrm{N}-\mathrm{Konzentrationen} \mathrm{im}$ Sickerwasser, Lysimeter 8, 6 und 5

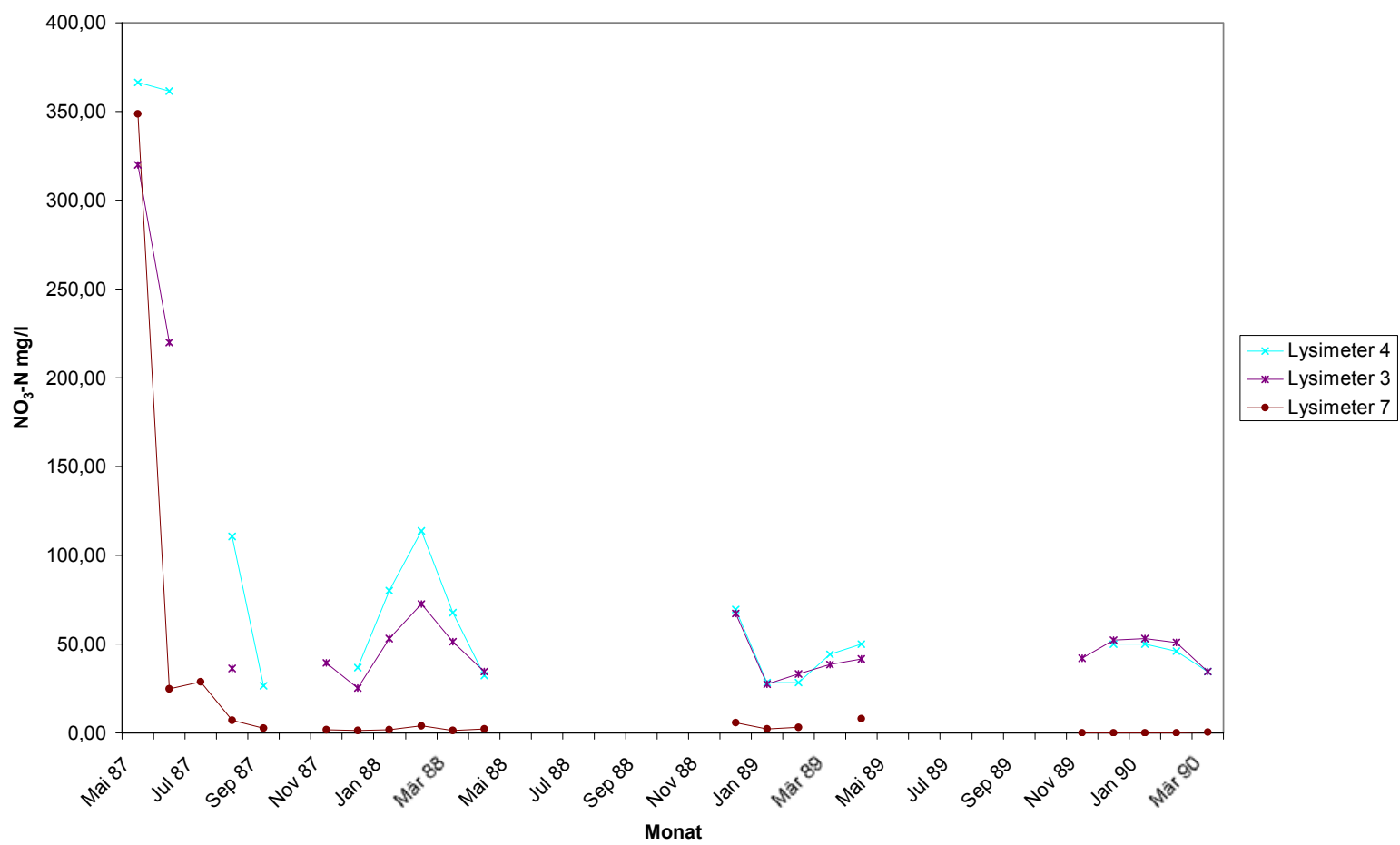

Abbildung 66: Verlauf der $\mathrm{NO}_{3}-\mathrm{N}-$ Konzentrationen im Sickerwasser, Lysimeter 4, 3 und 7

Die $\mathrm{N}_{\text {org }}$-Konzentrationen, die anhand der $\mathrm{N}_{\mathrm{t}}$-Gehalte der Abdampfrückstände für die Lysimeter 3 bis 6 und 8 berechnet wurden, liegen im Schnitt bei 32\% des $N_{t}$-Gehaltes. 


\subsubsection{Organische Substanz und Extinktion}

\section{Großlysimeter}

Das Filtrat des Sickerwassers wird auf seinen Gehalt an gesamtem organischen C untersucht, was hier als DOC des Gesamt-Sickerwassers bezeichnet wird.

Die DOC-Konzentration des Sickerwassers der Großlysimeter nimmt während der Versuchszeit zu. Sie steigt von durchschnittlich $450 \mathrm{mg} \mathrm{DOC/l} \mathrm{im} \mathrm{ersten} \mathrm{Jahr} \mathrm{bei} \mathrm{Lysimeter} 2$ auf $1160 \mathrm{mg} \mathrm{DOC/l}$, bei Lysimeter 1 auf $740 \mathrm{mg}$ DOC/l am Ende des Freilandversuches.

Abbildung 67 zeigt den Verlauf der gefundenen Monatsmittelwerte an gelöstem organischen Kohlenstoff (DOC) und anorganischem Kohlenstoff $\left(\mathrm{HCO}_{3}-\mathrm{C}\right)$ für die beiden Großlysimeter in den Perioden, in denen Sickerwasser geliefert wurde. Die Zeitabschnitte in denen keine Konzentrationen eingezeichnet sind, sind frei von gebildetem Sickerwasser.

Da die $\mathrm{HCO}_{3}$-Gehalte im Laufe der Versuchszeit abnehmen, sinkt der $\mathrm{HCO}_{3}$-C-Anteil am Gesamt-C im Sickerwasser von 37 auf $15 \%$ bei Lysimeter 1, bei Lysimeter 2 mit höheren $\mathrm{HCO}_{3}$-Gehalten zu Versuchsbeginn von 49 auf $12 \%$.

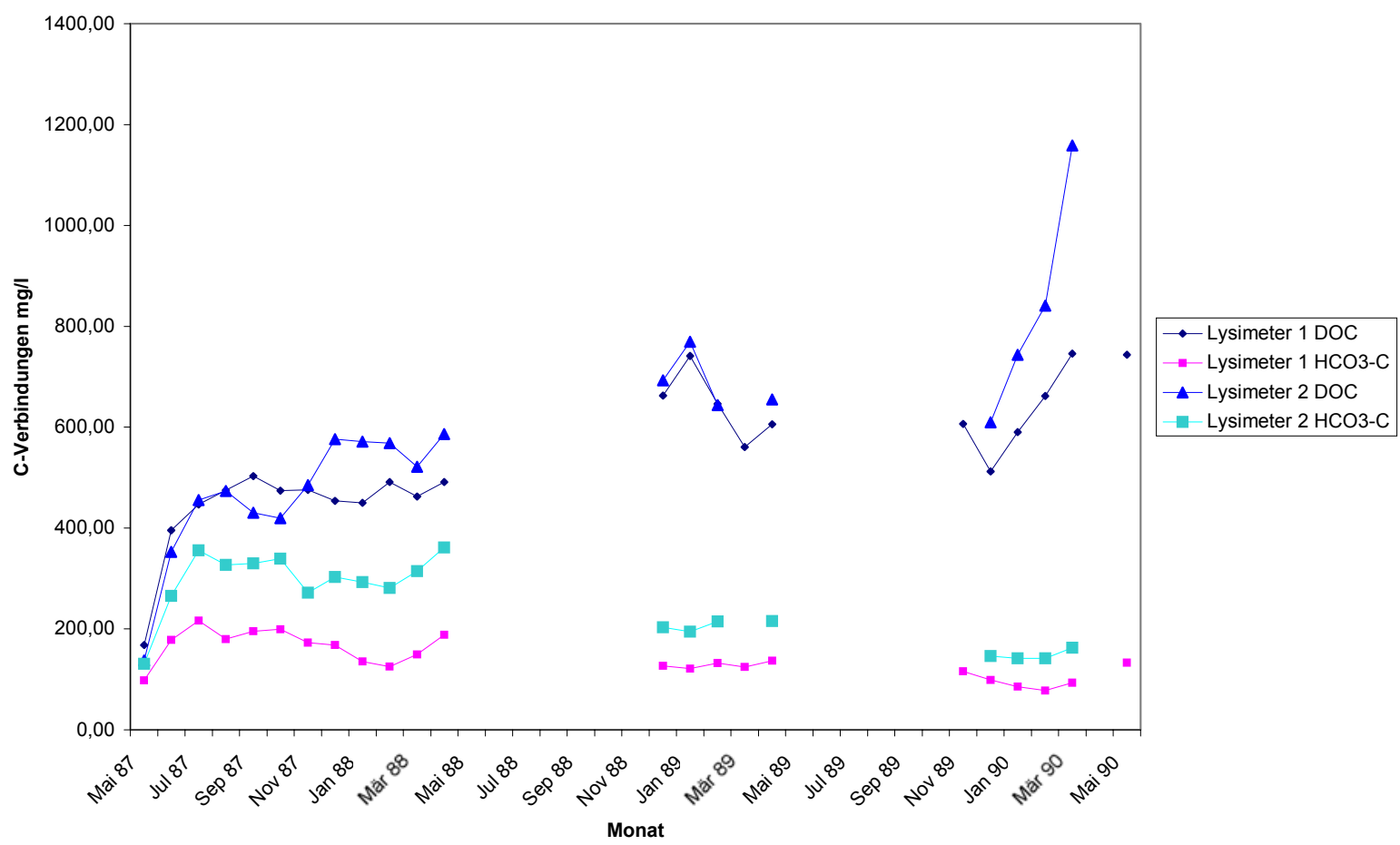

Abbildung 67: Verlauf der DOC- und $\mathrm{HCO}_{3}-\mathrm{C}-\mathrm{Konzentratio-}$ nen im Sickerwasser, Monatsmittelwerte, Lysimeter 1 und 2

Die Tabellen 6-11 und 6-12 beziehen sich auf die Filtrate des Sickerwassers. Sie bringen die Abdampfrückstände, die C-Gehalte und die Extinktionen der Sickerwasser-Einzelproben von Juli 1988 bis Januar 1991. Die analytische Bestimmung der $\mathrm{C}_{\mathrm{t}}$-Gehalte (Sp. 4) in den Abdampfrückständen (Sp. 2) ergibt im Vergleich zur Berechnung des $\mathrm{C}_{\mathrm{t}}$-Gehaltes als Summe von $\mathrm{DOC}$ und $\mathrm{HCO}_{3}-\mathrm{C}(\mathrm{Sp} .7)$ deutlich geringere Werte: Der $\mathrm{C}_{\mathrm{t}}$-Gehalt liegt (vergl. Sp. 8) bei rund $80 \%$ der Summe aus $\mathrm{DOC}$ und $\mathrm{HCO}_{3}-\mathrm{C}$. Dies ist vermutlich auf eine Zerstörung und Verdampfung von organischen Verbindungen beim Eindampfen der Probe zurückzuführen. Dies steht im Gegensatz zur Bestimmung von $\mathrm{N}_{t}$ aus dem Abdampfrückstand mittels $\mathrm{C}-/ \mathrm{N}$-Analysator. Das Verfahren ist somit nicht für die Bestimmung von $\mathrm{C}_{t}$ geeignet. Das heißt, auch die angegebenen $\mathrm{C} / \mathrm{N}-$ Verhältnisse in Kapitel 6.5.6 müssen als zu niedrig angesehen werden. 
Tabelle 6-11: Abdampfrückstände, C-Gehalte und Extinktionen der Sickerwasser Einzelproben, Lysimeter 1

\begin{tabular}{|c|c|c|c|c|c|c|c|c|c|c|c|}
\hline \multirow[b]{3}{*}{$\begin{array}{l}\text { Probenahme- } \\
\text { Datum }\end{array}$} & 2 & 3 & 4 & 5 & 6 & 7 & 8 & 9 & 10 & 11 & 12 \\
\hline & \multicolumn{11}{|c|}{ Lysimeter 1} \\
\hline & $\begin{array}{l}\text { Abdampf- } \\
\text { rückstand } \\
(\mathrm{ADR}) \mathrm{g} / \mathrm{l}\end{array}$ & $\begin{array}{c}\mathrm{C}_{\mathrm{t}} \text {-Gehalt } \\
\% \text { ADR TM }\end{array}$ & $\begin{array}{c}\mathrm{C}_{\mathrm{t}} \\
\mathrm{mg} / \mathrm{l}\end{array}$ & $\begin{array}{l}\mathrm{DOC} \\
\mathrm{mg} / \mathrm{l}\end{array}$ & $\begin{array}{c}\mathrm{HCO}_{3}-\mathrm{C} \\
\mathrm{mg} / \mathrm{l} \\
\end{array}$ & $\begin{array}{c}\mathrm{DOC}+ \\
\mathrm{HCO}_{3}-\mathrm{C} \\
\mathrm{mg} / \mathrm{l}\end{array}$ & $\begin{array}{c}\text { Vergleich } \\
\mathrm{C}_{\mathrm{t}} / \mathrm{C}_{\mathrm{su}} \\
\end{array}$ & $\begin{array}{l}\text { Extinktion bei } \\
400 \mathrm{~nm}\end{array}$ & $436 \mathrm{~nm}$ & E 400/ DOC & E 400/E 436 \\
\hline 22.07 .88 & 2,01 & 9,58 & 192,56 & 181,25 & 55,86 & 237,11 & 0,81 & 0,16 & 0,09 & 0,0044 & 1,78 \\
\hline 14.12 .88 & 2,50 & 21,40 & 535,00 & 581,00 & 116,27 & 697,27 & 0,77 & 0,56 & 0,39 & 0,0048 & 1,43 \\
\hline 22.12 .88 & 3,05 & 22,16 & 675,88 & 744,00 & 137,40 & 881,40 & 0,77 & 0,68 & & 0,0046 & \\
\hline 06.01 .89 & 3,11 & 20,72 & 644,39 & 768,00 & 117,47 & 885,47 & 0,73 & 0,64 & 0,41 & 0,0042 & 1,56 \\
\hline 11.01 .89 & 3,12 & 21,15 & 659,88 & 713,00 & 125,39 & 838,39 & 0,79 & 0,62 & & 0,0043 & \\
\hline 14.02 .89 & 2,89 & 20,88 & 603,43 & 673,00 & 137,64 & 810,64 & 0,74 & 0,62 & 0,43 & 0,0046 & 1,45 \\
\hline 27.02.89 & 2,81 & 22,51 & 632,53 & 620,00 & 126,59 & 746,59 & 0,85 & 0,70 & & 0,0056 & \\
\hline 06.03 .89 & 3,03 & 22,38 & 678,11 & 561,00 & 124,67 & 685,67 & 0,99 & 0,74 & 0,51 & 0,0066 & 1,47 \\
\hline 17.04.89 & 3,04 & 22,20 & 674,88 & 600,00 & 137,29 & 737,29 & 0,92 & 0,77 & 0,52 & 0,0064 & 1,47 \\
\hline 10.11 .89 & 3,11 & 18,30 & 569,13 & 606,50 & 116,03 & 722,53 & 0,79 & 0,55 & 0,36 & 0,0045 & 1,53 \\
\hline 08.12 .89 & 3,25 & 17,76 & 577,20 & 587,50 & 110,98 & 698,48 & 0,83 & 0,53 & 0,34 & 0,0045 & 1,55 \\
\hline 15.12 .89 & 3,01 & 13,52 & 406,95 & 437,50 & 87,44 & 524,94 & 0,78 & 0,37 & 0,23 & 0,0042 & 1,61 \\
\hline 18.12 .89 & & & & 175,00 & 37,47 & 212,47 & & 0,14 & 0,08 & 0,0039 & 1,68 \\
\hline 24.12 .89 & & & & 326,00 & 56,21 & 382,21 & & 0,26 & 0,16 & 0,0040 & 1,68 \\
\hline 03.01 .90 & 4,15 & 14,49 & 601,34 & 590,50 & 85,52 & 676,02 & 0,89 & 0,48 & 0,30 & 0,0041 & 1,61 \\
\hline 05.02 .90 & 3,77 & 13,89 & 523,65 & 609,50 & 72,31 & 681,81 & 0,77 & 0,49 & 0,31 & 0,0040 & 1,60 \\
\hline 16.02 .90 & 4,07 & 15,17 & 617,42 & 670,00 & 74,23 & 744,23 & 0,83 & 0,57 & 0,37 & 0,0043 & 1,54 \\
\hline 22.02 .90 & 3,79 & 17,35 & 657,57 & 705,00 & 87,44 & 792,44 & 0,83 & 0,65 & 0,43 & 0,0046 & 1,54 \\
\hline 09.03 .90 & 3,35 & 19,79 & 662,97 & 743,13 & 85,52 & 828,65 & 0,80 & 0,72 & 0,46 & 0,0049 & 1,58 \\
\hline 29.03 .90 & 3,23 & 21,94 & 708,66 & 749,50 & 101,37 & 850,87 & 0,83 & 0,75 & 0,51 & 0,0050 & 1,47 \\
\hline 11.05 .90 & 2,88 & 23,15 & 666,72 & 765,00 & 130,68 & 895,68 & 0,74 & 0,83 & 0,49 & 0,0054 & 1,69 \\
\hline 23.05 .90 & 3,18 & 23,29 & 740,62 & 722,50 & 135,48 & 857,98 & 0,86 & 0,85 & 0,51 & 0,0059 & 1,67 \\
\hline 08.01 .91 & 3,96 & 9,48 & 375,41 & 422,50 & 86,48 & 508,98 & 0,74 & 0,30 & 0,15 & 0,0036 & 2,02 \\
\hline 09.01 .91 & 3,30 & 10,80 & 356,40 & 397,50 & 77,35 & 474,85 & 0,75 & 0,28 & 0,16 & 0,0036 & 1,81 \\
\hline 11.01.91 & 3,11 & 11,46 & 356,41 & 395,00 & 73,75 & 468,75 & 0,76 & 0,28 & 0,15 & 0,0036 & 1,84 \\
\hline
\end{tabular}

Tabelle 6-12: Abdampfrückstände, C-Gehalte und Extinktionen der Sickerwasser Einzelproben, Lysimeter 2

\begin{tabular}{|c|c|c|c|c|c|c|c|c|c|c|c|}
\hline \multirow[b]{3}{*}{$\begin{array}{l}\text { Probenahme- } \\
\text { Datum }\end{array}$} & 2 & 3 & 4 & 5 & 6 & 7 & 8 & 9 & 10 & 11 & 12 \\
\hline & \multicolumn{11}{|c|}{ Lysimeter 2} \\
\hline & $\begin{array}{l}\text { Abdampf- } \\
\text { rückstand } \\
(A D R) g / l\end{array}$ & $\begin{array}{l}\mathrm{C}_{\mathrm{t}} \text {-Gehalt } \\
\% \text { ADR TM }\end{array}$ & $\begin{array}{c}\mathrm{C}_{\mathrm{t}} \\
\mathrm{mg} / \mathrm{l}\end{array}$ & $\begin{array}{l}\mathrm{DOC} \\
\mathrm{mg} / \mathrm{l}\end{array}$ & $\begin{array}{c}\mathrm{HCO}_{3}-\mathrm{C} \\
\mathrm{mg} / \mathrm{l}\end{array}$ & $\begin{array}{c}\mathrm{DOC}+ \\
\mathrm{HCO}_{3}-\mathrm{C} \\
\mathrm{mg} / \mathrm{l}\end{array}$ & $\begin{array}{c}\text { Vergleich } \\
\mathrm{C}_{\mathrm{t}} / \mathrm{C}_{\mathrm{su}}\end{array}$ & $\begin{array}{l}\text { Extinktion bei } \\
\quad 400 \mathrm{~nm}\end{array}$ & $436 \mathrm{~nm}$ & E 400/ DOC & E 400/E 436 \\
\hline 22.07 .88 & 4,32 & 6,92 & 298,94 & 285,25 & 134,52 & 419,77 & 0,71 & 0,15 & 0,08 & 0,0026 & 1,88 \\
\hline 14.12 .88 & 5,60 & 10,13 & 567,28 & 756,00 & 201,06 & 957,06 & 0,59 & 0,37 & 0,23 & 0,0024 & 1,61 \\
\hline 22.12 .88 & 6,44 & 10,14 & 653,02 & 630,00 & 206,11 & 836,11 & 0,78 & 0,46 & & 0,0036 & \\
\hline 06.01 .89 & 7,00 & 10,04 & 702,80 & 787,00 & 189,05 & 976,05 & 0,72 & 0,43 & 0,26 & 0,0027 & 1,64 \\
\hline 11.01 .89 & 6,73 & 9,70 & 652,81 & 752,00 & 200,10 & 952,10 & 0,69 & 0,43 & & 0,0028 & \\
\hline 14.02 .89 & 6,68 & 10,57 & 706,08 & 648,00 & 216,32 & 864,32 & 0,82 & 0,44 & 0,28 & 0,0034 & 1,56 \\
\hline 27.02 .89 & 6,01 & 11,02 & 662,30 & 636,00 & 212,83 & 848,83 & 0,78 & 0,46 & & 0,0036 & \\
\hline \multicolumn{12}{|l|}{06.03 .89} \\
\hline 17.04 .89 & 6,08 & 11,47 & 697,38 & 655,00 & 215,72 & 870,72 & 0,80 & 0,54 & 0,34 & 0,0041 & 1,61 \\
\hline \multicolumn{12}{|l|}{10.11 .89} \\
\hline \multicolumn{12}{|l|}{08.12 .89} \\
\hline 15.12 .89 & 6,67 & 9,22 & 614,97 & 610,00 & 146,05 & 756,05 & 0,81 & 0,38 & 0,23 & 0,0031 & 1,64 \\
\hline 18.12.89 & & & & 395,00 & 90,80 & 485,80 & & 0,15 & 0,26 & 0,0019 & 0,58 \\
\hline 24.12 .89 & & & & 351,00 & 72,79 & 423,79 & & 0,23 & 0,13 & 0,0033 & 1,74 \\
\hline 03.01 .90 & 7,59 & 10,06 & 763,92 & 743,50 & 141,73 & 885,23 & 0,86 & 0,49 & 0,30 & 0,0033 & 1,64 \\
\hline 05.02 .90 & 7,42 & 10,19 & 756,38 & 770,00 & 140,05 & 910,05 & 0,83 & 0,48 & 0,29 & 0,0031 & 1,65 \\
\hline 16.02 .90 & 7,61 & 10,55 & 802,86 & 825,00 & 138,85 & 963,85 & 0,83 & 0,55 & 0,34 & 0,0033 & 1,62 \\
\hline 22.02 .90 & 7,52 & 11,42 & 858,76 & 927,00 & 146,05 & 1073,05 & 0,80 & 0,60 & 0,38 & 0,0032 & 1,60 \\
\hline 09.03 .90 & 7,34 & 13,95 & 1024,31 & 1130,13 & 156,62 & 1286,75 & 0,80 & 0,82 & 0,55 & 0,0036 & 1,51 \\
\hline 29.03 .90 & 6,92 & 15,22 & 1053,63 & 1187,13 & 169,59 & 1356,72 & 0,78 & 0,88 & 0,62 & 0,0037 & 1,43 \\
\hline \multicolumn{12}{|l|}{11.05 .90} \\
\hline \multicolumn{12}{|l|}{23.05 .90} \\
\hline 08.01 .91 & 6,93 & 13,01 & 901,59 & 695,00 & 153,50 & 848,50 & 1,06 & 0,50 & 0,29 & 0,0036 & 1,74 \\
\hline 09.01 .91 & 4,23 & 13,77 & 582,20 & 715,00 & 150,86 & 865,86 & 0,67 & 0,53 & 0,30 & 0,0037 & 1,76 \\
\hline
\end{tabular}

Mit Hilfe der UV/VIS-Photometrie können qualitative und quantitative Bestimmungen gelöster Huminstoffe (HUS) durchgeführt werden. Die Absorptionsspektren isolierter HUS zeigen vom ultravioletten (UV) zum sichtbaren (VIS) Bereich (200 bis $700 \mathrm{~nm}$ ) einen kontinuierlichen Abfall der Absorption. Eine Zuordnung von Strukturmerkmalen anhand der Spektren ist für diesen Bereich nicht möglich. Zur Charakterisierung der Farbintensität wässriger Extrakte wird hier die spektrale Absorption verdünnter Lösungen bei 400 und $436 \mathrm{~nm}$ 
betrachtet, sowie deren Quotient und das Verhältnis zwischen der Extinktion und dem DOCGehalt des verdünnten Sickerwassers. Die Absorption bei diesen Wellenlängen kann von Elektronenübergängen zum Fe oder vom reinen Gerüst der hochmolekularen HUS herrühren. Da von verschiedenen Autoren eine lineare Abhängigkeit zwischen der UV-Extinktion bei $254 \mathrm{~nm}$ und den DOC-Werten einer Lösung festgestellt worden ist, können Extinktionsmessungen zur summarischen Quantifizierung der organischen Inhaltsstoffe eingesetzt werden. Für die betrachteten HUS-Lösungen unterschiedlicher Komposte und Mischungen mit Löss und den Wellenlängen 400 und 436 ist diese Linearität nicht gegeben, da die Farbintensität stärker von der Art der Agenzien als von deren Menge beeinflusst wird.

Die Braunfärbung der Sickerwässer wird im Laufe der Versuchszeit intensiver. Die Abbildung 68 zeigt für die Sickerwasser-Proben beider Lysimeter die Extinktionen bei 400 und $436 \mathrm{~nm}$. Im Durchschnitt erreicht das Sickerwasser von Lysimeter 1 gegenüber Lysimeter 2 für 400 und $436 \mathrm{~nm}$ die höheren Extinktionswerte. Dabei haben die Sickerwasser-Proben von Lysimeter $1 \mathrm{zu}$ Versuchsbeginn die dunklere Färbung aufgewiesen, die Proben von Lysimeter 2 dagegen am Ende des Versuchs. Der Rückgang der Färbung im Dezember 1989 bei beiden Lysimetern ist möglicherweise auf den Auslaugungseffekt der zeitlich direkt aufeinanderfolgenden Niederschlagsereignisse zurückzuführen.

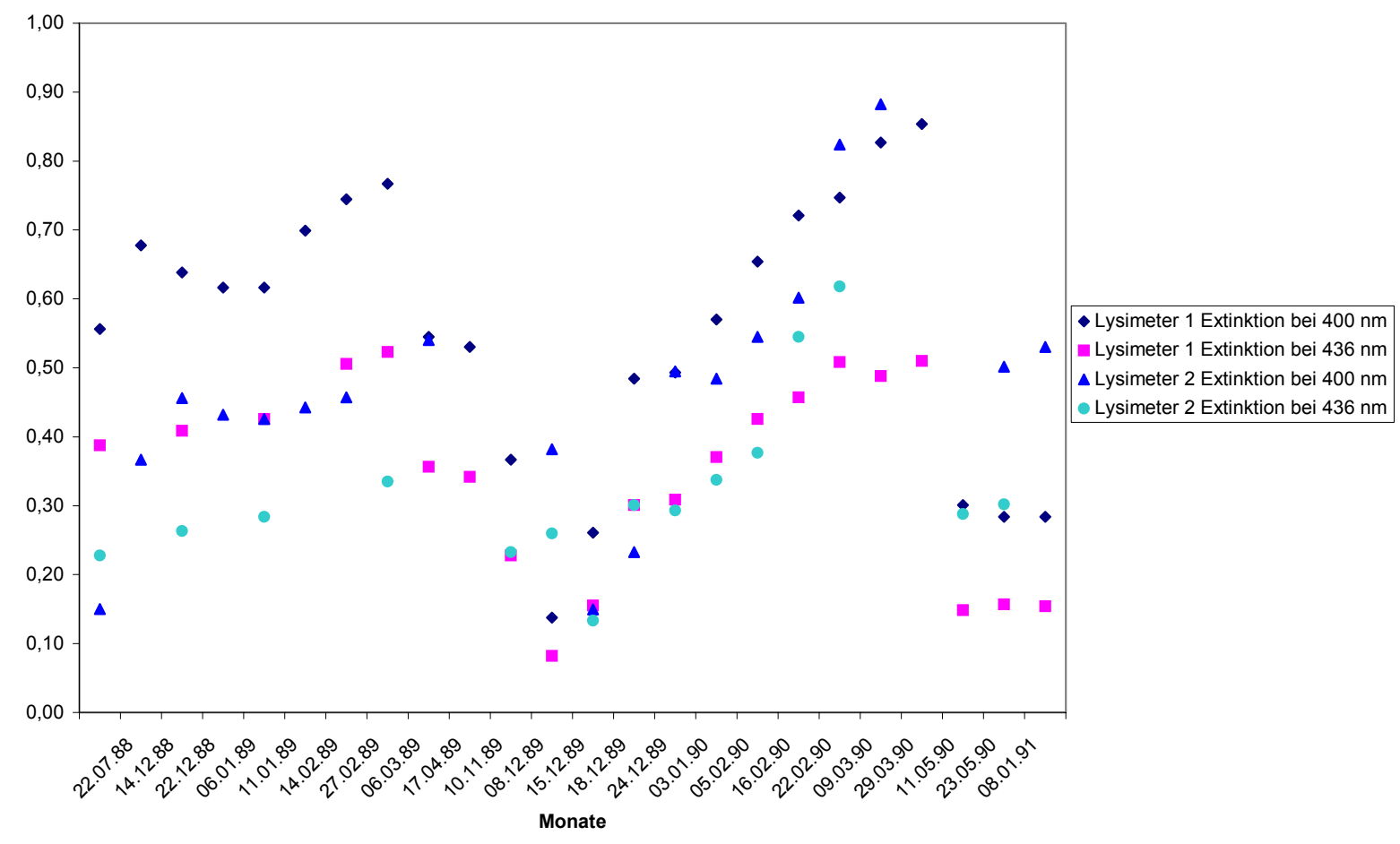

Abbildung 68: Verlauf der Extinktion bei 400 und $436 \mathrm{~nm}$ in den Sickerwasser-Proben, Lysimeter 1 und 2

Die Abbildungen 69 und 70 stellen die Quotienten aus den Extinktionen bei 400 und bei 436 $\mathrm{nm}$ dar sowie die Verhältnisse zwischen der Extinktion bei $400 \mathrm{~nm}$ und dem DOC-Gehalt für die Sickerwasser-Einzelproben der Lysimeter 1 und 2. Der Quotient zwischen den beiden Extinktionen ist weitgehend konstant, was den gleichen Ursprung der spektralen Eigenschaften bei 400 und $436 \mathrm{~nm}$ vermuten lässt. Im Durchschnitt liegt die Extinktion bei $400 \mathrm{~nm}$ um das 1,6-fache über der Extinktion bei $436 \mathrm{~nm}$. Die Beziehung zwischen der Extinktion bei $400 \mathrm{~nm}$ und dem DOC-Gehalt der Probe weist dagegen deutliche Schwankungen auf. Über die ersten drei Jahre der Versuchsbetreuung hinweg ist die Farbintensität der Sickerwasser-Proben aus Lysimeter 1 höher. Zum Abschluss der Freilandversuche im Januar 1991 liegt der Quotient bei Lysimeter 2 über dem von Lysimeter 1. Dies lässt auf eine Erhö- 
hung färbender makromolekularer Bestandteile in den Sickerwasser-Proben von Lysimeter 2 schließen. Zur Trennung der organischen Verbindungen im Sickerwasser siehe Kapitel 7. 


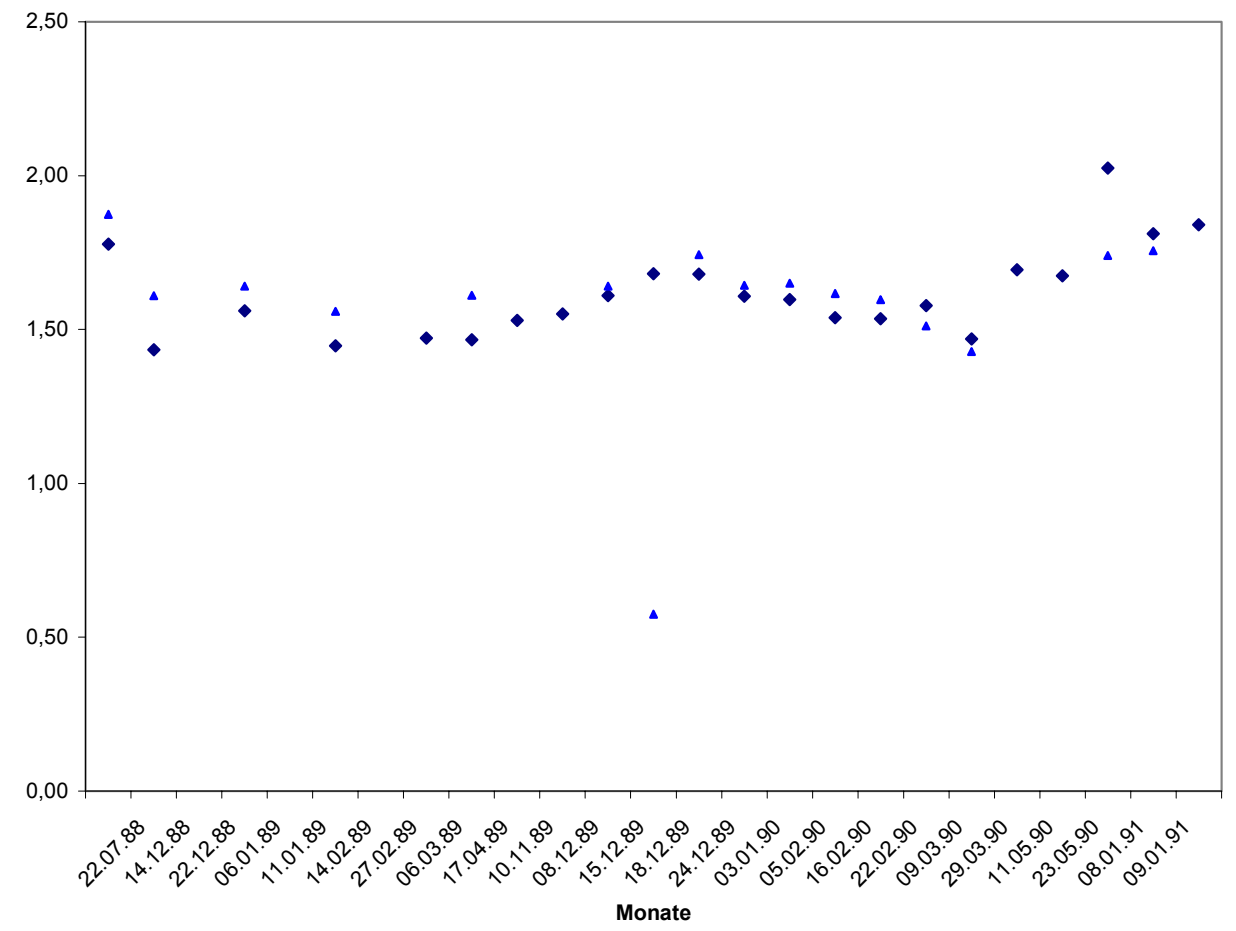

- Lysimeter 1 E 400/E 436 - Lysimeter 2 E 400/E 436

Abbildung 69: Quotienten der Extinktionen bei 400 und 436 $\mathrm{nm}$ der Sickerwasser-Proben, Lysimeter 1 und 2

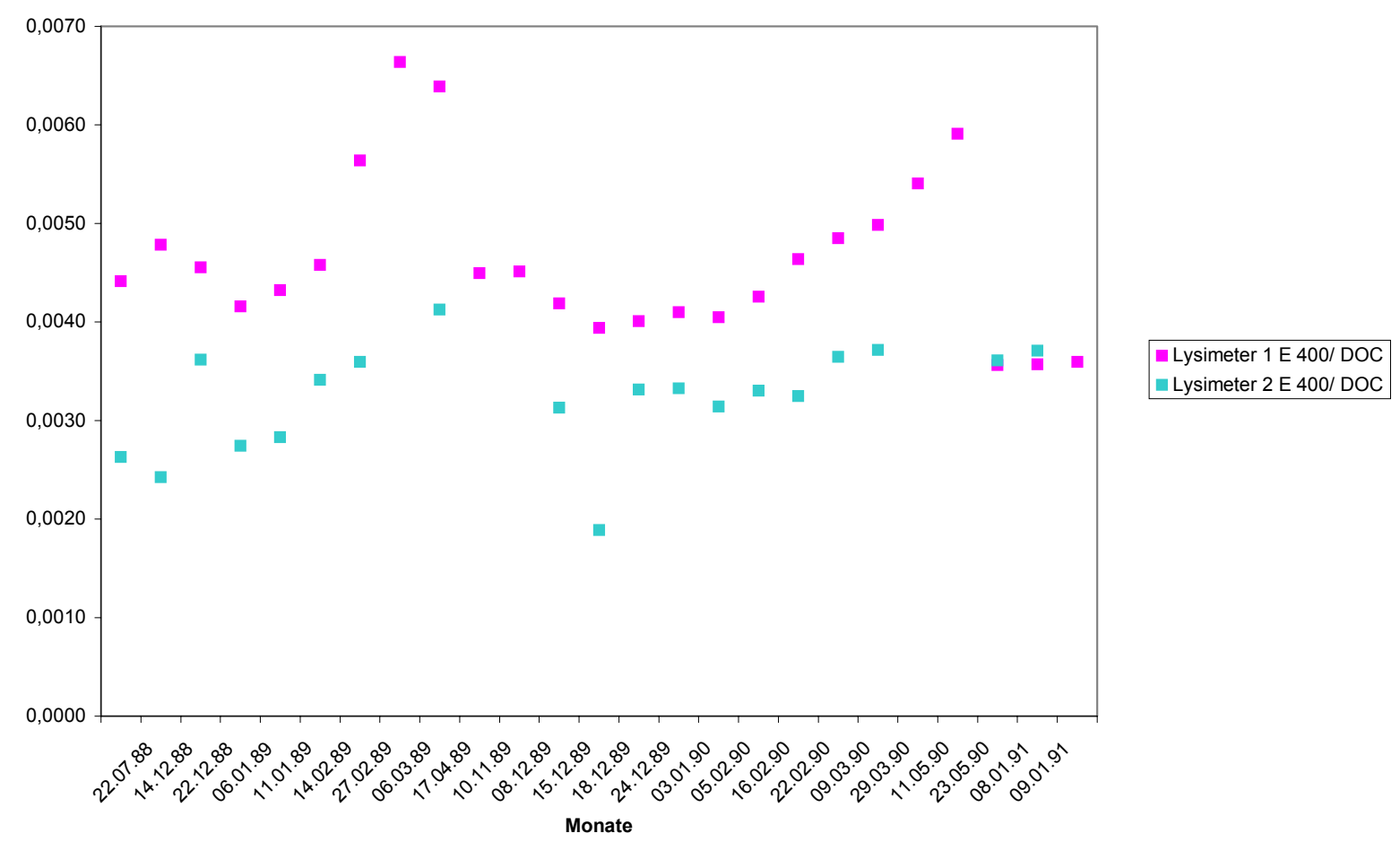

Abbildung 70: Quotienten der Extinktion bei $400 \mathrm{~nm}$ und dem DOC-Gehalt der Sickerwasser-Proben, Lysimeter 1 und 2

Kleinlysimeter

Die DOC-Konzentrationen im Sickerwasser der Kleinlysimeter, die mit reinem Kompost und Kompost-Beimengungen gefüllt sind, steigen im ersten Versuchsjahr stark an und fallen in 
den beiden folgenden Jahren allmählich auf Werte ab, die zu Versuchsende in Lysimeter 3 das den niedrigsten Kompost-Anteil hat bei 79 mg/l und in Lysimeter 8, dem reinen Kompost, bei $241 \mathrm{mg} / \mathrm{l}$ liegen. Der DOC-Gehalt im Sickerwasser der Löss-Variante, Lysimeter 7, liegt durchschnittlich bei $15 \mathrm{mg} / \mathrm{l}$. Bei allen Kleinlysimetern liegt im Gegensatz zu den beiden Großlysimetern insgesamt eine Abnahme der DOC-Konzentration im Sickerwasser vor.

Die Abbildungen 71 und 72 zeigen den Verlauf der DOC-Konzentrationen im Sickerwasser anhand der Monatsmittelwerte für die Kleinlysimeter. 


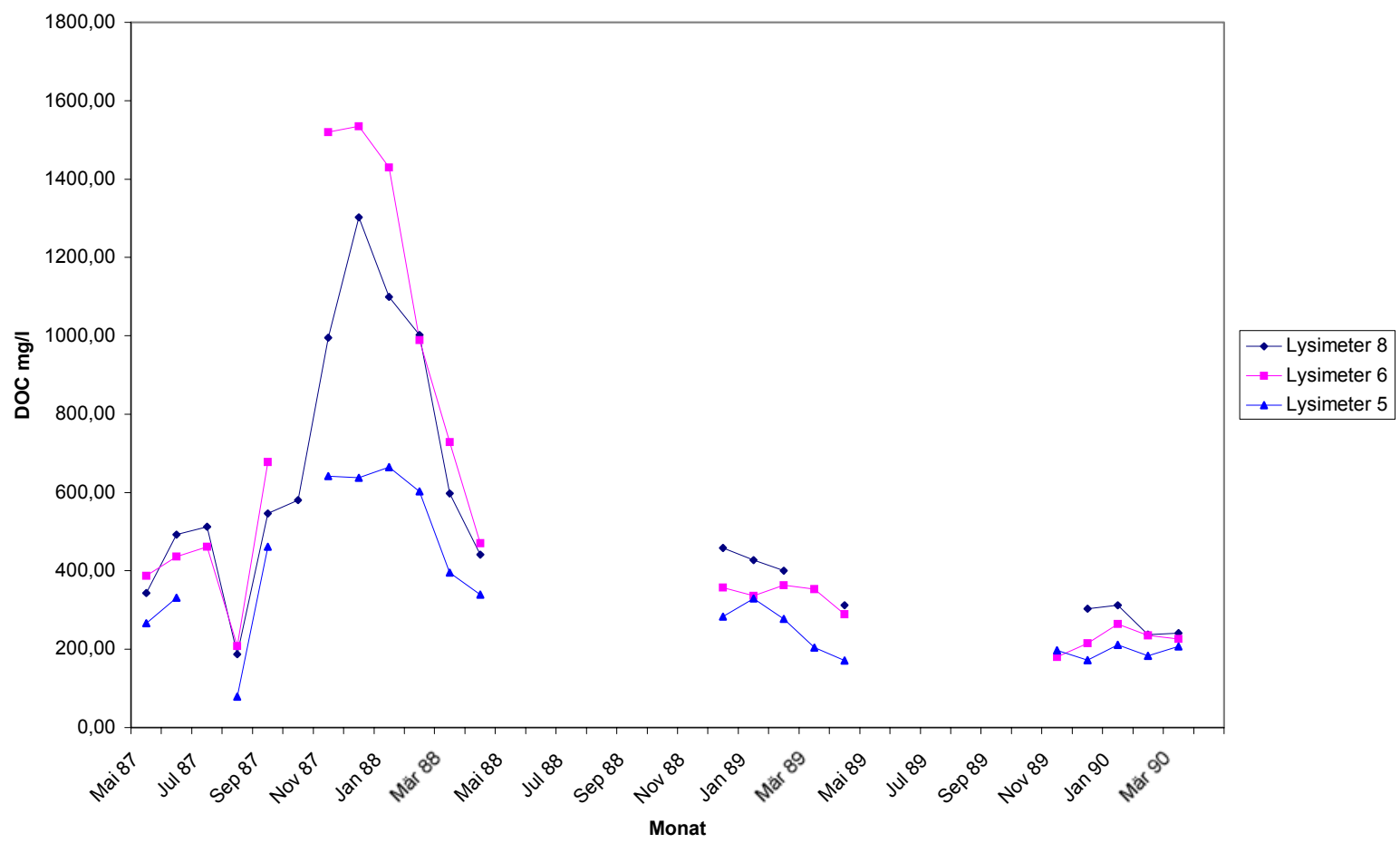

Abbildung 71: Verlauf der DOC-Konzentrationen im Sickerwasser, Monatsmittelwerte, Lysimeter 8, 6 und 5

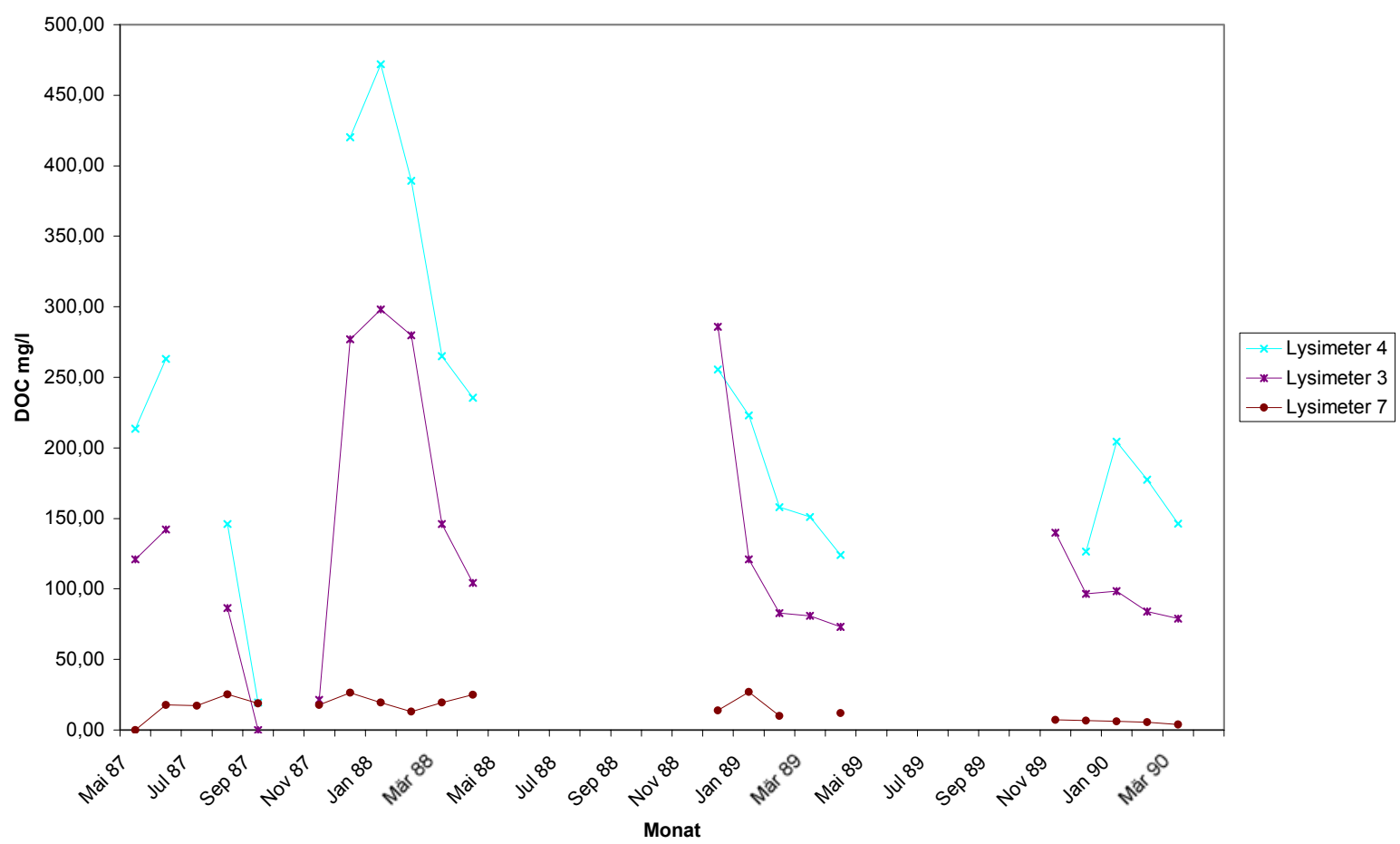

Abbildung 72: Verlauf der DOC-Konzentrationen im Sickerwasser, Monatsmittelwerte, Lysimeter 4, 3 und 7

Die im Sickerwasser der Kleinlysimeter festgestellten Extinktionswerte sinken mit zunehmendem Löss-Anteil im Lysimeter (siehe Abb. 73). So wie die DOC-Konzentration im Sickerwasser mit fortschreitender Versuchszeit abnimmt, ist auch ein Rückgang der Extink- 
tion zu erkennen, der allerdings, wie der Anstieg der Quotienten aus der Extinktion bei 400 $\mathrm{nm}$ und der DOC-Konzentration in Abbildung 74 zeigt, geringer ausfällt als die DOC-Abnahme und dementsprechend auf eine Zunahme färbender Bestandteile bzw. Steigerung der Farbintensität zurückzuführen ist. 


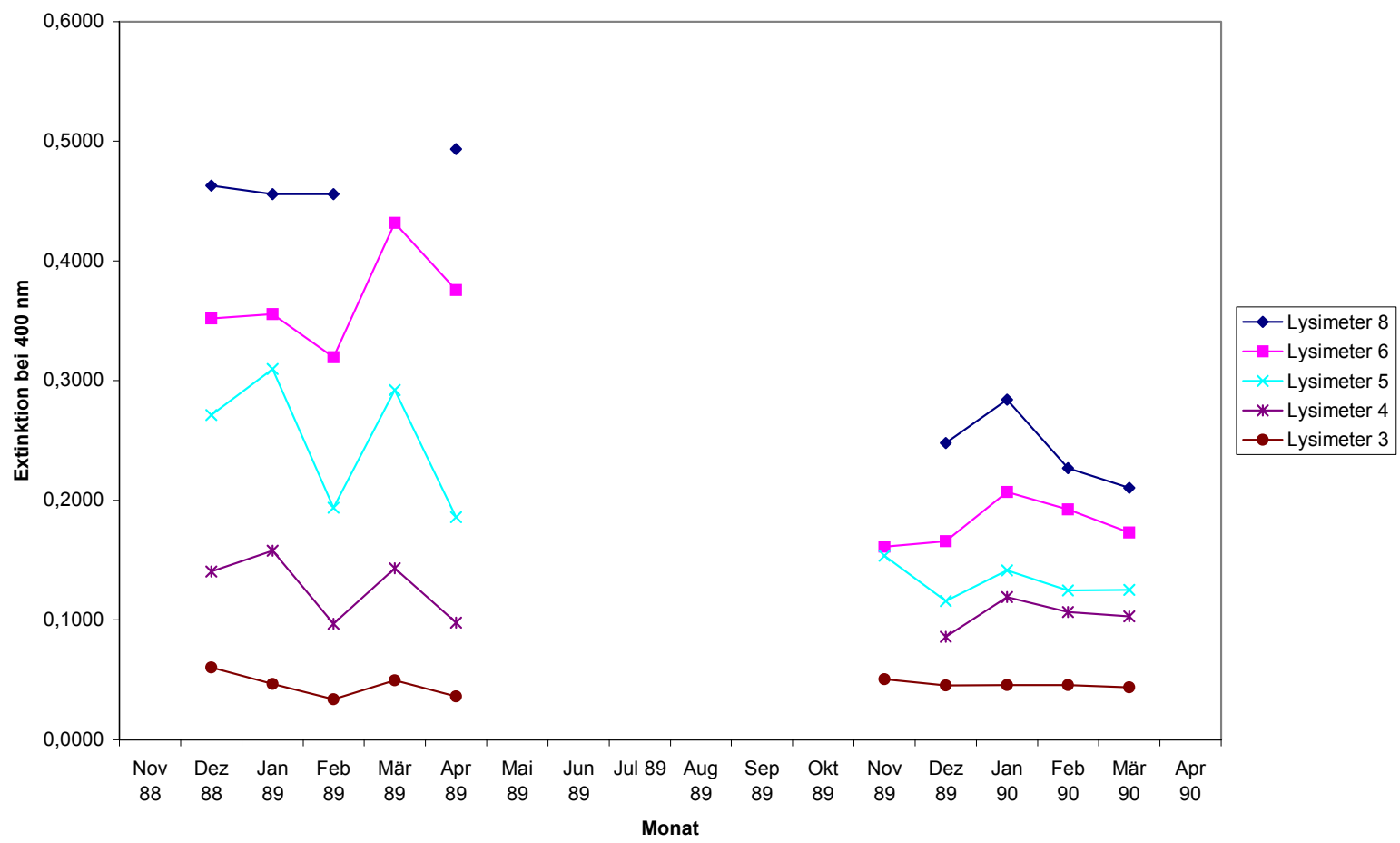

Abbildung 73: Verlauf der Extinktionen bei 400 nm, Monatsmittelwerte, Lysimeter 3 - 8

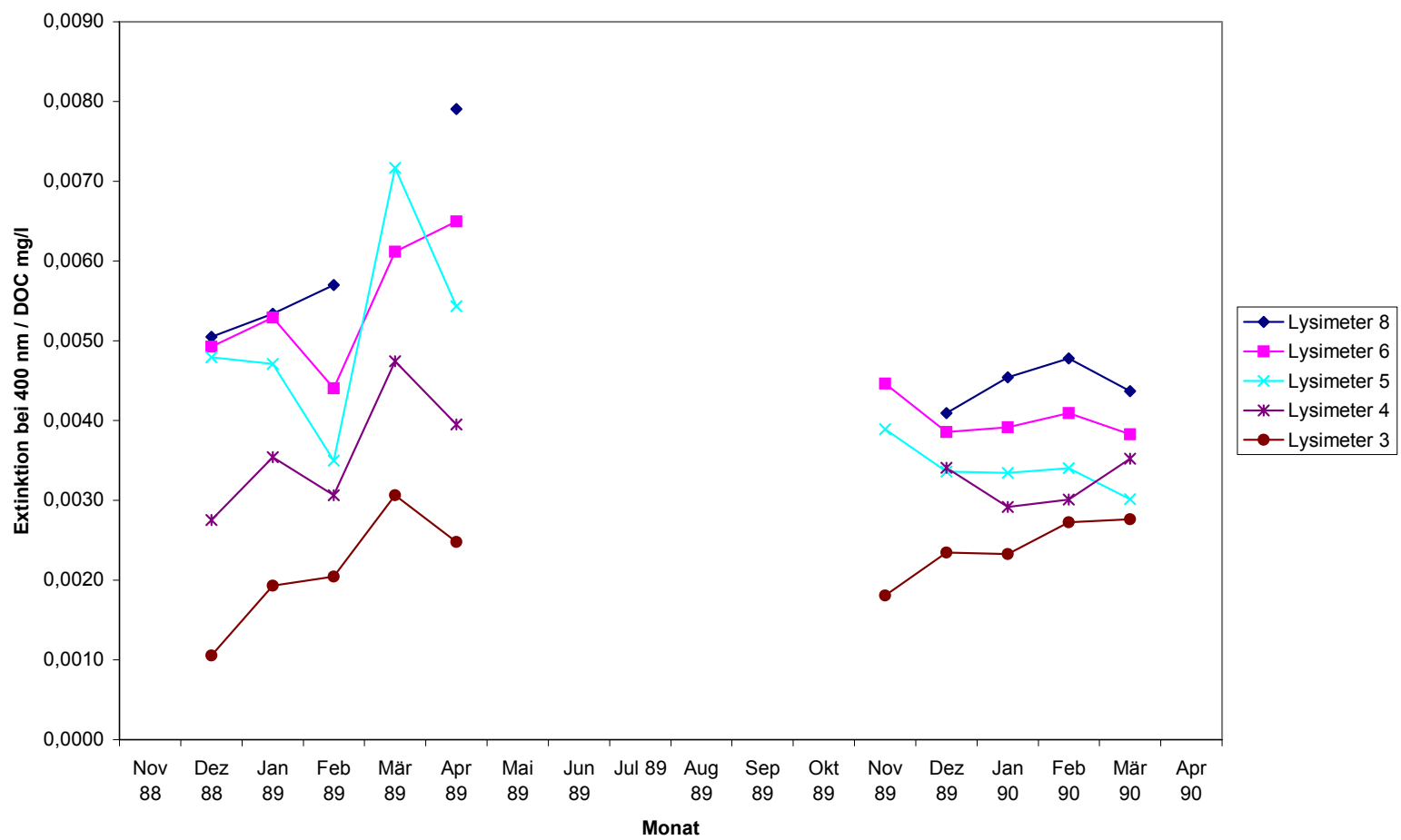

Abbildung 74: Kleinlysimeter 3-6 und 8: Zeitgang der Quotienten Extinktion 400 nm durch DOC mg/l, Monatsmittelwerte

Ebenso wie im Sickerwasser der Großlysimeter beträgt im Sickerwasser der Kleinlysimeter die Extinktion bei $400 \mathrm{~nm}$ das 1,6 fache der Extinktion bei 436 . Die für die Lysimeter $3-6$ und 8 errechneten Quotienten zeigt die Abbildung 75. 


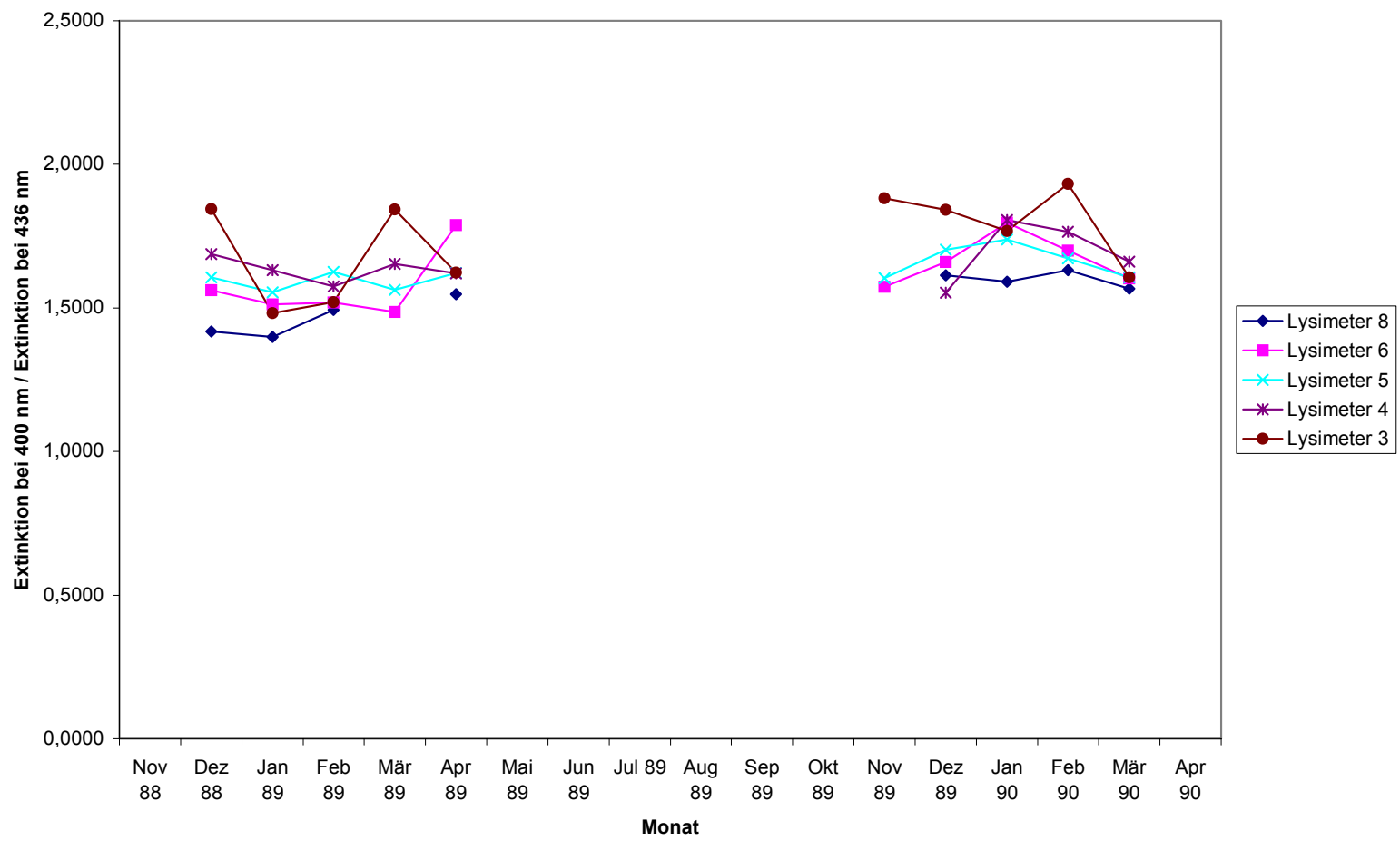

Abbildung 75: Kleinlysimeter 3-6 und 8: Zeitgang der Quotienten Extinktion bei 400 und bei $436 \mathrm{~nm}$, Monatsmittelwerte

Interpretation:

Eine Abnahme des Quotienten Extinktion bei $400 \mathrm{~nm}$ durch Konzentration an DOC (mg/l) ist als eine relative Abnahme der gefärbten Huminstoffe zu nicht oder anders gefärbten gelösten Stoffen im Sickerwasser zu deuten. Dies wird deutlich, wenn man in Abbildung 74 feststellt, dass mit abnehmendem Kompost-Anteil und zunehmendem Löss-Anteil in den Kleinlysimetern der gefärbte Extrakt-Anteil zugunsten der ungefärbten Lösungspartner zurückgeht. Möglicherweise führt der mit steigender Löss-Beimengung erhöhte Ton- und Eisenoxid-Anteil zu einer bevorzugten Sorption der Huminstoff-Derivate.

Bei Lysimeter 1 beträgt der durchschnittliche $\mathrm{E}_{400} / \mathrm{DOC}$-Quotient 0,0046 mit kurzfristigem zeitlichen Ausschlag bis 0,006 im Frühling 1989 und der generellen Tendenz zum Abfallen auf 0,0036 im Januar 1991. Bei Lysimeter 2 sind die entsprechenden Werte 0,0032 $0,0041-0,0037$. Sie sind bei 2 also überwiegend geringer, was bedeutet, dass hier mehr ungefärbte, möglicherweise noch weniger humifizierte Lösungspartner vorliegen, was dem allgemein geringeren Zersetzungsgrad des Kompostes 2 entsprechen könnte. Andererseits ist - das wäre eine Deutung für den Kompost in Lysimeter 1 - damit zu rechnen, dass mit fortschreitender „Reifung“ die Lieferung mobiler Humin- und Fulvosäuren abnimmt.

Das mit reinem Kompost gefüllte Lysimeter 8 ist mit einem Quotienten von 0,0052 offenbar in der Höchstphase des Huminstoff-Umsatzes, wie er bei Lysimeter 1 nur kurzfristig im Frühjahr 1989 erreicht wird.

Die Quotienten E400/E436 sind in allen Lysimetern mit Werten um 1,6 recht konstant. Dies lässt den Schluss zu, dass die extrahierten gefärbten Huminstoffe etwa den gleichen Ursprung haben, gleichen Produktionsprozessen unterliegen und etwa die gleiche Beschaffenheit haben. 


\subsubsection{Kationen und Anionen im Sickerwasser}

\section{Großlysimeter}

Die folgenden Ausführungen beschränken sich auf die im System-Boden-Pflanze mengenmäßig bedeutsamen Kationen $\mathrm{Na}, \mathrm{K}, \mathrm{Mg}$ und $\mathrm{Ca}$, sowie die Anionen $\mathrm{HCO}_{3}, \mathrm{Cl}, \mathrm{NO}_{3}$ und $\mathrm{SO}_{4}$. Das Phosphat bleibt hier außer Betracht, da die Analytik der braun gefärbten Proben erst nach der Zerstörung der organischen Substanz und der damit einhergehenden Entfärbung möglich war und dadurch auch organisch gebundes $\mathrm{P}$ in Lösung gebracht wurde.

\section{Zeitgang der Konzentration}

Abb. 76 und Abb. 77 stellen den Zeitgang der lonen-Konzentrationen im aufgefangenen Sickerwasser von Lysimeter 1 dar. Die Darstellungen sind in die Messjahre 1 (1987/1988), 2 (1988/1989) und 3 (1989/1990) unterteilt, wobei jedoch mehrmalige Phasen ohne Sickerwasser-Lieferung eingeschaltet sind. In diesen Phasen verharrt das Wasser im Kompost und wird damit langfristigen Einstellungen des Lösungsgleichgewichtes ausgesetzt.

In Tabelle 6-13 sind die durchschnittlichen Konzentrationen für die einzelnen Messjahre angegeben. Man berücksichtige jedoch, dass diese sich nur auf die Monatsfolgen mit Sickerwasser-Spende beziehen. 


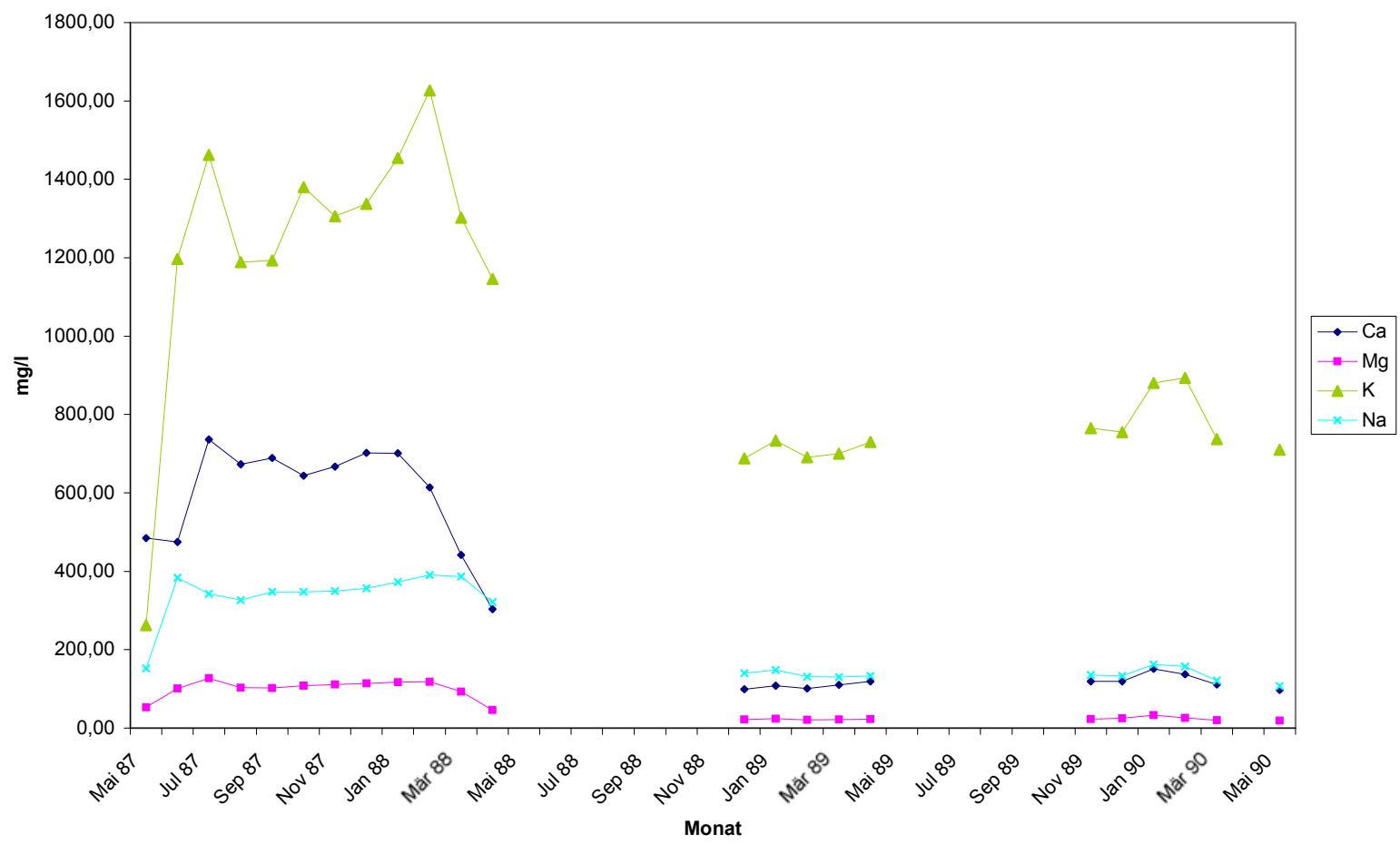

Abbildung 76: Konzentrationsverlauf der Kationen im Sickerwasser, Monatsmittelwerte, Lysimeter 1

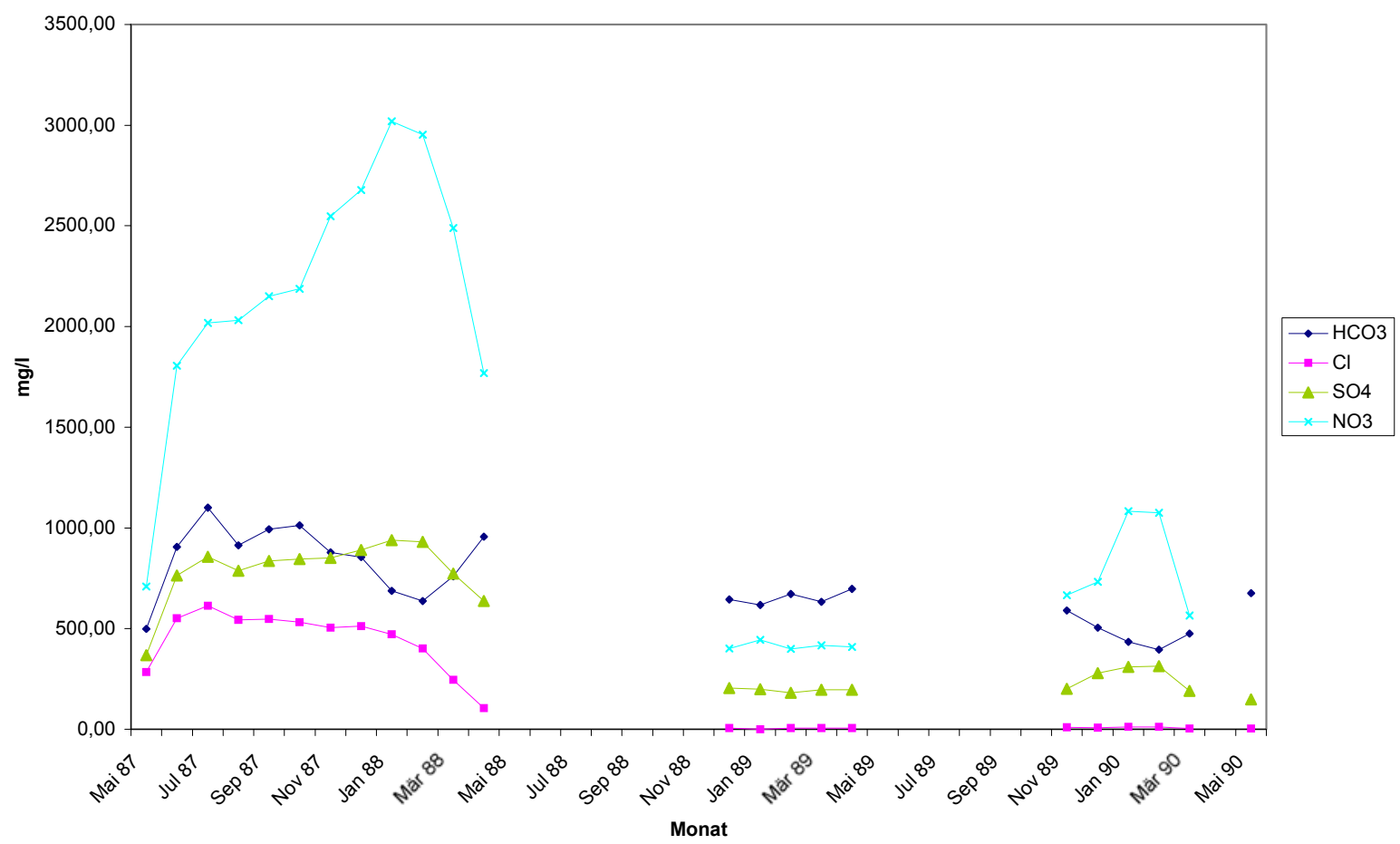

Abbildung 77: Konzentrationsverlauf der Anionen im Sickerwasser, Monatsmittelwerte, Lysimeter 1

Abb. 76 zeigt: Mit der Einfüllung des Kompostes in die Lysimeter steigen von Mai 87 bis in den Juli hinein die Konzentrationen aller vier Kationen auf ein erstes Maximum mit der Reihenfolge K, Ca, Na, Mg an. Am Ende des auswaschungsintensiven Winters 87/88 fallen 
zuerst die Ca- und Mg-Konzentrationen und dann die K- und Na-Konzentrationen ab. Sie erholen sich nach der nächsten Sommerpause und ebenfalls nach dem Sommer 89 nicht wieder, sondern verharren auf einem niedrigen Gleichgewichts-Niveau in der Reihenfolge $\mathrm{K}, \mathrm{Na}, \mathrm{Ca}, \mathrm{Mg}$.

Abb. 77 zeigt ebenfalls in der Anfangsphase ein schnelles Ansteigen aller Anionen, wobei das $\mathrm{Cl}$ nach Erreichen des ersten Maximums auf die Minimalwerte in den Folgejahren absinkt, während $\mathrm{NO}_{3}$ und $\mathrm{SO}_{4}$ in der Winterphase - vermutlich infolge fortschreitender durch Frost begünstigter Mineralisation - ein zweites noch höheres Konzentrationsmaximum ausbilden. Der Verlauf des $\mathrm{HCO}_{3}$ ist irregulär.

In den Folgejahren geht das in der kompostierten Pflanzenmasse kaum enthaltene $\mathrm{Cl}$ fast auf 0 zurück während beim $\mathrm{NO}_{3}$ und $\mathrm{SO}_{4}$ offenbar noch immer schwache anhaltende Mineralisationsvorgänge ablaufen (siehe auch $\mathrm{K}_{\text {und }} \mathrm{HCO}_{3}$ !).

Langanhaltende Niederschläge bewirken keine Verdünnung der Inhaltsstoff-Konzentrationen im Sickerwasser. Häufig bleiben die Konzentrationen auch nach längeren Phasen der Trockenheit auf gleichem Niveau. Die jeweils erste Sickerwasserprobe nach den Trockenphasen der Sommer 88 und 89 besitzt die annähernd gleiche Konzentration wie die letzte Frühjahrsprobe. Möglicherweise ist die Mineralisationsrate bei niedrigen Wassergehalten in den Sommermonaten reduziert. Maxima treten bei Lysimeter 1 und 2 einige Wochen nach Versuchsbeginn sowie zwischen Januar und März der folgenden Untersuchungsjahre auf.

Die Abbildungen 78 und 79 zeigen die Konzentrationsverläufe der Kationen und Anionen im Sickerwasser des Lysimeters 2 


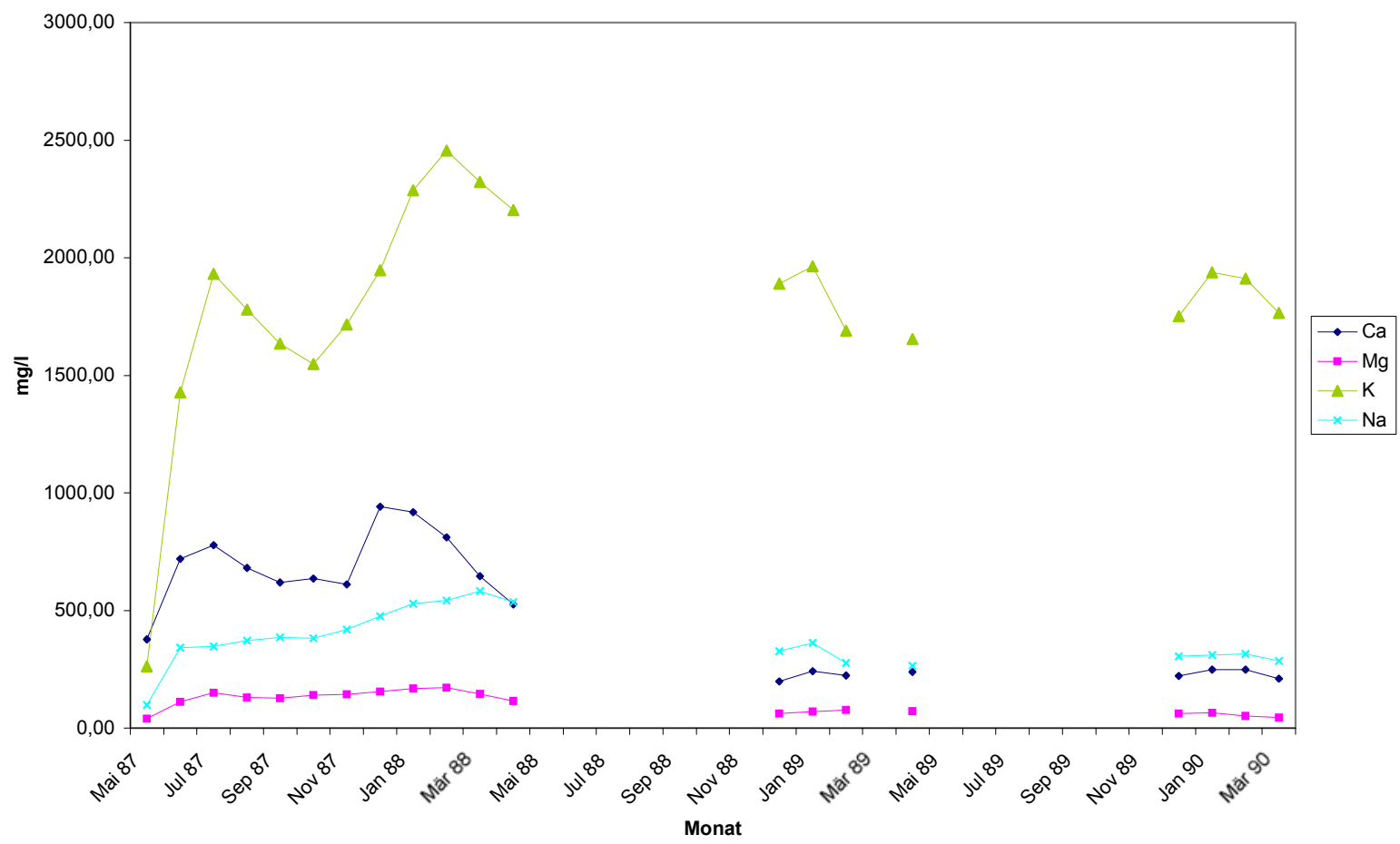

Abbildung 78: Konzentrationsverlauf der Kationen im Sickerwasser, Monatsmittelwerte, Lysimeter 2

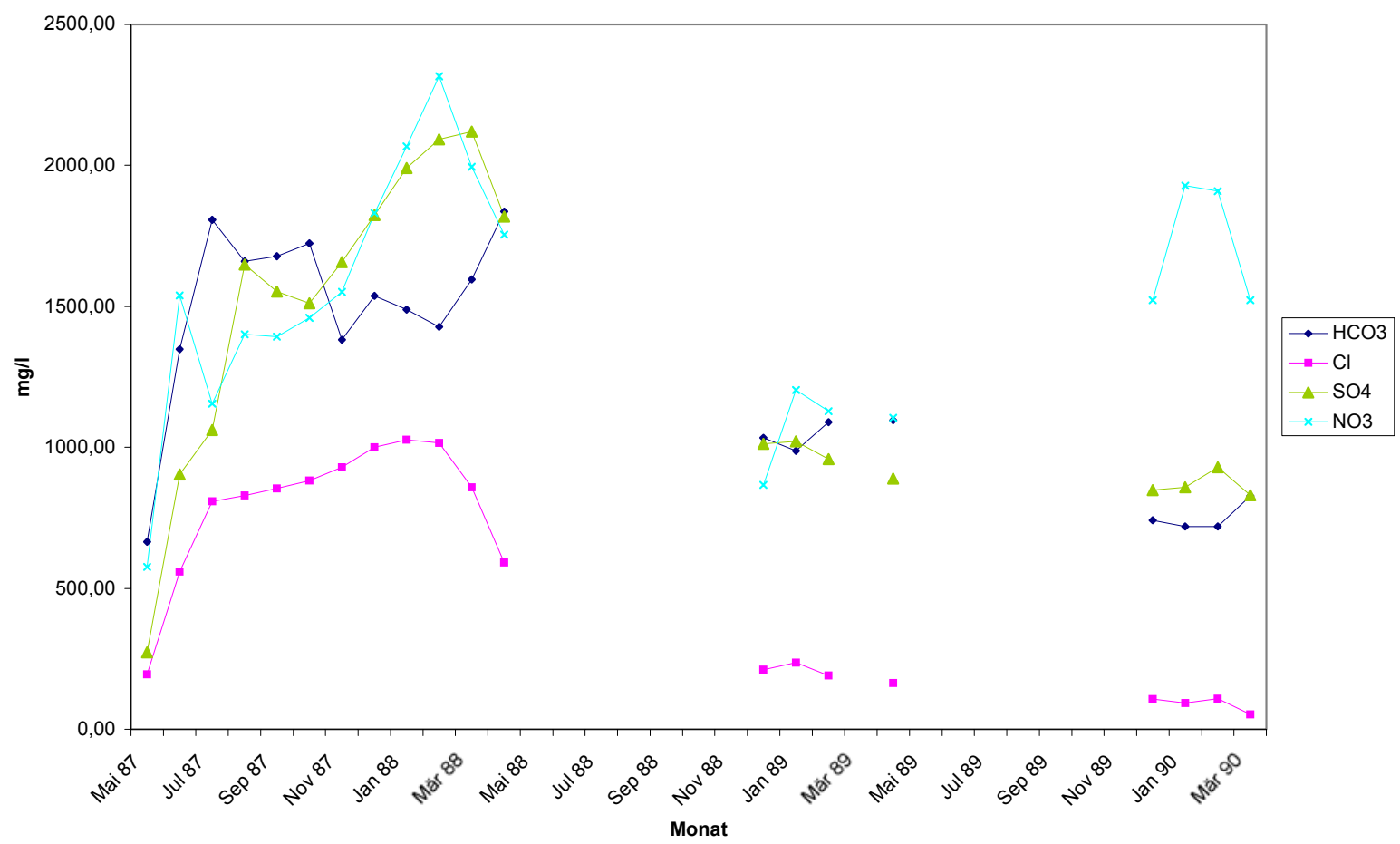

Abbildung 79: Konzentrationsverlauf der Anionen im Sickerwasser, Monatsmittelwerte, Lysimeter 2

Vergleich der Lysimeter 1 und 2 (Umsatz-Intensität):

Will man die Sickerwässer von Lysimeter 1 mit denen von Lysimeter 2 vergleichen, kann dies mit Hilfe von Tabelle 6-13 geschehen. Dabei ist jedoch zu bedenken, dass Lysimeter 2 
etwa das 1,5-fache an Trockensubstanz erhalten hat und dass dieser Kompost weniger stark vorverrottet gewesen ist.

K: Dementsprechend sind die K-Konzentrationen im 1. Jahr ca. 1,5 mal so hoch und sie fallen auch bis zum 3. Jahr kaum ab. Die für die Gesamt-Versuchsdauer errechnete Durchschnitts-Konzentration liegt mit $1875 \mathrm{mg} / \mathrm{l}$ etwa 1,8 mal so hoch wie bei Lysimeter 1 (1049 $\mathrm{mg} / \mathrm{l})$. Dies zeigt, dass das K bei den hier verwendeten kompostierten Materialien trotz der inm nachgesagten hohen Freisetzungsrate aus Pflanzenmaterial doch eine längere Freisetzungsdauer beansprucht. Das Material in Lysimeter 1 scheint dagegen infolge einer längeren Dauer der Vorkompostierung bereits an freisetzbarem $\mathrm{K}$ verarmt zu sein.

$\mathrm{Na}, \mathrm{Mg}$, Ca: Das für K Gesagte gilt - wenn auch für diese drei Kationen der Reihe nach in abschwächender Form - für deren Konzentrations-Zeitgang.

$\mathrm{Cl}$ : Das $\mathrm{Cl}$ ist in seinen Durchschnitts-Konzentrationen ebenfalls ein guter Indikator für das zum K Gesagte, aber für das größere Flüssigkeitsvolumen des Lysimeters 2. Bei diesem zeigt sich, dass in den Messjahren 2 und 3 noch erhebliche Mengen an gelöstem $\mathrm{Cl}$ zu verdrängen sind, ehe die Konzentrationswerte auf das Niveau des Lysimeters 1 abfallen können.

$\mathrm{NO}_{3}, \mathrm{HCO}_{3}$ : Bei diesen beiden Anionen sind die Unterschiede zwischen Lysimeter 1 und Lysimeter 2 schwerer zu interpretieren, da sie dem Wechselspiel von Mineralisation und gasförmiger Freisetzung unterliegen.

$\mathrm{SO}_{4}$ : Überraschend ist die Konzentration an $\mathrm{SO}_{4}$ in den Sickerlösungen des Lysimeters 2, die mehr als doppelt so hoch ist als in Lysimeter 1 und besonders in den Jahren 2 und 3 ein Mehrfaches beträgt. Diese Unterschiede dürften im Wesentlichen den größeren Vorräten an organischem Schwefel in Lysimeter 2 zu zuordnen sein.

\section{Kleinlysimeter}

Im Verlauf der Beobachtungszeit unterscheiden sich die beiden großen Lysimeter deutlich von den Lysimetern 3 - 8. Auffallend sind bei den kleinen Lysimetern die hohen Messwerte direkt nach Versuchsbeginn, gefolgt von einer starken Konzentrationsabnahme und einem erneuten Wiederansteigen im ersten Winter, wobei die zweiten Maxima für die Kationen Calcium, Magnesium, Kalium und Natrium sowie die Anionen Nitrat und Chlorid die Anfangswerte nicht wieder erreichen. Bei den Kleinlysimetern ist aufgrund des geringeren Vorrates und der fehlenden Nachlieferung ein starker Rückgang der Konzentrationen im Sickerwasser vom 1. zum 2. Messjahr festzustellen.

Die Konzentrationsverläufe der Kationen und Anionen im Sickerwasser der Kleinlysimeter werden in den Abbildungen 80 - 85 gezeigt. Zur Darstellung der zeitlichen Verläufe der Ionen-Konzentrationen im Sickerwasser der Kleinlysimeter werden exemplarisch die graphischen Darstellungen für die Lysimeter 8 (reiner Kompost), 4 ( etwa 50 \% Kompost und 50 \% Löss) und 7 (reiner Löss) ausgewählt und zwar die Abb. 80, 81, 82 für die Kationen und die Abb. 83, 84, 85 für die Anionen. Die Konzentrationsverläufe der Kationen und Anionen im Sickerwasser der Lysimeter 6, 5 und 3 sind im Anhang (Abb.1-2 bis 1-7) dargestellt. 


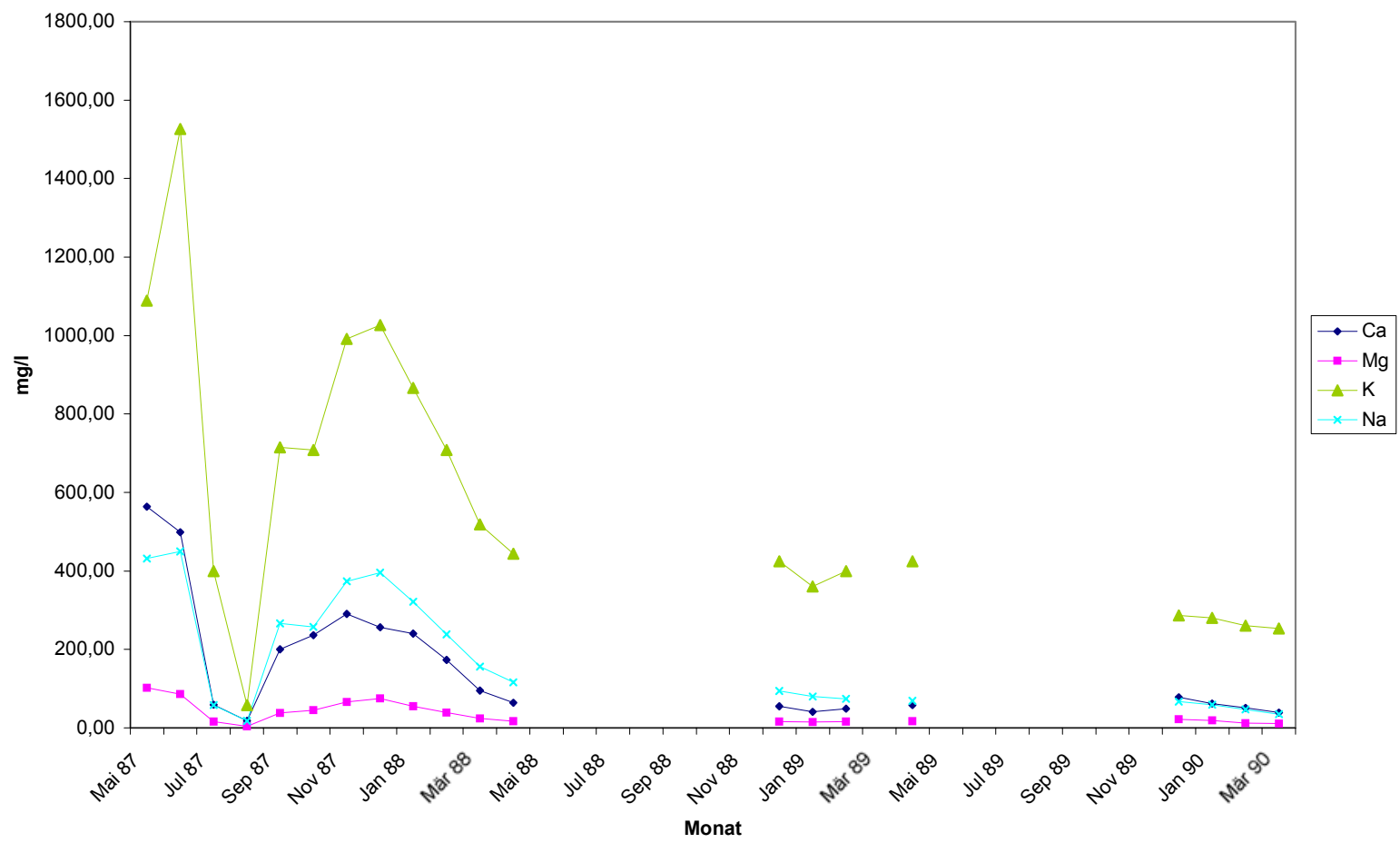

Abbildung 80: Konzentrationsverlauf der Kationen im Sickerwasser, Monatsmittelwerte, Lysimeter 8

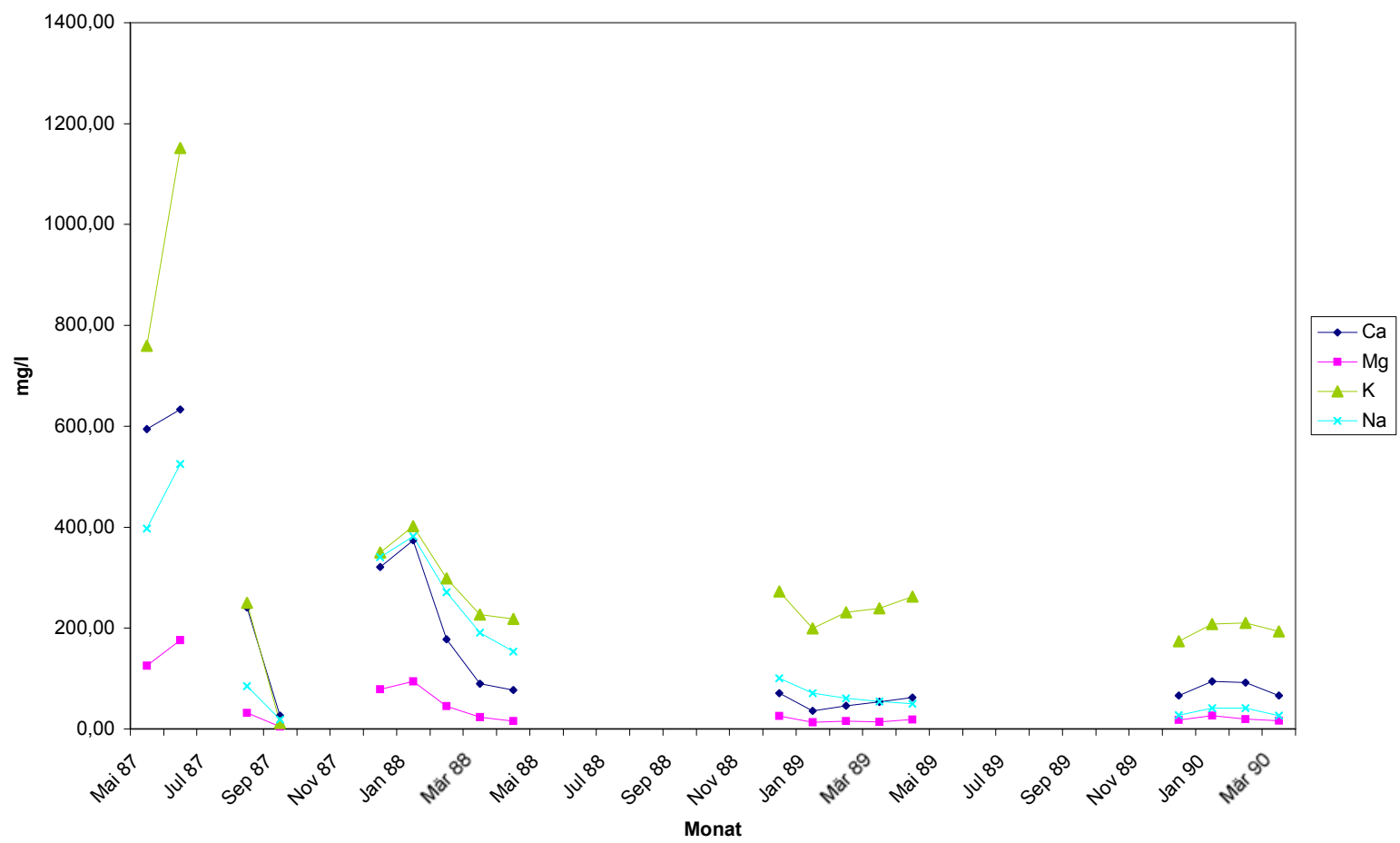

Abbildung 81: Konzentrationsverlauf der Kationen im Sickerwasser, Monatsmittelwerte, Lysimeter 4 


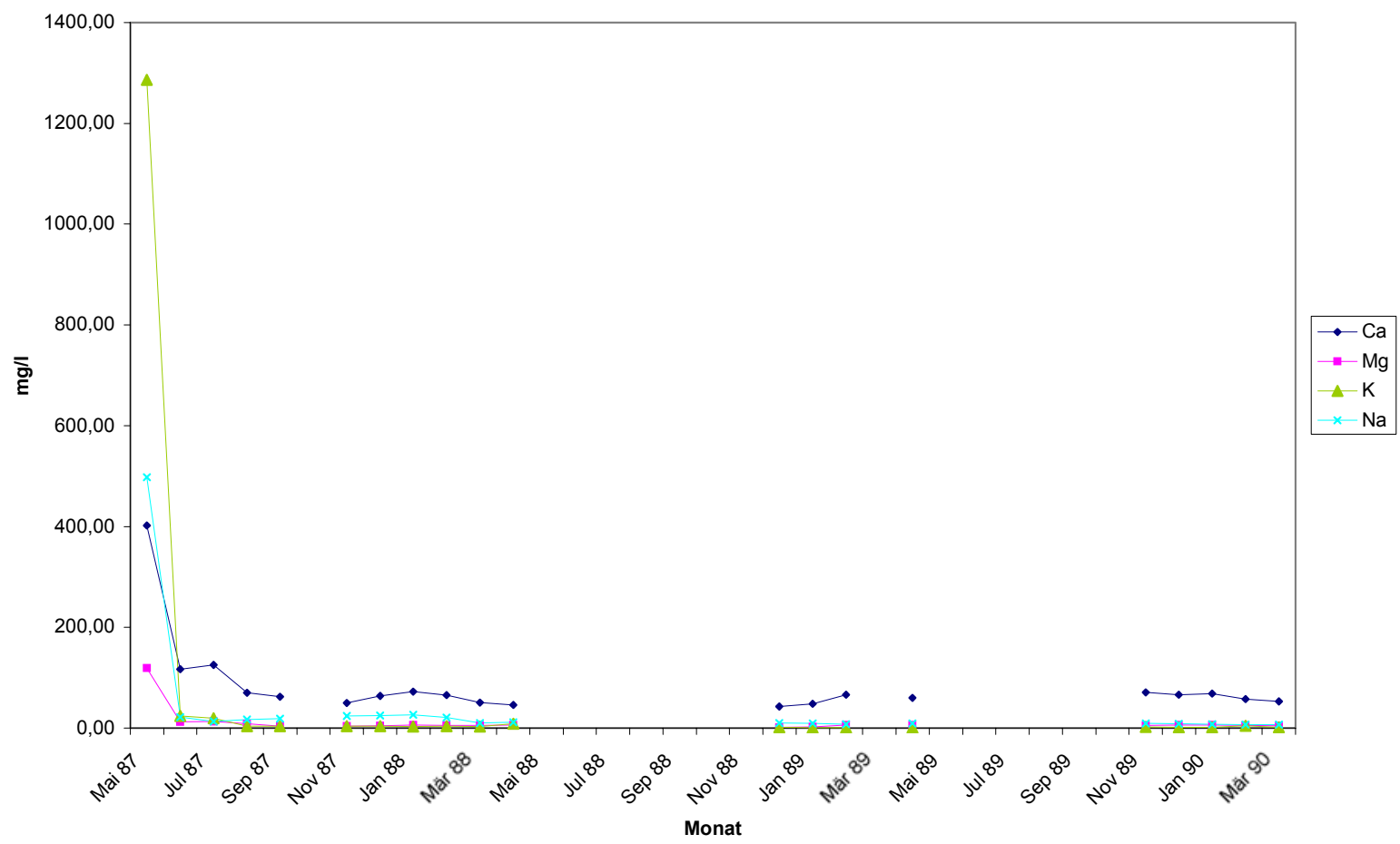

Abbildung 82: Konzentrationsverlauf der Kationen im Sickerwasser, Monatsmittelwerte, Lysimeter 7

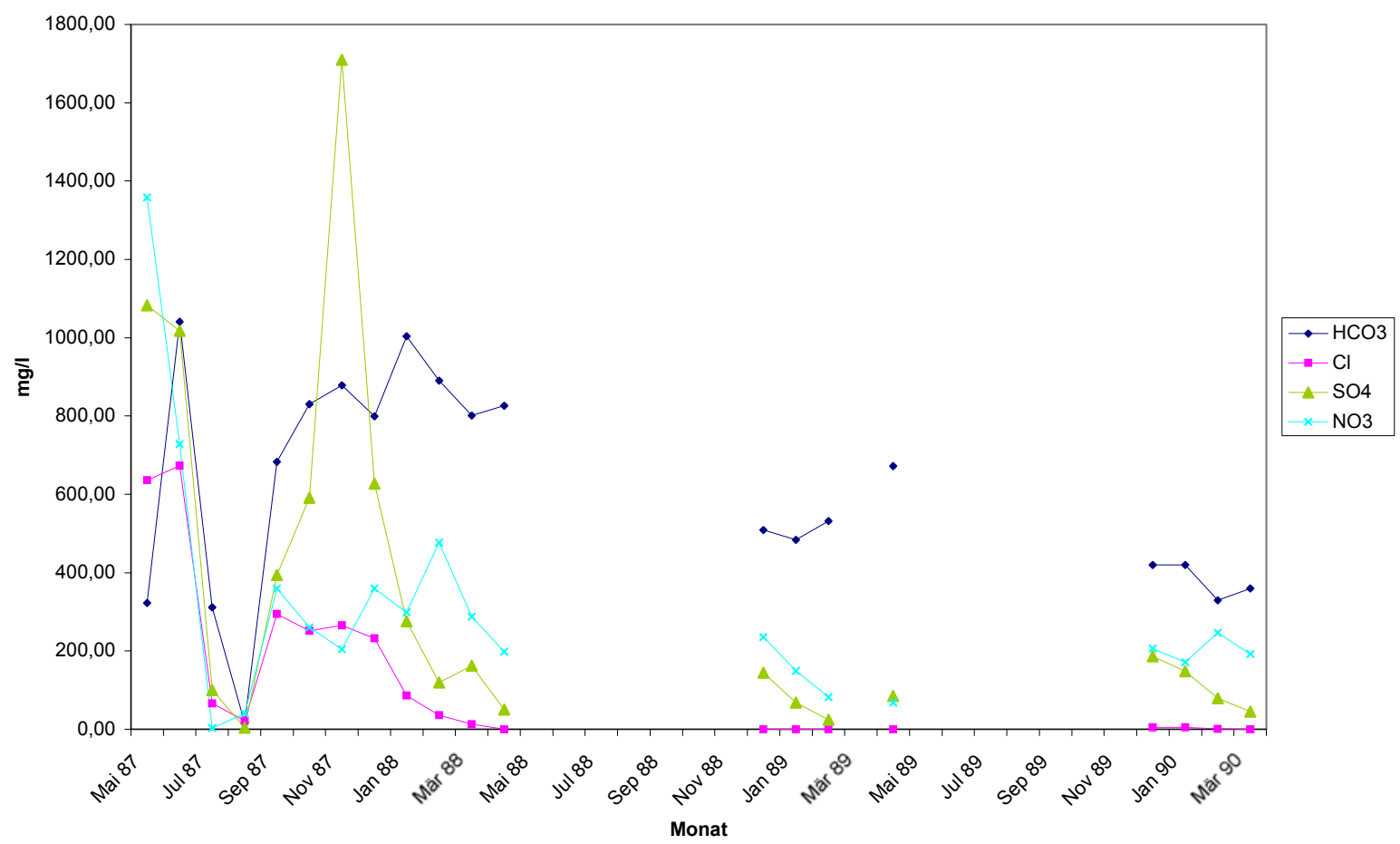

Abbildung 83: Konzentrationsverlauf der Anionen im Sickerwasser, Monatsmittelwerte, Lysimeter 8 


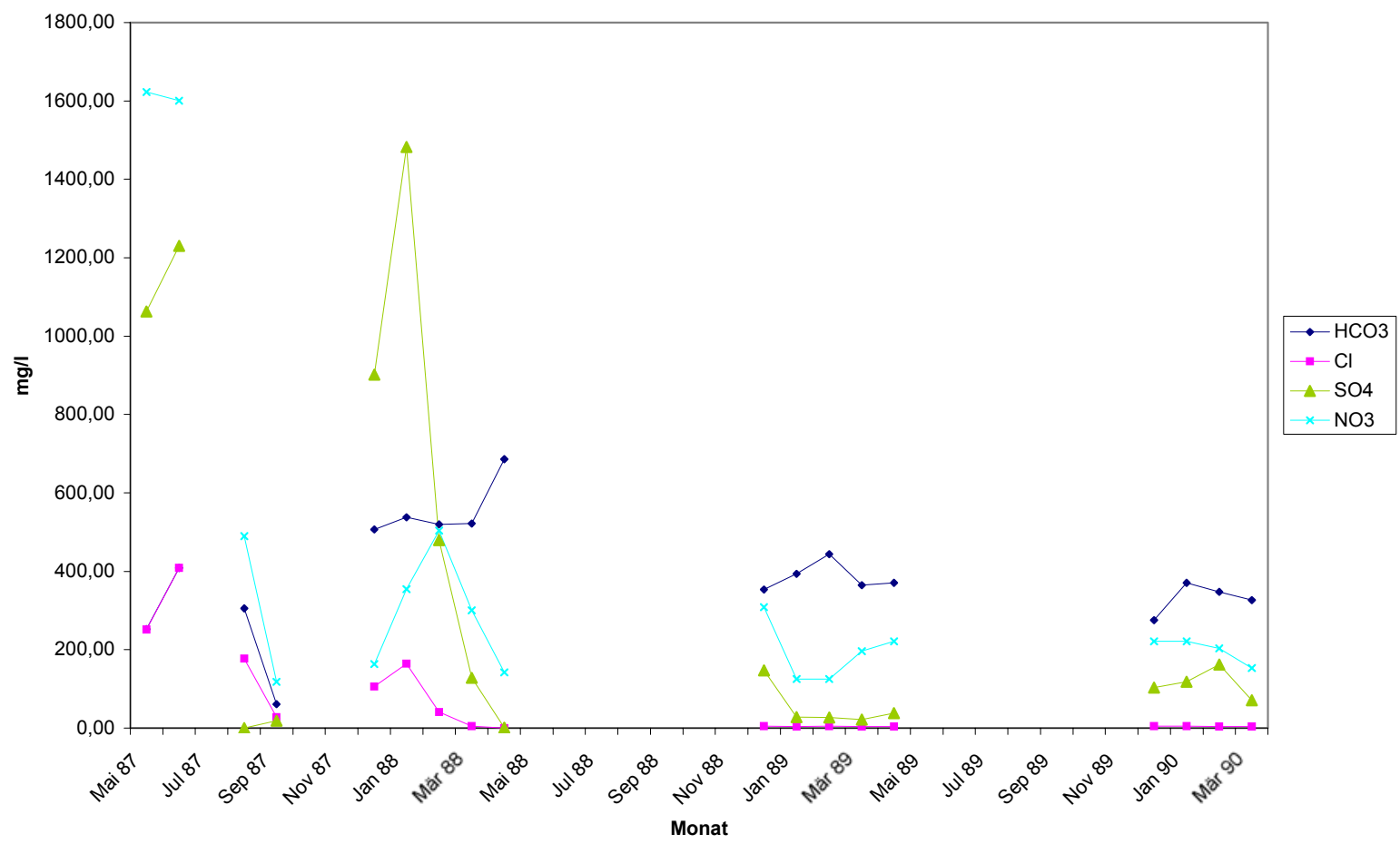

Abbildung 84: Konzentrationsverlauf der Anionen im Sickerwasser, Monatsmittelwerte, Lysimeter 4

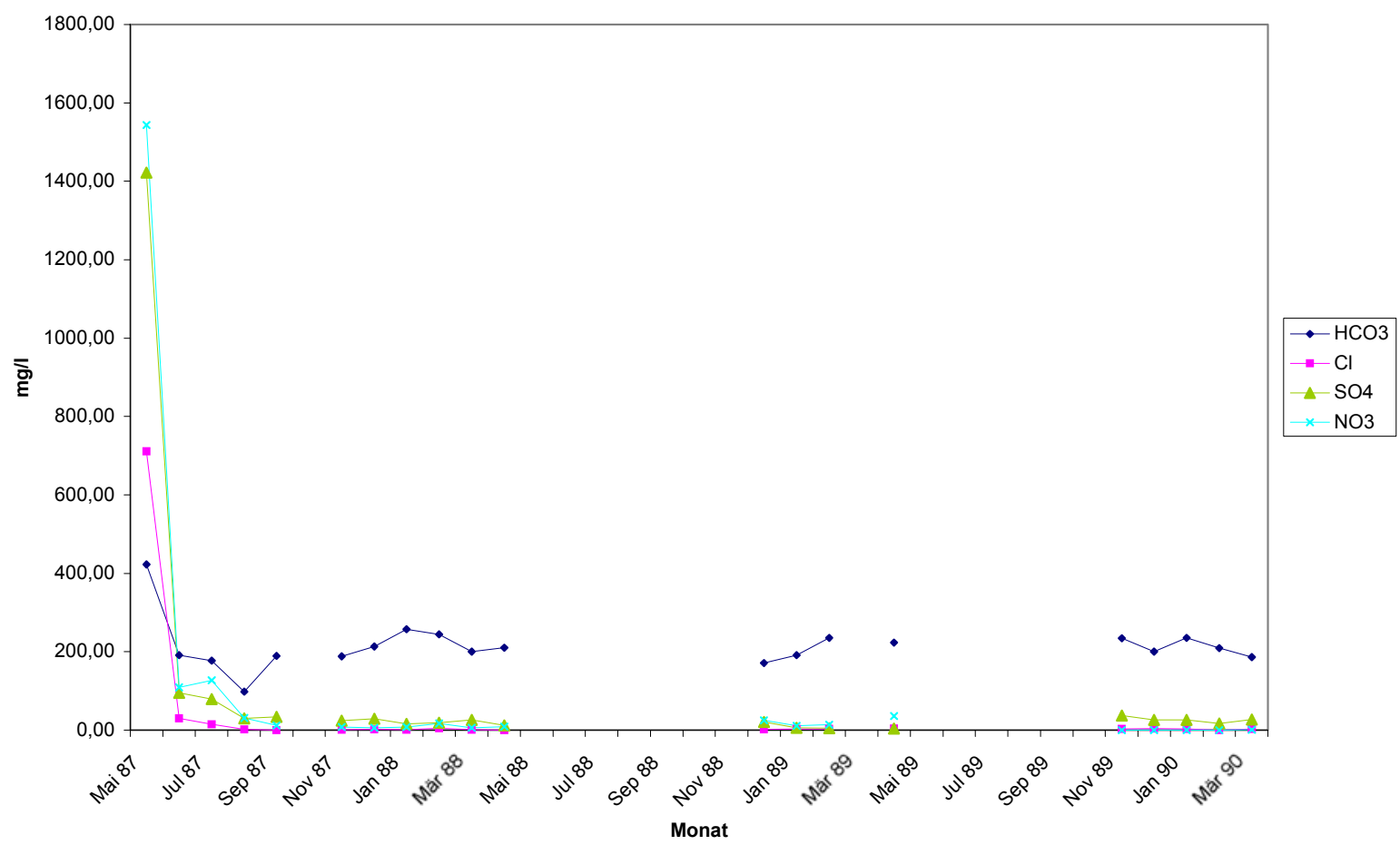

Abbildung 85: Konzentrationsverlauf der Anionen im Sickerwasser, Monatsmittelwerte, Lysimeter 7

In den ersten beiden Monaten nach dem Ansetzen der Versuche werden die in der Lysimeterfüllung gelöst vorliegenden lonen verdrängt: Bei den Kationen - sowohl beim Kompost wie beim Löss - das $\mathrm{K}$, das über $\mathrm{Ca}$, $\mathrm{Na}$ und weit über $\mathrm{Mg}$ dominiert, bei den Anionen 
das $\mathrm{NO}_{3}$, das - auch beim Löss - dominiert und zwar in der Reihenfolge über $\mathrm{SO}_{4}, \mathrm{Cl}$ und $\mathrm{HCO}_{3}$.

In den Herbst- und Wintermonaten erfolgt bei den Komposten offensichtlich eine Phase der Mineralisation mit einem erneuten Peak in den K-, Na-, Ca- und Mg-Austrägen. Beim Löss unterbleibt diese Phase erwartungsgemäß. In den Folgejahren setzt sich bei dem Kompostund dem Kompost-Löss-Lysimeter, deutlich abzuschätzen anhand des ausgetragenen Kaliums, die Mineralisation fort, jedoch abgeschwächt und abklingend.

Bei den Anionen zeigt sich ein ähnliches Bild: Nach dem rapiden ersten Austragen von bereits gelöst vorliegendem Sulfat und Hydrogencarbonat steigt in der nachfolgenden Mineralisationsphase des 1 . Versuchsjahres in den Kompost- und Kompost/Löss-Mischlysimetern noch einmal die $\mathrm{SO}_{4}$-Konzentration im Sickerwasser stark an, wird aber dann von den ebenfalls zunehmenden $\mathrm{HCO}_{3}$-und $\mathrm{NO}_{3}$-Konzentrationen übertroffen. Im weiteren Versuchsverlauf bleibt $\mathrm{HCO}_{3}$ auf niedrigem, aber relativ konstantem Niveau dominierend. Das gilt auch für das Löss-Lysimeter, aus dem nach der ersten 2-monatigen Auswaschungsphase kaum noch andere Anionen-Arten ausgetragen werden. Interessant ist, dass $\mathrm{Cl}$ und $\mathrm{NO}_{3}$ mit geringen Konzentrationspeaks die 1. Mineralisationsphase der Herbst- und Wintermonate $87 / 88$ begleiten.

\subsubsection{Jahresmittelwerte}

Tabelle 6-13 zeigt die Konzentrationen, der im Sickerwasser analysierten Elemente im Jahres- und Gesamtdurchschnitt. 
Tabelle 6-13: Konzentrationen der Inhaltsstoffe im Jahresdurchschnitt und Gesamtdurchschnitt, Lysimeter 1 - 8

\begin{tabular}{|c|c|c|c|c|c|c|c|c|c|c|c|c|c|}
\hline & DOC & $\mathrm{HCO}_{3}$ & $\mathrm{C}_{\mathrm{ges}}$ & $\mathrm{Ca}$ & $\mathrm{Mg}$ & $\begin{array}{c}\mathrm{K} \\
\mathrm{mg} / \mathrm{l}\end{array}$ & $\mathrm{Na}$ & $\mathrm{Fe}$ & $\mathbf{P}$ & $\mathrm{SO}_{4}$ & $\mathrm{Cl}$ & $\mathbf{N}_{\min }$ & $N_{\text {org }}$ \\
\hline $\begin{array}{l}\text { Lysimeter } 1 \\
\text { 1. Jahr }\end{array}$ & 421,25 & 784,26 & 575,67 & 553,76 & 96,99 & 1217,45 & 343,01 & 0,13 & 10,38 & 772,84 & 404,72 & 501,20 & k.A. \\
\hline 2. Jahr & 669,87 & 648,19 & 797,50 & 105,87 & 22,73 & 709,90 & 139,41 & 2,91 & 31,57 & 196,80 & 4,01 & 94,09 & 53,07 \\
\hline 3. Jahr & 619,82 & 478,47 & 714,03 & 124,58 & 24,79 & 799,82 & 139,21 & 1,35 & 21,47 & 262,85 & 8,32 & 182,43 & 67,24 \\
\hline 4. Jahr & 420,22 & 434,97 & 505,87 & 170,26 & 39,38 & 1073,60 & 163,08 & k.A. & k.A. & 270,65 & 6,47 & 325,85 & 47,82 \\
\hline $\begin{array}{l}\text { 1. - 4. Jahr } \\
\text { Lysimeter } 2\end{array}$ & 502,39 & 692,31 & 638,71 & 390,35 & 69,64 & 1048,84 & 266,63 & 0,80 & 21,14 & 572,80 & 255,52 & 369,87 & 23,31 \\
\hline 1. Jahr & 471,06 & 1478,53 & 762,18 & 711,51 & 133,91 & 1892,81 & 443,39 & 0,12 & 16,20 & 1551,18 & 765,53 & 389,18 & k.A. \\
\hline 2. Jahr & 706,42 & 1035,40 & 910,29 & 222,81 & 68,86 & 1851,33 & 322,98 & 1,34 & 16,90 & 991,33 & 210,85 & 239,47 & 93,16 \\
\hline 3. Jahr & 832,90 & 751,98 & 980,96 & 231,52 & 54,44 & 1827,00 & 304,92 & 1,17 & 15,35 & 875,93 & 94,08 & 382,66 & 122,61 \\
\hline 4. Jahr & 696,96 & 778,27 & 850,20 & 151,90 & 44,80 & 1416,15 & 235,15 & k.A. & k.A. & 318,50 & 26,75 & 334,79 & 30,28 \\
\hline $\begin{array}{l}\text { 1. - 4. Jahr } \\
\text { Lysimeter } 8\end{array}$ & 573,33 & 1277,38 & 824,85 & 550,67 & 109,54 & 1874,40 & 399,92 & 0,49 & 16,15 & 1343,12 & 558,93 & 366,58 & 36,57 \\
\hline 1. Jahr & 703,39 & 875,60 & 875,79 & 255,45 & 51,91 & 890,17 & 286,52 & k.A. & 14,45 & 452,72 & 232,95 & 104,39 & k.A. \\
\hline 2. Jahr & 432,30 & 531,98 & 537,04 & 54,07 & 16,39 & 418,95 & 88,65 & 3,03 & 18,86 & 125,29 & 0,31 & 44,79 & 35,14 \\
\hline 3. Jahr & 268,05 & 379,08 & 342,69 & 52,11 & 14,63 & 266,10 & 47,43 & 0,64 & 12,08 & 96,89 & 2,12 & 44,45 & 23,37 \\
\hline $\begin{array}{l}\text { 1. - 3. Jahr } \\
\text { Lysimeter } 6\end{array}$ & 537,25 & 677,59 & 670,67 & 159,35 & 34,63 & 631,57 & 183,15 & 0,90 & 15,00 & 290,73 & 122,86 & 76,00 & 14,02 \\
\hline 1. Jahr & 805,62 & 643,35 & 932,29 & 235,08 & 49,40 & 885,51 & 290,57 & k.A. & 15,73 & 466,34 & 216,88 & 175,75 & k.A. \\
\hline 2. Jahr & 343,47 & 381,16 & 418,52 & 53,26 & 14,85 & 380,40 & 80,91 & 2,41 & 19,03 & 69,42 & 1,51 & 63,05 & 25,99 \\
\hline 3. Jahr & 225,53 & 332,67 & 291,04 & 69,24 & 19,89 & 276,63 & 53,34 & 0,39 & 12,76 & 117,99 & 5,10 & 71,06 & 23,80 \\
\hline $\begin{array}{l}\text { 1. - 3. Jahr } \\
\text { Lysimeter } 5\end{array}$ & 574,01 & 516,37 & 675,68 & 158,91 & 35,41 & 638,39 & 191,72 & 0,58 & 15,68 & 303,33 & 122,98 & 128,08 & 10,91 \\
\hline 1. Jahr & 454,48 & 511,56 & 555,21 & 343,81 & 85,86 & 840,31 & 372,85 & k.A. & 6,43 & 1001,97 & 184,32 & 166,40 & k.A. \\
\hline 2. Jahr & 255,60 & 383,71 & 331,16 & 50,28 & 17,65 & 355,99 & 85,71 & 10,33 & 12,31 & 69,57 & 4,67 & 59,44 & 21,64 \\
\hline 3. Jahr & 191,31 & 388,32 & 267,77 & 79,31 & 22,10 & 275,92 & 45,62 & 0,48 & 9,88 & 123,18 & 4,62 & 50,74 & 24,75 \\
\hline $\begin{array}{l}\text { 1. - 3. Jahr } \\
\text { Lysimeter } 4\end{array}$ & 348,74 & 454,87 & 438,31 & 218,19 & 56,11 & 601,60 & 233,14 & 2,25 & 8,49 & 593,44 & 103,06 & 115,89 & 10,55 \\
\hline 1. Jahr & 308,55 & 477,89 & 402,65 & 312,38 & 76,87 & 478,16 & 313,14 & k.A. & 4,47 & 715,43 & 135,03 & 154,37 & k.A. \\
\hline 2. Jahr & 197,34 & 374,66 & 271,11 & 57,87 & 19,16 & 248,06 & 73,76 & 4,72 & 10,76 & 72,20 & 4,44 & 50,27 & 18,92 \\
\hline 3. Jahr & 173,97 & 338,14 & 240,55 & 85,37 & 21,77 & 199,71 & 37,22 & 0,35 & 6,19 & 126,65 & 4,66 & 47,84 & 7,79 \\
\hline $\begin{array}{l}\text { 1. - 3. Jahr } \\
\text { Lysimeter } 3\end{array}$ & 265,39 & 435,99 & 351,24 & 223,62 & 56,29 & 388,86 & 221,94 & 1,17 & 6,18 & 489,24 & 87,77 & 116,37 & 15,12 \\
\hline 1. Jahr & 178,00 & 360,01 & 248,89 & 239,34 & 45,58 & 151,77 & 208,24 & k.A. & 1,85 & 568,22 & 268,50 & 120,30 & k.A. \\
\hline 2. Jahr & 159,51 & 333,48 & 225,17 & 74,83 & 22,42 & 110,41 & 67,48 & 0,49 & 0,97 & 74,49 & 3,30 & 46,70 & 1,16 \\
\hline 3. Jahr & 97,83 & 326,18 & 162,06 & 111,84 & 24,39 & 121,99 & 22,82 & 0,16 & 2,46 & 93,52 & 2,46 & 46,86 & 13,07 \\
\hline $\begin{array}{l}\text { 1. - 3. Jahr } \\
\text { Lysimeter } 7\end{array}$ & 152,84 & 345,33 & 220,83 & 170,08 & 34,98 & 134,96 & 128,83 & 0,15 & 1,82 & 336,05 & 140,87 & 84,98 & 3,70 \\
\hline 1. Jahr & 19,57 & 202,39 & 59,42 & 68,98 & 6,90 & 13,00 & 22,46 & k.A. & 1,65 & 41,37 & 9,26 & 7,33 & k.A. \\
\hline 2. Jahr & 14,17 & 190,24 & 51,63 & 49,25 & 3,24 & 1,06 & 9,43 & 0,14 & u.B. & 14,61 & 2,11 & 5,60 & u.B. \\
\hline 3. Jahr & 5,70 & 211,87 & 47,42 & 62,60 & 5,80 & 2,18 & 7,76 & 0,11 & 0,07 & 26,00 & 2,68 & 0,09 & u.B. \\
\hline 1. - 3. Jahr & 14,77 & 200,92 & 54,33 & 61,59 & 5,55 & 6,94 & 15,18 & 0,07 & 0,79 & 29,81 & 5,61 & 5,15 & u.B. \\
\hline
\end{tabular}

Großlysimeter

Die Konzentrationen erreichen bei Lysimeter 2 häufig mehr als das doppelte der Werte von Lysimeter 1. Die Unterschiede verringern sich im Laufe der Versuchszeit, da die Konzentrationen bei Lysimeter $2 \mathrm{im}$ vierten Jahr weiterhin fallen, während sie bei Lysimeter 1 leicht steigen oder konstant bleiben. Der Übergang vom ersten zum zweiten Jahr macht sich bei einigen Elementen in einem deutlichen Konzentrationsrückgang bemerkbar, der um so stärker ausgeprägt ist, je höher der Kompost-Gehalt der Lysimeterfüllung ist. Eine Auslaugung der Kompost-Lysimeter an Chlorid ist bereits nach dem ersten Versuchsjahr zu erkennen.

\section{Kleinlysimeter}

Die Konzentrations-Unterschiede zwischen dem zweiten und dritten Messahr sind weitaus geringer als zwischen dem ersten und zweiten Messjahr. Die Konzentrationen stagnieren oder steigen leicht, bei Natrium setzt sich der Konzentrationsabfall fort. Bei den Mischungsvarianten hat Lysimeter 5 im ersten Versuchsjahr für Calcium, Magnesium, Natrium, Sulfat und Chlorid die höchsten Konzentrationen im Sickerwasser. Lysimeter 6 erreicht im Sickerwasser während der gesamten Versuchsdauer die höchsten P- und $\mathrm{N}_{\min }$-Werte. Auch die Konzentration löslicher organischer Kohlenstoffverbindungen ist im ersten Versuchsjahr bei Lysimeter 6 am größten. Für Kalium erreicht Lysimeter 8 im ersten und zweiten Jahr und für $\mathrm{C}_{\text {ges }}$ im zweiten und dritten Jahr die höchsten Werte. 
Die Abbildungen 86 - 89 zeigen die Jahresdurchschnittswerte der Lysimeter 1 - 8 für DOC, $\mathrm{SO}_{4}, \mathrm{HCO}_{3}$ und $\mathrm{P}$. Entsprechende Darstellungen für die übrigen lonen sind im Anhang aufgeführt (Abb. 1-8 bis 1-15). 


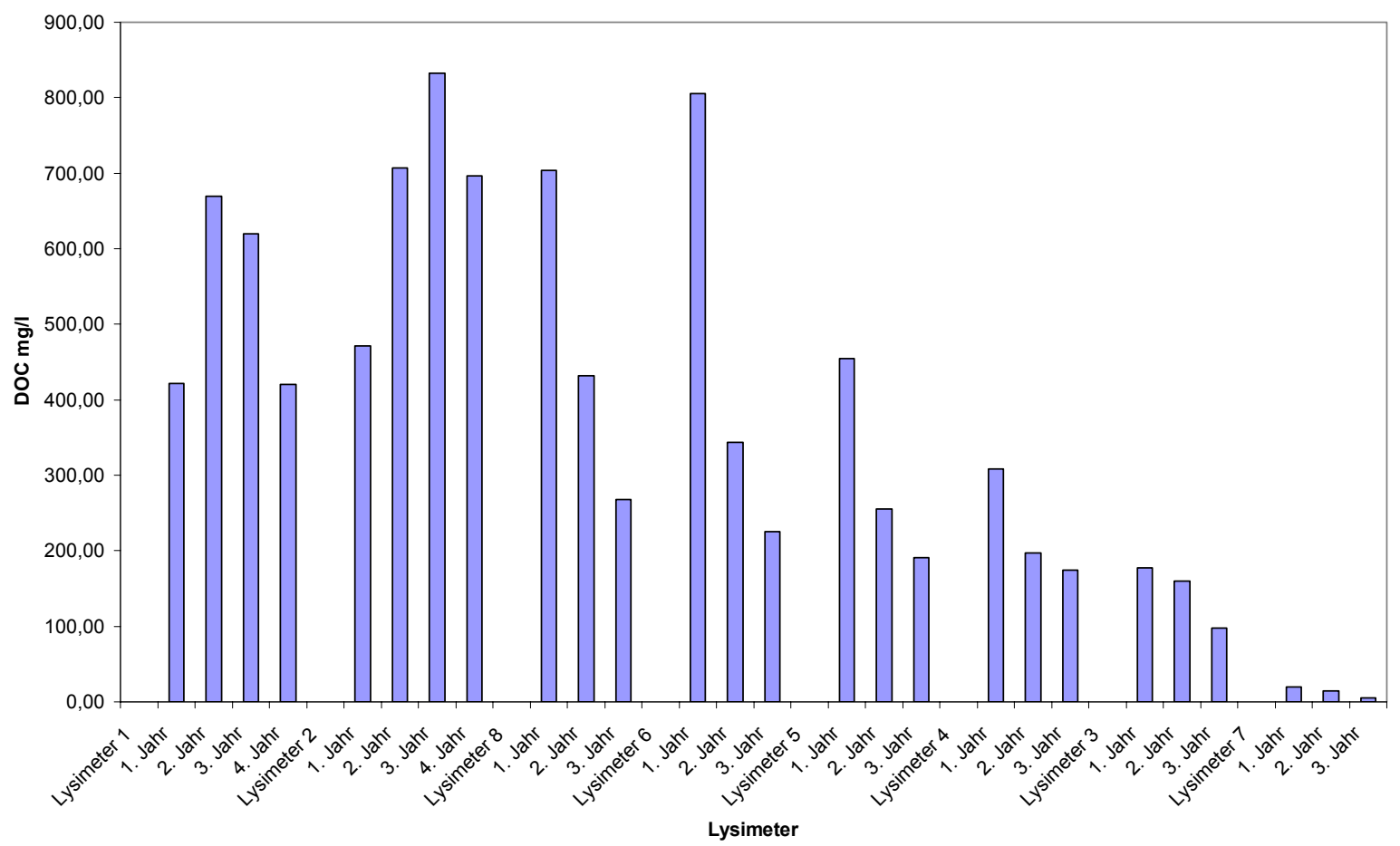

Abbildung 86: Vergleich der DOC-Jahres-Durchschnittskonzentrationen, Lysimeter 1 - 8

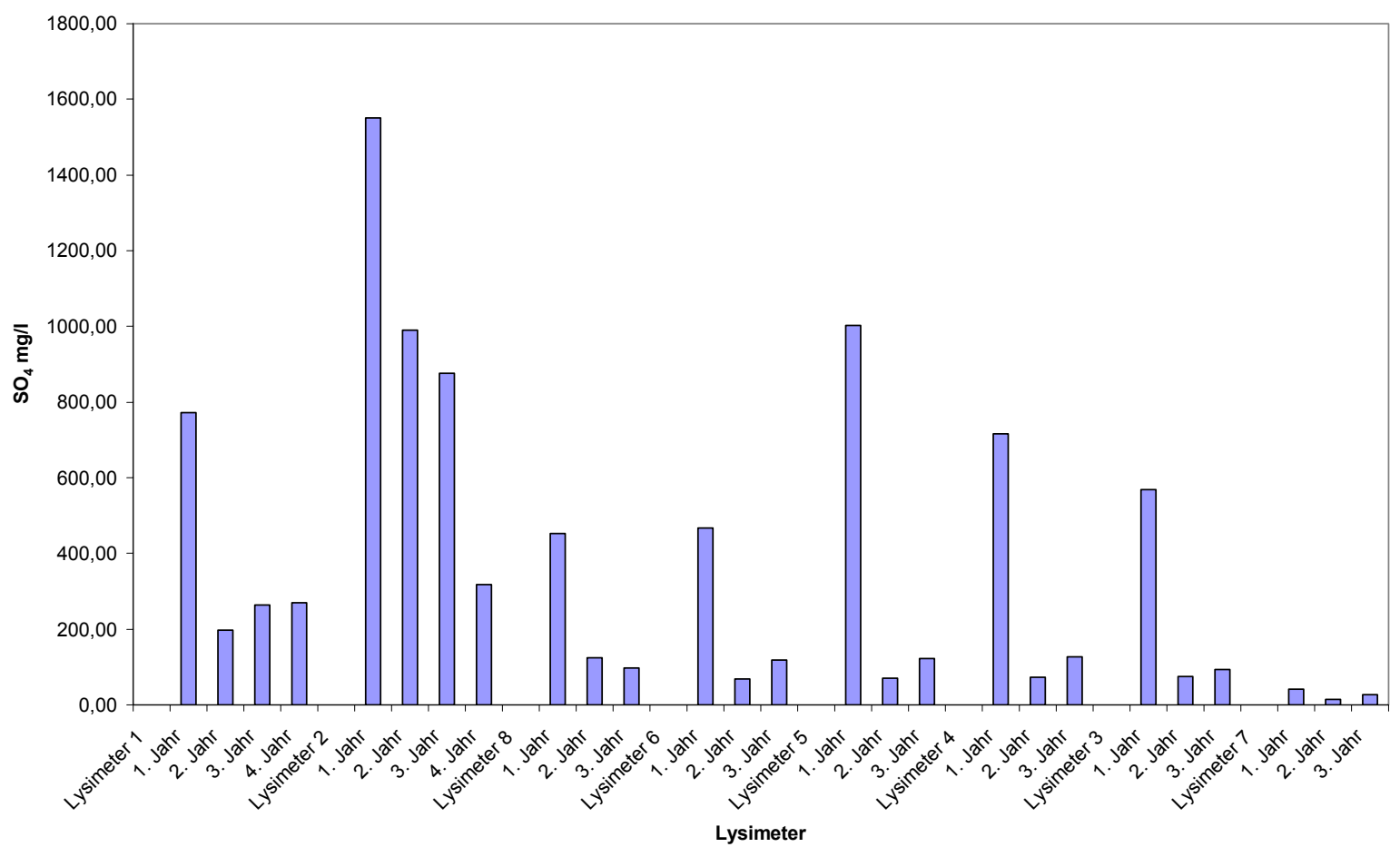

Abbildung 87: Vergleich der $\mathrm{SO}_{4}$-Jahres-

Durchschnittskonzentrationen, Lysimeter 1 - 8 


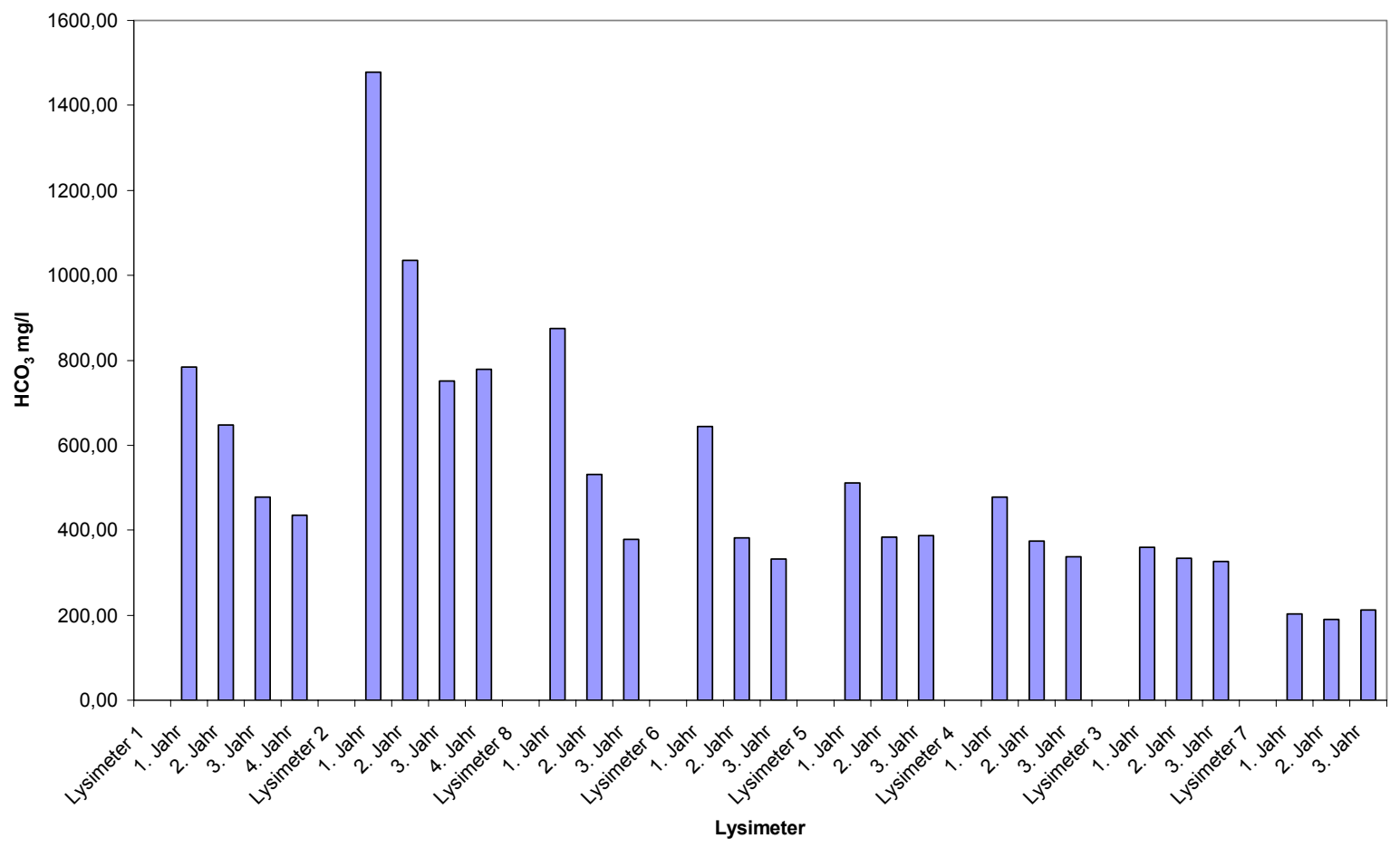

Abbildung 88: Vergleich der $\mathrm{HCO}_{3}$-Jahres-Durchschnittskonzentrationen, Lysimeter 1 - 8

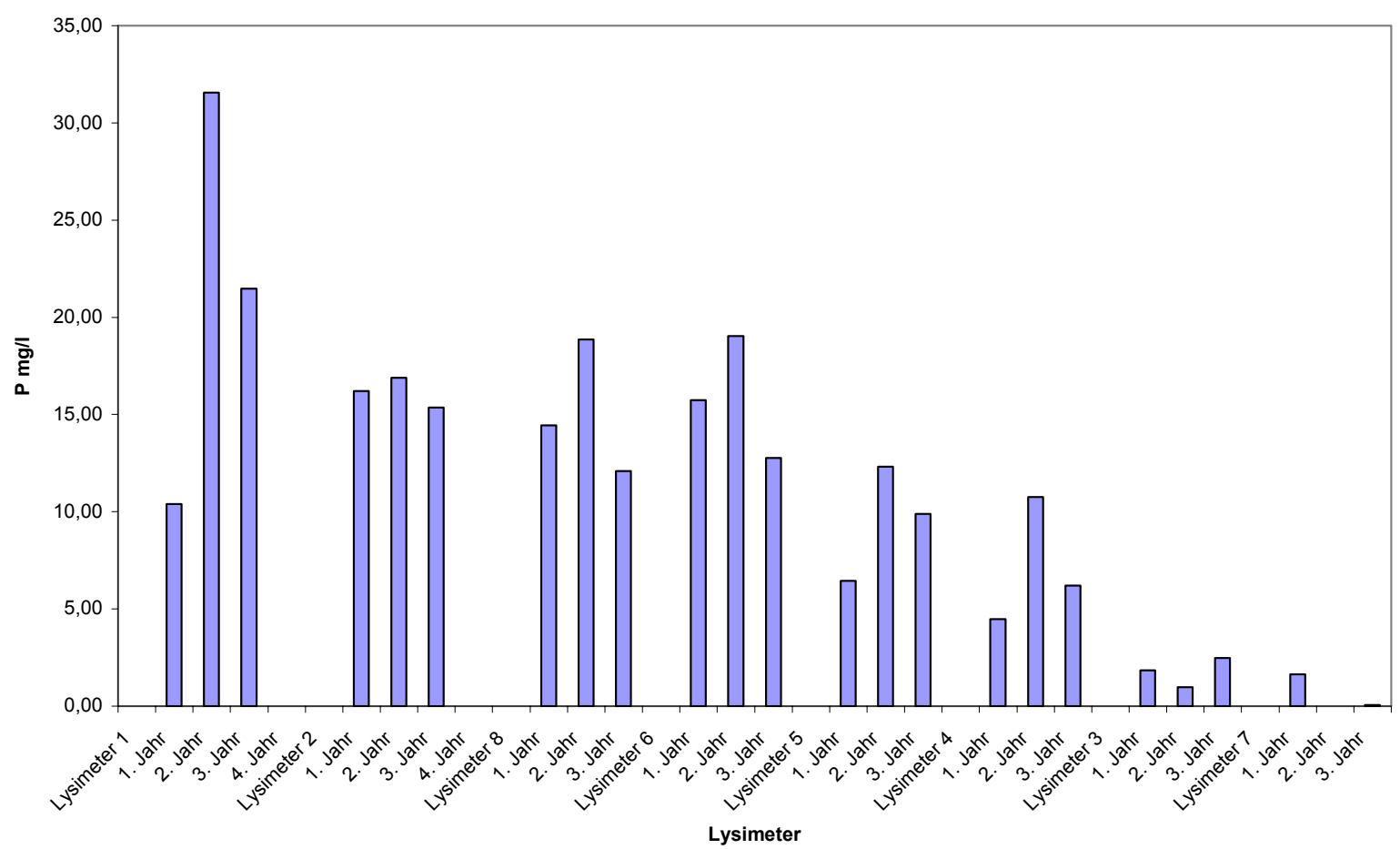

Abbildung 89: Vergleich der P-Jahres-

Durchschnittskonzentrationen, Lysimeter 1 - 8

$P$

In Abb. 89 sind die Jahresdurchschnittswerte der P-Konzentrationen der Sickerwasser-Proben dargestellt. Die P-Konzentrationen werden nicht in die Darstellung der Anionen aufge- 
nommen, da $\mathrm{P}$ als Gesamt-P der filtrierten Sickerwasser-Probe analysiert worden ist, also möglicherweise auch feinst korpuskuläres oder organisch gebundenes Phosphat umfasst.

Hervorzuheben ist, dass die Jahresdurchschnittswerte im Lauf der Zeit nicht absinken, sondern sich zum Teil noch steigern. Das heißt, dass wenn man davon ausgeht, dass dieses $\mathrm{P}$ durch langsam weiter fortschreitende Mineralisation der schwerer abbaubaren organischen Komponenten entsteht, dieser Prozess noch langsamer als die $\mathrm{HCO}_{3}$-Freisetzung erfolgt. Warum das Lysimeter 1, das bisher als in seiner Mineralisation weiter fortgeschritten gegenüber Lysimeter 2 betrachtet wird, eine höhere P-Mineralisationsrate aufweist ist vorerst nicht zu deuten.

\subsubsection{Verteilung der Ionen}

In Tab. 6-14 sind die prozentualen Anteile der analysierten Kationen und Anionen an der jeweiligen lonensumme in $\mathrm{mmol} / \mathrm{l}$ angegeben. Kalium stellt in den Kompost-Lysimetern den prozentualen Hauptanteil der Kationen dar. Der Anteil steigt mit zunehmendem KompostGehalt im Gemisch. Beim Löss-Lysimeter ist das Calcium-Kation im Sickerwasser am häufigsten vertreten, dementsprechend steigt der Calcium-Anteil mit zunehmendem Löss-Gehalt an. Die Kationenverteilung im Sickerwasser der Lysimeter 6 und 8 ist annähernd identisch.

Unter den Anionen im Sickerwasser nimmt das Nitrat den größten prozentualen Anteil ein. Die höchsten Werte erreicht hier Lysimeter 1. Während sich die lonen-Verhältnisse bei den beiden Großlysimetern zwischen den Kationen ähneln, weisen die Anionenverhältnisse größere Unterschiede auf. Beim Chlorid wird, wie bereits ausgeführt, das rasche Abklingen mit der Zeit deutlich, während das Nitrat eine nachhaltige, über Jahre fortschreitende Mineralisierung erkennen lässt. Beim Sulfat sinkt der Anteil, jedoch weniger stark als beim $\mathrm{Cl}$, während $\mathrm{HCO}_{3}$, ähnlich wie $\mathrm{NO}_{3}$, seinen Anteil hält. 
Tabelle 6-14: Prozentuale Anteile der Kationen- und

Anionen im Sickerwasser an der Kationen- bzw. Anionen-

Summe in $\mathrm{mmol} / \mathrm{l}$, Jahresmittelwerte und Gesamtmittelwert, Lysimeter 1 - 8

\begin{tabular}{|c|c|c|c|c|c|c|c|c|c|c|}
\hline & $\mathrm{Ca}$ & $\mathbf{M g}$ & $\begin{array}{l}\mathrm{K} \\
\% \\
\end{array}$ & $\mathrm{Na}$ & $\begin{array}{l}\text { Summe } \\
\text { Kationen }\end{array}$ & $\mathrm{HCO}_{3}$ & $\mathrm{SO}_{4}$ & $\begin{array}{l}\mathrm{Cl} \\
\% \\
\end{array}$ & $\mathrm{NO}_{3}$ & $\begin{array}{l}\text { Summe } \\
\text { Anionen }\end{array}$ \\
\hline $\begin{array}{l}\text { Lysimeter } 1 \\
\text { 1. Jahr }\end{array}$ & 21,64 & 6,25 & 48,75 & 23,36 & 100,00 & 18,88 & 11,81 & 16,76 & 52,55 & 100,00 \\
\hline 2. Jahr & 9,50 & 3,36 & 65,32 & 21,82 & 100,00 & 54,47 & 10,51 & 0,58 & 34,44 & 100,00 \\
\hline 3. Jahr & 10,14 & 3,33 & 66,76 & 19,76 & 100,00 & 32,90 & 11,48 & 0,98 & 54,64 & 100,00 \\
\hline 4. Jahr & 10,51 & 4,01 & 67,93 & 17,55 & 100,00 & 21,35 & 8,44 & 0,55 & 69,67 & 100,00 \\
\hline $\begin{array}{l}\text { 1. - 4. Jahr } \\
\text { Lysimeter } 2\end{array}$ & 19,09 & 5,61 & 52,57 & 22,73 & 100,00 & 22,28 & 11,71 & 14,15 & 51,86 & 100,00 \\
\hline 1. Jahr & 19,52 & 6,06 & 53,22 & 21,20 & 100,00 & 27,00 & 17,99 & 24,06 & 30,96 & 100,00 \\
\hline 2. Jahr & 7,97 & 4,06 & 67,84 & 20,13 & 100,00 & 33,71 & 20,50 & 11,82 & 33,97 & 100,00 \\
\hline 3. Jahr & 8,49 & 3,29 & 68,71 & 19,50 & 100,00 & 23,97 & 17,74 & 5,16 & 53,13 & 100,00 \\
\hline 4. Jahr & 7,28 & 3,54 & 69,54 & 19,64 & 100,00 & 31,32 & 8,14 & 1,85 & 58,69 & 100,00 \\
\hline $\begin{array}{l}\text { 1. - 4. Jahr } \\
\text { Lysimeter } 8\end{array}$ & 16,44 & 5,39 & 57,36 & 20,81 & 100,00 & 27,24 & 18,19 & 20,51 & 34,05 & 100,00 \\
\hline 1. Jahr & 14,57 & 4,88 & 52,05 & 28,49 & 100,00 & 43,37 & 14,24 & 19,86 & 22,52 & 100,00 \\
\hline 2. Jahr & 8,13 & 4,06 & 64,57 & 23,24 & 100,00 & 65,90 & 9,86 & 0,07 & 24,17 & 100,00 \\
\hline 3. Jahr & 12,07 & 5,59 & 63,19 & 19,16 & 100,00 & 59,42 & 9,65 & 0,57 & 30,36 & 100,00 \\
\hline $\begin{array}{l}\text { 1. - 3. Jahr } \\
\text { Lysimeter } 6\end{array}$ & 13,47 & 4,83 & 54,72 & 26,99 & 100,00 & 48,23 & 13,15 & 15,05 & 23,57 & 100,00 \\
\hline 1. Jahr & 13,58 & 4,71 & 52,44 & 29,27 & 100,00 & 30,95 & 14,25 & 17,96 & 36,83 & 100,00 \\
\hline 2. Jahr & 8,75 & 4,02 & 64,06 & 23,17 & 100,00 & 54,26 & 6,28 & 0,37 & 39,10 & 100,00 \\
\hline 3. Jahr & 14,47 & 6,85 & 59,25 & 19,43 & 100,00 & 45,83 & 10,32 & 1,21 & 42,64 & 100,00 \\
\hline $\begin{array}{l}\text { 1. - 3. Jahr } \\
\text { Lysimeter } 5\end{array}$ & 13,18 & 4,84 & 54,26 & 27,72 & 100,00 & 34,92 & 13,03 & 14,31 & 37,73 & 100,00 \\
\hline 1. Jahr & 17,22 & 7,09 & 43,14 & 32,55 & 100,00 & 23,36 & 29,06 & 14,48 & 33,10 & 100,00 \\
\hline 2. Jahr & 8,47 & 4,90 & 61,46 & 25,17 & 100,00 & 55,22 & 6,36 & 1,16 & 37,26 & 100,00 \\
\hline 3. Jahr & 16,59 & 7,62 & 59,15 & 16,63 & 100,00 & 55,83 & 11,25 & 1,14 & 31,78 & 100,00 \\
\hline $\begin{array}{l}\text { 1. - 3. Jahr } \\
\text { Lysimeter } 4\end{array}$ & 16,36 & 6,94 & 46,23 & 30,47 & 100,00 & 30,04 & 24,90 & 11,71 & 33,34 & 100,00 \\
\hline 1. Jahr & 21,18 & 8,59 & 33,22 & 37,01 & 100,00 & 26,01 & 24,74 & 12,65 & 36,60 & 100,00 \\
\hline 2. Jahr & 12,25 & 6,69 & 53,83 & 27,23 & 100,00 & 57,89 & 7,09 & 1,18 & 33,84 & 100,00 \\
\hline 3. Jahr & 21,84 & 9,18 & 52,37 & 16,60 & 100,00 & 0,00 & 27,10 & 2,70 & 70,20 & 100,00 \\
\hline $\begin{array}{l}\text { 1. - 3. Jahr } \\
\text { Lysimeter } 3\end{array}$ & 20,29 & 8,42 & 36,17 & 35,11 & 100,00 & 31,04 & 22,12 & 10,75 & 36,09 & 100,00 \\
\hline 1. Jahr & 28,73 & 9,02 & 18,67 & 43,58 & 100,00 & 21,09 & 21,14 & 27,07 & 30,70 & 100,00 \\
\hline 2. Jahr & 21,84 & 10,79 & 33,03 & 34,34 & 100,00 & 56,53 & 8,02 & 0,96 & 34,48 & 100,00 \\
\hline 3. Jahr & 35,29 & 12,69 & 39,46 & 12,56 & 100,00 & 54,92 & 10,00 & 0,71 & 34,37 & 100,00 \\
\hline $\begin{array}{l}\text { 1. - 3. Jahr } \\
\text { Lysimeter } 7\end{array}$ & 28,79 & 9,76 & 23,42 & 38,02 & 100,00 & 29,48 & 18,22 & 20,70 & 31,60 & 100,00 \\
\hline 1. Jahr & 51,93 & 8,56 & 10,03 & 29,48 & 100,00 & 73,18 & 9,50 & 5,77 & 11,55 & 100,00 \\
\hline 2. Jahr & 68,29 & 7,41 & 1,51 & 22,79 & 100,00 & 83,61 & 4,08 & 1,59 & 10,71 & 100,00 \\
\hline 3. Jahr & 71,19 & 10,88 & 2,54 & 15,38 & 100,00 & 90,77 & 7,08 & 1,98 & 0,17 & 100,00 \\
\hline 1. - 3. Jahr & 59,05 & 8,77 & 6,82 & 25,36 & 100,00 & 79,75 & 7,52 & 3,83 & 8,91 & 100,00 \\
\hline
\end{tabular}

\subsubsection{Ionenbilanz}

Zur Berechnung der Kationen- und Anionen-Summen werden jeweils die anhand der Äquivalentgewichte berechneten Konzentrationen (in mmol IE/l) der Kationen: Calcium, Magnesium, Natrium und Kalium und der Anionen: Hydrogencarbonat, Nitrat, Sulfat und Chlorid addiert. Aufgrund der geringen Gehalte an $\mathrm{NH}_{4}$, Fe und Silikat im Sickerwasser und der heterogenen Bindungsformen beim $\mathrm{P}$ werden diese Verbindungen bei der Erstellung der lonenbilanz nicht berücksichtigt. Da die lonenladungen in einer Lösung ausgeglichen sind, ist eine entsprechende Kompensation positiver Ladungen durch negativ geladene lonen zu erwarten.

Wie bereits in verschiedenen Arbeiten (z.B. ERKENBERG 1987, BANSE 1990) festgestellt worden ist, sind die Bilanzen der mineralischen lonen im Kompost-Sickerwasser und den aus Komposten hergestellten Extrakten nicht ausgeglichen. In der Summe ergeben sich Überschüsse an Kationen. Dagegen weisen die wässrigen Extrakte aus Materialien, die überwiegend aus Lössboden bestehen, meist ausgeglichene lonenbilanzen auf. Es liegt somit die Vermutung nahe, dass die in hoher Konzentration im Sickerwasser und in den Extrakten enthaltenen organischen Verbindungen an der Herstellung der Elektroneutralität beteiligt sind. Nimmt man den fehlenden Anionenunterschuss, d. h. die nicht durch mineralische Anionen abgedeckten Kationenvalenzen, und bezieht diese, in der Annahme, dass sie 
in organischen Säureresten bestehen, auf die Zahl der in der Lösung befindlichen C-Atome, so ergeben sich unterschiedliche C/Kationenüberschuss-Quotienten.

Die Anzahl an C-Atomen pro freier positiver Valenz liegt im Sättigungsextrakt unterschiedlich alter Komposte nach ERKENBERG (1987) zwischen 5,7 und 13,9. BANSE ermittelte 1990 für die Gesamt-Sickerwasserfracht der beiden Großlysimeter im ersten Beobachtungsjahr 13,15 C-Atome pro freier positiver Valenz für Lysimeter 1 und 14,38 C-Atome pro freier positiver Valenz für Lysimeter 2.

Die Berechnung der Anzahl an C-Atomen pro freier positiver Valenz ist nur dann sinnvoll, wenn der aus der lonenbilanz errechnete Kationenüberschuss größer als $1 \mathrm{mmol} I \mathrm{IE} / \mathrm{l}$ ist. Die Werte unter $1 \mathrm{mmol}$ IE/l liegen im Bereich der Messfehler der Anionen- und Kationenbestimmungen. Eine Korrelation des Kationenüberschusses mit den DOC-Konzentrationen in den Sickerwasser Proben ist anhand der Messwerte nicht abzuleiten. Das heißt, Sickerwasserlösungen mit hohen DOC-Gehalten zeichnen sich nicht unbedingt auch durch hohe Kationenüberschüsse aus.

Tabelle 6-15 gibt die Jahres-Durchschnittswerte für die Anzahl an C-Atomen in organischer Bindung pro freier positiver Valenz wieder. Erwartungsgemäß nehmen diese Quotienten in der Lysimeter-Reihe mit zunehmendem Löss-Anteil ab und erreichen bei der reinen Lössboden-Füllung mit nahezu ausgeglichener Bilanz der Sickerlösung wegen des geringen Austrags an organischer Substanz im ersten Jahr Werte von 1.

In der zeitlichen Abfolge der Jahre ist in den großen Lysimetern 1 und 2 eine geringe Tendenz der Abnahme, bei den kleinen Lysimetern dagegen die einer Zunahme zu beobachten. Dies kann damit zusammenhängen, dass die Menge eluierter Kationen im Laufe der Zeit stärker abnimmt als die durch anhaltende Umsetzung erzeugte organische Fracht.

Der Gesamt-Durchschnittswert für den Quotienten Zahl der C-Atome in organischer Bindung durch Zahl der Kationen-Überschuss-Valenzen beträgt 7,4, ist also verglichen mit den Werten für Sickerwässer aus Parabraunerden von 2, recht hoch. Man könnte sich vorstellen, dass die wirksamen organischen Anionen von oxyphenolischen Körpern mit 6 C-Atomen, wie sie Bestandteile von Huminstoffen und ihren Vorstufen sind, gebildet werden.

Tabelle 6-15: Jahres- und Gesamt-Durchschnittswerte der Anzahl an C-Atomen pro freier positiver Valenz

\begin{tabular}{|c|c|c|c|c|c|c|c|c|}
\hline \multirow[t]{2}{*}{ Lysimeter } & 1 & 2 & 8 & 6 & 5 & 4 & 3 & 7 \\
\hline & \multicolumn{8}{|c|}{ Anzahl C-Atome/mmol IE Kationenüberschuss } \\
\hline \multicolumn{9}{|l|}{ Mittelwerte: } \\
\hline 1. Jahr & 8,12 & 8,04 & 5,77 & 9,12 & 6,92 & 4,56 & 3,62 & 1,01 \\
\hline 2. Jahr & 5,54 & 3,77 & 7,32 & 6,19 & 5,38 & 6,27 & 2,70 & \\
\hline 3. Jahr & 6,40 & 4,48 & 17,91 & 14,31 & 7,19 & 11,88 & 5,13 & \\
\hline 1. - 3. Jahr & 7,11 & 6,08 & 8,65 & 9,71 & 6,54 & 6,47 & 3,92 & 1,01 \\
\hline
\end{tabular}

Abbildung 90 zeigt, dass alle stärker komposthaltigen Lysimeter besonders im 1. Jahr teilweise recht hohe und stark schwankende Kationen-Überschuss-Beträge aufweisen. Die Kationen-Überschuss-Beträge nehmen mit zunehmender Versuchsdauer ab. Die reine Lössboden-Variante und die Variante mit hohem Lössboden-Anteil zeigen nahezu ausgeglichene Bilanzen. 


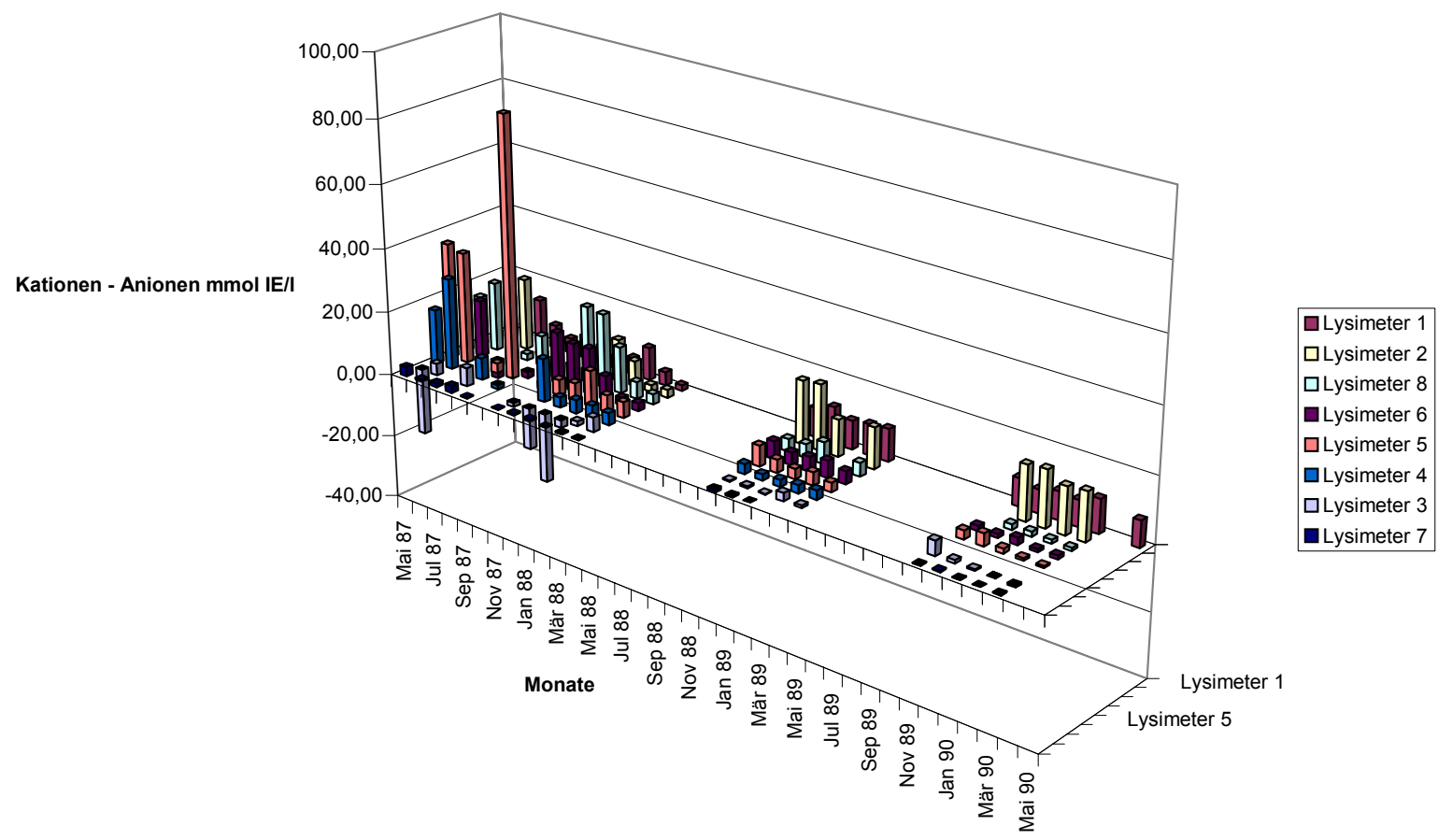

Abbildung 90: Kationen-Anionendifferenz im Sickerwasser, Monatsmittelwerte, Lysimeter 1 - 8

\subsubsection{Vergleich:Sickerwasser nach Bewässerung und nach Niederschlag}

In dem auf die Befüllung (1987) folgenden Jahr 1988 wurde durch künstliche Beregnung der Großlysimeter die Bildung von Sickerwasser herbeigeführt Sickerwasser-Probe vom 07.07.88). Dieses zeigt im Vergleich zu den übrigen Sickerwasser-Proben der beiden Großlysimeter deutlich niedrigere Konzentrationen an Inhaltsstoffen. Da die SickerwasserProbe vom 07.07.88 nach einer schnellen Passage der Lysimeter-Füllung gewonnen wurde, erlaubt der Vergleich der Konzentrationshöhen in dieser durch Beregnung hervorgerufenen Sickerwasser-Spende mit den übrigen Proben Rückschlüsse auf den Zeitbedarf von Lösungsprozessen. In Tabelle 6-16 werden für die beiden Großlysimeter die Jahresmittelwerte für 1988 und 1989 den Werten der Sickerwasser-Probe vom Juli 1988 gegenübergestellt.

Tabelle 6-16: Vergleich der Jahresmittelwerte 1988 und 1989 mit den Werten für die durch künstliche Beregnung erhaltene Sickerwasser-Probe vom Juli 1988

\begin{tabular}{|c|c|c|c|c|c|c|c|c|c|c|c|c|}
\hline & pH-Wert & $\begin{array}{c}\text { Leitfähigkeit } \\
\mathrm{mS} / \mathrm{cm}\end{array}$ & DOC & $\mathrm{HCO}_{3}$ & $\mathrm{Ca}$ & Mg & $\begin{array}{c}\mathrm{K} \\
\mathrm{mg} / \mathrm{l}\end{array}$ & $\mathrm{Na}$ & $\mathrm{SO}_{4}$ & $\mathrm{Cl}$ & $\mathbf{N}_{\min }$ & $\mathbf{N}_{\text {org }}$ \\
\hline \multicolumn{13}{|l|}{ Lysimeter 1} \\
\hline 1. Jahr Mw & 7,58 & 7,11 & 421,25 & 784,26 & 553,76 & 96,99 & 1217,45 & 343,01 & 772,84 & 404,72 & 501,20 & \\
\hline 2. Jahr MW & 8,10 & 2,72 & 669,87 & 648,19 & 105,87 & 22,73 & 709,90 & 139,41 & 196,80 & 4,01 & 94,09 & 53,07 \\
\hline Juli 88 & 7,21 & 1,90 & 181,25 & 283,70 & 128,50 & 9,00 & 410,69 & 71,50 & 126,00 & 26,10 & 122,50 & 31,43 \\
\hline \% vom 2. Jahr & & 69,85 & 27,06 & 43,77 & 121,38 & 39,59 & 57,85 & 51,29 & 64,02 & 650,75 & 130,20 & 59,22 \\
\hline \multicolumn{13}{|l|}{ Lysimeter 2} \\
\hline 1. Jahr Mw & 7,60 & 8,68 & 471,06 & 1478,53 & 711,51 & 133,91 & 1892,81 & 443,39 & 1551,18 & 765,53 & 389,18 & \\
\hline 2. Jahr Mw & 7,89 & 7,15 & 706,42 & 1035,40 & 222,81 & 68,86 & 1851,33 & 322,98 & 991,33 & 210,85 & 239,47 & 93,16 \\
\hline Juli 88 & 7,70 & 4,60 & 285,25 & 683,20 & 168,25 & 34,00 & 1435,28 & 182,50 & 809,99 & 249,63 & 204,40 & 7,97 \\
\hline \% vom 2. Jahr & & 64,34 & 40,38 & 65,98 & 75,51 & 49,38 & 77,53 & 56,50 & 81,71 & 118,39 & 85,36 & 8,56 \\
\hline
\end{tabular}

Vor dem Hintergrund, dass die Konzentrationen der Inhaltsstoffe in der Juliprobe den Sickerwasser-Konzentrationen der Folgemonate eher entsprechen als den Vormonaten 
werden in den Zahlen-Zeilen 4 und 8 die Konzentrationen im Juli 1988 in \% der Durchschnittswerte für das zweite Jahr angegeben. Die Salzgehalte im Sickerwasser der aus der Beregnung hervorgegangenen Proben, liegen deutlich unter den Frühjahr- und Herbst-Proben des gleichen Jahres. Während für Lysimeter 1 die vom ersten zum zweiten Untersuchungsjahr stark fallenden $\mathrm{Ca}, \mathrm{Cl}$ und $\mathrm{N}_{\min }$-Konzentrationen in der Juliprobe noch deutlich über $100 \%$ betragen, liegen für die übrigen Inhaltsstoffe - vor allem für die DOC-Konzentration - deutlich geringere Werte vor. Bei Lysimeter 2 liegt nur die Konzentration an Chlorid über der Durchschnittskonzentration des 2. Messjahres, etwas geringere Werte erzielen Ca, $\mathrm{K}, \mathrm{N}_{\min }$ und $\mathrm{SO}_{4}$, deutlich geringere Konzentrationen $\mathrm{DOC}, \mathrm{HCO}_{3}, \mathrm{Mg}, \mathrm{Na}$ und $\mathrm{N}_{\text {org }}$.

Das nach längerer Trockenheit durch Beregnung erzeugte Sickerwasser zeichnet sich durch niedrigere Stoffkonzentrationen als die vorhergehenden und nachfolgenden (außer $\mathrm{Ca}, \mathrm{C}$, und $\mathrm{N}_{\min }$ ) in den Sickerwasser-Proben aus. Dies könnte mit durch die geringe Durchfeuchtung des Kompostes und der kurzen Verweilzeit des Wassers kinetisch bedingt sein.

\subsubsection{Sonstige Inhaltsstoffe}

Die Konzentrationen an Eisen und Silikat wurden nicht durchgehend in allen SickerwasserProben analysiert. Beim Fe liegen für die Lysimeter 1 und 2 die Werte nahezu vollständig vor, während bei den Kleinlysimetern die Fe-Bestimmung in den Sickerwasser-Proben erst ab dem zweiten Messjahr erfolgte. Die hierbei ermittelten Werte zeigen die Tabellen 1-57, 1-58 und 1-61 - 1-66 im Anhang. Die Konzentrationen liegen im Durchschnitt bei rund 2 $\mathrm{mg} / \mathrm{l}$. Bei den Großlysimetern ist vom ersten zum zweiten Jahr ein deutlicher Konzentrationsanstieg zu erkennen. Die Konzentrationen sind bei Lysimeter 1 etwas höher als bei Lysimeter 2. Die niedrigsten Werte liegen in den Sickerwasser-Proben der Löss-Variante vor. Die höchsten Werte erzielt Lysimeter 5 mit durchschnittlich über $10 \mathrm{mg} F e$ pro I im zweiten Messjahr. Die Fe-Konzentrationen im Sickerwasser der Lysimeter 4 und 5 sind vergleichsweise hoch. In Anbetracht des festgestellten Kationen-Überschusses in den Sickerlösungen ist anzunehmen, dass das Eisen durch organische Liganden in Lösung gehalten wird.

Da die Vermutung bestand, dass in größerem Umfang amorphe Kieselsäure ausgewaschen werden würde, wurden stichprobenhaft Sickerwasser-Analysen durchgeführt. Mit der verwendeten Bestimmungsmethode werden freie Mono-Kieselsäure, Polykieselsäure und organisch gebundenes Silikat erfasst. Die Tabellen im Anhang zeigen die für die Proben der Lysimeter 1- $8 \mathrm{im}$ zweiten 2. Messjahr ermittelten Si-Werte in $\mathrm{mg} / \mathrm{l}$. Im Sickerwasser von Lysimeter 1 würden die ermittelten Si-Werte, allein dem 4fach negativen Monosilikat-lon zugerechnet, bereits $10 \mathrm{bzw}$. $6 \mathrm{mmol}$ IE/l ausmachen und damit die Kationen-AnionenBilanz ausgleichen, ohne dass organische Anionen benötigt würden. Dies ist aber allein im Hinblick auf die verschiedenen Bindungsformen des $\mathrm{Si}$ eine sicherlich unzulässige Annahme. Bei allen anderen Lysimetern und besonders beim Löss-Lysimeter sind die SiWerte wesentlich geringer. Die Konzentrationen liegen bei der Löss-Variante bei durchschnittlich $4 \mathrm{mg}$ Si pro I und bei den Kompost-Lysimetern zwischen 11 für Lysimeter 8 und $44 \mathrm{mg} \mathrm{Si} \mathrm{pro} \mathrm{I} \mathrm{für} \mathrm{Lysimeter} \mathrm{1.} \mathrm{Insgesamt} \mathrm{sind} \mathrm{die} \mathrm{Werte} \mathrm{mit} \mathrm{durchschnittlich} 14 \mathrm{mg}$ Si pro I niedriger als erwartet.

\subsubsection{Frachten/Gesamtaustrag}

Tabelle 6-17 zeigt für die im Sickerwasser analysierten Elemente und Verbindungen die pro Messjahr und knapp 4-jähriger (Großlysimeter) bzw. 3-jähriger (Kleinlysimeter) Untersuchungszeit durch das Sickerwasser ausgetragenen Stoffmengen in $\mathrm{g}$ je Lysimeter. Die Tabellenwerte sind aus den in Tabelle 6-13 aufgeführten Jahres-Durchschnitts-Konzentrationen und den jährlichen Sickerwassermengen für jedes Lysimeter berechnet worden.

Die Sickerwasser-Proben wurden in den ersten drei Messjahren kontinuierlich entnommen und untersucht. Bei den Kleinlysimetern beträgt die betrachtete und ausgewertete 
Versuchszeit drei Jahre. Für die beiden Großlysimeter werden darüber hinausgehend die Stoffausträge bis zum Zeitpunkt der Leerung der Lysimeter im Januar (Lysimeter 1) und im März (Lysimeter 2) 1991 das heißt nach etwa 4 Jahren hochgerechnet.

Für die Ermittlung der Stoffausträge mit dem Sickerwasser für Lysimeter 1 von Mai 1990 bis Januar 1991 und für Lysimeter 2 von Mai 1990 bis März 1991 werden folgende Konzentrationen herangezogen:

Lysimeter 1: Konzentrationen des Stand-Sickerwassers vom 08.01.1991,

Lysimeter 2: Mittelwert aus den Konzentrationen der Standprobe vom 08.01.1991 und dem frischen Durchfluss am 09.01.1991.

Zur Vervollständigung der Tabelle und der Bilanz werden für die im 4. Messjahr nicht bestimmten Messgrößen Fe und P Mittelwerte aus den Messwerten der Vorjahre herangezogen (siehe Tab. 1-60).

Der Regeneintrag im 4. Jahr wurde dem monatlichen Witterungsbericht $(1991,1990)$ für Göttingen West des deutschen Wetterdienstes entnommen und die Höhe des angefallenen Sickerwassers entsprechend den Vorjahreswerten berechnet. Danach ergeben sich für Lysimeter 1 von Mai 1990 bis Januar 1991479 mm Niederschlag und 658 I Sickerwasser, für Lysimeter 2 von Mai 1990 bis März 1991543 mm Niederschlag und entsprechend der geringeren Freisetzungsrate 511 I Sickerwasser.

Tabelle 6-17: Gesamt-Austräge mit dem Sickerwasser in

g/Lysimeter,

Lysimeter 1: Mai 1987 bis Januar 1991,

Lysimeter 2: Mai 1987 bis März 1991,

Lysimeter 3 - 8: Mai 1987 bis April 1990

\begin{tabular}{|c|c|c|c|c|c|c|c|c|c|c|c|c|c|c|}
\hline & DOC & $\mathrm{HCO}_{3}$ & $\mathrm{C}_{\text {ges }}$ & $\mathrm{Ca}$ & Mg & $\begin{array}{l}K \\
\mathrm{~g}\end{array}$ & $\mathrm{Na}$ & $\mathrm{Fe}$ & $\mathrm{Si}$ & $\mathbf{P}$ & $\mathrm{SO}_{4}$ & $\mathrm{Cl}$ & $\mathbf{N}_{\text {min }}$ & $\mathbf{N}_{\text {org }}$ \\
\hline \multicolumn{15}{|c|}{ Lysimeter 1} \\
\hline 1. Jahr & 785,55 & 1462,49 & 1073,51 & 1032,66 & 180,86 & 2270,29 & 639,65 & 0,25 & k.A. & 19,36 & 1441,19 & 754,71 & 934,65 & k.A. \\
\hline 2. Jahr & 270,25 & 263,27 & 322,09 & 44,35 & 9,22 & 289,98 & 56,80 & 1,16 & 17,48 & 12,73 & 83,17 & 2,03 & 39,55 & 21,69 \\
\hline 3. Jahr & 445,96 & 344,26 & 513,74 & 89,63 & 17,83 & 575,47 & 100,16 & 0,97 & k.A. & 15,45 & 189,12 & 5,99 & 131,26 & 48,38 \\
\hline 4. Jahr & 278,01 & 288,99 & 334,91 & 114,49 & 26,32 & 714,92 & 109,49 & 0,53 & k.A. & 13,91 & 183,94 & 4,21 & 209,25 & 32,98 \\
\hline Summe & 1779,76 & 2359,01 & 2244,25 & 1281,13 & 234,23 & 3850,66 & 906,10 & 2,91 & k.A. & 61,45 & 1897,43 & 766,94 & 1314,70 & 103,05 \\
\hline \multicolumn{15}{|c|}{ Lysimeter 2} \\
\hline 1. Jahr & 786,77 & 2469,44 & 1273,00 & 1188,37 & 223,66 & 3161,38 & 740,54 & 0,20 & k.A. & 27,06 & 2590,78 & 1278,59 & 650,02 & k.A. \\
\hline 2. Jahr & 253,54 & 372,90 & 326,97 & 80,35 & 24,75 & 667,79 & 116,18 & 0,48 & 5,42 & 6,06 & 357,78 & 76,47 & 86,47 & 33,30 \\
\hline 3. Jahr & 395,63 & 357,19 & 465,96 & 109,97 & 25,86 & 867,83 & 144,84 & 0,56 & k.A. & 7,29 & 416,07 & 44,69 & 181,76 & 58,24 \\
\hline 4. Jahr & 360,26 & 394,94 & 438,02 & 77,42 & 22,48 & 722,81 & 119,16 & 0,25 & k.A. & 8,25 & 155,45 & 13,76 & 158,75 & 17,31 \\
\hline Summe & 1796,19 & 3594,47 & 2503,94 & 1456,10 & 296,75 & 5419,80 & 1120,72 & 1,48 & k.A. & 48,66 & 3520,08 & 1413,50 & 1076,99 & 108,85 \\
\hline \multicolumn{15}{|c|}{ Lysimeter 8} \\
\hline 1. Jahr & 80,57 & 100,30 & 100,32 & 29,26 & 5,95 & 101,97 & 32,82 & k.A. & k.A. & 1,66 & 51,86 & 26,68 & 11,96 & k.A. \\
\hline 2. Jahr & 23,34 & 28,73 & 29,00 & 2,92 & 0,89 & 22,62 & 4,79 & 0,16 & k.A. & 1,02 & 6,77 & 0,02 & 2,42 & 1,90 \\
\hline 3. Jahr & 13,31 & 18,82 & 17,01 & 2,59 & 0,73 & 13,21 & 2,35 & 0,03 & k.A. & 0,60 & 4,81 & 0,11 & 2,21 & 1,16 \\
\hline $\begin{array}{l}\text { Summe } \\
\text { Lysimeter }\end{array}$ & 117,22 & 147,84 & 146,33 & 34,77 & 7,56 & 137,80 & 39,96 & 0,20 & k.A. & 3,27 & 63,43 & 26,81 & 16,58 & 3,06 \\
\hline 1. Jahr & 180,15 & 143,87 & 208,48 & 52,57 & 11,05 & 198,02 & 64,98 & k.A. & k.A. & 3,52 & 104,28 & 48,50 & 39,30 & k.A. \\
\hline 2. Jahr & 27,48 & 30,49 & 33,48 & 4,26 & 1,19 & 30,43 & 6,47 & 0,19 & 0,62 & 1,52 & 5,55 & 0,12 & 5,04 & 2,08 \\
\hline 3. Jahr & 21,58 & 31,84 & 27,85 & 6,63 & 1,90 & 26,47 & 5,10 & 0,04 & k.A. & 1,22 & 11,29 & 0,49 & 6,80 & 2,28 \\
\hline Summe & 229,21 & 206,20 & 269,81 & 63,46 & 14,14 & 254,92 & 76,56 & 0,23 & k.A. & 6,26 & 121,13 & 49,11 & 51,14 & 4,36 \\
\hline \multicolumn{15}{|c|}{ Lysimeter 5} \\
\hline 1. Jahr & 93,96 & 105,76 & 114,78 & 71,08 & 17,75 & 173,72 & 77,08 & k.A. & k.A. & 1,33 & 207,14 & 38,10 & 34,40 & k.A. \\
\hline 2. Jahr & 19,94 & 29,93 & 25,83 & 3,92 & 1,38 & 27,77 & 6,69 & 0,81 & 0,67 & 0,96 & 5,43 & 0,36 & 4,64 & 1,69 \\
\hline 3. Jahr & 17,73 & 36,00 & 24,82 & 7,35 & 2,05 & 25,58 & 4,23 & 0,04 & k.A. & 0,92 & 11,42 & 0,43 & 4,70 & 2,29 \\
\hline Summe & 131,63 & 171,68 & 165,43 & 82,35 & 21,18 & 227,06 & 87,99 & 0,85 & k.A. & 3,21 & 223,98 & 38,90 & 43,74 & 3,98 \\
\hline \multicolumn{15}{|c|}{ Lysimeter 4} \\
\hline 1. Jahr & 62,72 & 97,14 & 81,85 & 63,50 & 15,63 & 97,20 & 63,66 & k.A. & k.A. & 0,91 & 145,43 & 27,45 & 31,38 & k.A. \\
\hline 2. Jahr & 15,00 & 28,47 & 20,60 & 4,40 & 1,46 & 18,85 & 5,61 & 0,36 & 0,40 & 0,82 & 5,49 & 0,34 & 3,82 & 1,44 \\
\hline 3. Jahr & 6,85 & 13,32 & 9,48 & 3,36 & 0,86 & 7,87 & 1,47 & 0,01 & k.A. & 0,24 & 4,99 & 0,18 & 1,88 & 0,31 \\
\hline Summe & 84,58 & 138,94 & 111,93 & 71,26 & 17,94 & 123,92 & 70,73 & 0,37 & k.A. & 1,97 & 155,91 & 27,97 & 37,09 & 1,74 \\
\hline \multicolumn{15}{|c|}{ Lysimeter 3} \\
\hline 1. Jahr & 32,48 & 65,69 & 45,41 & 43,67 & 8,32 & 27,69 & 38,00 & k.A. & k.A. & 0,34 & 103,68 & 48,99 & 21,95 & k.A. \\
\hline 2. Jahr & 12,12 & 25,34 & 17,11 & 5,69 & 1,70 & 8,39 & 5,13 & 0,04 & 1,06 & 0,07 & 5,66 & 0,25 & 3,55 & 0,09 \\
\hline 3. Jahr & 9,07 & 30,24 & 15,02 & 10,37 & 2,26 & 11,31 & 2,12 & 0,02 & k.A. & 0,23 & 8,67 & 0,23 & 4,34 & 1,21 \\
\hline Summe & 53,67 & 121,27 & 77,55 & 59,72 & 12,28 & 47,39 & 45,24 & 0,05 & k.A. & 0,64 & 118,01 & 49,47 & 29,84 & 1,30 \\
\hline \multicolumn{15}{|c|}{ Lysimeter 7} \\
\hline 1. Jahr & 1,99 & 20,62 & 6,05 & 7,03 & 0,70 & 1,32 & 2,29 & k.A. & k.A. & 0,17 & 4,21 & 0,94 & 0,75 & k.A. \\
\hline 2. Jahr & 0,92 & 12,37 & 3,36 & 3,20 & 0,21 & 0,07 & 0,61 & 0,01 & 0,26 & u.B. & 0,95 & 0,14 & 0,36 & u.B. \\
\hline 3. Jahr & 0,28 & 10,53 & 2,36 & 3,11 & 0,29 & 0,11 & 0,39 & 0,01 & k.A. & 0,003 & 1,29 & 0,13 & u.B. & u.B. \\
\hline Summe & 3,20 & 43,51 & 11,77 & 13,34 & 1,20 & 1,50 & 3,29 & 0,01 & k.A. & 0,17 & 6,46 & 1,21 & 1,12 & u.B. \\
\hline
\end{tabular}


Die hohen Inhaltsstoff-Frachten im ersten Messjahr sind neben den höheren Konzentrationen vor allem auf die wesentlich höheren Sickerwassermengen des ersten Jahres zurückzuführen.

Die bei den Kleinlysimetern je Element ausgetragene Gesamtmenge ist bei den Mischungsvarianten größer als bei der reinen Kompost-Variante (Lysimeter 8). Nur für $\mathrm{HCO}_{3}, \mathrm{C}_{\text {ges }}, \mathrm{P}$ und $\mathrm{N}_{\text {org }}$ erreicht die reine Kompostvariante Sickerwasser-Gesamtfrachten die über denen der Mischungsvariante 4 mit $51 \%$ Kompost-Anteil liegen. Die höchsten Gesamtausträge erzielt überwiegend Lysimeter 6 mit einem Kompost-Anteil in der Mischung von 91,5 \% und insgesamt gesehen einer höheren Kompostmenge als bei Lysimeter 8 - der reinen Kompostvariante - aufgrund des größeren Fassungsvolumens des Behälters. Die Elemente $\mathrm{Ca}, \mathrm{Mg}, \mathrm{Na}, \mathrm{Fe}$ und $\mathrm{SO}_{4}$ dagegen zeigen einen maximalen Austrag für Lysimeter 5 mit 58,5 \% Kompost-Anteil in der Mischung mit Löss. Der Gesamtaustrag an Chlorid ist bei Lysimeter 3 am höchsten.

Die Gesamt-Austräge der Kleinlysimeter sind wegen der großen Massenunterschiede zwischen den Groß- und Kleinlysimetern um eine Vielfaches niedriger. Einen Vergleich der Gesamtausträge pro Element innerhalb der Kleinlysimeter ermöglichen die nachfolgenden Abbildungen 91 - 103. Wobei auch hier zu berücksichtigen ist, dass die Einfüllvolumina (siehe Tab. 3-4) der Lysimeter 7 und 8 geringer sind als bei den Lysimetern 3 bis 6 . 


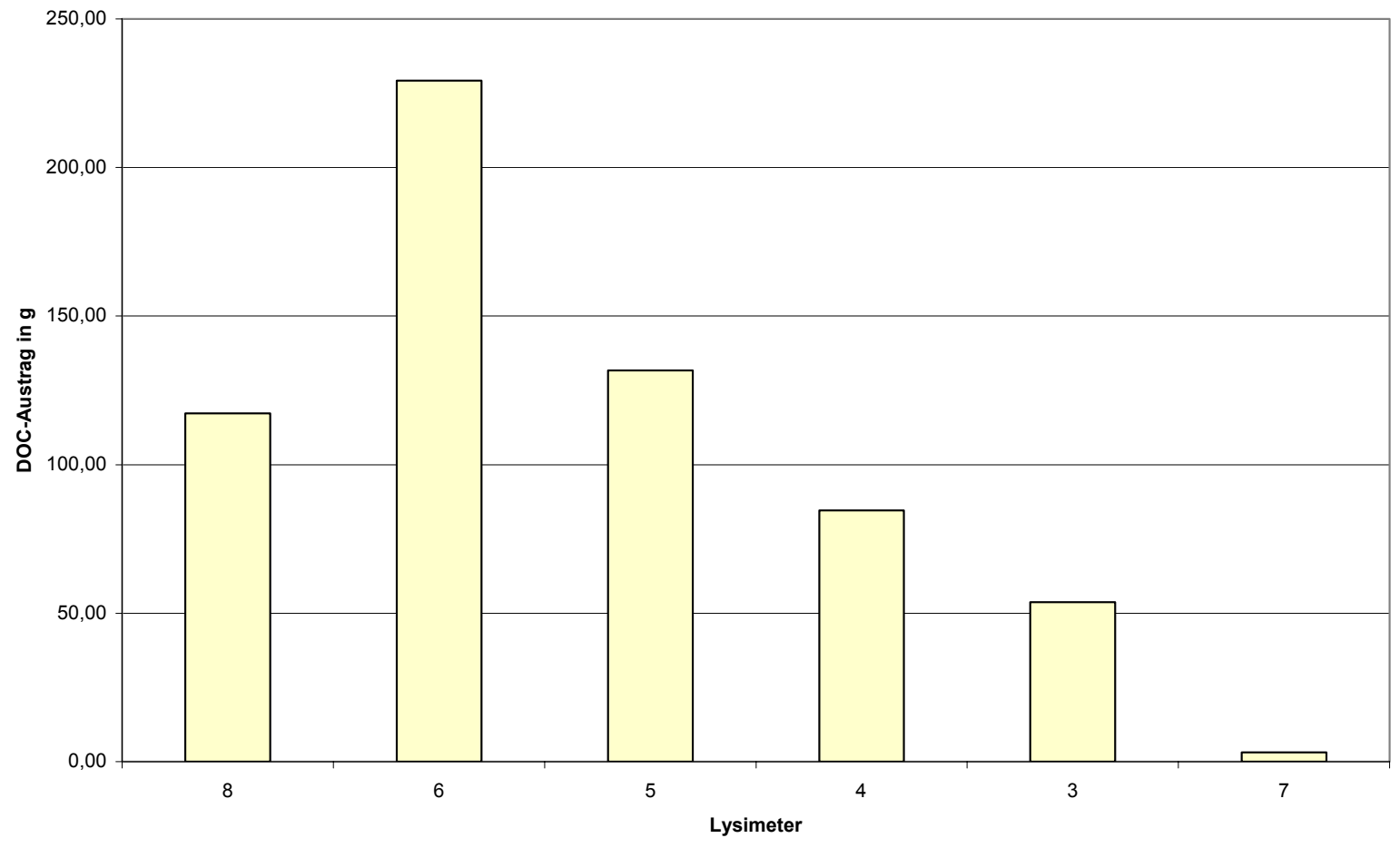

Abbildung 91: DOC-Sickerwasser-Austrag in g von Mai 87 bis April 90, Lysimeter 3 - 8

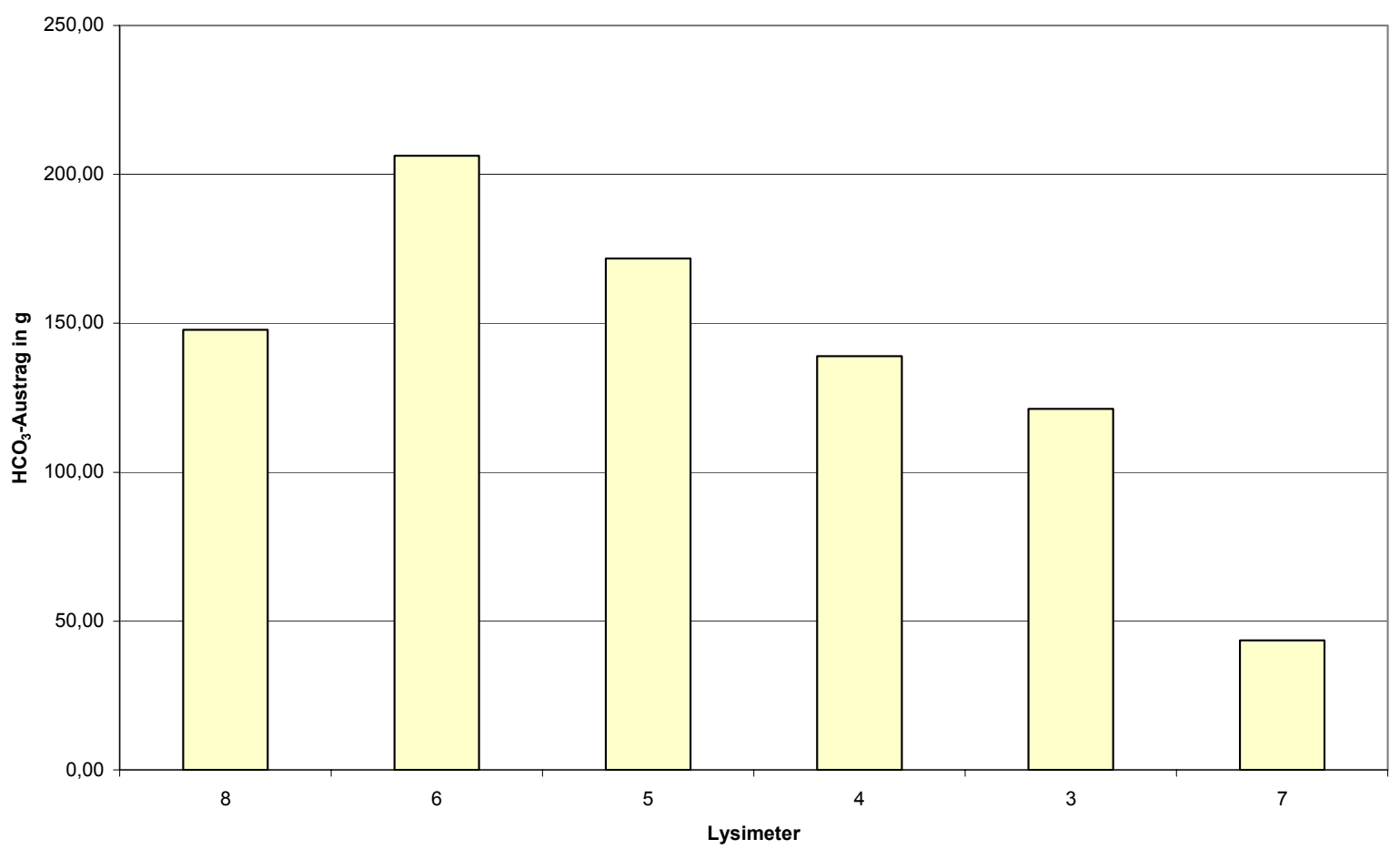

Abbildung 92: $\mathrm{HCO}_{3}$-Sickerwasser-Austrag in g von Mai 87 bis April 90, Lysimeter 3 - 8 


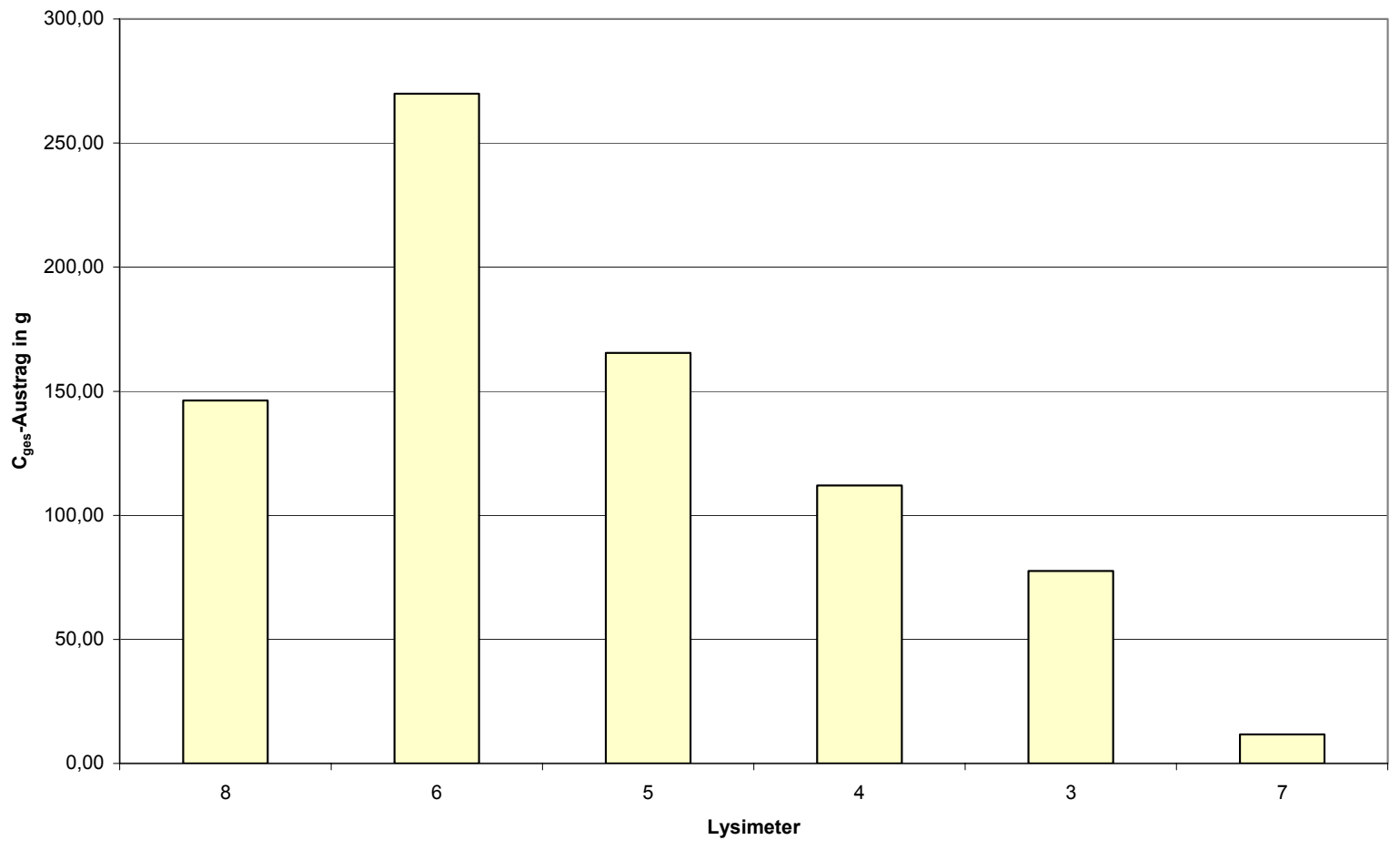

Abbildung 93: Gesamt-C- Sickerwasser-Austrag in g von Mai 87 bis April 90, Lysimeter 3 - 8

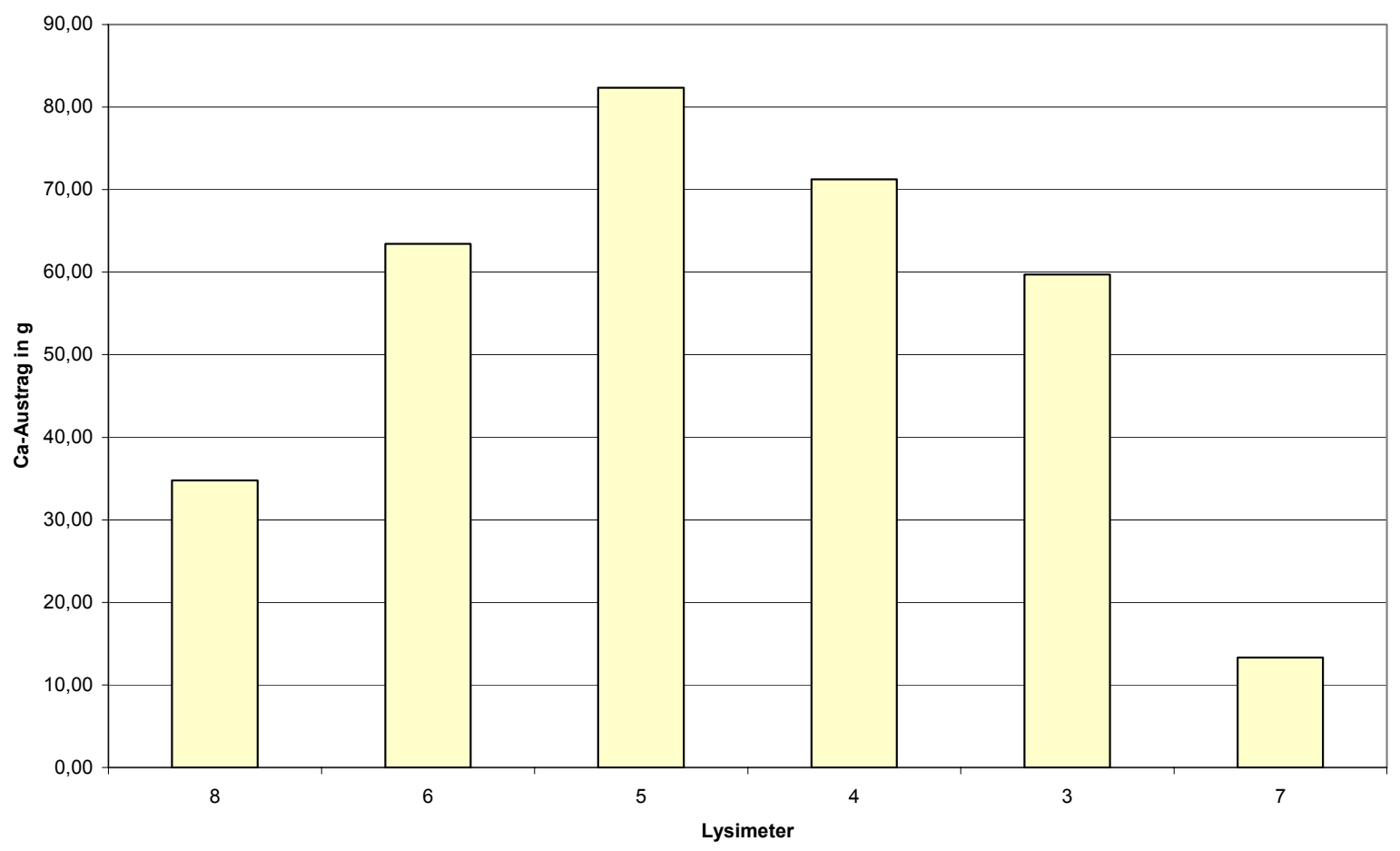

Abbildung 94: Ca-Sickerwasser-Austrag in g von Mai 87 bis April 90, Lysimeter 3 - 8 


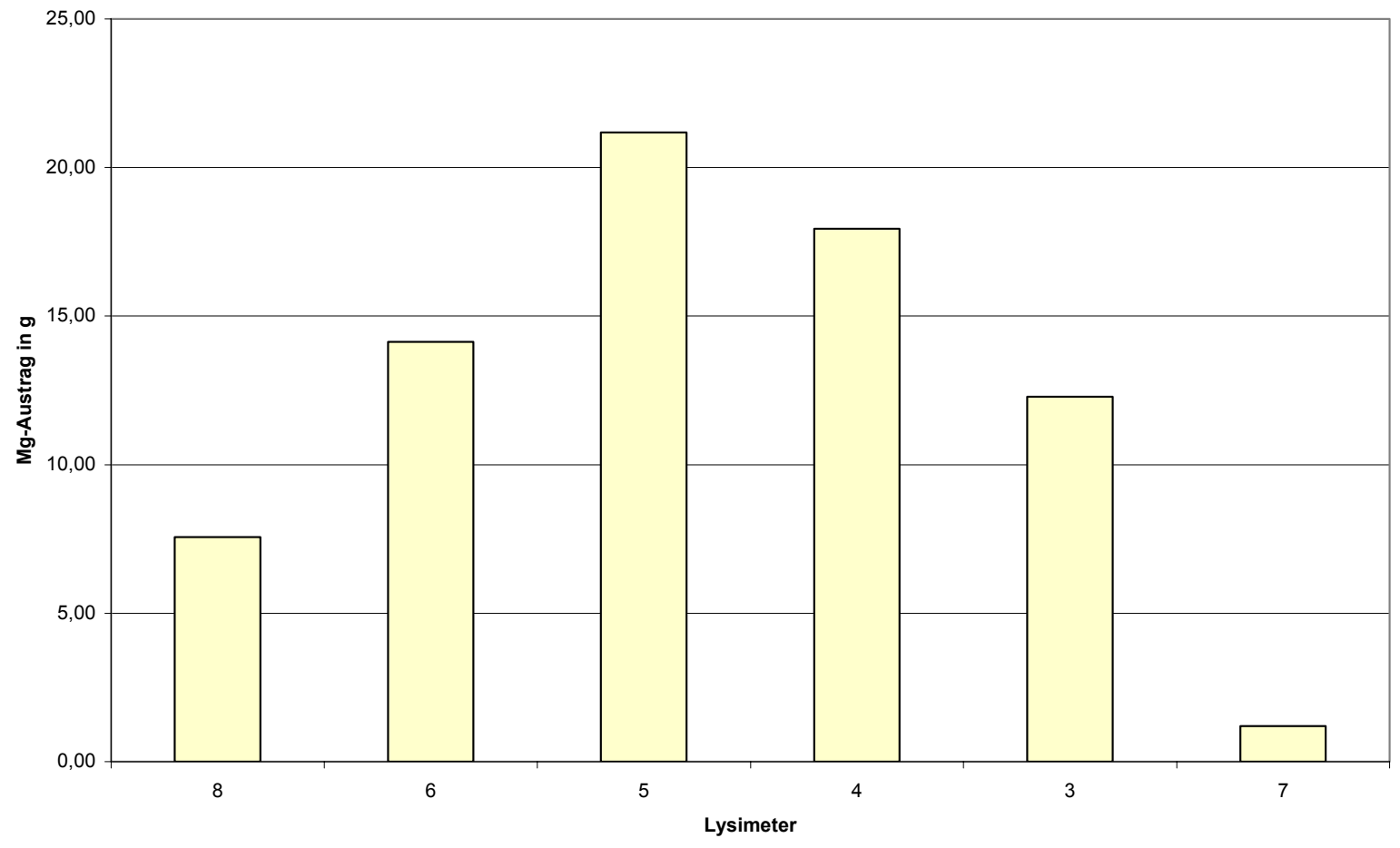

Abbildung 95: Mg-Sickerwasser-Austrag in g von Mai 87 bis April 90, Lysimeter 3 - 8

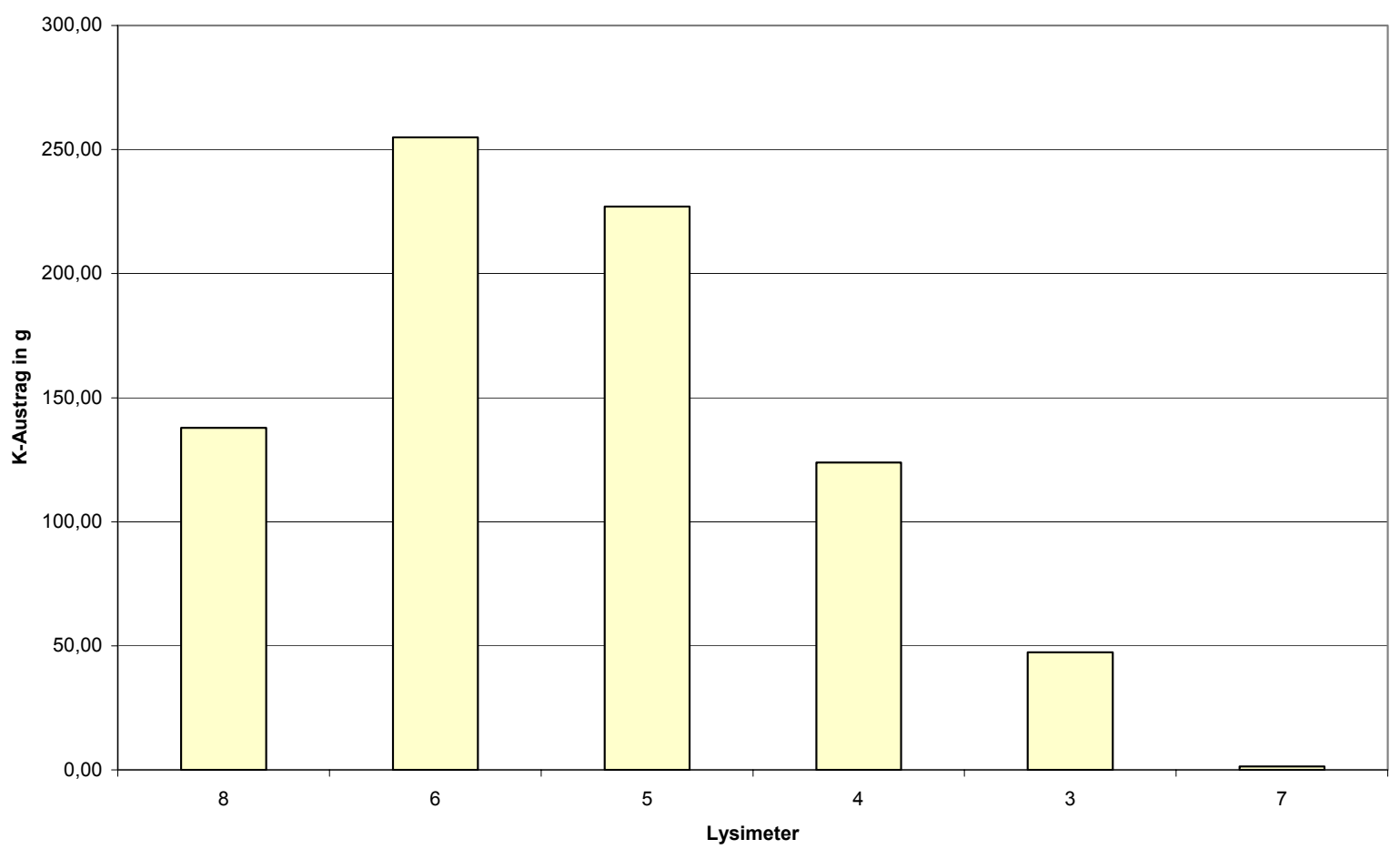

Abbildung 96: K-Sickerwasser-Austrag in g von Mai 87 bis April 90, Lysimeter 3 - 8 


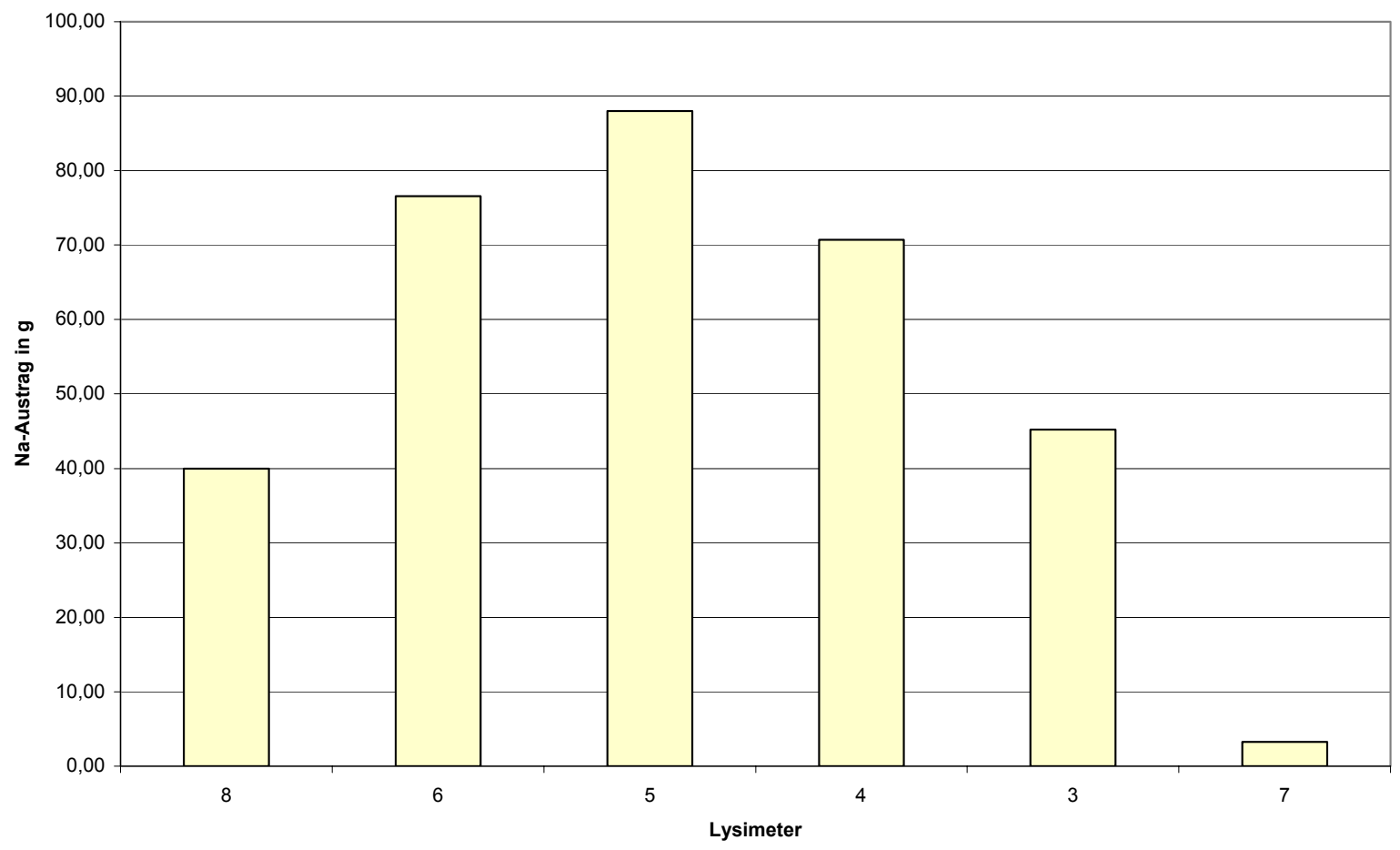

Abbildung 97: Na-Sickerwasser-Austrag in g von Mai 87 bis April 90, Lysimeter 3 - 8

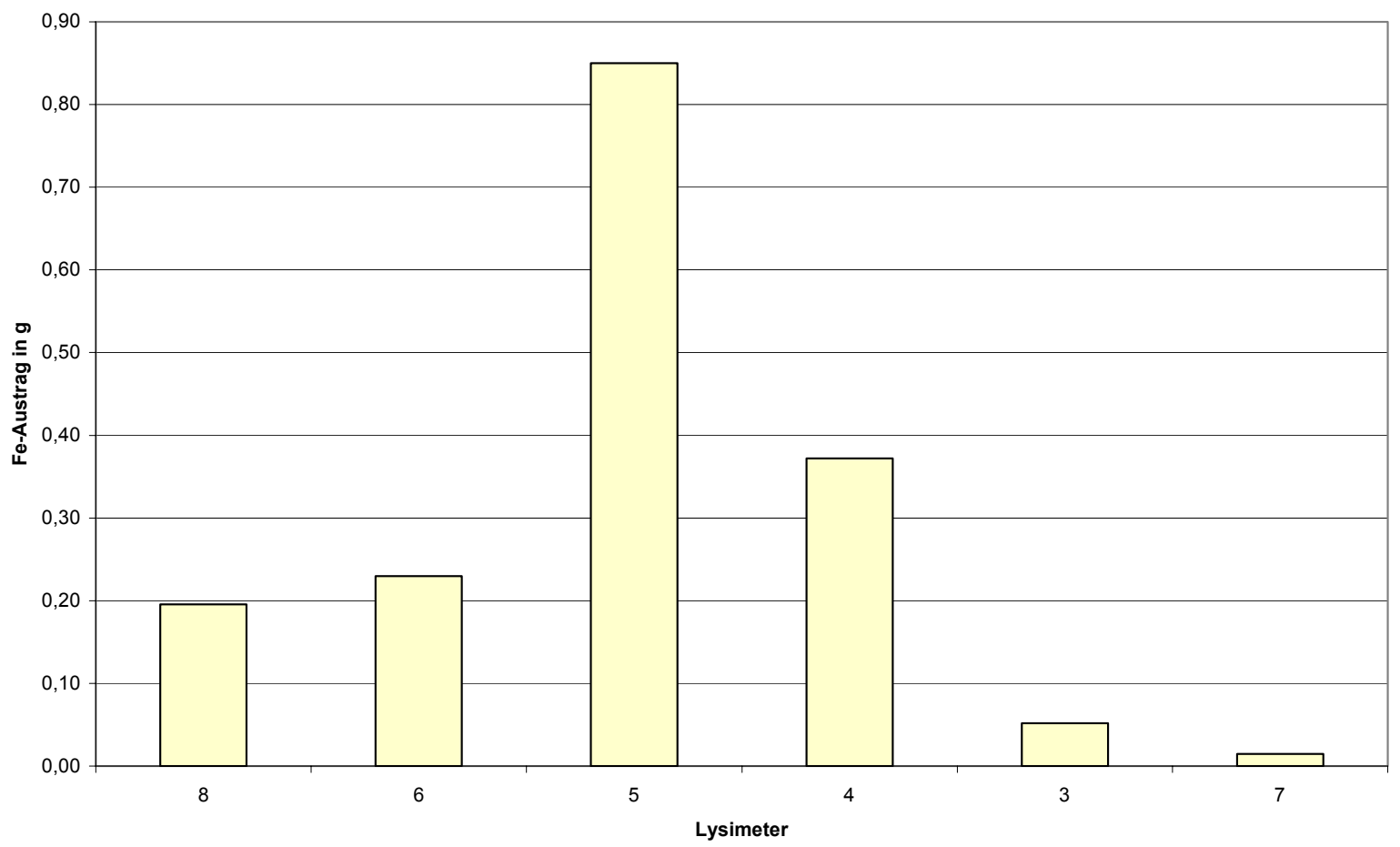

Abbildung 98: Fe-Sickerwasser-Austrag in g von Mai 87 bis April 90, Lysimeter 3 - 8 


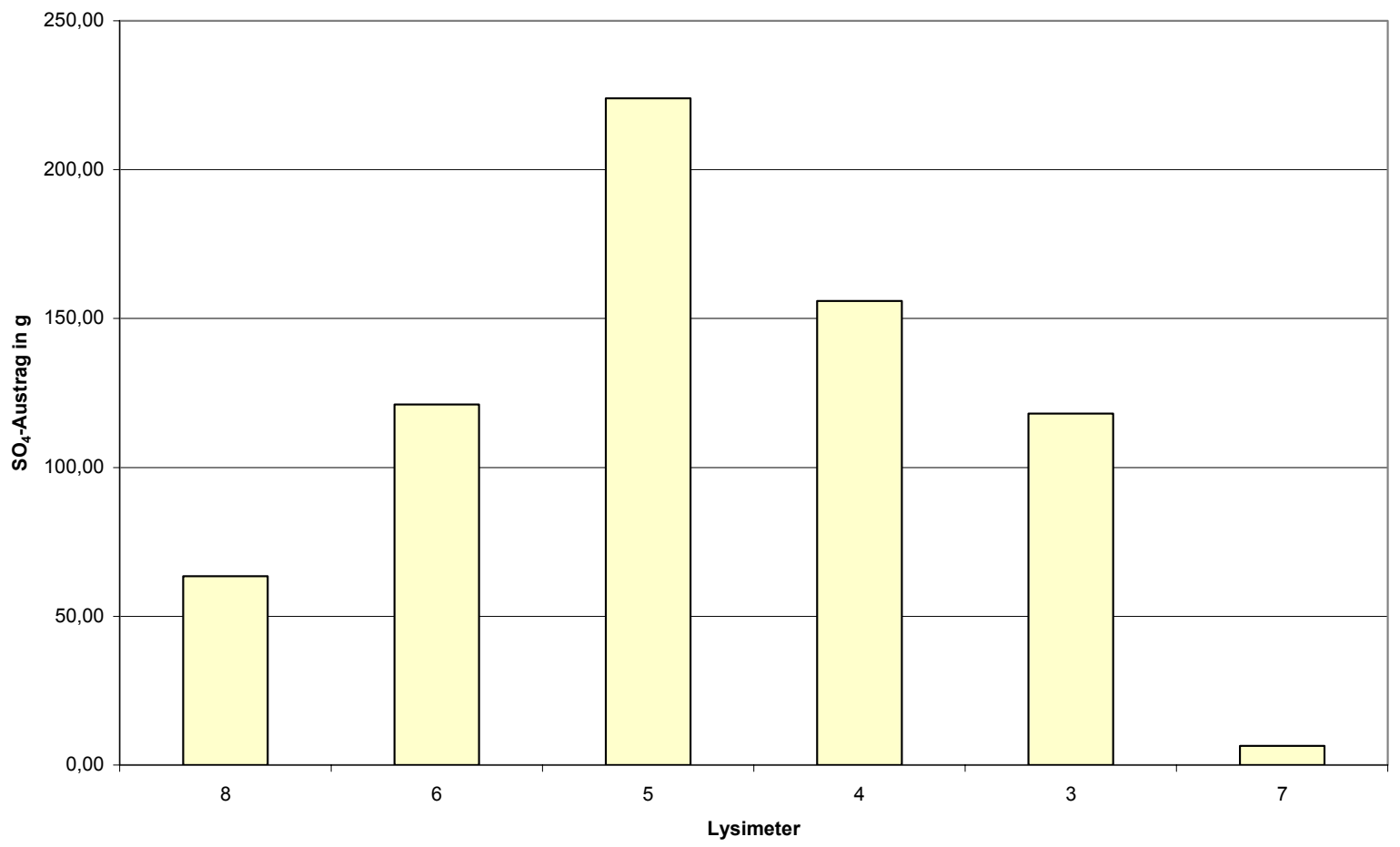

Abbildung 99: $\mathrm{SO}_{4}$-Sickerwasser-Austrag in g von Mai 87 bis April 90, Lysimeter 3 - 8

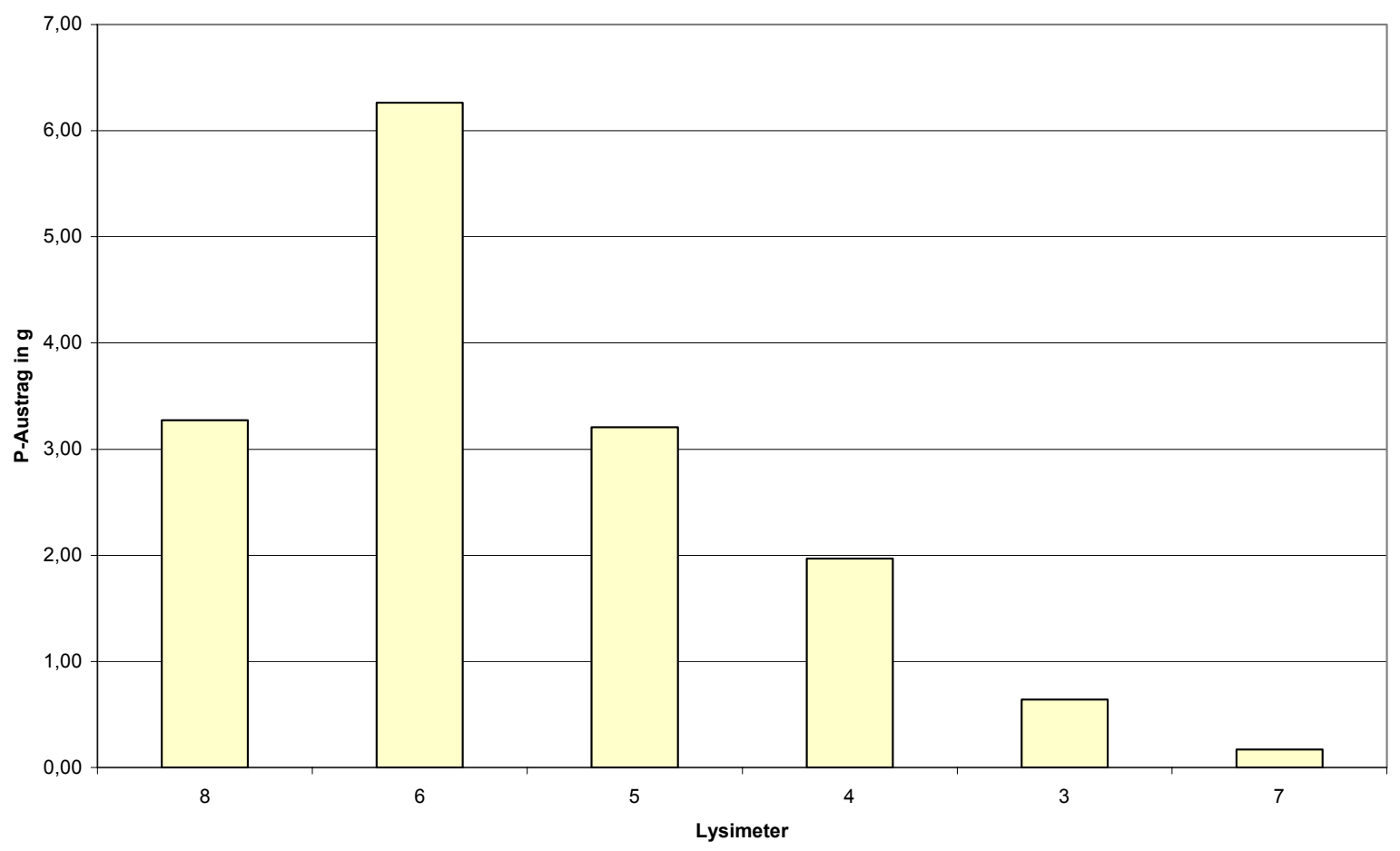

Abbildung 100: P-Sickerwasser-Austrag in g von Mai 87 bis April 90, Lysimeter 3 - 8 


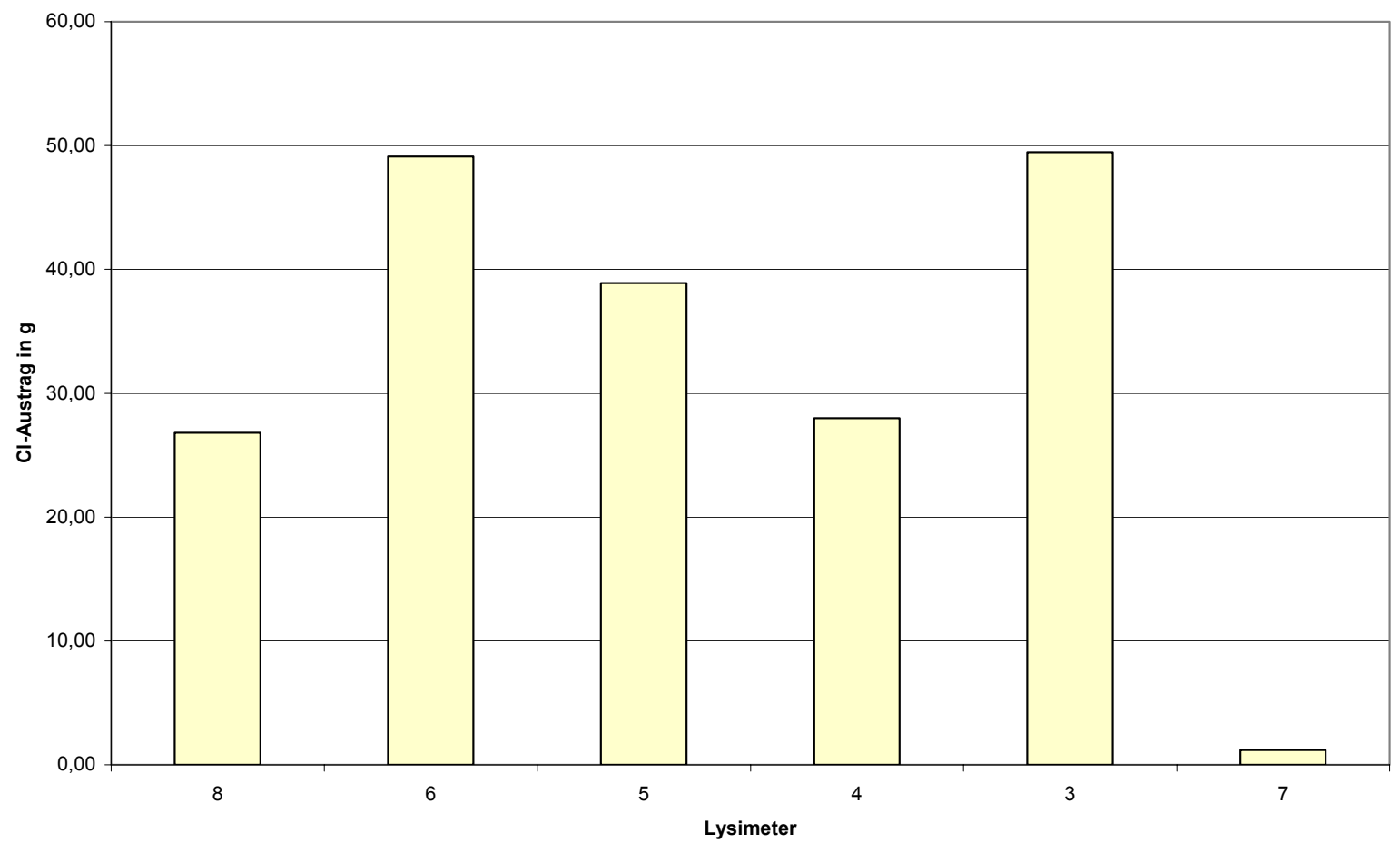

Abbildung 101: Cl-Sickerwasser-Austrag in g von Mai 87 bis April 90, Lysimeter 3 - 8

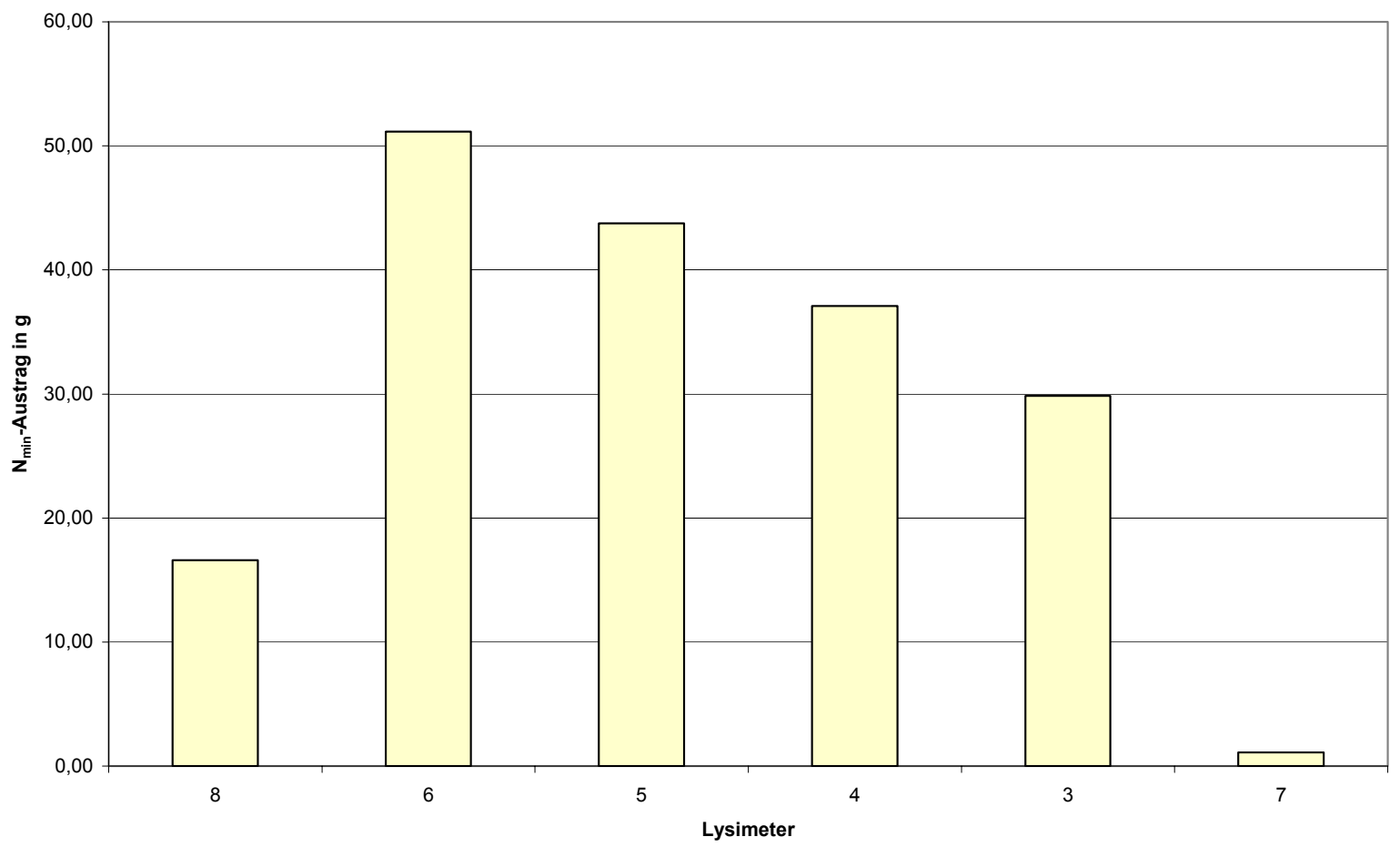

Abbildung 102: $\mathbf{N}_{\min }$-Sickerwasser-Austrag in $\mathrm{g}$ von Mai 87 bis April 90, Lysimeter 3 - 8 


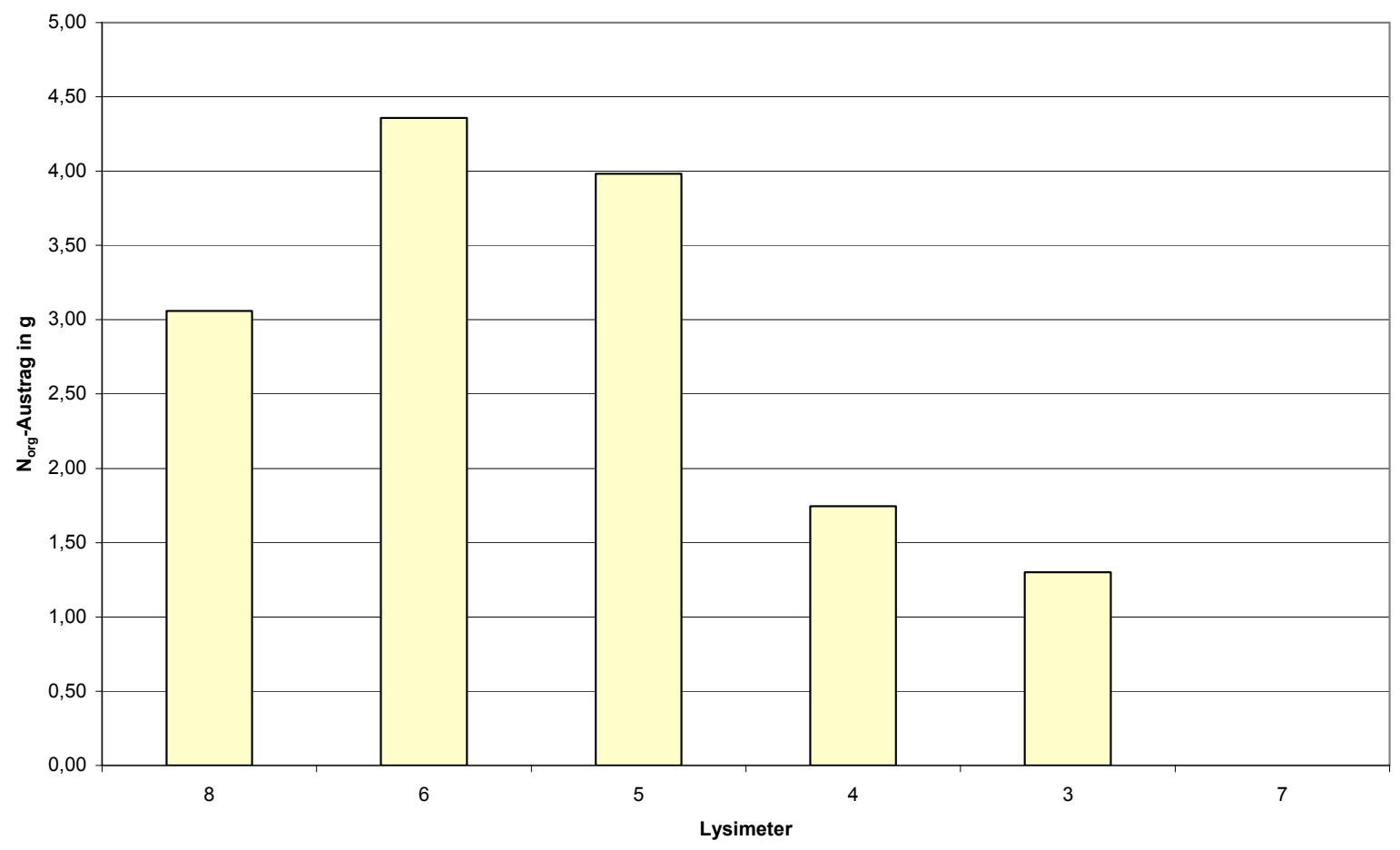

Abbildung 103: $\mathrm{N}_{\text {org }}$-Sickerwasser-Austrag in $\mathrm{g}$ von Mai 87 bis April 90, Lysimeter 3 - 8

In Tabelle 6-18 sind die ausgewaschenen Frachten in g für die ersten drei vollständig erhobenen Messjahre auf die für den Stoffaustrag relevante Größe der Lysimeter-Oberfläche in $\mathrm{m}^{2}$ bezogen worden. Die aus dieser Berechnung resultierenden Frachten in $\mathrm{g} / \mathrm{m}^{2}$ ergeben für die reinen Kompost-Lysimeter recht ähnliche Werte für $\mathrm{HCO}_{3}, \mathrm{~K}, \mathrm{Na}, \mathrm{Fe}, \mathrm{P}$ und $\mathrm{N}_{\text {org }}$. Die $\mathrm{Ca}-, \mathrm{Mg}-, \mathrm{SO}_{4^{-}}, \mathrm{Cl}-$ und $\mathrm{N}_{\min }$-Werte sind für die beiden Großlysimeter deutlich höher; bei den DOC-Werten erreichen die Kleinlysimeter mit 100 bzw. $91 \%$ die höheren Werte. Bei den beiden Großlysimetern sind überwiegend für Lysimeter 2 höhere Frachten zu verzeichnen.

Tabelle 6-18: Sickerwasser-Austrag von Mai 87 bis April 90 bezogen auf die Lysimeter-Oberfläche in $\mathrm{g} / \mathrm{m}^{2}$, Lysimeter 1 - 8

\begin{tabular}{|c|c|c|c|c|c|c|c|c|c|c|c|c|c|c|c|}
\hline Lysimeter & $\begin{array}{c}\text { Oberfläche } \\
\mathrm{m}^{2}\end{array}$ & DOC & $\mathrm{HCO}_{3}$ & $C_{\text {ges }}$ & $\mathrm{Ca}$ & $\mathrm{Mg}$ & $\begin{array}{c}K \\
g / m^{2} \text { Lysi }\end{array}$ & $\begin{array}{c}\mathrm{Na} \\
\text { eter-Obe }\end{array}$ & $\begin{array}{c}\mathrm{Fe} \\
\text { läche }\end{array}$ & $\mathbf{P}$ & $\mathrm{SO}_{4}$ & $\mathrm{Cl}$ & $\mathbf{N}_{\min }$ & $\mathbf{N}_{\text {org }}$ & $\begin{array}{c}\text { Füllhöhe } \\
\text { m }\end{array}$ \\
\hline 1 & 7,07 & 212,41 & 292,79 & 270,06 & 165,01 & 29,41 & 443,53 & 112,67 & 0,34 & 6,72 & 242,36 & 107,88 & 156,36 & 9,91 & 0,90 \\
\hline 2 & 7,07 & 203,10 & 452,55 & 292,21 & 195,01 & 38,79 & 664,35 & 141,66 & 0,17 & 5,72 & 475,90 & 197,98 & 129,88 & 12,95 & 0,90 \\
\hline 8 & 0,35 & 334,92 & 422,41 & 418,10 & 99,34 & 21,59 & 393,72 & 114,18 & 0,56 & 9,35 & 181,24 & 76,59 & 47,38 & 8,74 & 0,40 \\
\hline 6 & 0,68 & 337,08 & 303,23 & 396,78 & 93,32 & 20,79 & 374,89 & 112,58 & 0,34 & 9,21 & 178,13 & 72,22 & 75,21 & 6,41 & 0,48 \\
\hline 5 & 0,68 & 193,57 & 252,47 & 243,28 & 121,10 & 31,14 & 333,91 & 129,40 & 1,25 & 4,71 & 329,39 & 57,20 & 64,32 & 5,86 & 0,48 \\
\hline 4 & 0,68 & 124,38 & 204,33 & 164,61 & 104,80 & 26,38 & 182,24 & 104,01 & 0,55 & 2,90 & 229,28 & 41,13 & 54,54 & 2,57 & 0,49 \\
\hline 3 & 0,68 & 78,93 & 178,33 & 114,04 & 87,83 & 18,06 & 69,70 & 66,53 & 0,08 & 0,94 & 173,54 & 72,75 & 43,89 & 1,91 & 0,50 \\
\hline 7 & 0,35 & 9,14 & 124,32 & 33,62 & 38,11 & 3,43 & 4,29 & 9,39 & 0,04 & 0,49 & 18,45 & 3,47 & 3,19 & 0,00 & 0,36 \\
\hline
\end{tabular}

In den Tab. 6-17 und 6-18 ist das bei unterschiedlicher Füllhöhe der Lysimeter am Boden ausgetretene Sickerwasser zugrunde gelegt worden. Dabei ist der Umstand außer Betracht gelassen worden, dass bei höheren Lysimeterfüllungen die im oberen Teil gelösten Stoffe im unteren Teil durch Fällung, Wasserspeicherung oder Sorption wieder zurückgehalten werden können, was bei den geringen Lysimetertiefen wegfallen würde.

Aus diesem Grunde ist in den Tabelle 6-19 und 6-20 der Weg gewählt worden, die ausgetragenen Stoff- und Elementmengen auf das in die Lysimeter eingefüllte Kompost bzw. Kompost/Löss-Gemisch zu beziehen, wobei die Lysimeter-Oberfläche und die unterschiedlichen Füllhöhen vernachlässigt werden. 
Tabelle 6-19: Sickerwasser-Austrag von Mai 87 bis April 90 bezogen auf die Ausgangs-Lysimeter-Füllmenge an Kompost, Löss bzw. Kompost/Löss-Gemisch in $\mathrm{mg} / \mathrm{kg}$ TM, Lyimeter 1 - 8

\begin{tabular}{l|c|ccccccccccccc} 
Lysimeter & $\begin{array}{c}\text { Gesamt } \\
\text { kg TM }\end{array}$ & $\mathbf{D O C}$ & $\mathbf{H C O}_{\mathbf{3}}$ & $\mathbf{C}_{\text {ges }}$ & $\mathbf{C a}$ & $\mathbf{M g}$ & $\begin{array}{c}\mathbf{K} \\
\mathbf{m g} / \mathbf{k g} \text { TM } \mathbf{g e s a m t}\end{array}$ & $\mathbf{N a}$ & $\mathbf{F e}$ & $\mathbf{P}$ & $\mathbf{S O}_{\mathbf{4}}$ & $\mathbf{C l}$ & $\mathbf{N}_{\text {min }}$ & $\mathbf{N}_{\text {org }}$ \\
\hline $\mathbf{1}$ & 2146 & 699,79 & 964,59 & 889,72 & 543,63 & 96,88 & 1461,20 & 371,21 & 1,11 & 22,15 & 798,46 & 355,42 & 515,12 & 32,65 \\
$\mathbf{2}$ & 2982 & 481,53 & 1072,95 & 692,80 & 462,34 & 91,97 & 1575,11 & 335,87 & 0,41 & 13,55 & 1128,31 & 469,40 & 307,93 & 30,70 \\
$\mathbf{8}$ & 66,92 & 1751,69 & 2209,27 & 2186,70 & 519,54 & 112,93 & 2059,20 & 597,17 & 2,92 & 48,91 & 947,92 & 400,57 & 247,80 & 45,70 \\
$\mathbf{6}$ & 135,07 & 1697,00 & 1526,58 & 1997,58 & 469,80 & 104,68 & 1887,35 & 566,79 & 1,70 & 46,36 & 896,77 & 363,58 & 378,65 & 32,26 \\
$\mathbf{5}$ & 131,91 & 997,85 & 1301,51 & 1254,12 & 624,29 & 160,53 & 1721,34 & 667,07 & 6,44 & 24,30 & 1698,00 & 294,87 & 331,59 & 30,19 \\
$\mathbf{4}$ & 164,25 & 514,92 & 845,92 & 681,48 & 433,87 & 109,22 & 754,47 & 430,61 & 2,27 & 12,00 & 949,22 & 170,29 & 225,79 & 10,62 \\
$\mathbf{3}$ & 224,94 & 238,60 & 539,11 & 344,75 & 265,51 & 54,60 & 210,69 & 201,12 & 0,23 & 2,85 & 524,61 & 219,92 & 132,67 & 5,78 \\
$\mathbf{7}$ & 132,41 & 24,15 & 328,62 & 88,86 & 100,74 & 9,08 & 11,35 & 24,82 & 0,11 & 1,29 & 48,76 & 9,17 & 8,42 & 0,00
\end{tabular}

Tabelle 6-20: Sickerwasser-Austrag von Mai 87 bis April 90 bezogen auf die Ausgangs-Lysimeter-Füllmenge an reinem Kompost in $\mathrm{mg} / \mathrm{kg} \mathrm{TM}$, Lysimeter 1 - 8

\begin{tabular}{|c|c|c|c|c|c|c|c|c|c|c|c|c|c|c|}
\hline Lysimeter & $\left|\begin{array}{c}\text { Kompost } \\
\text { kg TM }\end{array}\right|$ & DOC & $\mathrm{HCO}_{3}$ & $C_{\text {ges }}$ & $\mathrm{Ca}$ & Mg & $\begin{array}{c}\mathrm{K} \\
\mathrm{mg} / \mathrm{kg} \text { TM }\end{array}$ & $\begin{array}{c}\mathrm{Na} \\
\text { Kompost }\end{array}$ & $\mathrm{Fe}$ & $\mathbf{P}$ & $\mathrm{SO}_{4}$ & $\mathrm{Cl}$ & $\mathbf{N}_{\min }$ & $\mathbf{N}_{\text {org }}$ \\
\hline 1 & 2146 & 699,79 & 964,59 & 889,72 & 543,63 & 96,88 & 1461,20 & 371,21 & 1,11 & 22,15 & 798,46 & 355,42 & 515,12 & 32,65 \\
\hline 2 & 2982 & 481,53 & 1072,95 & 692,80 & 462,34 & 91,97 & 1575,11 & 335,87 & 0,41 & 13,55 & 1128,31 & 469,40 & 307,93 & 30,70 \\
\hline 8 & 66,92 & 1751,69 & 2209,27 & 2186,70 & 519,54 & 112,93 & 2059,20 & 597,17 & 2,92 & 48,91 & 947,92 & 400,57 & 247,80 & 45,70 \\
\hline 6 & 123,55 & 1855,23 & 1668,93 & 2183,84 & 513,60 & 114,44 & 2063,33 & 619,63 & 1,86 & 50,68 & 980,38 & 397,48 & 413,96 & 35,26 \\
\hline 5 & 77,22 & 1704,57 & 2223,28 & 2142,33 & 1066,44 & 274,23 & 2940,46 & 1139,51 & 11,01 & 41,52 & 2900,59 & 503,72 & 566,44 & 51,57 \\
\hline 4 & 83,66 & 1010,94 & 1660,79 & 1337,95 & 851,82 & 214,44 & 1481,25 & 845,42 & 4,45 & 23,56 & 1863,61 & 334,34 & 443,29 & 20,86 \\
\hline 3 & 69,5 & 772,24 & 1744,86 & 1115,80 & 859,35 & 176,72 & 681,91 & 650,93 & 0,75 & 9,21 & 1697,93 & 711,78 & 429,39 & 18,70 \\
\hline
\end{tabular}

Betrachtet man zunächst die in Tabelle 6-19 dargestellten Werte mit der zu Versuchsbeginn eingefüllten Gesamt-TM als einheitlicher Bezugsbasis so zeigt sich folgendes Bild:

Die beiden Großlysimeter zeigen recht ähnliche Gesamt-Austräge. Höhere Werte als bei Lysimeter 2 liegen bei Lysimeter 1 für den Fe- (+ $170 \%), \mathrm{N}_{\min }-(+67 \%)$, P- (+ $\left.63 \%\right)$, DOC(+ $45 \%)$ und Ca- (+28 \%) Austrag vor, niedrigere Werte für $\mathrm{SO}_{4}(-41 \%)$ und $\mathrm{Cl}(-32 \%)$. Das würde die schon getroffene Annahme unterstützen, dass sich das in Lysimeter 2 eingefüllte Kompost-Material zu diesem Zeitpunkt in einem jüngeren Reifezustand befunden hat. Etwa gleich hoch sind die Austräge für $\mathrm{HCO}_{3}, \mathrm{Mg}, \mathrm{K}, \mathrm{Na}$ und $\mathrm{N}_{\text {org }}$. Die GesamtAusträge der Großlysimeter pro kg Substrat liegen bei dieser Umrechung deutlich unter den Austrägen der Kleinlysimeter. Die längere Passage der Lysimeterfüllung führt zu Umverteilungsprozessen im Filterkörper. Die oberen Schichten verarmen an Elementen während in tieferen Lysimeterschichten Stoffe angereichert werden.

Sehr große Unterschiede in der Auswaschung zwischen den beiden Großlysimetern und dem Kleinlysimeter 8 (ebenfalls nur reinem Kompost) zeigen sich beim DOC, $\mathrm{HCO}_{3}, \mathrm{Fe}$ und $P$. Hier sind die Werte für das Kleinlysimeter deutlich höher bis zum dreifachen des Wertes für die Großlysimeter. Ebenfalls deutlich erhöht wenn auch etwas niedriger als bei den vorher genannten (bis zu 50 \% über den Großlysimetern) ist die Auswaschung für $\mathrm{K}, \mathrm{Na}$ und $\mathrm{N}_{\text {org }}$, während die $\mathrm{N}_{\text {min }}$ - Auswaschung bei Lysimeter 8 geringer ist als bei den beiden Großlysimetern. In ähnlichen Größenordnungen liegen die Auswaschungen für $\mathrm{Ca}, \mathrm{Mg}$, Sulfat und Chlorid.

Betrachtet man nur die Kleinlysimeter so fällt auf, dass pro kg Gesamt-TM Gemisch die Auswaschung für DOC, $\mathrm{HCO}_{3}$, entsprechend auch $\mathrm{C}_{\text {ges }}, \mathrm{K}, \mathrm{P}, \mathrm{Cl}$ und $\mathrm{N}_{\text {org }}$ bei Lysimeter 8 mit 100\% Kompost am größten ist. Lysimeter 8 mit dem kleinsten Behältervolumen und nur Kompost besitzt die niedrigste Füllmenge dementsprechend bei Niederschlägen das höchste Extraktionsverhältnis. Bei den Elementen $\mathrm{Ca}, \mathrm{Mg}, \mathrm{Na}, \mathrm{Fe}$ und $\mathrm{SO}_{4}$ ist die Auswaschung bei Lysimeter 5 mit der nächst größeren Gesamt-Füllmenge am höchsten. Den höchsten $\mathrm{N}_{\min }$-Austrag pro $\mathrm{kg}$ Einfüllmenge hat Lysimeter 6 . Beim $\mathrm{N}_{\min }$ wäre der höchste Wert eigentlich auch bei Lysimeter 8 zu erwarten gewesen, ist aber möglicherweise auf- 
grund der schlechteren Wasserspeicherfähigkeit und geringeren Nachlieferung durch Mineralisation vergleichsweise niedrig ausgefallen (siehe auch Vergleich mit Lysimeter 1 und 2). Bei Lysimeter 7 liegen die Gesamt-Austräge pro kg eingefüllter TM - bis auf das Ergebnis für $\mathrm{HCO}_{3}$ - bei Bruchteilen unter denen der Kompost-Lysimeter.

Geht man davon aus, dass die ausgewaschenen Stofffrachten überwiegend aus dem Kompost geliefert werden und bezieht dementsprechend die Gesamt-Austräge auf die zu Versuchsbeginn eingefüllte Mengen an Kompost, so ergibt sich in der Mehrzahl der Fälle ein überragender Mehraustrag pro kg Kompost in der Mischung mit Löss zu 59 \% Kompost und 41 \% Löss in Lysimeter 5 gegenüber den Lysimetern ohne oder mit höherer Löss-Beimengung. Den höchsten Chlorid-Austrag pro kg Kompost erzielt Lysimeter 3. Die höchsten DOC- und P-Austräge erzielt Lysimeter 6 mit der größten Menge an eingefüllter KompostTM. Nur für den Summenwert aus organischem und anorganischen $C\left(C_{\text {ges }}\right)$ liegt Lysimeter 8 an erster Stelle innerhalb der nahezu identischen Werte für Lysimeter 5, 6 und 8.

Die Auswaschung pro kg Kompost wird durch die Lösszugabe erhöht.

Die Abbildungen 104 - 116 stellen die Gesamt-Austräge pro kg Kompost für die drei Messjahre von Mai 87 bis April 90 Element weise dar. Die hier zu diskutierenden Einflussgrößen für die Höhe des Austrags sind „Behältergröße“ und Anteil der Löss-Beimengung. 


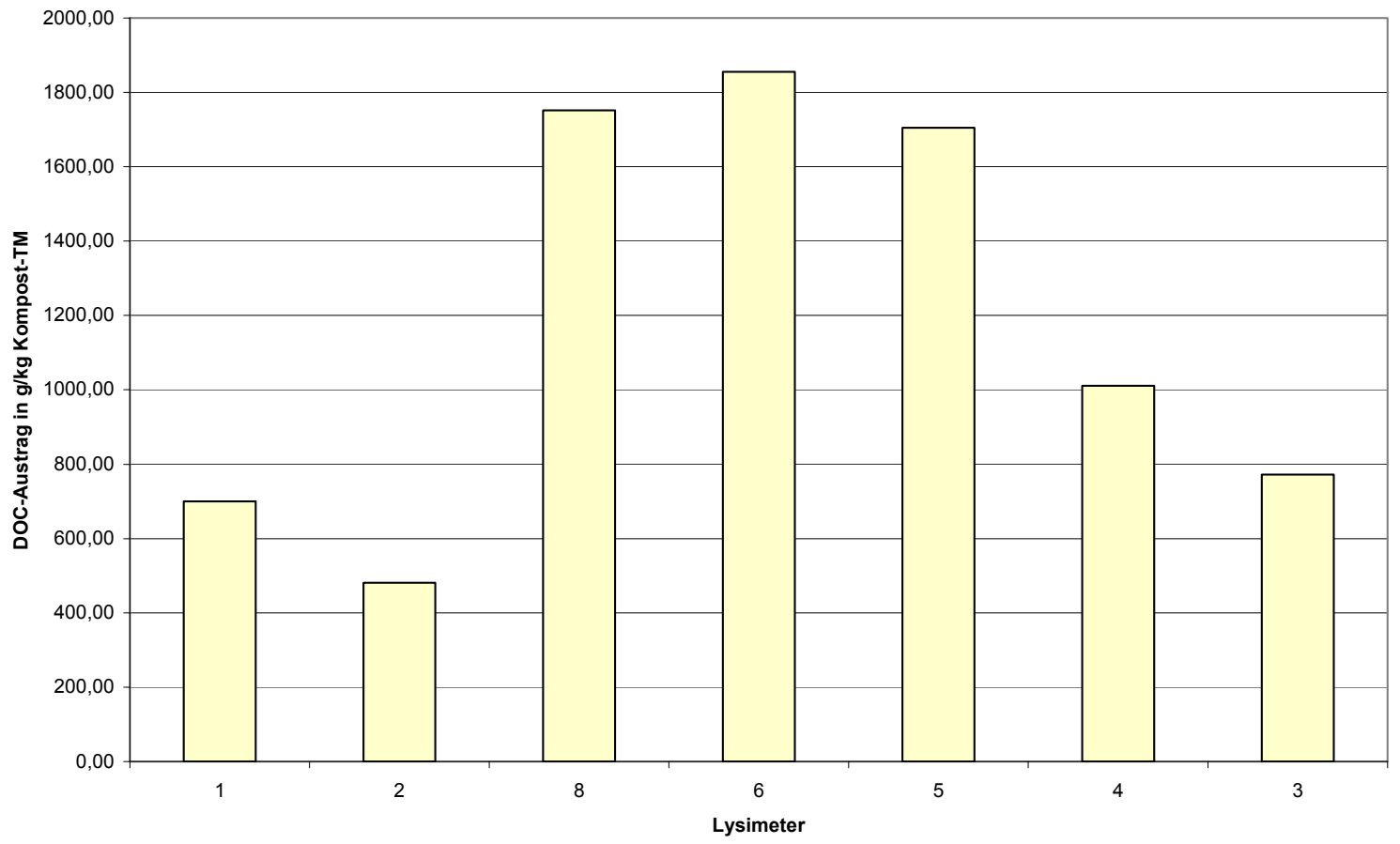

Abbildung 104: DOC-Sickerwasser-Austrag in $\mathrm{g} / \mathrm{kg}$

Kompost-TM von Mai 87 bis April 90, Lysimeter 1 - 8

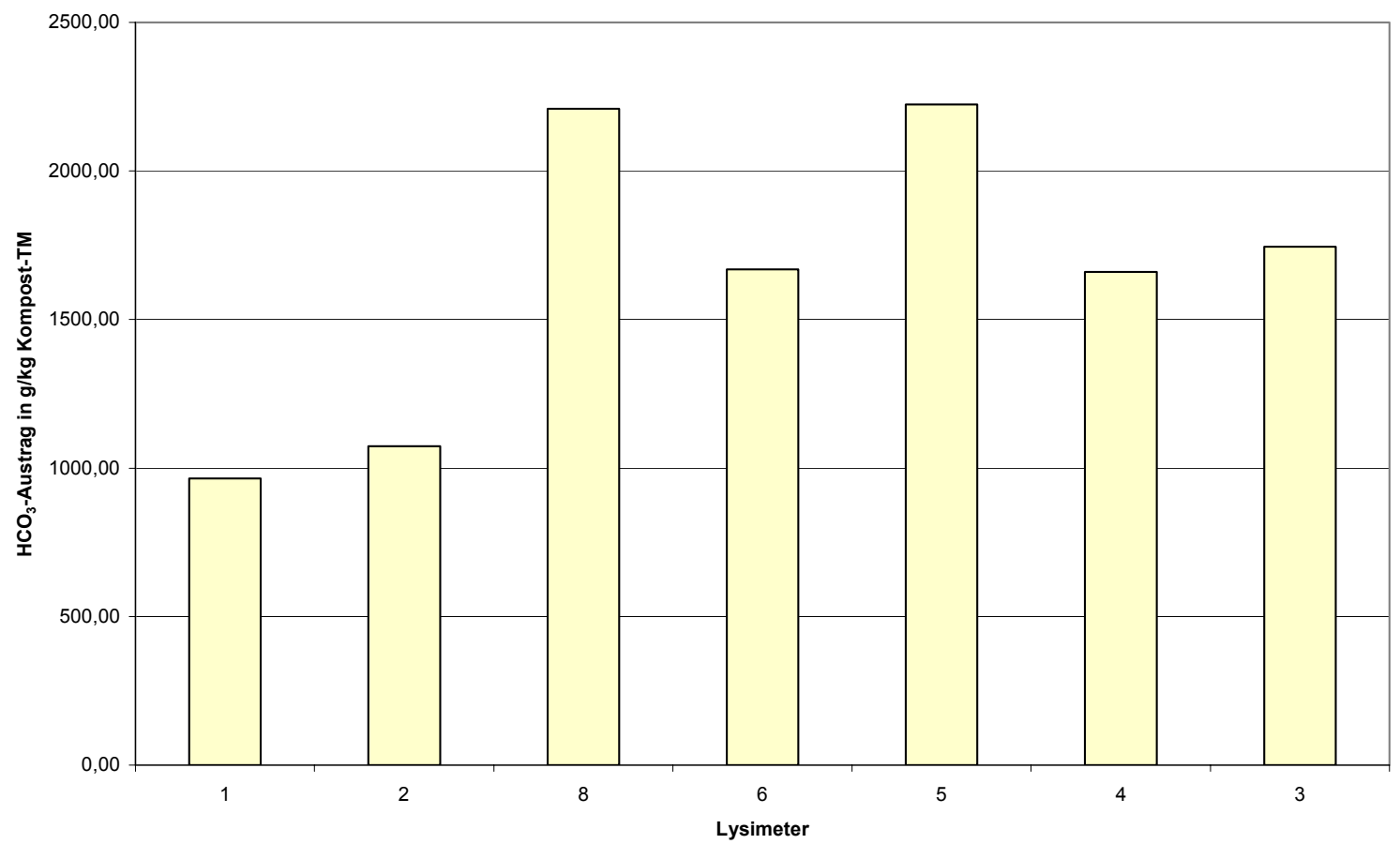

Abbildung 105: $\mathrm{HCO}_{3}$-Sickerwasser-Austrag in $\mathrm{g} / \mathrm{kg}$

Kompost-TM von Mai 87 bis April 90, Lysimeter 1 - 8 


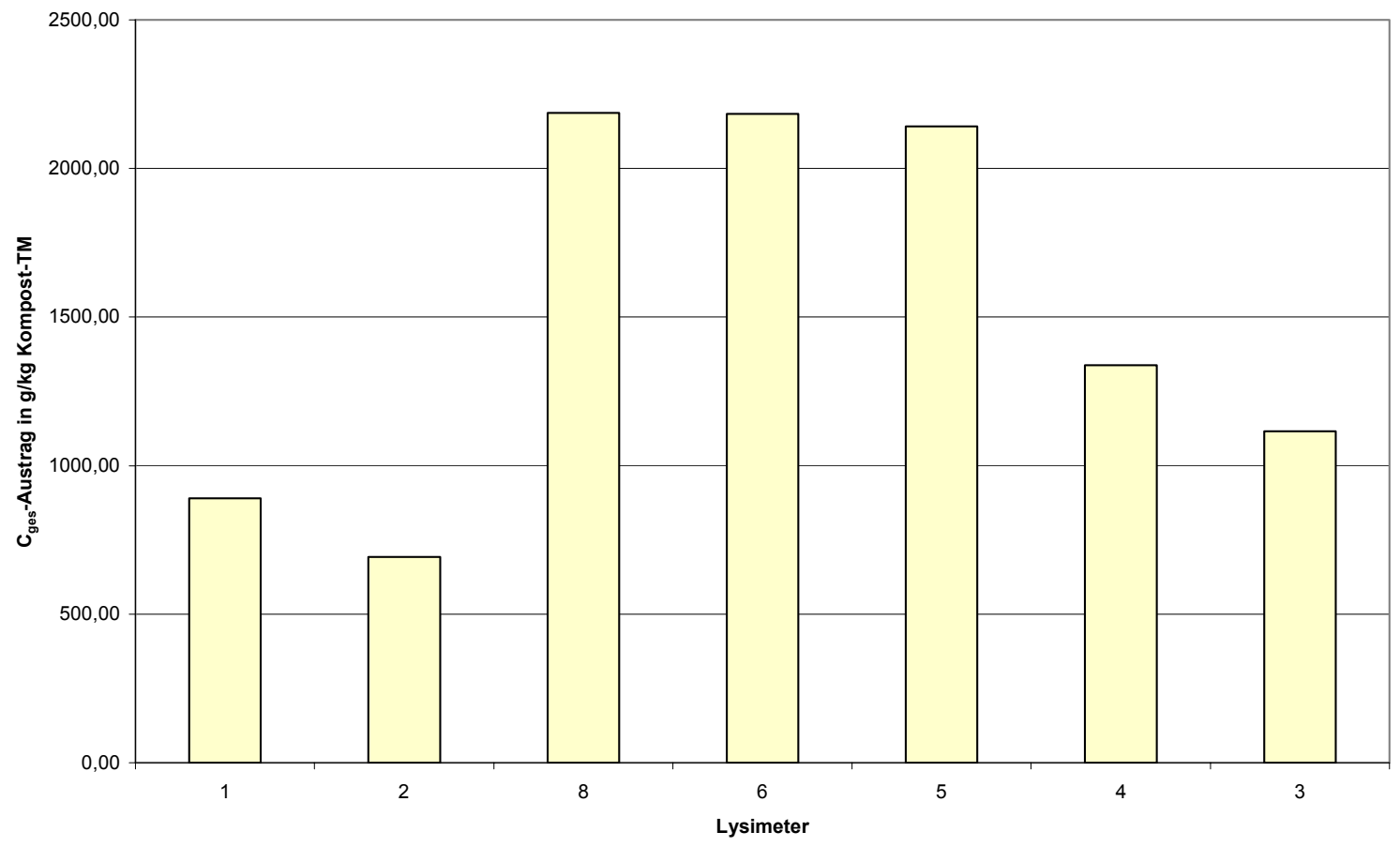

Abbildung 106: $\mathrm{C}_{\text {ges }}$-Sickerwasser-Austrag in g/kg KompostTM von Mai 87 bis April 90, Lysimeter 1 - 8

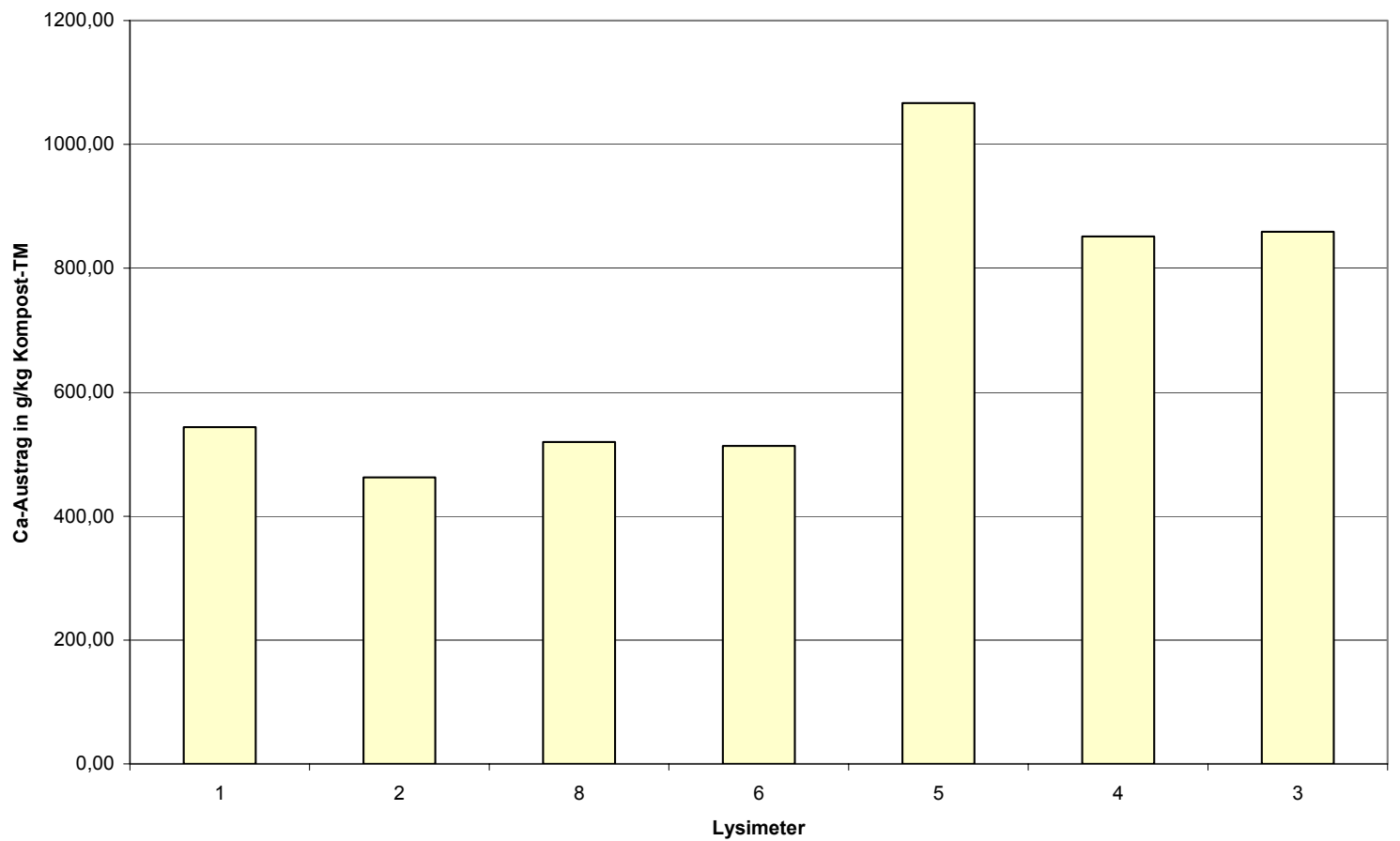

Abbildung 107: Ca-Sickerwasser-Austrag in g/kg KompostTM von Mai 87 bis April 90, Lysimeter 1 - 8 


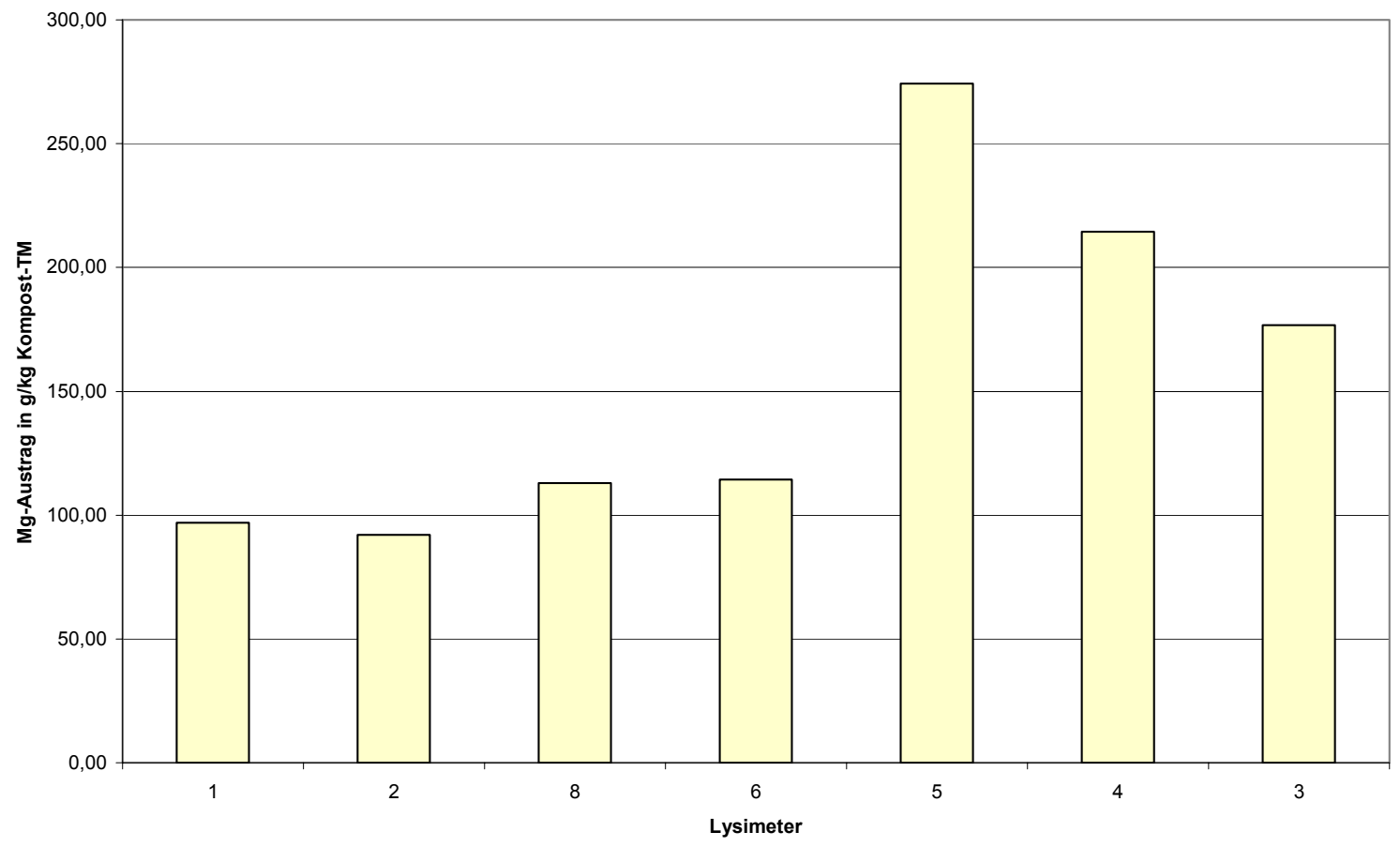

Abbildung 108: Mg-Sickerwasser-Austrag in g/kg KompostTM von Mai 87 bis April 90, Lysimeter 1 - 8

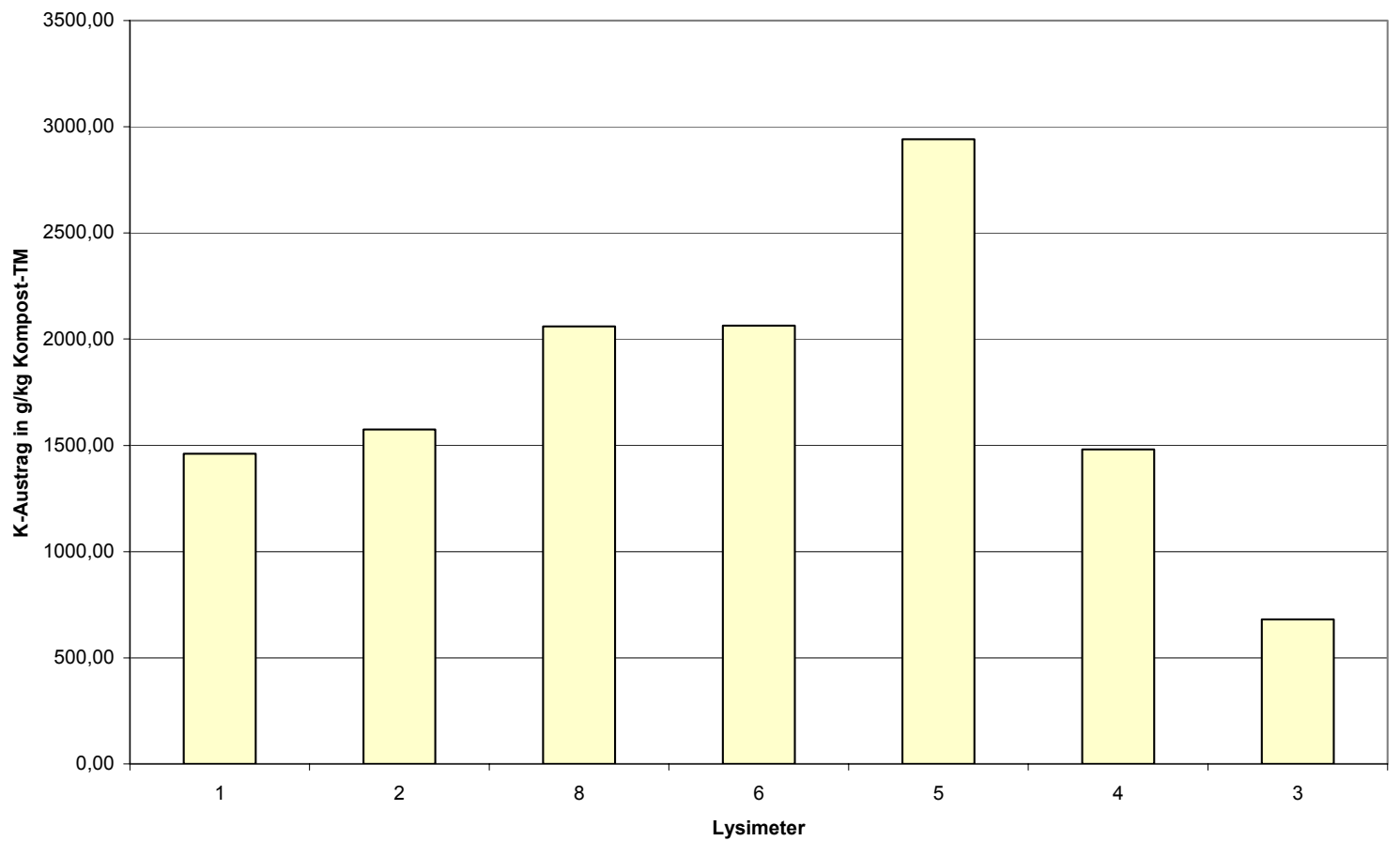

Abbildung 109: K-Sickerwasser-Austrag in g/kg KompostTM von Mai 87 bis April 90, Lysimeter 1 - 8 


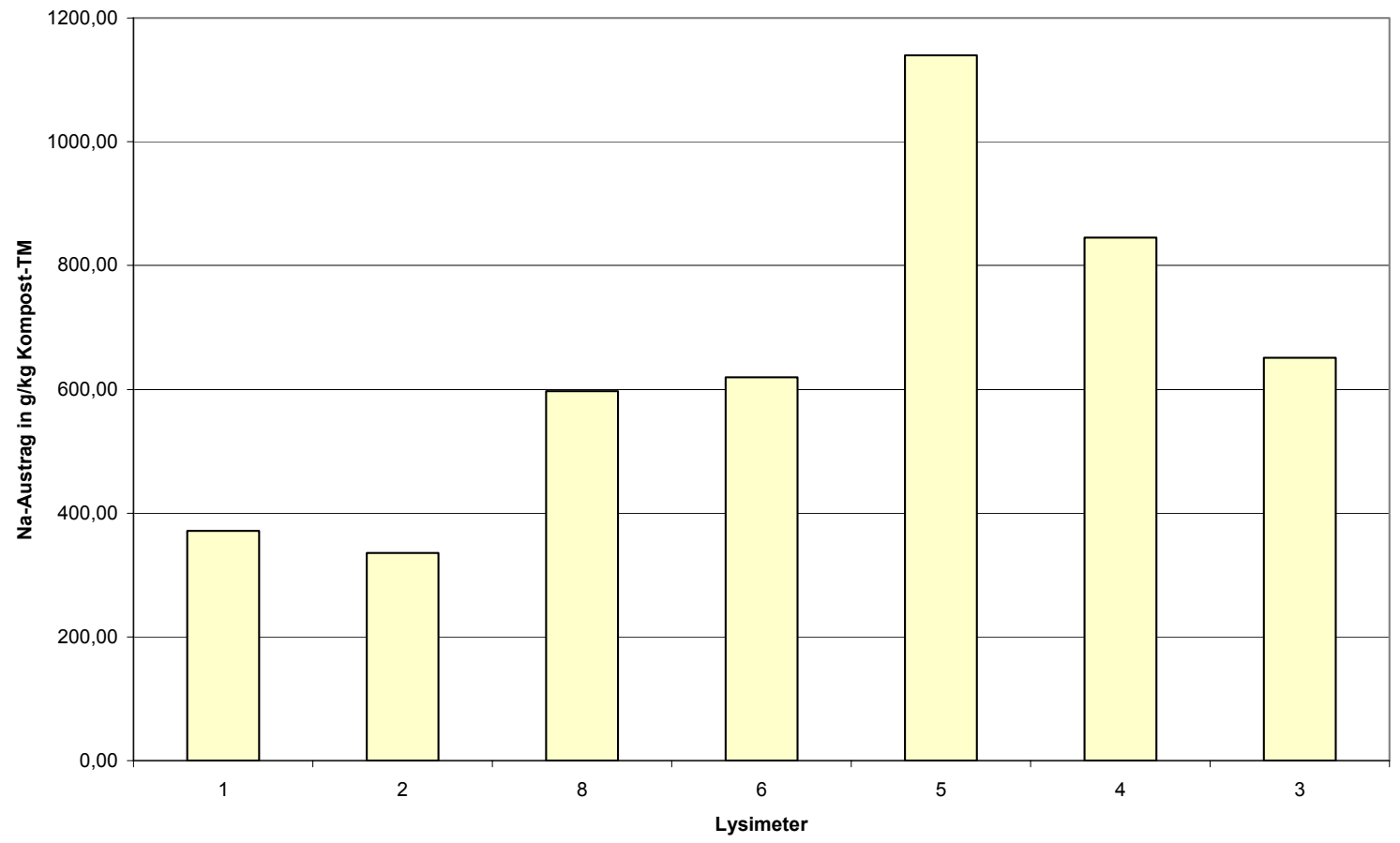

Abbildung 110: Na-Sickerwasser-Austrag in g/kg KompostTM von Mai 87 bis April 90, Lysimeter 1 - 8

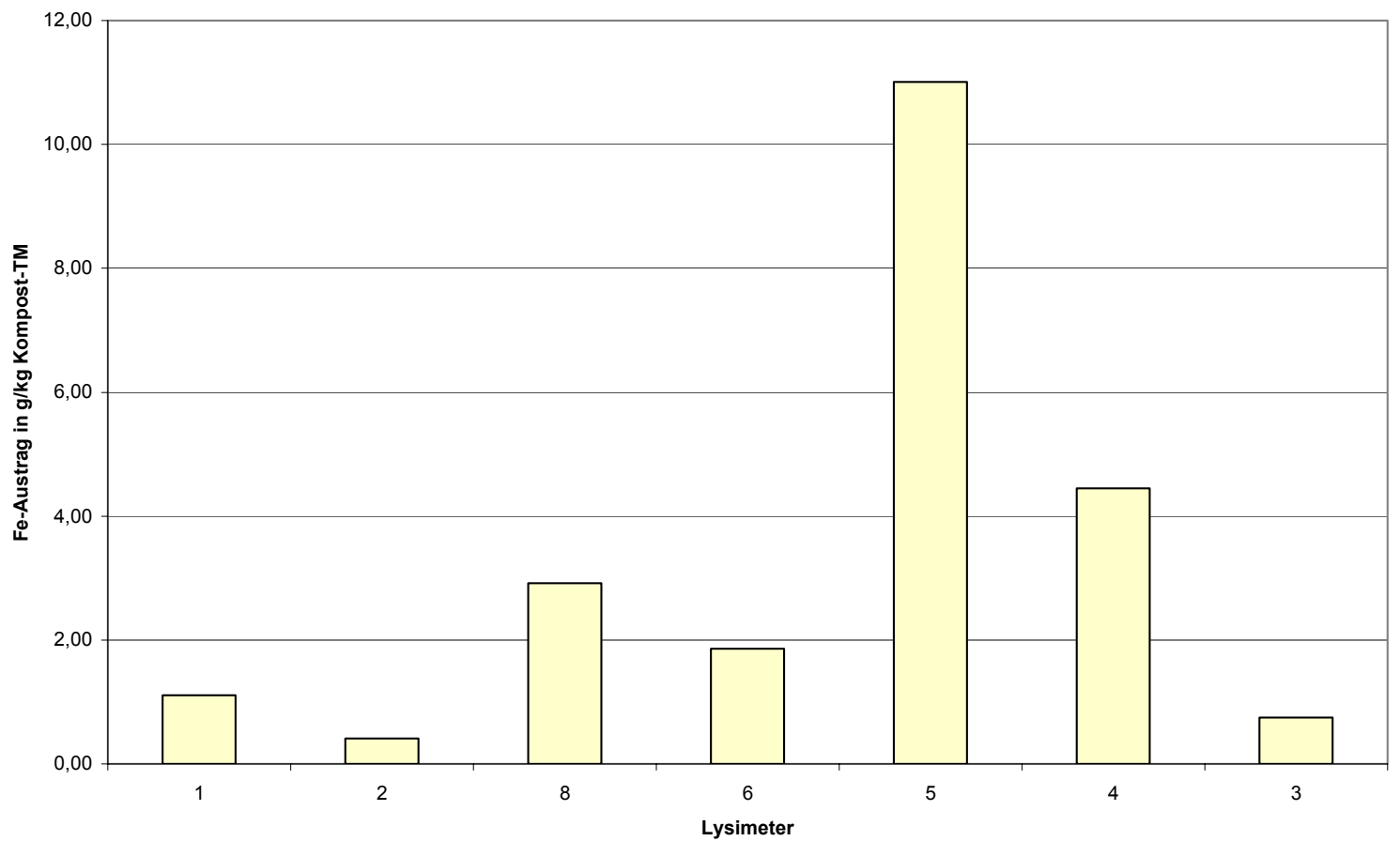

Abbildung 111: Fe-Sickerwasser-Austrag in g/kg KompostTM von Mai 87 bis April 90, Lysimeter 1 - 8 


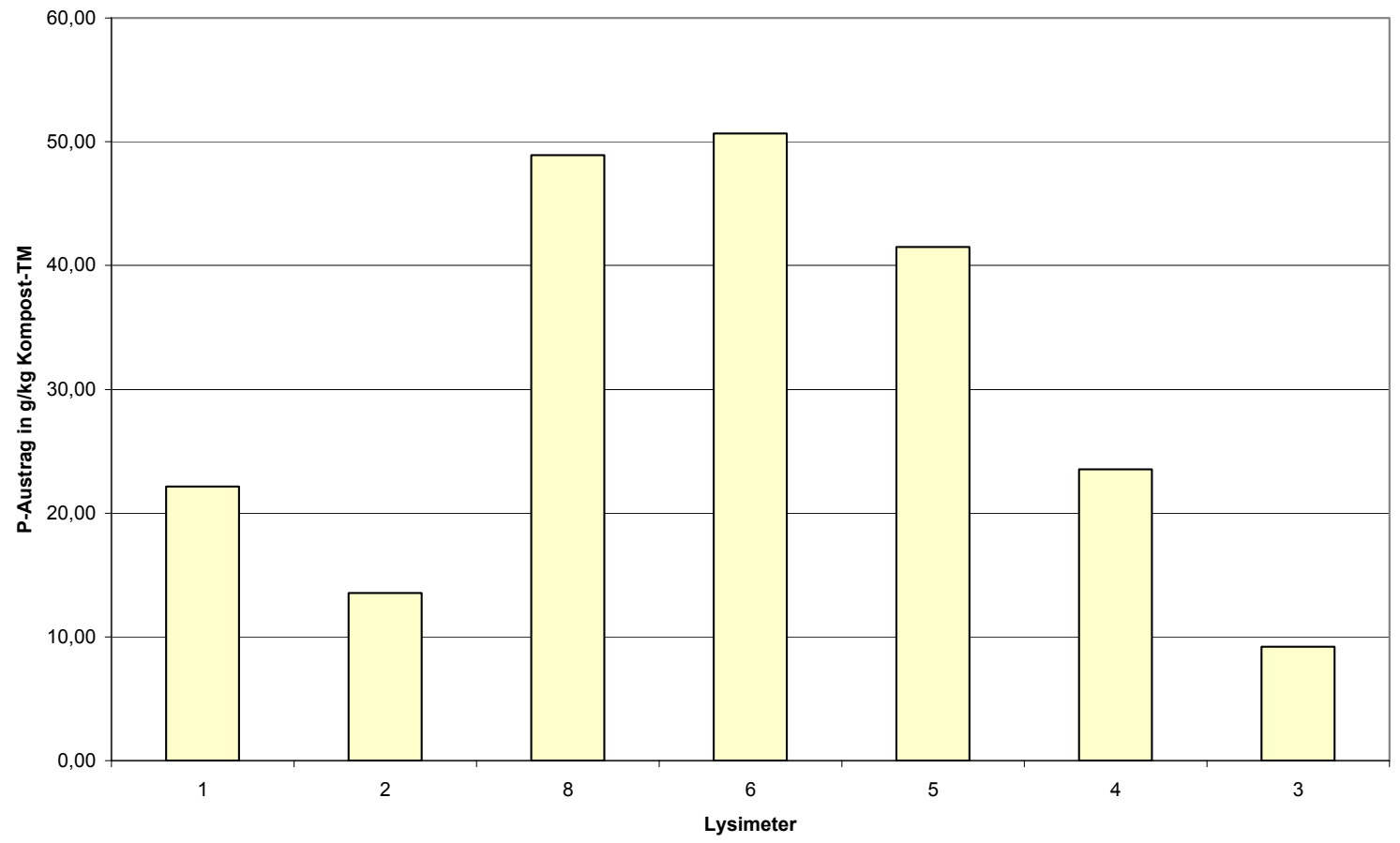

Abbildung 112: P-Sickerwasser-Austrag in g/kg Kompost-

TM von Mai 87 bis April 90, Lysimeter 1 - 8

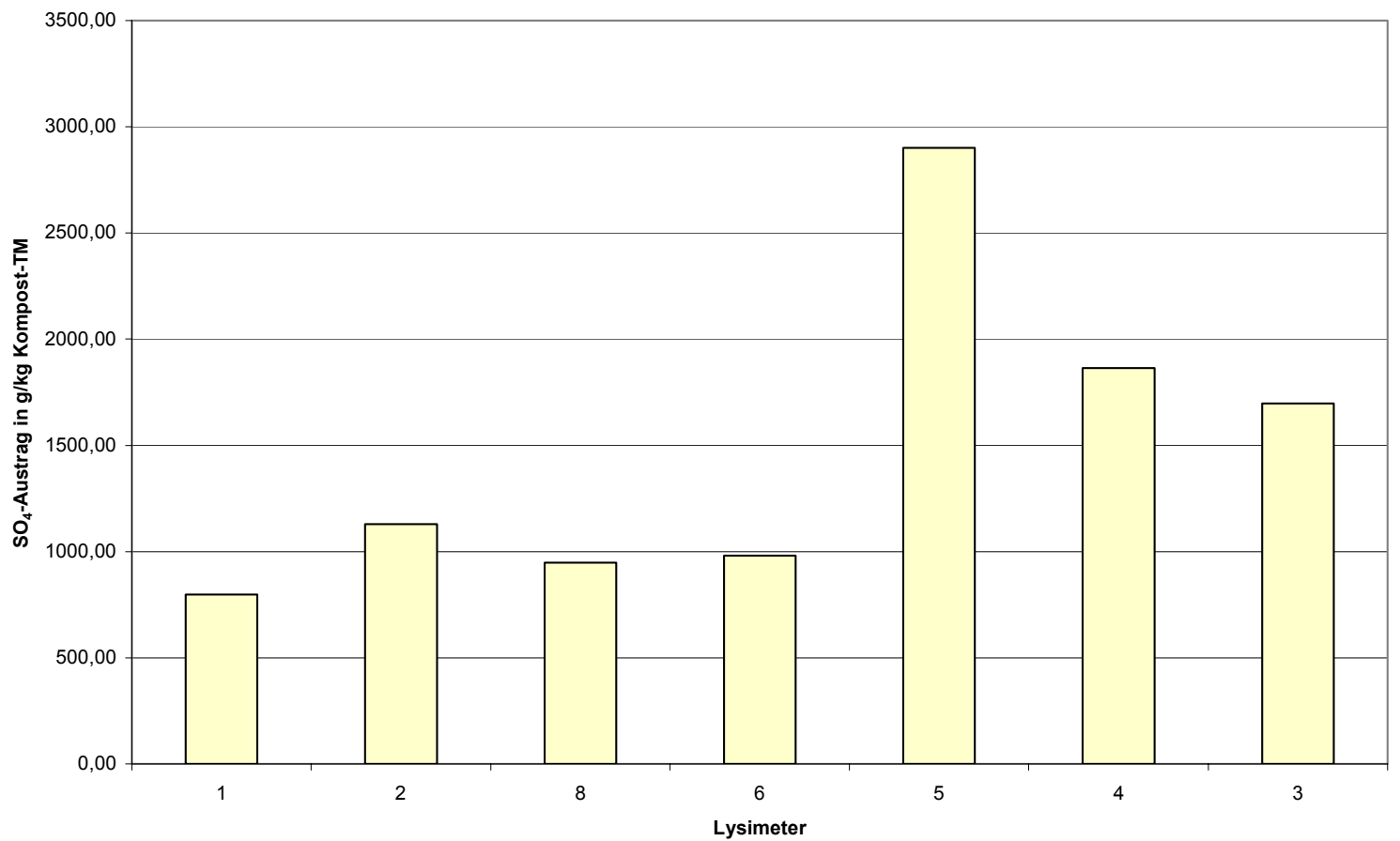

Abbildung 113: $\mathrm{SO}_{4}$-Sickerwasser-Austrag in g/kg KompostTM von Mai 87 bis April 90, Lysimeter 1 - 8 


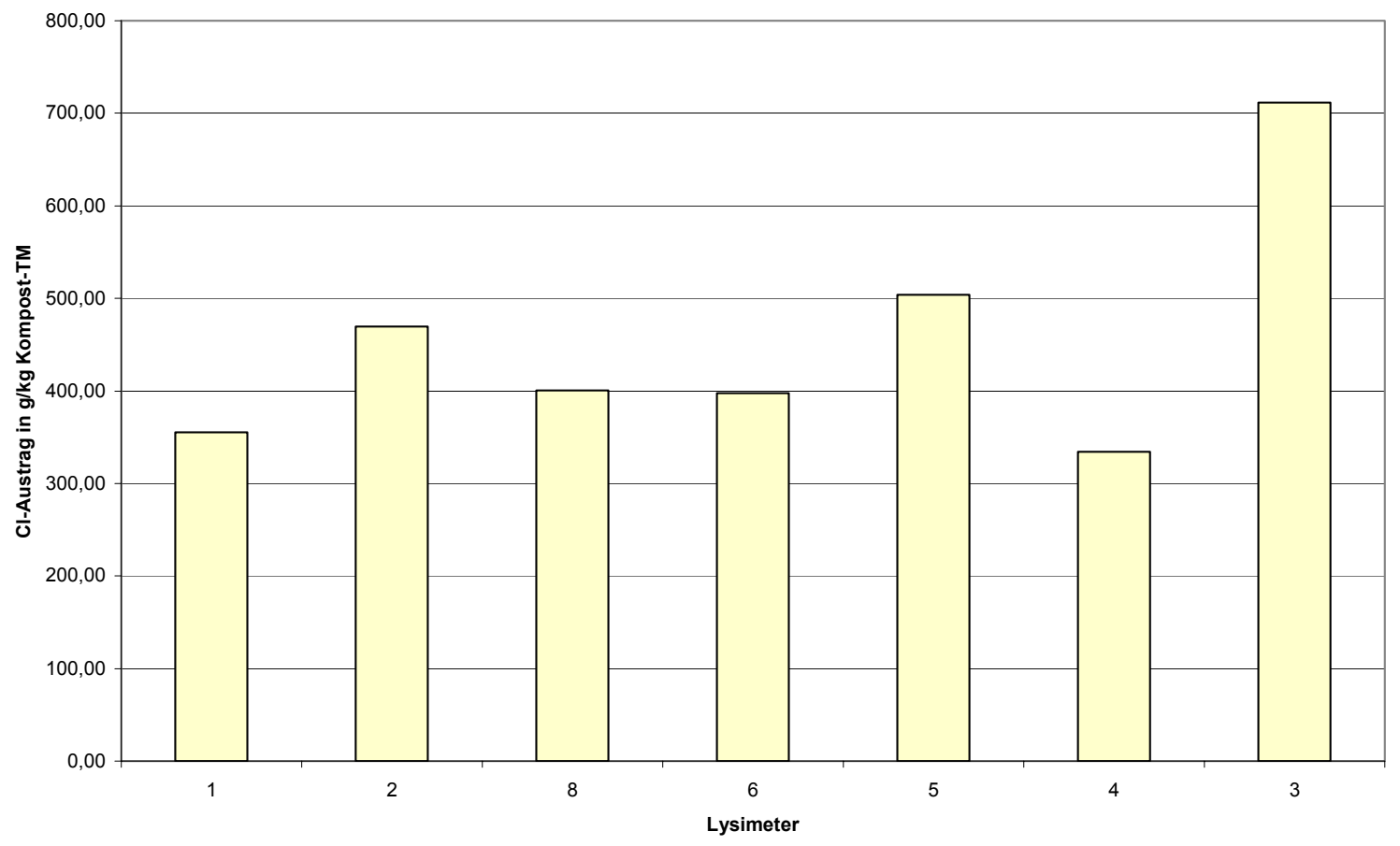

Abbildung 114: Cl-Sickerwasser-Austrag in g/kg KompostTM von Mai 87 bis April 90, Lysimeter 1 - 8

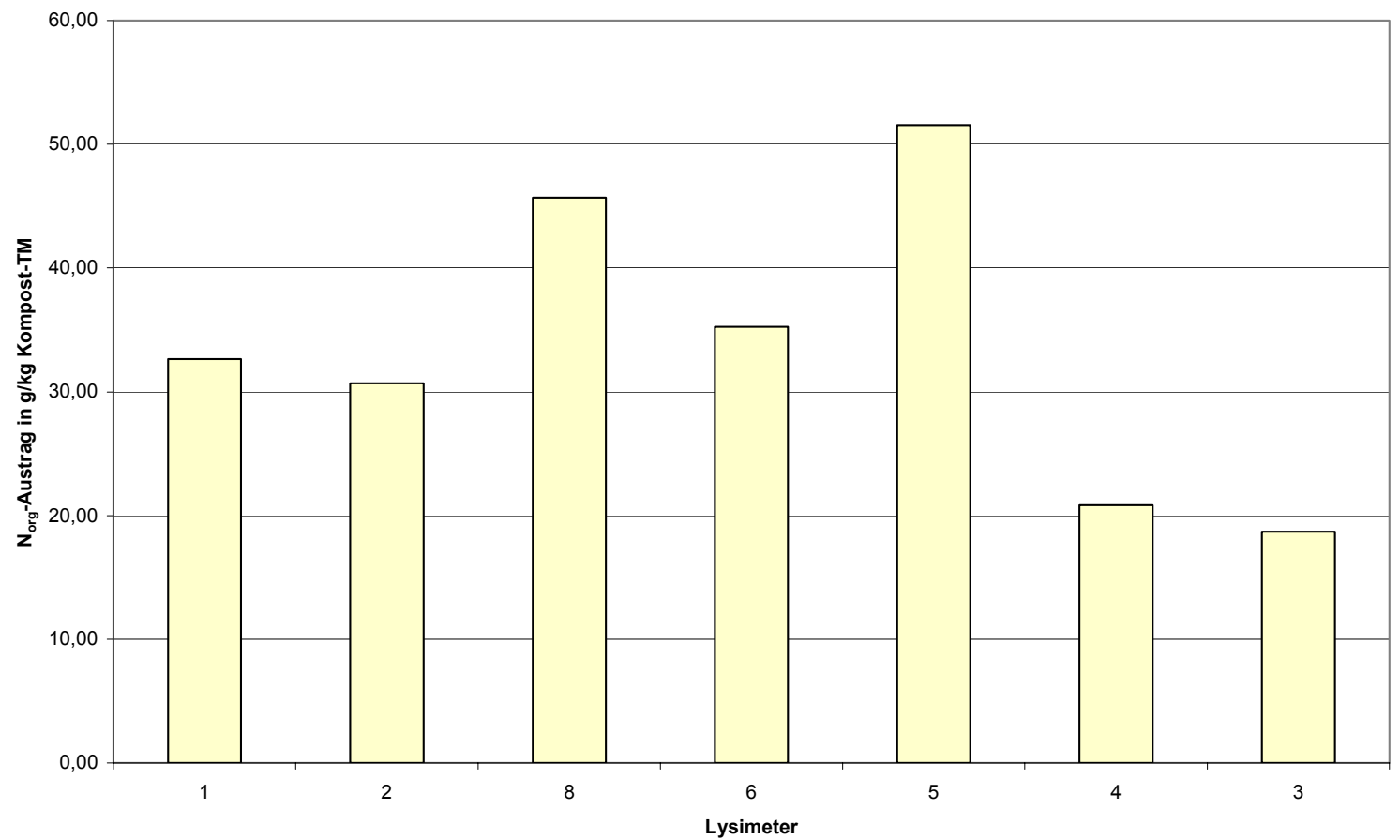

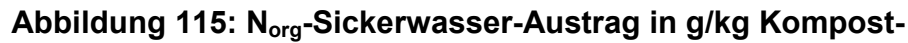
TM von Mai 87 bis April 90, Lysimeter 1 - 8 


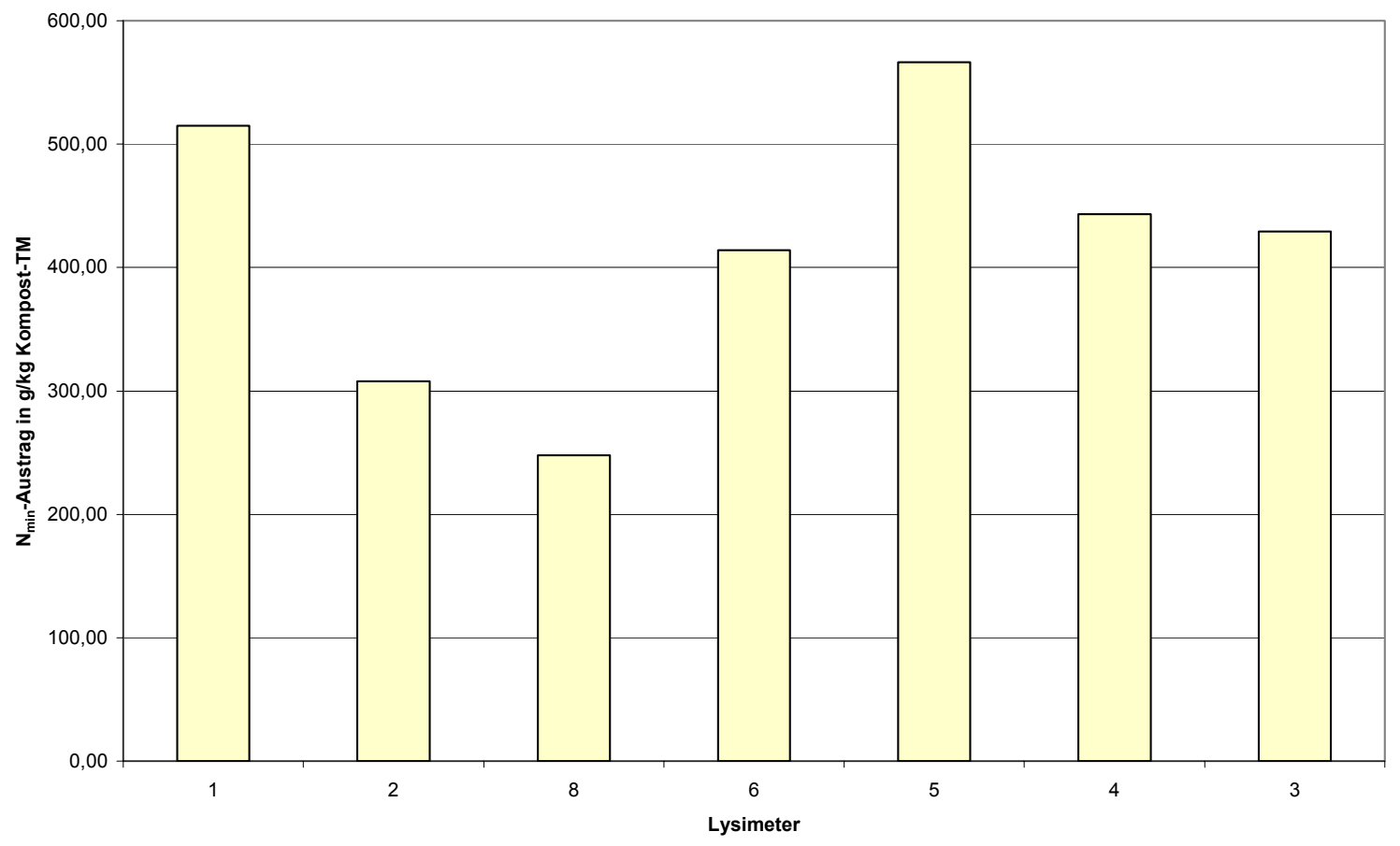

Abbildung 116: $\mathrm{N}_{\mathrm{min}}$-Sickerwasser-Austrag in $\mathrm{g} / \mathrm{kg}$ Kompost-TM von Mai 87 bis April 90, Lysimeter 1 - 8

Bei dem Vergleich der verschiedenen Lysimetertypen zeigen bestimmte Elemente ähnliche Trends, was darauf schließen lässt, dass die bestimmenden Faktoren für die Löslichkeit, Verlagerung und schließlich Auswaschung mit dem Sickerwasser elementspezifisch zugeordnet werden können.

Die "Verfügbarkeit“ eines Elementes oder einer Verbindung hängt neben dem Gesamtgehalt und dem sehr unterschiedlich in der Regel methodisch definierten Anteil leicht löslicher Verbindungen von zahlreichen weiteren Faktoren ab, die sich aus bodenchemischen und bodenphysikalischen sowie witterungsbedingten Faktoren ergeben (GROTHEER 1998).

Die an der Grenzschicht der flüssigen und festen Phase stattfindenden Ad- und Desorptionsprozesse gehören zu den wichtisten chemischen Vorgängen in Bezug auf Stoffverlagerungsvorgänge im Boden. Unter Freilandbedingungen wird in der Regel insbesondere für langsame Prozesse kein Gleichgewichtszustand erreicht (SPANG 2000).

Die zu diskutierenden Faktoren für die Auswaschung sind:

Mineralisations- und Immobilisationsvorgänge beeinflussen die Löslichkeit organisch gebundener Komponenten, insbesondere für N und P (UMWELTBUNDESAMT 1999).

Für Kalium, Natrium, Sulfat und Chlorid lässt sich feststellen, dass diese Elemente in den hier untersuchten Komposten überwiegend als Salze mit hoher Löslichkeit vorliegen und weitgehend unabhängig von Sorptionsprozessen ausgewaschen werden. Bei Chlorid führt die hohe Löslichkeit der Salze zu einer kontinuierlichen Abnahme während sich die Konzentrationen für Kalium, Natrium und Sulfat auf einem Gleichgewichtsniveau einstellen. Einzelne Anstiege der Konzentrationen im Sickerwasser bei Kalium und Sulfat werden auf mikrobiellen Abbau zurückgeführt.

Die Freisetzung von $\mathrm{DOC}, \mathrm{HCO}_{3}, \mathrm{P}$ und $\mathrm{N}_{\min }$ wird vorrangig durch Mineralisationsvorgänge beeinflusst. Bei den Bioabfall-Komposten handelt es sich um langsam nachliefernde $\mathrm{N}$ - und P-Quellen. 
Bei den Elementen DOC, Ca und Mg findet eine Verlagerung und Anreicherung in tieferen Schichten innerhalb der mächtigeren Lysimeterkörper statt. 


\section{Die Fraktionierung organischer und anorganischer Inhaltsstoffe nach Teilchengrößen und Stoffeigenschaften}

Die Klärung der Frage nach der Kopplung zwischen organischen und anorganischen Inhaltsstoffen in den wässrigen Eluaten (Sickerwasser und Extrakte) erfordert eine Trennung und Analyse der vorhandenen Stoffgruppen. Die für die Komplexbildung und Sorption in natürlichen Gewässern verantwortlichen Inhaltsstoffe können entsprechend ihrer Größe in die vier, in Tabelle 7-1 aufgezählten, Gruppen eingeteilt werden:

Tabelle 7-1: Für die Komplexbildung und Sorption in natürlichen Gewässern verantwortliche Inhaltsstoffe (nach BUFFLE et al. 1978)

\begin{tabular}{|c|c|l|}
\hline Fraktion & Größe & Inhaltsstoffe \\
\hline 1 & $<200 \mathrm{u}$ & $\begin{array}{l}\text { gelöste anorganische }\left(\mathrm{Cl}^{-}, \mathrm{SO}_{4}{ }^{2-} \text { etc.) und organische }\right. \\
\text { (Aminosäuren, Hydroxysäuren etc.) Liganden }\end{array}$ \\
\hline 2 & 200 bis $10.000 \mathrm{u}$ & $\begin{array}{l}\text { gelöste oberflächenaktive Komponenten wie Fulvosäuren, Poly- } \\
\text { hydroxo- Komplexe von Fe und Al, Polysilikate }\end{array}$ \\
\hline 3 & $10^{4}$ bis $10^{6} \mathrm{u}$ & $\begin{array}{l}\text { kolloidale Bestandteile: anorganische Silikate, Metallhydroxide; } \\
\text { organische Huminsäuren, Polysaccheride, Proteine }\end{array}$ \\
\hline 4 & $>0.45 \mu \mathrm{m}$ & suspendierte organische und anorganische Partikel \\
\hline
\end{tabular}

Als Grundlage der Trennung können physikalische oder chemische Stoffeigenschaften dienen. Das Hauptproblem eines Trennverfahrens ist die Beeinflussung der Speziesverteilung durch den Trennvorgang. Da jede Methode zwangsläufig eine Veränderung des zu untersuchenden Systems bewirkt, sind die erzielten Ergebnisse methodenabhängig und nur bedingt vergleichbar.

\subsection{Ultrafiltration}

\subsubsection{Methodik}

Die Ultrafiltration ist die Filtration einer Lösung durch eine Membran, deren Poren so eng sind, dass sie nur das Lösungsmittel und gelöste Stoffe bis zu einer bestimmten molaren Massen-Trenngrenze passieren lässt. Die treibende Kraft ist die Druckdifferenz zwischen den beiden Seiten der Membran. Sie erzwingt den Fluss des Lösungsmittels. Die Anwendung kann in verschiedenen Arbeitstechniken erfolgen, wobei die Konzentrierungs-Technik und die Diafiltration unterschieden werden. Bei der ersteren wird das Lösungsmittel, hier das Wasser, durch die Membran abgepresst, wobei die nicht das Filter passierenden Bestandteile (Kolloide) im verbleibenden Lösungsmittel angereichert werden. Bei der Diafiltration wird das durch die Membran abgepresste Lösungsmittel fortlaufend von außen ersetzt. Die Gleichgewichtslösung wird sozusagen kontinuierlich verdrängt. Die Ultrafiltration findet Anwendung u.a. bei der Konzentrierung, Fraktionierung und Entsalzung kolloiddisperser Lösungen (ROCHUS 1979, EBERLE 1979 et al.).

Die Abbildung 117 zeigt eine schematisierte Darstellung der Filtrationsanlage. 


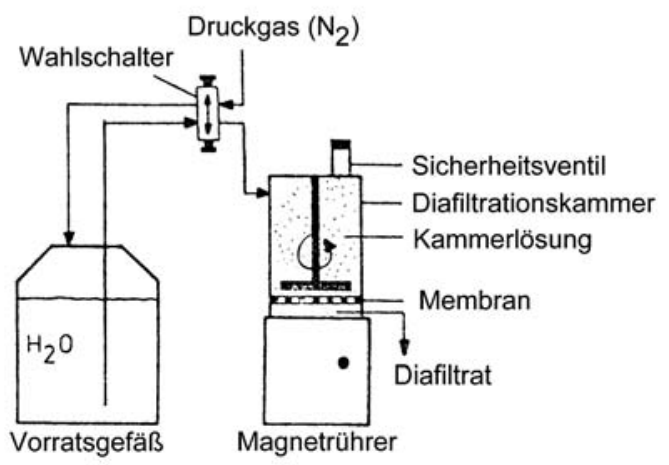

Abbildung 117: Filtrationsanlage (Abbildung nach EBERLE et al. 1979 verändert)

\subsubsection{Durchführung}

Bei der verwendeten Ultrafiltrations-Anlage handelt es sich um eine Niederdruck-Zelle des Typs GN 10-400 der Fa. Berghof mit integriertem Magnetrührer. Der Filter-Durchmesser liegt bei $76 \mathrm{~mm}$. Das Füllvolumen der Rührzelle beträgt maximal $400 \mathrm{ml}$. Der Druck wird zwischen 1,5 und 5 bar variiert. Die Rührgeschwindigkeit liegt bei $250-450$ Umdrehungen pro Minute.

Die verwendeten Membranfilter der Fa. Berghof und Amicon stellen eine Trennschicht aus einer asymmetrisch, d.h. oben fein, unten grob strukturierten Membranfolie dar, die aus einem aromatischen Polyamid besteht. Es wurden die in Tabelle 1-2 aufgelisteten Filtertypen verwendet:

Tabelle 7-2: Verwendete Filtertypen

\begin{tabular}{|c|c|c|c|}
\hline Filtertyp & Hersteller & $\begin{array}{c}\text { nominelle } \\
\text { Trenngrenze } \\
\text { in } \mathbf{~}^{\mathbf{2 0}}\end{array}$ & $\begin{array}{c}\text { Porendurchmesser } \\
\text { in } \mathbf{~ n m}^{\mathbf{2 1}}\end{array}$ \\
\hline BM 500 & Berghof & 50.000 & 3,10 \\
\hline BM 100 & Berghof & 10.000 & 1,60 \\
\hline BM 50 & Berghof & 5.000 & 1,40 \\
\hline BM 10 & Berghof & 1.000 & 1,30 \\
\hline YC 05 & Amicon & 500 & 1,04 \\
\hline
\end{tabular}

Hier wurde die Ultrafiltration nach dem Verfahren der diskontinuierlichen Diafiltration angewendet, um eine möglichst vollständige Auswaschung der niedermolekularen Verbindungen mit der Lösung zu erzielen. Dazu wurde im Anschluss an die Filtration der Probelösung Einengung des Probenvolumens auf ca. $10 \%$ der Ausgangsmenge - die Filtration als Dialyse mit dest. Wasser fortgesetzt. Die eingesetzten Volumina variierten in Abhängigkeit von der zu filtrierenden Lösung. Die Ausgangsmenge betrug zwischen 200 und 300 ml. Nachdi-

\footnotetext{
${ }^{19}$ Allgemeine Charakterisierung des Trennvermögens der Membran gegenüber sphärischen, ungeladenen Molekülen. Das tatsächliche Rückhaltevermögen kann beträchtlich von der nominellen Trenngrenze abweichen, da neben der Molekülgröße die Molekülform und etwaige Adsorptionseffekte an der Membran von Bedeutung sind.

${ }^{20}$ units atomare Masseneinheit

${ }^{21}$ Zum Größenvergleich diene das Benzol-Molekül mit 0,32 nm Durchmesser.
} 
alysiert wurde nach Bedarf mehrmals mit 50 bis $200 \mathrm{ml}$ dest. Wasser. Die ersten $\mathrm{ml} \mathrm{der}$ Filtrate wurden jeweils verworfen, da durch das Wasser des feucht gelagerten Filters die Gefahr der Verdünnung bestand. Die genannten Filtertypen wurden nacheinander in absteigender Reihenfolge eingesetzt.

Die Dauer der Ultrafiltration variierte in Abhängigkeit vom verwendeten Filtertyp und dem DOC-Gehalt der zu diafiltrierenden Lösung. Die Filtrationsgeschwindigkeiten lagen bei folgenden Durchschnittswerten:

BM $500 \quad$ 2,64 ml/min (16 Werte, Min: 1,04 Max: 4,69)

BM $100 \quad$ 15,83 ml/min (9 Werte, Min: 4,24 Max: 15,83)

BM $50 \quad$ 2,74 $\mathrm{ml} / \mathrm{min}$ (13 Werte, Min: 1,00 Max: 6,67)

BM $10 \quad 0,71 \mathrm{ml} / \mathrm{min}(10$ Werte, Min: 0,61, Max 0,91)

Die große Filtrationsrate bei BM 100 ist darauf zurückzuführen, dass zwischen den Filtern BM 500 und BM 100 praktisch keine vom Filter BM 100 zurückgehaltenen Korpuskel vorliegen (s. Ergebnisse).

Die Intensität des Rührens reichte in manchen Fällen nicht aus, um das Absetzen von Sediment und Adsorbat auf der Membran-Oberfläche zu unterbinden. Andererseits ist zu bedenken, dass während der verdünnenden Diafiltration grobe Polymere kontinuierlich in feinere depolymerisieren, so dass letztlich alles durch die Filterserie hindurch wandern würde, wenn bei intensivem Rühren mit langer Diafiltrationsdauer gearbeitet würde. Die bei dem gewählten zeitlich begrenzten Verfahren erzeugten Diafiltrate und Retentate sind also hier gewissermaßen ein durch konventionelle Bedingungen erzeugtes Produkt.

Die Filtrate und Dialysate wurden getrennt gewonnen und auf ihre Gehalte an DOC und Kationen analysiert. Die nach der Diafiltration verbliebenen Filter-Rückstände (Retentate) wurden in $200 \mathrm{ml}$ dest. Wasser aufgenommen und ebenfalls auf ihre DOC- und KationenGehalte hin untersucht.

Für die Bestimmung der säurefällbaren Anteile aus dem Retentat $>50.000 \mathrm{u}$ wurde ein Aliquot von $50 \mathrm{ml}$ entnommen und im Becherglas mit 3 Tropfen $25 \%$ iger $\mathrm{HCl}$ versetzt. Der Niederschlag wurde nach 2 bis 3 Stunden abfiltriert (Membranfilter 0,45 $\mu$ ) und im Exsikkator getrocknet. Im Filtrat wurden der DOC- und die Kationen-Gehalte bestimmt. Die DOCund Kationen-Gehalte der säuregefällten Fraktion wurden aus der Differenz zwischen Konzentrationen in den Lösungen vor und nach der Fällung und Abtrennung bestimmt.

Wenn bei der Ultrafiltration gemäß Tab. 7-3 Filtrate anfielen, ohne dass dabei Retentate zurückblieben, so z.B. bei der 2., 3. oder 4. Filtration von Lösungen aus den Kompost-LössMischungen mit zunehmendem Löss-Anteil, entfallen Angaben über Retentate und Dialysate. 
Tabelle 7-3: Fraktionen bei der Ultrafiltration von

Sickerwasser

Filtrat: Filter-Durchlauf ohne Nachwaschen,

Dialysat: Filter-Durchlauf unter Nachwaschen

\begin{tabular}{|c|l|l|}
\hline $\begin{array}{l}\text { Proben- } \\
\text { Nr. }\end{array}$ & Bezeichnung der Fraktion & $\begin{array}{l}\text { Nominelle Trenngrenze } \\
\text { der verwendeten Filter in } \\
\mathbf{u}\end{array}$ \\
\hline $1 \mathrm{a}$ & 1. Retentat & $>50.000$ \\
\hline $1 \mathrm{~b}$ & $\begin{array}{l}\text { 1. Retentat nach Membranfiltration } \\
\text { der säuregefällten HUS (RnHA) }\end{array}$ & \\
\hline 2 & 1. Filtrat $\rightarrow 5$ & $<50.000$ \\
\hline 3 & 1. Dialysat & $<50.000$ \\
\hline 4 & 2. Retentat & $<50.000>10.000$ \\
\hline 5 & 2. Filtrat $\rightarrow 8$ & $<10.000$ \\
\hline 6 & 2. Dialysat & $<10.000$ \\
\hline 7 & 3. Retentat & $<10.000>5.000$ \\
\hline 8 & 3. Filtrat $\rightarrow 11$ & $<5.000$ \\
\hline 9 & 3. Dialysat & $<5.000$ \\
\hline 10 & 4. Retentat & $<1.000>1.000$ \\
\hline 11 & 4. Filtrat $\rightarrow 14$ & $<1.000$ \\
\hline 12 & 4. Dialysat & $<1.000>500$ \\
\hline 13 & 5. Retentat & $<500$ \\
\hline 14 & 5. Filtrat & $<500$ \\
\hline 14 & 5. Dialysat & \multicolumn{2}{|c|}{} \\
\hline
\end{tabular}

In den gewonnenen Einzellösungen und den aufgerührten Suspensionen der Retentate (Proben-Nr. 1 - 15) wurden jeweils die DOC- und die Gehalte an den Kationen $\mathrm{Fe}, \mathrm{Ca}, \mathrm{Mg}$, $\mathrm{K}$ und $\mathrm{Na}$ bestimmt. Die Anionen Nitrat, Sulfat, Phosphat und Hydrogencarbonat werden nur stichprobenweise in den 4. Filtraten (Nr. 11) bestimmt. Die Analysenmethoden stimmen mit den in Tabelle 6-6 für das Sickerwasser aufgeführten Methoden überein. Für die Berechnung der Anteile in den einzelnen Größenfraktionen wurden die den Fraktionen zugehörigen Gehalte der Filtrate und Dialysate addiert. Der Nachweis der DOC- und Kationen-Gehalte in den Retentaten, Dialysaten und Filtraten führte in der Summe zu Gehalten, die um etwa $\pm 10 \%$ von den Gehalten der Ausgangsprobe abweichen.

Als problematisch erweist sich, wie oben bereits gesagt, bei der Ultrafiltration die Festlegung der Dialysedauer. Da keine exakten Trenngrenzen für die in den zu filtrierenden Lösungen vorhandenen Moleküle existieren, hängt die Trennung nicht nur von der molaren Masse dieser Teilchen, sondern auch von während der Ultrafiltration variablen Größen, wie ihrer Molekülform, Polarität, den Membraneigenschaften, dem Druck, der Konzentration und dem $\mathrm{pH}$-Wert ab. Gerade bei Huminstoffen ist zu berücksichtigen, dass es sich um in ihrer Größe flexible Kolloide handelt.

\subsubsection{Untersuchungsproben}

Untersucht wurden die Sickerwasserproben aller Lysimeter, die am 14.12.88 und am 22.12.88 aufgefangen worden waren, außerdem das am 07.07.88 aus den Großlysimetern angefallene Sickerwasser nach dem diese mit jeweils $45,5 \mathrm{~mm}$ dest. Wasser beregnet worden waren, sowie eine natürliche Sickerwasserprobe des Großlysimeters 1 vom 17.04.89 (jewils 4 Filtrations- und Dialysedurchgänge). Die Sickerwasserproben des Großlysimeters 1 vom 22.12.88 und vom 17.04.89 wurden einer weiteren 5. Filtration unterzogen. Hierfür wurde ein Membranfilter der Fa. Amicon (YC 05) mit der nominellen Trenngrenze von 500 u verwendet. 


\subsubsection{Ergebnisse}

\subsubsection{Gelöster organischer Kohlenstoff}

Die Ergebnisse der Ultrafiltrations-Analyse sind den Tabellen 7-4 bis 7-9 zu entnehmen. In Tab. 7-4 ist die Zusammensetzung der oben genannten Sickerwässer nach der Papierfiltration angegeben. Die Tabellen 7-5, 7-6 und 7-7 enthalten die Zusammensetzung der beiden Retentate der Größen > $50.000 \mathrm{u}$ und 50.000 bis $1000 \mathrm{u}$, sowie der vereinigten Filtrate und Dialysate < $1000 \mathrm{u}$. Da die Retentat-Mengen 50.000 bis $10.000 \mathrm{u}, 10.000$ bis $5.000 \mathrm{u}$ und 5.000 bis $1000 \mathrm{u}$ sehr gering sind, werden sie in den Tabelle 7-6 und 7-9 als Fraktion 50.000 bis 1000 u zusammengefasst.

Tabelle 7-4: Ausgangs-Konzentrationen an Inhaltsstoffen in den für die Druckfiltration verwendeten Sickerwasser-

Proben, Lysimeter $1-6$ und 8

\begin{tabular}{|c|c|c|c|c|c|c|c|c|c|c|c|}
\hline Lysimeter & \begin{tabular}{|c|} 
Datum der \\
Probenahme
\end{tabular} & $\begin{array}{l}\mathrm{DOC} \\
\mathrm{mg} / \mathrm{l}\end{array}$ & $\begin{array}{c}\mathrm{Fe} \\
\mathrm{mg} / \mathrm{l}\end{array}$ & $\begin{array}{c}\mathrm{Ca} \\
\mathrm{mg} / \mathrm{l}\end{array}$ & $\begin{array}{c}\mathrm{Mg} \\
\mathrm{mg} / \mathrm{l}\end{array}$ & $\begin{array}{c}\mathrm{K} \\
\mathrm{mg} / \mathrm{l}\end{array}$ & $\begin{array}{c}\mathrm{Na} \\
\mathrm{mg} / \mathrm{l}\end{array}$ & $\begin{array}{c}\mathrm{HCO}_{3} \\
\mathrm{mg} / \mathrm{l}\end{array}$ & $\begin{array}{c}\mathrm{Cl} \\
\mathrm{mg} / \mathrm{l}\end{array}$ & $\begin{array}{l}\mathrm{SO}_{4} \\
\mathrm{mg} / \mathrm{l}\end{array}$ & $\begin{array}{r}\mathrm{NO}_{3}-\mathrm{N} \\
\mathrm{mg} / \mathrm{l}\end{array}$ \\
\hline \multirow[t]{2}{*}{1} & 07.07.1988 & 181,30 & 0,94 & 108,00 & 9,00 & 410,70 & 71,50 & 283,70 & 26,10 & 126,00 & 122,50 \\
\hline & 22.12.1988 & 744,00 & 2,89 & 103,98 & 24,13 & 740,75 & 148,73 & 697,84 & 5,63 & 206,10 & 85,30 \\
\hline \multirow[t]{2}{*}{2} & 07.07.1988 & 285,30 & 0,10 & 140,50 & 34,00 & 1435,30 & 182,50 & 683,20 & 249,63 & 809,99 & 204,40 \\
\hline & 14.12 .1988 & 756,00 & 0,96 & 193,69 & 57,00 & 2003,08 & 302,00 & 1021,14 & 204,64 & 976,10 & 213,00 \\
\hline 8 & 22.12.1988 & 411,00 & 3,00 & 48,36 & 13,75 & 385,80 & 86,73 & 524,60 & 0,00 & 112,60 & 36,20 \\
\hline \multirow[t]{2}{*}{6} & 14.12.1988 & 383,00 & 2,00 & 66,15 & 21,13 & 440,79 & 111,17 & 383,08 & 0,22 & 100,00 & 72,50 \\
\hline & 22.12 .1988 & 332,00 & 3,64 & 50,87 & 11,88 & 345,80 & 88,82 & 401,38 & 5,36 & 77,90 & 63,60 \\
\hline \multirow[t]{2}{*}{5} & 14.12.1988 & 302,50 & 7,00 & 67,90 & 24,75 & 437,87 & 122,05 & 370,88 & 6,18 & 145,50 & 81,30 \\
\hline & 22.12 .1988 & 262,50 & 10,50 & 56,38 & 20,38 & 377,87 & 98,51 & 381,86 & 5,36 & 56,20 & 67,60 \\
\hline 4 & 14.12.1988 & 247,50 & 2,45 & 79,18 & 26,00 & 292,89 & 111,92 & 358,68 & 4,50 & 157,40 & 70,00 \\
\hline
\end{tabular}

Tabelle 7-5: DOC- und Kationen-Konzentrationen in $\mathrm{mg} / \mathrm{l}$ in der Fraktion > 50.000 u (1. Retentat), Lysimeter $1-6$ und 8

\begin{tabular}{|c|c|c|c|c|c|c|c|}
\hline \multirow[b]{2}{*}{ Lysimeter } & \multirow{2}{*}{\begin{tabular}{|c|} 
Datum der \\
Probenahme
\end{tabular}} & \multicolumn{6}{|c|}{ Retentat $>50.000 \mathrm{u}$} \\
\hline & & \begin{tabular}{|l} 
DOC \\
\end{tabular} & $\mathrm{Fe}$ & $\begin{array}{c}\mathrm{Ca} \\
\mathrm{mg} / \mathrm{l}\end{array}$ & $\mathrm{Mg}$ & $\mathbf{K}$ & $\mathrm{Na}$ \\
\hline \multirow[t]{3}{*}{1} & 22.07.1988 & 0,67 & u. B. & u. B. & u. B. & u. B. & u. B. \\
\hline & 14.12.1988 & 239,02 & 2,33 & 24,71 & 3,80 & 25,43 & 3,95 \\
\hline & 22.12.1988 & 387,03 & 1,55 & 43,28 & 6,33 & 43,26 & 6,26 \\
\hline \multirow[t]{3}{*}{2} & 22.07.1988 & 6,99 & u. B. & 0,53 & 0,10 & 0,11 & 0,08 \\
\hline & 14.12.1988 & 113,32 & 0,68 & 10,03 & 1,73 & 13,42 & 1,54 \\
\hline & 22.12.1988 & 266,68 & 0,75 & 30,78 & 1,83 & 45,46 & 5,98 \\
\hline \multirow[t]{2}{*}{8} & 14.12.1988 & 295,00 & 2,25 & 21,90 & 4,13 & 22,52 & 2,80 \\
\hline & 22.12.1988 & 184,99 & 1,67 & 18,06 & 3,46 & 13,66 & 1,90 \\
\hline \multirow[t]{2}{*}{6} & 14.12.1988 & 171,28 & 1,33 & 21,19 & 4,27 & 36,01 & 6,83 \\
\hline & 22.12.1988 & 171,68 & 1,10 & 17,00 & 3,27 & 17,39 & 2,13 \\
\hline \multirow[t]{2}{*}{5} & 14.12.1988 & 112,50 & 5,00 & 9,64 & 10,76 & 13,49 & 2,47 \\
\hline & 22.12.1988 & 115,00 & 2,90 & 11,50 & 2,64 & 8,69 & 1,47 \\
\hline \multirow[t]{2}{*}{4} & 14.12.1988 & 40,66 & 1,77 & 2,00 & 0,57 & 2,52 & 0,47 \\
\hline & 22.12.1988 & 34,01 & 1,83 & 3,00 & 0,63 & 1,24 & 0,20 \\
\hline \multirow[t]{2}{*}{3} & 14.12.1988 & u. B. & k. A. & u. B. & u. B. & u. B. & u. B. \\
\hline & 22.12.1988 & 0,84 & 0,70 & 0,13 & 0,00 & 0,50 & 0,03 \\
\hline
\end{tabular}


Tabelle 7-6: DOC- und Kationen-Konzentrationen in $\mathrm{mg} / \mathrm{l}$ in der Fraktion $<50.000$ und $>1000$ u (2. und 3. Retentat), Lysimeter $1-6$ und 8

\begin{tabular}{|c|c|c|c|c|c|c|c|}
\hline \multirow[b]{2}{*}{ Lysimeter } & \multirow{2}{*}{\begin{tabular}{|c|} 
Datum der \\
Probenahme \\
\end{tabular}} & \multicolumn{6}{|c|}{ Retentat $<50.000 \mathrm{u}>1000 \mathrm{u}$} \\
\hline & & DOC & $\mathrm{Fe}$ & $\begin{array}{c}\mathrm{Ca} \\
\mathrm{mg} / \mathrm{l}\end{array}$ & Mg & $\mathbf{K}$ & $\mathrm{Na}$ \\
\hline \multirow[t]{3}{*}{1} & 22.07.1988 & 37,20 & 0,60 & 3,18 & 0,42 & 1,92 & 0,77 \\
\hline & 14.12.1988 & 26,20 & 0,11 & 0,96 & 0,22 & 6,80 & 1,82 \\
\hline & 22.12.1988 & 62,79 & u. B. & 1,02 & u. B. & 0,67 & 0,07 \\
\hline \multirow[t]{3}{*}{2} & 22.07.1988 & 13,69 & 0,10 & 2,17 & 0,17 & 1,08 & 0,41 \\
\hline & 14.12.1988 & 49,74 & 0,13 & 8,52 & 1,12 & 7,41 & 0,85 \\
\hline & 22.12.1988 & 201,60 & 0,07 & 51,98 & 15,72 & 472,67 & 4,10 \\
\hline \multirow[t]{2}{*}{8} & 14.12.1988 & 4,60 & u. B. & 0,07 & 0,04 & 0,51 & 0,09 \\
\hline & 22.12.1988 & 9,86 & u. B. & 0,92 & 0,25 & 2,66 & 0,50 \\
\hline \multirow[t]{2}{*}{6} & 14.12.1988 & 5,86 & u. B. & 0,44 & 0,39 & 4,41 & 0,59 \\
\hline & 22.12.1988 & 70,02 & 0,71 & 7,68 & 1,88 & 22,58 & 3,54 \\
\hline \multirow[t]{2}{*}{5} & 14.12.1988 & 0,00 & 0,05 & 2,80 & 0,69 & 11,38 & 3,04 \\
\hline & 22.12.1988 & 11,26 & 0,00 & 2,15 & 0,53 & u. B. & 2,33 \\
\hline \multirow[t]{2}{*}{4} & 14.12.1988 & 3,42 & u. B. & 0,28 & 0,16 & 1,73 & 0,51 \\
\hline & 22.12.1988 & 0,63 & u. B. & u. B. & u. B. & 0,13 & 0,07 \\
\hline \multirow[t]{2}{*}{3} & 14.12.1988 & 11,63 & k. A. & 0,25 & 0,06 & 0,19 & 0,13 \\
\hline & 22.12.1988 & 10,52 & 0,02 & 3,56 & 0,78 & 3,91 & 3,93 \\
\hline
\end{tabular}

Tabelle 7-7: DOC- und Kationen-Konzentrationen in $\mathrm{mg} / \mathrm{l}$ in der Fraktion < 1000 u (4. Filtrat und Dialysat), Lysimeter 1 6 und 8

\begin{tabular}{|c|c|c|c|c|c|c|c|}
\hline \multirow[b]{2}{*}{ Lysimeter } & \multirow{2}{*}{\begin{tabular}{|c|} 
Datum der \\
Probenahme
\end{tabular}} & \multicolumn{6}{|c|}{ Filtrat/Dialysat $<1.000 \mathrm{u}$} \\
\hline & & \begin{tabular}{|l} 
DOC \\
\end{tabular} & $\mathrm{Fe}$ & $\begin{array}{c}\mathrm{Ca} \\
\mathrm{mg} / \mathrm{l}\end{array}$ & Mg & $\mathbf{K}$ & $\mathrm{Na}$ \\
\hline \multirow[t]{3}{*}{1} & 22.07.1988 & 153,81 & u. B. & 49,42 & 12,68 & 607,65 & 78,80 \\
\hline & 14.12.1988 & 233,10 & 0,07 & 50,01 & 13,10 & 620,50 & 124,07 \\
\hline & 22.12.1988 & 341,57 & u. B. & 70,65 & 17,59 & 690,90 & 86,14 \\
\hline \multirow[t]{3}{*}{2} & 22.07.1988 & 266,84 & u. B. & 152,20 & 57,61 & 1072,85 & 212,22 \\
\hline & 14.12.1988 & 448,01 & 0,23 & 157,39 & 55,80 & 1731,26 & 312,45 \\
\hline & 22.12.1988 & 206,51 & u. B. & 167,72 & 57,43 & 1500,04 & 262,48 \\
\hline \multirow[t]{2}{*}{8} & 14.12.1988 & 213,79 & 0,01 & 40,32 & 14,46 & 488,77 & 97,62 \\
\hline & 22.12.1988 & 205,09 & u. B. & 37,54 & 11,65 & 311,49 & 57,59 \\
\hline \multirow[t]{2}{*}{6} & 14.12.1988 & 160,59 & 0,10 & 45,79 & 16,07 & 466,53 & 105,19 \\
\hline & 22.12.1988 & 106,67 & 0,05 & 35,30 & 12,22 & 335,29 & 63,53 \\
\hline \multirow[t]{2}{*}{5} & 14.12.1988 & 199,62 & 0,13 & 64,61 & 16,07 & 418,21 & 123,12 \\
\hline & 22.12.1988 & 178,26 & 0,32 & 59,10 & 17,13 & 277,70 & 66,71 \\
\hline \multirow[t]{2}{*}{4} & 14.12.1988 & 179,69 & u. B. & 75,70 & 23,64 & 266,35 & 112,08 \\
\hline & 22.12.1988 & 182,26 & u. B. & 77,57 & 21,63 & 216,70 & 63,26 \\
\hline \multirow[t]{2}{*}{3} & 14.12.1988 & 139,49 & k. A. & 31,66 & 8,46 & 38,63 & 34,70 \\
\hline & 22.12.1988 & 114,96 & 0,07 & 81,06 & 19,14 & 104,15 & 57,62 \\
\hline
\end{tabular}


Die Tabellen 7-8, 7-9 und 7-10 drücken die Angaben der Tabellen 7-5, 7-6 und 7-7 als Prozente der Tabelle 7-4 aus.

Tabelle 7-8: DOC- und Kationen-Konzentrationen in \% der Gesamtmenge der Fraktion > 50.000 u (1. Retentat),

Lysimeter $1-6$ und 8

\begin{tabular}{|c|c|c|c|c|c|c|c|}
\hline \multirow[b]{2}{*}{ Lysimeter } & \multirow{2}{*}{$\begin{array}{c}\text { Datum der } \\
\text { Probenahme }\end{array}$} & \multicolumn{6}{|c|}{ Retentat $>50.000 \mathrm{u}$} \\
\hline & & DOC & $\mathrm{Fe}$ & $\begin{array}{c}\mathrm{Ca} \\
\% \\
\end{array}$ & Mg & K & $\mathrm{Na}$ \\
\hline \multirow[t]{3}{*}{1} & 22.07.1988 & 0,39 & 0,00 & 0,00 & 0,00 & 0,00 & 0,00 \\
\hline & 14.12.1988 & 41,14 & 88,60 & 26,30 & 19,00 & 4,00 & 3,00 \\
\hline & 22.12.1988 & 52,02 & 53,63 & 41,62 & 26,24 & 5,84 & 4,21 \\
\hline \multirow[t]{3}{*}{2} & 22.07.1988 & 2,59 & 0,00 & 0,36 & 0,19 & 0,01 & 0,04 \\
\hline & 14.12.1988 & 14,99 & 71,03 & 5,18 & 3,04 & 0,67 & 0,51 \\
\hline & 22.12.1988 & 42,33 & 48,70 & 14,75 & 2,75 & 2,56 & 1,69 \\
\hline \multirow[t]{2}{*}{8} & 14.12.1988 & 58,30 & 75,50 & 35,67 & 21,75 & 4,86 & 2,76 \\
\hline & 22.12.1988 & 45,01 & 55,56 & 37,35 & 25,18 & 3,54 & 2,19 \\
\hline \multirow[t]{2}{*}{6} & 14.12.1988 & 44,72 & 66,67 & 32,04 & 20,19 & 8,17 & 6,14 \\
\hline & 22.12.1988 & 51,71 & 30,09 & 33,42 & 27,53 & 5,03 & 2,40 \\
\hline \multirow[t]{2}{*}{5} & 14.12.1988 & 37,19 & 71,43 & 14,19 & 43,47 & 3,08 & 2,02 \\
\hline & 22.12.1988 & 43,81 & 27,62 & 20,40 & 12,93 & 2,30 & 1,49 \\
\hline \multirow[t]{2}{*}{4} & 14.12.1988 & 16,43 & 72,11 & 2,53 & 2,18 & 0,86 & 0,42 \\
\hline & 22.12 .1988 & 12,93 & 39,01 & 4,75 & 3,10 & 0,49 & 0,23 \\
\hline \multirow[t]{2}{*}{3} & 14.12.1988 & 0,00 & k. A. & 0,00 & 0,00 & 0,00 & 0,00 \\
\hline & 22.12 .1988 & 0,49 & 70,00 & 0,19 & 0,00 & 0,48 & 0,04 \\
\hline
\end{tabular}

Tabelle 7-9: DOC- und Kationen-Konzentrationen in \% der Gesamtmenge in der Fraktion $<50.000$ und $>1000$ u (2. und 3. Retentat), Lysimeter $1-6$ und 8

\begin{tabular}{|c|c|c|c|c|c|c|c|}
\hline \multirow[b]{2}{*}{ Lysimeter } & \multirow[b]{2}{*}{$\begin{array}{l}\text { Datum der } \\
\text { Probenahme }\end{array}$} & \multicolumn{6}{|c|}{ Retentat $<50.000 \mathrm{u}>1000 \mathrm{u}$} \\
\hline & & DOC & $\mathrm{Fe}$ & $\begin{array}{l}\mathrm{Ca} \\
\% \\
\end{array}$ & Mg & $\mathbf{K}$ & $\mathrm{Na}$ \\
\hline \multirow[t]{3}{*}{1} & 22.07.1988 & 21,50 & 64,29 & 6,07 & 3,27 & 0,33 & 1,00 \\
\hline & 14.12.1988 & 4,51 & 4,10 & 1,02 & 1,11 & 1,07 & 1,38 \\
\hline & 22.12.1988 & 8,44 & 0,00 & 0,98 & 0,00 & 0,09 & 0,05 \\
\hline \multirow[t]{3}{*}{2} & 22.07.1988 & 5,07 & 100,00 & 1,46 & 0,32 & 0,10 & 0,21 \\
\hline & 14.12.1988 & 6,58 & 13,35 & 4,40 & 1,97 & 0,37 & 0,28 \\
\hline & 22.12.1988 & 32,00 & 4,58 & 24,91 & 23,60 & 26,62 & 1,16 \\
\hline \multirow[t]{2}{*}{8} & 14.12.1988 & 0,91 & 0,00 & 0,11 & 0,21 & 0,11 & 0,09 \\
\hline & 22.12.1988 & 2,40 & 0,00 & 1,90 & 1,81 & 0,69 & 0,58 \\
\hline \multirow[t]{2}{*}{6} & 14.12.1988 & 1,53 & 0,00 & 0,66 & 1,84 & 1,00 & 0,53 \\
\hline & 22.12.1988 & 21,09 & 19,54 & 15,09 & 15,85 & 6,53 & 3,99 \\
\hline \multirow[t]{2}{*}{5} & 14.12.1988 & 0,00 & 0,71 & 4,13 & 2,80 & 2,60 & 2,49 \\
\hline & 22.12.1988 & 4,29 & 0,00 & 3,82 & 2,58 & 0,00 & 2,37 \\
\hline \multirow[t]{2}{*}{4} & 14.12.1988 & 1,38 & 0,00 & 0,35 & 0,63 & 0,59 & 0,46 \\
\hline & 22.12.1988 & 0,24 & 0,00 & 0,00 & 0,00 & 0,05 & 0,08 \\
\hline \multirow[t]{2}{*}{3} & 14.12.1988 & 5,80 & k. A. & 0,80 & 0,69 & 0,46 & 0,40 \\
\hline & 22.12.1988 & 6,15 & 1,70 & 5,04 & 4,73 & 3,75 & 5,07 \\
\hline
\end{tabular}


Tabelle 7-10: DOC- und Kationen-Konzentrationen in \% der Gesamtmenge in der Fraktion $<1000$ u (4. Filtrat und Dialysat), Lysimeter $1-6$ und 8

\begin{tabular}{|c|c|c|c|c|c|c|c|}
\hline \multirow[b]{2}{*}{ Lysimeter } & \multirow[b]{2}{*}{$\begin{array}{c}\text { Datum der } \\
\text { Probenahme }\end{array}$} & \multicolumn{6}{|c|}{ Filtrat/Dialysat < $1.000 \mathrm{u}$} \\
\hline & & DOC & $\mathrm{Fe}$ & $\begin{array}{c}\mathrm{Ca} \\
\% \\
\end{array}$ & Mg & $\mathbf{K}$ & $\mathrm{Na}$ \\
\hline \multirow[t]{3}{*}{1} & 22.07.1988 & 88,91 & 0,00 & 94,21 & 98,66 & 104,67 & 102,34 \\
\hline & 14.12.1988 & 40,12 & 2,49 & 53,22 & 65,52 & 97,60 & 94,18 \\
\hline & 22.12.1988 & 45,91 & 0,00 & 67,95 & 72,90 & 93,27 & 57,92 \\
\hline \multirow[t]{3}{*}{2} & 22.07.1988 & 98,83 & 0,00 & 102,59 & 106,80 & 99,73 & 108,14 \\
\hline & 14.12.1988 & 59,26 & 24,28 & 81,26 & 97,89 & 86,43 & 103,46 \\
\hline & 22.12.1988 & 32,78 & 6,47 & 80,37 & 86,23 & 84,48 & 74,19 \\
\hline \multirow[t]{2}{*}{8} & 14.12.1988 & 42,25 & 0,34 & 65,68 & 76,08 & 105,50 & 96,05 \\
\hline & 22.12.1988 & 49,90 & 0,00 & 77,63 & 84,71 & 80,74 & 66,40 \\
\hline \multirow[t]{2}{*}{6} & 14.12.1988 & 41,93 & 5,00 & 69,22 & 76,05 & 105,84 & 94,62 \\
\hline & 22.12.1988 & 32,13 & 1,38 & 69,39 & 102,90 & 96,96 & 71,53 \\
\hline \multirow[t]{2}{*}{5} & 14.12.1988 & 65,99 & 1,90 & 95,15 & 64,94 & 95,51 & 100,88 \\
\hline & 22.12.1988 & 67,91 & 3,00 & 104,83 & 84,06 & 73,49 & 67,72 \\
\hline \multirow[t]{2}{*}{4} & 14.12.1988 & 72,60 & 0,00 & 95,60 & 90,94 & 90,94 & 100,14 \\
\hline & 22.12.1988 & 69,30 & 0,00 & 122,85 & 106,05 & 85,69 & 71,46 \\
\hline \multirow[t]{2}{*}{3} & 14.12.1988 & 69,57 & k. A. & 103,24 & 105,35 & 95,39 & 103,62 \\
\hline & 22.12.1988 & 67,23 & 7,00 & 114,72 & 115,66 & 99,84 & 74,36 \\
\hline
\end{tabular}

Aus innen wird deutlich, dass die mit dem Sickerwasser aus den Lysimetern eluierte organische Substanz hauptsächlich in zwei Fraktionen auftritt: 1.) in dem Retentat $>50.000 \mathrm{u}$ und 2.) in dem Filtrat/Dialysat < $1000 \mathrm{u}$. Die Fraktionen 50.000 bis $1000 \mathrm{u}$ machen demgegenüber nur $5 \%$ des Ausgangsgehaltes an DOC aus. Bei den Lysimetern mit reinem Kompost (Großlysimeter 1, 2 und Kleinlysimeter 8) sind zwischen 30 und $58 \%$ des DOC-Gehaltes in der Fraktion $>50.000$ u enthalten, wobei die Werte für 2 geringer sind als die Werte für 1 und 8.

In den Kleinlysimetern 3 bis 8 sinken die DOC-Gehalte > 50.000 u mit abnehmendem Kompostgehalt der Lysimeter stark ab. Das Sickerwasser von 7 enthält keine gelösten organischen Kohlenstoffverbindungen der Größe > 50.000 u mehr, und in den Sickerwasserproben von 3 bestehen trotz rund $31 \%$ Kompost-Anteil der Lysimeter-Füllung nur 0,5\% des insgesamt im Sickerwasser enthaltenen DOC aus dem Retentat $>50.000 \mathrm{u}$. Entsprechend steigen die prozentualen DOC-Anteile der Fraktion < $1000 \mathrm{u}$ mit sinkenden KompostGehalten der Lysimeter-Füllung an.

Das nach der Beregnung der Großlysimeter erhaltene Sickerwasser vom 07.07.88 enthält abweichend von den genannten Ergebnissen deutlich geringere DOC-Anteile > $50.000 \mathrm{u}$. In diesen schwächer gefärbten Sickerwasser-Proben mit vergleichsweise geringen DOC- und Ionen-Gehalten werden überwiegend organische Kohlenstoffverbindungen < 1000 u nachgewiesen. Hier ist zu vermuten, dass die nur kurze Dauer der Sickerwasserpassage nicht ausreichend gewesen ist, um hochmolekulare organische Verbindungen in Lösung zu bringen.

Durch den höheren Anteil mineralischer Substanz in den Löss-Mischungen werden die hochmolekularen organischen Verbindungen möglicherweise sowohl durch mechanische Filterung als auch durch Sorption an der anorganischen Matrix vor der Auswaschung 
bewahrt. Die organischen Kohlenstoffverbindungen $>50.000 \mathrm{u}$ bilden dunkelbraun gefärbte Suspensionen, während die Filtrate $<50.000$ u eine hellgelbe Färbung besitzen.

Die weitere Auftrennung der Filtrate/Dialysate mit Hilfe des Membranfilters YC 05 lieferte farblose Filtrate mit geringen DOC-Gehalten. Die Tabellen 7-11 und 7-12 bringen diese Ergebnisse für Lysimeter 1. Hierbei ist der überwiegende Teil des DOC der Fraktion $<1000$ u, $91-97 \%$, im Retentat $>500$ u zurückgehalten worden ist. Der gefärbte Anteil organischer Substanz der Fraktion < $1000 \mathrm{u}$ ist danach seiner Molekülgröße nach in die Fraktion des Massenbereichs 1000 bis 500 u zu einzuordnen.

Tabelle 7-11:Fortsetzung der Ultrafiltration mit dem Filtertyp

YC 05 (nominelle Trenngrenze $500 \mathrm{u}$ ) mit dem 4. Filtrat der

Probe von Lysimeter 1 vom 22.12.88

\begin{tabular}{|c|c|c|c|c|c|c|c|c|c|c|c|c|c|}
\hline $\begin{array}{l}\text { Probe vom } \\
22.12 .1988 \\
\end{array}$ & \begin{tabular}{|l} 
Volumen \\
$\mathrm{ml}$
\end{tabular} & $\mathrm{mg} / \mathrm{l}$ & $\begin{array}{l}\mathrm{DOC} \\
\mathrm{mg}\end{array}$ & $\%$ & $\mathrm{mg} / \mathrm{l}$ & $\begin{array}{l}\mathrm{Ca} \\
\mathrm{mg}\end{array}$ & $\%$ & $\mathrm{mg} / \mathrm{l}$ & $\begin{array}{l}\mathrm{K} \\
\mathrm{mg} \\
\end{array}$ & $\%$ & $\mathrm{mg} / \mathrm{l}$ & $\begin{array}{l}\mathrm{Na} \\
\mathrm{mg}\end{array}$ & $\%$ \\
\hline 4. $F$ & 150 & 241,50 & 36,23 & 100,00 & 59,62 & 8,94 & 100,00 & 622,49 & 93,37 & 100,00 & 122,7 & 18,41 & 100,00 \\
\hline 5. $R$ & 63 & 498,50 & 31,41 & 86,70 & & & & & & & & & \\
\hline $5.1 \mathrm{~F}$ & 72 & 8,90 & 0,64 & 1,80 & 5,8 & 0,42 & 4,67 & 288,29 & 20,76 & 22,23 & 58,93 & 4,24 & 23,05 \\
\hline $5.2 \mathrm{~F}$ & 51 & 16,90 & 0,86 & 2,40 & & & & & & & & & \\
\hline 5. D & 100 & 16,60 & 1,66 & 4,60 & & & & & & & & & \\
\hline
\end{tabular}

Tabelle 7-12: Durchführung der Ultrafiltration mit zwei Filtertypen BM 500 (nominelle Trenngrenze $50.000 \mathrm{u}$ ) und YC 05 (nominelle Trenngrenze $500 \mathrm{u}$ ) mit dem Sickerwasser von Lysimeter 1 vom 17.04.89

\begin{tabular}{|c|c|c|c|c|c|c|c|c|c|c|c|c|c|c|c|c|}
\hline $\begin{array}{l}\text { Probe vom } \\
17.04 .1989 \\
\end{array}$ & \begin{tabular}{|l} 
Volumen \\
$\mathrm{ml}$
\end{tabular} & $\mathrm{mg} / \mathrm{l}$ & $\begin{array}{l}\mathrm{Ca} \\
\mathrm{mg}\end{array}$ & $\%$ & $\mathrm{mg} / \mathrm{l}$ & $\begin{array}{l}\mathrm{Mg} \\
\mathrm{mg}\end{array}$ & $\%$ & $\mathrm{mg} / \mathrm{l}$ & $\begin{array}{l}\mathrm{Fe} \\
\mathrm{mg}\end{array}$ & $\%$ & $\mathrm{mg} / \mathrm{l}$ & $\begin{array}{l}\mathrm{K} \\
\mathrm{mg}\end{array}$ & $\%$ & $\mathrm{mg} / \mathrm{l}$ & $\begin{array}{l}\mathrm{Na} \\
\mathrm{mg}\end{array}$ & $\%$ \\
\hline sw & 200 & 118,81 & 23,76 & 100 & 23 & 4,60 & 100 & 3,1 & 0,62 & 100 & 730 & 146,00 & 100 & 133,69 & 26,74 & 100 \\
\hline 1. $R$ & 100 & 112,84 & 11,28 & 47,49 & 16,25 & 1,63 & 35,33 & 5,5 & 0,55 & 88,71 & 138,12 & 13,81 & 9,46 & 22,77 & 2,28 & 8,52 \\
\hline 4. $R$ & 50 & 80,97 & 4,05 & 17,04 & 16,5 & 0,83 & 17,93 & 0,54 & 0,03 & 4,35 & 183,14 & 9,16 & 6,27 & 32,42 & 1,62 & 6,06 \\
\hline 5. $R$ & 50 & 93,66 & 4,68 & 19,71 & 25,5 & 1,28 & 27,72 & 0,39 & 0,02 & 3,15 & 303,71 & 15,19 & 10,40 & 86,25 & 4,31 & 16,13 \\
\hline 5. F & 200 & 3,67 & 0,73 & 3,09 & 1 & 0,20 & 4,35 & 0,51 & 0,10 & 16,45 & 327,31 & 65,46 & 44,84 & 86,45 & 17,29 & 64,66 \\
\hline
\end{tabular}

\subsubsection{Gelöste anorganische Bestandteile}

In den Tabellen 7-4 bis 7-12 sind zusammen mit den DOC-Werten für die einzelnen Fraktionen die Gehalte an Kationen aufgeführt. Die Anionen $\mathrm{Cl}, \mathrm{NO}_{3}, \mathrm{SO}_{4}, \mathrm{PO}_{4}$ und $\mathrm{HCO}_{3}$, die nur stichprobenhaft in einigen 4. Filtraten ermittelt wurden, sind in Tabelle 7-13 aufgeführt. 
Tabelle 7-13: Anionen-Konzentrationen im 4. Filtrat, Stichproben

\begin{tabular}{|c|c|c|c|c|}
\hline Lysimeter & $\begin{array}{c}\text { Datum der } \\
\text { Probenahme }\end{array}$ & $\begin{array}{l}\mathrm{SW} \\
\mathrm{mg} / \mathrm{l}\end{array}$ & $\begin{array}{c}\text { 4. Filtrat }<1000 \mathrm{u} \\
\mathrm{mg} / \mathrm{l}\end{array}$ & $\%$ \\
\hline & & & $\mathrm{Cl}$ & \\
\hline 1 & 07.07.1988 & 23,44 & 24,05 & 102,60 \\
\hline 2 & 07.07.1988 & 250,42 & 252,24 & 100,73 \\
\hline \multirow[t]{2}{*}{1} & \multirow[t]{2}{*}{ 14.12.1988 } & 6,25 & 6,26 & 100,16 \\
\hline & & \multicolumn{3}{|c|}{$\mathrm{PO}_{4}$} \\
\hline 1 & 14.12.1988 & 25,76 & 17,48 & 67,86 \\
\hline 1 & 22.12.1988 & 40,20 & 19,01 & 47,29 \\
\hline 2 & 14.12.1988 & 19,78 & 8,74 & 44,19 \\
\hline 3 & 14.12 .1988 & 22,08 & 6,75 & 30,56 \\
\hline 4 & 14.12.1988 & 8,34 & 7,05 & 84,56 \\
\hline \multirow[t]{2}{*}{8} & \multirow[t]{2}{*}{ 14.12.1988 } & 22,08 & 14,87 & 67,36 \\
\hline & & \multicolumn{3}{|c|}{$\mathrm{NO}_{3}$} \\
\hline 1 & 14.12.1988 & 424,95 & 376,26 & 88,54 \\
\hline 2 & 14.12.1988 & 942,87 & 973,85 & 103,29 \\
\hline \multirow[t]{2}{*}{3} & \multirow[t]{2}{*}{ 14.12.1988 } & 393,97 & 376,26 & 95,51 \\
\hline & & \multicolumn{3}{|c|}{$\mathrm{HCO}_{3}$} \\
\hline 1 & 07.07.1988 & 269,62 & 296,46 & 109,95 \\
\hline \multirow[t]{2}{*}{2} & \multirow[t]{2}{*}{ 07.07.1988 } & 661,24 & 628,30 & 95,02 \\
\hline & & \multicolumn{3}{|c|}{$\mathrm{SO}_{4}$} \\
\hline 1 & 07.07.1988 & 126,00 & 47,00 & 37,30 \\
\hline \multirow[t]{2}{*}{2} & \multirow[t]{2}{*}{ 07.07.1988 } & 780,00 & 775,00 & 99,36 \\
\hline & & \multicolumn{3}{|c|}{$\mathrm{SiO}_{4}$} \\
\hline 1 & 14.12.1988 & 227,17 & 174,72 & 76,91 \\
\hline 1 & 22.12.1988 & 145,87 & 139,97 & 95,96 \\
\hline 2 & 14.12 .1988 & 72,77 & 49,83 & 68,47 \\
\hline 4 & 14.12.1988 & 271,09 & 78,67 & 29,02 \\
\hline 3 & 14.12.1988 & 55,40 & 44,91 & 81,07 \\
\hline
\end{tabular}

Bei Vorliegen freier Kat- und Anionen in der Lösung ist deren ungehinderte Passage durch die verwendeten Membranfilter zu erwarten. Lediglich bei der Verwendung des Filters YC 05 ist mit einer Retardation dar Passage bei stark hydratisierten Anionen zu rechnen. Lassen sich Kat- und Anionen in den bei der Ultrafiltration gewonnenen Fraktionen $>1000 \mathrm{u}$ nachweisen, so liefert dies einen Hinweis auf das Vorliegen von Bindungen zwischen der in diesen Fraktionen enthaltenen hochmolekularen organischen Substanz und den nachgewiesenen Kationen. Hierbei ist allerdings zu berücksichtigen, dass das verwendete Dialysevolumen für die vollständige Auswaschung der Salze nicht ausreichend war, wie im Abschnitt 7.2.1. Methodik begründet worden ist.

Als mögliche Bindungsformen für die in den Retentaten > $1000 \mathrm{u}$ vorliegenden lonen an die organischen Komponenten kommen in Betracht:

- Physikosorption (Adsorption, VAN-DER-WAALS-Kräfte)

- Chemisorption an Austausch-Positionen

- Komplexbildung

\subsubsection{Anionen}

Nach Tabelle 7-13 sind die Ausgangsgehalte der Sickerwasser-Proben und Filtrate an den Anionen $\mathrm{Cl}, \mathrm{NO}_{3}, \mathrm{HCO}_{3}$ und $\mathrm{SO}_{4}$ im Großlysimeter 1 geringer als in 2, was bereits damit 
erklärt worden ist, dass sich der Kompost in Lysimeter 2 noch in einem jüngeren „Reifestadium" als im Lysimeter 1 befindet.

Die Anionen $\mathrm{Cl}, \mathrm{NO}_{3}, \mathrm{HCO}_{3}$ und $\mathrm{SO}_{4}$ der Ausgangslösungen von Lysimeter 2 gehen nahezu vollständig in die Filtrate < $1000 \mathrm{u}$ über. Sie liegen damit offensichtlich in freier Form vor. Dies ist zugleich ein wichtiger Hinweis auf die Tatsache, dass trotz der nicht erschöpfenden Dialyse-Wassermengen, die Bedingungen für den Übergang der freien Ionen in die Fraktion $<1000 \mathrm{u}$ völlig ausreichend gewesen sind. Anders ist die Situation beim Phosphat. Die Ausgangsgehalte bei den aus reinem Kompost bestehenden Lysimetern 1, 2 und 8 streuen zwischen 6,5 und $13 \mathrm{mg} \mathrm{P/l}$ und 44 bis $68 \%$ davon erscheinen im 4. Filtrat wieder. Der Rest ist offenbar an die Komplexe der gröberen Fraktionen gebunden. Bei den Kleinlysimetern deutet sich die Tendenz an, dass der freie Phosphat-Anteil mit zunehmendem Grad der Lössbeimischung absinkt.

\subsubsection{Kationen}

Die Ausgangsgehalte der Sickerwasser-Proben sind bereits in Tabelle 7-4 zusammengefasst dargestellt.

Der freie Anteil an Kationen, der die Ultrafilter-Sequenz bis zur Fraktion $<1000$ u passiert, beträgt im Durchschnitt bei
$\mathrm{Na} 96 \%$
K $94 \%$
$\operatorname{Mg} 82 \%$
Ca $78 \%$
Fe $0,2 \%$

Diese Reihenfolge ist plausibel und entspricht der Bindungsaffinität der Kationen in Abhängigkeit von den lonenradien und Ladungsstärken $(\mathrm{Na}<\mathrm{K}<\mathrm{Mg}<\mathrm{Ca}<\mathrm{Fe})$. Trotzdem ist zu fragen, in welchen Fraktionen der prozentuale Rest gebunden ist.

Das Beispiel des Lysimeters 1 zeigt Tabelle 7-14:

Tabelle 7-14: Kationenverteilung, Angaben in \% der Ausgangslösung, Lysimeter 1

\begin{tabular}{|c|c|c|c|c|}
\hline Kation & $\begin{array}{c}\text { "Freie“ Kationen im } \\
\text { Filtrat < } \mathbf{1 0 0 0} \mathbf{u}\end{array}$ & $\begin{array}{c}\text { Kationen im } \\
\text { Retentat } \mathbf{5 0 . 0 0 0} \mathbf{u}\end{array}$ & $\begin{array}{c}\text { Kationen im Retentat } \\
\mathbf{5 0 . 0 0 0} \mathbf{u}-\mathbf{1 0 0 0} \mathbf{u}\end{array}$ & $\begin{array}{c}\text { Rechn. } \\
\text { Rest }\end{array}$ \\
\hline $\mathrm{Na}$ & 88 & 5 & 1 & 6 \\
\hline $\mathrm{K}$ & 89 & 5 & 1 & 5 \\
\hline $\mathrm{Mg}$ & 66 & 23 & 1 & 10 \\
\hline $\mathrm{Ca}$ & 52 & 32 & 1 & 15 \\
\hline $\mathrm{Fe}$ & 5 & 89 & 2 & 4 \\
\hline
\end{tabular}

Die gebundenen Kationen befinden sich im Retentat $>50.000 \mathrm{u}$. Die Gegenüberstellung des rechnerischen Restes mit den geringen Mengen, die sich im Retentat 1000 bis $50.000 \mathrm{u}$ befinden zeigt, dass bei den mobilen Kationen methodisch bedingte Verluste aufgetreten sind (ähnliche Verluste sind auch bei den Anionen zu festzustellen).

Die Tabellen 7-8 bis 7-10 lassen erkennen, dass die in den beiden Retentaten zurückgehaltenen Kationen (\% der Menge in der Ausganglösung) mit den in diesen Fraktionen enthaltenen Mengen an organischer Substanz einhergehen. Eine Ausnahme macht dabei das Eisen, das fast vollständig im gröbsten Retentat zurückgehalten wird.

In der Reihe Kleinlysimeter mit zunehmendem Löss-Anteil in der Lysimeter-Füllung (Lysimeter $6,5,4,3$ ) verschiebt sich bei zunehmendem Löss-Gehalt die Retention vom Retentat $>50.000$ u zum Retentat 50.000 bis $1000 \mathrm{u}$. Auch hier ist eine Zunahme der Kationen mit steigenden DOC-Mengen festzustellen. 
In dem nach der Beregnung der Großlysimeter erhaltenen Sickerwasser vom 07.07.88 aus Lysimeter 1 wurden überwiegend organische Kohlenstoffverbindungen $<1000$ u nachgewiesen. Die Kationen in dieser Sickerwasser-Probe verteilen sich auf das Retentat 50.000 bis 1000 u (0,3 bis 5,6\% der Kationen der Ausgangslösung) und das Filtrat < 1000 u $(94,4$ bis $99 \%$ der Kationen der Ausgangslösung). Zur Erklärung könnte auf die bereits früher gegebene Deutung zurückgegriffen werde, dass die Passagedauer des Sickerwassers zu kurz gewesen ist, um hochmolekulare organische Verbindungen in Lösung zu bringen.

In Tabelle 7-15 sind die Quotienten der Kationen-Äquivalente in der Ausgangslösung und den gewonnenen Fraktionen zusammengestellt. Zwischen der Ausgangslösung und dem 4. Filtrat besteht bei dieser Betrachtung nur ein sehr geringer Unterschied.

In der Tabelle 7-16 sind Daten, die als Ausreißer weit außerhalb der Datenpopulation lagen, hier besonders die Sickerwässer vom 07.07.88, weggelassen worden, um Tendenzen deutlicher in Erscheinung treten zu lassen.

Tabelle 7-15: lonenäquivalent-Verhältnisse im Sickerwasser und in den Fraktionen der Ultrafiltration, Mittelwerte der gesamten Proben

\begin{tabular}{l|cccccc} 
Fraktion & $\mathbf{C a} / \mathbf{M g}$ & $\mathbf{C a} / \mathbf{K}$ & $\mathbf{C a} / \mathbf{N a}$ & $\mathbf{M g} / \mathbf{K}$ & $\mathbf{K} / \mathbf{N a}$ & $\mathbf{M g} / \mathbf{N a}$ \\
\hline \multirow{2}{*}{$\mathbf{S W}$} & 2,09 & 0,29 & 0,73 & 0,15 & 2,70 & 0,36 \\
& & & & & & \\
> 50.000 u & 3,52 & 2,62 & 7,60 & 0,99 & 3,73 & 3,00 \\
Quotient SW & 1,68 & 8,92 & 10,35 & 6,72 & 1,38 & 8,31 \\
& & & & & & \\
50.000 u bis $\mathbf{1 0 0 0 ~ u}$ & 2,98 & 1,39 & 3,67 & 0,31 & 2,72 & 0,77 \\
Quotient SW & 1,43 & 4,72 & 4,99 & 2,11 & 1,01 & 2,14 \\
& & & & & & \\
< $\mathbf{1 0 0 0}$ u & 2,00 & 0,28 & 0,74 & 0,14 & 2,96 & 0,37 \\
Quotient SW & 0,96 & 0,96 & 1,01 & 0,96 & 1,10 & 1,04 \\
& & & & & & \\
> 50.000 u säurefällbar & 5,37 & 1,56 & 4,28 & 0,39 & 4,13 & 1,77 \\
Quotient SW & 2,57 & 5,30 & 5,83 & 2,65 & 1,53 & 4,90
\end{tabular}

Tabelle 7-16: Ionenäquivalent-Verhältnisse im Sickerwasser und in den Fraktionen der Ultrafiltration, Mittelwerte ohne die Proben vom 07.07.88 und „Ausreißer“"

\begin{tabular}{l|cccccc} 
Fraktion & $\mathbf{C a} / \mathbf{M g}$ & $\mathbf{C a} / \mathbf{K}$ & $\mathbf{C a} / \mathbf{N a}$ & $\mathbf{M g} / \mathbf{K}$ & $\mathbf{K} / \mathbf{N a}$ & $\mathbf{M g} / \mathbf{N a}$ \\
\hline SW & 2,09 & 0,31 & 0,72 & 0,15 & 2,51 & 0,35 \\
& & & & & & \\
> 50.000 u & 3,00 & 1,73 & 5,72 & 0,63 & 3,44 & 2,04 \\
Quotient SW & 1,43 & 5,65 & 7,95 & 4,12 & 1,37 & 5,80 \\
& & & & & & \\
$\mathbf{5 0 . 0 0 0 ~ u ~ b i s ~ 1 0 0 0 ~ u}$ & 3,06 & 0,71 & 2,10 & 0,15 & 2,81 & 0,57 \\
Quotient SW & 1,46 & 2,31 & 2,92 & 1,01 & 1,12 & 1,61 \\
& & & & & & \\
< $\mathbf{1 0 0 0}$ u & 1,90 & 0,25 & 0,53 & 0,13 & 2,44 & 0,29 \\
Quotient SW & 0,91 & 0,80 & 0,74 & 0,85 & 0,97 & 0,81 \\
& & & & & & \\
> 50.000 u säurefällbar & 5,37 & 1,56 & 4,28 & 0,39 & 4,13 & 1,77 \\
Quotient SW & 2,57 & 5,10 & 5,95 & 2,56 & 1,65 & 5,03
\end{tabular}


Alle Quotienten zwischen den Eralkali- und Alkali-Ionen zeigen, dass im ersten Retentat eine bevorzugte Bindung beider Erdalkali-Kationen stattgefunden hat, im 2. Retentat nur eine des $\mathrm{Ca}$. Das $\mathrm{Ca} / \mathrm{Mg}$-Verhältnis ist dabei - besonders wenn man den unteren Teil der Tabelle betrachtet - recht konstant. Das ist aber bei dem säurefällbaren Anteil des Retentats $>50.000 \mathrm{u}$ anders, in den das Ca bevorzugt gegenüber dem Mg eingebaut ist.

Das K/Na-Verhältnis zeigt durchweg eine - wenn auch nur schwache - Bevorzugung des $\mathrm{K}$ gegenüber dem $\mathrm{Na}$ beim Einbau in Retentate und besonders in den säurefällbaren Anteil des Retentats $>50.000 \mathrm{u}$.

Die weitere Fraktionierung mit Hilfe des Membranfilters YC 05 liefert für das Retentat größer $500 \mathrm{u}$ neben den hohen Gehalten organischer Substanz auch eine Retardation der noch im 4. Filtrat enthaltenen Kationen. Die im 5. Filtrat vorliegenden Kationengehalte in \% der Gehalte in der Ausgangslösung für die untersuchten Sickerwasserproben des Lysimeters 1 zeigt die folgende Tabelle im Vergleich zu den "freien“ Kationen < $1000 \mathrm{u}$.

Tabelle 7-17: Vergleich der Kationen in \% der Konzentration der Sickerwasser-Probe in den Fraktionen $<1000 \mathrm{u}$ und $<$ $500 \mathrm{u}$, Lysimeter 1

\begin{tabular}{|c|c|c|}
\hline Kation & $\begin{array}{c}\text { „Freie Kationen“ } \\
<\mathbf{1 0 0 0} \mathbf{u}\end{array}$ & $\begin{array}{c}\text { „Freie Kationen“ } \\
\mathbf{5 0 0} \mathbf{~ u}\end{array}$ \\
\hline $\mathrm{Na}$ & 88 & 52 \\
\hline $\mathrm{K}$ & 89 & 42 \\
\hline $\mathrm{Mg}$ & 66 & 4 \\
\hline $\mathrm{Ca}$ & 52 & 4 \\
\hline
\end{tabular}

Dieses Ergebnis lässt die vorherige Bezeichnung der im Filtrat/Dialysat $<1000 \mathrm{u}$ vorliegenden Kationen als sogenannte „freie Kationen, sehr fragliche erscheinen. Offensichtlich besteht die Möglichkeit einer Kopplung von Kationen an die in der Fraktion 1000 bis $500 \mathrm{u}$ enthaltenen gefärbten niedermolekularen Verbindungen, wovon besonders wieder die Erdalkali-Kationen $\mathrm{Ca}$ und $\mathrm{Mg}$ und die Alkali-Kationen - wesentlich weniger - in der Reihenfolge $\mathrm{Na}-\mathrm{K}$ betroffen sind. Ob nun die Fraktionen $<500 \mathrm{u}$ als wirklich "frei“ zu bezeichnen sind, muss unter diesen Aspekten als fraglich hingestellt werden.

\subsubsection{Kationen-Anionen-Bilanz}

Tabelle 7-18 bringt die Gehalte an anorganischen Kationen und Anionen in den Sickerwässern verschiedener Entnahme-Zeitpunkte in mmol IE/l, geordnet nach der Gruppe der nur mit Kompost gefüllten Lysimeter 1, 2 und 8, gefolgt von den Kleinlysimetern 6 bis 3 mit zunehmendem Löss-Anteil in der Kompost-Löss-Mischung (siehe hierzu auch Kapitel 4.5.11). 
Tabelle 7-18: Kationen-Anionen-Bilanz und DOC in $\mathrm{mmol}$ IE/I und Anzahl an C-Atomen pro freie positive Valenz im Sickerwasser, Proben vom 07.07.88 (nur Lysimeter 1 und 2), 14. und 22.12.88, Lysimeter $1-6$ und 8

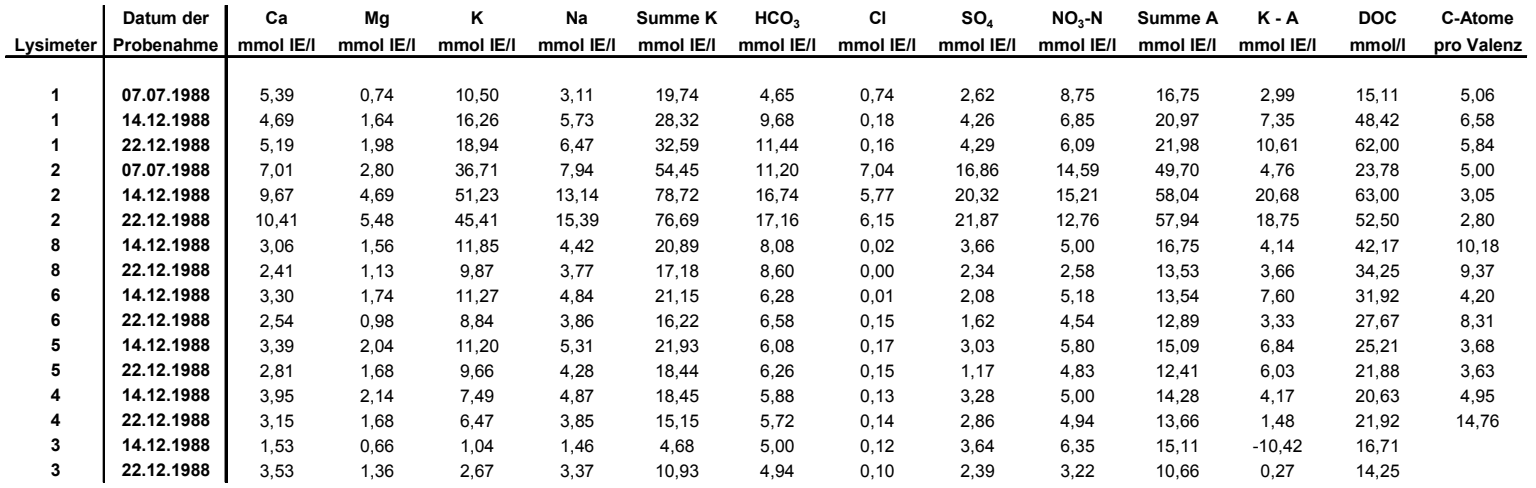

Die Abbildung 118 stellt die Werte für die Kationen-Anionen-Bilanz und den DOC in mmol $\mathrm{IE} / \mathrm{l}$ und die Anzahl an C-Atomen pro freie positive Valenz in den Sickerwasser-Proben vom 07.07.88 Lysimeter 1 und 2, 14. und 22.12.88 Lysimeter $1-6$ und 8 graphisch dar.

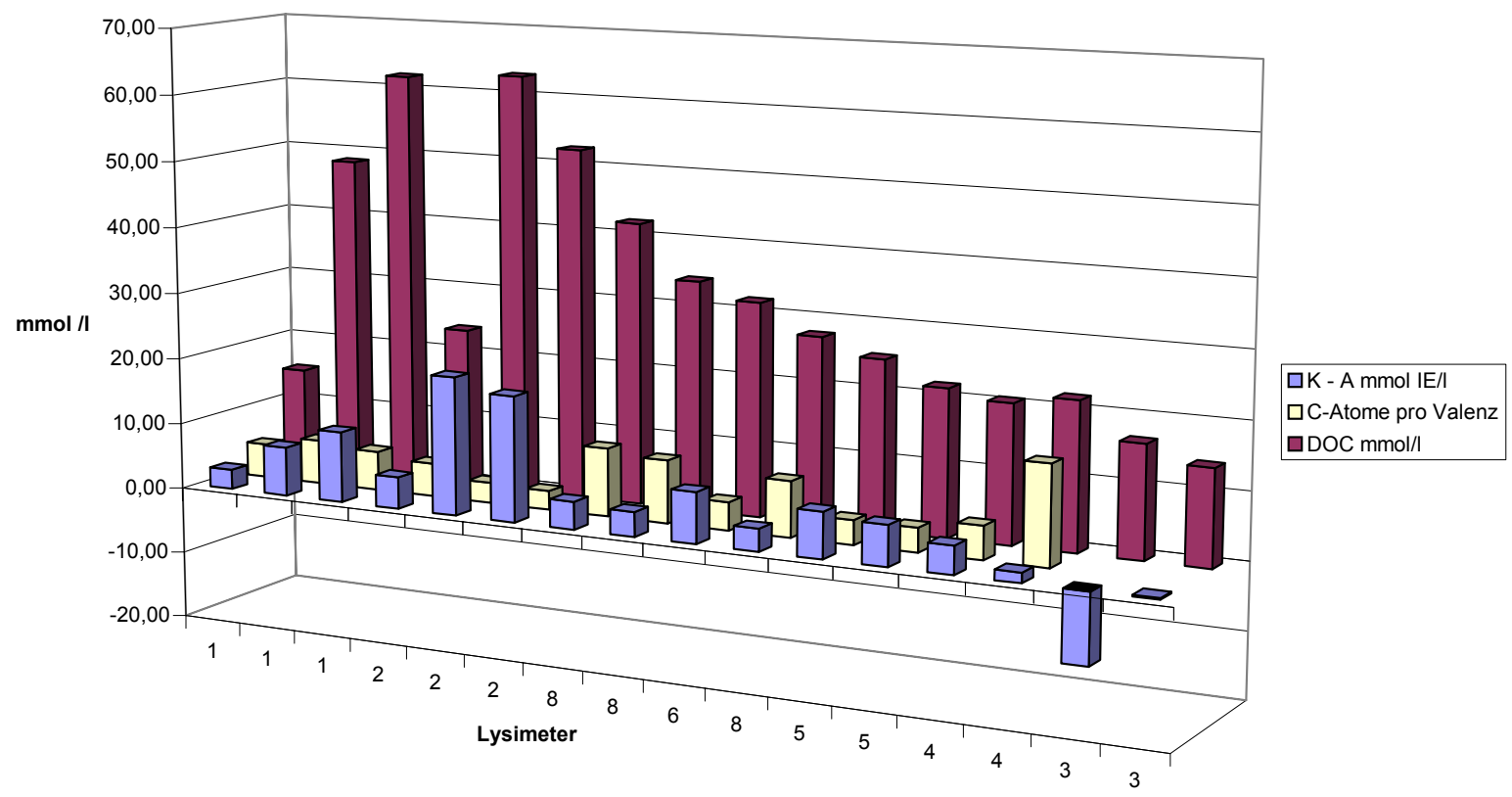

\begin{abstract}
Abbildung 118: Kationen-Anionen-Bilanz und DOC in mmol IE/l und Anzahl an C-Atomen pro freie positive Valenz im Sickerwasser, Proben vom 07.07.88 (nur Lysimeter 1 und 2), 14. und 22.12.88, Lysimeter $1-6$ und 8
\end{abstract}

Lassen wir die Sickerwasser-Werte des lössreichsten Lysimeters 3 außer Betracht, so ist überwiegend ein Überschuss der anorganischen Kationen über die anorganischen Anionen gegeben (Sp. 13), der durch organische Anionen zu kompensieren ist. Bei den KompostLysimetern ist im Durchschnitt ein Viertel der Kationen nicht durch anorganische Anionen kompensiert.

Um eine ungefähre Vorstellung darüber zu erhalten, wie viele der C-Atome einer negativen Valenz eines organischen Anions entsprechen, ist in Spalte 14 der totale Gehalt an Kohlen- 
stoff (DOC) in $\mathrm{mmol} / \mathrm{l}$ errechnet. In Spalte 15 ist dieser Gehalt durch die Kationen/AnionenBilanz dividiert. Im Durchschnitt entfallen 6 C-Atome auf eine negative Valenz. Dabei zeigt sich bei den Kompost-Lysimetern im Durchschnitt eine Zahl von 5 bis $6 \mathrm{C}$, gelegentlich auch weniger oder mehr pro negativer Valenz. Mit zunehmendem Löss-Beimischungsanteil wird die Differenz anorganische Kationen - anorganische Anionen kleiner, die Zahl der CAtome pro negativer Valenz streut stärker, bleibt aber im Durchschnitt bei 6 C-Atomen.

In Tabelle 7-19 ist eine Aufschlüsselung dieser summerischen Ergebnisse vorgenommen indem die Kationen-Anionen-Verteilung im Retentat 1 dargestellt ist. Wie bereits gesagt, befinden sich keine anorganischen Anionen darin. Alle Kationen sind durch organische Anionen kompensiert. Hier entfallen im Durchschnitt 8 C-Atome auf eine negative Valenz, also mehr als im Durchschnitt der gesamten wässrigen Probe. Zwischen den Kompost-Lysimetern und den Kompost-Löss-Mischlysimetern besteht auch in der Fraktion > 50.000 u kaum ein Unterschied.

Tabelle 7-19: Kationen-Anionen-Bilanz und DOC in $\mathrm{mmol}$ IE/I und Anzahl an C-Atomen pro freie positive Valenz in der Fraktion $>50.000$ u (1. Retentat) der Sickerwasser-Proben vom 07.07.88 (nur Lysimeter 1 und 2), 14. und 22.12.88, Lysimeter $1-6$ und 8

\begin{tabular}{|c|c|c|c|c|c|c|c|c|c|c|c|c|c|c|}
\hline Lysimeter & \begin{tabular}{|c|} 
Datum der \\
Probenahme \\
\end{tabular} & $\begin{array}{c}\mathrm{Ca} \\
\mathrm{mmol} \mathrm{IE} / \mathrm{I}\end{array}$ & $\begin{array}{c}\mathrm{Mg} \\
\mathrm{mmol} \mathrm{IE} / \mathrm{I}\end{array}$ & $\begin{array}{c}\mathrm{K} \\
\mathrm{mmol} \mathrm{IE} / \mathrm{I} \\
\end{array}$ & $\begin{array}{c}\mathrm{Na} \\
\mathrm{mmol} \text { IE/I }\end{array}$ & $\begin{array}{l}\text { Summe K } \\
\mathrm{mmol} \mathrm{IE} / \mathrm{I}\end{array}$ & $\begin{array}{c}\mathrm{HCO}_{3} \\
\mathrm{mmol} \mathrm{IE} / \mathrm{I}\end{array}$ & $\begin{array}{c}\mathrm{Cl} \\
\mathrm{mmol} \mathrm{IE} / \mathrm{I}\end{array}$ & $\begin{array}{c}\mathrm{SO}_{4} \\
\mathrm{mmol} \mathrm{IE} / \mathrm{I}\end{array}$ & $\begin{array}{c}\mathrm{NO}_{3}-\mathrm{N} \\
\mathrm{mmol} \\
\end{array}$ & $\begin{array}{l}\text { Summe A } \\
\mathrm{mmol} I \mathrm{IE} / \mathrm{I}\end{array}$ & $\begin{array}{c}\mathrm{K}-\mathrm{A} \\
\mathrm{mmol} \mathrm{IE} / \mathrm{I}\end{array}$ & $\begin{array}{c}\mathrm{DOC} \\
\mathrm{mmol} / \mathrm{I}\end{array}$ & $\begin{array}{c}\text { C-Atome } \\
\text { pro Valenz }\end{array}$ \\
\hline 1 & 07.07.1988 & 0,00 & 0,00 & 0,00 & 0,00 & 0,00 & 0,00 & 0,00 & 0,00 & 0,00 & 0,00 & 0,00 & 0,06 & \\
\hline 1 & 14.12.1988 & 1,23 & 0,31 & 0,65 & 0,17 & 2,37 & 0,00 & 0,00 & 0,00 & 0,00 & 0,00 & 2,37 & 19,92 & 8,41 \\
\hline 2 & 07.07.1988 & 0,03 & 0,01 & 0,00 & 0,00 & 0,04 & 0,00 & 0,00 & 0,00 & 0,00 & 0,00 & 0,04 & 0,62 & \\
\hline 2 & 14.12.1988 & 0,50 & 0,14 & 0,34 & 0,07 & 1,05 & 0,00 & 0,00 & 0,00 & 0,00 & 0,00 & 1,05 & 9,44 & 8,97 \\
\hline 2 & 22.12.1988 & 1,54 & 0,15 & 1,16 & 0,26 & 3,11 & 0,00 & 0,00 & 0,00 & 0,00 & 0,00 & 3,11 & 22,22 & 7,15 \\
\hline 8 & 14.12.1988 & 1,09 & 0,34 & 0,58 & 0,12 & 2,13 & 0,00 & 0,00 & 0,00 & 0,00 & 0,00 & 2,13 & 24,58 & 11,54 \\
\hline 5 & 14.12 .1988 & 0,48 & 0,88 & 0,34 & 0,11 & 1,82 & 0,00 & 0,00 & 0,00 & 0,00 & 0,00 & 1,82 & 9,37 & 5,16 \\
\hline 5 & 22.12.1988 & 0,57 & 0,22 & 0,22 & 0,06 & 1,08 & 0,00 & 0,00 & 0,00 & 0,00 & 0,00 & 1,08 & 9,58 & 8,90 \\
\hline 4 & 14.12.1988 & 0,10 & 0,05 & 0,06 & 0,02 & 0,23 & 0,00 & 0,00 & 0,00 & 0,00 & 0,00 & 0,23 & 3,39 & \\
\hline 4 & 22.12.1988 & 0,15 & 0,05 & 0,03 & 0,01 & 0,24 & 0,00 & 0,00 & 0,00 & 0,00 & 0,00 & 0,24 & 2,83 & \\
\hline 3 & 14.12.1988 & 0,00 & 0,00 & 0,00 & 0,00 & 0,00 & 0,00 & 0,00 & 0,00 & 0,00 & 0,00 & 0,00 & 0,00 & \\
\hline 3 & 22.12.1988 & 0,01 & 0,00 & 0,01 & 0,00 & 0,02 & 0,00 & 0,00 & 0,00 & 0,00 & 0,00 & 0,02 & 0,07 & \\
\hline
\end{tabular}

Die Abbildung 119 stellt die Werte für die Kationen-Anionen-Bilanz und den DOC in mmol IE/I und die Anzahl an C-Atomen pro freie positive Valenz im 1. Retentat der SickerwasserProben vom 07.07.88 Lysimeter 1 und 2, 14. und 22.12.88 Lysimeter 1 - 6 und 8 graphisch dar. 


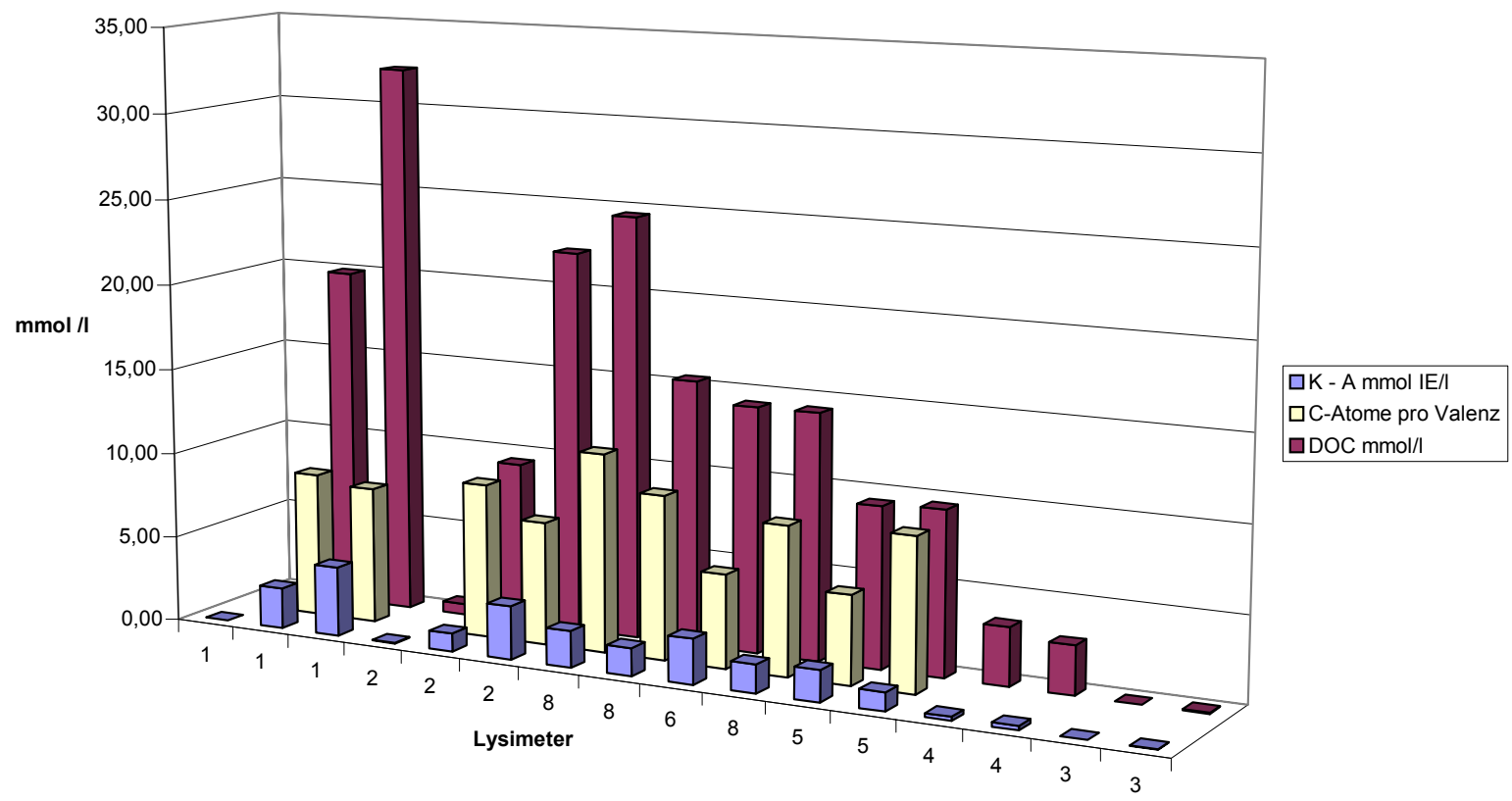

Abbildung 119: Kationen-Anionen-Bilanz und DOC in mmol IE/I und Anzahl an C-Atomen pro freie positive Valenz in der Fraktion $>50.000$ u (1. Retentat) der Sickerwasser-Proben vom 07.07.88 (nur Lysimeter 1 und 2), 14. und 22.12.88, Lysimeter $1-6$ und 8

Im Retentat 50.000 bis $1000 \mathrm{u}$ befinden sich ebenfalls keine anorganischen Anionen. Die Zahl der C-Atome je mmol organischer Anionen-Kapazität ist in dieser jedoch deutlich niedriger und liegt bei den Großlysimetern bei etwa 7. Bei den Kleinlysimetern geht sie sogar auf 3 zurück. Der Durchschnitt beträgt 5 . Die hier zugrunde gelegten Werte bringt Tabelle 720.

Tabelle 7-20: Kationen-Anionen-Bilanz und DOC in mmol

IE/I und Anzahl an C-Atomen pro freie positive Valenz in der

Fraktion $<50.000$ und $>1000$ u (2. und 3. Retentat) der

Sickerwasser-Proben vom 07.07.88 (nur Lysimeter 1 und 2),

14. und 22.12.88, Lysimeter $1-6$ und 8

\begin{tabular}{|c|c|c|c|c|c|c|c|c|c|c|c|c|c|c|}
\hline Lysimeter & $\begin{array}{c}\text { Datum der } \\
\text { Probenahme }\end{array}$ & $\begin{array}{c}\mathrm{Ca} \\
\mathrm{mmol} \mathrm{IE} / \mathrm{I}\end{array}$ & $\begin{array}{c}\mathrm{Mg} \\
\mathrm{mmol} \mathrm{IE} / \mathrm{I}\end{array}$ & $\begin{array}{c}\mathrm{K} \\
\mathrm{mmol} \mathrm{IE} / \mathrm{I}\end{array}$ & $\begin{array}{c}\mathrm{Na} \\
\mathrm{mmol} \mathrm{IE} / \mathrm{I}\end{array}$ & $\begin{array}{l}\text { Summe K } \\
\mathrm{mmol} \text { IE/I }\end{array}$ & $\begin{array}{c}\mathrm{HCO}_{3} \\
\mathrm{mmol} \mathrm{IE} / \mathrm{I}\end{array}$ & $\begin{array}{c}\mathrm{Cl} \\
\mathrm{mmol} \text { IE/I }\end{array}$ & $\begin{array}{c}\mathrm{SO}_{4} \\
\mathrm{mmol} \mathrm{IE} / \mathrm{I}\end{array}$ & $\begin{array}{c}\mathrm{NO}_{3}-\mathrm{N} \\
\mathrm{mmol} \\
\end{array}$ & $\begin{array}{l}\text { Summe A } \\
\mathrm{mmol} I E / /\end{array}$ & $\begin{array}{c}\mathrm{K}-\mathrm{A} \\
\mathrm{mmol} \mathrm{IE} / \mathrm{I}\end{array}$ & $\begin{array}{c}\mathrm{DOC} \\
\mathrm{mmol} / \mathrm{I}\end{array}$ & $\begin{array}{c}\text { C-Atome } \\
\text { pro Valenz }\end{array}$ \\
\hline 1 & 07.07.1988 & 0,1589 & 0,0346 & 0,0490 & 0,0335 & 0,28 & 0,00 & 0,00 & 0,00 & 0,00 & 0,00 & 0,28 & 3,10 & 11,23 \\
\hline 1 & 14.12.1988 & 0,0478 & 0,0183 & 0,1740 & 0,0791 & 0,32 & 0,00 & 0,00 & 0,00 & 0,00 & 0,00 & 0,32 & 2,18 & 6,84 \\
\hline 2 & 07.07.1988 & 0,1081 & 0,0142 & 0,0275 & 0,0179 & 0,17 & 0,00 & 0,00 & 0,00 & 0,00 & 0,00 & 0,17 & 1,16 & 6,95 \\
\hline 2 & 14.12.1988 & 0,4253 & 0,0923 & 0,1895 & 0,0368 & 0,74 & 0,00 & 0,00 & 0,00 & 0,00 & 0,00 & 0,74 & 4,15 & 5,57 \\
\hline 2 & 22.12 .1988 & 2,5940 & 1,2926 & 12,0881 & 0,1785 & 16,15 & 0,00 & 0,00 & 0,00 & 0,00 & 0,00 & 16,15 & 16,80 & 1,04 \\
\hline 8 & 14.12.1988 & 0,0034 & 0,0033 & 0,0130 & 0,0040 & 0,02 & 0,00 & 0,00 & 0,00 & 0,00 & 0,00 & 0,02 & 0,38 & \\
\hline 6 & 22.12 .1988 & 0,3830 & 0,1549 & 0,5775 & 0,1542 & 1,27 & 0,00 & 0,00 & 0,00 & 0,00 & 0,00 & 1,27 & 5,83 & 4,60 \\
\hline 5 & 14.12.1988 & 0,1399 & 0,0570 & 0,2912 & 0,1322 & 0,62 & 0,00 & 0,00 & 0,00 & 0,00 & 0,00 & 0,62 & 0,00 & \\
\hline 5 & 22.12.1988 & 0,1075 & 0,0432 & 0,0000 & 0,1016 & 0,25 & 0,00 & 0,00 & 0,00 & 0,00 & 0,00 & 0,25 & 0,94 & 3,72 \\
\hline 4 & 14.12.1988 & 0,0138 & 0,0135 & 0,0442 & 0,0224 & 0,09 & 0,00 & 0,00 & 0,00 & 0,00 & 0,00 & 0,09 & 0,28 & \\
\hline 4 & 22.12.1988 & 0,0000 & 0,0000 & 0,0032 & 0,0031 & 0,01 & 0,00 & 0,00 & 0,00 & 0,00 & 0,00 & 0,01 & 0,05 & \\
\hline 3 & 14.12.1988 & 0,0122 & 0,0046 & 0,0048 & 0,0058 & 0,03 & 0,00 & 0,00 & 0,00 & 0,00 & 0,00 & 0,03 & 0,97 & \\
\hline 3 & 22.12.1988 & 0,1777 & 0,0644 & 0,1000 & 0,1709 & 0,51 & 0,00 & 0,00 & 0,00 & 0,00 & 0,00 & 0,51 & 0,88 & 1,71 \\
\hline
\end{tabular}

In Tabelle 7-21 schließlich ist das Filtrat/Dialysat $<1000 \mathrm{u}$ dargestellt, in dem sich die anorganischen Anionen und der größte Teil der Erdalkali- und Alkali-Kationen befinden. In den Sickerwasser-Proben der drei Kompost-Lysimeter (1,2 und 8) werden in dieser Fraktion im Durchschnitt $14 \%$ der Kationen durch organischen Anionen kompensiert. Die Zahl der C- 
Atome pro negativer Valenz liegt auch hier im Durchschnitt bei 5, kann aber bis auf 2 heruntergehen.

Tabelle 7-21: Kationen-Anionen-Bilanz und DOC in mmol IE/I und Anzahl an C-Atomen pro freie positive Valenz in der Fraktion < 1000 u (4. Filtrat) der Sickerwasser-Proben vom 07.07.88 (nur Lysimeter 1 und 2), 14. und 22.12.88, Lysimeter $1-6$ und 8

\begin{tabular}{|c|c|c|c|c|c|c|c|c|c|c|c|c|c|c|}
\hline Lysimeter & $\begin{array}{l}\text { Datum der } \\
\text { Probenahme }\end{array}$ & $\begin{array}{c}\mathrm{Ca} \\
\mathrm{mmol} \mathrm{IE} / \mathrm{I}\end{array}$ & $\begin{array}{c}\mathrm{Mg} \\
\mathrm{mmol} \mathrm{IE} / \mathrm{I}\end{array}$ & $\begin{array}{c}\mathbf{K} \\
\mathrm{mmol} \text { IE/I } \\
\end{array}$ & $\begin{array}{c}\mathrm{Na} \\
\mathrm{mmol} \mathrm{IE} / \mathrm{I}\end{array}$ & $\begin{array}{l}\text { Summe K } \\
\mathrm{mmol} \mathrm{IE} / \mathrm{I}\end{array}$ & $\begin{array}{c}\mathrm{HCO}_{3} \\
\mathrm{mmol} \mathrm{IE} / \mathrm{I}\end{array}$ & $\begin{array}{c}\mathrm{Cl} \\
\mathrm{mmol} \mathrm{IE} / \mathrm{I}\end{array}$ & $\begin{array}{c}\mathrm{SO}_{4} \\
\mathrm{mmol} \mathrm{IE} / \mathrm{I}\end{array}$ & $\begin{array}{c}\mathrm{NO}_{3}-\mathrm{N} \\
\mathrm{mmol} \\
\end{array}$ & $\begin{array}{l}\text { Summe A } \\
\mathrm{mmol} \text { IE/I }\end{array}$ & $\begin{array}{c}\mathrm{K}-\mathrm{A} \\
\mathrm{mmol} \mathrm{IE/I}\end{array}$ & $\begin{array}{c}\mathrm{DOC} \\
\mathrm{mmol} / \mathrm{I}\end{array}$ & $\begin{array}{c}\text { C-Atome } \\
\text { pro Valenz }\end{array}$ \\
\hline 1 & 07.07.1988 & 2,47 & 1,04 & 15,54 & 3,43 & 22,48 & 4,65 & 0,74 & 2,62 & 8,75 & 16,75 & 5,72 & 12,82 & 2,24 \\
\hline 1 & 14.12.1988 & 2,50 & 1,08 & 15,87 & 5,40 & 24,84 & 9,68 & 0,18 & 4,26 & 6,85 & 20,97 & 3,87 & 19,42 & 5,02 \\
\hline 2 & 14.12.1988 & 7,85 & 4,59 & 44,28 & 13,59 & 70,31 & 16,74 & 5,77 & 20,32 & 15,21 & 58,04 & 12,27 & 37,33 & 3,04 \\
\hline 2 & 22.12.1988 & 8,37 & 4,72 & 38,36 & 11,42 & 62,87 & 17,16 & 6,15 & 21,87 & 12,76 & 57,94 & 4,94 & 17,21 & 3,49 \\
\hline 8 & 14.12.1988 & 2,01 & 1,19 & 12,50 & 4,25 & 19,95 & 8,08 & 0,02 & 3,66 & 5,00 & 16,75 & 3,20 & 17,82 & 5,58 \\
\hline 5 & 14.12.1988 & 3,22 & 1,32 & 10,70 & 5,36 & 20,60 & 6,08 & 0,17 & 3,03 & 5,80 & 15,09 & 5,51 & 16,63 & 3,02 \\
\hline 5 & 22.12.1988 & 2,95 & 1,41 & 7,10 & 2,90 & 14,36 & 6,26 & 0,15 & 1,17 & 4,83 & 12,41 & 1,96 & 14,86 & 7,60 \\
\hline 4 & 14.12.1988 & 3,78 & 1,94 & 6,81 & 4,88 & 17,41 & 5,88 & 0,13 & 3,28 & 5,00 & 14,28 & 3,13 & 14,97 & 4,79 \\
\hline 4 & 22.12.1988 & 3,87 & 1,78 & 5,54 & 2,75 & 13,94 & 5,72 & 0,14 & 2,86 & 4,94 & 13,66 & 0,28 & 15,19 & \\
\hline 3 & 14.12 .1988 & 1,58 & 0,70 & 0,99 & 1,51 & 4,77 & 5,00 & 0,12 & 3,64 & 6,35 & 15,11 & $-10,33$ & 11,62 & \\
\hline 3 & 22.12.1988 & 4,04 & 1,57 & 2,66 & 2,51 & 10,79 & 4,94 & 0,10 & 2,39 & 3,22 & 10,66 & 0,13 & 9,58 & \\
\hline
\end{tabular}

Die Abbildung 120 stellt die Werte für die Kationen-Anionen-Bilanz und den DOC in mmol IE/I und die Anzahl an C-Atomen pro freie positive Valenz im 4. Filtrat der SickerwasserProben vom 07.07.88 Lysimeter 1 und 2, 14. und 22.12.88 Lysimeter $1-6$ und 8 graphisch dar.

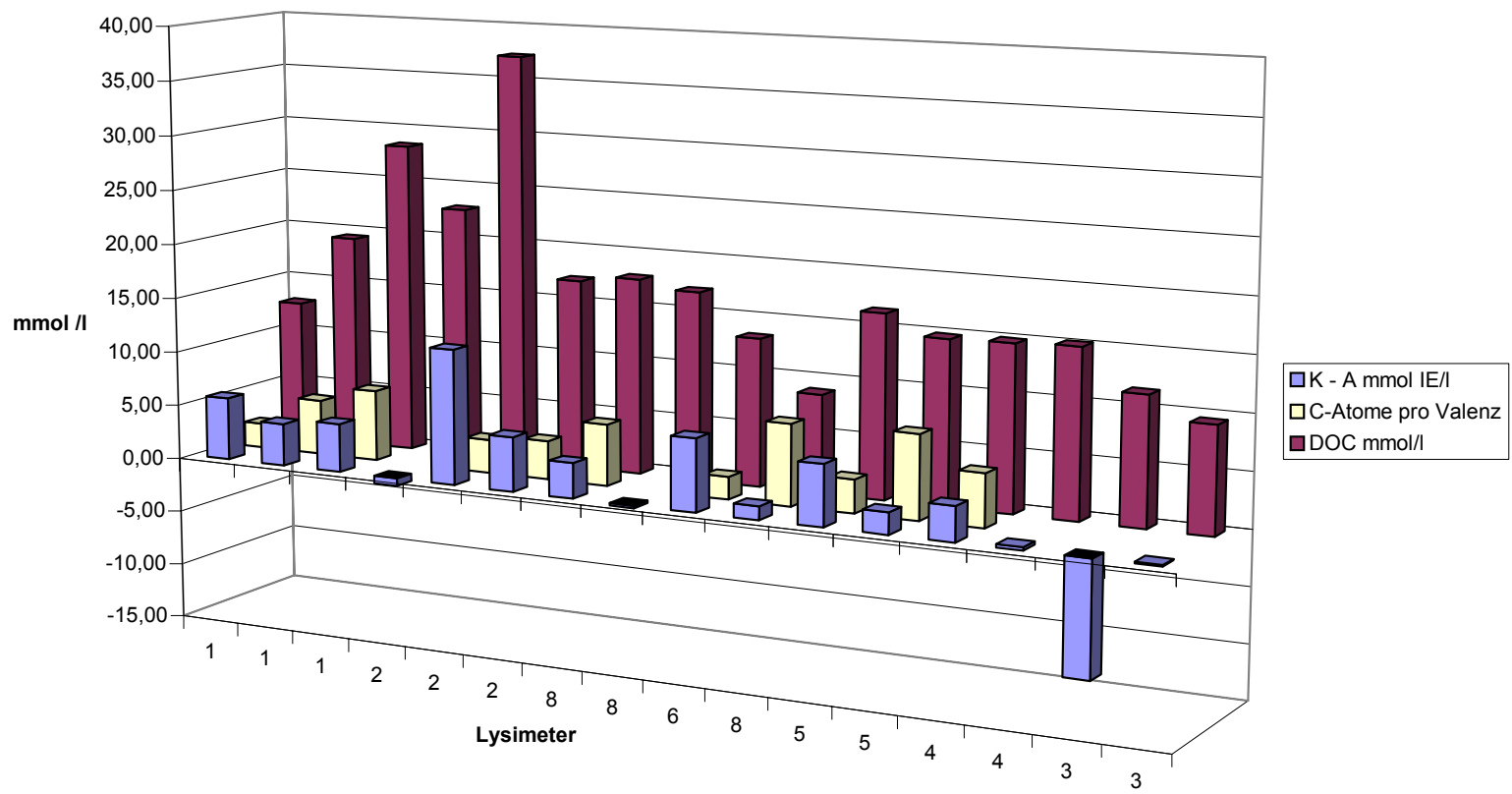

\begin{abstract}
Abbildung 120: Kationen-Anionen-Bilanz und DOC in mmol IE/I und Anzahl an C-Atomen pro freie positive Valenz in der Fraktion < 1000 u (4. Filtrat) der Sickerwasser-Proben vom 07.07.88 (nur Lysimeter 1 und 2), 14. und 22.12.88, Lysimeter $1-6$ und 8
\end{abstract}

Werte um 2 C-Atome je Anionen-Valenz werden häufig in Sickerwasserproben von Böden und Ultrafiltration mit 0,45 $\mu \mathrm{m}$ Membranfiltern gemessen. Sie lassen die Anwesenheit nie- 
dermolekularer organischer Säuren vermuten. Bei C/Kationenüberschuss-Quotienten von 5 und 6, wie sie im vorliegenden Fall dominieren, ist davon auszugehen, dass hier oxyphenolische Ringstrukturen Baustrukturen der organischen Anionen darstellen.

\subsubsection{Säurefällbare Huminstoff-Fraktion}

Aus dem 1.Retentat, > $50.000 \mathrm{u}$, wurden durch Säurefällung (siehe Methodik) die sogenannten „Huminsäuren“ abgetrennt.

Tabelle 7-22 gibt deren Anteile an. Sieht man einmal von den künstlich erzeugten Starkniederschlags-Durchlauf-Ereignissen in den Großlysimetern 1 und 2 am 07.07.88 ab, während derer offenbar nicht genügend Zeit für ein in Lösung bringen größerer Mengen an Huminstoffen gegeben war, so zeigt sich (Sp. 5), dass bei den Kompost-Lysimetern und den Kleinlysimetern mit kompostreicher Mischfüllung 30 bis $60 \%$ der organischen Eluate in die Fraktion > 50.000 u eingehen. Von dieser sind 40 bis $60 \%$ (Sp. 8) säurefällbare Huminstoffe, bezogen auf die extrahierte Gesamtmenge an organischem C (Sp. 7) 15 bis $26 \%$. Die prozentualen Anteile der säurefällbaren Huminstoffe am Gesamt-C bzw. C-Gehalt der Fraktion > 50.000 u zeigt die Abbildung 121.

Tabelle 7-22: Säurefällbare DOC-Anteile in der Fraktion > 50.000 (1. Retentat) und deren C-, N-Gehalte und C/N-Verhältnisse in der TM der Sickerwasser-Proben vom 07.07.88 (nur Lysimeter 1 und 2), 14. und 22.12.88, Lysimeter 1 - 6 und 8

\begin{tabular}{|c|c|c|c|c|c|c|c|c|c|c|}
\hline \multirow[t]{2}{*}{ Lysimeter } & $\begin{array}{c}\text { Sp. } 2 \\
\text { Datum der } \\
\text { Probenahme }\end{array}$ & $\begin{array}{l}\text { Sp. } 3 \\
\text { DOC } \\
\text { SW }\end{array}$ & $\begin{array}{c}\text { Sp. } 4 \\
\text { DOC } \\
\text { 1. Retentat }\end{array}$ & $\begin{array}{c}\text { Sp. } 5 \\
\text { DOC } \\
\text { Sp. } 4 \% \text { Sp. } 3\end{array}$ & \multicolumn{3}{|c|}{$\begin{array}{l}\text { säurefällbarer Anteil }^{*} \\
\text { Sp. } 6 \% \text { Sp. } 3 \text { Sp. } 6 \% \text { Sp. } 4\end{array}$} & \multicolumn{3}{|c|}{ säuregefällte Trockenmassen } \\
\hline & & $\mathrm{mg} / \mathrm{l}$ & $\mathrm{mg} / \mathrm{l}$ & $\%$ & $\mathrm{mg} / \mathrm{l}$ & $\%$ & $\%$ & $\% \mathrm{C}$ & $\% \mathbf{N}$ & $\mathrm{C} / \mathrm{N}$ \\
\hline 1 & 07.07.1988 & 181,30 & 0,73 & 0,40 & 0,00 & 0,00 & 0,00 & & & \\
\hline 1 & 14.12.1988 & 581,00 & 238,79 & 41,10 & 129,90 & 22,38 & 54,40 & 48,75 & 4,07 & 11,98 \\
\hline 1 & 22.12.1988 & 744,00 & 374,23 & 50,30 & 178,62 & 24,08 & 47,73 & 51,38 & 4,25 & 12,08 \\
\hline 2 & 22.12 .1988 & 630,00 & 266,49 & 42,30 & 98,25 & 15,61 & 36,87 & 50,93 & 4,56 & 11,16 \\
\hline 8 & 14.12.1988 & 506,00 & 295,00 & 58,30 & 180,83 & 25,23 & 61,30 & 50,73 & 4,99 & 10,17 \\
\hline 8 & 22.12.1988 & 411,00 & 184,95 & 45,00 & 119,96 & 29,20 & 64,86 & 49,57 & 5,03 & 9,85 \\
\hline 6 & 14.12.1988 & 383,00 & 171,20 & 44,70 & 70,24 & 18,34 & 41,03 & 47,81 & 4,88 & 9,80 \\
\hline 6 & 22.12.1988 & 332,00 & 161,68 & 48,70 & 76,91 & 24,60 & 47,57 & 48,75 & 4,58 & 10,64 \\
\hline 5 & 14.12.1988 & 302,50 & 112,53 & 37,20 & 43,12 & 15,70 & 38,32 & 27,57 & 3,03 & 9,10 \\
\hline
\end{tabular}




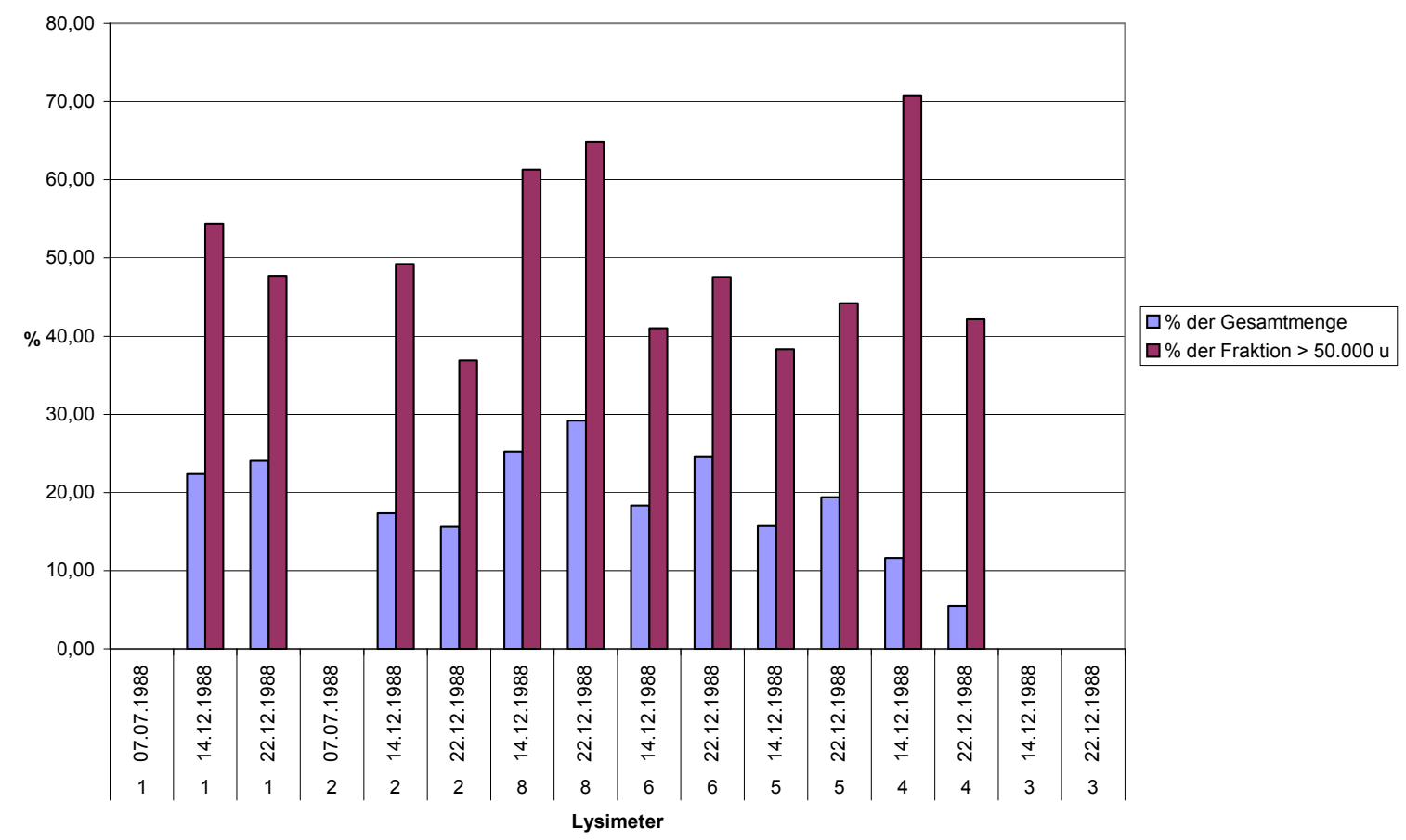

Abbildung 121: Säurefällbare DOC-Anteile in der Fraktion > 50.000 (1. Retentat) in \% von C-Gesamt im Sickerwasser und in $\%$ des C-Gehaltes der Fraktion $>50.000$ u der Sickerwasser-Proben vom 07.07.88 (nur Lysimeter 1 und 2), 14. und 22.12.88, Lysimeter 1, 2, 8, 6, 5 und 4

In der säurefällbaren Fraktion der Kompost-Lysimeter 1, 2 und 8 und des kompostreichen Löss-Mischlysimeters 6 beträgt der C-Gehalt der isolierten Huminsäuren im Schnitt $50 \%$ bei einem $\mathrm{C} / \mathrm{N}-$ Verhältnis von 10 bis 12 . Die entsprechenden Fraktionen der lössreichen Lysimeter 5 und 4 deuten mit ihren C-Gehalten von nur 20 bis $35 \%$ und $\mathrm{C} / \mathrm{N}-$ Verhältnissen von 8,5 bis 10,6 auf eine erhöhte Beimengung okkludierter Mineralsubstanz hin.

Abbildung 122 zeigt die in der Trockenmasse der Huminsäuren nachgewiesenen C- und NGehalte sowie deren Verhältnisse. 


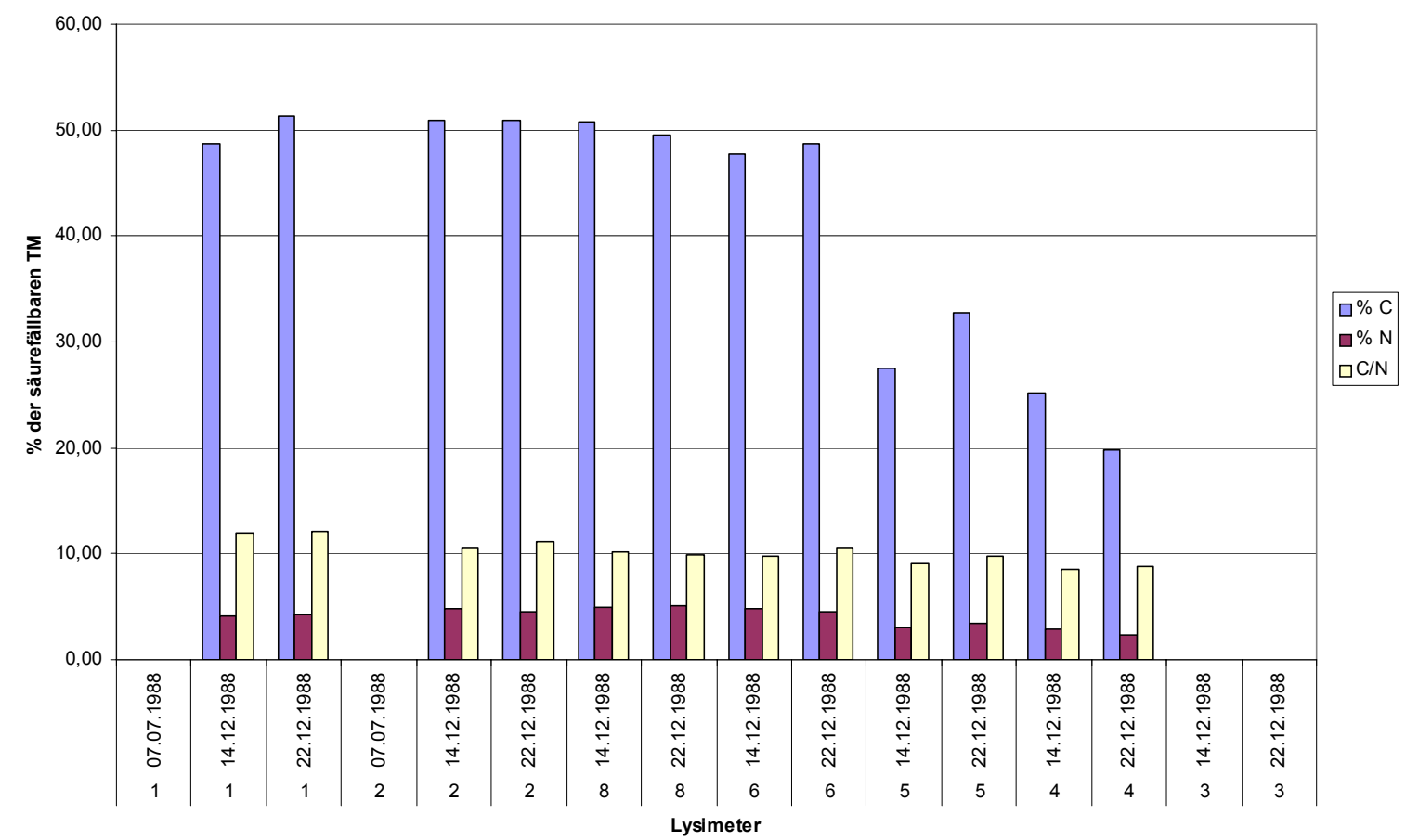

Abbildung 122: C-, N-Gehalte in \% der TM und C/N-Verhältnisse der säurefällbaren Huminstoffe der Fraktion $>\mathbf{5 0 . 0 0 0}$ in den Sickerwasser-Proben vom 07.07.88 (nur Lysimeter 1 und 2) 14. und 22.12.88, Lysimeter 1, 2, 8, 6, 5 und 4

Tabelle 7-23 zeigt, dass die säuregefällte Huminsäure-Fraktion kaum Kationen enthält bzw. bei ihrer Fällung mit Säure die Kationen zurücklässt und in den $\mathrm{H}^{+}$-Zustand (Säure) übergeht. Links sind in der Tabelle die Kationen im Retentat $>50.000 \mathrm{u}$ angegeben und zwar in $\%$ der in der Gesamtlösung enthaltenen Mengen, während rechts die Kationengehalte, ebenfalls bezogen auf die Ausgangslösung, in der säuregefällten Fraktion aufgeführt sind.

Tabelle 7-23: Kationen in \% des Gehaltes der Gesamtprobe in der Fraktion > 50.000 und in der säurefällbaren Fraktion > 50.000 der Sickerwasser-Proben vom 07.07.88 (nur Lysimeter 1 und 2), 14. und 22.12.88, Lysimeter 1, 2, 8, 6, 5 und 4

\begin{tabular}{|c|c|c|c|c|c|c|c|c|c|c|c|}
\hline \multirow{4}{*}{$\begin{array}{c}\text { Sp. } 1 \\
\text { Lysimeter }\end{array}$} & \multirow{4}{*}{$\begin{array}{c}\text { Sp. } 2 \\
\text { Datum der } \\
\text { Probenahme }\end{array}$} & \multirow{2}{*}{\multicolumn{5}{|c|}{ Kationen in der Fraktion $>50.000 \mathrm{u}$}} & Sp. 17 & Sp. 18 & Sp. 19 & Sp. 20 & Sp. 21 \\
\hline & & & & & & & \multicolumn{5}{|c|}{ säurefällbare Kationen in der Fraktion $>50.000 \mathrm{u}$} \\
\hline & & $\mathrm{Fe}$ & $\mathrm{Ca}$ & Mg & K & $\mathrm{Na}$ & $\mathrm{Fe}$ & $\mathrm{Ca}$ & Mg & K & $\mathrm{Na}$ \\
\hline & & \multicolumn{5}{|c|}{ in \% des Gehaltes der Gesamtprobe } & \multicolumn{5}{|c|}{ in \% des Gehaltes der Gesamtprobe } \\
\hline \multirow[t]{3}{*}{1} & 07.07.1988 & & & & & & & & & & \\
\hline & 14.12.1988 & 88,60 & 26,30 & 19,00 & 4,00 & 3,00 & 70,89 & 0,00 & 0,17 & 0,00 & 0,25 \\
\hline & 22.12.1988 & 88,60 & 37,90 & 26,70 & 5,60 & 6,70 & 54,10 & 0,73 & 0,00 & 0,10 & 0,00 \\
\hline \multirow[t]{3}{*}{2} & 07.07.1988 & & & & & & & & & & \\
\hline & 14.12.1988 & 71,00 & 5,20 & 3,00 & 0,70 & 0,50 & 17,93 & 0,17 & 0,00 & 0,00 & 0,00 \\
\hline & 22.12.1988 & 78,30 & 14,00 & 8,30 & 3,00 & 2,50 & 42,80 & 0,90 & 0,00 & 0,10 & 0,10 \\
\hline \multirow[t]{2}{*}{8} & 14.12.1988 & 75,50 & 35,70 & 21,80 & 4,90 & 2,80 & 50,34 & 1,47 & 0,00 & 0,00 & 0,00 \\
\hline & 22.12.1988 & 94,30 & 34,10 & 23,60 & 4,30 & 3,20 & 60,40 & 0,60 & 0,20 & 0,10 & 0,10 \\
\hline \multirow[t]{2}{*}{6} & 14.12 .1988 & 66,70 & 32,00 & 20,20 & 8,20 & 6,10 & 43,33 & 2,17 & 0,00 & 0,75 & 0,51 \\
\hline & 22.12.1988 & 89,40 & 28,80 & 19,10 & 5,70 & 4,20 & 58,00 & 2,00 & 1,20 & 0,40 & 0,00 \\
\hline \multirow[t]{2}{*}{5} & 14.12 .1988 & 71,40 & 14,20 & 18,50 & 3,10 & 2,00 & 66,43 & 0,00 & 1,88 & 0,57 & 0,16 \\
\hline & 22.12.1988 & 97,00 & 18,00 & 13,20 & 3,10 & 2,40 & 82,50 & 0,00 & 0,50 & 0,20 & 0,00 \\
\hline \multirow[t]{2}{*}{4} & 14.12 .1988 & 72,10 & 2,50 & 2,20 & 0,90 & 0,40 & 63,95 & 0,00 & 0,26 & 0,22 & 0,00 \\
\hline & 22.12.1988 & 94,80 & 4,40 & 3,10 & 0,60 & 0,50 & 83,60 & 0,00 & 0,00 & 0,00 & 0,00 \\
\hline \multirow[t]{2}{*}{3} & 14.12.1988 & 0,00 & 0,00 & 0,00 & 0,00 & 0,00 & & & & & \\
\hline & 22.12.1988 & 91,30 & 0,20 & 0,00 & 0,50 & 0,10 & & & & & \\
\hline
\end{tabular}

Hervorstechender Befund ist, dass der größte Teil des Eisens, der schon in der Fraktion > 50.000 u stark angereichert ist, zu durchschnittlich $70 \%$ in die Huminsäure-Fraktion über- 
geht, das heißt 10 bis $30 \%$ mehr als organischer Kohlenstoff. Damit scheint die säurefällbare Huminsäure-Fraktion das bei ihrer Entstehung im Kompost aufgenommene Eisen in Form eines fest okkludierten konstitutionellen Bestandteils zu binden, der nicht mehr dem Ionenaustausch unterliegt. Es ist offensichtlich die organische Fraktion, die als „sink“ für die bei der Mineralisation freiwerdenden Fe-lonen zu bewerten ist (FRIMMEL et al. 1981).

Tabelle 7-24: C- und Fe-Konzentrationen und C/Fe-

Atomverhältnisse in der Fraktion $>\mathbf{5 0 . 0 0 0} u$ und in der säurefällbaren Huminsäure-Fraktion $>50.000 \mathrm{u}$

\begin{tabular}{|c|c|c|c|c|c|c|c|c|c|c|c|}
\hline \multirow[b]{2}{*}{ Lysimeter } & \multirow[b]{2}{*}{$\begin{array}{c}\text { Datum der } \\
\text { Probenahme }\end{array}$} & \multicolumn{3}{|c|}{ in der Fraktion $>50.000 \mathrm{u}$} & \multirow[b]{2}{*}{$\begin{array}{c}\mathrm{Fe} \\
\mathrm{mmol} / \mathrm{l}\end{array}$} & \multirow{2}{*}{$\begin{array}{c}\text { Atom- } \\
\text { Verhältnis } \\
\text { C/Fe }\end{array}$} & \multicolumn{4}{|c|}{ in der säurefällbaren Fraktion $>50.000 \mathrm{u}$} & \multirow{2}{*}{$\begin{array}{c}\text { Atom- } \\
\text { Verhältnis } \\
\text { C/Fe }\end{array}$} \\
\hline & & $\begin{array}{c}\mathrm{C} \\
\mathrm{mg} / \mathrm{l}\end{array}$ & $\begin{array}{c}\mathrm{Fe} \\
\mathrm{mg} / \mathrm{l}\end{array}$ & $\underset{\mathrm{mmol} / \mathrm{I}}{\mathrm{C}}$ & & & $\begin{array}{c}\mathrm{C} \\
\mathrm{mg} / \mathrm{l}\end{array}$ & $\begin{array}{c}\mathrm{Fe} \\
\mathrm{mg} / \mathrm{l}\end{array}$ & $\underset{\mathrm{mmol} / \mathrm{I}}{\mathrm{C}}$ & $\begin{array}{c}\mathrm{Fe} \\
\mathrm{mmol} / \mathrm{I}\end{array}$ & \\
\hline 1 & 14.12.1988 & 238,79 & 2,33 & 19,90 & 0,04 & 476,95 & 129,90 & 1,86 & 10,83 & 0,03 & 324,28 \\
\hline 1 & 22.12.1988 & 374,23 & 2,56 & 31,19 & 0,05 & 680,22 & 178,62 & 1,56 & 14,89 & 0,03 & 531,72 \\
\hline 2 & 14.12.1988 & 223,02 & 0,68 & 18,59 & 0,01 & 1522,85 & 109,73 & 0,17 & 9,14 & 0,00 & 2966,88 \\
\hline 2 & 22.12.1988 & 266,49 & 1,20 & 22,21 & 0,02 & 1035,31 & 98,25 & 0,65 & 8,19 & 0,01 & 698,33 \\
\hline 8 & 14.12.1988 & 295,00 & 2,25 & 24,58 & 0,04 & 610,24 & 180,83 & 1,50 & 15,07 & 0,03 & 561,04 \\
\hline 8 & 22.12.1988 & 184,95 & 2,83 & 15,41 & 0,05 & 304,27 & 119,96 & 1,81 & 10,00 & 0,03 & 308,12 \\
\hline 6 & 14.12.1988 & 171,20 & 1,33 & 14,27 & 0,02 & 597,30 & 70,24 & 0,87 & 5,85 & 0,02 & 377,25 \\
\hline 6 & 22.12.1988 & 161,68 & 3,25 & 13,47 & 0,06 & 231,24 & 76,91 & 2,11 & 6,41 & 0,04 & 169,56 \\
\hline 5 & 14.12 .1988 & 112,53 & 5,00 & 9,38 & 0,09 & 104,79 & 43,12 & 4,65 & 3,59 & 0,08 & 43,16 \\
\hline 5 & 22.12.1988 & 101,85 & 10,19 & 8,49 & 0,18 & 46,54 & 45,02 & 8,66 & 3,75 & 0,16 & 24,19 \\
\hline 4 & 14.12.1988 & 40,59 & 1,77 & 3,38 & 0,03 & 106,94 & 28,75 & 1,57 & 2,40 & 0,03 & 85,39 \\
\hline 4 & 22.12.1988 & 33,93 & 4,46 & 2,83 & 0,08 & 35,44 & 14,30 & 3,93 & 1,19 & 0,07 & 16,94 \\
\hline
\end{tabular}

Tabelle 7-24 gibt einen Überblick über die C/Fe- Atomverhältnisse in dieser HuminsäureFraktion, rechter Tabellenteil) und in der Fraktion $>50.000$ u. In den Kompost und kompostreichen Lysimetern ist die Zahl von C-Atomen, die auf ein Fe-Atom entfallen hoch: 170 bis 3000 mit Schwerpunkt bei 500 bis 700 . Dort wo mehr Fe für die Reaktion zur Verfügung steht, in den Kleinlysimetern mit lössreicher Füllung sinkt dagegen die Zahl der C-Atome auf Werte zwischen 17 und 85 in der säurefällbaren Fraktion. Man vergleiche hierzu auch die oben getroffene Aussage zum höheren Mineralstoff-Gehalt der hier angefallenen säurefällbaren Fraktion.

\subsection{Gel-Chromatographie}

\subsubsection{Methodik}

Die Gel-Chromatographie wird einerseits zur Fraktionierung polydisperser Lösungen eingesetzt, andererseits als Methode zur Bestimmung der molaren Masse organischer Makromoleküle. Letzteres setzt Kenntnisse bezüglich der Struktur der zu untersuchenden Verbindungsklasse voraus, um die entsprechenden Eichsubstanzen auswählen zu können. Bei den hier vorliegenden Lösungen mit komplexen organischen Komponenten, deren räumliche Struktur nicht bekannt ist, wurde daher nur die Trennung und Zuordnung der Fraktionen in Molekül-Größenbereiche angestrebt.

Verwendet wurden modifizierte Dextran-Gele (Pharmacia) mit dreidimensional vernetzten Polysaccharidketten, die sich je nach Vernetzungsgrad in ihren Quelleigenschaften unterscheiden. Die jeweiligen Fraktionierbereiche, in denen eine nahezu lineare Funktion zwischen dem Elutionsvolumen und dem Logarithmus der molaren Masse für eine einheitliche Verbindungsklasse gegeben ist, werden durch den Quellgrad des Gels festgelegt. In Tabelle 7-25 sind die Eigenschaften der verwendeten Gele aufgeführt. 
Tabelle 7-25: Verwendete Gele, Übersicht und technischen Daten der verwendeten Sephadex-Geltypen (Angaben nach PHARMACIA 1967)

\begin{tabular}{|c|c|c|c|c|c|}
\hline Geltyp & $\begin{array}{c}\text { Perldurch- } \\
\text { messer } \\
\boldsymbol{\mu m}\end{array}$ & $\begin{array}{c}\text { Wasseraufnahme } \\
\text { ml/g trockenes } \\
\text { Sephadex }\end{array}$ & $\begin{array}{c}\text { Gelvolumen } \\
\text { ml/g trockenes } \\
\text { Sephadex }\end{array}$ & $\begin{array}{c}\text { Fraktionierbereich } \\
\text { für Peptide und } \\
\text { globuläre Proteine }\end{array}$ & $\begin{array}{c}\text { Fraktionier- } \\
\text { bereich } \\
\text { für Dextrane }\end{array}$ \\
\hline $\begin{array}{c}\text { Sephadex } \\
\text { G 25 Fine }\end{array}$ & $20-80$ & 2,5 & $4-6$ & $1000-5000 \mathrm{u}$ & $100-5000 \mathrm{u}$ \\
\hline $\begin{array}{c}\text { Sephadex } \\
\text { G 50 } \\
\text { Superfine }\end{array}$ & $10-40$ & 5,0 & $9-11$ & $1500-30.000 \mathrm{u}$ & $500-10.000 \mathrm{u}$ \\
\hline $\begin{array}{c}\text { Sephadex } \\
\text { G 100 }\end{array}$ & $40-120$ & 10 & $15-20$ & $4000-150.000 \mathrm{u}$ & $1000-100.000 \mathrm{u}$ \\
\hline
\end{tabular}

Die Fraktionierung nach Molekülgrößen lässt sich folgendermaßen beschreiben:

In der mit gequollenem Gel gefüllten Trennsäule können 3 Volumina unterschieden werden: das Totalvolumen $\left(\mathrm{V}_{\mathrm{t}}\right)$ das Volumen zwischen den Gelkörpern $\left(\mathrm{V}_{\mathrm{o}}\right)$ und das Volumen der Poren innerhalb der Gelkörper. Moleküle, die größer als die Poren der Gelkörper sind, können nicht in die Gelpartikel diffundieren ( $L=$ Auschlussgrenze), wohingegen kleinere Moleküle in direkter Abhängigkeit von ihrer Dimension in das Innere der Gelkörper eindringen und dadurch verzögert die Säule verlassen. Die Abbildung 123 stellt das beschriebene Prinzip graphisch dar.
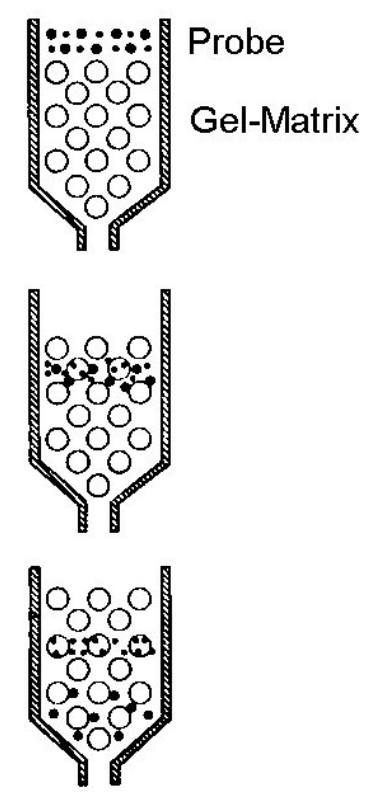

Abbildung 123: Prinzip der Molekülgrößentrennung bei der Gel-Chromatographie 
Da die mit Epichlorhydrin vernetzten Dextrane in der Gelmatrix sowohl Ethergruppen als auch einen geringen Anteil an Carboxylgruppen aufweisen, können ionogene, aber auch Wasserstoffbrücken-Bindungen mit den im Elutionsmittel gelösten Substanzen auftreten. Bei aromatischen und heterozyklischen Verbindungen, wie sie in Huminstoffen zu erwarten sind, wird die Trennung von Adsorptionseffekten überlagert, die zu Retardierungen in der Säule führen (FUCHS und RAUE 1981).

Bei der Fraktionierung der Proben wurden die Sephadex-Gel-Typen G 25 Fine, G 50 Superfine und G 100 verwendet. Es kam überwiegend das Gel G 50 Superfine zur Anwendung. Die Tabelle 7-26 und die Abbildung 124 zeigen die für das Gel G 50 Superfine aufgestellte Eichreihe.

Tabelle 7-26: Eichreihe für das Sephadex Gel G 50 superfine

\begin{tabular}{l|ccc} 
Substanz & $\begin{array}{c}\text { molare Masse } \\
\mathbf{u}\end{array}$ & $\begin{array}{c}\text { Logarithmus } \\
\text { der molaren Masse }\end{array}$ & $\begin{array}{c}\text { Elutionsvolumen } \\
\mathbf{m l}\end{array}$ \\
\hline Detxtranblau & & & \\
Chymotrypsinogen & 2000000 & 6,301 & 15,4 \\
Ribonuklease & 25000 & 4,398 & 20,0 \\
Trypsin & 13700 & 4,137 & 20,8 \\
Hydroxocobalamin & 6500 & 3,813 & 23,8 \\
& 1383 & 3,141 & 34,4
\end{tabular}

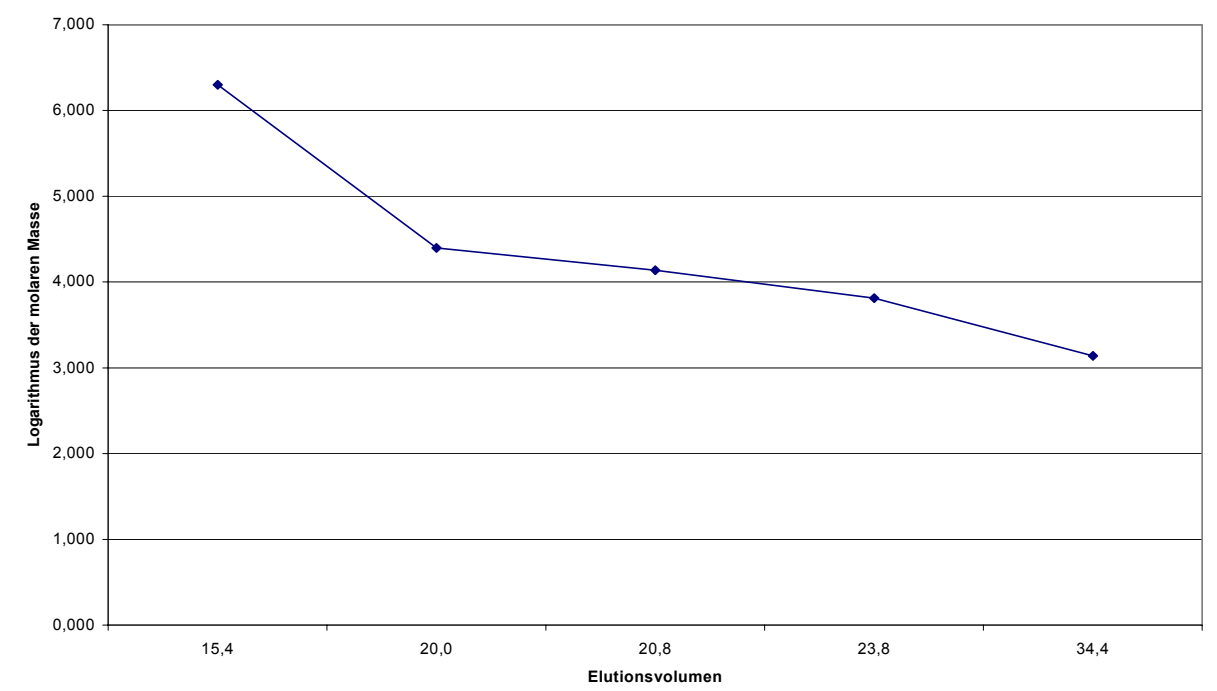
Abbildung 124: Eichgerade für das Sephadex Gel G 50
superfine

Die Gel-Typen G 25 Fine und G 100 der darüber und darunter liegenden Trennbereiche dienten einer Überprüfung der Möglichkeit, einer eventuellen weiteren Auftrennung der Molekülmassen-Fraktionen. Dies war nicht der Fall. Die Elution erfolgte mit destilliertem Wasser, um möglichst wenig in die Bindungsverhältnisse zwischen den Kationen und den organischen Inhaltsstoffen einzugreifen.

Die Detektion im Eluat erfolgte photometrisch bei $280 \mathrm{~nm}$. Die Absorption im UV-Bereich ist delokalisierten Elektronensystemen zu zuordnen. Somit bleiben nicht-UV-aktive Substanzen bei dieser Form der Detektion unberücksichtigt. Der apparative Aufbau ist in Abbildung 125 dargestellt. 


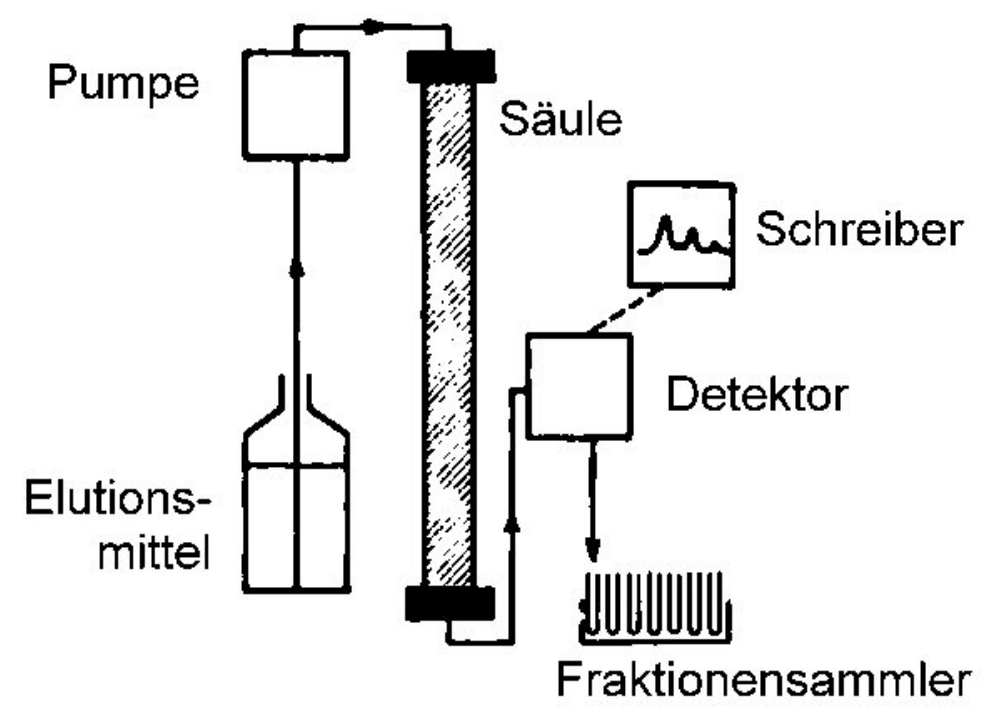
Abbildung 125: Schematische Darstellung der
Gelpermeations-Chromatographie-Anlage

Die Probenaufgabe erfolgte mittels Mikropipette. Die zugeführte Menge lag zwischen 0,1 und 0,5 ml. Die Eichung wurde mit den in Tabelle 7-26 aufgeführten Substanzen ausgeführt, wobei aufgrund der zu erwartenden Strukturen Polyphenole, Polydextrane und Proteine ausgewählt wurden.

Die Auswertung der Proben erfolgte durch Berechnung der mittleren molaren Massen anhand der Elutionsvolumina und Ausmessung der Peakhöhen.

Da nach mehrtägigem Betrieb eine zunehmende Verdichtung der Säulen beobachtet wurde, wurden die Säulen täglich frisch mit der gleichen Menge an vorgequollenem Gel befüllt und bei einheitlicher Durchflussrate von $1,5 \mathrm{ml} / \mathrm{min}$ betrieben. Die eingesetzte Gelmenge lag bei $16 \mathrm{~g}$ Gel TM. Bei der verwendeten Säule mit einem Innendurchmesser von $0,75 \mathrm{~cm}$ lag die Einfüllhöhe bei $20 \mathrm{~cm}$. Das Gel wurde 2 Stunden in $200 \mathrm{ml}$ a. bidest. gequollen.

Es wurden bei der Passage der Proben keine Verfärbungen des Gels beobachtet, woraus gefolgert werden kann, dass im Gegensatz zu den Filtermaterialien bei der Ultrafiltration keine irreversible Festlegung von Eluat-Bestandteilen eintrat.

\subsubsection{Untersuchungsproben}

Untersucht wurden Sickerwasserproben der Lysimeter 1, 2 und 8 (Kompost) sowie 6, 5, 4 und 3 mit zunehmendem Löss-Anteil aus dem Zeitabschnitt 07.07.88 bis 10.11.89, außerdem wässrige Extrakte des Kompostes (Probenahme 24.06.88) der Lysimeter 1, 2 und 3 sowie das Kompost-Ausgangsmaterial vom März 86 für die Befüllung der Kleinlysimeter. Darüber hinaus wurden auch Filtrate und Retentate der Ultrafiltration und ein Eluat der Adsorptions-Chromatographie gel-chromatographisch untersucht.

\subsubsection{Ergebnisse}

\subsubsection{Sickerwasser}

Die insgesamt für die Proben erhaltenen Ergebnisse sind in den Tabellen 1-80 bis 1-86 im Anhang aufgeführt. Tabelle 7-27 zeigt die Mittelwerte der anhand der Eichsubstanzen 
errechneten molaren Massen und die Höhen der ersten Fraktion (Peak 1) mit der höheren molaren Masse und der dritten Fraktion (Peak 3) mit der niedrigeren molaren Masse sowie die Quotienten der Peakhöhen P 1/P 3 für die Sickerwasser-Proben der Lysimeter $1-6$ und 8.

Bei allen untersuchten Sickerwasser- und Extrakt-Proben lassen sich zwei oder drei Molekülgrößen-Fraktionen unterscheiden:

Die erste im Säulen-Eluat erscheinende Fraktion liegt im Bereich der Ausschlussgrenze des Gels, so dass hier nur die orientierende Angabe größer als 15.000 bis maximal $80.000 \mathrm{u}$ möglich ist, was wahrscheinlich der Fraktion > $50.000 \mathrm{u}$ bei der Ultrafiltration entsprechen dürfte.

Der zweite Peak erscheint als freier Peak oder als Schulter der Peaks 1 und 3. Für die Molekülgröße ist hier der Bereich 1000 bis 6000 u anzugeben.

Die dritte Molekülgrößen-Fraktion liegt bei 700 bis $1500 \mathrm{u}$.

Während der erste und der dritte Peak bei allen Sickerwasserproben und Extrakten vorhanden sind, ist der zweite Peak bei etwa einem Drittel der untersuchten Proben nicht nachweisbar. Die Proben unterscheiden sich in ihren Peakhöhen und ihren Peakverhältnissen. In der Abbildung 126 sind die aus den Chromatogrammen ermittelten Peakhöhen und das Verhältnis der Höhe der Peaks 1 und 3 für die Sickerwasser-Proben der Kompost und Kompost/Löss-Lysimeter dargestellt. In den Sickerwasser-Proben ist die Höhe des ersten Peaks um so größer, je höher der Kompostgehalt im Füllmaterial des Lysimeters ist. Die Mittelwerte der Peakhöhen sinken von $8 \mathrm{~cm}$ bei 1 auf $1,2 \mathrm{~cm}$ bei 3. Diese Fraktion enthält hochmolekulare, dunkelbraun gefärbte organische Verbindungen, deren Menge im Sickerwasser mit dem Kompostgehalt der Lysimeter korreliert.

Die Peakhöhe der im Trennbereich 700 bis $1500 \mu$ erscheinenden Fraktion dagegen liegt, unabhängig vom Kompostgehalt der Lysimeter in den Mischungsvarianten, bei durchschnittlich $1,2 \mathrm{~cm}$, bei Lysimeter 1 bei $1,9 \mathrm{~cm}$ und bei 2 bei $3,9 \mathrm{~cm}$. Entsprechend unterscheiden sich die Peakverhältnisse von 1 und 3 deutlich. Sie betragen im Durchschnitt für Lysimeter 1 (P 1/P 3) 4,3 und für Lysimeter 2 1,8. In den Mischungsvarianten sinkt der Quotient von 6,8 bei Lysimeter 8 auf 1,2 für Lysimeter 3. 


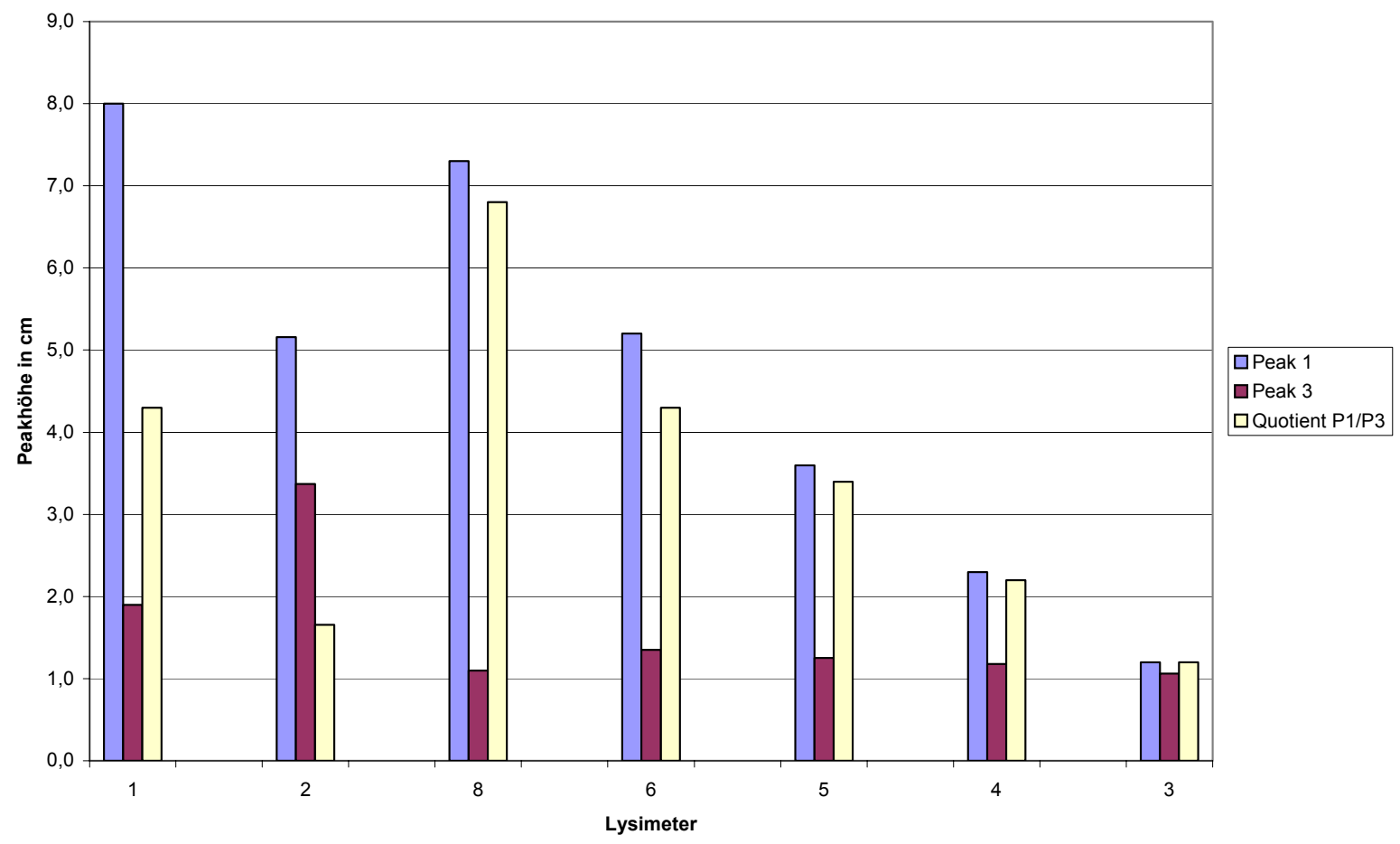

Abbildung 126: Vergleich der mittleren Peakhöhen und Quotienten P 1/P 3, Sickerwasser-Proben, Lysimeter 1 - 6 und 8

Tabelle 7-27: Anhand der GC berechnete mittlere molare Massen in u und Peakhöhen in cm sowie die Quotienten zwischen $P 1$ und $P \mathbf{3}$ für die Sickerwasser-Proben, Lysimeter $1-6$ und 8

\begin{tabular}{|c|c|c|c|c|c|c|c|}
\hline Lysimeter & $\begin{array}{c}\text { Anzahl der } \\
\text { Proben }\end{array}$ & \multicolumn{3}{|c|}{ molare Masse in $u$} & \multicolumn{2}{|c|}{ Peakhöhe in cm } & $\begin{array}{c}\text { Quotient } \\
\text { P1/P3 }\end{array}$ \\
\hline 1 & 13 & 36.940 & 2.700 & 1.207 & 8,0 & 1,9 & 4,3 \\
\hline 2 & 9 & 40.189 & 2.246 & 1.242 & 5,2 & 3,4 & 1,7 \\
\hline 8 & 3 & 44.341 & 6.069 & 1.496 & 7,3 & 1,1 & 6,8 \\
\hline 6 & 6 & 47.008 & 6.684 & 1.560 & 5,2 & 1,4 & 4,3 \\
\hline 5 & 8 & 34.979 & 5.674 & 1.245 & 3,6 & 1,3 & 3,4 \\
\hline 4 & 4 & 30.382 & 6.832 & 1.767 & 2,3 & 1,2 & 2,2 \\
\hline 3 & 5 & 26.644 & 5.072 & 972 & 1,2 & 1,1 & 1,2 \\
\hline Mw & 48 & 37.212 & 5.040 & 1.356 & & & \\
\hline
\end{tabular}

Bei den Mischungsvarianten steigt die berechnete mittlere molare Masse für die Fraktion 1 (P 1) mit zunehmenden Kompostanteil der Lysimeterfüllung. Im Durchschnitt liegen die molaren Massen für die den Peaks 1 - 3 entsprechenden Fraktionen bei folgenden Werten:

Fraktion 1 (P 1): 37.212 u, Fraktion 2 (P 2): 5.040 u und Fraktion 3 (P 3): 1.356 u. 
Bei den künstlich erzeugten Sickerwasser-Proben der beiden Großlysimeter vom 07.07.88 sind die ermittelten mittleren molaren Masse des ersten Peaks kleiner als in den zeitlich folgenden Sickerwasser-Proben und Peakverhältnisse enger bzw. bei Lysimeter 2 sogar kleiner 1. Dieses Ergebnis bestätigt die bereits angestellten Erklärungen in Bezug auf die Inhaltsstoff-Zusammensetzung dieser künstlich erzeutgten Sickerwasser-Proben.

\subsubsection{Extrakte}

Abbildung 127 zeigt den Ausgangszustand des Füllmaterials zu Beginn der Freilandversuche. Die mittlere Fraktion (Peak 2) fehlt, Peak 3 dominiert über Peak 1. Die gel-chromatographische Fraktionierung der wässrigen Extrakte der Lysimeterfüllungen (Lysimeter 2 und Lysimeter $3-8$ ) zeigen die Abbildungen 128 und 129. Nach einem Jahr Laufzeit hat die Fraktion 1 im Extrakt der Kompost-Variante, Lysimeter 8, deutlich zugenommen. Peak 2 ist als freier Peak vorhanden. Die Peaks 1 und 3 sind bei den Mischungsvarianten niedriger als beim reinen Kompost. Während die Menge an hochmolekularer organischer Substanz in den Exrakten mit zunehmendem Löss-Anteil abnimmt, bleiben die kleineren Molekülgrößen auf einem Niveau. Die mittlere Molekülgrößen-Fraktion ist zu größeren Molekülgrößen hin verschoben und bei den Lysimetern 4, 5 und 6 als Schulter von Peak 1 ausgebildet.

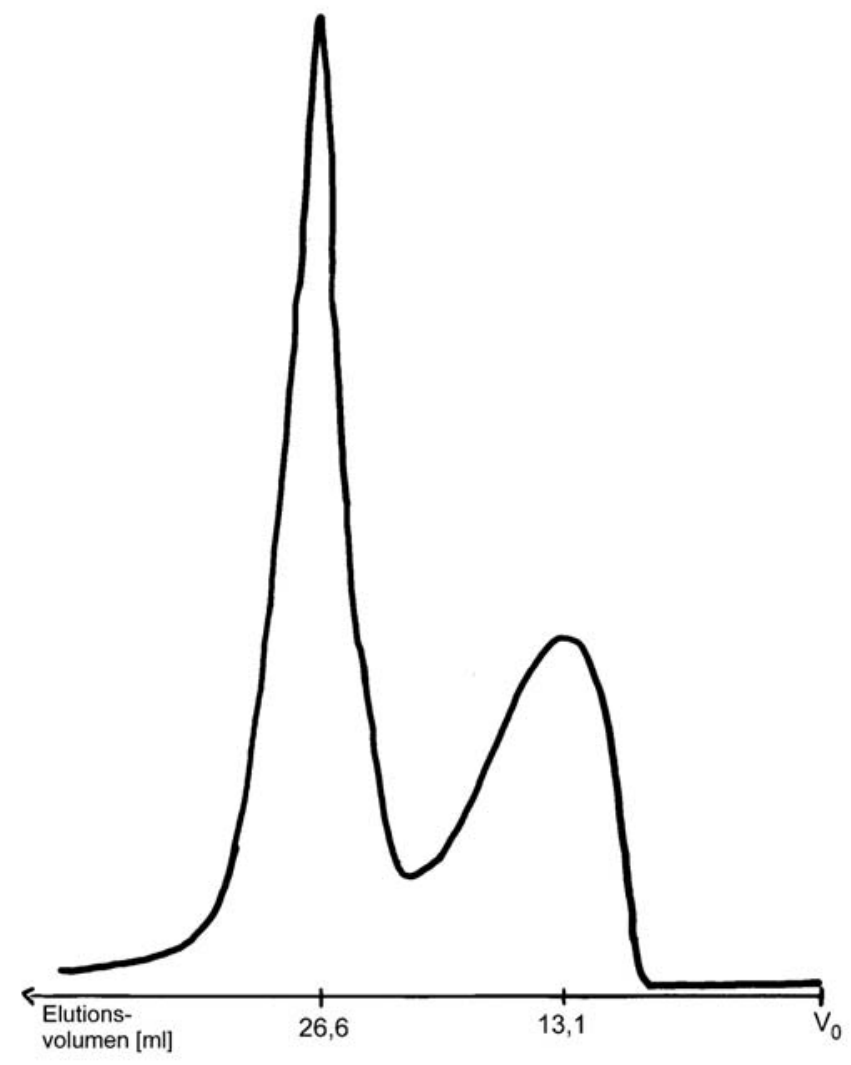


Abbildung 127: Nachskizziertes Chromatogramm der gelchromatographischen Fraktionierung, KompostAusgangsmaterial März 86

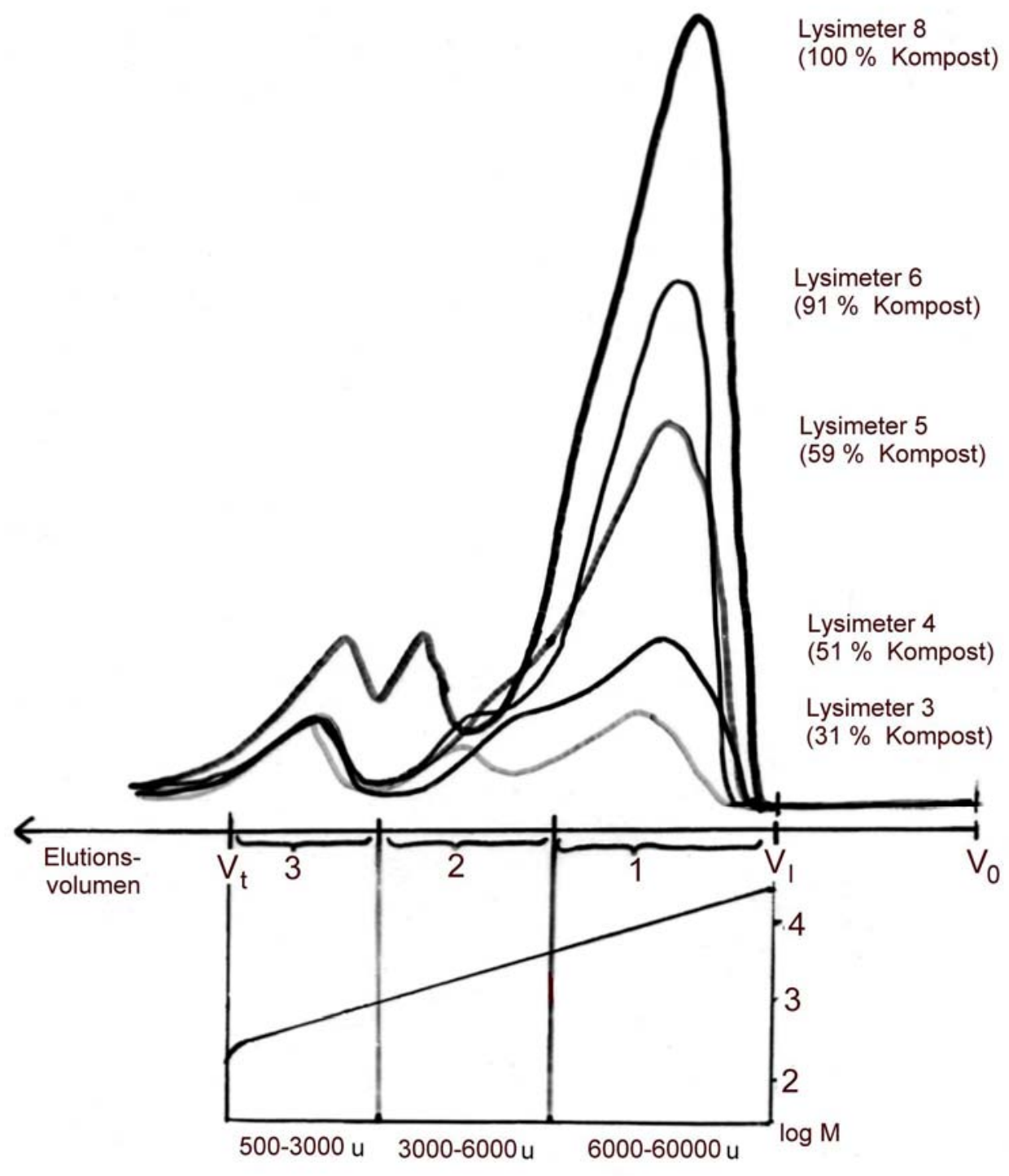

Abbildung 128: Nachskizzierte Chromatogramme der gelchromatographischen Fraktionierung, Kompost- und Kompost-/Löss-Mischungen, Extraktproben vom 24.06.88

Bei der Betrachtung der gel-chromatographischen Fraktionierung der Extrakte aus den verschiedenen Tiefenabschnitten des Lysimeters zeigt, dass der oberste Tiefen-Abschnitt die geringste Zunahme an an hochmolekularer organischer Substanz aufweist, wahrscheinlich aber schon die größte Abnahme. Peak 3 ist auf geringe Werte zurückgegangen, wobei auch hier wieder der oberste Lysimeter-Abschnitt die stärkste Abnahme aufweist. Peak 2 ist hier nur als Schulter von Peak 1 ausgebildet, während er in den Tiefenabschnitten 2 und 3 mehr oder weniger freistehend ist. 


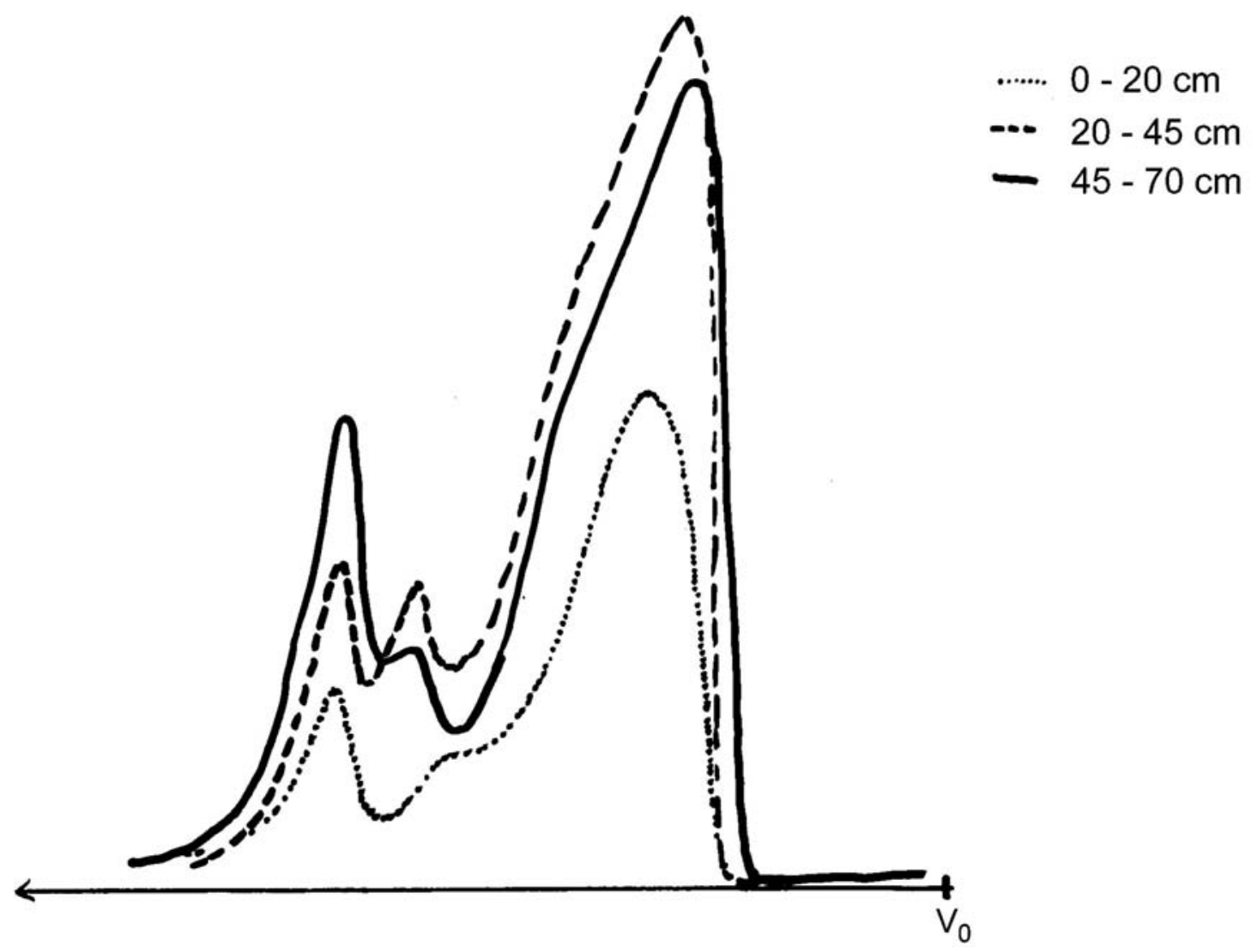

Abbildung 129: Nachskizzierte Chromatogramme der gelchromatographischen Fraktionierung, Lysimeter 2, verschiedene Tiefenabschnitte, Extraktproben vom 24.06.88

Die aufgezeigten Veränderungen lassen sich als Ergebnis des Abbaus der Fraktion 3 und Umbaus in die Fraktion 1 deuten, wobei die Auswaschung als 3. Prozess auch die Tiefendifferenzierung beeinflusst.

\subsubsection{Vergleich Ultrafiltration - Gel-Permeations-Chromatographie}

Um die Wirksamkeit der Fraktionierung der Ultrafiltration zu überprüfen, wurden Filtrate und Retentate aus der Ultrafiltration mit Hilfe der GC geprüft. Die Kombination der Ultrafiltration und Gel-Chromatographie wird von verschiedenen Autoren zur vergleichenden Interpretation der Ergebnisse und differenzierten Charakterisierung der HUS in Gewässern eingesetzt (GJESSING 1973, HIPPE 1985, SCNWEDT und HIPPE 1987).

Die Gel-Permeations-Chromatographie der Sickerwasser-Proben ergibt ein mit der Ultrafiltration vergleichbares Bild. Auch hier wird die organische Substanz überwiegend in zwei Hauptfraktionen aufgetrennt. Entsprechend der ermittelten Eichkurve liegen die Elutionsvolumina der Hauptfraktionen im Bereich der Ausschlussgrenze bei 35.000 bis $50.000 \mathrm{u}$ und bei $1000 \mathrm{u}$ und können mit den bei der Ultrafiltration gewonnen Fraktionen Retentat 1 (> $50.000 \mathrm{u}$ ) und Filtrat $4 \mathrm{bzw}$. Retentat 5 (500 bis $1000 \mathrm{u}$ ) gleichgesetzt werden.

Nimmt man aus dem Fraktionierungsgang der Ultrafiltration z.B. die Retentate (Filterrückstände) des ersten Filtrationsganges (Retentat 1), die von allen feineren, niedermolekularen organischen Inhaltsstoffen befreit sind, so zeigen diese auch bei der GC ein völliges Fehlen dieser feinen Fraktionen. Das heißt, dass im Hinblick auf die Abfilterung der feineren organischen Fraktionen der Ultrafiltrationsgang gut trennt. Die abgetrennten Filtrate weisen 
in der GC wie erwartet die das Filter passiert habenden feineren organischen Fraktionen auf.

Unerwarteterweise aber zeigt die GC auch, dass die Filtermembranen - das gilt besonders für die 1., wurde aber auch bei den übrigen Membranen bestätigt - scheinbar durchlässig für einen gewissen Teil der Molekülgrößen Fraktion > $50.000 \mathrm{u}$ sind. Dies ist ein Phänomen, das auch von anderen Autoren beobachtet worden ist (z. B. DUNEMANN und SCHWEDT 1984).

Zur Erklärung dieser Erscheinung ist zwar von „Durchrutschen“, eventuell unter flexibler Verformung gedacht worden (siehe dazu auch GHOSH und SCHNITZER 1980), doch ist als wahrscheinlicher anzusehen, dass es sich um Makromoleküle $>500.000 \mathrm{u}$ handelt, die sich hydrolytisch depolymerisierend unter Einstellung von Polymerisationsgleichgewichten in feinere Molekülgrößen zerteilen. Diese passieren mit dem Wasserstrom die Membran und polymerisieren danach unter Wiedereinstellung des Polymerisationsgleichgewichtes wieder sehr schnell unter Erzeugung sekundärer Polymer-Moleküle $>50.000$ sogenannter Supramoleküle (vergl. GONZÀLES-GAITANO und GARCÍA-MINA 2004). Untersuchungsergebnisse zum Polymerisationsverhalten von monomeren Huminsäurekomponenten zu polymeren Huminsäure-Aggregaten wurden bereits 1981 von ROCHUS veröffentlicht (ROCHUS 1981).

\subsection{Adsorptions-Chromatographie}

\subsubsection{Methodik}

Die Adsorption an makroporösen, nicht-ionischen Adsorberharzen kann für die Anreicherung, Isolierung oder Reinigung von Huminstoffen (HUS) aus wässriger Lösung eingesetzt werden. Die Adsorptions-Chromatographie gehört zu den gängigen Verfahren der Anreicherung von Humin- und Fulvosäuren aus Gewässern (MANTOURA und RILEY 1975, FRIMMEL 1977). Sie ist weniger zur Stoffgruppen-Fraktionierung als zur Anreicherung und Reinigung verschiedener organischer Verbindungen mit übereinstimmenden organischen Gruppen geeignet. Die treibende Kraft für die Sorption ist der hydrophobe Effekt der Säulenmatrix.

Die Anreicherung der HUS erfolgt aus sauren Lösungen, durch die Sorption des C-Skeletts nicht-ionischer Moleküle. Ohne Ansäuerung der Proben findet keine Adsorption von Huminstoffen an den Adsorberharzen statt. Die Desorption findet bei höheren pH-Werten statt, die eine Deprotonierung der funktionellen Gruppen und damit ein Überwiegen des hydrophilen Charakters bewirken. Hierbei soll eine effektive Trennung der Huminstoffe von organischen Nicht-Huminstoffen, wie Hydroxysäuren, Uronsäuren oder einfachen Kohlenhydraten, sowie sorbierten, ionisch gebundenen und teilweise sogar komplexierten Metallen stattfinden.

\subsubsection{Durchführung}

Die Untersuchungsproben wurden mit konz. $\mathrm{HCl}$ auf $\mathrm{pH}$-Werte zwischen 1,1 und 2,5 eingestellt. Anschließend wurden 0,9 bis 2 I der Probe auf die zuvor mit dest. Wasser, verd. $\mathrm{NaOH}(\mathrm{c}=0,2 \mathrm{~mol} / \mathrm{l})$, dest. Wasser und verd. $\mathrm{HCL}(\mathrm{c}=0,01 \mathrm{~mol} / \mathrm{l})$ gespülte Säule aufgebracht. Eingesetzt wurden die Harze des Amberlite-XAD-Typs (Merck) auf PolystyrolBasis (XAD 2) und aus Acrylester (XAD 8). Für die Anreicherung der HUS aus den Sickerwasserproben zeigte das XAD 2 Harz höhere Ausbeuten während für die Anreicherung der Fulvosäuren nach der Huminsäure-Fällung das XAD 8 Harz verwendet wurde.

\section{HUS-Konzentrierung mit XAD 2 und HA-Fällung}

Die Tropfgeschwindigkeit während der Anreicherungsphase lag bei etwa $2,5 \mathrm{ml} / \mathrm{min}$. Die Anreicherung der HUS am Adsorberharz war optisch durch die voranschreitende Braunfär- 
bung des Harzes zu erkennen. Obwohl in der Regel nur etwa ein Drittel der Säulenfüllung dunkelbraun gefärbt war und damit augenscheinlich noch freie Kapazität der Säulenfüllung gegeben war, wurde im Laufe der Perkolation der Sickerwasserprobe bereits eine zunehmende Gelbfärbung der Eluate festgestellt. Nach einem durch starke Gelbfärbung der Eluate angezeigten Abschluss der Anreicherung erfolgte eine Reinigung der Säule mit verd. $\mathrm{HCL}$ und dest. Wasser. Anschließend wurden die HUS mit verd. $\mathrm{NaOH}$ desorbiert. Hier lag die bei etwa $1 \mathrm{ml} / \mathrm{min}$.

In den alkalischen Eluaten wurden durch Zugabe von $25 \%$ iger $\mathrm{HCl}$ die Huminsäuren (HA) ausgefällt und abfiltriert (Membranfiltration 0,45 $\mu \mathrm{m}$ ).

\section{Fulvosäuren-Konzentrierung XAD 8 und Isolierung}

Die im Filtrat gelösten Fulvosäuren (FA) wurden adsorptions-chromatographisch an XAD 8 angereichert, gereinigt und nach der Desorption mit $\mathrm{NaOH}$ und nach anschließendem Kationenaustausch mit dem stark sauren lonenaustauscher IA Amberlite IR 120 im BatchVerfahren durch schonende Trocknung isoliert.

In den nach den Phasen Anreicherung - Reinigung - Desorption - Reinigung - HA-Fällung getrennten Säulen-Eluaten wurden die Leitfähigkeit, der pH-Wert, die DOC-Konzentrationen und die Konzentrationen der Kationen $\mathrm{Fe}, \mathrm{Ca}, \mathrm{Mg}$ und $\mathrm{K}$ bestimmt (Methoden siehe Tabelle 6-6). Die Bestimmungen erfolgten nicht durchgängig in allen Eluaten.

Tabelle 7-28 zeigt beispielhaft die Anzahl der getrennt aufgefangenen Eluate für jeden Prozessschritt der analytischen Trennung. Bei dem hier ausgewählten Beispiel sind die Eluate in die größte Anzahl an Einzelproben unterteilt. Die Volumina der Einzelproben lagen zwischen 50 und $1000 \mathrm{ml}$.

Tabelle 7-28: Arbeitsschritte und Zuordnung der Eluate der Adsorptions-Chromatographie

\begin{tabular}{|c|c|}
\hline $\begin{array}{c}\text { Proben- } \\
\text { Nummerierung }\end{array}$ & Arbeitsschritt \\
\hline \multicolumn{2}{|r|}{ HUS-Konzentrierung mit XAD 2 und HA-Fällung } \\
\hline $1 \rightarrow 17$ & Eluate der XAD 2-Säule mit Sickerwasser beaufschlagt, Anreicherung \\
\hline $18 \rightarrow 29$ & Eluate der XAD 2-Säule nach Spülung mit Wasser, Reinigung \\
\hline $30 \rightarrow 34$ & $\begin{array}{l}\text { Eluate der XAD 2-Säule alkalische Desorption und Elution der HUS- } \\
\text { Adsorbate, Desorption }\end{array}$ \\
\hline $35 \rightarrow 38$ & Eluate der XAD 2-Säule nach Spülung mit Wasser, Reinigung \\
\hline 40,41 aus $30 \rightarrow 34$ & HA, säuregefällt aus $30 \rightarrow 34$, HA-Gewinnung \\
\hline 42,43 aus $30 \rightarrow 34$ & Filtrat nach HA-Fällung \\
\hline \multicolumn{2}{|r|}{ Fulvosäuren-Konzentrierung XAD 8 und Isolierung } \\
\hline 44 & Eluate der XAD 8-Säule mit 42, 43 beaufschlagt, Anreicherung \\
\hline 45 & Eluate der XAD 8-Säule nach Spülung mit Wasser, Reinigung \\
\hline 46 & $\begin{array}{l}\text { Eluat der XAD 8-Säule alkalische Desorption und Elution der FA-Adsorbate, } \\
\text { Desorption }\end{array}$ \\
\hline 47 & Eluat der XAD 8-Säule nach Spülung mit Wasser, Reinigung \\
\hline 48 & Gereinigte FA, FA-Gewinnung \\
\hline
\end{tabular}




\subsubsection{Untersuchungsproben}

Untersucht wurden durch Zentrifugation gewonnene Sickerwasserproben der Großlysimeter 1 und 2 vom Juli 1988 und eine papierfiltrierte Probe von Lysimeter 1 vom Dezember 1988. Es wurden insgesamt nur 5 Adsorptions-Chromatographie-Durchgänge ausgewertet. In den ersten beiden Durchgängen mit der Sickerwasser-Probe vom 07.07.1988 von Lysimeter 1 wurde keine Bestimmung der DOC-Gehalte in den Eluaten durchgeführt. In den weiteren drei Durchgängen mit den Sickerwasser-Proben vom 07.07.1988 der Lysimeter 1 und 2 und der Sickerwasser-Probe vom 14.12.1988 von Lysimeter 1 wurden die Gehalte an organischer Substanz quantifiziert und nach Abtrennung der ausgefällten Huminsäuren (HA) aus den alkalischen HUS-Eluaten auch die Fulvosäuren (FA) isoliert. Bei dem AdsorptionsChromatographie-Durchlauf der Sickerwasser-Probe von Lysimeter 1 (14.12.1988) wurden durch die verlängerte Reinigung mit destilliertem Wasser bereits große Mengen an sorbierten Huminstoff-Verbindungen desorbiert.

\subsubsection{Ergebnisse}

Die Tabellen 1-87 bis 1-91 und Abbildungen 1-16 bis 1-18 im Anhang geben die in den Säulen-Eluaten ermittelten $\mathrm{pH}$-Werte, DOC- und Kationen-Konzentrationen für die Sickerwasserproben von Lysimeter 1 vom 07.07.1988 und 14.12.1988 und Lysimeter 2 vom 07.07.1988 wieder. Der Verlauf der DOC- und Kationen-Konzentrationen in den Eluaten der Sickerwasser-Probe von Lysimeter 1 vom 07.07.1988 ist in der Abbildung 130 graphisch dargestellt.

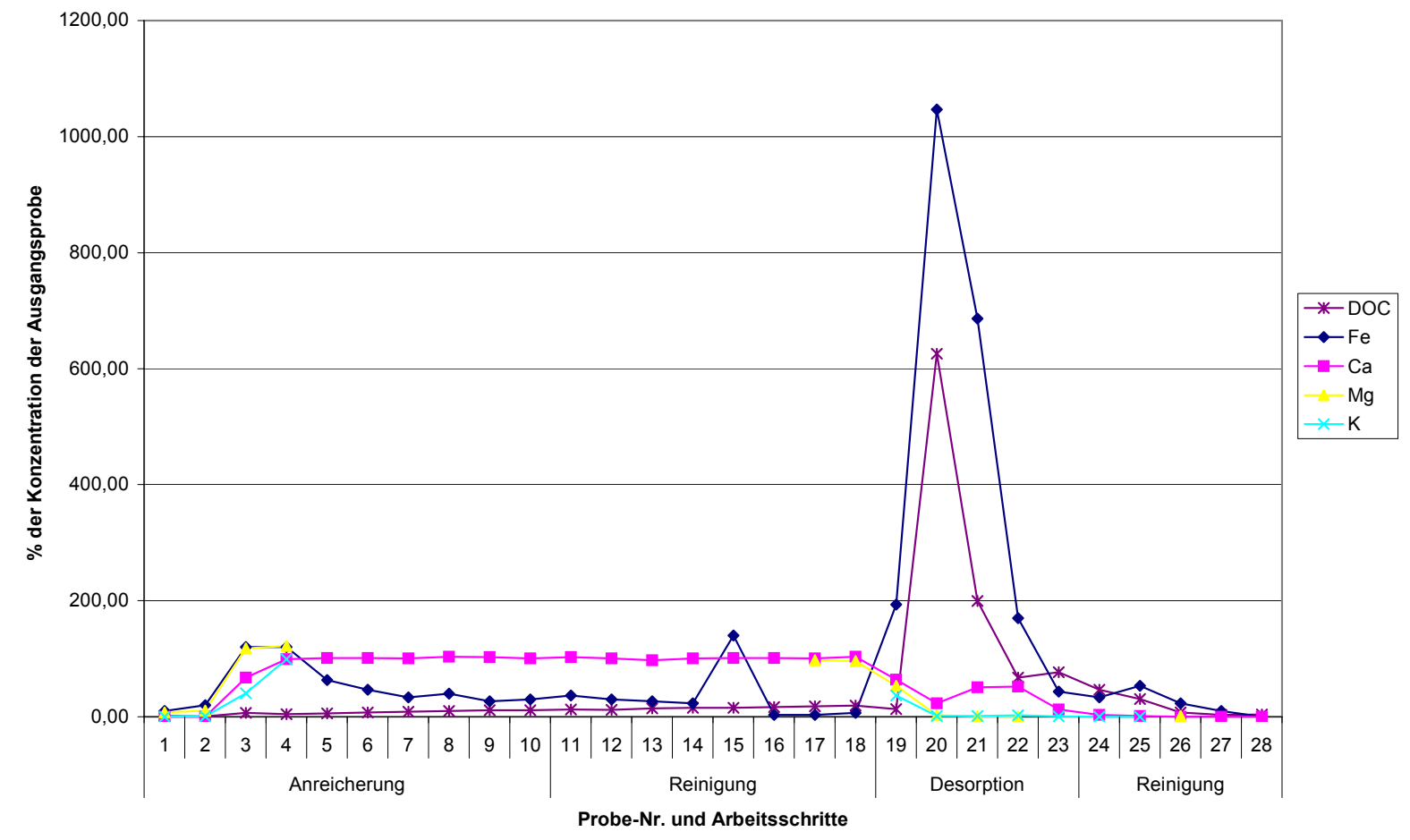

Abbildung 130: Verlauf der DOC- und KationenKonzentrationen in \% des Ausgangsgehaltes in den schrittweisen Eluaten der AC, Sickerwasserprobe vom 07.07.1988, Lysimeter 1

Die Abbildungen 130 und 1-16 bis 1-18 im Anhang zeigen Folgendes: 
Während der Beaufschlagung der Säulen mit dem Lysimeter-Sickerwasser passieren $\mathrm{K}, \mathrm{Mg}$ und $\mathrm{Ca}$ die Chromatographie-Säule in unveränderter Konzentration (100 \%) Beim Fe dagegen sinkt die Konzentration mit fortschreitender Durchlaufmenge ab: bei Lysimeter 1 von 100 in der Ausgangslösung auf $3 \%$ im Eluat, bei Lysimeter 2 auf $40 \%$ im Eluat. Nach Beendigung der Sickerwasser-Zufuhr, d.h. während des Spülens und Desorbierens verschwinden die Alkali- und Erdalkali-Kationen weitgehend aus dem System, während das Fe in 2- bis 4-facher Konzentrierung mit den adsorptiv angereicherten Huminstoffen desorbiert wird.

Die im Sickerwasser enthaltene organische Substanz wird weitgehend adsorbiert. In der Durchlauf-Lösung ist die DOC-Ausgangskonzentration des Sickerwassers auf $10-20 \%$ vermindert.

Tabelle 7-29 zeigt die Auswertung der DOC-Gehalte in den Eluaten der Adsorptios-Chromatographie.

Tabelle 7-29: DOC-Verteilung in den bei der AC gewonnenen Fraktionen für die Sickerwasser-Proben, Lysimeter 1 und 2 (07.07.1988) und Lysimeter 1 (14.12.1988)

\begin{tabular}{|c|c|c|c|c|c|c|}
\hline Lysimeter & & & & & 1 & \\
\hline $\begin{array}{l}\text { Probenahme-Datum } \\
\text { Probenmenge in I }\end{array}$ & $\begin{array}{r}07.07 .8 \\
1,6\end{array}$ & & $\begin{array}{r}07.07 .8 \\
0,8\end{array}$ & & $\begin{array}{r}14.12 .88 \\
2,00\end{array}$ & \\
\hline DOC-Gehalt im Sickerwasser & $\begin{array}{c}\mathrm{mg} \\
277,0\end{array}$ & $\begin{array}{c}\% \\
100,0\end{array}$ & $\begin{array}{c}\mathrm{mg} \\
214,0\end{array}$ & $\begin{array}{c}\% \\
100,0\end{array}$ & $\begin{array}{c}\mathrm{mg} \\
1162,0\end{array}$ & $\begin{array}{c}\% \\
100,0\end{array}$ \\
\hline DOC-Gehalte in den Eluaten d & & & & & & \\
\hline Anreicherung & & & & & 236,0 & 20,3 \\
\hline Reinigung & & & & & 135,0 & 11,6 \\
\hline $\begin{array}{l}\text { Summe nicht sorbierbar } \\
\text { neutralen Desorption }\end{array}$ & 40,0 & 14,4 & 20,0 & 9,3 & $\begin{array}{l}371,0 \\
459,0\end{array}$ & $\begin{array}{l}31,9 \\
39,5\end{array}$ \\
\hline alkalischen Desorption & 196,0 & 70,8 & 93,0 & 43,5 & 282,0 & 24,3 \\
\hline Summe desorbierbar & 196,0 & 70,8 & 93,0 & 43,5 & 741,0 & 63,8 \\
\hline rechnerischer Rest & 41,0 & 14,8 & 101,0 & 47,2 & 50,0 & 4,3 \\
\hline Ausbeute nach Säurefällung a & & & & & & \\
\hline HA & 31,0 & 11,2 & 6,0 & 2,8 & 405,0 & 34,9 \\
\hline FA & 165,0 & 59,6 & 87,0 & 40,7 & 336,0 & 28,9 \\
\hline
\end{tabular}

Die Berechnung ergibt einen adsorbierbaren Anteil organischer Substanz in Höhe von 60 bis $91 \%$ des Gehaltes in den Lysimeter-Abflüssen. Davon lassen sich 43 bis $71 \%$ alkalisch desorbieren. 4,3 bis $47 \%$ des DOC des Lysimeter-Abflusses verbleiben allerdings irreversibel an der Säulenmatrix.

Außer beim Fe findet unter den Bedingungen der AC keine nennenswerte Sorption von Kationen statt (siehe Tabelle 7-30). Im Vergleich zur Ultrafiltration wird bei der AdsorptionsChromatographie ein weitaus größerer Anteil der anorganischen Begleitstoffe von der organischen Matrix getrennt, nur ein gewisser offensichtlich sehr fest gebundener Anteil des Eisen verbleibt in organischer Bindung. Die fast vollständige Abtrennung der Erdalkali- und Alkali-Kationen bei der Adsorptions-Chromatographie ist auf die vorausgegangene Einstellung eines geringen $\mathrm{pH}$-Wertes während der Anreicherung zurückzuführen. Sie lässt - bis auf Eisen - auf labile Bindungen zwischen den Kationen und der organischen Substanz schließen. Die berechneten Kationenverhältnisse in den alkalischen Eluaten zeigen (siehe 
Tab. 1-87 bis 1-91 im Anhang), wie auch schon bei der Ultrafiltration, eine Bevorzugung des Ca gegenüber $\mathrm{Mg}$ und $\mathrm{K}$.

\begin{abstract}
Tabelle 7-30: Kationen in \% der Ausgangs-Konzentration der Sickerwasser-Probe in den alkalischen HUS-Eluaten, Lysimeter 1 und 2 (07.07.1988) und Lysimeter 1 (14.12.1988)
\end{abstract}

\begin{tabular}{l|c|cccc} 
Lysimeter & $\begin{array}{c}\text { Probenahme- } \\
\text { Datum }\end{array}$ & $\mathbf{F e}$ & $\begin{array}{c}\text { Ca } \\
\text { \% }\end{array}$ & Mg & K \\
\hline & & & & & \\
$\mathbf{1}$ & $\mathbf{0 7 . 0 7 . 1 9 8 8}$ & 100,00 & 4,50 & 0,20 & 0,20 \\
$\mathbf{2}$ & $\mathbf{0 7 . 0 7 . 1 9 8 8}$ & & 2,00 & 0,04 & 0,05 \\
$\mathbf{1}$ & $\mathbf{1 4 . 1 2 . 1 9 8 8}$ & 15,00 & 0,40 & 0,40 & 0,00
\end{tabular}

Das Adsorbat aus der Adsorptions-Chromatographie des Sickerwassers vom 14.12.1988 wurde zusätzlich durch Ultrafiltration und der Durchlauf der Adsorptions-Chromatographie zusätzlich durch Gelfiltration untersucht. Die organische Substanz des Durchlaufs hat danach eine Molmasse von $1086 \mathrm{u}$ (siehe Tabelle 1-80 im Anhang). Das Adsorbat müsste danach die Teilchengrößen von 1086 bis über 50.000 u umfassen.

Wie Tabelle 7-31 zeigt ergibt die Ultrafiltration der alkalischen Eluate des Adsorbats (Probenbez. M 3) nur einen sehr geringen Anteil von 6,3\% an Verbindungen größer als 50.000 $u$. Da in dem nicht vorbehandelten Sickerwasser durch Ultrafiltration $41 \%$ der organischen Verbindungen als Teilchen der Größe über 50.000 u nachgewiesen worden waren, muss die nach der Adsorptions-Chromatographie nachgewiesene Teilchen-Verkleinerung das Ergebnis der Vorbehandlung durch Anreicherung, Reinigung und Desorption sein.

Tabelle 7-31: DOC- Gehalte 1. Filtrat (F), 1. Dialysat (D) und 1. Retentat $(R)$ nach Ultrafiltration der alkalischen HUSEluate, Lysimeter 1 (14.12.1988)

\begin{tabular}{l|c|ccc}
$\begin{array}{l}\text { Proben- } \\
\text { Bezeichnung }\end{array}$ & $\begin{array}{c}\text { Volumen } \\
\text { ml }\end{array}$ & $\begin{array}{c}\text { DOC } \\
\text { mg/l }\end{array}$ & mg & \% \\
\hline M3 & & & & \\
1. F (1) & $\mathbf{2 5 8}$ & 705,00 & 181,89 & 100,00 \\
1. F (2) & $\mathbf{2 4 0}$ & 281,00 & 67,44 & 37,08 \\
1. D (1) & $\mathbf{1 1}$ & 7482,50 & 82,31 & 45,25 \\
1. D (2) & $\mathbf{1 0 0}$ & 236,50 & 23,65 & 13,00 \\
1. R & $\mathbf{1 0 0}$ & 26,00 & 2,60 & 1,43 \\
& $\mathbf{5 0}$ & 230,00 & 11,50 & 6,32
\end{tabular}

Bei der Versuchsvariante der Adsorptions-Chromatographie der Sickerwasser-Probe Lysimeter 1, 14.12.1988, ist nach erfolgter Adsorption der HUS in insgesamt 12 Spülgängen statt mit insgesamt nur ca. $500 \mathrm{ml}$ mit insgesamt 7 I dest. Wasser nachgewaschen worden. Dabei wurden nach und nach von der sorbierten organischen Substanz, $68 \%$ des im Sickerwasser enthaltenen DOC, 59 \% wieder eluiert, also $40 \%$ des Sickerwasser DOC. In diesen wässrigen Eluaten des Adsorbats erbrachte die Säurefällung eine Ausbeute von rund einem Drittel an fällbaren Huminsäuren, entsprechend zwei Drittel Fulvosäuren. Die Huminsäuren enthalten durchschnittlich $48,81 \% \mathrm{C}$ und $3,95 \% \mathrm{~N}$, was einem C/N-Verhältnis von 12,4 entspricht. Die Fulvosäuren weisen 40,20 \% C und 3,98 \% N bei einem C/NVerhältnis von 10,1 auf. 
Tabelle 7-32: Humin- und Fulvosäuren in den wässrigen Extrakten, Ausbeuten, C-, N-Gehalte und Verhältnisse, Lysimeter 1 (14.12.10988)

\begin{tabular}{l|c|c|c|ccc}
$\begin{array}{l}\text { Proben- } \\
\text { Bezeichnung }\end{array}$ & $\begin{array}{c}\text { Menge } \\
\mathbf{m l}\end{array}$ & Fraktion & $\begin{array}{c}\text { Ausbeute } \\
\mathbf{m g}\end{array}$ & $\begin{array}{c}\mathbf{C} \\
\mathbf{\%}\end{array}$ & $\begin{array}{c}\mathbf{N} \\
\mathbf{\%}\end{array}$ & $\mathbf{C / N}$ \\
\hline $\mathbf{3 1}$ & \multirow{2}{*}{1400} & HA & 64,8 & 50,31 & 4,103 & 12,3 \\
& & FA & 300,0 & 39,48 & 3,994 & 9,9 \\
& & & & & & \\
M2 & \multirow{2}{*}{950} & HA & 61,7 & 47,31 & 3,804 & 12,5 \\
& & FA & 32,4 & 40,91 & 3,972 & 10,3
\end{tabular}

Von der sorbierten organischen Substanz werden $59 \%$ nach und nach durch Wasser eluiert, von den verbleibenden $41 \%$ lassen sich durch alkalische Elution $35 \%$ extrahieren, während $6 \%$ irreversibel am Adsorbens verbleiben. Von den $35 \%$ sind $75 \%$ (26\% des im Sickerwasser enthaltenen DOC) Huminsäuren. Insgesamt liegt der Anteil der Huminsäuren am Gesamt-DOC des Sickerwassers bei rund $39 \%$.

Bei Adsorptionsgängen mit einer weniger ausgedehnten dest. Wasser Spülung sind im Adsorbat $100 \%$ des im Sickerwasser befindlichen Fe zu erwarten. Bei der hier durchgeführten intensiven Wasserspülung sind von den $100 \%$ Fe bereits $85 \%$ eluiert worden. Das heißt, dass das verbliebene Adsorbat relativ eisenärmer ist als das wässrige Eluat des Adsorbats. Das alkalische Extrakt des Rest-Adsorbats enthält noch $15 \%$ der Ausgangsmenge an Fe, während der nicht extrahierbare Anteil des Adsorbats rechnerisch als frei von Fe angesehen werden muss. Das wiederum würde heißen, dass die Komplexierung des Eisens schwerpunktmäßig in den mobileren Fraktionen des Adsorbats aus Huminsäuren und Fulvosäuren liegt.

Für die säurefällbaren C-Anteile im Wasserextrakt (WE) und im Laugenextrakt (LE) des Adsorbats lassen sich folgende Atom-Verhältnisse C:Fe errechnen: Huminstoffe (WE) 162 , Huminstoffe (LE) 1239.

Der Adsorptions-Chromatographie Versuch mit verlängerter Wasserspülung des Adsorbats lässt vermuten, obwohl dies hier nicht nachgewiesen ist, dass offenbar fortgesetzte Depolymerisations-Vorgänge an den höher molekularen Huminstoff-,,Aggregaten“ stattfinden, die zu einer Ablösung der niedermolekularen Depolymerisate führen. Diese wiederum sind in wässriger Lösung dazu befähigt, sich wieder zu höher molekularen Körpern zu aggregieren. Ob dieses physikochemischen Depolymerisations- / Polymerisations-Gleichgewichten folgt, sei dahingestellt.

Interessant ist in diesem Zusammenhang, dass das Eisen offenbar nicht die erwartete Polymerisat stabilisierende Rolle spielt, da die Ablösung von Adsorbat durch Wasser sogar die Fe-reichen Komponenten bevorzugt.

\subsubsection{Anionen-Transport}

Nach den im vorangegangenen Abschnitt dargestellten Befunden unterliegen die Sickerwasser und wässrigen Extrakten enthaltenen organischen Verbindungen der Gruppe Huminstoffe bei ihrer Fraktionierung mit Hilfe der Membran- und Ultrafiltration sowie der Adsorptions-Chromatographie Mengen-Umverteilungen, die in Zusammenhang mit einer fortlaufenden Störung und Neueinstellung von Polymerisationsgleichgewichten entstehen. Somit sind die Mengenangaben zu den einzelnen Fraktionen in erheblichem Maß durch Artefakt-Bildungen bedingt, die von der Art des jeweiligen Trenn-Verfahrens abhängig sind.

In diesem Kapitel soll das Verhalten der Anionen bei der Adsorptions-Chromatographie mit den übrigen Trennmethoden verglichen werden. Bei den Anionen $\mathrm{Cl}, \mathrm{NO}_{3}, \mathrm{SO}_{4}$ ist keine 
Verfahrensabhängigkeit festzustellen: Sie wandern bei der Aufbereitung ohne Retention in die ionar-feinmolekularen Lösungen (UF: 4. Filtrat, AC: Eluate 1 - 17).

Beim Silikat und auch annähernd bei $\mathrm{P}$ ist die Situation davon abweichend - ähnlich der bei den Huminstoffen:

Tab. 7-33 gibt die in den Filtraten und Eluaten gemessenen Si-, P- und N-Konzentrationen für Lysimeter 1 an. Die im papierfiltrierten Sickerwasser gewonnenen Si-Mengen werden gleich $100 \%$ gesetzt und die in den Filtraten der kombinierten Papier/Membran-Filtration, der Ultrafiltration (4. Filtrat) und der Adsorptions-Chromatographie (Eluate 1 - 17) analysierten Si-Mengen auf den $100 \%$ Wert bezogen.

Tabelle 7-33: Konzentrationen an Si, $\mathrm{P}$ und $\mathrm{N}$ in den Filtraten und Eluaten der Filtration und Adsorptions-Chromatographie, Lysimeter 1

\begin{tabular}{l|c|cc|cc|cc}
$\begin{array}{c}\text { Datum der } \\
\text { Probenahme }\end{array}$ & \multicolumn{2}{|c|}{$\mathbf{S i}$} & \multicolumn{2}{|c}{$\mathbf{P}$} & \multicolumn{2}{|c}{$\mathbf{N}$} \\
& Vorbehandlung & $\mathbf{m g} / \mathbf{l}$ & $\mathbf{\%}$ & $\mathbf{m g} / \mathbf{l}$ & $\mathbf{\%}$ & $\mathbf{m g} / \mathbf{l}$ & $\%$ \\
\hline $\mathbf{1 4 . 1 2 . 8 8}$ & $\mathbf{p}$ & 69,3 & 100,0 & 8,4 & 100,0 & 96,0 & 100,0 \\
$\mathbf{1 4 . 1 2 . 8 8}$ & $\mathbf{p} \mathbf{m}$ & 38,2 & 55,1 & & & & \\
$\mathbf{1 4 . 1 2 . 8 8}$ & UF 4. F & 53,3 & 76,9 & 5,7 & 67,9 & 85,0 & 88,5 \\
$\mathbf{1 4 . 1 2 . 8 8}$ & AC Eluate 1 - 17 & 1,8 & 2,6 & 7,1 & 84,5 & 96,0 & 100,0 \\
& & & & & & & \\
$\mathbf{2 2 . 1 2 . 8 8}$ & $\mathbf{p}$ & 44,5 & 100,0 & & & &
\end{tabular}

Die bloße Membran-Filtration hält $45 \%$ des offenbar in beträchtlichen Anteilen polymersiert im Sickerwasser vorliegenden Silikats zurück. Bei der Ultrafiltration mit ihrer Verhinderung der Niederschlagsbildung durch Rühren und der wässrigen Verdünnung bei der Dialyse führt die Depolymerisation zu einer stärkeren Si-Passage. Die stärkste Retention von Si findet bei der Adsorptions-Chromatographie statt, wobei zu bedenken ist, dass dabei die Ausgangslösung angesäuert wird, was die Löslichkeit von Kieselsäure senkt.

Beim Phosphat bewirkt die Ultrafiltration eine Retention von $32 \%$, die Adsorptions-Chromatographie eine solche von nur $15 \%$, was hier mit der löslichkeitsfördernden Wirkung der Ansäuerung zu erklären ist. 


\section{Bepflanzung}

\subsection{Anbau, Pflege und Ernte}

Von Mai 87 bis August 89 wurden verschiedene Kulturpflanzen auf den Lysimetern angepflanzt. Eine Zusammenstellung der Pflanzenarten, Aussaat- und Erntezeiten für die Lysimeter 1 bis 8 sind der Tabelle 8-1 zu entnehmen. Für die erste Anbauphase von Mai bis August 1987 sind die Stückzahlen in Klammern angegeben.

Tabelle 8-1: Anbauplan

\begin{tabular}{|c|c|c|c|}
\hline Lysimeter & Pflanzenart & Pflanzung/Aussaat & Erntezeitpunkt \\
\hline 1 & $\begin{array}{l}\text { Wirsing (14), Weißkohl ( 11), } \\
\text { Rotkohl (8), Steckrüben (17) }\end{array}$ & 07. - 27.05 .87 & Ab 05.08.87 \\
\hline 2 & Steckrüben (50) & 07. - 27.05.87 & $\mathrm{Ab} 05.08 .87$ \\
\hline $3,4,5$, und 6 & Steckrüben (8), Grünkohl (8) & 07. - 27.05.87 & Ab 05.08.87 \\
\hline 7 und 8 & Steckrüben (6), Grünkohl (6) & 07. - 27.05.87 & Ab 05.08.87 \\
\hline $1-8$ & Winterweizen I & 29.09.1987 & 28.06.1988 \\
\hline $1-8$ & Gelbsenf & 01.07.1988 & 30.09 .1988 \\
\hline $1-8$ & Winterweizen II & 01.10 .1988 & 16.08.1989 \\
\hline
\end{tabular}

Die Pflanzen dienten als Anzeiger für Salzschäden und bewirkten eine Erhöhung der Evapotranspiration. Aufgrund der anfangs noch hohen Salzgehalte der Komposte wurden zunächst Kohl und Steckrüben angepflanzt, die nach KUNTZE et al. 1983 und KNICKMANN \& TEPE 1966 eine mittlere bis hohe Salzverträglichkeit von 0,40-0,76 Gew. $\%$ Salz des Bodens aufweisen. Um unterschiedliche Auswirkungen der Salzkonzentration ermitteln zu können, wurden auf Lysimeter 1 verschiedene Kohlarten angepflanzt. Auf Lysimeter 2 wurden ausschließlich Steckrüben und auf den Lysimetern 3 bis 8 Steckrüben und Grünkohl gemeinsam angepflanzt. Während der ersten Anbauphase wurde regelmäßig Unkraut gejätet. Das Unkraut wurde auf dem jeweiligen Lysimeter belassen. Die Pflanzen wurden zur Behebung der Salzschäden und bei Wassermangel bewässert. Wegen der mit zunehmendem Lössanteil steigenden Verkrustung der Bodenoberfläche erfolgte eine mechanische Lockerung des Bodens.

Die Abbildungen 2-1 bis 2-7 im Anhang zeigen den Bewuchs der Lysimeter $1-8$ im Mai und im Juni 1987.

Nach der Ernte des Kohls und der Rüben und dem Rückgang der Salzkonzentration wurde Ende September 1987 auf allen Lysimetern Winterweizen (Winterweizen I) ausgesät. Nach dessen Ernte erfolgte von Juli bis September 1988 auf allen Lysimetern der Anbau von Gelbsenf und abschließend von Oktober 1988 bis August 1989 erneut der Anbau von Winterweizen (Winterweizen II). Es erfolgten während dieser Anbauphasen keine weiteren Pflegemaßnahmen mehr. Die Ernte der Pflanzen fand aus praktischen Gründen nicht zu den für die Pflanzen typischen Ernte-Zeitpunkten statt. Der Winterweizen I wurde sehr früh in noch milchreifem Zustand geerntet während der Winterweizen II erst sehr spät in der 
Totreife geerntet wurde. Hier traten bereits Körner-Verluste durch Herausfallen und Vogelfraß auf.

Nach der Ernte des zweiten Winterweizens wurde keine Bepflanzung mehr durchgeführt. Auf den Lysimetern stellte sich ein recht üppiger Wildkräuterbewuchs ein. Die Abbildungen 2-8 bis 2-15 im Anhang zeigen die Lysimeter bei Versuchsende im März 1990. Auffallend war die im Vergleich zu den übrigen Lysimetern geringe Pflanzendichte auf Lysimeter 1.

\subsection{Untersuchung der Pflanzen}

\subsubsection{Methodik}

\subsubsection{Ertrag}

Die geernteten Pflanzenteile wurden frisch gewogen. Bei den Steckrüben wurde die gesamte Pflanze geerntet, wohingegen bei den übrigen Pflanzen nur die oberirdische Pflanzenmasse entnommen wurde. Wurzelmasse und Halmreste verblieben danach in den Lysimetern. Die Steckrüben wurden in Rübenkörper und Rübenblatt getrennt. Die Bestimmung der Trockenmasse erfolgte gravimetrisch. Hierzu wurden ca. 50 - $100 \mathrm{~g}$ der zu untersuchenden Probe eingewogen und bei $105^{\circ} \mathrm{C}$ bis zur Gewichtskonstanz getrocknet. Die Trockensubstanz-Mengen werden in $\mathrm{g}$ angegeben und entsprechend den Anbau-Flächen in $\mathrm{dt} /$ ha umgerechnet.

\subsubsection{C- und N-Gehalte}

Die Bestimmung der Gesamtgehalte an Kohlenstoff und Stickstoff erfolgte mit dem Kohlenstoff-/Stickstoff-Analysator ANA 1500 der Firma CARLO ERBA. Hierzu wurden $1-4 \mathrm{mg}$ von dem bei $105{ }^{\circ} \mathrm{C}$ getrockneten und gemahlenen Pflanzenmaterial eingewogen. Es erfolgte eine vollständige Verbrennung der Probe bei $1200^{\circ} \mathrm{C}$ in einem geschlossen System. Die zu bestimmenden Gase $\mathrm{N}_{2}$ und $\mathrm{CO}_{2}$ wurden gaschromatographisch getrennt und anhand ihrer Wärmeleitfähigkeit quantitativ bestimmt.

\subsubsection{Bestimmung der Bioelemente}

Für die Bestimmung der mineralischen Bioelemente wurden zwei verschiedene Aufschlussarten angewendet. Die Bestimmung der Elemente $\mathrm{Ca}, \mathrm{Mg}, \mathrm{K}, \mathrm{Na}$ und $\mathrm{P}$ erfolgte im Gesamtaufschluss. Hierzu wurden jeweils 500 - $1000 \mathrm{mg}$ von dem getrockneten und gemahlenen Pflanzenmaterial in entsprechend vorbereitete Tiegel eingewogen und nach der Vorveraschung im Sandbad bei $620^{\circ} \mathrm{C}$ im Muffelofen geglüht. Anschließend wurde die abgekühlte Asche in $10 \mathrm{ml} 50 \%$ iger $\mathrm{HNO}_{3}$ aufgenommen, erhitzt und über aschefreie Filter von WHATMAN filtriert. In der Aufschlusslösung wurden die Kationen $\mathrm{Mg}, \mathrm{K}$ und $\mathrm{Na}$ mittels Atomabsorptions-Spektrometrie und $\mathrm{Ca}$ anhand der Flammenemissions-Spektrometrie bestimmt. Die P-Bestimmung in der Aufschlusslösung erfolgte photometrisch nach Zugabe von Ascorbinsäure-Lösung und Molybdat/Tartrat-Lösung bei $882 \mathrm{~nm}$.

Wegen der Verluste an $\mathrm{Cl}$ und $\mathrm{SO}_{4}$ in der so gewonnenen Aufschlusslösung wurde die getrennte Bestimmung dieser Anionen nach der von KAMP (1987) beschriebenen Methode durchgeführt. Hierzu wurden $2 \mathrm{~g}$ der getrockneten und gemahlenen Probe in $5-20 \mathrm{ml}$ $\mathrm{NaOH}(\mathrm{c}=0,1 \mathrm{~mol} / \mathrm{l})$ über Nacht gequollen und anschließend $10 \mathrm{~h}$ bei $480^{\circ} \mathrm{C}$ verascht. Die Asche wurde je nach zu bestimmendem Anion entweder in $\mathrm{H}_{2} \mathrm{SO}_{4}(\mathrm{c}=0,05 \mathrm{~mol} / \mathrm{l})$ oder $\mathrm{HCl}$ $(\mathrm{c}=0,1 \mathrm{~mol} / \mathrm{l})$ aufgenommen, $3 \mathrm{~h}$ stehen gelassen und anschließend über aschefreie Filter von WHATMAN filtriert. Die Bestimmung der Anionen in den so gewonnenen Aufschlusslösungen erfolgte potentiometrisch am Titroprozessor 636 des Herstellers METROHM nach Ausfällung von $\mathrm{AgCl}$ bzw. $\mathrm{BaSO}_{4}$.

\subsubsection{Ergebnisse}

Sichtbare Salzschäden an den Pflanzen traten zu Versuchsbeginn auf den Großlysimetern 1 und 2 auf. Die Salzschäden konnten durch Bewässerung aufgehoben werden. Im 
Jugendstadium zeigten die Steckrüben der Mischungsvarianten ebenfalls Beeinträchtigungen, die mit zunehmendem Alter abnahmen. Die Pflanzen auf Lysimeter 7 mit reinem LössBoden litten trotz der Pflegemaßnahmen während der ersten Anbauphase unter der Verkrustung.

Die Tabelle 8-2 zeigt die Erntemengen der angebauten Pflanzen in g für die Lysimeter 1 - 8. Auf Lysimeter 1 wurden Steckrüben und verschiedene Kohlarten gleichzeitig angepflanzt. Die jeweils bepflanzte Fläche wird anhand der Pflanzen-Verhältnisse berechnet. Ebenso wird bei Lysimeter $3-8$ verfahren, wo Steckrüben und Grünkohl gleichzeitig angepflanzt wurden. Die Anbauflächen entsprechen in diesen Fällen nur den jeweils berechneten Flächenanteilen. Die jeweils berechneten Anbauflächen sind in Tabelle 8-3 aufgeführt. In Tabelle 8-4 sind die Ertragsergebnisse in dt/ha der Lysimeter 1 - 8 für die verschiedenen Pflanzen aufgeführt, die anhand der Erntemengen und der Anbauflächen berechnet wurden.

Tabelle 8-2: Erntemengen in $\mathrm{g}$ TM für die verschiedenen

Pflanzen der Lysimeter 1 - 8

\begin{tabular}{|c|c|c|c|c|c|c|c|c|}
\hline Erntegut & $\begin{array}{c}\text { Lysimeter } \\
1 \\
\end{array}$ & 2 & 8 & 6 & 5 & 4 & 3 & 7 \\
\hline Wirsing u.a. & 10978,24 & & & & & & & \\
\hline Steckrüben-Blatt & 431,28 & 1971,82 & 124,09 & 198,52 & 226,33 & 164,01 & 176,11 & 18,27 \\
\hline Steckrüben-Rübe & 684,24 & 4058,89 & 224,28 & 191,35 & 174,49 & 175,11 & 199,97 & 27,34 \\
\hline Grünkohl & & & 72,95 & 269,78 & 349,86 & 338,98 & 219,36 & 21,11 \\
\hline Weizen I & 6714,40 & 6236,10 & 153,49 & 300,80 & 351,32 & 367,02 & 284,32 & 36,14 \\
\hline Weizen II & 5731,30 & 6635,40 & 63,27 & 107,72 & 92,84 & 91,95 & 114,33 & 15,74 \\
\hline Gelbsenf & 6364,40 & 6316,60 & 159,00 & 313,30 & 255,80 & 230,50 & 144,70 & 90,00 \\
\hline Summe & 30904 & 25219 & 797 & 1381 & 1451 & 1368 & 1139 & 209 \\
\hline
\end{tabular}

Tabelle 8-3: Anbaufläche in $\mathrm{m}^{2}$ (bei Mischbepflanzung anhand der Pflanzenverhältnisse berechneter Flächenanteil) für die verschiedenen Pflanzen der Lysimeter 1 - 8

\begin{tabular}{|c|c|c|c|c|c|c|c|c|}
\hline Erntegut & $\begin{array}{c}\text { Lysimeter } \\
1 \\
\end{array}$ & 2 & 8 & 6 & 5 & 4 & 3 & 7 \\
\hline Wirsing u.a. & 4,67 & & & & & & & \\
\hline Steckrüben-Blatt & 2,40 & 7,07 & 0,17 & 0,34 & 0,34 & 0,34 & 0,34 & 0,17 \\
\hline Steckrüben-Rübe & 2,40 & 7,07 & 0,17 & 0,34 & 0,34 & 0,34 & 0,34 & 0,17 \\
\hline Grünkohl & & & 0,17 & 0,34 & 0,34 & 0,34 & 0,34 & 0,17 \\
\hline Weizen I & 7,07 & 7,07 & 0,35 & 0,68 & 0,68 & 0,68 & 0,68 & 0,35 \\
\hline Weizen II & 7,07 & 7,07 & 0,35 & 0,68 & 0,68 & 0,68 & 0,68 & 0,35 \\
\hline Gelbsenf & 7,07 & 7,07 & 0,35 & 0,68 & 0,68 & 0,68 & 0,68 & 0,35 \\
\hline
\end{tabular}

Tabelle 8-4: TM-Ertrag in $\mathrm{dt} / \mathrm{ha}$ für die verschiedenen Pflanzen der Lysimeter 1 - 8

\begin{tabular}{|c|c|c|c|c|c|c|c|c|}
\hline Erntegut & \begin{tabular}{|c} 
Lysimeter \\
1
\end{tabular} & 2 & 8 & 6 & 5 & 4 & 3 & 7 \\
\hline Wirsing u.a. & 235 & & & & & & & \\
\hline Steckrüben-Blatt & 18 & 28 & 71 & 59 & 67 & 49 & 52 & 10 \\
\hline Steckrüben-Rübe & 28 & 57 & 129 & 57 & 52 & 52 & 59 & 16 \\
\hline Grünkohl & & & 42 & 80 & 104 & 100 & 65 & 12 \\
\hline Weizen I & 95 & 88 & 44 & 45 & 52 & 54 & 42 & 10 \\
\hline Weizen II & 81 & 94 & 18 & 16 & 14 & 14 & 17 & 5 \\
\hline Gelbsenf & 90 & 89 & 46 & 46 & 38 & 34 & 21 & 26 \\
\hline Summe & 547 & 356 & 350 & 302 & 326 & 303 & 257 & 79 \\
\hline
\end{tabular}

Abbildung 131 zeigt die Trockenmasse-Erträge in dt/ha in der ersten Anbauphase und zwar Steckrüben-Blatt, Steckrüben-Rübe für Lysimeter $1-8$, Grünkohl Lysimeter $3-8$ und Wirsing und andere Kohlarten für Lysimeter 1. 


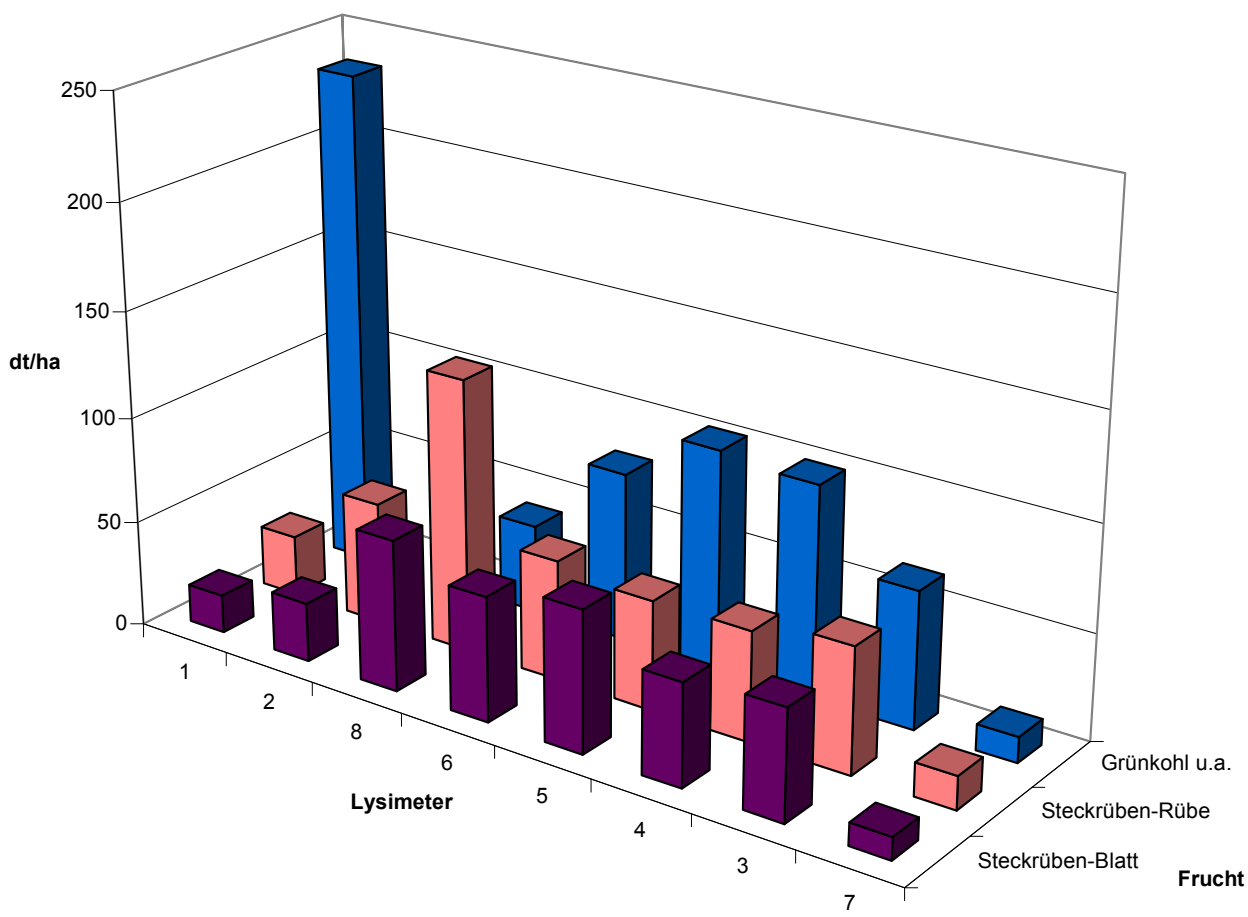

$\square$ Steckrüben-Blatt

$\square$ Steckrüben-Rübe

$\square$ Grünkohl u.a.

Abbildung 131: TM-Erträge in dt/ha für Steckrüben-Blatt

(Lysimeter 1 - 8), Steckrüben-Rübe (Lysimeter 1 - 8) und in einer Reihe Grünkohl (Lysimeter 3 - 8) u.a. Kohlarten

(Lysimeter 1)

In Abbildung 132 sind die Erträge für darauf folgenden Anbaufrüchte Weizen I, Gelbsenf und Weizen II dargestellt. 


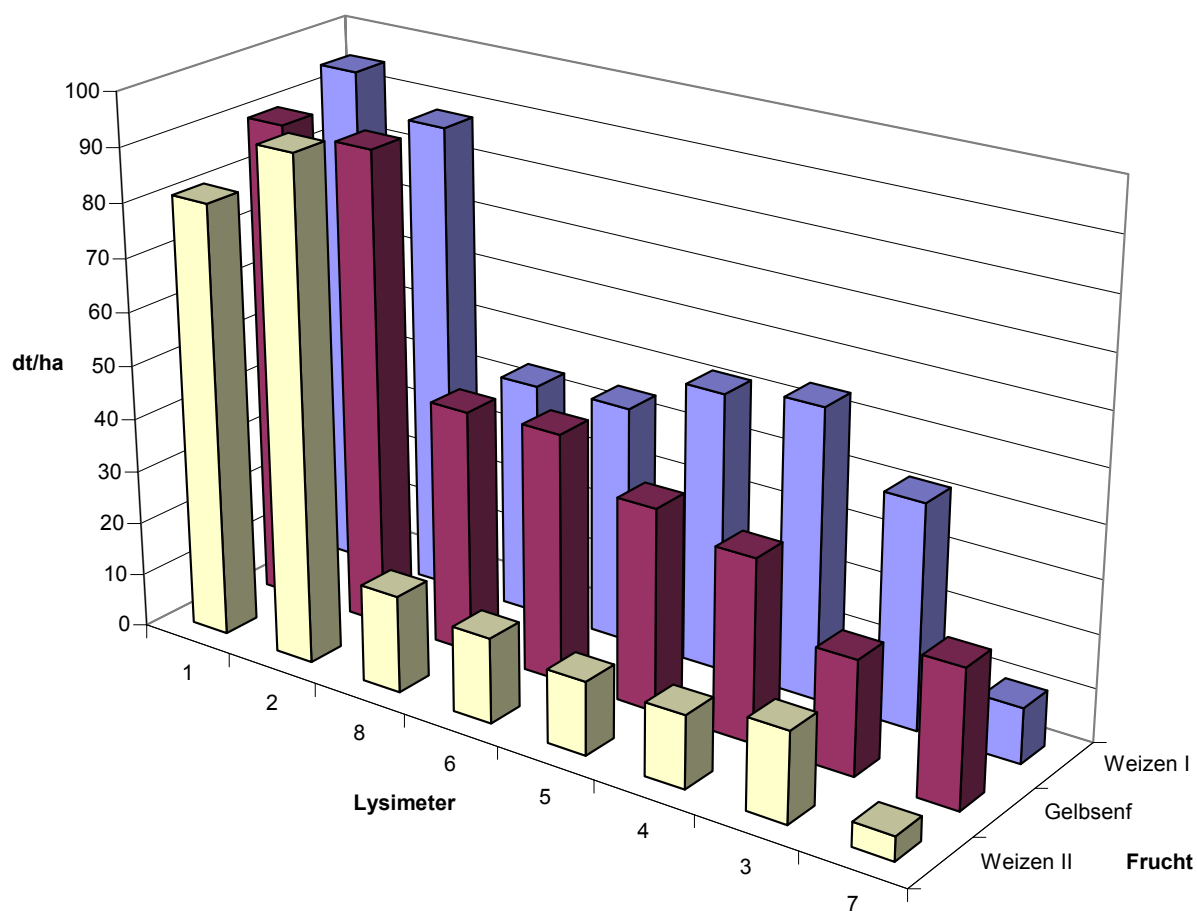

Abbildung 132: TM-Erträge in dt/ha für Weizen II, Gelbsenf und Weizen I (Lysimeter 1 - 8)

Auf allen Lysimetern wurden in der ersten Anbauphase Steckrüben angepflanzt. Die Erträge der einzelnen Lysimeter sind sehr unterschiedlich. Auf Lysimeter 8 wird der höchste TMErtrag für Blatt und Rübe mit insgesamt $200 \mathrm{dt} /$ ha gebildet. Auf den Großlysimetern wird zwar die höhere TM-Ausbeute pro Pflanze erzielt, aber aufgrund der geringeren Bepflanzungsdichte liegt der Gesamt-Ertrag deutlich unter den Erträgen der kleineren KompostLysimeter. Die Erträge der Lysimeter 3 bis 6 sind untereinander ähnlich. Sie liegen im Schnitt bei $111 \mathrm{dt} / \mathrm{ha}$. Der Ertrag auf Lysimeter 7 fällt mit $26 \mathrm{dt} / \mathrm{ha}$ deutlich gegenüber den übrigen Lysimetern zurück.

Bei dem auf den Kleinlysimetern zur gleichen Zeit mit den Steckrüben angepflanzten Grünkohl zeigt sich ein TM-Ertragsmaximum mit $104 \mathrm{dt} /$ ha bei Lysimeter 5, gefolgt von Lysimeter 4. Der geringe Ertrag auf Lysimeter 8 von nur $42 \mathrm{dt} /$ ha ist auf vermutlich auf den hohen konkurrierenden Steckrüben-Ertrag zu Ungunsten der Grünkohl-Ernte zurückzuführen. Der Ertrag von $12 \mathrm{dt} /$ ha auf Lysimeter 7 fällt ebenfalls deutlich gegenüber den übrigen Lysimetern zurück.

Die auf Lysimeter 1 in der ersten Anbauphase insgesamt gebildeten Erträge für die verschiedenen Kohlarten (Wirsing, Weißkohl, Rotkohl) liegen mit einem TM-Ertrag von 235 $\mathrm{dt} /$ ha deutlich über den übrigen Erträgen.

Nach Tabelle 8-4 liegen die TM-Erträge der Großlysimeter bei dem nachfolgenden Anbau von Weizen I, Gelbsenf und Weizen II über den Erträgen der Kleinlysimeter. Während der Weizen I Ertrag 1988 auf den Kleinlysimetern mit durchschnittlich $47 \mathrm{dt} /$ ha noch etwa $50 \%$ des Ertrages auf den Großlysimetern erzielt, liegt der Ertrag beim Weizen II 1989 mit 16 $\mathrm{dt} /$ ha nur noch bei rund $18 \%$ des Ertrages auf den Großlysimetern, der auch bei der 2 . Weizenernte wieder etwa die gleiche Höhe wie im Vorjahr erreicht. Die Weizen- und Gelbsenf-Erträge der Großlysimeter 1 und 2 unterscheiden sich kaum. Auch innerhalb der Mischungsvarianten fallen die Ertrags-Unterschiede bei Weizen gering aus. Bei Weizen I liegt das Ertragsmaximum bei Lysimeter 4, gefolgt von Lysimeter 5. Bei Weizen II werden die höchsten Erträge auf den Lysimetern 8 und 3 gebildet. Die Weizen-Erträge auf Lysime- 
ter 7 fallen wieder stark gegenüber den übrigen Lysimetern zurück. Sie liegen für Weizen I bei $10 \mathrm{dt} / \mathrm{ha}$ und Weizen II bei $5 \mathrm{dt} / \mathrm{ha}$. Auf den Lysimetern 1 und 2 wird auch bei dem als Zwischenfrucht angebauten Gelbsenf deutlich mehr Trockenmasse gebildet. $90 \mathrm{dt} / \mathrm{ha}$ Gelbsenf werden auf den Großlysimetern geerntet gegenüber durchschnittlich $35 \mathrm{dt} / \mathrm{ha}$ auf den Kleinlysimetern. Die Gelbsenf-Erträge der Mischungsvarianten sinken mit abnehmendem Kompost-Anteil der Lysimeter-Füllung. Der Gelbsenf-Ertrag von Lysimeter 7 (Löss) liegt in Höhe der Erträge der Lysimeter 3 und 4.

Ein Vergleich der Weizen-Erträge mit anderen Standorten ist aufgrund der untypischen Anbau- und Erntezeiten schlecht möglich. Die hier erzielten Erntemengen liegen deutlich unter den sonst üblichen Erträgen.

Für den Anbau von Weißem Senf als Sommer-Zwischenfrucht werden nach den Faustzahlen für Landwirtschaft und Gartenbau (HYDRO AGRI 1993) für den oberirdischen Aufwuchs $40 \mathrm{dt} / \mathrm{ha}$ TM-Ertrag und für die Wurzeln $15 \mathrm{dt} / \mathrm{ha}$ TM-Ertrag angegeben. Die auf den Lysimetern 4 bis 6 erzielten Erträge der oberirdischen Pflanzenmasse stimmen gut mit dem Literaturwert überein. Die Erträge auf Lysimeter 3 und 7 erreichen gut die Hälfte des Literaturwertes und die Großlysimeter 1 und 2 mehr als das Doppelte. Für Steckrüben und Kohl liegen keine Vergleichszahlen vor.

Die Bioelement-Gehalte der geernteten Pflanzenteile sind der Tabelle 8-5 zu entnehmen. Da für den Weizen die Bioelemente nicht durchgängig getrennt nach Korn und Stroh untersucht worden sind, sind in der Tabelle für Weizen I und Weizen II jeweils nur die Gehalte der gesamten Pflanzen aufgeführt. Die Bioelement-Gehalte der Steckrüben wurden durchgehend getrennt im Blatt und in der Rübe analysiert und sind entsprechend in der Tabelle aufgeführt. In den Gelbsenf-Ernten der Lysimeter 1 bis 8 wurden keine Bioelement-Gehalte bestimmt.

Tabelle 8-5: Stickstoff-Gehalte in \% der TM für die verschiedenen Pflanzen der Lysimeter 1 - 8

\begin{tabular}{|c|c|c|c|c|c|c|c|c|}
\hline Erntegut & $\begin{array}{c}\text { Lysimeter } \\
1 \\
\end{array}$ & 2 & 8 & 6 & 5 & 4 & 3 & 7 \\
\hline Wirsing u.a. & 4,25 & & & & & & & \\
\hline Steckrüben-Blatt & 3,39 & 3,39 & 2,56 & 2,66 & 2,92 & 2,09 & 1,79 & 1,71 \\
\hline Steckrüben-Rübe & 3,85 & 3,85 & 2,91 & 3,02 & 3,32 & 2,37 & 2,20 & 1,76 \\
\hline Grünkohl & & & 3,86 & 3,01 & 3,79 & 2,84 & 1,95 & 1,34 \\
\hline Weizen I & 2,25 & 1,61 & 1,97 & 1,74 & 1,59 & 1,42 & 1,23 & 0,92 \\
\hline Weizen II & 1,64 & 2,00 & 1,69 & 1,47 & 1,44 & 1,13 & 0,94 & 0,75 \\
\hline
\end{tabular}

Tabelle 8-6: Phosphor-Gehalte in \% der TM für die verschiedenen Pflanzen der Lysimeter 1 - 8

\begin{tabular}{|c|c|c|c|c|c|c|c|c|}
\hline Erntegut & $\begin{array}{c}\text { Lysimeter } \\
1\end{array}$ & 2 & 8 & 6 & 5 & 4 & 3 & 7 \\
\hline Wirsing u.a. & 0,42 & & & & & & & \\
\hline Steckrüben-Blatt & 0,48 & 0,48 & 0,38 & 0,48 & 0,41 & 0,42 & 0,38 & 0,25 \\
\hline Steckrüben-Rübe & 0,58 & 0,58 & 0,47 & 0,56 & 0,60 & 0,52 & 0,49 & 0,34 \\
\hline Grünkohl & & & 0,46 & 0,41 & 0,44 & 0,42 & 0,37 & 0,27 \\
\hline Weizen I & 0,72 & 0,45 & 0,53 & 0,43 & 0,42 & 0,45 & 0,43 & 0,49 \\
\hline Weizen II & 0,34 & 0,41 & 0,29 & 0,23 & 0,26 & 0,26 & 0,16 & 0,16 \\
\hline
\end{tabular}


Tabelle 8-7: Kalium-Gehalte in \% der TM für die verschiedenen Pflanzen der Lysimeter 1 - 8

\begin{tabular}{|c|c|c|c|c|c|c|c|c|}
\hline Erntegut & $\begin{array}{c}\text { Lysimeter } \\
1 \\
\end{array}$ & 2 & 8 & 6 & 5 & 4 & 3 & 7 \\
\hline Wirsing u.a. & 4,64 & & & & & & & \\
\hline Steckrüben-Blatt & 4,50 & 4,50 & 4,30 & 3,80 & 3,70 & 3,40 & 2,60 & 1,30 \\
\hline Steckrüben-Rübe & 3,90 & 3,94 & 2,50 & 3,00 & 3,20 & 2,70 & 2,10 & 1,30 \\
\hline Grünkohl & & & 4,00 & 4,00 & 4,10 & 4,10 & 3,20 & 1,80 \\
\hline Weizen I & 6,81 & 2,62 & 4,00 & 3,30 & 2,80 & 2,20 & 2,10 & 1,60 \\
\hline Weizen II & 1,80 & 4,51 & 0,90 & 1,10 & 1,70 & 1,20 & 0,02 & 0,02 \\
\hline
\end{tabular}

Tabelle 8-8: Calcium-Gehalte in \% der TM für die

verschiedenen Pflanzen der Lysimeter 1 - 8

\begin{tabular}{|c|c|c|c|c|c|c|c|c|}
\hline Erntegut & $\begin{array}{c}\text { Lysimeter } \\
1 \\
\end{array}$ & 2 & 8 & 6 & 5 & 4 & 3 & 7 \\
\hline Wirsing u.a. & 2,55 & & & & & & & \\
\hline Steckrüben-Blatt & 1,32 & 1,32 & 0,86 & 1,05 & 1,14 & 1,40 & 2,58 & 2,58 \\
\hline Steckrüben-Rübe & 0,34 & 0,34 & 0,23 & 0,27 & 0,23 & 0,50 & 0,28 & 0,41 \\
\hline Grünkohl & & & 0,66 & 1,21 & 1,32 & 1,14 & 1,48 & 1,44 \\
\hline Weizen I & 0,41 & 0,36 & 0,42 & 0,37 & 0,38 & 0,37 & 0,38 & 0,50 \\
\hline Weizen II & 0,24 & 0,41 & 0,45 & 0,41 & 0,51 & 0,39 & 0,19 & 0,19 \\
\hline
\end{tabular}

Tabelle 8-9: Magnesium-Gehalte in \% der TM für die verschiedenen Pflanzen der Lysimeter 1 - 8

\begin{tabular}{|c|c|c|c|c|c|c|c|c|}
\hline Erntegut & $\begin{array}{c}\text { Lysimeter } \\
1\end{array}$ & 2 & 8 & 6 & 5 & 4 & 3 & 7 \\
\hline Wirsing u.a. & 0,37 & & & & & & & \\
\hline Steckrüben-Blatt & 0,22 & 0,22 & 0,16 & 0,20 & 0,20 & 0,19 & 0,18 & 0,14 \\
\hline Steckrüben-Rübe & 0,13 & 0,13 & 0,10 & 0,11 & 0,10 & 0,14 & 0,09 & 0,13 \\
\hline Grünkohl & & & 0,16 & 0,21 & 0,20 & 0,21 & 0,17 & 0,14 \\
\hline Weizen I & 0,21 & 0,19 & 0,24 & 0,21 & 0,20 & 0,21 & 0,22 & 0,28 \\
\hline Weizen II & 0,18 & 0,24 & 0,21 & 0,17 & 0,19 & 0,17 & 0,02 & 0,09 \\
\hline
\end{tabular}

Tabelle 8-10: Schwefel-Gehalte in \% der TM für die verschiedenen Pflanzen der Lysimeter 1 - 8

\begin{tabular}{|c|c|c|c|c|c|c|c|c|}
\hline Erntegut & $\begin{array}{c}\text { Lysimeter } \\
1\end{array}$ & 2 & 8 & 6 & 5 & 4 & 3 & 7 \\
\hline Wirsing u.a. & 0,37 & & & & & & & \\
\hline Steckrüben-Blatt & 1,01 & 1,01 & 1,17 & 1,48 & 1,49 & 0,53 & 0,96 & 0,70 \\
\hline Steckrüben-Rübe & 0,24 & 0,24 & 0,28 & 0,35 & 0,35 & 0,12 & 0,30 & 0,29 \\
\hline Grünkohl & & & 1,39 & 1,36 & 1,44 & 0,50 & 0,58 & 0,29 \\
\hline Weizen I & 0,37 & 0,24 & 0,16 & 0,12 & 0,26 & 0,24 & 0,20 & 0,12 \\
\hline Weizen II & 0,40 & 0,45 & 0,16 & 0,12 & 0,26 & 0,20 & 0,20 & 0,11 \\
\hline
\end{tabular}


Tabelle 8-11: Chlorid-Gehalte in \% der TM für die verschiedenen Pflanzen der Lysimeter 1 - 8

\begin{tabular}{|c|c|c|c|c|c|c|c|c|}
\hline Erntegut & $\begin{array}{c}\text { Lysimeter } \\
1\end{array}$ & 2 & 8 & 6 & 5 & 4 & 3 & 7 \\
\hline Wirsing u.a. & 0,20 & & & & & & & \\
\hline Steckrüben-Blatt & 0,59 & 0,59 & 2,88 & 1,70 & 1,84 & 2,00 & 2,81 & 1,87 \\
\hline Steckrüben-Rübe & 0,33 & 0,33 & 1,61 & 0,96 & 1,03 & 1,12 & 1,57 & 1,01 \\
\hline Grünkohl & & & 1,26 & 1,05 & 0,95 & 1,43 & 1,40 & 0,15 \\
\hline Weizen I & 0,44 & 0,12 & 0,14 & 0,12 & 0,12 & 0,26 & 0,12 & 0,37 \\
\hline Weizen II & 0,10 & 0,06 & 0,14 & 0,12 & 0,12 & 0,26 & 0,12 & 0,37 \\
\hline
\end{tabular}

Tabelle 8-12: Natrium-Gehalte in \% der TM für die verschiedenen Pflanzen der Lysimeter 1 - 8

\begin{tabular}{|c|c|c|c|c|c|c|c|c|}
\hline Erntegut & $\begin{array}{c}\text { Lysimeter } \\
1\end{array}$ & 2 & 8 & 6 & 5 & 4 & 3 & 7 \\
\hline Wirsing u.a. & 0,35 & & & & & & & \\
\hline Steckrüben-Blatt & 0,36 & 0,36 & 0,15 & 0,16 & 0,18 & 0,19 & 0,18 & 0,08 \\
\hline Steckrüben-Rübe & 0,25 & 0,25 & 0,15 & 0,23 & 0,18 & 0,23 & 0,12 & 0,12 \\
\hline Grünkohl & & & 0,23 & 0,27 & 0,35 & 0,27 & 0,21 & 0,10 \\
\hline Weizen I & 0,13 & 0,08 & 0,13 & 0,08 & 0,13 & 0,13 & 0,07 & 0,07 \\
\hline Weizen II & 0,01 & 0,02 & 0,01 & 0,01 & 0,03 & 0,02 & 0,01 & 0,01 \\
\hline
\end{tabular}

Tabelle 8-13: Kohlenstoff-Gehalte in \% der TM für die verschiedenen Pflanzen der Lysimeter 1 - 8

\begin{tabular}{|c|c|c|c|c|c|c|c|c|}
\hline Erntegut & $\begin{array}{c}\text { Lysimeter } \\
1\end{array}$ & 2 & 8 & 6 & 5 & 4 & 3 & 7 \\
\hline Wirsing u.a. & 37,72 & & & & & & & \\
\hline Steckrüben-Blatt & 32,70 & 32,70 & 31,90 & 29,80 & 30,70 & 29,30 & 31,22 & 31,01 \\
\hline Steckrüben-Rübe & 40,32 & 40,32 & 39,34 & 36,74 & 37,86 & 36,13 & 38,49 & 37,56 \\
\hline Grünkohl & & & 41,60 & 40,05 & 40,96 & 41,70 & 41,60 & 41,18 \\
\hline Weizen I & 41,12 & 45,19 & 45,02 & 45,70 & 45,00 & 45,25 & 42,62 & 44,70 \\
\hline Weizen II & 44.25 & 42,67 & 45,01 & 43,97 & 43.12 & 43.40 & 44.43 & 43,28 \\
\hline
\end{tabular}

Tabelle 8-14: $\mathrm{C} / \mathrm{N}-$ Verhältnisse in den verschiedenen Pflanzen der Lysimeter 1 - 8

\begin{tabular}{|c|c|c|c|c|c|c|c|c|}
\hline Erntegut & $\begin{array}{c}\text { Lysimeter } \\
1\end{array}$ & 2 & 8 & 6 & 5 & 4 & 3 & 7 \\
\hline Wirsing u.a. & 8,88 & & & & & & & \\
\hline Steckrüben-Blatt & 9,65 & 9,65 & 12,46 & 11,20 & 10,51 & 14,02 & 17,44 & 18,13 \\
\hline Steckrüben-Rübe & 10,47 & 10,47 & 13,52 & 12,17 & 11,40 & 15,24 & 17,50 & 21,34 \\
\hline Grünkohl & & & 10,78 & 13,31 & 10,81 & 14,68 & 21,33 & 30,73 \\
\hline Weizen I & 18,28 & 28,07 & 22,85 & 26,26 & 28,30 & 31,87 & 34,65 & 48,59 \\
\hline Weizen II & 26,98 & 21,34 & 26,63 & 29,91 & 29,94 & 38,41 & 47,27 & 57,71 \\
\hline
\end{tabular}

Die N-, P-, K-, Mg- und Na-Gehalte der zweiten Weizenernte liegen bei allen Lysimetern außer bei Lysimeter 2 - deutlich unter den Gehalten der ersten Weizenernte. Bei den CaGehalten zeigt sich dagegen von der ersten zur zweiten Weizenernte eine Zunahme. Die 
Cl- und S-Gehalte des Weizens bei den Kleinlysimetern unterscheiden sich kaum während auf den Großlysimetern beim $\mathrm{Cl}$ ein deutlicher Rückgang, beim $\mathrm{S}$ eine Zunahme von der ersten zur zweiten Weizenernte beobachtet wird. Ein Vergleich der Bioelement-Gehalte im Weizen mit Literaturwerten (HYDRO AGRI 1993) zeigt vor allem höhere Kalium-Gehalte in den auf den Kompost-Lysimetern geernteten Weizenpflanzen.

Hohe Bioelement-Gehalte liegen im Steckrüben-Blatt vor. Sie sind deutlich höher als die Gehalte in der Steckrüben-Rübe, wahrscheinlich wegen der Speicherfunktion der Rübe. Auch die während der ersten Anbauphase angepflanzten Kohlarten haben hohe Bioelement-Gehalte. Für alle Mineralstoffe bis auf Schwefel zeigen die über alle Lysimeter gemittelten Bioelement-Gehalte einen Rückgang mit fortschreitender Versuchsdauer bzw. in der Reihenfolge der Pflanzen: Kohl > Steckrüben > Weizen I > Weizen II. Entsprechend gegenläufig steigen die $\mathrm{C} / \mathrm{N}$-Verhältnisse bei steigenden $\mathrm{C}$-Gehalten und abnehmenden $\mathrm{N}$ Gehalten mit fortschreitender Versuchdauer um ein Mehrfaches an, so z. B. von 9 für Wirsing u.a. auf durchschnittlich 35 bei der zweiten Weizenernte.

Die Unterschiede in den Bioelement-Gehalten der angebauten Pflanzen werden neben der Vorgabe durch die Art der Pflanze bzw. des Pflanzenteils von dem Rückgang an verfügbaren Bioelementen bei fortschreitender Versuchsdauer im Kompost und seinen Mischungen mit Löss beeinflusst.

Die Gehalte der Pflanzennährstoffe N, P und K in den Pflanzen steigen mit zunehmendem Kompost-Gehalt in der Lysimeter-Füllung an. Die Kalium-Gehalte der Pflanzen spiegeln die jeweilige Verfügbarkeit dieses Bioelementes in den unterschiedlichen Substraten am deutlichsten wieder. Sie steigen von durchschnittlich $1,2 \%$ in der TM der von Lysimeter 7 geernteten Pflanzenteile auf durchschnittlich 4,3\% in der TM der Pflanzen, die von Lysimeter 1 geerntet wurden. Besonders große Unterschiede zwischen den Kalium-Gehalten der Pflanzen von den verschiedenen Lysimetern liegen beim Weizen vor. Hier erreicht die erste Weizenernte von Lysimeter $16,8 \%$ in der TM.

Bei den Elementen $\mathrm{N}$ und $\mathrm{P}$ sind die Unterschiede zwischen den verschiedenen Mischungsvarianten weniger stark ausgeprägt. Die Gehalte liegen bei N zwischen 1,3 und $3,1 \%$ in der TM und für $\mathrm{P}$ bei 0,3 und $0,5 \%$ in der TM (jeweils Durchschnittswerte der geernteten Pflanzenteile von Lysimeter 7, reiner Löss, und Lysimeter 1, reiner Kompost).

Die Magnesium-Gehalte liegen trotz unterschiedlicher Gehalte der Substrate in den geernteten Pflanzenteilen in annähernd gleicher Höhe. Sie betragen durchschnittlich 0,18\% der TM. Dies gilt auch für Calcium und Schwefel. Die Ca-Gehalte erreichen im Durchschnitt $0,78 \%$. Die niedrigsten Ca-Gehalte finden sich in den Pflanzen auf Lysimeter 8. Die Schwefel-Gehalte in den Pflanzen von durchschnittlich 0,5\% in der TM korrelieren trotz der hohen Sulfat-Löslichkeit im Kompost nicht mit der Kompostzugabe. Die höchsten SchwefelGehalte werden in den auf Lysimeter 5 geernteten Pflanzen erreicht. Die Cl-Gehalte der Pflanzen liegen im Durchschnitt bei 0,8 \% der TM. Die Pflanzen der Großlysimeter 1 und 2 zeigen deutlich niedrigere $\mathrm{Cl}-\mathrm{Gehalte}$ als die Pflanzen der Kleinlysimeter. Dies ist vermutlich auf die unterschiedlichen $\mathrm{Cl}-$ Gehalte der verwendeten Komposte zurückzuführen. Natrium wird nur in geringem Umfang von den Pflanzen aufgenommen. Der Durchschnittswert liegt bei 0,15\% der TM. Höhere Natrium-Gehalte in den Pflanzen treten auf den Großlysimetern auf. Bei den Kleinlysimetern zeigen die Pflanzen der Lysimeter 4 und 5 mit Mischungsanteilen von 51 bzw. 59 Gew. \% Kompost die höchsten Na-Gehalte.

Die Kohlenstoff-Gehalte der Pflanzen liegen durchschnittlich bei etwa $40 \%$ der TM. Geringere C-Gehalte wurden in der TM der Steckrüben-Blätter ermittelt. Sie liegen hier bei durchschnittlich nur $31 \%$. Die C/N-Verhältnisse steigen mit abnehmendem Kompost-Gehalt stark an. 
Aus den Trockenmasse-Erträgen und den Bioelementgehalten der geernteten Pflanzen werden die pflanzlichen Entzüge berechnet und zu elementspezifischen Gesamt-Entzügen für jedes Lysimeter addiert. Diese Werte zeigt die Tabelle 8-6. Für die Berechnung der Gelbsenf-Entzüge wurden die Messwerte mit Literaturwerten von DIERFELD (1977) ergänzt (siehe Tabelle 1-92).

Tabelle 8-15: Gesamt-Bioelement-Entzüge in g für die

Lysimeter 1 - 8 in drei Erntejahren

\begin{tabular}{l|cccccccc} 
Lysimeter & $\mathbf{C a}$ & $\mathbf{M g}$ & $\mathbf{K}$ & $\mathbf{N a}$ & $\mathbf{P}$ & $\mathbf{S}$ & $\mathbf{C l}$ & $\mathbf{N}$ \\
\hline $\mathbf{1}$ & 429,47 & 90,30 & 1275,25 & 76,38 & 147,69 & 151,18 & 68,65 & 1027,55 \\
$\mathbf{2}$ & 188,89 & 60,27 & 869,23 & 48,86 & 115,57 & 136,17 & 42,98 & 728,89 \\
$\mathbf{8}$ & 5,53 & 1,62 & 24,48 & 1,55 & 3,18 & 4,17 & 8,57 & 21,39 \\
$\mathbf{6}$ & 12,34 & 3,11 & 41,70 & 3,00 & 5,24 & 8,56 & 8,85 & 34,14 \\
$\mathbf{5}$ & 13,42 & 3,14 & 44,24 & 3,44 & 5,69 & 10,96 & 10,08 & 38,08 \\
$\mathbf{4}$ & 12,37 & 3,01 & 37,69 & 2,78 & 5,35 & 4,76 & 10,94 & 27,56 \\
$\mathbf{3}$ & 12,95 & 2,35 & 24,15 & 1,80 & 4,13 & 4,72 & 11,78 & 18,41 \\
$\mathbf{7}$ & 2,51 & 0,53 & 2,90 & 0,46 & 0,57 & 0,52 & 0,91 & 2,43
\end{tabular}

Die Gesamt-Entzüge (Tabelle 8-15) sind in Tabelle 8-16 auf eine Einheitsfläche von $1 \mathrm{~m}^{2}$ umgerechnet.

Tabelle 8-16: Gesamt-Bioelement-Entzüge in $\mathrm{g} / \mathrm{m}^{2}$ für die Lysimeter 1 - 8 in drei Erntejahren

\begin{tabular}{l|cccccccc} 
Lysimeter & $\mathbf{C a}$ & $\mathbf{M g}$ & $\mathbf{K}$ & $\mathbf{N a}$ & $\mathbf{P}$ & $\mathbf{S}$ & $\mathbf{C l}$ & $\mathbf{N}$ \\
\hline $\mathbf{1}$ & 60,75 & 12,77 & 180,37 & 10,80 & 11,16 & 21,38 & 9,71 & 145,34 \\
$\mathbf{2}$ & 26,72 & 8,52 & 122,95 & 6,91 & 7,06 & 19,26 & 6,08 & 103,10 \\
$\mathbf{8}$ & 15,88 & 4,65 & 70,26 & 4,44 & 3,98 & 11,97 & 24,59 & 61,40 \\
$\mathbf{6}$ & 18,26 & 4,59 & 61,70 & 4,44 & 3,39 & 12,66 & 13,09 & 50,52 \\
$\mathbf{5}$ & 19,85 & 4,64 & 65,47 & 5,09 & 3,67 & 16,22 & 14,91 & 56,35 \\
$\mathbf{4}$ & 18,31 & 4,46 & 55,78 & 4,12 & 3,45 & 7,04 & 16,19 & 40,78 \\
$\mathbf{3}$ & 19,16 & 3,48 & 35,74 & 2,66 & 2,67 & 6,98 & 17,43 & 27,24 \\
$\mathbf{7}$ & 7,21 & 1,52 & 8,33 & 1,31 & 0,71 & 1,51 & 2,63 & 6,97
\end{tabular}

Die Abbildungen 133 - 136 stellen diese Werte graphisch dar. 


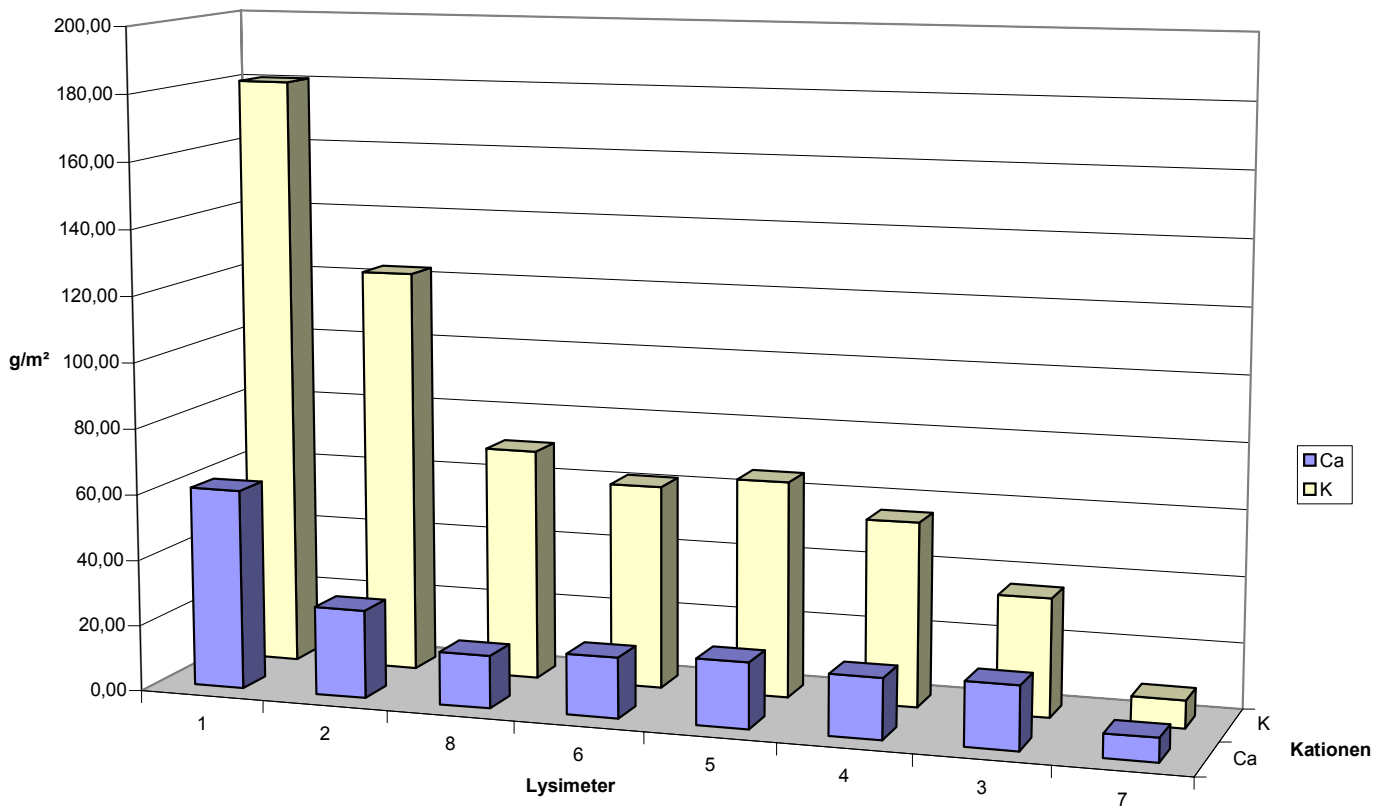

Abbildung 133: K- und Ca-Entzüge in $\mathrm{g} / \mathrm{m}^{2}$ in drei

Erntejahren, Lysimeter 1 - 8

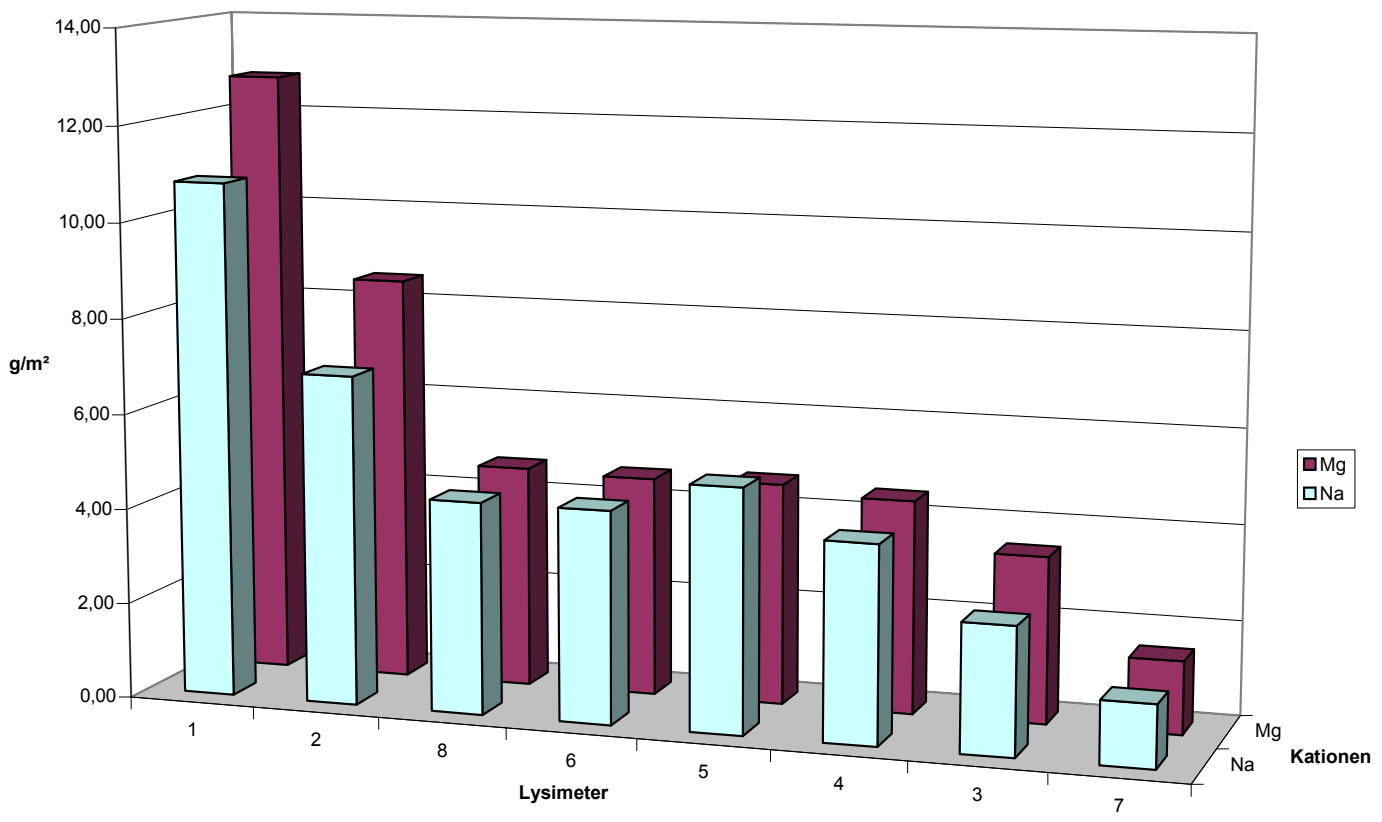

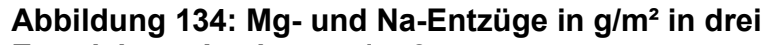
Erntejahren, Lysimeter 1 - 8 


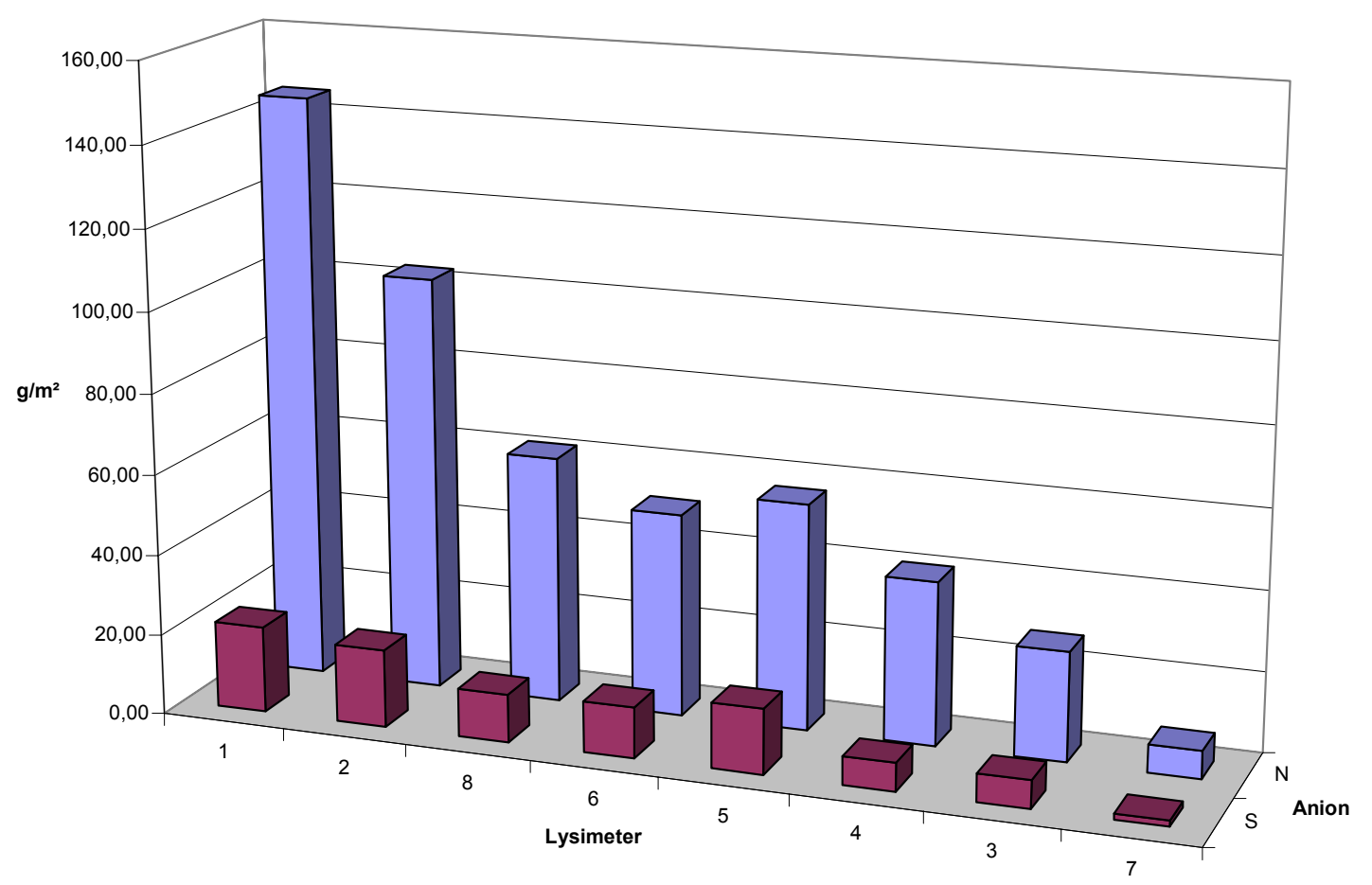

Abbildung 135: $\mathrm{N}$ - und $\mathrm{S}-$ Entzüge in $\mathrm{g} / \mathrm{m}^{2}$ in drei Erntejahren, Lysimeter 1 - 8

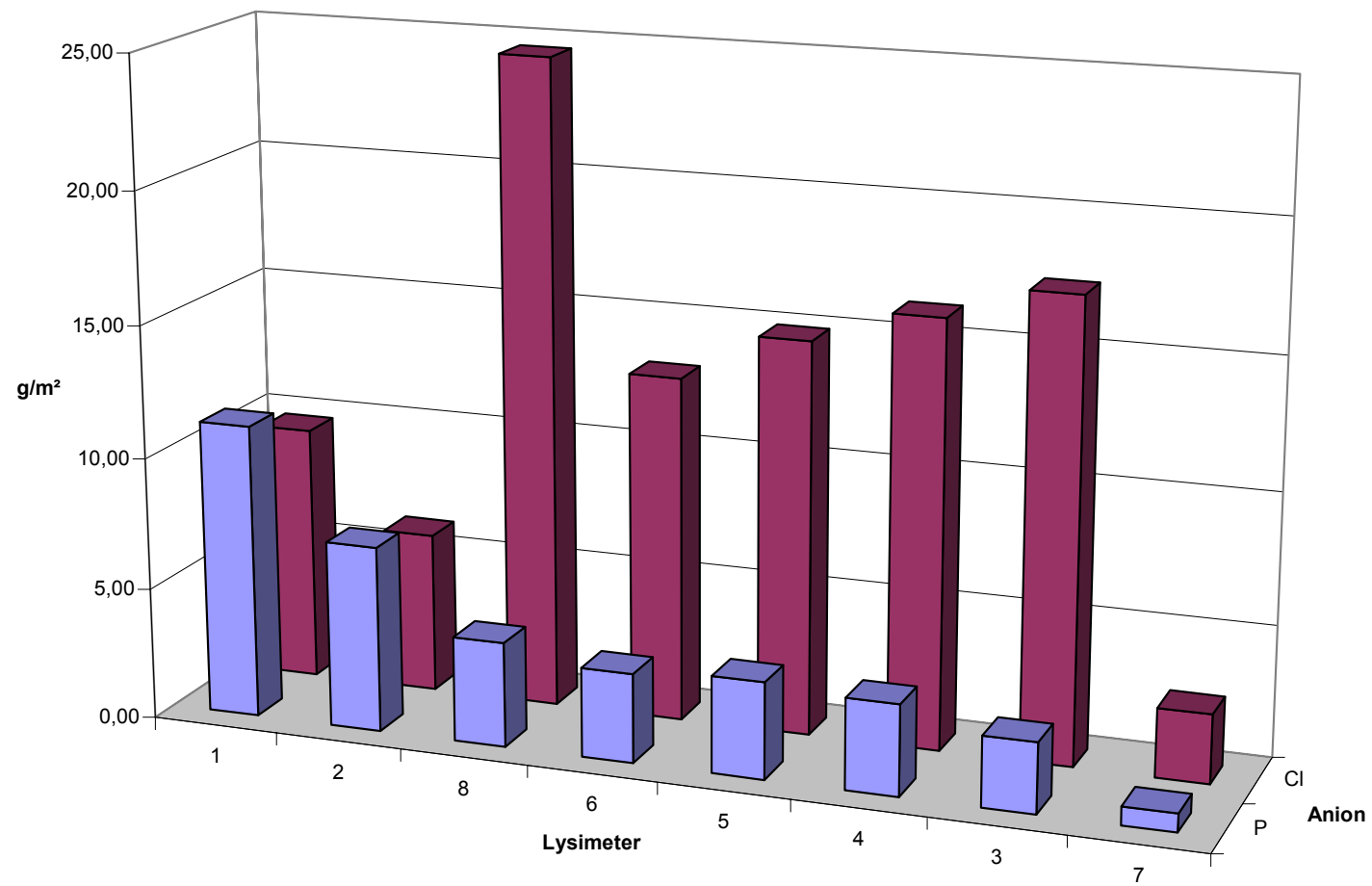

Abbildung 136: $\mathrm{Cl}$ - und P-Entzüge in $\mathrm{g} / \mathrm{m}^{2}$ in drei Erntejahren, Lysimeter $1-8$

Die Summen der pflanzlichen Entzüge in den drei Untersuchungsjahren 87, 88, und 89 für die unterschiedlichen Ernteprodukte sind für die Elemente $\mathrm{K}, \mathrm{Ca}, \mathrm{Mg}, \mathrm{Na}, \mathrm{S}, \mathrm{N}$ und $\mathrm{P}$ auf den Großlysimetern höher als auf den Kleinlysimetern. Bedingt durch die höheren Erträge 
auf Lysimeter 1 und die dort höheren Bioelement-Gehalte in den geernteten Pflanzenteilen liegen die pflanzlichen Entzüge auf Lysimeter 1 noch über den Entzügen auf Lysimeter 2. Nur für das Element $\mathrm{Cl}$ liegen die pflanzlichen Entzüge der Kleinlysimeter - bis auf die reine Lössvariante - über den Entzügen der Großlysimeter. Hier steigen sogar innerhalb der Mischungsvarianten die Cl-Entzüge mit abnehmendem Kompost-Gehalt der LysimeterFüllungen an.

Innerhalb der Mischungsvarianten sind bei den Elementen $\mathrm{K}, \mathrm{Ca}, \mathrm{Mg}, \mathrm{Na}, \mathrm{S}, \mathrm{N}$ und $\mathrm{P}$ die pflanzlichen Gesamt-Entzüge auf Lysimeter 5 mit 59 Gew. \% Kompost höher als auf Lysimeter 6 mit 91 Gew. \% Kompost. Auch dieses Ergebnis ist mit den höheren Erträgen und den höheren Bioelement-Gehalten der auf Lysimeter 5 geernteten Pflanzenteile zu erklären.

Die Volumenunterschiede zwischen den Groß- und den Kleinlysimetern insbesondere die geringere Füllhöhe der Kleinlysimeter und die stärkere Auswaschung führen zu einer rascheren Nährstoff-Ausschöpfung der Kleinlysimeter. Die daraus resultierenden geringeren Nährstoffvorräte der Kleinlysimeter bewirken bei zunehmender Versuchsdauer deutliche Ertragsunterschiede gegenüber den Großlysimetern. Während das Pflanzenwachstum bei Lysimeter 7, der reinen Lössvariante, zusätzlich durch Staunässe und Oberflächenverkrustung behindert wurde, hatten die Pflanzen auf Lysimeter 8, der reinen Kompostvariante, bei geringen Niederschlägen zu wenig verfügbares Wasser.

Die festgestellten Ertragsunterschiede fallen für die jeweiligen Anbaufrüchte unterschiedlich aus. Während bei Weizen ein deutlicher Ertragsabfall auf Lysimeter 7 zu verzeichnen ist, werden für den Gelbsenf mit den übrigen Lysimetern annähernd übereinstimmende Erträge erzielt.

Die höhere Kompostbeimengung in den Mischungsvarianten führte nur begrenzt zu höheren Erträgen. Vergleicht man die Ergebnisse für die Mischungsvarianten (Lysimeter 3-6) so zeigt sich, dass die Gesamtsummen der Erntemengen und der Erträge auf Lysimeter 5 mit einem Kompost-Anteil von $59 \mathrm{Gew}$ \% am höchsten sind. Der Gesamt-Ertrag auf dem Großlysimeter 2 entspricht etwa dem Gesamt-Ertrag der reinen Kompostvariante, d. h. dem Kleinlysimeters 8, trotz dessen geringere Substratmächtigkeit. Die TM-Gesamt-Erntemenge auf Lysimeter 1 liegt aufgrund der hohen Erntemengen für die verschiedenen Kohlarten rund $20 \%$ über dem Gesamtergebnis von Lysimeter 2.

Die Bioelement-Gehalte der Pflanzen nehmen mit fortschreitender Versuchdauer ab. Dies ist einerseits mit dem Wechsel der Kultur von salztoleranten Pflanzen, wie Kohl und Steckrüben, zu weniger salztoleranten Pflanzen, wie Weizen, zu begründen. Die Abnahme der Bioelement-Gehalte lässt aber auch auf einen Rückgang an pflanzenverfügbaren Bioelementen schließen. Eine hohe Korrelation der Gehalte in der Pflanze und im Substrat besteht für die Elemente $\mathrm{K}$ und $\mathrm{N}$. Insbesondere für das Element Kalium steigen die Werte in der Pflanze mit zunehmendem Kompost-Gehalt der Lysimeter-Füllung deutlich an.

Die pflanzlichen Gesamt-Nährstoffentzüge sind das Ergebnis der Erträge und der Bioelement-Gehalte der geernteten Pflanzenteile. Bei Lysimeter 1 sind diese Entzüge dementsprechend höher als bei Lysimeter 2, und innerhalb der Mischungsvarianten liegen die Maximal-Entzüge bei Lysimeter 8 mit reinem Kompost und bei Lysimeter 5 mit $51 \mathrm{Gew}$. $\%$ Kompost.

Für die Anwendung von Komposten zur Bodenverbesserung und Düngung gibt es zahlreiche Veröffentlichungen (VOGTMANN et al. 1992). Die in vielfach langjährig durchgeführten Feldversuchen mit unterschiedlichen Kulturen erzielten Erträge liegen in Höhe der mineralisch gedüngten Varianten bzw. darüber. In neueren Untersuchungen wurde auch die Qualität der Ernteprodukte anhand von Merkmalen, wie z.B. Geschmack, Selbstzersetzung, Nitrat- und Säure-Gehalt unterschiedlich gedüngter Varianten geprüft. In Bezug auf die Pflanzeninhaltstoffe wurden beispielsweise niedrigere Nitrat-Gehalte und höhere Kalium- 
Gehalte in Verbindung mit höheren Ascorbinsäure-Gehalten bei Sellerie festgestellt (MEIER-PLOEGER und VOGTMANN 2003).

Bei dem hier gewählten Versuchsansatz lag die Ertragbildung als solche nicht im Zentrum der Betrachtung. Vielmehr sollte mit der Bepflanzung

- eine Substrat-Eignung der verwendeten Komposte geprüft und verglichen werden,

- der Teilbaustein „pflanzliche Entzüge“ für das Bilanzmodells geliefert werden und

- der Sickerwasser-Austrag durch die Erhöhung der Evapotranspiration verringert werden.

Die erzielten Erträge liegen aufgrund untypischer Anbau-, Erntezeiten und Bestandsdichten hier deutlich unter sonst üblichen Erträgen. Die N-, P- und K-Gehalte der Pflanzen steigen mit zunehmender Kompost-Aufwandmenge. Da keine mineralische Düngung der 0-Variante durchgeführt wurde, liegen keine eigenen Daten für einen Vergleich zwischen Kompostund mineralischer Düngung vor. Die ertragssteigernde Wirkung durch Verwendung des reinen Komposts bzw. die Kompost-Beimischung zu Lössboden-Material gegenüber der reinen Löss-Variante ist offensichtlich. Vergleiche der Gehaltsangeben mit Literaturwerten sind aufgrund der spezifischen Anbaubedingungen nur eingeschränkt möglich. In der Tendenz ergeben sich vor allem höhere Kalium-, Stickstoff und Phosphor-Gehalte in den Pflanzen der Kompost-Lysimeter im Vergleich zu den Literaturwerten für mineralisch gedüngte Pflanzen. 


\section{Mineralstoff-Bilanz: Einträge, Austräge und Vorratsänderungen des Systems Lysimeter}

Die Bilanz gibt Rechenschaft über Einträge und Austräge sowie Vorratsänderungen innerhalb des Systems Lysimeter. Die im Niederschlag enthaltenen Inhaltsstoffe liefern die Einträge, die mit der Ernte der Pflanzen und durch den Sickerwasser-Abfluss entzogenen Stoffe den Austrag. Unberücksichtigt bleiben gasförmige Verluste und Kohlenstoff-Einträge durch den Verbleib von Wurzelmasse im Lysimeter.

Da keine exakten Wassergehalte der in die Großlysimeter eingefüllten Kompost-Frischmassen vorgelegen haben, wurden anhand der Endmengen und der bilanzmäßig erfassten Vorratsänderungen die ursprünglich eingefüllten Trockenmasse zurückgerechnet. Hierbei wurden auch die für Analysenzwecke entnommenen Materialmengen berücksichtigt. Diese Berechnung ergibt zu Versuchsbeginn eingefüllte Trockenmassen von $2146 \mathrm{~kg}$ für Lysimeter 1 und $2982 \mathrm{~kg}$ für Lysimeter 2. Diese Werte sind den weiteren Berechnungen zugrundegelegt worden. Bei den Kleinlysimetern sind die in Tabelle 3-5 angegebenen Einfülldaten verwendet worden.

Für die Berechnung der Ein- und Austräge pro Lysimter wurden die jeweils zu betrachtenden Frachten anhand der Konzentrationen der Inhaltsstoffe und der Stoffmengen berechnet. Für die Ernteentzüge wurden die jeweils in dem betrachteten Untersuchungszeitraum angebauten und geernteten Pflanzenteile berücksichtigt. Das waren im ersten Jahr auf Lysimeter 1 verschiedene Kohlarten und auf den Lysimetern 2 bis 8 Kohl und Steckrüben, im zweiten Jahr auf allen Lysimetern Winterweizen und Gelbsenf und im dritten Jahr auf allen Lysimetern nur Winterweizen. Die Sickerwasser-Austräge wurden aus den analysierten Inhaltstoff-Konzentrationen und der freigesetzten Sickerwasser-Menge berechnet. Die Einträge mit den Niederschlägen resultieren aus der Niederschlagshöhe und der Konzentration der darin enthaltenen Inhaltsstoffe.

Die Tabellen 1-93 bis 1-100 im Anhang zeigen die pro Lysimeter für den gesamten Untersuchungszeitraum berechneten Einträge, Austräge und Vorratsänderungen in g. Zur besseren Vergleichbarkeit der Einträge, Austräge und Vorratsänderungen pro Lysimeter sind in den nachfolgenden Tabellen 9-1 bis 9-8 die Werte in $\mathrm{g} / \mathrm{m}^{2}$ Lysimeter-Oberfläche für die einzelnen Messjahre und die drei Untersuchungsjahre insgesamt aufgeführt. Die Tabellen 1101 bis 1-108 im Anhang zeigen die Umrechnung in $\mathrm{mg} / \mathrm{kg}$ TM ebenfalls pro Jahr und für die einzelnen Messjahre und die drei Untersuchungsjahre insgesamt. 
Tabelle 9-1: DOC- und Mineralstoff-Bilanz in $\mathrm{g} / \mathrm{m}^{2}$, pro

Untersuchungsjahr und von Mai 87 bis April 90, Lysimeter 1

\begin{tabular}{|c|c|c|c|c|c|c|c|c|c|c|c|c|c|}
\hline $\begin{array}{l}\text { Bilanzglieder } \\
\text { Lysimeter } 1\end{array}$ & DOC & $\mathrm{HCO}_{3}$ & Summe-C & $\mathrm{Ca}$ & Mg & K & $\begin{array}{c}\mathrm{Na} \\
\mathrm{g} / \mathrm{m}^{2}\end{array}$ & $\mathbf{P}$ & $\mathrm{SO}_{4}-\mathrm{S}$ & $\mathrm{Cl}$ & $\mathbf{N}_{\min }$ & $\mathbf{N}_{\text {org }}$ & Summe-N \\
\hline Regen-Eintrag & 2,69 & & 2,69 & 1,73 & 0,40 & 1,23 & 0,35 & & 2,23 & 1,54 & 1,19 & & 1,19 \\
\hline Ernte-Entzug & & & & 40,77 & 6,08 & 78,60 & 5,89 & 7,37 & 6,56 & 3,82 & & & 71,79 \\
\hline SW-Austrag & 111,11 & 206,86 & 151,84 & 146,06 & 25,58 & 321,12 & 90,47 & 2,74 & 68,08 & 106,75 & 132,20 & & 132,20 \\
\hline $\begin{array}{l}\text { Vorratsänderung } \\
\text { 2. Jahr }\end{array}$ & $-108,42$ & $-206,86$ & $-149,15$ & $-185,10$ & $-31,26$ & $-398,49$ & $-96,01$ & $-10,11$ & $-72,42$ & $-109,03$ & $-131,01$ & & $-202,80$ \\
\hline Regen-Eintrag & 1,76 & & 1,76 & 1,29 & 0,19 & 0,82 & 0,62 & & 0,61 & 0,73 & 0,50 & & 0,50 \\
\hline $\begin{array}{l}\text { Vorratsänderung } \\
\text { 3. Jahr }\end{array}$ & $-36,47$ & $-37,24$ & $-43,80$ & $-23,01$ & $-6,35$ & $-127,38$ & $-12,25$ & $-12,54$ & $-14,88$ & $-4,64$ & $-5,09$ & $-3,07$ & $-68,42$ \\
\hline Regen-Eintrag & 2,65 & & 2,65 & 1,70 & 0,18 & 0,73 & 0,35 & & 0,70 & 0,97 & 0,62 & & 0,62 \\
\hline Ernte-Entzug & & & & 1,95 & 1,46 & 14,59 & 0,08 & 2,78 & 3,26 & 0,81 & & & 13,29 \\
\hline sw-Austrag & 63,08 & 48,69 & 72,67 & 12,68 & 2,52 & 81,40 & 14,17 & 2,19 & 8,93 & 0,85 & 18,57 & 6,84 & 25,41 \\
\hline $\begin{array}{l}\text { Vorratsänderung } \\
\text { 1. - 3. Jahr }\end{array}$ & $-60,43$ & $-48,69$ & $-70,02$ & $-12,93$ & $-3,80$ & $-95,25$ & $-13,90$ & $-4,97$ & $-11,50$ & $-0,69$ & $-17,95$ & $-6,84$ & $-38,09$ \\
\hline Vorratsänderung & $-205,31$ & $-292,79$ & $-262,96$ & $-221,04$ & $-41,41$ & $-621,12$ & $-122,15$ & $-27,61$ & $-98,80$ & $-114,36$ & $-154,05$ & $-9,91$ & $-309,30$ \\
\hline
\end{tabular}

Tabelle 9-2: DOC- und Mineralstoff-Bilanz in $\mathrm{g} / \mathrm{m}^{2}$, pro

Untersuchungsjahr und von Mai 87 bis April 90, Lysimeter 2

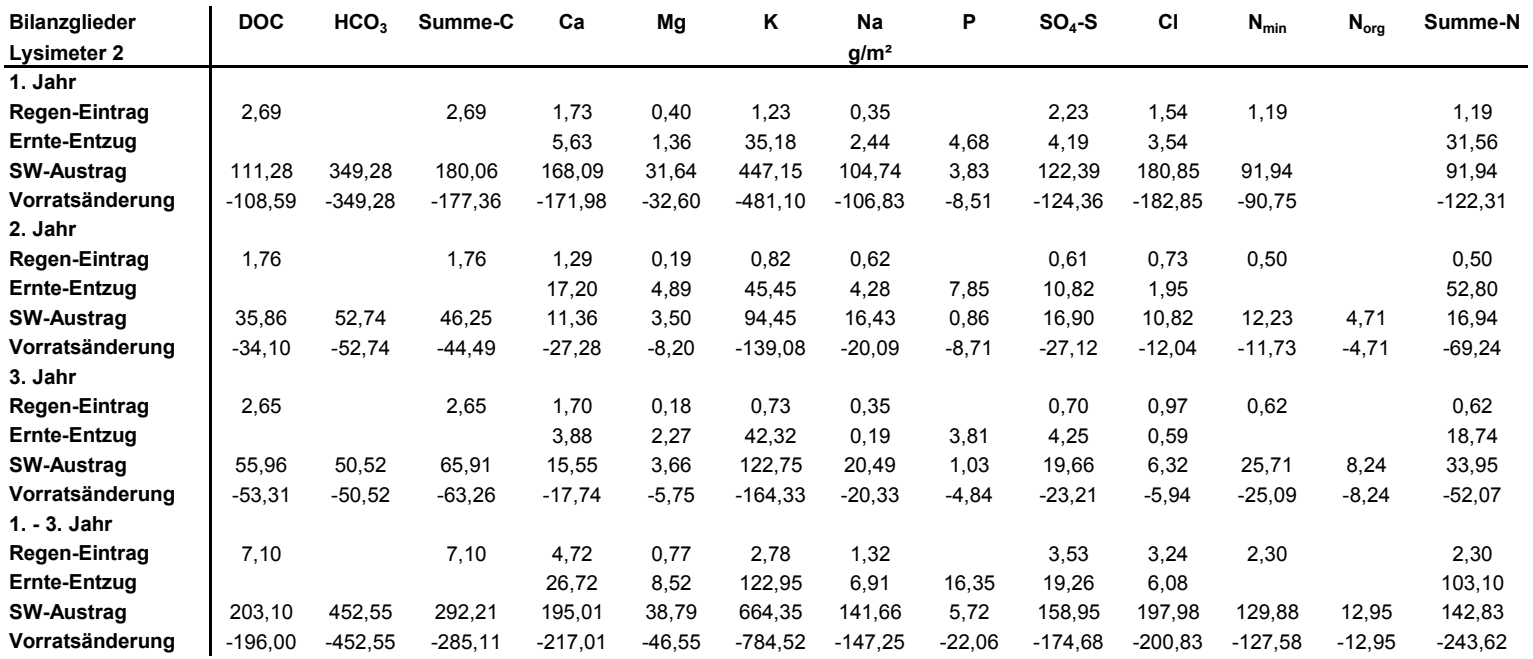

Tabelle 9-3: DOC- und Mineralstoff-Bilanz in $\mathrm{g} / \mathrm{m}^{2}$, pro

Untersuchungsjahr und von Mai 87 bis April 90, Lysimeter 8

\begin{tabular}{|c|c|c|c|c|c|c|c|c|c|c|c|c|c|}
\hline $\begin{array}{l}\text { Bilanzglieder } \\
\text { Lysimeter } 8 \\
\end{array}$ & DOC & $\mathrm{HCO}_{3}$ & Summe-C & $\mathrm{Ca}$ & Mg & $\mathbf{K}$ & $\begin{array}{c}\mathrm{Na} \\
\mathrm{g} / \mathrm{m}^{2}\end{array}$ & $\mathbf{P}$ & $\mathrm{SO}_{4}-\mathrm{S}$ & $\mathrm{Cl}$ & $\mathbf{N}_{\min }$ & $\mathbf{N}_{\text {org }}$ & Summe-N \\
\hline 1. Jahr & & & & & & & & & & & & & \\
\hline Regen-Eintrag & 2,69 & & 2,69 & 1,73 & 0,40 & 1,23 & 0,35 & & 2,23 & 1,54 & 1,19 & & 1,18 \\
\hline Ernte-Entzug & & & & 5,93 & 1,55 & 39,73 & 1,98 & 5,36 & 8,76 & 23,26 & & & 35,93 \\
\hline SW-Austrag & 231,27 & 287,89 & 287,95 & 83,99 & 17,07 & 292,68 & 94,20 & 4,75 & 49,72 & 76,59 & 34,32 & & 34,32 \\
\hline $\begin{array}{l}\text { Vorratsänderung } \\
\text { 2. Jahr }\end{array}$ & $-228,57$ & $-287,89$ & $-285,26$ & $-88,18$ & $-18,22$ & $-331,18$ & $-95,83$ & $-10,11$ & $-56,25$ & $-98,31$ & $-33,14$ & & $-69,08$ \\
\hline Regen-Eintrag & 1,76 & & 1,76 & 1,29 & 0,19 & 0,82 & 0,62 & & 0,61 & 0,73 & 0,50 & & 0,49 \\
\hline Ernte-Entzug & & & & 9,13 & 2,72 & 28,94 & 2,44 & 3,30 & 2,92 & 1,08 & & & 22,40 \\
\hline SW-Austrag & 67,00 & 82,45 & 83,24 & 8,38 & 2,54 & 64,93 & 13,74 & 2,92 & 6,49 & 0,05 & 6,94 & 5,45 & 12,39 \\
\hline $\begin{array}{l}\text { Vorratsänderung } \\
\text { 3. Jahr }\end{array}$ & $-65,24$ & $-82,45$ & $-81,48$ & $-16,23$ & $-5,07$ & $-93,06$ & $-15,56$ & $-6,23$ & $-8,80$ & $-0,40$ & $-6,45$ & $-5,45$ & $-34,30$ \\
\hline Regen-Eintrag & 2,65 & & 2,65 & 1,70 & 0,18 & 0,73 & 0,35 & & 0,70 & 0,97 & 0,62 & & 0,60 \\
\hline Ernte-Entzug & & & & 0,82 & 0,38 & 1,58 & 0,02 & 0,54 & 0,29 & 0,25 & & & 3,07 \\
\hline sW-Austrag & 38,19 & 54,01 & 48,83 & 7,42 & 2,08 & 37,91 & 6,76 & 1,72 & 4,61 & 0,30 & 6,33 & 3,33 & 9,66 \\
\hline $\begin{array}{l}\text { Vorratsänderung } \\
\text { 1. - 3. Jahr }\end{array}$ & $-35,54$ & $-54,01$ & $-46,18$ & $-6,54$ & $-2,28$ & $-38,76$ & $-6,43$ & $-2,26$ & $-4,20$ & 0,41 & $-5,73$ & $-3,33$ & $-12,13$ \\
\hline Regen-Eintrag & 7,10 & & 7,10 & 4,72 & 0,77 & 2,78 & 1,32 & & 3,53 & 3,24 & 2,30 & & 2,30 \\
\hline Ernte-Entzug & & & & 15,88 & 4,65 & 70,26 & 4,44 & 9,19 & 11,97 & 24,59 & & & 61,40 \\
\hline SW-Austrag & 336,46 & 424,35 & 420,02 & 99,79 & 21,69 & 395,53 & 114,70 & 9,40 & 60,81 & 76,94 & 47,60 & 8,78 & 56,37 \\
\hline Vorratsänderung & $-329,36$ & $-424,35$ & $-412,91$ & $-110,95$ & $-25,57$ & $-463,00$ & $-117,82$ & $-18,59$ & $-69,25$ & $-98,30$ & $-45,30$ & $-8,78$ & $-115,47$ \\
\hline
\end{tabular}


Tabelle 9-4: DOC- und Mineralstoff-Bilanz in $\mathrm{g} / \mathrm{m}^{2}$, pro

Untersuchungsjahr und von Mai 87 bis April 90, Lysimeter 6

\begin{tabular}{|c|c|c|c|c|c|c|c|c|c|c|c|c|c|}
\hline $\begin{array}{l}\text { Bilanzglieder } \\
\text { Lysimeter } 6\end{array}$ & DOC & $\mathrm{HCO}_{3}$ & Summe-C & $\mathrm{Ca}$ & Mg & $\mathbf{K}$ & $\begin{array}{c}\mathrm{Na} \\
\mathrm{g} / \mathrm{m}^{2}\end{array}$ & $\mathbf{P}$ & $\mathrm{SO}_{4}-\mathrm{S}$ & $\mathrm{Cl}$ & $\mathbf{N}_{\min }$ & $\mathbf{N}_{\text {org }}$ & Summe-N \\
\hline Regen-Eintrag & 3,02 & & 3,02 & 1,95 & 0,45 & 1,38 & 0,40 & & 2,50 & 1,73 & 1,33 & & 1,33 \\
\hline SW-Austrag & 266,58 & 212,88 & 308,49 & 77,79 & 16,35 & 293,01 & 96,15 & 5,21 & 51,54 & 71,77 & 58,15 & & 58,15 \\
\hline $\begin{array}{l}\text { Vorratsänderung } \\
\text { 2. Jahr }\end{array}$ & $-263,56$ & $-212,88$ & $-305,47$ & $-84,52$ & $-17,64$ & $-327,17$ & $-97,95$ & $-9,86$ & $-59,66$ & $-81,94$ & $-56,82$ & & $-85,20$ \\
\hline Regen-Eintrag & 1,76 & 0,00 & 1,76 & 1,29 & 0,19 & 0,82 & 0,62 & & 0,61 & 0,73 & 0,50 & & 0,50 \\
\hline Vorratsänderung & $-38,90$ & $-45,12$ & $-47,78$ & $-13,95$ & $-4,15$ & $-68,68$ & $-11,18$ & $-5,05$ & $-4,52$ & $-0,45$ & $-6,96$ & $-3,08$ & $-29,83$ \\
\hline 3. Jahr & & & & & & & & & & & & & \\
\hline Regen-Eintrag & 2,65 & & 2,65 & 1,70 & 0,18 & 0,73 & 0,35 & & 0,70 & 0,97 & 0,62 & & 0,62 \\
\hline Ernte-Entzug & & & & 0,65 & 0,27 & 1,69 & 0,02 & 0,37 & 0,19 & 0,19 & & & 2,34 \\
\hline SW-Austrag & 31,94 & 47,11 & 41,21 & 9,81 & 2,82 & 39,17 & 7,55 & 1,81 & 5,58 & 0,72 & 10,06 & 3,37 & 13,43 \\
\hline $\begin{array}{l}\text { Vorratsänderung } \\
\text { 1. - 3. Jahr }\end{array}$ & $-29,29$ & $-47,11$ & $-38,56$ & $-8,76$ & $-2,91$ & $-40,13$ & $-7,22$ & $-2,18$ & $-5,08$ & 0,05 & $-9,44$ & $-3,37$ & $-15,15$ \\
\hline Vorratsänderung & $-331,74$ & $-305,11$ & $-391,82$ & $-107,23$ & $-24,70$ & $-435,98$ & $-116,36$ & $-17,09$ & $-69,26$ & $-82,33$ & $-73,24$ & $-6,45$ & $-130,20$ \\
\hline
\end{tabular}

Tabelle 9-5: DOC- und Mineralstoff-Bilanz in $\mathrm{g} / \mathrm{m}^{2}$, pro

Untersuchungsjahr und von Mai 87 bis April 90, Lysimeter 5

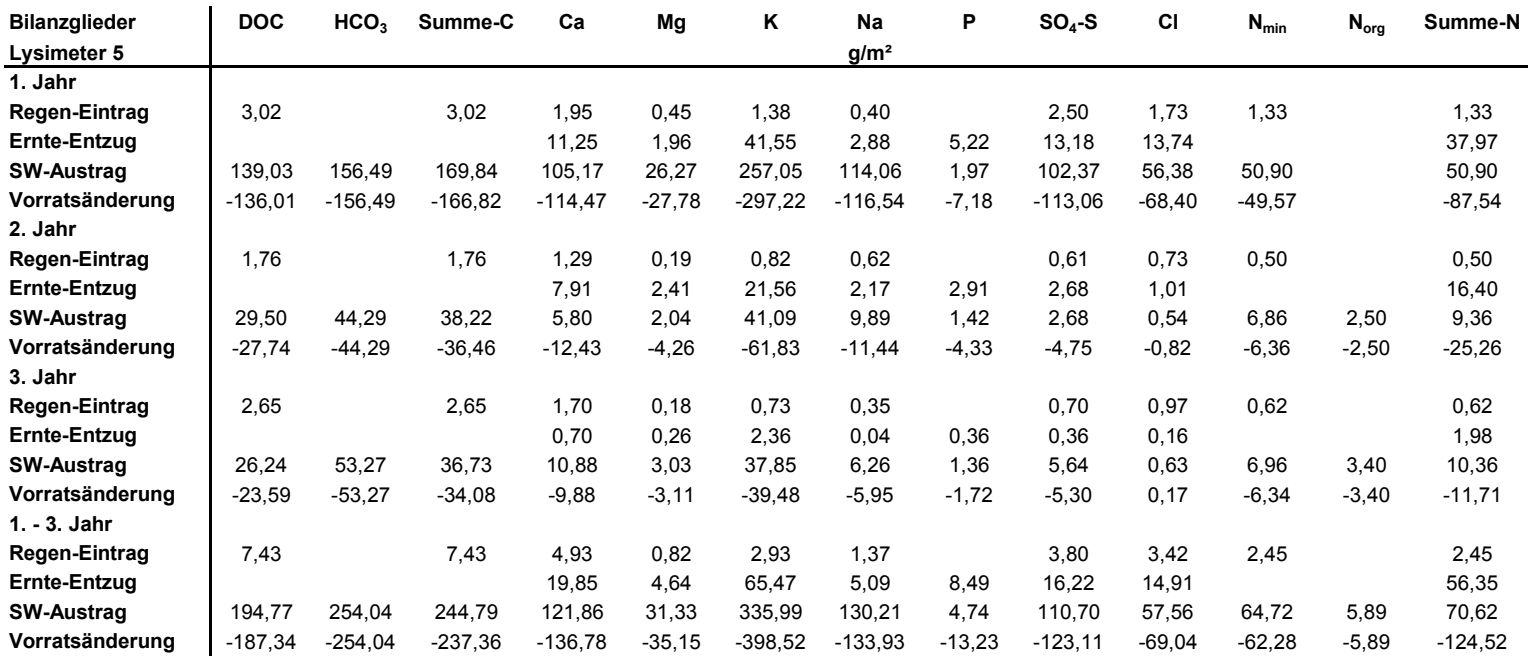

Tabelle 9-6: DOC- und Mineralstoff-Bilanz in $\mathrm{g} / \mathrm{m}^{2}$, pro Untersuchungsjahr und von Mai 87 bis April 90, Lysimeter 4

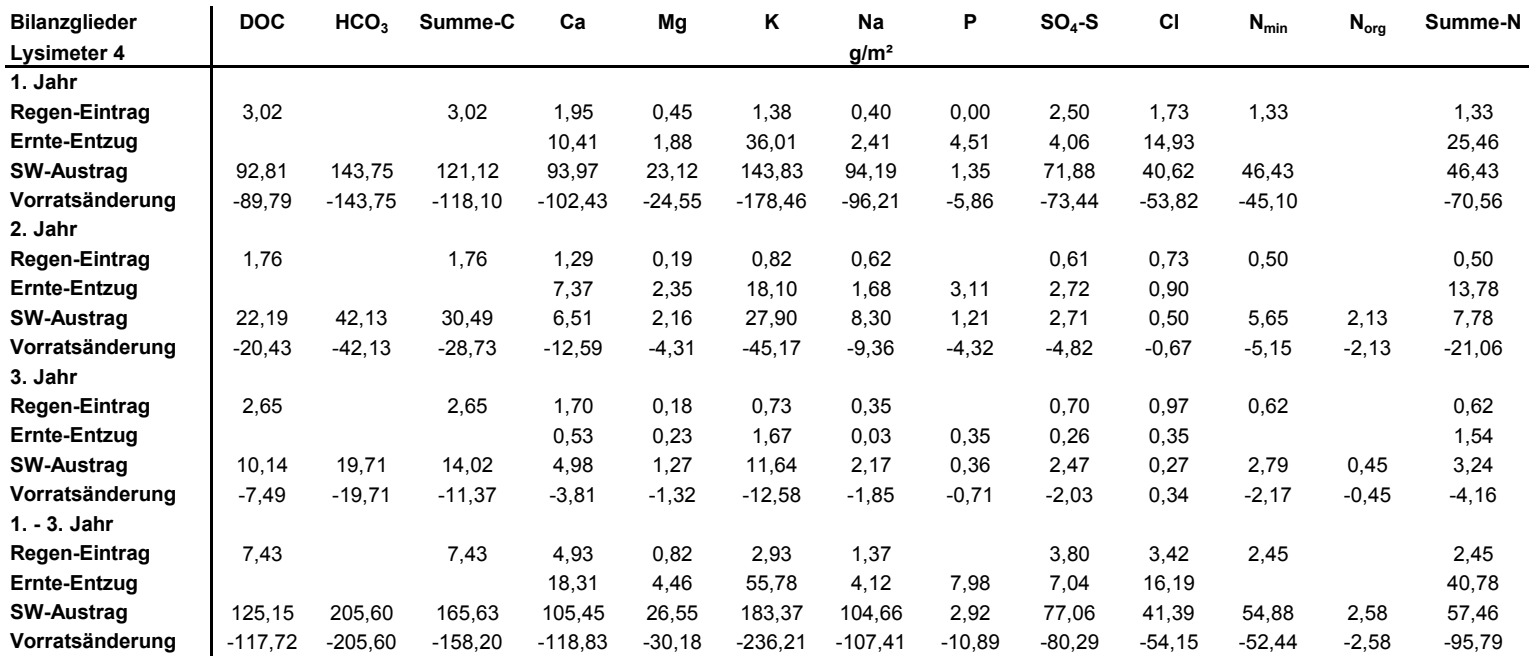


Tabelle 9-7: DOC- und Mineralstoff-Bilanz in $\mathrm{g} / \mathrm{m}^{2}$, pro

Untersuchungsjahr und von Mai 87 bis April 90, Lysimeter 3

\begin{tabular}{|c|c|c|c|c|c|c|c|c|c|c|c|c|c|}
\hline $\begin{array}{l}\text { Bilanzglieder } \\
\text { Lysimeter } 3\end{array}$ & DOC & $\mathrm{HCO}_{3}$ & Summe-C & $\mathrm{Ca}$ & Mg & $\mathbf{K}$ & $\begin{array}{c}\mathrm{Na} \\
\mathrm{g} / \mathrm{m}^{2}\end{array}$ & $\mathbf{P}$ & $\mathrm{SO}_{4}-\mathrm{S}$ & $\mathrm{Cl}$ & $\mathbf{N}_{\min }$ & $\mathbf{N}_{\text {org }}$ & Summe-N \\
\hline Regen-Eintrag & 3,02 & & 3,02 & 1,95 & 0,45 & 1,38 & 0,40 & & 2,50 & 1,73 & 1,33 & & 1,33 \\
\hline SW-Austrag & 48,06 & 97,20 & 67,20 & 64,62 & 12,31 & 40,98 & 56,22 & 0,50 & 51,24 & 72,49 & 32,48 & & 32,48 \\
\hline $\begin{array}{l}\text { Vorratsänderung } \\
\text { 2. Jahr }\end{array}$ & $-45,04$ & $-97,20$ & $-64,18$ & $-75,03$ & $-13,15$ & $-63,16$ & $-57,33$ & $-4,17$ & $-53,95$ & $-87,28$ & $-31,15$ & & $-48,65$ \\
\hline Regen-Eintrag & 1,76 & & 1,76 & 1,29 & 0,19 & 0,82 & 0,62 & & 0,61 & 0,73 & 0,50 & & 0,50 \\
\hline Vorratsänderung & $-16,18$ & $-37,50$ & $-23,56$ & $-13,61$ & $-4,37$ & $-23,75$ & $-8,11$ & $-2,33$ & $-3,63$ & $-0,36$ & $-4,75$ & $-0,13$ & $-13,03$ \\
\hline 3. Jahr & & & & & & & & & & & & & \\
\hline Regen-Eintrag & 2,65 & & 2,65 & 1,70 & 0,18 & 0,73 & 0,35 & & 0,70 & 0,97 & 0,62 & & 0,62 \\
\hline Ernte-Entzug & & & & 0,32 & 0,15 & 0,03 & 0,02 & 0,27 & 0,33 & 0,20 & & & 1,59 \\
\hline SW-Austrag & 13,42 & 44,74 & 22,23 & 15,34 & 3,35 & 16,73 & 3,13 & 0,34 & 4,28 & 0,34 & 6,43 & 1,79 & 8,22 \\
\hline Vorratsänderung & $-10,77$ & $-44,74$ & $-19,58$ & $-13,97$ & $-3,32$ & $-16,03$ & $-2,80$ & $-0,61$ & $-3,92$ & 0,43 & $-5,81$ & $-1,79$ & $-9,19$ \\
\hline Vorratsänderung & $\begin{array}{r}-71,99 \\
\end{array}$ & $-179,44$ & $-107,32$ & $-102,61$ & $-20,83$ & $-102,94$ & $-68,24$ & $-7,11$ & $-61,50$ & $-87,21$ & $-41,72$ & $-1,92$ & $-70,88$ \\
\hline
\end{tabular}

Tabelle 9-8: DOC- und Mineralstoff-Bilanz in $\mathrm{g} / \mathrm{m}^{2}$, pro Untersuchungsjahr und von Mai 87 bis April 90, Lysimeter 7

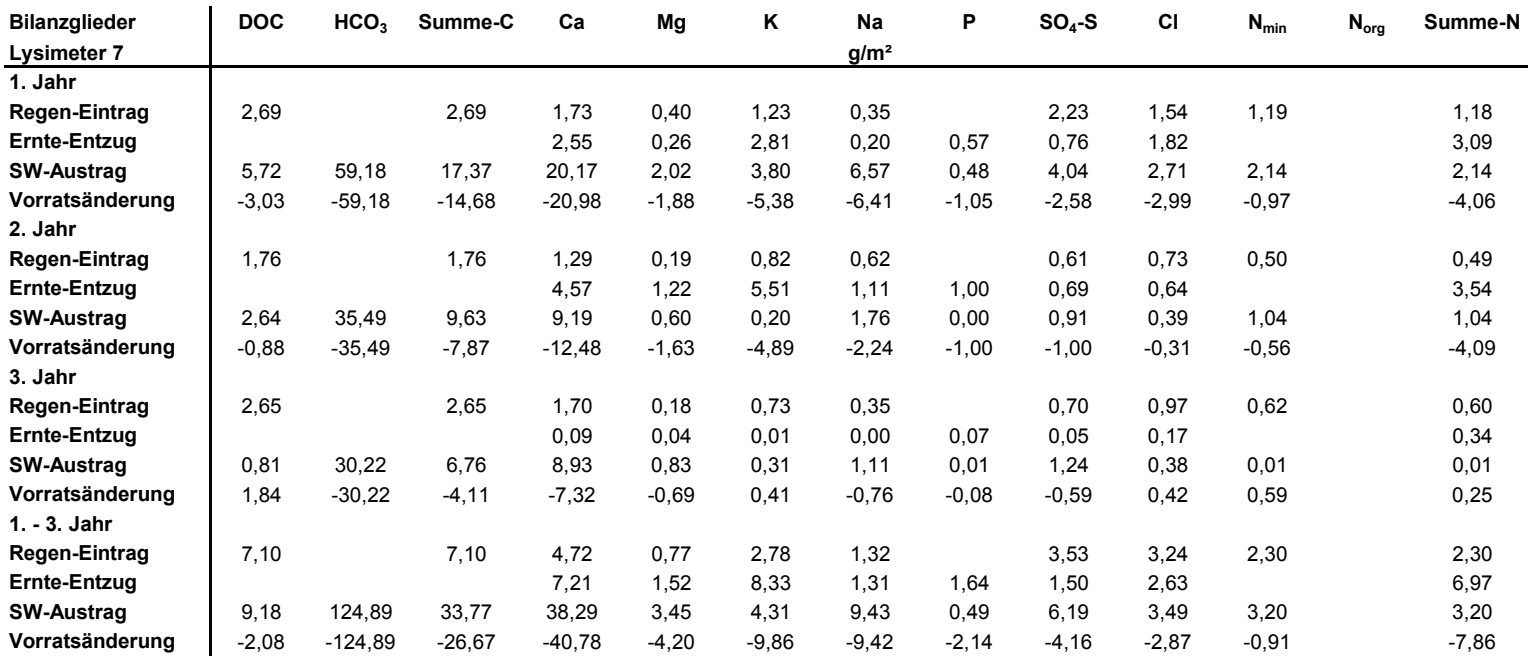

Die Ernte-Entzüge liegen außer für $\mathrm{P}$ unter den Sickerwasser-Austrägen. Deutlich geringere Entzüge als mit dem Sickerwasser sind bei $\mathrm{Cl}$ und $\mathrm{Na}$ zu beobachten, die kaum von den Pflanzen aufgenommen wurden. Etwa das Dreifache der pflanzlichen Entzüge gehen dem System Lysimeter für $\mathrm{Ca}, \mathrm{Mg}, \mathrm{K}$ und $\mathrm{S}$ durch die Sickerwasser-Austräge verloren. Der NVerlust durch das Sickerwasser liegt etwa das 1,5fache über dem Pflanzen-Entzug bzw. bei den kleinsten Lysimetern 7 und 8 (reiner Löss und reiner Kompost) liegt der N-Entzug durch die Ernte über dem Sickerwasser-Austrag.

Die größten Vorratsänderungen durch die Austräge (Sickerwasser und Ernte) und Einräge (Regen) liegen bei den beiden Großlysimetern in $\mathrm{g}$ pro Lysimeter mit Abstand für $\mathrm{K}$ vor gefolgt von $\mathrm{N}, \mathrm{C}, \mathrm{Ca}, \mathrm{Na}, \mathrm{Cl}, \mathrm{S}, \mathrm{Mg}$, und $\mathrm{P}$ bei Lysimeter 1 und $\mathrm{C}, \mathrm{N}, \mathrm{Ca}, \mathrm{Cl}, \mathrm{S}, \mathrm{Na}, \mathrm{Mg}$ und $P$ bei Lysimeter 2. Bei den Kleinlysimetern sind die Austräge für $K$ und $C$ in etwa gleicher Höhe, gefolgt von $\mathrm{N}$, Ca und $\mathrm{Na}$ dann $\mathrm{Cl}$ und ebenfalls niedrigeren Änderungen für $\mathrm{Mg}$ und $P$. Außer bei dem reinen Löss sind die Einträge mit dem Niederschlag nahezu vernachlässigbar.

Betrachtet man die jährlichen Vorratsänderungen in den Tabellen 9-1 bis 9-8 so fällt zunächst auf, dass die Änderungen im ersten Jahr sich deutlich von den Änderungen der 
beiden Folgejahre abheben. Dieses Ergebnis ist sowohl auf die höheren Erntemengen im ersten Jahr als auch die höheren Stoff-Frachten, die dem System Lysimeter durch den Sickerwasser-Abfluss verloren gegangen sind, zurückzuführen.

Bei einheitlichem Flächenbezug übersteigen die Vorratsänderungen für Kohlenstoff in der reinen Kompostvariante, Lysimeter 8, die Austräge bei den Großlysimetern. Bei den Kleinlysimetern nehmen die C-Vorratsänderungen mit abnehmenden Kompost-Anteil in der Mischung ab. Bei den übrigen mineralischen Stoffen den Kationen $\mathrm{Ca}, \mathrm{Mg}, \mathrm{K}$ und $\mathrm{Na}$ und den in Lösung überwiegend als Anionen vorliegenden Elementen $\mathrm{P}, \mathrm{S}, \mathrm{Cl}$, und $\mathrm{N}$ sind die größten Vorratsänderungen bei den Großlysimetern zu beobachten. Die Vorratsänderungen bei Lysimeter 1 und 2 sind ähnlich, Unterschiede treten bei $\mathrm{N}$ auf, hier hat Lysimeter1 die größere Abnahme während für $\mathrm{Cl}, \mathrm{S}, \mathrm{HCO}_{3}$ und $\mathrm{K}$ die höheren Austräge für Lysimeter 2 festzustellen sind. 


\section{Schlussbetrachtung}

Im Mittelpunkt dieser Arbeit stehen Transport- und Lösungsprozesse im Zusammenhang mit dem Abbau organischer Massen. Sickerwasser- und Extraktproben wurden auf ihre Gehalte an anorganischen und organischen Inhaltsstoffen hin untersucht. Zur Erreichung dieser Ziele wurden Methoden aus verschiedenen Fachdisziplinen herangezogen. Die übernommenen Arbeitsweisen wurden auf ihre Anwendbarkeit für die spezifischen Erfordernisse geprüft und durch die Kopplung mit anderen Methoden ergänzt.

Für die Untersuchungen der physikalischen und chemischen Eigenschaften der Komposte, des Lösses und der Kompost/Löss-Mischungen wurden übliche Boden-Untersuchungsmethoden eingesetzt. Dabei mussten in Einzelfällen Methoden aufgrund der hohen Salzgehalte und der hohen Gehalte an löslicher organischer Substanz abgewandelt werden. Außerdem wurden verschiedene Varianten der Probenvorbereitung und der Durchführung z. B. bei der Korngrößenanalyse, der Bestimmung der KAK und der Herstellung von Extrakten verglichen. Dabei hat sich gezeigt, das Randbedingungen der Probenvorbereitung und Durchführung erheblichen Einfluss auf das Ergebnis haben können. In vielen Fällen liefern die Ergebnisse daher vor allem methodisch begründete Werte, die nur näherungsweise die „Realität“ beschreiben.

Kant schreibt in seiner Kritik der reinen Vernunft: „Die Ordnung und die Regelmäßigkeit also an den Erscheinungen, die wir Natur nennen, bringen wir selbst hinein, und würden sie auch nicht darin finden können, hätten wir sie nicht (...) ursprünglich hineingelegt." (zitiert nach WEISCHEDEL 1974)

Erfassung bodenphysikalischer und bodenchemischer Kennwerte der untersuchten Substratvarianten / Qualitätsbestimmende Kompostmerkmale

Die Wassergehalte steigen mit zunehmendem Kompostanteil in den Substraten an. Im Durchschnitt liegen sie bei 40,4 \% der FM für Lysimeter 1 und bei 37,5 \% für Lysimeter 2. In den eingesetzten Komposten sind bei hohen Wassergehalten die Luftporen an der Wasserbindung beteiligt, bei geringen Bodenfeuchte-Werten liegen die Wassergehalte noch über dem Totwasser-Gehalt.

Im Laufe der Freilandversuche ist eine starke Volumenreduktion durch Sackung und die damit einhergehende Verdichtung der Lysimeterfüllungen (bis zu 53 \% geringere Höhe bei Lysimeter 1 nach annähernd 4 Jahren Versuchsdauer) festzustellen. Die Dichte am Ende der Versuchbetreuung liegt für den reinen Kompost bei $0,69 \mathrm{~g} / \mathrm{cm}^{3}$ (Großlysimeter) und $0,65 \mathrm{~g} / \mathrm{cm}^{3}$ (Kleinlysimeter). Im Vergleich dazu erreicht der Löss $1,53 \mathrm{~g} / \mathrm{cm}^{3}$. Die Materialdichten betragen $2,25 \mathrm{~g} / \mathrm{cm}^{3}$ für den Kompost und 2,65 g/ $/ \mathrm{cm}^{3}$ für den Löss. Während beim reinen Kompost (Großlysimeter 1 und 2) die Trockendichte innerhalb der Lysimeter nach unten zunimmt, zeigen die Lysimeter mit höheren Löss-Anteilen (ab Lysimeter 5 mit 41 \% Löss-Zugabe) eine stärkere witterungsbedingte Verdichtung der obersten Schicht. Durch die geringere Verdrängungsgeschwindigkeit von Wasser beim Kompost und dementsprechend mehr wassergefüllten Poren wird die Stabilität des Gefüges gegenüber Verschlämmung und Verdichtung der Oberfläche erhöht.

Das Gesamtporenvolumen steigt mit zunehmendem Kompost-Anteil vor allem durch die Zunahme an Luftporen im Kompost. Die nutzbare Feldkapazität wird gegenüber dem Löss nicht erhöht. 
Nach schonender aber weitest gehender Trennung verbackener Aggregate sind in den Komposten rund $26 \%$ der Aggregate größer als $2 \mathrm{~mm}$. Diese bestehen aus optisch wenig ansprechenden individuellen Festkörpern, wie Steinen, Scherben, verholzten Pflanzenteilen, Knochen, Textilresten sowie Plastik- und Metallteilen. Der Löss besteht vollständig aus Aggregaten, die kleiner als $2 \mathrm{~mm}$ sind. Während in den reinen Kompostfüllungen von der Tendenz her eine relative Zunahme der größeren Aggregate festzustellen ist, nimmt der Feinanteil bei den Lysimetern 5, 4 und 3 in Relation zur Gesamtmenge zu.

Die Korngrößen-Zusammensetzung der Komposte beträgt nach üblicher Probenvorbereitung im Mittel 38,9 \% Sand, 48,7 \% Schluff und 12,4 \% Ton. Die Unterschiede zwischen den verschiedenen Lysimetern, Tiefenabschnitten und Untersuchungszeitpunkten sind gering. Dagegen hat das Lössboden-Material folgende Zusammensetzung: 6,3\% Sand, $76,4 \%$ Schluff und $17,3 \%$ Ton.

Die organische Substanz im Kompost wird auch durch wiederholtes Kochen mit $\mathrm{H}_{2} \mathrm{O}_{2}$ nicht vollständig zerstört. Etwa ein Viertel des C-Gehaltes ist in den Schlämmfraktionen $<20 \mu \mathrm{m}$ $\varnothing$ enthalten, sowohl vor als auch nach der Behandlung mit $\mathrm{H}_{2} \mathrm{O}_{2}$. Der N-Gehalt wird durch die Behandlung mit $\mathrm{H}_{2} \mathrm{O}_{2}$ stärker reduziert, was die Vermutung nahe legt, dass mineralisiertes $\mathrm{C}$ in den in den in den Proben vorhandenen Erdalkalicarbonaten der Schlämmfraktion $<20 \mu \mathrm{m} \varnothing \mathrm{zu} 40$ bis $63 \%$ abgeschieden worden sind und als solche ihre verkittende Wirkung entfalten.

Die Kalkgehalte der Komposte liegen im Mittel bei $6,4 \%$ der TM $<2 \mathrm{~mm}$. Im Löss beträgt der Kalkgehalt durchschnittlich 0,6\% der TM $<2 \mathrm{~mm}$. Es findet eine geringe Kalkanreicherung mit fortschreitender Versuchszeit statt, was als Hinweis auf eine schwache Mineralisation gedeutet werden kann.

Die Glühverluste der Komposte liegen zu Beginn der Freilandversuche bei rund $32 \%$, am Ende der Versuche erreichen sie noch $25 \%$ der TM $<2 \mathrm{~mm}$. Bei den Mischungsvarianten hat Lysimeter 5 mit $42 \%$ Reduktion die größte prozentuale Abnahme des GlühverlustAnteils. Die Abnahme der Glühverluste ist bei der Löss-Variante und den Mischungen mit über $41 \%$ Löss deutlich größer als bei den Lysimeterfüllungen mit überwiegendem Kompost-Anteil.

Dagegen nehmen die $\mathrm{C}_{t}$-Gehalte in der Versuchszeit nur geringfügig ab bzw. nehmen sie sogar zu und korrelieren nicht mit den Glühverlust-Abnahmen. Sie liegen in den Komposten bei rund $14 \%$ der TM $<2 \mathrm{~mm}$. Der anhand des Glühverlust/ $\mathrm{C}_{\text {org }}$-Quotienten errechnete Umrechnungsfaktor für den Humusgehalt schwankt bei den Kompost und Kompost/LössLysimetern zwischen 1,5 und 3,2. Die hohen Faktoren beim reinen Löss (Mittelwert 16,7) weisen auf die Beteiligung von Kristallwasser bei der Bestimmung des Glühverlustes hin. Das im Laufe der Versuchszeit festgestellte Kleinerwerden der Umrechnungsfaktoren weist auf die Zunahme der C-Gehalte in der organischen Substanz hin.

Die Gesamt-N-Gehalte der Komposte liegen bei durchschnittlich 1,3\% der TM. Sie verändern sich über die betrachtete Versuchszeit von drei bzw. vier Jahren kaum. Die C/NQuotienten betragen beim Kompost und den Mischungsvarianten im Mittel 10,4, beim Löss 8,2 .

Die Komposte erreichen eine durchschnittliche $\mathrm{KAK}_{\text {pot }}$ von $565 \mathrm{mmol} \mathrm{IE} / \mathrm{kg} \mathrm{TM}<2 \mathrm{~mm}$. Bezieht man die Austauschkapazität ausschließlich auf die organische Kompost-Substanz so liegt der Wert für den Kompost bei durchschnittlich 2200 mmol IE/kg organischer Substanz. In der Mischung mit Löss steigt die Austauschkapazität der organischen Substanz bis auf $4600 \mathrm{mmol} \mathrm{IE} / \mathrm{kg}$. Die Vor-Auswaschung bewirkt bei den Mischungsvarianten eine Erhöhung der $\mathrm{KAK}_{\mathrm{pot}}$, die möglicherweise auf die Aufhebung räumlicher Behinderungen zurückzuführen ist. Das Kompost-Ausgangsmaterial enthält erhebliche Mengen auswasch- 
barer Na- und K-Salze. Während in der Auswaschlösung Kalium dominiert, ist am Ausstauscher Calcium am stärksten vertreten.

Veränderungen der Asche-Gehalte während der Versuchszeit beruhen im Wesentlichen auf einer Zunahme an Mineralsubstanz. Das würde bedeuten, dass der Verlust an organischer Substanz durch Mineralisation größer ist als der durch Auswaschung dem System verloren gegangene mineralische Anteil und dass somit die Mineralsubstanz relativ angereichert wurde. Gegenüber der Asche-Zusammensetzung von frischem organischen Material, wie z. B. Grassschnitt, sind im Kompost die Erdalkali-Kationen deutlich angereichert. Die lässt einerseits auf die bereits stattgefundene Auswaschung der leicht löslichen Alkali-Kationen, andererseits aber auch auf den von vorn herein hohen Anteil an beigemischtem BodenMaterial im angelieferten Bio-Abfall schließen. Berechnet man anhand der Al-Gehalte im Kompost den bodenbürtigen Asche-Anteil, so beziffert sich dieser auf 54,09 Prozentpunkte der 70,64 \% Glührückstand in der TM.

Die Schwermetall-Gehalte der untersuchten Komposte sind vergleichsweise hoch. Die Grenzwerte der BioAbfV und die Vorsorgewerte der BbodSchV für alle drei genannten Bodenarten werden für Blei, Cadmium und Zink überschritten. Für Kupfer werden darüber hinaus für die Bodenarten Lehm/Schluff und Sand und für Nickel nur bei sandigen Böden die Vorsorgewerte der BBodSchV überschritten. Die hier untersuchten Komposte, die aus angelieferten Bio-Abfällen vom Januar 1986, Februar 1986 und März 1986 hergestellt wurden, zeigen deutlich höhere Schwermetall-Gehalte als Untersuchungen der Bundesgütegemeinschaft Kompost für heutige Komposte und eigene Untersuchungen für Komposte aus der Eigenkompostierung ergeben.

Die Biomasse-Gehalte der Komposte betragen rund $1 \mathrm{~g}$ pro $\mathrm{kg}$ TM. Bezieht man die Bio-

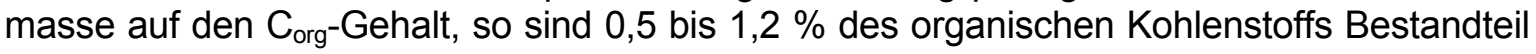
der Biomasse. Im Löss sind 1,3\% des organischen Kohlenstoffs Biomasse-C. Die Kompost-Charge in Lysimeter 2 mit dem unterstellten geringeren Zersetzungsgrad weist im Vergleich mit Lysimeter 1 die höheren Biomasse-C-Gehalte aus. Der Anteil der Biomasse nimmt bei Lysimeter 2 mit zunehmender Lysimetertiefe um bis zu $50 \%$ im Vergleich zur obersten Schicht zu. Die im Vergleich zu den Mischungen mit Löss geringeren Anteile an extrahierbarem Kohlenstoff unfumigierter und fumigierter Proben und entsprechend geringere Anteile an Biomasse-C, bezogen auf den Gehalt an organischem Kohlenstoff in den Komposten, legen die Annahme nahe, dass die organische Substanz der Komposte für eine Besiedlung durch Mikroorganismen nur beschränkt zugänglich ist oder dass die humifizierte organische Substanz generell nur noch eine geringe Wasserlöslichkeit besitzt. Möglicherweise handelt es sich um große $\mathrm{C}_{\text {org }}$-Körper oder von im Zuge der Mineralisation von sekundär abgeschiedener Mineralsubstanz umhüllte Körper, die für Mikroorganismen nicht als Substrat zugänglich sind.

\section{Organische und anorganische Inhaltsstoffe von Extrakten}

Obwohl Eluatprognosen auf der Basis von Schüttel- bzw. Batchversuchen unter unrealistischen Bedingungen durchgeführt wurden, liefern sie doch wichtige Informationen für die Abschätzung der langfristigen Stoffabgabe an das Grundwasser und die Vegetation.

Die Löslichkeit der Inhaltsstoffe bei Schüttelversuchen ist von verschiedenen Faktoren wie der Konzentration des Extraktionsmittels, dem pH-Wert, dem Feststoff/Lösungsmittel-Verhältnis, der Schütteldauer und der Probenvorbereitung abhängig. Bei der Art der Probenvorbereitung sind die Korngröße, der Grad der Zerkleinerung und die Trocknung von Bedeutung. Auf die Höhe der Konzentration der Inhaltsstoffe wirkt sich auch die Art der Abtrennung der flüssigen Phase aus. Dabei haben sich hier die Zentrifugation und die anschließende Filtration über Papierfilter bewährt. 
Die Ergebnisse der verschiedenen Extraktionsverfahren ergeben keine gesicherten Aussagen über die tatsächlichen Bindungsformen (ZEIEN 1995). Dennoch sind sie zur allgemeinen Charakterisierung von Substraten gut geeignet.

Bei der Extraktgewinnung wurden folgende Bedingungen der Extraktion variiert:

- Trocknung: Lufttrocknung / Trocknung bei $105^{\circ} \mathrm{C}$

- Zerkleinerung: Mörsern / schonendes Zerdrücken mit der Walze

- Siebdurchgang: $<1,12 \mathrm{~mm} /<2 \mathrm{~mm} />2 \mathrm{~mm}$

- Substrat:Wasser-Verhältnis: 1:2 / 1:10

- Schütteldauer: $24 \mathrm{~h} / 1 \mathrm{~h}$

Es zeigt sich, dass die in den Extrakten untersuchten Inhaltsstoffe in unterschiedlicher Weise von den genannten Bedingungen beeinflusst werden. Auch die Unterschiede innerhalb der Mischungsvarianten sind groß, insbesondere die Beimischung von Löss führt zu einer veränderten Freisetzung löslicher Verbindungen. Aber auch die unterschiedlichen Lysimetergrößen und die sich daraus ergebenden Auswaschungsbedingungen durch natürliche Niederschläge wirken sich auf die Inhaltsstoff-Konzentrationen der Extrakte aus.

Im Einzelnen wurden folgende Ergebnisse ermittelt:

Errechnet man näherungsweise den Salzgehalt der Kompostproben entsprechend dem Extraktionsverhältnis und dem in Kapitel 6.5 .5 berechneten Umrechnungsfaktor $(1 \mathrm{mS} / \mathrm{cm}=$ $0,69 \mathrm{~g}$ Salz/l), so erhält man für das Kompost-Ausgangsmaterial vom März 86 in der TM < $1,12 \mathrm{~mm}$ je nach Extraktionsverhältnis Salzgehalte zwischen $0,66 \%$ im 1:2-Extrakt und 0,97 \% im 1:10-Extrakt. Die Großlysimeter weisen in der TM $<1,12 \mathrm{~mm}$ zu Versuchsbeginn Werte zwischen 1,4 und 1,7\% Salz auf, die gegen Ende der Freilandversuche durch Auswaschung auf Werte zwischen 0,14 und 0,25 zurückgehen. Die Leitfähigkeit im 1:2Extrakt liegt beim reinen Löss bei Werten zwischen 0,5 (1987) und 0,4 (1988) $\mathrm{mS} / \mathrm{cm}$ und beim reinen Kompost zwischen 3,6 (1987) und 1,7 (1988) mS/cm. Die Leitfähigkeit im 1:2Extrakt des für die Kleinlysimeter verwendeten Kompost-Ausgangsmaterials März 86 liegt bei $4,8 \mathrm{mS} / \mathrm{cm}$.

Das dominierende Kation in den Extrakten der Großlysimeter ist K, gefolgt von $\mathrm{Ca}$, Na und Mg. Die löslichen Gehalte sinken innerhalb der ersten Untersuchungsmonate deutlich ab. Dies ist insbesondere für die Alkalielemente zu beobachten. Die Abnahme liegt bei Ca und Mg bei rund $50 \%$; bei K und Na bei rund $70 \%$. Während der Na-Gehalt zu Versuchsbeginn noch über dem Ca-Gehalt liegt, sinkt er im Laufe der Versuchszeit unter die Ca-Werte.

Bei der Mineralisation freigesetzte Kationen $\mathrm{Ca}$ und $\mathrm{Mg}$ werden als wenig lösliche Carbonate festgelegt, während die in all ihren Salzen hochlöslichen Kationen K und $\mathrm{Na}$ mobil bleiben und in tiefere Schichten verlagert bzw. ausgewaschen werden. Es liegt insgesamt keine gleichmäßige Abnahme der Gehalte bzw. der Tiefenverlagerung vor, so dass Veränderungen der Löslichkeit auch durch Nachlieferung aus Mineralisationsvorgängen und/oder physikalisch-chemischen Umwandlungen zu vermuten sind.

Bei den Kleinlysimetern liegt eine durchgängige Abnahme der Konzentrationen im Extrakt nur für Natrium vor. Für Kalium ist bei $L 8$ eine Abnahme, bei $L 3$ und $L 7$ sind geringe Änderungen und bei L 4, 5 und 6 Erhöhungen zu verzeichnen. Für Calcium ist bei allen Lysimetern eine Zunahme der löslichen Verbindungen während des Versuches erkennbar. Für Mg liegt eine Zunahme bei den Lysimetern 3, 4, 5 und 6 vor, eine Abnahme bei L 8 und geringe Unterschiede bei $L 3$. Möglicherweise bildet die Löss-Beimischung einen Senke für lösliche Verbindungen, die dadurch verzögert freigesetzt werden. Eine Erklärung dafür ist in der Befähigung des Lösses zur Fixierung des $\mathrm{K}$ im Zwischenschichtraum der Tonminerale 
zu suchen, die K vor der Auswaschung schützt. Die Kationengehalte in den Extrakten steigen bis auf wenige Abweichungen mit zunehmendem Kompostgehalt an.

Bei den im ersten Untersuchungsjahr im 1:2-Extrakt der Großlysimeter gemessenen Anionen $\mathrm{Cl}, \mathrm{SO}_{4}$ und $\mathrm{PO}_{4}$ (als $\mathrm{P}$ ) ist für $\mathrm{Cl}$ und $\mathrm{SO}_{4}$ ebenfalls eine starke Abnahme zu verzeichnen. Auch hier sind Verlagerungen in tiefere Kompostschichten erkennbar. Während $\mathrm{Cl}$ nahezu komplett ausgewaschen wird, bleibt bei $\mathrm{SO}_{4}$ eine gewisse Restmenge erhalten, die kontinuierlich aus der weiteren Mineralisation des Kompost-Materials nachgeliefert wird. Die Werte für P steigen während der Freilandversuche im Extrakt an. Bei den Kleinlysimetern ist für die ab 30.06.1987 im Extrakt gemessenen Anionen bis auf die N-Verbindungen eine Zunahme der löslichen Gehalte mit zunehmendem Kompostanteil erkennbar. Die $\mathrm{SO}_{4}{ }^{-}$ Werte gehen bei den Lysimetern 8, 5, 4 und 3 über die Versuchszeit hinweg zurück, während die Werte bei Lysimeter 3 ansteigen und bei den Lysimetern 6 und 7 etwa gleich bleiben. Die P-Gehalte steigen zum 2. Probenahmetermin im Juli 1987 hin an und sinken bis zum Versuchsende deutlich ab. Das dominierende Anion in den Extrakten der Kleinlysimeter ist $\mathrm{HCO}_{3}$ gefolgt von $\mathrm{SO}_{4}, \mathrm{PO}_{4}, \mathrm{Cl}$ und $\mathrm{NO}_{3}$.

Vergleicht man die unterschiedlichen Größen der Extraktionsverhältnisse, so stellt man fest, dass die auf die TM bezogenen Gehalte bei weitem Extraktionsverhältnis ansteigen. Für das Kompost-Ausgangsmaterial ergeben sich für alle Inhaltsstoffe - bis auf $\mathrm{NH}_{4}-\mathrm{N}$ - höhere Gehalte bei der 1:10-Extraktion. Besonders starke Steigerungen lassen sich für $\mathrm{P}$ (Faktor 9,9), $\mathrm{NO}_{3}-\mathrm{N}$ (Faktor 4,4), $\mathrm{K}$ (Faktor 3,3) und $\mathrm{HCO}_{3}$ (Faktor 2,4) erzielen. Der DOC steigt um $39 \%$ an. Die Werte für Ammonium sinken im 1:10-Extrakt um etwa $30 \%$ gegenüber dem 1:2-Extrakt.

Der Vergleich der Wirkung der Vorbehandlungsmethoden 1:2 mit Trocknung und 24 stündiger Extraktionszeit gegenüber 1:10 ohne Trocknung und nur 1 stündiger Extraktionszeit zeigt Folgendes: Bei den beiden Großlysimetern sind durch das weitere Extraktionsverhältnis nur noch $\mathrm{NO}_{3}-\mathrm{N}$ und $\mathrm{P}$ vermehrt extrahierbar. Die Gehalte für $\mathrm{HCO}_{3}, \mathrm{Na}, \mathrm{Mg}$ und $\mathrm{Ca}$ sinken, die Kalium-Werte bleiben konstant. Bei den Kleinlysimetern bringt der Trocknungsvorgang mehr an $\mathrm{Ca}, \mathrm{Mg}, \mathrm{DOC}$ und $\mathrm{HCO}_{3}$ in Lösung, bei $\mathrm{K}, \mathrm{Na}, \mathrm{N}_{\text {ges }}$ und $\mathrm{P}$ dagegen das Belassen in frischem Zustand bei weitem Extraktionsverhältnis. Bei den ersten vier genannten lonen und DOC steigt die extrahierte Menge mit der Zunahme des Kompostanteils in der Lysimeterfüllung von Lysimeter 4 bis 8 . Bei fast allen Frischsubstanz-Extraktionen tritt das lössarme Lysimeter 6 mit höheren Werten als das mit reinem Kompost gefüllte Lysimeter 8 hervor. Dies ist besonders in der 2. Gruppe, $\mathrm{K}, \mathrm{Na}, \mathrm{N}_{\text {ges }}$ und $\mathrm{P}$, deutlich.

Bei der Durchführung einer zweiten direkt auf die erste folgenden Extraktion zeigt sich, dass der zu erwartende Verdünnungseffekt von der ersten zur zweiten Extraktion nicht eintritt. Es werden weiterhin beträchliche Mengen an Salzen und organischer Substanz extrahiert, die teilweise sogar über den Werten der ersten Extraktion liegen. Höhere Werte liegen für $\mathrm{HCO}_{3}$ (Großlysimeter und Kleinlysimeter) und DOC (Großlysimeter) sowie einzelne Kationen und Anionen bei den Kleinlysimetern vor. Vermutlich bedingt die fortschreitende zeitbedürftige „Hydrolyse“ der organischen Substanz die Freilegung von ionischen Bindungen an den Wänden der Poren.

Bei den beschriebenen Extraktionsverfahren gehen 2,4 bis 3,5 g organischer Substanz bei Lysimeter 1 und 1,2 bis 1,7 g bei den Lysimetern 2 und 8 pro $\mathrm{kg}$ TM Kompost in Lösung. Sowohl der Trocknungsvorgang bei $105^{\circ} \mathrm{C}$ als auch das wiederholte Extrahieren bzw. das weitere Lösungsmittelverhältnis im 1:10-Extrakt steigern die Lösbarkeit der organischen Substanz. Die Färbung der Extrakte ist in den tieferen Lysimeterschichten der beiden Großlysimeter stärker. Über die Versuchszeit hinweg nimmt die Färbung der Extrakte stärker $a b$ als die Menge der gelösten organischen Substanz. Das Verhältnis zwischen der Extinktion bei $400 \mathrm{~nm}$ und bei $436 \mathrm{~nm}$ beträgt im Sickerwasser und in den Extrakten durchschnittlich 1,6. Dies lässt vermuten, dass es sich bei den färbenden Bestandteilen der orga- 
nischen Substanz um vergleichbare, möglicherweise homologe chemische Verbindungen handelt.

\section{Quantität und Qualität des Sickerwassers}

Da bei Feldlysimetern gegenüber Laborversuchen weitgehend natürliche Bedingungen vorliegen und die zeitliche Dimension unverändert bleibt, werden hier für die Voraussage des Langzeitverhaltens der Stoffabgabe realistischere Aussagen erzielt.

$\mathrm{Zu}$ bedenken ist allerdings, dass die für die Ermittlung der natürliche Stoff-Frachten notwendigen Sickerwassermengen mit den hier eingesetzten Lysimeterwerten nicht exakt ermittelt wurden.

Die Hauptkritikpunkte an der Sickerwasser-Mengen-Bestimmung sind

- Randeffekte

- nicht ausreichende Lysimeter-Tiefe

- Störung der Lagerungsverhältnisse

- Stauwirkungen an der Lysimeterbasis

Während sich Stauungen an der Lysimeterbasis negativ auf die anfallende SickerwasserMenge auswirken, führen Randeffekte zu überhöhten Sickerwasser-Mengen und schnellerem Wasserabfluss. Bei gering mächtigen Lysimetern wird die kapillare Wasserzufuhr aus tieferen Bereichen unterbunden.

Die aus der Differenz von Niederschlag (und Bewässerung) und Sickerwasser gebildeten Verdunstungswerte (Evapotranspiration und Interzeption) liegen bei den Großlysimetern mit $66 \%$ im ersten, $90 \%$ im zweiten und $84 \%$ im dritten Jahr deutlich über den Werten für die Kleinlysimeter mit Kompost und Kompost/Löss-Mischungen, die im Schnitt jährlich 61, 76 und $74 \%$ betragen und den reinen Löss mit 62, 64 und $73 \%$. Vermutlich führte die höhere seitliche Verdunstung aus den Randklüften bei den Großlysimetern zu den niedrigeren Sickerwasser-Mengen.

Bei dem untersuchten Sickerwasser der Kompost- und Kompost/Löss-Lysimeter handelt es sich um hellgelb bis dunkelbraun gefärbte Lösungen mit hohen Inhaltsstoff-Konzentrationen. Die pH-Werte der Sickerwässer liegen durchgängig im neutralen bis schwach alkalischen Bereich. Die Leitfähigkeiten der Kompost-Sickerwässer erreichen zu Versuchsbeginn etwa $10 \mathrm{mS} / \mathrm{cm}$. Sie sinken durch die Auswaschung auf 2,2 für Lysimeter 1, 3,7 für Lysimeter 2 und 1,3 für die Kleinlysimeter. Beim Löss liegen sie dann bei 0,4 mS/cm.

Die unterschiedlichen Inhaltsstoff-Konzentrationen der Sickerwasser-Proben werden neben den vom Substrat bedingten Unterschieden, von dem Verhältnis Kompost/Löss, von den Größenunterschieden der Lysimeter und den damit korrelierenden Substratmengen und Substrat:Wasser-Verhältnissen variiert. So zeigen sich vor allem Differenzen zwischen den Großlysimetern, den Kleinlysimetern mit Kompost und dem Löss-Lysimeter. Das in Lysimeter 2 eingefüllte Kompost-Material befindet sich in einem jüngeren „Reifezustand“ als das Material in Lysimeter 1.

Während für einige der untersuchten Inhaltsstoffe eine deutliche und kontinuierliche Abnahme zu beobachten ist, steigen die Konzentrationen für eine Reihe von Verbindungen nach anfänglichem Anstieg und Abfall wieder an bzw. bleiben auf einem recht konstanten Niveau. 
Bei den Großlysimetern ergibt sich folgendes Bild: Nach der Befüllung der Lysimeter steigen die Konzentrationen der Kationen im Sickerwasser mit der Reihenfolge $\mathrm{K}, \mathrm{Ca}, \mathrm{Na}$ und Mg zunächst rasch an. Am Ende des auswaschungsintensiven Winters 87/88 fallen zuerst die $\mathrm{Ca}$ - und Mg-Konzentrationen und dann die K- und Na-Konzentrationen ab. Sie erholen sich nach der nächsten Sommerpause und ebenfalls nach dem Sommer 89 nicht wieder, sondern verharren auf einem niedrigen Fließ-Gleichgewichts-Niveau in der Reihenfolge K, $\mathrm{Na}, \mathrm{Ca}, \mathrm{Mg}$.

Auch die Anionen zeigen ein in der Anfangsphase schnelles Ansteigen, wobei das $\mathrm{Cl}$ nach Erreichen des ersten Maximums auf die Minimalwerte in den Folgejahren absinkt, während $\mathrm{NO}_{3}$ und $\mathrm{SO}_{4}$ in der Winterphase - vermutlich infolge fortschreitender durch Frost begünstigter Mineralisation - ein zweites noch höheres Konzentrationsmaximum ausbilden. In den Folgejahren geht das in der kompostierten Pflanzenmasse kaum enthaltene $\mathrm{Cl}$ fast auf 0 zurück während beim $\mathrm{NO}_{3}$ und $\mathrm{SO}_{4}$ offenbar noch immer schwache anhaltende Mineralisationsvorgänge ablaufen.

In den ersten beiden Monaten nach dem Ansetzen der Versuche werden die in der Lysimeterfüllung bereits gelöst vorliegenden lonen verdrängt: Bei den Kationen - sowohl beim Kompost wie beim Löss - das $\mathrm{K}$, das über $\mathrm{Ca}$, $\mathrm{Na}$ und weit über $\mathrm{Mg}$ dominiert, bei den Anionen das $\mathrm{NO}_{3}$, das - auch beim Löss - dominiert und zwar in der Reihenfolge über $\mathrm{SO}_{4}, \mathrm{Cl}$ und $\mathrm{HCO}_{3}$.

In den Herbst- und Wintermonaten erfolgt bei den Komposten offensichtlich eine Phase der Mineralisation mit einem erneuten Peak in den K-, Na-, Ca- und Mg-Austrägen. Beim Löss unterbleibt diese Phase erwartungsgemäß. In den Folgejahren setzt sich bei dem Kompostund dem Kompost-Löss-Lysimeter, deutlich abzuschätzen anhand des ausgetragenen Kaliums, die Mineralisation fort, jedoch abgeschwächt und abklingend.

Bei den Anionen zeigt sich ein ähnliches Bild: Nach dem rapiden ersten Austragen von bereits gelöst vorliegendem Sulfat und Hydrogencarbonat steigt in der nachfolgenden Mineralisationsphase des 1 . Versuchsjahres in den Kompost- und Kompost/Löss-Mischlysimetern noch einmal die $\mathrm{SO}_{4}$-Konzentration im Sickerwasser stark an, wird aber dann von den ebenfalls zunehmenden $\mathrm{HCO}_{3}$-und $\mathrm{NO}_{3}$-Konzentrationen übertroffen. Im weiteren Versuchsverlauf bleibt $\mathrm{HCO}_{3}$ auf niedrigem, aber relativ konstantem Niveau dominierend. Das gilt auch für das Löss-Lysimeter, aus dem nach der ersten 2-monatigen Auswaschungsphase kaum noch andere Anionen-Arten ausgetragen werden. Interessant ist, dass $\mathrm{Cl}$ und $\mathrm{NO}_{3}$ mit geringen Konzentrationspeaks die 1. Mineralisationsphase der Herbst- und Wintermonate 87/88 begleiten. Beim Chlorid wird, wie bereits ausgeführt, das rasche Abklingen mit der Zeit deutlich, während das Nitrat eine nachhaltige, über Jahre fortschreitende Mineralisierung erkennen lässt. Beim Sulfat sinkt der Anteil, jedoch weniger stark als beim $\mathrm{Cl}$, während $\mathrm{HCO}_{3}$, ähnlich wie $\mathrm{NO}_{3}$, seinen Anteil hält.

Hervorzuheben ist, dass die Jahresdurchschnittswerte für $\mathrm{P}$ im Lauf der Zeit nicht absinken, sondern sich zum Teil noch steigern. Das heißt, dass wenn man davon ausgeht, dass dieses $\mathrm{P}$ durch langsam weiter fortschreitende Mineralisation der schwerer abbaubaren organischen Komponenten entsteht, dieser Prozess noch langsamer als die $\mathrm{HCO}_{3}$-Freisetzung erfolgt. Warum das Lysimeter 1, das bisher in seiner Mineralisation als weiter fortgeschritten gegenüber Lysimeter 2 betrachtet wird, eine höhere P-Mineralisationsrate aufweist, ist vorerst nicht zu deuten.

Die DOC-Konzentrationen im Sickerwasser der Großlysimeter nehmen mit fortschreitender Versuchsdauer zu. Sie liegen am Ende der Freilandversuche bei 740 mg/l (Lysimeter 1) und 1160 mg/l (Lysimeter 2). Die Braunfärbung der Sickerwässer wird im Laufe der Versuchszeit - entgegen den Ergebnissen der Extraktionsversuche - intensiver. Der Quotient $\mathrm{E}_{400} / \mathrm{E}_{436}$ beträgt auch im Sickerwasser 1,6. Das heißt, wenn auch die Menge an färbenden Bestandteilen aufgrund der Lösungsdynamik im Sickerwasser und im Extrakt unterschied- 
lich ist, scheint sich die Zusammensetzung der färbenden organischen Substanz nicht zu unterscheiden. Dagegen sinken die DOC-Gehalte im Sickerwasser der Kleinlysimeter. Möglicherweise führt der mit steigender Löss-Beimengung erhöhte Ton- und EisenoxidAnteil zu einer bevorzugten Sorption der Huminstoff-Derivate.

Da die lonenladungen in einer Lösung ausgeglichen sind, ist eine entsprechende Kompensation positiv geladener Valenzen durch negative zu erwarten. Kompost-Eluate weisen in der Regel einen Überschuss an freien positiven lonenladungen auf, die vermutlich durch negative Valenzen der organischen Substanz ausgeglichen werden. Der Gesamt-Durchschnittswert für die Anzahl an C-Atomen in organischer Bindung pro freier positiver Valenz beträgt 7,4, ist also - verglichen mit den Werten für Sickerwässer aus Parabraunerden die 2 betragen -, recht hoch. Man könnte sich vorstellen, dass die wirksamen organischen Anionen von oxyphenolischen Körpern mit 6 C-Atomen, wie sie Bestandteile von Huminstoffen und ihren Vorstufen sind, gebildet werden.

Geht man davon aus, dass die ausgewaschenen Stoff-Frachten überwiegend aus dem Kompost geliefert werden und bezieht man daher die Gesamt-Austräge auf die zu Versuchsbeginn eingefüllten Mengen an Kompost, so ergibt sich in Lysimeter 5 mit 59 \% Kompost und $41 \%$ Löss in der Mehrzahl der Fälle eine weit überragende Auswaschung gegenüber allen Lysimetern ohne oder mit höherer Löss-Beimengung. Die Auswaschung pro kg Kompost wird durch die Lösszugabe erhöht.

Vergleicht man die Gesamtfrachten im Sickerwasser in $\mathrm{mg} / \mathrm{kg}$ mit den extrahierbaren Stoffmengen aus der luftgetrockneten Probe beispielsweise für Lysimeter 2, so liegen die Sickerwasserfrachten, außer beim $\mathrm{DOC}, \mathrm{HCO}_{3}$ und $\mathrm{P}$, deutlich über den Werten der Laborextrakte. Zur Ermittlung des Wasser/Feststoff-Verhältnisses der Feldlysimeter wird die über die Versuchszeit wirksame Niederschlagsmenge der Substratmenge im Lysimeter gegenübergestellt. Dieser Vergleich ergibt eine stärkere Konzentration der Feldeluate gegenüber den stark verdünnten Extraktlösungen. Das Wasser/Feststoff-Verhältnis beträgt für Lysimeter $20,85 \mathrm{im}$ Gegensatz zu dem Wasser/Feststoff-Verhältnis des hier betrachteten Laborextrakts von 10. Die Wasser/Feststoff-Verhältnisse für die übrigen Lysimeter liegen in Abhängigkeit von der Substratmenge zwischen 1,4 für Lysimeter 1 und 3,3 für Lysimeter 8 mit der niedrigsten Substratmenge.

\section{Fraktionierung der organischen Substanz und Kopplung an Asche-Bestandteile}

Bei der nach dem Verfahren der diskontinuierlichen Diafiltration durchgeführten Ultrafiltration ergibt sich folgende Verteilung der gelösten organischen Substanz im Sickerwasser: Die mit dem Sickerwasser aus den Lysimetern eluierte organische Substanz tritt hauptsächlich in zwei Fraktionen auf: 1.) in dem Retentat > $50.000 \mathrm{u}$ und 2.) in dem Filtrat/Dialysat < 1000 u. Die Fraktionen 50.000 bis 1000 u machen demgegenüber nur $5 \%$ des Ausgangsgehaltes an DOC aus.

In den Sickerwasser-Proben der Kompost-Lysimeter (1,2 und 8 ) sind 30 bis $58 \%$ des DOCGehaltes in der Fraktion > 50.000 u enthalten, wobei die Werte für Lysimeter 2 geringer sind als die Werte für 1 und 8. Das nach der Beregnung der Großlysimeter erhaltene Sickerwasser vom 07.07.88 enthält abweichend von den genannten Ergebnissen deutlich geringere DOC-Anteile > $50.000 \mathrm{u}$. In diesen schwächer gefärbten Sickerwasser-Proben mit vergleichsweise geringen DOC- und lonen-Gehalten werden überwiegend organische Kohlenstoffverbindungen < 1000 u nachgewiesen. Hier ist zu vermuten, dass die nur kurze Dauer der Sickerwasserpassage nicht ausreichend gewesen ist, um hochmolekulare organische Verbindungen in Lösung zu bringen. 
In den Kleinlysimetern sinken die DOC-Gehalte $>50.000$ u stark ab. Das Sickerwasser von 7 enthält keine gelösten organischen Kohlenstoffverbindungen der Größe > 50.000 u mehr, und in den Sickerwasserproben von 3 bestehen trotz rund $31 \%$ Kompost-Anteil der Lysimeter-Füllung nur $0,5 \%$ des insgesamt im Sickerwasser enthaltenen DOC aus dem Retentat $>50.000 \mathrm{u}$. Entsprechend steigen die prozentualen DOC-Anteile der Fraktion < 1000 u mit sinkenden Kompost-Gehalten der Lysimeter-Füllung an.

Durch den höheren Anteil mineralischer Substanz in den Löss-Mischungen werden die hochmolekularen organischen Verbindungen möglicherweise sowohl durch mechanische Filterung als auch durch Sorption an der anorganischen Matrix vor der Auswaschung bewahrt. Die organischen Kohlenstoffverbindungen $>50.000$ u bilden dunkelbraun gefärbte Suspensionen, während die Filtrate $<50.000$ u eine hellgelbe Färbung besitzen. Die weitere Filtration der Filtrate/Dialysate $<1000 \mathrm{u}$ liefert farblose Filtrate $<500 \mathrm{u}$ bei geringen DOCGehalten. Der gefärbte Anteil organischer Substanz der Fraktion $<1000 \mathrm{u}$ ist danach seiner Molekülgröße nach in die Fraktion des Massenbereichs 1000 bis 500 u einzuordnen.

Die mittels Ultrafiltration festgestellte Molekülgrößen-Verteilung der organischen Substanz in den Sickerwasser-Proben wird durch die Gel-Chromatographie bestätigt. Auch hier können zwei bis drei Fraktionen anhand ihrer Molekülgröße unterschieden werden, die in inrer Verteilung der Ultrafiltration entsprechen. Die berechneten durchschnittlichen molaren Massen liegen bei folgenden Werten: Fraktion 1: $37.212 \mathrm{u}$, Fraktion 2: $5.040 \mathrm{u}$ und Fraktion 3: $1.356 \mathrm{u}$. Bei den Mischungsvarianten steigt die berechnete Masse für die Fraktion $1 \mathrm{mit}$ zunehmenden Kompostanteil.

Eine Quantifizierung der DOC-Gehalte der Molekülgrößen-Gruppen wurde bei der GelChromatographie nicht durchgeführt. Aussagen zur Menge können anhand der Peakhöhen nur abgeschätzt werden. In den Sickerwasser-Proben ist die Höhe des ersten Peaks (Fraktion 1) um so größer, je höher der Kompostgehalt im Füllmaterial des Lysimeters ist. Die Mittelwerte der Peakhöhen sinken von $8 \mathrm{~cm}$ bei Lysimeter 1 auf $1,2 \mathrm{~cm}$ bei Lysimeter 3. Die in dieser Fraktion enthaltenen hochmolekularen, dunkelbraun gefärbten organischen Verbindungen, deren Menge im Sickerwasser mit dem Kompostgehalt der Lysimeter korreliert, entsprechen den Retentaten $>50.000$ u der Ultrafiltration. Die Peakhöhen der im Trennbereich 700 bis 1500 u erscheinenden Fraktion dagegen liegen, unabhängig vom Kompostgehalt der Lysimeter in den Mischungsvarianten, auf gleicher Höhe bei durchschnittlich 1,2 $\mathrm{cm}$, bei Lysimeter 1 bei $1,9 \mathrm{~cm}$ und bei 2 bei $3,9 \mathrm{~cm}$.

Bei den künstlich erzeugten Sickerwasser-Proben der beiden Großlysimeter vom 07.07.88 sind die ermittelten mittleren molaren Massen der ersten Fraktion kleiner als in den zeitlich folgenden Sickerwasser-Proben. Bei Lysimeter 2 ist die Peakhöhe für die Fraktion 3 größer als die für Fraktion 1.

Die gel-chromatographische Untersuchung der Laborextrakte ergibt für den Extrakt des Kompost-Ausgangsmaterials vom März 86 einen höheren Anteil an kleineren Molekülgrößen-Fraktionen gegenüber dem Lysimeter-Sickerwasser. In den Freilandversuchen treten die kleineren Molekülgrößen-Fraktionen zugunsten der größeren Fraktionen zurück. Diese Veränderungen lassen sich als Ergebnis des Abbaus der kleineren Molekülgrößen-Fraktionen und des Umbaus in die größeren Molekülgrößen-Fraktionen deuten, wobei die Auswaschung und Tiefenverlagerung bei der Betrachtung der verschiedenen Tiefenabschnitte zu berücksichtigen ist.

Bei der Adsorptions-Chromatographie wird die organische Substanz aufgrund ihrer chemischen Eigenschaften fraktioniert. Das hier eingesetzte Verfahren wird zur Anreicherung von Huminsäuren und Fulvosäuren aus wässrigen Proben angewendet. 67,3 \% des DOC aus den Sickerwasser-Proben von Lysimeter 1 (Probe vom 07.07.88 und 14.12.88) und 44\% des DOC aus der Sickerwasser-Probe von Lysimeter 2 (Probe vom 07.07.88) können angereichert und als Huminsäure und Fulvosäure isoliert werden. Dabei ist in Lysimeter 1 der Huminsäure-Anteil in den Proben vom 07.07.88 sehr viel geringer als in der Probe vom 
14.12.88. Unabhängig von den kleineren molaren Massen der organischen Verbindungen in der Sickerwasser-Probe vom 07.07.88 können auch hier methodisch definierte HuminstoffFraktionen differenziert werden. Die Eluate der Adsorptions-Chromatographie in der Phase der Anreicherung sind farblos. Die molare Masse der nicht adsorbierten organischen Verbindungen liegt etwa bei $1000 \mathrm{u}$.

Nimmt man aus dem Fraktionierungsgang der Ultrafiltration z.B. die Retentate (Filterrückstände) des ersten Filtrationsganges (Retentat 1), die von allen feineren, niedermolekularen organischen Inhaltsstoffen befreit sind, so zeigen diese auch bei der GC ein völliges Fehlen dieser feinen Fraktionen. Das heißt, dass im Hinblick auf die Abfilterung der feineren organischen Fraktionen der Ultrafiltrationsgang gut trennt. Die abgetrennten Filtrate weisen in der GC wie erwartet die feineren organischen Fraktionen auf, die das Filter passiert haben. Unerwarteter Weise aber zeigt die GC auch, dass die Filtermembran BM 500 scheinbar durchlässig für einen gewissen Teil der Molekülgrößen Fraktion > $50.000 \mathrm{u}$ ist. Zur Erklärung dieser Erscheinung ist zwar an „Durchrutschen“ eventuell unter flexibler Verformung gedacht worden, doch ist als wahrscheinlicher anzusehen, dass es sich um Makromoleküle $>50.000 \mathrm{u}$ handelt, die sich hydrolytisch depolymerisierend unter Einstellung von Polymerisationsgleichgewichten in feinere Molekülgrößen zerteilen können. Diese passieren mit dem Wasserstrom die Membran und polymerisieren danach unter Wiedereinstellung des Polymerisationsgleichgewichtes wieder sehr schnell unter Erzeugung sekundärer Polymer-Moleküle (sogenannter Supramoleküle) > 50.000 u.

Während bei der Ultrafiltration die Anionen bis auf Phosphat und Silikat die Filter frei passieren, wird ein Teil der Kationen mit der organischen Substanz zurückgehalten. Der freie Anteil an Kationen, der die Ultrafilter-Sequenz bis zur Fraktion $<1000$ u passiert, beträgt im Durchschnitt bei Na 96 \%, K 94 \%, Mg 82 \%, Ca 78 \% und Fe 0,2\%.

Die gebundenen Kationen befinden sich überwiegend im Retentat $>50.000 \mathrm{u}$. Die in den Retentaten zurückgehaltenen Kationen gehen mit den in diesen Fraktionen enthaltenen Mengen an organischer Substanz einher. Eine Ausnahme macht dabei das Eisen, das fast vollständig im gröbsten Retentat zurückgehalten wird.

Außer beim Fe findet unter den Bedingungen der Adsorptions-Chromatographie keine nennenswerte Sorption von Kationen statt. Im Vergleich zur Ultrafiltration wird bei der Adsorptions-Chromatographie ein weitaus größerer Anteil der anorganischen Begleitstoffe von der organischen Matrix getrennt. Nur ein gewisser offensichtlich sehr fest gebundener Anteil des Eisens verbleibt in organischer Bindung (siehe hierzu FRIMMEL und GEYWITZ 1983). Die fast vollständige Abtrennung der Erdalkali- und Alkali-Kationen bei der Adsorptions-Chromatographie ist auf die vorausgegangene Einstellung eines geringen $\mathrm{pH}-$ Wertes während der Anreicherung zurückzuführen. Sie lässt - bis auf Eisen - auf labile Bindungen zwischen den Kationen und der organischen Substanz schließen. Wie schon bei der Ultrafiltration wird $\mathrm{Ca}$ gegenüber $\mathrm{Mg}$ und $\mathrm{K}$ bevorzugt mit der organischen Substanz angereichert.

Wie im Sickerwasser der Lysimeter wir auch in den bei Ultrafiltration erzeugten Lösungen ein Überschuss an Kationen erzeugt. Geht man auch hier davon aus, dass die positiven Überschussladungen durch negative Valenzen organischer Verbindungen kompensiert werden, so nimmt die Anzahl der C-Atome pro freier positiver Valenz von den großen zu den kleineren Molekülgrößen hin ab. Das würde heißen, dass die Ladungsdichte der organischen Verbindungen mit abnehmender Molekülgröße steigt.

Auch aus den Ultrafiltrations-Retentaten $>50.000 \mathrm{u}$ wurden durch Zugabe von Säure „Huminsäuren“ ausgefällt. Der prozentuale Anteil der durch Säurefällung aus den Retentaten $>50.000$ u erzeugten „Huminsäuren“ am Gesamt-DOC der Sickerwasser-Proben liegt bei 15 bis $26 \%$ und damit deutlich unter der für Lysimeter 1 in der Sickerwasser-Probe vom 14.12.88 adsorptions-chromatographisch gewonnenen Huminsäure-Menge von $35 \%$. 
Daraus kann geschlossen werden, dass auch in den Filtraten $<50.000$ u weitere „Huminsäuren“ hätten ausgefällt werden können.

Die C-Gehalte der isolierten Huminsäuren aus den Sickerwasser-Fraktionen der KompostLysimeter 1, 2 und 8 und des kompostreichen Löss-Mischlysimeters 6 betragen im Schnitt $50 \%$ bei einem C/N-Verhältnis von 10 bis 12 . Die entsprechenden Huminsäuren der lössreichen Lysimeter 5 und 4 deuten mit ihren C-Gehalten von nur 20 bis $35 \%$ und C/N-Verhältnissen von 8,5 bis 10,6 auf eine erhöhte Beimengung okkludierter Mineralsubstanz hin.

\section{Ernte-Entzüge}

Die mit der Ernte und der Abfuhr der Pflanzen entzogenen Stoffmengen unterscheiden sich je nach Lysimetertyp und angebauten Feldfrüchten. Die Pflanzen-Inhaltsstoffe N, P und K steigen in den geernteten Pflanzenteilen mit zunehmendem Kompost-Anteil der LysimeterFüllung an. Die Freisetzung gelöster Verbindungen übersteigt den Bedarf der angebauten Feldfrüchte, so dass hohe Frachten an Pflanzennährstoffen - insbesondere N - mit dem Sickerwasser verlagert und ausgewaschen werden.

\section{Fazit}

Hohe Kompost-Deckschichten bewirken einen hohen Austrag an organischen und mineralischen Verbindungen, die den pflanzlichen Bedarf übersteigen und eine Beeinträchtung des Bodens und des Grundwassers darstellen können. Dabei bewirkt die Zufuhr an organischer Substanz eine langanhaltende mineralisationsbedingte Nachlieferung von Stoffen zusätzlich zu den bereits im Kompost vorhandenen löslichen Verbindungen.

Komposte sollten entsprechend ihrer Düngewirkung bedarfsgerecht und bezogen auf die in innen enthaltenen Schadstoffe unter Berücksichtigung standortgerechter Grenzwertanforderungen angewendet werden. Langfristig sollten die Schadstoff-Gehalte in Komposten durch eine vorsorgende Chemikalienpolitik reduziert werden.

Die langsam fortschreitende Mineralisation führt nur zu einer geringen Anreicherung der Asche. In Gegenwart von Löss wird die Mineralisation beschleunigt. Die Auswirkungen der Löss-Zugabe sind insgesamt vielschichtig und nicht eindeutig zu interpretieren, da sich Freisetzungs- und Sorptionsprozesse überlagern.

Die lösliche organische Substanz des Kompostes lässt sich in zwei bis drei Fraktionen unterteilen. Sie besteht überwiegend aus braun gefärbten, hochmolekularen Huminstoffen. Die weitere Untersuchung dieser Stoffgruppe liefert Hinweise darauf, dass es sich hierbei um „Supramoleküle“ handelt, die unter Einstellung von Polymerisationsgleichgewichten in chemisch ähnliche Verbindungen depolymerisieren können. In den Eluaten nehmen die hochmolekularen organischen Verbindungen gegenüber niedermolekularen Verbindungen mit fortschreitender Versuchsdauer zu.

Die Kopplung der hier untersuchten Kationen $\mathrm{Mg}, \mathrm{K}$ und $\mathrm{Na}$ an die organische Substanz ist von untergeordneter Bedeutung. Die Freisetzung und Auswaschung dieser Asche-Bestandteile geschieht überwiegend unabhängig von der Verlagerung organischer Verbindungen. Eine stabile Bindung an die organische Substanz ist für Fe zu konstatieren und eine Beeinflussung durch labile Verbindungen beim $\mathrm{Ca}$. 


\section{Zusammenfassung}

Durch die getrennte Erfassung und Kompostierung von Bioabfällen werden jährlich große Mengen an Bioabfall-Kompost erzeugt, die zur Verwertung anstehen. Bioabfall-Komposte stellen nährstoffreiche organische Sekundärrohstoffdünger dar, die überwiegend in der Landwirtschaft und im Garten- und Landschaftsbau verwendet werden. Neben den wertgebenden Bestandteilen in Komposten, die zu einer Erhaltung der Bodenfunktionen beitragen, enthalten Komposte auch organische und anorganische Schadstoffe sowie Störstoffe. Aus der Sicht des vorsorgenden Bodenschutzes sind zu hohe Nährstoffeinträge und Schadstoffeinträge zu minimieren (Bundes-Bodenschutzgesetz BBodSchG 1998). Schadstoffvorgaben und Aufwandmengen für Bioabfall-Komposte sind in der Bioabfallverordnung (BioAbfV 1998) geregelt.

In der vorliegenden Arbeit werden die Veränderungen von Bioabfall-Kompost anhand von Feldlysimeter-Untersuchungen betrachtet. Hierzu wurden 8 Lysimeter über drei Jahre bilanzmäßig hinsichtlich ihres Wasser- und Stoffumsatzes erfasst. Die Untersuchungen erstreckten sich auf die wässrigen Eluate der Lysimeterfüllungen und auf den BioabfallKompost selbst. Dabei wurde der Zeitgang der stofflichen Veränderungen verfolgt.

Eingesetzt wurde werkseitig als fertig angesehener "Göttinger Kompost" in verschiedenen Schütthöhen und Mischungen mit Löss. Die Lysimeter wurden unter dem Gesichtspunkt angelegt, dass es eher zu vertreten sei, wenn der Kompost als stärkere pflanzentragende Boden-Deckschicht in die Landschaft eingebaut würde - z.B. zum Zwecke der Standortverbesserung -, weil durch Flächenbeschränkung mögliche Umweltwirkungen besser kontrollierbar bleiben.

Die Bestimmung bodenphysikalischer und bodenchemischer Eigenschaften der untersuchten Substratvarianten und der Anbau von Nutzpflanzen erlauben Aussagen zur langfristigen Wirkung von Bioabfall-Komposten auf die Bodenfruchtbarkeit. Die Erfassung der Sickerwasserbelastung und der jeweiligen Frachtraten ermöglichen Aussagen zur langfristigen Stoffabgabe an das Grundwasser. In den wässrigen Eluaten (Sickerwasser und Extrakte) werden organische Stoffgruppen anhand ihrer Molekülgröße und ihrer chemischen Eigenschaften fraktioniert und auf die Kopplung mit Asche-Bestandteilen hin untersucht. Organische Verbindungen - und hier vor allem als stabil angesehene, wasserlösliche Huminstoffe sind wesentlich für die Mobilität von Metall-Kationen verantwortlich.

Die Untersuchungen zeigen, dass die eingesetzten Bioabfall-Komposte hinsichtlich ihrer bodenphysikalischen Eigenschaften nur geringen weiteren Veränderungen unterliegen. Die Lösszugabe fördert die Aktivität der organischen Substanz, was sich beispielsweise in der Zunahme der potenziellen Kationen-Austauschkapazität und des Biomasse-C-Gehaltes der organischen Substanz in der Mischung mit Löss gegenüber dem reinen Kompost ausdrückt.

Die hohen Salzbelastungen in den Eluaten unterliegen zu Beginn der Freilandversuche einer raschen Abnahme. Während die leichtlöslichen Salze, insbesondere Chloride, nahezu komplett ausgewaschen werden, stellen sich für langfristig nachlieferbare Salze Gleichgewichtskonzentrationen im Sickerwasser ein. Die Konzentrationen an C-, N- (Nitrat-N) und PVerbindungen im Sickerwasser steigen. Die Art und die Menge der in den wässrigen Eluaten gelösten organischen Verbindungen wird durch das Alter der Komposte und die Beimischung von Löss deutlich beeinflusst. Dabei ist das Alter vor dem Hintergrund des Durchlaufens von Prozessen, wie z. B. der Mineralisation, Auswaschung und Humifizierung zu sehen. In Abhängigkeit von den jeweiligen Prozessbedingungen, wie zum Beispiel dem Zerkleinerungsgrad des Substrates oder dem Grad der Durchnässung (Ausbildung von anaeroben Bedingungen), verlaufen diese Prozesse in Bezug auf ihre Umsatzraten und die stofflichen Veränderungen unterschiedlich. 
Die Fraktionierung der in den wässrigen Eluaten gelösten organischen Substanz mit den Methoden der Ultrafiltration und Gel-Chromatographie ergibt zwei bis drei MolekülgrößenFraktionen. Aus der Molekülgrößen-Fraktion > 50.000 u können Huminsäuren und Fulvosäuren isoliert werden. Ein Vergleich verschiedener Fraktionierungs- und Anreicherungsverfahren legt die Vermutung des Vorhandenseins supramolekularer Huminstoff-Systeme nahe.

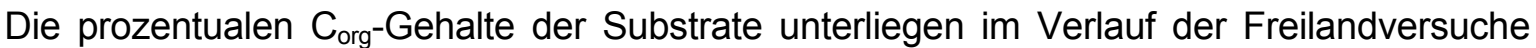
bei fortschreitender Mineralisation nur geringen Veränderungen. Dagegen sinken die prozentualen Glühverluste der Substrate, was auf eine Zunahme des Kohlenstoff-Anteils in der organischen Substanz hinweist. Die Bestimmung der organischen Substanz anhand des Glühverlustes ist vor dem Hintergrund der heterogenen Zusammensetzung und vielfältigen Wirkungen als zu grob vereinfachend zu beurteilen und im Hinblick auf eine Bewertung der Qualität der organischen Substanz zu wenig aussagekräftig.

Die Asche-Bestandteile in den wässrigen Eluaten sind nur zu einem geringen Teil an organische Verbindungen gekoppelt. Während bei den Anionen nur Silikat und Phosphat in nennenswertem Umfang mit der organischen Substanz zurückgehalten werden, sind die untersuchten Kationen bis auf Eisen überwiegend als "freie" Kationen in Lösung. Das Eisen wird offenbar überwiegend als gefälltes Fe-oxid-hydroxid kolloidal oder als Humatkomplex bewegt. Die Affinität der untersuchten Kationen zu Huminstoff-Systemen nimmt in der Reihe $\mathrm{Fe}, \mathrm{Ca}, \mathrm{Mg}, \mathrm{K}, \mathrm{Na}$ ab. Hierbei ist zu berücksichtigen, dass der mengenmäßig größere Anteil der Asche von den bereits vorab in den angelieferten Bioabfällen vorhandenen bodenbürtigen Einträgen herrührt.

Bei der Untersuchung von Bioabfall-Kompost hat sich gezeigt, dass Details und Randbedingungen der Probenvorbereitung und Versuchsdurchführung, die zum Teil methodisch nicht verbindlich festgelegt sind, wie zum Beispiel die Zerkleinerung der Probe, die Trocknung der Probe, oder die Art der Phasenabtrennung fest/flüssig, erheblichen Einfluss auf die Ergebnisse haben können. 


\section{Literaturverzeichnis}

aid Infodienst Verbraucherschutz, Ernährung, Landwirtschaft e. V. (Hrsg.) (2003): Kompost in der Landwirtschaft; Hannover

Alwast, H.; Hoffmeister, J.; Paschlau, H. (2003): 2005 oder „5 vor 12“? Was passiert, wenn nichts mehr passiert?; Müll und Abfall 1, S. 16-29

Arlt, A. (2003): Systemanalytischer Vergleich zur Herstellung von Ersatzbrennstoffen aus biogenen Abfällen am Beispiel von kommunalem Klärschlamm, Bioabfall und Grünabfall; Wissenschaftliche Berichte FZKA 6949, Forschungszentrum Karlsruhe GmbH, Karlsruhe

Bannick, G. C.; Kessler, H.; Hahn, J. (2003): Gute Qualität und sichere Erträge - die Konzeption dahinter; in: Fricke, K. (Hrsg.) "Die Zukunft der Getrenntsammlung von Bioabfällen“, 64. Informationsgespräch des ANS e. V. in Witzenhausen, S. 277 - 282, ORBIT-Verlag, Weimar

Banse, B. (1990): Biomüll-Kompost und Mischungen mit Lößboden-Material in Schütt-Lysimetern als Wuchsort von Kulturpflanzen: Wasser- und Bioelement-Haushalt, Lösungsaustrag von Kohlenstoff (Versuchsanlage und erstes Mess- und Beobachtungsjahr); Diplomarbeit an der Universität Göttingen, Fachbereich Agrarwissenschaften

Becker, R. (1987): Untersuchung zum Sorptionsverhalten von Boden-Huminsäuren gegenüber Metall-Ionen mit der statischen und der dynamischen Methode; Dissertation, Marburg

Beisecker, R.; Gäth, S.; Frede, H.-G. (1998): Landbauliche Verwertung von organischen Abfällen im Spannungsfeld von Bodenschutz und Kreislaufwirtschaft; Zeitschrift für Kulturtechnik und Landentwicklung 39, S. 54 - 59

Bidlingmaier, W. (Hrsg.) (2000): Biologische Abfallverwertung; Ulmer, Stuttgart (Hohenheim)

Bohn, H. L. (1976): Estimate of organic carbon in world soils; Soil Science Society American Journal 40, S. $468-469$

Bruemmer, G.W.; Gerth, J.; Herms, U. (1986): Heavy Metal Spezies, Mobility and Availability in Soils; Zeitschrift für Pflanzenernährung und Bodenkunde 149, S. 382-398

Bruns, C.; Schüler, C.; Waldow, F. (2003): Suppressive Effekte von Komposten gegenüber bodenbürtigen Krankheiten - Qualitätsmerkmal hochwertiger Komposte. Ein Überblick zum Stand des Wissens; in: Fricke, K. (Hrsg.) „Die Zukunft der Getrenntsammlung von Bioabfällen“, 64. Informationsgespräch des ANS e. V. in Witzenhausen, S. 11 - 63, ORBIT-Verlag, Weimar

Buffle, J.; Deladoey, P.; Haerdi, W. (1978): The Use of Ultrafiltration for the Separation and Fractionation of Organic Ligands in Fresh Waters; Analytica Chimica Acta 101, S. 339-357

Bundesgütegemeinschaft Kompost e. V. (Hrsg.) (1994): Methodenbuch zur Analyse von Kompost; Verlag Abfall Now e. V., Stuttgart

Bundesministerium für Verbraucherschutz, Ernährung und Landwirtschaft BMVEL; Bundesministerium für Umwelt, Naturschutz und Reaktorsicherheit BMU (2002): Gute Qualität und sichere Erträge - Wie sichern wir die langfristige Nutzbarkeit unserer landwirtschaftlichen Böden?; Berlin (im Internet unter: www.bmu.de/de/txt/download/b-konzept020603) 
Conte, P.; Piccolo, A. (1999): Conformational Arrangement of Dissolved Humic Substances. Influence of Solution Composition on Association of Humic Molecules; Environmental Science and Technology, 33, S. 1682 - 1690

Deschauer, H. (1995): Eignung von Bioabfallkompost als Dünger im Wald; Bayreuther Bodenkundliche Berichte, Band 43; Bayreuth

Deutscher Wetterdienst (1987 - 1991): Monatlicher Witterungsbericht; Amtsblatt des Dtsch Wetterdienstes, 35. Jahrgang Heft $5-13$ (1987), 36. Jahrgang Heft $1-13$ (1988), 37. Jahrgang Heft $1-13$ (1989), 38. Jahrgang Heft $1-13$ (1990), 39. Jahrgang Heft $1-13$ (1991), Druck und Verlag Deutscher Wetterdienst, Offenbach am Main

Dierfeld, S. (1977): Gefäßversuche zur Aufnahme von Quecksilber und Selen durch Senf, Klee und Sommerweizen und Auswirkung auf das Aminosäurespektrum des Kornproteins; Dissertation an der Universität Bonn, Landwirtschaftliche Fakultät

Dunemann, L.; Schwedt, G. (1984): Zur Analytik von Elementbindungsformen in Bodenlösungen mit Gel-Chromatographie und chemischen Reaktionsdetektoren; Fresenius Zeitschrift für analytische Chemie 317, S 394-399

Eberle, S.H.; Knobel, K.-P.; v. Hodenberg, S. (1979): Untersuchungen über die Bestimmung des hochmolekularen Anteils des DOC einer Wasserprobe durch Diafiltration; Vom Wasser 53, S. 61-67

Eikmann, Th.; Herr, C.E.W.; von Nieden, A. (2003): Beurteilung von Kompostierungsanlagen aus Sicht der Umweltmedizin, Ermittlung von Beschwerde- und Erkrankungshäufigkeit. Umweltmedizinischer Abschlussbericht; Universität Gießen, Förderkennzeichen 0330279

Erkenberg, A. (1985): Beeinflussung der Keimfähigkeit und Keimpotenz von Unkrautsamen durch Kompostierung; Diplomarbeit an der Universität Göttingen, Fachbereich Agrarwissenschaften

Finger, W. (1989): Isolierung und Charakterisierung von Boden-Fulvinsäuren und Untersuchung ihrer Komplexbildung mit Metall-lonen; Dissertation, Marburg

Forschungszentrum Jülich GmbH (Hrsg.) (1991): Auswirkungen von Siedlungsabfällen auf Böden, Bodenorganismen und Pflanzen; Arbeitsgemeinschaft „Siedlungsabfälle - Schwermetalle"; BMFT-Verbundvorhaben: FKZ 0339059 A - K

Franke, K.; Rössler, D.; Kupsch, H. (2004): Use of radioactive tracers for the characterization of humic and fulvic acids in high performance size exclusion chromatography; In Ghabbour, E.A.; Davies, G. (Hrsg.): Humic substances - Nature's most versatile materials, S. 3 8

Frimmel, F. H. (1977): Komplexbildung durch Huminstoffe eines Braunwassersees; Vom Wasser 49, S. 1 - 10

Frimmel, F. H.; Geywitz, J. (1983): Zur koordinativen Bindung von Metallionen an Gewässerhuminstoffe; Fresenius Zeitschrift für analytische Chemie 316, S. 582-588

Frimmel, F. H.; Geywitz, J.; Quentin, K.-E. (1981): Modelle für Eisen-Huminstoffkomplexe; Vom Wasser 57, S. 185 - 198

Fuchs, F.; Raue, B. (1981): Charakterisierung hochmolekularer organischer Wasserinhaltsstoffe durch Fraktionierung mittels Gelfiltration; Vom Wasser 57, S. 95-106 
Gäth, S. (1998): Verhalten ausgewählter Schwermetalle im Boden nach langjähriger Anwendung von Müllkompost als Grundlage für die Entwicklung einer nachhaltigen Verwertung von Bioabfällen; Zeitschrift für Kulturtechnik und Landentwicklung 39, S. 75 - 80

Gäth, S.; Schug, B. (1998): Bioabfallverwertung im Lahn-Dill-Bergland - Ansätze zur nachhaltigen Kreislaufwirtschaft im ländlichen Raum; VDLUFA-Schriftenreihe 49, S. 569-572

Gäth, S.; Schug, B.; Düring, R.-A. (1999): Szenarien zur Bioabfallverwertung - Ansätze zur nachhaltigen Kreislaufwirtschaft im ländlichen Raum; Zeitschrift für Kulturtechnik und Landentwicklung 40, S. 240 - 245

Garvert, U. (1977): Die Technik der Probenahme und jahreszeitliche Schwankungen wichtiger Kennwerte von Müll-Klärschlammkomposten; Dissertation, Landwirtschaftliche Fakultät, Universität Bonn

Genid, A. (1982): Wasser-Haushalt von Löss und Lysimetern mit unterschiedlich tiefem permanentem Grundwasserspiegel und landwirtschaftlichen Kulturen; Dissertation, Universität Göttingen

Georgi-Jänsch, K.; Knieling-Malek, A.; Wegener, H.-R. (1988): Kompostierung von getrennt gesammelten Küchen- und Gartenabfällen: Situation in der Bundesrepublik Deutschland und chemo-physikalische Untersuchung an Kompost und Sickerwasser der Kompostierungsanlage Cölbe (Landkreis Marburg-Biedenkopf); Diplomarbeit an der Justus-LiebigUniversität Gießen, Fachbereich Agrarwissenschaften

Ghosch, K.; Schnitzer, M. (1980) Macromolecular Structures of Humic Substances; Soil Science Vol. 129, No. 5, S. $266-276$

Gjessing, E.T.; (1973): Gel- and Ultramembrane Filtration of Aquatic Humus: A Comparison of the two Methods; Norwegian Institute for Water Research 35/2, S. 286 - 294

Glasow, A. (2000): Stoffliche Veränderung im Mikro- und Submikrobereich von Minerakörnern und Bildung neuer Phasen bei Verwitterung und Bodenbildung in Löß; Dissertation, Göttingen

González-Gaitano, G.; García-Mina, J. (2004): The macromolecular or supramolecular nature of humic substances: A dynamic light scattering study; In Ghabbour, E.A.; Davies, G. (Hrsg.): Humic substances - Nature's most versatile materials, S. 53 - 60

Grotheer, J. (1998): Umweltverträglichkeit von Kraftwerksreststoffen bei ihrem Einsatz im Landschaftsbau; Dissertation, Göttingen

Grundmann, J. (1990): Humifizierung und Mineralisation organischer Substanz bei der Biomüll-Kompostierung unter dem Einfluss verschiedener Zusätze; Dissertation an der Universität Göttingen, Fachbereich Agrarwissenschaften

Hartmann, R. (2003): Studien zur standortgerechten Kompostanwendung auf drei pedologisch unterschiedlichen, landwirtschaftlich genutzten Flächen der Wildeshauer Geest, Niedersachsen; Bremer Beiträge zur Geographie und Raumplanung, Heft 39; Universität Bremen

Hermening, B. (1994): Schwermetall-Gehalte von Pflanzen und Böden der Grünflächen städtischer Siedlungszonen; Diplomarbeit an der Universität Göttingen, Fachbereich Agrarwissenschaften 
Hippe, H. (1985): Entwicklung eines Verbundverfahrens aus Trenn- und photometrischen Bestimmungsmethoden zur Charakterisierung organischer Wasserinhaltsstoffe als Metallkomplexoren; Dissertation, Universität Göttingen

Hydro Agri (Hrsg.) (1993): Faustzahlen für Landwirtschaft und Gartenbau; Hydro Agri Dülmen $\mathrm{GmbH}$, Dülmen

Jackson, M.L. (1965): Soil chemical analysis; Prentice Hall, Englewood Cliffs, New York, S. 227-251

Jäkle, F. (2002): Struktur- und Größencharakterisierung von Huminstoffen und ihren methylierten Derivaten; Dissertation an der Technischen Universität München, Lehrstuhl Chemie und Umweltanalytik

Jörgensen, R., Meyer, B., Müller T. (1992): Zeitgang der mikrobiellen Biomasse in der Ackerkrume einer mitteleuropäischen Löß-Parabraunerde. Eine Ursache für die Mineralisation und Immobilisation des Bodenstickstoffs; Göttinger Bodenkundliche Berichte 100

Kämpfer, P., (2003): Vermessung der Mikroorganismenemissionen von Kompostierungsanlagen und Erfassung der Immissionen in deren Umfeld; Universität Gießen, Förderkennzeichen: 0330279

Kämpfer, P.; Weißenfels, W.D. (Hrsg.) (2001): Biologische Behandlung organischer Abfälle; Springer-Verlag, Berlin, Heidelberg

Kaimer, M.; Schade, D. (2002): Die Zukunft der Hausmüllentsorgung; Müllmagazin 1/2002, S. $25-29$

Kehres, B.; Goedecke, H.; Einzmann, U. (2003): Die Getrenntsammlung und Verwertung von Bioabfällen - Bestandsaufnahme 2003; in: Fricke, K. (Hrsg.) „Die Zukunft der Getrenntsammlung von Bioabfällen“, 64. Informationsgespräch des ANS e. V. in Witzenhausen; S. $11-63$, ORBIT-Verlag, Weimar

Kerzel, A. (2003): Untersuchungen zur gesundheitlichen Belastung durch Schimmelpilze bei Arbeitnehmern in Thüringer Kompostieranlagen und deren Bedeutung für die arbeitsmedizinische Prävention - Eine Verlaufsbobachtung; Dissertation an der medizinischen Fakultät Jena

Khairy, A. H., Ziechmann, W. (1981): Die Veränderung von Huminsäuren in alkalischer Lösung; Zeitschrift für Pflanzenernährung und Bodenkunde 144, S. 407 - 422

Knappe, F.; Friedrich, H.; Fehrenbach, H.; Böß, A.; Berger, J. (2002): Gute Ausgangsposition; Müllmagazin 4, S. 36 - 38

Knappe, F.; Vogt, R. (2003): Ökobilanz verschiedener Verwertungswegefür Bio- und Grünabfälle; in: Bio- und Restabfallbehandlung VII, biologisch - mechanisch - thermisch; Wiemer, K.; Kern, M. (Hrsg.), S. 149 - 171, Witzenhausen

Knickmann, E.; Tepe, W. (1966): Pflanzenernährung im Gartenbau; E. Ulmer Verlag, Stuttgart

Kögel-Knabner, I.; Beyer , L. (1995): Bodenökologie und Organische Substanz; Mitteilungen der Deutschen Bodenkundlichen Gesellschaft, 78, S. 57 - 62

Kögel-Knabner, I.; Guggenberger , G. (1995): Stabilisierungsprozesse der organischen Substanz in Böden; Mitteilungen der Deutschen Bodenkundlichen Gesellschaft, 76, S. 843 846 
König, W. (2003): Welche Anforderungen stellt der Bodenschutz an die Verwertung von Bioabfallkompost?; in: Fricke, K. (Hrsg.) „Die Zukunft der Getrenntsammlung von Bioabfällen“, 64. Informationsgespräch des ANS e. V. in Witzenhausen, S. 283 - 296, ORBIT-Verlag, Weimar

König, N.; Baccini, B.; Ulrich, B. (1986): Der Einfluß der natürlichen organischen Substanzen auf die Metallverteilung zwischen Boden und Bodenlösung in einem sauren Waldboden; Zeitschrift für Pflanzenernährung und Bodenkunde 149, S. 68-82

Kretschmar, R. (1972): Kulturtechnologisch-bodenkundliches Praktikum; Kiel, S. 131-145

Kuntze, H.; Niemann, J.; Roeschmann, G.; Schwerdtfeger, G. (1983): Bodenkunde; UlmerVerlag, Stuttgart

Länderarbeitsgemeinschaft Abfall (LAGA) (1985): LAGA-Informationsschrift: Sickerwasser aus Hausmüll- und Schlackendeponien; Mitteilungen der Länderarbeitsgemeinschaft Abfall (LAGA) 10, Erich Schmidt Verlag, Neuburg

Lavahun M.-F. E., Joergensen R.G., Meyer B. (1995): Depth and time function of microbial biomass in ploughed and grassland typudalfs of lower Saxony; Germany; Göttinger Bodenkundliche Berichte 102

Le Hung, A (2002): Untersuchungen zur Verwertung der Biomasse in Landwirtschaft und Gartenbau Vietnams unter besonderer Berücksichtigung der Kompostierung; Dissertation, Berlin

Leifeld, J.; Siebert, S.; Kögel-Knabner, I. (1998): Humuschemische Parameter von Böden nach mehrjähriger Kompostanwenung im Feldversuch; Zeitschrift für Kulturtechnik und Landentwicklung 39, S. 64 - 68

Loll, U.; (2003): Sind die neuen Grenzwertanforderungen an Sekundärrohstoffdünger aus Bioabfällen praxistauglich? In Wiemer, K.; Kern, M. (Hrsg.) : Bio- und Restabfallbehandlung VII: biologisch-mechanisch-thermisch; Fachbuchreihe Abfall-Wirtschaft des WitzenhausenInstituts für Abfall, Umwelt und Energie, S. 172-187, Witzenhausen

Ma, J,-Y. (1990): Abhängigkeit der Regen-Stabilität von Boden-Aggregaten von lonen-Belegung, Salzkonzentration und möglichen Kitt-Substanzen; Dissertation an der Universität Göttingen, Fachbereich Agrarwissenschaften

Mantoura, R. F. C.; Riley, J. P. (1975): Analytical concentration of humic substances from natural waters; Analytica Chimica Acta 76, S. 97 - 106

Martens, B. (1999): Die gesellschaftliche Resonanz auf das Abfallproblem; Deutscher Universitäts-Verlag, Wiesbaden

Mayr, H. (1999): Bilanzierung zur Verwertung von Biokompost im Wald; Umweltbundesamt (Hrsg.), Berichte BE 161, Eigenverlag, Wien

Meier, M. (2000): Depositionsuntersuchungen 1988 bis 1999 in Wallisellen und auf dem Buchtel; Züricher UmweltPraxis ZUP, 24, S. 27 - 31

Meier-Ploeger, A.; Vogtmann, H. (2003): Qualitätsaspekte der Düngung mit Bioabfallkompost; in: Fricke, K. (Hrsg.) „Die Zukunft der Getrenntsammlung von Bioabfällen“, 64. Informationsgespräch des ANS e. V. in Witzenhausen, S. 11 - 63, ORBIT-Verlag, Weimar

Meyer, B. (1988): Mündliche Mitteilungen, Institut für Bodenwissenschaft der Fakultät Agrarwissenschaften, Göttingen 
Meyer, B. (2004): Mündliche Mitteilungen, Institut für Bodenwissenschaft der Fakultät Agrarwissenschaften, Göttingen

Monteil-Rivera, F.; Chopart, J.-P. (2004): Comparison of dialysis, polarography and fluorimetry for quantification of Cobalt(II) binding by dissolved humic acid; In Ghabbour, E.A.; Davies, G. (Hrsg.): Humic substances - Nature's most versatile materials, S. 243 262

Mundhenke, R. C. (2002): Einfluß der Zerkleinerung auf die Bioverfügbarkeit von organischen Substraten; Dissertation an der TU Braunschweig, Cuvillier Verlag, Göttingen

Nendel, C. (2002): Die Wirkung von Bioabfallkompost auf den Stickstoffhaushalt in Rebflächen; Dissertation an der TU Braunschweig, Shaker Verlag, Aachen

Overesch, M.; Broll, G.; Höper, H. (2003): Humusversorgung von ackerbaulich genutzten Dauerflächen; Weiße Reihe, Band 21, Institut für Strukturforschung und Planung, Vechta

Oberstadtdirektor der Stadt Göttingen und Oberstadtdirektor des Landkreises Göttingen (Hrsg.) (1988): Gesamtausgabe (1) Modellversuch, Versuchsaufbau, Grüne, organische Abfalltonne (Komposttonne) Göttingen, (2) Komposttonne Göttingen, Zwischenbericht, Zwölf Monate Erfahrungen mit dem System Komposttonne, (3) Komposttonne Göttingen, Schlussbericht, Drei Jahre Erfahrungen; Göttingen

Pharmacia (1967): Sephadex - Gelfiltration in Theorie und Praxis; Uppsala

Pöhhacker, R. (1995): Steuerungsfaktoren des Streuabbaus; Bayreuther Bodenkundliche Schriften, Band 39, Bayreuth

Reinhold, J. (2003): Wie wertvoll ist Kompost? Bewertungsgrundsätze für Bodenverbesserungsmittel und Sekundärrohstoffdünger; in: Fricke, K. (Hrsg.) „Die Zukunft der Getrenntsammlung von Bioabfällen“, 64. Informationsgespräch des ANS e. V. in Witzenhausen, S. $11-63$, ORBIT-Verlag, Weimar

Rochus, W. (1981): Löslichkeit und Aggregationsverhalten von Huminsäuren und Humaten; Mitteilungen der Deutschen Bodenkundlichen Gesellschaft 30, S. 37 - 48

Rochus, W. (1979): Mittleres Teilchengewicht und Teilchengewichtsverteilung von Torfhuminsäuren unterschiedlicher Herkunft; Telma Band 9, S. 193-203

Roden, A.; Wittke, B. (1990): Inkubation und Perkolation von Mischungen aus BiomüllKompost und Bodenmaterial. Auswirkungen auf mikrobielle Biomasse und Aktivität die organisch-anorganischen Bestandteile von Substrat und Eluat; Diplomarbeit an der Universität Göttingen, Fachbereich Agrarwissenschaften

Rumpel, C. (1999): Differenzierung und Charakterisierung pedogener und geogener organischer Substanz in forstlich rekultivierten Kippböden; Cottbuser Schriften, Band 5, Cottbus

Schacht, B.; Neef, A.; Kämpfer, P. (1999): Mikrobiologische Charakterisierung unterschiedlich landwirtschaftlich genutzter Böden in peripheren Regionen; Zeitschrift für Kulturtechnik und Landentwicklung 40, S. 234 - 239

Scheffer, F.; Schachtschabel, P. (1989): Lehrbuch der Bodenkunde; Ferdinand Enke Verlag, Stuttgart

Schlichting, E.; Blume, H.-P. (1966): Bodenkundliches Praktikum; Verlag Paul Parey, Hamburg und Berlin 
Schwedt, G.; Hippe, H. (1987): Verbundverfahren zur Charakterisierung organischer Stoffe in Wässern im Hinblick auf Metallkomplexierungen (Elementspezies); Vom Wasser 68, S 151-164

Seier, H.; (2003): Ist die Bioabfallsammlung und -verwertung am Ende?; In Wiemer, K., Kern, M. (Hrsg.): Bio- und Restabfallbehandlung VII: biologisch-mechanisch-thermisch; Fachbuchreihe Abfall-Wirtschaft des Witzenhausen-Instituts für Abfall, Umwelt und Energie, S. 139-147, Witzenhausen

Siebert, S. (1998): Charakterisierung des Stickstoffpools in Böden nach der Anwendung von Kompost; Dissertation an der Fakultät für Geowissenschaften der Ruhr-Universität-Bochum

Simpson A. J.; Kingery, W. L.; Hayes, M. H. B.; Spraul, M.; Humpfer, E.; Dvortsak, P.; Kerssebaum, R.; Godejohann, M.; Hofmann, M. (2002): Molecular Structures and Associations of Humic Substances in the Terrestrial Environment; Naturwissenschaften 89, S. 84 88

Sollins, P.; Homann, P.; Caldwell, B. A. (1996): Stabilisation und destabilization of soil organic matter: mechanisms and control; Geoderma 74, S. $65-105$

Spang, G. (2000): Messung und Modellierung von Sorptions- und Diffusionsprozessen in einem Lößboden - Batch- und Säulenperkolationsversuche mit Stoffen unterschiedlicher Matrixaffinität; Bonner Bodenkundliche Abhandlungen, Band 33

SRU - Der Rat von Sachverständigen für Umweltfragen (Hrsg.) (2004): Umweltgutachten 2004, Nomos Verlagsgesellschaft, Baden-Baden

Stevenson, F. J. (1994): Humus Chemistry - Genesis - Composition - Reactions; Wiley and Sons, New York

Umweltbundesamt (Hrsg.) (1996): Kompostanwendung: Qualitätsverbesserung / Schadstoffabbau / Analytik; Teilvorhaben 6 und 12, Berlin

Umweltbundesamt (Hrsg.) (1997): Neue Techniken zur Kompostierung Verwertung auf landwirtschaftlichen Flächen; Teilvorhaben 7 und 13, Band I, Berlin

Umweltbundesamt (Hrsg.) (1999a): Jahresbericht 1998 aus dem Messnetz des Umweltbundesamtes; UBA-Texte 66/99, Berlin

Umweltbundesamt (Hrsg.) (1999b): Neue Techniken zur Kompostierung; Teilvorhaben 4, Weitergehende Elimination von Gerüchen aus Kompostwerken; Berlin

Umweltbundesamt (Hrsg.) (1999c): Neue Techniken zur Kompostierung Verwertung auf landwirtschaftlichen Flächen; Teilvorhaben 10.b Teil 1 und 2, Band II, Berlin

Van den Bergh, J. (2001): Vor-Ort-Charakterisierung von aquatischen Huminstoffen und ihren Metallspezies; Dissertation, Universität Dortmund

Vance, E.D.; Brookes, P.C.; Jenkinson, D.S. (1987): An extraction method for measuring soil microbial biomass C; Soil Biology and Biochemistry 19, S. 703-707

VDLUFA Verband Deutscher Landwirtschaftlicher Untersuchungs- und Forschungsanstalten (Hrsg.) (1991): Die Untersuchung von Böden, Methodenbuch Band 1; VDLUFA-Verlag, Darmstadt

Vogtmann, H.; Matthies, K.; Kehres, B.; Meier-Ploeger, A. (1992) Die Beeinflussung der Qualität pflanzlicher Produkte durch Bioabfallkompost; in: Kern, M. ; Wiemer, M. (Hrsg.): 
Gütesicherung und Vermarktung von Bioabfallkompost, Abfallwirtschaft 9, S. $305-344$, M.I.C. Baeza Verlag, Witzenhausen

Walkemeyer, S. (1987): Qualität des Biomüll-Kompostes „Göttinger Tonne“: Kriterien für Rottegrad und Eignung als Pflanzen-Substrat, Nähr- und Schadstoff-Gehalte und -Mobilität, Salz-Gehalte und Zusammensetzung; Diplomarbeit an der Universität Göttingen, Fachbereich Agrarwissenschaften

Wallmann, R.; Müller, W. (2003): Organische Düngemittel - Wertstoffe oder Gefährdungspotenziale; in: Fricke, K. (Hrsg.) „Die Zukunft der Getrenntsammlung von Bioabfällen“, 64. Informationsgespräch des ANS e. V. in Witzenhausen, S. 297 - 307, ORBIT-Verlag, Weimar

Weischedel, W. (Hrsg.) (1974): Kant, Immanuel (Deutschland, 1724 - 1804) Werkausgabe, Kritik der reinen Vernunft; Band III und IV, Frankfurt am Main

Wilden, R. W. (2000): Bodenlösungschemie und Elementbilanzen von vier forstlich genutzten Kippenstandorten im Lausitzer Braunkohlenrevier; Cottbuser Schriften, Band 12, Druckzone $\mathrm{GmbH} \& \mathrm{Co}$. KG, Cottbus

Wu, J.; Jörgensen, R.G.; Pommerening, G.; Chaussod, R.; Brookes, P.C. (1990): Measurement of soil microbial biomass $\mathrm{C}$ - an automated procedure, Soil Biology and Biochemistry 22, Nr. 8, S. 1167 - 1169

Zeien, H. (1995): Chemische Extraktionen zur Bestimmung der Bindungsformen von Schwermetallen in Böden; Bonner Bodenkundliche Abhandlung, 17, Dissertation, Bonn

Ziechmann, W. (1980): Huminstoffe, Verlag Weinheim 


\section{Anhang: Tabellen und Abbildungen}

Tabelle 13-1: Angaben zur Porenverteilung, Lysimeter 1 - 8

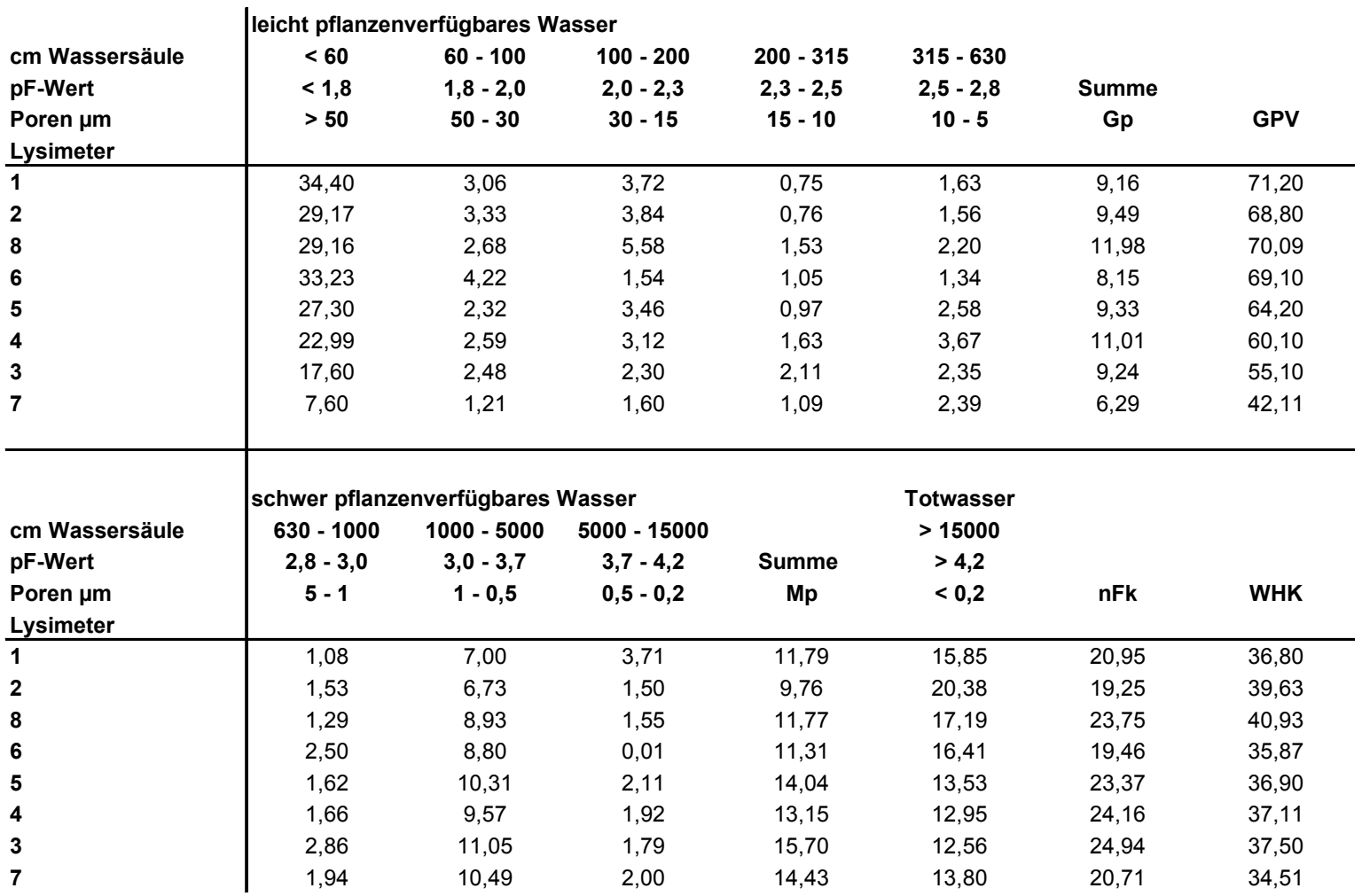

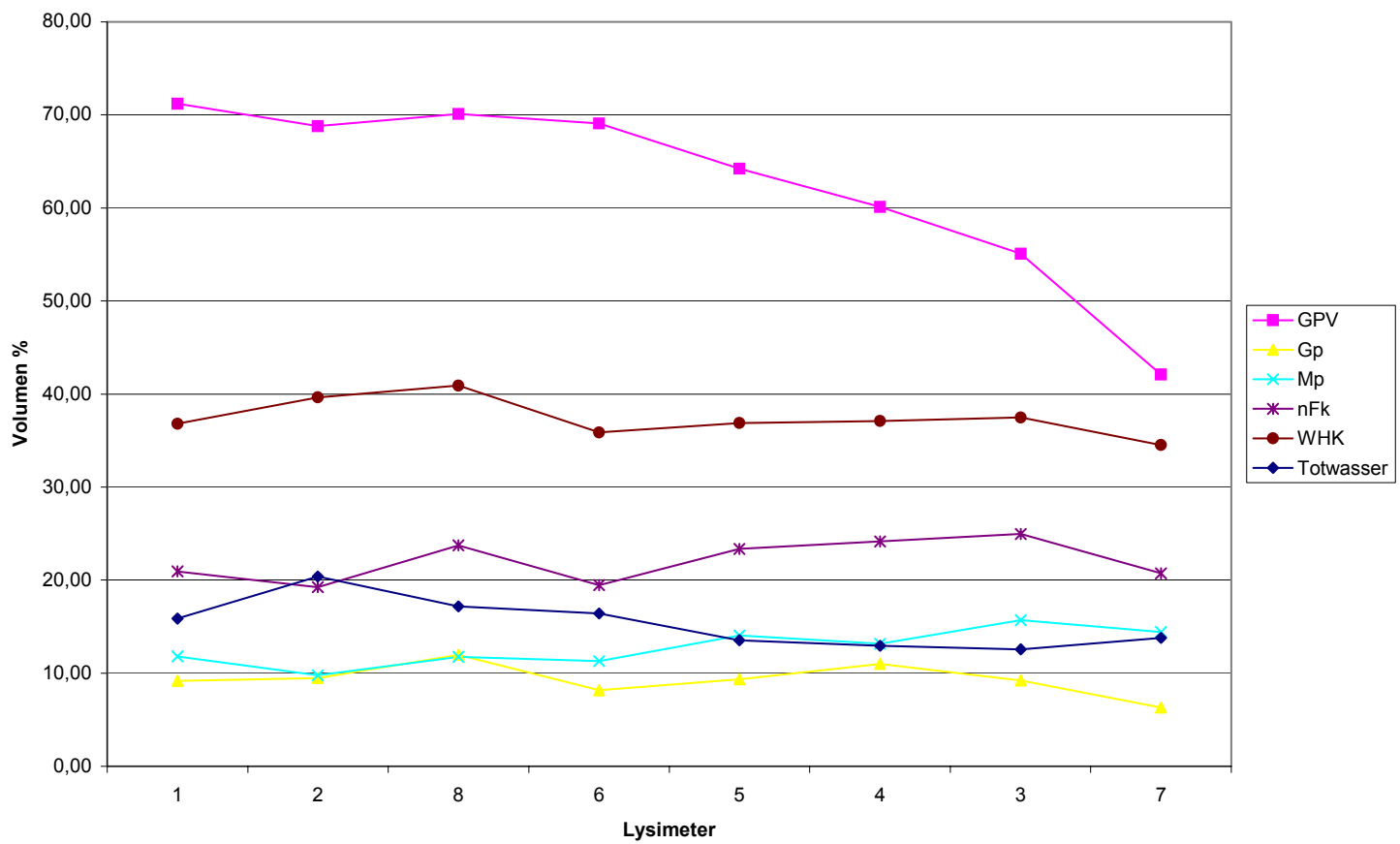

Abbildung 13-1: Porenverteilung, Lysimeter 1 - 8 
Tabelle 13-2: Korngrößenverteilung nach Anwendung der Vorbehandlungsmethode A, Lysimeter 1 - 8, Probenahme $L 1$ und $L 2$ 30.03.90 und L 3 - L 802.04 .90

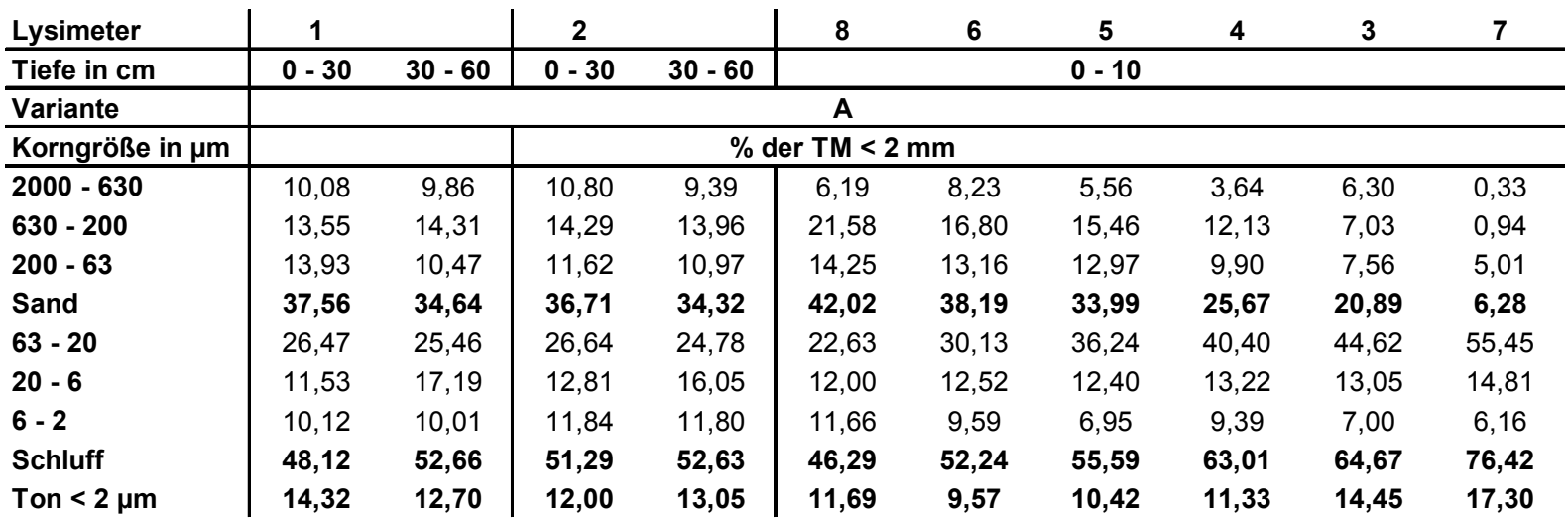

Tabelle 13-3: Korngrößenverteilung nach Anwendung der Vorbehandlungsmethoden B und C, Lysimeter 1 und 2, Probenahme L 1 09.01.91 und L 2 08.03.91

\begin{tabular}{|c|c|c|c|c|c|c|}
\hline Lysimeter & 1 & 2 & 0 & 1 & 2 & 0 \\
\hline Tiefe in $\mathrm{cm}$ & $0-10$ & $0-10$ & & $0-10$ & $0-10$ & \\
\hline Variante & & B & & & C & \\
\hline Korngröße in $\mu \mathrm{m}$ & \multicolumn{3}{|c|}{$\%$ der $\mathrm{TM}<2 \mathrm{~mm}$} & \multicolumn{3}{|c|}{$\%$ der $\mathrm{TM}<2 \mathrm{~mm}$} \\
\hline $2000-630$ & 11,82 & 12,53 & 16,06 & 9,95 & 11,03 & 16,20 \\
\hline $630-200$ & 16,70 & 14,83 & 19,57 & 17,17 & 13,82 & 17,76 \\
\hline $200-63$ & 11,63 & 12,15 & 10,72 & 23,31 & 20,62 & 21,24 \\
\hline Sand & 40,15 & 39,51 & 46,35 & 50,43 & 45,47 & 55,20 \\
\hline $63-36$ & 10,84 & 10,62 & 9,53 & 10,37 & 16,28 & 11,77 \\
\hline $36-20$ & 15,57 & 15,32 & 15,78 & 15,29 & 13,99 & 13,38 \\
\hline $20-6$ & 13,21 & 14,05 & 11,76 & 9,50 & 9,82 & 7,63 \\
\hline $6-2$ & 5,73 & 4,24 & 4,93 & 8,47 & 8,46 & 6,56 \\
\hline Schluff & 45,35 & 44,23 & 42,00 & 43,63 & 48,55 & 39,34 \\
\hline Ton $<2 \mu \mathrm{m}$ & 14,49 & 16,25 & 11,64 & 5,94 & 5,97 & 5,46 \\
\hline
\end{tabular}

Tabelle 13-4: Korngrößenverteilung nach Anwendung der Vorbehandlungsmethode D, Lysimeter 1, 2, 8, 6 und 5,

Probenahme $L 1$ und $L 230.03 .90$ und $L 8,6$ und 5 02.04.90

\begin{tabular}{|c|c|c|c|c|c|c|c|}
\hline Lysimeter & 1 & & 2 & & 8 & 6 & 5 \\
\hline Tiefe in $\mathrm{cm}$ & $0-30$ & $30-60$ & $0-30$ & $30-60$ & & $0-10$ & \\
\hline Variante & \multicolumn{7}{|c|}{ D } \\
\hline Korngröße in $\mu \mathrm{m}$ & \multicolumn{7}{|c|}{$\%$ der $\mathrm{TM}<2 \mathrm{~mm}$} \\
\hline $2000-630$ & 11,44 & 14,27 & 9,9 & 12,58 & 17,44 & 10,23 & 7,02 \\
\hline $630-200$ & 24,08 & 27,68 & 20,66 & 21,82 & 24,96 & 24,59 & 29,34 \\
\hline $200-63$ & 23,06 & 17,99 & 21,95 & 22,33 & 15,41 & 20,88 & 20,64 \\
\hline Sand & 58,58 & 59,94 & 52,51 & 56,73 & 57,81 & 55,7 & 57 \\
\hline $63-20$ & 26,48 & 27,42 & 33,15 & 28,93 & 29,31 & 28,56 & 27,62 \\
\hline$<20$ & 14,94 & 12,64 & 14,34 & 14,34 & 12,88 & 15,74 & 15,39 \\
\hline Schluff und Ton & 41,42 & 40,06 & 47,49 & 43,27 & 42,19 & 44,30 & 43,01 \\
\hline
\end{tabular}


Tabelle 13-5: Gesamtgehalte an Oxiden in der Feinerde in g/100g, Lysimeter 1 und 2 (März 1990 und Jan/März 1991) sowie Ausgangsmaterialien Kompost März 1986 und Löss

\begin{tabular}{|c|c|c|c|c|c|c|c|c|c|}
\hline $\begin{array}{l}\text { Datum der } \\
\text { Probenahme }\end{array}$ & $\begin{array}{c}\text { Tiefe } \\
\mathbf{c m} \\
\end{array}$ & $\mathrm{CaO}$ & \multicolumn{7}{|c|}{ g/100 g TM Feinerde } \\
\hline \multicolumn{10}{|c|}{ Lysimeter 1} \\
\hline 29.03.1990 & $0-30$ & 5,44 & 1,82 & 1,38 & 0,86 & 2,22 & 5,12 & 0,08 & 0,83 \\
\hline 29.03.1990 & $30-60$ & 5,59 & 1,93 & 1,42 & 0,98 & 2,35 & 5,02 & 0,10 & 0,79 \\
\hline \multicolumn{2}{|c|}{ Durchschnittswert } & 5,51 & 1,88 & 1,40 & 0,92 & 2,29 & 5,07 & 0,09 & 0,81 \\
\hline 08.01 .1991 & $0-10$ & 5,42 & 2,74 & 1,78 & 1,05 & 5,86 & 6,45 & 0,17 & 0,97 \\
\hline 08.01 .1991 & $10-20$ & 5,09 & 2,57 & 1,68 & 1,21 & 4,63 & 5,47 & 0,15 & 0,90 \\
\hline 08.01 .1991 & $20-30$ & 4,99 & 2,70 & 1,73 & 1,28 & 4,98 & 5,65 & 0,15 & 0,87 \\
\hline 08.01 .1991 & $30-42$ & 4,61 & 2,63 & 1,71 & 1,06 & 4,53 & 5,41 & 0,14 & 0,87 \\
\hline \multirow{2}{*}{\multicolumn{2}{|c|}{ Durchschnittswert }} & 5,03 & 2,66 & 1,72 & 1,15 & 5,00 & 5,74 & 0,15 & 0,90 \\
\hline & & \multicolumn{3}{|c|}{ Lysimeter 2} & & & & & \\
\hline 29.03 .1990 & $0-30$ & 5,49 & 1,80 & 1,50 & 0,92 & 2,36 & 5,11 & 0,10 & 0,82 \\
\hline 29.03.1990 & $30-60$ & 5,49 & 1,76 & 1,61 & 0,89 & 2,04 & 3,50 & 0,10 & 0,87 \\
\hline \multicolumn{2}{|c|}{ Durchschnittswert } & 5,49 & 1,78 & 1,56 & 0,90 & 2,20 & 4,30 & 0,10 & 0,84 \\
\hline 07.03.1991 & $0-10$ & 5,09 & 2,25 & 1,69 & 0,90 & 4,35 & 5,21 & 0,18 & 0,95 \\
\hline 07.03.1991 & $10-20$ & 4,95 & 2,21 & 1,68 & 0,92 & 4,19 & 5,19 & 0,16 & 0,91 \\
\hline 07.03.1991 & $20-30$ & 4,56 & 2,28 & 1,76 & 0,89 & 4,25 & 5,22 & 0,16 & 1,12 \\
\hline 07.03.1991 & $30-40$ & 4,30 & 2,21 & 1,82 & 0,89 & 4,12 & 5,16 & 0,16 & 0,87 \\
\hline 07.03.1991 & $40-50$ & 4,44 & 2,15 & 1,88 & 0,87 & 4,12 & 5,11 & 0,15 & 0,96 \\
\hline 07.03.1991 & $50-58$ & 4,54 & 2,06 & 2,02 & 0,88 & 3,96 & 5,25 & 0,13 & 1,07 \\
\hline \multicolumn{2}{|c|}{ Durchschnittswert } & 4,65 & 2,19 & 1,81 & 0,89 & 4,17 & 5,19 & 0,15 & 0,98 \\
\hline \multicolumn{10}{|c|}{ Ausgangsmaterial } \\
\hline \multicolumn{2}{|c|}{ Löss } & 0,27 & 0,56 & 2,02 & 1,09 & 2,62 & 8,24 & 0,08 & 0,11 \\
\hline \multicolumn{2}{|c|}{ Kompost Mrz 86} & 5,53 & 2,19 & 1,93 & 0,90 & 3,79 & 4,66 & 0,24 & 1,00 \\
\hline
\end{tabular}

Tabelle 13-6: Wassergehalte bei Sättigung (t-m-s) und nach

Lufttrocknung (f-w-s), Lysimeter $1-8$ und

Ausgangsmaterial Kompost März 86

\begin{tabular}{c|c|rcc} 
Lysimeter & $\begin{array}{c}\text { Datum der } \\
\text { Probenahme }\end{array}$ & \multicolumn{1}{|c}{$\begin{array}{c}\text { Tiefe } \\
\text { cm }\end{array}$} & $\begin{array}{c}\text { Wassergehalt } \\
\text { bei Sättigung } \\
\text { \% d. TM }\end{array}$ & $\begin{array}{c}\text { Wassergehalt } \\
\text { luftgetrocknet } \\
\text { \% d. TM }\end{array}$ \\
\hline & $\mathbf{2 9 . 0 3 . 9 0}$ & $0-30$ & 131,44 & 6,63 \\
$\mathbf{1}$ & $\mathbf{2 9 . 0 3 . 9 0}$ & $30-60$ & 123,14 & 5,85 \\
$\mathbf{2}$ & $\mathbf{2 9 . 0 3 . 9 0}$ & $0-30$ & 121,21 & 7,14 \\
& $\mathbf{2 9 . 0 3 . 9 0}$ & $30-60$ & 127,36 & 5,38 \\
$\mathbf{8}$ & $\mathbf{0 2 . 0 4 . 9 0}$ & $0-20$ & 116,62 & 8,63 \\
$\mathbf{6}$ & $\mathbf{0 2 . 0 4 . 9 0}$ & $0-30$ & 103,11 & 13,25 \\
$\mathbf{5}$ & $\mathbf{0 2 . 0 4 . 9 0}$ & $0-30$ & 84,35 & 11,09 \\
$\mathbf{4}$ & $\mathbf{0 2 . 0 4 . 9 0}$ & $0-30$ & 78,08 & 10,89 \\
$\mathbf{3}$ & $\mathbf{0 2 . 0 4 . 9 0}$ & $0-30$ & 66,50 & 7,23 \\
$\mathbf{7}$ & $\mathbf{0 2 . 0 4 . 9 0}$ & $0-20$ & 56,37 & 2,52 \\
\multicolumn{2}{l}{ Ausgangsmaterial Mrz 86 } & & &
\end{tabular}


Tabelle 13-7: Zeitgang löslicher lonen im 1:2-

Kompost:Wasser-Extrakt der Siebfraktion $<1,12 \mathrm{~mm}$ in $\mathrm{mg} / \mathrm{kg}$ TM mm, Lysimeter 1

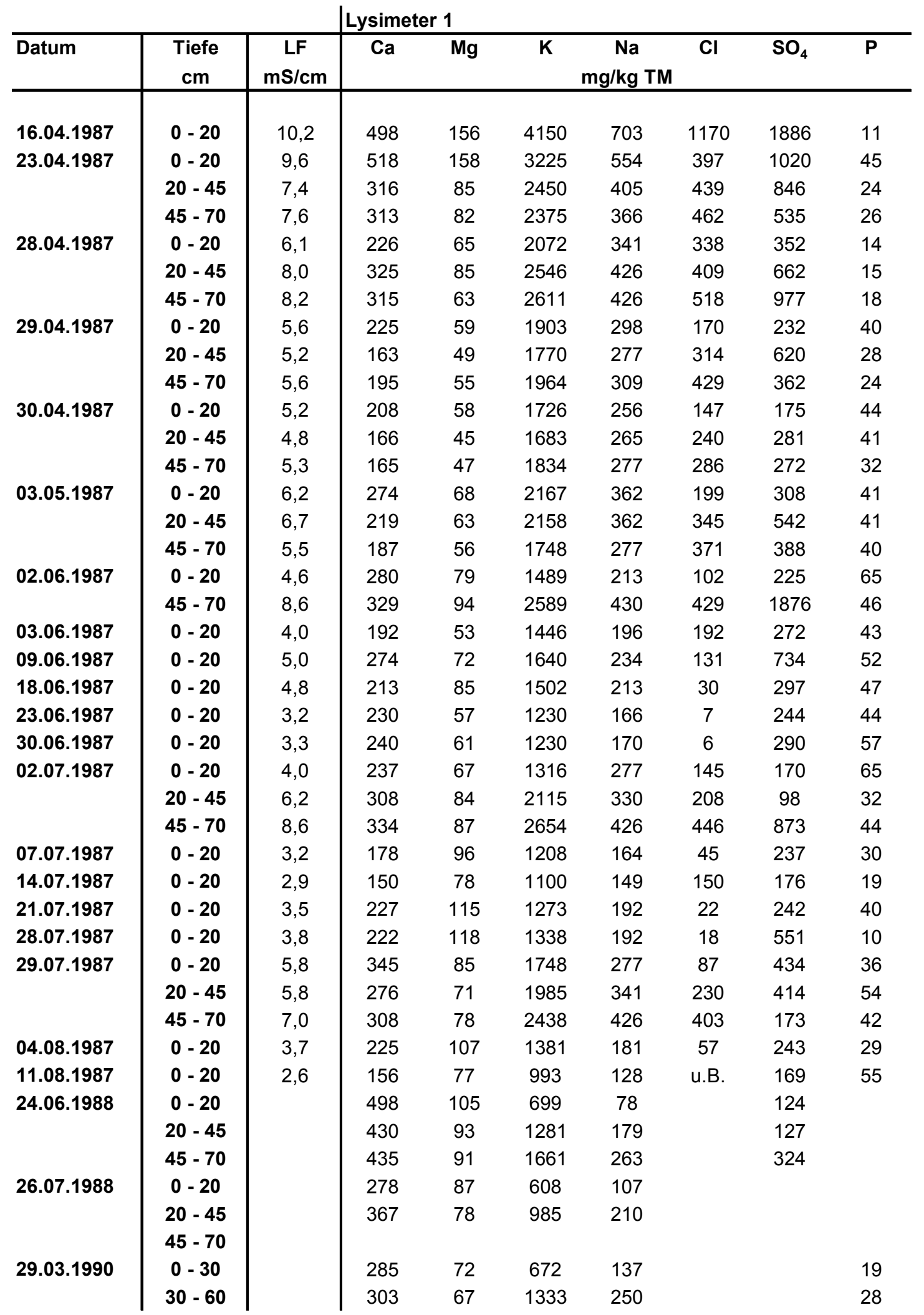


Tabelle 13-8: Zeitgang löslicher lonen im 1:2-

Kompost:Wasser-Extrakt der Siebfraktion $<1,12 \mathrm{~mm}$ in $\mathrm{mg} / \mathrm{kg}$ TM, Lysimeter 2

\begin{tabular}{|c|c|c|c|c|c|c|c|c|c|}
\hline \multirow{2}{*}{ Datum } & \multirow[b]{2}{*}{$\begin{array}{c}\text { Tiefe } \\
\text { cm }\end{array}$} & & \multicolumn{7}{|c|}{ Lysimeter 2} \\
\hline & & $\begin{array}{l}\mathrm{LF} \\
\mathrm{mS}\end{array}$ & \multicolumn{7}{|c|}{$\mathrm{mg} / \mathrm{kg}$ TM } \\
\hline 16.04 .1987 & $0-20$ & 10,2 & 498 & 156 & 4150 & 703 & 1170 & 1886 & 11 \\
\hline \multirow[t]{3}{*}{23.04 .1987} & $0-20$ & 8,6 & 446 & 145 & 2950 & 426 & 513 & 1099 & 17 \\
\hline & $20-45$ & 12 & 287 & 86 & 1475 & 320 & 849 & 1631 & 15 \\
\hline & $45-70$ & 7,6 & 253 & 76 & 2425 & 326 & 550 & 951 & 22 \\
\hline \multirow[t]{3}{*}{28.04 .1987} & $0-20$ & 6,4 & 300 & 85 & 1821 & 266 & 767 & 888 & 17 \\
\hline & $20-45$ & 14 & 292 & 262 & 1957 & 756 & 777 & 738 & 16 \\
\hline & $45-70$ & 8,2 & 266 & 148 & 2741 & 437 & 786 & 1367 & 7 \\
\hline \multirow[t]{3}{*}{29.04 .1987} & $0-20$ & 5,7 & 220 & 69 & 1825 & 277 & 303 & 551 & 11 \\
\hline & $20-45$ & 6,5 & 192 & 63 & 2180 & 320 & 427 & 1688 & 49 \\
\hline & $45-70$ & 9,2 & 283 & 82 & 2991 & 490 & 816 & 1539 & 35 \\
\hline \multirow[t]{3}{*}{30.04 .1987} & $0-20$ & 8,3 & 360 & 99 & 2439 & 388 & 385 & 977 & 46 \\
\hline & $20-45$ & 7,4 & 213 & 66 & 2451 & 266 & 601 & 1075 & 28 \\
\hline & $45-70$ & 8 & 227 & 70 & 2611 & 405 & 679 & 1181 & 27 \\
\hline \multirow[t]{3}{*}{03.05 .1987} & $0-20$ & 6,7 & 310 & 84 & 2369 & 362 & 401 & 1332 & 44 \\
\hline & $20-45$ & 5,2 & 156 & 48 & 1748 & 251 & 382 & 724 & 36 \\
\hline & $45-70$ & 10,2 & 181 & 119 & 3807 & 618 & 909 & 1800 & 38 \\
\hline \multirow[t]{2}{*}{02.06 .1987} & $0-20$ & 5,6 & 260 & 79 & 1683 & 224 & 146 & 461 & 39 \\
\hline & $45-70$ & 12,2 & 401 & 134 & 4221 & 639 & 1042 & 2329 & 36 \\
\hline 03.06.1987 & $0-20$ & 5 & 243 & 73 & 1683 & 224 & 120 & 77 & 35 \\
\hline 09.06 .1987 & $0-20$ & 4,8 & 241 & 75 & 1597 & 202 & 131 & 300 & 38 \\
\hline 18.06.1987 & $0-20$ & 4 & 260 & 76 & 1252 & 149 & 6 & 246 & 55 \\
\hline 23.06.1987 & $0-20$ & 2,8 & 201 & 50 & 1014 & 124 & 50 & 198 & 19 \\
\hline 30.06 .1987 & $0-20$ & 3,4 & 245 & 69 & 1122 & 128 & 23 & 290 & 12 \\
\hline \multirow[t]{3}{*}{02.07 .1987} & $0-20$ & 9,4 & 332 & 94 & 2978 & 490 & 733 & 1418 & 52 \\
\hline & $20-45$ & 9,8 & 329 & 92 & 3215 & 532 & 646 & 1350 & 43 \\
\hline & $45-70$ & 2,9 & 193 & 106 & 1122 & 128 & 41 & 205 & 39 \\
\hline 07.07.1987 & $0-20$ & 12,2 & 491 & 154 & 4126 & 639 & 977 & 1937 & 43 \\
\hline 14.07.1987 & $0-20$ & 2,8 & 158 & 85 & 1230 & 170 & 79 & 857 & 22 \\
\hline 21.07.1987 & $0-20$ & 3,2 & 190 & 105 & 1230 & 149 & 18 & 251 & 35 \\
\hline 28.07.1987 & $0-20$ & 3 & 230 & 99 & 1109 & 138 & n.b. & 107 & 15 \\
\hline \multirow[t]{3}{*}{29.07 .1987} & $0-20$ & 5,2 & 333 & 90 & 1511 & 196 & 57 & 143 & 16 \\
\hline & $20-45$ & 6,2 & 268 & 77 & 2223 & 447 & 260 & 206 & 39 \\
\hline & $45-70$ & 8,2 & 271 & 79 & 2848 & 341 & 597 & 808 & 41 \\
\hline 04.08 .1987 & $0-20$ & 3,4 & 220 & 118 & 1230 & 160 & 6 & 269 & 29 \\
\hline 11.08 .1987 & $0-20$ & 3 & 183 & 84 & 1113 & 149 & 56 & 182 & 46 \\
\hline \multirow[t]{3}{*}{24.06 .1988} & $0-20$ & 2,2 & 363 & 89 & 911 & 75 & & 157 & \\
\hline & $20-45$ & 2,9 & 388 & 89 & 1820 & 204 & & 206 & \\
\hline & $45-70$ & 3,5 & 378 & 85 & 2416 & 274 & & 174 & \\
\hline \multirow[t]{3}{*}{ 26.07.1988 } & $0-20$ & & 300 & 87 & 655 & 110 & & & \\
\hline & $20-45$ & & 355 & 78 & 1190 & 262 & & & \\
\hline & $45-70$ & & & & & & & & \\
\hline \multirow[t]{2}{*}{29.03 .1990} & $0-30$ & & 297 & 80 & 688 & 117 & & & 20 \\
\hline & $30-60$ & & 306 & 66 & 1070 & 209 & & & 27 \\
\hline
\end{tabular}


Tabelle 13-9: Lösliche Verbindungen im 1:2-

Kompost:Wasser-Extrakt der Siebfraktion < 1,12 mm in $\mathrm{mg} / \mathrm{l}$

Extraktlösung, Lysimeter 1 und 2, 3 - 8

\begin{tabular}{|c|c|c|c|c|c|c|c|c|c|c|c|c|c|c|c|}
\hline Probenahme & Lysimeter & $\begin{array}{c}\text { Tiefe } \\
\mathrm{cm}\end{array}$ & \begin{tabular}{|c} 
Einwaage \\
$\mathbf{g}$
\end{tabular} & $\begin{array}{c}\text { Wasser } \\
\mathrm{ml}\end{array}$ & $\begin{array}{c}\text { pH- } \\
\text { Wert }\end{array}$ & $\begin{array}{c}\mathrm{LF} \\
\mathrm{mS} / \mathrm{cm} \\
\end{array}$ & $\begin{array}{l}\mathrm{DOC} \\
\mathrm{mg} / \mathrm{l}\end{array}$ & $\begin{array}{c}\mathrm{Na} \\
\mathrm{mg} / \mathrm{l}\end{array}$ & $\begin{array}{c}\mathrm{K} \\
\mathrm{mg} / \mathrm{l}\end{array}$ & $\begin{array}{c}\mathrm{Mg} \\
\mathrm{mg} / \mathrm{l}\end{array}$ & $\begin{array}{c}\mathrm{Ca} \\
\mathrm{mg} / \mathrm{l}\end{array}$ & $\begin{array}{c}\mathrm{HCO}_{3} \\
\mathrm{mg} / \mathrm{l}\end{array}$ & $\begin{array}{c}\mathrm{Cl} \\
\mathrm{mg} / \mathrm{l}\end{array}$ & $\begin{array}{l}\mathrm{SO}_{4} \\
\mathrm{mg} / \mathrm{l}\end{array}$ & $\begin{array}{l}\mathrm{NO}_{3} \\
\mathrm{mg} / \mathrm{l} \\
\end{array}$ \\
\hline 24.06.1988 & 1 & $0-20$ & 20,08 & 40 & 7,76 & & 1219,17 & 39,40 & 350,71 & 52,50 & 250,00 & 1098,00 & & 123,93 & \\
\hline 24.06.1988 & 1 & $20-45$ & 15,12 & 30 & 8,08 & & 1418,00 & 90,00 & 645,59 & 46,88 & 216,88 & 1110,20 & & 126,82 & \\
\hline 24.06.1988 & 1 & $45-70$ & 15,00 & 30 & 7,97 & & 1746,67 & 131,25 & 830,50 & 45,63 & 217,50 & 1079,70 & & 324,10 & \\
\hline 24.06.1988 & 2 & $0-20$ & 40,00 & 80 & 7,44 & 2,20 & 596,00 & 37,50 & 455,67 & 44,38 & 181,25 & 786,90 & & 56,81 & 167,40 \\
\hline 24.06 .1988 & 2 & $20-45$ & 40,03 & 80 & 7,56 & 2,90 & 695,00 & 101,88 & 910,49 & 44,38 & 194,38 & 884,50 & & 205,50 & 186,00 \\
\hline 24.06 .1988 & 2 & $45-70$ & 40,08 & 80 & 7,46 & 3,50 & 860,00 & 137,50 & 1210,37 & 42,50 & 189,38 & 811,30 & & 173,87 & 124,00 \\
\hline 24.06.1988 & 8 & $0-20$ & 27,56 & 55 & 7,30 & 1,70 & 599,79 & 30,00 & 193,13 & 50,00 & 176,25 & 542,90 & 12,88 & 90,35 & 102,30 \\
\hline 24.06.1988 & 6 & $0-30$ & 30,10 & 60 & 7,25 & 1,40 & 485,00 & 24,50 & 174,50 & 46,00 & 177,50 & & & 149,57 & \\
\hline 24.06.1988 & 5 & $0-30$ & 50,05 & 100 & 7,13 & 1,20 & 873,75 & 25,50 & 157,00 & 32,50 & 171,50 & 369,10 & & 65,34 & 86,80 \\
\hline 24.06 .1988 & 4 & $0-30$ & 40,01 & 80 & 7,15 & 0,90 & 217,25 & 15,00 & 121,39 & 23,00 & 134,50 & 341,60 & & 22,11 & 83,70 \\
\hline 24.06 .1988 & 3 & $0-30$ & 50,29 & 100 & 7,00 & 0,75 & 399,25 & 14,00 & 70,41 & 16,50 & 53,00 & 237,90 & & 119,85 & 111,60 \\
\hline 24.06.1988 & 7 & $0-20$ & 45,10 & 95 & 7,40 & 0,44 & 101,75 & 13,00 & 5,50 & 3,50 & 66,00 & 176,90 & 5,77 & 37,09 & 11,07 \\
\hline 26.07.1988 & 1 & $0-20$ & 25,10 & 50 & 8,63 & & 730,00 & 53,50 & 305,00 & 43,50 & 139,50 & 1146,80 & & 60,81 & \\
\hline 26.07.1988 & 1 & $20-45$ & 25,02 & 50 & 8,82 & & 1162,50 & 105,00 & 493,00 & 39,00 & 183,50 & 1384,70 & & 121,72 & \\
\hline 26.07.1988 & 2 & $0-20$ & 25,00 & 50 & 8,65 & & 782,50 & 55,00 & 327,50 & 47,50 & 150,00 & 1250,50 & & 48,84 & \\
\hline 26.07 .1988 & 2 & $20-45$ & 25,01 & 50 & 8,77 & & 1442,50 & 131,00 & 595,00 & 42,50 & 177,50 & 1592,10 & & & \\
\hline
\end{tabular}

Tabelle 13-10: Lösliche Verbindungen im 1:2-

Kompost:Wasser-Extrakt der Siebfraktion $<1,12 \mathrm{~mm}$ in

$\mathrm{mg} / \mathrm{kg}$ TM, Lysimeter 1 und 2, 3 - 8

\begin{tabular}{|c|c|c|c|c|c|c|c|c|c|c|c|}
\hline Probenahme & Lysimeter & $\begin{array}{c}\text { Tiefe } \\
\text { cm }\end{array}$ & $\begin{array}{c}\text { DOC } \\
\mathrm{mg} / \mathrm{kg}\end{array}$ & $\begin{array}{c}\mathrm{Na} \\
\mathrm{mg} / \mathrm{kg}\end{array}$ & $\begin{array}{c}\mathrm{K} \\
\mathrm{mg} / \mathrm{kg}\end{array}$ & $\begin{array}{c}\mathrm{Mg} \\
\mathrm{mg} / \mathrm{kg}\end{array}$ & $\begin{array}{c}\mathrm{Ca} \\
\mathrm{mg} / \mathrm{kg}\end{array}$ & $\begin{array}{l}\mathrm{HCO}_{3} \\
\mathrm{mg} / \mathrm{kg}\end{array}$ & $\begin{array}{c}\mathrm{Cl} \\
\mathrm{mg} / \mathrm{kg}\end{array}$ & $\begin{array}{c}\mathrm{SO}_{4} \\
\mathrm{mg} / \mathrm{kg}\end{array}$ & $\begin{array}{c}\mathrm{NO}_{3} \\
\mathrm{mg} / \mathrm{kg}\end{array}$ \\
\hline 24.06 .1988 & 1 & $0-20$ & 2428,63 & 78,49 & 698,63 & 104,58 & 498,01 & 2187,25 & & 246,87 & \\
\hline 24.06.1988 & 1 & $20-45$ & 2813,49 & 178,57 & 1280,93 & 93,02 & 430,32 & 2202,78 & & 251,63 & \\
\hline 24.06 .1988 & 1 & $45-70$ & 3493,34 & 262,50 & 1661,00 & 91,26 & 435,00 & 2159,40 & & 648,20 & \\
\hline 24.06 .1988 & 2 & $0-20$ & 1192,00 & 75,00 & 911,34 & 88,76 & 362,50 & 1573,80 & & 113,62 & 334,80 \\
\hline 24.06.1988 & 2 & $20-45$ & 1388,96 & 203,61 & 1819,62 & 88,69 & 388,47 & 1767,67 & & 410,69 & 371,72 \\
\hline 24.06.1988 & 2 & $45-70$ & 1716,57 & 274,45 & 2415,91 & 84,83 & 378,00 & 1619,36 & & 347,05 & 247,50 \\
\hline 24.06 .1988 & 8 & $0-20$ & 1196,97 & 59,87 & 385,42 & 99,78 & 351,73 & 1083,44 & 25,70 & 180,31 & 204,15 \\
\hline 24.06.1988 & 6 & $0-30$ & 966,78 & 48,84 & 347,84 & 91,69 & 353,82 & & & 298,15 & \\
\hline 24.06.1988 & 5 & $0-30$ & 1745,75 & 50,95 & 313,69 & 64,94 & 342,66 & 737,46 & & 130,55 & 173,43 \\
\hline 24.06.1988 & 4 & $0-30$ & 434,39 & 29,99 & 242,72 & 45,99 & 268,93 & 683,03 & & 44,21 & 167,36 \\
\hline 24.06.1988 & 3 & $0-30$ & 793,90 & 27,84 & 140,01 & 32,81 & 105,39 & 473,06 & & 238,32 & 221,91 \\
\hline 24.06.1988 & 7 & $0-20$ & 214,33 & 27,38 & 11,59 & 7,37 & 139,02 & 372,63 & 12,15 & 78,13 & 23,32 \\
\hline 26.07.1988 & 1 & $0-20$ & 1454,18 & 106,57 & 607,57 & 86,65 & 277,89 & 2284,46 & & 121,14 & \\
\hline 26.07.1988 & 1 & $20-45$ & 2323,14 & 209,83 & 985,21 & 77,94 & 366,71 & 2767,19 & & 243,25 & \\
\hline 26.07.1988 & 2 & $0-20$ & 1565,00 & 110,00 & 655,00 & 95,00 & 300,00 & 2501,00 & & 97,68 & \\
\hline 26.07.1988 & 2 & $20-45$ & 2883,85 & 261,90 & 1189,52 & 84,97 & 354,86 & 3182,93 & & & \\
\hline
\end{tabular}


Tabelle 13-11: Lösliche Verbindungen im 1:2-

Kompost:Wasser-Extrakt der Siebfraktion $<1,12 \mathrm{~mm}$ in mmol IE/kg TM, Lysimeter 1 und 2, 3 - 8

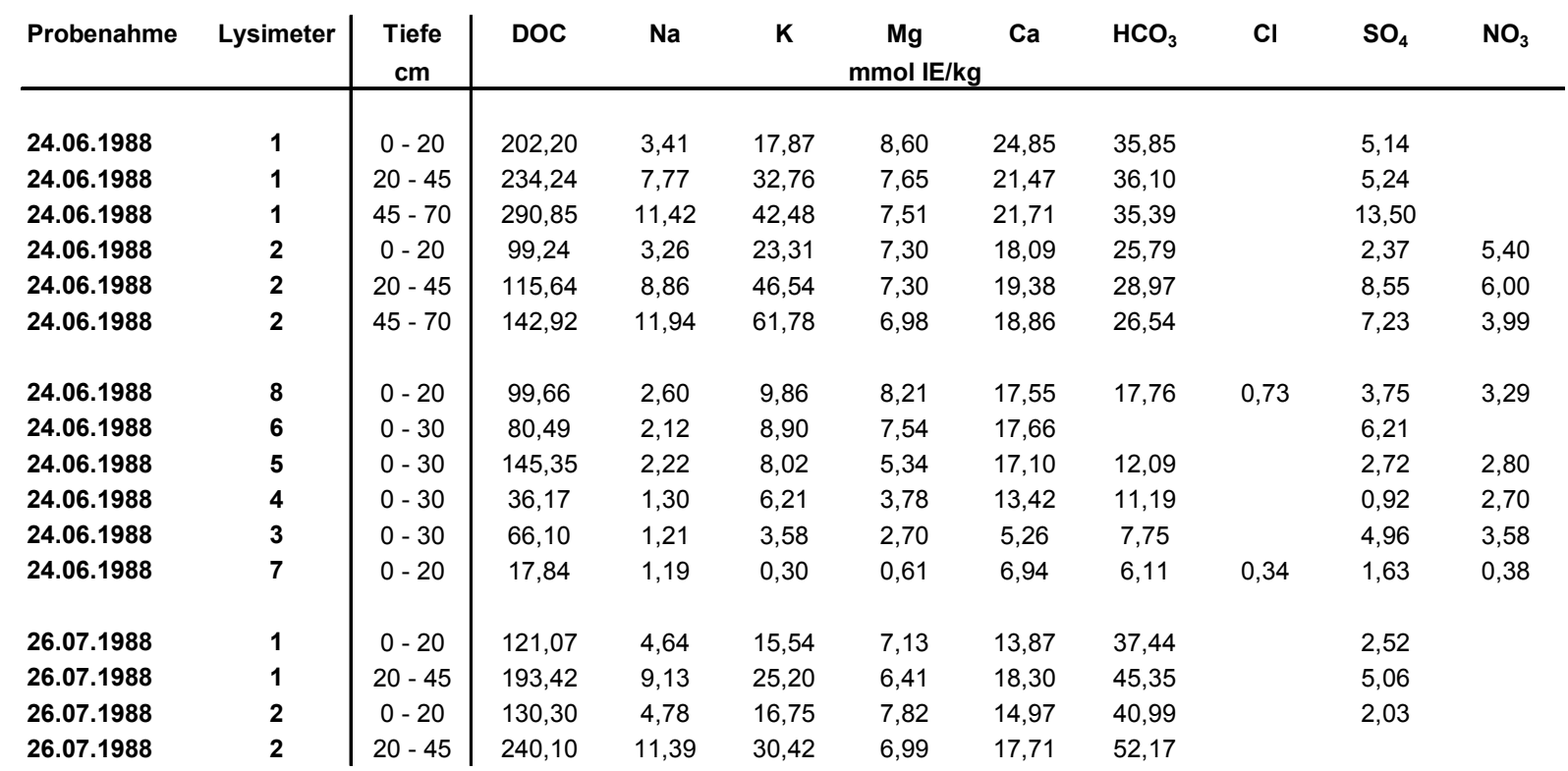

Tabelle 13-12: Lösliche Verbindungen im zweiten 1:2-

Kompost:Wasser-Extrakt der Siebfraktion < 1,12 mm in $\mathrm{mg} / \mathrm{l}$

Extraktlösung, Lysimeter 1 und 2, 3 - 8

\begin{tabular}{|c|c|c|c|c|c|c|c|c|c|c|c|c|c|c|c|}
\hline Probenahme & Lysimeter & $\begin{array}{l}\text { Tiefe } \\
\mathrm{cm}\end{array}$ & $\begin{array}{c}\text { Einwaage } \\
\mathbf{g}\end{array}$ & $\begin{array}{c}\text { Wasser } \\
\mathrm{ml}\end{array}$ & $\begin{array}{c}\text { pH- } \\
\text { Wert }\end{array}$ & $\begin{array}{c}\mathrm{LF} \\
\mathrm{mS} / \mathrm{cm} \\
\end{array}$ & $\begin{array}{l}\mathrm{DOC} \\
\mathrm{mg} / \mathrm{l}\end{array}$ & $\begin{array}{c}\mathrm{Na} \\
\mathrm{mg} / \mathrm{l}\end{array}$ & $\begin{array}{c}\mathrm{K} \\
\mathrm{mg} / \mathrm{l}\end{array}$ & $\begin{array}{c}\mathrm{Mg} \\
\mathrm{mg} / \mathrm{l}\end{array}$ & $\begin{array}{c}\mathrm{Ca} \\
\mathrm{mg} / \mathrm{l}\end{array}$ & $\begin{array}{c}\mathrm{HCO}_{3} \\
\mathrm{mg} / \mathrm{l}\end{array}$ & $\begin{array}{c}\mathrm{Cl} \\
\mathrm{mg} / \mathrm{l}\end{array}$ & $\begin{array}{l}\mathrm{SO}_{4} \\
\mathrm{mg} / \mathrm{l}\end{array}$ & $\begin{array}{l}\mathrm{NO}_{3} \\
\mathrm{mg} / \mathrm{l} \\
\end{array}$ \\
\hline 24.06.1988 & 1 & $0-20$ & 20,08 & 40 & 8,24 & 1,20 & 1332,50 & 31,50 & 208,00 & 38,00 & 129,00 & 927,20 & & 105,48 & 86,76 \\
\hline 24.06.1988 & 1 & $20-45$ & 15,12 & 30 & 8,44 & 1,50 & 1793,00 & 58,00 & 276,00 & 33,00 & 118,50 & 1049,20 & & 51,19 & 68,17 \\
\hline 24.06.1988 & 1 & $45-70$ & 15,00 & 30 & 8,56 & & 1846,00 & 75,00 & 296,50 & 29,50 & 120,00 & 1140,70 & & 194,68 & \\
\hline 24.06.1988 & 2 & $0-20$ & 40,00 & 80 & 7,95 & 1,60 & 618,75 & 31,00 & 214,00 & 40,00 & 115,50 & 838,75 & & 43,39 & 68,17 \\
\hline 24.06.1988 & 2 & $20-45$ & 40,03 & 80 & 7,96 & 2,10 & 852,50 & 65,50 & 320,50 & 35,50 & 112,70 & 1018,70 & 19,53 & 152,77 & 55,78 \\
\hline 24.06.1988 & 2 & $45-70$ & 40,08 & 80 & 7,94 & 2,20 & 853,75 & 85,00 & 353,00 & 35,00 & 128,00 & 1003,45 & 34,35 & 182,22 & 65,07 \\
\hline 24.06.1988 & 8 & $0-20$ & 27,56 & 55 & 7,86 & 1,30 & 512,50 & 25,00 & 145,00 & 48,00 & 152,50 & 805,20 & 14,52 & 94,77 & 49,58 \\
\hline 24.06.1988 & 6 & $0-30$ & 30,10 & 60 & 8,08 & 1,40 & 448,75 & 20,00 & 128,50 & 46,50 & 157,00 & 841,80 & 11,36 & 42,64 & 61,97 \\
\hline 24.06.1988 & 5 & $0-30$ & 50,05 & 100 & 7,88 & 1,10 & 362,50 & 16,00 & 96,00 & 32,00 & 107,00 & 719,80 & 6,51 & 58,96 & 55,78 \\
\hline 24.06.1988 & 4 & $0-30$ & 40,01 & 80 & 8,11 & 0,90 & 230,00 & 13,00 & 60,00 & 27,00 & 115,00 & 506,30 & & 37,65 & 65,07 \\
\hline 24.06 .1988 & 3 & $0-30$ & 50,29 & 100 & 8,03 & 0,70 & 176,25 & 18,50 & 54,50 & 20,00 & 89,00 & 387,55 & & & 52,68 \\
\hline 24.06.1988 & 7 & $0-20$ & 45,10 & 95 & 8,01 & 0,25 & 52,25 & 1,00 & 10,50 & 6,00 & 55,50 & 167,75 & 7,45 & 6,98 & 55,78 \\
\hline
\end{tabular}

Tabelle 13-13: Lösliche Verbindungen im zweiten 1:2-

Kompost:Wasser-Extrakt der Siebfraktion $<1,12 \mathrm{~mm}$ in $\mathrm{mg} / \mathrm{kg}$ TM, Lysimeter 1 und 2, 3 - 8

\begin{tabular}{|c|c|c|c|c|c|c|c|c|c|c|c|c|c|}
\hline Probenahme & Lysimeter & $\begin{array}{l}\text { Tiefe } \\
\mathrm{cm}\end{array}$ & $\begin{array}{c}\text { Einwaage } \\
\mathbf{g}\end{array}$ & $\begin{array}{c}\text { Wasser } \\
\mathrm{ml}\end{array}$ & DOC & $\mathrm{Na}$ & K & Mg & $\begin{array}{c}\mathrm{Ca} \\
\mathrm{mg} / \mathrm{kg}\end{array}$ & $\mathrm{HCO}_{3}$ & $\mathrm{Cl}$ & $\mathrm{SO}_{4}$ & $\mathrm{NO}_{3}$ \\
\hline 24.06.1988 & 1 & $0-20$ & 20,08 & 40 & 2654,38 & 62,75 & 414,34 & 75,70 & 256,97 & 1847,01 & & 210,12 & 172,83 \\
\hline 24.06.1988 & 1 & $20-45$ & 15,12 & 30 & 3557,54 & 115,08 & 547,62 & 65,48 & 235,12 & 2081,75 & & 101,57 & 135,26 \\
\hline 24.06.1988 & 1 & $45-70$ & 15,00 & 30 & 3692,00 & 150,00 & 593,00 & 59,00 & 240,00 & 2281,40 & & 389,36 & 0,00 \\
\hline 24.06.1988 & 2 & $0-20$ & 40,00 & 80 & 1237,50 & 62,00 & 428,00 & 80,00 & 231,00 & 1677,50 & & 86,78 & 136,34 \\
\hline 24.06.1988 & 2 & $20-45$ & 40,03 & 80 & 1703,72 & 130,90 & 640,52 & 70,95 & 225,23 & 2035,87 & 39,03 & 305,31 & 111,47 \\
\hline 24.06.1988 & 2 & $45-70$ & 40,08 & 80 & 1704,09 & 169,66 & 704,59 & 69,86 & 255,49 & 2002,89 & 68,56 & 363,71 & 129,88 \\
\hline 24.06.1988 & 8 & $0-20$ & 27,56 & 55 & 1022,77 & 49,89 & 289,37 & 95,79 & 304,34 & 1606,89 & 28,98 & 189,13 & 98,94 \\
\hline 24.06.1988 & 6 & $0-30$ & 30,10 & 60 & 894,52 & 39,87 & 256,15 & 92,69 & 312,96 & 1678,01 & 22,64 & 85,00 & 123,53 \\
\hline 24.06.1988 & 5 & $0-30$ & 50,05 & 100 & 724,28 & 31,97 & 191,81 & 63,94 & 213,79 & 1438,16 & 13,01 & 117,80 & 111,44 \\
\hline 24.06.1988 & 4 & $0-30$ & 40,01 & 80 & 459,89 & 25,99 & 119,97 & 53,99 & 229,94 & 1012,35 & & 75,28 & 130,11 \\
\hline 24.06.1988 & 3 & $0-30$ & 50,29 & 100 & 350,47 & 36,79 & 108,37 & 39,77 & 176,97 & 770,63 & & & 104,75 \\
\hline 24.06.1988 & 7 & $0-20$ & 45,10 & 95 & 110,06 & 2,11 & 22,12 & 12,64 & 116,91 & 353,35 & 15,69 & 14,70 & 117,49 \\
\hline
\end{tabular}


Tabelle 13-14: Lösliche Verbindungen im zweiten 1:2-

Kompost:Wasser-Extrakt der Siebfraktion $<1,12 \mathrm{~mm}$ in mmol IE/kg TM, Lysimeter 1 und 2, 3 - 8

\begin{tabular}{|c|c|c|c|c|c|c|c|c|c|c|c|}
\hline Probenahme & Lysimeter & $\begin{array}{c}\text { Tiefe } \\
\text { cm }\end{array}$ & DOC & $\mathrm{Na}$ & $\mathbf{K}$ & $\begin{array}{c}\mathrm{Mg} \\
\mathrm{mmol} \text { IE/kg }\end{array}$ & $\mathrm{Ca}$ & $\mathrm{HCO}_{3}$ & $\mathrm{Cl}$ & $\mathrm{SO}_{4}$ & $\mathrm{NO}_{3}$ \\
\hline 24.06 .1988 & 1 & $0-20$ & 221,00 & 2,73 & 10,60 & 6,23 & 12,82 & 30,27 & & 4,37 & 2,79 \\
\hline 24.06.1988 & 1 & $20-45$ & 296,19 & 5,01 & 14,00 & 5,38 & 11,73 & 34,12 & & 2,11 & 2,18 \\
\hline 24.06.1988 & 1 & $45-70$ & 307,38 & 6,52 & 15,17 & 4,85 & 11,98 & 37,39 & & 8,11 & 0,00 \\
\hline 24.06.1988 & 2 & $0-20$ & 103,03 & 2,70 & 10,95 & 6,58 & 11,53 & 27,49 & & 1,81 & 2,20 \\
\hline 24.06.1988 & 2 & $20-45$ & 141,85 & 5,69 & 16,38 & 5,83 & 11,24 & 33,37 & 1,10 & 6,36 & 1,80 \\
\hline 24.06 .1988 & 2 & $45-70$ & 141,88 & 7,38 & 18,02 & 5,75 & 12,75 & 32,83 & 1,93 & 7,57 & 2,09 \\
\hline 24.06.1988 & 8 & $0-20$ & 85,15 & 2,17 & 7,40 & 7,88 & 15,19 & 26,34 & 0,82 & 3,94 & 1,60 \\
\hline 24.06 .1988 & 6 & $0-30$ & 74,47 & 1,73 & 6,55 & 7,62 & 15,62 & 27,50 & 0,64 & 1,77 & 1,99 \\
\hline 24.06.1988 & 5 & $0-30$ & 60,30 & 1,39 & 4,91 & 5,26 & 10,67 & 23,57 & 0,37 & 2,45 & 1,80 \\
\hline 24.06.1988 & 4 & $0-30$ & 38,29 & 1,13 & 3,07 & 4,44 & 11,47 & 16,59 & & 1,57 & 2,10 \\
\hline 24.06.1988 & 3 & $0-30$ & 29,18 & 1,60 & 2,77 & 3,27 & 8,83 & 12,63 & & & 1,69 \\
\hline 24.06.1988 & 7 & $0-20$ & 9,16 & 0,09 & 0,57 & 1,04 & 5,83 & 5,79 & 0,44 & 0,31 & 1,89 \\
\hline
\end{tabular}

Tabelle 13-15: Lösliche Verbindungen im 1:2-

Kompost:Wasser-Extrakt der Siebfraktion < 1,12 mm in $\mathrm{mg} / \mathrm{l}$

Extraktlösung, Lysimeter 1 und 2, 3 - 8

\begin{tabular}{|c|c|c|c|c|c|c|c|c|c|c|c|c|c|c|}
\hline Probenahme & Lysimeter & $\begin{array}{c}\text { Tiefe } \\
\mathbf{c m} \\
\end{array}$ & \begin{tabular}{|c} 
Einwaage \\
$\mathbf{g}$
\end{tabular} & $\begin{array}{c}\text { Wasser } \\
\mathrm{ml}\end{array}$ & DOC & $\mathrm{Na}$ & $\mathbf{K}$ & $\mathrm{Mg}$ & $\begin{array}{c}\mathrm{Ca} \\
\mathrm{mg} / \mathrm{l}\end{array}$ & $\mathrm{Fe}$ & $\mathrm{Zn}$ & $\mathrm{HCO}_{3}$ & $\mathbf{N}_{\text {ges }}$ & $\mathrm{P}_{2} \mathrm{O}_{5}$ \\
\hline 29.03.1990 & 1 & $0-30$ & 47,74 & 100,65 & & 55,65 & 326,20 & 37,75 & 141,06 & 0,74 & 0,15 & 725,90 & & 20,29 \\
\hline 29.03 .1990 & 1 & $30-60$ & 45,90 & 91,93 & & 104,45 & 534,15 & 32,75 & 152,90 & 1,63 & 0,22 & 863,15 & 25,90 & 31,76 \\
\hline 29.03.1990 & 2 & $0-30$ & 49,54 & 99,75 & & 68,15 & 333,85 & 35,75 & 141,34 & 0,82 & 0,14 & 732,00 & 16,10 & 23,08 \\
\hline 29.03.1990 & 2 & $30-60$ & 54,47 & 109,67 & & 124,30 & 662,00 & 33,50 & 150,65 & 5,38 & 0,35 & 979,05 & 27,30 & 30,63 \\
\hline 02.04.1990 & 8 & $0-20$ & 64,36 & 132,21 & 738,61 & 14,63 & 180,09 & 47,75 & 185,63 & 1,48 & 0,24 & 785,68 & 4,90 & 18,14 \\
\hline 02.04.1990 & 6 & $0-20$ & 70,13 & 142,52 & 496,28 & 16,57 & 202,22 & 40,00 & 154,88 & 1,19 & 0,17 & 721,02 & 41,46 & 13,21 \\
\hline 02.04 .1990 & 5 & $0-20$ & 100,14 & 201,80 & 468,57 & 11,92 & 133,16 & 24,00 & 125,26 & 1,09 & 0,13 & 492,88 & 28,18 & 9,88 \\
\hline 02.04.1990 & 4 & $0-20$ & 100,44 & 209,43 & 391,77 & 11,35 & 114,46 & 20,75 & 105,95 & 1,40 & 0,09 & 407,48 & 24,15 & 4,66 \\
\hline 02.04 .1990 & 3 & $0-20$ & 100,05 & 209,43 & 234,00 & 6,84 & 57,23 & 13,00 & 84,07 & 0,84 & 0,05 & 286,70 & 20,93 & 8,55 \\
\hline 02.04.1990 & 7 & $0-20$ & 99,34 & 205,07 & & 5,40 & 2,10 & 2,70 & 37,52 & 0,41 & u.B. & 143,96 & & \\
\hline
\end{tabular}

Tabelle 13-16: Lösliche Verbindungen im 1:2-

Kompost:Wasser-Extrakt der Siebfraktion < 1,12 $\mathrm{mm}$ in $\mathrm{mg} / \mathrm{kg}$ TM, Lysimeter 1 und 2, 3 - 8

\begin{tabular}{|c|c|c|c|c|c|c|c|c|c|c|c|c|c|c|}
\hline Probenahme & Lysimeter & $\begin{array}{c}\text { Tiefe } \\
\mathbf{c m}\end{array}$ & $\begin{array}{c}\text { Einwaage } \\
\mathbf{g}\end{array}$ & $\begin{array}{c}\text { Wasser } \\
\mathrm{ml}\end{array}$ & DOC & $\mathrm{Na}$ & $\mathbf{K}$ & $\mathrm{Mg}$ & $\begin{array}{c}\mathrm{Ca} \\
\mathrm{mg} / \mathrm{kg}\end{array}$ & $\mathrm{Fe}$ & $\mathrm{Zn}$ & $\mathrm{HCO}_{3}$ & $\mathbf{N}_{\text {ges }}$ & $\mathrm{P}_{2} \mathrm{O}_{5}$ \\
\hline 29.03 .1990 & 1 & $0-30$ & 47,74 & 100,65 & & 117,33 & 687,73 & 79,59 & 297,40 & 1,56 & 0,32 & 1530,41 & & 42,78 \\
\hline 29.03.1990 & 1 & $30-60$ & 45,90 & 91,93 & & 209,20 & 1069,81 & 65,59 & 306,23 & 3,26 & 0,44 & 1728,74 & 51,87 & 63,61 \\
\hline 29.03.1990 & 2 & $0-30$ & 49,54 & 99,75 & & 137,22 & 672,22 & 71,98 & 284,59 & 1,65 & 0,28 & 1473,90 & 32,42 & 46,47 \\
\hline 29.03 .1990 & 2 & $30-60$ & 54,47 & 109,67 & & 250,27 & 1332,87 & 67,45 & 303,32 & 10,83 & 0,70 & 1971,22 & 54,97 & 61,67 \\
\hline 02.04 .1990 & 8 & $0-20$ & 64,36 & 132,21 & 1517,27 & 30,05 & 369,95 & 98,09 & 381,33 & 3,04 & 0,49 & 1613,96 & 10,07 & 37,26 \\
\hline 02.04 .1990 & 6 & $0-20$ & 70,13 & 142,52 & 1008,55 & 33,67 & 410,96 & 81,29 & 314,75 & 2,42 & 0,35 & 1465,28 & 84,26 & 26,85 \\
\hline 02.04.1990 & 5 & $0-20$ & 100,14 & 201,80 & 944,25 & 24,02 & 268,34 & 48,36 & 252,42 & 2,20 & 0,26 & 993,24 & 56,79 & 19,91 \\
\hline 02.04.1990 & 4 & $0-20$ & 100,44 & 209,43 & 816,89 & 23,67 & 238,66 & 43,27 & 220,92 & 2,92 & 0,19 & 849,65 & 50,36 & 9,72 \\
\hline 02.04.1990 & 3 & $0-20$ & 100,05 & 209,43 & 489,82 & 14,32 & 119,80 & 27,21 & 175,98 & 1,76 & 0,10 & 600,14 & 43,81 & 17,90 \\
\hline 02.04 .1990 & 7 & $0-20$ & 99,34 & 205,07 & & 11,15 & 4,34 & 5,57 & 77,45 & 0,85 & & 297,18 & & \\
\hline
\end{tabular}


Tabelle 13-17: Lösliche Verbindungen im 1:2-

Kompost:Wasser-Extrakt der Siebfraktion $<1,12 \mathrm{~mm}$ in mmol IE/kg TM, Lysimeter 1 und 2, 3 - 8

\begin{tabular}{|c|c|c|c|c|c|c|c|c|c|c|c|c|}
\hline Probenahme & Lysimeter & $\begin{array}{c}\text { Tiefe } \\
\mathrm{cm} \\
\end{array}$ & DOC & $\mathrm{Na}$ & K & $\begin{array}{c}\mathrm{Mg} \\
\mathrm{mmol} \text { IE/kg }\end{array}$ & $\mathrm{Ca}$ & $\mathrm{Fe}$ & $\mathrm{Zn}$ & $\mathrm{HCO}_{3}$ & $\mathbf{N}_{\text {ges }}$ & $\mathrm{P}_{2} \mathrm{O}_{5}$ \\
\hline 29.03.1990 & 1 & $0-30$ & & 5,10 & 17,59 & 6,55 & 14,84 & 0,08 & 0,01 & 25,08 & & 0,90 \\
\hline 29.03.1990 & 1 & $30-60$ & & 9,10 & 27,36 & 5,39 & 15,28 & 0,18 & 0,01 & 28,33 & 3,70 & 1,34 \\
\hline 29.03.1990 & 2 & $0-30$ & & 5,97 & 17,19 & 5,92 & 14,20 & 0,09 & 0,01 & 24,16 & 2,31 & 0,98 \\
\hline 29.03.1990 & 2 & $30-60$ & & 10,89 & 34,09 & 5,55 & 15,14 & 0,58 & 0,02 & 32,31 & 3,92 & 1,30 \\
\hline 02.04.1990 & 8 & $0-20$ & 126,32 & 1,31 & 9,46 & 8,07 & 19,03 & 0,16 & 0,02 & 26,45 & 0,72 & 0,79 \\
\hline 02.04 .1990 & 6 & $0-20$ & 83,97 & 1,46 & 10,51 & 6,68 & 15,71 & 0,13 & 0,01 & 24,01 & 6,02 & 0,57 \\
\hline 02.04.1990 & 5 & $0-20$ & 78,62 & 1,04 & 6,86 & 3,98 & 12,60 & 0,12 & 0,01 & 16,28 & 4,05 & 0,42 \\
\hline 02.04.1990 & 4 & $0-20$ & 68,01 & 1,03 & 6,10 & 3,56 & 11,02 & 0,16 & 0,01 & 13,92 & 3,60 & 0,21 \\
\hline 02.04 .1990 & 3 & $0-20$ & 40,78 & 0,62 & 3,06 & 2,24 & 8,78 & 0,09 & 0,00 & 9,84 & 3,13 & 0,38 \\
\hline 02.04.1990 & 7 & $0-20$ & & 0,48 & 0,11 & 0,46 & 3,86 & 0,05 & 0,00 & 4,87 & & \\
\hline
\end{tabular}

Tabelle 13-18: Lösliche Verbindungen im 1:10-

Kompost:Wasser-Extrakt der Siebfraktion $<2 \mathrm{~mm}$ in $\mathrm{mg} / \mathrm{l}$

Extraktlösung, Lysimeter 1, 2, 8, 6, 5 und 4

\begin{tabular}{|c|c|c|c|c|c|c|c|c|c|c|c|c|c|c|c|c|}
\hline Probenahme & Lysimeter & $\begin{array}{c}\text { Tiefe } \\
\mathrm{cm}\end{array}$ & $\begin{array}{c}\text { Einwaage } \\
\mathrm{g} \mathrm{TM}\end{array}$ & $\begin{array}{c}\text { Wasser } \\
\mathrm{ml}\end{array}$ & $\begin{array}{c}\mathrm{LF} \\
\mathrm{mS} / \mathrm{cm}\end{array}$ & $\begin{array}{l}\mathrm{DOC} \\
\mathrm{mg} / \mathrm{l}\end{array}$ & $\begin{array}{c}\mathrm{Na} \\
\mathrm{mg} / \mathrm{l}\end{array}$ & $\begin{array}{c}\mathrm{K} \\
\mathrm{mg} / \mathrm{l}\end{array}$ & $\begin{array}{c}\mathrm{Mg} \\
\mathrm{mg} / \mathrm{l}\end{array}$ & $\begin{array}{c}\mathrm{Ca} \\
\mathrm{mg} / \mathrm{I}\end{array}$ & $\begin{array}{c}\mathrm{Fe} \\
\mathrm{mg} / \mathrm{l}\end{array}$ & $\begin{array}{l}\mathrm{Zn} \\
\mathrm{mg} / \mathrm{I}\end{array}$ & $\begin{array}{c}\mathrm{HCO}_{3} \\
\mathrm{mg} / \mathrm{l}\end{array}$ & $\begin{array}{c}\mathrm{Cl} \\
\mathrm{mg} / \mathrm{l}\end{array}$ & $\begin{array}{l}\mathrm{N}_{\text {ges }} \\
\mathrm{mg} / \mathrm{l}\end{array}$ & $\begin{array}{l}\mathrm{P}_{2} \mathrm{O}_{5} \\
\mathrm{mg} / \mathrm{l}\end{array}$ \\
\hline 29.03.1990 & 1 & $0-30$ & 19,61 & 209,12 & 0,20 & 63,60 & 5,19 & 61,81 & 2,75 & 13,54 & 0,96 & 0,05 & 70,76 & 0,00 & 15,40 & 16,28 \\
\hline 29.03.1990 & 1 & $30-60$ & 21,00 & 222,41 & 0,30 & 121,68 & 11,20 & 106,83 & 3,45 & 15,52 & 3,28 & 0,10 & 109,80 & 0,00 & 15,40 & 25,07 \\
\hline 29.03 .1990 & 2 & $0-30$ & 21,43 & 229,06 & 0,20 & 63,49 & 5,19 & 62,95 & 2,50 & 11,28 & 0,82 & 0,05 & 75,64 & 0,00 & 12,60 & 13,47 \\
\hline 29.03.1990 & 2 & $30-60$ & 21,57 & 227,89 & 0,34 & 137,12 & 13,69 & 126,67 & 3,00 & 14,67 & 2,66 & 0,10 & 130,54 & 0,00 & 20,30 & 21,72 \\
\hline 02.04.1990 & 8 & $0-20$ & 20,36 & 225,01 & 0,16 & 43,42 & 3,96 & 35,10 & 3,00 & 12,13 & 0,58 & 0,05 & 56,12 & 0,00 & 7,00 & 8,55 \\
\hline 02.04 .1990 & 6 & $0-20$ & 19,43 & 220,28 & 0,17 & 62,09 & 5,66 & 49,60 & 3,20 & 12,13 & 1,43 & 0,05 & 81,74 & 0,00 & 22,40 & 9,55 \\
\hline 02.04 .1990 & 5 & $0-20$ & 18,98 & 220,70 & 0,15 & 47,32 & 4,79 & 34,72 & 2,55 & 11,28 & 3,26 & 0,06 & 69,54 & 3,14 & 13,30 & 7,93 \\
\hline 02.04 .1990 & 4 & $0-20$ & 17,59 & 194,95 & 0,16 & 42,33 & 12,57 & 30,52 & 2,55 & 11,85 & 2,05 & 0,05 & 71,98 & 10,85 & 16,80 & 6,34 \\
\hline
\end{tabular}

Tabelle 13-19: Lösliche Verbindungen im 1:10-

Kompost:Wasser-Extrakt der Siebfraktion $<2 \mathrm{~mm}$ in $\mathrm{mg} / \mathrm{kg}$

TM, Lysimeter 1, 2, 8, 6, 5 und 4

\begin{tabular}{|c|c|c|c|c|c|c|c|c|c|c|c|c|c|c|c|}
\hline Probenahme & Lysimeter & $\begin{array}{l}\text { Tiefe } \\
\mathrm{cm}\end{array}$ & $\begin{array}{c}\text { Einwaage } \\
\mathbf{g}\end{array}$ & $\begin{array}{c}\text { Wasser } \\
\mathrm{ml}\end{array}$ & DOC & $\mathrm{Na}$ & $\mathrm{K}$ & $\mathrm{Mg}$ & $\mathrm{Ca}$ & $\begin{array}{c}\mathrm{Fe} \\
\mathrm{mg} / \mathrm{kg}\end{array}$ & $\mathrm{Zn}$ & $\mathrm{HCO}_{3}$ & $\mathrm{Cl}$ & $\mathbf{N}_{\text {ges }}$ & $\mathrm{P}_{2} \mathrm{O}_{5}$ \\
\hline 29.03 .1990 & 1 & $0-30$ & 19,61 & 209,12 & 678,23 & 55,35 & 659,14 & 29,33 & 144,39 & 10,24 & 0,53 & 754,58 & & 164,22 & 173,61 \\
\hline 29.03.1990 & 1 & $30-60$ & 21,00 & 222,41 & 1288,71 & 118,62 & 1131,43 & 36,54 & 164,37 & 34,74 & 1,06 & 1162,89 & & 163,10 & 265,52 \\
\hline 29.03.1990 & 2 & $0-30$ & 21,43 & 229,06 & 678,63 & 55,47 & 672,86 & 26,72 & 120,57 & 8,76 & 0,53 & 808,50 & & 134,68 & 143,98 \\
\hline 29.03.1990 & 2 & $30-60$ & 21,57 & 227,89 & 1448,69 & 144,64 & 1338,29 & 31,70 & 154,99 & 28,10 & 1,06 & 1379,17 & & 214,47 & 229,47 \\
\hline 02.04.1990 & 8 & $0-20$ & 20,36 & 225,01 & 479,86 & 43,76 & 387,91 & 33,15 & 134,06 & 6,41 & 0,55 & 620,21 & & 77,36 & 94,49 \\
\hline 02.04 .1990 & 6 & $0-20$ & 19,43 & 220,28 & 703,92 & 64,17 & 562,32 & 36,28 & 137,52 & 16,21 & 0,57 & 926,70 & & 253,95 & 108,27 \\
\hline 02.04 .1990 & 5 & $0-20$ & 18,98 & 220,70 & 550,24 & 55,70 & 403,73 & 29,65 & 131,16 & 37,91 & 0,70 & 808,61 & 36,51 & 154,65 & 92,21 \\
\hline 02.04 .1990 & 4 & $0-20$ & 17,59 & 194,95 & 469,14 & 139,31 & 338,25 & 28,26 & 131,33 & 22,72 & 0,55 & 797,75 & 120,25 & 186,19 & 70,27 \\
\hline
\end{tabular}

Tabelle 13-20: Lösliche Verbindungen im 1:10-

Kompost:Wasser-Extrakt der Siebfraktion $<2 \mathrm{~mm}$ in $\mathbf{m m o l}$

IE/kg TM, Lysimeter 1, 2, 8, 6, 5 und 4

\begin{tabular}{|c|c|c|c|c|c|c|c|c|c|c|c|c|}
\hline Probenahme & Lysimeter & $\begin{array}{c}\text { Tiefe } \\
\text { cm }\end{array}$ & $\mathrm{Na}$ & $\mathbf{K}$ & Mg & $\mathrm{Ca}$ & $\begin{array}{c}\mathrm{Fe} \\
\mathrm{mmol} \mathrm{IE} / \mathrm{kg}\end{array}$ & $\mathrm{Zn}$ & $\mathrm{HCO}_{3}$ & $\mathrm{Cl}$ & $N_{\text {ges }}$ & $\mathrm{P}_{2} \mathrm{O}_{5}$ \\
\hline 29.03.1990 & 1 & $0-30$ & 2,41 & 16,86 & 2,41 & 7,21 & 0,55 & 0,02 & 12,37 & & 11,72 & 3,67 \\
\hline 29.03.1990 & 1 & $30-60$ & 5,16 & 28,94 & 3,00 & 8,20 & 1,87 & 0,03 & 19,06 & & 11,64 & 5,61 \\
\hline 29.03.1990 & 2 & $0-30$ & 2,41 & 17,21 & 2,20 & 6,02 & 0,47 & 0,02 & 13,25 & & 9,62 & 3,04 \\
\hline 29.03.1990 & 2 & $30-60$ & 6,29 & 34,23 & 2,61 & 7,73 & 1,51 & 0,03 & 22,60 & & 15,31 & 4,85 \\
\hline 02.04 .1990 & 8 & $0-20$ & 1,90 & 9,92 & 2,73 & 6,69 & 0,34 & 0,02 & 10,16 & & 5,52 & 2,00 \\
\hline 02.04.1990 & 6 & $0-20$ & 2,79 & 14,38 & 2,98 & 6,86 & 0,87 & 0,02 & 15,19 & & 18,13 & 2,29 \\
\hline 02.04 .1990 & 5 & $0-20$ & 2,42 & 10,32 & 2,44 & 6,55 & 2,04 & 0,02 & 13,25 & 1,03 & 11,04 & 1,95 \\
\hline 02.04 .1990 & 4 & $0-20$ & 6,06 & 8,65 & 2,32 & 6,55 & 1,22 & 0,02 & 13,07 & 3,39 & 13,29 & 1,49 \\
\hline
\end{tabular}


Tabelle 13-21: Lösliche Verbindungen im zweiten 1:10-

Kompost:Wasser-Extrakt der Siebfraktion $<2 \mathrm{~mm}$ in $\mathrm{mg} / \mathrm{l}$

Extraktlösung, Lysimeter 1, 2, 8, 6, 5 und 4

\begin{tabular}{|c|c|c|c|c|c|c|c|c|c|c|c|c|c|c|c|}
\hline Probenahme & Lysimeter & $\begin{array}{c}\text { Tiefe } \\
\mathrm{cm}\end{array}$ & $\begin{array}{c}\text { Einwaage } \\
\text { g TM }\end{array}$ & $\begin{array}{c}\begin{array}{c}\text { Wasser } \\
\mathrm{ml}\end{array} \\
\end{array}$ & $\begin{array}{c}\mathrm{LF} \\
\mathrm{mS} / \mathrm{cm}\end{array}$ & $\begin{array}{l}\mathrm{DOC} \\
\mathrm{mg} / \mathrm{l}\end{array}$ & $\begin{array}{c}\mathrm{Na} \\
\mathrm{mg} / \mathrm{l}\end{array}$ & $\begin{array}{c}\mathrm{K} \\
\mathrm{mg} / \mathrm{l}\end{array}$ & $\begin{array}{c}\mathrm{Mg} \\
\mathrm{mg} / \mathrm{l}\end{array}$ & $\begin{array}{c}\mathrm{Ca} \\
\mathrm{mg} / \mathrm{l}\end{array}$ & $\begin{array}{c}\mathrm{Fe} \\
\mathrm{mg} / \mathrm{l}\end{array}$ & $\begin{array}{c}\mathrm{Zn} \\
\mathrm{mg} / \mathrm{l}\end{array}$ & $\begin{array}{c}\mathrm{HCO}_{3} \\
\mathrm{mg} / \mathrm{l}\end{array}$ & $\begin{array}{l}\mathrm{N}_{\text {ges }} \\
\mathrm{mg} / \mathrm{l}\end{array}$ & $\begin{array}{l}\mathrm{P}_{2} \mathrm{O}_{5} \\
\mathrm{mg} / \mathrm{l}\end{array}$ \\
\hline 29.03.1990 & 1 & $0-30$ & 19,61 & 193,03 & 0,16 & & 3,93 & 41,97 & 2,30 & 11,00 & 2,28 & 0,03 & 84,18 & 8,83 & 10,03 \\
\hline 29.03.1990 & 1 & $30-60$ & 21,00 & 214,17 & 0,22 & & 8,21 & 76,69 & 1,65 & 11,00 & 9,53 & 0,10 & 111,02 & 11,27 & 12,08 \\
\hline 29.03.1990 & 2 & $0-30$ & 21,43 & 228,84 & 0,17 & & 3,49 & 45,02 & 2,10 & 9,31 & 3,18 & 0,04 & 82,96 & 9,66 & 6,65 \\
\hline 29.03.1990 & 2 & $30-60$ & 21,57 & 249,75 & 0,23 & & 9,04 & 83,94 & 1,50 & 9,03 & 8,35 & 0,10 & 118,34 & 10,47 & 10,12 \\
\hline 02.04 .1990 & 8 & $0-20$ & 20,36 & 174,45 & 0,16 & 26,94 & 3,60 & 26,33 & 3,55 & 17,21 & 0,85 & 0,02 & 81,74 & 4,03 & 4,54 \\
\hline 02.04.1990 & 6 & $0-20$ & 19,43 & 164,60 & 0,17 & & 4,32 & 42,35 & 2,25 & 11,28 & 12,08 & 0,10 & 90,28 & 4,03 & 6,90 \\
\hline 02.04.1990 & 4 & $0-20$ & 17,59 & 167,64 & 0,16 & & 1,90 & 62,95 & 1,25 & 8,75 & 20,72 & 0,35 & 87,84 & 8,86 & 11,78 \\
\hline 02.04 .1990 & 5 & $0-20$ & 18,98 & 225,15 & 0,11 & & 2,88 & 26,71 & 1,25 & 7,90 & 11,40 & 0,08 & 61,00 & 6,44 & 4,64 \\
\hline
\end{tabular}

Tabelle 13-22: Lösliche Verbindungen im zweiten 1:10-

Kompost:Wasser-Extrakt der Siebfraktion $<2 \mathrm{~mm}$ in $\mathrm{mg} / \mathrm{kg}$

TM, Lysimeter 1, 2, 8, 6, 5 und 4

\begin{tabular}{|c|c|c|c|c|c|c|c|c|c|c|c|c|c|c|}
\hline Probenahme & Lysimeter & $\begin{array}{c}\text { Tiefe } \\
\mathbf{c m}\end{array}$ & $\begin{array}{c}\text { Einwaage } \\
\mathrm{g}\end{array}$ & $\begin{array}{c}\text { Wasser } \\
\mathrm{ml}\end{array}$ & DOC & $\mathrm{Na}$ & K & Mg & $\mathrm{Ca}$ & $\begin{array}{c}\mathrm{Fe} \\
\mathrm{mg} / \mathrm{kg}\end{array}$ & $\mathrm{Zn}$ & $\mathrm{HCO}_{3}$ & $\mathbf{N}_{\text {ges }}$ & $\mathrm{P}_{2} \mathrm{O}_{5}$ \\
\hline 29.03.1990 & 1 & $0-30$ & 19,61 & 193,03 & & 38,68 & 413,13 & 22,64 & 108,28 & 22,44 & 0,30 & 828,62 & 86,92 & 98,73 \\
\hline 29.03.1990 & 1 & $30-60$ & 21,00 & 214,17 & & 83,73 & 782,13 & 16,83 & 112,18 & 97,19 & 1,02 & 1132,25 & 114,94 & 123,20 \\
\hline 29.03 .1990 & 2 & $0-30$ & 21,43 & 228,84 & & 37,27 & 480,75 & 22,42 & 99,42 & 33,96 & 0,43 & 885,89 & 103,15 & 71,01 \\
\hline 29.03.1990 & 2 & $30-60$ & 21,57 & 249,75 & & 104,67 & 971,91 & 17,37 & 104,55 & 96,68 & 1,16 & 1370,21 & 121,23 & 117,18 \\
\hline 02.04 .1990 & 8 & $0-20$ & 20,36 & 174,45 & 230,83 & 30,85 & 225,60 & 30,42 & 147,46 & 7,28 & 0,17 & 700,37 & 34,53 & 38,90 \\
\hline 02.04 .1990 & 6 & $0-20$ & 19,43 & 164,60 & & 36,60 & 358,77 & 19,06 & 95,56 & 102,33 & 0,85 & 764,80 & 34,14 & 58,45 \\
\hline 02.04 .1990 & 5 & $0-20$ & 18,98 & 225,15 & & 34,16 & 316,85 & 14,83 & 93,71 & 135,23 & 0,95 & 723,61 & 76,39 & 55,04 \\
\hline 02.04.1990 & 4 & $0-20$ & 17,59 & 167,64 & & 18,11 & 599,94 & 11,91 & 83,39 & 197,47 & 3,34 & 837,15 & 84,44 & 112,27 \\
\hline
\end{tabular}

Tabelle 13-23: Lösliche Verbindungen im zweiten 1:10-

Kompost:Wasser-Extrakt der Siebfraktion $<2 \mathrm{~mm}$ in $\mathrm{mmol}$

IE/kg TM, Lysimeter 1, 2, 8, 6, 5 und 4

\begin{tabular}{|c|c|c|c|c|c|c|c|c|c|c|c|}
\hline Probenahme & Lysimeter & $\begin{array}{c}\text { Tiefe } \\
\mathrm{cm}\end{array}$ & $\mathrm{Na}$ & $\mathbf{K}$ & Mg & $\mathrm{Ca}$ & $\begin{array}{c}\mathrm{Fe} \\
\mathrm{mmol} \mathrm{IE} / \mathrm{kg}\end{array}$ & $\mathrm{Zn}$ & $\mathrm{HCO}_{3}$ & $N_{\text {ges }}$ & $\mathrm{P}_{2} \mathrm{O}_{5}$ \\
\hline 29.03.1990 & 1 & $0-30$ & 1,68 & 10,57 & 1,86 & 5,40 & 1,21 & 0,01 & 13,58 & 6,21 & 2,09 \\
\hline 29.03 .1990 & 1 & $30-60$ & 3,64 & 20,00 & 1,38 & 5,60 & 5,22 & 0,03 & 18,56 & 8,21 & 2,60 \\
\hline 29.03.1990 & 2 & $0-30$ & 1,62 & 12,29 & 1,84 & 4,96 & 1,82 & 0,01 & 14,52 & 7,36 & 1,50 \\
\hline 29.03.1990 & 2 & $30-60$ & 4,55 & 24,86 & 1,43 & 5,22 & 5,19 & 0,04 & 22,46 & 8,65 & 2,48 \\
\hline 02.04 .1990 & 8 & $0-20$ & 1,34 & 5,77 & 2,50 & 7,36 & 0,39 & 0,01 & 11,48 & 2,47 & 0,82 \\
\hline 02.04 .1990 & 6 & $0-20$ & 1,59 & 9,18 & 1,57 & 4,77 & 5,50 & 0,03 & 12,53 & 2,44 & 1,24 \\
\hline 02.04 .1990 & 5 & $0-20$ & 1,49 & 8,10 & 1,22 & 4,68 & 7,26 & 0,03 & 11,86 & 5,45 & 1,16 \\
\hline 02.04 .1990 & 4 & $0-20$ & 0,79 & 15,34 & 0,98 & 4,16 & 10,61 & 0,10 & 13,72 & 6,03 & 2,37 \\
\hline
\end{tabular}

Tabelle 13-24: Lösliche Verbindungen im 1:10-

Kompost:Wasser-Extrakt der Siebfraktionen $<2 \mathrm{~mm}$ und

$>2 \mathrm{~mm}$ in $\mathbf{m g} / \mathrm{l}$ Extraktlösung, Lysimeter 1

\begin{tabular}{|c|c|c|c|c|c|c|c|c|c|c|c|c|c|c|c|c|c|}
\hline Probenahme & Lysimeter & $\begin{array}{l}\text { Tiefe } \\
\mathrm{cm}\end{array}$ & $\begin{array}{c}\text { Sieb- } \\
\text { Fraktion }\end{array}$ & $\begin{array}{c}\text { Einwaage } \\
\text { g TM }\end{array}$ & $\begin{array}{c}\text { Wasser } \\
\mathrm{ml}\end{array}$ & $\begin{array}{c}\mathrm{LF} \\
\mathrm{mS} / \mathrm{cm}\end{array}$ & $\begin{array}{l}\mathrm{DOC} \\
\mathrm{mg} / \mathrm{l}\end{array}$ & $\begin{array}{c}\mathrm{Na} \\
\mathrm{mg} / \mathrm{l}\end{array}$ & $\begin{array}{c}\mathrm{K} \\
\mathrm{mg} / \mathrm{l}\end{array}$ & $\begin{array}{c}\mathrm{Mg} \\
\mathrm{mg} / \mathrm{l}\end{array}$ & $\begin{array}{c}\mathrm{Ca} \\
\mathrm{mg} / \mathrm{l}\end{array}$ & $\begin{array}{c}\mathrm{Fe} \\
\mathrm{mg} / \mathrm{l}\end{array}$ & $\begin{array}{c}\mathrm{Zn} \\
\mathrm{mg} / \mathrm{l}\end{array}$ & $\begin{array}{r}\mathrm{HCO}_{3} \\
\mathrm{mg} / \mathrm{l}\end{array}$ & $\begin{array}{c}\mathrm{Cl} \\
\mathrm{mg} / \mathrm{l}\end{array}$ & $\begin{array}{l}\mathrm{N}_{\text {ges }} \\
\mathrm{mg} / \mathrm{l}\end{array}$ & $\begin{array}{l}\mathrm{P}_{2} \mathrm{O}_{5} \\
\mathrm{mg} / \mathrm{l}\end{array}$ \\
\hline & 1 & $0-5$ & $<2 \mathrm{~mm}$ & 20,41 & 206,85 & 0,36 & 183,92 & 4,97 & 53,42 & 8,05 & 51,63 & 0,35 & 0,02 & 123,22 & 44,49 & 14,4 & 14,52 \\
\hline 18.04.1990 & 1 & $0-5$ & $>2 \mathrm{~mm}$ & 34,98 & 372,57 & 0,37 & 143,68 & 5,76 & 50,75 & 8,25 & 50,78 & 0,74 & 0,03 & 132,98 & 19,21 & 37,8 & 21,99 \\
\hline
\end{tabular}

Tabelle 13-25: Lösliche Verbindungen im 1:10-

Kompost:Wasser-Extrakt der Siebfraktionen $<2 \mathrm{~mm}$ und

$>2 \mathrm{~mm}$ in $\mathrm{mg} / \mathrm{kg} \mathrm{TM}$, Lysimeter 1

\begin{tabular}{cc|cc|cc|ccccccccccc} 
Probenahme Lysimeter & $\begin{array}{c}\text { Tiefe } \\
\text { cm }\end{array}$ & $\begin{array}{c}\text { Sieb- } \\
\text { Fraktion }\end{array}$ & $\begin{array}{c}\text { Einwaage } \\
\mathbf{g}\end{array}$ & $\begin{array}{c}\text { Wasser } \\
\mathbf{m l}\end{array}$ & DOC & $\mathbf{N a}$ & $\mathbf{K}$ & $\mathbf{M g}$ & $\mathbf{C a}$ & $\begin{array}{c}\mathbf{F e} \\
\mathbf{m g} / \mathbf{k g}\end{array}$ & $\mathbf{Z n}$ & $\mathbf{H C O}$ & $\mathbf{C l}$ & $\mathbf{N}_{\text {ges }}$ & $\mathbf{P}_{\mathbf{2}} \mathrm{O}_{\mathbf{5}}$ \\
\hline $\mathbf{1 8 . 0 4 . 1 9 9 0}$ & $\mathbf{1}$ & $0-5$ & $<2 \mathrm{~mm}$ & 20,41 & 206,85 & 1863,98 & 50,37 & 541,40 & 81,58 & 523,26 & 3,55 & 0,20 & 1248,80 & 450,89 & 145,94 & 147,16 \\
$\mathbf{1 8 . 0 4 . 1 9 9 0}$ & $\mathbf{1}$ & $0-5$ & $>2 \mathrm{~mm}$ & 34,98 & 372,57 & 1530,33 & 61,35 & 540,54 & 87,87 & 540,85 & 7,88 & 0,32 & 1416,36 & 204,60 & 402,61 & 234,21
\end{tabular}


Tabelle 13-26: Lösliche Verbindungen im 1:10-

Kompost:Wasser-Extrakt der Siebfraktionen $<2 \mathrm{~mm}$ und

$>2 \mathrm{~mm}$ in $\mathrm{mmol}$ IE/kg TM, Lysimeter 1

\begin{tabular}{cc|cc|cccccccccc} 
Probenahme & Lysimeter & $\begin{array}{c}\text { Tiefe } \\
\mathbf{c m}\end{array}$ & $\begin{array}{c}\text { Sieb- } \\
\text { Fraktion }\end{array}$ & $\mathbf{N a}$ & $\mathbf{K}$ & $\mathbf{M g}$ & $\mathbf{C a}$ & $\begin{array}{c}\mathbf{F e} \\
\mathbf{m m o l} \text { IE/kg }\end{array}$ & $\mathbf{Z n}$ & $\mathbf{H C O}_{3}$ & $\mathbf{C l}$ & $\mathbf{N}_{\text {ges }}$ & $\mathbf{P}_{\mathbf{2}} \mathrm{O}_{\mathbf{5}}$ \\
\hline $\mathbf{1 8 . 0 4 . 1 9 9 0}$ & $\mathbf{1}$ & $0-5$ & $<2 \mathrm{~mm}$ & 2,19 & 13,85 & 6,71 & 26,11 & 0,19 & 0,01 & 20,47 & 12,72 & 10,42 & 3,11 \\
$\mathbf{1 8 . 0 4 . 1 9 9 0}$ & $\mathbf{1}$ & $0-5$ & $>2 \mathrm{~mm}$ & 2,67 & 13,82 & 7,23 & 26,99 & 0,42 & 0,01 & 23,21 & 5,77 & 28,74 & 4,95
\end{tabular}

Tabelle 13-27: Lösliche Verbindungen im 1:10-

Kompost:Wasser-Extrakt der Siebfraktionen $<2 \mathrm{~mm}$ und

$>2 \mathrm{~mm}$ in $\mathrm{mg} / \mathrm{l}$ Extraktlösung, Lysimeter 1

\begin{tabular}{|c|c|c|c|c|c|c|c|c|c|c|c|c|c|c|c|c|}
\hline Probenahme & Lysimeter & $\begin{array}{c}\text { Tiefe } \\
\mathrm{cm}\end{array}$ & $\begin{array}{c}\text { Sieb- } \\
\text { Fraktion }\end{array}$ & $\begin{array}{c}\text { Einwaage } \\
\text { g TM }\end{array}$ & $\begin{array}{c}\text { Wasser } \\
\mathrm{ml}\end{array}$ & $\begin{array}{c}\mathrm{LF} \\
\mathrm{mS} / \mathrm{cm}\end{array}$ & $\begin{array}{l}\mathrm{DOC} \\
\mathrm{mg} / \mathrm{l}\end{array}$ & $\begin{array}{c}\mathrm{Na} \\
\mathrm{mg} / \mathrm{l}\end{array}$ & $\begin{array}{c}\mathrm{K} \\
\mathrm{mg} / \mathrm{l}\end{array}$ & $\begin{array}{c}\mathrm{Mg} \\
\mathrm{mg} / \mathrm{l}\end{array}$ & $\begin{array}{c}\mathrm{Ca} \\
\mathrm{mg} / \mathrm{l}\end{array}$ & $\begin{array}{c}\mathrm{Fe} \\
\mathrm{mg} / \mathrm{I}\end{array}$ & $\begin{array}{c}\mathrm{Zn} \\
\mathrm{mg} / \mathrm{I}\end{array}$ & $\begin{array}{c}\mathrm{HCO}_{3} \\
\mathrm{mg} / \mathrm{l} \\
\end{array}$ & $\begin{array}{l}\mathrm{N}_{\mathrm{ges}} \\
\mathrm{mg} / \mathrm{l}\end{array}$ & $\begin{array}{l}\mathrm{P}_{2} \mathrm{O}_{5} \\
\mathrm{mg} / \mathrm{l}\end{array}$ \\
\hline & 1 & $0-5$ & $<2 \mathrm{~mm}$ & 20,41 & 266,91 & 0,152 & 58,45 & 3,31 & 15,26 & 3,1 & 14,11 & 0,36 & 0,01 & 62,22 & 4,83 & 6,41 \\
\hline 18.04.1990 & 1 & $0-5$ & $>2 \mathrm{~mm}$ & 34,98 & 205,93 & 0,289 & 101,14 & 5,58 & 26,71 & 5,6 & 27,24 & 0,38 & 0,01 & 140,3 & 8,86 & 10,21 \\
\hline
\end{tabular}

Tabelle 13-28: Lösliche Verbindungen im 1:10-

Kompost:Wasser-Extrakt der Siebfraktionen $<2 \mathrm{~mm}$ und

$>2 \mathrm{~mm}$ in $\mathrm{mg} / \mathrm{kg} \mathrm{TM}$, Lysimeter 1

\begin{tabular}{|c|c|c|c|c|c|c|c|c|c|c|c|c|c|c|c|}
\hline Probenahme & Lysimeter & $\begin{array}{l}\text { Tiefe } \\
\mathrm{cm}\end{array}$ & $\begin{array}{l}\text { Sieb- } \\
\text { Fraktion }\end{array}$ & $\begin{array}{c}\text { Einwaage } \\
\mathbf{g}\end{array}$ & $\begin{array}{c}\text { Wasser } \\
\mathrm{ml}\end{array}$ & DOC & $\mathrm{Na}$ & $\mathrm{K}$ & $\mathrm{Mg}$ & $\mathrm{Ca}$ & $\begin{array}{c}\mathrm{Fe} \\
\mathrm{mg} / \mathrm{kg}\end{array}$ & $\mathrm{Zn}$ & $\mathrm{HCO}_{3}$ & $\mathbf{N}_{\text {ges }}$ & $\mathrm{P}_{2} \mathrm{O}_{5}$ \\
\hline 18.04.1990 & 1 & $0-5$ & $<2 \mathrm{~mm}$ & 20,41 & 266,91 & 764,37 & 43,29 & 199,56 & 40,54 & 184,52 & 4,71 & 0,13 & 813,68 & 63,16 & 83,83 \\
\hline 18.04 .1990 & 1 & $0-5$ & $>2 \mathrm{~mm}$ & 34,98 & 205,93 & 595,42 & 32,85 & 157,24 & 32,97 & 160,36 & 2,24 & 0,06 & 825,96 & 52,16 & 60,11 \\
\hline
\end{tabular}

Tabelle 13-29: Lösliche Verbindungen im 1:10-

Kompost:Wasser-Extrakt der Siebfraktionen $<2 \mathrm{~mm}$ und

$>2 \mathrm{~mm}$ in $\mathrm{mmol} \mathrm{IE} / \mathrm{kg}$, Lysimeter 1

\begin{tabular}{|c|c|c|c|c|c|c|c|c|c|c|c|c|}
\hline Probenahme & Lysimeter & $\begin{array}{c}\text { Tiefe } \\
\mathrm{cm}\end{array}$ & $\begin{array}{c}\text { Sieb- } \\
\text { Fraktion }\end{array}$ & $\mathrm{Na}$ & $\mathbf{K}$ & Mg & $\mathrm{Ca}$ & $\begin{array}{c}\mathrm{Fe} \\
\mathrm{mmol} \text { IE/kg }\end{array}$ & $\mathrm{Zn}$ & $\mathrm{HCO}_{3}$ & $\mathbf{N}_{\text {ges }}$ & $\mathrm{P}_{2} \mathrm{O}_{5}$ \\
\hline 18.04.1990 & 1 & $0-5$ & $<2 \mathrm{~mm}$ & 1,88 & 5,10 & 3,33 & 9,21 & 0,25 & 0,00 & 13,34 & 4,51 & 3966,43 \\
\hline 18.04.1990 & 1 & $0-5$ & $>2 \mathrm{~mm}$ & 1,43 & 4,02 & 2,71 & 8,00 & 0,12 & 0,00 & 13,54 & 3,72 & 2844,10 \\
\hline
\end{tabular}

Tabelle 13-30: Extinktion bei $400 \mathrm{~nm}$ in den Extrakten,

Lysimeter 1

\begin{tabular}{|c|c|c|c|c|c|c|c|c|c|}
\hline $\begin{array}{l}\text { Probenahme- } \\
\text { Datum }\end{array}$ & $\begin{array}{c}\text { Probenvor- } \\
\text { bereitung }\end{array}$ & $\begin{array}{c}\text { Extraktions- } \\
\text { verhältnis }\end{array}$ & Durchgang & $\begin{array}{c}\text { Tiefe in cm } \\
0-5\end{array}$ & $0-20$ & $0-30$ & $20-45$ & $30-60$ & $45-70$ \\
\hline 24.06.1988 & $\mathrm{t}-\mathrm{m}-\mathrm{s}<1,12 \mathrm{~mm}$ & $1: 2$ & 1. Extraktion & & 3,53 & & 5,84 & & 8,38 \\
\hline 24.06.1988 & $\mathrm{t}-\mathrm{m}-\mathrm{s}<1,12 \mathrm{~mm}$ & $1: 2$ & 2. Extraktion & & 1,90 & & 2,50 & & 4,50 \\
\hline 26.07.1988 & $\mathrm{t}-\mathrm{m}-\mathrm{s}<1,12 \mathrm{~mm}$ & $1: 2$ & 1. Extraktion & & 2,45 & & 5,40 & & \\
\hline 29.03.1990 & $\mathrm{t}-\mathrm{m}-\mathrm{s}<1,12 \mathrm{~mm}$ & $1: 2$ & 1. Extraktion & & & 0,40 & & 0,64 & \\
\hline 29.03.1990 & $f-w-s<2 m m$ & $1: 10$ & 1. Extraktion & & & 0,11 & & 0,20 & \\
\hline 29.03.1990 & $f-w-s<2 m m$ & $1: 10$ & 2. Extraktion & & & & & & \\
\hline 18.04.1990 & $\mathrm{f}-\mathrm{w}-\mathrm{s}<2 \mathrm{~mm}$ & $1: 10$ & 1. Extraktion & 0,12 & & & & & \\
\hline 18.04.1990 & $\mathrm{f}-\mathrm{w}-\mathrm{s}<2 \mathrm{~mm}$ & $1: 10$ & 2. Extraktion & 0,05 & & & & & \\
\hline 18.04.1990 & $f-w-s>2 m m$ & $1: 10$ & 1. Extraktion & 0,14 & & & & & \\
\hline 18.04.1990 & $f-w-s>2 m m$ & $1: 10$ & 2. Extraktion & 0,07 & & & & & \\
\hline
\end{tabular}


Tabelle 13-31: Extinktion bei $436 \mathrm{~nm}$ in den Extrakten, Lysimeter 1

\begin{tabular}{|c|c|c|c|c|c|c|c|c|c|}
\hline $\begin{array}{l}\text { Probenahme- } \\
\text { Datum }\end{array}$ & $\begin{array}{c}\text { Probenvor- } \\
\text { bereitung }\end{array}$ & $\begin{array}{c}\text { Extraktions- } \\
\text { verhältnis }\end{array}$ & Durchgang & \begin{tabular}{|c} 
Tiefe in $\mathrm{cm}$ \\
$0-5$ \\
\end{tabular} & $0-20$ & $0-30$ & $20-45$ & $30-60$ & $45-70$ \\
\hline 24.06.1988 & $\mathrm{t}-\mathrm{m}-\mathrm{s}<1,12 \mathrm{~mm}$ & $1: 2$ & 1. Extraktion & & 2,55 & & 3,90 & & 5,03 \\
\hline 24.06.1988 & $\mathrm{t}-\mathrm{m}-\mathrm{s}<1,12 \mathrm{~mm}$ & $1: 2$ & 2. Extraktion & & 1,10 & & 1,60 & & 3,10 \\
\hline 26.07.1988 & $\mathrm{t}-\mathrm{m}-\mathrm{s}<1,12 \mathrm{~mm}$ & $1: 2$ & 1. Extraktion & & 1,60 & & 3,50 & & \\
\hline 29.03.1990 & $\mathrm{t}-\mathrm{m}-\mathrm{s}<1,12 \mathrm{~mm}$ & $1: 2$ & 1. Extraktion & & & 0,24 & & 0,43 & \\
\hline 29.03.1990 & $\mathrm{f}-\mathrm{w}-\mathrm{s}<2 \mathrm{~mm}$ & $1: 10$ & 1. Extraktion & & & 0,07 & & 0,13 & \\
\hline 18.04.1990 & f-w-s $<2 \mathrm{~mm}$ & $1: 10$ & 1. Extraktion & 0,07 & & & & & \\
\hline 18.04.1990 & f-w-s $<2 \mathrm{~mm}$ & 1:10 & 2. Extraktion & 0,03 & & & & & \\
\hline 18.04.1990 & $f-w-s>2 m m$ & $1: 10$ & 1. Extraktion & 0,08 & & & & & \\
\hline 18.04.1990 & $f-w-s>2 m m$ & $1: 10$ & 2. Extraktion & 0,05 & & & & & \\
\hline
\end{tabular}

Tabelle 13-32: Qotient $\mathrm{E}_{400} / \mathrm{DOC} 10^{-3}$ in den Extrakten, Lysimeter 1

\begin{tabular}{|c|c|c|c|c|c|c|c|c|c|}
\hline $\begin{array}{l}\text { Probenahme- } \\
\text { Datum }\end{array}$ & $\begin{array}{l}\text { Probenvor- } \\
\text { bereitung }\end{array}$ & $\begin{array}{c}\text { Extraktions- } \\
\text { verhältnis }\end{array}$ & Durchgang & $\mid \begin{array}{c}\text { Tiefe in } \mathrm{cm} \\
0-5\end{array}$ & $0-20$ & $0-30$ & $20-45$ & $30-60$ & $45-70$ \\
\hline 24.06 .1988 & $\mathrm{t}-\mathrm{m}-\mathrm{s}<1,12 \mathrm{~mm}$ & 1:2 & 1. Extraktion & & 2,89 & & 4,11 & & 4,79 \\
\hline 24.06 .1988 & $\mathrm{t}-\mathrm{m}-\mathrm{s}<1,12 \mathrm{~mm}$ & $1: 2$ & 2. Extraktion & & 1,43 & & 1,39 & & 2,44 \\
\hline 26.07.1988 & $\mathrm{t}-\mathrm{m}-\mathrm{s}<1,12 \mathrm{~mm}$ & $1: 2$ & 1. Extraktion & & 3,36 & & 4,65 & & \\
\hline 29.03.1990 & $\mathrm{f}-\mathrm{w}-\mathrm{s}<2 \mathrm{~mm}$ & $1: 10$ & 1. Extraktion & & & 1,77 & & 1,63 & \\
\hline 18.04.1990 & $\mathrm{f}-\mathrm{w}-\mathrm{s}<2 \mathrm{~mm}$ & $1: 10$ & 1. Extraktion & 0,65 & & & & & \\
\hline 18.04.1990 & $\mathrm{f}-\mathrm{w}-\mathrm{s}<2 \mathrm{~mm}$ & $1: 10$ & 2. Extraktion & 0,83 & & & & & \\
\hline 18.04.1990 & $f-w-s>2 m m$ & $1: 10$ & 1. Extraktion & 0,99 & & & & & \\
\hline 18.04.1990 & $f-w-s>2 m m$ & $1: 10$ & 2. Extraktion & 0,67 & & & & & \\
\hline
\end{tabular}

Tabelle 13-33: Quotient $\mathrm{E}_{436} / \mathrm{DOC} 10^{-3}$ in den Extrakten, Lysimeter 1

\begin{tabular}{|c|c|c|c|c|c|c|c|c|c|}
\hline $\begin{array}{l}\text { Probenahme- } \\
\text { Datum }\end{array}$ & $\begin{array}{c}\text { Probenvor- } \\
\text { bereitung }\end{array}$ & $\begin{array}{c}\text { Extraktions- } \\
\text { verhältnis }\end{array}$ & Durchgang & $\begin{array}{c}\text { Tiefe in } \mathrm{cm} \\
0-5\end{array}$ & $0-20$ & $0-30$ & $20-45$ & $30-60$ & $45-70$ \\
\hline 24.06.1988 & $\mathrm{t}-\mathrm{m}-\mathrm{s}<1,12 \mathrm{~mm}$ & $1: 2$ & 1. Extraktion & & 2,09 & & 2,75 & & 2,88 \\
\hline 24.06.1988 & $\mathrm{t}-\mathrm{m}-\mathrm{s}<1,12 \mathrm{~mm}$ & $1: 2$ & 2. Extraktion & & 0,83 & & 0,89 & & 1,68 \\
\hline 26.07.1988 & $\mathrm{t}-\mathrm{m}-\mathrm{s}<1,12 \mathrm{~mm}$ & $1: 2$ & 1. Extraktion & & 2,19 & & 3,01 & & \\
\hline 29.03.1990 & $\mathrm{f}-\mathrm{w}-\mathrm{s}<2 \mathrm{~mm}$ & 1:10 & 1. Extraktion & & & 1,13 & & 1,07 & \\
\hline 18.04.1990 & $\mathrm{f}-\mathrm{w}-\mathrm{s}<2 \mathrm{~mm}$ & 1:10 & 1. Extraktion & 0,40 & & & & & \\
\hline 18.04.1990 & $f-w-s<2 m m$ & 1:10 & 2. Extraktion & 0,54 & & & & & \\
\hline 18.04.1990 & $f-w-s>2 m m$ & 1:10 & 1. Extraktion & 0,56 & & & & & \\
\hline 18.04 .1990 & $f-w-s>2 m m$ & 1:10 & 2. Extraktion & 0,45 & & & & & \\
\hline
\end{tabular}

Tabelle 13-34: Quotient $\mathrm{E}_{400} / \mathrm{E}_{436}$ in den Extrakten, Lysimeter 1

\begin{tabular}{|c|c|c|c|c|c|c|c|c|c|}
\hline $\begin{array}{l}\text { Probenahme- } \\
\text { Datum }\end{array}$ & $\begin{array}{c}\text { Probenvor- } \\
\text { bereitung }\end{array}$ & $\begin{array}{c}\text { Extraktions- } \\
\text { verhältnis }\end{array}$ & Durchgang & \begin{tabular}{|c} 
Tiefe in $\mathrm{cm}$ \\
$0-5$
\end{tabular} & $0-20$ & $0-30$ & $20-45$ & $30-60$ & $45-70$ \\
\hline 24.06 .1988 & $\mathrm{t}-\mathrm{m}-\mathrm{s}<1,12 \mathrm{~mm}$ & $1: 2$ & 1. Extraktion & & 1,38 & & 1,50 & & 1,67 \\
\hline 24.06.1988 & $\mathrm{t}-\mathrm{m}-\mathrm{s}<1,12 \mathrm{~mm}$ & $1: 2$ & 2. Extraktion & & 1,73 & & 1,56 & & 1,45 \\
\hline 26.07.1988 & $\mathrm{t}-\mathrm{m}-\mathrm{s}<1,12 \mathrm{~mm}$ & $1: 2$ & 1. Extraktion & & 1,53 & & 1,54 & & \\
\hline 29.03.1990 & $\mathrm{t}-\mathrm{m}-\mathrm{s}<1,12 \mathrm{~mm}$ & $1: 2$ & 1. Extraktion & & & 1,63 & & 1,50 & \\
\hline 29.03.1990 & $\mathrm{f}-\mathrm{w}-\mathrm{s}<2 \mathrm{~mm}$ & $1: 10$ & 1. Extraktion & & & 1,57 & & 1,52 & \\
\hline 18.04.1990 & $f-w-s<2 m m$ & $1: 10$ & 1. Extraktion & 1,62 & & & & & \\
\hline 18.04.1990 & $\mathrm{f}-\mathrm{w}-\mathrm{s}<2 \mathrm{~mm}$ & $1: 10$ & 2. Extraktion & 1,55 & & & & & \\
\hline 18.04.1990 & $f-w-s>2 m m$ & $1: 10$ & 1. Extraktion & 1,77 & & & & & \\
\hline 18.04.1990 & $f-w-s>2 m m$ & $1: 10$ & 2. Extraktion & 1,48 & & & & & \\
\hline
\end{tabular}


Tabelle 13-35: Extinktion bei $400 \mathrm{~nm}$ in den Extrakten,

Lysimeter 2

\begin{tabular}{|c|c|c|c|c|c|c|c|c|}
\hline $\begin{array}{l}\text { Probenahme- } \\
\text { Datum }\end{array}$ & $\begin{array}{c}\text { Probenvor- } \\
\text { bereitung }\end{array}$ & $\begin{array}{c}\text { Extraktions- } \\
\text { verhältnis }\end{array}$ & Durchgang & $\begin{array}{c}\text { Tiefe in cm } \\
0-20\end{array}$ & $0-30$ & $20-45$ & $30-60$ & $45-70$ \\
\hline 24.06.1988 & $\mathrm{t}-\mathrm{m}-\mathrm{s}<1,12 \mathrm{~mm}$ & $1: 2$ & 1. Extraktion & 3,38 & & 6,95 & & 6,88 \\
\hline 24.06 .1988 & $\mathrm{t}-\mathrm{m}-\mathrm{s}<1,12 \mathrm{~mm}$ & $1: 2$ & 2. Extraktion & 1,50 & & 3,10 & & 4,00 \\
\hline 26.07.1988 & $\mathrm{t}-\mathrm{m}-\mathrm{s}<1,12 \mathrm{~mm}$ & $1: 2$ & 1. Extraktion & 2,50 & & 7,45 & & \\
\hline 29.03.1990 & $\mathrm{t}-\mathrm{m}-\mathrm{s}<1,12 \mathrm{~mm}$ & $1: 2$ & 1. Extraktion & & 0,39 & & 0,72 & \\
\hline 29.03.1990 & $f-w-s<2 m m$ & $1: 10$ & 1. Extraktion & & 0,11 & & 0,24 & \\
\hline
\end{tabular}

Tabelle 13-36: Extinktion bei $436 \mathrm{~nm}$ in den Extrakten,

Lysimeter 2

\begin{tabular}{|c|c|c|c|c|c|c|c|c|}
\hline $\begin{array}{l}\text { Probenahme- } \\
\text { Datum }\end{array}$ & $\begin{array}{c}\text { Probenvor- } \\
\text { bereitung }\end{array}$ & $\begin{array}{l}\text { Extraktions- } \\
\text { verhältnis }\end{array}$ & Durchgang & $\begin{array}{c}\text { Tiefe in } \mathrm{cm} \\
0-20\end{array}$ & $0-30$ & $20-45$ & $30-60$ & $45-70$ \\
\hline 24.06 .1988 & $\mathrm{t}-\mathrm{m}-\mathrm{s}<1,12 \mathrm{~mm}$ & 1:2 & 1. Extraktion & 2,63 & & 4,90 & & 4,70 \\
\hline 24.06.1988 & $\mathrm{t}-\mathrm{m}-\mathrm{s}<1,12 \mathrm{~mm}$ & $1: 2$ & 2. Extraktion & 0,90 & & 1,90 & & 2,70 \\
\hline 26.07.1988 & $\mathrm{t}-\mathrm{m}-\mathrm{s}<1,12 \mathrm{~mm}$ & $1: 2$ & 1. Extraktion & 1,75 & & 4,95 & & \\
\hline 29.03.1990 & $\mathrm{t}-\mathrm{m}-\mathrm{s}<1,12 \mathrm{~mm}$ & $1: 2$ & 1. Extraktion & & 0,24 & & 0,60 & \\
\hline 29.03.1990 & $\mathrm{f}-\mathrm{w}-\mathrm{s}<2 \mathrm{~mm}$ & $1: 10$ & 1. Extraktion & & 0,07 & & 0,16 & \\
\hline
\end{tabular}

Tabelle 13-37: Qotient $\mathrm{E}_{400} / \mathrm{DOC} 10^{-3}$ in den Extrakten, Lysimeter 2

\begin{tabular}{|c|c|c|c|c|c|c|c|c|}
\hline $\begin{array}{l}\text { Probenahme- } \\
\text { Datum }\end{array}$ & $\begin{array}{c}\text { Probenvor- } \\
\text { bereitung }\end{array}$ & $\begin{array}{c}\text { Extraktions- } \\
\text { verhältnis }\end{array}$ & Durchgang & $\begin{array}{c}\text { Tiefe in cm } \\
0-20\end{array}$ & $0-30$ & $20-45$ & $30-60$ & $45-70$ \\
\hline 24.06.1988 & $\mathrm{t}-\mathrm{m}-\mathrm{s}<1,12 \mathrm{~mm}$ & 1:2 & 1. Extraktion & 5,66 & & 10,00 & & 7,99 \\
\hline 24.06.1988 & $\mathrm{t}-\mathrm{m}-\mathrm{s}<1,12 \mathrm{~mm}$ & 1:2 & 2. Extraktion & 2,42 & & 3,64 & & 4,69 \\
\hline 26.07.1988 & $\mathrm{t}-\mathrm{m}-\mathrm{s}<1,12 \mathrm{~mm}$ & $1: 2$ & 1. Extraktion & 3,19 & & 5,16 & & \\
\hline 29.03.1990 & $\mathrm{t}-\mathrm{m}-\mathrm{s}<1,12 \mathrm{~mm}$ & $1: 2$ & 1. Extraktion & & & & & \\
\hline 29.03 .1990 & $\mathrm{f}-\mathrm{w}-\mathrm{s}<2 \mathrm{~mm}$ & 1:10 & 1. Extraktion & & 1,69 & & 1,95 & \\
\hline
\end{tabular}

Tabelle 13-38: Quotient $E_{436} / D O C 10^{-3}$ in den Extrakten,

Lysimeter 2

\begin{tabular}{|c|c|c|c|c|c|c|c|c|}
\hline $\begin{array}{l}\text { Probenahme- } \\
\text { Datum }\end{array}$ & $\begin{array}{l}\text { Probenvor- } \\
\text { bereitung }\end{array}$ & $\begin{array}{c}\text { Extraktions- } \\
\text { verhältnis }\end{array}$ & Durchgang & $\begin{array}{c}\text { Tiefe in } \mathrm{cm} \\
0-20\end{array}$ & $0-30$ & $20-45$ & $30-60$ & $45-70$ \\
\hline 24.06.1988 & $\mathrm{t}-\mathrm{m}-\mathrm{s}<1,12 \mathrm{~mm}$ & $1: 2$ & 1. Extraktion & 4,40 & & 7,05 & & 5,47 \\
\hline 24.06.1988 & $\mathrm{t}-\mathrm{m}-\mathrm{s}<1,12 \mathrm{~mm}$ & $1: 2$ & 2. Extraktion & 1,45 & & 2,23 & & 3,16 \\
\hline 26.07.1988 & $\mathrm{t}-\mathrm{m}-\mathrm{s}<1,12 \mathrm{~mm}$ & $1: 2$ & 1. Extraktion & 2,24 & & 3,43 & & \\
\hline 29.03.1990 & $\mathrm{t}-\mathrm{m}-\mathrm{s}<1,12 \mathrm{~mm}$ & $1: 2$ & 1. Extraktion & & & & & \\
\hline 29.03.1990 & f-w-s $<2 \mathrm{~mm}$ & $1: 10$ & 1. Extraktion & & 1,13 & & 1,31 & \\
\hline
\end{tabular}

Tabelle 13-39: Quotient $\mathrm{E}_{400} / \mathrm{E}_{436}$ in den Extrakten, Lysimeter 2

\begin{tabular}{|c|c|c|c|c|c|c|c|c|}
\hline $\begin{array}{l}\text { Probenahme- } \\
\text { Datum }\end{array}$ & $\begin{array}{l}\text { Probenvor- } \\
\text { bereitung }\end{array}$ & $\begin{array}{c}\text { Extraktions- } \\
\text { verhältnis }\end{array}$ & Durchgang & $\begin{array}{l}\text { Tiefe in } \mathrm{cm} \\
0-20\end{array}$ & $0-30$ & $20-45$ & $30-60$ & $45-70$ \\
\hline 24.06.1988 & $\mathrm{t}-\mathrm{m}-\mathrm{s}<1,12 \mathrm{~mm}$ & $1: 2$ & 1. Extraktion & 1,29 & & 1,42 & & 1,46 \\
\hline 24.06.1988 & $\mathrm{t}-\mathrm{m}-\mathrm{s}<1,12 \mathrm{~mm}$ & $1: 2$ & 2. Extraktion & 1,67 & & 1,63 & & 1,48 \\
\hline 26.07.1988 & $\mathrm{t}-\mathrm{m}-\mathrm{s}<1,12 \mathrm{~mm}$ & $1: 2$ & 1. Extraktion & 1,43 & & 1,51 & & \\
\hline 29.03.1990 & $\mathrm{t}-\mathrm{m}-\mathrm{s}<1,12 \mathrm{~mm}$ & $1: 2$ & 1. Extraktion & & 1,60 & & 1,20 & \\
\hline 29.03.1990 & $\mathrm{f}-\mathrm{w}-\mathrm{s}<2 \mathrm{~mm}$ & $1: 10$ & 1. Extraktion & & 1,50 & & 1,48 & \\
\hline
\end{tabular}


Tabelle 13-40: Extinktion bei $400 \mathrm{~nm}$ in den Extrakten, Kleinlysimeter 3-8 (Tiefe: $0-20 \mathrm{~cm}$ )

\begin{tabular}{|c|c|c|c|c|c|c|c|c|c|}
\hline $\begin{array}{l}\text { Probenahme- } \\
\text { Datum }\end{array}$ & $\begin{array}{l}\text { Probenvor- } \\
\text { bereitung }\end{array}$ & $\begin{array}{c}\text { Extraktions- } \\
\text { verhältnis }\end{array}$ & & \begin{tabular}{|c} 
Lysimeter \\
8
\end{tabular} & 6 & 5 & 4 & 3 & 7 \\
\hline 24.06.1988 & $\mathrm{t}-\mathrm{m}-\mathrm{s}<1,12 \mathrm{~mm}$ & $1: 2$ & 1. Extraktion & 3,30 & 3,00 & 2,28 & 1,50 & 1,13 & 0,11 \\
\hline 24.06.1988 & $\mathrm{t}-\mathrm{m}-\mathrm{s}<1,12 \mathrm{~mm}$ & $1: 2$ & 2. Extraktion & 1,40 & 0,99 & 0,94 & 0,59 & 0,39 & 0,19 \\
\hline 02.04.1990 & $\mathrm{t}-\mathrm{m}-\mathrm{s}<1,12 \mathrm{~mm}$ & $1: 2$ & 1. Extraktion & 0,42 & 0,35 & 0,31 & 0,34 & 0,15 & \\
\hline 02.04.1990 & f-w-s $<2 \mathrm{~mm}$ & $1: 10$ & 1. Extraktion & 0,07 & 0,11 & 0,08 & 0,07 & & \\
\hline 02.04.1990 & $f-w-s<2 m m$ & $1: 10$ & 2. Extraktion & 0,05 & & & & & \\
\hline
\end{tabular}

Tabelle 13-41: Extinktion bei $436 \mathrm{~nm}$ in den Extrakten,

Kleinlysimeter $3-8$ (Tiefe: $0-20 \mathrm{~cm}$ )

\begin{tabular}{|c|c|c|c|c|c|c|c|c|c|}
\hline $\begin{array}{l}\text { Probenahme- } \\
\text { Datum }\end{array}$ & $\begin{array}{l}\text { Probenvor- } \\
\text { bereitung }\end{array}$ & $\begin{array}{c}\text { Extraktions- } \\
\text { verhältnis }\end{array}$ & & \begin{tabular}{|} 
Lysimeter \\
8
\end{tabular} & 6 & 5 & 4 & 3 & 7 \\
\hline 24.06.1988 & $\mathrm{t}-\mathrm{m}-\mathrm{s}<1,12 \mathrm{~mm}$ & $1: 2$ & 1. Extraktion & 2,00 & 1,60 & 1,40 & 0,98 & 0,70 & 0,09 \\
\hline 24.06 .1988 & $\mathrm{t}-\mathrm{m}-\mathrm{s}<1,12 \mathrm{~mm}$ & $1: 2$ & 2. Extraktion & 1,05 & 0,55 & 0,56 & 0,28 & 0,28 & 0,14 \\
\hline 02.04.1990 & $\mathrm{t}-\mathrm{m}-\mathrm{s}<1,12 \mathrm{~mm}$ & $1: 2$ & 1. Extraktion & 0,28 & 0,22 & 0,22 & 0,27 & 0,10 & \\
\hline 02.04.1990 & $\mathrm{f}-\mathrm{w}-\mathrm{s}<2 \mathrm{~mm}$ & $1: 10$ & 1. Extraktion & 0,05 & 0,07 & 0,06 & 0,05 & & \\
\hline 02.04.1990 & $\mathrm{f}-\mathrm{w}-\mathrm{s}<2 \mathrm{~mm}$ & 1:10 & 2. Extraktion & 0,03 & & & & & \\
\hline
\end{tabular}

Tabelle 13-42: Qotient $\mathrm{E}_{400} / \mathrm{DOC} 10^{-3}$ in den Extrakten, Kleinlysimeter $3-8$ (Tiefe: $0-20 \mathrm{~cm}$ )

\begin{tabular}{|c|c|c|c|c|c|c|c|c|c|}
\hline $\begin{array}{l}\text { Probenahme- } \\
\text { Datum }\end{array}$ & $\begin{array}{l}\text { Probenvor- } \\
\text { bereitung }\end{array}$ & $\begin{array}{c}\text { Extraktions- } \\
\text { verhältnis }\end{array}$ & & \begin{tabular}{|} 
Lysimeter \\
8
\end{tabular} & 6 & 5 & 4 & 3 & 7 \\
\hline 24.06.1988 & $\mathrm{t}-\mathrm{m}-\mathrm{s}<1,12 \mathrm{~mm}$ & $1: 2$ & 1. Extraktion & 5,50 & 6,19 & 2,60 & 5,53 & 2,82 & 1,07 \\
\hline 24.06.1988 & $\mathrm{t}-\mathrm{m}-\mathrm{s}<1,12 \mathrm{~mm}$ & $1: 2$ & 2. Extraktion & 2,73 & 2,21 & 2,59 & 2,57 & 2,21 & 3,64 \\
\hline 02.04.1990 & $\mathrm{t}-\mathrm{m}-\mathrm{s}<1,12 \mathrm{~mm}$ & $1: 2$ & 1. Extraktion & 0,57 & 0,70 & 0,66 & 0,87 & 0,66 & \\
\hline 02.04.1990 & f-w-s $<2 \mathrm{~mm}$ & $1: 10$ & 1. Extraktion & 1,72 & 1,71 & 1,73 & 1,67 & & \\
\hline 02.04 .1990 & $f-w-s<2 m m$ & $1: 10$ & 2. Extraktion & 1,68 & & & & & \\
\hline
\end{tabular}

Tabelle 13-43: Quotient $\mathrm{E}_{436} / \mathrm{DOC} 10^{-3}$ in den Extrakten, Kleinlysimeter $3-8$ (Tiefe: $0-20 \mathrm{~cm}$ )

\begin{tabular}{l|c|c|c|cccccc}
$\begin{array}{l}\text { Probenahme- } \\
\text { Datum }\end{array}$ & $\begin{array}{c}\text { Probenvor- } \\
\text { bereitung }\end{array}$ & $\begin{array}{c}\text { Extraktions- } \\
\text { verhältnis }\end{array}$ & & $\mathbf{8}$ & $\mathbf{6}$ & $\mathbf{5}$ & $\mathbf{4}$ & $\mathbf{3}$ & $\mathbf{7}$ \\
\hline & & & & & & & & & \\
$\mathbf{2 4 . 0 6 . 1 9 8 8}$ & $\mathbf{t}-\mathbf{m}-\mathbf{s}<\mathbf{1 , 1 2} \mathbf{~ m m}$ & $1: 2$ & 1. Extraktion & 3,33 & 3,30 & 1,60 & 3,61 & 1,75 & 0,87 \\
$\mathbf{2 4 . 0 6 . 1 9 8 8}$ & $\mathbf{t}-\mathbf{m}-\mathbf{s}<\mathbf{1 , 1 2} \mathbf{~ m m}$ & $1: 2$ & 2. Extraktion & 2,05 & 1,23 & 1,54 & 1,22 & 1,59 & 2,68 \\
$\mathbf{0 2 . 0 4 . 1 9 9 0}$ & $\mathbf{t}-\mathbf{m}-\mathbf{s}<\mathbf{1 , 1 2} \mathbf{~ m m}$ & $1: 2$ & 1. Extraktion & 0,38 & 0,45 & 0,47 & 0,68 & 0,43 & \\
$\mathbf{0 2 . 0 4 . 1 9 9 0}$ & $\mathbf{f}-\mathbf{w}-\mathbf{s}<\mathbf{2 m m}$ & $1: 10$ & 1. Extraktion & 1,21 & 1,14 & 1,17 & 1,08 & & \\
$\mathbf{0 2 . 0 4 . 1 9 9 0}$ & $\mathbf{f}-\mathbf{w}-\mathbf{s}<\mathbf{2 m m}$ & $1: 10$ & 2. Extraktion & 1,16 & & & &
\end{tabular}

Tabelle 13-44: Quotient $\mathrm{E}_{400} / \mathrm{E}_{436}$ in den Extrakten, Kleinlysimeter $3-8$ (Tiefe: $0-20 \mathrm{~cm}$ )

\begin{tabular}{|c|c|c|c|c|c|c|c|c|c|}
\hline $\begin{array}{l}\text { Probenahme- } \\
\text { Datum }\end{array}$ & $\begin{array}{l}\text { Probenvor- } \\
\text { bereitung }\end{array}$ & $\begin{array}{c}\text { Extraktions- } \\
\text { verhältnis }\end{array}$ & & \begin{tabular}{|c} 
Lysimeter \\
8 \\
\end{tabular} & 6 & 5 & 4 & 3 & 7 \\
\hline 24.06.1988 & $\mathrm{t}-\mathrm{m}-\mathrm{s}<1,12 \mathrm{~mm}$ & $1: 2$ & 1. Extraktion & 1,65 & 1,88 & 1,63 & 1,53 & 1,61 & 1,22 \\
\hline 24.06.1988 & $\mathrm{t}-\mathrm{m}-\mathrm{s}<1,12 \mathrm{~mm}$ & $1: 2$ & 2. Extraktion & 1,33 & 1,80 & 1,68 & 2,11 & 1,39 & 1,36 \\
\hline 02.04 .1990 & $\mathrm{t}-\mathrm{m}-\mathrm{s}<1,12 \mathrm{~mm}$ & $1: 2$ & 1. Extraktion & 1,47 & 1,56 & 1,40 & 1,28 & 1,52 & \\
\hline 02.04 .1990 & $\mathrm{f}-\mathrm{w}-\mathrm{s}<2 \mathrm{~mm}$ & $1: 10$ & 1. Extraktion & 1,42 & 1,50 & 1,48 & 1,54 & & \\
\hline 02.04 .1990 & f-w-s $<2 \mathrm{~mm}$ & $1: 10$ & 2. Extraktion & 1,45 & & & & & \\
\hline
\end{tabular}


Tabelle 13-45: Mischungsanteile Kompost/Löss berechnet für die Fraktion < $2 \mathrm{~mm}$ in $\mathbf{k g ~ T M}$, Lysimeter 3 - 8

\begin{tabular}{l|cccccc} 
& $\mathbf{7}$ & $\mathbf{3}$ & $\begin{array}{c}\mathbf{4} \\
\text { Lysimeter }\end{array}$ & \multicolumn{5}{|c}{$\mathbf{k g}<\mathbf{2} \mathbf{~ m m}$} & $\mathbf{6}$ & $\mathbf{8}$ \\
\hline Kompost & 0 & 26,8 & 45,94 & 53,62 & 89,78 & 100 \\
Löß & 100 & 73,2 & 54,06 & 46,38 & 10,22 & 0
\end{tabular}

Tabelle 13-46: Anhand der Mischungsanteile berechnete lösliche Ca-Gehalte in den Extrakten in $\mathrm{mg} / \mathrm{kg} \mathrm{TM}<1,12 \mathrm{~mm}$ bzw. 2 mm, Lysimeter 3 - 8

\begin{tabular}{|c|c|c|c|c|c|c|c|c|c|}
\hline $\begin{array}{l}\text { Probenahme- } \\
\text { Datum }\end{array}$ & $\begin{array}{c}\text { Probenvor- } \\
\text { bereitung }\end{array}$ & $\begin{array}{c}\text { Extraktions- } \\
\text { verhältnis }\end{array}$ & Durchgang & $\begin{array}{c}\text { Lysimeter } \\
7 \\
\end{array}$ & 3 & 4 & 5 & 6 & 8 \\
\hline 30.06 .1987 & $\mathrm{t}-\mathrm{m}-\mathrm{s}<1,12 \mathrm{~mm}$ & $1: 2$ & 1. Extraktion & 34,50 & 86,22 & 123,16 & 137,99 & 207,78 & 227,50 \\
\hline 28.07.1987 & $\mathrm{t}-\mathrm{m}-\mathrm{s}<1,12 \mathrm{~mm}$ & $1: 2$ & 1. Extraktion & 23,50 & 73,62 & 109,41 & 123,77 & 191,39 & 210,50 \\
\hline 24.06.1988 & $\mathrm{t}-\mathrm{m}-\mathrm{s}<1,12 \mathrm{~mm}$ & $1: 2$ & 1. Extraktion & 139,02 & 196,03 & 236,74 & 253,08 & 329,99 & 351,73 \\
\hline 02.04.1990 & $\mathrm{t}-\mathrm{m}-\mathrm{s}<1,12 \mathrm{~mm}$ & $1: 2$ & 1. Extraktion & 77,45 & 158,89 & 217,05 & 240,39 & 350,27 & 381,33 \\
\hline 02.04.1990 & $\mathrm{f}-\mathrm{w}-\mathrm{s}<2 \mathrm{~mm}$ & $1: 10$ & 1. Extraktion & 0,00 & 35,93 & 61,59 & 71,88 & 120,36 & 134,06 \\
\hline 02.04.1990 & $f-w-s<2 m m$ & $1: 10$ & 2. Extraktion & 0,00 & 39,52 & 67,74 & 79,07 & 132,39 & 147,46 \\
\hline
\end{tabular}

Tabelle 13-47: Anhand der Mischungsanteile berechnete lösliche Na-Gehalte in den Extrakten in $\mathrm{mg} / \mathrm{kg} \mathrm{TM}<1,12 \mathrm{~mm}$ bzw. 2 mm, Lysimeter 3 - 8

\begin{tabular}{|c|c|c|c|c|c|c|c|c|c|}
\hline $\begin{array}{l}\text { Probenahme- } \\
\text { Datum }\end{array}$ & $\begin{array}{l}\text { Probenvor- } \\
\text { bereitung }\end{array}$ & $\begin{array}{c}\text { Extraktions- } \\
\text { verhältnis }\end{array}$ & Durchgang & $\begin{array}{c}\text { Lysimeter } \\
7 \\
\end{array}$ & 3 & 4 & 5 & 6 & 8 \\
\hline 30.06.1987 & $\mathrm{t}-\mathrm{m}-\mathrm{s}<1,12 \mathrm{~mm}$ & $1: 2$ & 1. Extraktion & 43,00 & 75,70 & 99,05 & 108,42 & 152,53 & 165,00 \\
\hline 28.07.1987 & $\mathrm{t}-\mathrm{m}-\mathrm{s}<1,12 \mathrm{~mm}$ & $1: 2$ & 1. Extraktion & 23,00 & 68,16 & 100,41 & 113,35 & 174,28 & 191,50 \\
\hline 24.06.1988 & $\mathrm{t}-\mathrm{m}-\mathrm{s}<1,12 \mathrm{~mm}$ & $1: 2$ & 1. Extraktion & 27,38 & 36,09 & 42,31 & 44,80 & 56,55 & 59,87 \\
\hline 02.04.1990 & $\mathrm{t}-\mathrm{m}-\mathrm{s}<1,12 \mathrm{~mm}$ & $1: 2$ & 1. Extraktion & 11,15 & 16,22 & 19,83 & 21,28 & 28,12 & 30,05 \\
\hline 02.04.1990 & $\mathrm{f}$-w-s $<2 \mathrm{~mm}$ & 1:10 & 1. Extraktion & 0,00 & 11,73 & 20,10 & 23,46 & 39,29 & 43,76 \\
\hline 02.04.1990 & $\mathrm{f}-\mathrm{w}-\mathrm{s}<2 \mathrm{~mm}$ & $1: 10$ & 2. Extraktion & 0,00 & 8,27 & 14,17 & 16,54 & 27,70 & 30,85 \\
\hline
\end{tabular}

Tabelle 13-48: Anhand der Mischungsanteile berechnete Iösliche K-Gehalte in den Extrakten in $\mathrm{mg} / \mathrm{kg} \mathrm{TM}<1,12 \mathrm{~mm}$ bzw. 2 mm, Lysimeter 3 - 8

\begin{tabular}{|c|c|c|c|c|c|c|c|c|c|}
\hline $\begin{array}{l}\text { Probenahme- } \\
\text { Datum }\end{array}$ & $\begin{array}{c}\text { Probenvor- } \\
\text { bereitung }\end{array}$ & $\begin{array}{c}\text { Extraktions- } \\
\text { verhältnis }\end{array}$ & Durchgang & $\begin{array}{c}\text { Lysimeter } \\
7 \\
\end{array}$ & 3 & 4 & 5 & 6 & 8 \\
\hline 30.06 .1987 & $\mathrm{t}-\mathrm{m}-\mathrm{s}<1,12 \mathrm{~mm}$ & $1: 2$ & 1. Extraktion & 22,00 & 334,22 & 557,20 & 646,67 & 1067,94 & 1187,00 \\
\hline 28.07.1987 & $\mathrm{t}-\mathrm{m}-\mathrm{s}<1,12 \mathrm{~mm}$ & $1: 2$ & 1. Extraktion & 0,00 & 286,22 & 490,64 & 572,66 & 958,85 & 1068,00 \\
\hline 24.06.1988 & $\mathrm{t}-\mathrm{m}-\mathrm{s}<1,12 \mathrm{~mm}$ & $1: 2$ & 1. Extraktion & 11,59 & 111,78 & 183,33 & 212,04 & 347,21 & 385,42 \\
\hline 02.04 .1990 & $\mathrm{t}-\mathrm{m}-\mathrm{s}<1,12 \mathrm{~mm}$ & $1: 2$ & 1. Extraktion & 4,34 & 102,32 & 172,30 & 200,38 & 332,58 & 369,95 \\
\hline 02.04 .1990 & $\mathrm{f}-\mathrm{w}-\mathrm{s}<2 \mathrm{~mm}$ & $1: 10$ & 1. Extraktion & 0,00 & 103,96 & 178,21 & 208,00 & 348,27 & 387,91 \\
\hline 02.04 .1990 & $f-w-s<2 m m$ & $1: 10$ & 2. Extraktion & 0,00 & 60,46 & 103,64 & 120,97 & 202,54 & 225,60 \\
\hline
\end{tabular}

Tabelle 13-49: Anhand der Mischungsanteile berechnete lösliche Mg-Gehalte in den Extrakten in $\mathrm{mg} / \mathrm{kg} \mathrm{TM}<1,12$ mm bzw. 2 mm, Lysimeter 3 - 8

\begin{tabular}{|c|c|c|c|c|c|c|c|c|c|}
\hline $\begin{array}{l}\text { Probenahme- } \\
\text { Datum }\end{array}$ & $\begin{array}{c}\text { Probenvor- } \\
\text { bereitung }\end{array}$ & $\begin{array}{c}\text { Extraktions- } \\
\text { verhältnis }\end{array}$ & Durchgang & $\begin{array}{c}\text { Lysimeter } \\
7 \\
\end{array}$ & 3 & 4 & 5 & 6 & 8 \\
\hline 30.06 .1987 & $\mathrm{t}-\mathrm{m}-\mathrm{s}<1,12 \mathrm{~mm}$ & $1: 2$ & 1. Extraktion & 15,00 & 61,23 & 94,25 & 107,49 & 169,87 & 187,50 \\
\hline 28.07.1987 & $\mathrm{t}-\mathrm{m}-\mathrm{s}<1,12 \mathrm{~mm}$ & $1: 2$ & 1. Extraktion & 17,50 & 44,03 & 62,98 & 70,58 & 106,38 & 116,50 \\
\hline 24.06.1988 & $\mathrm{t}-\mathrm{m}-\mathrm{s}<1,12 \mathrm{~mm}$ & $1: 2$ & 1. Extraktion & 7,37 & 32,14 & 49,82 & 56,92 & 90,34 & 99,78 \\
\hline 02.04.1990 & $\mathrm{t}-\mathrm{m}-\mathrm{s}<1,12 \mathrm{~mm}$ & $1: 2$ & 1. Extraktion & 5,57 & 30,37 & 48,07 & 55,18 & 88,63 & 98,09 \\
\hline 02.04.1990 & $\mathrm{f}-\mathrm{w}-\mathrm{s}<2 \mathrm{~mm}$ & 1:10 & 1. Extraktion & 0,00 & 8,88 & 15,23 & 17,78 & 29,76 & 33,15 \\
\hline 02.04.1990 & $\mathrm{f}-\mathrm{w}-\mathrm{s}<2 \mathrm{~mm}$ & $1: 10$ & 2. Extraktion & 0,00 & 8,15 & 13,97 & 16,31 & 27,31 & 30,42 \\
\hline
\end{tabular}


Tabelle 13-50: Anhand der Mischungsanteile berechnete Leitfähigkeitswerte in $\mathrm{mS} / \mathrm{cm}$ in den Extrakten,

Lysimeter 3 - 8

\begin{tabular}{|c|c|c|c|c|c|c|c|c|c|}
\hline $\begin{array}{l}\text { Probenahme- } \\
\text { Datum }\end{array}$ & $\begin{array}{c}\text { Probenvor- } \\
\text { bereitung }\end{array}$ & $\begin{array}{c}\text { Extraktions- } \\
\text { verhältnis }\end{array}$ & Durchgang & $\begin{array}{c}\text { Lysimeter } \\
7 \\
\end{array}$ & 3 & 4 & 5 & 6 & 8 \\
\hline 30.06 .1987 & $\mathrm{t}-\mathrm{m}-\mathrm{s}<1,12 \mathrm{~mm}$ & 1:2 & 1. Extraktion & 0,50 & 1,33 & 1,92 & 2,16 & 3,28 & 3,60 \\
\hline 28.07.1987 & $\mathrm{t}-\mathrm{m}-\mathrm{s}<1,12 \mathrm{~mm}$ & 1:2 & 1. Extraktion & 0,40 & 1,15 & 1,69 & 1,90 & 2,91 & 3,20 \\
\hline 24.06.1988 & $\mathrm{t}-\mathrm{m}-\mathrm{s}<1,12 \mathrm{~mm}$ & $1: 2$ & 1. Extraktion & 0,44 & 0,78 & 1,02 & 1,12 & 1,57 & 1,70 \\
\hline
\end{tabular}

Tabelle 13-51: Anhand der Mischungsanteile berechnete lösliche DOC-Gehalte in den Extrakten in $\mathrm{mg} / \mathrm{kg}$ TM $<1,12 \mathrm{~mm}$ bzw. $2 \mathrm{~mm}$, Lysimeter 3 - 8

\begin{tabular}{|c|c|c|c|c|c|c|c|c|c|}
\hline $\begin{array}{l}\text { Probenahme- } \\
\text { Datum }\end{array}$ & $\begin{array}{c}\text { Probenvor- } \\
\text { bereitung }\end{array}$ & $\begin{array}{c}\text { Extraktions- } \\
\text { verhältnis }\end{array}$ & Durchgang & $\begin{array}{c}\text { Lysimeter } \\
7 \\
\end{array}$ & 3 & 4 & 5 & 6 & 8 \\
\hline 24.06.1988 & $\mathrm{t}-\mathrm{m}-\mathrm{s}<1,12 \mathrm{~mm}$ & $1: 2$ & 1. Extraktion & 214,33 & 477,68 & 665,75 & 741,22 & 1096,54 & 1196,97 \\
\hline 02.04 .1990 & $\mathrm{t}-\mathrm{m}-\mathrm{s}<1,12 \mathrm{~mm}$ & $1: 2$ & 1. Extraktion & 0,00 & 406,63 & 697,03 & 813,56 & 1362,21 & 1517,27 \\
\hline 02.04 .1990 & $\mathrm{f}-\mathrm{w}-\mathrm{s}<2 \mathrm{~mm}$ & $1: 10$ & 1. Extraktion & 0,00 & 128,60 & 220,45 & 257,30 & 430,82 & 479,86 \\
\hline 02.04 .1990 & $f-w-s<2 m m$ & $1: 10$ & 2. Extraktion & 0,00 & 61,86 & 106,04 & 123,77 & 207,24 & 230,83 \\
\hline
\end{tabular}

Tabelle 13-52: Anhand der Mischungsanteile berechnete lösliche $\mathrm{HCO}_{3}$-Gehalte in den Extrakten in $\mathrm{mg} / \mathrm{kg}$ TM $<1,12$ mm bzw. 2 mm, Lysimeter 3 - 8

\begin{tabular}{|c|c|c|c|c|c|c|c|c|c|}
\hline $\begin{array}{l}\text { Probenahme- } \\
\text { Datum }\end{array}$ & $\begin{array}{c}\text { Probenvor- } \\
\text { bereitung }\end{array}$ & $\begin{array}{c}\text { Extraktions- } \\
\text { verhältnis }\end{array}$ & Durchgang & $\begin{array}{c}\text { Lysimeter } \\
7 \\
\end{array}$ & 3 & 4 & 5 & 6 & 8 \\
\hline 24.06.1988 & $\mathrm{t}-\mathrm{m}-\mathrm{s}<1,12 \mathrm{~mm}$ & $1: 2$ & 1. Extraktion & 372,63 & 563,13 & 699,18 & 753,77 & 1010,80 & 1083,44 \\
\hline 02.04.1990 & $\mathrm{t}-\mathrm{m}-\mathrm{s}<1,12 \mathrm{~mm}$ & $1: 2$ & 1. Extraktion & 295,73 & 650,77 & 904,32 & 1006,07 & 1485,10 & 1620,49 \\
\hline 02.04.1990 & $f-w-s>2 m m$ & 1:10 & 1. Extraktion & 0,00 & 166,22 & 284,92 & 332,56 & 556,82 & 620,21 \\
\hline 02.04.1990 & $f-w-s>2 m m$ & 1:10 & 2. Extraktion & 0,00 & 187,70 & 321,75 & 375,54 & 628,79 & 700,37 \\
\hline
\end{tabular}

Tabelle 13-53: Anhand der Mischungsanteile berechnete lösliche $\mathrm{SO}_{4}$-Gehalte in den Extrakten in $\mathrm{mg} / \mathrm{kg} \mathrm{TM}$ $<1,12 \mathrm{~mm}$ bzw. $2 \mathrm{~mm}$, Lysimeter 3 - 8

\begin{tabular}{|c|c|c|c|c|c|c|c|c|c|}
\hline $\begin{array}{l}\text { Probenahme- } \\
\text { Datum }\end{array}$ & $\begin{array}{c}\text { Probenvor- } \\
\text { bereitung }\end{array}$ & $\begin{array}{c}\text { Extraktions- } \\
\text { verhältnis }\end{array}$ & Durchgang & $\begin{array}{c}\text { Lysimeter } \\
7 \\
\end{array}$ & 3 & 4 & 5 & 6 & 8 \\
\hline 30.06 .1987 & $\mathrm{t}-\mathrm{m}-\mathrm{s}<1,12 \mathrm{~mm}$ & $1: 2$ & 1. Extraktion & 0,00 & 130,38 & 223,50 & 260,86 & 436,78 & 486,50 \\
\hline 28.07.1987 & $\mathrm{t}-\mathrm{m}-\mathrm{s}<1,12 \mathrm{~mm}$ & $1: 2$ & 1. Extraktion & 72,50 & 156,79 & 216,98 & 241,13 & 354,86 & 387,00 \\
\hline 24.06.1988 & $\mathrm{t}-\mathrm{m}-\mathrm{s}<1,12 \mathrm{~mm}$ & 1:2 & 1. Extraktion & 78,13 & 105,51 & 125,07 & 132,92 & 169,87 & 180,31 \\
\hline
\end{tabular}

Tabelle 13-54: Anhand der Mischungsanteile berechnete lösliche $\mathrm{NO}_{3}-\mathrm{N}-$ Gehalte in den Extrakten in $\mathrm{mg} / \mathrm{kg} \mathrm{TM}$ $<1,12 \mathrm{~mm}$ bzw. $2 \mathrm{~mm}$, Lysimeter 3 - 8

\begin{tabular}{|c|c|c|c|c|c|c|c|c|c|}
\hline $\begin{array}{l}\text { Probenahme- } \\
\text { Datum }\end{array}$ & $\begin{array}{c}\text { Probenvor- } \\
\text { bereitung }\end{array}$ & $\begin{array}{c}\text { Extraktions- } \\
\text { verhältnis }\end{array}$ & Durchgang & $\begin{array}{c}\text { Lysimeter } \\
7 \\
\end{array}$ & 3 & 4 & 5 & 6 & 8 \\
\hline 24.06.1988 & $\mathrm{t}-\mathrm{m}-\mathrm{s}<1,12 \mathrm{~mm}$ & $1: 2$ & 1. Extraktion & 5,27 & 16,21 & 24,03 & 27,16 & 41,93 & 46,10 \\
\hline 24.06 .1988 & $\mathrm{t}-\mathrm{m}-\mathrm{s}<1,12 \mathrm{~mm}$ & $1: 2$ & 2. Extraktion & 26,54 & 25,42 & 24,62 & 24,29 & 22,78 & 22,35 \\
\hline
\end{tabular}


Tabelle 13-55: Anhand der Mischungsanteile berechnete lösliche $\mathrm{Cl}-$ Gehalte in den Extrakten in $\mathrm{mg} / \mathrm{kg}$ TM

$<1,12 \mathrm{~mm}$ bzw. $2 \mathrm{~mm}$, Lysimeter 3 - 8

\begin{tabular}{|c|c|c|c|c|c|c|c|c|c|}
\hline $\begin{array}{l}\text { Probenahme- } \\
\text { Datum }\end{array}$ & $\begin{array}{c}\text { Probenvor- } \\
\text { bereitung }\end{array}$ & $\begin{array}{c}\text { Extraktions- } \\
\text { verhältnis }\end{array}$ & Durchgang & $\begin{array}{c}\text { Lysimeter } \\
7 \\
\end{array}$ & 3 & 4 & 5 & 6 & 8 \\
\hline 30.06 .1987 & $\mathrm{t}-\mathrm{m}-\mathrm{s}<1,12 \mathrm{~mm}$ & $1: 2$ & 1. Extraktion & 0,00 & 12,06 & 20,67 & 24,13 & 40,40 & 45,00 \\
\hline 28.07.1987 & $\mathrm{t}-\mathrm{m}-\mathrm{s}<1,12 \mathrm{~mm}$ & $1: 2$ & 1. Extraktion & 0,00 & 12,33 & 21,13 & 24,67 & 41,30 & 46,00 \\
\hline 24.06.1988 & $\mathrm{t}-\mathrm{m}-\mathrm{s}<1,12 \mathrm{~mm}$ & $1: 2$ & 1. Extraktion & 12,15 & 15,78 & 18,37 & 19,42 & 24,32 & 25,70 \\
\hline 24.06.1988 & $\mathrm{t}-\mathrm{m}-\mathrm{s}<1,12 \mathrm{~mm}$ & $1: 2$ & 2. Extraktion & 15,69 & 19,25 & 21,80 & 22,82 & 27,62 & 28,98 \\
\hline
\end{tabular}

Tabelle 13-56: Anhand der Mischungsanteile berechnete lösliche $\mathrm{PO}_{4}$-Gehalte in den Extrakten in $\mathrm{mg} / \mathrm{kg}$ TM $<1,12 \mathrm{~mm}$ bzw. $2 \mathrm{~mm}$, Lysimeter 3 - 8

\begin{tabular}{|c|c|c|c|c|c|c|c|c|c|}
\hline $\begin{array}{l}\text { Probenahme- } \\
\text { Datum }\end{array}$ & $\begin{array}{c}\text { Probenvor- } \\
\text { bereitung }\end{array}$ & $\begin{array}{c}\text { Extraktions- } \\
\text { verhältnis }\end{array}$ & Durchgang & $\begin{array}{c}\text { Lysimeter } \\
7 \\
\end{array}$ & 3 & 4 & 5 & 6 & 8 \\
\hline 28.07.1987 & $\mathrm{t}-\mathrm{m}-\mathrm{s}<1,12 \mathrm{~mm}$ & $1: 2$ & 1. Extraktion & 1,50 & 15,89 & 26,17 & 30,29 & 49,71 & 55,20 \\
\hline 02.04.1990 & $\mathrm{t}-\mathrm{m}-\mathrm{s}<1,12 \mathrm{~mm}$ & $1: 2$ & 1. Extraktion & 0,00 & 6,68 & 11,45 & 13,37 & 22,38 & 24,93 \\
\hline 02.04.1990 & $f-w-s>2 m m$ & 1:10 & 1. Extraktion & 0,00 & 16,94 & 29,04 & 33,90 & 56,76 & 63,22 \\
\hline
\end{tabular}

Tabelle 13-57: Stoffdaten der Sickerwasseruntersuchung Mai 1987 bis Mai 1990, Lysimeter 1

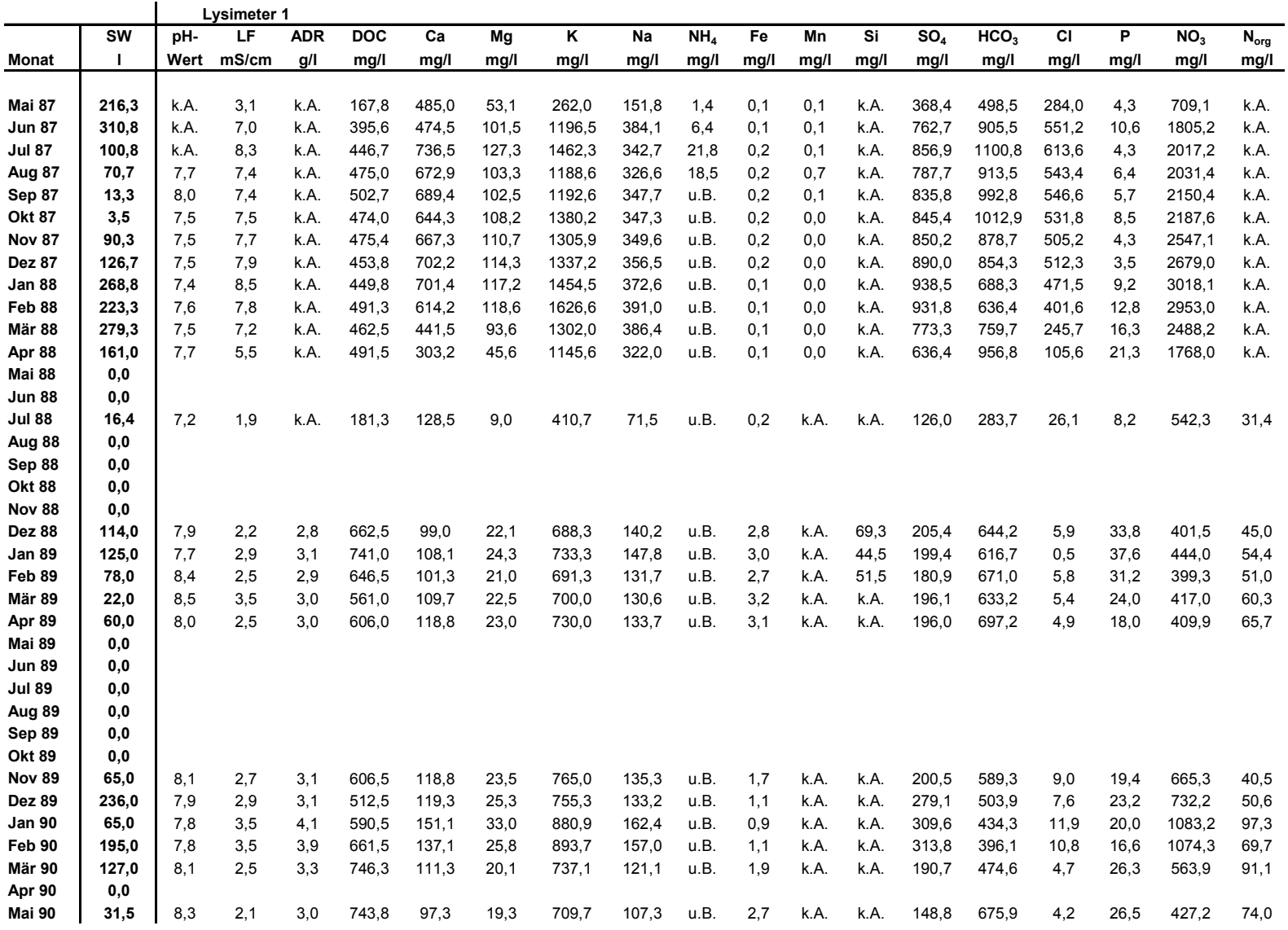


Tabelle 13-58: Stoffdaten der Sickerwasseruntersuchung Mai 1987 bis April 1990, Lysimeter 2

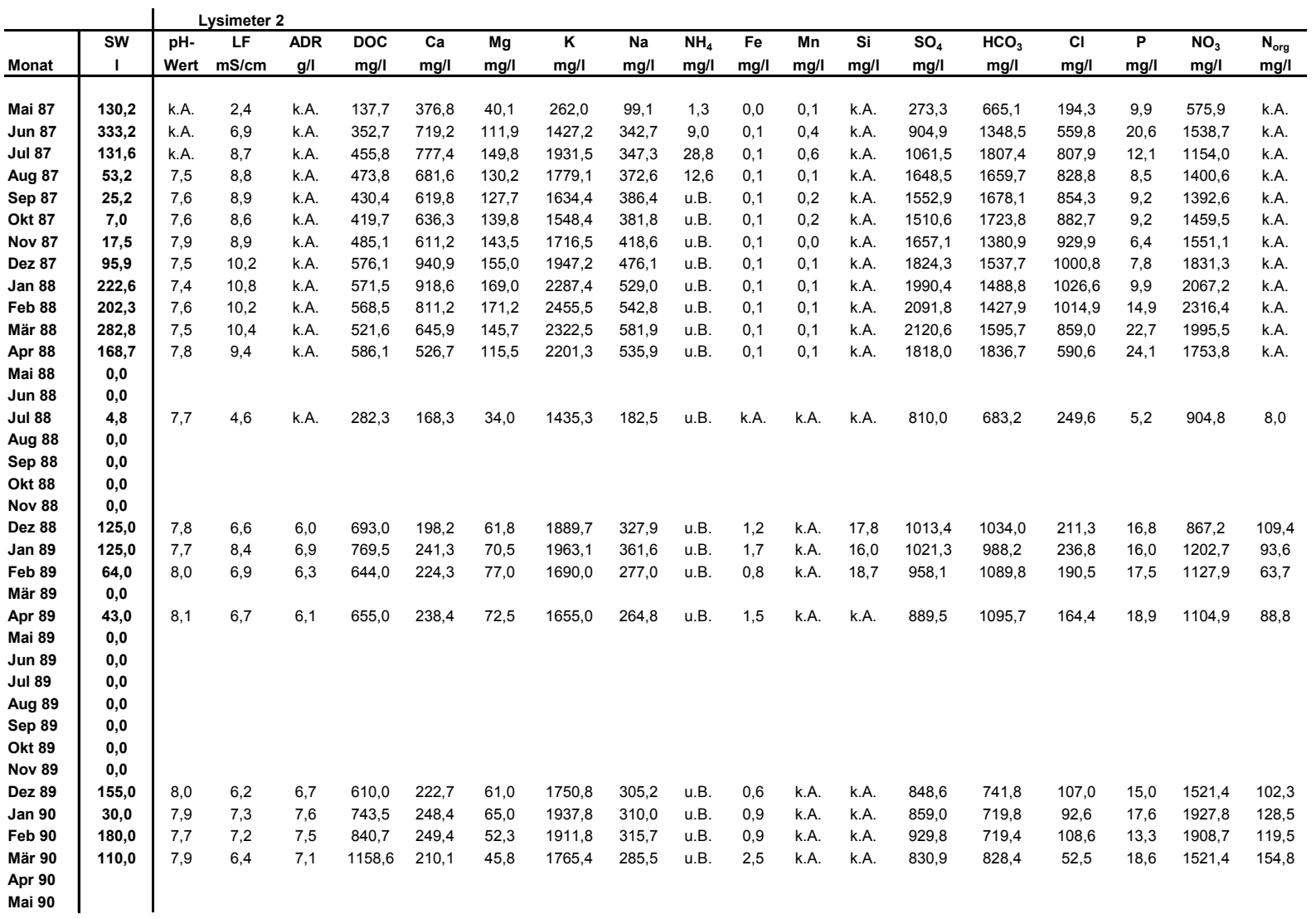

Tabelle 13-59: Stoffdaten der Sickerwasseruntersuchung

Januar 1991, Lysimeter 1 und 2

\begin{tabular}{|c|c|c|c|c|c|c|c|c|c|c|c|c|c|c|}
\hline Lysimeter & $\begin{array}{l}\text { SW- } \\
\text { Probe }\end{array}$ & $\begin{array}{c}\text { Entnahme } \\
\text { Datum }\end{array}$ & $\begin{array}{l}\mathrm{pH}- \\
\text { Wert }\end{array}$ & $\begin{array}{c}\text { ADR } \\
g / l\end{array}$ & $\begin{array}{l}\mathrm{DOC} \\
\mathrm{mg} / \mathrm{l}\end{array}$ & $\begin{array}{c}\mathrm{Ca} \\
\mathrm{mg} / \mathrm{l}\end{array}$ & $\begin{array}{c}\mathrm{Mg} \\
\mathrm{mg} / \mathrm{l}\end{array}$ & $\begin{array}{c}\mathrm{K} \\
\mathrm{mg} / \mathrm{l}\end{array}$ & $\begin{array}{c}\mathrm{Na} \\
\mathrm{mg} / \mathrm{l}\end{array}$ & $\begin{array}{l}\mathrm{SO}_{4} \\
\mathrm{mg} / \mathrm{l}\end{array}$ & $\begin{array}{c}\mathrm{HCO}_{3} \\
\mathrm{mg} / \mathrm{l}\end{array}$ & $\begin{array}{c}\mathrm{Cl} \\
\mathrm{mg} / \mathrm{l}\end{array}$ & $\begin{array}{l}\mathrm{NO}_{3} \\
\mathrm{mg} / \mathrm{l}\end{array}$ & $\begin{array}{l}\text { Norg } \\
\mathrm{mg} / \mathrm{l}\end{array}$ \\
\hline \multirow[t]{2}{*}{1} & Nov/Dez 91 & 8.1 .91 & 7,6 & 4,0 & 422,5 & 174,0 & 40,0 & 1086,5 & 166,4 & 279,6 & 439,2 & 6,4 & 1420,2 & 50,1 \\
\hline & Jan 91 & 9.1 .91 & 7,5 & 3,3 & 397,5 & 133,0 & 33,3 & 945,1 & 130,0 & 181,9 & 392,8 & 7,7 & 1089,4 & 24,9 \\
\hline \multicolumn{2}{|c|}{ nur Kies- und Sandschicht } & 11.1.91 & 7,9 & 3,1 & 395,0 & 126,0 & 30,8 & 900,0 & 123,5 & 139,1 & 374,5 & 7,5 & 1000,2 & 25,8 \\
\hline \multirow[t]{2}{*}{2} & Nov/Dez 91 & 8.1 .91 & 7,7 & 6,9 & 695,0 & 152,0 & 45,0 & 1416,6 & 235,6 & 322,0 & 779,6 & 26,7 & 1438,2 & 29,4 \\
\hline & Jan 91 & 9.1 .91 & 7,7 & 4,2 & 715,0 & 151,0 & 43,0 & 1412,5 & 230,8 & 286,5 & 766,2 & 27,1 & 1336,6 & 38,4 \\
\hline
\end{tabular}

Tabelle 13-60: Verwendete Stoffdaten für den Sickerwasser-

Austrag 4. Jahr, Lysimeter 1 und 2

\begin{tabular}{|c|c|c|c|c|c|c|c|c|c|c|c|c|c|c|c|c|c|}
\hline Lysimeter & $\begin{array}{c}\text { sw } \\
\text { I }\end{array}$ & DOC & $\mathrm{Ca}$ & $\mathbf{M g}$ & $\mathrm{K}$ & $\mathrm{Na}$ & $\mathrm{Fe}$ & $\mathrm{SO}_{4}$ & $\begin{array}{c}\mathrm{HCO}_{3} \\
\mathrm{mg} / \mathrm{l}\end{array}$ & $\mathrm{HCO}_{3}-\mathrm{C}$ & $\mathrm{Cl}$ & $\mathbf{P}$ & $\mathrm{NO}_{3}$ & $\mathrm{NO}_{3}-\mathrm{N}$ & $\mathrm{NH}_{4}-\mathrm{N}$ & $\mathbf{N}_{\min }$ & $\mathbf{N}_{\text {org }}$ \\
\hline 1 & 658,0 & 422,5 & 174,0 & 40,0 & 1086,5 & 166,4 & 0,8 & 279,6 & 439,2 & 86,5 & 6,4 & 21,1 & 1420,2 & 318,0 & 0,0 & 318,0 & 50,1 \\
\hline 2 & 511,0 & 705,0 & 151,5 & 44,0 & 1414,5 & 233,2 & 0,5 & 304,2 & 772,9 & 152,2 & 26,9 & 16,2 & 1387,4 & 310,7 & 0,0 & 310,7 & 33,9 \\
\hline
\end{tabular}


Tabelle 13-61: Stoffdaten der Sickerwasseruntersuchung Mai 1987 bis April 1990, Lysimeter 8

\begin{tabular}{|c|c|c|c|c|c|c|c|c|c|c|c|c|c|c|c|c|c|}
\hline Monat & $\begin{array}{c}\text { SW } \\
\text { I }\end{array}$ & $\begin{array}{l}\mathrm{r} 8 \\
\mathrm{pH}- \\
\text { Wert }\end{array}$ & $\begin{array}{c}\mathrm{LF} \\
\mathrm{mS} / \mathrm{cm}\end{array}$ & $\begin{array}{c}\text { ADR } \\
\text { g/l }\end{array}$ & $\begin{array}{l}\mathrm{DOC} \\
\mathrm{mg} / \mathrm{l}\end{array}$ & $\begin{array}{c}\mathrm{Ca} \\
\mathrm{mg} / \mathrm{l}\end{array}$ & $\begin{array}{c}\mathrm{Mg} \\
\mathrm{mg} / \mathrm{l}\end{array}$ & $\begin{array}{c}\mathrm{K} \\
\mathrm{mg} / \mathrm{l}\end{array}$ & $\begin{array}{c}\mathrm{Na} \\
\mathrm{mg} / \mathrm{l}\end{array}$ & $\begin{array}{c}\mathrm{Fe} \\
\mathrm{mg} / \mathrm{l}\end{array}$ & $\begin{array}{c}\mathrm{Si} \\
\mathrm{mg} / \mathrm{l}\end{array}$ & $\begin{array}{l}\mathrm{SO}_{4} \\
\mathrm{mg} / \mathrm{l}\end{array}$ & $\begin{array}{c}\mathrm{HCO}_{3} \\
\mathrm{mg} / \mathrm{l}\end{array}$ & $\begin{array}{c}\mathrm{Cl} \\
\mathrm{mg} / \mathrm{l}\end{array}$ & $\begin{array}{c}P \\
\mathrm{mg} / \mathrm{l}\end{array}$ & $\begin{array}{l}\mathrm{NO3} \\
\mathrm{mg} / \mathrm{l}\end{array}$ & $\begin{array}{l}\mathbf{N}_{\text {org }} \\
\mathrm{mg} / \mathrm{l}\end{array}$ \\
\hline Mai 87 & 5,7 & k.A. & 6,6 & & 343,7 & 563,9 & 102,3 & 1088,9 & 431,9 & k.A. & k.A. & 1083,1 & 322,8 & 636,3 & 5,0 & 1309,2 & k.A. \\
\hline Jun 87 & 28,1 & k.A. & 6,3 & & 492,6 & 499,0 & 86,1 & 1526,1 & 449,7 & k.A. & k.A. & 1017,8 & 1040,4 & 672,8 & 18,5 & 702,2 & k.A. \\
\hline Jul 87 & 0,3 & k.A. & k.A. & & 513,0 & 58,9 & 16,1 & 400,0 & 58,4 & k.A. & k.A. & 99,8 & 311,2 & 65,9 & 18,5 & 3,0 & k.A. \\
\hline Aug 87 & 0,6 & k.A. & 4,3 & & 187,6 & 18,4 & 4,5 & 57,9 & 18,4 & k.A. & k.A. & 3,8 & 15,9 & 22,3 & 13,5 & 38,8 & k.A. \\
\hline Sep 87 & 0,5 & 8,1 & 3,9 & & 547,0 & 200,4 & 37,7 & 715,5 & 266,8 & k.A. & k.A. & 393,9 & 683,4 & 294,2 & 4,3 & 346,4 & k.A. \\
\hline Okt 87 & 0,0 & 8,3 & 4,0 & & 580,5 & 236,5 & 45,0 & 707,7 & 257,6 & k.A. & k.A. & 590,8 & 829,9 & 251,7 & 6,4 & 250,8 & k.A. \\
\hline Nov 87 & 0,5 & 8,3 & 5,3 & & 995,1 & 290,6 & 65,7 & 991,2 & 373,8 & k.A. & k.A. & 1709,9 & 878,7 & 265,9 & 5,7 & 197,1 & k.A. \\
\hline Dez 87 & 6,0 & 8,0 & 5,2 & & 1302,9 & 256,5 & 74,8 & 1026,4 & 395,6 & k.A. & k.A. & 626,8 & 799,4 & 232,6 & 5,7 & 346,4 & k.A. \\
\hline Jan 88 & 19,1 & 7,9 & 4,1 & & 1099,0 & 240,5 & 55,0 & 866,5 & 321,1 & k.A. & k.A. & 275,7 & 1003,2 & 85,8 & 8,5 & 288,0 & k.A. \\
\hline Feb 88 & 11,3 & 8,0 & 3,3 & & 1001,7 & 172,9 & 39,3 & 707,7 & 238,1 & k.A. & k.A. & 119,1 & 890,9 & 36,5 & 11,4 & 459,9 & k.A. \\
\hline Mär 88 & 31,1 & 8,0 & 2,1 & & 597,9 & 94,8 & 24,1 & 519,2 & 156,4 & k.A. & k.A. & 162,3 & 801,2 & 13,1 & 17,0 & 277,3 & k.A. \\
\hline Apr 88 & 11,4 & 8,3 & 1,4 & & 441,3 & 64,1 & 17,0 & 443,8 & 116,2 & k.A. & k.A. & 50,4 & 826,8 & u. B. & 20,6 & 191,1 & k.A. \\
\hline Mai 88 & 0,0 & & & & & & & & & & & & & & & & \\
\hline Jun 88 & 0,0 & & & & & & & & & & & & & & & & \\
\hline Jul 88 & 0,0 & & & & & & & & & & & & & & & & \\
\hline Aug 88 & 0,0 & & & & & & & & & & & & & & & & \\
\hline Sep 88 & 0,0 & & & & & & & & & & & & & & & & \\
\hline Okt 88 & 0,0 & & & & & & & & & & & & & & & & \\
\hline Nov 88 & 0,0 & & & & & & & & & & & & & & & & \\
\hline Dez 88 & 40,0 & 8,1 & 1,5 & 1,7 & 458,5 & 54,9 & 16,4 & 424,5 & 94,2 & 3,0 & 12,5 & 144,1 & 508,7 & 0,4 & 17,4 & 226,5 & 36,3 \\
\hline Jan 89 & 4,0 & 8,3 & 1,2 & 1,5 & 427,0 & 41,1 & 15,0 & 360,8 & 80,2 & 4,0 & 8,8 & 68,2 & 484,3 & u.B. & 20,5 & 144,2 & 28,7 \\
\hline Feb 89 & 2,0 & 8,6 & 1,3 & k.A. & 400,0 & 49,3 & 16,5 & 400,0 & 74,4 & 1,7 & 16,0 & 24,5 & 532,0 & 0,3 & 7,9 & 78,9 & 32,7 \\
\hline Mär 89 & 0,0 & & & & & & & & & & & & & & & & \\
\hline Apr 89 & 8,0 & 8,4 & 1,5 & 1,6 & 312,0 & 57,6 & 17,0 & 425,0 & 68,7 & 3,0 & k.A. & 85,0 & 672,2 & u.B. & 28,1 & 65,3 & 33,2 \\
\hline Mai 89 & 0,0 & & & & & & & & & & & & & & & & \\
\hline Jun 89 & 0,0 & & & & & & & & & & & & & & & & \\
\hline Jul 89 & 0,0 & & & & & & & & & & & & & & & & \\
\hline Aug 89 & 0,0 & & & & & & & & & & & & & & & & \\
\hline Sep 89 & 0,0 & & & & & & & & & & & & & & & & \\
\hline Okt 89 & 0,0 & & & & & & & & & & & & & & & & \\
\hline Nov 89 & 0,0 & & & & & & & & & & & & & & & & \\
\hline Dez 89 & 6,0 & 8,0 & 1,6 & 1,6 & 303,0 & 77,8 & 22,0 & 286,8 & 67,2 & 0,5 & k.A. & 186,5 & 419,7 & 5,5 & 15,2 & 199,2 & 27,3 \\
\hline Jan 90 & 14,0 & 8,2 & 1,6 & 1,6 & 312,5 & 62,1 & 19,0 & 280,3 & 58,6 & 0,8 & k.A. & 148,2 & 419,7 & 4,7 & 11,6 & 164,7 & 30,4 \\
\hline Feb 90 & 8,0 & 8,1 & 1,4 & 1,3 & 237,5 & 50,8 & 11,8 & 260,9 & 46,7 & 0,6 & k.A. & 78,9 & 329,4 & 0,8 & 10,0 & 237,2 & 14,5 \\
\hline Mär 90 & 21,6 & 8,2 & 1,1 & 1,2 & 240,9 & 39,0 & 10,8 & 253,1 & 35,0 & 0,6 & k.A. & 45,5 & 359,9 & u.B. & 12,3 & 185,6 & 21,1 \\
\hline Apr 90 & 0,0 & & & & & & & & & & & & & & & & \\
\hline
\end{tabular}


Tabelle 13-62: Stoffdaten der Sickerwasseruntersuchung Mai 1987 bis April 1990, Lysimeter 6

\begin{tabular}{|c|c|c|c|c|c|c|c|c|c|c|c|c|c|c|c|c|c|}
\hline Monat & $\begin{array}{c}\text { SW } \\
\text { I }\end{array}$ & $\begin{array}{c}\text { pH- } \\
\text { Wert }\end{array}$ & $\begin{array}{c}\mathrm{LF} \\
\mathrm{mS} / \mathrm{cm}\end{array}$ & $\begin{array}{c}\text { ADR } \\
\text { g/l }\end{array}$ & $\begin{array}{l}\mathrm{DOC} \\
\mathrm{mg} / \mathrm{l}\end{array}$ & $\begin{array}{c}\mathrm{Ca} \\
\mathrm{mg} / \mathrm{l}\end{array}$ & $\begin{array}{c}\mathrm{Mg} \\
\mathrm{mg} / \mathrm{l}\end{array}$ & $\begin{array}{c}\mathrm{K} \\
\mathrm{mg} / \mathrm{l}\end{array}$ & $\begin{array}{c}\mathrm{Na} \\
\mathrm{mg} / \mathrm{l}\end{array}$ & $\begin{array}{c}\mathrm{Fe} \\
\mathrm{mg} / \mathrm{l}\end{array}$ & $\begin{array}{c}\mathrm{Si} \\
\mathrm{mg} / \mathrm{l}\end{array}$ & $\begin{array}{l}\mathrm{SO}_{4} \\
\mathrm{mg} / \mathrm{l}\end{array}$ & $\begin{array}{c}\mathrm{HCO}_{3} \\
\mathrm{mg} / \mathrm{l}\end{array}$ & $\begin{array}{c}\mathrm{Cl} \\
\mathrm{mg} / \mathrm{l}\end{array}$ & $\begin{array}{c}P \\
\mathrm{mg} / \mathrm{l}\end{array}$ & $\begin{array}{l}\mathrm{NO3} \\
\mathrm{mg} / \mathrm{l}\end{array}$ & $\begin{array}{l}\mathrm{N}_{\text {org }} \\
\mathrm{mg} / \mathrm{l}\end{array}$ \\
\hline Mai 87 & 44,3 & k.A. & 7,0 & & 387,5 & 433,9 & 97,6 & 1445,1 & 454,3 & k.A. & k.A. & 836,7 & 432,6 & 582,1 & 5,0 & 1359,1 & k.A. \\
\hline Jun 87 & 32,8 & k.A. & 7,3 & & 436,5 & 361,9 & 68,3 & 1776,3 & 471,5 & k.A. & k.A. & 1015,9 & 760,9 & 547,7 & 12,1 & 1363,0 & k.A. \\
\hline Jul 87 & 0,5 & k.A. & k.A. & & 461,8 & 74,5 & 17,3 & 373,4 & 59,6 & k.A. & k.A. & 86,0 & 396,6 & 503,0 & 2,1 & 20,9 & k.A. \\
\hline Aug 87 & 4,5 & k.A. & 6,6 & & 208,5 & 56,1 & 12,2 & 260,4 & 75,2 & k.A. & k.A. & 58,6 & 24,4 & 74,4 & 2,1 & 59,7 & k.A. \\
\hline Sep 87 & 2,0 & 8,2 & 2,8 & & 677,5 & 160,3 & 26,8 & 48,9 & 209,3 & k.A. & k.A. & 124,9 & 659,0 & 127,6 & 6,4 & 334,5 & k.A. \\
\hline Okt 87 & 0,0 & & & & & & & & & & & & & & & & \\
\hline Nov 87 & 0,7 & 8,2 & 3,2 & & 1520,0 & 270,5 & 48,6 & 582,6 & 303,6 & k.A. & k.A. & 562,0 & 854,3 & 60,3 & 7,1 & 131,4 & k.A. \\
\hline Dez 87 & 17,6 & 8,1 & 3,1 & & 1534,7 & 237,1 & 45,8 & 579,9 & 274,4 & k.A. & k.A. & 538,0 & 758,5 & 48,2 & 13,5 & 191,1 & k.A. \\
\hline Jan 88 & 32,8 & 8,0 & 3,2 & & 1429,1 & 212,0 & 44,7 & 642,0 & 270,5 & k.A. & k.A. & 342,5 & 764,0 & 42,5 & 14,9 & 428,7 & k.A. \\
\hline Feb 88 & 29,6 & 7,9 & 2,6 & & 989,1 & 140,9 & 30,8 & 542,7 & 210,5 & k.A. & k.A. & 184,0 & 662,1 & 34,7 & 16,3 & 564,4 & k.A. \\
\hline Mär 88 & 55,2 & 7,8 & 1,8 & & 728,9 & 93,2 & 20,1 & 455,5 & 146,1 & k.A. & k.A. & 121,5 & 668,2 & 11,7 & 28,4 & 482,5 & k.A. \\
\hline Apr 88 & 3,7 & 8,2 & 1,4 & & 470,9 & 72,1 & 12,2 & 402,7 & 115,0 & k.A. & k.A. & 43,2 & 726,1 & u.B. & 25,6 & 271,7 & k.A. \\
\hline Mai 88 & 0,0 & & & & & & & & & & & & & & & & \\
\hline Jun 88 & 0,0 & & & & & & & & & & & & & & & & \\
\hline Jul 88 & 0,0 & & & & & & & & & & & & & & & & \\
\hline Aug 88 & 0,0 & & & & & & & & & & & & & & & & \\
\hline Sep 88 & 0,0 & & & & & & & & & & & & & & & & \\
\hline Okt 88 & 0,0 & & & & & & & & & & & & & & & & \\
\hline Nov 88 & 0,0 & & & & & & & & & & & & & & & & \\
\hline Dez 88 & 31,0 & 8,0 & 1,6 & 1,5 & 357,5 & 58,5 & 16,5 & 393,3 & 100,3 & 2,8 & 11,5 & 89,0 & 392,2 & 2,8 & 15,5 & 290,3 & 22,9 \\
\hline Jan 89 & 12,0 & 8,1 & 1,0 & 1,2 & 336,0 & 36,3 & 16,1 & 285,8 & 65,9 & 2,5 & 10,7 & 23,6 & 392,8 & 0,3 & 21,1 & 147,6 & 16,9 \\
\hline Feb 89 & 7,0 & 8,3 & 1,2 & 1,5 & 363,0 & 47,9 & 12,0 & 350,0 & 65,6 & 2,7 & 18,7 & 61,8 & 372,0 & 3,7 & 25,6 & 192,4 & 26,7 \\
\hline Mär 89 & 18,0 & 7,9 & 1,5 & 1,7 & 353,0 & 57,0 & 12,5 & 400,0 & 70,7 & 2,3 & k.A. & 35,8 & 364,8 & u.B. & 23,2 & 309,3 & 32,4 \\
\hline Apr 89 & 12,0 & 8,3 & 1,5 & 1,6 & 289,0 & 54,2 & 14,5 & 430,0 & 70,1 & 1,3 & k.A. & 119,5 & 370,9 & 0,4 & 16,0 & 319,5 & 33,0 \\
\hline Mai 89 & 0,0 & & & & & & & & & & & & & & & & \\
\hline Jun 89 & 0,0 & & & & & & & & & & & & & & & & \\
\hline Jul 89 & 0,0 & & & & & & & & & & & & & & & & \\
\hline Aug 89 & 0,0 & & & & & & & & & & & & & & & & \\
\hline Sep 89 & 0,0 & & & & & & & & & & & & & & & & \\
\hline Okt 89 & 0,0 & & & & & & & & & & & & & & & & \\
\hline Nov 89 & 10,0 & 8,3 & 1,5 & 1,4 & 180,5 & 56,5 & 16,8 & 289,1 & 45,9 & 0,2 & k.A. & 102,6 & 292,8 & 4,9 & 13,4 & 295,2 & 36,7 \\
\hline Dez 89 & 31,5 & 8,0 & 1,5 & 1,4 & 214,8 & 75,5 & 23,3 & 271,4 & 55,0 & 0,3 & k.A. & 135,4 & 306,2 & 6,2 & 13,1 & 343,4 & 21,5 \\
\hline Jan 90 & 16,0 & 8,1 & 1,9 & 1,8 & 264,0 & 82,8 & 28,0 & 297,8 & 64,5 & 0,4 & k.A. & 153,5 & 396,5 & 4,7 & 13,4 & 288,8 & 45,4 \\
\hline Feb 90 & 17,0 & 8,2 & 1,6 & 1,6 & 235,0 & 69,4 & 15,0 & 283,3 & 64,5 & 0,4 & k.A. & 129,8 & 347,7 & 4,3 & 11,0 & 316,1 & 26,9 \\
\hline Mär 90 & 21,2 & 8,2 & 1,3 & 1,1 & 226,1 & 55,6 & 14,1 & 257,2 & 37,0 & 0,6 & k.A. & 63,1 & 330,6 & 4,5 & 12,9 & 247,4 & 2,4 \\
\hline Apr 90 & 0,0 & & & & & & & & & & & & & & & & \\
\hline
\end{tabular}


Tabelle 13-63: Stoffdaten der Sickerwasseruntersuchung Mai 1987 bis April 1990, Lysimeter 5

\begin{tabular}{|c|c|c|c|c|c|c|c|c|c|c|c|c|c|c|c|c|c|}
\hline Monat & $\begin{array}{c}\text { SW } \\
\text { I }\end{array}$ & $\begin{array}{c}\text { pH- } \\
\text { Wert }\end{array}$ & $\begin{array}{c}\mathrm{LF} \\
\mathrm{mS} / \mathrm{cm}\end{array}$ & $\begin{array}{c}\text { ADR } \\
\text { g/l }\end{array}$ & $\begin{array}{l}\mathrm{DOC} \\
\mathrm{mg} / \mathrm{l}\end{array}$ & $\begin{array}{c}\mathrm{Ca} \\
\mathrm{mg} / \mathrm{l}\end{array}$ & $\begin{array}{c}\mathrm{Mg} \\
\mathrm{mg} / \mathrm{l}\end{array}$ & $\begin{array}{c}\mathrm{K} \\
\mathrm{mg} / \mathrm{l}\end{array}$ & $\begin{array}{c}\mathrm{Na} \\
\mathrm{mg} / \mathrm{l}\end{array}$ & $\begin{array}{c}\mathrm{Fe} \\
\mathrm{mg} / \mathrm{l}\end{array}$ & $\begin{array}{c}\mathrm{Si} \\
\mathrm{mg} / \mathrm{l}\end{array}$ & $\begin{array}{l}\mathrm{SO}_{4} \\
\mathrm{mg} / \mathrm{l}\end{array}$ & $\begin{array}{c}\mathrm{HCO}_{3} \\
\mathrm{mg} / \mathrm{l}\end{array}$ & $\begin{array}{c}\mathrm{Cl} \\
\mathrm{mg} / \mathrm{l}\end{array}$ & $\begin{array}{c}P \\
\mathrm{mg} / \mathrm{l}\end{array}$ & $\begin{array}{l}\mathrm{NO3} \\
\mathrm{mg} / \mathrm{l}\end{array}$ & $\begin{array}{l}\mathrm{N}_{\text {org }} \\
\mathrm{mg} / \mathrm{l}\end{array}$ \\
\hline Mai 87 & 32,3 & k.A. & 7,7 & k.A. & 266,6 & 658,1 & 159,9 & 1367,3 & 519,6 & k.A. & k.A. & 1537,0 & 267,3 & 282,4 & 3,5 & 1364,7 & k.A. \\
\hline Jun 87 & 27,6 & k.A. & 9,3 & k.A. & 331,0 & 735,1 & 176,3 & 1701,6 & 616,6 & k.A. & k.A. & 1776,7 & 433,9 & 457,0 & 2,8 & 1768,3 & k.A. \\
\hline Jul 87 & 0,0 & & & & & & & & & & & & & & & & \\
\hline Aug 87 & 0,4 & k.A. & & k.A. & 78,8 & 77,8 & 16,4 & 99,7 & 38,4 & k.A. & k.A. & 95,6 & 59,8 & 61,3 & 13,5 & 100,3 & k.A. \\
\hline Sep 87 & 2,6 & 8,1 & 2,5 & k.A. & 461,8 & 136,3 & 19,5 & 3394,9 & 181,7 & k.A. & k.A. & 134,5 & 518,7 & 145,3 & 6,4 & 310,6 & k.A. \\
\hline Okt 87 & 0,0 & & & & & & & & & & & & & & & & \\
\hline Nov 87 & 4,0 & 8,1 & 4,7 & k.A. & 641,8 & 390,8 & 87,6 & 645,2 & 411,7 & k.A. & k.A. & 1762,8 & 628,5 & 262,3 & 2,8 & 286,7 & k.A. \\
\hline Dez 87 & 18,1 & 8,1 & 5,0 & k.A. & 637,3 & 386,8 & 96,4 & 715,5 & 435,4 & k.A. & k.A. & 1777,2 & 581,5 & 286,1 & 3,5 & 300,3 & k.A. \\
\hline Jan 88 & 34,9 & 7,9 & 4,9 & k.A. & 664,3 & 340,3 & 89,3 & 718,7 & 425,5 & k.A. & k.A. & 1544,7 & 577,2 & 229,0 & 5,0 & 451,3 & k.A. \\
\hline Feb 88 & 21,4 & 8,0 & 2,8 & k.A. & 602,2 & 162,9 & 42,0 & 482,9 & 284,1 & k.A. & k.A. & 235,4 & 579,7 & 59,6 & 7,8 & 539,2 & k.A. \\
\hline Mär 88 & 46,7 & 8,1 & 1,7 & k.A. & 395,1 & 84,8 & 25,3 & 361,7 & 200,8 & k.A. & k.A. & 182,5 & 555,3 & 9,9 & 9,9 & 346,4 & k.A. \\
\hline Apr 88 & 18,7 & 8,5 & 1,7 & k.A. & 339,7 & 66,1 & 19,5 & 316,7 & 157,1 & k.A. & k.A. & 72,0 & 654,7 & u. B & 12,8 & 155,3 & k.A. \\
\hline Mai 88 & 0,0 & & & & & & & & & & & & & & & & \\
\hline Jun 88 & 0,0 & & & & & & & & & & & & & & & & \\
\hline Jul 88 & 0,0 & & & & & & & & & & & & & & & & \\
\hline Aug 88 & 0,0 & & & & & & & & & & & & & & & & \\
\hline Sep 88 & 0,0 & & & & & & & & & & & & & & & & \\
\hline Okt 88 & 0,0 & & & & & & & & & & & & & & & & \\
\hline Nov 88 & 0,0 & & & & & & & & & & & & & & & & \\
\hline Dez 88 & 30,0 & 8,1 & 1,7 & 1,7 & 283,0 & 62,1 & 22,6 & 407,9 & 110,3 & 8,7 & 13,3 & 100,9 & 376,4 & 5,8 & 9,1 & 317,8 & 22,5 \\
\hline Jan 89 & 12,0 & 8,6 & 1,1 & 1,5 & 329,0 & 30,3 & 12,5 & 295,4 & 86,6 & 22,7 & 16,0 & 29,2 & 422,1 & 4,3 & 13,8 & 130,5 & 18,1 \\
\hline Feb 89 & 8,0 & 8,0 & 1,1 & 1,5 & 277,0 & 41,1 & 13,5 & 311,3 & 68,1 & 12,7 & 9,8 & 46,5 & 441,4 & 4,7 & 16,2 & 154,4 & 25,1 \\
\hline Mär 89 & 15,0 & 8,1 & 1,2 & 1,3 & 204,0 & 46,1 & 15,5 & 327,5 & 65,6 & 8,5 & k.A. & 48,8 & 366,0 & 3,7 & 16,4 & 216,3 & 27,0 \\
\hline Apr 89 & 13,0 & 8,1 & 1,2 & 1,3 & 171,0 & 51,9 & 16,0 & 352,5 & 62,2 & 3,3 & k.A. & 72,7 & 350,1 & 3,5 & 11,2 & 322,9 & 14,7 \\
\hline Mai 89 & 0,0 & & & & & & & & & & & & & & & & \\
\hline Jun 89 & 0,0 & & & & & & & & & & & & & & & & \\
\hline Jul 89 & 0,0 & & & & & & & & & & & & & & & & \\
\hline Aug 89 & 0,0 & & & & & & & & & & & & & & & & \\
\hline Sep 89 & 0,0 & & & & & & & & & & & & & & & & \\
\hline Okt 89 & 0,0 & & & & & & & & & & & & & & & & \\
\hline Nov 89 & 11,0 & 8,4 & 1,4 & 1,3 & 197,5 & 72,4 & 21,0 & 268,1 & 53,3 & 0,6 & k.A. & 104,5 & 484,3 & 6,3 & 7,6 & 92,6 & 40,3 \\
\hline Dez 89 & 31,0 & 8,1 & 1,5 & 1,4 & 172,5 & 88,0 & 25,8 & 332,3 & 48,4 & 0,4 & k.A. & 141,6 & 353,8 & 4,9 & 14,6 & 259,4 & 26,6 \\
\hline Jan 90 & 16,0 & 8,3 & 1,7 & 1,6 & 211,5 & 92,1 & 28,8 & 259,2 & 53,8 & 0,5 & k.A. & 156,7 & 389,2 & 6,8 & 8,4 & 274,7 & 35,6 \\
\hline Feb 90 & 15,5 & 8,2 & 1,4 & 1,3 & 183,5 & 77,8 & 17,0 & 245,7 & 45,5 & 0,4 & k.A. & 133,5 & 340,4 & 4,5 & 6,9 & 254,3 & 17,4 \\
\hline Mär 90 & 19,2 & 8,1 & 1,1 & 1,0 & 207,6 & 59,8 & 15,3 & 227,7 & 30,0 & 0,6 & k.A. & 67,9 & 427,0 & 1,5 & 7,2 & 139,1 & 9,8 \\
\hline Apr 90 & 0,0 & & & & & & & & & & & & & & & & \\
\hline
\end{tabular}


Tabelle 13-64: Stoffdaten der Sickerwasseruntersuchung Mai 1987 bis April 1990, Lysimeter 4

\begin{tabular}{|c|c|c|c|c|c|c|c|c|c|c|c|c|c|c|c|c|c|}
\hline Monat & $\begin{array}{c}\text { SW } \\
\mathrm{I}\end{array}$ & $\begin{array}{c}\mathrm{pH}- \\
\text { Wert } \\
\end{array}$ & $\begin{array}{c}\mathrm{LF} \\
\mathrm{mS} / \mathrm{cm}\end{array}$ & $\begin{array}{c}\text { ADR } \\
\text { g/l }\end{array}$ & $\begin{array}{l}\text { DOC } \\
\mathrm{mg} / \mathrm{l} \\
\end{array}$ & $\begin{array}{c}\mathrm{Ca} \\
\mathrm{mg} / \mathrm{l}\end{array}$ & $\begin{array}{c}\mathrm{Mg} \\
\mathrm{mg} / \mathrm{l}\end{array}$ & $\begin{array}{c}\mathrm{K} \\
\mathrm{mg} / \mathrm{l} \\
\end{array}$ & $\begin{array}{c}\mathrm{Na} \\
\mathrm{mg} / \mathrm{l}\end{array}$ & $\begin{array}{c}\mathrm{Fe} \\
\mathrm{mg} / \mathrm{l}\end{array}$ & $\begin{array}{c}\mathrm{Si} \\
\mathrm{mg} / \mathrm{l}\end{array}$ & $\begin{array}{l}\mathrm{SO}_{4} \\
\mathrm{mg} / \mathrm{l} \\
\end{array}$ & $\begin{array}{c}\mathrm{HCO}_{3} \\
\mathrm{mg} / \mathrm{l}\end{array}$ & $\begin{array}{c}\mathrm{Cl} \\
\mathrm{mg} / \mathrm{l}\end{array}$ & $\begin{array}{c}P \\
\mathrm{mg} / \mathrm{l}\end{array}$ & $\begin{array}{l}\mathrm{NO3} \\
\mathrm{mg} / \mathrm{l}\end{array}$ & $\begin{array}{l}\mathrm{N}_{\text {org }} \\
\mathrm{mg} / \mathrm{l}\end{array}$ \\
\hline Mai 87 & 31,3 & k.A. & 6,4 & k.A. & 213,5 & 594,4 & 125,5 & 759,7 & 397,0 & k.A. & k.A. & 1062,9 & 252,0 & 251,7 & 3,5 & 1563,5 & k.A. \\
\hline Jun 87 & 28,2 & k.A. & 7,3 & k.A. & 263,0 & 633,5 & 175,7 & 1151,1 & 524,9 & k.A. & k.A. & 1230,1 & 408,2 & 409,1 & 2,1 & 1542,6 & k.A. \\
\hline Jul 87 & 0,0 & & & & & & & & & & & & & & & & \\
\hline Aug 87 & 0,1 & 7,4 & 2,2 & k.A. & 146,0 & 240,5 & 31,6 & 250,2 & 85,1 & k.A. & k.A. & u. B & 305,1 & 177,3 & 0,0 & 471,8 & k.A. \\
\hline Sep 87 & 1,9 & 8,1 & 0,2 & k.A. & 19,4 & 26,1 & 4,9 & 11,3 & 18,4 & k.A. & k.A. & 19,2 & 61,0 & 28,4 & 0,7 & 113,5 & k.A. \\
\hline Okt 87 & 0,0 & & & & & & & & & & & & & & & & \\
\hline Nov 87 & 0,0 & & & & & & & & & & & & & & & & \\
\hline Dez 87 & 18,0 & 7,8 & 3,7 & k.A. & 420,2 & 320,6 & 79,0 & 349,9 & 340,4 & k.A. & k.A. & 901,6 & 506,5 & 106,4 & 2,8 & 157,0 & k.A. \\
\hline Jan 88 & 29,9 & 8,0 & 3,9 & k.A. & 471,9 & 373,6 & 93,9 & 401,9 & 381,8 & k.A. & k.A. & 1482,3 & 538,2 & 164,5 & 2,8 & 341,7 & k.A. \\
\hline Feb 88 & 21,0 & 7,9 & 2,7 & k.A. & 389,3 & 178,0 & 45,0 & 298,3 & 270,9 & k.A. & k.A. & 479,4 & 520,2 & 40,8 & 2,8 & 485,5 & k.A. \\
\hline Mär 88 & 52,2 & 7,9 & 1,4 & k.A. & 264,9 & 89,8 & 23,5 & 226,8 & 190,9 & k.A. & k.A. & 128,7 & 522,3 & 5,3 & 7,1 & 289,7 & k.A. \\
\hline Apr 88 & 20,6 & 8,5 & 1,1 & k.A. & 235,5 & 76,8 & 15,8 & 217,8 & 153,4 & k.A. & k.A. & 1,4 & 686,5 & 0,0 & 8,5 & 137,4 & k.A. \\
\hline Mai 88 & 0,0 & & & & & & & & & & & & & & & & \\
\hline Jun 88 & 0,0 & & & & & & & & & & & & & & & & \\
\hline Jul 88 & 0,0 & & & & & & & & & & & & & & & & \\
\hline Aug 88 & 0,0 & & & & & & & & & & & & & & & & \\
\hline Sep 88 & 0,0 & & & & & & & & & & & & & & & & \\
\hline Okt 88 & 0,0 & & & & & & & & & & & & & & & & \\
\hline Nov 88 & 0,0 & & & & & & & & & & & & & & & & \\
\hline Dez 88 & 28,0 & 8,0 & 1,5 & 1,4 & 255,5 & 71,2 & 26,0 & 272,9 & 100,2 & 3,6 & k.A. & 147,5 & 353,8 & 4,7 & 9,9 & 296,9 & 15,4 \\
\hline Jan 89 & 12,0 & 8,2 & 1,1 & 1,2 & 223,0 & 35,8 & 13,2 & 199,2 & 70,8 & 14,2 & 22,2 & 28,3 & 394,1 & 3,9 & 15,9 & 120,3 & 23,2 \\
\hline Feb 89 & 8,0 & 8,2 & 1,0 & 1,0 & 158,0 & 46,1 & 15,5 & 231,3 & 60,9 & 4,0 & 16,9 & 27,0 & 443,9 & 4,7 & 9,5 & 120,3 & 12,7 \\
\hline Mär 89 & 16,0 & 8,0 & 1,0 & 1,0 & 151,0 & 53,6 & 14,0 & 238,8 & 54,2 & 2,7 & k.A. & 21,9 & 364,8 & 4,3 & 10,5 & 189,0 & 22,3 \\
\hline Apr 89 & 12,0 & 8,4 & 1,1 & 1,1 & 124,0 & 62,4 & 18,5 & 262,5 & 49,7 & 1,0 & k.A. & 37,6 & 370,9 & 4,4 & 8,8 & 212,9 & 22,5 \\
\hline Mai 89 & 0,0 & & & & & & & & & & & & & & & & \\
\hline Jun 89 & 0,0 & & & & & & & & & & & & & & & & \\
\hline Jul 89 & 0,0 & & & & & & & & & & & & & & & & \\
\hline Aug 89 & 0,0 & & & & & & & & & & & & & & & & \\
\hline Sep 89 & 0,0 & & & & & & & & & & & & & & & & \\
\hline Okt 89 & 0,0 & & & & & & & & & & & & & & & & \\
\hline Nov 89 & 0,0 & & & & & & & & & & & & & & & & \\
\hline Dez 89 & 9,5 & 8,0 & 0,9 & 0,8 & 126,5 & 66,2 & 18,3 & 174,0 & 27,6 & 0,3 & k.A. & 102,8 & 275,7 & 5,1 & 7,3 & 212,9 & u.B. \\
\hline Jan 90 & 15,0 & 7,9 & 1,4 & 1,3 & 204,5 & 94,2 & 26,8 & 207,8 & 41,4 & 0,4 & k.A. & 118,3 & 370,9 & 5,0 & 7,0 & 212,9 & 2,1 \\
\hline Feb 90 & 13,0 & 8,2 & 1,3 & 1,3 & 177,5 & 92,0 & 19,3 & 210,1 & 41,0 & 0,3 & k.A. & 161,8 & 347,7 & 4,1 & 4,6 & 195,8 & 20,1 \\
\hline Mär 90 & 1,9 & 8,2 & 1,1 & 1,0 & 146,2 & 66,1 & 16,4 & 193,4 & 26,5 & 0,5 & k.A. & 71,4 & 326,4 & 3,7 & 5,1 & 147,6 & 7,4 \\
\hline Apr 90 & 0,0 & & & & & & & & & & & & & & & & \\
\hline
\end{tabular}


Tabelle 13-65: Stoffdaten der Sickerwasseruntersuchung Mai 1987 bis April 1990, Lysimeter 3

\begin{tabular}{|c|c|c|c|c|c|c|c|c|c|c|c|c|c|c|c|c|c|}
\hline Monat & $\begin{array}{c}\text { sw } \\
\mathrm{I}\end{array}$ & $\begin{array}{c}\mathrm{pH}- \\
\text { Wert } \\
\end{array}$ & $\begin{array}{c}\mathrm{LF} \\
\mathrm{mS} / \mathrm{cm}\end{array}$ & $\begin{array}{c}\text { ADR } \\
\text { g/l }\end{array}$ & $\begin{array}{l}\text { DOC } \\
\mathrm{mg} / \mathrm{l} \\
\end{array}$ & $\begin{array}{c}\mathrm{Ca} \\
\mathrm{mg} / \mathrm{l}\end{array}$ & $\begin{array}{c}\mathrm{Mg} \\
\mathrm{mg} / \mathrm{l}\end{array}$ & $\begin{array}{c}\mathrm{K} \\
\mathrm{mg} / \mathrm{l}\end{array}$ & $\begin{array}{c}\mathrm{Na} \\
\mathrm{mg} / \mathrm{l}\end{array}$ & $\begin{array}{c}\mathrm{Fe} \\
\mathrm{mg} / \mathrm{l}\end{array}$ & $\begin{array}{c}\mathrm{Si} \\
\mathrm{mg} / \mathrm{l}\end{array}$ & $\begin{array}{l}\mathrm{SO}_{4} \\
\mathrm{mg} / \mathrm{l}\end{array}$ & $\begin{array}{c}\mathrm{HCO}_{3} \\
\mathrm{mg} / \mathrm{l}\end{array}$ & $\begin{array}{c}\mathrm{Cl} \\
\mathrm{mg} / \mathrm{l}\end{array}$ & $\begin{array}{c} \\
\mathrm{mg} / \mathrm{l}\end{array}$ & $\begin{array}{l}\mathrm{NO} 3 \\
\mathrm{mg} / \mathrm{l}\end{array}$ & $\begin{array}{l}\mathrm{N}_{\text {org }} \\
\mathrm{mg} / \mathrm{l}\end{array}$ \\
\hline Mai 87 & 26,4 & k.A. & 4,3 & k.A. & 121,0 & 441,5 & 86,2 & 268,6 & 264,5 & k.A. & k.A. & 667,2 & 226,4 & 992,2 & 2,8 & 1365,1 & k.A. \\
\hline Jun 87 & 32,6 & k.A. & 4,6 & k.A. & 142,0 & 553,5 & 77,6 & 269,0 & 317,9 & k.A. & k.A. & 821,3 & 335,6 & 453,8 & 2,6 & 937,7 & k.A. \\
\hline Jul 87 & 0,0 & & & & & & & & & & & & & & & & \\
\hline Aug 87 & 0,0 & 7,5 & k.A. & k.A. & 86,6 & 160,3 & 12,2 & 31,3 & 18,4 & k.A. & u.B. & u.B. & 134,2 & u.B. & u.B. & 155,3 & k.A. \\
\hline Sep 87 & 0,0 & & & & & & & & & & & & & & & & \\
\hline Okt 87 & 0,0 & & & & & & & & & & & & & & & & \\
\hline Nov 87 & 0,2 & 7,1 & 0,4 & k.A. & 21,3 & 46,1 & 6,1 & 15,6 & 18,4 & k.A. & k.A. & 4,8 & 109,8 & 17,7 & 4,3 & 167,2 & u.B. \\
\hline Dez 87 & 6,6 & 8,2 & k.A. & k.A. & 277,1 & 82,2 & 28,0 & 109,5 & 133,4 & k.A. & k.A. & 816,5 & 384,4 & 99,3 & 1,4 & 107,5 & k.A. \\
\hline Jan 88 & 25,8 & 7,9 & 3,3 & k.A. & 298,2 & 138,9 & 63,0 & 117,3 & 164,5 & k.A. & k.A. & 1321,8 & 396,6 & 213,4 & 1,4 & 227,0 & k.A. \\
\hline Feb 88 & 19,7 & 8,0 & 2,6 & k.A. & 279,8 & 170,3 & 34,3 & 115,0 & 224,0 & k.A. & k.A. & 616,3 & 402,7 & 63,1 & 1,4 & 309,3 & k.A. \\
\hline Mär 88 & 52,8 & 8,0 & 1,3 & k.A. & 146,1 & 95,8 & 14,3 & 77,4 & 166,8 & k.A. & k.A. & 117,7 & 442,4 & 10,6 & 1,4 & 219,7 & k.A. \\
\hline Apr 88 & 18,3 & 8,2 & 1,0 & k.A. & 104,4 & 76,2 & 14,6 & 93,8 & 125,4 & k.A. & k.A. & 79,3 & 256,3 & u.B. & 1,7 & 146,3 & k.A. \\
\hline Mai 88 & 0,0 & & & & & & & & & & & & & & & & \\
\hline Jun 88 & 0,0 & & & & & & & & & & & & & & & & \\
\hline Jul 88 & 0,0 & & & & & & & & & & & & & & & & \\
\hline Aug 88 & 0,0 & & & & & & & & & & & & & & & & \\
\hline Sep 88 & 0,0 & & & & & & & & & & & & & & & & \\
\hline Okt 88 & 0,0 & & & & & & & & & & & & & & & & \\
\hline Nov 88 & 0,0 & & & & & & & & & & & & & & & & \\
\hline Dez 88 & 27,0 & 8,0 & 1,1 & 0,9 & 286,0 & 86,4 & 21,7 & 119,7 & 94,6 & 0,6 & 16,9 & 144,9 & 303,2 & 3,9 & 1,1 & 286,2 & u.B. \\
\hline Jan 89 & 13,0 & 8,5 & 0,8 & 1,0 & 121,0 & 53,4 & 13,9 & 98,1 & 59,8 & 1,6 & 27,6 & 39,8 & 330,6 & 3,8 & 0,8 & 116,9 & 6,8 \\
\hline Feb 89 & 8,0 & 8,1 & 0,9 & 0,7 & 83,0 & 68,5 & 17,0 & 102,0 & 56,4 & 0,0 & 31,1 & 39,1 & 384,4 & 4,9 & 0,9 & 140,8 & u.B. \\
\hline Mär 89 & 15,0 & 8,6 & 0,9 & 0,7 & 81,0 & 71,9 & 36,5 & 107,3 & 50,8 & 0,0 & k.A. & 28,9 & 340,4 & 3,8 & 0,9 & 164,7 & u.B. \\
\hline Apr 89 & 13,0 & 8,5 & 1,0 & 0,7 & 73,0 & 79,5 & 19,5 & 112,3 & 44,9 & 0,0 & k.A. & 37,3 & 359,9 & u.B. & 1,0 & 176,6 & u.B. \\
\hline Mai 89 & 0,0 & & & & & & & & & & & & & & & & \\
\hline Jun 89 & 0,0 & & & & & & & & & & & & & & & & \\
\hline Jul 89 & 0,0 & & & & & & & & & & & & & & & & \\
\hline Aug 89 & 0,0 & & & & & & & & & & & & & & & & \\
\hline Sep 89 & 0,0 & & & & & & & & & & & & & & & & \\
\hline Okt 89 & 0,0 & & & & & & & & & & & & & & & & \\
\hline Nov 89 & 14,0 & 8,0 & 1,7 & 1,3 & 140,0 & 171,3 & 38,5 & 161,6 & 40,4 & 0,0 & k.A. & 149,3 & 417,7 & u.B. & 2,3 & 178,7 & 51,1 \\
\hline Dez 89 & 29,0 & 8,0 & 1,2 & 0,9 & 96,5 & 120,8 & 27,5 & 117,9 & 23,9 & 0,1 & k.A. & 103,2 & 324,5 & 4,5 & 2,5 & 221,8 & 8,0 \\
\hline Jan 90 & 16,0 & 8,0 & 1,2 & 0,9 & 98,5 & 115,9 & 26,5 & 121,9 & 22,3 & 0,1 & k.A. & 115,0 & 323,3 & 4,2 & 2,5 & 226,5 & 8,9 \\
\hline Feb 90 & 14,5 & 7,9 & 1,0 & 0,8 & 84,0 & 89,8 & 16,0 & 112,7 & 17,8 & 0,2 & k.A. & 68,1 & 270,8 & u.B. & 2,2 & 216,3 & u.B. \\
\hline Mär 90 & 19,2 & 8,0 & 0,8 & 0,6 & 79,0 & 68,2 & 14,0 & 106,4 & 12,6 & 0,4 & k.A. & 39,5 & 306,2 & 1,6 & 2,7 & 147,6 & 6,3 \\
\hline Apr 90 & 0,0 & & & & & & & & & & & & & & & & \\
\hline
\end{tabular}


Tabelle 13-66: Stoffdaten der Sickerwasseruntersuchung Mai 1987 bis April 1990, Lysimeter 7

\begin{tabular}{|c|c|c|c|c|c|c|c|c|c|c|c|c|c|c|c|c|c|}
\hline Monat & $\begin{array}{c}\text { SW } \\
\text { I }\end{array}$ & $\begin{array}{c}\mathrm{pH}- \\
\text { Wert }\end{array}$ & $\begin{array}{c}\mathrm{LF} \\
\mathrm{mS} / \mathrm{cm}\end{array}$ & $\begin{array}{c}\text { ADR } \\
\text { g/l }\end{array}$ & $\begin{array}{l}\mathrm{DOC} \\
\mathrm{mg} / \mathrm{l}\end{array}$ & $\begin{array}{c}\mathrm{Ca} \\
\mathrm{mg} / \mathrm{l}\end{array}$ & $\begin{array}{c}\mathrm{Mg} \\
\mathrm{mg} / \mathrm{l}\end{array}$ & $\begin{array}{c}\mathrm{K} \\
\mathrm{mg} / \mathrm{l}\end{array}$ & $\begin{array}{c}\mathrm{Na} \\
\mathrm{mg} / \mathrm{l}\end{array}$ & $\begin{array}{c}\mathrm{Fe} \\
\mathrm{mg} / \mathrm{l}\end{array}$ & $\begin{array}{c}\mathrm{Si} \\
\mathrm{mg} / \mathrm{l}\end{array}$ & $\begin{array}{l}\mathrm{SO}_{4} \\
\mathrm{mg} / \mathrm{l}\end{array}$ & $\begin{array}{c}\mathrm{HCO}_{3} \\
\mathrm{mg} / \mathrm{l}\end{array}$ & $\begin{array}{c}\mathrm{Cl} \\
\mathrm{mg} / \mathrm{l}\end{array}$ & $\begin{array}{c}\mathrm{P} \\
\mathrm{mg} / \mathrm{l}\end{array}$ & $\begin{array}{l}\mathrm{NO3} \\
\mathrm{mg} / \mathrm{l}\end{array}$ & $\begin{array}{l}\mathrm{N}_{\text {org }} \\
\mathrm{mg} / \mathrm{l}\end{array}$ \\
\hline Mai 87 & 0,5 & k.A. & k.A. & k.A. & u.B. & 401,8 & 119,0 & 1286,4 & 498,0 & k.A. & k.A. & 1422,7 & 422,3 & 710,8 & u.B. & 1487,1 & k.A. \\
\hline Jun 87 & 15,4 & k.A. & 0,8 & k.A. & 17,8 & 116,6 & 12,3 & 23,9 & 21,9 & k.A. & k.A. & 95,1 & 191,6 & 30,1 & 9,9 & 104,9 & k.A. \\
\hline Jul 87 & 0,1 & k.A. & 0,7 & k.A. & 17,2 & 125,5 & 13,0 & 19,2 & 12,9 & k.A. & k.A. & 79,3 & 177,6 & 15,2 & 2,8 & 122,4 & k.A. \\
\hline Aug 87 & 7,1 & 8,1 & 0,5 & k.A. & 25,3 & 70,3 & 8,4 & 3,9 & 16,8 & k.A. & k.A. & 30,3 & 98,2 & 2,5 & 2,1 & 29,9 & k.A. \\
\hline Sep 87 & 1,5 & 8,1 & 0,4 & k.A. & 18,8 & 62,1 & 3,6 & 3,9 & 18,4 & k.A. & k.A. & 33,6 & 189,2 & u.B. & u.B. & 11,9 & k.A. \\
\hline Okt 87 & 0,0 & & & & & & & & & & & & & & & & \\
\hline Nov 87 & 22,1 & 8,1 & 0,4 & k.A. & 17,7 & 50,1 & 3,6 & 3,9 & 24,2 & k.A. & k.A. & 24,0 & 187,9 & 1,1 & u.B. & 7,7 & k.A. \\
\hline Dez 87 & 10,0 & 7,9 & 0,4 & k.A. & 26,3 & 64,1 & 4,9 & 3,9 & 25,3 & k.A. & k.A. & 28,8 & 213,6 & 1,8 & u.B. & 6,0 & k.A. \\
\hline Jan 88 & 13,9 & 8,0 & 0,4 & k.A. & 19,6 & 72,1 & 6,1 & 3,5 & 26,7 & k.A. & k.A. & 16,2 & 257,5 & 1,1 & u.B. & 7,3 & k.A. \\
\hline Feb 88 & 6,9 & 8,0 & 0,4 & k.A. & 13,0 & 65,5 & 5,7 & 3,9 & 20,7 & k.A. & k.A. & 19,2 & 244,1 & 4,6 & u.B. & 16,2 & k.A. \\
\hline Mär 88 & 21,4 & 7,6 & 0,4 & k.A. & 19,6 & 50,7 & 5,5 & 3,1 & 10,4 & k.A. & k.A. & 26,4 & 200,1 & 1,1 & u.B. & 6,0 & k.A. \\
\hline Apr 88 & 2,9 & 7,8 & 0,3 & k.A. & 25,0 & 46,1 & 6,1 & 8,6 & 11,5 & k.A. & k.A. & 12,0 & 210,5 & u.B. & u.B. & 9,0 & k.A. \\
\hline Mai 88 & 0,0 & & & & & & & & & & & & & & & & \\
\hline Jun 88 & 0,0 & & & & & & & & & & & & & & & & \\
\hline Jul 88 & 0,0 & & & & & & & & & & & & & & & & \\
\hline Aug 88 & 0,0 & & & & & & & & & & & & & & & & \\
\hline Sep 88 & 0,0 & & & & & & & & & & & & & & & & \\
\hline Okt 88 & 0,0 & & & & & & & & & & & & & & & & \\
\hline Nov 88 & 0,0 & & & & & & & & & & & & & & & & \\
\hline Dez 88 & 40,0 & 8,0 & 0,3 & k.A. & 14,0 & 43,0 & 1,9 & 1,2 & 9,8 & 0,2 & 5,1 & 20,9 & 171,4 & 2,5 & u.B. & 23,9 & u.B. \\
\hline Jan 89 & 5,0 & 7,8 & 0,3 & k.A. & 27,0 & 48,1 & 2,1 & 0,9 & 9,2 & 0,2 & 4,3 & 5,8 & 191,5 & 3,2 & u.B. & 10,2 & u.B. \\
\hline Feb 89 & 7,0 & 8,0 & 0,4 & k.A. & 10,0 & 66,2 & 6,6 & 0,9 & 7,9 & u.B. & 4,7 & 5,0 & 235,6 & 3,0 & u.B. & 13,7 & u.B. \\
\hline Mär 89 & 0,0 & & & & & & & & & & & & & & & & \\
\hline Apr 89 & 13,0 & 8,2 & 0,3 & k.A. & 12,0 & 59,8 & 6,0 & 0,8 & 9,2 & u.B. & k.A. & 3,8 & 223,3 & 4,3 & u.B. & 34,6 & u.B. \\
\hline Mai 89 & 0,0 & & & & & & & & & & & & & & & & \\
\hline Jun 89 & 0,0 & & & & & & & & & & & & & & & & \\
\hline Jul 89 & 0,0 & & & & & & & & & & & & & & & & \\
\hline Aug 89 & 0,0 & & & & & & & & & & & & & & & & \\
\hline Sep 89 & 0,0 & & & & & & & & & & & & & & & & \\
\hline Okt 89 & 0,0 & & & & & & & & & & & & & & & & \\
\hline Nov 89 & 7,0 & 8,0 & 0,4 & k.A. & 7,2 & 71,2 & 5,5 & 2,4 & 9,0 & u.B. & k.A. & 36,7 & 234,2 & 3,5 & 0,2 & u.B. & u.B. \\
\hline Dez 89 & 9,0 & 7,8 & 0,4 & k.A. & 6,7 & 66,2 & 6,6 & 1,6 & 8,3 & u.B. & k.A. & 26,0 & 200,1 & 3,9 & 0,1 & u.B. & u.B. \\
\hline Jan 90 & 12,0 & 8,0 & 0,4 & k.A. & 6,1 & 68,7 & 6,4 & 1,4 & 7,8 & u.B. & k.A. & 26,1 & 235,5 & 3,2 & u.B. & u.B. & u.B. \\
\hline Feb 90 & 9,5 & 8,2 & 0,3 & k.A. & 5,6 & 57,6 & 5,8 & 4,3 & 7,0 & 0,2 & k.A. & 17,1 & 209,8 & u.B. & 0,0 & 0,4 & u.B. \\
\hline Mär 90 & 12,2 & 8,0 & 0,3 & k.A. & 3,8 & 52,9 & 4,8 & 1,6 & 7,2 & 0,3 & k.A. & 26,7 & 186,1 & 2,9 & 0,1 & 1,3 & u.B. \\
\hline Apr 90 & 0,0 & & & & & & & & & & & & & & & & \\
\hline
\end{tabular}

Tabelle 13-67: C-Gehalte und Extinktionen bei 400 und 436 $n m$ sowie Qotienten $E_{400} / D O C, E_{400} / E_{436}$ des Sickerwassers, Monatsmittelwerte, Lysimeter 8

\begin{tabular}{l|c|c|c|c|c} 
Lysimeter & $\mathbf{8}$ & \multicolumn{5}{|c}{} \\
\hline Monat & $\begin{array}{c}\text { DOC } \\
\mathbf{m g} / \mathbf{l}\end{array}$ & $\begin{array}{c}\text { Extinktion bei } \\
\mathbf{4 3 6} \mathbf{~ n m}\end{array}$ & $\begin{array}{c}\text { Extinktion bei } \\
\mathbf{4 0 0} \mathbf{~ n m}\end{array}$ & E 400/DOC & E 400/E 436 \\
\hline Dez 88 & 458,50 & 0,3266 & 0,4630 & 0,0050 & 1,42 \\
Jan 89 & 427,00 & 0,3261 & 0,4559 & 0,0053 & 1,40 \\
Feb 89 & 400,00 & 0,3054 & 0,4559 & 0,0057 & 1,49 \\
Mär 89 & & & & & \\
Apr 89 & 312,00 & 0,3188 & 0,4935 & 0,0079 & 1,55 \\
Mai 89 & & & & & \\
Jun 89 & & & & & \\
Jul 89 & & & & & \\
Aug 89 & & & & & \\
Sep 89 & & & & & \\
Okt 89 & & & & & \\
Nov 89 & & & & & \\
Dez 89 & 303,00 & 0,1537 & 0,2480 & 0,0041 & 1,61 \\
Jan 90 & 312,50 & 0,1785 & 0,2840 & 0,0045 & 1,59 \\
Feb 90 & 237,50 & 0,1391 & 0,2269 & 0,0048 & 1,63 \\
Mär 90 & 240,90 & 0,1344 & 0,2105 & 0,0044 & 1,57
\end{tabular}


Tabelle 13-68: C-Gehalte und Extinktionen bei 400 und 436 $n m$ sowie Qotienten $E_{400} / D O C, E_{400} / E_{436}$ des Sickerwassers, Monatsmittelwerte, Lysimeter 6

\begin{tabular}{|c|c|c|c|c|c|}
\hline Lysimeter & 6 & & & & \\
\hline Monat & $\begin{array}{l}\mathrm{DOC} \\
\mathrm{mg} / \mathrm{l}\end{array}$ & \begin{tabular}{|c|} 
Extinktion bei \\
$436 \mathrm{~nm}$
\end{tabular} & \begin{tabular}{|c|}
$\begin{array}{c}\text { Extinktion bei } \\
400 \mathrm{~nm}\end{array}$ \\
\end{tabular} & E 400/DOC & E 400/E 436 \\
\hline Dez 88 & 357,50 & 0,2256 & 0,3522 & 0,0049 & 1,56 \\
\hline Jan 89 & 336,00 & 0,2351 & 0,3556 & 0,0053 & 1,51 \\
\hline Feb 89 & 363,00 & 0,2104 & 0,3197 & 0,0044 & 1,52 \\
\hline Mär 89 & 353,00 & 0,2907 & 0,4318 & 0,0061 & 1,49 \\
\hline Apr 89 & 289,00 & 0,2100 & 0,3757 & 0,0065 & 1,79 \\
\hline Mai 89 & & & & & \\
\hline Jun 89 & & & & & \\
\hline Jul 89 & & & & & \\
\hline Aug 89 & & & & & \\
\hline Sep 89 & & & & & \\
\hline Okt 89 & & & & & \\
\hline Nov 89 & 180,50 & 0,1024 & 0,1612 & 0,0045 & 1,57 \\
\hline Dez 89 & 214,80 & 0,0999 & 0,1658 & 0,0039 & 1,66 \\
\hline Jan 90 & 264,00 & 0,1152 & 0,2069 & 0,0039 & 1,80 \\
\hline Feb 90 & 235,00 & 0,1133 & 0,1925 & 0,0041 & 1,70 \\
\hline Mär 90 & 226,10 & 0,1080 & 0,1731 & 0,0038 & 1,60 \\
\hline
\end{tabular}

Tabelle 13-69: C-Gehalte und Extinktionen bei 400 und 436 $\mathrm{nm}$ sowie Qotienten $\mathrm{E}_{400} / \mathrm{DOC}, \mathrm{E}_{400} / \mathrm{E}_{436}$ des Sickerwassers, Monatsmittelwerte, Lysimeter 5

\begin{tabular}{|c|c|c|c|c|c|}
\hline Lysimeter & \multicolumn{5}{|l|}{5} \\
\hline Monat & $\begin{array}{l}\mathrm{DOC} \\
\mathrm{mg} / \mathrm{l}\end{array}$ & \begin{tabular}{|c|} 
Extinktion bei \\
$436 \mathrm{~nm}$ \\
\end{tabular} & $\begin{array}{c}\text { Extinktion bei } \\
400 \mathrm{~nm}\end{array}$ & E 400/DOC & E 400/E 436 \\
\hline Dez 88 & 283,00 & 0,1689 & 0,2714 & 0,0048 & 1,61 \\
\hline Jan 89 & 329,00 & 0,1993 & 0,3098 & 0,0047 & 1,55 \\
\hline Feb 89 & 277,00 & 0,1192 & 0,1938 & 0,0035 & 1,63 \\
\hline Mär 89 & 204,00 & 0,1871 & 0,2924 & 0,0072 & 1,56 \\
\hline Apr 89 & 171,00 & 0,1146 & 0,1858 & 0,0054 & 1,62 \\
\hline \multicolumn{6}{|l|}{ Mai 89} \\
\hline \multicolumn{6}{|l|}{ Jun 89} \\
\hline \multicolumn{6}{|l|}{ Jul 89} \\
\hline \multicolumn{6}{|l|}{ Aug 89} \\
\hline \multicolumn{6}{|l|}{ Sep 89} \\
\hline \multicolumn{6}{|l|}{ Okt 89} \\
\hline Nov 89 & 197,50 & 0,0958 & 0,1537 & 0,0039 & 1,60 \\
\hline Dez 89 & 172,50 & 0,0681 & 0,1159 & 0,0034 & 1,70 \\
\hline Jan 90 & 211,50 & 0,0814 & 0,1415 & 0,0033 & 1,74 \\
\hline Feb 90 & 183,50 & 0,0747 & 0,1249 & 0,0034 & 1,67 \\
\hline Mär 90 & 207,60 & 0,0779 & 0,1251 & 0,0030 & 1,61 \\
\hline
\end{tabular}


Tabelle 13-70: C-Gehalte und Extinktionen bei 400 und 436 $n m$ sowie Qotienten $E_{400} / D O C, E_{400} / E_{436}$ des Sickerwassers, Monatsmittelwerte, Lysimeter 4

\begin{tabular}{|c|c|c|c|c|c|}
\hline Lysimeter & 4 & & & & \\
\hline Monat & $\begin{array}{l}\mathrm{DOC} \\
\mathrm{mg} / \mathrm{l}\end{array}$ & $\begin{array}{c}\text { Extinktion bei } \\
436 \mathrm{~nm} \\
\end{array}$ & $\begin{array}{c}\text { Extinktion bei } \\
400 \mathrm{~nm}\end{array}$ & E 400/DOC & E 400/E 436 \\
\hline Dez 88 & 255,50 & 0,0833 & 0,1406 & 0,0028 & 1,69 \\
\hline Jan 89 & 223,00 & 0,0969 & 0,1580 & 0,0035 & 1,63 \\
\hline Feb 89 & 158,00 & 0,0615 & 0,0969 & 0,0031 & 1,58 \\
\hline Mär 89 & 151,00 & 0,0867 & 0,1433 & 0,0047 & 1,65 \\
\hline Apr 89 & 124,00 & 0,0605 & 0,0980 & 0,0040 & 1,62 \\
\hline Mai 89 & & & & & \\
\hline Jun 89 & & & & & \\
\hline Jul 89 & & & & & \\
\hline Aug 89 & & & & & \\
\hline Sep 89 & & & & & \\
\hline Okt 89 & & & & & \\
\hline Nov 89 & & & & & \\
\hline Dez 89 & 126,50 & 0,0555 & 0,0862 & 0,0034 & 1,55 \\
\hline Jan 90 & 204,50 & 0,0660 & 0,1192 & 0,0029 & 1,81 \\
\hline Feb 90 & 177,50 & 0,0605 & 0,1068 & 0,0030 & 1,77 \\
\hline Mär 90 & 146,20 & 0,0620 & 0,1030 & 0,0035 & 1,66 \\
\hline
\end{tabular}

Tabelle 13-71: C-Gehalte und Extinktionen bei 400 und 436 $n m$ sowie Qotienten $E_{400} / D O C, E_{400} / E_{436}$ des Sickerwassers, Monatsmittelwerte, Lysimeter 3

\begin{tabular}{|c|c|c|c|c|c|}
\hline Lysimeter & 3 & & & & \\
\hline Monat & $\begin{array}{l}\mathrm{DOC} \\
\mathrm{mg} / \mathrm{l}\end{array}$ & \begin{tabular}{|c|} 
Extinktion bei \\
$436 \mathrm{~nm}$ \\
\end{tabular} & \begin{tabular}{|c|} 
Extinktion bei \\
$400 \mathrm{~nm}$ \\
\end{tabular} & E 400/DOC & E 400/E 436 \\
\hline Dez 88 & 286,00 & 0,0327 & 0,0603 & 0,0011 & 1,84 \\
\hline Jan 89 & 121,00 & 0,0315 & 0,0467 & 0,0019 & 1,48 \\
\hline Feb 89 & 83,00 & 0,0223 & 0,0339 & 0,0020 & 1,52 \\
\hline Mär 89 & 81,00 & 0,0269 & 0,0496 & 0,0031 & 1,84 \\
\hline Apr 89 & 73,00 & 0,0223 & 0,0362 & 0,0025 & 1,62 \\
\hline Mai 89 & & & & & \\
\hline Jun 89 & & & & & \\
\hline Jul 89 & & & & & \\
\hline Aug 89 & & & & & \\
\hline Sep 89 & & & & & \\
\hline Okt 89 & & & & & \\
\hline Nov 89 & 140,00 & 0,0269 & 0,0506 & 0,0018 & 1,88 \\
\hline Dez 89 & 96,50 & 0,0246 & 0,0453 & 0,0023 & 1,84 \\
\hline Jan 90 & 98,50 & 0,0259 & 0,0458 & 0,0023 & 1,77 \\
\hline Feb 90 & 84,00 & 0,0237 & 0,0458 & 0,0027 & 1,93 \\
\hline Mär 90 & 79,00 & 0,0272 & 0,0437 & 0,0028 & 1,61 \\
\hline
\end{tabular}


Tabelle 13-72: Ionenbilanz, Sickerwasser, Lysimeter 1

\begin{tabular}{|c|c|c|c|c|c|c|c|c|c|c|c|c|c|}
\hline Monat & DOC & $\mathrm{Ca}$ & $\mathrm{Mg}$ & $\mathrm{K}$ & $\begin{array}{c}\mathrm{Na} \\
\mathrm{mmol} I \mathrm{I} / \mathrm{I}\end{array}$ & Summe K & SO4 & $\mathrm{Cl}$ & NO3 & $\mathrm{HCO} 3$ & Summe A & $\begin{array}{c}\text { Differenz } \\
\text { K - A }\end{array}$ & C pro Valenz \\
\hline Mai 87 & 13,98 & 24,20 & 4,37 & 6,70 & 6,60 & 41,87 & 7,67 & 8,01 & 11,44 & 8,17 & 35,29 & 6,58 & 2,12 \\
\hline Jun 87 & 32,97 & 23,68 & 8,35 & 30,60 & 16,71 & 79,33 & 15,88 & 15,55 & 29,11 & 14,84 & 75,38 & 3,95 & 8,35 \\
\hline Jul 87 & 37,23 & 36,75 & 10,47 & 37,40 & 14,91 & 99,52 & 17,84 & 17,31 & 32,53 & 18,04 & 85,72 & 13,80 & 2,70 \\
\hline Aug 87 & 39,58 & 33,58 & 8,50 & 30,40 & 14,21 & 86,68 & 16,40 & 15,33 & 32,76 & 14,97 & 79,46 & 7,22 & 5,49 \\
\hline Sep 87 & 41,89 & 34,40 & 8,43 & 30,50 & 15,12 & 88,45 & 17,40 & 15,42 & 34,68 & 16,27 & 83,77 & 4,68 & 8,95 \\
\hline Okt 87 & 39,50 & 32,15 & 8,90 & 35,30 & 15,11 & 91,45 & 17,60 & 15,00 & 35,28 & 16,60 & 84,48 & 6,97 & 5,67 \\
\hline Nov 87 & 39,62 & 33,30 & 9,10 & 33,40 & 15,21 & 91,01 & 17,70 & 14,25 & 41,08 & 14,40 & 87,43 & 3,57 & 11,08 \\
\hline Dez 87 & 37,82 & 35,04 & 9,40 & 34,20 & 15,51 & 94,14 & 18,53 & 14,45 & 43,21 & 14,00 & 90,19 & 3,96 & 9,56 \\
\hline Jan 88 & 37,48 & 35,00 & 9,64 & 37,20 & 16,21 & 98,04 & 19,54 & 13,30 & 48,68 & 11,28 & 92,80 & 5,25 & 7,14 \\
\hline Feb 88 & 40,94 & 30,65 & 9,75 & 41,60 & 17,01 & 99,01 & 19,40 & 11,33 & 47,63 & 10,43 & 88,78 & 10,22 & 4,00 \\
\hline Mär 88 & 38,54 & 22,03 & 7,70 & 33,30 & 16,81 & 79,83 & 16,10 & 6,93 & 40,13 & 12,45 & 75,61 & 4,22 & 9,13 \\
\hline Apr 88 & 40,96 & 15,13 & 3,75 & 29,30 & 14,01 & 62,18 & 13,25 & 2,98 & 28,51 & 15,68 & 60,42 & 1,76 & 23,28 \\
\hline \multicolumn{14}{|l|}{ Mai 88} \\
\hline \multicolumn{14}{|l|}{ Jun 88} \\
\hline \multicolumn{14}{|l|}{ Jul 88} \\
\hline \multicolumn{14}{|l|}{ Aug 88} \\
\hline \multicolumn{14}{|l|}{ Sep 88} \\
\hline \multicolumn{14}{|l|}{ Okt 88} \\
\hline \multicolumn{14}{|l|}{ Nov 88} \\
\hline Dez 88 & 55,21 & 4,94 & 1,82 & 17,60 & 6,10 & 30,46 & 4,28 & 0,17 & 6,48 & 10,56 & 21,48 & 8,98 & 6,15 \\
\hline Jan 89 & 61,75 & 5,39 & 2,00 & 18,75 & 6,43 & 32,57 & 4,15 & 0,01 & 7,16 & 10,11 & 21,43 & 11,14 & 5,54 \\
\hline Feb 89 & 53,88 & 5,05 & 1,73 & 17,68 & 5,73 & 30,19 & 3,77 & 0,16 & 6,44 & 11,00 & 21,37 & 8,82 & 6,11 \\
\hline Mär 89 & 46,75 & 5,47 & 1,85 & 17,90 & 5,68 & 30,91 & 4,08 & 0,15 & 6,73 & 10,38 & 21,34 & 9,57 & 4,89 \\
\hline Apr 89 & 50,50 & 5,93 & 1,89 & 18,67 & 5,82 & 32,30 & 4,08 & 0,14 & 6,61 & 11,43 & 22,26 & 10,05 & 5,03 \\
\hline \multicolumn{14}{|l|}{ Mai 89} \\
\hline \multicolumn{14}{|l|}{ Jun 89} \\
\hline \multicolumn{14}{|l|}{ Jul 89} \\
\hline \multicolumn{14}{|l|}{ Aug 89} \\
\hline \multicolumn{14}{|l|}{ Sep 89} \\
\hline \multicolumn{14}{|l|}{ Okt 89} \\
\hline Nov 89 & 50,54 & 5,93 & 1,93 & 19,56 & 5,89 & 33,31 & 4,17 & 0,25 & 10,73 & 9,66 & 24,82 & 8,49 & 5,95 \\
\hline Dez 89 & 42,71 & 5,95 & 2,08 & 19,32 & 5,79 & 33,14 & 5,81 & 0,21 & 11,81 & 8,26 & 26,09 & 7,05 & 6,06 \\
\hline Jan 90 & 49,21 & 7,54 & 2,71 & 22,53 & 7,06 & 39,85 & 6,45 & 0,34 & 17,47 & 7,12 & 31,37 & 8,48 & 5,81 \\
\hline Feb 90 & 55,13 & 6,84 & 2,12 & 22,86 & 6,83 & 38,65 & 6,53 & 0,30 & 17,33 & 6,49 & 30,66 & 7,99 & 6,90 \\
\hline Mär 90 & 62,19 & 5,55 & 1,65 & 18,85 & 5,27 & 31,33 & 3,97 & 0,13 & 9,10 & 7,78 & 20,98 & 10,35 & 6,01 \\
\hline \multicolumn{14}{|l|}{ Apr 90} \\
\hline Mai 90 & 61,98 & 4,86 & 1,59 & 18,15 & 4,67 & 29,26 & 3,10 & 0,12 & 6,89 & 11,08 & 21,18 & 8,08 & 7,67 \\
\hline
\end{tabular}


Tabelle 13-73: Ionenbilanz, Sickerwasser, Lysimeter 2

\begin{tabular}{|c|c|c|c|c|c|c|c|c|c|c|c|c|c|}
\hline Monat & DOC & $\mathrm{Ca}$ & Mg & $\mathbf{K}$ & $\begin{array}{c}\mathrm{Na} \\
\mathrm{mmol} \mathrm{IE} / \mathrm{I}\end{array}$ & Summe K & SO4 & $\mathrm{Cl}$ & NO3 & $\mathrm{HCO} 3$ & Summe A & $\begin{array}{c}\text { Differenz } \\
\text { K - A }\end{array}$ & C pro Valenz \\
\hline Mai 87 & 11,48 & 18,80 & 3,30 & 6,70 & 4,31 & 33,11 & 5,69 & 5,48 & 9,29 & 10,90 & 31,36 & 1,75 & 6,55 \\
\hline Jun 87 & 29,39 & 35,89 & 9,20 & 36,50 & 14,91 & 96,50 & 18,84 & 15,79 & 24,82 & 22,10 & 81,55 & 14,95 & 1,97 \\
\hline Jul 87 & 37,98 & 38,79 & 12,32 & 49,40 & 15,11 & 115,61 & 22,10 & 22,79 & 18,61 & 29,62 & 93,12 & 22,49 & 1,69 \\
\hline Aug 87 & 39,48 & 34,01 & 10,71 & 45,50 & 16,21 & 106,43 & 34,32 & 23,38 & 22,59 & 27,20 & 107,49 & $-1,06$ & $-37,10$ \\
\hline Sep 87 & 35,87 & 30,93 & 10,50 & 41,80 & 16,81 & 100,04 & 32,33 & 24,10 & 22,46 & 27,50 & 106,39 & $-6,36$ & $-5,64$ \\
\hline Okt 87 & 34,98 & 31,75 & 11,50 & 39,60 & 16,61 & 99,45 & 31,45 & 24,90 & 23,54 & 28,25 & 108,14 & $-8,68$ & $-4,03$ \\
\hline Nov 87 & 40,43 & 30,50 & 11,80 & 43,90 & 18,21 & 104,41 & 34,50 & 26,23 & 25,02 & 22,63 & 108,38 & $-3,97$ & $-10,18$ \\
\hline Dez 87 & 48,01 & 46,95 & 12,75 & 49,80 & 20,71 & 130,20 & 37,98 & 28,23 & 29,54 & 25,20 & 120,95 & 9,26 & 5,19 \\
\hline Jan 88 & 47,63 & 45,84 & 13,90 & 58,50 & 23,01 & 141,24 & 41,44 & 28,96 & 33,34 & 24,40 & 128,14 & 13,11 & 3,63 \\
\hline Feb 88 & 47,38 & 40,48 & 14,08 & 62,80 & 23,61 & 140,97 & 43,55 & 28,63 & 37,36 & 23,40 & 132,94 & 8,03 & 5,90 \\
\hline Mär 88 & 43,47 & 32,23 & 11,98 & 59,40 & 25,31 & 128,92 & 44,15 & 24,23 & 32,18 & 26,15 & 126,72 & 2,20 & 19,74 \\
\hline Apr 88 & 48,84 & 26,28 & 9,50 & 56,30 & 23,31 & 115,39 & 37,85 & 16,66 & 28,29 & 30,10 & 112,90 & 2,49 & 19,62 \\
\hline $\begin{array}{l}\text { Mai } 88 \\
\text { Jun } 88 \\
\text { Jul } 88 \\
\text { Aug } 88 \\
\text { Sep } 88 \\
\text { Okt } 88 \\
\text { Nov } 88\end{array}$ & & & & & & & & & & & & & \\
\hline Dez 88 & 57,75 & 9,89 & 5,08 & 48,33 & 14,26 & 77,56 & 21,10 & 5,96 & 13,99 & 16,95 & 57,99 & 19,57 & 2,95 \\
\hline Jan 89 & 64,13 & 12,04 & 5,80 & 50,20 & 15,73 & 83,77 & 21,26 & 6,68 & 19,40 & 16,20 & 63,54 & 20,24 & 3,17 \\
\hline $\begin{array}{l}\text { Feb } 89 \\
\text { Mär } 89\end{array}$ & 53,67 & 11,19 & 6,33 & 43,22 & 12,05 & 72,80 & 19,95 & 5,37 & 18,19 & 17,86 & 61,37 & 11,42 & 4,70 \\
\hline $\begin{array}{l}\text { Apr } 89 \\
\text { Mai } 89 \\
\text { Jun } 89 \\
\text { Jul } 89 \\
\text { Aug } 89 \\
\text { Sep } 89 \\
\text { Okt } 89 \\
\text { Nov } 89\end{array}$ & 54,58 & 11,90 & 5,96 & 42,33 & 11,52 & 71,70 & 18,52 & 4,64 & 17,82 & 17,96 & 58,93 & 12,77 & 4,28 \\
\hline Dez 89 & 50,83 & 11,11 & 5,02 & 44,78 & 13,28 & 74,18 & 17,67 & 3,02 & 24,54 & 12,16 & 57,38 & 16,80 & 3,03 \\
\hline Jan 90 & 61,96 & 12,40 & 5,35 & 49,56 & 13,48 & 80,78 & 17,88 & 2,61 & 31,09 & 11,80 & 63,39 & 17,40 & 3,56 \\
\hline Feb 90 & 70,06 & 12,45 & 4,30 & 48,89 & 13,73 & 79,37 & 19,36 & 3,06 & 30,78 & 11,79 & 65,00 & 14,37 & 4,87 \\
\hline Mär 90 & 96,55 & 10,48 & 3,77 & 45,15 & 12,42 & 71,82 & 17,30 & 1,48 & 24,54 & 13,58 & 56,89 & 14,92 & 6,47 \\
\hline
\end{tabular}


Tabelle 13-74: Ionenbilanz, Sickerwasser, Lysimeter 8

\begin{tabular}{|c|c|c|c|c|c|c|c|c|c|c|c|c|c|}
\hline \multirow{2}{*}{ Monat } & \multicolumn{13}{|c|}{ Lysimeter 8} \\
\hline & DOC & $\mathrm{Ca}$ & Mg & $\mathrm{K}$ & $\begin{array}{c}\mathrm{Na} \\
\mathrm{mmol} \text { IE/I }\end{array}$ & Summe K & SO4 & $\mathrm{Cl}$ & $\mathrm{NO3}$ & $\mathrm{HCO} 3$ & Summe A & $\begin{array}{c}\text { Differenz } \\
\text { K - A }\end{array}$ & C pro Valenz \\
\hline Mai 87 & 28,64 & 28,14 & 8,41 & 27,85 & 18,79 & 83,19 & 22,55 & 17,95 & 21,91 & 5,29 & 67,70 & 15,49 & 1,85 \\
\hline Jun 87 & 41,05 & 24,90 & 7,08 & 39,03 & 19,56 & 90,57 & 21,19 & 18,98 & 11,75 & 17,05 & 68,97 & 21,60 & 1,90 \\
\hline Jul 87 & 42,75 & 2,94 & 1,32 & 10,23 & 2,54 & 17,03 & 2,08 & 1,86 & 0,05 & 5,10 & 9,09 & 7,95 & 5,38 \\
\hline Aug 87 & 15,63 & 0,92 & 0,37 & 1,48 & 0,80 & 3,57 & 0,08 & 0,63 & 0,65 & 0,26 & 1,62 & 1,95 & 8,01 \\
\hline Sep 87 & 45,58 & 10,00 & 3,10 & 18,30 & 11,61 & 43,00 & 8,20 & 8,30 & 5,80 & 11,20 & 33,50 & 9,51 & 4,79 \\
\hline Okt 87 & 48,38 & 11,80 & 3,70 & 18,10 & 11,20 & 44,81 & 12,30 & 7,10 & 4,20 & 13,60 & 37,20 & 7,61 & 6,36 \\
\hline Nov 87 & 82,93 & 14,50 & 5,40 & 25,35 & 16,26 & 61,51 & 35,60 & 7,50 & 3,30 & 14,40 & 60,80 & 0,71 & 116,46 \\
\hline Dez 87 & 108,58 & 12,80 & 6,15 & 26,25 & 17,21 & 62,41 & 13,05 & 6,56 & 5,80 & 13,10 & 38,51 & 23,90 & 4,54 \\
\hline Jan 88 & 91,58 & 12,00 & 4,52 & 22,16 & 13,97 & 52,65 & 5,74 & 2,42 & 4,82 & 16,44 & 29,42 & 23,23 & 3,94 \\
\hline Feb 88 & 83,48 & 8,63 & 3,23 & 18,10 & 10,36 & 40,32 & 2,48 & 1,03 & 7,70 & 14,60 & 25,81 & 14,51 & 5,75 \\
\hline Mär 88 & 49,83 & 4,73 & 1,98 & 13,28 & 6,80 & 26,79 & 3,38 & 0,37 & 4,64 & 13,13 & 21,52 & 5,27 & 9,45 \\
\hline Apr 88 & 36,78 & 3,20 & 1,40 & 11,35 & 5,05 & 21,00 & 1,05 & 0,00 & 3,20 & 13,55 & 17,80 & 3,20 & 11,48 \\
\hline \multicolumn{14}{|l|}{ Mai 88} \\
\hline \multicolumn{14}{|l|}{ Jun 88} \\
\hline \multicolumn{14}{|l|}{ Jul 88} \\
\hline \multicolumn{14}{|l|}{ Aug 88} \\
\hline \multicolumn{14}{|l|}{ Sep 88} \\
\hline \multicolumn{14}{|l|}{ Okt 88} \\
\hline \multicolumn{14}{|l|}{ Nov 88} \\
\hline Dez 88 & 38,21 & 2,74 & 1,35 & 10,86 & 4,10 & 19,04 & 3,00 & 0,01 & 3,79 & 8,34 & 15,14 & 3,90 & 9,79 \\
\hline Jan 89 & 35,58 & 2,05 & 1,23 & 9,23 & 3,49 & 16,00 & 1,42 & 0,00 & 2,41 & 7,94 & 11,77 & 4,23 & 8,41 \\
\hline Feb 89 & 33,33 & 2,46 & 1,36 & 10,23 & 3,24 & 17,28 & 0,51 & 0,01 & 1,32 & 8,72 & 10,56 & 6,72 & 4,96 \\
\hline \multicolumn{14}{|l|}{ Mär 89} \\
\hline Apr 89 & 26,00 & 2,87 & 1,40 & 10,87 & 2,99 & 18,13 & 1,77 & 0,00 & 1,09 & 11,02 & 13,88 & 4,25 & 6,12 \\
\hline \multicolumn{14}{|l|}{ Mai 89} \\
\hline \multicolumn{14}{|l|}{ Jun 89} \\
\hline \multicolumn{14}{|l|}{ Jul 89} \\
\hline \multicolumn{14}{|l|}{ Aug 89} \\
\hline \multicolumn{14}{|l|}{ Sep 89} \\
\hline \multicolumn{14}{|l|}{ Okt 89} \\
\hline \multicolumn{14}{|l|}{ Nov 89} \\
\hline Dez 89 & 25,25 & 3,88 & 1,81 & 7,33 & 2,92 & 15,95 & 3,88 & 0,16 & 3,33 & 6,88 & 14,25 & 1,70 & 14,87 \\
\hline Jan 90 & 26,04 & 3,10 & 1,56 & 7,17 & 2,55 & 14,38 & 3,09 & 0,13 & 2,76 & 6,88 & 12,85 & 1,53 & 17,06 \\
\hline Feb 90 & 19,79 & 2,53 & 0,97 & 6,67 & 2,03 & 12,21 & 1,64 & 0,02 & 3,97 & 5,40 & 11,03 & 1,18 & 16,84 \\
\hline Mär 90 & 20,08 & 1,95 & 0,89 & 6,47 & 1,52 & 10,83 & 0,95 & 0,00 & 3,11 & 5,90 & 9,95 & 0,88 & 22,86 \\
\hline
\end{tabular}


Tabelle 13-75: Ionenbilanz, Sickerwasser, Lysimeter 6

\begin{tabular}{|c|c|c|c|c|c|c|c|c|c|c|c|c|c|}
\hline Monat & DOC & $\mathrm{Ca}$ & Mg & $\mathbf{K}$ & $\begin{array}{c}\mathrm{Na} \\
\mathrm{mmol} \text { IE/I }\end{array}$ & Summe K & SO4 & $\mathrm{Cl}$ & NO3 & $\mathrm{HCO} 3$ & Summe A & $\begin{array}{c}\text { Differenz } \\
\text { K - A } \\
\end{array}$ & C pro Valenz \\
\hline Mai 87 & 32,29 & 21,65 & 8,03 & 36,96 & 19,76 & 86,40 & 17,42 & 16,42 & 22,75 & 7,09 & 63,67 & 22,72 & 1,42 \\
\hline Jun 87 & 36,38 & 18,06 & 5,62 & 45,43 & 20,51 & 89,61 & 21,15 & 15,45 & 22,81 & 12,47 & 71,88 & 17,73 & 2,05 \\
\hline Jul 87 & 38,48 & 3,72 & 1,42 & 9,55 & 2,59 & 17,28 & 1,79 & 14,19 & 0,35 & 6,50 & 22,83 & $-5,55$ & $-6,94$ \\
\hline Aug 87 & 17,38 & 2,80 & 1,00 & 6,66 & 3,27 & 13,73 & 1,22 & 2,10 & 1,00 & 0,40 & 4,72 & 9,02 & 1,93 \\
\hline Sep 87 & 56,46 & 8,00 & 2,20 & 1,25 & 9,10 & 20,56 & 2,60 & 3,60 & 5,60 & 10,80 & 22,60 & $-2,04$ & $-27,68$ \\
\hline \multicolumn{14}{|l|}{ Okt 87} \\
\hline Nov 87 & 126,67 & 13,50 & 4,00 & 14,90 & 13,21 & 45,60 & 11,70 & 1,70 & 2,20 & 14,00 & 29,60 & 16,00 & 7,92 \\
\hline Dez 87 & 127,89 & 11,83 & 3,77 & 14,83 & 11,94 & 42,36 & 11,20 & 1,36 & 3,20 & 12,43 & 28,19 & 14,17 & 9,02 \\
\hline Jan 88 & 119,09 & 10,58 & 3,68 & 16,42 & 11,77 & 42,44 & 7,13 & 1,20 & 7,17 & 12,52 & 28,03 & 14,41 & 8,26 \\
\hline Feb 88 & 82,43 & 7,03 & 2,53 & 13,88 & 9,16 & 32,60 & 3,83 & 0,98 & 9,45 & 10,85 & 25,11 & 7,49 & 11,00 \\
\hline Mär 88 & 60,74 & 4,65 & 1,65 & 11,65 & 6,35 & 24,31 & 2,53 & 0,33 & 8,07 & 10,95 & 21,89 & 2,42 & 25,08 \\
\hline Apr 88 & 39,24 & 3,60 & 1,00 & 10,30 & 5,00 & 19,90 & 0,90 & 0,00 & 4,55 & 11,90 & 17,35 & 2,55 & 15,36 \\
\hline \multicolumn{14}{|l|}{ Mai 88} \\
\hline \multicolumn{14}{|l|}{ Jun 88} \\
\hline \multicolumn{14}{|l|}{ Jul 88} \\
\hline \multicolumn{14}{|l|}{ Aug 88} \\
\hline \multicolumn{14}{|l|}{ Sep 88} \\
\hline \multicolumn{14}{|l|}{ Okt 88} \\
\hline \multicolumn{14}{|l|}{ Nov 88} \\
\hline Dez 88 & 29,79 & 2,92 & 1,36 & 10,06 & 4,36 & 18,70 & 1,85 & 0,08 & 4,86 & 6,43 & 13,22 & 5,48 & 5,44 \\
\hline Jan 89 & 28,00 & 1,81 & 1,32 & 7,31 & 2,87 & 13,31 & 0,49 & 0,01 & 2,47 & 6,44 & 9,41 & 3,90 & 7,17 \\
\hline Feb 89 & 30,25 & 2,39 & 0,99 & 8,95 & 2,85 & 15,18 & 1,29 & 0,10 & 3,22 & 6,10 & 10,71 & 4,47 & 6,76 \\
\hline Mär 89 & 29,42 & 2,84 & 1,03 & 10,23 & 3,08 & 17,18 & 0,75 & 0,00 & 5,18 & 5,98 & 11,90 & 5,28 & 5,57 \\
\hline Apr 89 & 24,08 & 2,70 & 1,19 & 11,00 & 3,05 & 17,94 & 2,49 & 0,01 & 5,35 & 6,08 & 13,93 & 4,02 & 5,99 \\
\hline \multicolumn{14}{|l|}{ Mai 89} \\
\hline \multicolumn{14}{|l|}{ Jun 89} \\
\hline \multicolumn{14}{|l|}{ Jul 89} \\
\hline \multicolumn{14}{|l|}{ Aug 89} \\
\hline \multicolumn{14}{|l|}{ Sep 89} \\
\hline \multicolumn{14}{|l|}{ Okt 89} \\
\hline Nov 89 & 15,04 & 2,82 & 1,38 & 7,39 & 2,00 & 13,59 & 2,14 & 0,14 & 4,94 & 4,80 & 12,01 & 1,58 & 9,54 \\
\hline Dez 89 & 17,90 & 3,77 & 1,92 & 6,94 & 2,39 & 15,02 & 2,82 & 0,17 & 5,75 & 5,02 & 13,76 & 1,26 & 14,24 \\
\hline Jan 90 & 22,00 & 4,13 & 2,30 & 7,62 & 2,81 & 16,86 & 3,20 & 0,13 & 4,83 & 6,50 & 14,66 & 2,20 & 10,02 \\
\hline Feb 90 & 19,58 & 3,46 & 1,23 & 7,25 & 2,81 & 14,75 & 2,70 & 0,12 & 5,29 & 5,70 & 13,81 & 0,93 & 20,95 \\
\hline Mär 90 & 18,84 & 2,77 & 1,16 & 6,58 & 1,61 & 12,12 & 1,31 & 0,13 & 4,14 & 5,42 & 11,00 & 1,12 & 16,80 \\
\hline
\end{tabular}


Tabelle 13-76: Ionenbilanz, Sickerwasser, Lysimeter 5

\begin{tabular}{|c|c|c|c|c|c|c|c|c|c|c|c|c|c|}
\hline Monat & DOC & $\mathrm{Ca}$ & Mg & $\mathbf{K}$ & $\begin{array}{c}\mathrm{Na} \\
\mathrm{mmol} \mathrm{IE} / \mathrm{l}\end{array}$ & Summe K & SO4 & $\mathrm{Cl}$ & NO3 & $\mathrm{HCO} 3$ & Summe A & $\begin{array}{c}\text { Differenz } \\
\text { K - A } \\
\end{array}$ & C pro Valenz \\
\hline Mai 87 & 22,22 & 32,84 & 13,15 & 34,97 & 22,60 & 103,56 & 32,00 & 7,97 & 22,84 & 4,38 & 67,19 & 36,37 & 0,61 \\
\hline $\begin{array}{l}\text { Jun } 87 \\
\text { Jul } 87\end{array}$ & 27,58 & 36,68 & 14,50 & 43,52 & 26,82 & 121,52 & 36,99 & 12,89 & 29,59 & 7,11 & 86,59 & 34,93 & 0,79 \\
\hline Aug 87 & 6,56 & 3,88 & 1,35 & 2,55 & 1,67 & 9,45 & 1,99 & 1,73 & 1,68 & 0,98 & 6,38 & 3,07 & 2,14 \\
\hline $\begin{array}{l}\text { Sep } 87 \\
\text { Okt } 87\end{array}$ & 38,48 & 6,80 & 1,60 & 86,82 & 7,90 & 103,13 & 2,80 & 4,10 & 5,20 & 8,50 & 20,60 & 82,53 & 0,47 \\
\hline Nov 87 & 53,48 & 19,50 & 7,20 & 16,50 & 17,91 & 61,11 & 36,70 & 7,40 & 4,80 & 10,30 & 59,20 & 1,91 & 27,94 \\
\hline Dez 87 & 53,11 & 19,30 & 7,93 & 18,30 & 18,94 & 64,47 & 37,00 & 8,07 & 5,03 & 9,53 & 59,63 & 4,84 & 10,98 \\
\hline Jan 88 & 55,36 & 16,98 & 7,34 & 18,38 & 18,51 & 61,21 & 32,16 & 6,46 & 7,55 & 9,46 & 55,63 & 5,58 & 9,92 \\
\hline Feb 88 & 50,18 & 8,13 & 3,45 & 12,35 & 12,36 & 36,29 & 4,90 & 1,68 & 9,02 & 9,50 & 25,11 & 11,18 & 4,49 \\
\hline Mär 88 & 32,93 & 4,23 & 2,08 & 9,25 & 8,73 & 24,30 & 3,80 & 0,28 & 5,80 & 9,10 & 18,98 & 5,32 & 6,19 \\
\hline $\begin{array}{l}\text { Apr } 88 \\
\text { Mai } 88 \\
\text { Jun } 88 \\
\text { Jul } 88 \\
\text { Aug } 88 \\
\text { Sep } 88 \\
\text { Okt } 88 \\
\text { Nov } 88\end{array}$ & 28,31 & 3,30 & 1,60 & 8,10 & 6,83 & 19,83 & 1,50 & 0,00 & 2,60 & 10,73 & 14,83 & 5,01 & 5,65 \\
\hline Dez 88 & 23,58 & 3,10 & 1,86 & 10,43 & 4,80 & 20,19 & 2,10 & 0,16 & 5,32 & 6,17 & 13,75 & 6,43 & 3,66 \\
\hline Jan 89 & 27,42 & 1,51 & 1,03 & 7,55 & 3,77 & 13,86 & 0,61 & 0,12 & 2,18 & 6,92 & 9,83 & 4,03 & 6,80 \\
\hline Feb 89 & 23,08 & 2,05 & 1,11 & 7,96 & 2,96 & 14,08 & 0,97 & 0,13 & 2,58 & 7,23 & 10,92 & 3,17 & 7,29 \\
\hline Mär 89 & 17,00 & 2,30 & 1,27 & 8,38 & 2,85 & 14,80 & 1,02 & 0,10 & 3,62 & 6,00 & 10,74 & 4,07 & 4,18 \\
\hline $\begin{array}{l}\text { Apr } 89 \\
\text { Mai } 89 \\
\text { Jun } 89 \\
\text { Jul } 89 \\
\text { Aug } 89 \\
\text { Sep } 89 \\
\text { Okt } 89\end{array}$ & 14,25 & 2,59 & 1,32 & 9,01 & 2,71 & 15,63 & 1,51 & 0,10 & 5,40 & 5,74 & 12,75 & 2,87 & 4,96 \\
\hline Nov 89 & 16,46 & 3,61 & 1,73 & 6,86 & 2,32 & 14,51 & 2,18 & 0,18 & 1,55 & 7,94 & 11,84 & 2,67 & 6,15 \\
\hline Dez 89 & 14,38 & 4,39 & 2,12 & 8,50 & 2,11 & 17,12 & 2,95 & 0,14 & 4,34 & 5,80 & 13,23 & 3,89 & 3,69 \\
\hline Jan 90 & 17,63 & 4,60 & 2,37 & 6,63 & 2,34 & 15,93 & 3,26 & 0,19 & 4,60 & 6,38 & 14,43 & 1,50 & 11,72 \\
\hline Feb 90 & 15,29 & 3,88 & 1,40 & 6,28 & 1,98 & 13,54 & 2,78 & 0,13 & 4,26 & 5,58 & 12,74 & 0,80 & 19,05 \\
\hline Mär 90 & 17,30 & 2,98 & 1,26 & 5,82 & 1,30 & 11,37 & 1,41 & 0,04 & 2,33 & 7,00 & 10,78 & 0,59 & 29,38 \\
\hline
\end{tabular}


Tabelle 13-77: Ionenbilanz, Sickerwasser, Lysimeter 4

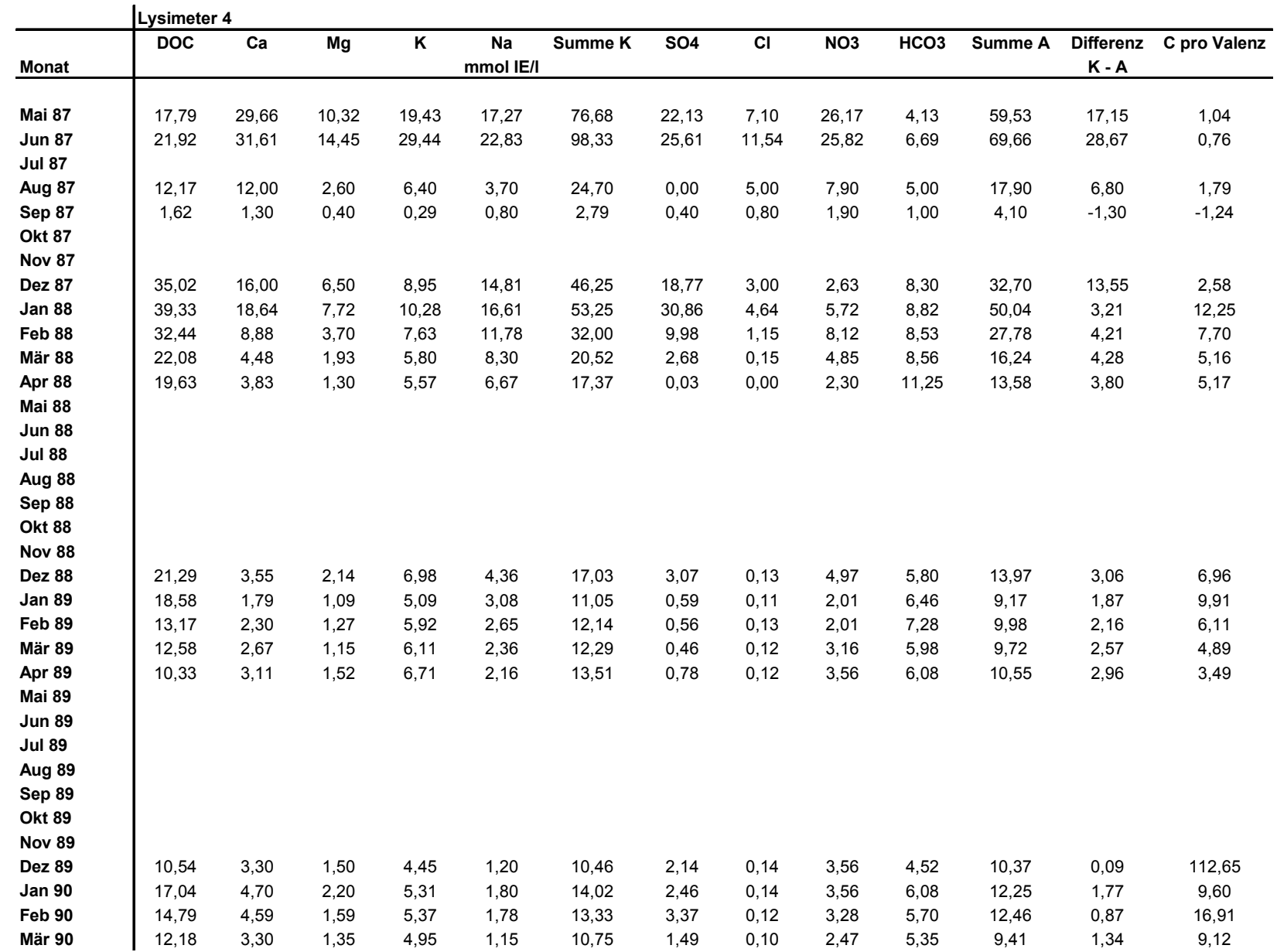


Tabelle 13-78: Ionenbilanz, Sickerwasser, Lysimeter 3

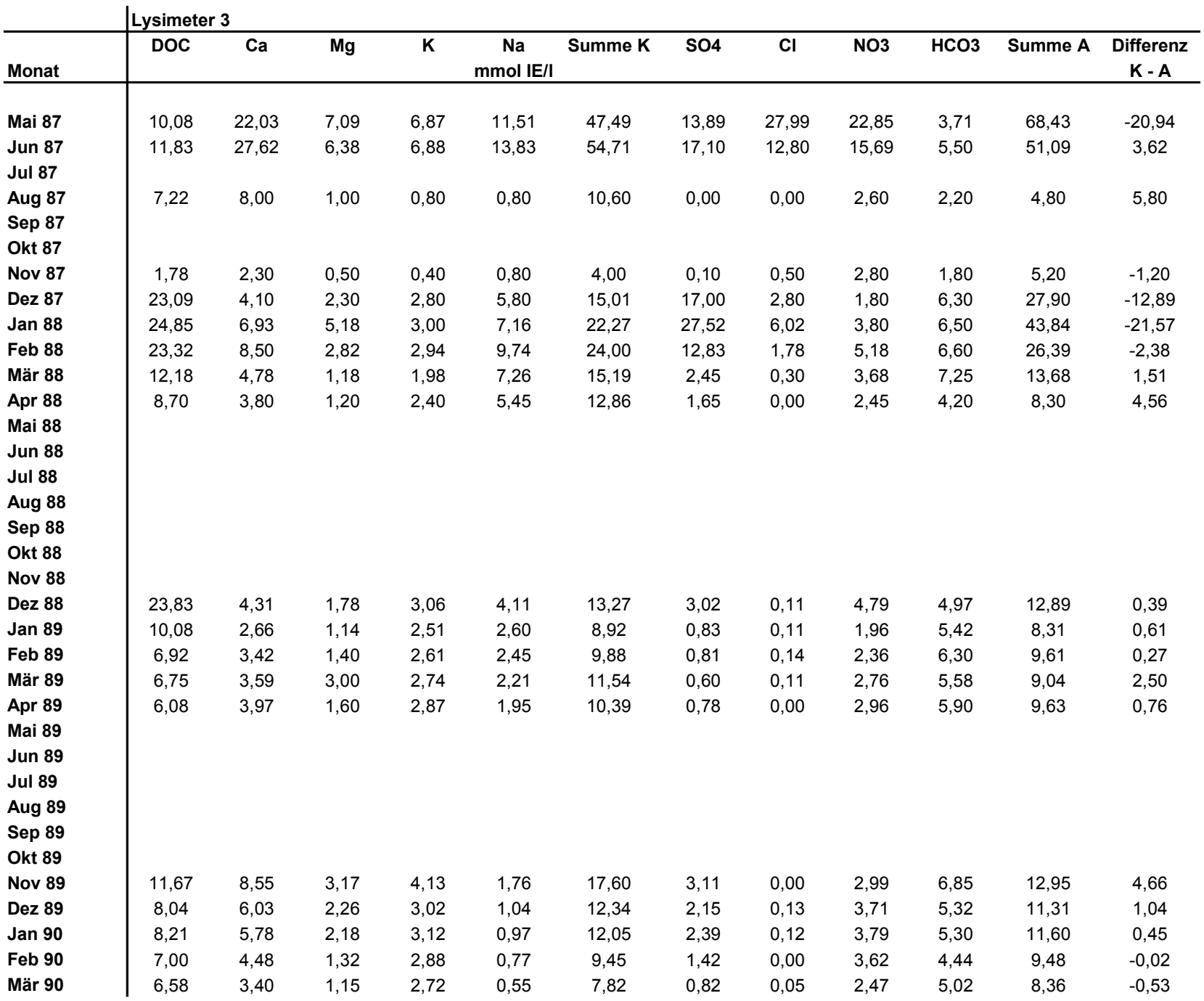


Tabelle 13-79: Ionenbilanz, Sickerwasser, Lysimeter 7

\begin{tabular}{|c|c|c|c|c|c|c|c|c|c|c|c|c|c|}
\hline $\begin{array}{l}\text { Monatsmittel } \\
\text { Monat }\end{array}$ & DOC & $\mathrm{Ca}$ & Mg & $\mathbf{K}$ & $\mathrm{Na}$ & $\begin{array}{l}\text { Summe K } \\
\mathrm{mmol} \mathrm{IE} / \mathrm{l}\end{array}$ & SO4 & $\mathrm{Cl}$ & $\mathrm{NO3}$ & $\mathrm{HCO} 3$ & Summe A & $\begin{array}{c}\text { Differenz } \\
\text { K - A }\end{array}$ & C pro Valenz \\
\hline Mai 87 & 0,00 & 20,05 & 9,79 & 32,90 & 21,66 & 84,40 & 29,62 & 20,05 & 24,89 & 6,92 & 81,48 & 2,92 & \\
\hline Jun 87 & 1,48 & 5,82 & 1,01 & 0,61 & 0,95 & 8,39 & 1,98 & 0,85 & 1,76 & 3,14 & 7,73 & 0,67 & 2,22 \\
\hline Jul 87 & 1,43 & 6,26 & 1,07 & 0,49 & 0,56 & 8,38 & 1,65 & 0,43 & 2,05 & 2,91 & 7,04 & 1,34 & 1,07 \\
\hline Aug 87 & 2,11 & 3,51 & 0,69 & 0,10 & 0,73 & 5,03 & 0,63 & 0,07 & 0,50 & 1,61 & 2,81 & 2,22 & 0,95 \\
\hline Sep 87 & 1,57 & 3,10 & 0,30 & 0,10 & 0,80 & 4,29 & 0,70 & 0,00 & 0,20 & 3,10 & 4,00 & 0,29 & 5,32 \\
\hline \multicolumn{14}{|l|}{ Okt 87} \\
\hline Nov 87 & 1,48 & 2,50 & 0,30 & 0,10 & 1,05 & 3,95 & 0,50 & 0,03 & 0,13 & 3,08 & 3,74 & 0,21 & 7,03 \\
\hline Dez 87 & 2,19 & 3,20 & 0,40 & 0,10 & 1,10 & 4,80 & 0,60 & 0,05 & 0,10 & 3,50 & 4,25 & 0,55 & 3,98 \\
\hline Jan 88 & 1,63 & 3,60 & 0,50 & 0,09 & 1,16 & 5,35 & 0,34 & 0,03 & 0,12 & 4,22 & 4,71 & 0,64 & 2,55 \\
\hline Feb 88 & 1,08 & 3,27 & 0,47 & 0,10 & 0,90 & 4,74 & 0,40 & 0,13 & 0,27 & 4,00 & 4,80 & $-0,06$ & $-16,92$ \\
\hline Mär 88 & 1,63 & 2,53 & 0,45 & 0,08 & 0,45 & 3,51 & 0,55 & 0,03 & 0,10 & 3,28 & 3,96 & $-0,45$ & $-3,66$ \\
\hline Apr 88 & 2,08 & 2,30 & 0,50 & 0,22 & 0,50 & 3,52 & 0,25 & 0,00 & 0,15 & 3,45 & 3,85 & $-0,33$ & $-6,36$ \\
\hline \multicolumn{14}{|l|}{ Mai 88} \\
\hline \multicolumn{14}{|l|}{ Jun 88} \\
\hline \multicolumn{14}{|l|}{ Jul 88} \\
\hline \multicolumn{14}{|l|}{ Aug 88} \\
\hline \multicolumn{14}{|l|}{ Sep 88} \\
\hline \multicolumn{14}{|l|}{ Okt 88} \\
\hline \multicolumn{14}{|l|}{ Nov 88} \\
\hline Dez 88 & 1,17 & 2,15 & 0,16 & 0,03 & 0,43 & 2,76 & 0,44 & 0,07 & 0,40 & 2,81 & 3,71 & $-0,96$ & $-1,22$ \\
\hline Jan 89 & 2,25 & 2,40 & 0,17 & 0,02 & 0,40 & 3,00 & 0,12 & 0,09 & 0,17 & 3,14 & 3,52 & $-0,52$ & $-4,29$ \\
\hline Feb 89 & 0,83 & 3,30 & 0,54 & 0,02 & 0,34 & 4,21 & 0,10 & 0,08 & 0,23 & 3,86 & 4,28 & $-0,07$ & $-12,69$ \\
\hline \multicolumn{14}{|l|}{ Mär 89} \\
\hline \multicolumn{14}{|l|}{ Apr 89} \\
\hline \multicolumn{14}{|l|}{ Mai 89} \\
\hline \multicolumn{14}{|l|}{ Jun 89} \\
\hline \multicolumn{14}{|l|}{ Jul 89} \\
\hline \multicolumn{14}{|l|}{ Aug 89} \\
\hline \multicolumn{14}{|l|}{ Sep 89} \\
\hline \multicolumn{14}{|l|}{ Okt 89} \\
\hline Nov 89 & 0,60 & 3,55 & 0,45 & 0,06 & 0,39 & 4,46 & 0,76 & 0,10 & 0,00 & 3,84 & 4,70 & $-0,24$ & $-2,47$ \\
\hline Dez 89 & 0,56 & 3,30 & 0,54 & 0,04 & 0,36 & 4,25 & 0,54 & 0,11 & 0,00 & 3,28 & 3,93 & 0,32 & 1,76 \\
\hline Jan 90 & 0,51 & 3,43 & 0,53 & 0,04 & 0,34 & 4,33 & 0,54 & 0,09 & 0,00 & 3,86 & 4,49 & $-0,16$ & $-3,10$ \\
\hline Feb 90 & 0,47 & 2,87 & 0,48 & 0,11 & 0,30 & 3,77 & 0,36 & 0,00 & 0,01 & 3,44 & 3,80 & $-0,04$ & $-12,99$ \\
\hline Mär 90 & 0,32 & 2,64 & 0,39 & 0,04 & 0,31 & 3,39 & 0,56 & 0,08 & 0,02 & 3,05 & 3,71 & $-0,32$ & $-0,99$ \\
\hline
\end{tabular}




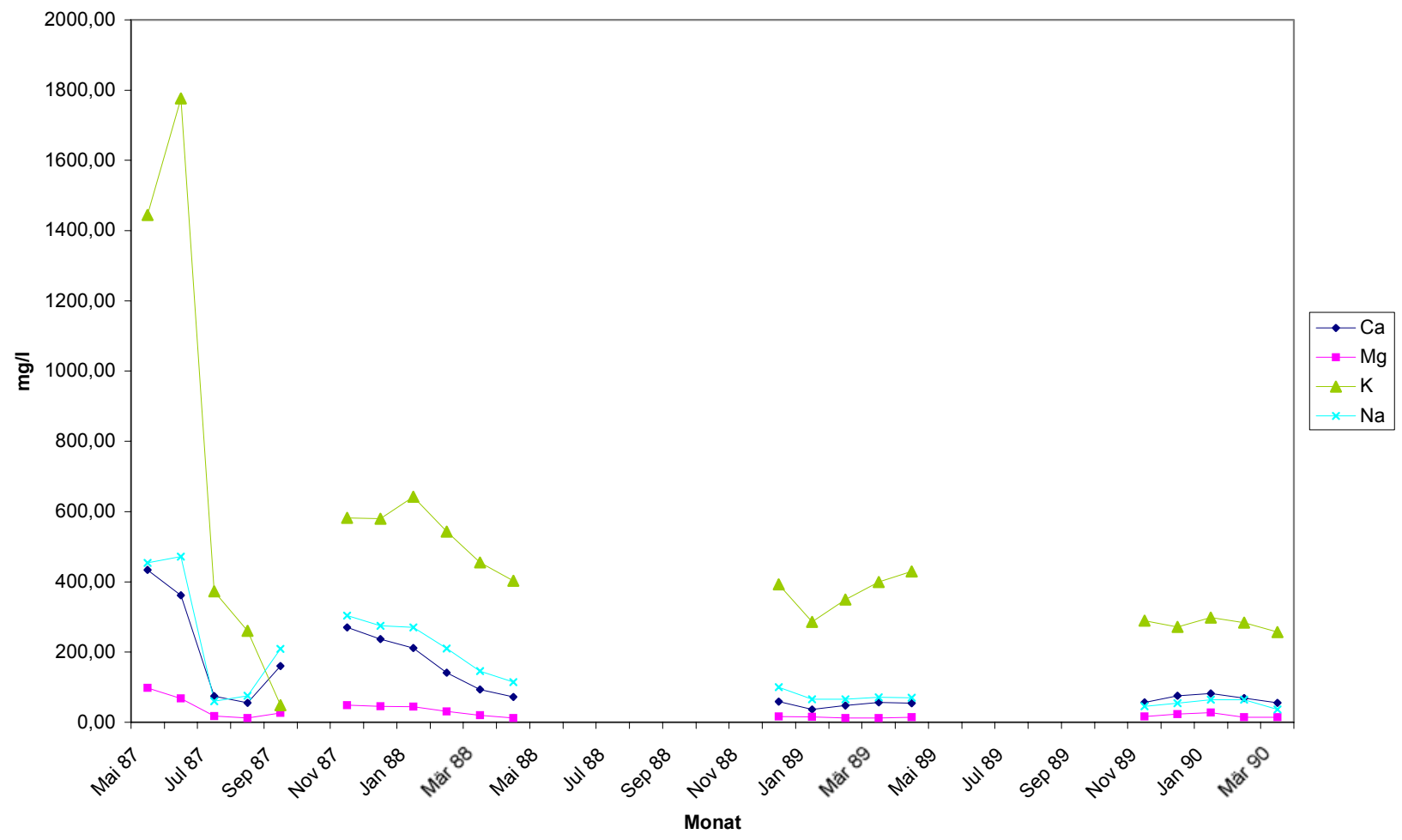

Abbildung 13-2: Konzentrationsverlauf der Kationen im Sickerwasser, Monatsmittelwerte, Lysimeter 6

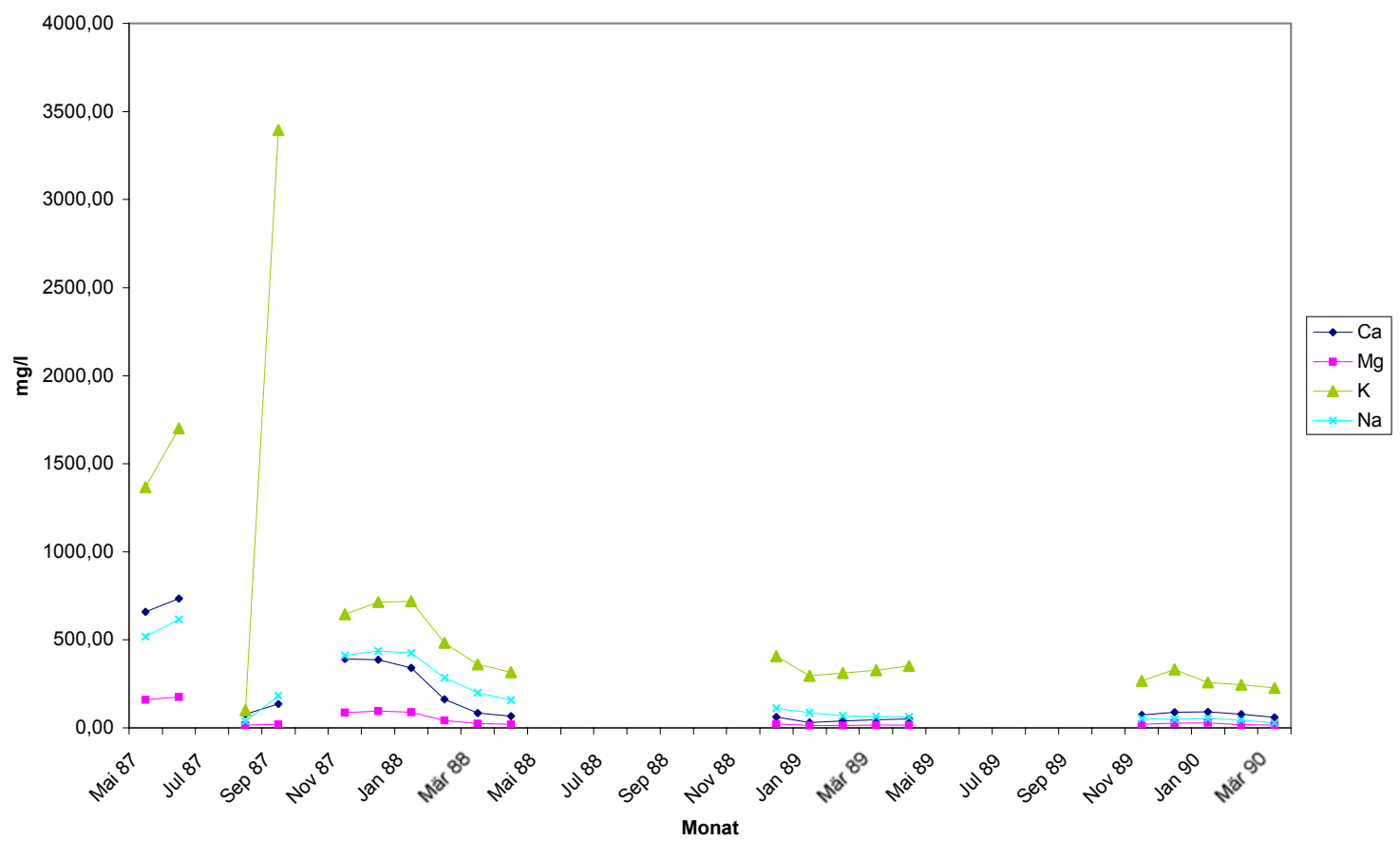

Abbildung 13-3: Konzentrationsverlauf der Kationen im Sickerwasser, Monatsmittelwerte, Lysimeter 5 


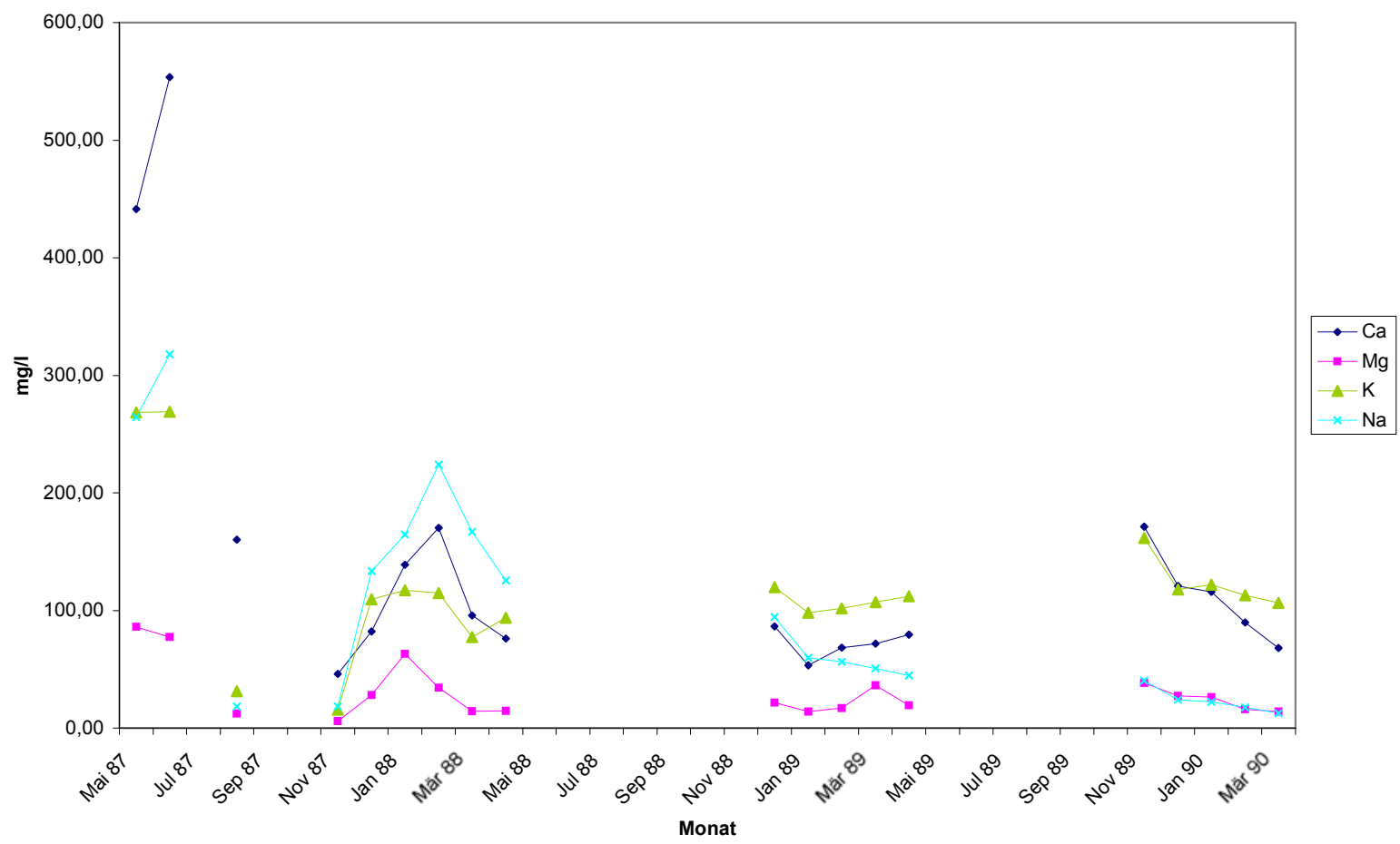

Abbildung 13-4: Konzentrationsverlauf der Kationen im Sickerwasser, Monatsmittelwerte, Lysimeter 3

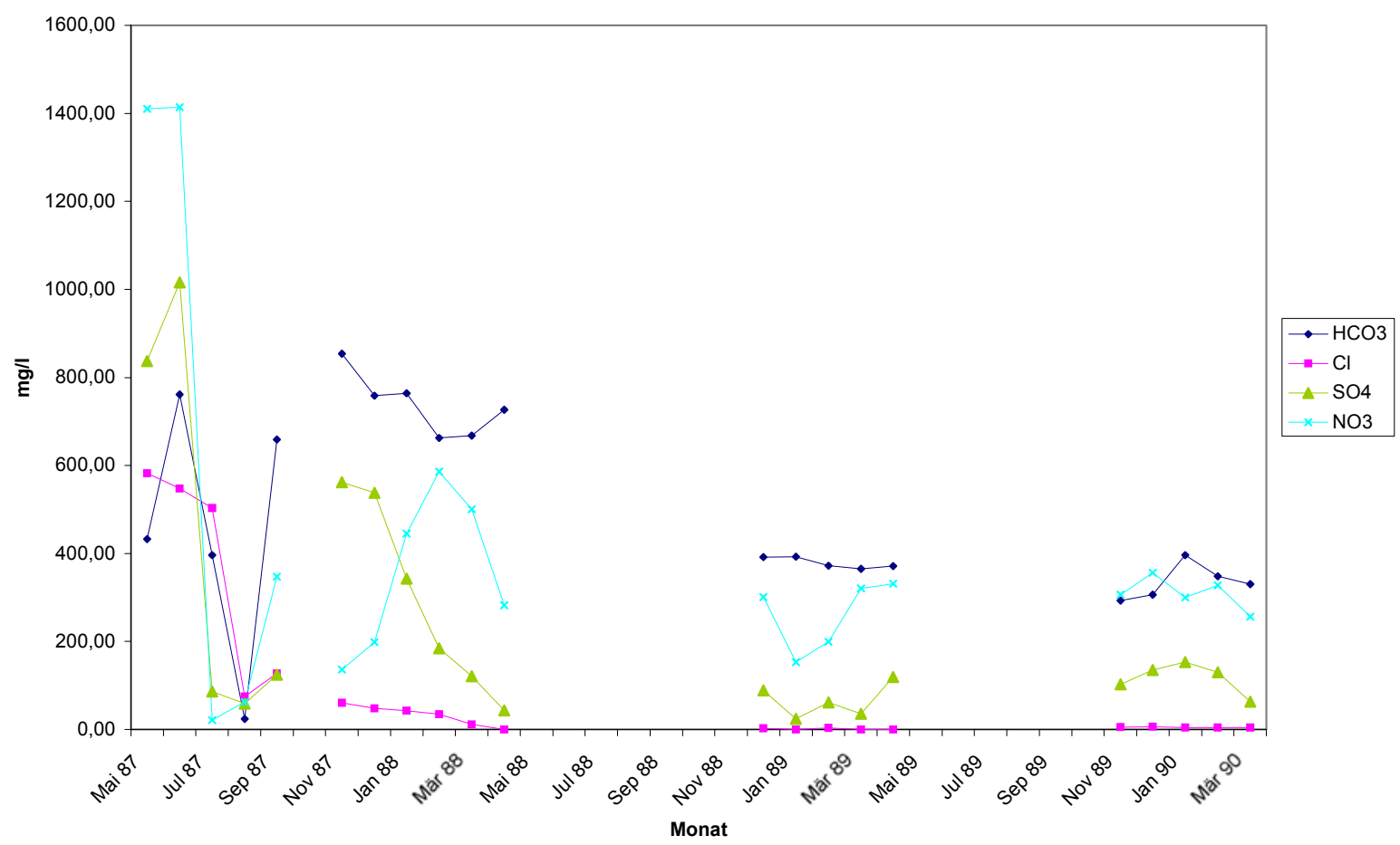

Abbildung 13-5: Konzentrationsverlauf der Anionen im Sickerwasser, Monatsmittelwerte, Lysimeter 6 


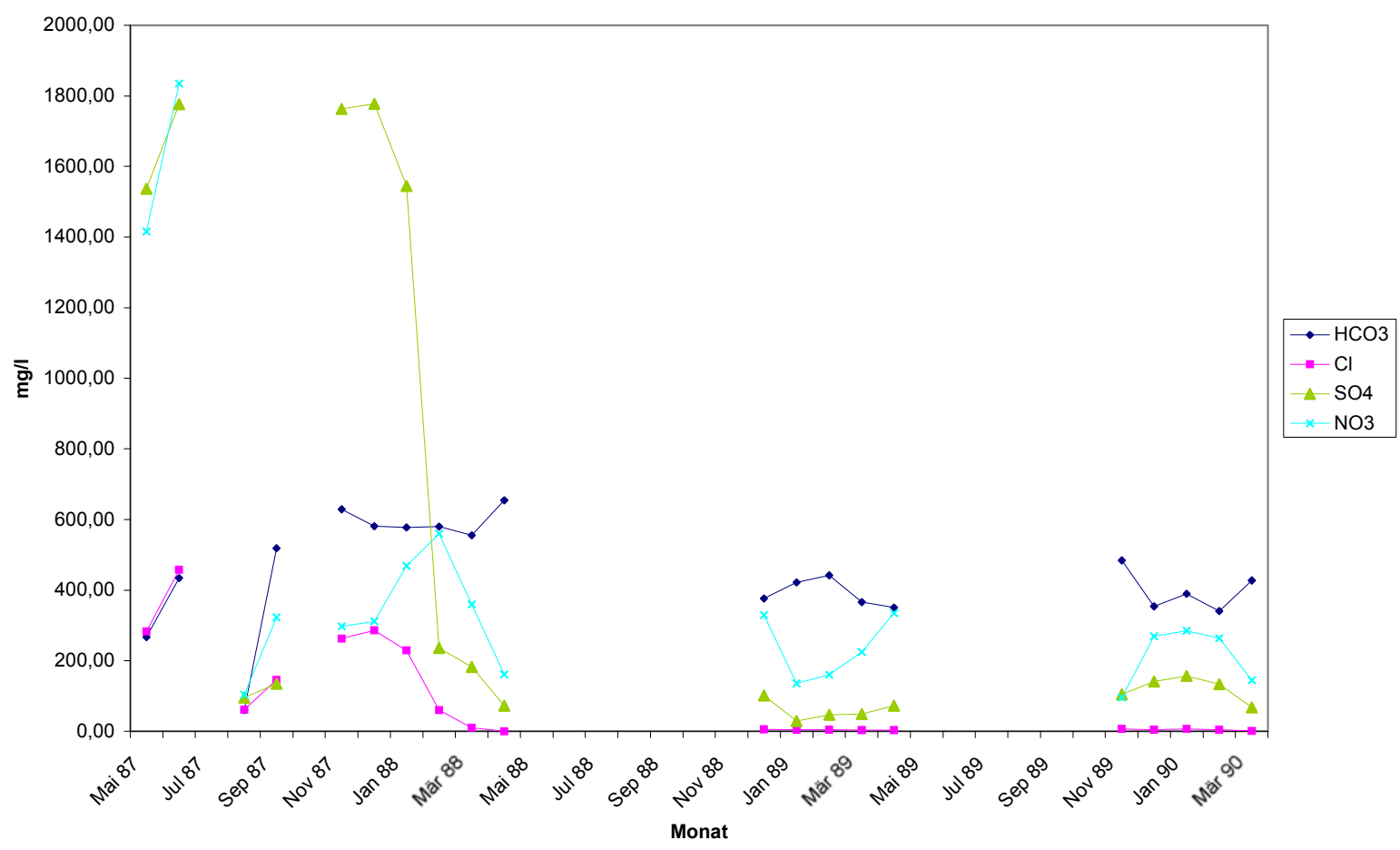

Abbildung 13-6: Konzentrationsverlauf der Kationen im Sickerwasser, Monatsmittelwerte, Lysimeter 5

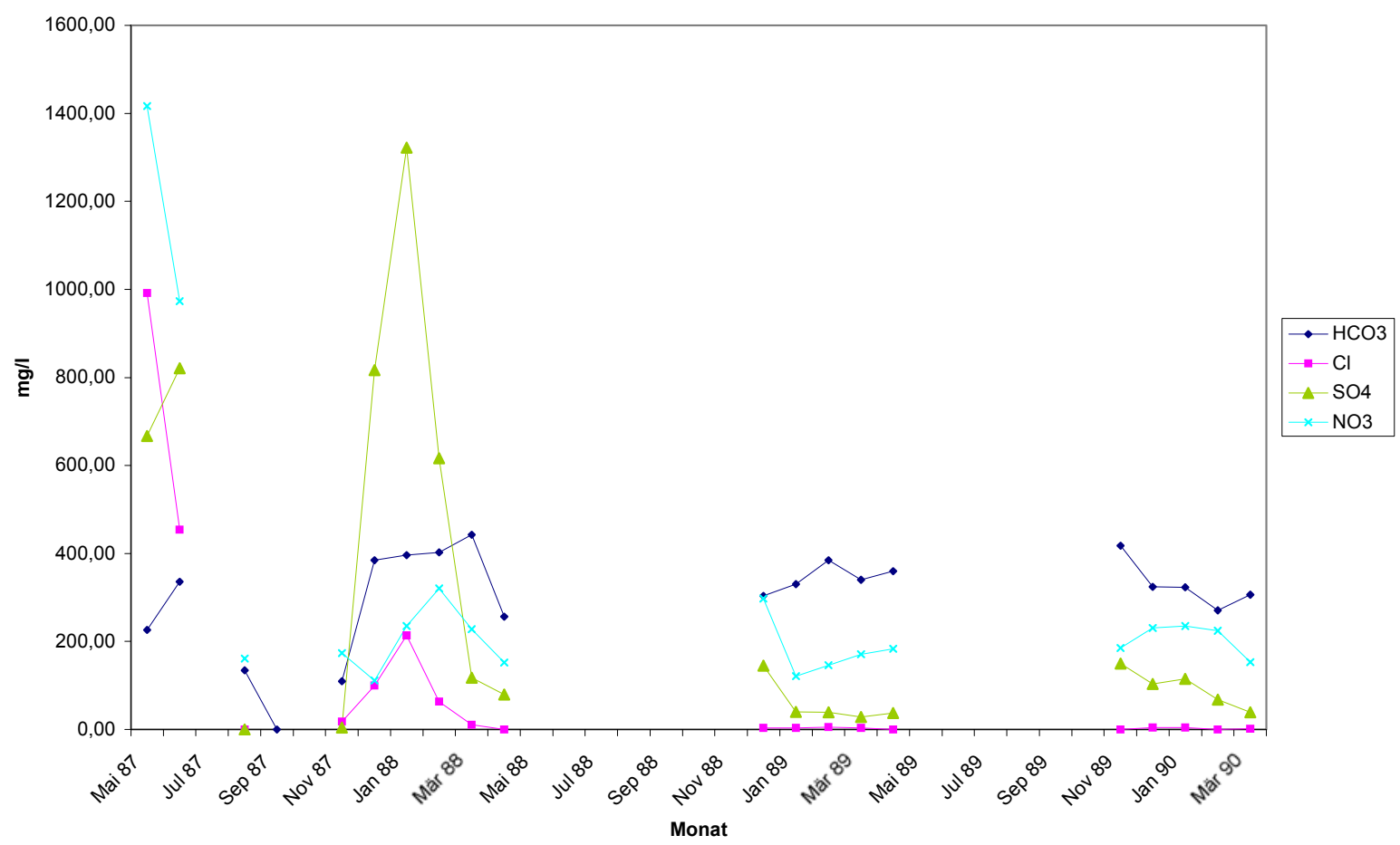

Abbildung 13-7: Konzentrationsverlauf der Anionen im Sickerwasser, Monatsmittelwerte, Lysimeter 3 


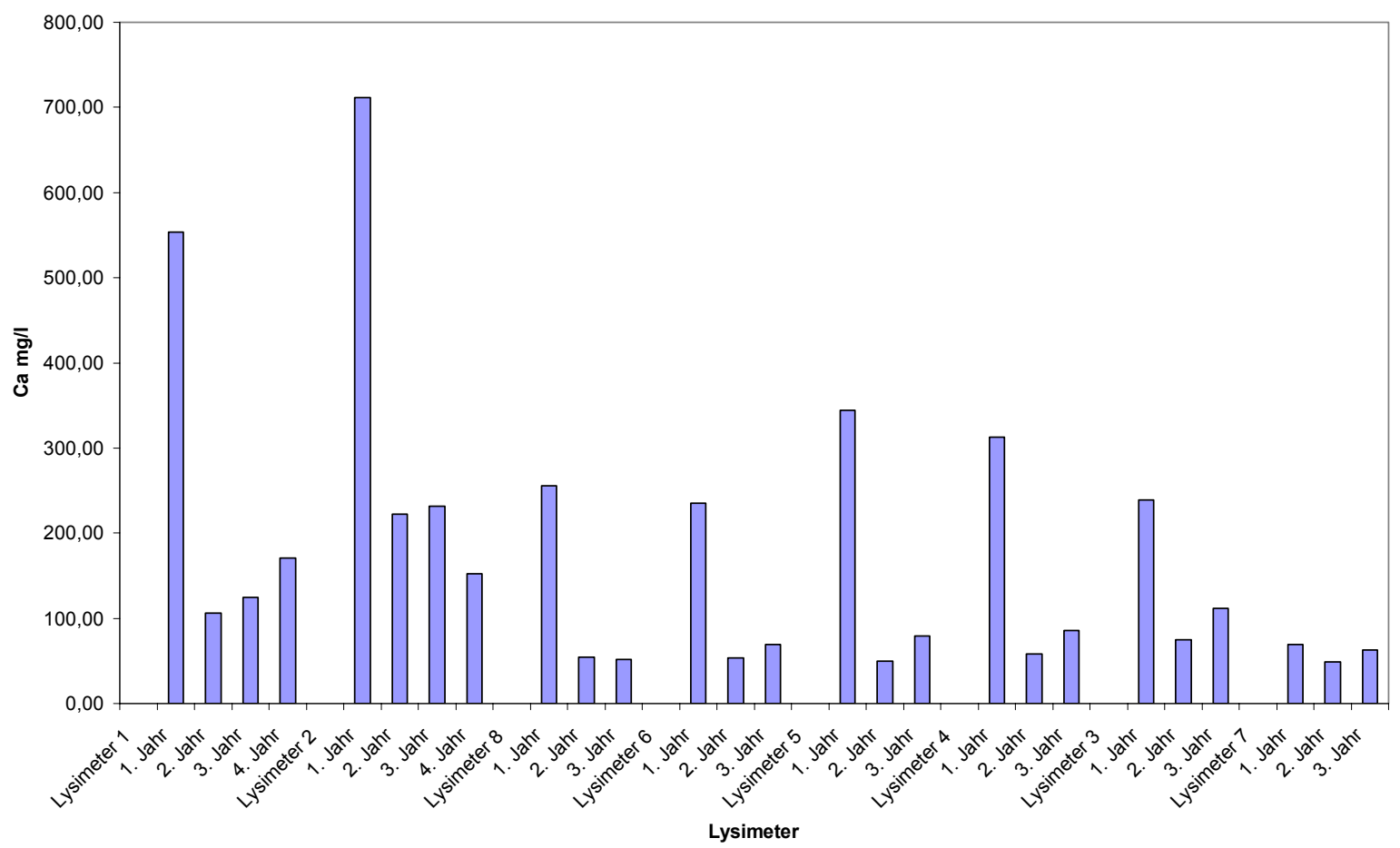

Abbildung 13-8: Vergleich der Ca-Jahres-

Durchschnittskonzentrationen, Lysimeter 1 - 8

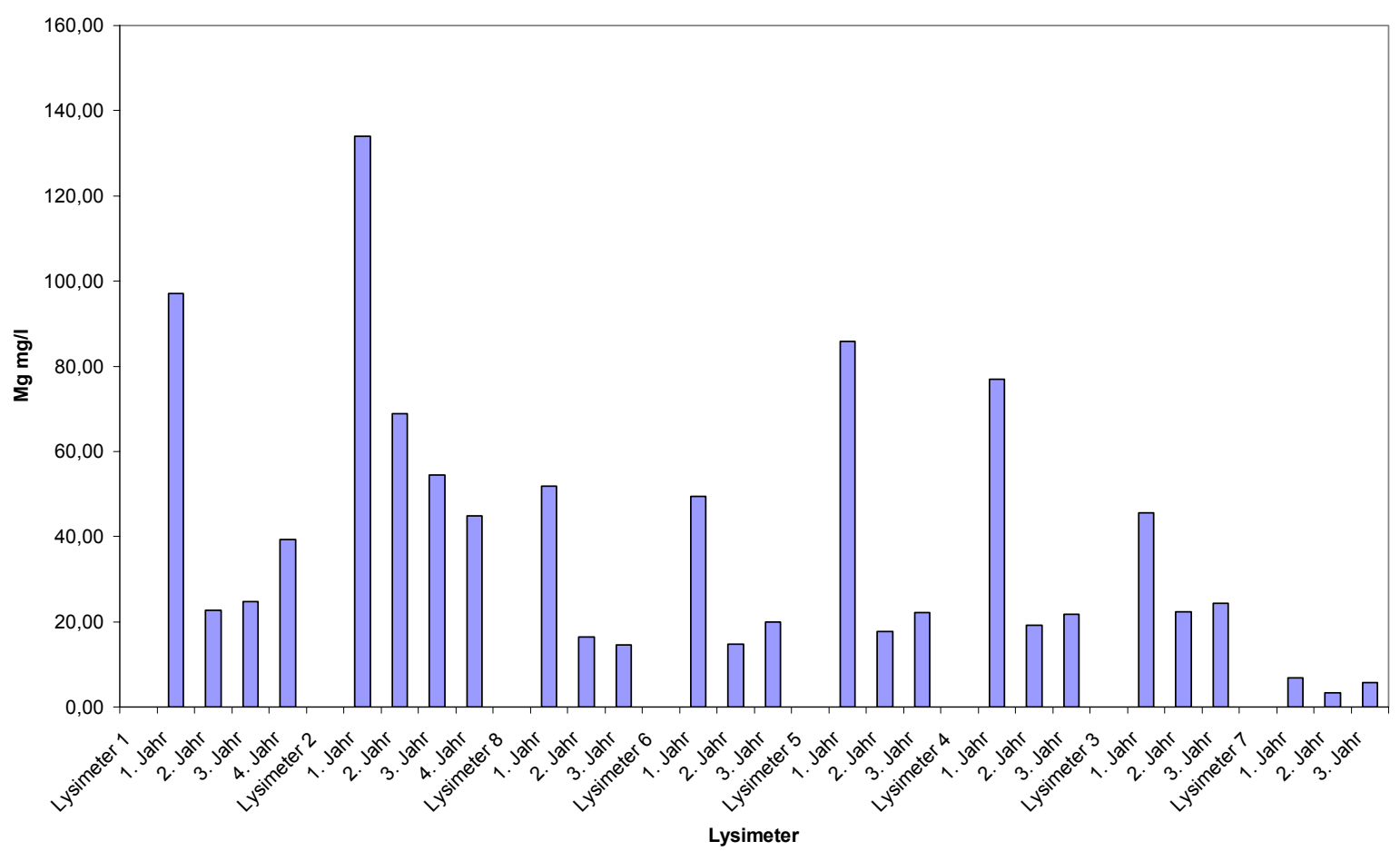

Abbildung 13-9: Vergleich der Mg-Jahres-

Durchschnittskonzentrationen, Lysimeter 1 - 8 


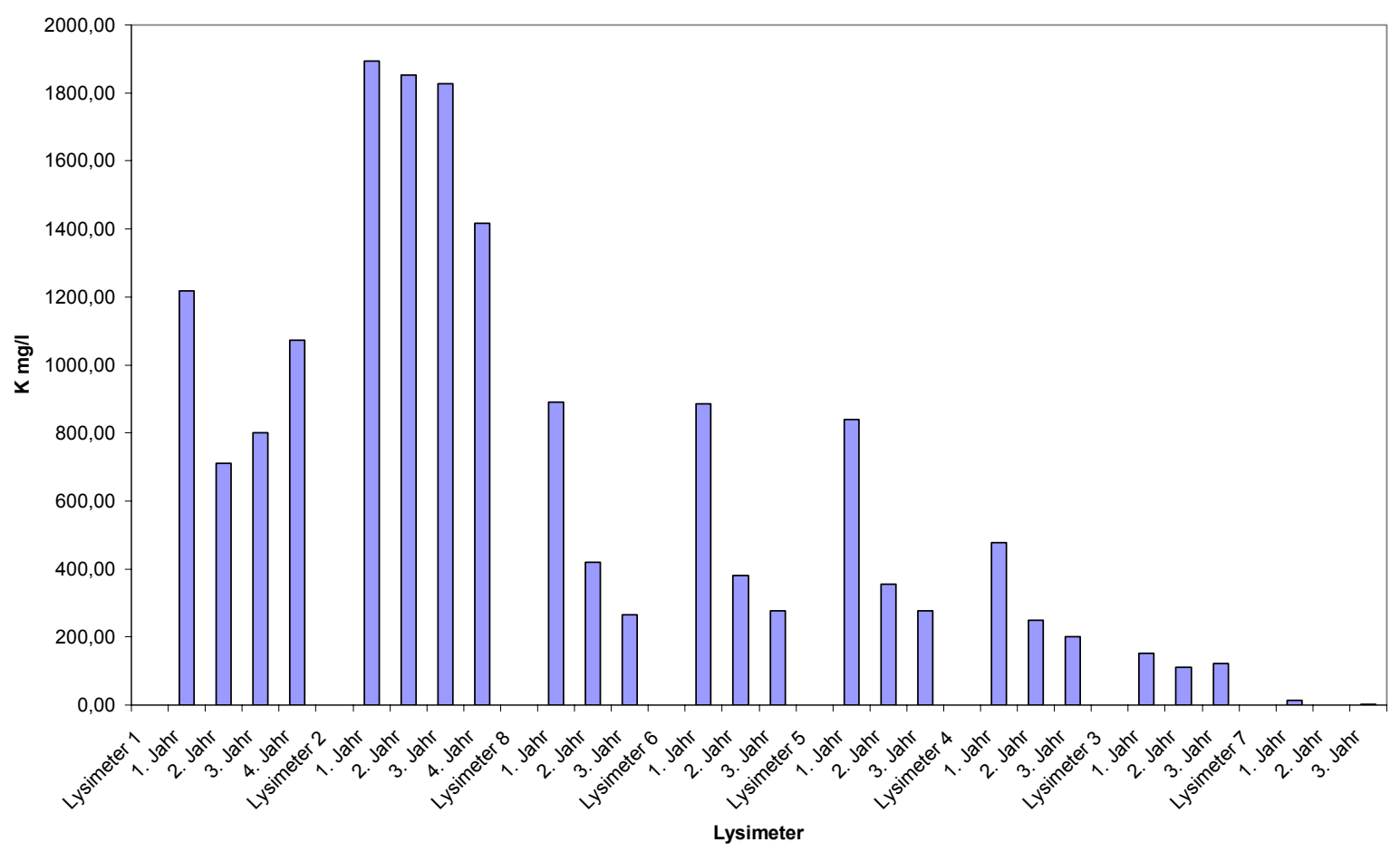

Abbildung 13-10: Vergleich der K-Jahres-

Durchschnittskonzentrationen, Lysimeter 1 - 8

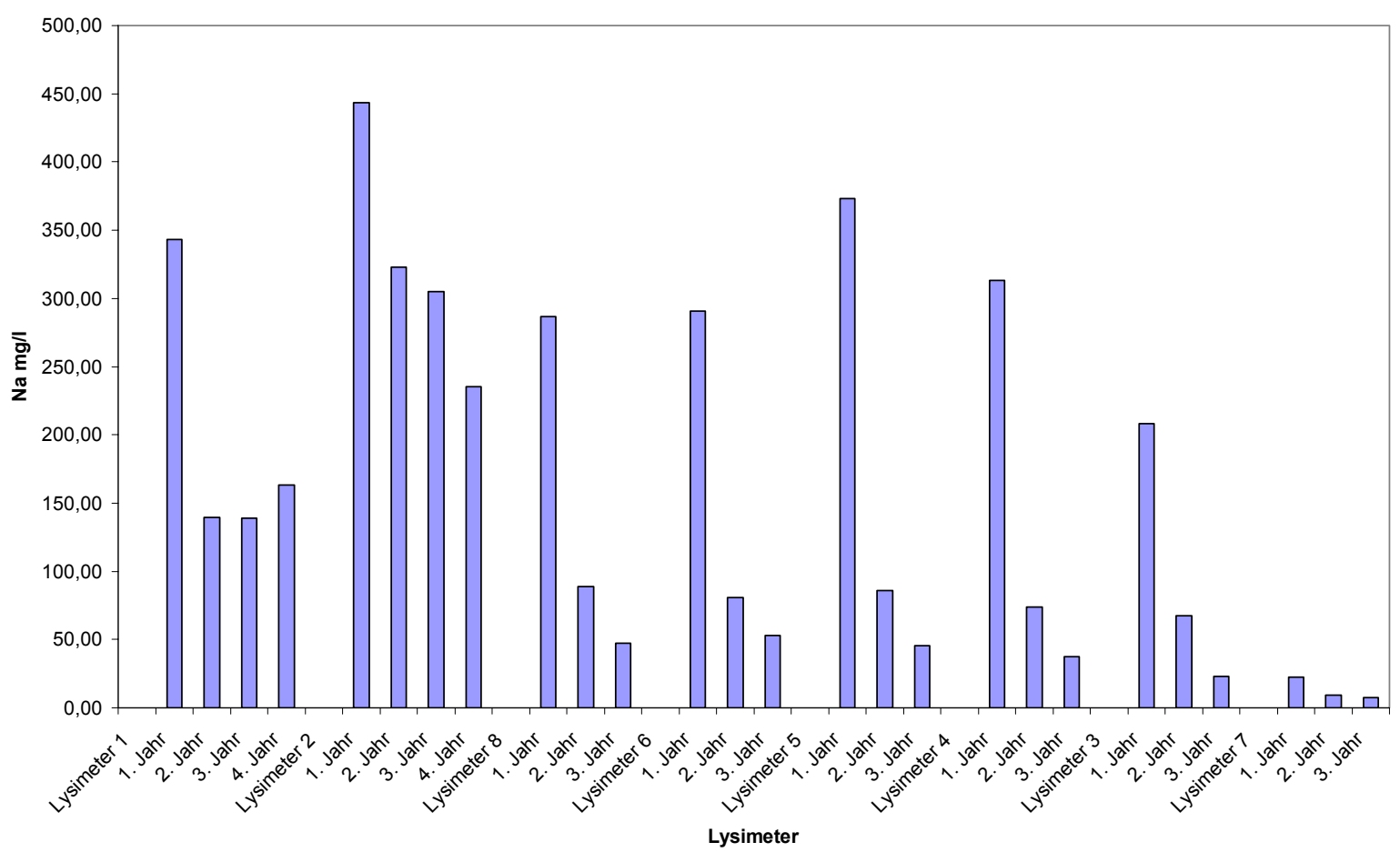

Abbildung 13-11: Vergleich der Na-Jahres-

Durchschnittskonzentrationen, Lysimeter 1 - 8 


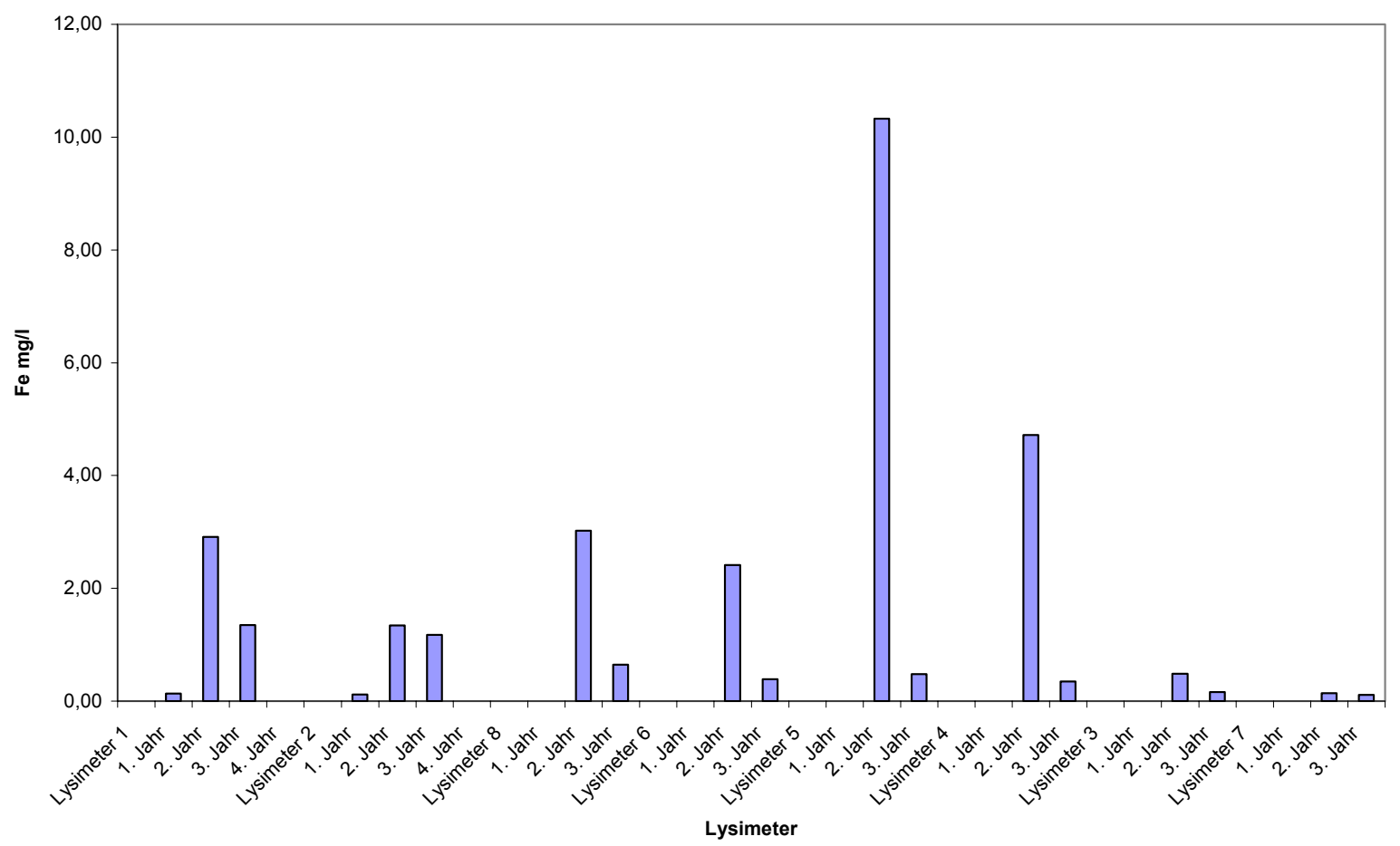

Abbildung 13-12: Vergleich der Fe-Jahres-

Durchschnittskonzentrationen, Lysimeter 1 - 8

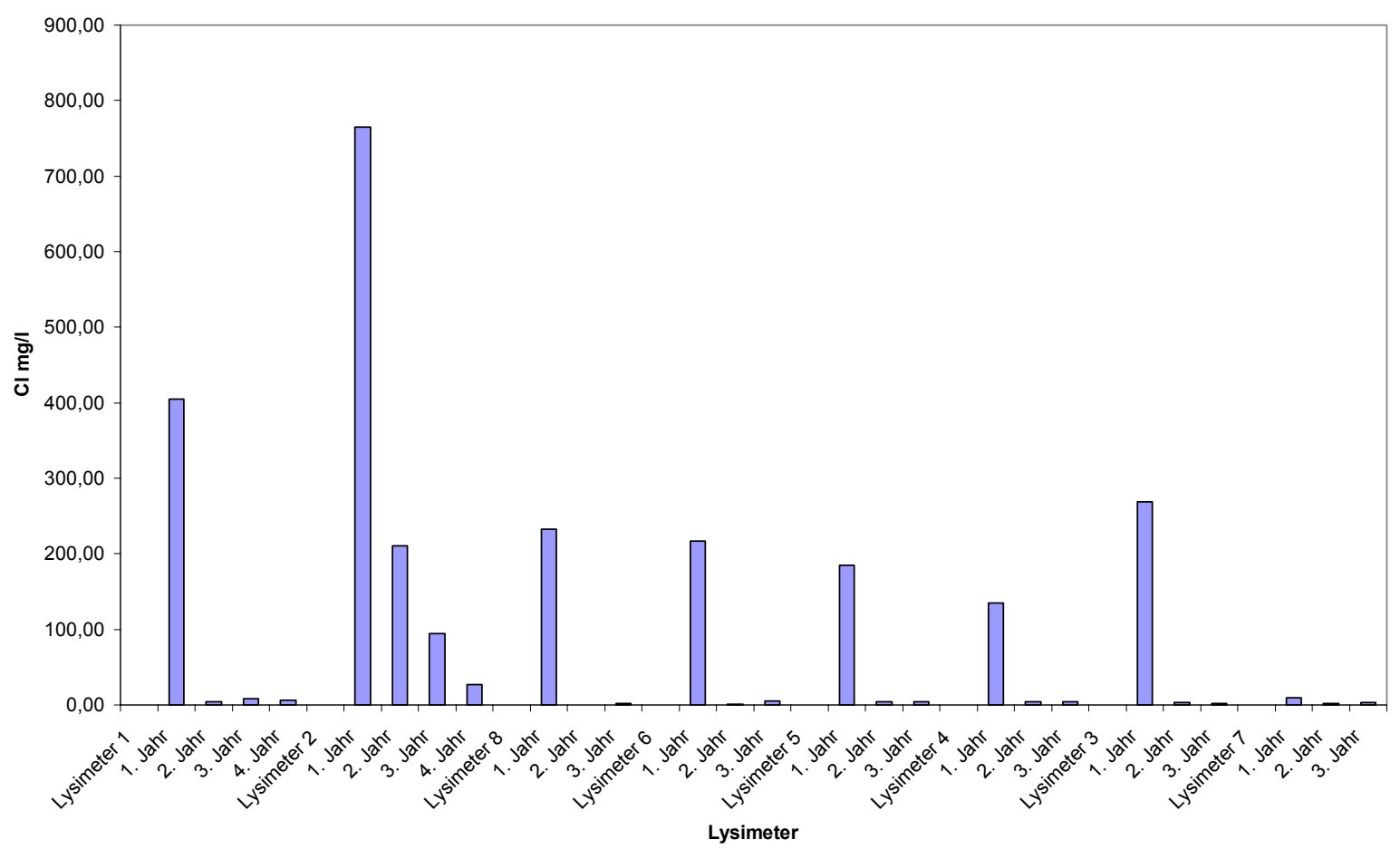

Abbildung 13-13: Vergleich der Cl-Jahres-

Durchschnittskonzentrationen, Lysimeter 1 - 8 


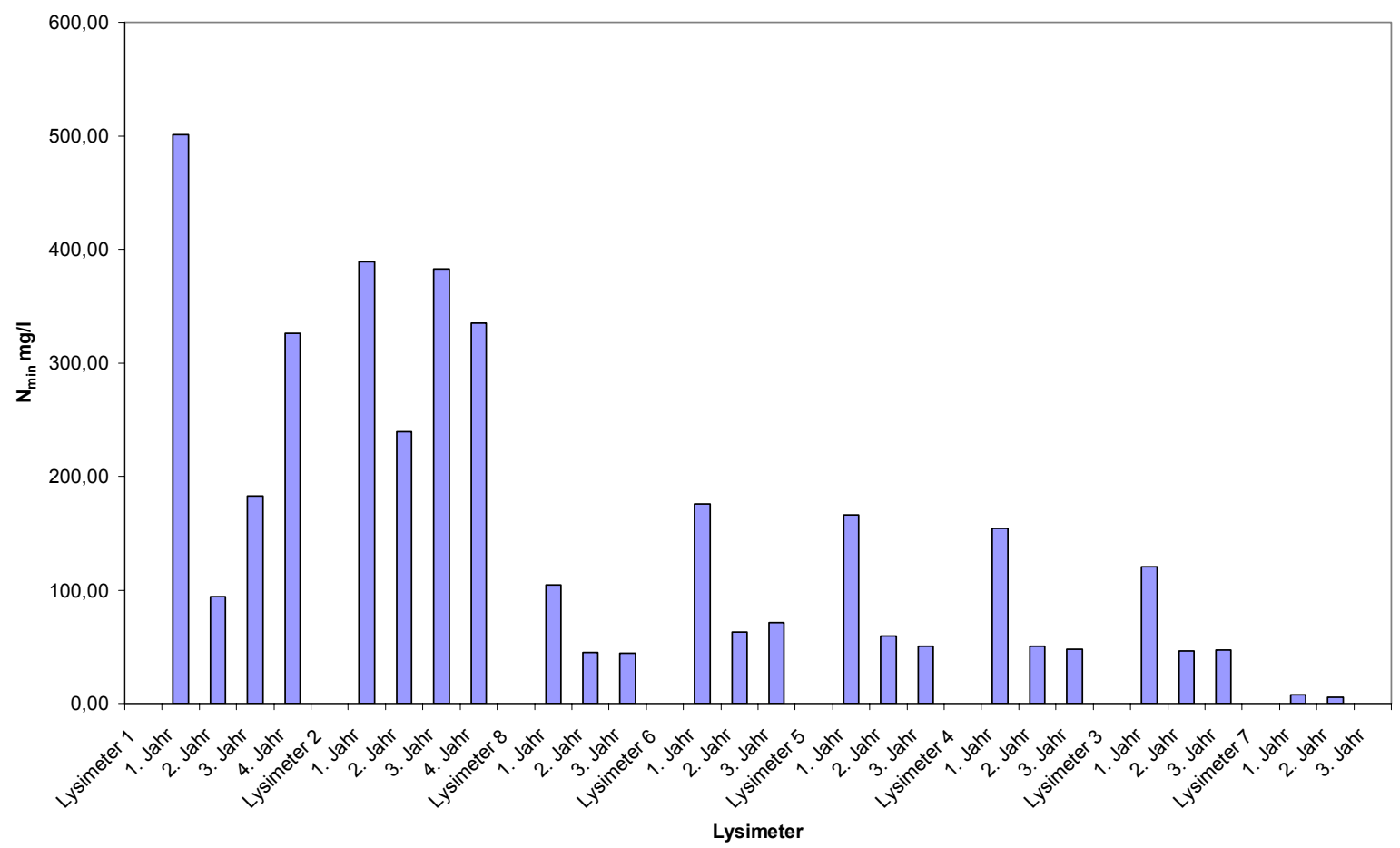

Abbildung 13-14: Vergleich der $\mathrm{N}_{\text {min }}$-Jahres-

Durchschnittskonzentrationen, Lysimeter 1 - 8

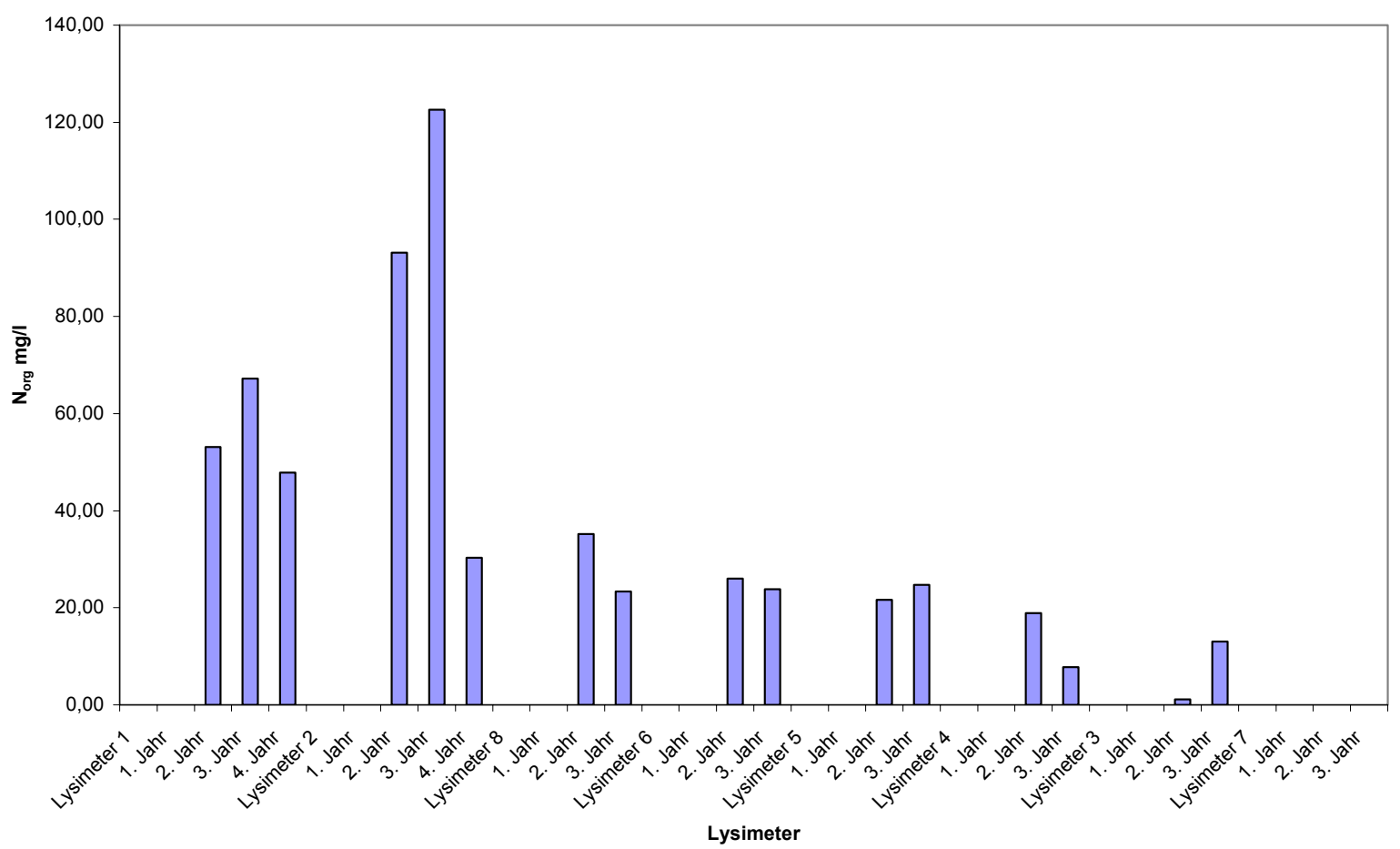

Abbildung 13-15: Vergleich der $\mathrm{N}_{\text {org-Jahres- }}$

Durchschnittskonzentrationen, Lysimeter 1 - 8 
Tabelle 13-80: Gel-chromatographische Fraktionierung der organischen Substanz, Lysimeter 1

\begin{tabular}{|c|c|c|c|c|c|c|c|c|}
\hline Probenart & $\begin{array}{c}\text { Tiefe } \\
\text { cm }\end{array}$ & $\begin{array}{c}\text { Datum der } \\
\text { Probenahme }\end{array}$ & \multicolumn{3}{|c|}{ molare Masse in $u$} & \multicolumn{2}{|c|}{ Peakhöhe in cm } & $\begin{array}{c}\text { Quotient } \\
\text { P1/P3 }\end{array}$ \\
\hline BE 1.1 & $0-20$ & 24.06.1988 & 30.345 & 6.353 & 1.146 & & & \\
\hline UF 1. F & & 22.12 .1988 & 53.275 & & 807 & & & \\
\hline UF 1. F & & 22.12.1988 & 35.187 & 3.174 & 1.373 & & & \\
\hline UF 1. F & & 22.12.1988 & 48.629 & 3.448 & 1.384 & & & \\
\hline UF 1. D & & 22.12.1988 & 49.854 & & & & & \\
\hline UF 1. RnHA & & 22.12.1988 & 36.324 & 2.593 & 1.156 & & & \\
\hline AC-Eluat & & & & & 1.086 & & & \\
\hline sw & & 07.07.1988 & 26.654 & 2.405 & 940 & 4,3 & 1,6 & 2,7 \\
\hline sw & & 07.07.1988 & 15.182 & 1.944 & 736 & 4,6 & 1,7 & 2,7 \\
\hline sw & & 14.12.1988 & 22.623 & 1.666 & 736 & 6,4 & 1,3 & 4,9 \\
\hline sw & & 14.12.1988 & 40.603 & 2.976 & 2.054 & 7,3 & 2,0 & 3,7 \\
\hline sw & & 14.12.1988 & 50.359 & 1.120 & 615 & & & \\
\hline sw & & 22.12.1988 & 26.589 & & 670 & & & \\
\hline sw & & 11.01.1989 & 47.495 & 4.422 & 1.878 & 7,4 & 1,9 & 3,9 \\
\hline sw & & 14.02.1989 & 29.892 & 2.432 & 1.045 & 8,6 & 2,2 & 3,9 \\
\hline sw & & 27.02.1989 & 58.898 & 2.875 & 1.314 & & & \\
\hline sw & & 06.03.1989 & 44.560 & 2.932 & 1.314 & & & \\
\hline sw & & 17.04.1989 & 31.377 & 2.345 & 1.012 & 11,1 & 1,8 & 6,2 \\
\hline sw & & 10.11.1989 & 38.498 & 2.862 & 1.504 & 8,1 & 2,1 & 3,9 \\
\hline sw & & 10.11.1989 & 47.495 & 4.422 & 1.878 & 7,4 & 1,9 & 3,9 \\
\hline Mw & & & 36.940 & 2.700 & 1.207 & 8,0 & 1,9 & 4,3 \\
\hline
\end{tabular}

Tabelle 13-81: Gel-chromatographische Fraktionierung der organischen Substanz, Lysimeter 2

\begin{tabular}{|c|c|c|c|c|c|c|c|c|c|}
\hline Probenart & $\begin{array}{c}\text { Tiefe } \\
\mathbf{c m} \\
\end{array}$ & $\begin{array}{c}\text { Datum der } \\
\text { Probenahme } \\
\end{array}$ & $\begin{array}{c}\text { Probenmenge } \\
\mathrm{ml}\end{array}$ & \multicolumn{3}{|c|}{ molare Masse in $u$} & $\begin{array}{r}\text { Peak 1 } \\
\text { Peakhöl } \\
\end{array}$ & $\begin{array}{l}\text { Peak } 3 \\
\text { in } \mathrm{cm}\end{array}$ & $\begin{array}{c}\text { Quotient } \\
\text { P1/P3 }\end{array}$ \\
\hline BE 1.1 & $0-20$ & 24.06.1988 & & 30.000 & 2.000 & 950 & 5,9 & 2,5 & 2,4 \\
\hline BE 1.1 & $20-45$ & 24.06.1988 & & 30.000 & 2.000 & 950 & 10,5 & 3,8 & 2,8 \\
\hline BE 1.1 & $45-70$ & 24.06.1988 & & 30.000 & 2.000 & 950 & 9,9 & 5,8 & 1,7 \\
\hline BE 1.1 & $20-45$ & 24.06.1988 & & 30.000 & 2.000 & 950 & 8,5 & 1,9 & 4,5 \\
\hline BE 1.1 & $45-70$ & 24.06.1988 & & 30.000 & 2.000 & 950 & 3,0 & 0,8 & 3,8 \\
\hline sw & & 07.07 .1988 & 0,5 & 15.558 & & $707 / 399$ & 4,1 & 7,3 & 0,6 \\
\hline sw & & 07.07 .1988 & 0,2 & 27.763 & & 805 & 3,6 & 2,6 & 1,4 \\
\hline sw & & 07.07.1988 & 0,1 & 30.869 & 2.041 & 1.201 & 2,3 & 1,7 & 1,4 \\
\hline sw & & 14.12.1988 & 0,1 & 30.197 & & 1.417 & 4,7 & 3,3 & 1,4 \\
\hline sw & & 22.12.1988 & 0,5 & 37.545 & & 842 & 13,7 & 14,0 & 1,0 \\
\hline sw & & 11.01.1989 & 0,1 & 41.679 & 1.869 & 1.111 & 6,8 & 2,8 & 2,4 \\
\hline sw & & 14.02.1989 & 0,1 & 40.702 & & 1.094 & 4,6 & 6,6 & 0,7 \\
\hline sw & & 27.02.1989 & 0,1 & 65.915 & 2.765 & 1.642 & 6,3 & 3,5 & 1,8 \\
\hline sw & & 17.04.1989 & 0,1 & 44.198 & 2.307 & 1.426 & 7,8 & 3,1 & 2,5 \\
\hline Mw & & & & 40.189 & 2.246 & 1.242 & 5,2 & 3,4 & 1,7 \\
\hline
\end{tabular}


Tabelle 13-82: Gel-chromatographische Fraktionierung der organischen Substanz, Lysimeter 8

\begin{tabular}{|c|c|c|c|c|c|c|c|}
\hline Probenart & $\begin{array}{c}\text { Datum der } \\
\text { Probenahme }\end{array}$ & \multicolumn{3}{|c|}{ molare Masse in $u$} & $\begin{array}{c}\text { Peak } 1 \\
\text { Peakhöhe }\end{array}$ & $\begin{array}{l}\text { Peak } 3 \\
\text { in } \mathrm{cm}\end{array}$ & $\begin{array}{c}\text { Quotient } \\
\text { P1/P3 }\end{array}$ \\
\hline UF 1. R & 22.12.1988 & 51.788 & & & & & \\
\hline UF 1. RnHA & 22.12.1988 & 66.054 & & 1.187 & 1,2 & 1,0 & 1,2 \\
\hline sw & 14.12.1988 & 52.599 & 3.582 & 1.556 & 7,5 & 1,8 & 4,2 \\
\hline sw & 16.02.1989 & 40.347 & 6.785 & 1.506 & 6,9 & 0,9 & 7,7 \\
\hline sw & 17.04.1989 & 40.076 & 7.841 & 1.426 & 7,6 & 0,9 & 8,4 \\
\hline Mw & & 44.341 & 6.069 & 1.496 & 7,3 & 1,2 & 6,8 \\
\hline A 0 & März 1986 & 21855 & & 823 & 5,5 & 15,1 & 0,4 \\
\hline
\end{tabular}

Tabelle 13-83: Gel-chromatographische Fraktionierung der organischen Substanz, Lysimetr 6

\begin{tabular}{|c|c|c|c|c|c|c|c|}
\hline Probenart & $\begin{array}{c}\text { Datum der } \\
\text { Probenahme }\end{array}$ & \multicolumn{3}{|c|}{ molare Masse in $u$} & \multicolumn{2}{|c|}{ Peakhöhe in cm } & $\begin{array}{c}\text { Quotient } \\
\text { P1/P3 }\end{array}$ \\
\hline sw & 14.12.1988 & 47.645 & 2.976 & 1.418 & 7,5 & 2,4 & 3,13 \\
\hline sw & 22.12.1988 & 43.900 & 5.980 & 1.596 & 4,3 & 1,6 & 2,69 \\
\hline sw & 06.01 .1989 & & & & & & \\
\hline sw & 16.02.1989 & 51.207 & 9.803 & 1.731 & 5,5 & 1 & 5,50 \\
\hline sw & 06.03.1989 & 40.504 & 5.704 & 1.273 & 6,5 & 1 & 6,50 \\
\hline sw & 17.04.1989 & 46.452 & & 1.273 & 5,1 & 1,6 & 3,19 \\
\hline sw & 10.11.1989 & 52.337 & 8.958 & 2.070 & 2,3 & 0,5 & 4,60 \\
\hline Mw & & 47.008 & 6.684 & 1.560 & 5,2 & 1,4 & 4,3 \\
\hline
\end{tabular}

Tabelle 13-84: Gel-chromatographische Fraktionierung der organischen Substanz, Lysimeter 5

\begin{tabular}{|c|c|c|c|c|c|c|c|}
\hline Probenart & $\begin{array}{c}\text { Datum der } \\
\text { Probenahme }\end{array}$ & \multicolumn{3}{|c|}{ molare Masse in u } & $\begin{array}{c}\text { Peak } 1 \\
\text { Peakhöh }\end{array}$ & $\begin{array}{l}\text { Peak } 3 \\
\text { in cm }\end{array}$ & $\begin{array}{c}\text { Quotient } \\
\text { P1/P3 } \\
\end{array}$ \\
\hline UF 1. F & 22.12.1988 & 58.758 & 7.073 & 2.692 & & & \\
\hline UF 1. R & 22.12.1988 & 48.826 & & & 6,0 & & \\
\hline UF 1. RnHA & 22.12.1988 & 79.443 & & 1.207 & 0,4 & 1,2 & 0,3 \\
\hline UF 4. F & 22.12.1988 & 66.834 & & & 1,0 & & \\
\hline SW & 14.12.1988 & 33.139 & & 1.293 & 3,2 & 1,1 & 2,9 \\
\hline SW & 22.12.1988 & 33.727 & 1.130 & 875 & 4,1 & 0,9 & 4,6 \\
\hline sw & 22.12.1988 & 23.584 & 1.724 & 614 & 4,6 & 2,7 & 1,7 \\
\hline SW & 16.02.1989 & 45.444 & 9.580 & 1.878 & 2,9 & 0,7 & 4,1 \\
\hline SW & 06.03 .1989 & 32.736 & & 1.070 & 4,8 & 1,0 & 4,8 \\
\hline SW & 17.04.1989 & 43.483 & 12.688 & 1.651 & 4,0 & 1,0 & 4,0 \\
\hline SW & 17.04.1989 & 23.070 & 3.249 & 763 & 2,8 & 2,0 & 1,4 \\
\hline SW & 10.11.1989 & 44.649 & & 1.813 & 2,0 & 0,6 & 3,3 \\
\hline Mw & & 34.979 & 5.674 & 1.245 & 3,6 & 1,3 & 3,4 \\
\hline
\end{tabular}


Tabelle 13-85: Gel-chromatographische Fraktionierung der organischen Substanz, Lysimeter 4

\begin{tabular}{lc|ccc|ccc} 
Probenart & $\begin{array}{c}\text { Datum der } \\
\text { Probenahme }\end{array}$ & $\begin{array}{r}\text { Peak 1 } \\
\text { molare Masse in u }\end{array}$ & $\begin{array}{c}\text { Peak 2 } \\
\text { Peakhöhe in cm }\end{array}$ & $\begin{array}{c}\text { Peak 3 } \\
\text { P1/P3 }\end{array}$ \\
\hline SW & & & & & & & \\
SW & $\mathbf{1 4 . 1 2 . 1 9 8 8}$ & 27.499 & 3.930 & 892 & 2,8 & 1,5 & 1,9 \\
SW & $\mathbf{1 6 . 0 2 . 1 9 8 9}$ & 36.446 & 10.136 & 1.617 & 2,0 & 0,6 & 3,3 \\
SW & $\mathbf{0 6 . 0 3 . 1 9 8 9}$ & 29.037 & 6.431 & 949 & 2,1 & 1,0 & 2,1 \\
& $\mathbf{1 7 . 0 4 . 1 9 8 9}$ & 28.544 & & 3.610 & 2,4 & 1,6 & 1,5 \\
Mw & & & & & & & \\
& & $\mathbf{3 0 . 3 8 2}$ & $\mathbf{6 . 8 3 2}$ & $\mathbf{1 . 7 6 7}$ & $\mathbf{2 , 3}$ & $\mathbf{1 , 2}$ & $\mathbf{2 , 2}$
\end{tabular}

Tabelle 13-86: Gel-chromatographische Fraktionierung der organischen Substanz, Lysimeter 3

\begin{tabular}{lcc|ccc|ccc} 
Probenart & $\begin{array}{c}\text { Tiefe } \\
\text { cm }\end{array}$ & $\begin{array}{c}\text { Datum der } \\
\text { Probenahme }\end{array}$ & $\begin{array}{c}\text { Peak 1 } \\
\text { molare Masse in u }\end{array}$ & $\begin{array}{c}\text { Peak 2 } \\
\text { Peak 3 }\end{array}$ & $\begin{array}{c}\text { Peak 1 } \\
\text { Peakhöhe in cm }\end{array}$ & $\begin{array}{c}\text { Peak 3uotient } \\
\text { P1/P3 }\end{array}$ \\
\hline BE 1.1 & $\mathbf{0 - 2 0}$ & $\mathbf{2 4 . 0 6 . 1 9 8 8}$ & 25.319 & 3.338 & 906 & & & \\
& & & & & & & & \\
SW & & $\mathbf{1 4 . 1 2 . 1 9 8 8}$ & 24.889 & 2.256 & 854 & 1,4 & 1,6 & 0,9 \\
SW & & $\mathbf{1 6 . 0 2 . 1 9 8 9}$ & 26.769 & 9.362 & 1.126 & 0,9 & 0,7 & 1,3 \\
SW & & $\mathbf{0 6 . 0 3 . 1 9 8 9}$ & 21.490 & 3.781 & 817 & 1,2 & 0,8 & 1,5 \\
SW & & $\mathbf{1 7 . 0 4 . 1 9 8 9}$ & 25.133 & 7.006 & 944 & 1,5 & 1,5 & 1,0 \\
SW & & $\mathbf{1 0 . 1 1 . 1 9 8 9}$ & 34.938 & 2.956 & 1.120 & 0,8 & 0,7 & 1,1 \\
& & & & & & & & \\
Mw & & $\mathbf{1 4 . 0 2 . 1 9 8 9}$ & $\mathbf{2 6 . 6 4 4}$ & $\mathbf{5 . 0 7 2}$ & $\mathbf{9 7 2}$ & $\mathbf{1 , 2}$ & $\mathbf{1 , 1}$ & $\mathbf{1 , 2}$
\end{tabular}

Tabelle 13-87: Kationen in $\mathrm{mg} / \mathrm{l}$ und \% der Ausgangsprobe sowie Kationenverhältnisse im Eluat, AdsorptionsChromatographie der Sickerwasserprobe vom 07.07.1988 (1), Lysimeter 1

\begin{tabular}{|c|c|c|c|c|c|c|c|c|c|c|c|c|}
\hline Arbeitsschritt & $\begin{array}{c}\text { Proben- } \\
\text { Nr. }\end{array}$ & $\mathrm{Fe}$ & $\begin{array}{c}\mathrm{Ca} \\
\mathrm{mg} / \mathrm{l}\end{array}$ & Mg & $\mathbf{K}$ & $\mathrm{Fe}$ & $\begin{array}{c}\mathrm{Ca} \\
\% \\
\end{array}$ & Mg & $\mathbf{K}$ & $\begin{array}{l}\mathrm{Ca} / \mathrm{Mg} \\
\text { lonene } \\
\end{array}$ & $\begin{array}{l}\mathrm{K} / \mathrm{Mg} \\
\text { alentv }\end{array}$ & $\begin{array}{c}\mathrm{Ca} / \mathrm{K} \\
\text { ältnisse }\end{array}$ \\
\hline SW L 1 & & 0,30 & 48,00 & 14,00 & 145,00 & 100,00 & 100,00 & 100,00 & 100,00 & 2,08 & 3,22 & 0,65 \\
\hline \multicolumn{13}{|c|}{ Eluate der HUS-Konzentrierung an XAD 2 und HA-Fällung: } \\
\hline \multirow[t]{3}{*}{ Anreicherung } & 1 & 0,01 & 14,25 & 4,50 & 111,50 & 3,33 & 29,69 & 32,14 & 76,90 & 1,92 & 7,71 & 0,25 \\
\hline & 2 & 0,08 & 42,50 & 12,00 & 143,25 & 26,67 & 88,54 & 85,71 & 98,79 & 2,15 & 3,71 & 0,58 \\
\hline & 3 & 0,05 & 44,00 & 12,50 & 143,75 & 16,67 & 91,67 & 89,29 & 99,14 & 2,14 & 3,58 & 0,60 \\
\hline \multirow[t]{3}{*}{ Reinigung } & 4 & 0,23 & 13,25 & 13,00 & 23,75 & 76,67 & 27,60 & 92,86 & 16,38 & 0,62 & 0,57 & 1,09 \\
\hline & 5 & 0,04 & 0,00 & 1,25 & 1,25 & 13,33 & 0,00 & 8,93 & 0,86 & & 0,31 & \\
\hline & 6 & 0,00 & 0,00 & 0,00 & 0,25 & 0,00 & 0,00 & 0,00 & 0,17 & & & \\
\hline \multirow[t]{3}{*}{ Desorption } & 7 & 0,03 & 2,00 & 0,00 & 5,25 & 10,00 & 4,17 & 0,00 & 3,62 & & & 0,74 \\
\hline & 8 & 0,80 & 0,00 & 0,00 & 6,25 & 266,67 & 0,00 & 0,00 & 4,31 & & & \\
\hline & 9 & 0,10 & 0,00 & 0,00 & 6,50 & 33,33 & 0,00 & 0,00 & 4,48 & & & \\
\hline Reinigung & 10 & 0,14 & 0,00 & 0,00 & 5,50 & 46,67 & 0,00 & 0,00 & 3,79 & & & \\
\hline
\end{tabular}




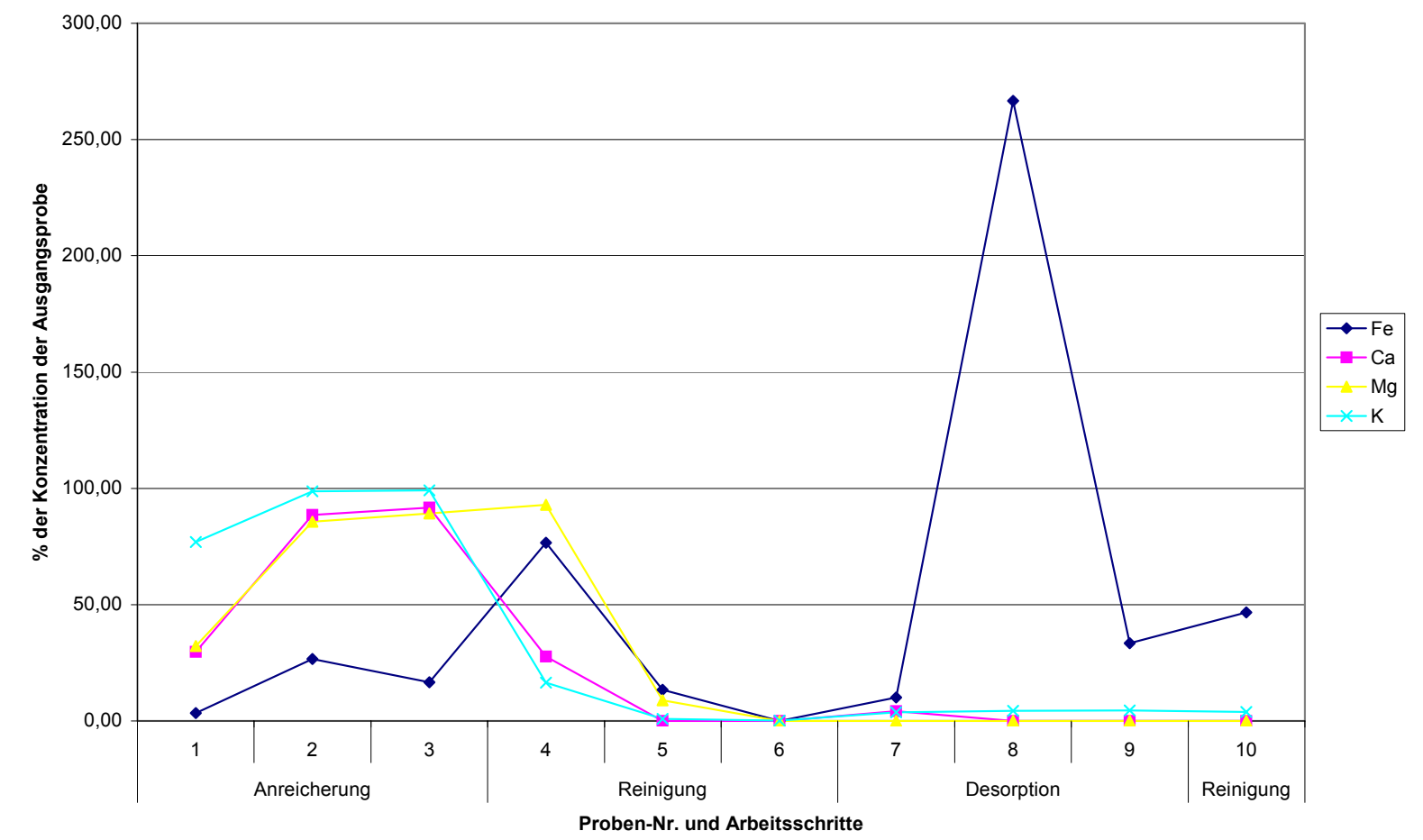

Abbildung 13-16: Kationen in \% der Ausgangsprobe im Eluat, Adsorptions-Chromatographie der Sickerwasserprobe vom 07.07.1988 (1), Lysimeter 1

Tabelle 13-88: Kationen in $\mathrm{mg} / \mathrm{l}$ und \% der Ausgangsprobe sowie Kationenverhältnisse im Eluat, Adsorptions-

Chromatographie der Sickerwasserprobe vom 07.07.1988 (2), Lysimeter 1

\begin{tabular}{|c|c|c|c|c|c|c|c|c|c|c|c|c|}
\hline Arbeitsschritt & $\begin{array}{c}\text { Proben- } \\
\text { Nr. }\end{array}$ & $\mathrm{Fe}$ & $\begin{array}{c}\mathrm{Ca} \\
\mathrm{mg} / \mathrm{l}\end{array}$ & Mg & $\mathbf{K}$ & $\mathrm{Fe}$ & $\begin{array}{c}\mathrm{Ca} \\
\% \\
\end{array}$ & Mg & $\mathbf{K}$ & $\begin{array}{l}\mathrm{Ca} / \mathrm{Mg} \\
\text { lonene }\end{array}$ & $\begin{array}{l}\mathrm{K} / \mathrm{Mg} \\
\text { lentve }\end{array}$ & $\begin{array}{l}\mathrm{Ca} / \mathrm{K} \\
\text { Itnisse }\end{array}$ \\
\hline SW L 1 & & 0,30 & 48,00 & 14,00 & 145,00 & 100,00 & 100,00 & 100,00 & 100,00 & 2,08 & 3,22 & 0,65 \\
\hline \multicolumn{13}{|c|}{ Eluate der HUS-Konzentrierung an XAD 2 und HA-Fällung: } \\
\hline \multirow[t]{7}{*}{ Anreicherung } & 1 & 0,07 & 21,50 & 6,25 & 106,50 & 23,33 & 44,79 & 44,64 & 73,45 & 2,09 & 5,30 & 0,39 \\
\hline & 2 & 0,44 & 41,75 & 13,00 & 139,25 & 146,67 & 86,98 & 92,86 & 96,03 & 1,95 & 3,33 & 0,59 \\
\hline & 3 & 0,40 & 46,50 & 13,50 & 141,50 & 133,33 & 96,88 & 96,43 & 97,59 & 2,09 & 3,26 & 0,64 \\
\hline & 4 & 0,38 & 48,75 & 13,50 & 145,00 & 126,67 & 101,56 & 96,43 & 100,00 & 2,19 & 3,34 & 0,66 \\
\hline & 5 & 0,59 & 47,50 & 14,25 & 141,75 & 196,67 & 98,96 & 101,79 & 97,76 & 2,02 & 3,09 & 0,65 \\
\hline & 6 & 0,19 & 35,00 & 10,50 & 142,50 & 63,33 & 72,92 & 75,00 & 98,28 & 2,02 & 4,22 & 0,48 \\
\hline & 7 & 0,26 & 40,75 & 11,50 & 141,50 & 86,67 & 84,90 & 82,14 & 97,59 & 2,15 & 3,83 & 0,56 \\
\hline \multirow[t]{4}{*}{ Reinigung } & 8 & 0,16 & 47,25 & 12,75 & 144,50 & 53,33 & 98,44 & 91,07 & 99,66 & 2,25 & 3,52 & 0,64 \\
\hline & 9 & 0,18 & 47,00 & 13,00 & 140,50 & 60,00 & 97,92 & 92,86 & 96,90 & 2,19 & 3,36 & 0,65 \\
\hline & 10 & 0,15 & 46,50 & 12,75 & 150,75 & 50,00 & 96,88 & 91,07 & 103,97 & 2,21 & 3,68 & 0,60 \\
\hline & 11 & 0,11 & 38,75 & 10,75 & 142,50 & 36,67 & 80,73 & 76,79 & 98,28 & 2,19 & 4,12 & 0,53 \\
\hline \multirow[t]{6}{*}{ Desorption } & 12 & 0,05 & 11,25 & 3,00 & 75,25 & 16,67 & 23,44 & 21,43 & 51,90 & 2,28 & 7,80 & 0,29 \\
\hline & 13 & 0,27 & 1,50 & 0,25 & 10,25 & 90,00 & 3,13 & 1,79 & 7,07 & 3,64 & 12,75 & 0,29 \\
\hline & 14 & 0,96 & 0,00 & 0,00 & 7,50 & 320,00 & 0,00 & 0,00 & 5,17 & & & \\
\hline & 15 & 1,34 & 8,75 & 2,25 & 36,75 & 446,67 & 18,23 & 16,07 & 25,34 & 2,36 & 5,08 & 0,46 \\
\hline & 16 & 0,99 & 0,00 & 0,00 & 6,25 & 330,00 & 0,00 & 0,00 & 4,31 & & & \\
\hline & 17 & 0,39 & 0,00 & 0,00 & 11,25 & 130,00 & 0,00 & 0,00 & 7,76 & & & \\
\hline \multirow[t]{3}{*}{ Reinigung } & 18 & 0,07 & 0,00 & 0,00 & 8,25 & 23,33 & 0,00 & 0,00 & 5,69 & & & \\
\hline & 19 & 0,00 & 0,00 & 0,00 & 7,00 & 0,00 & 0,00 & 0,00 & 4,83 & & & \\
\hline & 20 & 0,00 & 0,00 & 0,00 & 7,25 & 0,00 & 0,00 & 0,00 & 5,00 & & & \\
\hline
\end{tabular}




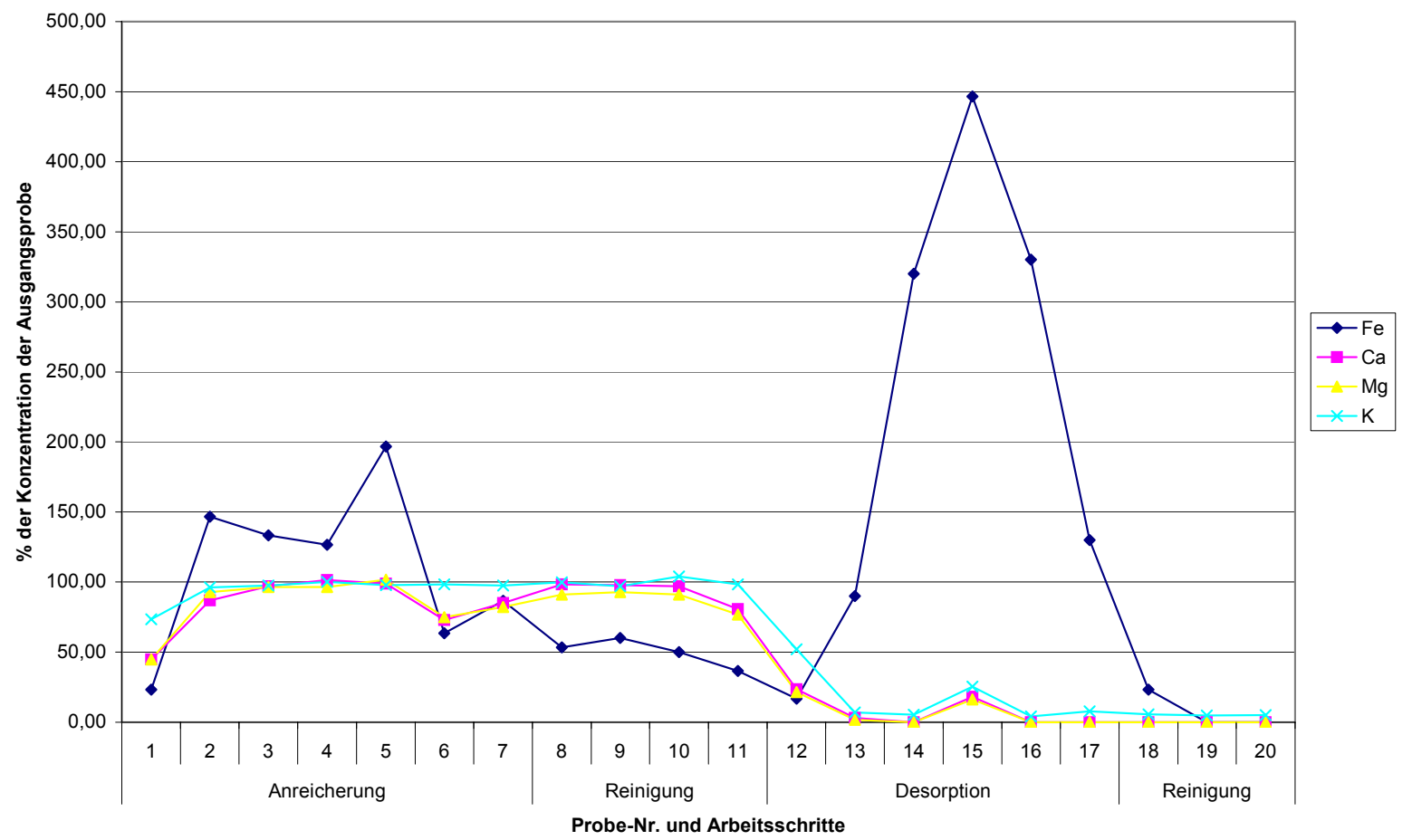

Abbildung 13-17: Kationen in \% der Ausgangsprobe im Eluat, Adsorptions-Chromatographie der Sickerwasserprobe vom 07.07.1988 (2), Lysimeter 1

Tabelle 13-89: pH-Wert, DOC, Kationen in mg/l und \% der Ausgangsprobe sowie Kationenverhältnisse im Eluat, Adsorptions-Chromatographie der Sickerwasserprobe vom 07.07.1988 (3), Lysimeter 1

\begin{tabular}{|c|c|c|c|c|c|c|c|c|c|c|c|c|c|c|c|}
\hline Arbeitsschritt & $\begin{array}{c}\text { Proben- } \\
\text { Nr. }\end{array}$ & pH-Wert & $\begin{array}{l}\mathrm{DOC} \\
\mathrm{mg} / \mathrm{l}\end{array}$ & $\begin{array}{c}\mathrm{Fe} \\
\mathrm{mg} / \mathrm{l}\end{array}$ & $\begin{array}{c}\mathrm{Ca} \\
\mathrm{mg} / \mathrm{I}\end{array}$ & $\begin{array}{c}\mathrm{Mg} \\
\mathrm{mg} / \mathrm{l}\end{array}$ & $\begin{array}{c}\mathrm{K} \\
\mathrm{mg} / \mathrm{l}\end{array}$ & $\begin{array}{c}\text { DOC } \\
\%\end{array}$ & $\begin{array}{l}\mathrm{Fe} \\
\%\end{array}$ & $\begin{array}{l}\mathrm{Ca} \\
\%\end{array}$ & $\begin{array}{c}\mathrm{Mg} \\
\%\end{array}$ & $\begin{array}{l}\mathbf{K} \\
\%\end{array}$ & $\begin{array}{l}\mathrm{Ca} / \mathrm{Mg} \\
\text { loneneq }\end{array}$ & $\begin{array}{c}\mathrm{K} / \mathrm{Mg} \\
\text { ivalentver }\end{array}$ & $\begin{array}{r}\mathrm{Ca} / \mathrm{K} \\
\text { Itnisse }\end{array}$ \\
\hline SW L 1 & & 2,24 & 184,50 & 0,30 & 50,33 & 12,50 & 689,67 & 100,00 & 100,00 & 100,00 & 100,00 & 100,00 & 2,44 & 17,16 & 0,14 \\
\hline \multicolumn{16}{|c|}{ Eluate der HUS-Konzentrierung an XAD 2 und HA-Fällung: } \\
\hline \multirow{10}{*}{ Anreicherung } & 1 & 4,21 & 2,20 & 0,03 & 0,00 & 0,90 & 2,16 & 1,19 & 10,00 & 0,00 & 7,20 & 0,31 & 0,00 & 0,75 & 0,00 \\
\hline & 2 & 5,38 & 1,40 & 0,06 & 0,10 & 1,30 & 5,57 & 0,76 & 20,00 & 0,20 & 10,40 & 0,81 & 0,05 & 1,33 & 0,04 \\
\hline & 3 & 2,61 & 12,74 & 0,36 & 33,95 & 14,75 & 280,46 & 6,91 & 120,00 & 67,45 & 118,00 & 40,67 & 1,40 & 5,91 & 0,24 \\
\hline & 4 & 2,23 & 8,70 & 0,36 & 49,93 & 15,25 & 684,71 & 4,72 & 120,00 & 99,21 & 122,00 & 99,28 & 1,99 & 13,96 & 0,14 \\
\hline & 5 & 2,22 & 11,30 & 0,19 & 51,03 & & & 6,12 & 63,33 & 101,39 & & & & & \\
\hline & 6 & 2,20 & 13,80 & 0,14 & 51,03 & & & 7,48 & 46,67 & 101,39 & & & & & \\
\hline & 7 & 2,23 & 15,98 & 0,10 & 50,73 & & & 8,66 & 33,33 & 100,79 & & & & & \\
\hline & 8 & 2,25 & 17,95 & 0,12 & 51,93 & & & 9,73 & 40,00 & 103,18 & & & & & \\
\hline & 9 & 2,24 & 20,50 & 0,08 & 51,63 & & & 11,11 & 26,67 & 102,58 & & & & & \\
\hline & 10 & 2,24 & 20,86 & 0,09 & 50,83 & & & 11,31 & 30,00 & 100,99 & & & & & \\
\hline \multirow[t]{8}{*}{ Reinigung } & 11 & 2,22 & 22,93 & 0,11 & 51,73 & & & 12,43 & 36,67 & 102,78 & & & & & \\
\hline & 12 & 2,22 & 22,00 & 0,09 & 50,83 & & & 11,92 & 30,00 & 100,99 & & & & & \\
\hline & 13 & 2,29 & 26,70 & 0,08 & 49,13 & & & 14,47 & 26,67 & 97,62 & & & & & \\
\hline & 14 & 2,43 & 28,60 & 0,07 & 50,83 & & & 15,50 & 23,33 & 100,99 & & & & & \\
\hline & 15 & 2,44 & 28,40 & 0,42 & 51,09 & & & 15,39 & 140,00 & 101,51 & & & & & \\
\hline & 16 & 2,48 & 31,10 & 0,01 & 50,93 & & & 16,86 & 3,33 & 101,19 & & & & & \\
\hline & 17 & 2,48 & 33,64 & 0,01 & 50,73 & 12,20 & & 18,23 & 3,33 & 100,79 & 97,60 & & 2,52 & & \\
\hline & 18 & 3,50 & 35,70 & 0,02 & 51,93 & 12,00 & & 19,35 & 6,67 & 103,18 & 96,00 & & 2,63 & & \\
\hline \multirow[t]{5}{*}{ Desorption } & 19 & 3,10 & 24,40 & 0,58 & 32,35 & 6,70 & 252,28 & 13,22 & 193,33 & 64,28 & 53,60 & 36,58 & 2,93 & 11,71 & 0,25 \\
\hline & 20 & 12,18 & 1154,25 & 3,14 & 11,68 & 0,30 & 8,72 & 625,61 & 1046,67 & 23,21 & 2,40 & 1,26 & 23,62 & 9,04 & 2,61 \\
\hline & 21 & 12,98 & 367,75 & 2,06 & 25,46 & 0,05 & 11,36 & 199,32 & 686,67 & 50,59 & 0,40 & 1,65 & 308,98 & 70,66 & 4,37 \\
\hline & 22 & 12,63 & 124,00 & 0,51 & 26,26 & 0,03 & 19,73 & 67,21 & 170,00 & 52,18 & 0,24 & 2,86 & 531,14 & 204,52 & 2,60 \\
\hline & 23 & 12,35 & 142,00 & 0,13 & 6,54 & & 5,59 & 76,96 & 43,33 & 12,99 & & 0,81 & & & 2,28 \\
\hline \multirow[t]{5}{*}{ Reinigung } & 24 & 10,16 & 86,75 & 0,10 & 1,72 & & 1,37 & 47,02 & 33,33 & 3,42 & & 0,20 & & & 2,45 \\
\hline & 25 & 9,85 & 56,00 & 0,16 & 0,63 & & 1,04 & 30,35 & 53,33 & 1,25 & & 0,15 & & & 1,18 \\
\hline & 26 & 9,63 & 13,80 & 0,07 & 0,15 & 0,20 & & 7,48 & 23,33 & 0,30 & 1,60 & & 0,46 & & \\
\hline & 27 & 9,42 & 6,10 & 0,03 & 0,12 & & & 3,31 & 10,00 & 0,24 & & & & & \\
\hline & 28 & 9,39 & 6,90 & 0,00 & 0,13 & & & 3,74 & 0,00 & 0,26 & & & & & \\
\hline $20 \mathrm{n}$. HA-Fällung & 29 & 2,00 & 958,25 & 1,12 & 13,18 & 1,53 & 24,50 & 519,38 & 373,33 & 26,19 & 12,24 & 3,55 & 5,23 & 4,98 & 1,05 \\
\hline $21 \mathrm{n}$. HA-Fällung & 30 & 2,00 & 317,25 & 0,66 & 24,96 & 0,15 & 20,04 & 171,95 & 220,00 & 49,59 & 1,20 & 2,91 & 100,97 & 41,55 & 2,43 \\
\hline \multicolumn{16}{|c|}{ Eluate der FA-Konzentrierung an XAD 8: } \\
\hline gereinigte FA & 31 & & 672,50 & 0,53 & 14,98 & 0,45 & 5,76 & 364,50 & 176,67 & 29,76 & 3,60 & 0,84 & 20,20 & 3,98 & 5,07 \\
\hline
\end{tabular}


Tabelle 13-90: pH-Wert, DOC, Kationen in $\mathrm{mg} / \mathrm{l}$ und \% der

Ausgangsprobe sowie Kationenverhältnisse im Eluat,

Adsorptions-Chromatographie der Sickerwasserprobe vom

07.07.1988 (3), Lysimeter 2

\begin{tabular}{|c|c|c|c|c|c|c|c|c|c|c|c|c|c|c|c|}
\hline Arbeitsschritt & $\begin{array}{c}\text { Proben- } \\
\mathrm{Nr} .\end{array}$ & pH-Wert & DOC & $\mathrm{Fe}$ & $\begin{array}{c}\mathrm{Ca} \\
\mathrm{mg} / \mathrm{l}\end{array}$ & Mg & $\mathrm{K}$ & DOC & $\mathrm{Fe}$ & $\begin{array}{l}\mathrm{Ca} \\
\% \\
\end{array}$ & Mg & K & $\begin{array}{l}\mathrm{Ca} / \mathrm{Mg} \\
\text { loneneqive }\end{array}$ & $\begin{array}{l}\mathrm{K} / \mathrm{Mg} \\
\text { alentverhä }\end{array}$ & $\begin{array}{l}\mathrm{Ca} / \mathrm{K} \\
\text { ätnisse }\end{array}$ \\
\hline SW L 2 & & 7,96 & 266,90 & 0,30 & 180,92 & 52,00 & 1782,26 & 100,00 & 100,00 & 100,00 & 100,00 & 100,00 & 2,11 & 10,66 & 0,20 \\
\hline \multicolumn{16}{|c|}{ Eluate der HUS-Konzentrierung an XAD 2 und HA-Fällung: } \\
\hline \multirow{2}{*}{ Anreicherung } & 1 & 2,30 & 33,63 & 0,13 & 169,68 & 51,25 & 1686,62 & 12,60 & 43,33 & 93,79 & 98,56 & 94,63 & 2,01 & 10,23 & 0,20 \\
\hline & 2 & 2,30 & 45,28 & 0,13 & 173,43 & 52,75 & 1716,05 & 16,97 & 43,33 & 95,86 & 101,44 & 96,29 & 1,99 & 10,12 & 0,20 \\
\hline Reinigung & 3 & 2,29 & 55,10 & 0,13 & 172,93 & 52,50 & 1708,69 & 20,64 & 43,33 & 95,58 & 100,96 & 95,87 & 2,00 & 10,12 & 0,20 \\
\hline \multirow[t]{3}{*}{ Desorption } & 4 & 2,36 & 34,85 & 0,07 & 36,06 & 10,25 & 225,33 & 13,06 & 23,33 & 19,93 & 19,71 & 12,64 & 2,13 & 6,84 & 0,31 \\
\hline & 5 & 12,21 & 853,90 & 0,62 & 13,75 & 0,15 & 5,56 & 319,93 & 206,67 & 7,60 & 0,29 & 0,31 & 55,62 & 11,53 & 4,83 \\
\hline & 6 & 12,78 & 85,86 & 0,09 & 12,68 & 0,00 & 2,98 & 32,17 & 30,00 & 7,01 & 0,00 & 0,17 & & & 8,30 \\
\hline \multirow[t]{2}{*}{ Reinigung } & 7 & 11,00 & 30,90 & 0,02 & 0,22 & 0,04 & 0,00 & 11,58 & 6,67 & 0,12 & 0,08 & 0,00 & 3,34 & & \\
\hline & 8 & & 6,33 & 0,00 & 0,00 & 0,58 & 0,00 & 2,37 & 0,00 & 0,00 & 1,12 & 0,00 & & & \\
\hline $5 \mathrm{n}$. HA-Fällung & 9 & & 802,30 & 0,57 & 16,02 & 1,41 & 33,03 & 93,96 & 91,94 & 116,51 & 940,00 & 594,06 & 6,89 & 7,28 & 0,95 \\
\hline \multicolumn{16}{|c|}{ Eluate der FA-Konzentrierung an XAD 8: } \\
\hline Anreicherung & 10 & & 110,50 & 0,51 & 13,69 & 0,44 & 21,53 & 12,94 & 82,26 & 99,56 & 293,33 & 387,23 & 18,88 & 15,22 & 1,24 \\
\hline Reinigung & 11 & & 289,90 & 0,40 & 9,28 & 0,00 & 13,80 & 33,95 & 64,52 & 67,49 & 0,00 & 248,20 & & & 1,31 \\
\hline Desorption & 12 & & 1308,50 & 0,54 & 6,23 & 0,88 & 0,60 & 153,24 & 87,10 & 45,31 & 586,67 & 10,79 & 4,30 & 0,21 & 20,26 \\
\hline Reinigung & 13 & & 291,00 & 0,23 & 14,73 & 0,00 & 4.97 & 34,08 & 37,10 & 107,13 & 0,00 & 89,39 & & & 5,78 \\
\hline
\end{tabular}

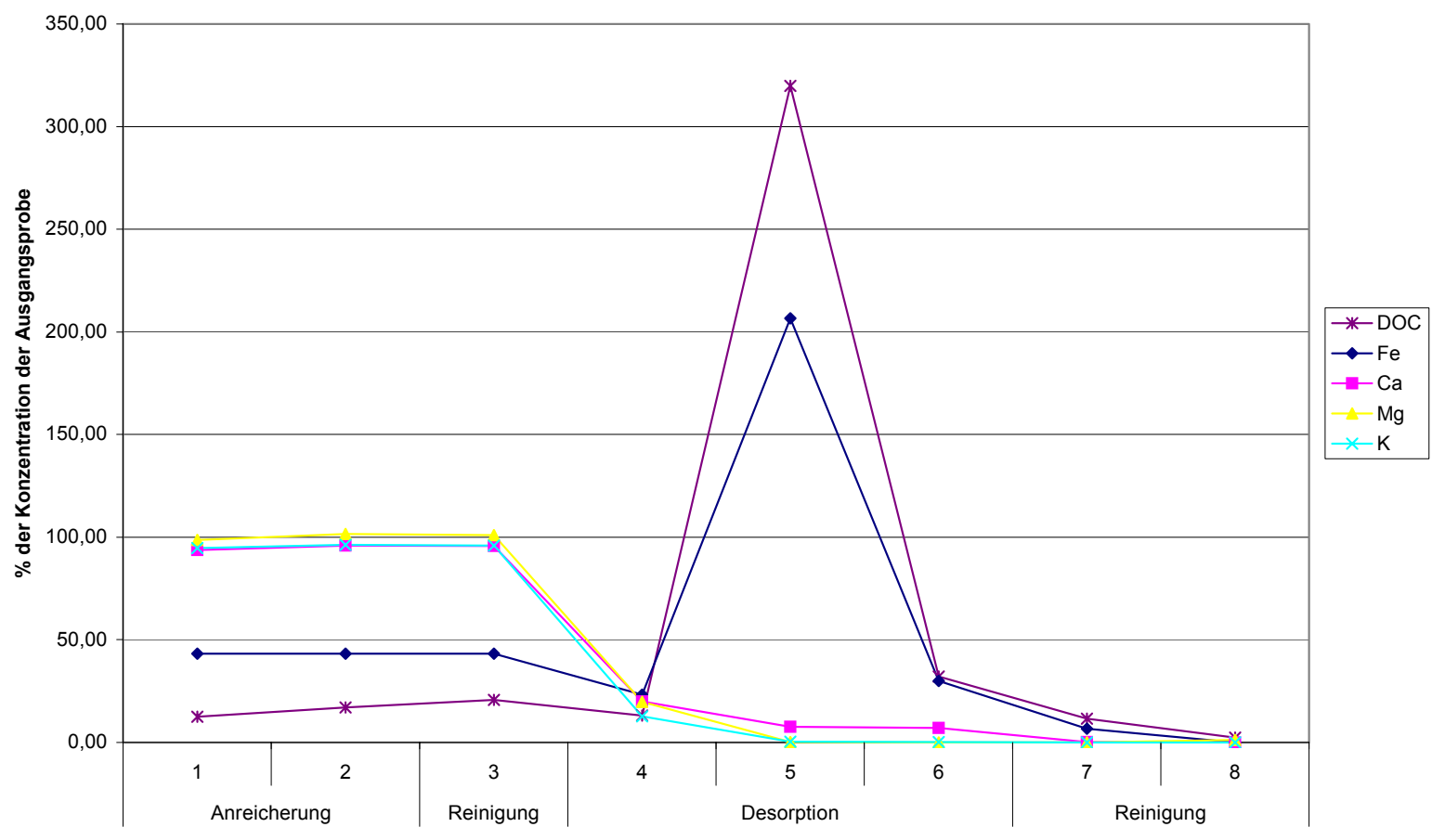

Probe-Nr. und Arbeitsschritte

Abbildung 13-18: DOC, Kationen \% der Ausgangsprobe im

Eluat, Adsorptions-Chromatographie der

Sickerwasserprobe vom 07.07.1988, Lysimeter 2 
Tabelle 13-91: pH-Wert, DOC, Kationen in $\mathrm{mg} / \mathrm{l}$ und \% der Ausgangsprobe sowie Kationenverhältnisse bei verlängerter 1. Reinigungsphase im Eluat, AdsorptionsChromatographie der Sickerwasserprobe vom 14.12.1988, Lysimeter 1

\begin{tabular}{|c|c|c|c|c|c|c|c|c|c|c|c|c|c|c|c|}
\hline Arbeitsschritt & $\begin{array}{c}\text { Proben- } \\
\text { Nr. }\end{array}$ & pH-Wert & DOC & $\mathrm{Fe}$ & $\begin{array}{c}\mathrm{Ca} \\
\mathrm{mg} / \mathrm{l}\end{array}$ & Mg & $\mathbf{K}$ & DOC & $\mathrm{Fe}$ & $\begin{array}{l}\mathrm{Ca} \\
\%\end{array}$ & Mg & $\mathbf{K}$ & $\begin{array}{l}\mathrm{Ca} / \mathrm{Mg} \\
\text { loneneqiv }\end{array}$ & $\begin{array}{l}\mathrm{K} / \mathrm{Mg} \\
\text { alentverh }\end{array}$ & $\begin{array}{c}\mathrm{Ca} / \mathrm{K} \\
\text { alltnisse }\end{array}$ \\
\hline SW L 1 & & 1,59 & 581,00 & 2,60 & 93,96 & 20,00 & 635,76 & 100,00 & 100,00 & 100,00 & 100,00 & 100,00 & 2,85 & 9,89 & 0,29 \\
\hline \multicolumn{16}{|c|}{ Eluate der HUS-Konzentrierung an XAD 2 und HA-Fällung: } \\
\hline \multirow[t]{6}{*}{ Anreicherung } & 1 & 1,86 & 118,00 & 1,15 & 90,95 & 19,75 & & 20,31 & 44,23 & 96,80 & 98,75 & & 2,79 & & \\
\hline & 2 & 2,05 & 233,00 & 0,86 & 49,63 & 11,75 & & 40,10 & 33,08 & 52,82 & 58,75 & & 2,56 & & \\
\hline & 3 & 2,87 & 65,00 & 0,46 & 1,75 & 0,45 & 6,90 & 11,19 & 17,69 & 1,86 & 2,25 & 1,09 & 2,36 & 4,77 & 0,49 \\
\hline & 4 & & 55,10 & & & & 0,90 & 9,48 & & & & 0,14 & & & \\
\hline & 5 & 3,09 & 113,00 & 0,76 & 0,88 & 0,30 & 2,00 & 19,45 & 29,23 & 0,94 & 1,50 & 0,31 & 1,78 & 2,07 & 0,86 \\
\hline & 6 & & & & & & & & & & & & & & \\
\hline \multirow[t]{10}{*}{ Reinigung } & 7 & 3,70 & 60,00 & 0,44 & 1,15 & 0,20 & & 10,33 & 16,92 & 1,22 & 1,00 & & 3,49 & & \\
\hline & 8 & 3,24 & & 0,74 & 0,94 & 0,30 & & & 28,46 & 1,00 & 1,50 & & 1,90 & & \\
\hline & 9 & 3,24 & & & & & & & & & & & & & \\
\hline & 10 & 3,63 & 0,00 & & & & & 0,00 & & & & & & & \\
\hline & 11 & 3,53 & & & & & & & & & & & & & \\
\hline & 12 & 3,66 & & & 0,00 & & & & & 0,00 & & & & & \\
\hline & 13 & 3,54 & & & & & & & & & & & & & \\
\hline & 14 & 3,49 & 1147,00 & & 0,90 & & & 197,42 & & 0,96 & & & & & \\
\hline & 15 & & 298,00 & 0,98 & 1,49 & 0,45 & 0,00 & 51,29 & 37,69 & 1,59 & 2,25 & 0,00 & 2,01 & & \\
\hline & 16 & 4,27 & 810,00 & & 3,24 & & & 139,41 & & 3,45 & & & & & \\
\hline \multirow[t]{3}{*}{ Desorption } & 17 & 9,92 & 705,00 & & 1,49 & & & 121,34 & & 1,59 & & & & & \\
\hline & 18 & 10,16 & & & 0,00 & 0,00 & & & & 0,00 & 0,00 & & & & \\
\hline & 19 & 7,72 & 0,00 & & & & & 0,00 & & & & & & & \\
\hline Reinigung & 20 & 6,65 & & & & 0,00 & & & & & 0,00 & & & & \\
\hline
\end{tabular}

Tabelle 13-92: Zur Berechnung der Entzüge verwendete Bioelement-Gehalte in \% der TM für Senf, $\left(^{*}=\right.$ Literaturwerte nach DIERFELD 1977)

\begin{tabular}{l|cccccccc} 
Lysimeter & $\mathbf{N}$ & $\mathbf{P}^{*}$ & $\mathbf{K}$ & $\mathbf{C a}$ & $\mathbf{M g}^{*}$ & $\mathbf{S}$ & $\mathbf{N a}$ \\
\hline $\mathbf{1}$ & & & & & & & \\
$\mathbf{2}$ & 4,32 & 0,43 & 2,50 & 1,57 & 0,36 & 1,20 & 0,40 \\
$\mathbf{8}$ & 4,32 & 0,43 & 2,50 & 1,57 & 0,36 & 1,20 & 0,40 \\
$\mathbf{6}$ & 3,00 & 0,43 & 2,30 & 1,57 & 0,36 & 1,00 & 0,40 \\
$\mathbf{5}$ & 2,60 & 0,43 & 2,10 & 1,57 & 0,36 & 0,80 & 0,40 \\
$\mathbf{4}$ & 2,20 & 0,43 & 1,90 & 1,57 & 0,36 & 0,70 & 0,40 \\
$\mathbf{3}$ & 1,80 & 0,43 & 1,70 & 1,57 & 0,36 & 0,70 & 0,40 \\
$\mathbf{7}$ & 1,40 & 0,43 & 1,50 & 1,57 & 0,36 & 0,60 & 0,10 & 0,10 \\
\end{tabular}

Tabelle 13-93: DOC- und Mineralstoff-Bilanz in g pro Lysimeter von Mai 87 bis Januar 91, Lysimeter 1

\begin{tabular}{|c|c|c|c|c|c|c|c|c|c|}
\hline Lysimeter 1 & C & $\mathrm{Ca}$ & Mg & $\mathbf{K}$ & $\mathrm{Na}$ & $\mathbf{P}$ & $\mathbf{S}$ & $\mathrm{Cl}$ & $\mathbf{N}$ \\
\hline \multicolumn{10}{|l|}{ Eintrag: } \\
\hline Regen & 69,4 & 46,2 & 6,6 & 28,8 & 11,5 & & 30,0 & 28,7 & 19,4 \\
\hline \multicolumn{10}{|l|}{ Austrag: } \\
\hline Sickerwasser & 2244,2 & 1281,1 & 234,2 & 3850,7 & 906,1 & 61,4 & 633,7 & 766,9 & 1417,7 \\
\hline Ernte & & 429,5 & 90,3 & 1275,2 & 76,4 & 147,7 & 151,2 & 68,7 & 1027,5 \\
\hline Vorratsänderung & $-2174,8$ & $-1664,4$ & $-318,0$ & $-5097,1$ & $-971,0$ & $-209,1$ & $-755,0$ & $-806,8$ & $-2425,9$ \\
\hline
\end{tabular}


Tabelle 13-94: DOC- und Mineralstoff-Bilanz in g pro

Lysimeter von Mai 87 bis März 91, Lysimeter 2

\begin{tabular}{|c|c|c|c|c|c|c|c|c|c|}
\hline Lysimeter 2 & C & $\mathrm{Ca}$ & Mg & $\mathbf{K}$ & $\mathrm{Na}$ & $\mathbf{P}$ & $\mathbf{S}$ & $\mathrm{Cl}$ & $\mathbf{N}$ \\
\hline \multicolumn{10}{|l|}{ Eintrag: } \\
\hline Regen & 69,4 & 46,2 & 6,6 & 28,8 & 11,5 & & 30,0 & 28,7 & 19,4 \\
\hline \multicolumn{10}{|l|}{ Austrag: } \\
\hline Sickerwasser & 2503,9 & 1456,1 & 296,7 & 5419,8 & 1120,7 & 48,7 & 1175,7 & 1413,5 & 1185,8 \\
\hline Ernte & & 188,9 & 60,3 & 869,2 & 48,9 & 115,6 & 136,2 & 43,0 & 728,9 \\
\hline Vorratsänderung & $-2434,5$ & $-1598,8$ & $-350,5$ & $-6260,2$ & $-1158,1$ & $-164,2$ & $-1281,9$ & $-1427,7$ & $-1895,3$ \\
\hline
\end{tabular}

Tabelle 13-95: DOC- und Mineralstoff-Bilanz in g pro

Lysimeter von Mai 87 bis April 90, Lysimeter 8

\begin{tabular}{|c|c|c|c|c|c|c|c|c|c|}
\hline Lysimeter 8 & $\mathbf{C}$ & $\mathrm{Ca}$ & Mg & $\mathbf{K}$ & $\mathrm{Na}$ & $\mathbf{P}$ & $\mathbf{s}$ & $\mathrm{Cl}$ & $\mathbf{N}$ \\
\hline \multicolumn{10}{|l|}{ Eintrag: } \\
\hline Regen & 3,4 & 2,3 & 0,3 & 1,4 & 0,6 & & 1,5 & 1,4 & 1,0 \\
\hline \multicolumn{10}{|l|}{ Austrag: } \\
\hline Sickerwasser & 146,3 & 34,8 & 7,6 & 137,8 & 40,0 & 3,3 & 21,2 & 26,8 & 19,6 \\
\hline Ernte & & 5,5 & 1,6 & 24,5 & 1,5 & 3,2 & 4,2 & 8,6 & 21,4 \\
\hline Vorratsänderung & $-142,9$ & $-38,0$ & $-8,9$ & $-160,9$ & $-40,9$ & $-6,5$ & $-6,0$ & $-34,0$ & $-41,6$ \\
\hline
\end{tabular}

Tabelle 13-96: DOC- und Mineralstoff-Bilanz in g pro

Lysimeter von Mai 87 bis April 90, Lysimeter 8

\begin{tabular}{|c|c|c|c|c|c|c|c|c|c|}
\hline Lysimeter 6 & $\mathbf{C}$ & $\mathrm{Ca}$ & Mg & $\mathbf{K}$ & $\mathrm{Na}$ & $\mathbf{P}$ & $\mathbf{s}$ & $\mathrm{Cl}$ & $\mathbf{N}$ \\
\hline \multicolumn{10}{|l|}{ Eintrag: } \\
\hline Regen & 6,9 & 4,6 & 0,7 & 2,9 & 1,1 & & 3,0 & 2,9 & 2,0 \\
\hline \multicolumn{10}{|l|}{ Austrag: } \\
\hline Sickerwasser & 269,8 & 63,5 & 14,1 & 254,9 & 76,6 & 6,3 & 40,5 & 49,1 & 55,5 \\
\hline Ernte & & 12,3 & 3,1 & 41,7 & 3,0 & 5,2 & 8,6 & 8,8 & 34,1 \\
\hline Vorratsänderung & $-263,0$ & $-71,2$ & $-16,6$ & $-293,8$ & $-78,4$ & $-11,5$ & $-11,8$ & $-55,1$ & $-72,6$ \\
\hline
\end{tabular}

Tabelle 13-97: DOC- und Mineralstoff-Bilanz in g pro

Lysimeter von Mai 87 bis April 90, Lysimeter 5

\begin{tabular}{|c|c|c|c|c|c|c|c|c|c|}
\hline Lysimeter 5 & C & $\mathrm{Ca}$ & Mg & $\mathbf{K}$ & $\mathrm{Na}$ & $\mathbf{P}$ & $\mathbf{S}$ & $\mathrm{Cl}$ & $\mathbf{N}$ \\
\hline \multicolumn{10}{|l|}{ Eintrag: } \\
\hline Regen & 6,9 & 4,6 & 0,7 & 2,9 & 1,1 & & 3,0 & 2,9 & 2,0 \\
\hline \multicolumn{10}{|l|}{ Austrag: } \\
\hline Sickerwasser & 165,4 & 82,4 & 21,2 & 227,1 & 88,0 & 3,2 & 74,8 & 38,9 & 47,7 \\
\hline Ernte & & 13,4 & 3,1 & 44,2 & 3,4 & 5,7 & 11,0 & 10,1 & 38,1 \\
\hline Vorratsänderung & $-158,6$ & $-91,2$ & $-23,7$ & $-268,4$ & $-90,3$ & $-8,9$ & $-11,1$ & $-46,1$ & $-110,9$ \\
\hline
\end{tabular}


Tabelle 13-98: DOC- und Mineralstoff-Bilanz in g pro

Lysimeter von Mai 87 bis April 90, Lysimeter 4

\begin{tabular}{|c|c|c|c|c|c|c|c|c|c|}
\hline Lysimeter 4 & $\mathbf{C}$ & $\mathrm{Ca}$ & Mg & $\mathbf{K}$ & $\mathrm{Na}$ & $\mathbf{P}$ & $\mathbf{s}$ & $\mathrm{Cl}$ & $\mathbf{N}$ \\
\hline \multicolumn{10}{|l|}{ Eintrag: } \\
\hline Regen & 6,9 & 4,6 & 0,7 & 2,9 & 1,1 & & 3,0 & 2,9 & 2,0 \\
\hline \multicolumn{10}{|l|}{ Austrag: } \\
\hline Sickerwasser & 111,9 & 71,3 & 17,9 & 123,9 & 70,7 & 2,0 & 52,1 & 28,0 & 38,8 \\
\hline Ernte & & 12,4 & 3,0 & 37,7 & 2,8 & 5,3 & 4,8 & 10,9 & 27,6 \\
\hline Vorratsänderung & $-105,1$ & $-79,1$ & $-20,3$ & $-158,8$ & $-72,4$ & $-7,3$ & $-3,7$ & $-36,0$ & $-77,7$ \\
\hline
\end{tabular}

Tabelle 13-99: DOC- und Mineralstoff-Bilanz in g pro

Lysimeter von Mai 87 bis April 90, Lysimeter 3

\begin{tabular}{|c|c|c|c|c|c|c|c|c|c|}
\hline Lysimeter 3 & C & $\mathrm{Ca}$ & Mg & $\mathbf{K}$ & $\mathrm{Na}$ & $\mathbf{P}$ & $\mathbf{S}$ & $\mathrm{Cl}$ & $\mathbf{N}$ \\
\hline \multicolumn{10}{|l|}{ Eintrag: } \\
\hline Regen & 6,9 & 4,6 & 0,7 & 2,9 & 1,1 & & 3,0 & 2,9 & 2,0 \\
\hline \multicolumn{10}{|l|}{ Austrag: } \\
\hline Sickerwasser & 77,5 & 59,7 & 12,3 & 47,4 & 45,2 & 0,6 & 39,4 & 49,5 & 31,1 \\
\hline Ernte & & 12,9 & 2,4 & 24,2 & 1,8 & 4,1 & 4,7 & 11,8 & 18,4 \\
\hline Vorratsänderung & $-70,7$ & $-68,1$ & $-14,0$ & $-68,7$ & $-45,9$ & $-4,8$ & $-2,3$ & $-58,4$ & $-55,9$ \\
\hline
\end{tabular}

Tabelle 13-100: DOC- und Mineralstoff-Bilanz in g pro Lysimeter von Mai 87 bis April 90, Lysimeter 7

\begin{tabular}{l|ccccccccc} 
Lysimeter 7 & $\mathbf{C}$ & $\mathbf{C a}$ & $\mathbf{M g}$ & $\mathbf{K}$ & $\mathbf{N a}$ & $\mathbf{P}$ & $\mathbf{S}$ & $\mathbf{C l}$ & $\mathbf{N}$ \\
\hline $\begin{array}{l}\text { Eintrag: } \\
\text { Regen }\end{array}$ & & & & & & & & & \\
& & & & & & & & & \\
Austrag: & 3,4 & 2,3 & 0,3 & 1,4 & 0,6 & & 1,5 & 1,4 \\
$\begin{array}{l}\text { Sickerwasser } \\
\text { Ernte }\end{array}$ & 11,8 & 13,3 & 1,2 & 1,5 & 3,3 & 0,2 & 2,2 & 1,2 & 1,1 \\
& & 2,5 & 0,5 & 2,9 & 0,5 & 0,6 & 0,5 & 0,9 & 2,4 \\
Vorratsänderung & $-8,3$ & $-13,6$ & $-1,4$ & $-3,0$ & $-3,2$ & $-0,7$ & 0,8 & $-0,7$ & $-3,6$
\end{tabular}


Tabelle 13-101 DOC- und Mineralstoff-Bilanz in g/kg TM, pro Untersuchungsjahr und von Mai 87 bis April 90, Lysimeter 1

\begin{tabular}{|c|c|c|c|c|c|c|c|c|c|c|c|c|c|}
\hline $\begin{array}{l}\text { Bilanzglieder } \\
\text { Lysimeter } 1\end{array}$ & DOC & $\mathrm{HCO}_{3}$ & Summe-C & $\mathrm{Ca}$ & Mg & $\mathbf{K}$ & $\begin{array}{c}\mathrm{Na} \\
\mathrm{mg} / \mathrm{kg} \mathrm{TM}\end{array}$ & $\mathbf{P}$ & $\mathrm{SO}_{4}-\mathrm{S}$ & $\mathrm{Cl}$ & $\mathbf{N}_{\min }$ & $N_{\text {org }}$ & Summe-N \\
\hline 1. Jahr & & & & & & & & & & & & & \\
\hline Regen-Eintrag & 8,9 & & 8,9 & 5,7 & 1,3 & 4,1 & 1,2 & & 7,3 & 5,1 & 3,9 & & 3,9 \\
\hline Ernte-Entzug & & & & 134,3 & 20,0 & 259,0 & 19,4 & 24,3 & 21,6 & 12,6 & & & 236,5 \\
\hline SW-Austrag & 366,1 & 681,5 & 500,2 & 481,2 & 84,3 & 1057,9 & 298,1 & 9,0 & 224,3 & 351,7 & 435,5 & & 435,5 \\
\hline $\begin{array}{l}\text { Vorratsänderung } \\
\text { 2. Jahr }\end{array}$ & $-357,2$ & $-681,5$ & $-491,4$ & $-609,8$ & $-103,0$ & $-1312,8$ & $-316,3$ & $-33,3$ & $-238,6$ & $-359,2$ & $-431,6$ & & $-668,1$ \\
\hline Regen-Eintrag & 5,8 & & 5,8 & 4,2 & 0,6 & 2,7 & 2,0 & & 2,0 & 2,4 & 1,6 & & 1,6 \\
\hline Ernte-Entzug & & & & 59,4 & 17,2 & 287,2 & 15,9 & 35,4 & 38,1 & 16,7 & & & 198,5 \\
\hline SW-Austrag & 125,9 & 122,7 & 150,1 & 20,7 & 4,3 & 135,1 & 26,5 & 5,9 & 12,9 & 0,9 & 18,4 & 10,1 & 28,5 \\
\hline $\begin{array}{l}\text { Vorratsänderung } \\
\text { 3. Jahr }\end{array}$ & $-120,1$ & $-122,7$ & $-144,3$ & $-75,8$ & $-20,9$ & $-419,6$ & $-40,3$ & $-41,3$ & $-49,0$ & $-15,3$ & $-16,8$ & $-10,1$ & $-225,4$ \\
\hline Regen-Eintrag & 8,7 & & 8,7 & 5,6 & 0,6 & 2,4 & 1,1 & & 2,3 & 3,2 & 2,0 & & 2,0 \\
\hline Ernte-Entzug & & & & 6,4 & 4,8 & 48,1 & 0,3 & 9,2 & 10,8 & 2,7 & & & 43,8 \\
\hline SW-Austrag & 207,8 & 160,4 & 239,4 & 41,8 & 8,3 & 268,2 & 46,7 & 7,2 & 29,4 & 2,8 & 61,2 & 22,5 & 83,7 \\
\hline $\begin{array}{l}\text { Vorratsänderung } \\
\text { 1. - 3. Jahr }\end{array}$ & $-199,1$ & $-160,4$ & $-230,7$ & $-42,6$ & $-12,5$ & $-313,8$ & $-45,8$ & $-16,4$ & $-37,9$ & $-2,3$ & $-59,1$ & $-22,5$ & $-125,5$ \\
\hline Regen-Eintrag & 23,4 & 0,0 & 23,4 & 15,5 & 2,5 & 9,2 & 4,4 & & 11,6 & 10,7 & 7,6 & & 7,6 \\
\hline Ernte-Entzug & & & & 200,1 & 42,1 & 594,2 & 35,6 & 68,8 & 70,4 & 32,0 & & & 478,8 \\
\hline sW-Austrag & 699,8 & 964,6 & 889,7 & 543,6 & 96,9 & 1461,2 & 371,2 & 22,2 & 266,7 & 355,4 & 515,1 & 32,6 & 547,8 \\
\hline Vorratsänderung & $-676,4$ & $-964,6$ & $-866,3$ & $-728,2$ & $-136,4$ & $-2046,3$ & $-402,4$ & $-91,0$ & $-325,5$ & $-376,7$ & $-507,5$ & $-32,6$ & $-1019,0$ \\
\hline
\end{tabular}

Tabelle 13-102: DOC- und Mineralstoff-Bilanz in $\mathrm{g} / \mathrm{kg} \mathrm{TM}$, pro Untersuchungsjahr und von Mai 87 bis April 90,

Lysimeter 2

\begin{tabular}{|c|c|c|c|c|c|c|c|c|c|c|c|c|c|}
\hline $\begin{array}{l}\text { Bilanzglieder } \\
\text { Lysimeter } 2 \\
\end{array}$ & DOC & $\mathrm{HCO}_{3}$ & Summe-C & $\mathrm{Ca}$ & Mg & $\mathbf{K}$ & $\begin{array}{c}\mathrm{Na} \\
\mathrm{mg} / \mathrm{kg} \mathrm{TM}\end{array}$ & $\mathbf{P}$ & $\mathrm{SO}_{4}-\mathrm{S}$ & $\mathrm{Cl}$ & $\mathbf{N}_{\min }$ & $\mathbf{N}_{\text {org }}$ & Summe-N \\
\hline 1. Jahr & & & & & & & & & & & & & \\
\hline Regen-Eintrag & 6,4 & 0,0 & 6,4 & 4,1 & 0,9 & 2,9 & 0,8 & & 5,3 & 3,7 & 2,8 & & 2,8 \\
\hline Ernte-Entzug & & & & 13,4 & 3,2 & 83,4 & 5,8 & 11,1 & 9,9 & 8,4 & & & 74,8 \\
\hline SW-Austrag & 263,8 & 828,1 & 426,9 & 398,5 & 75,0 & 1060,2 & 248,3 & 9,1 & 290,2 & 428,8 & 218,0 & & 218,0 \\
\hline $\begin{array}{l}\text { Vorratsänderung } \\
\text { 2. Jahr }\end{array}$ & $-257,5$ & $-828,1$ & $-420,5$ & $-407,8$ & $-77,3$ & $-1140,6$ & $-253,3$ & $-20,2$ & $-294,8$ & $-433,5$ & $-215,2$ & & $-290,0$ \\
\hline Regen-Eintrag & 4,2 & & 4,2 & 3,0 & 0,5 & 1,9 & 1,5 & 0,0 & 1,4 & 1,7 & 1,2 & & 1,2 \\
\hline Ernte-Entzug & & & & 40,8 & 11,6 & 107,7 & 10,1 & 18,6 & 25,7 & 4,6 & & & 125,2 \\
\hline SW-Austrag & 85,0 & 125,1 & 109,6 & 26,9 & 8,3 & 223,9 & 39,0 & 2,0 & 40,1 & 25,6 & 29,0 & 11,2 & 40,2 \\
\hline $\begin{array}{l}\text { Vorratsänderung } \\
\text { 3. Jahr }\end{array}$ & $-80,9$ & $-125,1$ & $-105,5$ & $-64,7$ & $-19,4$ & $-329,7$ & $-47,6$ & $-20,6$ & $-64,3$ & $-28,5$ & $-27,8$ & $-11,2$ & $-164,2$ \\
\hline Regen-Eintrag & 6,3 & & 6,3 & 4,0 & 0,4 & 1,7 & 0,8 & & 1,7 & 2,3 & 1,5 & & 1,5 \\
\hline Ernte-Entzug & & & & 9,2 & 5,4 & 100,3 & 0,5 & 9,0 & 10,1 & 1,4 & & & 44,4 \\
\hline SW-Austrag & 132,7 & 119,8 & 156,3 & 36,9 & 8,7 & 291,0 & 48,6 & 2,4 & 46,6 & 15,0 & 61,0 & 19,5 & 80,5 \\
\hline $\begin{array}{l}\text { Vorratsänderung } \\
\text { 1. - 3. Jahr }\end{array}$ & $-126,4$ & $-119,8$ & $-150,0$ & $-42,1$ & $-13,6$ & $-389,6$ & $-48,2$ & $-11,5$ & $-55,0$ & $-14,1$ & $-59,5$ & $-19,5$ & $-123,5$ \\
\hline Regen-Eintrag & 16,8 & & 16,8 & 11,2 & 1,8 & 6,6 & 3,1 & & 8,4 & 7,7 & 5,5 & & 5,5 \\
\hline Ernte-Entzug & & & & 63,3 & 20,2 & 291,5 & 16,4 & 38,8 & 45,7 & 14,4 & & & 244,4 \\
\hline SW-Austrag & 481,5 & 1072,9 & 692,8 & 462,3 & 92,0 & 1575,1 & 335,9 & 13,6 & 376,9 & 469,4 & 307,9 & 30,7 & 338,6 \\
\hline Vorratsänderung & $-464,7$ & $-1072,9$ & $-676,0$ & $-514,5$ & $-110,4$ & $-1860,0$ & $-349,1$ & $-52,3$ & $-414,1$ & $-476,1$ & $-302,5$ & $-30,7$ & $-577,6$ \\
\hline
\end{tabular}


Tabelle 13-103: DOC- und Mineralstoff-Bilanz in g/kg TM, pro Untersuchungsjahr und von Mai 87 bis April 90,

Lysimeter 8

\begin{tabular}{|c|c|c|c|c|c|c|c|c|c|c|c|c|c|}
\hline $\begin{array}{l}\text { Bilanzglieder } \\
\text { Lysimeter } 8\end{array}$ & DOC & $\mathrm{HCO}_{3}$ & Summe-C & $\mathrm{Ca}$ & Mg & $\mathbf{K}$ & $\begin{array}{c}\mathrm{Na} \\
\mathrm{mg} / \mathrm{kg} \mathrm{TM}\end{array}$ & $\mathbf{P}$ & $\mathrm{SO}_{4}-\mathrm{S}$ & $\mathrm{Cl}$ & $\mathbf{N}_{\min }$ & $\mathbf{N}_{\text {org }}$ & Summe-N \\
\hline \multicolumn{14}{|l|}{ 1. Jahr } \\
\hline Regen-Eintrag & 14,0 & & 14,0 & 9,0 & 2,1 & 6,4 & 1,8 & & 11,6 & 8,0 & 6,1 & & 6,1 \\
\hline Ernte-Entzug & & & & 30,9 & 8,1 & 206,8 & 10,3 & 27,9 & 45,6 & 121,1 & & & 187,1 \\
\hline SW-Austrag & 1204,0 & 1498,8 & 1499,1 & 437,3 & 88,9 & 1523,8 & 490,4 & 24,7 & 258,8 & 398,7 & 178,7 & & 178,7 \\
\hline Vorratsänderung & $-1190,0$ & $-1498,8$ & $-1485,1$ & $-459,1$ & $-94,8$ & $-1724,2$ & $-498,9$ & $-52,6$ & $-292,9$ & $-511,8$ & $-172,6$ & & $-359,6$ \\
\hline \multicolumn{14}{|l|}{ 2. Jahr } \\
\hline Regen-Eintrag & 9,2 & 0,0 & 9,2 & 6,7 & 1,0 & 4,3 & 3,2 & & 3,2 & 3,8 & 2,5 & & 2,5 \\
\hline Ernte-Entzug & & & & 47,6 & 14,2 & 150,7 & 12,7 & 17,2 & 15,2 & 5,6 & & & 116,6 \\
\hline SW-Austrag & 348,8 & 429,3 & 433,4 & 43,6 & 13,2 & 338,1 & 71,5 & 15,2 & 33,8 & 0,2 & 36,1 & 28,4 & 64,5 \\
\hline Vorratsänderung & $-339,7$ & $-429,3$ & $-424,2$ & $-84,5$ & $-26,4$ & $-484,5$ & $-81,0$ & $-32,4$ & $-45,8$ & $-2,1$ & $-33,6$ & $-28,4$ & $-178,6$ \\
\hline \multicolumn{14}{|l|}{ 3. Jahr } \\
\hline Regen-Eintrag & 13,8 & & 13,8 & 8,8 & 0,9 & 3,8 & 1,8 & & 3,6 & 5,0 & 3,1 & & 3,1 \\
\hline Ernte-Entzug & & & & 4,3 & 2,0 & 8,2 & 0,1 & 2,8 & 1,5 & 1,3 & & & 16,0 \\
\hline SW-Austrag & 198,8 & 281,2 & 254,2 & 38,7 & 10,9 & 197,4 & 35,2 & 9,0 & 24,0 & 1,6 & 33,0 & 17,3 & 50,3 \\
\hline Vorratsänderung & $-185,0$ & $-281,2$ & $-240,4$ & $-34,1$ & $-11,9$ & $-201,8$ & $-33,5$ & $-11,7$ & $-21,9$ & 2,1 & $-29,8$ & $-17,3$ & $-63,2$ \\
\hline \multicolumn{14}{|l|}{ 1. - 3. Jahr } \\
\hline Regen-Eintrag & 37,0 & & 37,0 & 24,6 & 4,0 & 14,5 & 6,9 & & 18,4 & 16,8 & 12,0 & & 12,0 \\
\hline Ernte-Entzug & & & & 82,7 & 24,2 & 365,8 & 23,1 & 47,9 & 62,3 & 128,0 & & & 319,7 \\
\hline SW-Austrag & 1751,7 & 2209,3 & 2186,7 & 519,5 & 112,9 & 2059,2 & 597,2 & 48,9 & 316,6 & 400,6 & 247,8 & 45,7 & 293,5 \\
\hline Vorratsänderung & $-1714,7$ & $-2209,3$ & $-2149,7$ & $-577,6$ & $-133,1$ & $-2410,5$ & $-613,4$ & $-96,8$ & $-360,5$ & $-511,8$ & $-235,8$ & $-45,7$ & $-601,2$ \\
\hline
\end{tabular}

Tabelle 13-104: DOC- und Mineralstoff-Bilanz in g/kg TM, pro Untersuchungsjahr und von Mai 87 bis April 90, Lysimeter 6

\begin{tabular}{|c|c|c|c|c|c|c|c|c|c|c|c|c|c|}
\hline $\begin{array}{l}\text { Bilanzglieder } \\
\text { Lysimeter } 6\end{array}$ & DOC & $\mathrm{HCO}_{3}$ & Summe-C & $\mathrm{Ca}$ & Mg & $\mathbf{K}$ & $\begin{array}{c}\mathrm{Na} \\
\mathrm{mg} / \mathrm{kg} \text { TM }\end{array}$ & $\mathbf{P}$ & $\mathrm{SO}_{4}-\mathrm{S}$ & $\mathrm{Cl}$ & $\mathbf{N}_{\min }$ & $\mathbf{N}_{\text {org }}$ & Summe-N \\
\hline 1. Jahr & & & & & & & & & & & & & \\
\hline Regen-Eintrag & 15,1 & 0,0 & 15,1 & 9,7 & 2,2 & 6,9 & 2,0 & & 12,5 & 8,6 & 6,7 & & 6,7 \\
\hline Ernte-Entzug & & & & 43,4 & 8,7 & 177,8 & 11,0 & 23,3 & 53,1 & 59,6 & & & 142,0 \\
\hline sw-Austrag & 1333,8 & 1065,1 & 1543,5 & 389,2 & 81,8 & 1466,0 & 481,1 & 26,0 & 257,9 & 359,1 & 291,0 & & 291,0 \\
\hline $\begin{array}{l}\text { Vorratsänderung } \\
\text { 2. Jahr }\end{array}$ & $-1318,7$ & $-1065,1$ & $-1528,4$ & $-422,9$ & $-88,2$ & $-1636,9$ & $-490,1$ & $-49,3$ & $-298,5$ & $-410,0$ & $-284,3$ & & $-426,3$ \\
\hline Regen-Eintrag & 8,8 & & 8,8 & 6,4 & 1,0 & 4,1 & 3,1 & & 3,0 & 3,6 & 2,5 & & 2,5 \\
\hline Ernte-Entzug & & & & 44,7 & 12,9 & 122,4 & 11,1 & 14,0 & 11,9 & 5,0 & & & 99,0 \\
\hline SW-Austrag & 203,4 & 225,8 & 247,9 & 31,5 & 8,8 & 225,3 & 47,9 & 11,3 & 13,7 & 0,9 & 37,3 & 15,4 & 52,7 \\
\hline $\begin{array}{l}\text { Vorratsänderung } \\
\text { 3. Jahr }\end{array}$ & $-194,6$ & $-225,8$ & $-239,1$ & $-69,8$ & $-20,8$ & $-343,6$ & $-56,0$ & $-25,3$ & $-22,6$ & $-2,2$ & $-34,8$ & $-15,4$ & $-149,2$ \\
\hline Regen-Eintrag & 13,3 & & 13,3 & 8,5 & 0,9 & 3,7 & 1,7 & & 3,5 & 4,8 & 3,1 & & 3,1 \\
\hline Ernte-Entzug & & & 0,0 & 3,3 & 1,4 & 8,5 & 0,1 & 1,9 & 1,0 & 1,0 & & & 11,7 \\
\hline sw-Austrag & 159,8 & 235,7 & 206,2 & 49,1 & 14,1 & 196,0 & 37,8 & 9,0 & 27,9 & 3,6 & 50,3 & 16,9 & 67,2 \\
\hline $\begin{array}{l}\text { Vorratsänderung } \\
\text { 1. - 3. Jahr }\end{array}$ & $-146,5$ & $-235,7$ & $-192,9$ & $-43,8$ & $-14,5$ & $-200,8$ & $-36,1$ & $-10,9$ & $-25,4$ & 0,3 & $-47,2$ & $-16,9$ & $-75,8$ \\
\hline Regen-Eintrag & 37,2 & & 37,2 & 24,7 & 4,1 & 14,7 & 6,8 & & 19,0 & 17,1 & 12,2 & & 12,2 \\
\hline Ernte-Entzug & & & & 91,4 & 23,0 & 308,7 & 22,2 & 39,1 & 66,0 & 65,5 & & & 252,7 \\
\hline SW-Austrag & 1697,0 & 1526,6 & 1997,6 & 469,8 & 104,7 & 1887,3 & 566,8 & 46,4 & 299,5 & 363,6 & 378,7 & 32,3 & 410,9 \\
\hline Vorratsänderung & $-1659,8$ & $-1526,6$ & $-1960,4$ & $-536,5$ & $-123,6$ & $-2181,4$ & $-582,2$ & $-85,5$ & $-346,5$ & $-411,9$ & $-366,4$ & $-32,3$ & $-651,4$ \\
\hline
\end{tabular}


Tabelle 13-105: DOC- und Mineralstoff-Bilanz in g/kg TM, pro Untersuchungsjahr und von Mai 87 bis April 90,

Lysimeter 5

\begin{tabular}{|c|c|c|c|c|c|c|c|c|c|c|c|c|c|}
\hline $\begin{array}{l}\text { Bilanzglieder } \\
\text { Lysimeter } 5\end{array}$ & DOC & $\mathrm{HCO}_{3}$ & Summe-C & $\mathrm{Ca}$ & Mg & $\mathbf{K}$ & $\begin{array}{c}\mathrm{Na} \\
\mathrm{mg} / \mathrm{kg} \mathrm{TM}\end{array}$ & $\mathbf{P}$ & $\mathrm{SO}_{4}-\mathrm{S}$ & $\mathrm{Cl}$ & $\mathbf{N}_{\min }$ & $\mathbf{N}_{\text {org }}$ & Summe-N \\
\hline \multicolumn{14}{|l|}{ 1. Jahr } \\
\hline Regen-Eintrag & 15,5 & & 15,5 & 10,0 & 2,3 & 7,1 & 2,0 & & 12,8 & 8,8 & 6,8 & & 6,8 \\
\hline Ernte-Entzug & & & 0,0 & 57,6 & 10,1 & 212,9 & 14,8 & 26,7 & 67,5 & 70,4 & & & 194,5 \\
\hline SW-Austrag & 712,3 & 801,7 & 870,1 & 538,8 & 134,6 & 1316,9 & 584,3 & 10,1 & 524,5 & 288,9 & 260,8 & & 260,8 \\
\hline Vorratsänderung & $-696,8$ & $-801,7$ & $-854,7$ & $-586,5$ & $-142,3$ & $-1522,7$ & $-597,1$ & $-36,8$ & $-579,2$ & $-350,4$ & $-254,0$ & & $-448,5$ \\
\hline \multicolumn{14}{|l|}{ 2. Jahr } \\
\hline Regen-Eintrag & 9,0 & & 9,0 & 6,6 & 1,0 & 4,2 & 3,2 & & 3,1 & 3,7 & 2,6 & & 2,6 \\
\hline Ernte-Entzug & & & & 40,5 & 12,4 & 110,4 & 11,1 & 14,9 & 13,7 & 5,2 & & & 84,0 \\
\hline SW-Austrag & 151,1 & 226,9 & 195,8 & 29,7 & 10,4 & 210,5 & 50,7 & 7,3 & 13,7 & 2,8 & 35,1 & 12,8 & 47,9 \\
\hline Vorratsänderung & $-142,1$ & $-226,9$ & $-186,8$ & $-63,7$ & $-21,8$ & $-316,7$ & $-58,6$ & $-22,2$ & $-24,4$ & $-4,2$ & $-32,6$ & $-12,8$ & $-129,4$ \\
\hline \multicolumn{14}{|l|}{ 3. Jahr } \\
\hline Regen-Eintrag & 13,6 & 0,0 & 13,6 & 8,7 & 0,9 & 3,8 & 1,8 & 0,0 & 3,6 & 5,0 & 3,2 & & 3,2 \\
\hline Ernte-Entzug & & & & 3,6 & 1,3 & 12,1 & 0,2 & 1,9 & 1,8 & 0,8 & & & 10,1 \\
\hline sW-Austrag & 134,4 & 272,9 & 188,2 & 55,7 & 15,5 & 193,9 & 32,1 & 6,9 & 28,9 & 3,2 & 35,7 & 17,4 & 53,1 \\
\hline Vorratsänderung & $-120,9$ & $-272,9$ & $-174,6$ & $-50,6$ & $-15,9$ & $-202,2$ & $-30,5$ & $-8,8$ & $-27,2$ & 0,9 & $-32,5$ & $-17,4$ & $-60,0$ \\
\hline \multicolumn{14}{|l|}{ 1. - 3. Jahr } \\
\hline Regen-Eintrag & 38,1 & & 38,1 & 25,2 & 4,2 & 15,0 & 7,0 & 0,0 & 19,5 & 17,5 & 12,5 & & 12,5 \\
\hline Ernte-Entzug & & & & 101,7 & 23,8 & 335,4 & 26,1 & 43,5 & 83,1 & 76,4 & & & 288,7 \\
\hline SW-Austrag & 997,9 & 1301,5 & 1254,1 & 624,3 & 160,5 & 1721,3 & 667,1 & 24,3 & 567,1 & 294,9 & 331,6 & 30,2 & 361,8 \\
\hline Vorratsänderung & $-959,8$ & $-1301,5$ & $-1216,1$ & $-700,8$ & $-180,1$ & $-2041,7$ & $-686,1$ & $-67,8$ & $-630,7$ & $-353,7$ & $-319,1$ & $-30,2$ & $-637,9$ \\
\hline
\end{tabular}

Tabelle 13-106: DOC- und Mineralstoff-Bilanz in g/kg TM, pro Untersuchungsjahr und von Mai 87 bis April 90, Lysimeter 4

\begin{tabular}{|c|c|c|c|c|c|c|c|c|c|c|c|c|c|}
\hline $\begin{array}{l}\text { Bilanzglieder } \\
\text { Lysimeter } 4\end{array}$ & DOC & $\mathrm{HCO}_{3}$ & Summe-C & $\mathrm{Ca}$ & Mg & $\mathbf{K}$ & $\begin{array}{c}\mathrm{Na} \\
\mathrm{mg} / \mathrm{kg} \mathrm{TM}\end{array}$ & $\mathbf{P}$ & $\mathrm{SO}_{4}-\mathrm{S}$ & $\mathrm{Cl}$ & $\mathbf{N}_{\min }$ & $\mathrm{N}_{\text {org }}$ & Summe-N \\
\hline \multicolumn{14}{|l|}{ 1. Jahr } \\
\hline Regen-Eintrag & 12,4 & & 12,4 & 8,0 & 1,8 & 5,7 & 1,6 & & 10,3 & 7,1 & 5,5 & & 5,5 \\
\hline Ernte-Entzug & & & & 42,8 & 7,7 & 148,2 & 9,9 & 18,6 & 16,7 & 61,4 & & & 104,7 \\
\hline SW-Austrag & 381,9 & 591,4 & 498,3 & 386,6 & 95,1 & 591,8 & 387,5 & 5,5 & 295,7 & 167,1 & 191,1 & & 191,1 \\
\hline Vorratsänderung & $-369,4$ & $-591,4$ & $-485,9$ & $-421,4$ & $-101,0$ & $-734,3$ & $-395,8$ & $-24,1$ & $-302,2$ & $-221,4$ & $-185,6$ & & $-290,3$ \\
\hline \multicolumn{14}{|l|}{ 2. Jahr } \\
\hline Regen-Eintrag & 7,2 & & 7,2 & 5,3 & 0,8 & 3,4 & 2,6 & & 2,5 & 3,0 & 2,1 & & 2,1 \\
\hline Ernte-Entzug & & & & 30,3 & 9,7 & 74,5 & 6,9 & 12,8 & 11,2 & 3,7 & & & 56,7 \\
\hline SW-Austrag & 91,3 & 173,4 & 125,4 & 26,8 & 8,9 & 114,8 & 34,1 & 5,0 & 11,2 & 2,1 & 23,3 & 8,8 & 32,0 \\
\hline Vorratsänderung & $-84,1$ & $-173,4$ & $-118,2$ & $-51,8$ & $-17,7$ & $-185,9$ & $-38,5$ & $-17,8$ & $-19,8$ & $-2,8$ & $-21,2$ & $-8,8$ & $-86,6$ \\
\hline \multicolumn{14}{|l|}{ 3. Jahr } \\
\hline Regen-Eintrag & 10,9 & & 10,9 & 7,0 & 0,7 & 3,0 & 1,4 & & 2,9 & 4,0 & 2,6 & & 2,6 \\
\hline Ernte-Entzug & & & & 2,2 & 1,0 & 6,9 & 0,1 & 1,5 & 1,1 & 1,5 & & & 6,3 \\
\hline SW-Austrag & 41,7 & 81,1 & 57,7 & 20,5 & 5,2 & 47,9 & 8,9 & 1,5 & 10,1 & 1,1 & 11,5 & 1,9 & 13,3 \\
\hline Vorratsänderung & $-30,8$ & $-81,1$ & $-46,8$ & $-15,7$ & $-5,4$ & $-51,8$ & $-7,6$ & $-2,9$ & $-8,4$ & 1,4 & $-8,9$ & $-1,9$ & $-17,1$ \\
\hline \multicolumn{14}{|l|}{ 1. - 3. Jahr } \\
\hline Regen-Eintrag & 30,6 & & 30,6 & 20,3 & 3,4 & 12,1 & 5,6 & & 15,7 & 14,1 & 10,0 & & 10,1 \\
\hline Ernte-Entzug & & & & 75,3 & 18,3 & 229,5 & 17,0 & 32,8 & 29,0 & 66,6 & & & 167,8 \\
\hline SW-Austrag & 514,9 & 845,9 & 681,5 & 433,9 & 109,2 & 754,5 & 430,6 & 12,0 & 317,0 & 170,3 & 225,8 & 10,6 & 236,4 \\
\hline Vorratsänderung & $-484,3$ & $-845,9$ & $-650,9$ & $-488,9$ & $-124,2$ & $-971,9$ & $-441,9$ & $-44,8$ & $-330,3$ & $-222,8$ & $-215,7$ & $-10,6$ & $-394,1$ \\
\hline
\end{tabular}


Tabelle 13-107: DOC- und Mineralstoff-Bilanz in g/kg TM, pro Untersuchungsjahr und von Mai 87 bis April 90,

Lysimeter 3

\begin{tabular}{|c|c|c|c|c|c|c|c|c|c|c|c|c|c|}
\hline $\begin{array}{l}\text { Bilanzglieder } \\
\text { Lysimeter } 3\end{array}$ & DOC & $\mathrm{HCO}_{3}$ & Summe-C & $\mathrm{Ca}$ & Mg & $\mathbf{K}$ & $\begin{array}{c}\mathrm{Na} \\
\mathrm{mg} / \mathrm{kg} \mathrm{TM}\end{array}$ & $\mathbf{P}$ & $\mathrm{SO}_{4}-\mathrm{S}$ & $\mathrm{Cl}$ & $\mathbf{N}_{\min }$ & $\mathbf{N}_{\text {org }}$ & Summe-N \\
\hline \multicolumn{14}{|l|}{ 1. Jahr } \\
\hline Regen-Eintrag & 9,1 & & 9,1 & 5,8 & 1,3 & 4,1 & 1,2 & & 7,5 & 5,2 & 4,0 & & 4,0 \\
\hline Ernte-Entzug & & & & 37,1 & 3,9 & 70,8 & 4,5 & 11,0 & 15,6 & 49,6 & & & 52,6 \\
\hline SW-Austrag & 144,4 & 292,0 & 201,9 & 194,1 & 37,0 & 123,1 & 168,9 & 1,5 & 153,9 & 217,8 & 97,6 & & 97,6 \\
\hline Vorratsänderung & $-135,3$ & $-292,0$ & $-192,8$ & $-225,4$ & $-39,5$ & $-189,7$ & $-172,2$ & $-12,5$ & $-162,1$ & $-262,2$ & $-93,6$ & & $-146,2$ \\
\hline \multicolumn{14}{|l|}{ 2. Jahr } \\
\hline Regen-Eintrag & 5,3 & & 5,3 & 3,9 & 0,6 & 2,5 & 1,9 & & 1,8 & 2,2 & 1,5 & & 1,5 \\
\hline Ernte-Entzug & & & & 19,5 & 6,1 & 36,5 & 3,4 & 6,7 & 4,3 & 2,2 & & & 24,5 \\
\hline SW-Austrag & 53,9 & 112,7 & 76,1 & 25,3 & 7,6 & 37,3 & 22,8 & 0,3 & 8,4 & 1,1 & 15,8 & 0,4 & 16,2 \\
\hline Vorratsänderung & $-48,6$ & $-112,7$ & $-70,8$ & $-40,9$ & $-13,1$ & $-71,4$ & $-24,4$ & $-7,0$ & $-10,9$ & $-1,1$ & $-14,3$ & $-0,4$ & $-39,1$ \\
\hline \multicolumn{14}{|l|}{ 3. Jahr } \\
\hline Regen-Eintrag & 8,0 & & 8,0 & 5,1 & 0,5 & 2,2 & 1,0 & & 2,1 & 2,9 & 1,9 & & 1,9 \\
\hline Ernte-Entzug & & & & 1,0 & 0,5 & 0,1 & 0,1 & 0,8 & 1,0 & 0,6 & & & 4,8 \\
\hline SW-Austrag & 40,3 & 134,4 & 66,8 & 46,1 & 10,1 & 50,3 & 9,4 & 1,0 & 12,9 & 1,0 & 19,3 & 5,4 & 24,7 \\
\hline Vorratsänderung & $-32,4$ & $-134,4$ & $-58,8$ & $-42,0$ & $-10,0$ & $-48,2$ & $-8,4$ & $-1,8$ & $-11,8$ & 1,3 & $-17,4$ & $-5,4$ & $-27,6$ \\
\hline \multicolumn{14}{|l|}{ 1. - 3. Jahr } \\
\hline Regen-Eintrag & 22,3 & & 22,3 & 14,8 & 2,5 & 8,8 & 4,1 & & 11,4 & 10,3 & 7,3 & & 7,4 \\
\hline Ernte-Entzug & & & & 57,6 & 10,4 & 107,4 & 8,0 & 18,5 & 21,0 & 52,4 & & & 81,8 \\
\hline sW-Austrag & 238,6 & 539,1 & 344,8 & 265,5 & 54,6 & 210,7 & 201,1 & 2,8 & 175,2 & 219,9 & 132,7 & 5,8 & 138,4 \\
\hline Vorratsänderung & $-216,3$ & $-539,1$ & $-322,4$ & $-308,3$ & $-62,6$ & $-309,3$ & $-205,0$ & $-21,4$ & $-184,8$ & $-262,0$ & $-125,3$ & $-5,8$ & $-212,9$ \\
\hline
\end{tabular}

Tabelle 13-108: DOC- und Mineralstoff-Bilanz in g/kg TM, pro Untersuchungsjahr und von Mai 87 bis April 90,

Lysimeter 7

\begin{tabular}{|c|c|c|c|c|c|c|c|c|c|c|c|c|c|}
\hline $\begin{array}{l}\text { Bilanzglieder } \\
\text { Lysimeter } 7\end{array}$ & DOC & $\mathrm{HCO}_{3}$ & Summe-C & $\mathrm{Ca}$ & $\mathrm{Mg}$ & $\mathbf{K}$ & $\begin{array}{c}\mathrm{Na} \\
\mathrm{mg} / \mathrm{kg} \mathrm{TM}\end{array}$ & $\mathbf{P}$ & $\mathrm{SO}_{4}-\mathrm{S}$ & $\mathrm{Cl}$ & $\mathbf{N}_{\text {min }}$ & $\mathbf{N}_{\text {org }}$ & Summe-N \\
\hline \multicolumn{14}{|l|}{ 1. Jahr } \\
\hline Regen-Eintrag & 7,1 & & 7,1 & 4,6 & 1,0 & 3,2 & 0,9 & & 5,9 & 4,1 & 3,1 & & 3,1 \\
\hline Ernte-Entzug & & & & 6,7 & 0,7 & 7,4 & 0,5 & 1,5 & 2,0 & 4,8 & & & 8,1 \\
\hline SW-Austrag & 15,1 & 155,7 & 45,7 & 53,1 & 5,3 & 10,0 & 17,3 & 1,3 & 10,6 & 7,1 & 5,6 & & 5,6 \\
\hline Vorratsänderung & $-8,0$ & $-155,7$ & $-38,6$ & $-55,2$ & $-4,9$ & $-14,2$ & $-16,9$ & $-2,8$ & $-6,8$ & $-7,9$ & $-2,5$ & & $-10,7$ \\
\hline \multicolumn{14}{|l|}{ 2. Jahr } \\
\hline Regen-Eintrag & 4,6 & & 4,6 & 3,4 & 0,5 & 2,2 & 1,6 & & 1,6 & 1,9 & 1,3 & & 1,3 \\
\hline Ernte-Entzug & & & & 12,0 & 3,2 & 14,5 & 2,9 & 2,6 & 1,8 & 1,7 & & & 9,3 \\
\hline sW-Austrag & 7,0 & 93,4 & 25,3 & 24,2 & 1,6 & 0,5 & 4,6 & 0,0 & 2,4 & 1,0 & 2,7 & & 2,7 \\
\hline Vorratsänderung & $-2,3$ & $-93,4$ & $-20,7$ & $-32,8$ & $-4,3$ & $-12,9$ & $-5,9$ & $-2,6$ & $-2,6$ & $-0,8$ & $-1,5$ & & $-10,8$ \\
\hline \multicolumn{14}{|l|}{ 3. Jahr } \\
\hline Regen-Eintrag & 7,0 & & 7,0 & 4,5 & 0,5 & 1,9 & 0,9 & & 1,8 & 2,5 & 1,6 & & 1,6 \\
\hline Ernte-Entzug & & & & 0,2 & 0,1 & 0,0 & 0,0 & 0,2 & 0,1 & 0,4 & & & 0,9 \\
\hline SW-Austrag & 2,1 & 79,5 & 17,8 & 23,5 & 2,2 & 0,8 & 2,9 & 0,0 & 3,3 & 1,0 & 0,0 & & 0,0 \\
\hline Vorratsänderung & 4,8 & $-79,5$ & $-10,8$ & $-19,3$ & $-1,8$ & 1,1 & $-2,0$ & $-0,2$ & $-1,6$ & 1,1 & 1,6 & & 0,7 \\
\hline \multicolumn{14}{|l|}{ 1. - 3. Jahr } \\
\hline Regen-Eintrag & 18,7 & & 18,7 & 12,4 & 2,0 & 7,3 & 3,5 & & 9,3 & 8,5 & 6,0 & & 6,1 \\
\hline Ernte-Entzug & & & & 19,0 & 4,0 & 21,9 & 3,4 & 4,3 & 4,0 & 6,9 & & & 18,3 \\
\hline SW-Austrag & 24,2 & 328,6 & 88,9 & 100,7 & 9,1 & 11,3 & 24,8 & 1,3 & 16,3 & 9,2 & 8,4 & & 8,4 \\
\hline Vorratsänderung & $-5,5$ & $-328,6$ & $-70,2$ & $-107,3$ & $-11,1$ & $-25,9$ & $-24,8$ & $-5,6$ & $-10,9$ & $-7,6$ & $-2,4$ & & $-20,7$ \\
\hline
\end{tabular}


14. Anhang: Fotoaufnahmen

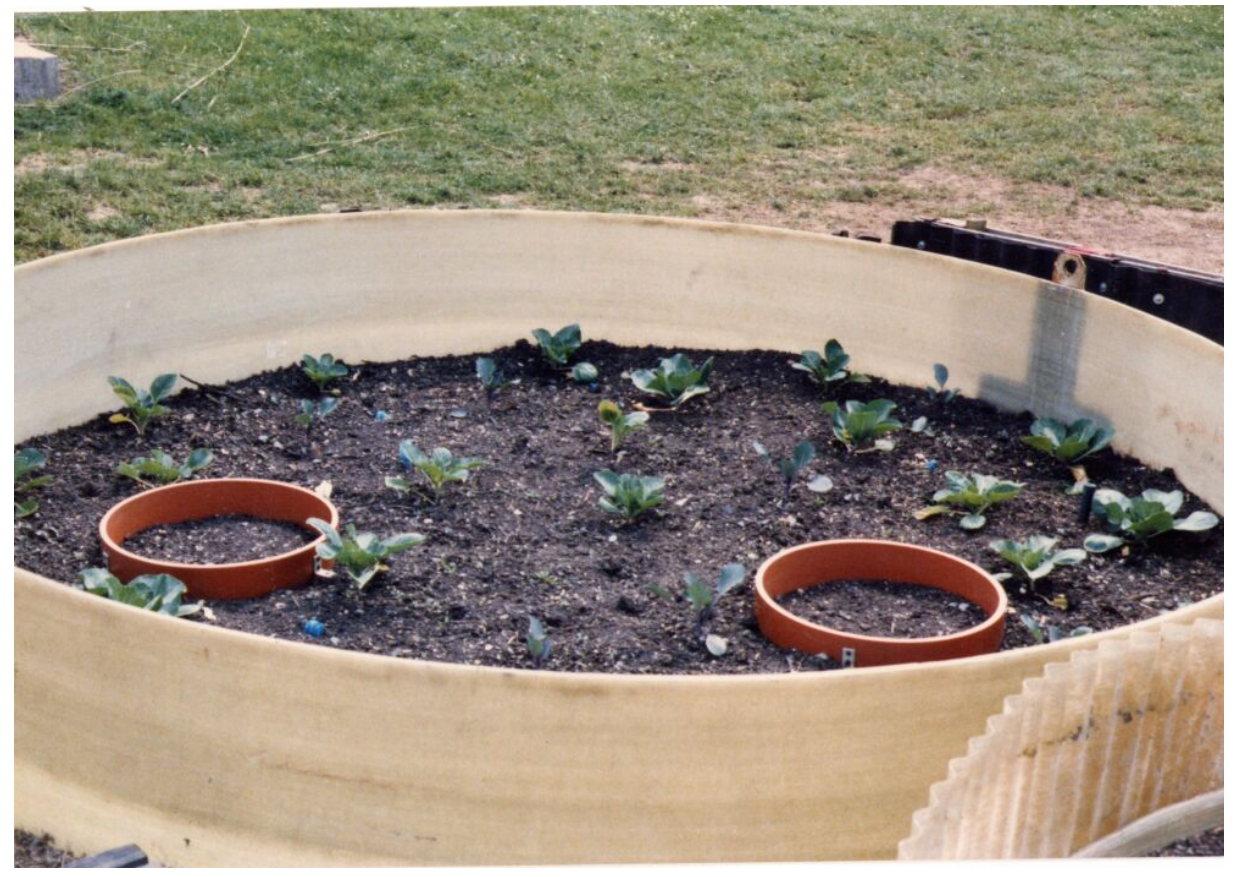

Abbildung 14-1: Lysimeter 1; Aufnahme vom 27.05.87 (zu Beginn der Freilandversuche)

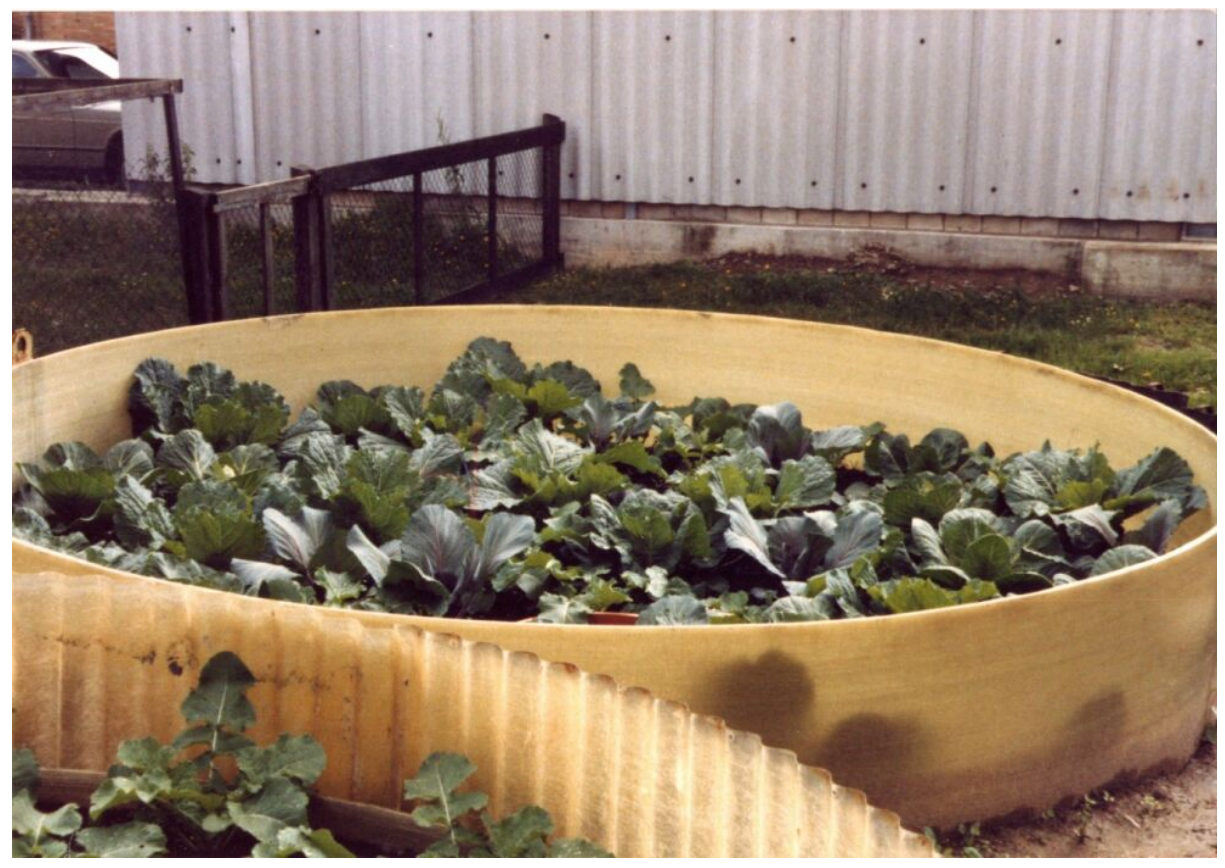

Abbildung 14-2: Lysimeter 1; Aufnahme vom 16.06.87 


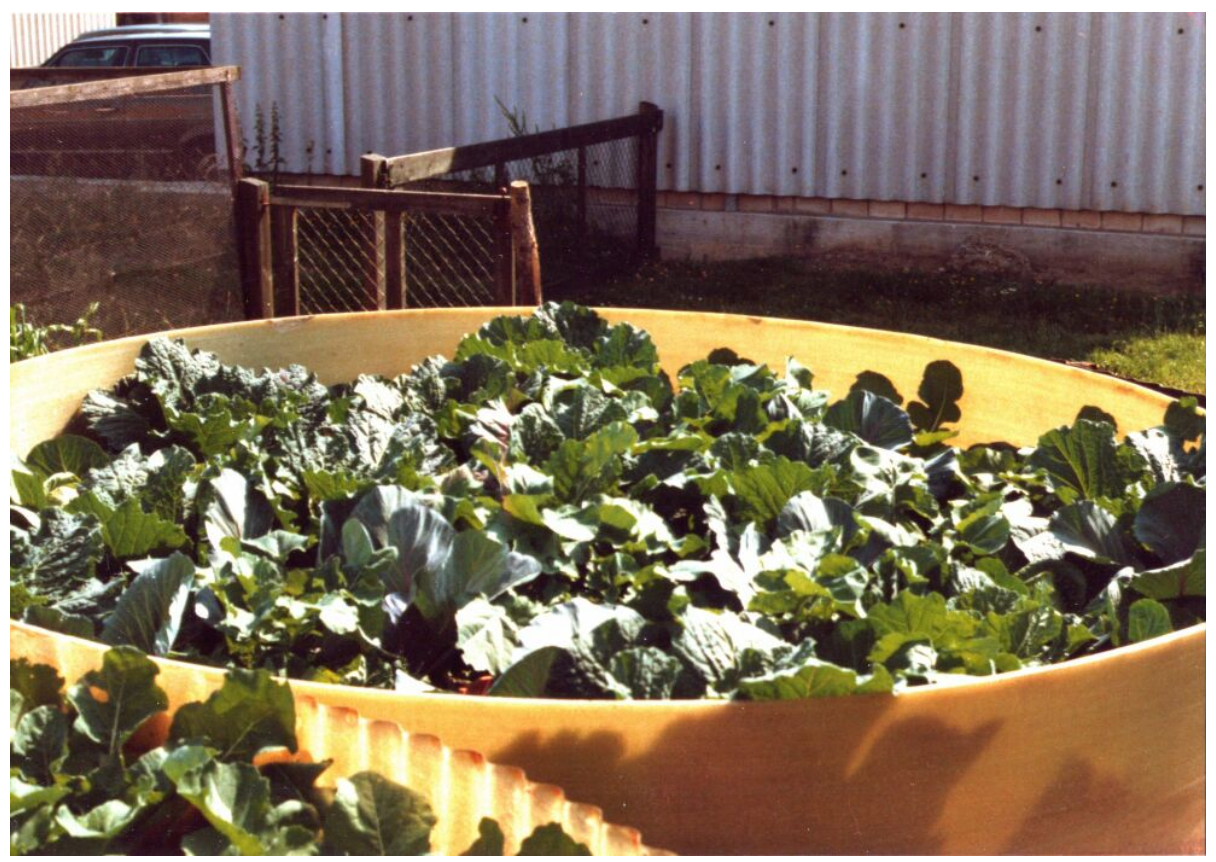

Abbildung 14-3: Lysimeter 1; Aufnahme vom 28.07.87

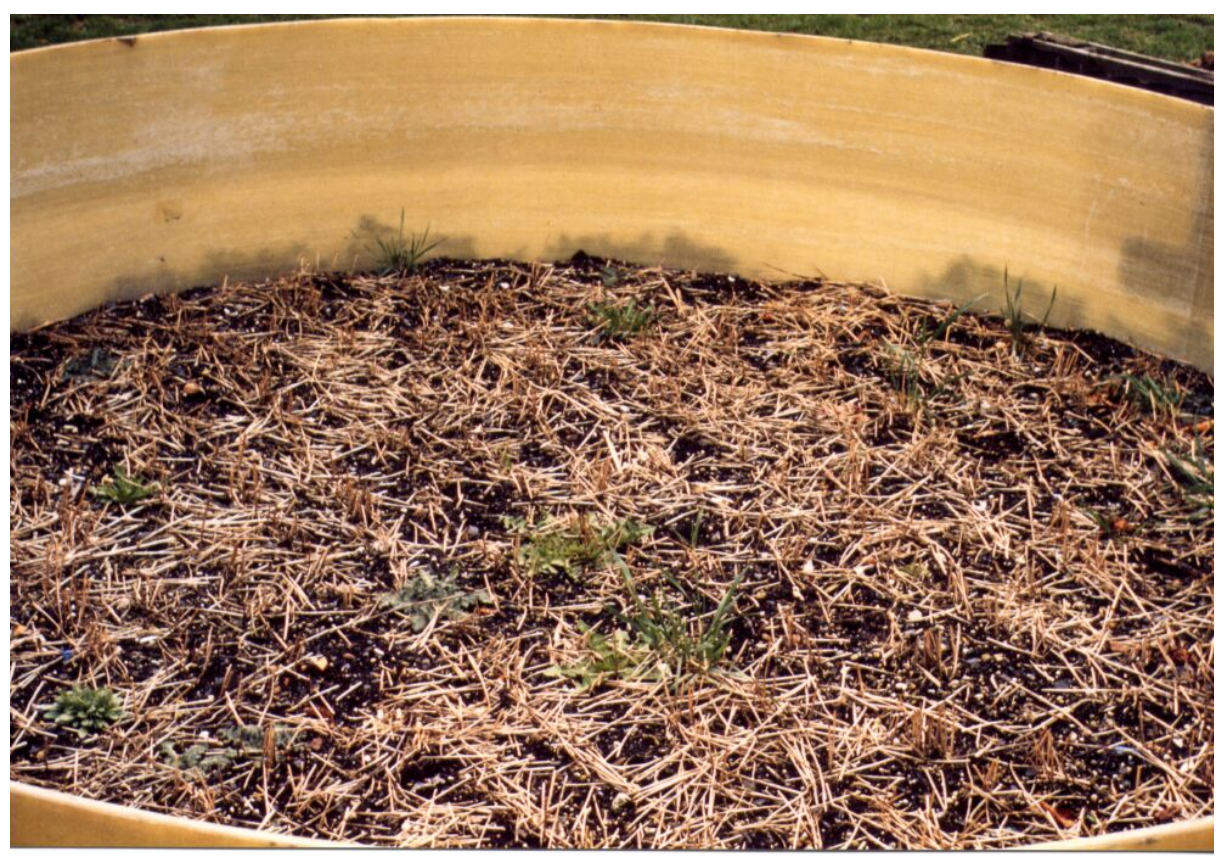

Abbildung 14-4: Lysimeter 1; Aufnahme vom 28.03.90 (gegen Ende der Freilandversuche) 


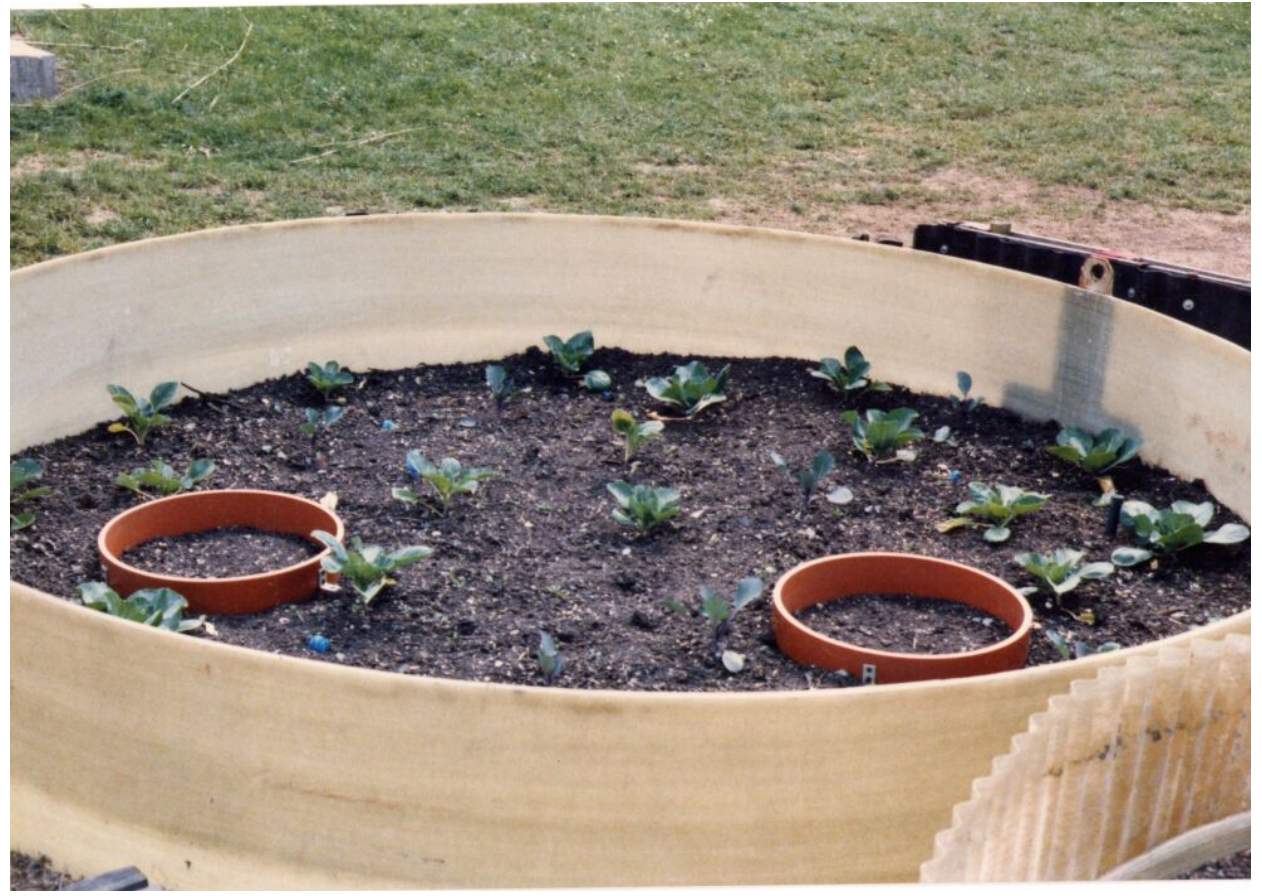

Abbildung 14-5: Lysimeter 2; Aufnahme vom 27.05.87 (zu Beginn der Freilandversuche)

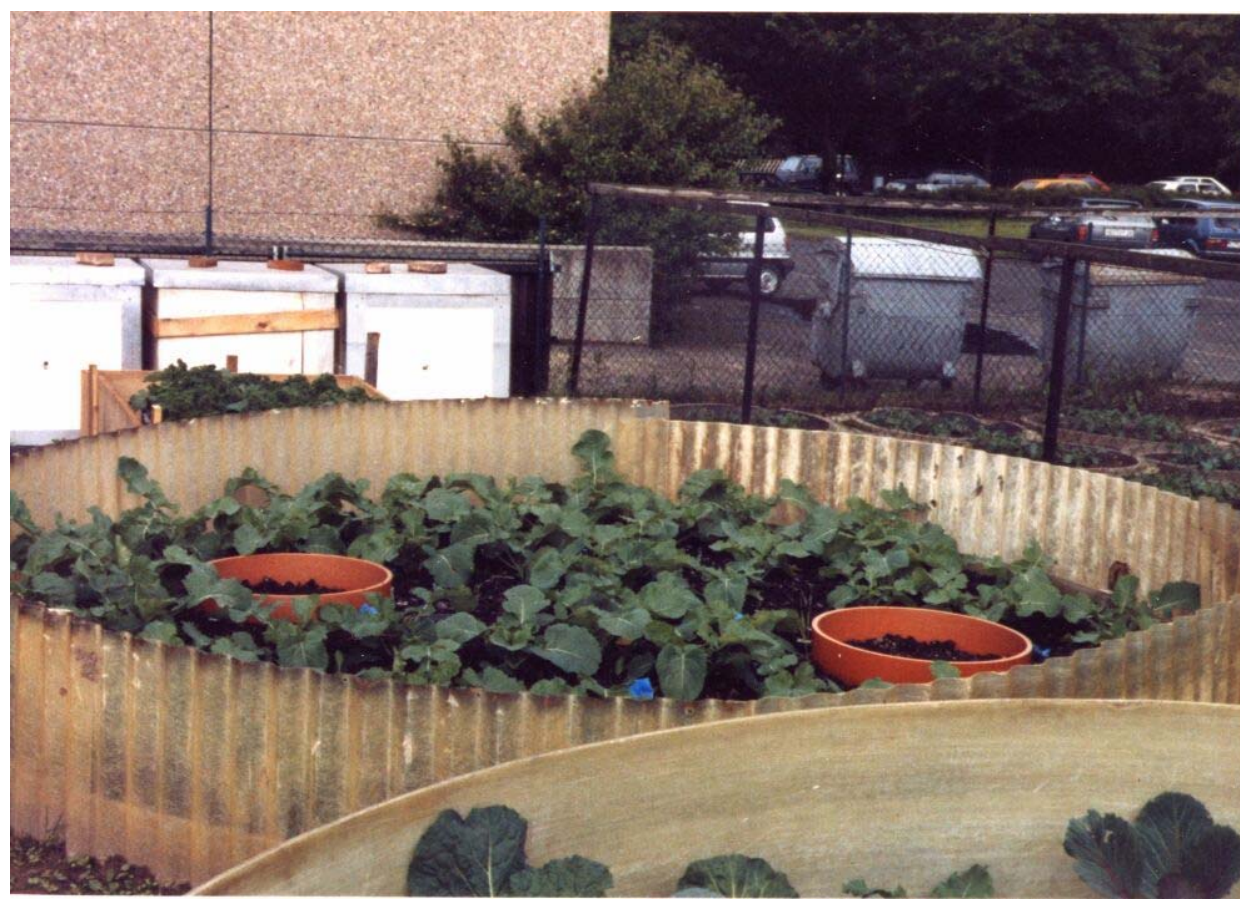

Abbildung 14-6: Lysimeter 2; Aufnahme vom 16.06.87 


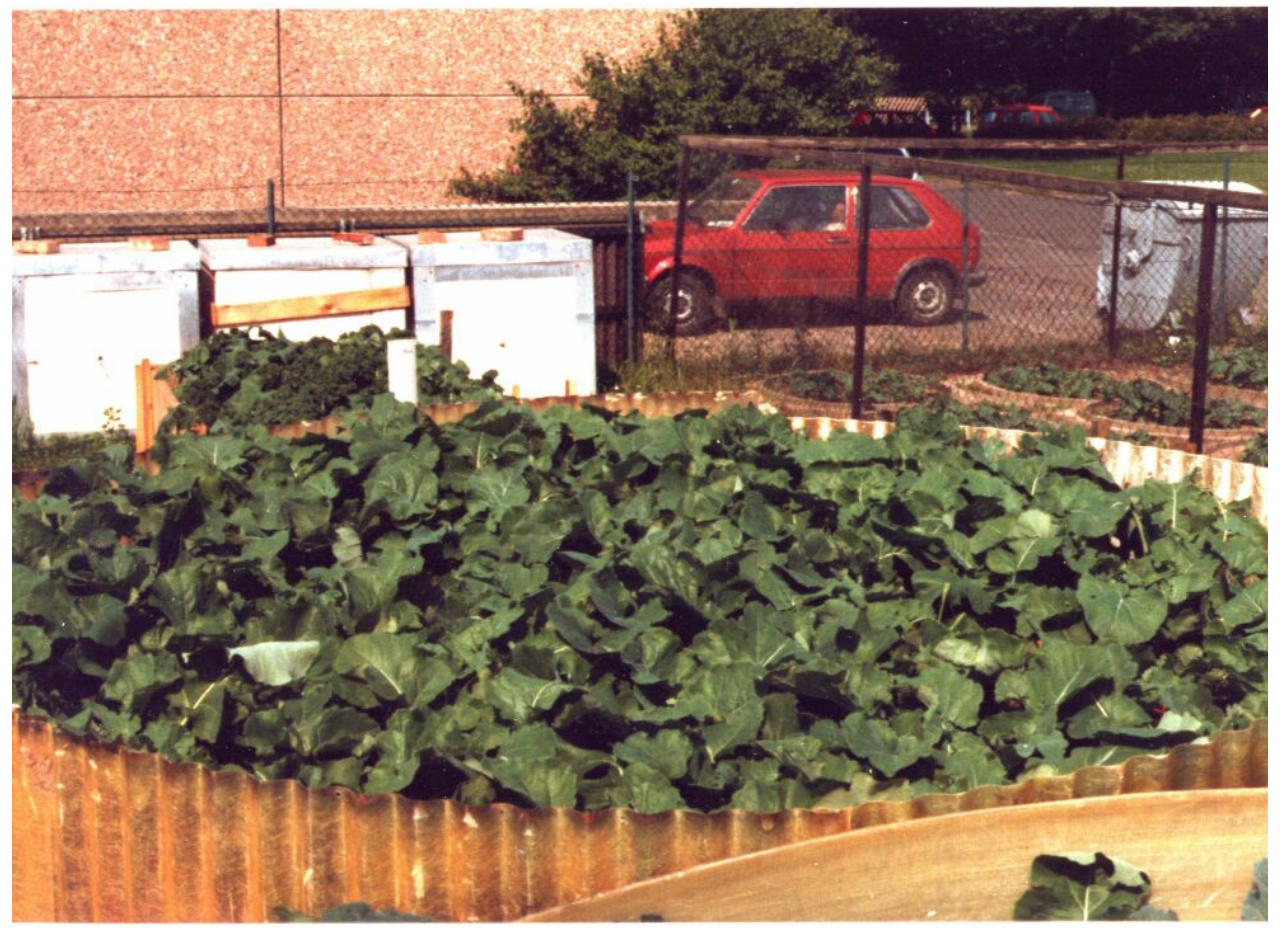

Abbildung 14-7: Lysimeter 2; Aufnahme vom 30.06.87

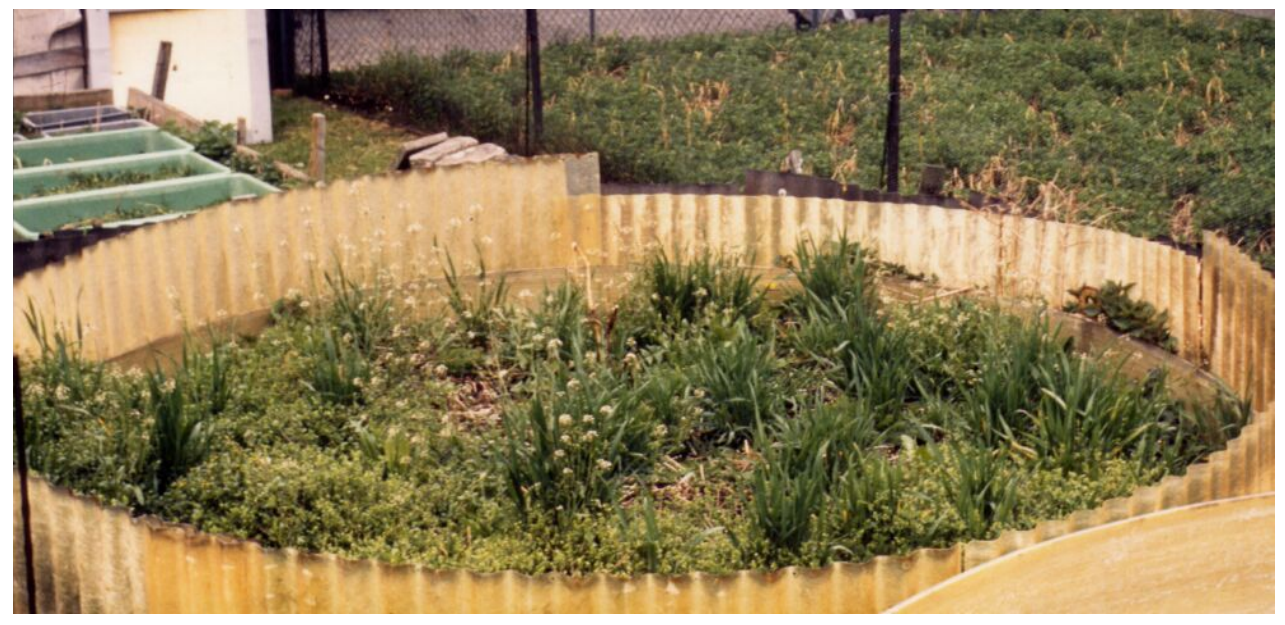

Abbildung 14-8: Lysimeter 2; Aufnahme vom 28.03.90 (gegen Ende der Freilandversuche) 


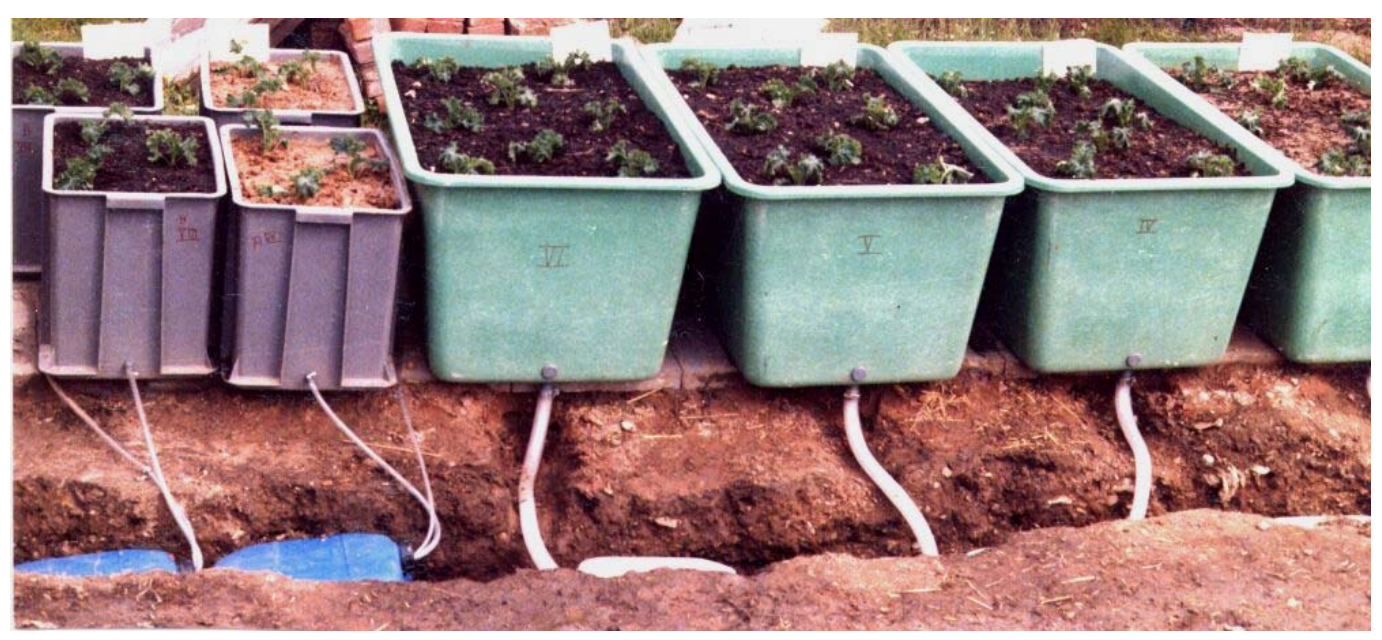

Abbildung 14-9: Lysimeter 3 - 8; Aufnahme vom 27.05.87 (zu Beginn der Freilandversuche)

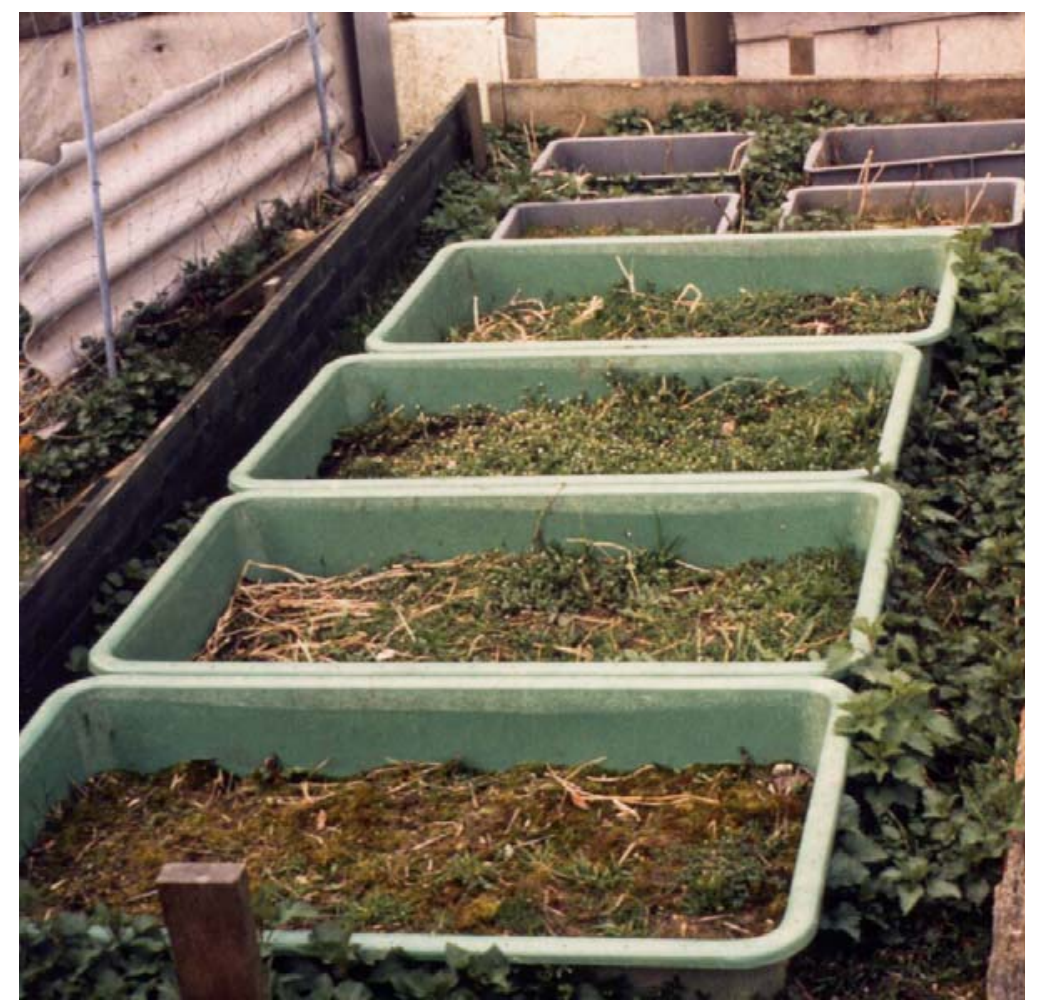

Abbildung 14-10: Lysimeter 3 - 8; Aufnahme vom 28.03.90 (am Ende der Freilandversuche) 


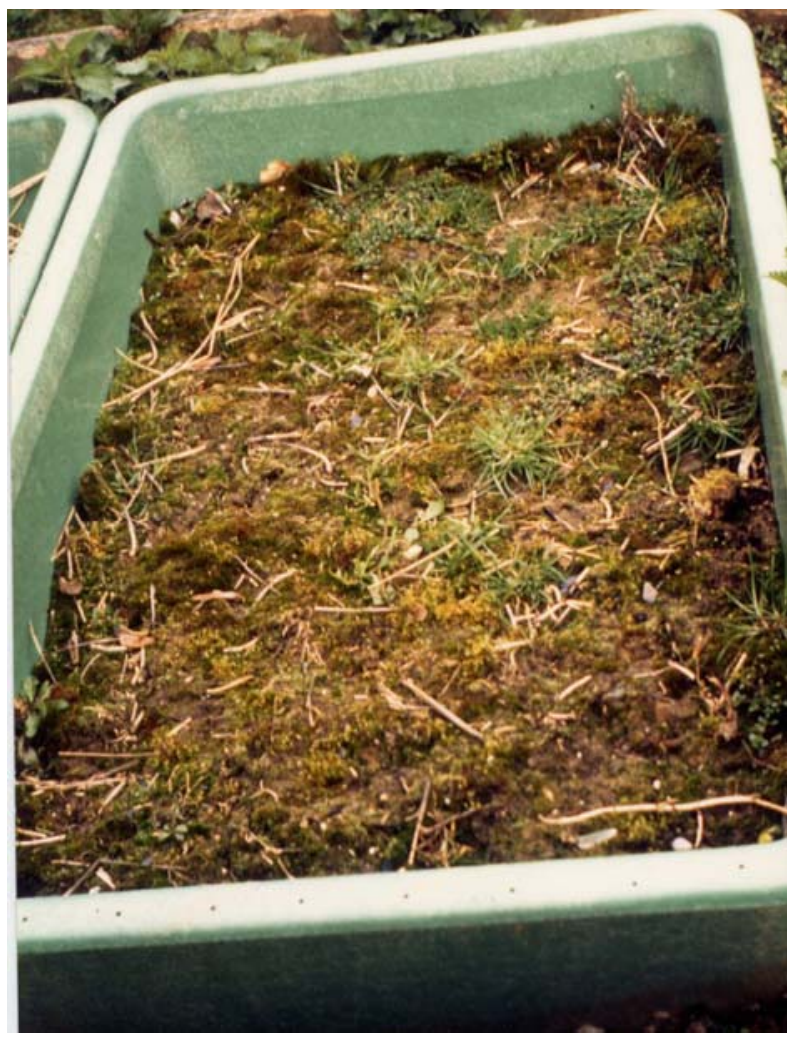

Abbildung 14-11: Lysimeter 3; Aufnahme vom 28.03.90 (am Ende der Freilandversuche)

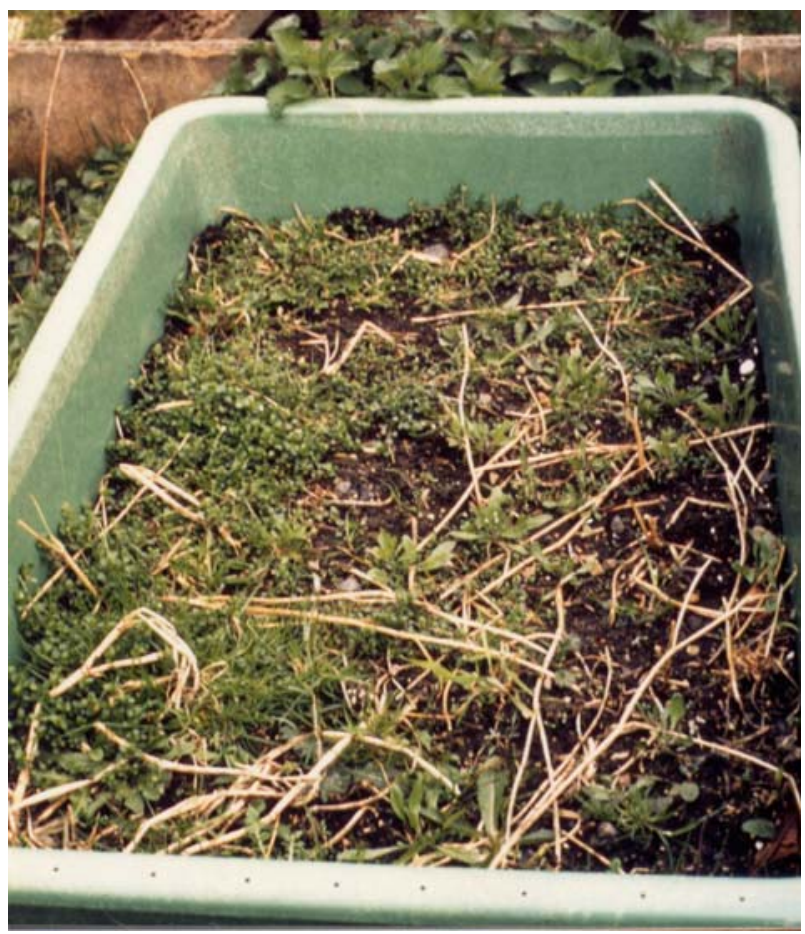

Abbildung 14-12: Lysimeter 4; Aufnahme vom 28.03.90 (am Ende der Freilandversuche) 


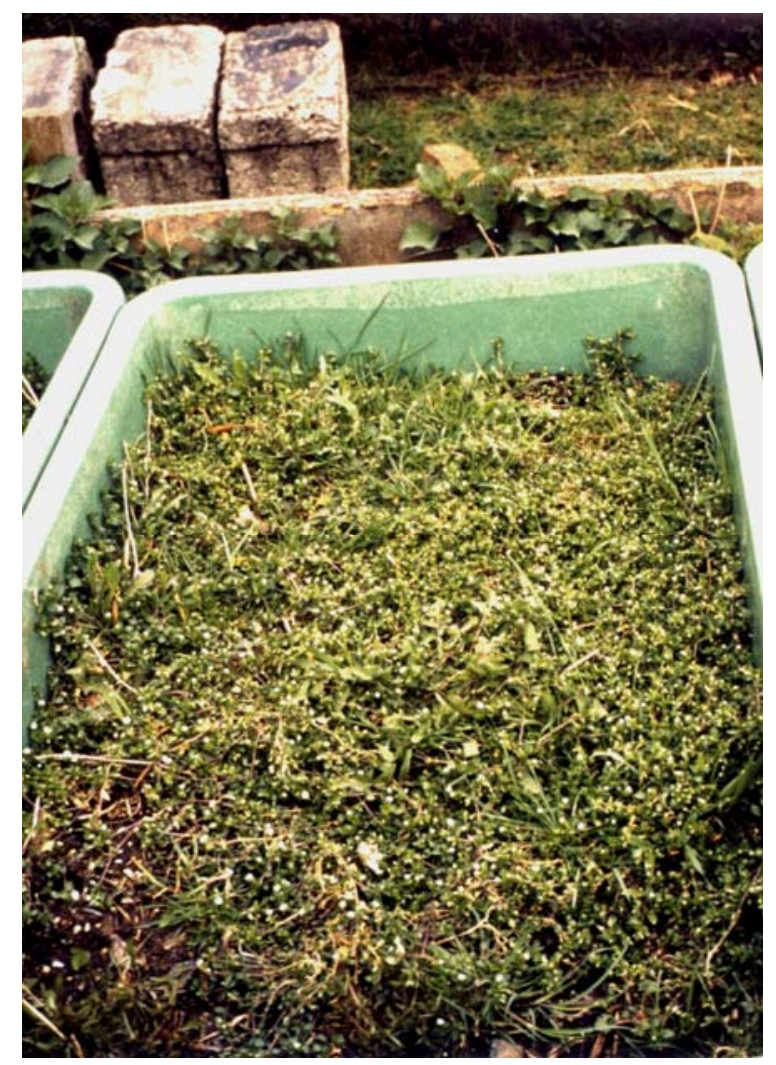

Abbildung 14-13: Lysimeter 5; Aufnahme vom 28.03.90 (am Ende der Freilandversuche)

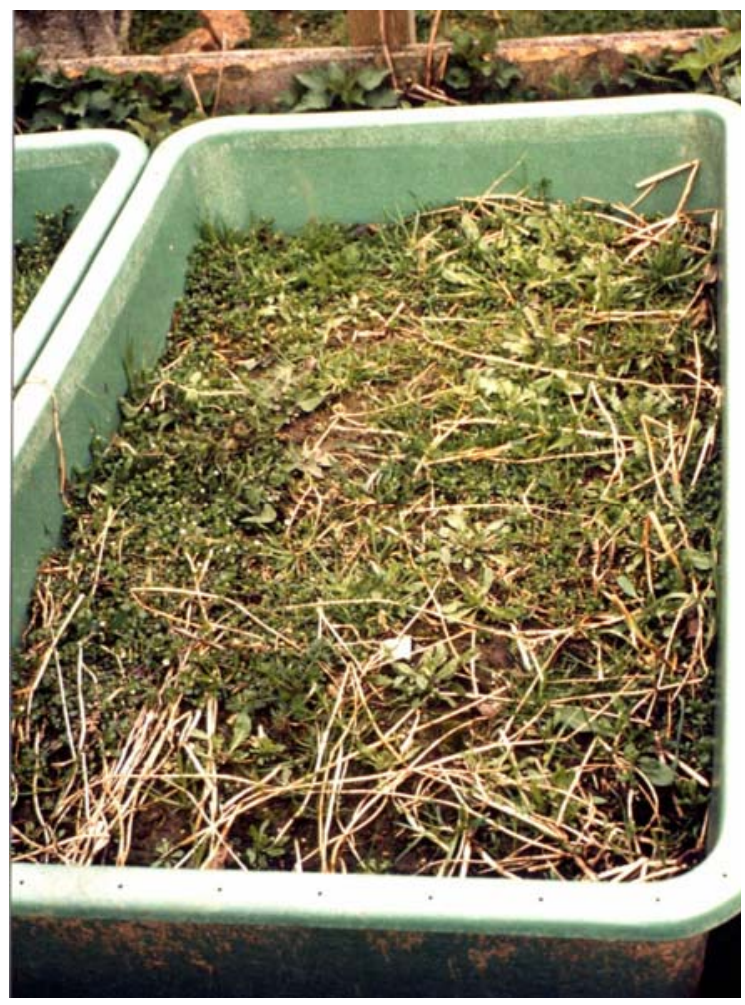

Abbildung 14-14: Lysimeter 6; Aufnahme vom 28.03.90 (am Ende der Freilandversuche) 


\section{Danksagung}

Mein ganz besonderer Dank gilt Herrn Prof. Dr. Brunk Meyer. Er hat mir das spannende Thema des Abbaus organischer Massen und ihrer Kopplung mit Asche-Anteilen übertragen. Mit seinem anhaltenden Interesse an den Ergebnissen meiner Arbeit, seiner Begeisterung für die Gewinnung neuer Erkenntnisse und seiner Zuversicht in Bezug auf die Fertigstellung dieser Dissertation ist es mir gelungen, diese Arbeit nach längjähriger Unterbrechung noch zu beenden. Der Abschluss ist mir nach über 10 Jahren Pause durch Familiengründung und die Bearbeitung von Gutachten und Forschungsprojekten in ganz anderen inhaltlichen Bereichen doch schwerer gefallen und hat deutlich mehr Zeit beansprucht, als ich angenommen hatte.

Für die Zeit der experimentellen Bearbeitung des Themas stand mir ein Promotionsstipendium des Evangelischen Studienwerks e. V. Villigst zur Verfügung, für das ich mich sehr bedanke.

Die bodenphysikalischen und bodenchemischen Untersuchungen der zahlreichen Proben waren dank der zuverlässigen und gewissenhaften Bearbeitung von Bärbel Diebel-Geries, Ingrid Ostermeyer und Karin Schmidt sehr gut zu bewältigen.

Meinen herzlichen Dank an Herrn Prof. Dr. Stefan Gäth für die „spontane“ Bereitschaft zur Übernahme des Koreferats.

Vielen Dank meinem Lebensgefährten Mario Müller, der mir in der Laborphase hin und wieder tatkräftig zur Seite stand und in der Endphase an vielen Abenden und Wochenenden das Familienmanagement allein zu bewältigen hatte.

Dass die EDV-Bearbeitung insgesamt so problemlos verlaufen ist, verdanke ich meinem geduldigen und hilfsbereiten Mitbewohner Ralf Baufeld, der mir nicht nur sein Büro überlassen hat, sondern auch in allen EDV-Fragen ein exzellenter Ratgeber war.

Ohne den Zuspruch durch das Team des Göttinger Umwelt-Labors Dr. Erhard Kühnle und Dr. Carsten Schultze hätte ich den Schritt, nach so vielen Jahren meine Dissertation noch fertig machen zu wollen, vielleicht nicht gewagt.

Ich danke meiner Oma und vielen anderen für ihren „sanften Druck“. Ihr beharrliches Interesse an meinem Vorankommen hat mich sehr unterstützt.

Meinen Eltern danke ich für ihr Vertrauen, das mir die Möglichkeit gegeben hat, diesen Weg zu gehen. 


\section{Lebenslauf}

Heidrun Hofmann

geb. am 01.06.1961 in Mandeln

Mutter von 2 Kindern, Willi Hofmann und Clarissa Hofmann

\section{Schulbildung}

1967 - $1971 \quad$ Besuch der Grundschule in Mandeln.

1971 - $1980 \quad$ Besuch der Wilhelm-von-Oranien-Schule in Dillenburg,

Abschluss: Allgemeine Hochschulreife.

\section{Hochschulausbildung}

10/80 - 06/87 Gymnasiales Lehramtsstudium der Biologie und Chemie in Marburg und Teilnahme an zusätzlichen Diplompraktika im Fachgebiet Analytische Chemie.

Abschluss: 1. Staatsexamen. Wissenschaftliche Hausarbeit in Chemie: „Untersuchung des Sorptionsverhaltens von Boden-Huminsäuren gegenüber Calcium- und Zink-lonen."

\section{Berufliche Entwicklung und ehrenamtliche Aktivitäten}

06/88 - 11/91 Wissenschaftliche Mitarbeiterin am Institut für Bodenwissenschaft der Fakultät Agrarwissenschaften der Universität Göttingen.

Durchführung des experimentellen Teils des Promotionsvorhabens: „Die Eluate des mikrobielllen Abbaus organischer Massen in ihrer organischchemischen Zusammensetzung und ihrer Kopplung mit freigesetzten Asche-Anteilen". Promotionsförderung durch das Evangelische Studienwerk e. V. Villigst.

12/91-06/93 Erziehungsurlaub

seit 07/93 Mitarbeiterin als Sachverständige für Innenraumschadstoffe im Göttinger Umwelt-Labor e. V. GUL :

- Einrichtung des Probenahmebereichs für die Entnahme von Luft, Staub und Material zur Untersuchung auf chemische und biologische Noxen,

- Erstellung von Gutachten zur Raumlufthygiene und gesundheitlichen Bewertung von Bauprodukten und Einrichtungsgegenständen,

- Entwicklung von Prüfstrategien, z.B. für mikrobielle Belastungen, PCB und PAK in Schulen und Kindergärten,

- Übernahme geschäftsführender Aufgaben in der Organisationsentwicklung und Finanzsteuerung.

02/94 - 06/97 Mitarbeit im Arbeitskreis „Innenraum“ der bundesweiten Arbeitsgemeinschaft ökologischer Forschungsinstitute AGÖF:

- Ausarbeitung der AGÖF-Qualitätskriterien,

- Erstellung von Fragebögen zur Gebäudebestandsaufnahme,

- Ableitung von Orientierungswerten für Innenraumschadstoffe. 
09/96 - 09/01 Sprecherin des Arbeitskreises „AGÖF-Haus“. Zusammenschluss von ca. 20 Instituten aus den Bereichen Gebäudeplanung, Energie, Chemie und Baubiologie zur Entwicklung von Mindestanforderungen für ökologisches Bauen, Wohnen und Sanieren.

01/98-02/99 Erziehungsurlaub

02/99 - 05/01 Konzeptionelle und inhaltliche Entwicklung eines Umweltzeichens für ökologische Bauprodukte, Vorbereitung der Konstitutionierung des wissenschaftlichen Beirats.

10/00 - 03/01 Freiberufliche Tätigkeit für das Institut für ökologische Raumentwicklung IÖR, Abteilung Wohnungswesen und Bauökologie, Dresden:

Erstellung eines Gutachtens im Auftrag des Innenministeriums SchleswigHolstein zum Thema „Gebäudepass Schleswig-Holstein“.

03/01 - 05/04 Koordination des Projektes „Instrumente zur Beschreibung und Bewertung von Gebäuden - Systematik und Überblick" für die Schwäbisch Hall Stiftung bauen - wohnen - leben im Auftrag der AGÖF.

seit $01 / 02$ Fortsetzung des Promotionsvorhabens: Ausarbeitung der Dissertation.

seit $03 / 02$

Mitglied des Vorstands der Arbeitsgemeinschaft ökologischer Forschungsinstitute AGÖF. 